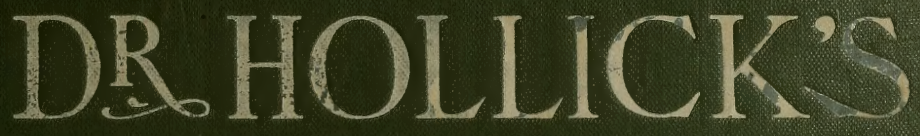

\title{
COMPLETE WORKS
}

DISEASES MALE MARRIAGR MANUAL

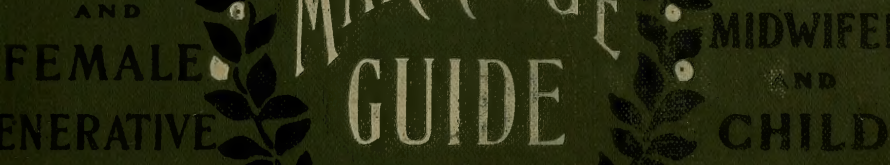
ORGANS $\frac{0}{2} \theta^{4} \mathrm{BIRTH}$

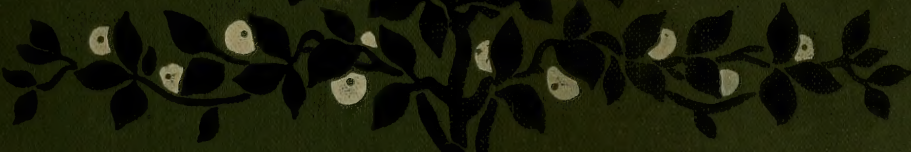
THE DISEASES FAM ILIARLY OF WOMEN $70000 \times 2<0<000$ NEW REVISED AND ENLARCEDEDITION COMPLETE IN ONE VOLUME @ PLAIN AND PRACTICAL FOR POPULAR USE

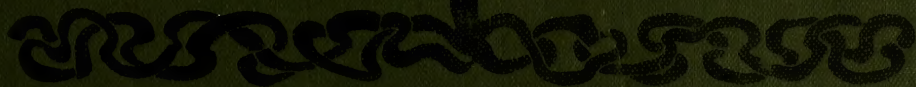




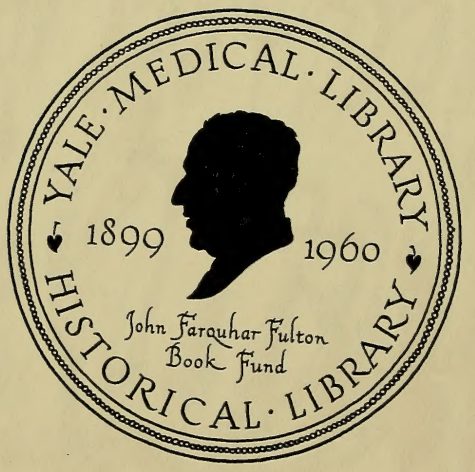


Tannie Dace 

THE ORIGIN OF LIFE 


\section{THIS COMPLETE WORK}

Embraces all of the Author's former Books.

The Marriage Guide.

The Male Generative Organs in Health and Disease.

The Female Generative Organs and Diseases of Women Familiarly Explained.

The Matron's Manual of Midwifery and Childbirth, etc., etc.

"It will be understood, therefore, that there is nothing in the single volumes that is not in this one, and that it contains also an amount of new matter fully equal to a new volume."

-Author's Preface. 


\title{
T H E
}

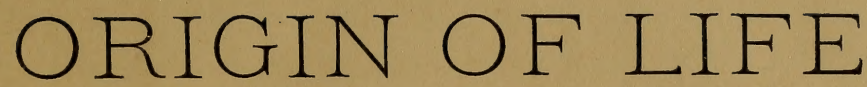

AND PROCESS OF

\section{REPRODUCTION \\ - IN PLANTS AND ANIMALS,}

WITH THE ANATOMY AND PHYSIOLOGY

OF THE

HUMAN GENERATIVE SYSTEM。 MALE AND FEMALE,

AND THE CAUSES, PREVENTION AND CURE OF THE SPECIAL DISEASES TO WHICH IT IS LIABLE.

g

\author{
BY \\ DR. F. HOLLICK,
}

THE AUTHOR AND LECTURER.

IULUSTRATED BY ENGRAVINGS AND COLORED PLATES.

NEW EDITION, WITH ADDITIONS.

PHILA DELPHIA:

DAVID MCKAY, PUBLISHER, 604-8 SOUTH WASHINGTON SQUARE. 


\section{COPYRIGHT}

By F. Hollick, M.D.

I878.

ALL RIGHTS RESERVED

COPYRIGHT, I9O2,

David MCKay.

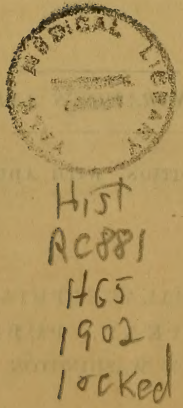




\section{TO THE PUBLIC.}

Is the course of our business as dealers in and disseminators of use. ful information, we have become aware, necessarily, of what kinds of books the people are in need, by their being asked for. Among others, especially in the last few years, there has been a constant and increasing demand for a practically useful, popular, and unobjectionable book on the Reproductive System and its derangements; suitable for private and family use. This demand comes from a most intelligent and worthy class; from a class fully capable of appreciating such a book, and of profiting by it.

For many years Dr. Hollick's works in several books, on the separate topics connected with this subject, have satisfied the demand; but at present there is urgent call for One Work, embracing the whole matter; and to this call we now respond.

We have requested Dr. Hollick to re-write all his works, and compile them into one volume, with new illustrations, and comprising all the newest information. This the Doctor has done in the present book, which we venture to assert will be found, in every respect, the very work that has so long been required.

No expense has been spared in getting it up, for we were determined it should be complete. The illustrations especially, both engravings and colored plates, are profuse, and done in the very best style.

In regard to the matter it is sufficient to refer to the well-known reputation and great experience of the Author. The public may rest 
assured that he would not write, nor would we publish, a book which was not, in every way, deserving of their approbation and support.

Without undervaluing the merits and utility of many books of a similar character, by other physicians, we may be permitted to state that the present volume differs in many ways from any one hitherto published. It takes a wider range, and is more complete in every way, being, in fact, an Encyclopedia of practically useful information, upon matters which must ever be of the deepest interest and of the greatest importance to the whole human race.

In regard to illustrations, and the general manufacture of the book, our directions have simply been, make it perfect, and spare no expense!

\section{The Publishers.}




\section{PREFACE}

\section{AND HISTORICAL SUMMARY.}

AT the commencement of my medical career circumstances led me into the studv of the Generative System, its Anatomy, Physiology, and diseases ; and this became, subsequently, a specialty with me, both as a matter of scientific pursuit and as a particular subject of medical practice. All my life since has been devoted to the same pursuit, and my practice has been almost exclusively connected with diseases of the Reproductive Organs, in men and women.

I have therefore had much opportunity for acquiring knowledge on such matters, and have endeavored, as far as I could, to turn that opportunity to good account. By means of careful observations, both in human beings and animals, and by dissections and regular experiments in every practicable way, it has always been an object with me to learn as much as possible of the great mystery of Generation! This knowledge I sought not only as a medical man, to enable me to mitigate human suffering, or to fulfill legitimate human hopes, but because it is intensely interesting in itself, and of immense importance to the human race in many ways.

The further my study and practice extended, the more I became convinced that this subject was one of the most important, medically and morally, that could possibly engage our attention, and yet at the same time the most neglected, and the least understood. The conclusion forced itself upon me that the prevailing ignorance in regard to sexual matters, and the consequent errors of thought and conduct thereupon, is the real cause of the most serious physical and moral evils that afflict society.

Having come to this conclusion, it became at once a duty with me to try and remove that ignorance, and then the question arose, how this could best be effected ? I made it a point to consult all those whom I came in contact with, who took an interest in human welfare, as to the best steps to be taken. I spoke with Lawyers, Clergymen, experienced Judges, Teachers, and Medical Men of liberal views, and they one and all agreed, with me, that a certain amount of knowledge concerning the Anatomy and Physiology of the human body, in both sexes, was the first thing needed. A celebrated professor in one of our colleges made the remark, "What is the use of talking to a man about the proper care and use of that which he knows nothing about?". This is true enough, and all our moral teaching and appeals to 
the fears of people, in regard to sexual wrong-doing, will have but little practical effect, in correcting sexual evils, so long as people are so shamefully ignorant in regard to their own sexual natures. Another one made the equally true remark, that "All human beings, from the necessities of nature, must be more or less occupied, in thought, about sexual matters. It is impossible to prevent this, nor is it necessary to do so; all that is needed is to guide their thoughts aright, and to give early enough, in a proper manner, that knowledge which is the surest safeguard against errors of conduct."

A little reflection will show the common-sense value of this remark. The most ignorant man is as full of thought about sexual matters as he who is well informed about them, perhaps more so. The difference simply is that the well-informed man has correct ideas-knows the truth-while the ignorant man has his mind filled with all kinds of errors and absurdities.

Unfortunately the view has been held, and is now, by many well-meaning people, that this state of ignorance is in some way favorable to morality, and necessary to the general well-being! These people think ignorance and innocence are the same thing, and that a man is more likely to walk straight if left in the dark than if you give him a light.

My experience however has convinced me that the less we know about anything which interests us deeply, the more active is the imagination about it, and that no explanation of a natural function, if properly given, will ever injure any one either morally or physically. On the contrary, such explanations, very frequently, are the only means by which we can correct the evils caused by insane fancy, urged on by blind passion. As a rule, ignorance on sexual matters results in either prurience or prudery, and is never either necessary or conducive to true innocence.

Knowing however the prevalence of mistaken views on these matters, and foreseeing also the opposition of many whose interests would be imperiled, as they think, by popular enlightenment on such subjects, I was well aware of the difficulties before me. And let me remind my readers that these difficulties were much greater, even a few years ago, than can well be conceived now. It was scarcely possible, then, without obloquy, to speak or write of the stomach or bowels even, in a popular manner! How then could the sexual system be popularly approached? To attempt it was to fly in the face of a very general popular prejudice, and to risk even legal penalties. Nevertheless, I determined to make the attempt, having the promises of numerous persons, eminent in many walks of life, to stand by me and support me in the undertaking. Contrary to what was then feared, the open countenance of these liberal and enlightened men was not required, but I shall ever hold their names in grateful remembrance. Many of them are since dead, but from those still living, as well as from others, I constantly receive congratulations and encouragement.

The great practical difficulty in the way of popular instruction in Anatomy and Physiology lay in obtaining suitable objects with which to make the requisite expla. 
nations understood. Mere verbal explanations are of small use, and pictures only half explain. Something is required which will take the place of the dead body, as used by the student in the dissecting-room; actual dissection before a popular audience being, of course, out of the question. Fortunately, during a visit to France, I became acquainted with Dr. Auzou, and saw his wonderful models of the human body, made of papier-maché, full-sized, and formed and colored to life-so exact, in fact, that it might often be difficult to distinguish the model from the real body. Here, then, I found just what was needed; and I at once purchased a complete set suitable for my purposes, consisting of the human body, which could be taken to pieces, and shown part by part, externally and internally, all molded and colored true to nature; and also separate organs of the male and female generative system, with a complete series showing the development of the new being in the womb at every stage. Besides these, I had a large number of paintings and plates, full size, and two complete skeletons, male and female.

With these I undertook to give a complete course of Popular Lectures on human Anatomy and Physiology in New York-the first ones of the kind, and the first ever illustrated in this way. Many of my friends were doubtful as to how they would be received; but I felt quite sure, in my own mind, that if the subject were properly presented, it would be properly received, and I had no misgivings.

The result more than justified my anticipations. The Lectures were received with unbounded favor, congratulations and votes of thanks being given me repeatedly, and request after request made for repetition; so that I lectured in New York continuously for over six months to crowded and enthusiastic audiences.

Private Lectures were given, both to ladies and gentlemen, on those topics that could not well be spoken of before a promiscuous audience, and they were as well attended, and as much commended, as the others; perhaps even more so. During the whole series I nerer heard a word of disapprobation, nor saw nor heard the slightest indication of impropriety in any way whatever. In fact, as one gentleman remarked, so far as lewdness was concerned, the Lectures were more repressive and corrective than any sermons he had ever listened to. To show the estimation in which they were held, I will here quote a few of the voluntary, unsolicited notices of them from the New York Press, on their first delivery :

Dr. Hollick AND Physiology.-The second of a series of Lectures, by this gentleman, on human physiology and all the important truths connected with our physical constitution, was attended by a full house, in National Hall, last evening. The time was well spent, and so appeared to think the audience. On the delivery of the first of these Lectures on Tuesday evening, the speaker, in a comprehensive and well-digested exordium, placed himself and the subject right with the public. His manner, language, and style did the first; his sound logic, his argument, his candor and research accomplished the second. Apart from the interesting and apposite details of the wonders of reproduction, the illustrations of the immutable wisdom of nature, which teem in the animal and vegetable worlds-which

"Glows in each stem, and blossoms in each tree;

Lives through all life, extends through all extent,

Spreads undivided, operates unspent-" 
apart from all this, Dr. Hollick's Lecture was excellent as a defense of truth, a vindication of the right of free and unshackled inquiry, and as a convincing refutation of that silly, but far too-prevalent opinion that there are truths of which it is better to remain in a state of ignorance. Had nothing else been imparted in the forcible and well-defined exordium of Dr. Hollick than this judicious demolition of that fallacious, silly, but injurious twaddle which would forbid research tc pass in advance of the old landmarks prescribed by custom, ignorance, or a spurious moralityeven that wonld well deserve the public patronage. Truths, well set forth, will make an impression, whether their investigation be fashionable or not. There is an affinity between the capacity to learn, and the truths to be learned, which always results, when a fitting opportunity is presented, in a free inquiry; and the gentleman who is bringing, in a judicious and elevated manner, a knowledge of those fundamental principles of our corporeal existence which are abused because unknown, will accomplish more good than half a dozen teachers of higher prétensions and lower ability. It was gratifying to observe the decorum, the sense of respect for both speaker and subject, that was observed throughout the evening, which evidently shows that those who go there are actuated by higher motives than mere curiosity ; by desires more ennobling than a passing gratification : in a word, it was clear that those who composed Dr. H.'s hearers, weremen who know and dare to think, and who will profit by these most useful discourses.-New York Herald. .

The Ladies' Course was attended, among others, by Mrs. L. M. Child, the Authoress, who, in one of her letters to the Boston Courier, thus speaks of them :

"LETTERS FROM NEW YORK,-NO. 11.

“* * * * There have been several courses of lectures on Anatomy this winter, adapted to popular comprehension. I rejoice at this : for it has long been a cherished wish with me that a general knowledge of the structure of our bndies, and the laws which govern it, should extend from the scientific few into the common education of the people. I know of nothing so well calcrilated to diminish vice and vulgarity as universal and rational information on these subjects. But the impure state of society has so perverted nature, and blinded common sense, that intelligent women, though eagerly studying the structure of the earth, the attractions of the planets, and the reproduction of plants, seem ashamed to know anything of the structure of the human body, and of those physiological facts most intimately connected with their deepest and parest emotions, and the holiest experience of their lives. I am often tempted to say, as Sir Charles Grandison did to the prude, 'Wottest thou not how much in-delicacy there is in thy delicacy !'

"The only lectures I happened to attend were those of Dr. Hollick, which interested and edified me murh. They were plain, familiar conversations, uttered and listened to with great modesty of language and propriety of demeanor. The manikin, or Artificial Anatomy, by which he illustrated his subject, is a most wonderful machine, invented by a French physician. It is made of papier-maché, and represents the human body with admirable perfection in the shape, coloring, and arrangement, even to the minutest fibers. By the removal of wires it can be dissected com. pletely, so as to show the locality and functions of the various organs, the interior of the heart, lungs, \&c.

" Until I examined this curious piece of mechanism, I had very faint and imperfect ideas of the miraculous machinery of the house we live in. I found it highly suggestive of many things to my mind. * * * *

L. M. C."

I could fill many pages with similar notices, given by the various New York papers during my stay there, and the same approval met me in other places, as the following notices will show:

Dr. H.'s style of lecturing is exceedingly plain, lucid, and intelligible. He relies on no trick or art of oratory -no effort to surprise or startle-to obtain or keep up the interest of his lectures. But they are deeply interesting. They are listened to in silence and with enchained attention-an attention that would feel annoyed at any fictitious arts of the speaker. The reason of this is obvious. The entirely novel character of the lectures, the deep and pervading interest of the subjects discussed-subjects embracing all that is mysterious and of momentous importance in the matter 
of man's reproduction and existence in this world-give to the lectures a solid and inestimable value as well as enchanting freshness and interest.

We believe Dr. Hollick is the only man in the conntry who has devoted years of study to this important but too-much neglected branch of human knowledge, or rather, of human ignorance, and who is now trying to extend the lights of wholesome understanding on the subjects embraced among the people.

In this matter we recognize in Dr. H. a public benefactor, and we owe it to the welfare of our fellows to commend him as such in this decided manner. We give utterance to no formal or paidfor puff in this matter. Our readers know us to be incapable of such a prostitution of our columns. The large numbers of ladies and gentlemen who have attended Dr. H.'s lectures know that we do but speak of this subject as it merits.-St. Louis Intelligencer.

MEssRs. Editons :-The most scientific and useful lectures of the present day, which should claim the attention of every one, are now being delivered at Masonic Hall, by Dr. Hollick, on the subject of Paternal Physiology and Health. The writer of this heard his first course, delivered during the last week, and, having been educated to the medical profession, is, perhaps, capable of judging of their usefulness. There is no doubt that the general feeling of the medical faculty, and of an enlightened community, toward itinerant lecturers has been one of disapprobation and apprehension of quackery; but in the present instance there is certainly an exception.

Dr. Dunbar (formerly Professor at the Washington College), who attended Dr. H.'s last lecture, on Friday evening, was so well pleased with the manner and matter of the lecture that he came out openly at the close of the lecture, and stated, before the audience had dispersed, that he had come there at the request of a patient, prejudicer against the lecturer ; but on hearing him, he thought it his duty to say that the lecture was perfectly fair, scientific, calculated to do a vast amount of good, and that every man, young or old, should hear and would be benefited thereby. His illustrations are complete and beautiful, and his explanations couched in such delicate language that the most fastidious can find no fault. Those of your numerous readers who may devote an hour to his remaining lectures will thank you for giving this publicity.-Baltimore American-Communicated.

DR. HoLl.ICK's LECTURES.-These Lectures continue to attract much attention, and are commended by all who hear them. During the past week Dr. H. has given a private Lecture and exhibition of his models to many of our prominent senators and public men, all of whom expressed themselves highly gratified, and desirous that another class should be formed to accommodate their friends who had not attended.-National Intelligencer, Washington, $D . O$.

DR. HowircK. - This distinguished lecturer had a crowded house at the Apollo last evening, and his delighted audience expressed their approbation at the close of his discourse by loud applause.

Dr. H. is indeed a most entertaining and instructive lecturer. We heard a medical gentleman say last evening, after listening to him, that he would not fail to hear the whole series, even if he should have to sell his coat to raise the means. The information imparted by Dr. H. must be truly invaluable to every one who possesses it.-Louisville Journal.

At a meeting of the class attendant upon Dr. Hollick's Select Lectures on the Physiology and Philosophy of the "Origin of Life" in Plants and Animals, held at the Lecture Room of the Museum, Wednesday evening, George G. West, Esq., was called to the chair, and Samuel W. Black appointed secretary.

Resolved, That we have listened with unfeigned pleasure and interest to the Course of Lectures delivered by Dr. Hollick, and now brought to a close, and that we deem it an act of justice to him and the community, to express our entire confidence in his character, ability, and the manner of illustrating his subject, which, to use the words of a daily journal, "is couched in such delicate as well as perspicuous language, that the most fastidious could find no fault, nor the idlest curiosity go away unimproved."

Resolved, That a committee of three be appointed to tender to Dr. H. the thanks of the class for his courtesy to the members in affording them every facility for obtaining information upon the subject of his Lectures, and that he be requested to repeat the course at the earliest period consistent with his other engagements. 
Published in all the Philadelphia daily papers, and signed by one hundred and forty of the most respectable and influential inhabitants.

(See similar resolutions, with over two hundred names attached, in the Philadelphia daily papers subsequently.)

\section{From the Philadelphia Daily Papers.}

At a meeting of the ladies composing Dr. Hollick's Class, held on Wednesday afternoon, in the Lecture Room of the Museum, the following resolutions were unanimously adopted, and ordered to be published in one or more of the city papers :

Resolved, That we have listened with great pleasure and interest to Dr. Hollick's Lectures, and are happy to add our testimony to the many already recorded in behalf of such Lectures; and regarding Dr. Hollick as a benefactor of his race, and especially of our sex, we cordially wish for him abundant success, and ample reward in the consciousness of doing good.

Resolved, That we will exert ourselves to induce our female friends and acquaintances to avail themselves of the great and rare privilege of obtaining the valuable instruction imparted in these Loctures in so chaste and dignified a manner.

Signed on behalf of the meeting by

SUSAN WOOD, President.

SARAH WEBB, Secretary.

Dis With over fifty names attached thereto.

(See also similar resolutions, with over three hundred names attached, subsequently.)

These are but a very few out of an immense number of similar notices, North, East, South, and West; and I can truly say that I never asked nor paid for a single one of them. They were all freely and spontaneously given.

Besides these I had a vast number of letters from individuals, thanking me for the lectures, and was presented by my audience, on one occasion, with a handsome writing-desk and gold pen, and on another occasion with a commemorative GCLD MEDAL.

These reminiscences are introduced to show how the lectures were received by those who heard them. Many persons, in all the cities where I lectured, still re member them, and often write to me to know if I shall ever resume tuem. This, however, I cannot now do. The exigencies of my practice are such that I cannot leave New York.

It gives me great pleasure, however, to see that my example has been extensively followed. Popular lectures on Physiology, illustrated in various ways, are now common everywhere, and anatomical museums are established in most of our principal cities, open to the public at large. No one is offended at such things now ; and a man would be laughed at to-day who should say that the people ought not to see and hear such things. But when I first began to lecture, this sentiment was quite common, and had to be met. One of the first anatomical museums established in New York City was complained of to the authorities, as an indecent exhibition, and an effort was made to have it suppressed. Public sentiment, however, was then somewhat enlightened, and the attempt failed. Among those who volunteered their evidence in favor of such establishments, and argued for their utility, nay, even necessity, was a celebrated Professor of Anatomy and Surgery in the College of Physicians and Surgeons, since dead.

The same gentleman also gave me great encouragement, and once remarked to 
me: "Doctor, if you live to be old, you will see the most orthodox physicians and surgeons of the day following your example. They will give popular lectures, and write popular books on the very subjects you are lecturing upon. They will have to do it, or the people will turn their backs on them, and get such informition elsewhere."

The result has shown how well he forecast the future. Professors in colleges do write such books, and eminent men connected with the profession give popular lec. tures, such as they dare not have thought of a few years ago.

To me it seems a waste of time to argue further the advantage of knowledge over ignorance, nor is it necessary; for the public mind now sees that advantage clearly enough.

It is equally unnecessary to contend for the right of the people to the possession of knowledge of any kind which they may desire. Anil yet I have formerly heard this right denied, and the assertion made that all knowledge such as given in my lectures should be confined exclusively to professional men; that the common people had no right to it; and that any one trying to impart it to them should be punished by law.

Such sentiments prevail, even at the present day, among a very few; but the great public voice is heard so unmistakably demanding knowledge as a right on every subject interesting to humanity, not asking it as a favor from any one, that no one dare openly say that demand shall be refused.

It used to be contended as one argument against popular instruction on anatomy and physiology, that the amount of it which could be given was too small to be of any use. This, however, is a great mistake. The smallest amount is useful, and better than none; but setting aside this, and the obvious fact that we must begin by little to arrive at more, it is not true that the instruction given is so very small. The means of illustration we possess now, and the extent to which such subjects have been simplified, enable us to give an amount of real practical information to a non-professional audience, such as even medical men could not get a generation back. Yes; some of the greatest medical men, even a few years ago, would have been glad of the advantages, in the way of instruction on the topics we are speaking of, that are now possessed by twenty-five-cent audiences of common people!

For myself, I rejoice at this, and trust the day will come, and soon too, when all restriction, and all mystery, and all fear in regard to knowledge of any kind shall be swept away into the limbo of the past!

It has always been a consolation to me that I have been able to do something, even if it be butlittle, towards enlightening the popular mind, especially on those muchneglected subjects which have more especially engaged my attention. While I live, my labors shall be continued in the same direction; and with greater experience, and more extended research, I trust my present and future efforts may be more effective than those I have made before. 
My books originated from the lectures. Many people who could not attend the lectures wished for the information they gave, and many who did attend were desirous of having that information always by them, in an available form. I was therefore repeatedly requested, by my audiences and by others, to write out the Lectures, and publish them, which I eventually did.

The first book I wrote was a small treatise called "The Origin of Life in Plants and Animals." It obtained immediately an immense sale, and I soon had to revise and enlarge it. It was then published in the new form as "The Marriage Guide," which became still more popular, running to 200 editions!

The next work was one for men, called "The Male Generative Organs, in Health and Disease." This was songht for with avidity from the first, and has gone through numerous editions.

One for women followed next, called "The Diseases of Woman familiarly explained," which was equally popular.

For married women there was still another, called "The Matron's Manual of Midwifery and Childbirth," also for private and popular use. This has become a standard book, always in demand.

These books were all written for popular and private use, by non-professional people. They were intended to give just that kind of information, on the topics treated upon, which all intelligent people desire to possess, and which my experience has shown me is the most practically useful.

I said to myself, "Here are men and women constantly coming to consult me on these matters, either as suffering patients, or as earnest seekers after knowledge, and I have to satisfy them all individually. Now, why cannot I publish my consultive explanations in a plain, practical form, so that they may satisfy those who do not wish for a personal interview, or who cannot, for one reason or another, have one?" And this was my leading idea in the manner of writing these several books. I wished to consider my readers as so many patients, or seekers after knowledge, coming to consult me, and I spoke to them, in these works, just as I should have done in my office. In the books, in short, I merely consulted with, instructed, and advised a large number at once, speaking to them in the same way, and prescribing for them just as I should have done had they all come in separately, and paid me five doliars each as patients.

This, then, is how the books originated, and this sums up their character. I will venture to assert that nothing can be found in one of them that is not scientifically true, or in any way whatever offensive to either morality or good taste. Noto withstanding they are strictly scientific, however, they are so written that any one can understand them, and they are all made practically servicable for private use. In a word, they are PEOPLE's BOoKs, such as American citizens desire, and even demand, from those that they consider popular teachers.

Of the success of these books it is necessary for me to say but little. They have 
gone throngh hundreds of editions for many years, and are in demand to-day just as they were at first. They have been commended in all ways, publicly and privately, and I have yet to hear of the first well-founded objection to them. The commendatory letters and notices I have received about them would fill a large volume, and, as an agent wrote me from the West, "They have become, over a large part of the country, household books, so that not a house, cabin, nor miner's camp can be found without them for hundreds of miles. There are few men more extensive. known than you are, or more appreciated."

The number of the books, although convenient for those who wished for infor. mation on one special matter only, was, nevertheless, not so well for those who wished the information contained in all of them, but who did not want to buy several separate works. And this led to the issuing of the present volume, which contains the matter of all the separate works, and much more besides! thus giving an opportunity for any one to possess in a single volume, and in a compact form, the whole series, with all the new information in addition, at much less cost.

It will be understood, therefore, that there is nothing in the single volumes that is not in this one, and that it contains also an amount of new matter fully equal to a new volume. The old matter has also been revised and corrected, and all brought down to the latest date. Any persons, therefore, purchasing this book may feel assured that they possess, in a plain, practically useful, and popular form, all the information on the special topics it treats upon that is now available.

Among the new matter will be found a full and plain account of the new discoveries, opinions, and investigations relating to the origin of life, spontaneous generation, and evolution. This matter I had intended to publish separately, as a new edition of my first book, "The Origin of Life" (long since out of print, and superseded by "The Marriage Guide"); but, upon second thought, it seemed best to make it a part of this new and complete issue, which thus comprises all I have written on these matters.

I need scarcely say that the original book on the Origin of Life was necessarily incomplete, because, at that date, most of the interesting and important facts now known on that subject were not discovered. In fact, since I first wrote that book, the whole science of Biology (life) has been remodeled, and the views of scientific men, on many topics concerning man, and life in general, are completely changed. This is especially the case with regard to the primal origin of life, and the evolution of living organisms from simple original forms.

It is now well established that man is, in no sense, apart from nature, but only a portion of it; and, to understand him properly, he must be studied in connection with other beings. I have, therefore, commenced this work with an explanation of man's true place in nature, showing how he is related to the animals below him, and how both he and they, probably, first began. This is followed by a further 
ernlanation of the manrer in which all indiridual life commences now, and how it is maintained.

This includes the relations between liring beings and inorganic material, cell-life. and spontaneous generation. Afterward follows the rarious modes of reproduction in plants and animals, with full details in regard to human beings, including all the diseases incident to the generatire organs in both sexes, with rules for their prevention mù cure.

The whole book is so illustrated with cuts and plates that any one can readily understand erery topic. It is, therefore, a reliable prirate instructor for those who wish to understand themselves, and a confidential hygienic and medical adviser, to which all can refer at need.

DR. F. HOLLICK,

P. 0. Box 3606 , New York City. 


\section{CONTENTS.}

\section{PAR T I.}

PRGLTMTNART EXPLANATIONS ON MAN, MATTER, AND FORCR.

\section{CHAPTER I.}

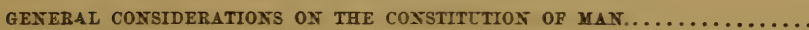

CHAPTER II.

DIFFERENCE BETWEEN WHAT ARE CALLED LIVING BODIFS AND INORGANIC

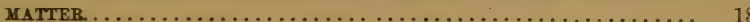

\section{P A R T II.}

LFF; WHAT IT IS.-PROTOPLASM, THE MATTER OF LIFE-PRTMARY OR SPONTANEOCS GEIERATIOX, TATCRAL AXD ARTIFICLAL,-THE DIFFERENT KINDS OF LIFE-SIMILARITY BETWEWY

PLANTS AND ANTMALS.

CHAPTER III.

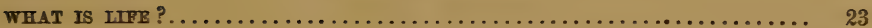

\section{CHAPTER TV.}

ORIGIN OF PROTOPLASM, ITS LSES, AND ITS PROGRESSION FROM THE ITORGAIIC TO THE ORGANIC TORLDS.................... 25

\section{CHAPTER V.}

BPONTANEOUS GENERATION, AND ONEXESS OF LIFE ALL THROUGH YATLRE. 


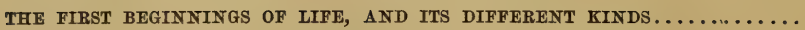

\section{CHAPTER VII.}

THF DIFFERENCE BETWEEN ORGANIC AND INORGANIC MATTER, AND THE RE-

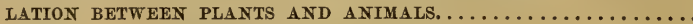

\section{P A R T III.}

CELLS AND CELL LIFE.-ANIMAL AND VEGETABLE CELLS, AND THE DIFFERENCE IN THEIR COMPOSITION.-THE LOWEST FORMS OF LIVING BEINGS : THEIR UNIVERSAL DIFFUSION AND VARIETIES.-THE GERM THEORY OF DISEASE.

CHAPTER VIII.

THE FIRST FORMS OF LIVING ORGANISMS-VESICLES AND CELLS. . . . . .

CHAP'TER IX.

UNIVERSALITY OF THE LOWER ORGANISMS, AND THEIR VARIETIES........

\section{P A R T IV.}

AGGREGATION OF CELLS INTO COMPOUND ORGANISMS.

CHAPTER X.

AGGREGATION OF CELLS INTO COLONIES AND COMPOUND ORGANISMS.......

\section{P A R T V.}

EVOLUTION.-ORGANIC AND EMBRYONIC DEVELOPMENT

CHAPTER XI.

EVOLUTION

A Change of Species.................................. 109 


\section{PAR T VI.}

CLASSIFICATION OF ANIMALS, AND THEIR DIFFERENT TYPES.

CHAPTER XII.

PAGE

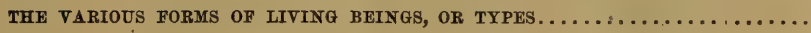

CHAPTER XIII.

THE DIFFERENT TYPES OF ANIMALS.

CHAPTER XIV.

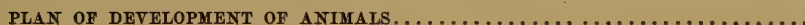

\section{PAR T VII.}

REPRODUCTION IN PLANTS AND ANIMALS, SEXUAL AND NON-SEXUAL, INCLUDING HERMAPHRODISM.

CHAPTER XV.

REPRODUCTION

CHAPTER XVI.

NON-SEXUAL REPRODUCTION

CHAPTER XVII.

SEXUAL REPRODUCTION

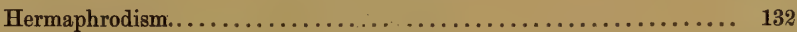

The Two Sexes united in One Individual.................. 13?

\section{P A R T VIII.}

DIOCIOUS GENERATION,-THE TWO SEXES DIVIDED,-THE FEMALE EGG AND MALE SPERM.-CONJUNCTION OF THE SEXES.

-IMPREGNATION.

\section{CHAPTER XVIII.}

THE SEXES DIVIDED, THE MALE ORGANS BEING IN ONE INDIVIDUAL AND THE FEMALE IN ANOTHER........................ 
Dimeious. .......

The Ovarium or Ovary, with the Ovum or Egg................... 141

The Ovary or Ovarium, and the Ovum.................... 143

The Testicles and the Semen.......................... 161

Anomalies in the Size and Apparent Number of the Testes.......... 164

The Semen and the Seminal Animalcules................... 170

CHAPTER XIX.

IMPREGNATION, EXTERNAL AND INTERNAL.................... 184

Pouchet's Ten Fundamental Laws which Govern the Process of Fecundation.................................... 184

When Conception is Possible and Impossible................. 191

Manner of Impregnation............................. 194

CHAPTER XX.

SEXUAI UNION, OR COPULATION............................. 203

\section{P. A R T IX.}

THE ORGANS OF GENERATION IN BOTH SEXES, AND IN THE DIFFERENT TYPES OF ANIMALS.

CHAPTER XXI.

THE ORGANS OF GENERATION IN OVIPAROUS ANIMALS $\ldots \ldots \ldots \ldots \ldots \ldots 211$

\section{CHAPTER XXII.}

ORGANS OF GENERATION IN VIVIPAROUS ANIMALS. . . . . . . . . . . 220

Human Female Organs............................. 220

Proofs of Violation.................................. 2288

The Fallopian Tubes................................. 230

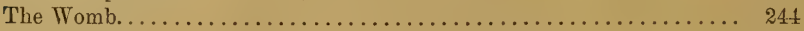

The Vagina...................................... 238

Human Male Organs................................ 241

Absence and Malformation of the Penis..................... 247

Want of Development, or Congenital Small Size of the Penis......... 248

Generative Organs of the Marsupials....................... 258

Monotremata..................................... 261

Non-Sexual Generation.............................. 263

Sexual Generation.................................... 263

Manner of Development.............................. 263 


\section{P A R T X.}

REPRODUCTIVE ORGANS IN PLANTS, AND THEIR CORRESPONDENCE WITH THOSE OF ANIMALS.

CHAPTER XXIV.

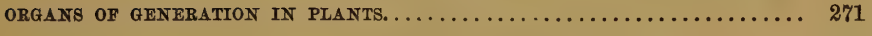

\section{P A R T XI.}

PARTHENOGENESIS, OR VIRGIN GENERATION ; AND THE ALTERNATION OF GENERATIONS.

CHAP'IER XXV.

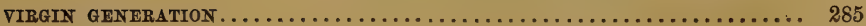

\section{P A R T XII.}

DEVELOPMENT OF THE NEW BEING.

\section{CHAPTER XXVI.}

FIRST CHANGES OBSERVED IN THE OVUM AFTER FECUNDATION, AND THE WAY THE EMBYRO BECOMES CONNECTED WITH THE MOTHER........

\section{CHAPTER XXVII.}

DEVELOPMENT OF THE NEW BEING FROM THE GERM............. 302

CHAPTER XXVIII.

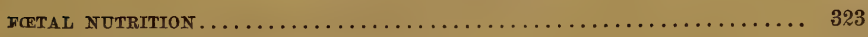

Peculiarities of the Fœtal Circulation................... 325 


\section{CHAPTER XXIX.}

EXTRA-UTERINE CONCEPTION, AND UNNATURAL OR MONSTROUS GROWTHS...

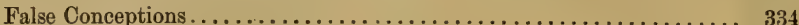

Deformities and Monstrosities......................... 335

Remarkable Case of a Fotal Monstrosity.................. 337

Monstrosity.-Deficiency of Parts...................... 338

Redundancy of Parts........................... 340

Origin of Monstrosities........................... 345

Double People................................. 344

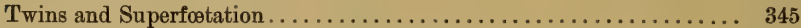

Plural Births..................................... 347

Miscellaneous Matters Connected with the Foregoing Topics........ 350

\section{CHAPTER XXX.}

DURATION OF PREgNANCY, AND PERIOD WHEN THE CHILD CAN LIVE..... 353

CHAPTER XXXI.

MENSTRUATION

\section{CHAPTER XXXII.}

CAUSE OF THE DIFFERENCE IN SEX, AND PRODUCTION OF SEX AT WILL ....

Production of Sex at Will.

Rules to Insure Either Sex

\section{CHAPTER XXXIII.}

DOUBTFUL OR DOUBLE SEX.-HERMAPHRODISM. . . . . . . . .

Mr. Wright's Free-Martin, five years old ................. 385

Mr. Arbuthnot's Free-Martin . ...................... 386

\section{PART XIII.}

MISCELLANEOUS TOPICS CONNECTED WITH MARRIAGE.

CHAPTER XXXIV.

ON CONNECTION AFTER CONCEPTION, AND ITS CONSEQUENCES..........

\section{OHAPTER XXXV.}

INFLUENCE OF THE IMAGINATION OVER THE GENERATIVE FUNCTIONS, AT

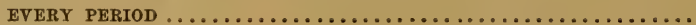


CHAPTER XXXVI.

\section{CHAPTER XXXVII.}

INFLUENCE OF DRUGS OVER THE SEXUAL POWERS

\section{CHAPTER XXXVIII.}

ON THE PREVENTION OF CONCEPTION.

\section{CHAPTER XXXIX.}

TOPICS OF SPECIAL INTEREST

Influence of Food and Drink over the Sexual Powers............ 431

Proper Time for Sexual Indulgence ........................ 433

Effects of Over-Excitement and Abstraction of Mind. ........... 434

Duration of the Sexual Power........................... 435

Proper Age for Marriage........................... 438

Advantage of Temporary Separation ..................... 439

Precautions at the Time of Marriage.................... 439

\section{CHAPTER XL.}

PHILOSOPHY OF AMATIVE INDULGENCE

\section{CHAPTER XLI.}

INFLUENCE OF THE BRAIN OVER THE GENERATIVE POWERS.

\section{CHAPTER XLII.}

STERILITY, AND ARTIFICIAL IMPREGNATION

\section{CHAPTER XLIII.}

AGE WHEN BOTH SEXES BEGIN TO BE CAPABLE OF BEING PARENTS, AND WHEN

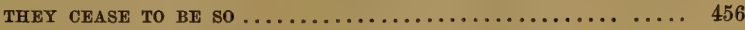

On the State of Mind in Females at the Time of Delivery ......... 460

\section{CHAPTER XLIV.}

HEREDITARY DESCENT, AND IMPROVEMENT OF THE RACE.......... 462

Intermarriage and Pairing $\ldots \ldots \ldots \ldots \ldots \ldots \ldots \ldots \ldots \ldots \ldots \ldots \ldots, 473$

Improvement of Breed $\ldots \ldots \ldots \ldots \ldots \ldots \ldots \ldots \ldots \ldots \ldots \ldots \ldots \ldots \ldots \ldots \ldots \ldots$ 
HYBRIDS, HYBRIDIZATION, AND CROSS-BREEDING $\ldots \ldots \ldots \ldots \ldots \ldots \ldots, 481$

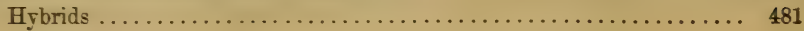

\section{PART XIV.}

SPECIAL DISEASES OF THE GENERATIVE ORGANS, MALE AND FEMALE.

\section{CHAPTER XLVI.}

DISEASES, MALFORMATIONS, AND DERANGEMENTS OF THE MALE STSTEM.... 489

Hydrocele, or Dropsy of the Testicle .................... 489

Sarcocele, or Chronic Fleshy Swelling of the Testicle ........... 495

Fungus of the Testicle............................... 497

Ossification of the Testicle............................. 502

Arrest of Derelopment and Wasting of the Testes............. 502

Tubercular Disease, or Consumption of the Testicle............ 505

Foreign Bodies in the Scrotum along with the Testicles .......... 506

Nerrous Affections of the Testicles. ...................... 506

Spermatocele, or Swelling of the Testes from Engorgement of Semen .. 509

Scrotocele, or Rupture of the Intestines or Omentum into the Scrotum. 510

Taricocele and Circocele, or Swelling of the Veins of the Scrotum and

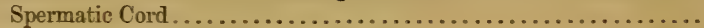

Hæmatocele, or Swelling of the Scrotum and Spermatic Cord from the

Effusion of Blood................................. 513

Prurigo, or Itching of the Scrotum . . . . . . . . . . . . . . . . 513

Elephantiasis Scroti.................................. 514

Falling of the Spermatic Cord......................... 516

Relaxation of the Scrotum............................ 517

Diseases of the Vasa Deferentia.......................... 518

Diseases of the Seminal Vesicles .......................... 519

Hypospadias. . . . . . . . . . . . . . . . . . . . . . . . . . . . . . 519

Epispadias ....................................... 521

Phymosis ............................................ 522

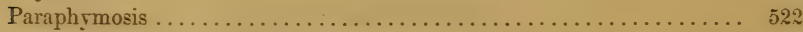

Paralysis of the Muscles of the Penis....................... 523

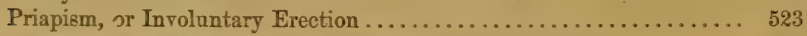

Diseases of the Urethra and the Parts contained therein ........... 526

The Prostate Gland.................................. 529

Excessire Sensibility of the Genital Organs.................. 531

\section{CHAPTER XLVII.}

RPERMITORRHCA, OR EXCESSTVE LOSS OP SEMEN $\ldots \ldots \ldots \ldots \ldots \ldots \ldots \ldots \ldots \ldots \ldots \ldots \ldots$

Causes of Spermatorrhøa.......................... 536 
Symptoms by which the Spermatorrhœea may be Detected......... 553

Impotence from Involuntary Emission . . . . . . . . . . . . . . . 555

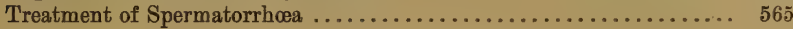

\section{CHAPTER XLVIII.}

THE INFLUENCE OF MEDICINES IN PRODUCING AND CURING IMPOTENCE AND SPERMATORRHEA .

CHAPTER XLIX.

MASTURBATION AND OTHER SEXUAL ABUSES

CHAPTER L.

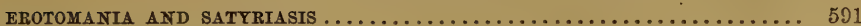

CHAPTER LI.

GENERAL REMARKS ON THE PRESERVATION AND RESTORATION OF THE SEXUAL POWERS.

\section{PART XV. \\ DISEASES OF THE FEMALE ORGANS.}

CHAPTER LII.

MALFORMATION, OR IMPERFECT DEVELOPMENT OF THE DIFFERENT FEMALE

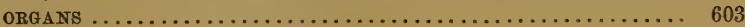

Cohesion of the External Lips......................... 603

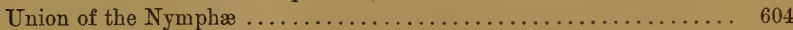

Unnatural Growth of the Nymphæ ...................... 604

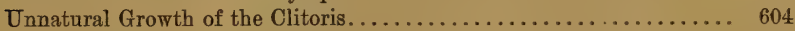

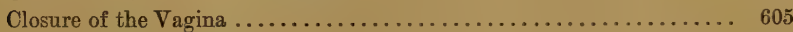

Partial Closure, or Narrowness of the Vagina ................ 606

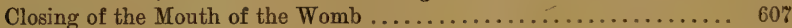

Absence of the Vagina, or Womb, or both ................. 607

\section{CHAPTER IIII.}

DISPLACEMENT OR WRONG POSITION OF THE FEMALE ORGANS.......... 609

Prolapsus Uteri, or Falling of the Womb................. 609

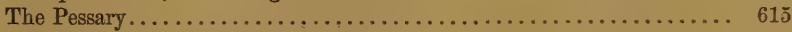

Treatment and Probability of Cure .......................... 619 
Anteflexion and Retroflexion of the Womb.......................... 627

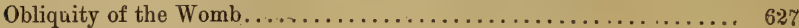

Inversion of the Womb............................... 627

Fixture of the Womb, or Immobility...................... 628

Hysterocele, or Hernia of the Womb....................... 630

Cystocele, or Hernia of the Bladder...................... 630

Vaginal Enterocele, or Hernia of the Intestine into the Vagina....... 632

Inversion aud Swelling of the Lining Membrane of the Vagina....... 632

\section{CHAPTER LIV.}

VIT.3. IND ORGANIC DISEASES $\ldots \ldots \ldots \ldots \ldots \ldots \ldots \ldots \ldots \ldots \ldots \ldots \ldots \ldots \ldots \ldots \ldots, 634$

Inflammation of the Vulva and External Lips................ 634

Prurigo of the Vulva, or Itching of the External Parts............ 635

Vaginitis, or Inflammation of the Vagina ................... 636

Metritis, or Inflammation of the Womb .................... 636

Engorgement, or Enlargement of the Womb................. 640

Scirrhous, or Cancerous Engorgement of the Womb ............ 641

Rheumatism of the Womb ........................... 642

Leucorrhœea, or Fluor Albus ........................... 643

Polypus of the Womb ............................... 648

Hydrometra, or Dropsy of the Womb..................... 650

Hydatids of the Womb .............................. 651

Calculus, or Stone in the Womb and Vagina ................. 654

Inflammation of the Ovaries and Fallopian Tubes................ 655

Dropsy of the Ovaries and Fallopian Tubes .................. 657

\section{CHAPTER LV.}

DERANGEMENT OF THE FUNCTIONS OF THE FEMALE ORGANS, AND OF THE NERVES. . . . . . . . . . . . . . . . . . . . . . 660

Amenorrhoea, or Non-appearance, or Stoppage, of the Menses....... 660

Dysmenorrhøea, or Painful Menstruation .................... 666

Profuse Menstruation, or Flooding...................... 670

Chlorosis, or Green Sickness........................... 673

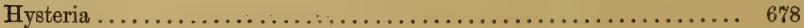

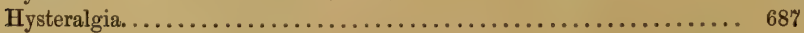

\section{CHAPTER LVI.}

GENERAL REMARKS ON FEMALE HEALTH AT EVERY PERIOD OF LIFE, AND ON CERTAIN PECULIARITIES OF FEMALE DISEASE, AND ITS TREATMENT.

Puberty and Menstruation............................... 689

The Change of Life .................................. 693

Useful Hints for all Ages $\ldots \ldots \ldots \ldots \ldots \ldots \ldots \ldots \ldots \ldots \ldots \ldots \ldots \ldots . \ldots \ldots$ 
CHAPTER LVII.

ON SOLITARY VICES, AND OTHER ABUSES

\section{CHAPTER LVIII,}

INTERESTING FACTS RELATING TO PAIRING AND COURTSHIP $\% 12$

\section{CHAPTER LIX.}

MARRIAGE, AND THE POSITION OF WOMEN, AMONG DIFFERENT PEOPLE, AND AT DIFEERENT PERIODS. . . . . . . . . . . . . . . . . . .

\section{PART XVI.}

MIDWIFERY, AND THE DISEASES AND ACCIDENTS PECULIAR TO PREGNANCY AND CHILDBIRTH.

\section{CHAPTER LX.}

STRUCTURE OF THE PRINCIPAL ORGANS AND PARTS.............. 757

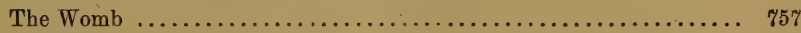

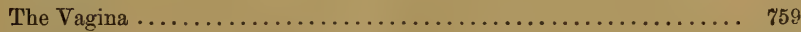

The Vulva ..................................

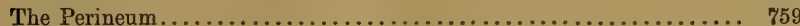

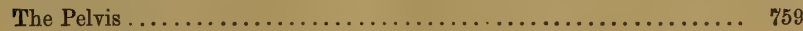

\section{CHAPTER LXI.}

THE BREAST

\section{CHAPTER LXII.}

SIGNS OF PREGNANCY, AND THE MEANS OF DETECTING IT........... 767

Presumptive Signs . . . . . . . . . . . . .

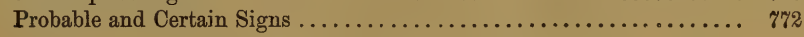

\section{CHAPTER LXIII.}

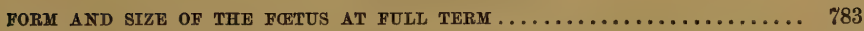

Size and Form of the Body . . . . . . . .

Size and Form of the Head. ............................ 783

Attitude of the Fretus at the Full Term .................. 785 
THE APPENDAGES OF THE FETUS AT TERM $\ldots \ldots \ldots \ldots \ldots \ldots \ldots \ldots \ldots \ldots \ldots \ldots \ldots, 787$

The Membranes................................... 787

The Placenta.....................................

The Umbilical Cord $\ldots \ldots \ldots \ldots \ldots \ldots \ldots \ldots \ldots \ldots \ldots \ldots \ldots \ldots \ldots \ldots \ldots \ldots, \quad 788$

\section{CHAPTER LXV.}

PRESENTATIONS AND POSITIONS OF THE FETUS. . . . . . . . . . . . . . 789

Presentations....................................... ${ }_{789}^{78}$

Positions......................................... ${ }^{789}$

Mode of Ascertaining the Presentation and Position............. 791

\section{CHAPTER LXVI.}

THE MECHANISM OF DELIVERY, IN A PRESENTATION OF THE HEAD ....... 794

The Left Anterior Occipito-Iliac Position.................... 794

Mechanism of Delivery in all other Positions of the Head........... 796

General Remarks on the Different Positions of the Head........... 797

\section{CHAPTER LXVII.}

MECHANISM OF DELIVERY IN PRESENTATIONS OF THE LOWER EXTREMITIES... 799

Delivery in a Breech Presentation in the Left Anterior Sacro-Iliac Posi-

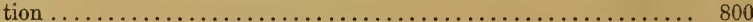

Delivery by the Breech in the Right Posterior Sacro-Iliac Position..... 801

Delivery by the Breech in the Full Posterior, or Sacro-Sacral Position.. 801

General Remarks on the Presentations of the Lower Extremities...... 801

\section{CHAPTER LXVIII.}

MECHANISM OF DELIVERY IN PRESENTATIONS OF THE FACE .......... 803

Delivery in the Right Posterior Mento-Iliac Position of the Face...... 803

Delivery in Other Positions of the Face.................... 804

\section{CHAPTER LXIX.}

MECHANISM OF DELIVERT IN PRESENTATIONS OF THE TRUNK $\ldots \ldots \ldots \ldots \ldots$

Mechanism of Delivery in Presentations of the Trunk by Spontaneous 
THE PHYSIOLOGY OF SPONTANEOUS DELIVERY, OR CHILDBIRTH, AND THE MANNER OF CONDUCTING A NATURAL LABOR............ 808

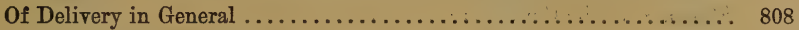

Different Kinds of Delivery........................... 808

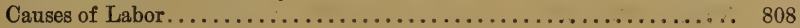

Signs of Delivery ................................. 809

\section{CHAPTER LXXI.}

THE PROGRESS, PHENOMENA, AND DURATION OF NATURAL LABOR........ 810

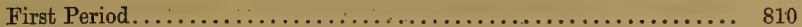

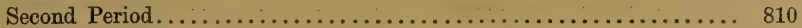

Duration of Natural Labor. ........................ 813

\section{CHAPTER LXXII.}

THE CONDUCT OR MANAGEMENT OF A NATURAL LABOR............ 814

Preliminary Requisites. .......................... 814

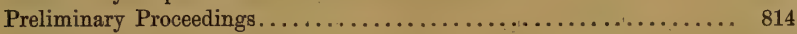

Preparations for the Delivery .......................... 816

Attendance after the Preparations are Made, and During the Delivery.. 81?

Delivery of the After-Birth, or Placenta and Membranes......... 821

Attentions to the Female after the Delivery of the After-Birth....... 822

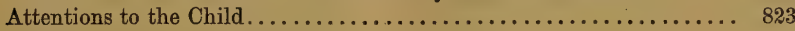

Accidents which may Happen . . . . . . . . . . . . . . . . . . 824

Subsequent Attentions to Mother and Child................. 825

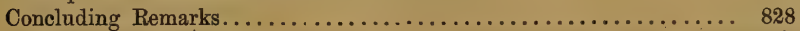

Protracted and Difficult Labors. . . . . . . . . . . .

\section{CHAPTER LXXIII.}

IHE CAUSES AND CONSEQUENCES, TO BOTH MOTHER AND CHILD, OF PROLONGED LABOR........................... $\$ 30$

The Consequences of Prolonged Labor. ................... 830

Causes Connected with the Mother which may Impede Labor, or Make

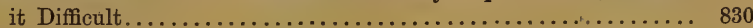

Inertia, or Want of Sufficiently Powerful Contraction in the Womb. .. 830

Rigidity of the Mouth of the Womb, Vagina, and Vulva........... 832

Obliquities of the Womb. ............................... 833

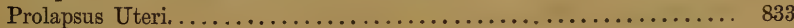

Smallness, and Deformity of the Pelvis...................... 834

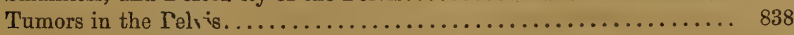

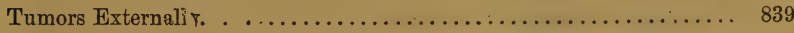

Obstructions in the Vagina, and Narrowness or Obstinate Resistance of the Vulva and Pe.iweurn....................... 840 
Causes connected with the Child, or Children, which may Impede Delivery, or make it Difficult and Dangerous................. 840

Procidentia of the Umbilical Cord........................ 840

Shortness of the Cord .............................. 842

Descent of Other Parts with the Head ..................... 842

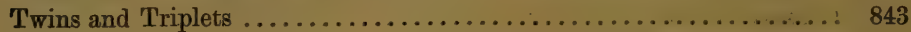

Excessive Size of the Foetus, or the Diseased Development of Certain

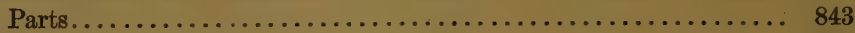

Ossification of the Head .................................. 844

Various Presentations and Positions of the Fœtus, from which the Labor may be Difficult or Protracted ....................... 844

Presentations of the Lower Extremities................... 845

Presentations of the Shoulder $\ldots \ldots \ldots \ldots \ldots \ldots \ldots \ldots \ldots \ldots \ldots \ldots, 84 \%$

\section{CHAPTER LXXIV.}

UTERINE HEMORRHAGE, OR ELOODING, DURING LABOR.

\section{CHAPTER LXXV.}

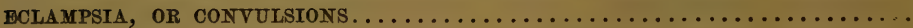

\section{CHAPTER LXXVI.}

RUPTURE OF THE WOMB OR VAGINA

CHAPTER LXXVII.

OPERATIONS WITH INSTRUMENTS............................ 864

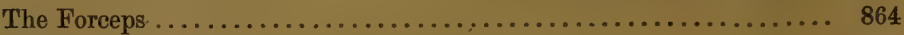

Other Instruments................................. 868

\section{CHAPTER LXXVIII.}

OPERATIONS WITH THE HAND

Turning....

\section{CHAPTER LXXIX.}

THE DISEASES OF WOMEN DURING PREgNANCY, AND IN CHILDBED.......

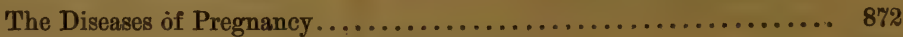

Sympathetic Diseases oćcurring during Pregnancy............ 872

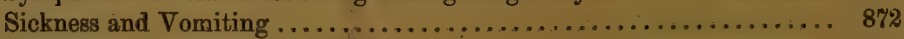

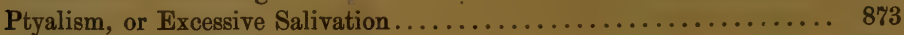

Odontalgia, or Toothache............................ 874

Derangements of the Appetite..................... 875 
PAGB

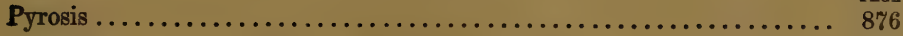

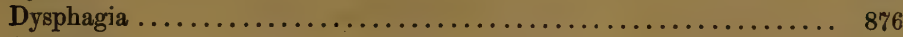

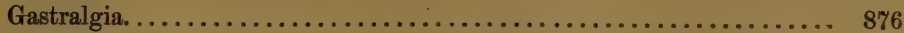

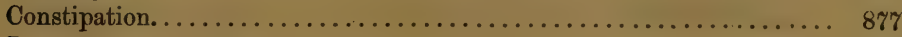

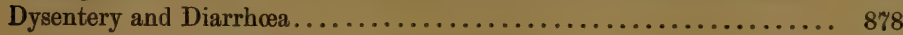

Dyspncea, or Difficulty of Breathing. ................... 879

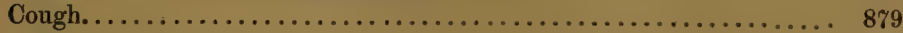

Palpitation of the Heart. . . . . . . . . . . . . . . . . . . . 880

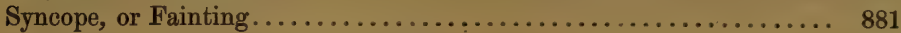

Headache and Dizziness in the Head.................... 881

Insomnia, or Sleeplessness . . . . . . . . . . . . . . . . . . . . . 882

Temporary Affections of the Sight, Hearing, and Smell . . . . . . . . 883

Disordered Judgment, Inclinations, and Propensities. . . . . . . . . . . 884

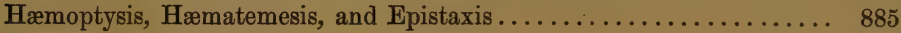

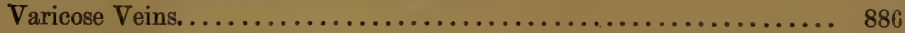

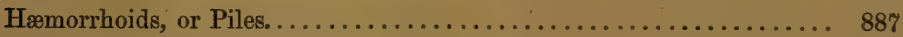

CEdema, or Watery Swellings. . . . . . . . . . . . . . . . . . . . 888

Hydrorrhœa, or Profuse Discharge of Water . . . . . . . . . . . 888

Pustules, and Mucous Discharges........................... 888

Derangements of the Urinary Organs. . . . . . . . . . . . . . . . 889

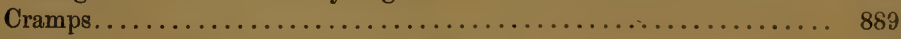

Pruritus, or Itching of the External Parts............... 890

CHAPTER LXXX.

IDIOPATHIC OR PRIMARY DISEASES INCIDENT TO PREGNANCY $\ldots \ldots \ldots \ldots \ldots 891$

Flooding or Hemorrhage. . . . . . . . . . . . . . . . . . . . . 891

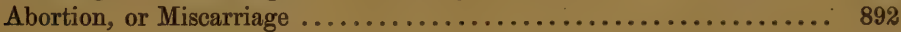

\section{CHAPTER LXXXI.}

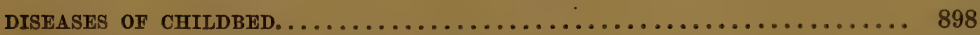

Puerperal Fever, or Childbed Fever..................... 898

Affections of the Breast occurring after Pregnancy.............. 903

Bronchocele, or Swelling in the Throat. ................... 906

Phlegmasia, Alba-dolens, or Milk Leg.................... 907

Trouble with the Urine............................... 908

\section{CHAPTER LXXXII.}

USE OF CHLOROFORM IN MIDWIFERY.

An Inquiry in io the Utility and Propriety of Preventing the Pain and Suffering which usually attend Childbirth, with an Account of the Means to be employed for that Purpose. 


\section{A D D E N U M.}

ILLUSTRATIONS OF EVOLUTION AND THE PEDIGREE OF MAN.

\section{CHAPTER LXXXIII.}

EVOLUTION AND THE PEDIGREE OF MAN...................... 915 


\section{LIST OF ILLUSTRATIONS.}

\section{FULL PAGE PLATES.}

PL.ATE

I. The World during the Coal Period....................... 46

II. Sap-Gathering in a Canadian Forest.................... 59

III. Fungus Caterpillar .............................. 86

IV. Ovary of Human Female........................... 150

V. Expulsion of the Ovum, and formation of the Corpus Luteum ...... 152

VI. Ovary of a Rabbit, at various stages ..................... 154

VII. Ovary of a Trout, at various stages....................... 156

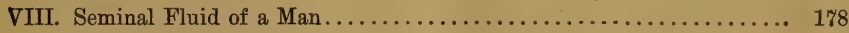

IX. Seminal Animalcules of the Frog........................ 180

X. Seminal Animalcules, and Egg, of a Rabbit ................ 182

XI. Generative Organs of a Bird......................... 214

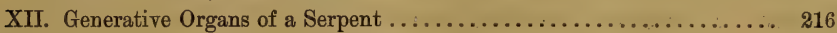

XIII. Generative Organs of Crustaceans...................... 216

XIV. The Surinam Toad, and Pouched Frog .................. 232

XV. The Female Uterus and its Appendages................... 240

XVI. The Human Male Generative Organs................... 242

XVII. Structure of the Penis and Testicle...................... 246

XVIII. Generative Organs of the Marsupials.................... $26 \mathrm{C}$

XIX. Kangaroo, with Young; and the Ornythorynchus............ 262

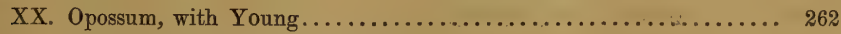

XXI. The Womb, after Impregnation ...................... 306

XXII. Human Embryo at a very early Period, Magnified.............. 308

XXIII. More Advanced Stages of the Embryo ; before third week, Magnified. 310 XXIV. Human Embryo at three weeks, and four weeks, Natural Size, and

Magnified............................. 312

XXV. Human Embryo at five, and six weeks, Natural Size, and Magnified. . 314 XXVI. Head of Human Embryo at five, six, seven, and eight weeks, Magni-

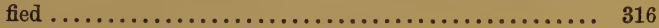
$\mathrm{xxxi}$ 
XXVII. Head of Human Embryo at two weeks, sixteen days, three weeks, four weeks, and five weeks old, Magnified............ 318

XXVIII. Embryo at seven and eight weeks, Natural Size, Magnified. ..... 320

XXIX. All the parts connected with the embryo on a Larger Scale...... 322

XXX. Development of the Genital Organs, before birth............ 324

XXXI. The Placenta, Umbilical Cord, and Fotus............... 326

XXXII. Extra Uterine Conception, Ovarian................... 332

XXXIII. Spermatic Cord, and Vessels of the Groin............... 418

XXXIV. Organs of the Chest and Abdomen................... 447

XXXV. Descent of the Testicle .......................... 533

XXXVI. Varieties of Scrotal Hernia....................... 486

XXXVII. The Womb and Embryo at three, and at six months, in a First

Pregnancy, and in a Subsequent one............. 774

XXXVIII. Ditto at four and five months ..................... 782

XXXIX. Ditto at eight and nine months.................... 788

XL. Comparison of the Male and Female bodies in Form and Size... 802

XLI. The Evolution of Life, and Pedigree of Man............. 914

XLII. Embryonic Development of a Chicken,Turtle, Salamander, and Fish 918

XLIII. Embryonic Development of a Man, a Rabbit, a Calf, and a Pig... 918

XLIV. Embryonic Development of the face in a Man, a Cat, and a Bat.. 918

\section{ENGRAVINGS.}

Figure 1.-Origin of Paramecia, from the Primary Pellicle........... 32

" 2.-Mode of Origin of Paramecia..................... 32

“ $\quad 3$-Ciliated Infusoria ........................... 33

“ 4.-First Stage of Hay Pellicle, forming Life Spots and Monads... 35

“ 5.-Second Stage of Hay Pellicle : Monads changing to Amœbæ... 35

“ 6.-Bacteria growing into Vibriones and other forms.......... 38

" $\quad$ \%-First Forms of Life in an Organic Infusion............. 39

“ 8.-Monera................................... 41

"6 9.-Development of Protomyxa...................... 41

" 10.-Leaf of the Drosera, showing tentacles bent over and erect... 49

“ 11.-Leaf of Drosera, with a bit of meat in the center, the tentacles all round bent down upon it.................... 49

s6 12.-The sensitive end of a leaf of the Dionera. The pointed bristles act like the teeth of a trap, and assist in holding the prey. $\quad 50$

13.-Leaf of Butterwort, or Pinguicula, showing how it curls over to

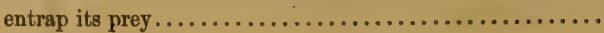


FiguRE 14.-Utricularia, or Bladderwort, showing the bladders, or sacs, in which it catches its prey........................

15. - One of the Bladders of the Utricularia, cut open and spread flat, to show the fringes, and the ribs which work the valve to

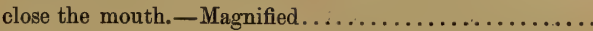

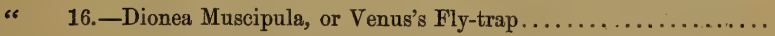
52

" 1\%.-Mimosa Pudica, or Sensitive Plant, asleep and awake........ 54

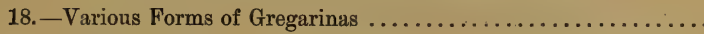
19. - Various Forms of Amøba-like Bodies, resulting from the bursting of Naviculas........................... 68

21. - The Gaping Leucophrys ...........................

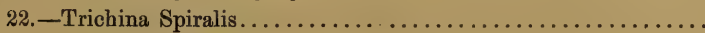

23. - A thin slice of ham, magnified, showing the Trichinas actively at work, boring among the muscular fibers ...

25.-Infusoria, dredged from the bottom of the Antarctic Ocean....

26. - The Surirella-Diatom

2\%.-Various Forms of Foraminifera

28. - Nummulites, from the Eocene Strata

29. - Miliola, magnified.

30.-Radiolaria

31.-Mucus, from the Nostril of a Diseased Horse, much magnified. 


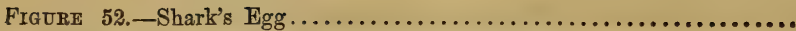

53.-Diagrammatic Section of a Bird's Egg

54.-Ovum of the Human Female.

55.-Ovary of the common Fowl

56.-Seminal Tubes and Appendages of the Testicles.

5\%.-Testicles of Helix.

168

58. - Testes of Scolopendra, or Centipede.

59. - Testicle of Staphylinus Maxillosus.

60. - Testicle of Silpha Obscura

61.-Male Organs of Buccinum, or Water Snail.

62.-External Sexual Organs of the Human Female, before mar-

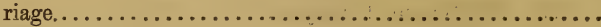

63.-External Organs of the Human Female after marriage.......

64. - The Womb shown cut open.

65.-Human Semen, Recent and Dried

66.-Perfect Hymen.

6\%.-After Violent Rupture

71, 12. - The Womb and its Appendages separate from the body.... 73.- Section of the Male Pelvis, to show the Situation of the Different Parts.

76.-Young Kangaroo in its Mother's Pouch, adhering to the Teat .

78, 79, 80, 81.-The Stamens, Pistils, and Germs, in Plants.......

82.-The Stamens placed on the lower part of the Petals..........

83. -The Stamens placed on the Germ Cell.

84.- Pistil of the Poppy.

85.-Pistil of the Madder-plant.

86. - The Vallisneria Spiralis.

8\%.-Various forms of Pollen Grains.

88. - A Plant of the Bastard Dittany, inclosed in a glass case to confine the Inflammable Vapors which arise from it

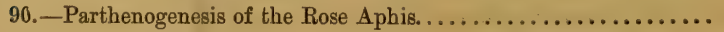


FIGURE 93.-Various stages in the Development of the Jelly-Fish..........

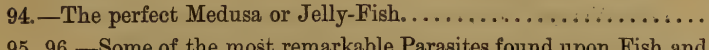

“ 95, 96.-Some of the most remarkable Parasites found upon Fish and

Crustaceans............................. 294

". $9 \%$-0vum from the Ovary of a Female Dog, in heat............

" 98.-The same Ovum as in the preceding plate, showing the disap-

pearance of the club-shaped cells................. 300

" . 99, 100.-Formation of the Decidua......................

" 101.-Division of the Yelk in Eggs of Ascaris. .................

" 102.-Division of the Yelk in Egg of the Dog.................

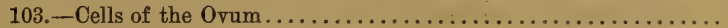

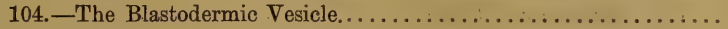

106.--Ovum more advanced, showing the beginning of the Brain and

Spinal Column............................ 304

10\%.-Diagram of the Human Ovum at about the Second Month of

Embryonic Life...............................

108. - Urinary and Generative Organs of the Human Embryo, when

about three and $a$ half inches long. ................. 313

109. -Connection between the Womb and Placenta................

111.-Double Monstrosity united at the Sternum ................

112. -Double Monstrosity united laterally.....................

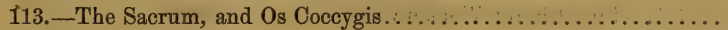

114, 115. -A Remarkable Case of Hermaphrodism..............

116. - Waist of Venus de Medicis.

11\%.-Waist of a Fashionable Lady.

304

304

328

337

338

339

352

381

417

417

118. -Remarkable Hybrid, from the New Forest. Drawn from Life

by George Landseer........................ 484

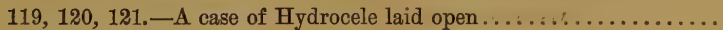

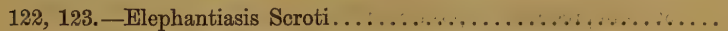

124. - Varicocele, Falling of the Cord, or Dropped Testicle.........

125. - Lateral Section of the Female Pelvis, to show the position of the

Organs in their Natural State.................... 610

126. - Lateral Section of the Female Pelvis, to show the position of the Womb in the First Stage of Prolapsus. . ............. 12\%-Lateral Section of the Pelvis, to show the position of the Womb, and other Organs, in the Second Stage of Prolapsus 128. -A Globe Pessary, supporting the Uterus. ................... 


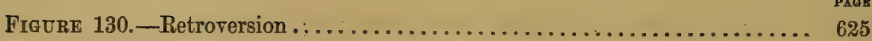

" 131. - Vertical Section of the Womb and Vagina, natural size...... 757

“ 132, 133, 134 and 135.-The Muscular Fibers of the Womb....... 758

" 136.-Bones of the Pelvis........................ 760

" $13 \%$ - Section of the Pelvis......................... 760

" 138.-Diameters of the Upper Strait. .................. 761

6، 139. - The Bones of the Pelvis viewed from below, looking through

the Inferior Strait, to show its Diameters.......... 761

" 140.-The Diameters of the Pelvis..................... 762

" 141. -Fotus at 3 months inclosed in the Membranes............ 763

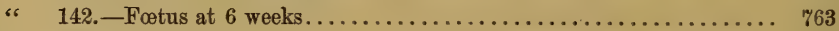

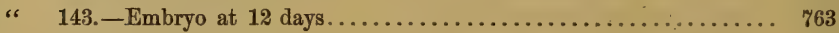

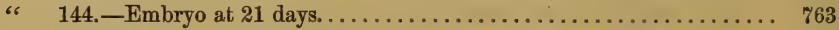

" 145. -Form of Fœtus at 45 days..................... 763

" 146. -The Breast.............................. 764

" 14\%. - View of the Breast about the fourth month............ 770

"6 14. $, 149,150$. - The form and size of the body, neck, and mouth of the Womb, at about the third, seventh, and ninth months. 7773

6 151. - Primipara, or the First Pregnancy...................

" 152.-Woman who has borne Children before.................

"6 153. - Mode of performing Ballotment to detect Pregnancy..........

6 154. - Neck of the Womb in a First Pregnancy, and in a Female who has borne Children before....................

“ 155. - First Child; Woman who has borne Children ............ 779

6 156.-Represents the Foetus in the most usual position, the head downward, and the back of it presenting to the left side...... 780

" 15\%.-Represents the Foetus in the next most frequent position, the head downward, but the back of it presenting to the right side. 774 $7 \% 4$ $7 \% 5$ 780

s6 158.-Shows the position of the Fœetus in a Presentation of the Pel-

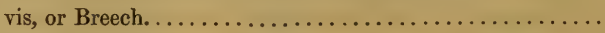
:81

159.-Represents the position of Twins, as most usually observed, one having a Head Presentation, and the other a Breech..... c6 160.-Neck of the Womb, at or near the end of nine months in a Primipara, and in a Woman who has previously borne

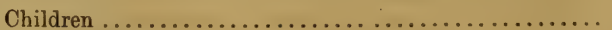

161-2. - The Fotal Head ......................... 783

163-4.-Diameters of the Head..................... 784

165. - Attitude of the Fotus......................... 785

66 166. -Represents the Neck straightened out, and the Two Fontanelies

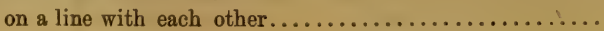


Figure 16\% - - Represents the Head descended still lower in the Pelvis.......

168. - Represents the Head still further down, and beginning to rotate.

"6 169. - Represents the back of the Head nearly under the Pubic Bone, while the Forehead is just passing the External Opening below. .

170. - Represents the back of the Head completely extruded, and also the Chin, so that the whole Hrad is now born..........

171.-Head in the Right Anterior Occipito-Hiac Position...........

172.-Delivery in a Breech Presentation, the Buttocks having just passed the Vulva.............................

173.-Anterior Posterior Position of the Head, the Occiput being in front, after the delivery of the Body............... 800

174. -The Chin just passed, in Presentation of the Face......... 803

175. - The Head full born, in Face Presentation............. 803

176. - Position of the Fœtus in a Presentation of the Right Shoulder, and in the Left Cephalo-Iliac Position...............

17\%--Descent of the Shoulder in a Trunk Presentation, at a more advanced period.......................... 806

178. -Descent of the Shoulder and Trunk at a still later period..... 806

179. - The Trunk fully descended, and only the Head left, with one Arm .............................. 806

180. - State of the Parts at the beginning of Labor............ 810

181.- State of the Parts at the end of the First Period........... 810 182.-The manner of supporting the Perineum, during the Passage of the Head............................... 819

183. -Represents the Standard Form of the Pelvis............ 835

184. - Masculine Pelvis............................. 835

185. - Represents the peculiar Deformity most frequently produced by Mollities Ossium ............................

186. -An Ovate Pelvis.............................. 835

18\%. - Another Deformity, in which one side is sunk below the other, and both twisted round the Sacrum.............. 836

188. -The effect of Corroding Disease in the Pelvis............. 836 189. - Represents the Head fixed or impacted at the Upper Strait of a narrow Pelvis ............................... 837

190.-Case of Tumor in the Vagina..................... 839

191. - Case of Polypus in the Vagina...................... 839

192, 193. -Limbs cut off by the Cord................... 842

$194,195$. -Forceps ................................... 864

196. -The Head being drawn through a narrow Pelvis, by the Forceps. 867 
FiguRe 19\%-Correspondence of Structure in Man and Apes.

“ . 198. -The Nosed Ape ............................... 919

\& $\quad 199$. Julian Pastrana ................................. 919

66 200.-African Woman............................... 919 


\section{PART I.}

\section{PRELIMINARY EXPLANATIONS ON MAN, MATTER,}

AND FORCE. 



\section{CHAPTER I.}

\section{GENERAL CONSIDERATIONS ON THE CONSTITUTION OF MAN.}

UNTIL quite recently the notion was universally entertained that human beings were, in many respects, quite different from all other beings, forming, as it were, a world by themselves. This notion is even now very generally held by those not versed in natural science, and is often put forward by those who are considered teachers of the people. The fact is, however, as all observation proves, that man is, in all respects, like other animals. His body is composed of the same elements, he has the same organs, acting in the same way, the same passions and propensities, and the same mental faculties, only more fully developed. In short, man is a part of the animal world, and not something separate and distinct from it. This is important to be borne in mind, because this notion of man being different, essentially, from other animated beings, is the source of most of our errors in regard to him. Instead of studying the real man, and so coming to properly understand his needs and requirements, we have all along been studying an imaginary being that had no real existence.

People who constantly repeat, parrot-like, the saying that "Man is but Dust," nevertheless do not in any way realize the fact that in man, as in all other animals, and also in the whole vegetable world, there is not a single material element but what is common to the whole world. When arranged in a certain way and in certain proportions, these same elements compose a plant, one of the lower animals, or a man, as the case may be, just as the same stones and mortar may build a palace, a bridge, or any other structure.

So far as we know at present the world is composed of about sixty-four elements, or different kinds of matter, of which the greater part are metals. In the composition of a human being there enters essentially only about eighteen of these, all told, and many of them only in small amounts.

Of these, several of the most important are known only in the form of gases. Analysis shows that a human body weighing one hundred and fifty-four pounds would be composed of eighty-eight pounds of water and sixty-six pounds of solid matter. The separate elements would be Oxygen, Hydrogen, Nitrogen, Chlorine, Fluorine (all gases), with Carbon, Phosphorus, Sulphur, Silicon, Potassium, Sodium, Calcium, Lithium, Magnesium, Iron, Manganese, Copper, and Lead (solids). The metals are in small amount, Iron being the most abundant, next to Lime (the oxide of the metal Calcium), which forms the bulk of the bones, the framework of the body. The whole eighty-eight pounds of water in the body is formed 
of the two gases, Hydrogen and Oxygen, and Oxygen enters largely into the com. position of other parts also. The solid portion of the body is composed nearly wholly of Oxygen, Nitrogen, and Carbon; the metals and other elements forming only a small part. To put it in another form, the constituents of the human body, taking elements the names of which will be familiar to the general reader, rather than compounds, are sixteen in number, seven of them being metals, nine nonmetallic. The metals weigh altogether (eleven stone or one hundred and fifty-four pounds being taken as the standard weight of the whole body) something less than fire pounds, nearly four of which are Calcium, the basis of Lime, supplying the chief part of the bones and teeth. Of Iron there are sixty-five grains, a small amount, but very important, as giving color to the blood. Among non-metallio elements Oxygen is the most important, amounting to no less than one hundred and nine pounds; and next to this Carbon, weighing not quite nineteen pounds. Of Phosphorus, which, if some physiologists are to be believed, supplies the motive power of the whole, there is one pound twelve ounces twenty-five grains.

Now, these are the same elements that make up nearly all other animal bodies, there being no substance known peculiar to man alone, nor, indeed, to animals generally, though Nitrogen is found more especially in animal substances than elsewhere, and is, therefore, usually spoken of as the Animal Element. Both Carbon and Nitrogen are obtained, principally, from the air we breathe. The Carbon, or solid wood of trees, is also obtained from the air in the same way, and not from the earth.

Although the various forms matter assunies are endless, they can all be resolved into the primitive elements above named, but these we cannot make undergo any further change, and they are indestructible. We may decompose matter, and recompose its constituent parts in a thousand ways, but not an atom is ever either destroyed or created. A piece of wood may be burned, and apparently nothing but a few ashes be left, but careful observation can account for every grain of it, and if it be burned under proper conditions, every portion, weight for weight, can be shown in other forms, principally gas and water. There is never a grain more, nor less, of matter in existence at one time than another, though it may be presented to us in many different forms, and this is an important fact to bear in mind.

Some naturalists are of opinion that matter is essentially one; and that what we regard as different kinds of matter are only different states or conditions of it. There are many good reasons for considering this opinion well founded, and the time may come when it will be demonstrated to be true. Many of the so-called elements of the ancients have been decomposed into simpler ones-water and air, for instance, -and there is good reason for supposing that many of those we now call simple will be finally decomposed, and resolved into yet simpler ones in the same way.

The next thing to be observed is that matter is always possessed of certain proyerties, or attributes, which are always the same in the same form of matter. It i:iso invariably exhibits what we call force, energy, or power, varying in degree and kind according as matter itself varies. There is no such thing as dead, or inert matter, though theologians and others often speak of it. Matter is always, under all conditions, endowed with force, or power, and cannot exist without it. There can be no matter without force, nor, so far as we know, can there be force of any kind without matter; they seem inseparable.

In the same way that matter presents itself to us in many different forms, so 
does force exhibit itself in many different ways, such as motion, light, heat, electricity, chemical action, and thought; but all these can be transformed into each other, backward and forward, so that they must all be regarded merely as modifications of the primal force. The most competent observers and reasoners now accept this view, of the oneness of force, as fully proved. Force cannot be destrored any more than matter can be; it may be changed, but remains erer the same in amount. Thus light can be transformed into chemical action, and that into electricity, which again can be transformed into motion, heat, or back again into light. Force, like matter, is never created, never lost, nerer destroyed.

These are primary facts, of the first importance, when we come to study man bodily and mentally. To understand him as we should, we must nerer forget that he is composed of the common elements of the world, endowed only with the same properties and forces that we find in them when they form other bodies. As remarked before, man is not something apart from the world, but is a portion of it, and subject to the same laws and conditions as all other portions, both in his body and his mind. Startling as it may seem to some, man's thoughts and emotions are only forms or modifications of nervous force, which again is only a transformation of the chemical, electrical, and other forces inherent in his bodily structure. The light of the sun in past ages, stored up in the form of coal, may become light, heat, electricity, or motion in this age; and these may eren become thought, or mind, by simple transformation. 


\section{CHAPTER II.}

\section{DIFFERENCE BETWEEN WHAT ARE CALLED LIVING BODIES AND INORGANIC}

\section{MATTER.}

Aцtноugh all bodies, both those called living or organic, and those called dead or inorganic, are made of the same elements, yet there is a difference between them in the way these elements are compounded. In inorganic matter the elements are more numerous, and are primarily combined into twos only, or threes. Thus common limestone is composed of the metal calcium, oxygen, and carbon; clay is composed of the metal aluminum combined with oxygen, and rock crystal is composed of the metal silicum combined with oxygen; these are called binary and ternary compounds, and they exhibit only the more ordinary forms of force, chemical and mechanical.

Organic bodies, on the contrary, are composed for the most part of a smaller number of elements, combined into a more complex combination. They are almost always threes or fours. In all organic bodies also water is invariably found, which makes them more soft and mobile, and very liable to decomposition; and this is the reason why organic matter is not so fixed as inorganic. Albumen, for instance, or white of egg, is composed of oxygen, nitrogen, hydrogen, carbon, and sulphur. In organic bodies force also is exhibited in ways never seen in the inorganic, as, for instance, in the form of nerve power. The principal elements composing the human body, as in all other animals, are those found in albumen, as stated above ; indeed, the lowest animated beings are composed almost wholly of albumen, to which lime and other mineral matters are added, merely to give strength and hardness. Inorganic bodies, such as stone, for instance, either have no particular form, or else they are crystallized, and then their sides are nearly always straight; but organic bodies usually have a regular form, or structure, with curved sides.

It used to be taken for granted that living or organized beings could not in any way spring from inorganic bodies, or dead matter, as it was called. It was thought that there was a peculiar vital power, upon which life depended, and which was totally distinct from any kind of force existing in inorganic bodies, so that all living beings had to be generated by other living beings like themselves, and that they never came into existence in any other way. Modern investigation has, however, modified this view very materially. We can now make artificially, from inorganic elements, many well-known organic compounds; and many competent and careful experimenters are confident that living beings can be, and are, formed artificially 
also from these same compounds thus artificially produced. In other words, they believe that inorganic and organic matter can change from one into the other, and that life can originate independent of previous similar life. That is to say, they believe in spontaneous generation, or the origin of life without a preceding parentage. Many eminent scientific men, who are not yet convinced that life has thus been artificially produced, still admit its possibility, and believe that matter contains within itself all the powers necessary to produce every kind of life. They believe that all living beings have thus originated, from the inorganic elements, by the action of natural force, and that if they were to be all destroyed, and material conditions be as they have been, others would inevitably originate in their stead. Man, and every other animal, has thus been produced from the inorganic elements; not directly, in his present shape, but by gradual change from the simplest form of life, through numerous organic stages, up to his present development.

Once let matter assume the organized form, and what we call life begins at once. In its simplest manifestations life is not distinguishable from the motions of inorganic or dead matter, so that we cannot tell where one ends and the other begins. In short, life is only one mode in which the universal force inherent in matter shows itself. The first living organisms are neither animal nor vegetable, but simpler than either, and apparently may become either the one or the other. And yet, from these simple beginnings, by gradual change, or progressive development, the most perfectly organized beings, man himself included, may be slowly evolved.

We will now proceed to show, as far as can be done, how the inorganic elements pass into organic material, and how life first originates or shows itself in its simplest forms. This is called primary or spontaneous generation. Then we will show how organized beings, man included, continue their species, or originate other beings like themselves by the process of reproduction. 



\section{PART II.}

LIFE; WHAT IT IS.-PROTOPLASM, THE MATTER OE LIFE.-PRIMARY OR SPONTANEOUS GENERATION, NATURAL AND ARTIFICIAL.-THE DIFFERENT KINDS OF LIFE.-SIMILARITY BETWEEN PLANTS AND ANIMALS. 



\section{CHAPTER III.}

\section{WHAT IS LIFE?}

IT may seem, at first sight, very easy to state the difference between living organized beings and bodies that are not organized and living; or, in other words, to define Life! But when the attempt to do so is made, many difficulties arise. One of the most obvious differences is the way in which growth or increase takes place. Inorganic bodies can increase only by the addition of other matter of a similar kind externally, as when a crystal gets larger by more material depositing upon it of the same kind and in the same form. But organized beings grow by taking matter into their interior, or stomach, and depositing it from the inside, after decomposing and changing it in many ways from what it was.

Organized, or living beings, are also usually made up of different parts, or organs, each adapted for a different use, such as the limbs and internal organs. Still, there are living beings that have no definite form, nor any separate organs, or parts, but every portion of the whole being is capable of performing every function necessary to its existence, as will be explained farther on.

One thing may be said of all living beings, that they are continually undergoing change. The substance of their bodies is being continually decomposed and got rid of in various ways, while new matter takes its place, so that the individual is perpetually changing, and yet remains the same. The repairing process is effected by what is commonly called Nutrition, or the digestion and assimilation of food. Inorganic bodies exhibit nothing of the kind. The question then naturally arises, whether life is caused by, or results from, organization, or whether organization results from life. To this it may be said that we know nothing of life without organization, and that we invariably see it exhibited whenever organization takes place. We find also that, just in proportion as the organization becomes complicated or perfected, so does the life, correspondingly, and when the organization is so injured or deranged that its various organs can no longer mutually interact life ceases. We are justified, therefore, in assuming that life is a result of organization, and that it is evolved by the play of the natural forces acting upon the material elements.

But as all matter does not show a tendency to organize, it becomes an interesting question what it is that determines it in special cases to do so, and what kinds of matter are most prone to organize? We find, then, on examination, that the four primitive elements, carbon, hydrogen, oxygen, and nitrogen, when combined in cer- 
tain proportions, are those which form, as it were, the basis of life! Of these carbon is the only one we know in a solid form, as wood, charcoal, and diamond, while the other three we know only as gases. These elements, when so combined, form a jelly-like substance called protoplasm, which is nearly identical with white of egg; it is also sometimes called proteine. This primary substance may be properly considered the matter or basis of life; for a living organization can under no conditions begin without it; and when once we have it, under proper conditions, life invariably is manifested. When once formed, protoplasm is sensitive in many ways to the action of the natural forces. Heat stiffens or hardens it, and electricity, which is everywhere active, makes it contract or move, and this is probably the first vital effort or beginning of life! Then chemical change becomes active, and the protoplasm and surrounding bodies act upon and influence each other, whenever the conditions in which it is placed are suitable. There must be, as a rule, a certain amount of water and free oxygen present, and the temperature must not be above nor below a certain point. There are, however, certain low organizations, chiefly funguses, that are capable of developing from protoplasm, though all these conditions may not exist together. But in every case water, warmth, and oxygen are necessary to the maintenance of protoplasmic life, or, at least, to its manifestation ; for without these it soon appears inert or dead. Certain forms of it, however, display an astonishing power of recuperation, or retain life, if we may so express it, with most wonderful tenacity. Thus seeds of plants, and the eggs of certain animals, may be dried and kept for many years, and yet develop or grow when placed under proper conditions. There is a little microscopic being called the wheel animalcule, or rotifer, which lives in ponds and streams, smaller than the smallest, grain of dust we can conceive, and yet a perfect animal, having nerves, reproductive organs, a stomach, and even eyes. Some of these beings may be dried and rubbed into mere dust, and kept so for many years; and yet if this dust be put in water, the rotifers will immediately resume their vitality, and all their organs become as active as before they were dried; from which it will be seen that a being may still be possessed of life, though showing no signs of it, as remarked before.

Seeds and vegetable germs of all kinds, it should be observed, are composed of protoplasm, the same as animal germs, and it is but slightly different from animal protoplasm. It is probable that life, as seen in these primitive humble forms, and also in more perfect organizations, as in man himself, is only a modified manifestation of those natural forces that we see active in all forms of matter. In fact, all matter may be said to be living, and all life is fundamentally the same, whether in animals, plants, or stones ; it merely differs in variety and activity according as matter is more or less combined, the higher organizations having the combined life of all the different elements and minor combinations of which they are composed. Dead or inert matter does not exist, and vital force is merely a modification of the universal force appertaining to all matter alike. 


\section{CHAPTER IV.}

ORIGIN OF PROTOPLASM, ITS USES AND ITS PROGRESSION FROM THE INORGANIC TO THE ORGANIC WORLDS.

Protoplasm, as before observed, is a compound of the primitive elements, oxygen, hydrogen, carbon, and nitrogen, in certain definite proportions. Neither of these elements alone, nor any smaller number of them, can, so far as we know, form living substance nor sustain life; they must be compounded together in this particular form. All plants, and all animals, from the highest to the lowest, are made up of protoplasm, and animals are nutrified, or supported alive, by protoplasm alone,it is the basis of their food. Animals get their protoplasmic food by eating either other animals or plants ; they cannot, so far as we certainly know, make protoplasm from the primary elements : so that animal life is dependent upon vegetable life. The plant, on the contrary, forms protoplasm from the primary elements by compounding them together, and thus acts as the animal's provider, or the agent by which the primary elements are brought into a form fit for animal nutrition.

But even the plant cannot take the four elements, oxygen, hydrogen, nitrogen, and carbon separately, and form protoplasm from them. They must first combine in this way: the hydrogen and oxygen first combine and form water; hydrogen and nitrogen combine and form ammonia; oxygen and carbon combine and form carbonic acid. These three new substances, water, carbonic acid, and ammonia, will feed the plant, and by it are built up into one substance called vegetable protoplasm, which forms the bulk of its own substance, and becomes food for animals, in whom it is slightly modified and becomes animal protoplasm. We thus have:

First. The primary elements, oxygen, hydrogen, nitrogen, and carbon.

Second. These combine and form carbonic acid, water, and ammonia.

Third. The carbonic acid, water, and ammonia are used by the plant as food, and converted by it into protoplasm.

Fourth. This protoplasm, made by the plant and forming its own substance, is used as food by the animal and maintains its existence.

Fifth. The animal dies; its body decomposes, and is resolved again into carbonic acid, water, ammonia, and simple elements, upon which the plant feeds, and thus begins the round over again. It is a circle of operations never ending, but always beginning. Break the circle at any point, and the whole operation ceases at once; each part is dependent upon the other.

Now, we have always existing in nature the three elementary compounds, carbonic acid, water, and ammonia, but, as we have shown, they require the plant to 
combine them together into protoplasm, so that the pre-existence of the plant seems necessary. The question then arises, Do we know of any conditions under which protoplasm is formed without plant agency? Many other organic substances have been formed artificially by the chemist, and substances very similar to protoplasm, but not the thing itself, as yet. Doubtless it is formed in nature, or has been at some former time, and when once formed, as previously shown, it organizes and forms a living being, by the action of the natural forces. The first living beings formed were, in all probability, neither plants nor animals, but between the two-what will be described farther on as Protista.

For a long time it was doubtful if protoplasm did exist ready formed, independent of plant life, anywhere; but the discovery of what Professor Huxley calls Bathybius (deep life) seems to prove that it does. This substance is a kind of ooze, or jelly, which is deposited on the bottom of the sea in certain places, and which in all essential particulars is identical with protoplasm! It is apparentiy formed naturally, by the combination of the primitive elements, or their primary compounds, independent of plant agency. A similar material is also found in stagnant ponds.

This substance, under the influence of the natural forces, separates or divides into small portions, like specks of jelly, which soon exhibit contractility, or motion, and thus become endowed with life in its simplest form. These earliest living bodies may become either plants or animals, for, as before said, there is primarily no distinction between them; but probably the first distinctly formed organisms are plants, and thus the circle begins to be formed, and living beings are evolved from inorganic matter by its own inherent force, to be again decomposed at death and returned to what they came from. The matter of which they are formed, and the forces they exhibit while living, are neither lost nor lessened by death, but both are returned to the inorganic world in the same quantity, but in different forms.

A thoughtful and careful observation of natural processes, then, leads inevitably to this conclusion, that the simple natural elements, oxygen, hydrogen, carbon, and nitrogen, first combine and form protoplasm, and that this, by the action of electricity, heat, and other natural agencies, begins to contract, or move, and finally becomes a living being !

Protoplasm itself varies within certain limits in its composition, having more or less of one or the other of the elements. Vegetable protoplasm, for instance, is slightly different from true animal protoplasm, and, of course, the primary simple beings formed from it will be more or less different in consequence. They will then be differently acted upon by the surrounding objects, and by each other, and thus varieties of living beings will originate. Some will also use lime, which is always found in sea-water, and thus form a lime shell, or case, while others will absorb silica, and make a stony case. In short, variety once begun, no matter how slight it may be, tends to increase, and living beings will gradually become more and more dissimilar. The death of the first formed simple beings also makes a richer and more abundant protoplasm, which nourishes later succeeding generations, and so disposes them to vary still more, -or progress. Finally comes in evolution, or that process by which surrounding agencies act upon living beings so as gradually to modify or change them, till finally, perhaps after millions of years, they become entirely diffcrent. In this way have all the living creatures on the earth, animal 
and vegetable, in all probability, been produced from the first formed simple animalcules, which originally sprang from protoplasm evolved by natural agency from the inorganic elements.

In short, nothing is needed but matter, and the forces inherent in it, to account for all the life that is found on the earth, of every kind.

This is primal generation, or the first Origin of Life!

It should be remarked here, in relation to Huxley's Bathybius, that the oozy matter, so named, is almost wholly composed, in some places, of Hocculent sulphats of lime! But, in other places, it contains more or less true protoplasmic material, as above described. It is, therefore, a variable substance, which is sometimes composed, more or less, of protoplasm. 


\section{CHAPTER V}

\section{SPONTANEOUS GENERATION, AND ONENESS OF LIFE ALL THROUGH NATURE.}

In the very earliest times we find that there was a belief in spontaneous generation; that is, that under favorable conditions, living beings of certain kinds could, by natural agency, come into existence from the common elements, without being derived from parents. This was even orthodox Church belief for a long time, so singularly does theology change in regard to natural processes, at different periods. The Church formerly taught that only man was created directly by God, and that all other beings sprang ready formed from the earth. St. Ambrose, and St. Basil, both contended that where the Bible says, "Let the earth bring forth grass, the herb," etc., and "let the waters bring forth abundantly the moving creature that hath life," it means that the earth and the water really had the power to bring forth animals and plants. Nay, they contended further that this power remains still, and that in a similar way new plants and animals may come into existence.

Strange as it may seem, when Redi first announced that the maggots in meat were not generated spontaneously, but were developed from eggs laid by the flies, his statement was denounced by the Church as heresy ! So that we see the same scientific doctrine may be heretical in one age, and orthodox in another. Let those who are afraid of modern scientific teaching remember this; it is a lesson which many should study at the present day. Men early observed that when putrefaction took place, for instance, swarms of living creatures were produced, and not looking close enough to trace how they originated, jumped to the conclusion that they were spontaneously generated. Flies especially were thought to be generated in this way, and also lice; indeed, many people even at the present day still think the same. Aristotle taught that every dry substance when it became moist, and every moist substance when it became dry, produced living creatures, if the surrounding conditions were farorable. Others of the ancient philosophers taught that all living beings originated at first in this way; Virgil actually gives directions how to produce a swarm of bees by spontaneous generation; and even so late as 1542 Cardan taught that water engendered fishes. Van Helmont went so far as to give special directions for the creation of mice; and Kircher informs us that he saw certain animals produced by the action of water on bits of the stems of plants. It was not till 1668, that an Italian scientist, named Redi, first showed that the worms and insects found in putrefying substances really came from eggs, deposited by other insects of the same kind; and, still later, by means of the microscope, Leuwenhoek and others made this yet more evident. The doctrine of spontaneous generation in consequence 
fell into disfavor; but still there was a difficulty in regard to many beings, such as the worms, flukes, and hydatids found in the intestines, liver, brain, and eyes, both of man and other animals. But even these were finally traced to pre-existing parents, and it was proved satisfactorily that they are not, so far as we know, spontaneously generated.

In more modern times the improved microscope has, however, discovered to us beings much more minute, and much more simply organized, which appear under such peculiar circumstances, so suddenly, and in such astonishing numbers, that ordinary parental generation does not seem to account for them. Many eminent scientists, after careful observation and experiment, have come to the conclusion that these beings really are generated spontaneously, from protoplasmic matter. Among the most eminent of these may be named Pouchet in France, and Bastian in England. With these men it is no mere theory, but the result of careful experiment. The opponents of their views, equally eminent men, such as Tyndall and Huxley, contend that the atmosphere is full of germs, or organized bodies, too minute to be seen even by the most powerful microscopes, but which are really the origin of all these beings-plants and animals-supposed to be spontaneously generated. That these germs do exist there is no doubt; and it is equally certain that they often originate living organisms of various kinds where they had previously not existed. Many diseases are believed to originate in this way, both in plants and animals, and it is asserted, by those who do not believe in spontaneous generation, that if the air is carefully excluded from any kind of material already free from these germs that no life will ever originate in it.

The object of the experimenters has therefore been, to prepare different fluids, suitable for the purpose, under such conditions that all germs which might be in them, or in the air that reached them, should be destroyed, so that it could be tested whether life would then originate in them or not. Both Pouchet and Bastian have done this hundreds of times, submitting their solutions to intense and prolonged heat, and roasting and filtering the air admitted to them till it would seem impossible for anything living to remain, and yet in most cases living things did originate in the solutions. Their opponents contend that either the germs could stand the heat uninjured, or else they gained admission to the solutions in some unsuspected way. Experiments and counter-experiments have been made on the most extensive scale, and are still being made ; for the matter is by no means decided. It has, however, been demonstrated that, if these germs do exist, they are capable of enduring a héat very far beyond that of boiling water for many hours, and yet be capable afterward of developing into living organisms. The air even in which they have been thought to be conveyed has been passed through powerful acids and white-hot tubes, and still the supposed germs, if there, remained unhurt. This in itself is a wonderful fact, and gives us a new idea of the tenacity with which life, or the capability of it, is held. It is well known, however, that many seeds, and even animal eggs, may be boiled for a long time without killing them.

It may be remarked, however, that though the existence of germs of life in the air is well established, still we have not been able to isolate and show them. It is not certain therefore that these germs are of the nature of eggs or seeds, derived from living beings. They may be only minute portions of protoplasm, floating in the air, which develop into living beings when they find a suitable fluid. The generation therefore may be, properly speaking, spontaneous, though originating in a germ. In other words, there may be no parentage. 
The question, however, arises, How comes the protoplasm in the air? The opponents of spontaneous generation say that it is only the cast-off material of living beings, and that it would not be in the air if there were no living beings from which it could come. This view, it is evident, makes the generation not strictly a new one, or spontaneous, because it really depends upon life, and is, therefore, only a propagation of it in a novel manner. To be really spontaneous, the protoplasm itself must originate from the inorganic elements, and life must be produced in it without the intervention of previous life in any way.

A little consideration here will show that it is no more unlikely for protoplasm to originate in the air than for it to originate in the sea, in the form of bathybius ! There are always in the air carbonic acid, water, and often ammonia, the three compounds which form protoplasm, and it would be surprising indeed, if the electric agency, always at work in the atmosphere, did not sometimes cause them to combine. We know that an electric spark will cause oxygen and hydrogen to combine and form water, and that it will also cause other chemical combinations instantaneously. We know also that lightning, or natural electricity, striking through the air, causes combinations of the elements to occur, of many kinds, as will be more fully shown farther on.

Here, then, we have a simple explanation of the origin of atmospheric protoplasm, the universal life-germ, which probably orginates one form of life under one condition, and other forms under other conditions. Bathybius does the same in the sea, and in this way inorganic matter combines and becomes living protoplasm, the basis of every living being, plant or animal. A little reflection will show that life in its simplest form is but little more than mere motion, and protoplasm can scarcely exist without becoming mobile. Imagine a little speck of this jelly-like substance formed in the air or in the sea. One part of it will harden more than another, from mere heat, or some chemical agent adjoining; then, a current of electricity will traverse it-for such currents are everywhere-and this will make it contract! One part however, being harder than the other, the contraction will be unequal; this unequal contraction will corrugate it, or draw it into channels and furrows, along which the surrounding fluids will traverse with different degrees of velocity. One part will thus gain more new material than other parts in the same time, because it has more presented to it, and there is always a tendency in matter to aggregate with that for which it has an affinity. Repulsion also comes into play as well as attraction, and between the two matter can never be at rest, or without life. The softer parts will easily extend, or stretch out, when attracted by other substances, while the denser parts will not, or will do so to a less degree, and thus motion for the purpose of attaching new material will begin, or, in other words, nutrition in its simplest form. Many of the lowest organisms, in fact, show but little more life than this, if any. They simply bulge out in some parts and contract in others, and attach to themselves any matter which floats near them with which they have an affinity. In this way life may, and probably does, originate spontaneously, from the inorganic elements; and probably in past ages of the world the conditions were much more favorable for this process than they are now. We know that there were periods of constant and great heat, with much watery rapor, abundant carbonic acid, and intense electric action, as will be more fully shown farther on. It would seem, from what we now know, that under such conditions life must have originated, to an extent, and in a degree of perfection, far beyond anything of 
which we can now conceive. Those who would wish to pursue this matter further should read any good modern treatise on geology, and observe the state of the world, as shown by that science, in past ages.

We cannot judge, from what we now see, what must have taken place when the world was young, when all the natural forces were intensely active, and the elements were in what chemists call the nascent state.

That life did originate naturally, at a former period, cannot be doubted, and that it often originates even now, under certain conditions, is more than probable: and these conditions may be either natural or artificial : such, at least, is the opinion of those who believe in spontaneous generation. It should be observed further, in regard to the probable origin of motion in protoplasm, that all organic substances similar to this exhibit, under the microscope, peculiar movements, called the Brownian movements, so named after their discoverer. These movements so closely resemble those that take place in living bodies that observers are often deceived by them. These specks of organic matter will not only move, but whirl about, just like the animalcules, so that the closest attention is needed to distinguish them.

It is probable that the Brownian movements are merely the first efforts, as it were, toward life, and that they easily pass into those that we observe to be truly vital. Nature is nowhere at rest, and organic motion is only a modification of inorganic. There is no such thing as lifeless matter! To make this subject better understood, we will now show how living beings. usually first show themselves, in the fluids used in the experiments above referred to, and then describe some of the experiments more fully.

If any animal or vegetable substance be soaked in water, so as to make an infusion of it, and this infusion be exposed to the air, within certain degrees of temperature, certain changes are always observed to take place in it.

First there forms on the top a scum, or film, called the primary pellicle, which is seen, under the microscope, to be made up of an immense number of small round bodies, or molecules, like grains of sand.

Next we find many of these molecules begin to lengthen in one direction, forming bodies like small threads, sticks, or wands. These are called bacteria.

The bacteria continue to lengthen till they form still longer thread-like bodies, called vibriones.

Finally, both the bacteria and vibriones begin to move in a serpentine manner, through the fluid.

After a time, in most cases, they all become again motionless, and finally break up into molecules, which aggregate together into a new or secondary pellicle.

The next stage shows us a number of small round bodies, formed from the pellicle, each one possessed of a fringe of threads or hairs called a cilium. These it uses like oars, and by their means paddles rapidly about in the fluid.

These infusoria, as they are called, are often much varied in form, but all possess the cilia, or hairs, with which they move about, and from which they are namei cilia. Some of them are extremely simple in organization, while others have a mouth and stomach, and are more perfect every way. They are by no means all alike.

This is the order of change that is noticed in most cases where an organic infusion is exposed to the air ; but it is not invariably the same in all the details.

The advocates of spontaneous generation say that this is all a natural process; that the primary pellicle and its molecules are produced by chemical change in the 
infusion. The subjoined figure will show the appearance of the primary pellicle formed on the surface of an infusion of isinglass. It will be seen that the course of development is slightly different from that above described. Among the granules will be seen larger, cell-like bodies, called paramecia viride, some containing in the interior a spot called the nucleus, while others are without it.

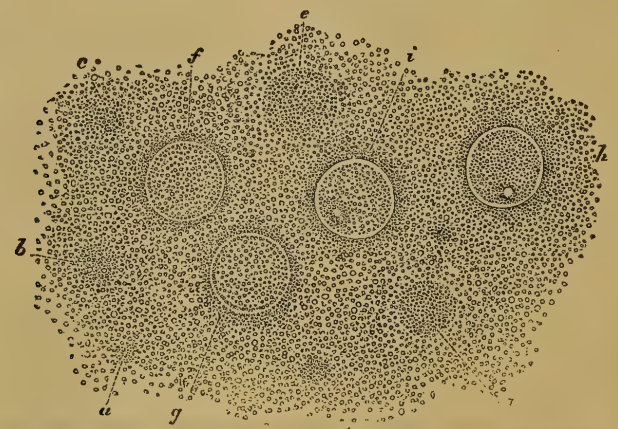

Figure 1.-Mode of Origin of Paramecia, from the Primary Pellicle.

These round bodies, or paramecia, will be seen forming, at first faintly, by the granules merely drawing together $(a, b, c, d)$; next a clear border is seen to form around them, and finally the exterior hardens into an investing membrane, and then we have a perfect cell $(f, g, i)$. The granules in the interior then coalesce, and begin to move round and round, having evidently organized into a living being. The slow circular motion first observed becomes quicker, and irregular, till at last the investing membrane is burst, and there issues forth a free-swimming infusorial animalcule.

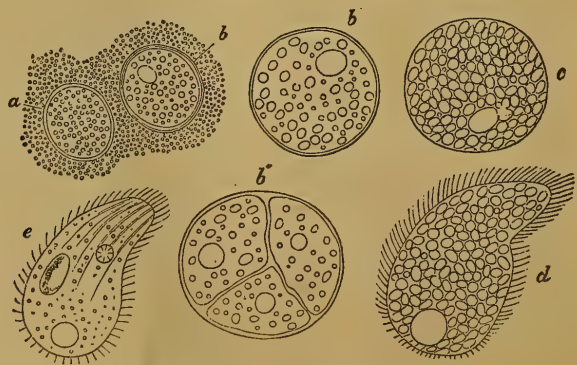

Frgure 2.-Mode of Origin of Paramecia.

a. First stage of differentiation. $b$. I ater stage, showing a vacuole formed. $b$ '. The same still further advanced. $b^{\prime \prime}$. The same divided into three parts. c. A later stage; the embryo filled with large particles, and revolving. $d$. A paramecium after emerging from its cyst. e. Another form into which they sometimes pass. 
Ciliated infusoria are better organized, or more advanced, than bacteria or vibriones, and we seldom see them in the primary pellicle; but in the second they are abundant, probably because it is now richer in organized material, from the death and decomposition of the more simple beings first developed.

The cilia, or hair-like threads, which all these animals possess, are probably used ooth as oars, to move the body within the surrounding fluid, and also as arms with which they reach any small portions of nutritious matter near them.

The simpler beings-bacteria, vibriones, and monads-which come first in the primary pellicle, have no cilia; but the monads have a long tail, usually called a flagellum.

It should be observed, however, that this order of succession is not invariable; for sometimes we have all these forms appear at once, and they pass so rapidly into one another that the process can scarcely be seen.

The beings thus produced are citiated infusoria of various forms, as shown in the following figure.

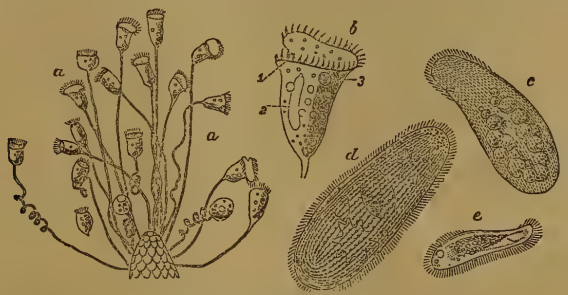

FrguRe 3.-Ciliated Infusoria.

a. A group of vorticella. $b$. A single vorticella more highly magnified. $c$. A kolpoda. d. A paramecium. e. Enchelys. The paramecium $d$ is seen to be changed from the globular form, and is approaching that of $c$, the kolpoda.

All these beings result from changes in the paramecium, which begins from a simple aggregation of the granules of the primary pellicle, one change following the other. The air may be necessary to the change, but the advocates of spontaneous generation deny that any so-called germs are in any way necessary, or, if they be, that they are anything more than particles of naturally formed protoplasm, not necessarily derived from any pre-existing organism.

The Panspermists, as they are called, of course contend that the germs are essential, and that they are all derived from pre-existing beings, of the same kind as those that grow in the fluid. There is no proof of the existence of these germs, and each one must judge for himself as to the probability, or otherwise, of their existence, after reading the account of the experiments referred to.

Pouchet, Bastian, and others, have made infusions of hay, turnip, cheese, animal muscle, and various other organic substances. These they introduced into small glass bulbs, with very long fine necks, drawn out to mere points ; then the solution was boiled, sometimes for hours, and, while boiling, the thin neck was melted together by a blow-pipe, or hermetically sealed.

Of course it would seem that no germs could be left alive in the solution after this prolonged heating, nor could any pass into the bulb from the air, because the hot steam was all the time rushing out, till the instant they were closed. 
Nevertheless, when these glass bulbs were left undisturbed, sooner or later, all the changes above described often took place, the same as if they had been in the open air, and the same living beings appeared.

The experiment was varied in every possible way, and with all kinds of infusions, almost always with the same results.

To show that the ordinary air was not really necessary, Pouchet even made artifi. cial air, by mixing oxygen and nitrogen gases in the proper proportions, and still the same results followed. In other cases the air was passed through white-hot metal tubes, and the infusion was heated, under pressure, till far beyond the heat 0 boiling water; but it made no difference: the pellicle and the infusoria appeared after a time just as before.

Pure oxygen even was used, instead of air, and many of the bulbs, after being sealed, were again boiled, for several minutes, to kill anything which might pessibly have got introduced; but in spite of all these precautions, in due time the same changes occurred, and the animalcules appeared, in most cases, just as they do in the open air.

Dr. Bastian still further varied the experiments by using artificial chemical mixtures, containing the organic elements carbonic acid and ammonia, such as oxalate of ammonia, carbonate of ammonia, cream of tartar, and phosphate of ammonia. Even in these the same organisms would develop, and live, as in the natural organic infusions.

It should be observed that the resulting animalcules vary as the character of the infusion is varied; but in most cases bacteria and vibriones are first formed. The surrounding conditions also exert their influence, and we cannot therefore always predicate what particular forms any infusion may bring forth. It is more than probable that all the first seen, simple forms, are only stages of development of the more perfect beings we see later; and in many cases some of these stages may be missed, so that we see the being in its final form without its having gone through the first and simpler forms.

If horse-hair be left in stagnant water, it will usually be found associated with thousands of small worms in a very short time, and nninformed people think the hair is shanged into the worms, which they therefore call hair-snakes! They are however only a kind of worm, which lives naturally in such places, and which probably finds the hair a good breeding-place. If it were not there they would breed on something else, as they ordinarily do. They develop from eggs or by division.

In one of Bastian's experiments he boiled some dry hay in water at $120^{\circ}$ to $130^{\circ}$ for three hours ; then put some of the infusion in a wide-mouthed bottle under a bell jar, which perfectly covered it. In three days this infusion was quite muddy-looking, and covered with a thin pellicle, portions of which were examined with the microscope and found to contain numerous monads, each about the three-thousandth of an inch in diameter, the pellicle itself being formed chiefly of bacteria, with some torulæ (yeast plant). Patches of the pellicle, however, were seen of different sizes, of a whitish color, evidently made by the granules of the pellicle undergoing some change in these places. These patches, in consequence of what resulted from ther were called embryonal areas, or life spots. They gradually separated from the genera! mass, and the substance contained in them began to have a different look. Evensually it aggregated into distinct round bodies, like cells, which finally assumed the forms of monads. When this stage was reached, the aggregated patch seemed to spontaneously resolve itself, and the monads became free, as seen below. 
These monads were seen in perfect clouds, most of them with long tails, or flagellums, and they gradually increased in size and varied somewhat in appearance, having more the look of amcebas (which will be described farther on). In fact, the change from the monad to the amcob could be plainly seen, and sometimes took place very rapidly, the animal losing its tail, and becoming a mere sac, which could

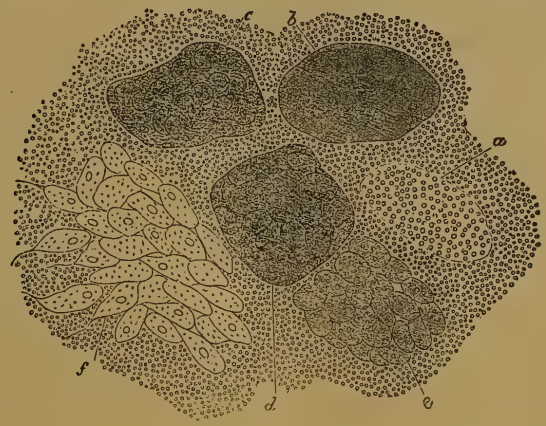

FiguRe 4.-First Stage of Hay Pellicle, forming Life Bpots and Monads.

$a$. The first stage, the white patch. $\quad b$. The second stage. $e$ and $d$. More advanced stages, the round bodies just showing. $e$. The round bodies beginning to separate. $f$. The fully developed monads, resulting from the breaking up of the collection of round bodies.

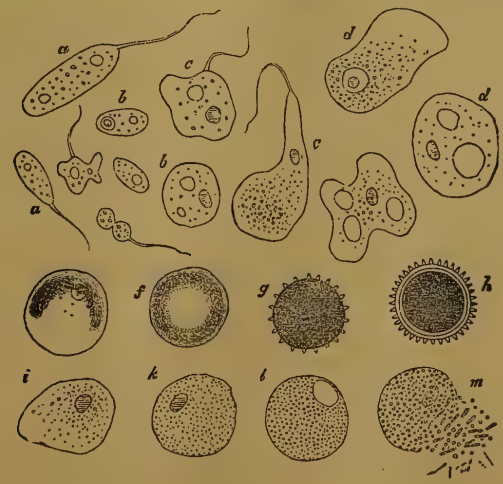

FigURE 5.-Second Stage of Hay Pellicle: Monads changing to Amoba.

$a, a$. Monads in different stages. $b, b$. Monads which have lost their tails. c, c. Monads being transformed into amcebas. $d, d$. The amcebas perfectly formed. $e, f, g$. Different stages in the encysting of an amoba. $h$. One encysted. $i, k, l, m$ show the various stages by which an amcba develops into a germ vesicle, and finally bursts $(m)$, giving issue to a swarm of bacteria. 
protrude false limbs. On the seventh day there were many thousands of perfect amoba, and on the eighth day they were as numerous as the monads.

This change from monad to amoba was often very rapid, one hour sufficing in many instances. Some of the amœba remained motionless and became encysted, or enclosed in a sac, while others, filled with germs, burst and gave forth swarms of bacteria.

All these changes are shown in the plate above-Fig. 5.

On the ninth day, the pellicle had a darker color, and developed a large number of brown fungus germs; portions of it also began to separate, and sink to the bottom. On the tenth day, similar changes had progressed much further, and a large number of the amœba had become encysted. In this stage they somewhat resembled a drop of oil in a thin membrane, and when perfect had the appearance seen at $g$, being surrounded by a fringe of short hair-like cilia, the color being dark brown. Many of these finally gave birth to brown fungus bodies, like those before mentioned.

Here, then, we have monads, amœba, bacteria, and fungus, all developing from the same pellicle and from one another. In fact, one seems imperceptibly to change into the other.

The infusion afterward underwent numerous other changes, too confused for us to follow. Similar experiments have been made by the hundreds, by different experimenters, and with varied results. Sometimes the living beings appeared, and sometimes not, under apparently the same conditions. In all such contradictory cases there was, no doubt, some unnoticed small difference in the process, and, in a matter of so much delicacy, it is very difficult to always conduct an experiment with every little detail exactly the same.

It is possible that the electrical condition of the atmosphere, or of surrounding objects, may have an influence, and so may light, changes of temperature, and various other influences, some perhaps unknown.

Professor Tyndall asserts positively that, by thoroughly filtering the air which acts on the infusions they will not form a pellicle, and go through the ordinary changes resulting in the production of living beings. His experiments appear to have been very carefully conducted, and apparently prove his assertion true. Dr. Bastian, however, controverts them, and shows, to the satisfaction of his friends, that Tyndall's experiments are defective, and in no way disprove spontaneous gener. ation.

It is certain that the simpler forms of life do often appear in a very incomprehensible manner, and there seems nothing impossible in the way of spontaneous generation; but, on the contrary, it seems to naturally follow from a careful consideration of the facts in the case.

It should be remarked here that the nature of the vibrios and bacteria is quite uncertain. They may be either plants or animals, or something between them, capable of becoming one or the other. Many scientists think the lower organisms are neither animal nor vegetable, but may develop into either. The plant and the animal both commence the same, and at first there is no distinction whatever between them. The organisms which succeed the dead vibrios appear to be more distinctly animal, and those which succeed them are animal beyond doubt. These, again, are succeeded by others still more perfect, so that there is a regular progress upward, beginning with inorganic matter. It has been objected to the theory of artificial spontaneous generation that, in all the experiments, some organic matter 
had to be used to make the infusion, and that, as this had to be obtained from some organic being which existed before, there was no new start! And this is quite true; for though it was dead organic matter when used, still it coulu not have been had at all if there had not been a living being before. Chemists, however, now form organic substances of different kinds in their laboratories from inorganic material, and the number of these substances so made artificially is increasing every day. In fact, the general opinion among chemists is, that we shall, by-and-by, form artificially every organic substance known, even the food we eat, and not be dependent upon agriculture, or other animals, for it, as we are now. It will be quite possible, therefore, to first make the organic matter artificially with which the infusion is made, and thus the whole process becomes artificial from the start, and the life produced will be truly spontaneous, or independent of parentage in any way.

As an instance of how spontaneous generation, as it is called, may be affected by the conditions under which the experiment is conducted, reference may be made to a communication by Mr. Downes and Mr. Blunt, to the Royal Society, England. These gentlemen found that when glass tubes were filled with an organic infusion, such as those used by Dr. Bastian, and some placed in the light while others were left in the dark, only those in the dark became cloudy, and developed bacteria; while those left in the light did not.

It is evident from this that light is unfavorable to those changes in organic matter, or protoplasm, which result in the development of bacteria, and probably other infusoria.

With chlorophyl (the coloring matter of leaves), which may be called green protoplasm, it is exactly the reverse ; for this forms only in the light, and best in the full sunlight.

It is probable that the same speck of protoplasm, therefore, may become plant or animal, according as it is affected by light during its first stages of growth.

In regard to the nature of the germs, as they are called, floating in the air, which, when they fall into organic solutions, appear to be the origin of bacteria, these gentlemen remark that they may be considered simply as isolated cells, or minute protoplasmic masses.

Professor Tyndall may be quite right when he says that infusorial animals never develop in any solution, if the air be perfectly excluded from them, or even if it be only perfectly filtered. Indeed, his experiments prove this. When he conducted them in the rooms of the Royal Institution, in London, it was scarcely possible, with every care, to prevent infusoria appearing in the solutions; but when exactly the same experiments were performed in purer country air, they did not appear. The inference he draws is this-that in the city the germs are so numerous that it is not possible to exclude them all, but in the country there are so few that they can easily be kept out.

To show that these germs do float about in the air, he filtered it through cottonwool, and in this way got air perfectly free from them, which had no effect on any organic infusion. The same result followed if the air was only left for some time perfectly still, in a box. All the germs then settled down, on the bottom and sides, which were wet with glycerine to hold them fast. The air thus clarified would not affect the solutions any more than that passed through the cotton-wool.

Still, granting all this, it does not follow that the so-called gerrns are like eggs, or seeds, derived from living beings. They are probably only specks of protoplasm 
(some of which may be formed naturally), ready to develop anywhere, under proper eonditions, into animals in the dark, and into plants in the light. Other natural conditions also, as before remarked, probably exert their influence, especially electricity, heat, and chemical action.

It is quite possible that what are called disease germs are only minute portions of the diseased part itself, floating about in the air, which, if they meet with a human body in favorable condition, may start the disease anew. In a healthy state they may not infect ; but if the body be prepared for them, they act at once, like the matter used in inoculation.

The minuteness of these germs is almost inconceivable. The smallest crack in a glass vessel will admit them, and if the very point of the finest needle touch the surface of an organic infusion, in which there are germs, and be then introduced into one perfectly clear, it will start their development immediately.

We must beinhaling clouds of these germs all the time; but in a normal condition they do no harm. In fact, in a healthy body living bacteria may be introduced into the blood without injury. In an enfeebled or unhealthy body it may, however, be very different; and pure air, under all conditions, is safer to breathe than impure.

FiguRe 6.-Bacteria groving into Vibriones and other Frorms.

- $a, a$. Different kinds of bacteria and vibriones. $b, b$, and $c$. Different forms of leptothris. $d, d$. Spirilla, which change into fungus. $e, e$. Torulæ, or yeast plant, developing into fungus mycelia.

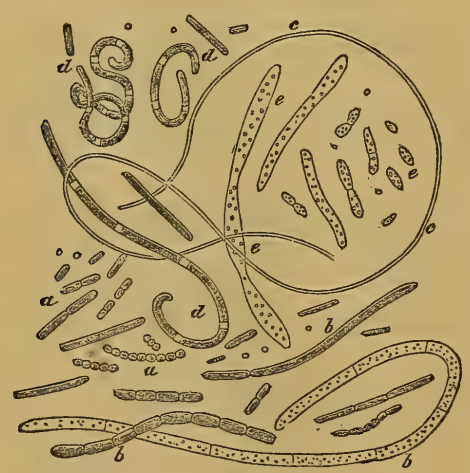

It is well known that surgical operations seldom succeed well in large hospitals, owing to the air being contaminated with morbid matter, acting germ-like. An open wound in such a place almost always becomes filled with bacteria, and has a tendency to gangrene. In a place free from such surroundings this seldom occurs. The bacteria may be harmless in a healthy body, but very hurtful in the morbid material of a wound.

Bacteria are among the simplest regular-formed beings, and are usually the first met with. They resemble wands, or straight, flat rods, like minute laths, sometimes single, but more usually jointed, as if several short ones had grown together, end to end. They are supposed to be formed by the union, in a straight line, of mole. cules of the original protoplasm. The longer vibriones resemble bacteria, and are supposed to be formed by many of them joining together. In fact, Dr. H. Bennet asserts he has seen them form in this way. They are often twisted or bent at various angles.

The nature of bacteria is much in dispute, as to whether they are animal or vegetable, or whether they are beings of a definite character, or merely transitory forms of other and higher beings which follow them. Bastian takes this view, and . it is probably correct. In size they vary from the fifteenth to the twenty-thousandth of an inch in diameter. They move often quite rapidly, and are undoubtedly living. 
The following plate shows the more common forms of monads, bacteria, vibriones, and torulæ, or yeast plant.

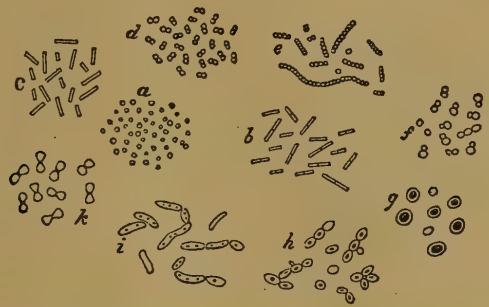

FIGURE 7.-First Forms of Life in an Organic Infusion.

a. Monads. $b, c, d$, e. Bacteria. $f, g, h$. Torulæ. $i, k$. First forms of vibriones.

The yeast plant, which causes the rising of bread, and the working of beer, is probably only a modification of bacteria. The rapidity of its growth is well known. A small portion of yeast will soon set a hogshead of wort working, or fermenting. In fact, the growth can be seen under the microscope. 


\section{CHAPTER VI.}

\section{THE FIRST BEGINNINGS OF LIFE, AND ITS DIFFERENT KINDS.}

IT was formerly thought, and taught, by naturalists, that every living thin $\varepsilon$ must be either plant or animal ; but, as before remarked, this view cannot now be maintained. The very lowest organisms cannot be called either the one or the other, but are something between the two, or lower than both. Professor Haeckel was the first to point out and illustrate this important fact. He called these intermediate beings Protista (meaning "the first of all," from a Greek word), and showed that they all propagate in a strictly non-sexual manner. He is of opinion also that these are the real beginnings of organic life, and that both plants and animals are produced from them, by further developments.

The very lowest of these, which he calls Monera, or Monads, cannot even be termed organized, for they consist only of specks of jelly-like protoplasm, without form or structure of any kind. They are probably the first bits of the protoplasm which separate from the rest, and are simpler than cells (which are described farther on), because they have neither investing membrane, nor nucleus, nor, in fact, any difference of parts. As they become acted upon by chemical, and other agencies, they become hardened on the surface, or form a membrane, and afterward, by osmose, a nucleus and granules in the interior, and so become true cells, the first real organisms.

The first spontaneous beginnings of life, however, as far as can be ascertained, are these moners, or jelly-like specks of protoplasm, and these are merely detached portions oi protoplasm, which may be formed naturally in any waters, like bathybius in the sea-or in the atmosphere by electric agency.

First, then, we have the natural simple elements, with their inherent powers and attributes, and next we have the combinations of certain of these-carbon, hydrogen, oxygen, and nitrogen, into water, ammonia, and carbonic acid. Then, by electric and chemical action, these compounds form protoplasm, and from protoplasm, as above explained, first come the mere unorganized specks, the moners, and from them other beings; and, finally, cells. From the cells are formed the beings next above, the infusoria, and eventually, by gradual building up, still higher beings, till we reach the vertebrates and man-all going back, however, to the moners, and protoplasm or the matter of life, at last!

Many of the lowest orders of beings obviously pass into each other, or possibly they may all be only different stages in the development of the highest among them, as stated before. The following plates show the appearance of some of these beginnings of life.

A very interesting variety of animalcule may be produced quite readily by making thick paste of fine flour and water, which should be stirred daily for several days with a bit of wood. In four or five days it will swarm with what are called 
paste-eels, a kind of little worm. They can be readily seen with a common mi. croscope.
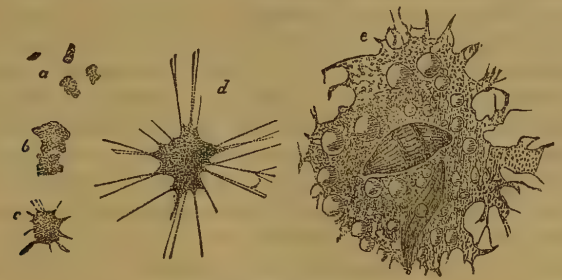

FiguRE 8.-Monera.

a. Mere specks of protoplasm, from the surface of the mud in a fresh-water pond. $b$. A larger mass which begins to resemble an amoeba. It has just divided in two, by fission. $c$ is a still far. ther development, prolongations being thrown out, like limbs; this form is called a vampyrelica. $d$ is still more like anamoeba. $e$ is a mass called a plasmodium, formed by many of the simpler bodies uniting. Two infusoria are seen entangled in it, being probably absorbed, or used as nutriment.
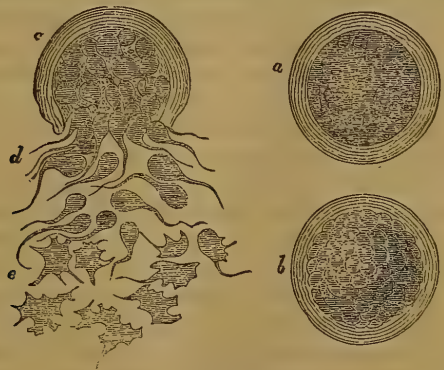

FigdRe 9.-Development of Protomyxa.

$a$ shows one of the amcbas, as observed by Haeckel, drawn together into a ball, and incloser? in a membrane, or encysted. It then becomes filled with granules, which enlarge, and begin to move round and round, as seen in $b$. Finally, the cyst bursts open, as seen in $c$, and the developed granules are expelled in the form of moners, with tails, as seen at $d$. The tails gradually disappear, and they become true amcbas, as seen at $e$. Then, any of these amcbas may draw together, become encysted, and go through the same round again, from simple protoplasmic granules to moners, and from these to amcebas.

This particular form is called Protomyxa Aurantiaca.

All these earliest forms of life are utterly without definite shape or structure, and have neither investing membrane, nucleus, nor granules. The amœba, one of the next above, though still a mere lump of protoplasm, has a skin, and can form limbs and a stomach, when it needs them, and is, therefore, an adrance, though a slight one.

One of the very simplest of the moners, and one of the first Haeckel discovered, was taken from the mud of a shallow pond, and was named the Protamoba. It was observed as a minute protoplasmic ball, abont one-thousandth of an inch in diameter, perfectly alike in every part, and resembling exactly a speck of jelly. It 
however exhibited a power of motion, by pushing out and drawing back again, at intervals, different portions of its substance.

This simple motion, or mere contraction and expansion, caused by the unequal action of heat on different portions of its mass, or by chemical action, is probably the first manifestation of life, and is in no way different from ordinary motion. The next vital manifestation is probably fission, or division, by which it multiplies or propagates; for we see this take place in the most primitive forms, as in the protamceba. Osmose, or nutrition, of course commences the moment the exterior, by any agency, becomes denser than the interior, and so forms an investing membrane. Then results a cell, with all the higher organisms formed from it, as will be shown when we come to speak of cell-life.

It will be seen from this that spontaneous generation is much simpler than is usually supposed. We are not required to believe that one of the higher beings is spontaneously produced; not even one of the infusoria or amøba, nor even a cell, but only the separate speck of protoplasm called the moner, from which all the others are developed! In short, once form protoplasm, the matter of life, and portions of it inevitably become separated, and form moners, and then cells, and so on, all by natural force acting on the simple elements. And that protoplasm itself is naturally formed in water, and in the air also, scarcely admits of doubt.

In this way, then, we trace the very beginnings of life, and see how living, organized beings are produced from the simple inorganic elements by the powers or forces inherent in matter itself.

Once produce the matter of life, protoplasm, and all forms and qualities of life result from it naturally, by the process of evolution!

In conclusion of the topic of spontaneous generation, a few additional facts are worthy of notice, and a few more inferences seem fairly deducible from the facts already given. It is observable that the same infusion, in the same conditions, always produces the same beings, or with very few exceptions; beginning with the simplest kind, which die, and are succeeded by others more perfect, and larger, in successive crops, each one an advance upon the one before it. Finally, the infusion, though by no means exhausted of material, fails to produce any more.

This would seem to favor the idea that the kind of being produced depends upon the kind of material used, and the state it is in : if in one condition, it produces and supports one kind of beings, and if in another condition another kind. The decay of the first crop probably enriches the infusion, and so enables it to produce next a more advanced kind.

It is also worthy of observation that when the infusion contains but little water, and much organic matter, it usually produces vegetation, such as mould or fungus; but when there is much water animal organisms most frequently appear. This seems hardly consistent with the theory that the new organisms result from germs floating in the air, but rather favors the idea that they are spontaneously produced, and that their nature rlepends upon the character of the infusion used. The number of beings produced also is no way dependent upon the quantity of air present.

Another point is also well worth consideration, namely, that many of the infusoria produced in the infusions do not, so far as known, produce ovæ or germs of any kind, but always propagate by division, or by buds ! Where, then, do the germs come from which are supposed to produce them? If they do result from any particles 
floating in the air, the fact would seem to prove that such particles are not real germs, coming from the ovaries of pre-existing animals, but only specks of protoplasmic matter, naturally formed and floating about, as before explained. Such specks of matter may, if such be their nature, produce anything found in the infusions, vegetable or animal.

The Entozoa, or those beings that live in animals' bodies, would also seem to favor strongly the idea of spontaneous generation. They are found in almost every part, not only where the air has access, but where it has not also: in the chambers of the eye, for instance, in the blood-vessels, in all the closed cavities, in the substance of the liver, and in the most secret recesses of the brain. Each place has its own special kind of being, which cannot live long anywhere else, and which soon dies when the animal dies in which it has its habitation.

Now, if these beings are not spontaneously generated, how do they reach these places so difficult of access? We cannot conceive of their germs getting there from the air, and it is still more difficult to imagine themselves being transmitted from the parents ; besides, many of them do not form eggs at all, but bring forth their young alive; and when eggs are produced, they are entirely too large and heavy to be floated in the air; nor are these the only difficulties in the way of supposing such beings to come from germs.

Carnivorous animals, which feed upon others, might naturally be supposed more liable to be infested with entozoa, and of the same kind as those natural to the animals they feed upon; but such is by no means the case. Herbivorous animals are quite as much infested with such pests as the carnıvorous ones; and, what is worthy of notice, each kind of animal has its own peculiar kind of entozoa. The same kind also infests the same animals in all parts of the world. And land animals have different entozoa to the water animals of the same district.

It has been supposed by some that the ovæ of these parasites may reach the secret parts of the body where they are found, through the blood ; but this cannot be admitted, with regard to many at least, because they are too large to pass the capillaries. Of course, it is still more impossible for the young of those to pass who bring forth their young alive, instead of eggs. Still more is it inadmissible that either one or the other can pass from mother to child, during gestation; and besides, mother and child are not always infested with the same kind of parasite. In some cases entozoa have been discovered in the human fotus at birth, and it becomes exceedingly difficult to give any reasonable explanation of such an occurrence, except by spontaneous generation; for they can hardly be supposed to have come, by any route, from either mother or father.

It is remarkable also that animals of the same kind, living at the same time and place, and in the same way, will have different kinds of entozoa.

All these parasitic beings, however they may come, when once produced, propagate like others of a similar kind, some by eggs, and others producing living young.

The whole subject is beset with difficulties, and must not be considered by any means as settled, either one way or the other. Careful and long-continued observation and experiment, with candid and fair discussion, can alone lead us to the truth, which is all we want, let it be whichever way it may.

Another remarkable fact may also be stated. Dr. Bastian found that an organic infusion, such as he experimented with, could be sterilized by long subjection to great heat, so that when left still, without any contact with the air, no life would 
appear in it. But if he then added only a little potash, to neutralize its acidity, bacteria appeared at once.

Apparently the life resulted, in this experiment, from a mere chemical change in the infusion. But it may be said that the germ was there, but could not develop while the infusion was acid. If this be supposed, however, we are then obliged to admit that the germ could withstand an amazing degree of heat for a long period.

In short, though spontaneous generation has not been proved beyond dispute by these experiments, it seems, in many of them, te be undeniably the most probable explanation of the phenomena observed.

All this shows that, properly speaking, there is no beginning of life in an absolute sense, nor any real separation between what is called dead, and living, matter. All is living; every single atom has life; and the life of any compound body is merely the aggregated life of the atoms composing it, varied according to the manner in which they are associated.

Although in their simplest forms organic beings are neither plants nor animals, but may become either; yet in their fully developed state, when their characters are fixed, they are distinct enough. The plant works for the animal, by taking the inorganic matter and working it up into organic material suitable for animal food. This the animal cannot do for itself, and therefore it is dependent upon the plant for its existence. The great work of vegetation is to take carbon from the air, in the form of carbonic acid gas, decompose it, fix the carbon in the solid form of woody matter, and return the oxygen to the atmosphere. The animal, on the contrary, consumes the carbonaceous matters the plant has formed, using them for food, recombines the carbon with oxygen, in the process of breathing, and returns it to the air in the form of carbonic acid again. Thus the two different organisms work in a circle.

All this is accomplished primarily by the sun, whose action on the leaves of plants enables them to decompose carbonic acid gas, and fix the carbon, with other elements, in the form of starch, gum, sugar, and other vegetable products upon which animals subsist. Without the sun plants could not fix carbon, and, consequently, animals. as well as plants depend upon the sun for life. The amount of other elements, in most vegetable matters, is comparatively small, carbon being always the main ingredient, as we see by the amount of charcoal that wood will leave, when properly burned-charcoal being nothing but carbon. The quantity of mere mineral matter is always small, and only of subordinate importance.

The leaves of plants also decompose water to obtain its hydrogen, and ammonia to obtain its nitrogen, and this is effected solely by the action of sunlight, without which no such decomposition would take place.

In regard to the sources whence the secondary compounds are derived on which plants subsist, M. Dumas remarks : "They are, in fact, produced upon the grand scale by the action of those magnificent electric sparks which dart from the stormcloud, and, furrowing vast fields of air, engender in their course the nitrate of ammonia which analysis detects in the thunder-shower. . . As it is from the mouths of volcanoes, whose convulsions so often make the crust of our globe tremble, that the principal food of plants, carbonic acid, is incessantly poured out; so it is from the atmosphere, on fire with lightnings from the bosom of the tempest, that the second scarcely less necessary aliment of plants, nitrate of ammonia, is showered down for their use." 
The air, therefore, is the great storehouse from which the organic material both of plants and animals is derived, and in one sense they may all be called the chitdren of the air.

The common notion of many people that plants draw all their nourishment from the earth is therefore erroneous. The mineral constituents of plants are derived from the earth ; but they are small in amount, and of subsidiary importance for the most part. Plants grown in pure sand, and wet with distilled water, will form solid woody fibre, the same as if they grew in the earth ; and this of course comes solely from the air, for it is mostly carbon, and there is none of that element either in the sand or the water.

The amount of carbon thus fixed by plants from carbonic acid gas is something astounding to contemplate. Take a forest, for instance,--in one that is properly worked it is estimated that an acre will yield annually, only by due thinning out, at least four thousand pounds of dry wood, or about one thousand pounds of solid carbon. Then reflect upon the millions of acres on the globe covered by forests, besides other vegetation, and some idea may be formed of the immense annual production.

These facts are important to bear in mind, as they not only serve to explain vital processes now going on, but also make it clear how immensely different were the conditions under which life originated in past times.

There was a period in the early history of the earth when the atmosphere contained immensely more carbonic acid gas than it does now ; so much, indeed, that land animals could not live in it. But such an atmosphere as that, surcharged with hot watery vapor also, is just what plants thrive upon, and we accordingly find that vegetation, at that period, attained to a size and luxuriance of which we can have but faint conception. Ferns and mosses which now are small and insignificant were then large trees, and grew in dense forests. From this superabundant vegetation is derived our coal-beds, which thus represent, in reality, the concentrated sun power of a former age.

This very abundance of plant life, however, of itself ultimately changed the atmosphere, and made it fit to be breathed by land animals, which then came into existence. By continually decomposing the abundant carbonic acid gas and fixing the carbon, it gradually brought the air nearer to its present constitution.

If this process of active vegetation had gone on alone, all the carbonic acid gas in the world would finally have been decomposed, and the carbon fixed. But next came in the era of great animals, who by reversing the process, as before explained, burned up this carbon in the process of nutrition, and in their breath returned it, as carbonic acid gas, to the air, so that the plants could use it over again. In this way the balance was maintained as it is at the present day.

Plant life could not go on alone, because it would ultimately fix all the carbon solid, and have none left in an available gaseous form ; and animal life could not go on alone, because it could not obtain solid carbonic and nitrogenous food from the simple elements. The two are necessary to each other, and each works for the other in working for itself.

Even in the small field of infusorial life, in plants and animals, such as we have been describing, this great fact is exhibited, and microscopic plants and animals act and react upon each other just like their larger representatives. Funguses, moulds, and animaleules appear together in the same infusion, follow one another, and apparently pass into one another by insensible gradations. 
Possibly the simple protista, which are either plants or animals, or neither, may be capable of assimilating carbon either in the fixed form, as animals, or of decomposing carbonic acid gas, as plants, and thus truly belong to both the animal and the vegetable kingdoms at the same time, in the same way that amphibious animals can breathe either in air or in water.

When we see how life has thus changed on the large scale on our giobe, by the change in its condition, we can the more easily understand how it can be similarly varied on the small scale of our experimental infusions. By varying their composition and strength, the amount of heat to which they are subjected, and the electric and other conditions around them, we should naturally expect to vary the result; and such is in fact the case, as we have already shown.

The large plate here introduced shows admirably the astonishing luxuriance of vegetation in the age which produced the material of our coal-beds, when the atmosphere was filled with carbonic acid.

For the primary beginning of life, -as a starting-point for all the plants and animals that now live, or that ever have lived,- the minutest speck of protoplasm would be sufficient. This speck, too small for our best microscopes to detect, would inevitably form a moner, or some kindred organism, which would speedily multiply by simple division into millions like itself ; and these would soon pass into other forms, in the way we have shown, and these again into others, each a stage higher, till the whole organic world would, slowly and surely, be evolved.

The death of one generation, by providing more abundant organic material, would give increased development to the rest; and thus the simple primary forms would insensibly pass into the complicated organisms we now see.

Such, it would seem, must be the result of the production of even the minutest portion of protoplasm, the matter of life! And, from what we know of the properties of matter, it seems scarcely open to doubt that, in the ceaseless whirl of activity and change in the material world, all kinds of combinations of its elements must take place, protoplasm among the rest! It is scarcely possible even to suppose that it should not! If all organic matter were now destroyed by heat, nature would, in all probability, again produce a protoplasm, and the circle of organic life would begin anew. Under former conditions, it was probably produced abundantly ; but even now, there is every reason to suppose, it not unfrequently springs into existence. For protoplasm, it must be remembered, is not a new kind of matter, but only a particular combination of the simple elements common to the whole universe.

"Bee! through this air, this ocean, and this earth, All matter quick, and bursting into birth!"-POPE. 


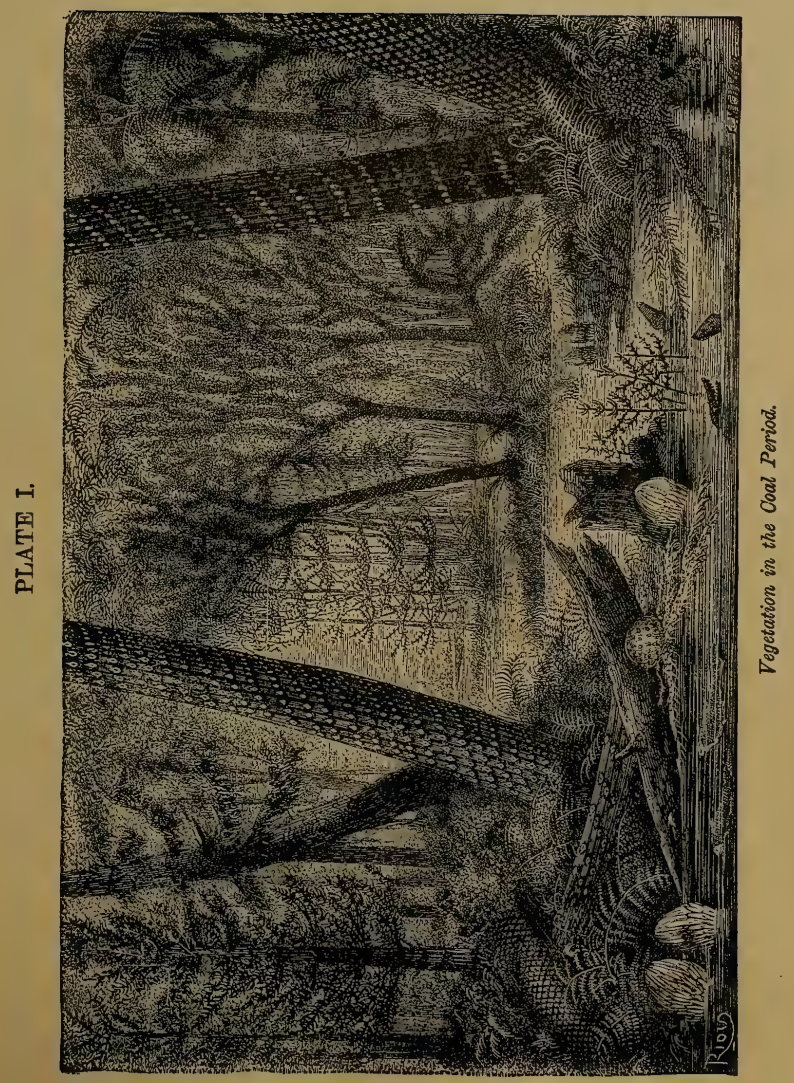





\section{OHAPTER VII.}

\section{IHE DIFFERENCE BETWEEN ORGANIC AND INORGANIC MATTER, AND EPA RELATION BETWEEN PLANTS AND ANIMALS.}

Protoplasm, or the matter of life, both animal and vegetable, differs from mere mineral matter in this way: inorganic matter, as a solution of salt, for instance, when it solidifies nearly always assumes some regular form, usually geometrical, or crystallizes, the crystals having certain definite angles and, usually, straight sides.

Organic matter, on the contrary, instead of being crystallized, usually assumes what is termed the colloid form, as we see in gum, or sirup, and never has a definite shape, like a crystallized body. This difference probably results from the difference in the character, and number, of the elements of which the two kinds of matter are composed. An inorganic crystalline body is formed of few elements, usually of only two, and these of a stable character, most of them being solids, so that it is not prone to change. There are, therefore, but few formative forces at work, and hence comparative simplicity and regularity of outline. An organic compound, on the contrary, is most frequently formed of many elements, mostly gaseous, and mobile ; so that its form is determined by numerous formative forces acting in contrary directions, and hence its homogeneous or apparently formless appearance. The same causes also make it more prone to decomposition or decay, because its varied and mobile constituents are but loosely held together.

Organic matter, in consequence of this peculiarity of composition and structure, forms itself into some rounded, soft, and mobile form, which being easily acted upon by the forces around, readily contracts and expands, or moves, and so begins to live; or, in other words, it organizes into a living being.

Inorganic matter, on the contrary, in consequence of its structural simplicity, and the more stable character of its constituents, always assumes rigid determinate forms, straight and angular, which are said to be inorganic, or dead, to distinguish them from organic bodies, which are called living. It would perhaps be more proper to say that both kinds are living, in different ways and degrees. The crystal bas fewer constituent atoms than the animalcule, and they are less varied; it has, therefore, a less amount, and less variety of life. As Schwann obserres, "The formation of crystals bears the same relation to inorganic matter as the formation of cell does to organic." Each is an advance in life.

Not only, however, are plants and animals the same at the beginning, so that one cannot be distinguished from the other, but, even when full grown, they often have wany functions in common. In fact, it is very difficult to state any essential and constant differences between them.

It was once thonght that the difference lay in the power of motion, animals being able to change from one place to another, while plants were fixed. It is now 
known that there are plants which move about from place to place, and animals that are fixed to one place, rooted like plants.

It was then supposed that animals were exclusively gifted with sensation, or feeling; but this also is more than doubtful. The sensitive plant, for instance, will draw its leaves together, and even bend down its leaf-stem, when the finger is pointed to it. Like many other plants, it is also affected by electricity ; and may be killed by poisons, - by piercing with the fang of a rattlesnake, for instance, just as animals are,

The grand distinction, however, was thought to be in the nature of their food, and the mode of nutrition. Animals have stomachs, it was said, in which they , digest their food, which must be organized material, either animal or vegetable ; while plants have but roots and leaves, by which they absorb the inorganic elements only. There are, however, many plants known that make prey of animals, and digest them, a portion of their structure acting as a stomach, and secreting a true gastric juice, exactly like that found in the stomachs of animals.

The Dionea Muscipula, or Venus's flytrap, for instance, and the Drosera, are each provided with an apparatus by which they catch insects, kill them, and afterward digest them. In these plants parts of certain leaves are endowed with a peculiar sensibility, which causes them to fold over upon any insect that alights upon them, and imprison it till it dies. Then certain glands pour out a fluid, which has the same properties as the gastric juice secreted in the stomachs of animals, and which dissolves and digests the insect the same as the animal digests flesh. If a small piece of raw meat even be placed on a sensitive leaf, the plant will eat it in the same way, and we can thus feed the plant as we would an animal. A list can be made out, by careful observation, of the substances it will eat, and those it will not, and some will be found even that will disagree with it, or cause sickness, as with our own stomachs.

It is not mere common sensibility which these plants exhibit; for if any other body is placed on the leaf, or other sensitive part, it will not fold over to hold it, though it may throw it off, as it does the indigestible parts of the insect.

That this is really a process of digestion, and that the leaf acts just as an animal's stomach, there can be no doubt. If we take a piece of meat, and place it in a bottle, with some gastric juice taken from an animal's stomach, it will not taint, nor decompose, but will slowly dissolve, or be digested, just as it would be in the stomach itself; and the secretion from the leaf of a Dionea, or Drosera, acts in exactly the same way : it is, therefore, true gastric juice. As a further proof that this is the way the plant feeds, or, at least, the chief way, its roots are but very partially developed; they seem adapted only for anchoring the plant in the ground, and keeping it upright, and not for purposes of nutrition, as we usually find them in the vegetable world. The leaves also retain their power of seizing and digesting animal food for a long time after they are torn from the plant-even till they are beginning to wither - which shows that they act independently of the roots.

Besides the two above mentioned, there are many other plants now known that exhibit this remarkable habit of insect-eating. In fact, new ones are being discovered all the time, the habit being more general than was formerly supposed.

The sensitive leaf of the Drosera is somewhat like a flat button, surrounded on the edge by a fringe of arms, or tentacles, as they are called. These are formed oi thin stems, or filaments, each with a small round disk, or gland, on the top. These arms easily bend at the lower part, and curl over, so as to bring the gland on the 
top down to the central disk. They act just like the limbs of an animal. If an insect alights on the small disk on the top of one of these arms, it bends over till it touches the center of the leaf. What is very remarkable, also, all the arms near enough to help bend over at the same time, and to the one point; but none of those do so that are too far away.

In Fig. 10, a bit of meat has been placed on the central disk, near one side, and all the arms on that side have bent down on to it, or are bending down, to secure the prey, while those on the opposite side out of reach remain erect.

In Fig. 11, the bit of meat being placed in the center of the leaf, all the arms are bent down on to it alike, from all parts of the circumference.

It will be observed that the arms bend only at the lower part, but their sensibility rests in the gland, and upper part. No animal could detect its prey quicker by sight than these plants do theirs by the sensibility of their glandular hairs. It seems as if they were continually on the watch. But place any substance on the disk not suitable for food for them, and they will not notice it.

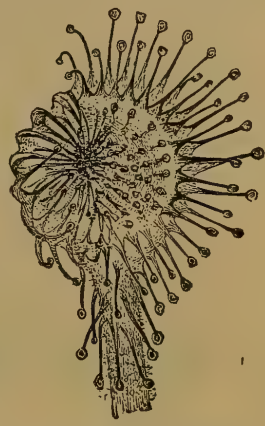

FIGURE 10.-Leaf of the Drosera, showing part of the tentacles bent over, and part erect.

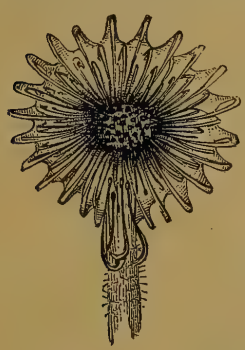

Frgure 11. - Leaf of Drosera, with a bit of meat in the center, the tentacles all round bent down upon it.

If two or more bits of meat be placed on the central disk, at different points, all the tentacles nearest to each one will bend over to that, and seize it. They seem never to make a mistake, but each one helps to seize the piece that is nearest within its reach. Any one might readily imagine it was an animal, grasping its prey.

The minutest portion of animal substance is sufficient to cause this wonderful action. A fragment of hair, weighing not more than the seven-thousandth part of a grain, will cause a tentacle to bend over. It is remarkable however, that, in spite of this extreme sensibility, drops of rain may fall on the glands without any effect.-The tendrils of climbing plants also, which are extremely sensitive to almost everything, are similarly unaffected by rain-drops.

It is observable, further, that after these arms have been active, in bending over, a remarkable change takes place, for the time being, in the molecular structure of the base, where the bend occurs In other words, cell transformation takes place as it does in animal muscle, when that is active.

In regard to the digestion of the animal matters thus seized, Mr. Darwin says that the action of the fluid secreted by the glands of the Drosera, on albuminous matters, is exactly like that of animal gastric juice. Chemical tests, and experiments, in fact, show the two to be identical.

It is very curious, also, that if leaves of the Drosera be stripped from the plant. they still retain, for a long time, this power of seizing prey, and digesting it. A leaf will seize an insect even when it has begun to wither.

As another instance of the wonderful sensitiveness of the glands of the Drosera, it 
has been found that the two-hundred-thousandth part of a grain of carbonate of ammonia will affect them; while the same salt, absorbed by the root, exerts no influence whatever. Of phosphate of ammonia not more than the nineteen-millionth part of a grain is needed to produce the same result.

This shows a degree of sensibility in the glands of the Drosera, a plant, far beyond anything with which we are acquainted in the nervous systems of animals. How far this may be accompanied by anything corresponding to consciousness, we do not know, but we scarcely seem justified in saying positively, that there is nothing of the kinc.

These wonderful vegetable glands may also be poisoned, by many substances, just

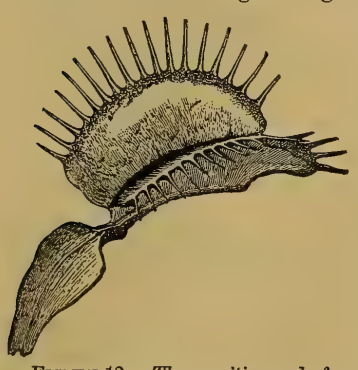

FIGURe 12.-The sensitive end of $a$ Leaf of the Dionea. The pointed bristles act like the teeth of a trap, and assist in holding the prey.

pears to reside, and which assist caught.

The closed leaf in this case is a real stomach, as well as a trap, and the fluid it secretes is true gastric juice, like that of the Drosera. See also Fig. 16, on page 52, in which the leaves will be seen fully expanded, and in all stages of contraction.

Besides these two, there are many other animal-eating plants known, and daily being discovered. The common Butterwort, or Pinguicula, is one of these : it is shown in Fig. 13. The edge of the leaf is seen bending over a row of flies, attracted there by the secretion of the leaf glands, which holds them fast. Once inclosed, the leaf remains curled over till they are digested, and then opens, to act the same part over again. This plant, however, will dissolve some vegetable matters, as well as animal ones, especially those that are nitrogenous.

Fig. 14 shows the common Utricularia, or Bladderwort, a water plant, which is also an animal-feeder, but catches its prey in a different manner. This figure is about twice the natural size. It will be seen that on the branches there are a number of small round

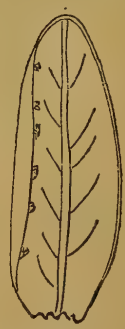

Figure 13. Leaf of Butter. wort, or Pinguicula, showing how it curls over to trap its prey. bodies, most of them with hair-like fringes, or bunches of bristles, on the top. These are the bladders; they are about the tenth of an inch in diameter, hollow, with a mouth, and the hair-like tentacles around the lips, exactly like some of 
the infusorial animalcules. The mouth is closed by a kind of valve, which opens only inward. Into these bladders, or traps, small animals enter, and find it impossible to escape, owing to the valve. They are then retained till they die, and are used as food. The bladder is thus a stomach, which catches its own animal food, by which the whole plant is nourished.

It does not appear, however, that the animals so caught are digested in the same way as in the Drosera, or Dionea, for there is no proper gastric juice secreted. They simply remain there till they decompose, and are then absorbed, probably in the gaseous form.

Fig. 15 shows one of the bladders cut open, and much enlarged, so that the mode in which the valve acts may be better understood.

Besides the mechanical action of the leaves and tentacles, most insect-feeding plants are also covered with a shiny, sticky fluid, which both attracts their prey, and also helps to retain it. This is the reason for the name of Sun-dew applied to the Drosera, because it shines in the sun like dew.

The common Catchfly, or Campion, catches

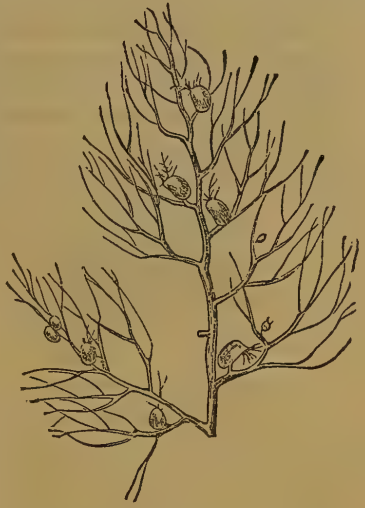

FTGURE 14.-Utricularia, or Bladder. wort, showing the bladders or sacs in which it catches its prey. insects in this way only, and is nearly always covered with them. It has no ten. tacles or other apparatus, but holds them merely by the sticky secretion till they die. Many other plants do the same, but in what way they use the prey so caught, if

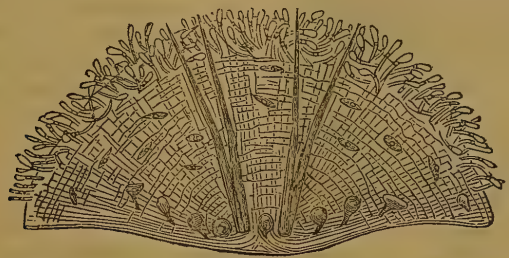

FrguRE 15.-One of the Bladders of the Utricularia, cut open and spread frat, to show the fringes, and the ribs which work the valve to close the mouth.-Magnified.

they do use it, we do not know ; probably it mereiy decays, and they absorb its gaseous emanations.

Mrs. Mary Treat has contributed to the American Naturalist some very curious observations made upon the Drosera. She found the specimens upon which she experimented in New Jersey. The plant was in full bloom, and growing very thickly on either side of an extensive cranberry plantation. The first experiment was made with the best-known species, the Drosera filiformis. Some living flies were pinned half an inch from the leaves near the apex, about 10 o'clock in the morning. In forty minutes the leaves had bent perceptibly toward the flies. In two hours the 
leaves had reached the flies, and their limbs were entangled among the bristles, and held fast. The flies were then removed three-quarters of an inch farther from the leaves, which still remained bent toward the flies, but could not reach them at this distance. The observer thinks that the action of the flies' wings may have created sufficient force to bring the leaves near enough to entangle the flies, for dead flies fail to produce the same result as living ones. On the same day bits of raw beef were placed on some of the most vigorous leaves of another species of the plant, the Drosera longifolia. In two hours two of the leaves had folded around the beef, hiding it from sight. Liring flies were also placed upon the same species of the

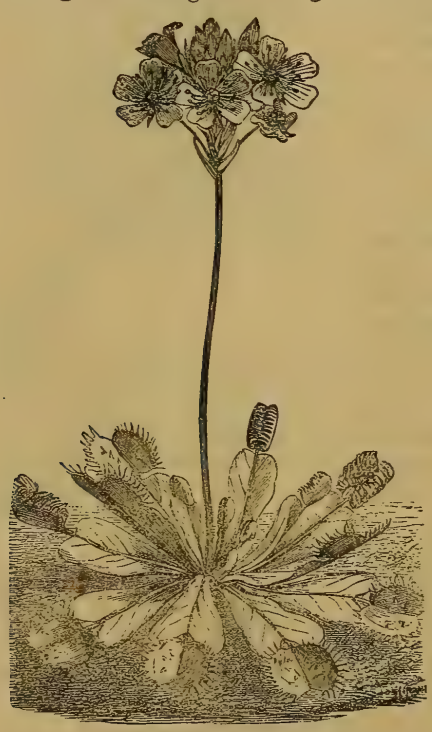

FiguRe 16.-Dionea Muscipula, or Venus's F'lytrap.

In this cut the structure of the Dionea is well shown. The trap, it will be seen, is on the end of each broad leaf, and is shown both opened flat, with the hairs spread out, and also closed, in various stages. Those tightly shut up contain insects being digested. captive till they died, the treacherous flowers and shining dew luring them to destruction. The larger insects, after death, fell around the roots of the plants, as if to fertilize them, while the smaller flies remained adhering to the leares. These curious plants thus seem to manifest a decided preference for meat diet, absorbing the animal substances throngh their leaves.

The dog's-bane-Apocynum androsemifolium-catches insects in a different way plant. In a little more than an hour one of the leaves had folded entirely around its victim, the other leaves had partially folded, and the flies had ceased to struggle. Two hours later, four leaves had each folded around a fly.

The Droser a manifests a very decided choice in regard to its gustatory fancies. Experiments were made with bits of dry chalk, magnesia, and pebbles, but the plant would have nothing to do with them, and after twenty-four hours neither leaves nor. bristles had made the slightest movemen $i$ toward clasping these articles. A similar result was produced upon the Drosera rotundifolia. - This variety has longer bristles around the edge of the leaf, and simply curls its bristles around its victims, the glands on the ends of the bristles touching the substance, like so many mouths receiving nourishment. Some bits of raw beef were placed upon the leaves about 10 o'clock in the morning. In two hours the inner bristles were curving about it, and the longer bristles at the edge of the leaf were curving upward. At 9 o'clock in the evening the bristles of the three most vigorous leaves were clasping the beef, almost concealing it from sight. Nor is this ferocious plant contented with small insects. Flies of the largest size, moths without number, and butterflies, many of them measuring two inches across, were held (n) 
but probably for the same purpose : whenever a fly is attracted by the honey of the flower, and protrudes its trunk to take it, the filaments close tightly on the trunk, and hold the fly there till it dies, when they relax, and let it fall.

Another very striking proof has been obtained of the identity between the secretion from the leaf of the Dionea, and animal gastric juice. It is well known that. the gastric juice will dissolve almost all organic matters, even bones, if allowed sufficient time. It has been known to dissolve the stomach itself even, after death. The juice from the leaf of the dionea, as before stated, will dissolve meat, and digest it, the same as the animal gastric juice ; and recently, instead of meat, a piece of the bony part of a dog's tooth was placed on one of these leaves, which closed upon it at once, and retained it. It a few days the leaf was opened, and the piece of tooth found perfectly softened, and fibrous, so that the mere opening of the leaf tore it into shreds.

A further proof of the similarity between the animal and regetable gastric juice is also found in the fact, that the presence of food in both causes the juice to be immediately secreted.

The difference then, between the animal and vegetable kingdoms, disappears when we come to understand both more fully, and it is really very difficult to say if there he any faculty, or property, peculiar to either one alone. It would seem rather that the plant and the animal should be looked upon as one and the same, at the beginring, and diverging more or less in different directions as they develop. Possibly any primary protoplasmic germ may become plant or animal according as it is influenced by surrounding conditions, such as light, heat, electricity, etc., when it starts upon its career of development.

There is a peculiar fungus found in tanpits, which, when placed under new conlitions, changes completely. From a decided plant, growing in one spot, it becomes an entirely different being, capable of moving about, and of eating, and digesting solid food. In fact, it becomes an animal, to all intents and purposes.

Such an occurrence still further increases the difficulty of determining what is the real, essential difference, if any, between the two kingdoms. We have plants that move about, and animals that are rooted; we have plants with sensation, and animals apparently without; we have plants that digest animal food, and animals that live upon vegetables ; and, lastly, as stated above, we find that one can change into the other. The simple explanation of these seeming anomalies, is, as previously stated, that they are both fundamentally the same.

Recent observations have also shown another point of resemblance, of a very interesting and important kind. It is well known that, in animals, muscular exertion is always accompanied by an electric current in the muscle, the force of which is in exact proportion to the violence of the exertion. This electric condition remains in the muscle even after death, till the body becomes rigid. The current is strongest in the warm-blooded mammals, gets less in reptiles, and scarcely observable in fishes. This, it must be observed, is different from the electric battery of the torpedo-fish, which is developed by a special apparatus. These electric currents in animals have been known for some time, and recently similar currents have been detected also in plants. When any of the insect-eating plants contract their leaves, to seize their prey, an electric current is established in them exactly similar to that which is found in an animal's muscles when they are exerted. This is another and very interesting point of identity between the two kingdoms. 
When the leaves of the sensitive plant contract and expand, from a touch, the same thing is observed, an electric current being immediately established. And Mr. Darwin says that by pricking a point in the leaf of Drosera, he can paralyze half of it, and this indicates the existence of nerves or something analagous.

After all, it may be said the grand distinction lies in the possession of mind by animals alone. This, however, may be more apparent than real, or may be only a matter of degree. When we observe the apparent intelligence, or sense, often shown by plants, we are quite justified in supposing that it may be the same as anim 6 intel-

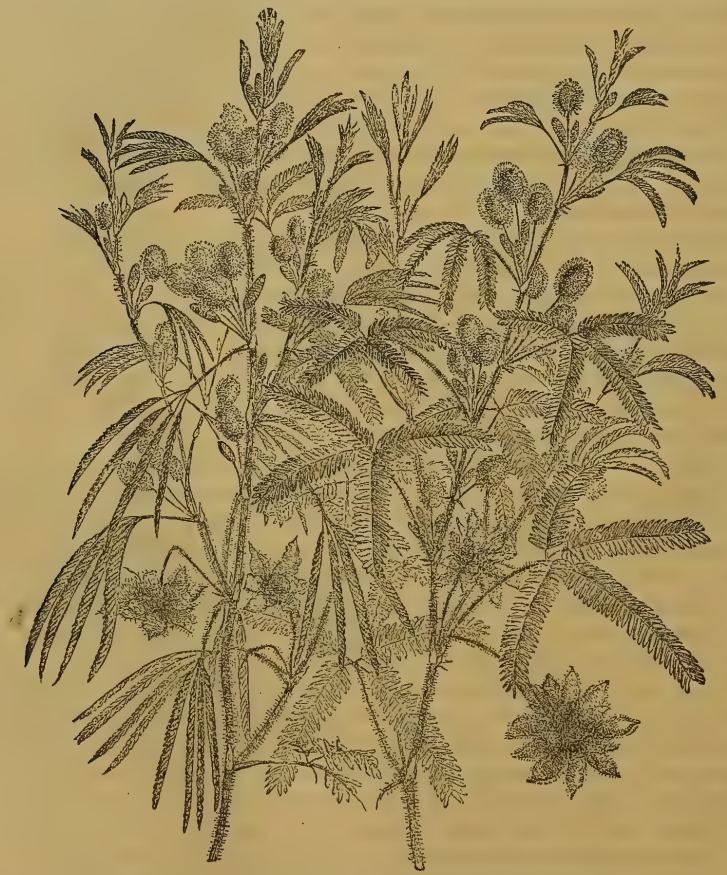

FIGURE 17.-Mimosa Pudica, or Sensitive Plant, asleep and arake.

The leaves on the left side will be seen fully erect, and the little leaflets expanded. On the other side the whole leaf is drooping, and the little leaflets are closed, just as they are when the plant is touched, or frightened.

ligence, only less in degree, and manifested by less perfect organs. Observe how singularly a plant will stretch and bend its branches to get into the light; and how its roots will turn, even at right angles, or around corners, to reach rich soil. Many of them always close their leaves, or flowers, on the approach of storms, and some will not unclose at all, if the weather is going to be unfavorable. 
It will be said, I know, that this is all mechanical, and that there is nothing like mind about it! But we cannot be sure about that; for, as said before, it may only be a very low degree of mentality. Some idiots have scarcely any more mind than some plants; and the vital functions they perform are almost, if not quite, as mechanical. In fact, the difference between a thorough idiot and some plants, seems not greater than that between the same idiot and a perfectly sane man of large mental capacity.

We may even go beyond this, and when we see one kind of matter unite with a certain other kind only, selecting it by preference from among many others, we may not unreasonably say, - here is the same faculty, in a less degree, that we see in plants and animals, - that of choice!

The formation of crystals, of frost figures on our window-panes, and numerous other familiar instances, show us that matter always arranges itself according to fixed and unchangeable laws, whose action is simply more perfectly manifested in organized bodies than in simple ones. What we call attraction only in the crystal, is selection in the plant, and choice in the animal. Nature is one, and the same powers exist in her atoms, and primary forms, as in the most complicated organizations.

The well-known sensitive plant, Mimosa pudica, exhibits sensibility in a very marked manner, and has, in consequence, always been an object of interest and wonderment.

In Fig. $1 \%$, the Mimosa is seen asleep and awake. On the left-hand side the leaf-stalks are seen all erect, and the little leaflets spread out. If one be touched with the finger, even slightly, the small leaflets close together, and the stalk bends down, as seen on the other side. After remaining closed, and drooping for some minutes, if not further irritated, the leaflets again slowly open, and the stalk again becomes erect. This may be repeated over and over again, and the Mimosa may in this way be readily put to sleep, and kept so for a long time. A drop of acid on one of the leaves will make the whole plant close up, and the same effect follows if we throw the focus of a burning-glass on any part. Even striking the ground, some distance away, will affect it; or a loud noise, like thunder, or the discharge of a gun. It is also sensitive to sudden sunlight or shadow, and can be stupefied by opium, or killed by an electric shock. Prussic acid is instantly as fatal to it as it is to animals ; ether spray paralyzes the leaves ; and a current of galvanism from Ruhmkorff 's coil closes them immediately.

In short, it is affected by any of these agencies just like an animal, and can become accustomed to many of them, as an animal does. A sensitive plant when first taken into a carriage closes up, from the motion, but after a while seems to get used to it, opens out again and remains open, but closes when the carriage stops, to open again as before.

Undoubtedly, this is true sensation, of the same kind as that we experience ourselves, and quite as strong as we see in many of the lower animals.

Many other plants, however, are known to be sensitive, more or less, and probably all are so in some degree.

Motion in plants is also common enough, and sometimes is quite vigorous. The Colocassia esculenta moves in regular periods, like the beating of the pulse, and sometimes so violently that it will almost overturn the pot in which it is growing. The Desmodium gyrans, or telegraph plant, is still more remarkable. Its leaves 
are in threes-one at the end of the stem, and one on each side. The two side ones flap up and down all the time, day and night, at regular intervals, while the center one moves up and down, according as there is more or less light.

If we touch the stamens of some plants with a needle or knife, especially those of the Barberry, Nettle, and Cactus, they obvionsly shrink away from it; and in other plants the pistils will draw together when so touched.

The pollen of some plants resembles animalcules, and will swim about in water, just as they do, being provided with little oars, or cilia, for the purpose. Some pollens are even formed like eels, and move about by means of two long filaments on their heads. Others, again, resemble the tadpoles of frogs, and flit about just like them.

Many plants move in a remarkable manner, and put forth astonishing efforts, to reach water or light. Thus, M. Grimàrd tells us of a little plant-Lathrea squamaria -which, happening to germinate at the bottom of a mine, extended itself 120 feet to reach the light at the top, and yet its ordinary height is not more than six inches.

In short, we find in plants the power of motion, apparently voluntary-selection, or choice-and sensibility, exactly as we see them in animals; and the conriction forces itself upon us that they are the same in both kingdoms of nature, only modified and different in degree.

When we come to speak upon reproduction, other points of resemblance will be shown still more striking.

In a lecture delivered at the London Institution, Mr. Francis Darwin gave some rery interesting information concerning the analogies between plant and animal life, in addition to what had preriously been imparted by his father, Mr. Charles Darwin.

After first illustrating, in a very felicitous manner, the striking resemblance between a vegetable seed and an animal egg, in their structure and manner of development, he alluded to the recent discovery, by a German chemist, of the existence in all germinating seeds of a peculiar ferment, which acts like the pancreatic juice in animals. This ferment changes the starch and nitrogenous matters of the seeds, which the young plant cannot use as nutriment, into sugar, and other compounds, which it can use. In other words, it digests them, just as they are digested in the stomachs of animals.

A ferment of this kind exists in all seeds, when they are germinating, and thus a young plant acts just like a young animal, in regard to its food, and is nourished in a similar manner. Farina or arrowroot, which are forms of starch, will not nourish a child until they are changed into sugar, and other compounds, and this change is effected by digestion. In the same manner exactly, the starch in a seed cannot nourish the joung plant, till it undergoes a similar change, by the action of the digestive ferment.

If we carefully examine a seed, as a bean, for instance, we find it composed of two similar halves, called the cotyledons, which may be compared to the yelk of the egg. They are composed chiefly of starch, with some nitrogenous material, and between them lies the embryo, or germ, of the future plant, which, when it begins to grow, sends one shoot down as the root, and another up as the stem. All its nourishment, before the root and leaves are formed, is derived from these two halves of the seed, which are gradually converted, by its digestive ferment, into suitable nutritive 
material. They gradually change from white to green, and finally become the first pair of leaves, charged with chlorophyl, or green protoplasm.

To prove that this is what really occurs, Van Tieghem cut away from a growing seed all the substance of the cotyledons, leaving the shoot, or embryo, only, which of course could not then grow, any more than a young chicken could grow without the yelk of the egg. When placed, however, in a paste made of starch and water, it began to develop, the same as it would have done had it been left in connection with its own store of nutriment; but first, by the action of its digestive ferment, changing the starch into suitable material.

The young plant, therefore, digests its food just as the young animal does, and when we eat a grain of wheat it undergoes, in our stomachs, just the same change as it would have undergone, had it grown into a plant.

Among animals, we have some kinds that live entirely on flesh, and others that live entirely on vegetable matters, and it is just so with plants. The Drosera, for instance, feeds on insects, or meat, while the bean feeds on starch. But both digest their food just the same. It is the same function in all, modified only by difference of structure.

In the degree of development to which they attain, before being left to themselves, young plants also vary the same as young animals. Some young animals are connected with the mother till fully grown; others are cast off imperfect; and in many the egg develops entirely away from the parent. It is the same in plants. Most seeds are thrown off and develop independently, but others remain attached to the parent till fully grown and rooted; as the mangrove, for instance. As a rule, those seeds that have the largest cotyledons, or stores of food, grow the most vigorously at first, before they become rooted, and thus have the advantage over others not so well provided, and crowd them out. Some young animals have a similar advantage, and in the struggle for existence hold their own better in consequence.

Even. what are called instinctive actions, in young animals, are paralleled by similar actions in young plants. The child will take the breast as soon as born; the chick, just hatched, will peck at its food; and the young caterpillar will work its way out of the cocoon. In the same way the young plant sends its root down into the ground, and its stem up to the light with unerring certainty. The root will twist and turn in various directions to find water, or food, and the stem will similarly turn and bend to reach the light. These actions are just as wonderful as those of the animal, and probably are fundamentally the same, only modified by difference of organization.

Some plants even sleep, just like animals : the Mimosa, for instance, closes its leaves at night, just as an animal closes its eyes, and droops its fronds, just as the animal does its limbs. Many others always close their flowers at night. These sleeping plants may also be awakened, just like animals, and kept awake, by artificial light and stimulation.

Mr. F. Darwin even supposes that the sensitive plant may dream, because sometimes at night, when asleep, it will suddenly awake, as it were, with a start, and then go to sleep again, just as a man often does from a vivid dream.

Many of the systematic motions of plants, and many of their periodic actions, are wonderfully like memory. They do the same things at regular times, or under the proper conditions, just as we do from habit. And we often do things thus habitually, with no more thought than the plant. 
It is certain the plant knows, in some way, the right thing to do, and does it, at the right time, just as the animal does; and it is quite reasonable to suppose that the moving impulse is fundamentally the same in both.

Mr. Darwin says, in conclusion, "Until a man begins to work at plants, he is apt to grant to then the word alive in rather a meager sense, but, the more he works at them, the more vivid does his sense of their vitality become!"

All which goes still further to show, as we have endeavored to illustrate elsewhere also, that nature is one all through, and that in the organic world, animal and vegetable are fundamentally the same. That all the phenomena we call mental-consciousness, desire, aversion, will-are attributes of matter, existing in all forms and quantities of it, down to the merest molecule, is now considered probable by many of the first thinkers and observers of the day. It is even conceived that mind may be only a form of the force, or power, inherent in matter, which underlies all natural phenomena of every kind, so that the world of thought is a part of the material universe, and not something outside of it.

Von Zellner, in his work on the nature of comets, distinctly states that position, and argues that it is only the imperfection of our own faculties which prevents us seeing the life and mind that are in all material bodies, whether organized or not. We are not justified, he says, in asserting that the motions which oceur in an injured crystal are totally unaccompanied by sensation. If our faculties were acute enough to trace all the changes accompanying the injury, and to appreciate the conditions they give rise to, we might find in the crystal a sensation strictly analogous to the pain felt by an animal when hurt. It would, of course, be modified, and be in lesser degree, from the greater simplicity of composition and structure of the crystal, compared with that of the animal.

In short, if our senses were acute enough, and our brains sufficiently developed, we could probably trace all the complicated phenomena of life and mind from one stage to another, down to the simple motions of protoplasmic animalcules, and from thence down to the force which is inseparable from molecules and atoms.

Geiger has well remarked that there may be, farther down, below the world of nerves, a sensation which we cannot understand. Indeed, he says, "It probably must be so. For as a body that we feel could not exist unless it consisted of atoms that we do not feel, and as we could not see a motion, were it not accompanied by waves of light which we do not see, neither could a complex living being experience a sensation strong enough for us to feel it also, in consequence of the motion by which it is manifested, if something similar, though far weaker, and imperceptible to us, did not occur in the elements, that is to say, in the atoms."

It is true we do not know that the stone we break with a hammer really feels the blow, in some sense; but neither do we know that it does not feel! Each one must decide for himself as to which is the most probable.

It has been argued that plants have no nerves, so far as known, and therefore cannot feel! But there are also animals in whom not a trace of a nervous system can be found, and yet they plainly exhibit some kind of a sense. The Amoba is apparently as nerveless as any plant, and yet it feels when any bit of nutriment touches its body, and folds around it at once. Several others of the lower organisms will direct their tentacles toward their food and seize it, as certainly as if they saw it, and yet no nerves can be traced in them.

The fact seems to be that all organic bodies possess nervous currents, which 


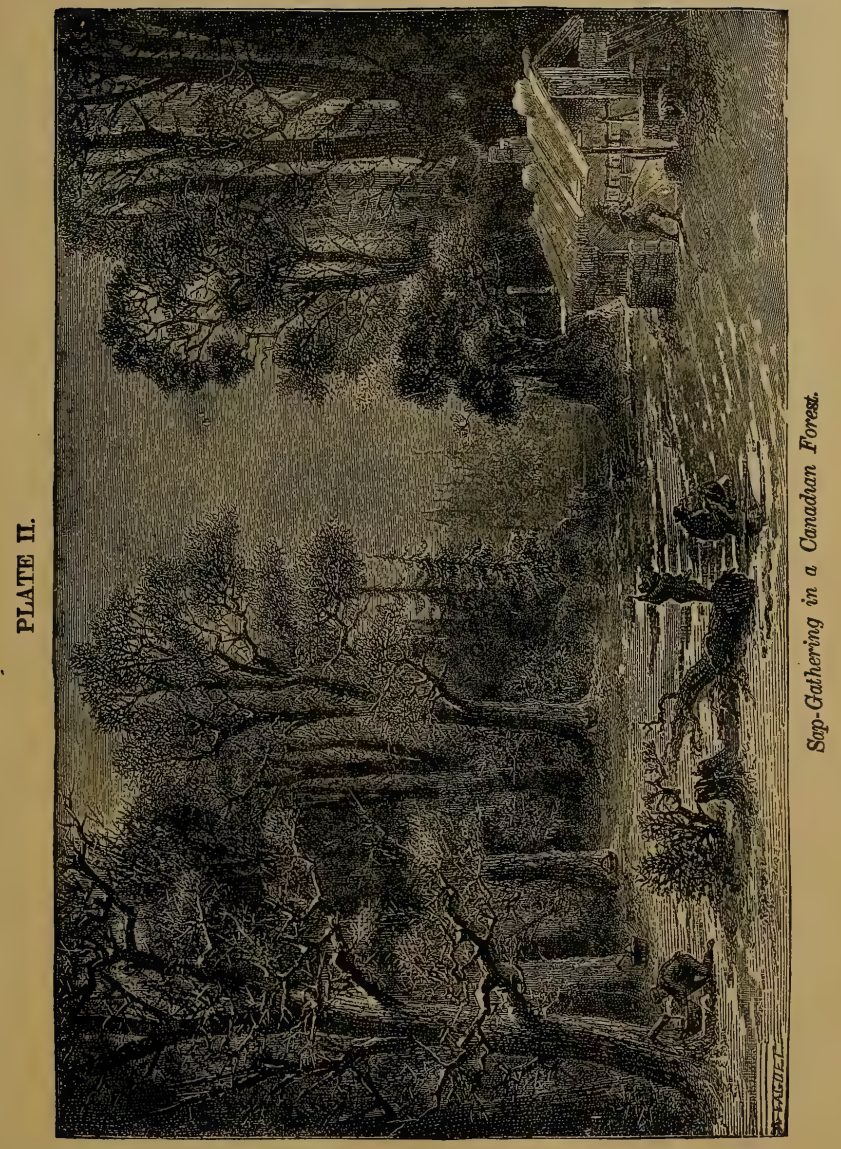



influence their motions, just as all simple inorganic molecules possess polarity. These currents run in certain lines, and, as the organization becomes more perfect, these lines become specialized as nerves or conductors. The power is there, whether the nerves are or not; but with them it is distributed with more precision and intensity.

The circulation of the sap in plants may also be referred to as another correspondence between them and animals; for it is strictly analogous to the circulation of the blood, and undergoes similar changes, by osmotic cell action, to convert it into protoplasmic material. The subjoined plate, showing the yearly gathering of sap in a maple-sugar forest, will serve to show the immense scale upon which this circulation and conversion takes place.

[It should be remarked here that many of the names made use of in this chapter, and many of the things referred to, will be more fully explained farther on. It was necessary to speak of them here, by way of illustration, before they had been properly introduced. In fact, this chapter should be read again after the next one on cell life.] 



\section{PART III.}

CELLS AND CELL LIFE. - ANIMAL AND VEGETABLE CELLS, AND THE DIFFERENCE IN THEIR COMPOSITION.-THE LOWEST FORMS OF LIVING BEINGS; THEIR UNIVERSAL DIFFUSION AND

VARIETIES.-THE GERM THEORI OF DISEASE. 



\section{CHAPTER VIII.}

\section{THE FIRST FORMS OF LIVING ORGANISMS-VESICLES AND CELLS.}

THE first forms of life, as already shown, are simply minute specks of protoplasm like spots of jelly, or white of egg. They have no definite form, no organs, nor any investing membrane. The only sign of life they exhibit is simple motion. They are probably nourished solely by absorption, from the fluid in which they live and move. Many of them are exceedingly minute, requiring a powerful microscope to distinguish them, and often can scarcely be told from the inorganic matter around them.

In all probability protoplasm is formed from inorganic matter, as before explained, and then portions of it are so acted upon, by surrounding agencies, that they separate from the mass, and assume the first form of independant vital action-simple motion. The passage from inorganic matter to this form is probably all the time taking place, imperceptibly, without any sudden transition, as we see in the beds of protoplasmic ooze at the bottom of the sea-the Bathybius of Huxley,-and also in atmospheric protoplasm, formed in the air by the union of water, ammonia, and carbonic acid. Small molecules may also, in all probability, be formed independently ; and these may really be the germs found floating in the atmosphere. These germs, therefore, which are said by the opponents of spontaneous generation, to be necessary to the origin of life, in organic infusions, may, in part at least, be simply protoplasmic specks, formed in the air, and not necessarily derived from other beings previously existing.

The first advance from this simple protoplasmic speck is to what is called the cell, or vesicle. The surface of the speck becomes firm,-probably from heat, or from the chemical action of some of its surroundings, -and forms a covering, like a bag. We then have a true vesicle, or cell, which may be likened to a minute bladder, filled with a fluid, containing often a number of little granules, or grains, and sometimes a dark speck called a Nucleus. The Nucleus also is often found to contain a fluid, and to have a speck of its own, called the Nucleolus! That is, there is one cell within another; and how far this may go we cannot tell. Perhaps if we could see farther, we should find still other nuclei within these. It was formerly thought that the cell was the ultimate unit of erery organism, or the first stage upward from inorganic material. We now, however, go beyond the cell, to the primal protoplasmic speck,or the moner,-from which the cell originates. When formed, from the primal protoplasmic molecule, the cell is the actual building unit of every organism, animal and vegetable, they all being built up from it. It may, in short, be properly called the primary Universal Organic Germ. All cells are essentially the same, and begin in the same way from specks of protoplasm, no matter what kind of being they may build up, or how they may be modified. All kinds of animals and plants are, therefore, made in the same way, by the aggregating together of cells, as will be shown more fully farther on. All eggs and seeds are only cells. 
Numerous animals, and plants also, consist only of single cells, and are therefore called unicellular, or one-celled. They are the lowest and simplest of all organisms.

These simple cell beings can seldom be classified as either animal or vegetable; probably they are neither, but capable of becoming either, according to the conditions under which they may be placed. The only difference between those cells known to be vegetable, and the animal ones, is this ; that the membrane of the plant cell usually becomes hard, or woody, while that of the animal remains soft and pliable; and this difference arises in this way. They both start from the same kind of germ, as already explained, and are afterward nutrified by the same elements. Circumstances, how. ever, so influence some that they absorb a large amount of carbon, and this element makes the investing membrane, and all the tissues formed after, dense and firm; makes them woody, in fact-carbon being the solid element in wood. In this way, the cell develops into a plant. Other cells, on the contrary, are so situated that they absorb more nitrogen, in the form of ammonia ; and this makes a soft and pliable membrane or tissue -a skin, in fact-and these cells, in consequence, form animals. Nitrogen, therefore, is essentially the animal element, as carbon is the vegetable element. The life process in each is afterward modified by this primary difference in constitution. The plant needs carbon to effect its growth ; it is, in fact, its nutriment, and it obtains the element from the atmosphere. The carbonic acid, always present in the air, is taken up by the plant, and decomposed, the oxygen being restored to the air, and the carbon retained to form fresh wood.

All the immense amount of wood in our present forests-all that has ever been before, and all our coal-have been taken by plants from the air, by the influence of suntight, without which the plant cannot decompose the carbonic acid.

The animal needs nitrogen, and obtains it by absorbing ammonia, which it decomposes, and then uses both the nitrogen and the hydrogen. In its food this animal also takes more or less carbon, in the solid form, or combined with other. elements ; but it retains only a portion, the rest being got rid of in the process of breathing. In the lungs, the blood, containing more or less carbon, is acted upon by the air, the oxygen of which unites with the carbon to form carbonic acid gas, which is expelled as part of the expired breath. In other words, the carbon is burned, just as wood is burned in the fire; only the combustion is slow and smothering, instead of active. In this way the carbon is got rid of, and heat produced at the same time.

The animal thus throws out what the plant needs, - carbonic acid, - and the plant forms what the animal needs,-protoplasmic material from inorganic matter;-so that the two mutually work for each other. To show, however, how the two kingdoms approach each other, some of the funguses not only decompose carbonic acid, appropriating the carbon and expelling the oxygen, but also absorb nitrogen, like plants.

This will explain the essential differences, in structure and action, between plants and animals, so far as they exist.

Oxygen, it should be remembered, is the destroying, or changing, element. It has a tendency to unite with, or burn up, almost every known element or compound. In the case of wood, we know how it unites with it, or burns it up, in an open fire. But it does the same in the air without fire, though more slowly. If we leave a clean piece of new board out in the air, we know how soon it becomes discolored, or darkens, and finally slowly decays. This is owing to the action of oxygen, which unites with it and burns it slowly, but just as surely, as if it were burned in the fire. 
Even metals are consumed by this all-devouring element in the same way. A bright piece of iron, or zinc, left in the light and air, soon becomes coated with rusi, as it is commonly called, or oxidized. The oxygen combines with it, or burns it, and forms the rust, or oxide. All substances, both organic and inorganic, are constantly being consumed in this way.

This is important to be remembered, as it will have to be referred to subsequently.

Animal activity, of every kind, may be said, in one sense, to be dependent upon a constant oxidation, or burning, of the materials of the body. Plants deoxidize carbon and other substances, and animals oxidize them again; so that animal life is as much a result of fire action, or combustion, as is the steam of the steam-engine.

The lowest forms of cell animals-called protozoa, from two Greek words meaning first, and animal - the very simplest, as already stated, are only single cells, vithout organs or definite form : but, by almost imperceptible stages, we can trace a gradual advance to more perfect forms; that is, to the development of organs for special functions. These organs, at first, are but few, and the most simple conceivable.

The minuteness of some cells may be conceived when it is stated that, in a general way, as many as twenty millions could be placed on a twenty-five-cent piece.

The cell membrane, or outer skin, is so formed that fluids ean pass through it, either way, under certain conditions, although it seems perfectly uniform and without pores. This is the case with every animal membrane, as with a bladder, for instance. If an ordinary pig's bladder be filled with water, and hung in the air, no water will pass through it to the outside, but if, when filled with water, it be put into strong brine, some of the brine will soon pass through to the water, and some of the water to the brine.

This curious and very important property of animal membrane may be stated thus : when the fluid on one side of the membrane is denser than that on the other, the two will pass through it, in opposite directions, and mix together, by what is called the action of osmose. This property of membrane is now much used to separate different substances from each other, by what is called dialysis. The way in which the growth and nutrition of the cell is effected by means of osmose, can now be readily understood.

Whenever the fluid in which the cell is placed is of a different density to that inside the cell, this process of osmose takes place. Part of the cell contents go to the surrounding fluid, and part of that enters the cell. All substances chemically different, act and react upon each other, and very quickly, if they are fluids. The contents of the cell, therefore, become affected by this admixture, and a series of changes takes place, resulting, sometimes, in the further growth of the cell, and, at other times, possibly in its death and decomposition. The whole time this process must be going on ; so that the functional life of a cell, insignificant as it may seem, is as active in its way as that of a man.

The whole process of the first formation of a cell and its subsequent growth can now be easily shown.

We have only to conceive a speck of protoplasmic matter,--a monad formed by natural agency (as above explained),--placed in a fluid medium, and the cell results inevitably. The protoplasmic speck is at first homogeneous ; that is, all alike, outside and inside, all through. It has no investing skin, nor any internal cavity. This is the first and simplest form of life, so far as we know. 
If, in the surrounding fluid, there be any substance that acts chemically on the albuminous protoplasm, so as to harden the outside, as many substances do, a skin or membrane is formed, which surrounds or incloses the fluid inside, just as the bladder does the water. A certain amount of heat will also do the same. This is the first step. Then begins the process of osmose through the membrane, by which the surrounding fluid is sucked into the interior of the cell, and still further modifies iis contents. Once these changes are begun they continue, in a thousand different ways, thus producing all the modifications of cells, and of the beings formed from them, as revealed to us by the microscope.

One of the changes which thus result from osmose is the formation of new cells inside the original one. A portion of the hardening chemical matter is drawn in through the membrane, and acts on the fluid it comes in contact with inside just ns it did outside, forming a membrane, which incloses a portion of the fluid, and thus makes a new cell. In fact, this process often goes on so fast that it can be watched under the microscope, and the new cells will sometimes multiply so rapidly that the parent cell bursts, and a swarm of new cells issues forth, while we are looking at them.

This is probably the first and simplest form of reproduction; and under conditions favorable to cell growth countless millions are thus incessantly issuing forth.

Many of them live and die only simple cells; others assume various forms, and aggregate together, so as to form compound beings. In fact, as we have already shown, the cell is the fundamental organic unit of every organism. Man himself is built up of cells, and nothing else ; and all the time, without intermission, new cells are being formed in all parts of his body, to take the place of the old and wornout ones that are being cast off. Nutrition is nothing but continued cell action, or the production and assimilation of new protoplasm. If this cell action supplies new material faster than the old decays, the being grows; if the contrary, it wastes. When full grown, for a long time, waste and restoration keep pace with each other, and it holds its own, as we commonly say. The duration of cell life, however, is limited, and this power of continued reproduction ultimately fails, and waste, or cell death, goes on faster than cell reproduction. Then decline begins, and finally, the reproductive impulse being totally exhausted, death ensues.

This death, however, is only a change. There is still the same matter there, to the utmost atom, with the same amount of force, and new combinations at once take place. It is only the form, or particular aggregation of cells, that is broken up, and destroyed. It is the same as if a mechanic should take to pieces a complicated machine, and out of its separated parts make a number of smaller new machines. There is still the same material, possessed of the same properties; and the sum of the power that was in the original large machine is embodied in the many smaller ones. He destroys neither matter nor power when he breaks up the original, nor does he create any new matter or power when he reconstructs. It is only a rearrangement, or new birth.

Death is, therefore, the breaking up of one arrangement of cells, and birth is their re-arrangement in a new form. Life is in everything, - there is no such thing as creation, - nor death, in the sense of annihilation or total inertness.

If, after the death of a man, we could bring together again the same elements, in the same way, and under the same conditions, we should reproduce the man, just as he was. 
Among the lowest forms of living cells are those called the Gregarinas. These are globular, ovoid, rod-like, thread-like, and of various other forms; for it must be borne in mind that the cell is not always like a ball, but may be pulled out in one direction, like a thread, or be of any irregular shape, and still be but one vesicle. In the fluid interior of a gregarina is usually seen a mass of small grains, and generally a larger body, the nucleus, which is usually free from the granules, surrounded by fluid, and containing a nucleolus. It has neither mouth nor limbs, is colorless, and with but little capability of motion.

The subjoined cuts will show some of the prevailing forms of gregarinas. But, besides these, there are innumerable others; and they are all the time varying, so that no form is constant.

The usual residence of the gregarinas is in the intestines of various animals, especially the cockroach, where they live as parasites. In size, they are found from that of a small pin's head up to sometimes half an inch long, when they have a worm-like form, and occasionally one end is turned round like a hook, apparently as a means of hanging on to any object. This is the only approach to the formation of a limb ever seen in them.

The psorosperms are usually found in the bodies of fishes, and are supposed to be only imperfect forms of gregarinas.

When being examined under the microscope, two gregarinas may frequently be seen to come together. They

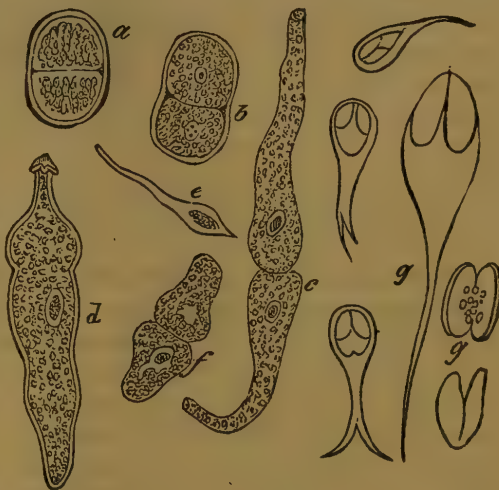

FiGURE 18.-Various Forms of Gregarinas.

$a, b, c, d$. Different forms of Gregarinas. $f$. A younger stage of $a . g, g$. Psornsperms. $e$ is a peculiar modification, called a Navicula, or little boat. The Psorosperms are probably only imma. ture Gregarinas, or germs not fully developed. then flatten out at the points of contact, a membrane forms around them both, and they become one, but double. This is shown in the first stage, in $f$, and, when completed, in $a_{0}$.

This union of two seems to be something like a sexual effort, for, when it takes place, the interior soon fills up with a number of globular bodies larger than the ordinary granules, each one of which ultimately develops into a navicula, or little boat $(e)$. Finally, the partition between the two parts of the double cell disappears; it bursts open; and the naviculas escape into the surrounding fluid. After a time they burst also, and out of them arise a number of curious bodies resembling those called amoba, some of which are shown in the plate on the following page.

These amœbas ultimately return to the usual forms of the gregarinas.

The navicula, it should be observed, sometimes forms in the interior of single individuals, as well as from the union of two.

The real nature of the gregarinas is still in dispute. Some naturalists contend they are vegetable forms, and not animals. This, however, is of little moment, for they may be either or neither, originally, and yet become the one or the other. They are simple one-celled beings, of the most primitive kind. 


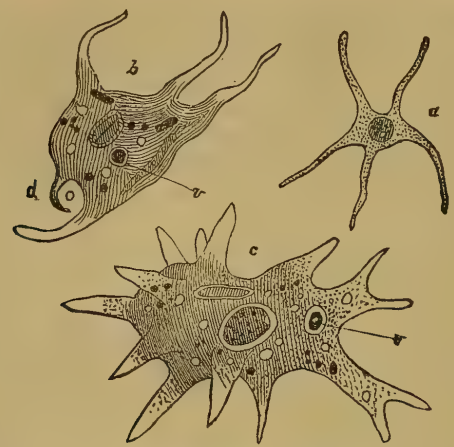

FradRe 19. - Tarious Forms of Amceba-like Bodies, resulting from the bursting of Naviculas.

$a$. Young Amœba. b. An older one. c. A peculiar variety. v. A Nucleus.

A few years ago great consternation was excited, among ladies who wore false hair, by the announcement that in nearly all cases it abounded with gregarinas; and
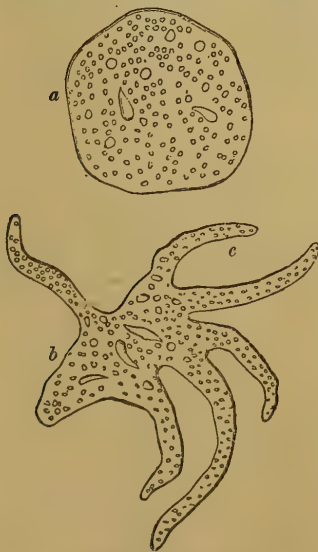

FigURe 20.-Amaba.

a. An Amoba at rest. $b$. One with limbs thrown out. At $c$ two limbs are seen forming a temporary stomach. $\Lambda t d$, Fig. 19, the stomach is more nearly completed, and is seen folding round a grain of starch. such is really the case, for dead hair, when closely packed, especially if not perfectly clean, is one of the most likely things to produce them. It was shown, by a celebrated microscopist, that many a lady carried millions of these creatures in her false locks, and that from them they probably often passed to her own hair. As no special harm was shown to follow from them, the excitement died away; but the idea of their presence is not agreeable, to say the least.

The true amœba is a being a little further advanced; for we see in it the rudiments of a stomach, and limbs. It is simply a unicellular organism, like a small bag filled with jelly-like protoplasm, living in fresh water, usually when it is stagnant and full of putrefying matter. It may be said to possess a stomach, a circulating apparatus, and limbs, but of the most simple and strange character. It propagates either by dividing itself, or by casting off bits of its substance, which grow into new beings, or it gives off buds, which develop in the same way.

The ordinary form of the amøba is that of a shapeless bag containing granules, and a nucleus, as seen in $a$, Fig. 20.

In this being, then, we have the first definite organs, not permanent, but formed as the animal needs them. When an amoba. as $\alpha$, for instance, needs a limb, to reach anything not close by, it simply pushes 
out, or elongates, a portion of its substance, like a finger, till it is long enough, and then, when the purpose is effected, the limb is drawn back, and is again lost in the substance of the body. When active, the amcoba pushes out a number of these false limbs, of all shapes and sizes, in all directions, as shown in $b$, and when no longer needed, draws them all in, and becomes again a shapeless bag.

It is this constant change of form which has caused it to be sometimes called the Proteus, meaning the changeable.

When it needs a stomach, for a temporary purpose, it is formed similarly to an arm. Rolling about in the surrounding fluid, the amœba comes in contact with a portion of matter suitable for food, but, having no mouth nor stomach ready formed, one has to be made on the instant, in order to appropriate the morsel, and it proceeds in this way: As soon as touched by the object, the amœba draws itself in at the point of contact, so as to form a hollow place, the sides of which roll round the object till it is entirely inclosed. Or a limb may form the stomach, as at $d$, Fig. 19. The substance may be said thus to be swallowed, and the cavity in which it is shut serves as a stomach, in which it is dissolved, and such parts as are fit for food are absorbed, by osmose, into the general body. When this is fully effected, the temporary stomach pushes itself out again, level with the general surface, or possibly becomes a limb. Any indigestible portion of the object so swallowed is thus thrown out and got rid of.

Nothing can be imagined more simple than this, but it serves its purpose perfectly. Every part may be stomach or limb at any moment, just as it may be needed.

The following is another being of the same class, called the Gaping Leucophrys. This animal is merely a bag of jelly, a single cell, like the amœba, but it may be considered a slight advance, inasmuch as it is formed like a pouch, or pocket, the cavity inside serving as a permanent stomach. It does not need, therefore, to make a new stomach each time it takes food. This stomach, however, is only like a fold of the skin pushed in, and is in no way specialized. To facilitate nutrition it has no mouth, properly speaking, but the entrance to the inner cavity is always gaping open, so that the surrounding fluid flows in and out all the time, without hinderance, and from this fluid the walls of the cavity imbibe nutriment, as needed, - or practice osmose.

It may be said that the movement of the amoba in taking its food

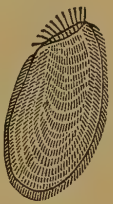

Figure 21.

The Gaping Leucophrys. is. simply automatic, or like that of a plant in the process of growth, with no element of intelligence or mind in it whatever. This view, however, does not accord with the facts. There may be numerous portions of matter floating around, and it will take only the appropriate one, which it will separate from the rest. If a portion of its proper food be dropped in while the arms of the amcoba are extended, they will immediately turn and seize it, as an animal does its prey. In some cases it has even been seen to lie in wait, or watch, for starch granules floating out of a piece of a torn plant. If this be not intelligence and will, though in a low degree, we cannot truly say what is, nor can we begin to imagine where mere automatic motion ends and true mind begins.

The more reasonable supposition seems to be, that what we call attraction and repulsion in inorganic matter, or selection in the lower organisms, is the same power that we call intelligent will, or choice, in the higher animals. It is merely 
different in degree or amount, according as the parts of the organism are more or less differentiated and perfected.

This fact of the original oneness of power, and function, in every part of the cell body alike, is very important and interesting. All our senses-sight, hearing, smell, and taste-are only modifications of touch or feeling. The eye feels one way, the ear another, the nose another, and the tongue still another. It is all touch, or feeing, with different instruments.

Now, in the simple cell, this sense is exhibited in one form only, because there is no variety of structure, no special organs, but every part is capable, under proper conditions, of being specialized, and so modified as to become eye, ear, nose, or tongue, or equivalent to them.

A man, being built up of cells, exhibits their properties, and, in his early existence, before his organs have been differentiated to their special uses, he probably has, like them, only the simple sense of touch all over his body ; and if either of the special sense organs becomes imperfect, as we well know, it becomes capable of simple touch only. Thus, an imperfect eye feels only, but does not see.

It is this fact, that every part of the living structure, primarily, is alike, in regard to sensation, and that certain parts are specialized so as to modify it, which has led some people to suppose that any and every part may, under peculiar conditions, be so modified as to see, hear, smell, or taste. In some forms of disease, it is said, or in highly wrought nervous states, various parts of the body may become so intensely sensitive to light that they can see, like the eye; or they may eren hear, smell, or taste. Thus, people are reported to have been able to see with the backs of their heads, or with the ends of the fingers.

Without stopping here to discuss the truth of this assumption, it is useful to show on what it is founded. All parts of the body are endowed with common touch, or feeling; but whether any part can be so over-sensitive as to have special sensation without a special organ is doubtful, to say the least of it. In the lower animals, simple touch serves every purpose of sensation, and they have no need of special senses. 


\section{CHAPTER IX.}

UNIVERSALITY OF THE LOWER ORGANISMS, AND THEIR VARIETIES.

To those not accustomed to the wonders of the microscope, some of the details we give of the minute beings, called infusoria or animalcules, must appear very astonishing. When it is remembered, however, that some of our best microscopes, in ordinary use, will enlarge objects fifteen hundred times their natural size, and some even many thousands of times, the wonder will lessen. Numerous classes of these beings are totally invisible to the unaided eye, and but for the discovery of the lens, we should never have known of their existence.

The great difficulty in examining these beings, next to their smallness, is their extreme transparency, and absence of definite color: they form no vivid contrast with their surroundings. This difficulty, however, has, in a great measure, been overcome by the application of a very simple discovery. It is found that if carmine, a bright-red coloring matter, be put in the fluid where animalcules are, they will fill themselves with it, so that they become deep red and very plainly visible.

It must be remembered, also, that among the animalcules there is great diversity of size. Some of the monads, for instance, are so minute that powerful glasses are needed to make them visible; while others, like the kolpodes, can be plainly seen with the naked eye. In fact, there is as much comparative difference of size between the two, as between a mouse and an elephant.

In one respect, they are all very peculiar. Every other known being requires stated periods of rest : in animals, this is taken in the form of sleep; but these primitive beings never rest! They are always, so far as examined, in incessant motion, night or day. Owen thought that this never-ceasing activity was the result of their immense powers of digestion.

These beings are found in all decaying matter, in water, in the polar ice, in snow, in the depths of the ocean, and in the air. In short, no place is free from them, and though so minute, yet are their numbers so enormous, that in mere bulk they go far beyond all the larger beings that ever existed. Their tenacity of life, under every variety of condition, is another wonderful trait. At the extreme North, where only a few scattered large animals are met with, and where all ordinary vegetation ceases entirely, the animalcule, in some form, is always found living and active. Sir James Ross collected over fifty species of microzoa on the ice, in the polar seas, all living, and many of them were even brought home alive. In the same regions, mud brought up from an ocean depth of 12,000 feet was also found to contain them.

All muddy water is full of them, and even most of that we drink contains them in immense numbers, so that we swallow constantly millions of them, fortunately without injury.

The luminosity of the sea, so often seen, is caused by myriads of phosphorescent animalcules, and the shining of dead wood in the forest results in the same wayfrom fungus growth. 
Sometimes water has been known to turn red, like blood, to the great terror of superstitious people, and many strange explanations have been given of the phenomenon. The microscope, however, shows us that the blood-red appearance is caused. by infusoria of a deep-red color. These at times, from some favorable conditions, multiply in enormous numbers in an incredibly short time. They appear to be both plants and animals, and many different species of them are known. The Red Sea owes its color to this cause.

It will be remembered that in the time of Moses, it is said, the water turned to blood.

Even in the bowels of the earth we find the infusoria in such incredible numbers, dead and alive, that they form beds many feet thick; and yet several of them are not more than the forty-five-thousandth of an inch in diameter. The city of Berlin, in Prussia, is built upon a living, moving bed of this kind, and so is Richmond, in Virginia. In other places they form a large part of the soil, especially where this has resulted from muddy deposits.

Travelers in snowy regions have often been astonished to see the snow, as the water sometimes is, quite red, and this is now known to be caused by the rapid multiplication of a peculiar microscopic organism, called the Discera nivalis, which lives and propagates on the snow. This appearance has been noticed in various parts of the world, and it is always found to be owing to the same cause.

The astonishing rapidity with which these peculiar beings multiply will be better understood by considering their mode of propagation. They simply subdivide, by fission, and the process is constantly repeated with every individual, and with all its descendants. Thus, one divides into two, each of these into two, and so on without ceasing. Imagine, then, one hundred of them only, to begin with; their descendauts would soon be countless. Ehrenberg says, one individual may produce a million in twenty-four hours, and in four days one hundred and forty billions, or equal to a cubic foot of ground.-The rapidity with which funguses grow in a single night is also well known.

The dead and living microscopical organisms, of various kinds, in the air, are perhaps as numerous as those in the earth or the water. Sometimes they form real clouds, like fogs, which intercept the light, and make it difficult to breathe. And in this way are probably often formed those showers of flesh, as it is called-a jellylike matter-which often fall over a large extent of country. It is simply a rapiri formation of fungoid protoplasm, and it may be of a nutritious character, like resi flesh. It is also sometimes red in color, and more fluid, so as to stain whatever it falls upon red. It is then often called a shower of blood, and the world has frequently been alarmed by such showers, which are, however, just as natural as ordinary rains. The manna in the wilderness, it is thought, was of this char. acter.

But, in addition to all these varied conditions, similar beings are found, in per. haps equal numbers, in the very material of all plants and animals, and in all substances we consume as food or drink. On our teeth. in the saliva, all through the intestines, in the liver, the brain, the eye, and every other part, strange beings live and multiply their kind. The staggers in sheep is caused in this way, by colonies of small worms, which develop in the brain ; and peculiar liver affections result in the same way, while intestinal worms are only too well known.

Most of them, however, do no serious harm, and some are perhaps natural and 
ineritable; but there are others which cause great suffering and loss of life. Among them may be mentioned the Trichina spiralis. This terrible little worm seems natural to the pig, and from it is often transferred to man. To the pig itself, the trichina is not especially hurtful, except when very abundant, but in man it causes intense suffering and even death. The trichina and its young are contained in the flesh of the plg, and that being eaten by man, they are taken into his intestines, from whence they burrow through the intestinal walls and make their way into the muscles, where they live, causing pains like those of rheumatism, with fever, diarrhœea, and even death.

The trichina is found only in the lean or muscle of the pig, and not in the fat, and may be killed by thorough cooking. It will apparently stand boiling-heat for a short time, but if it be kept up long enough to perfectly cook the flesh, the trichina is killed. The ham is the part worst affected, and many fatal cases of trichinosis, as it is called, have resulted from eating ham raw, or only smoked. Many Germans have lost their lives from so using it, and also from eating half-cooked sausages. When fried or broiled, some part may easily escape being perfectly cooked. Thorough boiling is the only safe mode of preparation. It should never be eaten raw!

Below is shown the trichina in its various stages.

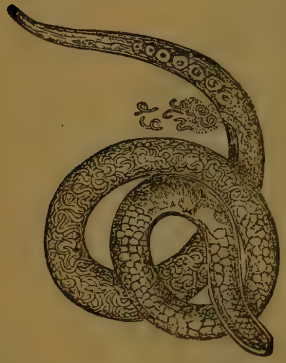

FIGURE 22.-Trichina Spiralis.

This figure shows a Female Trichina, giving birth to her young. They are developed from eggs within her body, and ejected alive, as seen in the picture. This is magnified sis bundred diameters, from which the navural size can be estimated.

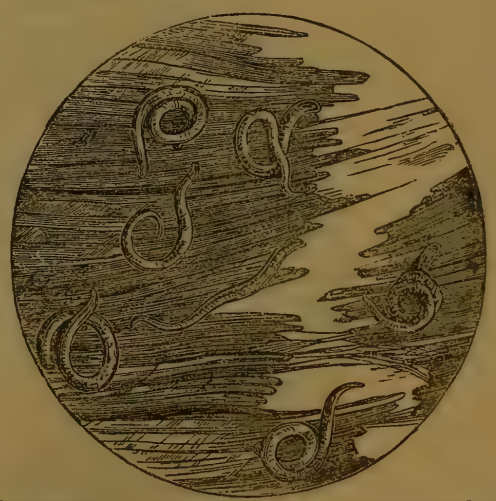

FraURE 23.-A tîin slice of ham, magnified, showing the Trichinas actively at work, boring among the musealar fibers.

Once introduced into the body, we know of no way to dislodge them, and thercfore extreme care should be exercised in having pork always thoroughly cooked. Smoking, salting, or pickling will not kill trichina.

Measly pork, it should be stated, is by some thought to result from trichina.

Numerous as infusorial beings are at the present day, there is good reason to sup. pose that in former ages they were still more so, for in some parts whole mountains are composed of their remains. Some siliceous beds even, the hardest material we generally find among rocks, are made up of similar remains. The powder called iripoli, used for polishing, is almost entirely made of the flint skeletons of infrsoria, many of which are so perfectly preserved that their species can be deter. mined. 

ages.

A bed of tripoli is, therefore, only the cemetery of the infusoria of past

The deposit on which the city of Richmond, Virginia, is built, is of a similar character, and is several hundred yards deep.

The material called electro silicon is a similar deposit, being formed almost entirely of flint-shell diatoms; and there are many other deposits of a like character in various parts of the United States. They all make excellent polishing powders.

In the Isle of France there is a similar deposit, which extends some ten leagues, and is from ten to fifteen feet thick. A cubic inch of this will contain forty million infusoria. The numbers in the whole deposit are, therefore, past all our power of expression.

We find similar remains in solid flints, and other hard stones, sometimes richly colored. The red stone called carnelian, used in jewelry, owes its beautiful color to red infusoria.

It has long been known that in some parts of the world there are peculiar beds of earth, a sort of clay, which is eaten both by men and animals in large quan-

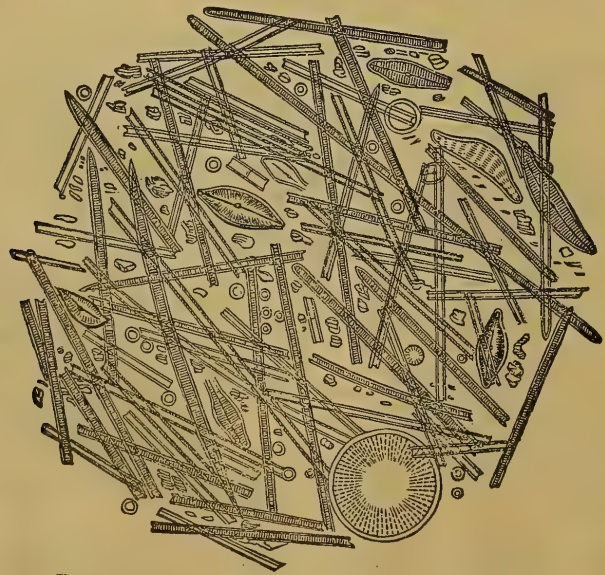

FIGURE 24.-Infusoria in Mountain Meal, from Ebstorf.

tities, and it is beyond doubt capable of serving as food. The nature of this earth was long a mystery, till the microscope showed that it was mainly composed of minute infusoria. It is, therefore, an organic matter, probably both animal and vegetable. An earth of this kind is sold in the markets in Bolivia, and is often preferred to other food. In the forests of Carolina, and Florida, the negroes also use a similar substance for food.

A common name for such earth in Europe is mountain meal, and it is often mixed wich real meal, to increase the quantity. In some regions hundreds of wagon loads 
wre used in a season. The preceding cut shows the appearance, under the micro scope, of a few grains of mountain meal from Ebstorf, in Germany.

In Lapland a variety of this material is found so highly nutritious, and so much like real meal, that it is even made into bread.

Many varieties of limestone used for building are composed almost entirely of infusoria and other small beings. The stone of which the Pyramids of Egypt are made is of this kind, being mostly composed of the shells of nummulites, which lived in a far-distant period. There were other builders, therefore, millions of years before the Pyramids were erected.

At the present moment, the same process is going on as of old. In the bed of the sea just such formations, of unknown thickness, are being made by similar beings to those which made the fossil beds which we have spoken of.

In fact, the minute, simple, and apparently insignificant beings, such as those we have been describing, both animal and vegetable, have made a large portion of the bulk of the earth with which we are acquainted.

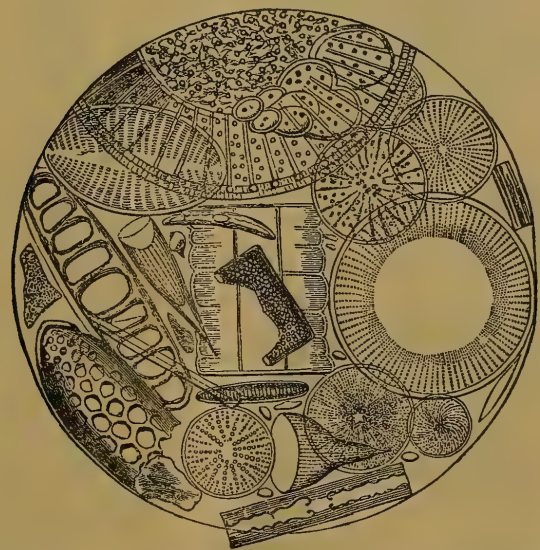

FrauRe 25.-Infusoria, dredged from the bottom of the Antarctic Ocean.

This shows the abundance and variety of these beings in the ocean ooze, now forming new beds, similar to the ancient chalk. They are mixed, in many parts, with bathybius, Huxley's protoplasmic jelly, from which new beings are probably being continually generated spontaneously. When the membrane of one of the protozoa assimilates lime, or silex, to form a shell or framework, it often assumes the most beautiful geometrical forms, instead of being without regular form, as in those that remain soft.

This is probably due to the fact that crystallization, an inorganic process, here comes in and modifies the organic animal development. The variety, beauty, and perfect regularity of these coverings of simple cell beings, are truly wonderful. 
Inorganic matter, like lime, or silex, always has this tendency to assume reg. alar geometric forms, while organic protoplasmic or albuminous matter is never arystalline, nor regular in any form. It is called colloid. White of egg, and gum, or jelly, are instances of this colloid tendency. The smooth, soft, curved bodies of animals could not be formed with crystallized matter, which is also fixed in form, and unyielding. They require soft, formless, colloid matter. This explains why the goft animals are so variable, and those with hard shells, or frames, so regular in form.

There is a large class of these shell-coversd unicellular beings, the foraminifera, that are very interesting in many ways. They belong to that indeterminate region of life midway between animals and vegetables, not being definitely established as either the one or the other. They are of various forms and sizes, though mostly minute, and they exist in countless numbers in various conditions, but especially at the lowest depths of the ocean, where their shells, minute as they are individually, form immense beds. Even at the depth of three miles the dredge brings up these foraminifera, dead or living, and often nothing else.

The deposit which results from their decay is almost identical with the chalk found so abundantly in England, and which contains similar remains. Apparently, at the present time, just such a formation is being made in various places at the bottom of the present ocean.

Among the various forms of the foraminifera, we find triangles, quadrangles,

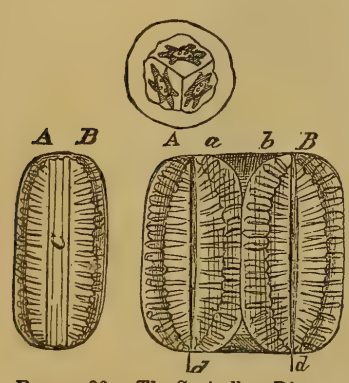

Frgure 26.-The Surirella-Diatom.

In the smaller figure, $A$ and $B$ are two Diatoms, held together by a broad band, $C$. This band becomes gradually wider, as shown by the space $d, d$. in the larger figure, and there is formed from it a new half for each of the original diatoms, and there are then four individuals - the two originals, $A$ and $B$, and two new ones, $a$ and $b$, thrust in between them. The next step is the division of the four into two pairs, by a separation down the middle, $A$ and $a$ going together, and $B$ and $b$. Then each of these new pairs divides again, just as $A$ and $B$ did at first. crescents, disks, objects like boats, and all kinds of beautiful curves. The little shields, or shells, often of pure flint, are sometimes most beautifully dotted, or regularly marked with arabesque lines, in various ways, but nearly always in regular patterns. They are sometimes called brittleworts, from their extreme fragility. They move about in the water by spasmodic jerks, with various degrees of rapidity, apparently from the impetus given to them by currents of fluid established between them and the surrounding medium, by osmose.

Although they are single-celled animals, the foraminifera are generally found in pairs, closely united, so that the two look like one individual divided by a line into two equal parts. This arises, however, from their peculiar mode of multiplication, each individual splitting in two, and each part becoming a perfect individual. Each of these new beings divides in two again, and so on indefinitely. Owing to this peculiarity of form they are called Diatoms, from a Greek word meaning cut in two. They are always seen in this process of dividing, so that each one always a)pears to be a pair. The accompanying figure shows this peculiarity very well : it represents a diatom called the Surirella.

The foraminifer is not completcly surrounded by its shell, or case; there is always 
some part, or parts, where it is open, and where osmose can take place, as it does in the whole surface of the amoba. In many cases, also, the shell is full of little holes, resembling dots, through which it can at any time push ready-formed limba os thread-like arms, like an amoba.

The following cut shows various forms of the foraminifera.

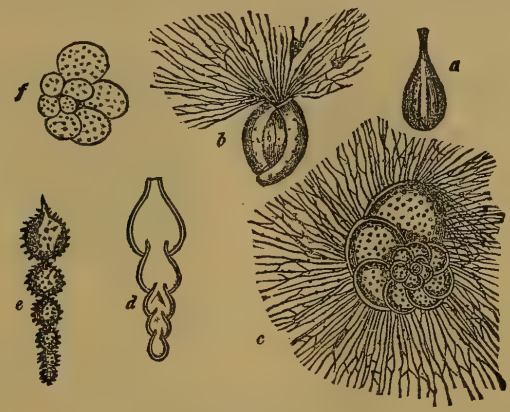

FrGURe 27.-Tarious Forms of Foraminifera.

a. A flask-formed Foraminifera, $b$ shows the temporary limbs pushed out in large numbers, from the opening in the shell which serves as a mouth. c. Another form, showing the limbs protruding, like a bunch of hair, from the little holes of the shell: $d$ and $e$ are other forms. $f$ is a peculiar foraminifera, called Globigerina, found in immense numbers in the sea, down to the lowest depths, being sometimes dredged up from three miles below the surface.

The oldest known fossil animal is one of the foraminifera. It is called the Eoroon, or dawn animal, and was disonvered, quite recently, in Canada, in one of the most ancient known rocks, previousily thought to be qrite destitute of all animal remains.

There is one form of limestone, found in large beds, called nummulitic limestone, from the immense number of shells called Nummulites found in it. They are all shells of foraminifera that lived untold ages ago. The stone is in parts almost entirely formed of them. A few forms are shown below.
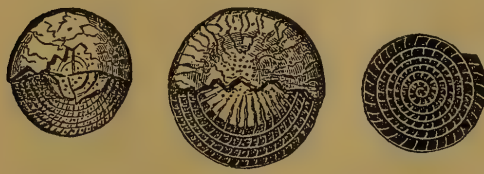

FIGURE 28.-Nummulites, from the Eocene Strata.

This is the stone used so largely in building the Pyramids of Egypt.

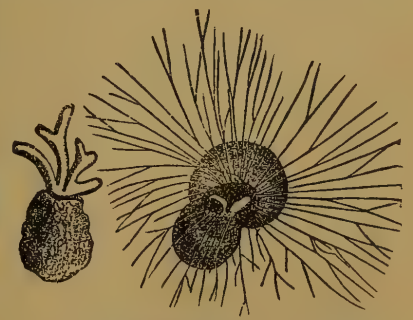

Figure 29.-Mitiola. The Infusoria which mainly composes the limestone of which Paris is largely built.-Mag. nified. 
Some other forms with hard skeletons, and numerous spines, are called Radiolaria. Two of these are figured below.

They are both single-celled animals, or protozoa, and the kind represented by $a$ is called acanthrometra, or thorny. The large spines are formed of flint, and are hollow, forming tubes through which the thread-like limbs are thrust, as seen in the figure; but there are limbs that do not come out of the spines, as will be seen.
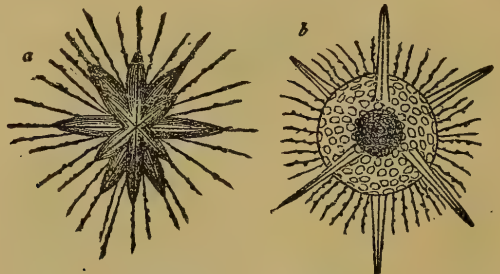

FIGURE 30.-Radiolaria.

$a$ is the Acanthrometra ; $b$ the Haliomma.

In $b$ the thread-like limbs are seen protruding all over the surface, as well as through the six large spines.

The variety of form, structure, size, and mode of living of these primitive organisms is simply indescribable. As we advance upward among them, we begin to find permanent limbs, true stomachs, proper mouths, and a circulatory apparatus. In other words, different parts of their structure become differentiated, or specialized, for particular uses. From these we ascend to others, still more specialized or perfected in their development, and formed of larger aggregations of cells, till we arrive, by successive gradations, through various types, up to the most perfect of all.

To show how difficult it is to destroy the germs of the lower organisms, it may be stated that Mr. J. Wyman found that some of them were able to withstand four hours' boiling; and Mr. Grace Calvert asserts they can endure either 400 degrees of heat, or 17 degrees below freezing !-an astonishing range, far beyond what higher organizations can pass through unhurt. But it is quite possible that the original germs did not withstand this treatment. New ones may have been spontaneously generated in place of them.

To still further prove their universality and importance as regards health, it has recently been shown that the miasma, or poisonous air, which makes the Campagna near Rome so unhealthy, is probably caused by a microscopic fungus. The atmosphere, in the sickly season, is filled with this minute organism, which being inhaled with the breath causes malarial fever.

Professor Low found funguses in both the milk and the blood of cows that dran. water containing numerous diatoms, and other similar beings. Many of the cows were made sick from this cause; and it is quite probable that their milk might cause sickness when drunk. This shows the need for pure water to our animals as well as to ourselves.

In short, microscopical infusoria are everywhere, and have more to do with health and disease, and with changes in the world at large, than many people suspect.

The lower organisms, bacteria, vibriones, and funguses of various kinds, are 
very generally found in many epidemic diseases. The horse disease, so prevalent a few years ago, illustrates this very well. The following cut shows the appearance of the discharge from the nostrils of a horse affected with the eprzootic influenza.

Most of these are fungoid growths of various kinds. Their spores, or germs, were very numerous, some thousands being found in a single drop. They were also detected floating in the air, which shows the necessity of keeping diseased animals away from healthy ones, and of properly ventilating and cleansing their stables.
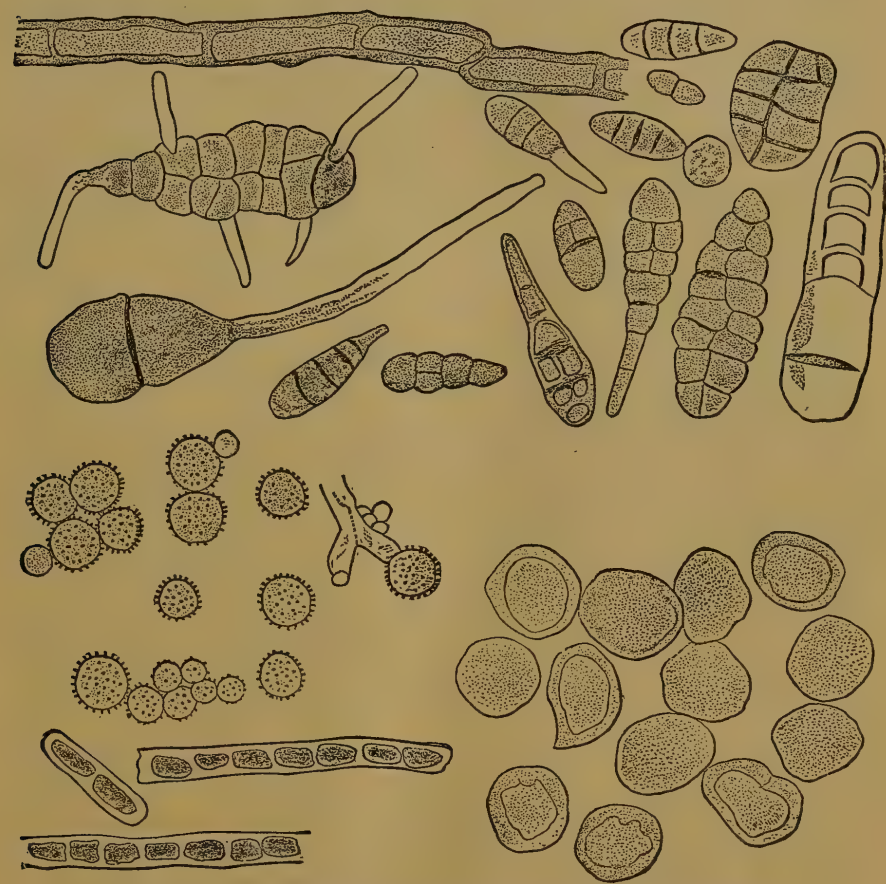

FravRE 31.-Mucus, from the Nostril of a Diseased Horse, much magnified.

It is very probable that many kinds of chronic catarrh, especially what is calle". hay fever, may originate from similar growths, the mucous membranes of some people being favorable to their development, while those of other people are not.

In connection with this topic, the new views on disease germs, and also the most recent experiments of Professor Tyndall on spontaneous generation, should not be passed over without special mention. As far as the artificial generation of life is concerned, in infusions confined in sealed tubes, without air, or with air perfectly 
clean, they are conclusive; for they show undoubtedly that life nerer appears if the air is yerfectly clean. They also show the difficulty there is in getting air that is perfectly clean, especially in cities. It almost everywhere contains clouds of minute specks of floating matter, which it is very hard to get rid of. They are mostly starch grains, probably from the pollen of plants ; minute fragments of woody fiber, and of animal substances of various kinds, such as hair, skin, and dried mucus. These are what we see when a beam of sunshine passes across a dark space, no matter how clear the air may seem. They are commonly called motes.

It is these particles of organized material, which are called the atmospherio germs, and which, when they fall into any of the organic infusions, develop infusoria. There is, however, no good reason for considering them all as true germs; that is, eggs, or seeds, which have been produced by other organisms like those into which they develop. In fact, we do not know that many of these produce germs at all, at least not such as float in the air. It is quite reasonable to suppose, also, that many of these protoplasmic particles, as before remarked, may be formed spontaneously in the air, by natural means, and may be just as effective as those derived from pre-existing organisms.

It follows, therefore, that the generation of life in these infusions may be spontaneous, strictly speaking, even granting the necessity for the presence of these organic atmospheric particles.

But even if this be not allowed, it does not prove that spontaneous generation is impossible, but merely that it does not occur under certain experimental conditionz. It may occur under other conditions, and probably does.

The difficulty of getting air perfectly clear of organic particles is very great, and this has caused the failure of many experiments, apparently carefully conducted. In some places they are very abundant, and in others, very scarce, so that an infusion may escape being impregnated with them in one locality, and yet be immediately impregnated in another. Thus, Pasteur prepared a number of flasks, filled with organic infusions and carefully sealed, some of which he opened on the Alps, by the Glaciers, and others in the plains. Of those opened on the mountains, only one out of twenty showed some signs of life, while of those opened in the plains, eight out of twenty soon swarmed with living beings! Others, tbat were opened in the caves under the Paris Observatory, where the air is perfectly clear, showed no signs of life whatever.

Air may be passed through oil of vitriol, solution of caustic potash, alcohol, ether, and various other substances, and yet apparently retain these organic particles unchanged and unhurt.

If they exist they cannot be killed that way, nor be washed out, exsept with the greatest care, and by working slowly. This is why many experimenters still found unclean air, after all their precautions, and when they thought it must be perfectly pure.

In all cases, however, if air be confined, and left perfectly still, all the organic particles will settle down, as floating matter does in water, and it will become in time perfectly clean. This is the way in which Tyndall clears air ; by simply letting it stand undisturbed, in a proper vessel; and when this is coated with sticky matter, like glycerine, all the preeipitated particles are firmly held. Such air, when a beam of light is sent through it, shows no motes or dust, and will not cause infusoria to appear in any infusions it may come in contact with.

To show the difference in the air of different places, Tyndall improved on Pas. 
teur's experiments. He prepared, in London, sixty glass flasks, illed with an infusion of turnip, which is known to be one in which life quickly appears, under ordinary circumstances. The ends of these flasks were lrawn out to a fine point, and after the infusion in them had been boiled for five minutes, this small end was hermetically sealed, by melting the glass with a blow-pipe. Here, then, were sixty flasks, containing the infusion which had been boiled, and the air in which had been subject of course to the same heat. Now we will sec what happened to these in difierent circumstances. They were taken to Switzerland, to the incuntains, seven thousand feet above the lerel of the sea, in the month of July. F'uur of them, it was found, when they got there, had the small ends broken, and these were full of life, all the rest being quite clear; two were accidentally destroyed. The remaining firty-four flasks were then exposed to the sun by day, and placed in the warm kitchen at night, for a month; four of them were casually broken, but the remaining fifty remained perfectly clear, with not a sign of life in them. It was then determined to let the air into them, to see what would result. Twenty-three of them were opened, by breaking off the small ends, in a hayloft, and twenty-seven were opened in the same way on the edge of a cliff, overlooking the Glacier, where the air might be supposed to be clear.

As soon as the ends of the flasks were broken off, there was, of course, an in-rush of air, because the boiling had made a more or less perfect vacuum. All the flasks were then placed in a warm situation, by a stove, with the necles open, and in three days twenty-one out of the twenty-three opened in the hayloft were filled with living beings; while, after three weeks. not one of those opened on the mountain ledge had the least sign of life, all being yerfectly clear. Now, these flasks were all alike, to commence with, and were all treated exactly the same, the difference in the result being caused, it is obvious, by the difference in the air ; that from the hayloft being loaded with particles of organic matter, while that from off the Glacier was clean. Such experiments seem conclusive as to the need of organic particles, in those particular solutions, under those conditions, to cause evolution of life ; but they do not prove that those particles are either seeds, or eggs, by any means, nor that the result might not have been different in the same solutions in other conditions.

In other experiments, Professor Tyndall showed how much the air of London, like that of all cities, is loaded with organic particles, and how difficult it is to perfectly get rid of them. He, bowever, proved that if the air in a tight box be left perfectly still, it will in a few days become quite clear, all the organic particles having settled on its sides and bottom, which should be coated with glycerine, to retain them. In such a box he left open flasks, filled with various animal and vegetable infusions; but in no case did living beings appear in any of them, while in the clear air of the box. But in three days after the box was opened, and common air admitted, all of them were filled with infusoria. This was again conclusive that the dust particles in the air were the cause, in this case, of life in the infusions.

The quantity of these organic particles in the air is very variable, as before stated, in different places, and under different circumstances. Some localities abound with them, while others are comparatively free, and even in the same place they may be much more abundant at one time than at another. They are not all of one kind, as might, indeed, be surmised, and have very different properties; some being easily killed, while others are so only with difficulty. Thus, some of these so-called germs, Tyndall tells us, will be quite killed by five minutes' boiling, while others endure fif. 
teen or thirty minutes, and others, again, almost every period up even to eight hours boiling. Possibly there are even some that will survive more than that, while there are others that will be killed if the water be no hotter than can be bcrne by the hand. The infusoria themselves do not endure these intense and prolonged boilings; it is only the dry, hard particles, which are so dense that probably the boiling water does not penetrate them, except with extreme dificulty. In proof of this, Tyndall shows that if any infusion full of infusoria and their germs, be only slightly boiled, at repeated intervals, so as to attack the living beings as they develop, one after another, the whole infusion will in time become quite sterile. He shows further, by another experiment, that an artificial mineral fluid, which infusoria will live and propagate in, if placed there, will not develop them, though it be plentifully supplicd with atmospheric germs.

In a more recent communication, Dr. Bastian argues that Tyndall's exreriments by no means justify the conclusion he comes to. He especially calls attention to the fact, that animal germs, or, indeed, animal tissue of any kind, cannot be compared with seeds, and plant tissues. The horny coating of many seeds niay, as experiment proves, withstand very prolonged boiling ; but animal germs are essentially composed of albuminous and fatty matters, which are entirely changed by a very moderate degree of heat. In fact, all known germs of the lower animal organisms are mere naked specks of protoplasm, none of which, as experiment has shown, can stand a heat of even $180^{\circ}$ for a single minute. How, then, could they survive a much greater heat for a much longer time?

Dr. Bastian does not deny that the organic particles in the air may materially hasten the development of organisms, in an infusion, and, perhaps, even detorrine it, in some cases, when it would not otherwise take place; but he still contends that this development does often occur, in sealed and boiled infusions, without their aid ; and Dr. Burdon Sanderson testifies that he has watched Bastian's experiments, and is certain of the truth of this. Other experimenters, also, have obtained similar results, so that Bastian's statements seem fully confirmed. There are, then, but two conclusions which can be arrived at in regard to this matter: either the organisms formeù under such circumstances are spontaneously generated, or they, or their germs, can withstand boiling for an indefinite period, and yet live! Bastian contends that it is more consonant with known facts, and more reasonable, to suppose that spontaneous generation does occur, in such cases, than that the organisms we find have withstood such treatment; and many agree with him. The question, therefore, is by no means decided, and it is fortunate there are such excellent champions, on both sides, hard at work in support of their respective views ; for it is only by continued experiments and observation that the truth can possibly be arrived at.

A few remarks from eminent men, bearing upon this question, may here be useful to note. Burdach very pithily reminds the germ theorists that they have never shown their germs; and that when they say, they are too small to be discovered, it is tantamount to saying they know nothing about them.

Mr. G. H. Lewes, in his "Physical Basis of Mind," says: "I cannot see the evidence which would warrant the belief that life originated solely in one microscropic lump of protoplasm, on one single point of the earth's surface. On the contrary, it is more probable that from innumerable and separate points of this teeming earth, myriads of protoplasts sprang into existence, wherever, and whenover the conditions of the formation of organized substance were present. It is 
probable that this has been incessantly going on, and that every day new protoplasts appear, struggle for existence, and serve as food for more highly organized rivals !"

Huxley says : "It is not probable that there is any real difference in the nature of the molecular forces which compel the carbonate of lime to assume and retain the crystalline form, and those which cause the albuminoid matter to move and grow, select and form, and maintain its particles in a state of incessant motion. The property of crystallizing is, to crystallizable matter, what the vital property is to albuminoid matter (protoplasm). The crystalline form corresponds to the organic form, and its internal structure to tissue structure. Crystalline force being a property of matter, vital force is but a property of matter."

All this fully accords with what has previously been stated, and shows that the idea of all matter being alive, in different degrees and ways, is very generally held, by those whose studies make them competent judges. Life is but a form of motion, and all matter is constantly in motion, no matter in what form or condition it may be.

The atoms composing a solid mass of rock, or iron, are not fixed and at rest, though they appear to be so; but, on the contrary, are perpetually changing their position in regard to each other. A bar of freshly hammered iron will appear uniformly fibrous, or lamellated, when examined, but after being left for a while will be found, on breaking, to have become perfectly crystallized. The atoms comprising it have rearranged themselves, according to the laws of their polarity, just as particles of salt in solution arrange themselves in crystals when the solution evaporates. Solidity is not motionless fixity, as commonly supposed, but merely a state in which change takes place slowly. Motionless or dead matter does not exist. Every atom is instinct with life, and organized bodies represent the combined vitality of all the atoms which compose them. As Huxley says : "Beast and fowl, reptile and fish, mollusk, worm, and polyp, are all composed of structural units of the same character, namely, masses of protoplasm, with a nucleus (cells). . . . What has been said of the animal world is no less true of plants. . . Protoplasm, simple or nucleated, is the formal basis of all life. . . Thus it becomes clear that all living powers are cognate, and all living forms are fundamentally of one character."

Further than this, it may be remarked, the protoplasm of which they are all made is merely part of the ordinary world material, such as helps to form thousands of other bodies, commonly thought to be dead, or inert, but which merely live in a different way.

In regard to special disease germs, some of the most eminent physicians and sanitarians, Dr. Richardson, of London, especially, have expressed their decided disbelief in thom, and the reasons they give seem very cogent. It is true that in many diseases peculiar infusoria are found in abundance, in various parts of the body, and there seems no reason to doubt but that these organisms, when placed in contact with a healthy body will, at least in most cases, inoculate it with the same disease; but it by no means follows that such diseases are always caused by the germs of these infusoria, carried in the air. If it were so, few would escape, and our struggle against such diseases would be almost hopeless. It seems much more probable that the infusoria are effects of the disease more than causes of it, but that, when produced, they may extend it by being conveyed into healthy bodies.

The theory of Panspermism, or the universal diffusion of germs in the atmosphere, from which all the inferior organisms originate, has certainly many difficulties 
to contend with, and some of them seem insuperable. M. Trecul has demonstrated that in the very interior of the substance of several plants, especially the caladium, in the hermetically sealed cellular tissue, numerous rudimentary plants are to be found. Now, it seems scarcely possible that either these or their germs could have been conveyed there, and the more reasonable supposition is, that they arose spontaneously, either from perverted cell-growth, or as some necessary adjunct to the caladium itself.

There are plants, also, that only appear occasionally, at long intervals, under exceptional circumstances, and it seems scarcely possible that their germs should remain in the air, waiting, as it were, for these conditions to be established. Thus, there is a fungus which is found only on dead spiders, and another appears only on horses' hoofs when they are decaying. Certain moths also hare peculiar parasites, found only on them, and there is a tropical caterpillar on whose neck grows a fungus of enormous size, proportionately, and which is found nowhere else.

Is it conceivable that these germs were in existence, floating in the atmosphere, waiting for dead spiders, decaying horse-hoofs, and certain caterpillars? Is it not more reasonable to suppose that they originate spontaneously, whenerer these peculiar conditions are established.

Every form of fermentation is accompanied by the growth of a peculiar plant, which is never known to come into existence except when this kind of fermentation takes place; thus there is the yeast-plant, torulce, found always in fermenting beer. Now, man must have existed many centuries before be discovered the art of making beer, and during all that time, according to the Panspermists, the germs of the tor. ulæ must have been floating round in the air, waiting for the first brewing. Is it not more likely that the fermentation gave rise to the torulæ, without any previously existing germs?

But, stranger still, there is a plant called the Racodium cellare. which is never found except on the casks in our cellars, and the question naturally arises, Where were the germs previous to the first cask and the first cellar being made?

Bérard even tells us that there is a plant which is found only on the drops of tallow which fall from miners' candles. If these come from germs, they must have bcen floating round for thousands of years, waiting for the first miner to come with his dip! Is it not more likely that the first drop of tallow, in such circumstances, generated spontaneously the first of these singular plants?

It is also well known that every sick plant is immediately attacked by its peculiar parasite, which never appears elsewhere ; and when we think of the thousands of different plants, it seems scarcely reasonable to suppose that there are as many thousands of peculiar germs waiting for some of them to become sick, so that they may grow upon them.

It would seem, in fact, that if all these thousands of peculiar growths come from germs, the atmosphere must be loaded with them to such an extent as to be quite unfit for breathing; but we know this is not the case. It must be remembered that if Panspermism be trne, every kind of germ must exist everywhere-that which grows on the dead spider only, for instance; for, take the spider anywhere and kill him, and the peculiar plant is immediately found upon him.

Besides, as before remarked, the closest observation with the most powerfu' glasses fails to detect these germs, so that their existence is only hypothetical. The are inferred, not proved, to exist. 
It is true the air is full of organic matter-in cities, at least,-but the nature of it is well known. The microscope shows us that the atmospheric aust which we see in the form of motes in the sunlight, is composed of fragments of animal bodies, of our clothes, our furniture, and of everything that we handle or use. Furina especially, or wheat-flour in small grains, is everywhere, being carried by the air. Pouchet says he found it in the dust of Egyptian tombs, where it had probably remained from the time of the Pharaohs. It is constantly falling upon us, and upon all other objects, so that no place is free from it. Insects, as they fly through the alr, constantly receive grains of it on their wings, and it is alwajs found in the falling snow.

The skeletons of infusoria also abound in the air, and even live infusoria of various kinds. Fragments of wool, cotton, silk, leather, smoke, remains of insects, and numerous other things are revealed by the microscope, but very rarely eggs or sceds of any kizd, although according to the Panspermists, they ought to be the most abundant of all.

All the above-mentioned matters reach our lungs as we breathe, and may be sorncl there after death; even living infusoria are sometimes so met with. The hollow bones of birds, to the interiors of which air gains access, are also occupied by them, sometimes one ingredient preponderating, and sometimes another, according to the conditions under which the animals live. Thus, Pouchet found in the bones of a peacock, which lived at a châtean, remains of the dresses of the ladies who promenaded on the same terrace with the bird. In a common fowl also, from a baker's, he found abundance of flour, and remains of the coarse woolen clothes of the baker and his family.

In like manner, birds from the fields, woods, or cities, will all show different kinds of remains in the air of their bones, so that from these remains we could judge what kind of life the animal had led, or where it had lived.

Now these organic fragments, as before explained, may probably assist in the primary production of simple organisms; or by their decomposition they may help to form protoplasm; but they are not true germs or seeds.

In short, we find peculiar living organisms under all circumstances, appearing instantly when the conditions are suitable, and varying with these conditions, but we do not always find the germs or seeds from which they originate. In fact, such seeds, or germs, are found but very rarely, and all this certainly favors the theory of spontaneous generation.

The large plate shows a peculiar moth, found in New Zealand, called the swiftmoth (Hepialus virescens), with its caterpillar, on the head of which grows a peculiar fungus (Cordiceps Robertii). The fungus finally roots the caterpillar to the soil, as will be seen, and literally transforms the whole of the animal into the fungus.

Dr. Jos. Hooker describes, in the London Journal of Botany, an allied specie called the Spharia Robertii, of which a representation is here given. The caterpilaa. is seen buried in the ground, and the fungus growing above from it.

The following is Dr. Hooker's description :

Spharia Robertii, N. Zealand: HooKER.-“"They are found in spring, generally nuder tree. ferns; the caterpillar is buried in the ground, as is the lower portion of the fungus. The entire body of the insect is filled with a pith, or corky vegetable substance, and the intestines are displaced. What does the muscular fiber of the animal become? It must, I suppose, be all turned 
tento vegetable, for the skin of the creature remains quite sound all the time.... The whole veseot seems entirely metamorphosed into vegetable, with the exception of the skin and intestines.

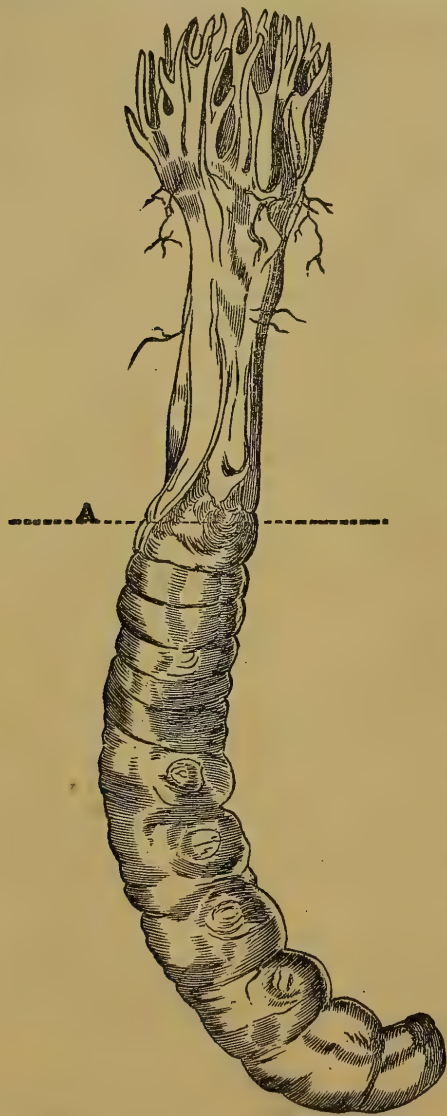

Frouke 32.-Spharia Robertii, or Fungus Caterpillar.

$A$ is the level of the ground, the part below being the caterpillar, and the part above the fungas which has grown from it. ing a solution which had thus been a long time under electric influence, he was surprised to see around the negative pole of the battery several living insects, of the

Mr. Taylor and Mr. Colenso hold the same opinion, that in the act of working the soil (to bury itself), the spores of the fungus are lodged in the first joint of the neck, and the caterpillar settles, head upward, to undergo its changes when the fungus develops itself. It is like the green mottled caterpillar, which produces a large brown moth, numbers of which skim all about.

The body of the insect was solid and pithy, the outer skin attached to the substance of the center, which has no roots in it, and, moreover, the pith is of the same substance as the stem, which is as thick, if not thicker, than the body of the caterpillar. Both the pith and the stem, when burned, have a strong animal smell."

Reference should also be made, in this connection, to the interesting experiments of Mr. Crosse, Mr. Weekes, and others, in the production of insects in mimeral solutions by means of a current of electricity.

Mr. Crosse was the first who observed this phenomenon, now many years ago. He was engaged in experiments upon chemical decomposition and crystallization, under the influence of electricity, without any thought as to the production of living beings. In fact, such a thing would have been thought impossible, from the nature of the materials operated upon. These consisted of powerful acids and other chemicals, used as solvents, with flints and similar hard mineral substances.

His idea was to submit his solutions to a long-continued slow action of the electric current, so that change might occur gradually, as it does in nature, and the results gained were extremely interesting and valuable. Many sub. stances were thus formed, artificially, for the first time, and the manner in which others are naturally produced was 
PLATE III.

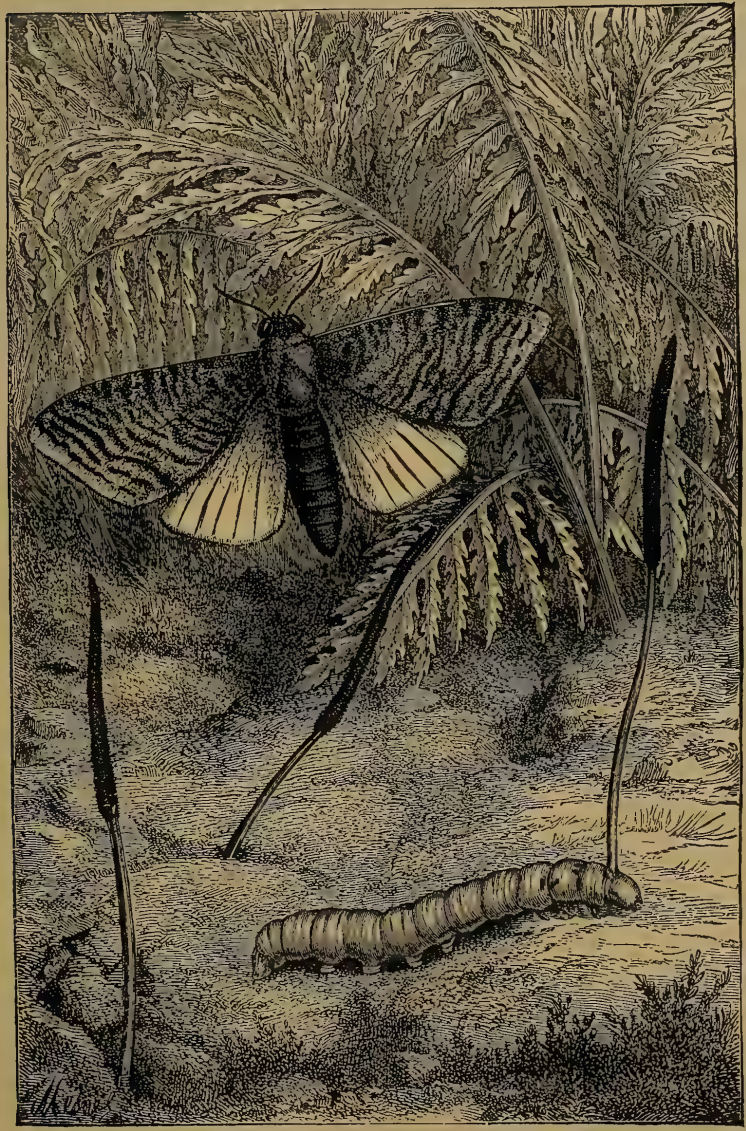

The Caterpillar Fungus. 

species called Acarus! They were of a peculiar kind, and seemed to be quite at home in the chemical solution where they were found; in fact, they lived only in that, as others live in water.

Subsequent experiment showed that insects always appeared, under the same circumstances, and not only in that solution, but in others-even in poisonous onesunder the influence of the electric current. The insects varied according to the materials used, and each kind, as a rule, could live only in the medium in which it was formed.

The announcement of this discovery caused the wildest excitement in scientific and theological circles, and Mr. Crosse was subjected to so much abuse for his discovery that he almost regretted having made it. He was denounced as materialist, atheist, and everything that was dreadful ; but nevertheless the Acarus Crossii was there, and had to be recognized.

Attempts were then made to show that it was merely a case of generation from atmospheric germs, and not spontaneous. But still there remained the questions, Why do particular kinds of insects appear only in certain solutions, mineral and poisonous? - and Why is the electric current always needed ? To these questions no satisfactory answer has been given, and many very competent judges are still of opinion that these Acari are spontaneously generated by the influence of electricity. Such experiments have been repeated, since Crosse's time, by many persons, and always with similar interesting results. Among others, Mr. W. H. Weekes has perhaps been the most successful.

In a communication made by him to the author of the "Vestiges of the Natural History of Creation," he gives full details of some very carefully conducted experiments, made specially as tests. He took a glass vessel, so made that no air could gain access to the interior, except as he wished, and this was connected by inserted wires with a constant galvanic battery. Into this vessel be conveyed a solution of prussiate of potash (a very poisonous salt), and also a quantity of oxygen gas, so that the vessel was filled in the lower part with the solution, and in the upper part by the gas, there being no common air admitted, and consequently no germs could possibly find their way there. Every precaution was taken, both by boiling the poisonous solution and by sending the gas into it straight from the white-hot retort in which it was generated. There was, therefore, only the gas and the solution in a perfectly air-tight vessel.

Then some of the same solution was put in a vessel open to the air, and the electric current was made to pass incessantly through both-entering the open vessel first.

Various chemical changes took place, but no insects were seen till one hundred and sixty-six days after the electric current began to flow. Then, in the open vessel, the first ones were seen, and they continued to be produced in quantities for several months. During this time nothing of the kind took place in the closed vessel, but after two years the solution therein seemed to change very much, and the insects 'appeared in it also, just the same as in the open vessel! This would seem to be con. clusive, for if it be granted that the open vessel might have received germs from the air, certainly none such could have reached the interior of the closed one, with its oxygen atmosphere.

Mr. Weekes also describes another experiment, in which a thin solution of refined sugar was submitted to continuous electric action. The result was the production of a peculiar fungus different from any previously known, and which only came under 
the electric influence. Both this and the insects, it is worthy of remark, always first appeared in connection with the negative pole of the battery.

Now, the whole earth, with its beds of metallic minerals, and other chemical substances, is a rast galvanic battery, through which electric currents are constantly passing, causing chemical changes on a stupendous scale, and, probably, also engendering life, as they do in the experiments above described. It would be strange indeed if it were not so, for natural forces act uniformly and unerringly, on the small scale and the large alike.

In the earlier ages of the world also, as before remarked, the general condition were more farorable for organic development, and the electric force more intense, so that living beings were much more readily and abundantly originated.

Experiments of this kind are now being persistently conducted, by men who have no fear as to what may be discovered; and I feel a firm conviction that we are on the eve of discoveries which will revolutionize the whole science of Biology, -so far as the first origin of life is concerned.

Observations have shown that bacteria, and other such forms of life, often appear in different internal parts of the body, apparently as a result of deranged nutrition, or circulation, in that part. It would seem that if any such internal.part be cut off, as it were, from the general organic life, or isolated, a morbid condition sets in which entirely changes its mode of cell development. In such circumstances infusoria of various kinds are produced, and probably intensify the diseased condition. They may also, as before observed, propagate the disease in any healthy body to which they may gain access. They are therefore, properly speaking, the products of disease, though quite capable of extending it.

Dr. Richardson is decidedly of opinion that the so-called contagious diseases result from diseased secretion, caused by glandular derangement; but that the contagion, whatever it may be, which they give off, may also be an active cause of the disease in those who encounter it, providing they are in a condition to be affected. This is a very different doctrine to that held formerly-that these diseases always began from germs disseminated from one body to another-and it is not only more likely to be the true theory, but it is also much more encouraging to us in our contest with disease.

As a further confirmation of this view, another fact may be noticed, which apparently proves the theory of spontaneous generation. On carefully dissecting a body some time after death, bacteria will often be found, in abundance, in the fluids of various internal parts, where it is certain they could not have been while that body was living ; and where observation, immediately after death, had shown conclusively that there was nothing of the kind. The condition of the parts is such, being closed cavities, that it is certain germs could not reach them from the air; and as they could not always have been there, the inference seems warranted that they were spontaneously generated when death occurred. These parts, being no longer working portions of the whole body, are thrown, as it were, on their own resources; the fluids in them decompose, fresh cellular development sets in, and infusorial life results. This seems very probable, and I see no other way in which the existence of these living organisms, in such circumstances, can be accounted for.

In all probability every animal body, immediately after death, is filled with various forms of infusoria, thus spontaneously generated, and they very likely assist materially in its decomposition. 
In what is called Splenic Fever there is developed a peculiar animalcule, called the Bacillius anthracis, which undoubtedly is a main agent in aggravating and extending the disease. It is in no way whatever distinguishable from the common Bacillius subtilis, which is quite harmless.

Now a man may be attacked with Splenic Fever, in any part of the world, where it had never been known before, and this animalcule would immediately show itself. Whence, then, does it come, if it be not spontaneously developed in the diseased secretion? It is true this organism may cause the same disease in another person, if he be in an apt condition; but it seems certain that both disease and bacillius will arise spontaneously, where neither was known before. This certainly supports the view, that the disease may originate the bacillius, in the first instance, though this may extend the disease afterward.

The important part which the lowest organisms, or unicells, play in the general economy of nature is every day being made more and more apparent. In fact, pretty much all organic change is effected by their agency. One of our latest and most eminent physiologists-Foster-asserts, in regard to the human being, that the total action of the whole body, of every kind, is nothing but the aggregated action of countless amoeba-like organisms of which it is composed.

It was long a mystery in regard to the natural nitrate salts, such as saltpeter, whence came the nitric acid they contain? The oxygen and nitrogen which form this acid, of course, exist in the air ; but by what agency are they brought together and united chemically? Many theories have been advanced to explain this, but none of them have been satisfactory. Latterly, however, it has been shown that nitrogen is oxidized by the action of certain simple-celled organisms, which, during their rapid growth and extension, effect the combination of the two elements. They operate in the same way as the yeast-plant-torulce-which by its rapid growth causes alcoholic fermentation; or like the vinegar plant-the Mycodermi aceti-which during its growth causes the elements of acetic acid to unite, and form vinegar.

This discovery connects nitric acid with the organic world equally with acetic acid, and shows that the old distinction between organic and inorganic chemistry is unfounded. It is a further proof that all natural processes are essentially the same, and that there is no absolute break between organic and inorgamic life, but that one passes insensibly into the other. 



\section{PART IV.}

\section{AGGREGATION OF CELLS INTO COMPOUND ORGANISMS.}





\section{CHAPTER $\mathrm{X}$.}

\section{AGGREGATION OF CELLS INTO COLONIES AND COMPOUND ORGANISMS.}

SoMe of the ceils, when formed, do not remain solitary, each one living by itself, but numbers of them aggregate together, into colonies, or societies, in which all the individuals live their own independent lives, but all together form one community.

Fig. 33.

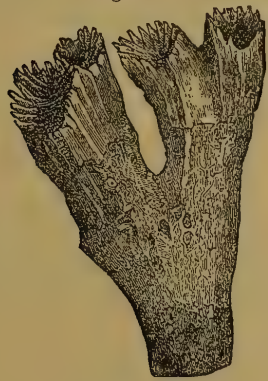

Fig. 35 .

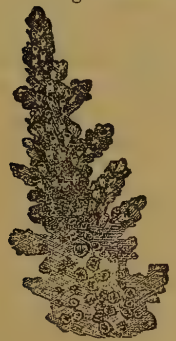

Fig. 34.

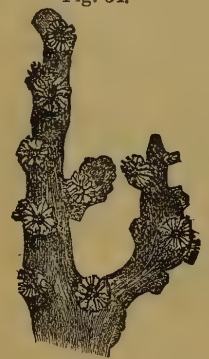

Fig. 36.

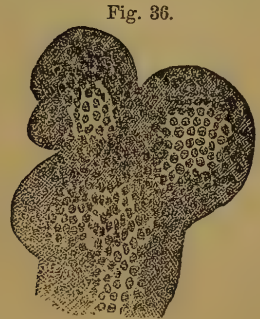

FiguRes 33, 34, 35, 36.-Different Forms of Coral Branches.

The spots, stars, and finger-like projections are the separate Polypes, all united to one main stem.

Instances of this are found in the Corals, a mass of which consists of the limebuilt cases of a number of distinct polypes, all united, just as bricks are in a wall. Each one, however, lives by itself, and for itself alone, in its own cell, coated with lime. The animal itself is soft and jelly-like. The separate polypes act together, 
in this way,-they form conjointly the internal skeleton, or framework, usually like the branch of a tree, on which they all live, each one separately in its own cell. Such an arrangement may be called the first approach toward the formation of a society.

The Sponges also exhibit somewhat similar habits. A ball of sponge is only a mass of animals somewhat like amcebas, all quite independent, all nutrifying themselves like other amœbas, and in no way vitally connected with each other. They, however, act together so far as to form a common framework, or skeleton, on and in which they live, like so many separate people in a tenement house.

What we call a sponge is one of the common skeletons cleansed of the jelly-like inhabitants, and of the lime which had served to somewhat harden it.

The difference between the corals and sponges is this : the corals form a common skeleton of lime only, while in many of the sponges it is more or less an animal substance, and sometimes quite horny. There are sponges, however, that form lime skeletons, and they nearly always have a lime or silex center, somewhat like an incipient backbone.

For a long time both corals and sponges were thought to be plants, and eren till quite lately the sponges were considered as much vegetable as animal. They are now, however, by general consent, classed as animals. Many of them, nevertheless, contain a green-colored substance, apparently identical with chlorophyl, the greencolored matter found in the leaves of plants.

The stony skeletons of the sponges, and other allied beings, are the most beautiful and regularly formed objects that can be conceived, and their varieties are endless. Many of them are microscopic; others large enough to be seen by the naked eye. They are often visible in the clear interior of the flints found in the English chalk, which when polished make beautiful ornamental stones.

In some very simple cellular organisms the separate beings merely hang or stick together, in bunches, more or less large, each one being still quite independent.

Simple and unimportant as this kind of union may seem, it is still an advance on detached single-cell life, where each one lives and dies by itself, and where there is no kind of mutual help. Both the coral and the sponge, humble though they be, have made an advance, and are nearer to the higher animals than the gregarinas, or amcebas. They show us one of the first steps in that process of evolution by which all the higher animals, man himself included, have been produced from the simple single cell.

Cells propagate, either by forming a new brood inside, and then bursting and scattering them, or by dividing themselves into bits, or by budding, as will be shown elsewhere; and the rapidity with which this is done is amazing. It has been stated, by competent observers, that as many as sixty-six millions of new cells are formed in a minute, in some cases, all originating from a single parent; but how far this car proceed is not known.

It is supposed by some, that each cell, when it begins this astounding rate of propagation, starts with a certain amount of force, which can carry it only so far, and that when this original force is exhausted, the propagation of new cells ceases. If this be so, it follows that every family of cells has its limit of duration, and must, sooner or later, come to an end. In the simplest single-cell beings, as soon as a new brood is formed, it is scattered far and wide, each individual living and dying independently by itself, so that the fate of the family cannot be followed step by 
step in each of its members. When we ascend higher however, all the family originated by one cell have a tendency to hang together, more or less, either in strings, chains, cones, or regular-formed bodies. Probably the coral and sponge societies start in this way, from one parent originally.

In still higher organisms, as in the vertebrate animals, all the cells produced from the one primitive parent cell are held together by a single integumert, or skin. The egg, from which every such animal is produced, is the primitive parent cell, from which are produced the millions of other cells that finally form the full-grown body. None of these are thrown off till the new individual is fully developed; then some of them are specialized, and thrown off in the form of eggs, or sperm, to begin the formation of other new beings in the same way.

It is just the same with a plant, which starts from a single cell, in the form of a seed or bulb, and this by ceaseless multiplication forms continually new cells, which build up the perfect plant; and when complete, some of the cells are specialized into seeds or bulbs, to form other new plants, just as some of the animal cells are specialized into eggs, or sperm.

In the plant, however, as in some of the lowest animals, a piece of the perfected body may be cut off, as a small branch, for instance, and, being planted, will grow into a new plant just as a seed or bulb would do. This branch is, in fact, only a cluster of cells, which can go on propagating, in proper conditions, just as if still attached to the parent body.

The question has been asked, however, if this continued division, and redivision, in the case of a plant grown from a seed or bulb, could go on forever. Many physiologists say no, but that it must come to an end some time, because as the original cell, the seed, started with only a certain stock of force, this must in time be exhausted, and then its final descendants will no longer have the power to continue propagation.

In this way they account for the enfeeblement, and dying out, of many kinds of trees and plants once vigorous and healthy. Many varieties of fruits, formerly well known, have been

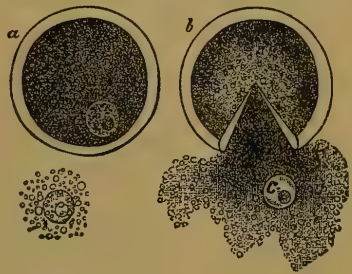

FIGURE 37.-The Human Egg, or Ovum.

$a$ represents the parent cell, cortaining the primitive germ, or vesicle, as seen in the female ovary. $b$ shows the parent cell ruptured, as it is when fully ripe, and the germ vesicle escaping, surrounded by the nutritious granules, by which it first begins to nutrify itself, and develop. $c$ is the germinal vesicle. HERE, THEN, IS THE FUTURE MAN, IN HIS FIRST BTAGE, much magnified.

so extensively propagated by budding and grafting, that the power of reproduction-so these men say-has been all expended, and they are now fast becoming extinct. Every bud, or graft, it must be borne in mind, is, in reality, oniy a continuation of the parent tree, and not a new start from a parent cell, or seed.

Observation has not been as yet long enough continued, nor systematic enough, to settle this point; but it certainly seems reasonable to suppose that there is a limit to the duration of a family derived by continual re-propagation from one original parent; and that it is necessary, in the course of time, to get a new start from a seed or egg; that is, a primal germ.

In the higher animals, of course, nothing of the kind has to be considered, because they are all propagated singly, each one from a new cell or germ, and cannot be multiplied by subdivision. 
A century ago, owing to the ravages of syphilis, it was common for men to lose their noses, and those who could afford it paid poor men to consent to having a new one cut from some part of their bodies, and grafted upon the mutilated face. The operation was usually successful, but great consternation was caused by some one suggesting that if the poor man died first, the nose taken from his body would die at the same time. Hudibras alludes to this in his well-known lines-

\footnotetext{
"And when the date of Knock was out, Off dropt the sympathetic snout,"
}

It is needless, perhaps, to say that the fear was groundless.

Every animal, high and low, starts from a simple cell, and begins its life like a simple monad. In the monad, however, the primitive stock of force earries its future development only to a certain extent, and in a certain way, while in the higher animal it is capable of carrying it farther, and in a different way.

Man, for instance, begins life as a little vesicle, or bag of fluid-a simple cell-as all other animals do. In his first stage, or beginning, man is shown in the preceding figure, which represents the female ovum, or egg, from which every human being originates.

This germ vesicle immediately begins, by osmose, to suck in the surrounding nutritive fluid, and to develop, like any other cell, and finally divides and subdivides into millions of other cells, all of which are appropriated, in the process of growth, to forming the body of the future full-grown man.

The new cells as they are produced are formed into what are called the tissues of the body-a tissue being an aggregation of cells, modified or specialized in a certain way, for a particular use. Some of them, for instance, form into threads, or fibers, as in the museles; others into pipes or tubes, as in the nerves and blood-ressels; while others form a congeries of interlaced cavities, which become filled with lime, and so form bone. Every part of the future body, in short, is built up of cells, produced at first from the multiplication, or division, of the primitive parent cell.

A man is, in fact, an aggregation of cells, as is a coral or sponge, only, in his case, they are so vitally united, and interact so in concert for a common purpose, that, conjointly, they form a compound organism, having an independent life of its own. This larger life, however, is really a result of the combined forces of all the individual cell lives of which it is composed, and each of which still lives its own little life as an independent being.

It is the same as in a working steam-engine, where every particle of wood, iron, coal, and water possesses, through all its workings and changes, its own individual power and properties (or life), while all together form the compound life, the engine.

The engine has no power that did not exist before it was made, in the material it is composed of, or in that which works it. Nor has man any powers but what exist in the cells of which he is composed, and which, primarily, existed also in the inorganic elements of which they are made.

The nervly developing being remains connected with the parent organism till its own structure is so far perfected that it can begin to live by itself; then, its organs being so far perfected that it can form new cells from the food which it takes, for a while it simply grows, or increases, and afterward maintains itself in equilibrium, till the time comes when the power of cell formation and assimilation ceases, and then it dies.

The growth of a man, and his after-maintenance, are effected from the blood, a 
peculiar fluid that circulates in his veins and arteries, and which is derived chiefly from the food he eats.

Blood consists, mainly, of a large number of little vesicles floating in a clear liquid, which is albuminous or protoplasmic, and contains also several salts and other inorganic ingredients. In it is found the material of the body, but not in a proper form for assimilation. By the action of the cells, this crude material, which is only digestec food, is sorted and recombined into true protoplasm, suitable for nourishing every part of the body.

There are two kinds of cells in the blood,- - one globular and colorless, dotted with little grains; the other flattened, with no dots, and filled with a deep-red fluid. Each of these cells is a distinct individual, with a life of its own, but all co-operate together to support the life of the compound being in whose vessels they circulate.

The various changes required in this protoplasmic fluid, to fit it for nutrition, are effected by these cells, by the action of osmose, and if they are deficient in number or activity, those changes do not fully take place. The individual then becomes feeble and loses flesh,- he has poor blood. The life of a man depends, therefore, on the life of these little cells in his blood.

Such is the power of selection and combination possessed by the blood-cells, that they can form true protoplasmic material out of any other albuminous fluid, as well as out of the true blood fluid. In many cases of great hemorrhage or extreme exhaustion, it is well known that blood from other and healthier bodies can be transfused into the veins of the sufferer, and life and strength be restored. It is not so well known however that, in case blood cannot be obtained, milk may be used; and many cases are on record where life has been saved by injecting it into the veins. Even weak infusions of many farinaceous matters will serve the same purpose, after great loss of blood.

In such cases the blood resicles select the needed material from the milk, or other albuminous fluid, the same as they would do from the true blood fluid.

Nothing shows more clearly than this that man is but an aggregate of cells, and that his life is the sum of all their lives. While they live, he lives; when they die, he dies, and his powers, whatever they may be, are but the sum of their powers combined.

Every part of the body, bone, muscle, brain, hair, nails, and skin, all are composed of cells more or less modified. Some of them are fixed (as those of the bones, for instance), or change but very slowly. Others, especially those of the brain and nerves, are all the time in a state of

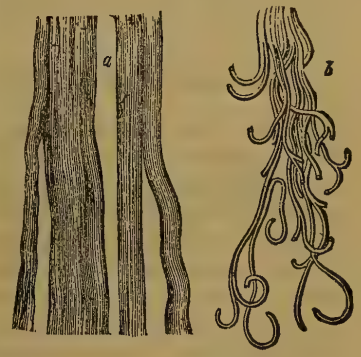
rapid change, and so are those of the blood. The more active any part of the body 
is, the more rapidly do its component cells become disorganized and die, and new ones take their place.

In fact, it is upon this rapid change that activity depends; the consumption of cell material, and its constant formation, resembling the fire in the engine, by which the steam is produced. Muscular motion rapidly uses up the muscle cells, and new ones have to be supplied from the blood. Thought and emotion consume cell matter, in the brain, still faster, and the blood has to circulate in it with a rapidity proportionate to the work it performs.

In the next cut is shown the cells in the brain of a cat. These are all globuo lar, and soft, being filled only with fluid. At $a$ and $b$, some of these cells are shown separately, each with its nucleus.

The skin is simply a layer of flattened cells, and even the claws, narls, and horns
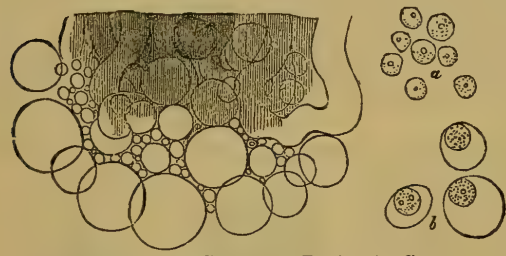

Fraure 39.-Cells in the Brain of a Cat. of animals are formed from them ; the liver, kidneys, and all other secreting glands, are but clusters of cells, each cluster specialized for its particular purpose.

It will be readily seen from the above explanation, that the cell is the foundation of the man, and that even when he is full grown, his life and active usefulness depend entirely upon the ability of his organs to form, and assimilate, new cell material. If he then make too little of this, he becomes poor and feeble; and if the depreciation be carried too far, he dies. If the cells in his blood are deficient in number, or perform their functions imperfectly, his whole system suffers. Debility and disease both come from deranged cell growth, and neither can be got rid of till the cell action again becomes perfect. In some diseases, as in cancer for instance, a morbid or unusual growth of cells takes place, different from those normally existing in the system ; and these new diseased colls often increase with astonishing rapidity, at the expense of the proper cells of the body. They resemble those fungus cells which often spring up in a few hours, and choke, or poison, the ordinary regetation of the place they grow in. The osmotic activity of cells is past all conception. Compared with it, the most rapid action we know of is mere stillness, and it is incessant. A man, therefore, represents not one life only, but untold millions of lives!

In all probability disease cells, as those of cancer above referred to, have become, from some unknown cause, different in structure from healthy ones, and in their osmotic action, instead of selecting that material from the blood which the body needs for healthy growth, they select hurtful material.

It is highly probable that those who suffer from cancer, if they have children, will transmit to them a tendency to this abnormal cell formation, and in this way perpetuate the dire disease. The same may be said of many other diseases, and the first practical step toward getting permanently rid of them will be for people so afflicted not to propagate. In future and wiser ages, I have no doubt, this will be attended to. In fact we do attend to it now, in the lower animals, but neglect it in man! 


\section{PART V.}

EVOLUTION.

ORGANIC AND EMBRYONIC DEVELOPMENT. 



\section{CHAPTER XI.}

\section{EVOLUTION.}

ALL real knowledge of Nature, and natural phenomena, is of very recent growth. It was formerly the custom with men, even with philosophers, when they interested themselves about Nature at all, to sit down and imagine how things were, and invent theories about them. No matter how little those theories accorded with known facts, if they were put forward by authority, they were generally accepted, and the facts entirely ignored. Even at the present day this is a very common process, and when any new discovery is announced, the first impulse with many men is, not to investigate, and so find out if it be true, but to see if it agrees with some old theory.

It took mankind many thousands of years to find out, simple as it may seem, that to know about anything they must investigate it, and that they can investigate only by using their senses, corrected and controlled by their reason.

Man can really gain true knowledge, about any natural object, or process, only by using his eyes, ears, nose, tongue, and touch. With them he gains the foundation facts, by means of which he can truly investigate, and gain knowledge; but without which all his speculations amount to nothing, being like houses built on sand.

It would be amusing, if it were not so pitiful, to narrate the strange and absurd theories which have been put forward, by the greatest men of former times, in regard to the various departments of Nature. The early history of every science is only a record of such theories, one superseding another, according to the weight of authority it could command, and not at all because it was more true. And yet the simple examination of the facts, by means of the senses, - that is, experimentation, and observation,-would have revealed the real truth at once.

No knowledge whatever can be gained of Nature by mere reasoning, unless it be based upon facts taken cognizance of by the senses. And yet it is quite common for men to commence such reasoning, without any previous acquaintance with the necessary facts whaterer. Such a course necessarily leads them to all kinds of absurd conclusions, and makes all their reasonings utterly valueless, because they have no foundation.

An anecdote recorded of King Charles II. illustrates this well. He was a very shrewd man, and fond of quizzing the learned pundits around him, whose weak points he well knew. One day, having a large circle of them, he propounded the following question: "Why is it that if you put a vessel of water in a scale, weigh it accurately, and then put in a live fish, it will not weigh any more; while if you put in a dead one of the same size, it does weigh more ?"

The learned men discussed this question, reasoned about it, started all kinds of theories, but could come to no satisfactory conclusion. Finally the king asked a hard-headed old Scotchman, who had said nothing, what explanation he gave. 
The old man simply replied, "I doubt the fact;" and, sure enough, on trying the experiment, it was found that whether the fish was dead or alive made no differe ice, they both made the vessel weigh so much the more.

Now, this is exactly the course the world has hitherto pursued, and which a large number of peoplc habitually pursue now. Whenever any question presents itself to them, out of the ordinary run of their experience, they immediately begin to theorize and speculate about it, instead of first finding out how much they can get to know about it. Fortunately, however, there are always some common-sense men, who, like the old Scotchman, "doubt the fact," and will have it put to the test of experiment.

We are, in fact, indebted to the doubters, and to those who always insist upon rigid examination, for all the real knowledge we possess; and they have had a hard fight of it against the theorists. At one time it was dangerous to doubt or, at least to question, many prevalent theories, and men had to profess belief in them, even when they knew them to be untrue.

This is especially the case in regard to man, and other animals. Men who despised Nature as something vile and brutish, sat down in their closets to explain all about it, without making any observation or experiments whatever. Each one formed his own hobby or theory, which he put forward as infallible, and denounced all the others as heterodox and wicked.

It is hard to judge which are the most absurd and unfounded-the theories about man's body, or those about his mind. We find them vary from age to age, but all alike baseless in fact. It never occurred to these theorists that the only way to understand a man was to examine and observe him in every possible way; to take him to pieces, and to submit every part and parcel, so far as was possible, to direct observation and experiment, by means of the senses. If such a course had been proposed at one time, it would have been denounced as gross, materialistic, and wicked; and the individual suggesting it would have run no little danger. In fact, many of the greatest men who ever lived have lost their lives, after horrible tortures, for doing so. And yet it is the only true course to take, as people are now beginning ti see.

If a man should present to the public a curious machine, working in some unknown way, but keep it under a glass case while he asked mechanicians to explain it, we should think him very unreasonable. 'They would naturally demand to be allowed to examine it, to take it to pieces, and to ascertain the motive power. Till this had been done, they might theorize about it, but nothing could really be known, and all their theories might be utterly wrong.

This, however, is exactly the course hitherto taken in regard to man; he has been kept under a glass case of old theories and prejudices, and no real examination of him allowed to be made, till, finally, some bold spirits, with the sledge-hammer of scientific fact, smashed the case and took the man to pieces! The result proved that he was altogether a different being to what the old theories had made him, and that he stood in very different relations to his surroundings. The orthodox theory has always been that man had a different origin and destiny from all other living beings, and that he stood in a different relation to Nature generally. It was supposed that he was created, just as we find him, by some outside process, out of the inorganic elements of the world, with inherent powers, different from any existing elsewhere in Nature. To doubt this, or to suggest that possibly he might not thus 
stand apart, but be really only a product of Nature, originating from her inherent creative power, like everything else, was something undreamed of till recently.

Even now the mere proposal to inquire into the matter, to collect facts, and to make observations, with a view to ascertaining how far the prevalent theory may be corroborated or disproved by them, causes the most absurd apprehensions and the most uncharitable denunciations.

Nevertheless, the doubters have determined to weigh the fish, dead and alive, with the water, and to see what is the fact. They decline any longer to take any theory for granted without proof; but resolutely determine to examine all, and test them by facts alone.

It is the age of weighing and measuring; of seeing and hearing; of bringing together in all possible ways the different natural substances, to see how they act and react upon each other. It is the age when a material cause is assumed and sought for every known phenomenon. It is the age when observation and experiments take the place of mere speculation, and when authority alone is not allowed to decide any matter in dispute, especially if it can be submitted to investigation. Men discover that the more they study Nature by observation and experiments, the more capability they find in her, and the less need for outside influence in any way. One after another, the events and things formerly thought to be supernatural are found to be only parts of the natural chain of events, so that the supernatural is steadily receding.

It is now beginning to be seen that Nature includes everything within herself; that there is nothing outside of her in any way, so far as we know; and that she possesses inherently the full capacity for originating all beings that exist, organic and inorganic, man included, with all their powers and capacities of every kind. $\Lambda$ stronomy and geology show us that the world was once very different to what it is now ; that it had a beginning, probably in a state of vapor, and afterward a long infancy in which no life was possible, but in which the natural forces were constantly acting with an energy of which we now seldom see an example. It had to be cooled; its watery vapor condensed; its jagged, hard rocks softened and worn down into mud and sand to form other kinds of rock, laid in regular beds, one above another, on the floor of the ocean. Finally, the time came when the protoplasmic elements-ammonia, carbonic acid, and water-could exist and combine together, to form the primitive germinal matter which we now call protoplasm, when it forms animals, and chlorophyl when it forms plants.

When once this substance was formed, portions of it would inevitably become endued with vitality, from the influence of chemical action, of heat, and electricity, as shown elsewhere. And in this way would originate the primitive protozoa, similar to those we now see; beings that are neither plants nor animals, or perhaps either, according to the conditions under which they develop.

As these multiplied and decayed, leaving their own protoplasmic substance to add to that naturally formed, and the general conditions became more favorable to life, other and superior beings would naturally take their place.

In this way began Evolution, or that gradual bringing forth, from the primitive unorganized elements, step by step, the long succession of living beings, ending in those now existing.

No organized beings above the lowest protozoa originated in the form we now see them. All have resulted, by gradual change, in a long succession of ages, from 
other and lorrer forms. The largest and most perfect animals, with man himself, can be traced back, step by step, till we come finally down to the speck of protoplasm which is the first beginning of all.

Thus matter, and the force inherent in it, or what we call Nature, has originated all that exists; and there is no reason to doubt that, if all life were to become extinct, on this earth, Nature herself would again produce it; but probably it would begin rery differently to what it did at first, because the conditions are different.

This is Evolution, the progress upward, from an immature primitive state to a more perfect one, both bodily and mental. For it is not only that animals have, in many ways, become more differentiated, or specialized, in their bodily derelopment, but their mental or reasoning powers hare progressed also, notably in man.

This has resulted from a steady improvement in the quality and capacity of the brain, on the working of which all mental power depends. Nothing is more striking, in studying the successire stages of fossil animal life, than the steady advance that is shown in brain power.

In former epochs, we find enormous mastodons, and other gigantic creatures, with bodily bulk and strength far beyond the mightiest now existing, but with moreily rudimentary brains. It was not necessary for them to think, and so the thinking organ was not developed.

As the world changed, however, in its conditions, it became fitted for other kinds of beings. Mere bodily bulk and strength began to lessen, the brain became more developed, and intelligence came into play.

This new form of natural potrer soon made itself felt in many ways, and all other forms became more or less subordinate to it. The small and weak animal, with much intelligence, could more than hold his own with the big, strong animal, whose intelligence was small.

The particular type of animals, to which man belongs, are the only ones with highly specialized brains; and the next class below him, the apes, have the most perfect brains, next to man's.

Recent investigations, especially those of Darwin, have shown that if we take the lowest man as a starting-point, there is less difference between him and the highest ape, on one side, than there is between him and the highest man on the other side. In other words, the Bushman is farther removed from the cultivated Caucasian than the highest ape is from the Bushman. And the difference is mainly in intelligence, or brain development.

Evolution has not ceased, but is going on all the time, all through nature, but especially in man and the animals under his control. The cultirated man of today is as far abore the barbarian of a past age, in available intellectual power, as that barbarian was then above the apes from which he sprang; and probably the man of the future, by the same process of evolution, will be as far above the most cultivated men of the present day.

The principle of cvolution prevails not only in individual life, but in society itself. We see how the first crude social arrangements, such as prevail among savage tribes, are gradually advanced to larger associations, under hereditary chiefs, and how these finally become settled nations. The most powrerful and perfecteci societies of the present day, such as we see in the more cultivated parts of Europe, have al? been gradually evolved from savage tribes. History shows us how their laws, their customs, their religiens, and their systems of education have all advanced, from the 
simplest beginnings, to what we see them now, and in all settled societies they are still advancing. In fact, the only real and permanent progress is made in this way, by gradual evolution; and any attempt to advance society by a jump, to the more perfect stage of a future generation, is sure to end in failure. Many instances of this are to be found in modern history, and even in our present experience.

And this explains why it is that important discoveries are frequently made, and announced to the world, without attracting any attention whatever. They are simply ahead of their time, and the public mind has got to be evolved to a certain point before they can be appreciated. A rery short time since there died a gentleman who made, many years ago, a perfect electric telegraph, almost exactly like what we are now using, and invited all the world to come and see it, but it attracted very little notice, and was finally laid aside. Government officials informed him that they did not want anything better than the old semaphore telegraph, with its movable arms, seen through a telescope.

It is just so with everything else : not only have scientific inventions to wait till the public brain is sufficiently evolved to comprehend them, but all truths must do the same. And this explains why obvious improvements in laws, in customs, and in religion, are so slow in being made. A few advanced minds can see them, and may urge their adoption, but they have to wait till the dull, inert masses get nearer to their stand-point. It is, however, a sufficient consolation to know that time, by gradual evolution, will certainly bring round all the progress and amelioration that the best minds can conceive of, and probably even much more.

Many excellent people are much alarmed at our present rapid progress, from fear that institutions and opinions, now held sacred, will be swept away, or so modified that they will not resemble what they are now. And this will, doubtless, be the case; but such people should remember that in former ages the same opinions and institutions, which they now hold so sacred, were condemned and dreaded as much as they now fear and condemn the present advanced views. The mcst orthodox views of to-day, on many subjects, were rank heresies among our forefathers, and many of the much-dreaded heresies and infidelities of to-day will be orthodox in the future.

The human mind must progress, and it is vain and irrational to suppose that the more enlightened future will be bound and trammeled by the immature views of the present. Evolution never ceases, and fortunately all the efforts of ignorant and timid conservatism can never seriously impede its progress.

A remarkable instance of inherited experience, showing itself as improved perception, is shown in the behavior of animals toward railroads and their engines. When they first began to traverse the country, all the animals in the fields used to run away in crowds, in the utmost terror, and constant accidents were oceurring with them on the roads. Now, however, the same animals, both in the fields and roads, see the trains pass and repass, and scarceiy notice them. This is not only because they have got used to them individually; for the offspring of these animals, born away from railroads, and brought to them when grown up, usually show just the same indifference. This is evolution! The animals who first got accustomed to the engines underwent a change of brain, owing to their new experience, and this change of brain their offspring are born with, and hence their behavior.

The existing knowledge of any community, its habits, customs, modes of thought and beliefs, are only the inherited experiences of past ages, transmitted to the pres. ent. The present is the child of the past by the process of evolution. 
It would be a great mistake to suppose that the process of evolution is limited to any one or several kinds of phenomena. It extends to all nature, and is everywhere, at all times, going on; in the mental and moral world, as well as in the physical.

The present may be said to be always, not only pregnant, but even in the actual throes of labor, with the future. No age is self-born, nor stands alone, but each is the child of the one before, and the parent of the next beyond.

The present clear conception of this great law of evolution, and its wide acceptance, is mainly due to the labors of CHARLES DARWIN-a man who may be truly said to have created a new era in science.

Before his time the development of an egg into a bird was regarded as a simple unconnected phenomenon, wonderful in itself, but not specially related to other phenomena of a similar kind on a larger scale. But we know now that the changes the egg undergoes, before it is fully developed into the bird, are the exact counterpart of those which the progenitors of the bird went through in former ages.

The egg is only a simple cell ; but under the influence of heat and moisture, we see it gradually change, going through various inferior forms up to that of the fish, thence to the amphibia, thence to the reptile, and finally to the bird. And if we trace back the bird through its organic descent, as shown by the fossil record, we go back, step by step, first to the reptile, thence to the amphibia, thence to the fish, and finally down to the single cell. It is the same process, traced forward in one case, and backward in the other.

The same fact is shown when we trace the development of a man in his mother"s womb. He begins with the simple cell, goes through all the lower forms, ascencis to the fish, the amphibia, the reptile, the bird, and still further through all the more advanced forms, till he becomes finally a man.

We can also trace him back, in the past, just as we did the bird. We can track him from his present development, back to the apes, from them to the lemurs, and so on from one form to another of the mammalia down to the bird, the reptile, the amphibia, the fish, and so on finally to the simple cell.

And not only can we thus trace his bodily evolution, but his mental powers, and what are called his moral instincts, can all be traced back to the simple instinctive actions of the beings below him. In them are the germs of the highest mental developments, and the most elevated moral impulses, that we see in the world's sages, heroes, and philanthropists. Even religion, the sublimity of law and veneration for that we fear or love, but do not comprehend, is plainly to be seen, in its first faint glimmerings, in the conduct of a dog to his master.

Every living organism, therefore, develops from a simple cell, and in its progress upward to its final form, gives us an exact representation of the way in which its type originated, in the past, from the primordial protoplasm.

The conclusion also seems inevitable that all the individuals, past and present, of any type, in all their varieties, must have originated from one single ancestor, the first of that type! And this first original parent-say of the vetebrates-was probably evolved from the type below by a combination of conditions that may never exist again. If any type, therefore, should become totally extinet, it would, in all probability, never be brought into existence again. Any of its varieties might die out, and be again reproduced by selection from the other varieties; but the type once gone, is gone forever.

Evolution, then, teaches us that not only have all organic forms been derived 
from pre-existing and simpler ones, but also all our social organizations, our moral impulses, and our mental powers. It teaches us, also, that all the various departments of knowledge have not only developed individually in this way; but that they have also developed communistically-if we may use the term-or conjointly, as a whole. No one science ever did or could originate and perfect itself, standing alone, but each one hangs upon every other one, and develops only as that does, so that knowledge advances as a whole by separate steps.

The whole universe, therefore, is one in every department, and the same law rules all, from the atom to the mountain, and from simple motion to thought. Everything that is, is indissolubly connected with everything else that is, and there is nothing that exists or acts alone.

It is impossible to overestimate the influence that the perception of this law of evolution will exert upon society in many ways. It will gradually change all our views and practices in regard to government, and revolutionize completely our systems of education. It will bring order out of the present chaos, and immensely aid in bringing about that further and higher development of which man is obviously capable, and to which he will finally surely attain.

It is inevitable, however, that the prospect of such a sweeping change as evolution foreshadows, should alarm those who have always considered the prevailing systems of government, education, and morals as finally established on the basis of immutable truth.

Mr. Charles Darwin, in his matchless work on The Descent of Man, thus sums up the conclusions to which his investigations have led him : "We thus learn that man is descended from a hairy-tailed quadruped, probably arboreal in its habits, and an inhabitant of the old world. This creature, if its whole structure had been examined by a naturalist, would have been classed among the quadrumana, as surely as the still more ancient progenitor of the old and new world monkeys. The quadrumana, and all the higher mammals, are probably derived from an ancient marsupial animal, and this, through a long line of diversified forms, from some amphibian-like creature, and this again from some fish-like animal. In the dim obscurity of the past we can see that the progenitor of all the vertebrata must have been an aquatic animal, provided with branchiæ, with the two sexes united in the same individual, and with the most important organs of the body (such as the brain and heart) imperfectly, or not at all developed. This animal seems to have been more like the larvæ of the existing marine Ascidians than any other known form."

From this low form it is easy to pass further, till we get to the simple moner, and from that to mere formless protoplasm, naturally produced.

The following table will still further illustrate this idea. In it the different strata or rocks, composing the crust of the earth-beginning with the lowest con. taining animal remains-are arranged in GROUPS, and a list is given of the characteristic animals found in each group.

The progress of evolution, from the simple zoophyte up to man, can thus be seen at a glance, by observing the advance from group to group, from the very lowest up to formations of the present age.

The development of the Humax Brain, in the footus, from stage to stage, in each month, is also shown, and the remarkable correspondence between it and animal evolution, from the first beginning of life to the appearance of man. 


\section{TA B L E}

Showing the Progressional Development of the human Bratn in the Fotus, as Compared with the Evolutional Development of animal life ON THE GLOBE.

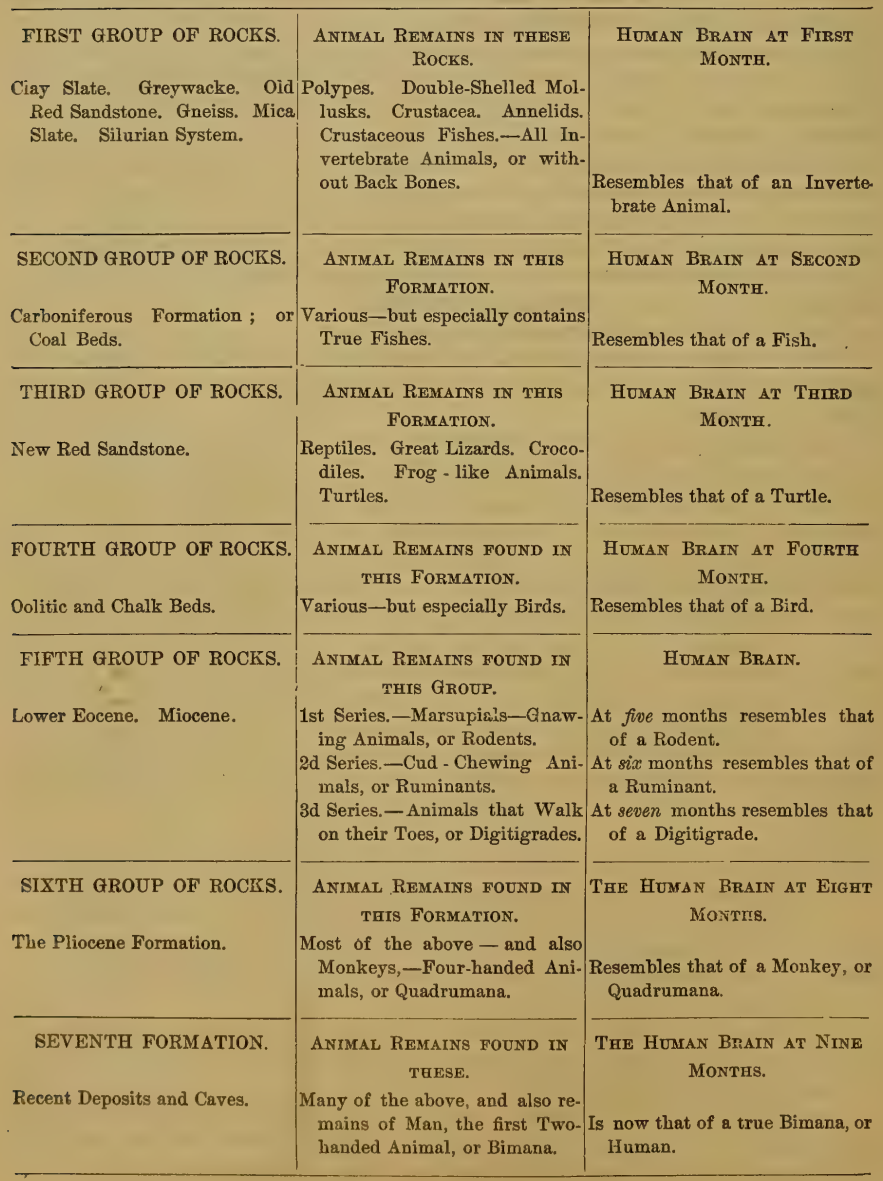


It is not intended in the above table to give a list of all the animals in each group of rocks, but merely to show how the various distinctive types succeed each other, in an ascending order, as we go upward, from the lowest groups to recent formations.

The remarkable correspondence between the development of the human foetal brain from month to month, and the evolution of animal life, will be evident at a glance.

The animal world at first was all invertebrate-so is the human brain at the first month. Later on the animal world advances to the first stage-and so does the human brain at two months. The next advance in the animal world is to the reptile stage, and at three months the human fœtal brain resembles that of a turtle. And so it goes on from group to group, and from stage to stage, the development of the human brain being a strict counterpart of the general animal evolution which has taken place upon the globe. The two are strictly analogous, and man may, in one sense, be said to be an epitome of the whole animal world.

That the world of life, animal and vegetable, has gradually grown frem the simplest beginning, or been evolved, just as man grows from the egg, is evident. We may not be able to show every link in the chain of succession, in its exact order, because our knowlege of geology is yet imperfect, and also of existing animals and plants. We know enough, however, to assure us of the general truth, and every day the different parts of the chain that are still disconnected, are being linked together by new discoveries.

\section{A CHANGE OF SPECIES.}

DEgENERATe RabBits. - In the year 1419 a few rabbits were born on a Spanish ship, and put on the island of Porto Santo. There were no beasts of prey there, and these little animals increased so enormously as to become a pest to the country, and compelled a colony to remove from it. They are still there, but in the course of 450 years they have become a "species;" they have a peculiar color, a rat-like shape, are small in size, live a nocturnal life, and are of extreme wildness. And now they refuse even to pair with the European form from which they arose. The London Quarterly Review. 



\section{PART VI.}

CLASSIFICATION OF ANTMALS, AND THEIR DIFFERENT TYPES. 



\section{CHAPTER XII.}

\section{THE VARIOUS FORMS OF LIVING BEINGS, OR TYPES.}

IT is well known that animals, like plants, vary very widely in form. They also differ quite as much in respect to simplicity or complication of structure, some having a large number of organs, for the performance of different functions, and others having but few. In all cases, however, whether the animal perform many functions or few, they all serve for three grand purposes, which are identical in all alike.

These three fundamental physiological processes, which all animals must perform, no matter how they are made, are nutrition, reproduction, and correlation, or communication with the external world.

Any animal that could not nourish itself could not develop, but must die; and if it could not reproduce others like itself, the kind must become extinct. It is equally necessary it should be able to establish certain relations with other beings, snd with surrounding objects, because all are mutually dependent, in many ways, upon each other, and upon the world in which they live.

The manner in which these three essential functions are performed, however, in different kinds of beings, is remarkably varied. In fact, this is the case with all the organic functions, but, perhaps, more especially so with those concerned in reproduction.

In the lowest kinds of organisms, where there is great simplicity of structure, nutrition, reproduction, and correlation are effected with few organs, and those of a simple type, as we have already shown. But in the more highly organized beings, we find a greater number of separate parts of the body modified, and adapted for different purposes. Commonly they are said to be more differentiated, and each part, or organ, so devoted to a special function performs that function alone, and never that of another part or organ. Thus the eye sees, the nose smells, the stomach digests, and so on. The higher the animal is in the scale of being, the greater the number of the separate organs, for special purposes; or, in other words, the being is more highly organized, or differentiated.

As we go down in the scale, we find the lower animals with fewer, and fewer separate organs, devoted to special functions. In other words, they are less differentiated. In them one organ may perform two or three functions, instead of being devoted to one alone. They must all, of course, perform the three functions of nutrition, reproduction, and correlation, but all three functions may be performed with a small number of differentiated parts, compared with the beings above them in the scale.

In the very lowest beings, in fact, there may be said to be no differentiation at all, or no special organs for the special functions. Every part of these beings can effect nutrition, reproduction, and correlation alike, so that every part is stomach, generative apparatus, or organ of correlation, being sometimes the one and sometimes the other, as in the infusoria already described, especially in the amoeba. This 
is the case with both plants and animals, and it is important to be borne in mind, in connection with subsequent explanations.

In the highest animals, especially in man, the number of differentiated parts, or special organs, is rery great. Every function is divided into many sub-functions, instead of being simple. Thus, nutrition, which in the lowest beings is only one simple process, that of direct absorption from the surrounding fluid, through every part of its structure, in man is divided into mastication, digestion, assimilation, defecation, respiration, and numerous other processes. It is the same with the other functions-in reproduction for instance, which in man requires a series of different acts, in many of the lower beings is effected simply by the parent throwing off a fragment of its own body, which grows into another being like itself. In many of them this process of simple division may be carried to almost any extent; as in the case of the hydra.

The fundamental organism from which all beings start, as stated before, is the same in all alike. At the beginning man is like every other animal, or even like every plant; he is simply a germ, a speck of organizable protoplasm. What it is that causes some of these primary germs to develop only to a certain extent, and others to develop further, we do not know. Some remain simple infusoria, while others progress to vegetables, or animals, more or less perfectly organized; and others, again, develop into human beings. What this is owing to, we have not yet learned. Whether there be innate differences in the primary germs at the start, which we have not yet detected, which decide what they shall ultimately become, or whether their future is influenced by surrounding circumstances alone, is at present undecided. Probably, in the beginning, when organic germs first originated, they were acted upon in different degrees, and in various ways, by the natural forces then so active, and carried to various degrees of development, some taking one direction, and some another. The several kinds of beings thus originated would afterward continue their kinds, each in its own way, as they do now, by modifying the germs they contain in their own organisms, in the process of reproduction.

Any animal, or plant, when placed in new circumstances will undergo change, and this' change may, by gradual stages, proceed so far as to create, in time, an entirely different being. Differentiation of parts will begin, new organs will form, as new functions are needed, and thus gradually, step by step, highly organized animals are gradually originated from the very simplest. This is called Evolution; and Darwin has shown, conclusively, that all beings, no matter how perfect or complicated they may be, can be traced back, step by step, to the mere speck of protoplasm from which all alike have sprung, from the highest to the lowest.

Every new animal, or plant, living or fossil, that is discovered, fits into the chain of being at a place where such a link was needed. There is not one that stands alone, but each is connected with one above and one below; and if in any part the chain of life is imperfect, we feel sure it is so only because the links have not yet been discovered. That they exist, or have existed, naturalists feel assured, and every day we are picking up some of the still missing ones.

Life progresses, not in one straight line, but in many different ones, all starting from the same central point, but radiating in different directions, like the spokes of a wheel.

These different lines of development form the different types of animals, or kinds, of which naturalists recognize six, and of these it will now be necessary to give "short description. 


\section{CHAPTER XIII.}

\section{THE DIFFERENT TYPES OF ANIMALS.}

1st. The Protozoa.-These are minute jelly-like organisms, of no special form, and with no differentiation of parts, except that in some there is an imperfect mouth. There is no special organ for any purpose, and every part can digest or reproduce a new being, if separated. The whole body is stomach or generative apparatus. They live mostly in the water, and are often joined together in large numbers. The Vibriones, Bacteria, Monads, Diatoms, and others, referred to before, belong to this type.

2d. The Coelenterata, formerly called Radiata.-These animals have an internal cavity, or pocket, which serves as a stomach. This, however, is not localized in a particular part, but occupies the whole interior, and communicates with every part. The substance of the body is made up of two membranes, or skins, one outside and one inside. Most of them have tentacles, or arms, and some of them have traces of a nervous system. They all have distinct organs of generation. Usually there is a proper mouth, but in no case is there an alimentary canal that traverses the whole length of the body, with a mouth at one end and an anus at the other. They reproduce their kind in different ways, either sexually, or by simple division, as in the Protozoa, on which they are a slight advance. In this type we find corals of all kinds, sea-anemones, polyps, and jelly-fishes.

3d. Annuloida. - In this type we have a complete alimentary canal, separate from the rest of the body, and extending from one end of the body to the other, with a mouth at one end and an anus at the other. There is also a distinct nervous system, and, in many, distinct parts, which act as arms, or legs.

Among animals of this type we have sea-urchins, star-fishes, sea-slugs, and some kinds of worms, which are a great advance upon those of the preceding types.

4th. Annulosa.-The animals of this type are divided into segments, or parts, arranged like the links of a chain. They have a tolerably perfect nervous system and distinct alimentary organs : most of them have regular limbs.

In this type we find leeches, lobsters, barnacles, woou-lice, crabs, spiders, centipedes, and insects. Among them we see many specialized functions and more complexity of parts. They are far in advance of the previous types.

5th. Mollusca.-In this type we find clams, oysters, and other shell-fish, periwinkles, snails, and cuttle-fish. They all have a nervous system, with a distinct alimentary apparatus, and often an imperfect heart. The cuttle-fish even has a rudimentary backbone.

All the above five types, it will be seen, are very imperfectly developed, though each - one is a slight advance on the preceding. In regard to reproduction, as will be be'ter shown farther on, they have various modes. Among the simplest the parent simply throws off a part of its body, or divides, and the separated part grows 


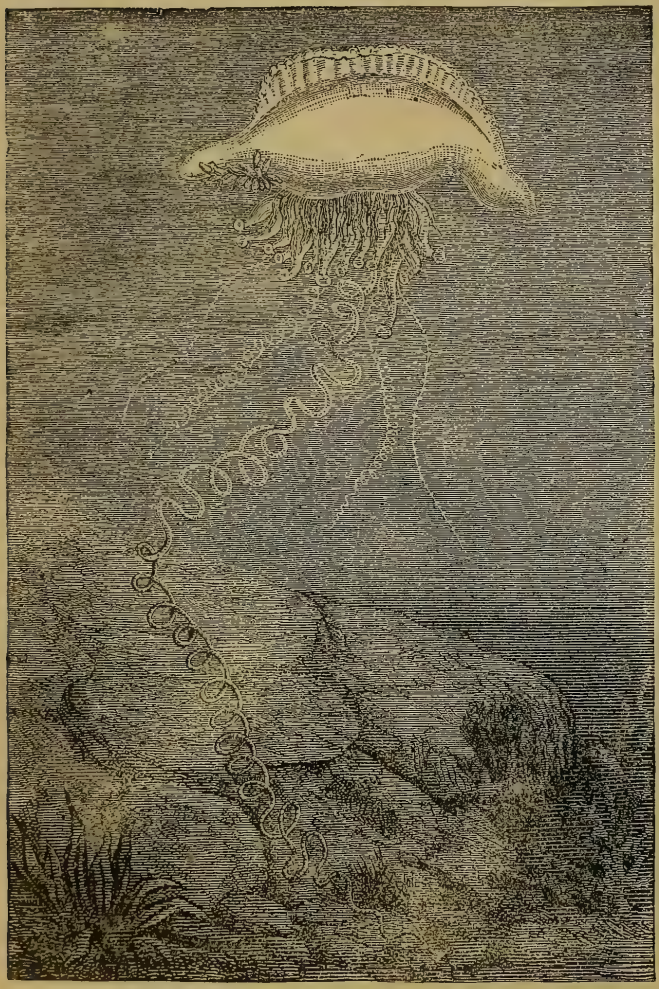

Frgore 40.-Physalia, or Portuyuese Man-of-war.

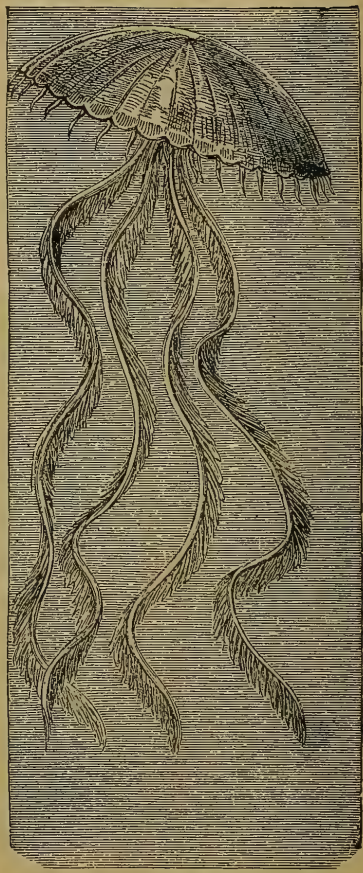

FigdRE 41.-The Chrysaora Lutea.

Different forms of Medusw, ox Jelly. fish, Type 2, Colenterata.

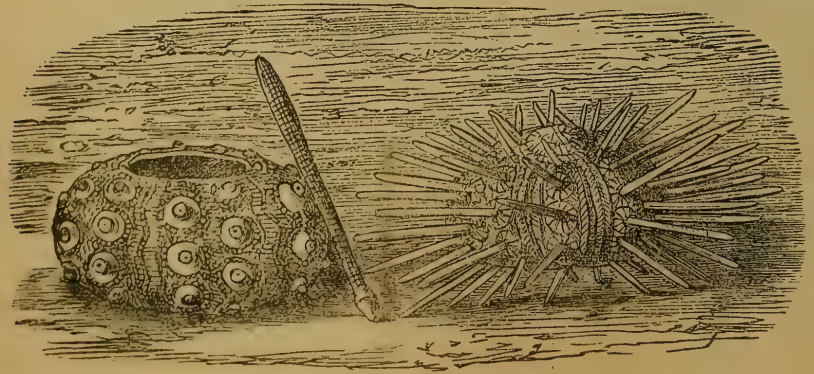

This snows the Piper Sea-urchin with its spines, and also with the spines broken off, and one spine leaning against the empty shell. To illustrate Type 3, Annuloida. 
into a similar new being; but there is no special part for the purpose. This mode runs through several types, and after the first we find also that they throw off buds, or germs, which grow into new beings, and some are even truly sexual, or male and female; but often the same being will propagate in all the various modes at once, or one individual will propagate one way, and another differently, or the whole members of a type will propagate in one way at one time, and in another way at another time. They have no fixed mode. All the preceding types are called invertebrate, that is, without a backbone, though some of them have a faint approach to one, as the cuttle-fish, for instance.

6th. Vertebrates.-Animals of this type are well known. Man stands at the head of them. They all have a distinct spine, or backbone, with four limbs, in pairs, and the body may be divided into two similar halves. In animals of this type we find the largest amount of differentiation, with the greatest number of separate organs for special purposes. They propagate strictly sexually, though in many different ways.

This summary of animal classification will enable the reader to understand the references which may be made to the different types when explaining the various modes of reproduction.

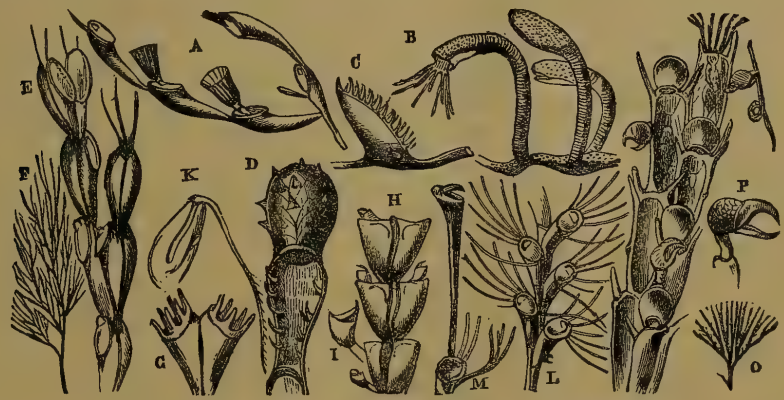

Frgure 43.-Various Forms of Polyzoa. Type 5, Molluscoida.

A the Lady's-slipper Coralline. B the Snake-head. C Beania Mirabilis. D the Spiny Farctminaria. E the Coat-of-Mail Coralline, magnified. F the same, natural size. $G$ the Dimetopia Spicata. I the Shepherd's-purse Coralline. K the Caberea Patagonica, or Saw-blade Vibracalum. I the Bicellaria Ciliata-from the thorny cilia around its mouth. M and $P$ different forms of the Bird's. hoad Coralline. 


\section{CHAPTER XIV.}

\section{PLAN OF DEVELOPMENT OF ANIMALS.}

ALL animals belonging to either of the six types are formed upon the same general plan, but some are more differentiated than the others, or, in other words, have more separate organs for the performance of a greater number of special functions. Thus, one may have a stomach, but no true mouth nor anus, while another may have one or both of these in addition to the stomach, and is then said to be more highly organized. The simplest formed of the two animals performs the function of nutrition as perfectly, for its needs, as the more perfect one, but with fewer organs. This makes the difference between the various beings of the same type.

When we study the development of animals from the primary germs, or eggs, we observe that they all begin the same, but some progress farther than others in differentiation. Some stop at one stage of development, and others at another, and each one on reaching its limit has gone through all the stages below that limit. Thus, taking the most perfectly organized being in either type, and tracing its embryonic growth, from the primary germ upward, we find that it has gone through every stage, and has been, at some period of its growth, like every one of the lower animals of its type.

This is the case with man, the most perfect of all the rertebrates. He starts the same as all the rest below him; but they stop at various inferior stages, while he passes on. Thus the human embryo, after it has passed the simpler stages, from the germ, resembles first a fish, then it becomes like one of the amphibia, and, still progressing, it next becomes a reptile, then a bird, and finally a true mammifer. Thus man may be said to be a true epitome of his type, or to comprise it wholly in himself in the course of his foetal development. We can comprehend from this how different beings have originated from those below them, by the gradual evolution of new organs for special purposes. In one sense all animals are the same. They are all, when primary germs, alike in every respect, but some derelop farther than others. Fundamentally there is no difference.

In the development of an egg, nothing is needed but a certain degree of heat, continued for a certain time; and for a seed, we need only heat and moisture. It is the same with the germ of an animal, which is meroly an egg. In the body of the mother it meets all the conditions required, and develops as the seed does in the ground. If similar conditions of warmth, moistnre, and appropriate nutrient fluirl conld be supplied, it is quite possible that a germ might develop out of the mother's body as well as in it; and it is well known that the human being is often formed in other parts of the body besides the womb. 
It is conceivable that in some former stage of the world's history, its condition was such that any germ, or speck of naturally formed protoplasm, might be developed, just as the animal embryo is in the womb. The whole world, the universal mother, was perhaps then one grand matrix, in which living beings of various types originated spontaneously. As the conditions varied, so would the degree and direction of the development be effected, and thus the resulting beings would vary. Afterward their descendants would continue to vary more and more, by the influence of surrounding circumstances, or by selection, as shown by Darwin. Such would seem to be a much more probable explanation of the first origin of life, and its diversity, than that of separate creation of each kind, just as we find it.

When once a certain type of animal is produced, the influence of heredity probably impresses a character, or constitution, upon the germs it forms, so that they have a tendency to produce the like of their parents, and for this reason each type continues its kind. There is no reason to suppose any fundamental difference in the germs of the different types, although the germ of one type never produces beings of another type, but always those of its own.

Many animals, in the process of development, go through some of the lower stages as independent beings, having no connection with the parent. Thus the egg of the dragon-fly develops, in the water, into a perfect being, utterly unlike its parent, and lives as an aquatic. But, finally, this animal crawls out of the water, throws off its skin, develops wings, and becomes a true dragon-fly. The frog likewise develops as a tadpole, and so does the newt, and breathes by gills, like a fish. In the course of time a change occurs, its tail drops off, legs appear, and it walks out upon the land, and breathes by lungs.

Insects, it is well known, go through several of these stages ; from the egg to the larva, from that to the chrysalis, and from that to the perfect insect. Some insects even propagate in their inferior stages, and originate new beings, either like themselves or like the parent, or different from either. We can readily imagine that in this way new forms of beings might originate, from one of the lower forms becoming fixed, and so remaining permanent.

The development of most metamorphic animals, in fact, is often stopped at one of the lower stages, and goes no farther. Thus, the tadpole, with insufficient light and heat, will remain a tadpole, and never develop into a frog. It is the same with many others. A lizard-like animal in Mexico, known as the Axolotl, which lives and propagates its kind as a gill or water-breathing animal, will often lose its gills, and breathe by lungs, becoming a totally different being. There is another somewhat similar animal, found in the Western States, called the Siredon lichenoides, which has gills and fins like a fish, and is perfectly aquatic. If this animal be confined under new conditions, it changes completely, losing its gills and fins, and breathing by lungs. It, in fact, becomes a different animal, and is called a salamander.

Until these remarkable changes had been carefully observed, the two animals were always described separately, and were never suspected to have any connection whatever with each other.

Possibly many other animals, which we think distinct, are thus merely different larval forms of the same being; only we have never yet seen the change take place.

The lower types pass gradually into one another, their organization being so indeterminate that they are sometimes referred to one type and sometimes to another. 
It is highly probable that they are all only stages of development from the primal germ, by which nature gradually evolves the most perfect of all. Even the highest type, the vertebrate, approximates so closely to the type below, in its most primitive forms, that the two almost merge together. It is possible, also, that other beings exist, or have existed, in which the transition could be still more certainly established. Every day new beings are being discovered, living or fossil, and each new one invariably bridges over some gap that before existed between different kinds. 


\section{PART VII.}

\section{REPRODUCTION IN PLANTS AND ANIMALS, SEXUAL AND NON-SEXUAL, INCLUDING HERMAPHRODISM.}





\section{CHAPTER XV.}

\section{REPRODUCTIOT.}

ArL living organisms, of every type, when perfect, possess the power to originate other beings similar to themselves, by the process of reproduction. The way in which this process is effected, however, varies exceedingly, being sometimes very simple, and at others very complicated. Essentially it is the same in all, but in some the generative organs are more differentiated, and there are more separate stages in the process.

The one general fundamental fact, in which all agree, is this : organisms of every type throw off from themselves some of the cells which have been evolved during their own process of development, and these cells so thrown off grow into a new being, like the parent, just as the parent grew from its primary cell.

These cells so thrown off, to produce new beings, are called germs, eggs, or seeds. In the higher beings these generative cells are not fully developed till after the parent attains its full growth, and their evolution ceases entirely at a certain age. In the lowest orders of beings, however, reproduction begins at once, and goes on without ceasing.

There is also another difference : in the lower beings, there is usually but one kind of cell concerned in the process; but in the higher beings there are always two, called the male and female, or the sperm and the ovum, which must be united together to form the new being. This is called impregnation, and it is effected in various modes, as will be shown farther on.

Although the male and female principles of generation, as we see them, are different, and each plays a part of its own in the process, still there is every reason to suppose that they are both only simple cells, but in different stages of development. In the very highest animals at times, and commonly in many of the lower, the female germ, or ovum, will develop into a new being without impregnation by the male sperm at all. This virgin generation is seen sometimes in the human being even.

There is reason to suppose that the female germ, the egg, or seed, differs from the male germ only in this, that it contains a larger amount of protoplasm, which serves as nutriment, by which the new being is enabled to effect its first development. The one germ has more substance, the other more energy, but either, under fit conditions, might develop alone.

This difference is well shown in the egg of a bird. The real germ cell, in the largest of these, is quite small, but it is surrounded by a larger mass of nutritive protoplasm, the yelk, and the albuminous white, which are all used up in forming the body of the young hird; so that when it comes out of the shell the whole substance of the 
egg has disappeared : it has been made into flesh, bones, blood, and feathers, by the action of heat and moisture.

The male sperm is not surrounded in this way by nutritive protoplasm, and is therefore small. Such material is not needed in both.

All the different modes of reproduction may be classed first under two kinds, sexual, and non-sexual, and each has many varieties. We will therefore consider each separately, beginning with the non-sexual. 


\section{CHAPTER XVI.}

\section{NON-SEXUAL REPRODUCTION.}

THE non-sexual mode is confined almost exclusively to the lower animals, and there are two varieties of it.

First. Gemmation, on BUDding.-This means the formation of gemmules, or luds, similar to what we see form on trees. These buds are produced either on the outside of the parent or in the inside. They grow into new beings like the one they sprang from, and may either remain attached to it, so as to form a colony, as in the corals, or they may separate, and each bud grow into a perfect new being.

In some cases the parent gives off a bud from one side, and this another, in the same way, and the process goes on till there is quite a family of them, all developed in one line, from the original parent. When this is a shell animal, as in the one called logena, a common shell forms over the whole colony, and incloses them.

In the common sea-mat, as it is called (flustra), the parent begins in the same way, by sending off a bud, and that another, and so on indefinitely, each one developing like the parent, and all remaining attached, so that they seem to form one being, liut each one is really an independent organism, and leads a life of its own. In such cases the gemmation may be called continuous.

In other beings, however, the buds form, and develop into new beings, like the parent, but then separate from it, and live quite independently. This form of gemmation may be called discontinuous, or disconnected.

In the animal called the Hydra, or fresh-water polyp, we see this illustrated very well. As soon as the buds have sufficiently developed, like to the parent, they are detached from it at once, and begin life on their own account. The Hydra virida, a fresh-water polyp, is easily found on the under sides of the leaves floating on ponds, and can be examined with any good lens.

We sometimes see this process of gemmation, or budding, in plants. In the lily, for instance, at the bottom of the leaf-stalks, small black buds form, which fall off, when ripe, and in the ground grow into new bulbs. Buds may also be cut from most trees, and inserted in the bark of others, of the same order, when they will grow into perfect branches. A bud, in short, is only a cell, pushed out from the parent's body, and developed as that was, into a perfect organism.

Some of the lower animals possess the power of reproducing lost parts, by a process almost identical with that of gemmiparous generation. Thus, crabs and lobsters will reproduce lost limbs; some lizards will form new tails, and some even new eyes. But this is only a process of repairing the individual, not of reproduction of a new being.

Second. Fission, or Division.-In this mode of reproduction the parent simply divides, or separates itself spontaneously into two or more parts, each of which 
grows into a new being like itself. This mode of reproduction has already been shown in the diatom and others.

We commonly practice this form of propagation with plants artificially; as when cuttings are taken, for instance, and planted, to grow into new trees. And the same can be done with some animals. In nature, the parent either divides spontaneously, or it is broken up by some external agency.

In the fresh-water polyp, or hydra, before spoken of, this is very beautifully illusirated. It propagates by buds, ordinarily, but it may be divided artificially into any number of parts, each one of which will grow into a new being, like the parent. We can take one of these beings, and cut it up to almost any extent, and so make any number of new beings, each one as perfect as the original, and each one of them may again be divided in the same way.

The following shows one of the hydras, such as are common in ponds, on the under sides of the duckweed leaves.

In some respects these beings are like the amobas. They resemble little bags of jelly, capable of protruding thread-like limbs, to take their food with, and convey it to the stomach.

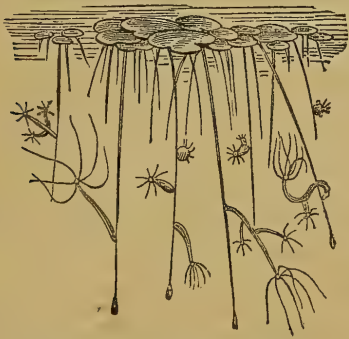

FIGURE 44.-Hydra, or Fresh-water Poiyp.

In this picture new animals are seen forming from buds all over the parent orgánism.

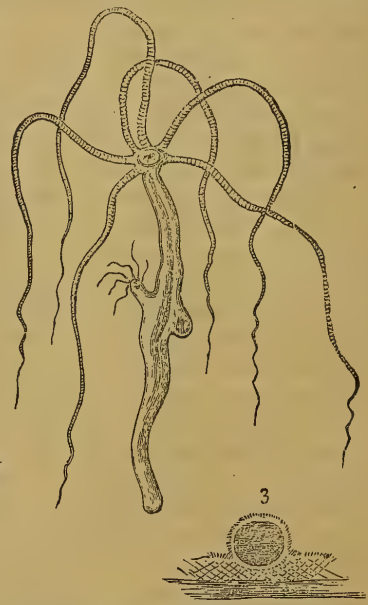

FIGURE 45.-Hydra Vulgaris.

1. Hydra magnified. 2. Natural size, attached to under surface of a weed. 3. An egg nearly ripe.

The stomach, however, is only like that of the amoba, made by folding in of the skin, and the animal may be turned inside out without suffering any inconvenience. When this is done the stomach becomes the outer skin, while the outer skin becomes the stomach, and this change may be repeated over and over again. All parts are therefore alike, and this is why it propagates so readily by fission, or simple division, as any part contains all the requisites for a new animal.

It is not a little remarkable that when one of these fissiparous animals is cut in two, each portion reproduces the identical part it needs to form a perfect being. Thus, when a hydra is cut across, the upper part immediately produces a new hind part, and the hind part a new head part. If it be cut through lengthways, it doubles up, so that the two ends meet together, forming a new head, while the two halves of the stomach combine to form a new complete one. 
Many kinds of worms may be cut into pieces, and each part will soon form a perfect new worm.

In many cases, when the young, formed from buds, are attached to the exterior of the parent's body, their stomachs communicate with the parent's stomach, and they are nourished from that. This continues even after they form limbs, and take food for themselves. It is observable, however, that if the supply of food be limited, the connection between parent and offspring is often shut off promptly, and the new animal is detached, and sent off to seek food for itself elsewhere. The connection will, however, often be maintained indefinitely, even after the offspring has begun to propagate, when the supply of food in the surrounding fluid is abundant, so that there is enough for both.

As long as the parent's stomach can nourish both easily, it continues to do so ; but when the task is too difficult, the child is got rid of.

In many cases the buds, or sporules, are loose, instead of being attached to the parent, and they are found in various parts, sometimes in the cavity of the stomach, and at other times scattered in many places not otherwise occupied. These loose buds were probably originally attached, and afterward thrown off. They closely resemble true ovæ, or eggs, excepting that they are not formed by a special organ. Not infrequently they exhibit active motion, darting about as if they were already alive, as probably they are, being most likely one-celled animals. All buds, sporules, and eggs are only animals undeveloped, but truly living, even in that undeveloped state.

Some of these sporules have a kind of hook, by which they attach themselves to surrounding objects.

Fissiparous division, when spontaneous, is usually into two parts, or some other even number-four, six, or eight, for instance. The Gonium pectorale divides into sixteen. In many cases the place of division is indicated by a slight crack, or contraction, which gradually deepens till the original body is separated into two or more parts, as already shown in the diatom. In some of the infusoria the division is effected in a very singular manner. A portion of the end of the tail is marked off by a shallow notch, which gradually deepens, making the separation constantly more complete. While this is going on, the part so marked off forms, by degrees, all the organs found in the parent, till finally it becomes perfect, and then drops off and begins life on its own account. That part which was attached to the parent always forms the head of the new animal. All the beings of this kind that now exist, therefore, or that have ever existed, may be considered as only the continuance of the tail of the first one, and this tail may therefore be said, in one sense, to have perpetual life. Among some of the Annelid worms a similar process takes place, but more extensively. When they are going to propagate, two or more rings form round the tail end, and between the first ring and the part in front there is a notch, or groove. The ring develops into a head, with eyes and feelers, like those of the parent, thus making two individuals, united together only by the skin and intestines. All the food needed by both has to be taken by the first one, so that the new-formed one lives at its expense. Still the two are quite independent as living beings, and they may often be seen struggling as if to get free.

After a certain period the body of the new-formed Annelid becomes swollen, and is found to be filled with sexual germs, either male or female, or both, but none are found in the original animal. Finally the two beings become separated, and then the body of the offspring bursts open; the sexual germs contained in it are liberated; and the two kinds, male and female, intermix, so that the eggs become 
impregnated, and develop into new Annelids, like the original, which itself does not propagate in that way.

In the case of one such animal, called the Myriana, as many as six new beings have been seen to form in this way, each one being sexual, forming eggs or sperm, or both, though the parent has neither. This is shown in the cut below.

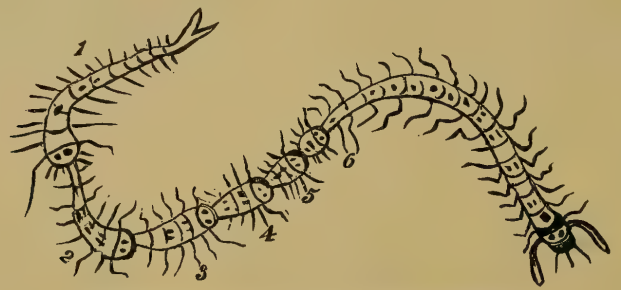

FraURe 46.-Myriana, with Six Nero Individuals.

It will be seen that No. 1 at the end is the largest, and that they go on getting less toward the head. No. 1 drops off first, then No. 2, and so on, till all are separated, each one growing as large as No. 1 before its turn comes to separate. In these cases, instead of a bit of the parent's body being separated, and growing afterward into a new being, as in the hydra and others, it remains attached to the parent till it is perfected, and then separates. This apparently strange mode of reproduction is, in reality, exactly like the formation of a child in the mother's womb. In both cases the new being is developed from one of the cells of the parent's body; but in one case the development takes place in the inside, in a womb, and in the other case outside. When developed in the womb, the cell is also specialized into a true ovum; but when developed on the outside, it may be only an ordinary cell.

The joints of the tape-worm multiply much in the same way. In each joint, excepting the small ones near the head, there is a long tube, in which the eggs are formed, at certain times, and in the walls of this are other smaller tubes, which appear to secrete a fluid, like semen, or which serves the same purpose, by fecundating the eggs. Every joint, therefore, is capable of propagating by itself, being strictly hermaphrodite.

As each egg hatches, it forms a head joint, which attaches itself to the intestines, and new joints grow out from it, one after another, like a chain, each one of which can form eggs to produce others.

The naturalist Bonnet divided a small worm of a certain species into twenty. six parts, and almost every part formed a new head and tail, and became a new individual. When sufficient time had been allowed for each of these to obtain growth, they could every one be divided in the same way.

In short, in the lower beings, where there is no differentiation of parts, every portion of the organism is alike, and any fragment of it will form a new being, no matter how it may be separated from the parent. A bud, or germ, is, however, a step toward specialization. Below is seen the mode of reproduction, by fission, of the Vorticella. 

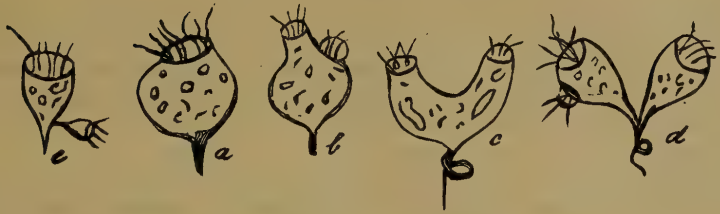

FIGURE 47.-Propagation of the Vorticelli, by division.

In this illustration the parent is seen, Fig. $a$, as one globular body, with a mouth, or what serves for one, surrounded by fringes, or threads, used as limbs. In $b$ the mouth is dividing into two. In $c$ the two mouths are quite separate, and the body also is arys partially so. In $d$ the separation is complete, and the two new beings soon become completely sundered. In one of the new bodies even, a fresh separation is already commencing. In $e$ we see a new animal being formed from a bud, instead of by fission.

In fissiparous generation, the division of the parent organism is not always in the same direction, being sometimes across, and sometimes lengthways, and at other times even oblique, in no particular di- ticella, showing the gradual develop. di- ment from the germ $a$ through $b, c$, rection. Owing to this the new-formed beings differ $d, e, f$, up to $g$.

from each other very much, and also from the original, so much so, in fact, that they appear like other kinds of beings altogether. In the vorticella, shown above, the newformed being often changes in a very curious manner, the head becoming the tail, and the tail the head. The mouth closes up, the cilia disappear, and a single tail-like appendage forms in their place, while at the other end a mouth appears with cilia round it, the same as originally belonged to the opposite extremity.

These new-formed vorticella float about free for some time, and in that state were formerly taken for different kinds of animals, and described as such. After a time, however, the tails become fixed, as a stem, and each forms a true vorticella, as seen above, ready to go through the same changes as its progenitor.

The body of the Gonium pectorale is composed of sixteen small transparent globes of jelly, of unequal size, the four larger in the middle, and all lying flat, like a plate. When propagating, it divides into four parts, all exactly alike, each one with a single large globe, and three smaller ones. Immediately the division is effected every one of the four divides into two more, making again sixteen, the same as in the original parent, and so the process goes on.

The Gonium pulvinatum, when young, is like a flat piece of thin skin, almost square, which moves about in the water with greater rapidity than might be thought possible from its form. As it grows, the surface is seen to be marked with lines, crossing at right angles, which divide it into small squares. Ultimately these lines deepen, the animal divides, and each little square becomes a new Gonium.

It is quite remarkable how regular this division is, in many of these beings. It is often strictly geometrical, and in this respect approaches to inorganic crystallization. 
Some of the hydras, it should be observed, not only propagate by division, or gemmation, but sexually also. They throw out a special ovum, or sexual germ, on the surface of the body, and if this meets with a male germ, the two unite, and form a new hydra. Ordinary germs, or buds, it will be remembered, always develop by themselves; and this shows the difference between them and a specialized sexual germ, or cell.

In some of the polyzoa, the animal can reproduce itself either by fission, by gemmation, or by a true sexual process, and also by a peculiar kind of internal budding. There is a certain band, or cord, which stretches across the parent's stomach, inside, and on which the buds form. and grow. As soon as they they are developed to a certain stage they drop off this cord, one by one, and lie loose in the stomach. The parent then dies and breaks up, and the buds are liberated into the surrounding fluid. Here they soon burst also, and further develop into young polyzoons, which have to undergo still further growth, by gemmation, before they fully resemble the parent.

These are really a peculiar kind of bud, and not eggs, or real sexual germs, which the same animal only possesses in another part of its body.

We see by these examples that, in these lower beings, almost every kind of reproduction occurs, and often every kind in the same individual, and at the same time. In the very lowest beings, where the whole organism is alike, any part may be separated in any way, and become a new being, because no change is required, only growth ; but in those which possess different organs, or specialized parts, it is different. In these, as in the vorticella, and especially the myriana, given above, the part to form the new being is separated slowly, and gradually forms into a new being, more or less perfect, before it is entirely detached from the parent. The more perfectly the animal is organized, or the more its parts are differentiated, the longer the new being has to be held by the parent, and the more perfect it must become before it is cast off, to give all the organs time to form. This principle is shown in the extreme in man, and all the higher animals.

Buds, sporules, or ordinary germs of any kind, though forming new beings, as eggs or seeds do, are yet different from these. The true egg or seed is a cell that has been specialized or differentiated, and is always produced in a special organ, called the ovarium, while buds, sporules, or ordinary germs, may spring from any part.

In true sexual beings there are in reality always two specializing sexual organs, the male testicles, to form the sperm or male cell, and the female ovarium, to form the egg, or ovum.

Many of the lower orders of plants propagate by spores or sporules, which are only single cells, separated from the parent organism. This is the case with funguses, lichens, and ferns. These plants are called cryptogamous, meaning secret generation. In the ferns the spores may be readily seen on the under side of the leaves, where they are distributed in regular rows. They are usually brownish in color. When these spores are ripe they separate, and are blown about by the wind. They will grow from any part, unlike seeds, which always have one definite point where growth begins. Spores are, in fact, only single cells, and are much like the pollen grains of regular sexual plants. They are very small, even in large plants, and are produced in immense numbers. A common puff-ball, for instance, when ripe, bursts open and emits a perfect cloud of spores.

Like seeds, spores may be kept for years, and may also be submitted to extreme 
drought, for apparently an indefinite period, and still retain their power of development. The special part of the plant producing the spores is usually called the sporocarp or sporospore, but in the mushroom it is called the hymenium!

The air is almost everywhere filled with vegetable spores, of all kinds, especially those that develop mould, which, under the microscope, is a very beautiful object, resembling often a real forest. It is well known how rapidly this will form, a single night bringing forth the most profuse growth. The ground in a damp forest, on a warm autumn morning, will frequently be found covered with moulds, or funguses, of which there were no signs the previous evening. 


\section{CHAPTER XVII.}

\section{SEXUAL REPRODUCTION.}

Is the lower animals, as we have seen, sexual reproduction is only occasional, and occurs along with the non-sexual, but in the higher animals propagation is effected in no other way, they being all sexual.

Sexual reproduction consists in the union of two distinct kinds of cells, one called the male element, and the other the female element. The male element in the animal is called the sperm, or semen, and the female element is called the ovum, or egg. The male element in a plant is called the pollen, and the female element the germ, or seed. It is from the union of these two different elements that the new being results, and, as a rule, each has no power of development without the other; but, in some cases, as before stated, the egg, or seed, will develop without uniting with the sperm, or pollen.

Usually, in animals, the two generative elements are found in different individuals-the sperm, or semen, in the male, and the egg, or ovum, in the female. This arrangement is termed diocious, meaning separate, or in two houses. This, however, is not universally the case, for sometimes the two elements are united in the same body. In plants this is generally the case.

The in lividual which thus comprises both sexes in itself is called hermaphrodite, or androgynous, in animals, and monocious in plants, meaning singly, or in one house.

In all cases, the two generative elements have to be brought together, with or without the concurrence of different individuals; and in the diocious, or separate sexes, many curious and interesting contrivances are found for effecting this, as will be shown farther on.

The first distinction, therefore, among sexually propagating beings is that between the double-sexed and the single-sexed, each of which will be described separately.

\section{HERMAPHRODISM.}

\section{The Two Sexes united in One Individual.}

Hermaphrodism, or both sexes in the one individual, prevails chiefly among the lower animals, such as the annelids, or worms, and the gasteropods. In insects, the crustaceans, many of the mollusca, and all of the vertebrates, the male and female organs are placed in different individuals, or, in other words, the sexes are separate.

There are two different kinds of hermaphrodites : one in which each individual can impregnate itself, as the holothurias, or sea-anemones, the mussels, and the oysters; and the other in which self-impregnation cannot occur. In this case two individuals always unite, each one impregnating the other, and being impregnated by it in return-a double act on the part of both. This is the case with snails, with earth-worms, and leeches. Sometimes even three, or more, individuals all act 
together, forming a chain, or circle, each impregnating the one in front, and being impregnated at the same time by the one behind.

In those beings that impregnate themselves, there are no distinct male and female organs, and no act analogous to copulation takes place. It would rather seem, in fact, as if there were only an ovarium, or germ-producing organ, which evolves the eggs, or germs; and somewhere in the neighborhood there is a part that secretes a fluid, which, being added to the germs, enables them to develop. This fluid, therefore, is analogous to the male sperm, and apparently serves just the same purpose. Still there is not always a distinct semen-forming organ, like a testicle, and this - fluid may be only a nutritive one, or a form of protoplasm, which the germs absorb as nutriment. In some beings, in fact, it is produced by a part of the same organ that forms the germs themselves; and in some others it is doubtful if there be any fecundating fluid at all, the egg probably developing of itself.

Strictly speaking, therefore, these beings, instead of being double-sexed, are either imperfectly sexual, or only of one sex, the formation of the germs in them being often, in fact, little more sexual than the formation of sporules in cryptogamous plants.

In the common mussel the eggs are contained in a kind of sac, or bag, just underneath the skin, and at the period when they are ripe a fluid is secreted by this sac itself, which flows over the eggs and impregnates them, after which they develop into little mussels, before they leave the parent inclosure, and may be seen with a lens quite readily, each one covered by its tiny shell. The mussel, therefore, brings forth its young living.

In the oyster the process is very similar, there being really but one sexual organ, which acts as both male and female, and the young are brought forth alive, like the young mussels. They are very minute when first emitted, and are called the spat. As soon as free, they attach themselves to any suitable surrounding object, and there remain and grow. In some others, as in the barnacles, the male and female organs are a little more distinct. There are real testicles, in which a true seminal fluid is formed, which is conveyed by a long tube through the whole length of the animal's body, to the place where it meets with the eggs, and then it fecundates them, and they are thrown off.

This kind of hermaphrodism is the first and simplest form of true sexuality. The two principles are to some extent differentiated, and a first step is taken toward separate and distinct male and female organs. There is no instance known in which both male and female organs, in a perfect state, and capable of sexual union, are found in the same individual; so that, strictly speaking, there are no true hermaphrodites, who can form and impregnate their own germs, by the act of copulation. In one sense, however, the beings already described are true hermaphrodites, because each individual can propagate its kind by itself, without the concurrence of any other individual. If only one were left, therefore-say one mussel-it would be able to continue the species.

In the next kind of hermaphrodites, we have distinct male and female organs; one secreting semen, and the other forming germs; - but they are so placed that they cannot co-operate, so that the individual cannot impregnate itself. Two individuals, or sometimes more, unite in the double act, being impregnated, and impregnating in return. This kind of hermaphrodite, therefore, although more perfect, as far as the sexual organs are concerned, than the kind first described, is yet less perfect in 
regard to propagation, because it cannot impregnate itself, and one indiridual would not be able to continue the species.

Among those hermaphrodites that perform this double act, there are many curious varieties. of structure and function, some of which we will describe.

In the common snail we find in each individual a true ovary, and true testicles, so that it makes both eggs and semen. It also has a curiously formed penis, a kind of tube, which can be drawn in or thrust out, like the finger of a glove. In the interior of the right side of the body there is a kind of canal, with which the ovaries are connected, and in which also lies the penis. This canal opens on the right side of the head, between the great and little horns.

When the eggs are ripe they are passed into this common canal, where they await impregnation. The animal's own testicles, however, do not communicate with this canal in such a way that their semen can be thrown into it, so that it cannot selfimpregnate. They empty only into the penis. When two individuals meet, however, each one projects its penis outward, and thrusts it into the other's sexual canal, where it emits the semen among the eggs there lying. This is done by both at once, so that each one impregnates the other, and is impregnated by it in return; or, in other words, each acts both as male and female at the same time. They often remain united in this way for a considerable period.

A similar double union occurs in earth-worms. When they lie on the ground in a dewy morning, they may be seen to be united at two places, in a way that enables each one to perform both sexual acts at the same time.

The same thing occurs in leeches, and many other beings of the same class. Eels are also hermaphrodite.

There is one species of snail, however-the Helix pomatia-which possesses a special sexual organ of a very singular character, whose real nature and uses are not known. In the common sexual canal of this animal there is a tube, or long sac, which has at its lower end a little projection which secretes a bony material that forms into a kind of long needle, called the love dart, which can be thrust out like the penis. When two of these snails meet, they push out these darts and thrust them into one another, apparentily to cause amative excitement, for after having done this, they proceed to copulate. There is, usually, quite a long period of dalliance before the dart is actually used, the two beings rubbing their bodies together, in all parts, and touching one another in various caressing ways. When this has gone on for some time, one of them suddenly projects his dart and tries to prick the other with it, but the one attacked draws quickly into his shell and avoids it, making, perhaps, a similar attack in return. This love battle often continues for a long time, till one or both are pierced; then the mimic eombat ceases, and they perform the double sexual union.

The dart is often broken off during the fight, and many observers formerly imagined it was really thrown; but this is now generally acknowledged to be an error. The dart is almost square, having four sharp ridges and a tapering point. When one is lost, or broken, another is soon formed, so that the animal is never long without one. The use of this curious instrument is probably simply to stimulate or cause excitement, so as to make the act of conjugation more perfect, and possibly more pleasurable. It is formed only in the season of copulation.

There are various other parts, more or less connected with those named, but as we do not know what part they play, it is not necessary to refer to them any more. 
It will be understood, of course, that these parts are shown as they appear whe, LBsected out of the body and displayed. It would not be possible in a picture to sow them just as they are in the snail. This will serve, however, to show how they are connected, so that their mutual action in the process of copulation can be understood.

Both the testicle and the womb are ordinarily quite small, but in the pairing season both enlarge very much, and the womb seems to fill with eggs. The penis is a very singular organ, resembling a long whip-lash, but hollow. It is shown in the

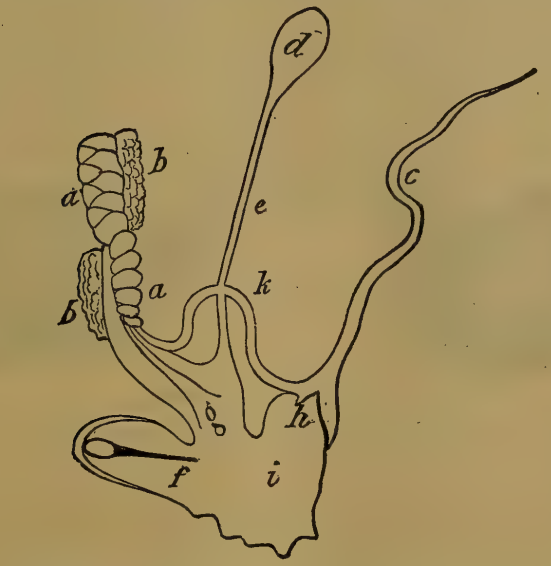

Fraure 49.-Generative Organs of the Snail called Helix Pomatia.

$a a$ are the oraries; $b b$ the testicles; $c$ the penis; $d$ the bladder; $e$ the tube leading from the bladder; $f$ the love dart; $g$ the beginning of the passage leading to the ovaries, the lower part of which may be called the vagina, and the upper part the womb; $k$ is the vas deferens, or tube which conveys the semen from the testicles $(b b)$ to the root of the penis: $h$ is the place where the semen is emitted; $i$ is the common generative cavity with which ail the parts communicate. The passage to the womb $(g)$ ends in it, and also the tube from the bladder $(e)$, and the semina] tube $(k)$ ends in it at $(h)$. It also contains the love dart $(f)$. It is supposed to be cut open and spread flat. The actual use of the part called the bladder $(d)$, and of the fluid it contains, are not known, and there are some other parts connected not here shown, because nothing is known about them, and this is intended merely to show those parts actually concerned in copulation and im. pregnation.

cut protruded, and it can be drawn in on itself, like a glove finger, till it is quite small, and easily contained in the body.

The testes, $b b$, and the womb or ovary, $a a$, which contains the eggs, it will be seen, are associated together, but with no actual connection, so that the animal's own. semen cannot impregnate its own eggs. Instead of doing so, it is conveyed by the vas deferens, $k$, to the penis, $c$, and by that is conveyed to the eggs of another snail, whose penis does the same in return. The copulating passage is the common generative cavity, $i$, which opens exteriorly on the outside of the head. The fluid secreted by the bladder, $d$, is thought to be used in covering the eggs as a kind of rarnish; but this is not sure. 
The act of copulation will now be understood. When two snails meet, and are amorously inclined, they begin a series of coquetish dalliances which may last for an hour or more, and during which their activity belies the old adage, "as slow as a snail." When this has continued long enough, they begin to use the love darts, in the way already described, and when both have been pierced by them, the real copulation begins. The two penises are thrust out, and each one inserts his into the common generative cavity of the other, till it reaches the womb by the passage $g$, and impregnates the eggs. Each one, therefore, impregnates the other, and is impreg. nated in the same way in return.

The appearance of two of these animals in the act of copulation is shown in the following cut :

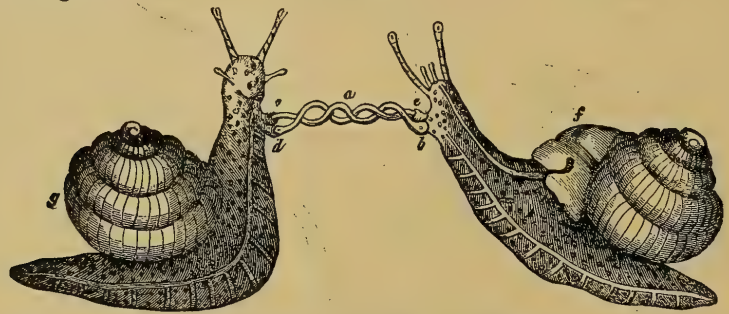

Frgure 50.-Two Snails Copulating.

The two penises, it will be seen, twist together, each leaving its own body at $d$, and entering the body of the other at $e$. The union will often continue for a long time.

It will astonish many people to learn that in snails sexual union should be so complicated, and apparently attended by so many pleasure-giving processes. It is probable, however, that even in beings still lower, the process may be equally curious and equally pleasurable.

In some snails the male organs are at one end of the body, and the female organs at the other, and that is why three or four individuals must always unite together, in order that each one may be brought into play.

In other similar beings the generative apparatus is still more curious and complicated ; so much so, in fact, that the uses of many parts of it cannot even be conjectured. Some others of them have a kind of love dart, besides the one above described, but differently situated, and whether used in the same way or not is unknown.

Snails have a great power of reproducing lost parts. If their horns be cut off, new ones will grow again ; and, in fact, if the whole head be removed a new one will be reproduced. Nevertheless, they do not propagate by either fission or budding, but by eggs, which may be found in clusters, at the proper season, on the under sides of leaves. They are, therefore, truly sexual and hermaphrodite.

Many of the water-snails are also hermaphrodite, but they have the separate male and female organs so far apart, and so situated, that two of them cannot copulate, like the Pomatia, above described. There must always be three at least, and when there is but three, it is only the middle one in which the double act is performed. One of the others can act only as male, and the other only as female, to the one 
between them. Usually, however, a number join together in such a way that each one can act both male and female with two others, and long chains or rings of them thus act together.

These snails lay eggs, also, like the others, but they develop in the water.

Hermaphrodites in the higher animals are only monstrosities, from malformation of the parts. None of them are truly hermaphrodite naturally, although at one period of its growth even the human embryo is neither male nor female, or more properly speaking, it cannot be told which it is, for there is no difference in the two sexes, as will be seen farther on.

In plants hermaphrodism is the rule, the male and female organs being in nearly all cases on the same plant, and usually on the same flower. To find them separated on the same or on different plants is the exception. But even in the hermaphrodites the male and female organs are nearly always quite separate and distinct, even where the male grows out of the female, as is the case in sume classes.

The male and female organs, and the male and female germs, in plants, correspond very nearly to those in animals, and they even have, in many cases, a similar function of copulation, without which fecundation would not occur. This, however, will be better understood farther on.

We will now proceed to speak of those beings in whom the two sexes are always in separate individuals. 



\section{PART VIII.}

DICEIOUS GENERATION.-THE TWO SEXES DIVIDED,

THE FEMALE EGG AND MALE SPERM.

CONJUNCTION OF THE SEXES.

IMPREGNATION. 



\section{CHAPTER XVIII.}

\section{THE SEXES DIVIDED, THE MALE ORGANS BEING IN ONE INDIVINUSL AND THK FEMALE IN ANOTHER.}

\section{Dicecious.}

WHEN the two sexes are placed in different individvals, the two generative principles, the sperm or semen, and the ovum or egg, are always distinct, and easily distinguished from each other. In all cases they have to be brought together, and then the semen is said to impregnate, or vivify the egg. Sometimes the two are united within the body and sometimes without, and sometimes they develop into the new being within the female body and at other times without. These differences necessitate different organs, and various subsidiary functions, which will be explained as we proceed.

First, however, it will be necessary to more fully describe the two generative principles separately, and we will commence with the ovum, called also the egg or germ.

THE OVARIUM OR OVARY, WITH THE OVUM OR EGG.

The celebrated anatomist, Haller, who was one of the first to thoroughly examine and study the generative organs practically, laid down the rule that every living thing sprang from an egg. And in one sense he was perfectly correct. Before his day, anatomists had not gone beyond the egg, as seen in birds and reptiles, and few of them had any idea that other beings, least of all man, originated also from eggs. Haller, however, demonstrated that the germ from which all animals commence, man the same as the rest, is a true egg, identical in all essential particulars with the egg of a bird, and developing in the same way, as will be fully shown farther on. At a later period, when the microscope had enabled anatomists to penetrate deeper into organized structures, they became acquainted with the cell, and found that to be the true commencement of everything living. It was then discovered that the egg is only a specialized cell, thrown off from the parent's body at a certain stage of growth, and capable, under proper conditions, of forming a new being.

This discovery went farther than was at first suspected, for it proved that all living beings originate the same; and that the minute Infusoria, equally with the mighty elephant, and man, the master of creation, all began and were afterward perfected in exactly the same way.

After the cell came the discovery of unorganized protoplasm, and its first separate mobile portions, the moners; going still deeper, and making it evident that all living things originate, primarily, not merely in an egg or cell, but in a small speck of protoplasmic jelly. All are, therefore, fundamentally the same. given.

This will be evident from the explanations of cell life and cell growth already 
When, however, we come to the higher orders of beings, especially the vertebrates, including man, it is the egg, or fully differentiated cell, with which we practically have to deal. The origin of the egg itself, from the simple cell, and that from protoplasm, may be passed by here, because fully explained eisewhere.

In all beings above the simple ones before described, generation is always effected by the union of two different principles, the egg and the semen. And these, though they differ much, as we see them, are in all probability the same thing, that is, a cell, one varied a little one way and the other in another.

In some of the simple beings already referred to, as the mussel and oyster for instance, there is probably but one kind of cell, which is able to develop by itself. In many other beings it is also common for the egg alone to form a new being; and the same thing eren occurs, as an exception, in the very highest organisms, even in man; the male semen ocsasionally being dispensed with.

Practically, however, we have in all the higher animals, and especially in man, the two distinct principles, the male semen and the female ovum, and these are always united to form a new being.

In plants, also, it must be borne in mind, the generative process is essentially the same, there being the two principles, male and female, corresponding to those of the animal, and they are united in the same way to form the new organism.

To many people it will sound strange to speak of eggs in connection with the higher animals, and especially with man. The idea of an egg is usually formed from that of a bird, though smaller ones, such as those of insects, are recognized, and they are always seen to be developed externally to the female's body, by the action of heat. It is not generally known that animals which are born alive are also developed from eggs, the same as birds, or insects, man himself not excepted.

The essential parts of the egg are the same in all cases, but when they have to be developed out of the body, as those of birds for instance, it is necessary for them to be protected by a firm covering, and provided with a large stock of nutritious material from which the body of the new being can be formed. Hence the hard shell and the great bulk of the bird's egg. But in the case of those that develop their young within the body, and bring them forth alive, the shell is not needed for protection, and the mother supplies nutriment direct from her own blood. The eggs of all such animals are therefore small, and for a long time were both undiscovered and unsuspected. Nevertheless, every vertebrate animal, to whatever class he may belong, develops from an egg formed in the body of the mother.

Those that bring forth eggs, to be hatched externally by heat, are called oviparous, or egg-bearing animals. Those that hatch the eggs within their bodies and bring them forth alive are called viviparous, or life-bearing animals.

The human female is, of course, viviparous, bringing forth her young alive, but still it is always developed from an egg, produced in a special organ in her body, called the ovary, or ovarium.

All eggs are very much alike when divested of accidental accessories, such as shells and nutritious matters, and they are all composed of similar parts, so that a description of any one explains all.

Another thing to be explained is that all females, of every kind, form eggs, and expel them from the body, whether they have intercourse with a male or not. At a certain age, called that of puberty, the human female, for instance, begins to form perfect germs, ovæ, or eggs, in the organ called the ovary, and at regular intervals. 
usually of one month, one or more of these eggs are expelled. This takes place, it must be remembered, independent of any sexual intercourse whatever. If intercourse does take place, and the egg be fecundated, it remains within the female's body and develops into a new being, but if no fecundation takes place the egg is expelled, by a natural process. The same thing takes place in the females of all other animals, each kind having its own peculiar laws as to time and manner of formation and expulsion.

In birds this process is seen, and is therefore familiar, but in the case of viviparous animals it is only by anatomical and physiological investigation that it becomes shown. Nevertheless, the laying of eggs is as regular and natural a function in the human female as in a bird, and in both it takes place just the same in those that are virgin as in those that have sexual intercourse. The ovary contains the rudiments of a large number of ovæ, more than enough, in the human being, to produce a perfect one, or more, every month, from twenty to forty years. They come forward in succession, one or more ripening each month, and being either expelled or developed, if fecundated, into new beings.

As a rule, unless the female egg receires the male semen it is abortive, comes to nothing, and is expelled, but sometimes, without receiving this, it will form into a new being more or less perfect, just as any other cell might do.

It is, therefore, necessary to be borne in mind, in reference to the reproduction of the higher animals, that the female principle, the ovum or egg, is regularly produced, like the male semen, whether there ever be sexual intercourse or not. The first production of ripe ovæ, as also that of perfect semen, is always accompanied by great bodily and mental changes, and marks a critical period of life. The production of semen in the male continues to an indefinite period, but the egg ceases to be perfected in the female usually about forty-five years of age, and this marks another critical period. These matters, however, will be more especially referred to farther on.

The egg is essentially a cell, but it is modified in structure in the ovary, and takes on certain peculiarities which will be described. All eggs of whatever kind or size, as before stated, are essentially the same in structure and component parts, so that in describing one we describe all.

It will be necessary, however, first to describe the ovary, or organ in which the egg is formed, and which also is essentially the same in all the higher animals.

\section{THE OVARY OR OVARIUM, AND THE OVUM.}

In the females of all truly sexual animals there is a special part devoted to the production of those specialized cells called ovæ, germs, or eggs. Even in the imperfect hermaphrodites there is an ovarium, though anything analogous to the male testes is doubtful.

The form of this organ, its mode of action, its appearance and location, vary much in different beings. Usually, in the higher animals, it is located in the pelvis. It is not formed at any particular period of life, but apparently exists, in a rudimentary state, in the embryo itself. It grows gradually with the rest of the system, and becomes capable of producing perfect ovæ at a certain age, in the human female at about fourteen years. In all the mammalia there are two ovaries, one on each side of the body, corresponding with the two testicles of the male, with which, in fact, at an early stage, they are identical. Formerly they were called the female testicles, 
and before their true function was known they were supposed to secrete a kind of semen, which united with that of the male, at the time of impregnation. It is now known, however, that they really produce ovæ or eggs, like those of a bird.

In the human female the ovaries are placed one in each groin, and they are both connected with the womb, as will be shown farther on. They are each about the size of an almond nut, light in color, of a soft fleshy consistence, and filled with granular matter. At the age of puberty they are seen to be studded with small vesicles or cells, both in their substance and on the surface, somewhat like pustules. These are called the Graafian vesicles; they all contain a small round kernel which is an ovum or egg, at some stage of development. Some of the vesicles are merely rudimentary, others more developed, and others again approaching maturity, but. usually one is fully ripened at each month, and is then thrown off. Generally about twenty or thirty are distinctly visible at a time. The formation of the ovae in the female ovary begins at the very earliest period, for we find them regularly produced and thrown off in young children even. But they are not fully developed till puberty. This, it will be seen, is exactly the same process that occurs in a bird, excepting that the eggs of the bird are expelled, and developed, if at all, outside of the body, while in the mammal they are retained within the body and there developed, if fecundated.

Whether the ovary starts with a certain number of rudimentary ovae, ready formed, and gradually develops them all in succession, or whether their formation goes on regularly during the laying season, we do not know. But judging from the analogy of other cell development, it would rather seem that the ovary should be considered as a simple cell at commencement, which continues to propagate itself till its powers of reproduction are exhausted, as we see in simpler organisms.

After the change of life, when the ovary has ceased to produce ovae, it changes in appearance, loses all signs of Graafian vesicles, diminishes in size, and becomes totally inert.

That portion of a plant which produces the seeds is called also the ovarium, and it acts in all essential particulars like the ovarium of an animal. Not being permanent, however, 'but only formed from season to season, it of course does not change in the same way nor present the same features.

In all cases, both eggs and seeds are regularly produced, whether the female receives any fecundating influence from the male or not. The eggs or seeds are formed just the same but remain unfruitful, if not fecundated. A female bird which has never had intercourse with a male produces eggs the same as one that has, but they cannot be hatched when unfertilized by the male sperm. And it is exactly the same with the human female. Nor is there any difference, so far as can be seen, between the egg of a virgin animal and that of one which has had intercourse with a male, until they are subject to warmth and other favorable conditions, when one will develop into the new being, and the other will not, except, occasionally, to an imperfect stage.

It is the same with all the mammalia likewise, although there are great differences, as to the frequency of the development, and in some of the minor phenomena attending it. Thus, for instance, in the lion and elephant, only one egg is ripened in two or three years, while in most horned cattle one or more are ripened every year, and in the rabbit, quite a large number are ripened several times a year. Each animal, therefore, has its appropriate period, and it is, of course, only at that particular time that it can conceive, because there can be an impregnation only when 
the egg is fully developed, and has left the ovary. If no connection occurs with the other sex at that time, or, in other words, not till after the ripened egg has left the body, there can be no conception till another period returns again. Nature, however, has so arranged, in the lower animals, that connection is desired only at that time, and then very strongly. In them the maturation of the egg, and its passage into the womb, is always attended with great irritation and inflammation of the whole generative apparatus, which causes the peculiar excitement we term sexual or amorous, and makes them desire association with the other sex. This is what is called the Rut, or Heat, or, scientifically, the Estrum, and it is well known that the males and females of the lower animals have no inclination whatever for each other, except at those times, and if connection were to occur between them at any other period, no conception could ensue, because there would be no egg ripened and ready to receive the semen. In the human being we see precisely the same phenomena, with slight variation. Thus the development of the egg in the human female is monthly, one coming to perfection, as a general rule, every twenty-eight days, and continuing to do so regularly, from puberty till the turn of life. This is why conception is not confined in our species, to any particular part of the year, as it is in many others, but can occur much more frequently. Even in the human female, however, the same as in every other, there is a time-a certain part of each month-when she cannot conceive, and that is after one ripened egg has left the womb, and before the other has reached it. This will, however, be more fully explained in the article on Conception.

The monthly ripening of the egg in the human female is attended with similar phenomena to the annual ripening in others, only slightly different in their manifestation. Thus, in the lower animals at the time of heat, we have inflammation, and strong sexual excitement, with a discharge from the parts, of a thin, almost colorless fluid, of a peculiar odor. In the human female also, at the time of the monthly ripening, they have considerable inflammation, with a copious discharge of blood and mucus, termed the menstrual or monthly flow, more fully explained in another article. The sexual desire however is not generally confined to that particular time in our species, though it is frequently much the strongest then, and is always. most readily induced.

The manner in which the egg is expelled is very curious, and when understood it explains many of the attendant phenomena. If we examine the ovary, at about three weeks previous to one of the monthly periods, none of the Graafian vesicles, or their contained ova, appear very different from the others, but, in about a week later, one of them is seen to be somewhat enlarged, and is more prominent upon the surface. This enlargement continues to be more manifest as the period is approached, till it assumes the form of a pustule, or pimple, with a prominent point in the center, indicating that it is ready to burst; and eventually it does burst, and the little egg escapes through the torn opening. This is called ovulation, or the laying of the egg, and is analogous to the expulsion of the egg from the body of the bird, but in the human being it is then passed into the womb, to remain there for a time.

The manner in which the egg is transmitted to the womb is very curious, and can be understood fully only by referring to the parts. Each of the two ovaries are connected with the womb by a short, firm cord, or ligament, down which there is a passage. Immediately above each ovary is an organ, called "The Fallopian Tube," 
which is much longer than the orarian ligament, and is in shape like a trumpet, the large end, which is loose, being close by the ovaries, while the other end is connected with the womb. The open end of this tube by the ovary, is as large as a half dime, and is divided into a number of little finger-like prolongations, called its Fimbriæ. From this wide opening a small passage extends, down the interior of the tube, into the womb, between which and the ovary a communication is thus established.

At the time when the egg is expelled from the vesicle, in the manner already explained, the open end of the tube is directed over that part of the ovary where it lies, and the finger-like ends, or Fimbriæ, cling round the egg, and pick it up. By these means, it is taken into the commencement of the tube, which then contracts behind it, and thus, by continued successive contractions, it is passed onwards till it reaches the womb.

The egg usually escapes from the ovary just about the time when the flow ceases, though occasionally not till two or three days after, and it is then from two to six days in passing down the tube. It never, therefore, reaches the womb till the flow is fully over, and most frequently it does so about the second day after, but sometimes not till the fourth or fifth day. When it reaches the womb, it is prevented from passing immediately out, by a peculiar thin membrane, or skin, called the $\mathrm{De}$ cidua, which is formed during the latter part of the flow, and which lines the whole interior cavity. As the egg passes out of the Uterine end of the tube, it pushes on this thin membrane, and makes a kind of nest or depression, in which it lies. While this membrane remains, therefore, the egg is necessarily retained in the womb, and can be impregnated; but in a certain period, varying in different persons, the membrane looses, and passes out of the body, taking the egg along with it, after which, of course, there can be no conception till another period comes round, because there is no ripe egg in the womb to be impregnated. From which it follows, as before remarked, that there is only a part of each month in which conception is possible, and that will be stated farther on, in the article on Conception. If impregnation occurs, the egg, instead of being expelled, attaches itself to the walls of the womb, and remains, $t \varepsilon$ develop into the new being, while the decidua forms one of the fotal membranes, or envelopes.

In every female, therefore, married or virgin, an egg is formed and thrown off every month, unless conception takes place, and then a new being is produced. During pregnancy and nursing, however, the ripening of the ova is usually suspended, for reasons given in the article on Menstruation; and at the change of life it ceases entirely, because all have been developed.

As a general rule, only one vesicle is ripened each month, but, occasionally, there are two or more, in which case, if all the ovæ are impregnated, there may be twins or triplets, as the case may be. Probably, also, the ovaries act alternately, generally one one month, and the other the next; but this is not always the case, for one will sometimes lie dormant for a length of time, or even be destroyed altogether, and yet the other will act perfectly regular alone. Each vesicle usually contains but one ovun, though sometimes two are seen within, and even more. Twins, therefore, or other numbers may result either from several vesicles bursting, with an ovum in each, or from one vesicle containing several ovæ. Probably, in those remarkable instances where we have four or five at a birth, both these unusual occurrences take place. In the lower animals, as many vesicles burst as they have young, unless some of the 
vesicles contain more than one ovum, which is sometimes the case, and then the number of the young is greater.

The ovaries are among the very first organs formed, the rudiments of them being found in the bodies of little girls two or three years old, and more or less distinctly eren before birth. They are also plainly distinguishable in the minutest beingsin the Infusoria for instance, though they require to be magnified thousands of times before they become visible. In many of the smaller animals, however, the ovary is larger than all the rest of the body, at particular times. The body of the Queen Bee, for instance, is much enlarged when filled with ripe eggs, and in some female ants, the ovary attains such an enormous size, that the head and trunk are almost lost sight of. The number of eggs found in the ovaries of some beings, is almost incredible. Thus in a female sturgeon there has been counted Ten Millions, and in all probability, many species form even more than this number. In most insects the depositing of the egg is the last act they perform; it is not done till they attain the perfect stage, and then, when the reproduction of their young is provided for, they die. In the more perfect beings, however, the ovulation is repeated many times.

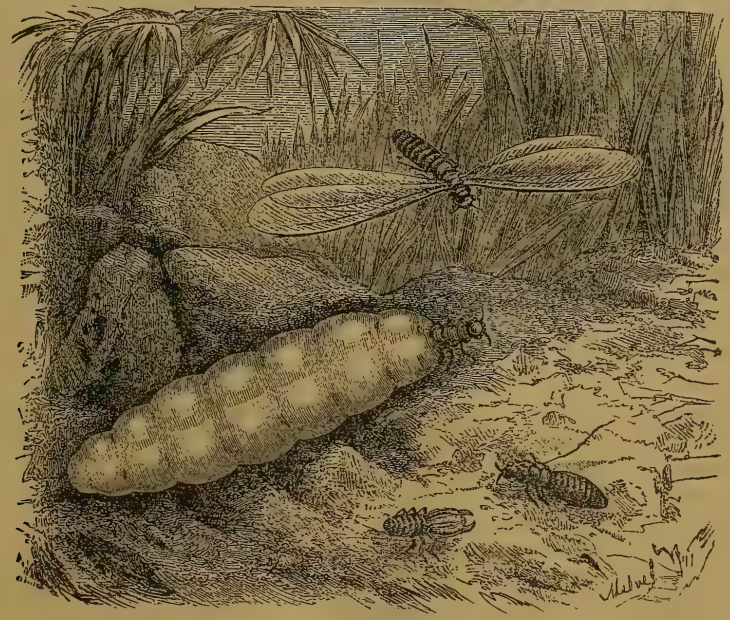

FraURE 51.-The Female Ant, when distended with Eggs, showing the enormous increase in size. The Male is shown with wings, the Soldier Ant with mandibles. The other is a common Working Ant.

The immediate cause of the expulsion of the egg from the ovary is very curious, and shows that there is a peculiar vital action in these parts which accumulates its force at periodic intervals. On examining the Graafian resicles, they are found to be surrounded by several distinct membranes, or layers, between the two inner ones of which the egg is placed, at the bottom of the resicle; the mnermost of all the membranes containing the whitish fluid, formerly mentioned. The outer membrane 
of the two inner ones is traversed by a number of minute blood-vessels, which ordi narily are barely seen, but about three weeks before each period, some of them aro seen to be much enlarged and engorged with blood. This engorgement continues to increase, till eventually some of the blood-vessels break, and the blood is thus exuded between the two membranes, and, of course, under the egg, which is lifted up by it, and as the effusion of blood continues, and the quantity increases, it is eventually forced up to the top of the vesicle, against which it presses. The white fluid is in the meantime all absorbed, and its place occupied by the effused blood, which, by its constant increase, causes the enlargement of the vesicle, and its ultimate rupture, when the egg escapes. This secretion of blood in the interior of the Graafian vesicle is precisely analogous to the secretion of the menstrual fluid in the womb, which it always precedes and probably originates.

On examining the ovary just when the egg is expelled, which is usually about the cessation of the flow, there will be found, somewhere on the surface of it, a small space much inflamed, in the center of which will be seen a minute rent, or torn place. This is the spot where the resicle has broken open and the egg escaped. Sometimes, when the dissection occurs at the proper moment, the egg may be seen between the lips of the rent, or may be found on the surface of the ovary ; it is then just large enough to be visible, and appears like a minute globe of bluish-colored starch. The vesicle itself, about the size of a small pea, may be readily opened by enlarging the rent, and will be found filled with dark-colored blood, with the walls somewhat shrunken together. Occasionally, a portion of the blood, in the form of a dark clot, passes out with the egg, and both may be found together. This may be as readily seen in any of the lower animals, about the commencement of the rut or heat, as in the human being; especially in rabbits or pigs, and better still in larger animals.

After the expulsion of the egg, the empty vesicle gradually shrinks up, by the contraction of its walls, and eventually appears like a mere scar, of a yellowish brown color. This scar is called the Corpus Luteum, or yellow body, and it was formerly thought to result only from conception. Until recently, every anatomist regarded the presence of a corpus luteum on the ovary as a proof of previous conception. It was known that they were produced by the expulsion of an egg, but it was thoughtas it is now, by many persons - that the egg was expelled only when it was impregnated, and that, consequently, the corpus luteum was a proof of conception. It is now known, however, that the eggs are formed just the same when there is no conception as when there is, and that consequently the corpus luteum is only an indication of ordinary ovulation, and is not necessarily connected with impregnation. This mistake, however, was once universal, and had its influence in medical jurisprudence. On examining the bodies of females, for instance, in connection with certain criminal trials, if any of these scars were found on the ovaries, it was at once decided that conception must have taken place, some time or other, and such testimony would have a most important bearing on the case. Suppose there should be a charge of seduction, it might be important to the defendant to prove that the female had not heen virtuous, and if medical men testified, from these signs, that she had formerly conceived, that object would be accomplisher. In fact, many such cases are on record, and, no doubt, many young women have thus had their characters unjustly aspersed, after death, and many guilty persons have escaped punishment in consequence of this error. This fact may be important for lawyers to bear in mind, as well as medical men, more especially as they will find no reference to it in the works 
on medical jurisprudence in ordinary use. Haller, the celebrated anatomist, used to dissect animals extensively, and, on asking the dealers to bring him heifers, frequently accused them of deceiving him, because he sometimes found corpora lutea upon their ovaries. No matter how strongly the men affirmed that the animal had never known the male, so firmly was he convinced of the truth of his notion that all they could say was disbelieved. In 1808, a Miss Angus died in Liverpool, under circumstances that excited suspicions against her master, and an examination of her body being deemed requisite, the ovaries were seen by many of the most celebrated anatomists in England, the greater part of whom decided that she had been a mother because a perfect corpus luteum was found. Some anatomists even now, who are not practically acquainted with these subjects, conceive that, though a scar may be formed at each month, yet, that the one formed at conception is larger and somewhat different; but this is altogether erroneous, there being no difference whatever in them, let them be formed when they may.

From what has been stated, it follows that a corpus luteum is formed every month, and it might be supposed, therefore, that there would always be just as many as the individual had had menstruations. This, however, is not the case, because they gradually fade away and disappear, so that only three or four are seen at most, and frequently only one. I have seen traces of a larger number under a microscope, however, and, possibly, in some persons, they endure longer than in others. As the turn of life is approached, they become more lasting, probably from the weakened power of the ovaries to absorb them ; and, after the change has fully taken place, the whole surface of the organ is often covered by them, and in many old persons, the ovary is one mass of wrinkles, and shrunken very much in size; in fact, it sometimes almost totally disappears. The old physiologists, who thought that a corpus luteum was formed only when a conception occurred, used to say that by counting the number of these scars, they could tell how many children a female had borne. The fallacy of this, however, will be apparent, after the above explanation, and indeed, many of the physiologists had begun to suspect it was not correct themselves, from the fact that sometimes four or five corpora lutea would be found in the ovaries of a young person of fifteen or sixteen.

In most instances the ova go on developing regularly, those on the surface coming forward first, and those in the center working their way outwards, to succeed them, till all have been ripened, and then the ovaries shrink up and waste away. But, sometimes, one or more of the vesicles and ova will either be buried so deeply, or be so very rudimentary, that they do not attain nearly their full development at the turn of life, and are, consequently, left in the ovary in an imperfect state. In such cases, if the organ remains healthy, these delayed ova may develop many years after, and may even be impregnated. This accounts for those curious instances of old females sometimes menstruating a second time, at sixty or seventy years of age, and also of some of them bearing children when very old, as I knew one at sixty-two. In such cases, there have simply been one or more of the eggs left imperfect, at the turn of life, and afterwards developed.

In some persons the ovaries are organically weak, and in others they are diseased, so that they either cannot derelop the eggs at all, or else they do so imperfectly. Such persons are always irregular in their menstrual periods, and disposed to flooding, from the debilitated state of the organs. If the ova are not formed at all, they are always barren, of course, and even if they are merely imperfect, conception is not 


\section{PLATE IV.}

OVARY OF THE HUMAN FEMALE AT DIFFERENT AGES AND PERTODS, SHOWING GRAAFIAN VESICLES AND CORPORA LUTEA.

Figure 1 is the ovary of a girl aged twenty, who died in the hospital at Rouen. The surface is smooth, reddish yellow in color, and with three cicatrices, or scars, showing where eggs have been expelled in former menstruations.

Figure 2 is the other ovary of the same girl. On this are two scars, one quite small, and the other large. (These scars each form a Corpus Luteum.)

Figure 3 is the ovary of a woman who died a few days after confinement. On this may be seen quite a large cicatrice.

Figure 4 is the ovary of a woman of thirty-two years of age. It is seen to be wrinkled all over with the scars of Corpora Lutea, showing where the eggs of former menstruations were discharged.

Figure 5 is the same ovary laid open. This shows the two last Graafian vesicles still open, though the lower one is nearly closed up. The upper of the two is the one from which the last egg was expelled. The body of the ovary is full of vesicles still undeveloped. 
athes 48
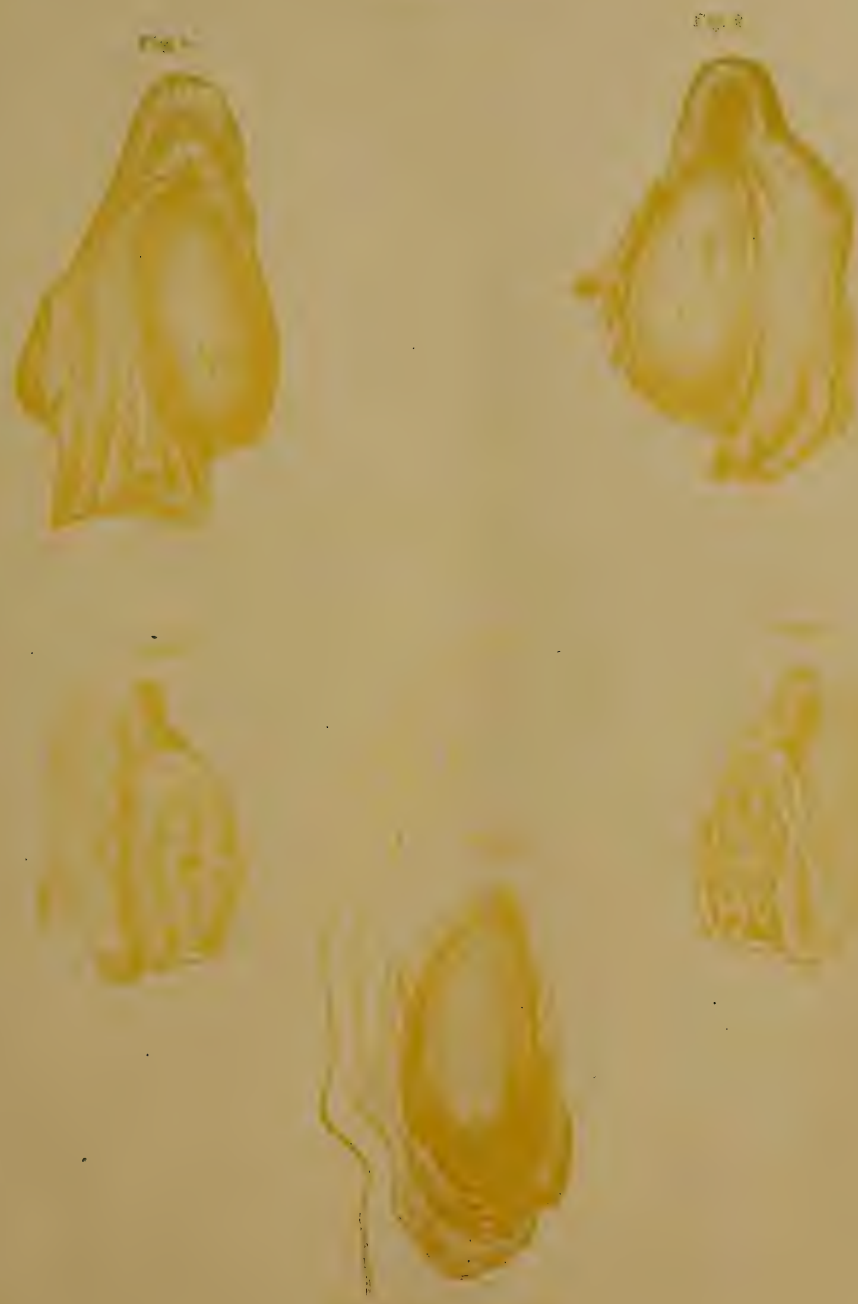

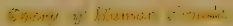



likely to occur, because the germ is deficient in vitality. It has been conjectured further, that deformity in the child also may arise from imperfect ova, there being merely vital force enough to allow of impregnation taking place, but not sufficient to insure a perfect development afterwards. I once had a patient who had borne five children, all deformed or imperfect, as I surmised, from diseased and weakened ovaries, who had two others subsequently, quite perfect, after proper means bad been used to stimulate and strengthen those organs, and to regulate their action. Those who have ever observed what imperfect plants are usually produced from diseased and imperfect seed, will readily understand the philosophy of this, and will see the necessity of a healthy condition of the ovaries, to insure both conception and perfect offspring.

It must not be supposed, however, that the state of the ora alone influences the quality of the offspring, or affects the liability to conception, it being equally important that the male organs, and the male principle, too, should be perfect, as will be shown farther on.

The ripening of the egg in the ovary is, in many respects, analogous to the ripening of a fruit upon a tree. It remains in the vesicle till it has attained a certain size, and exhausted all the nutriment provided, and then leaves it, or is cast off, like a foreign body. This is the reason why eggs cannot be impregnated if they are taken from the ovary, because they are not perfect till they leave it spontaneously, but when found in the uterus and Fallopian tubes, they may be impregnated.

Although, as before explained, neither the female egg nor the male semen can develop into a new human being alone, yet, under certain peculiar circumstances, the egg will occasionally develop into a partial and imperfect likeness of a child itself, without any impregnation. What the conditions are upon which this unusual power depends, are unknown, but such occurrences have, undoubtedly, been observed. Possibly, the power of the ovary may be much exalted during a state of inflammation, as the power of other organs frequently is. Thus, for instance, in many cases of inflamed eyes, the power of vision is so preternaturally increased that the patient can see in the dark, or, rather, in what is darkness to healthy eyes. In what is commonly termed darkness there are always some few rays of light, and the diseased eye can see with those few, though it is blinded by a full light. In the same manner, though the healthy ovary can only develop the germ into the ovum or egg, yet, when inflamed, it may be capable of partially developing it into an organized being. The celebrated Hufeland gives us a remarkable instance of this kind, in which there was found in a girl of thirteen years, the rudiments of an imperfect fœtus very distinct, contained in a sac in one of the ovaries, which was diseased. Some few such cases I have also noticed myself, and it is not at all unusual, under such circumstances, to find detached bones, hair, teeth, and single limbs, as if the ovary had not power enough to organize them together, though it could originate them individually. These occur in undoubted virgins - even in children, and the fact is both interesting and important. There are many circumstances under which such diseased growths might be found, that would seriously affect the individual's reputation, and originate most unjust suspicions.

This shows one use of sexual excitement. It is true that this peculiar sensation is not necessary, neither to the formation of the ova, nor to conception, but it is also equally true that it may often conduce to both. There is no question but what amative enjoyment stimulates the ovaries very much, and in many cold and torpid systems, 


\section{PLATE V.}

EXPULSION OF THE EGG FROM THE GRAAFIAN VESICLE, AND FORMATION OF THE CORPUS LUTEUM.

In Figure 1 the ovum, about the size of a pin's head, is seen at the bottom of the Graafian vesicle, which is filled with the white fluid.

In Figure 2 a little blood has formed underneath it, raising it up.

Figures $3,4,5,6,7$, the blood is seen to increase, raising the egg still higher, and displacing the white fluid.

In Figure 8 the whole vesicle is filled with blood, and the egg is forced up against the membrane at the top.

In Figure 9 the vesicle is shown full size, and burst open, the egg just escaping through the opening, as fully explained farther back.

Figure 10 shows the cell after the egg has been expelled, full of dark blood.

Figures 11 and 12 show the blood beginning to be absorbed.

In Figures 13, 14, 15, 16, the blood is still less, and the inner membrane is corragating, so as to fill up.

In Figure 17 the blood is nearly all gone, and the corrugated inner membrane has taken its place.

In Figure 18 the old membrane fills the cavity, and is become yellow, forming a true Corpus Luteum, or yellow scar.

This Plate shows very clearly how the egg is expelled, and how the Corpus Luteum takes the place of the Graafian vesicle. This is what occurs in the human female each month. 


\section{PLATE V.}
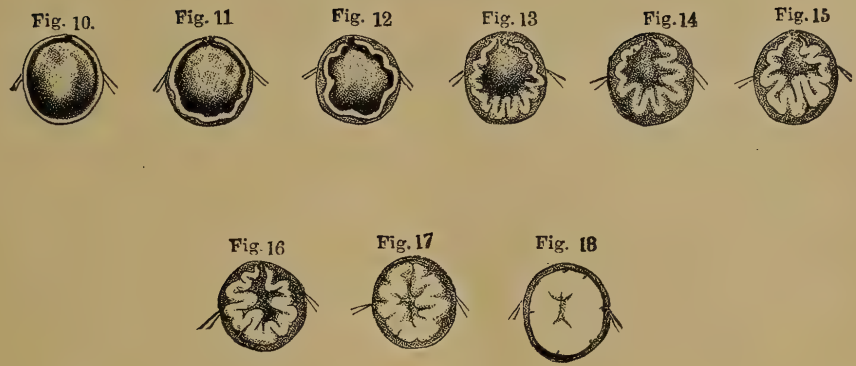

Fig. 9.
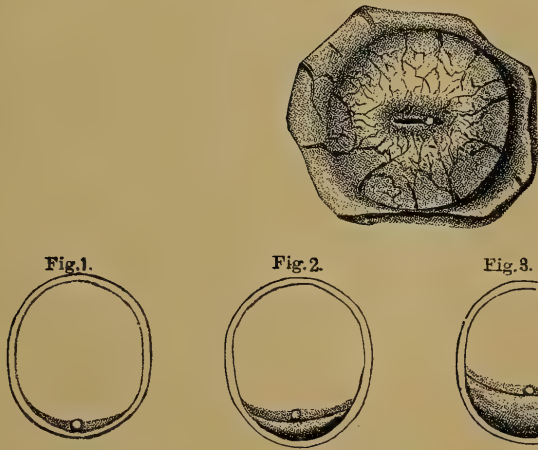

Fig. 3.

Fig.4.

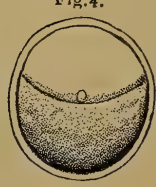

Fig.5.
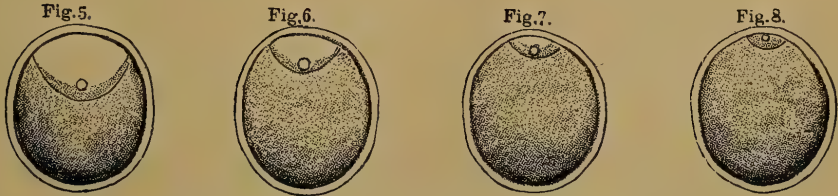

Expulsion of Ovum, and Formation of the Corpus Luiesin. 

nothing else succeeds so well in doing so, which is the reason why marriage is often recommended for young females who are irregular or deficient. On the other hand there are others whose ardor it is necessary to moderate, because their over-indulgence excites the ovaries too much, and they form the ova too frequently. I have often found that producing the sexual feeling in females who had their periods too seldom, and who were cold in their temperaments, led immediately to a more frequent and regular menstruation, although medical treatment had utterly failed in doing so. In like manner I have known conception to result from the same change, after every other means had been resorted to in vain. Blumenbach gives us a singular confirmation of this principle, for he tells us that he has seen some kinds of birds practice a species of masturbation, or excite themselves with their bills, and that immediately afterward they always laid an egg, even though there was only a half-formed one in the body to be expelled.

The condition in which animals live has a great influence over the action of the ovaries, so as to completely change it in many respects. Thus, for instance, the wild turkey lays but one lot of eggs in a year, and probably most other species of fowls do the same in a state of nature, but when domesticated, regularly and well fed, and sheltered, they will lay many more; sometimes even they will continue to do so almost constantly. This is owing to the influence of rich and plentiful food, with the absence of privation and exposure, which allows more nutriment, and more vital power to be expended upon the ovaries. It is probable that all cattle, when wild, have their cestrum, or heat, at some particular season of the year, but whenever they are domesticated, it occurs in them irregularly and usually more frequently.

Among human beings, however, the manners and customs of society have more influence, perhaps, than any other causes, because the sexual instinct in them can be awakened and exalted through the medium of the imagination, and because the action of the ovaries is so frequent as to keep the whole system more or less constantly under their influence. In the human being Love is a compound feeling, embracing a variety of propensities and desires, domestic and social, besides the animal propensity, so that it is awakened in very many different ways, while in the animal it is ealled forth only by one impulse. In the article on Menstruation the effects of social conditions are made apparent; and the early amative manifestations of young persons, in all places, when their intercourse is unrestricted, also affords abundant proof of the same.

'Too high feeding often impairs the generative power, by unnaturally stimulating the formation of fat, owing to which the functions of the ovaries, in common with those of many other organs, are then in a great measure suspended, because all vital power is concentrated on the one absorbing process of Nutrition. On the other hand, a meager and poor diet is also apt to impair the vigor of the sexual organs, or if it does not do so, the other organs suffer, because there is not nutrition enough to maintain them all in full action. In the human being, however, as already remarked, there are so many other causes operating upon the sexual system, that the physical condition is not of such paramount importance as it is in the lower animals. Thus we often see whole classes of people, who live in the most wretched manner, and are half starved, who, nevertheless, are remarkably prolific, and much disposed to amative indulgence. In all these cases, however, it will be found that the intercourse of the sexes is entirely unrestrained, there being no considerations of prudence, no calculation of means or consequences, but a perfect abandonment to the mere 


\section{PLATE VI.}

OVARY AND GRAAFLAN VESICLE OF A RABBIT, AT VARIOUS STAGES.

Figure 1 shows a Graafian vesicle from a rabbit, in its primitive state, before ita orolution begins.

Figure 2, it is grown larger.

Figure 3 begins to show the blood-ressels.

In Figure 4 the blood-vessels are very apparent, and the black dot in the center shows where it will open.

In Figure 5 the same change is still further advanced.

In Figure 6 the egg is just escaping.

Figure 7 shows the empty vesicle after the egg has escaped.

Figure 8 shows the blood-ressels and the cavity gradually fading out.

In Figure 9 they are still more faint.

In Figure 10 it has dwindled much in size.

In sigure 11 it is still more indistinct, and in

Figure 12 it has become very small, and yellow in color-a true Corpus Luteum.

Figure 13 shows the vitellus, or yellow of a rabbit's egg, with the germinal vesicle in the midst of it.

Figure 14 shows the same fully developed and burst open, so that the granules end the germinal resicle are escaping,

Figure 15 shows the ovary of a rabbit, with the Graafian vesicles on the surface in various stages of development, but none quite ripe. 
PLATE VI.

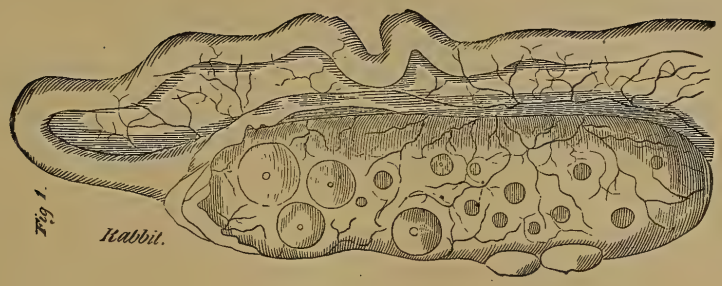

Fig. 14

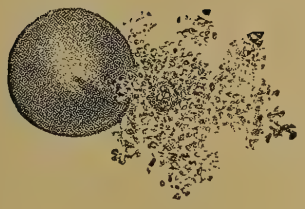

vig. 13
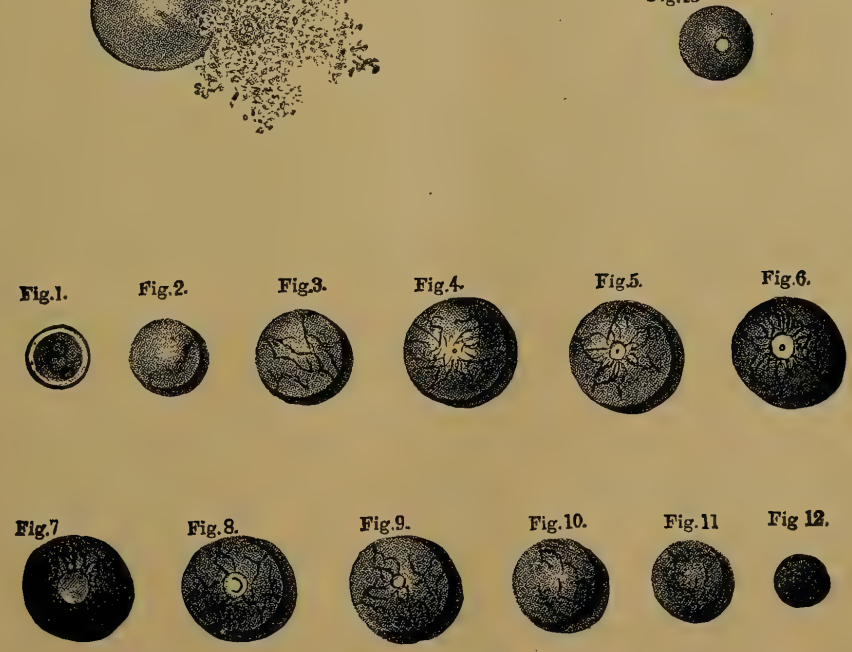

Ovulation of Rabbit. 

sexual impulse. Consequently, marriages occur early, and there is no motive whatever for restraint afterwards. In these people, however, the virile power does not endure so long as in those who are better circumstanced, and its exercise being one of the few indulgences left them, they are apt to abuse it.

At the present time, we know of many means by which the power of the ovaries can be either increased or decreased, as may be most advisable, and by which also the egg itself can be made more perfect.

The yellow part, or vitellus, is composed of little round vesicles or grains, which are hollow, and filled with still smaller bodies, called granules. The membrane which covers each vesicle is also granulated, and thus we have first the round egg itself, made up of little round vesicles, and each of these made up again of still smaller bodies or granules, while the covering of each vesicle is also granulated like the interior. There is, in fact, a succession of vesicles, or spheres, one set included within another, as far as we can observe.

The germinal vesicle, which is larger than the vitelline vesicles, among which it is placed, is also composed of granules, and is covered with a granulated membrane, the granules in the center of it being much condensed, or crushed together, so as to be opaque, and thus form the germinal dot.

The vitellus, or yellow, is the material from which the new being is first formed, and it is found in the egg of the virgin precisely the same as in that of a married person. In fact, the perfect formation of the vitellus constitutes the ripening of the ovum, which escapes from the ovary immediately that is formed. Many singular and interesting changes take place in this substance, after the egg enters the tube, some of which throw great light on the manner of the first commencement of the new being. On examining the vitelline vesicles immediately on the escape of the ovum from the ovary, the inclosed granules are seen to be in rapid motion, round a number of different centers, and this motion continues till the primary arrangement of the vesicles is entirely broken up. They then re-arrange themselves in a different order, and begin to form the principal vital organs of the new being. This, however, will be more fully explained farther on.

Another remarkable change which takes place soon after the egg enters the tube, is the escape of the germinal vesicle. This is first placed, as before remarked, in the center of the yellow vitellus, where it is readily distinguished by its greenish color, and by the darker dot in the center. Just at the time when the egg escapes, however, the germinal vesicle mounts to the upper part of the vitellus, the membrane surrounding which then tears open and allows it to pass out. This leaves an open passage into the interior of the ovum, which, it will be seen farther on, is essential to impregnation. The germinal vesicle always escapes in this way immediately, so that we can never find it in the egg except at the moment when that is leaving the ovary ; after that event we merely discover the rent through which it passed. This is the reason why many microscopical observers never found the germinal vesicle, because they only examined ova taken from the tubes, or uterus, and from all those it had, of course, escaped. The reader will see, from this, what a singular analogy there is between this event and the ovarian expulsion of the ovum. As soon as the vitellus is fully formed the egg is expelled from the Graafian vesicle, and immediately afterwards the germinal vesicle is expelled from the vitellus in a similar way.

The yellow vesicles forming the vitellus are disposed so closely that they press 


\section{PLATE VII.}

OVARY OF A TROUT, WITH THE GRAAFIAN VESICLES IN VARIOUS STAGES ON DEVELOPMENT.

In Figure 1 the vesicles are seen in various stages of development.

In Figure $1 a$ they are cut open to show the interior; some of them are dried up into Corpora Lutea.

In Figure 2 they are more advanced, and the eggs are just escaping.

In Figure $2 a$ the same are shown cut open; some of the cells from which the eggs have just escaped being filled with blood, while one is dried up into a Corpus Liteum.

Figure 3 shows the ruptured ripe vesicles, after the eggs have been expelled; with many smaller ones at different stages of growth.

Figure $3 a$ shows two cells cut open, from which the eggs have not long been expelled. They are still filled with clotted blood, and the internal membrane is beginning to wrinkle up. 
PLATE VI.

Fig. 1. $a$

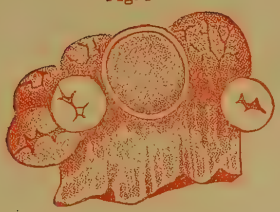

Eig. 1.

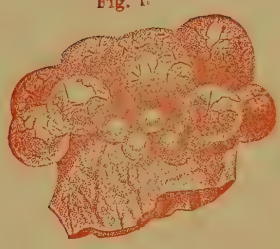

Fig. 2.

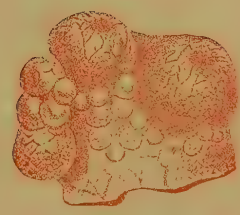

Fig. 3.

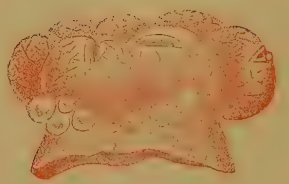

Quary ofं Tr Truti 

upon one another, which makes them not round, but many-sided, like the cells in a honey-comb. In the spaces between the larger vesicles smaller are seen, so that the whole substance is very dense. This may be seen very perfectly in the yelk of a bird's egg, when boiled hard and broken across. The vesicles, like small round grains, can be readily distinguished with an ordinary lens.

Sometimes one or more of the vesicles will burst while we are examining them, and the contained granules will flow out. In such cases they always pass in a steady current, and it takes some ten minutes or more before the vesicle is completely emptied.

To discover all these curious formations and changes requires, of course, numer. ous and careful observations, with the most perfect instruments, which is the reason why they have not been made before. They are, however, of the greatest value, and until we were acquainted with them, many of the most important generative processes could not be explained.

It was formerly thought that the Graafian vesicles themselves were the ovæ, but Baer, in 182\%, discovered the real ovum in the protoplasmic albumen of a vesicle which he was examining with the microscope. As before stated, it is very minute, being in the human being not more than the two-hundredth part of an inch in diameter. Nevertheless, this small body contains similar parts to those found in the egg of a bird, and resembles it in every essential particular.

The vitellus or yelk, which is the larger part of the egg, is covered by a kind of skin, called the germinal membrane, in the midst of which is placed a small round body, called the germinal vesicle, and in this is seen a still smaller body, called the germinal dot, appar. ently the real starting-point of the new being. This germinal vesicle is very minute, a good microscope being required for its detection. It is sometimes called the vessel of Purkinge, after its discoverer. The germinal spot is, of course, still smaller. And yet, minute though it be, every human begins with just such a speck. Illustrations showing these particulars in the structure of the egg will be given farther on.

In those animals that bring forth their young alive, these parts comprise the whole ovum, but in those that expel the eggs from the body, to be developed outside, as in birds, a shell, with a lining membrane, is superanded for their protection, but this is no part of the real egg.

The outer covering of the egg, or shell, is variable, being sometimes formed of lime, as in the bird, while at others it is tough or leathery, as in snakes, whose eggs are joined together in bunches, like grapes. In some cases the covering is hard and horny, as in the shark's egg. The shape is usually round or oval, though oceasionally it is different. 'The shark's egg is a common object on the sea-shore, and may often be found with the young shark in

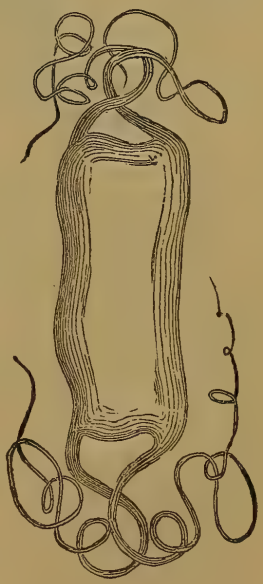

FTGURE 52.-Shark's Egg. it. The eggs of some of the lower animals, in the sea, are strung together like ropes

The following plates will show the structure of a bird's egg, and of a human egg, so that their real identity can be seen. 
It is in the germinal dot that the development of the new bird begins. The germinal vesicle, and its germinal dot, are parts of the egg, and do not result from

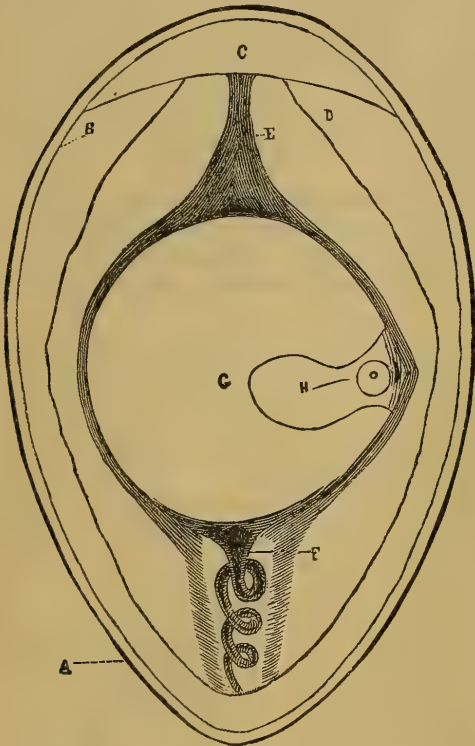

Figure 53.-Diagrammatic Section of a Bird's Egg.

$A$ is the shell. B. The nembrane lining the shell. c. The space filled with air, made by the shell membrane splitting in two and separating. $D$ is one of the thin membranes of the white or albumen. $E$ is the denser white next the yelk. F shows this dense white twisted like a rope. This part is called chalaise. $G$ is the round yelk, in the center of the white, which fills all the space between it and the sheli. At $\mathrm{E}$ is seen the germinal vesicle, with the germinal dot. impregnation. They are found in all eggs, whether the female has ever had intercourse with the male or not. Many people erroneously suppose that the germinal vesicle is the male sperm. but that is a mistake.

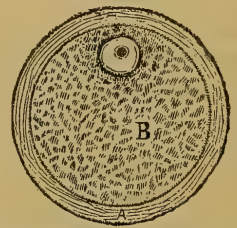

FiguRe 54.-Ovum of the Human Female, to show its correspondence with that of the bird. The membranes are the same, but there is no shell. B is the vitellus or yelk, in which is seen the germinal vesicle, and germinal dot.

The strict correspondence between the bird's egg and that of the human being, will be evident from a comparison of the two, as shown in the pictures of both in this article. The eggs of a bird, however, are found in a mass, like a bunch of grapes, and not separately in the ovary, as in the liuman being. When first formed, they are without a shell, that being gradually added to them during their passage from the body. Frequently, from fright, or injury, the bird will expel an egg prematurely, covered only by the membrane, without any shell, and they may be always seen in that state in the body, in various stages of development. In many reptiles the eggs have no shell, only a thick, tough membrane.

The real essential part of the egg, from which the new being starts, is the germinal vesicle and dot; the yelk, or vitellus, is needed only as nutriment during the first stages of its development. The white is often absent, and the shell is needed only for protection.

The number of eggs in the human ovum is said, by some observers, to be thirty thousand or more. In some animals there are many millions. As before stated, the eggs are formed and expelled in female children, even, though they are not perfcet till puberty. From this fact it will be seen how early sex affects woman. 
Before being fecundated, the egg is called an ovule or ovulum, and when fecundated, an ovum.

The removal of the ovaries in women-called spaying in animals-produces effects in them analogous to castration in men. Those who are so mutilated have none of that roundness of form usually characteristic of women; the breasts do not grow, the voice is masculine, they do not menstruate, and seldom have any venereal desire. They are made in fact more like men, as castrated men are made more like women. They also change in disposition, character, and habits, inclining more to the mascle line nature in every way.

Cows are sometimes spayed, to make them continue to give milk constantly, instead of breeding; and the females of other animals are often so treated to make them fatten quicker. To merely prevent breeding the Fallopian tube is often tied, which merely prevents the semen reaching the egg, or the egg the womb. Male fowls are castrated, or made into capons, so that they may fatten quicker.

In the East, in ancient times, young girls were often castrated, with the idea of keeping them always young, by preventing them becoming mothers. This practice was followed by the kings of Lydia, and especially by King Gyges, as we learn from Hesychius and others. Doctor Robert assures us that the practice is still pursued in some parts of India, and that he had seen and examined some of these females, who formed a caste by themselves. They told him they had no recollection when they were mutilated, nor exactly what had been done to them.

Occasionally, from disease, and for other reasons, removal of the ovaries has been effected by the surgeon's knife, and when done in early life the effects noted above have always followed.

The celebrated surgeon, Percival Pott, removed the ovaries from a young girl, and noticed that she afterwards lost all her bosom, and changed in other ways to a remarkable extent.

In some such cases a beard has even appeared.

There is a curious book to be found in some European libraries, written in Latin, entitled "Joannis Wieri opera Omnia," in which may be found a full account of a pork-butcher, whe removed the ovaries of his young daughter, to cure her of being too amorous. The operation, it is said by Wieri, was successful every way.

The removal of the ovaries is often necessary when they are diseased, but is then a serious operation, and very often apt to be fatal.

The spermatic granules in the male semen are called, by some physiologists, the male ovæ, or eggs, and they certainly are as truly such as the ovæ of the female, but in the male they produce the spermatic animalcules, as will be shown farther on. This shows that male and female are fundamentally the same, or have the same parts developed in different ways.

M. Coste directs attention to the interesting fact, that a woman pregnant with a female child, really carries in her body three generations of human beings besides herself. There is the generation represented by her own ovaries. There is her child -and in that female child are the rudimentary ovæ from which its future children may be developed.

This may serve to show how far the injurious consequences of any mental, moral, or bodily derangement in a pregnant woman may extend.

Although, as before stated, the eggs are formed regularly when there is no intercourse with the male, the same as if there had been, still there seems no doubt that 
sexual intercourse often hastens their formation, and probably makes it more perfect Evon sexual excitement alone has its effect on the ovary, and will often even cause a partial and imperfect development of an egg !

M. Pouchet gives several instances of this virgin conception! Sometimes he found little sacs, or pockets, in the womb or ovary, which contained hairs, bones, teeth, membranes, and fibers. The excitement was apparently sufficient to commenct development, but could not continue and perfect it. In such cases the formations are always irregular and imperfect, but in one case a tolerably well-formed jaw was seen, containing teeth. Hufeland tells us that he once dissected a woman thirty years old, who had long been addicted to masturbation, but who had never associated with men. He found in the left ovary a kind of sac, eight inches long by fire wide, containing a quantity of hair, bones, and cartilage, with a fragment of a jaw, containing rudimentary teeth, like those of a young child.

These cases of partial and incomplete development of the egg, probably all resulted merely from sexual excitement alone, without any concurrence of male semen, and it is possible that many diseases of the ovaries in unmarried females originate in the same way; especially when they are strongly amative.

In many insects there is found, in connection with the ovary, a curious instrument, called the ovipositor, a kind of flexible needle, with a strong sharp point. This is

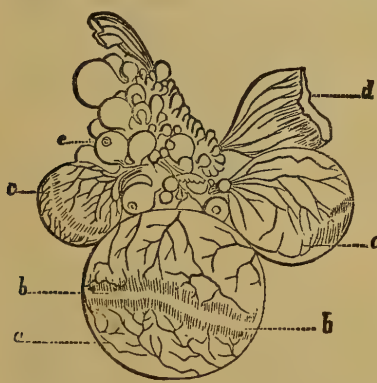

FiguRe 55.-Ovary of the common Forol.

These sacs, or bags, are the Graafian vesicles, like those in the human ovary. When the egg in one of these vesicles is ripe the sac bursts open, and the egg is discharged, just as in the human female. At $d$, one of them is seen burst open, hav. ing parted with its egg; the other letters show Graafian vesicles at various stages.

'organs of all the other bees remain undeveloped, not being needed.

used to bore holes in the ground, or in the bark of trees, or other bodies, in which the eggs are placed to undergo their development. Many insects do much mischief by stinging trees in this way. The gall-nuts, seen on the oak, result from a puncture by the ovipositor of an insect, and each one of these balls, when fresh made, contains one or more eggs.

The ovaries are double in nearly all insects, and are composed of a variable number of separate tubes, in some cases as many as thirty to a hundred or more, in each ovary. The number of eggs an insect will produce depends upon the way in which these tubes are divided; some will lay two, four, six, or eight eggs, others sixty or seventy, and others again several thousands. Some of the ants produce so many that the number is actually incalculable. In beings of this kind, as in the hive-bee, for instance, every generation is produced by one female only, who lays all the eggs. No other female is produced, unless she should die, and the sexual

In some insects and crustaceans there is also a remarkable apparatus, called the spermatheca, in which the male semen is deposited and kept for use as wanted. This is especially the case with those insects that take a long time to place their eggs, with the ovipositor, each one of them as laid having to pass by the spermatheca to be fertilized. In the hive-bee the spermatheca retains the semen so perfectly that one connection with the male will impregnate all the eggs the female lays in two years, -some twenty or thirty thousand. 
In spiders there are two ovaries or egg bags, one on each side of the body, quite separated from each other, and each having an opening of its own on the outside of the body. They are so totally disconnected that the eggs in one bag may be fecundated and discharged while those of the other are unaffected.

Audebert tells us that some spiders are made fertile for two years, by one association with a male.

The eggs of birds are formed like a bunch of grapes, as before stated, and develop in succession. As they become ripe they are detached from the ovary, and enter the cloaca, or passage common to the dung and urine. It is during their passage from the ovary that they acquire the shell and its membrane.

Although there are two ovaries in birds, the eggs are nearly always produced from the left one alone, the right being only rudimentary, or wasted away.

We will now give some beautiful illustrations of the ovaries, with the Graafian vesicles and ovum, in various stages of development. These are taken from that splendid work of M. Pouchet, "L'Ovulation spontanée." They portray the ovary of the human female, and also that of the rabbit. The process is exactly the same in both, and as in the rabbit the parts are larger, and more ova are developed at a time, the illustration is more instructive. In the rabbit, also, they ean be taken at any known period, which cannot of course be done with the human female.

By studying these plates, in connection with the explanations already given, the whole process of the formation and expulsion of the egg, in the human female as well as in other animals, will be readily understood.

\section{THE TESTICLES AND THE SEMEN.}

The most essential organs in the male system are two glandular bodies, called the testes or testicles, which are placed, after birth, outside of the body in an external envelope, called the scrotum, hanging from the pubic bone. The use of these organs is to produce the maie principle, or semen, as the ovaries produce the female ovum or egg. The testes, like the ovaries, are not capable of performing their proper functions till a certain period of life, called puberty, but, unlike them, they are not liable to lose their powers at any particular age, but may preserve them indefinitely. In the early stages of existence in the womb the testes are contained in the abdomen, and only descend to the scrotum just before birth.

On dissecting one of the testicles, it is found to be chiefly composed of bloodvessels and numerous small tubes containing semen. A branch of the spermatic artery is sent from the abdomen down to each teste, in which it divides and subdivides into thousands of little branches, many of which are too small to be seen by the naked eye. It is this artery that brings to the testes the pure blood from which probably the semen is formed. The extreme ends of the minute arterial branches are apparently continuous with the commencements of the seminal tubes, so that in examining them we gradually lose sight of the blood and begin to find semen. The seminal tubes are at first exceedingly minute, but very numerous, and they gradually unite together to form larger branches, and trunks, till eventually the whole form but one tube, called the vas deferens, by which the semen is conveyed to the urethra. The number of these little tubes has been estimated at over sixty thousand in one testicle, and it has been shown, that, if they were put in a straight line, they would measure many hundreds, if not thousands of feet. There is also a 
branch of the spermatic vein connected with each of the testes, which ramifies in its substance similarly to the artery. This vein is to take away the blood when it has become impure and imperfect.

The testicles are therefore mainly composed of three kinds of tubes, or vessels, namely, arteries, veins, and seminal tubes. In addition to which there are also numerous nerves, and lymphatics, or absorbents, the whole being connected together by a cellular substance or tissue. Each one is connected with the body by what is termed the spermatic cord, which is a kind of sheath, or tube, about half an inch in diameter, containing the main branches of the artery, nerves, and lymphatics, going to the teste, with the main branch of the vein, and the vas deferens, coming from it. This spermatic cord ascends into the abdomen, where the different vessels composing it are distributed to their respective places. Each teste is also surrounded by a distinct coat, or tunic, besido the scrotum, or outer skin, in which both are inclosed.

The manner in which the semen is actually made is explained elsewhere ; we can only point out now the place where it originates, and explain its progress toward the exterior of the body.

The vas deferens from each teste, into which all its seminal tubes have poured their contents, ascends into the abdomen through the spermatic cord, and rises nearly as high as the top of the bladder, behind which it turns, and then begins to descend till it meets, near its lower

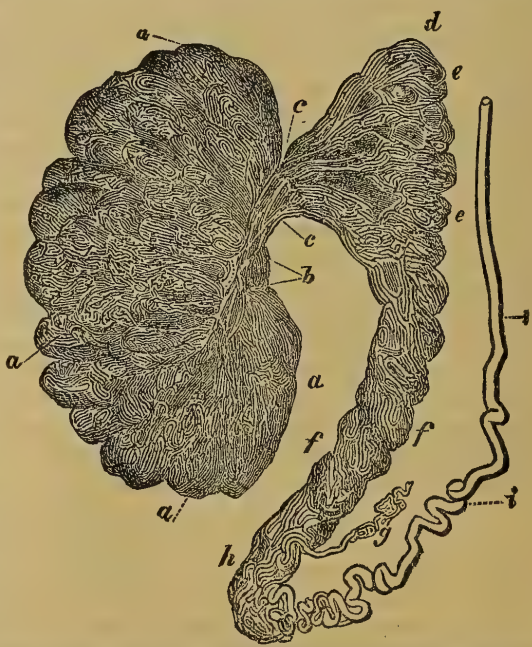

FIGURE 56.-Seminal Tubes and Appendages of the Testicles.

$a, a, a$. Lobules of the small seminiferous tubes, sim. ilar to the convolutions of the brain. $b$. The rete testis, a number of nearly straight tubes into which the smaller ones enter. $c$. The vasa efferentia, or larger tubes, 12 or 18 in number, into which the semen passes from the rete testis. $d$. Plexuses, or conglomerations of the vasa efferentia, which form a kind of head, almost like a small testicle, called the epididymis. $e, e$. The head of the epididymis. $f, f$. The body of the epididymis. $g$. An appendix of the epididymis, called the aberans, which is not always met with. $h$. The tail, or cauda of the epididymis. $i, i$. The vas deferens, which is at first very much twisted, but becomes finally straight.

From this view it will be seen, that the small seminal tubes gradually merge into the large straight ones, called the rete testis, then into the still larger, called the vasa, efferentia, and finally they all coalesce into one tube, the vas deferens.

part, with two small organs called the seminal vesicles, with which it becomes connected. From the seminal vesicles the semen passes down a sraail tube called the ejaculatory canal, which is attached to the bladder, and which joins immediately under it, an organ called the prostate gland. Finally, by means of some minute openings through the prostate gland, the seminal fluid is passed into the urethra, 
or passage down the penis, by which the urine escapes from the bladdez, and is thus ejected from the body.

These several parts comprise the whole male generative system, and in the act. of impregnation each one has a special function to perform. The testes secrete the semen, the vas deferens and ejaculatory canal convey it to the urethra, and the penis deposits it in the female organs, while the seminal vesicles and prostate gland either secrete some necessary addition, or effect some modification in it.

As before remarked, the testes are usually two in number, the one on the left side being lower and larger than that on the right. But sometimes more than two appear to exist, and at other times only one, or perhaps none. The arrangement of one being higher than the other, when there are two, prevents them from being crushed together when the limbs are crossed, by allowing one to slide over the other. The internal structure of them having already been explained, it is only requisite further to describe their envelopes and attachments.

Immediately around each one is an envelope, or membrane, called the tunica albuginea or peri-testis, which surrounds every part, and also sends branches, or leaves, into the substance of the testicle, so as to divide it to a certain depth into lobes, or sections, similar to the lobes of the brain, only of a triangular shape.

The outside inclosure is called the scrotum, or purse, and is the same as the skin of the thighs. It is divided vertically into two parts by a small ridge, called the raphe, and is usually covered with hairs at puberty. Underneath the scrotum we next find a reddish cellular membrane, called the dartos, which makes a separate sac for each of the two testicles, which are separated from each other by a vertical membrane placed between them, called the septum scroti, which acts as a partition, and thus the two organs are perfectly unconnected with each other. The nature of the dartos has been a subject of dispute among anatomists, some considering it to be merely a cellular tissue, and others thinking it to be a muscle. It is undoubtedly partly muscular, and consists mainly of long fibers, which cross and interlace each other in every direction. It is the contraction of these fibers of the dartos that corrugates or wrinkles the scrotum, as is well seen when sudden cold is applied to the external parts. Next under the dartos comes a true muscular coat, called the cremaster muscle, or tunica erythoides, the use of which is to draw the testicle upwards. This is derived from one of the muscles of the abdomen, and comes down through the abdominal ring, forming part of the sheath of the spermatic cord. The last coat is called the tunica vaginalis, which is a true serous membrane interlaced with blood-vessels, and comes next to the tunica albuginea.

In a healthy state the muscular fibers of the scrotum are usually contracted, so as to draw the skin into folds and brace the testes up against the abdomen; but during a state of debility, or from great fatigue, they become relaxed, so that the testes hang low, and pull upon the cord. It is an almost certain sign of ill health when this relaxation of the scrotum occurs, at any period of life, and often its re moval is the first indication of improvement. In old people, and in those of a bad habit of body, this relaxed state becomes permanent.

By inspecting antique statuary, it will be seen that the ancients were practically acquainted with this physiological fact, and they have accordingly accurately represented it in their works of art. The figures of all their men in health and vigor kave the scrotum invariably drawn up to the abdomen, while those of old men, or sufferers, hang pendent. 
As a general rule the muscles of the scrotum are independent of the will, or act involuntarily, but instances have been known of men who made them act as they pleased. Some boys exhibit this power before puberty, being able to draw the testes up to the abdominal ring, and let them fall again, but it is seldom this command over them continues, though one instance is on record. This man drew the testes up into the groin, so as to form apparent ruptures, in order to escape being impressed into the army. Being detected, however, he confessed the trick, and made an exhibition of his extraordinary power to the examining physicians. He could pull up either one alone or both together, and could also make one go up while the other was coming down; in short, he had the same command over them as over nis arms, and could move them as quickly. In another instance, a man who was charged with being the father of an illegitimate child, endeavored to evade the responsibility by alleging he had no testicles, and, therefore, could not be the father; but it was discovered that he could draw them up into the groin at pleasure. In a healthy state the scrotal muscles are brought powerfully into action during coition, so as to brace the testes tightly against the pelvis; and one cause of partial impotence in very weak or old people, is the loss of this power, owing to which the semen is not expelled with sufficient force. In children the relaxed or firm condition of these museles is often a valuable indication of the state of their health.

The form of the testes is that of a somewhat flattened oval, with one end a little larger than the other. The average weight is about one ounce.

The vas deferens, or common tube into which all the small ones are emptied, commences at the globus minor, or lower end of the epididymis, and then passes into the spermatic cord by which it enters the abdomen, where i is course has already been traced. It is altogether about thirty-two feet long. The sheath of the spermatic cord is composed of two coats, the outer one of which is very firm, like cartilage, so that the tube is not easily compressed; the inner coat is a mucous membrane, similar to that inside the urethra. The cord can be readily felt externally.

This description of the testes and their envelopes, combined with that before given, will be sufficient to give a clear understanding of the various diseases and derangements to which they are liable, and also of the reasons for the line of treatment laid down. It will be seen that they are so placed, without the body, as to have no direct connection with any other organs, and they mav, therefore, be removed without any other part being interfered with. This operation, termed castration, is sometimes necessary in certain diseases, and sometimes it is the effect of accident, or, in some parts of the world, even of design. The removal of the testes, however, in whatever way it may be effected, not only destroys the power of procreation, but interferes in a remarkable manner with the growth and functions of various other parts of the system, from which it is evident that they are necessary for the perfection of the individual's own system, as well as for the purpose of bringing new beings into existence.

\section{ANOMALIES IN THE SIZE AND APPARENT NUMBER OF THE TESTES.}

The usual size of the testes is about that of an ordinary pigeon's egg, and their weight, as before stated, is ahout one ounce. Occasionally, however, they are seen much larger, and sometimes much smaller, and their weight may be also considerably greater or less than the average. I have scen them as large as a full-sized hen's egg. yet perfectiy healthy, and as small as marbles without being in any way deficient in 
power. This is important to bear in mind in many cases that may come under the physician's notice. I have known men hesitate about marrying when the testes were very small, from fear that they would be deficient in power, and it was with difficulty they could be convinced to the contrary. In one instance, of a young man aged twenty-six, they were no larger than those of a child of nine years old, yet his powers were but little, if any, inferior to those of persons generally. After a great deal of hesitation, and much persuasion, he married and became the father of a large family. It is necessary to remark, however, that in these cases all the other organs were of proper size, and that the smallness of the testes had existed from childhood, and was therefore a natural state. If they had decreased in size, after having been properly developed, it would have been very different. The falling away or wasting of the testes, which follows many diseases, and sometimes takes place without any'assignable cause, is usually a serious matter, and is nearly certain to be followed by a loss of power. The injudicious use of certain drugs, particularly of Iodine, will frequently cause the testes to waste, and so will the exhalations from some metals, as lead for instance, many workmen in which I have known so affected. In giving an opinion in such cases, therefore, their previous history must always be known, as well as the condition of the other parts, and the physician will then have but little difficulty in coming to a proper decision. Sometimes one only will be small, and the other of average size, or one only may waste away, without injuring the other.

An unusually large size of the testes should always excite suspicion of its being the result of disease, and a most careful examination and inquiry should therefore be made. If they have always been of that size, or nearly so, from puberty, and especially if the other organs are large also, there may be nothing to excite apprehension. The symptoms of the different diseases hereafter described should, however, be carefully studied, particularly those that cause enlargement, as Hydrocele and Hernia Humoralis, for instance. I have known the testes of a youth of fourteen to be much larger than those of most men, and yet perfectly healthy; such cases of unusual development are not necessarily accompanied by extra power.

In some instances the development of all the genital organs is very tardy, owing to the slow growth of the testes. I have seen a youth of nineteen that was in every respect in the same state, in these parts, as when about seven years old. He was also but very little grown in other parts of the body, having the appearance of one about twelve years old. In this case there were perfect evidences of sexual power, though slight, and all the parts were evidently healthy. It was therefore a case of torpid action, or retarded development, and I thought that in all probability nature could be aroused. I accordingly gave him directions to use stimulating lotions, with frictions and shampooing, and to have a stimulating diet, with regular warm bathing and plenty of out-door exercise. The effects of this practice was soon evident; in less than six months an evident increase had taken place, both in the size of the parts and in the intensity of the sexual feeling. The external parts, which had pre• riously been perfectly bare and smooth, like those of a child, became covered; the voice assumed a more manly tone, the muscles were more solid, the mind more active, and manhood began to dawn. This improvement continued going on till he was twenty-one, when there was but little difference between him and other young men of that age. If this case had not been promptly and properly attended to, in all probability no further development would ever have taken place, and an early death would have terminated his imperfect existence. To what age an improvement of 
this kind is possible we cannot of course tell, though I feel sure it may be effected in older persons than is generally supposed, perhaps till nearly thirty. The younger, of sourse, the better. Several cases have been known of the testes growing after twentysix years old.

Sometimes there appear to be three testicles, and possibly in some of these cases there may really be three, but more frequently one of the three bodies is either an epididymis, somewhat enlarged, and much separated from the teste, or else it is a small tumor. Most of those that hare been observed in dissection have been small harmless tumors, existing from birth. Three perfect testicles, however, are occasionally found, but they are not always accompanied by any unusual sexual power.

At other times there appears but one testicle, or perhaps none, and I have known young men in the deepest distress from this cause. In some of these instances there is really but one organ, as has been proved after. death, and yet the individual has had full average powers. It is more often the case, however, that these deficiencies are apparent rather than real. Before birth the tes'es are contained in the abdomen, and they usually descend into the scrotum in the last month. It sometimes happens, however, that the descent of one or both does not take place, and the individual then appears so far deficient. In these cases the power of the testes is not impaired by their unusual position, but perhaps is often increased, and this has led uninformed persons to think that men sometimes had procreative powers without testicles, because they could not be found. A man once died in one of the London hospitals who had long been noted as haring no testicles, and yet having all the usual powers. On dissection, two perfect ones were found in the abdomen that had never come down, and thus the wonder was solved. These cases, however, are but rare. Dr. Marshall examined ten thousand eight hundred young recruits, among whom he found five in whom the right testicle had not come down, and six in whom the left had not; there being but one man in whom both were not descended.

It is much better for the testes to remain totally in the abdomen than to descend only to the groin, as they sometimes do, because in the last position they are apt to be compressed, by the other parts crowding about them in the ring, and then waste away. The partial or complete non-descent of the testes must, however, always be considered an imperfection, and though it may not cause inconvenience, or loss of power, these are nevertheless always to be feared. The teste itself is as liable to all its diferent diseases while in these unusual positions as when in the scrotum, and unfortunately cannot then be reached. The neighboring parts also become affected from it, and thus life may be lost from a simple affection which could have been easily removed, if the teste had been in its natural position.

In some instances the retained testes descend late in life, and if they then become fast in the ring, great swelling and severe inflammation may result, with ultimate wasting away of the organs. Such cases have been mistaken for ruptures, and some men, from want of information, have thought that the testicles really grew at that time, all at once.

When there are reaily no testicles from birth, there is always an imperfect development of the whole system, and a total absence of sexual power and feeling.

In some animals it is natural for the testes never to descend, but always to remain in the abdomen, and in others they descend only at certain seasons, that is, when they attain their periodical development, owing to the full growth of the animalcules.

It is stated, on the authority of several travelers, that there is a tribe of Hottentots 
at the Cape of Good Hope that never have but one testrcie; but many naturalists think that more likely it is a custom among them to remove one in youth. It is quite possible, however, that this deficiency may be natural, and it is not in any way more singular than many peculiarities observed in the genital organs of the females of those tribes. I have known two brothers, twins, one of whom had three testes and the other but one.

In some instances the two testes have been found grown together, so as apparently to form but one, owing to the absence of the usual septum.

The testicles are sometimes drawn so close up against the abdomen, owing to a contraction of the cremaster muscle, that they cannot be discovered without close examination, and are then often thought to be absent, though they are quite perfect, and even outside of the body. Medical men have even testified that there were no testicles, in such cases as these, which shows the necessity for a close and thorough examination of such apparent monstrosities.

This state of things is not dangerous in itself, but had better be removed if possible, because the testes are likely to adhere to the neighboring parts and waste away, so as to cause perfect impotence. A surgical operation is necessary to liberate them, which is both difficult and somewhat dangerous. In some few dissections the testes have been found completely absent, and without any trace of their baving existed. Sometimes the vas deferens exists by itself, and sometimes with the epididymis, though at other times there are no traces of either. These cases of total congenital absence are, however, very rare, and are always indicated by deficiencies in other parts of the system.

In some rare instances the testes have descended into the perineum, instead of the scrotum, most probably from some imperfection in the parts, existing before birth.

In the course of my practice I have been consulted in many of these cases of testicular anomalies, and have often had the pleasure of removing unfounded apprehensions, and of giving happiness and confidence to those who had previously been the victims of hopeless despair.

The testes are liable to many different diseases and derangements, some from birth, and others that originate afterwards, many of which ought to forbid marriag altogether. A full account of every one, with directions both how to treat and avord them, may be found in the chapter on diseases of the Male Organs, and if every young man was in possession of that information in time, we should see but few of these diseases compared with what we do now.

Many men are alarmed very much at any affection of these organs-and with good reason, too, considering the inefficiency of much of the medical treatment of them-till very recently. Now, however, some of the worst of these affections, both organic and functional, are cured very readily, and means are used successfully to increase power when deficient, or restore it, in many cases, if lost. Some most extraordinary cases of this kind will be found farther on, that have been treated by myself, and I have also a number of letters from persons who have successfully treated themselves, by following the directions given them.

In those animals the females of which only admit the male during one particular season of the year, that of the rut, a necessary adaptation is found in the male, by which the two are made to correspond. The testicles of these animals do not secrete semen continuously, as they do in others, but only at those times when the female 
ovaries act, so that both experience the sexual impulse at the same time. At all other periods the testicles are quite small, but then they suddenly enlarge, and when the season is over they decrease again. In some animals the testicles descend from the body only at that time, and at every other period are drawn up into the abdomen. In many, the enlargement of these organs during the time of connection is very evident, even when, as in insects, and some others of the lower animals, there is only sufficient semen secreted for one single act.

According to recent observations, it appears that the seminiferous tubes are about one two-hundredth part of an inch in diameter, and that the ras deferens, in all its convolutions, is nearly thirty-two feet in length, while the whole of the tubes are, probably, full five thousand feet. The epididymis when unrolled will measure Jver twenty feet in length,

The condition and mode of action of the testes exert a similar influence over the male to that which is exerted over the female by the ovaries, the secretion of the semen being strictly analogous to the maturation of the ova. The development of the body is also totally dependent upon their growth, and both intellectual power ind moral disposition are, to an immense extent, influenced by them.

The form of the testicles varies among the different mammiferous animals, equally with the other organs, being sometimes round, at others oval, and at others again long and slender, as in the whale. It is seldom, however, that they are contained in a scrotum, as in man, except among the carnivori, the ape, the horse, and the cud-chewing beasts. In the beaver, the testicles are contained in the perineum, and in some similar animals, in the abdomen, whlle in the bat, and some others, they always glide back into the belly during the rut. The whale, kangaroo, opossum, elephant, and some others, have the testicles fixed permanently in the abdomen, one on each side of the rectum. This is the case also with the porpoise, whose testicles at the time of heat attain an enormous size, having been found nine inches long and four wide, and weighing two pounds each.

In all cases the internal structure is much the same, and probably the formation of the semen is always much the same process. The composition of it is also similar, and in every case it possesses animalcules, though they differ in form.

The seminal vesicles and prostate gland also vary in form, though, probably, they always serve a similar purpose. Some animals have only one prostate, like man, while others appear to have several, or rather, it is much divided. Cowper's glands, also, though usually present, vary much in their development, and so do the vasa deferentia.

The testicles vary very much in form in different beings, and also in size, being

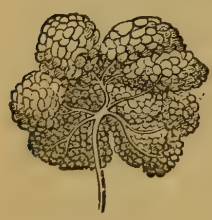

FIGURE 57. Testicles of Helix. often very large in proportion to the rest of the body. In the snail (Helix), whose double copulation was described in the. article Hermaphrodism, the testes resemble somewhat a bunch of grapes, as shown in the following illustration.

All the separate seminal saes unite, and pour their contents into the common vas deferens, which may be seen proceeding from them.

In the entozoa, or body worm, the testes are in the form of a long small tube, which winds round and round the intestines. It occupies a large part of the interior cavity of the animal, and when unrolled is found to be many times its length. One end of this tube 
becomes so fine as to be hardly distinguishable, and floats loosely in the juices of the body, from which probably it absorbs the cells that form the semen. The other end terminates in a long tubular penis, which is placed near the opening of the nus.

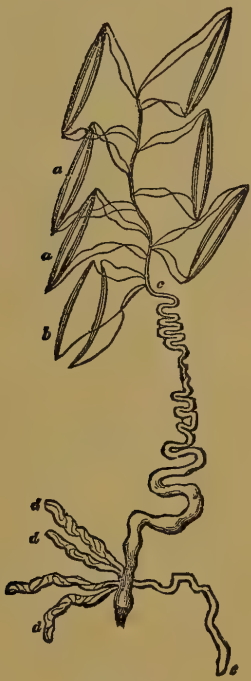

FIGURE 58.

Testes of Scolopendra, or Centipede.

$a, a$, are two pairs of testes united in the usual way. $b$ shows two separated. $c$ is the beginning of the common vas deferens. $d, d$, $\boldsymbol{d}, e$, are other glands joining the vas deferens, not connected with generation.

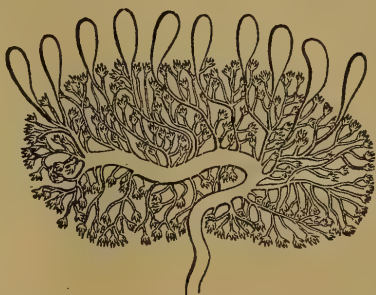

FraUR: 59. - Testicle of Staphylinus Maxillosus, one of the beetle family, com. monly called the cock-tail beetle.

In the Scolopendra morsitans, one of the centipede family, the testes are seven in number, and each one is composed of two parts exactly alike. Each part is hol. low, and has a little duct of its own, and these all unite in a common vas deferens, so that there are fourteen pairs of these ducts. The common vas deferens is very long and tortuous, terminating finally near the anus.

In insects the forms of the sexual organs, especially in the male, are often very curious indeed, and no reason can be given, in many cases, for the singularity.

In many insects, besides the testes, there are other glands connected with them, supposed to be seminal vesicles, like those of man. Sometimes there are a large number of these vesicles, and they occasionally reach an enormous length, as mucb 
even as twenty times that of the animal's body, which shows what bountiful provision nature has made for propagation in these beings.

The testicles in most fishes are quite large, in proportion to their bulk, and are placed one on each side of the body, similarly to the ovaries in the females. At the time of spawning they become very much enlarged, so as to increase the size of the fish considerably. Some fishes copulate, and have a penis connected with the testes for that purpose. In the ray-fishes and sharks, there are two testicles, and each one is double, the two parts being quite different in structure, and probably in function.

The testes of the frog appear like a collection of simple cells, as they probably are, which are connected with numerous minute tubes which pass into the kidney, and convey the semen into the one tube which is common both to the semen and the urine.

In birds the testes are always two in number, and quite small, but composed of an immense number of very minute tubes, not more, in most cases, than the millionth of an inch in diameter. In many other beings the seminal tubes are also exceedingly small, and the smaller they are the more there are of them, and the longer they are. In many beings their diameter is only some millionths of an inch.

In the marsupials the testes are placed in front of the pelvis, as will be shown farther on.

The testes are of the first importance in the animal economy, especially in man, not only for their use in reproduction, but also from the influence which they exert, when active, upon all the rest of the system. In a subsequent article an account will be given of the principal diseases and derangements to which they are liable.

\section{THE SEMEN AND THE SEMINAL ANIMALCULES.}

The vivifying principle secreted by the male testes is a yellowishly-white semi. fluid substance, having a peculiar odor. It is slightly viscid, and of a saltish savor, when fresh. On examination it is found to consist of two distinct parts, one nearly fluid and the other like globules of half-dissolved starch; but they both melt together when it is exposed some time to the air. The peculiar odor of the semen appears to be derived from some of the parts through which it passes, for when taken from the testes it has scarcely any smell at all.

Chemical analysis shows us that the semen differs but little, in its composition, from other substances found in the body. In 1,000 parts there are about 900 water ; 60 animal mucilage ; 10 soda ; and 30 of phosphate of lime, with a peculiar animal principle, the composition of which is unknown. This analysis it must be recollected is that of the semen as it leaves the body, that is, the secretion of the testes, vesicles, prostate gland, and other parts, united together. How far the pure semen, from the testes alone, differs from this is not known. By some the starchy portion only is supposed to be produced by the testes.

The Seminal Animalculce.-The most curious peculiarity of the semen, and in many respects the most important, is that there always exists in it, when perfect, anumber of remarkable living beings, called the Zoospermes, or seminal animalculæ. These beings were discove ed many years ago, but have not been accurately studied and described till very recently. The representations and descriptions given of them in old works are mostly incorrect, and sometimes very extravagant, and calculated to mislead rather than inform. Some physiologists, who saw them imperfectly, even doubted if they were living beings. The perfection of that magical instrument, 
the microscope, however, and the patient investigation of such men as Pouchet and his coadjutors have not only corrected these old errors, but have also disclosed to us new truths, more wonderful even than the wild dreams of former times.

As far as yet investigated these animalcules exist universally, in the semen of all animals whatever, but have a peculiar form in each.

It is also ascertained that they are developed from a species of egg, or orum, called the seminal granules, or vesicles. Under the microscope a number of these can always be detected, like little globules of mucus, and they are observed to undergo a regular series of changes similar to those of the female ovary. When first observed they are round, and merely contain a number of small granules, which are the animalcules, in a rudimentary state. At a farther stage these granules are found to be developed into small animalcules, while the containing vesicles have expanded and become elongated, or egg-shaped. Finally, the vesicle breaks open at one end, and the animalcules escape; being at first very small and gradually growing afterwards to the size we ordinarily see them.

In different beings the form both of the vesicle and the animalculæ varies much, and occasionally the zoospermes undergo some remarkable metamorphoses before assuming their final form.

In the human being there are about thirty zoospermes in each vesicle, but in some beings there are more, and in others not so many. The number of vesicles varies very much, at different times, even in the same individual.

The precise size of the zoospermes is of course difficult to ascertain, but M. Pouchet estimates their length at about the ten thousandth part of the breadth of an ordinary hair, and their weight at about the hundred and forty thousand milliontih part of a grain! A spot as large as a mustard-seed, he remarks, sometimes contains fifty thousand of them.

Notwithstanding this extreme minuteness, we are now tolerably well acquainter with their peculiarities of structure, and even with many of their habits, nor neei? this excite much surprise when it is recollected that there are beings still smaller that have been studied with even greater success. In the perfect state they possess a sucker at the larger end, by which they can attach themselves to any object. They are observed to change their skins at certain periods, like snakes, and we sometimes find the loose skin hanging about them in shreds; or cast off quite whole. In some animals they have a number of hairs, or cilia, by the motion of which they move in the fluid, and some even have perfect fins. One physiologist assures us that he distinctly saw they were sexual, and that he could readily distinguish the male and female! They are usually lively and active, with peculiar motions, some of which are performed in concert and others singly, with great perseverance and regularity; thus, a number of them will sometimes form into a ring, with their heads all one way, and run round and round in a circle for a considerable time; or one may be seen by itself pushing before it a large globule of mucus, or blood, many times heavier than itself, for several minutes together. One peculiarity is observable in all of them, and that is an almost invariable tendency to move only straight forward, and they will seldom turn to go back even though they meet with an obstruction, but often attach themselves to it by the sucker and remain till they die. Very often they are seen to enter into combats, and a number of them will fight till only one is left alive. They will live for some hours out of the body, particularly if put in warm water, in which their motions may be readily seen. 
The zoospermes are not found before puberty, nor usually in extreme old age. Many diseases also destroy them, and several drugs have the same power. In all cases where they are absent or destroyed, from whatever cause it may be, the semen cannot impregnate, though in every other respect it may be quite perfect, and the vigor of the patient seem not in the least impaired. This has been proved by filtering them away, and by destroying them. The development of the zoospermes, it will be observed, is strictly analogous to that of the ova or eggs in the females. Thus they are first found in the form of little granules, inclosed in a vesicle which bursts as they become more perfect, and allows them to escape. In some animals there is even a periudical development of them, similar to that of the ova in the female, with which it usually corresponds. In such animals the testes are small at other times, and increase in size at these periods, because the vesicles only attain their full growth then.

In tracing the semen from its source, we find that the animalcules are not developed till it reaches the seminal vesicles, and are sometimes not perfect till it has reached the prostate gland. In the testicles we never find the zoospermes themselves, but only the vesicles containing the granules, which gradually develop as the semen proceeds farther on.

The testes may therefore be compared to the ovaries, the seminal vessels to the Graafian vesicles, and the seminal granules to the ova. Some physiologists consider the granules to be the ova of the animalcules themselves, but this we cannot yet decide, though it is certain the animalcules originate from them.

The importance of these facts, in giving us a correct knowledge of the nature and proper treatment of many diseases of these organs, will be seen as we proceed, particularly when treating on impotence, and seminal losses.

The actual process of conception is also made more clear from some of these details. For instance, the tendency which the animalcules have to move only straight forward, is, in all probability, the reason why they make their way up into the womb from the vagina, and impregnate the egg. If it were not for this tendency, co:nbined with their great motive power, the two principles could not be brought together. Their power of living out of the male organs for some time is also necessary to impregnation, because they may not reach their destination immediately. It is found that they will live in the female organs, when these are healthy, as long as twenty-six hours, and of course during any part of that time conception may take place. Sometimes conception may take place in a few minutes, and at other times not till as many hours after the association of the two sexes. It has been found on dissecting an animal killed ten hours after connection, that the semen had not then reached the ovum, though it usually passes into the womb almost immediately.

It is evident from this how incorrect it is to speak of the moment of conception, as if it were a period certainly known. No greater mistake could be made than ta suppose that it always corresponds with the moment of connection, because it may be as much as twenty hours after, or more. It is also evident from these facts why it is that conception is possible without actual connection. If the semen is merely deposited in the external lips it may impregnate, because the animalcules may make their way from thence up to the womb. It is also of little consequence how the semen is deposited in the female organs, providing it be perfect, and this explains why it is that, conception can be effected artificially, by merely injecting the semen in the female organs with a syringe, or otherwise, which has often been done. The 
mere presence of the male organ is in no way essential; and this explains why a certain mode of attempting to prevent conception often fails. It was also remarked, in a previous part, that sexual feeling in the female was not necessary to conception, and this will now be evident when it is recollected that the animalculæ move up into the womb by their own vital power. It is probable, however, that this feeling often conduces to conception, by establishing certain favorable conditions of the parts, and therefore that event is not so likely to occur during sleep or unconsciousvess, though it is possible for it to do so.

The old idew that it was only the odor or aura of the semen that ascended into the female organs ana :mpregnated the ovum, is obviously incorrect, and, indeed, has been fully refuted.

The presence or absence of the zoospermes in the female organs, and other parts, is the chief evidence sought for in cases of alleged violation, because in such cases they may certainly be found alive, if the act has been committed, for as long as twenty-six hours after, and dead for almost any period if the fluids be dried.

It is considered by some that the animalcule is the true rudiment or germ of the future human being, which is supposed to be developed from it in the same way as the plant is developed from the seed; or rather, the human being is thought to be one of these zoospermes developed to a more perfect form by the power of the egg in which it is placed.

It is uncertain in what part the animalcules first issue from their vesicles; nor is it clear how they are influenced by the seminal vesicles and prostate, though it is well known that the semen must pass through those parts before the animalcules become perfect, for in no case will it impregnate when taken from the testes. It is conjectured, in explanation of this, that the vesicles and prostate supply some peculiar food or nutriment, without which the animalcules are never perfect.

There are several drugs that will destroy the animaleules immediately, among which may be mentioned opium, Prussic acid, iodine, and strychnine. The latter article even throws them into convulsions, precisely like those seen in human beings.

The most curious effects are produced upon the animalcules by alcohol. If only a drop or two be put into the warm water which contains them, they become singularly excited, and dash about as if in a perfect frenzy. Some will whirl rapidly round and round, till they stop all at once, and are found to be dead; others become more than usually pugnacious, and they will fight with such fury, that in a short time all will be slain. Others, again, are evidently thrown into spasms, or attach themselves by their suckers, and vibrate the body in the most energetic manner. After a short time these effects pass off, and they become listless and dull. If a larger portion of alcohol be used, they are killed immediately, many of them being first thrown into convulsions. I have good reason for supposing that similar effects are often produced upon them when alcohol is taken internally, in excess, and that many inebriates are thus made impotent. I have frequently examined the semen of impotent patients who were addicted to excessive drinking, and have often found them exhibit precisely the same peculiarities as above described. I feel confident also that the injudicious use of the drugs above mentioned, often produces impotence, by destroying the animalcules; and, indeed, I have proved this by direct experiment upon animals. It is well known that confirmed opium-eaters nearly always become impotent, and that iodine will often cause the testes to waste away, probably by preventing the development of the animalcules. In all proba. 
bility many persons are made impotent, or, at least, have their sexual powers much impaired, by these drugs being imprudently given to them while they are children. I have seen many cases in which the ovaries and testes were undeveloped from this cause; and I am inclined to think that the evil exists to a great extent.

In some instances the use of alcohol, and other drugs, does not absolutely destroy the animalcules, but prevents their full development, or makes them imperfect, so that we find them smaller than usual, or deformed. This is especially the case from alcohol and tobacco, as shown by experiments upon animals, and in all probabilitv this explains why persons who use these articles to excess are apt to have stunted deformed, and diseased children, as it is well known they often do. If the animal cule is, even in part only, the rudiment of the future child, of which there seems little doubt, it is natural to suppose that if it be stunted or deformed, the child will be so likewise, and thus the vices of the father may entail imperfection and disease upon his offspring.

The animalcules are often destroyed by many of the discharges which take place from the female organs during disease, and in this way sterility often results. Electricity kills them immediately, and so will sudden cold, which accounts for some persons being able to prevent conception by using cold water as an injection, immediately after connection.

Before puberty, no animalcules can be discovered, but the resicles containing them usually begin to appear about eleven or twelve years of age. In old age, the number of them generally becomes less, and very often none at all are found, though tine time when they cease to be found is very variable. Some men, though in good health, and robust, become impotent when they are fifty, and others, on the contrary, retain full possession of their powers till over a hundred years of age. In like manner, some children have had the animalcules perfectly developed at ten years of age, and some young men not till they were twenty. I have known those who had no trace of them at twenty years of age, who were, nevertheless, perfect enough at twenty-three; and I once was cognizant of a painful instance in which a young girl of seventeen was impregnated by a boy of eleven, she having improperly conducted herself with him without the slightest suspicion of there being any danger in doing so.

It is important to bear in mind that both puberty and decay may be either hastened or postponed, by proper attention to diet and general conduct.

It is a singular circumstance, that though an electrical discharge will destroy the animalcules instantly, yet the continuous galvanic current, even when very strong, has no effect whatever upon them, which shows the impossibility of preventing conception by the use of galvanic instruments, as some have proposed.

Our present comparatively perfect knowledge of the seminal animalcules is important both to physiologists and to the physician, as it enables us both to discover disease, and, in many cases, to suggest a remedy. Formerly, the reason could not be even surmised why certain married persons were childless, though both seemed to be in perfect health, and in the full possession of their sexual powers. It is now known, however, that in many of these cases, though the semen is formed, yet it contains no animalcules; from some cause or other they have not developed, and the vesicles only are found. This condition is more or less natural to some men, and they can, therefore, never become fathers, though fully capable of association. In such cases of sterility, when no obrious imperfection existed, medical men always assumed that 
the fault was in the female, it being an axiom that if the male could associate and deposit semen, he could impregnate. This, however, we have shown to be erroneous, because the semen may be imperfect, though it be produced. It is wrong, therefore, to suppose, as most people do, that in cases of sterility the fault is most frequently with the female; it is, in fact, fully as often with the male, only the principal cause of it has but just been discovered. Men who are imperfect in this way, are in the same condition as they were before pulerty, and are similar to mules, many of whom secrete semen, and can associate with the other sex, but having no animalcules, cannot impregnate. In these men the sexual desire is never strong, nor does it last long, and they are always incapable of exciting much ardor in the other sex. This is explained by supposing that the presence of the animalcules is necessary to excite the organs of both, or to develop their peculiar sensibility.

A number of facts have made it probable that the primary rudiments of the animalcules are exceedingly minute, and abundant in the semen, so that a small portion of it may suffice for impregnation for a long time. Thus instances have been known in which both men and animals have impregnated many times though castrated, and for a long time after. Which is explained by supposing that, when the testicles were removed, a quantity of semen must have been left in the vas deferens, vesicles, and prostate gland, which being mixed with the fluids of those parts formed the discharge which impregnated. There must, however, bave been a large number of animalcular vesicles in it, and they mnst have been at first very rudimentary, to continue developing so long. Some physiologists, in fact, suppose that the semen can produce the resicles spontaneously, and that, consequently, they will always be found in it when perfect, no matter what part of the body it may be taken from.

One of the worst forms of spermatorrhœe, or involuntary seminal loss, that in which it escapes with the urine only, could never be discovered if it were not for the animalcules. In every case of this form of the disease, they can always be detected in the urine, by means of the microscope, and thus the true nature of the trouble can be ascertained beyond a doubt. Before this discovery was made, such a mode of seminal loss was unknown and unsuspected, though it is now known to be more frequent than any other, and, doubtless, thousands have died from it without either them or their medical attendants having the remotest idea what was wrong.

Though the form of the animalcules varies in different animals very much, it is always alike in all individuals of the same species, which is probably the true reason why totally different species cannot, as a general rule, breed together. The outline of the animalcule, as will be seen by the figure of that of the human being, is almost identical with the outline of the main part of the Nervous System, the large part representing the brain, and the long extremity, the spinal marrow. It is conjectured, therefore, that the animalcule really constitutes the first rudiment of the nervous matter, while the ovum or egg, as already shown, forms all the other parts. The form of the animalculæ must, therefore, be adapted to the form of the body produced by the egg, and if the two be very much unlike, no union, or impregnation, can take place. I hare ascertained, by repeated examinations, that there is a perceptible difference between the animalcule of the negro and that of the white man, sufficient, apparently, to mark a difference in kind, though not sufficient to prevent their fruitful intercourse.

The delineations of the animalcules as given in old works are nearly always false, and sometimes grossly exaggerated. It is, in fact, extremely difficult to make a proper 
examination of them, owing to their being so transparent, and differing so little in density from the fluid in whicb they are contained. It is requisite both to have good and powerful microscopes, and to be skilled in their use. With regard to specimens of semen, a phrsician who sees many cases of spermatorrhœa will never be at a loss for plenty.

In the course of my orn practice I hare examined these interesting beings unde: erers rarietr of circumstances, and from a number of different animals, besides from our own species. Nothing can well be conceived more absorbing than such a pursuit, and no discoreries are more suggestire of raluable and unlooked-for explanations, both medical and physiological.

The illustrations in the large plates will give a perfect idea of these curious organisms in rarious animals.

According to Rölliker and Wagner there are first formed in the semen a number of parent cells, filled with a white albuminous fluid, which becomes granular, and then erolres one or more seminal granules, or resicles. Each resicle, according to their obserrations, contains only one animalcule, but this does not accord with the obserrations of others, who hare counted as many as thirty from a single resicle. The discrepancr, howerer, is accounted for in this way. As each resicle ripens it bursts open, and the animalcule escapes into the fluid semen, and if a number burst at onetime all the animalcules from them may be thought to come from the one obserred. The seminal resicles in the parent cells ripen in succession, one or more at a time, in the human being, but in birds all usually ripen at once, and then the animalcules form into bundles, or masses, and this is occasionally so in the human being. In all probability all these processes rary in different indiriduals, according to the strength and rigor of the organs. One man, undoubtedly, produces very many more animalcules than another, and more vigorous ones. Possibly each resicle in one man may produce only one animalcule, and in another man sereral, just as one female produces more ovæ than another.

The parent cells, from which both the resicles and their contained animalcules originate, are formed from the epithelial lining of the seminal tubes in the testicles; this peels off, and the fragments form into the parent cells. Chemical analysis shorrs that the composition of the semen, and of the epithelial cells of the testicular tubes is exactly the same, which is corroborative still further of their fundamental identity.

The whole process, therefore, is one of cell growth, just as is the formation of the oræ. The cellular lining of the testicular tubes throws off small portions, just as many of the simpler organisms already described throw off parts of their structure, and these portions begin at once to derelop. It is, in fact, a process of fissiparous propagation!

The formation of the orum in the orary, and of the seminal resicle with its animaleule, in the testicle, are, therefore, both effected in the same way. Each is simply a bit of the parent cellular structure, separated from the main body, and possessing the power, under proper conditions, of continuing its development. The reproduction of man, therefore, and of all other rertebrates, is really only fissiparous in the beginning.

The animalcules will live in the human semen twenty minutes or more after a man's death, and in cold-blooded reptiles they have been found alive several days after

In reference to their production Dr. Burnett says that the changes in the sperm 
cells, which precede the development of the perfect animalcules, are exactly similar to those which occur in the orum preceding the formation of the new being. So that both the female egg and the male seminal animalcale are produced in the same way independent of each other; and when united they together produce the new human being.

Male mules form semen, but it very rarely contains animalcules, which is the reason it scarcely ever impregnates. The female mule, also, only occasionally forms a perfect egg, and brings iorth young, even if impregnated by a perfect male. The male mule, therefore, is more generally sterile than the female.

Spallanzani and Prevost attempted to calculate the amount of semen that would be required to fecundate a certain number of eggs, and Damas even tried to ascer. tain how many animaleules are needed to impregnate one egg. It was found that two grains of the semen of the male toad was sufficient to impregnate one hundred and thirteen eggs. Five grains of semen were mixed with eighteen ounces of water, and the point of a needle being dipped in this, and then made to touch an egg for an instant only, caused impregnation, The proportion of semen to egg. in this experiment, has been estimated as 1 to $1,064,000,000$. The impregnation was no more complete when the amount of semen was larger, nor when the needle remained longer in contact with the egg. It was observed that in the fecundation of a given number of eggs, by a given amount of semen, the number of eggs was always less than the number of animalcules in the semen, which showed that several animalcules were taken into each egg, and endearors were made to find how many. Experiments showed that a quantity of semen containing 225 animaleules impregnated 61 eggs, or about 3 to each. I am not aware that these experiments have ever been repeated, and it is doubtful how far their results, if correct, are applicable generally.

If only one animalcule is required as tie rudiment of the new being, it is evident the others are superfluous, unless they serve some subordinate purpose, which is quite possible. As the essential parts of the nervous system are all double, it may need always two to form them.

Spallanzani demonstrated the fact that contact of the semen with the oræ was all that was needed to impregnate. He kept a slut carefully confined, and when she was in heat injected the semen from a dog into her vagina; the result was, that she had a litter of puppies like the dog from whom the semen was taken. This operation, as will be shown farther on, is often resorted to, successfully, in human beings, when some impediment prerents impregnation in the usual way.

Impregnation is, therefore, essentially a material act, and not the result of any mysterious agency, or unknown spiritual power, as was formerly thought. It is simply the union of two different kinds of cells, or masses of protoplasm, each more or lass specialized, or differentiated; the result of the union being the derelopment of a new organism, made up of a mass of cells, propagated from these two primary ones.

Although not formed perfectly, till the age of puberty, semen is yet produced Eometimes in children, and accompanied by strong sexual excitement : a fact which should not be forgotten. Probably in most cases semen which: will excite, is formed long before it is perfect enough to impregnate. There is no doubt, however, that quite young boys are often capable of impregnating, as women have sometimes discovered to their shame.

The state of the mind, and the direction giren to the feelings and emotions, has much to do with this. There is, perhaps, no function of the body more influenced 


\section{PLATE VIII.}

\section{SEMINAL FLUID OF A MAN.}

Figure 1 is a parent cell, containing three seminal vesicles.

Figure 2 is a seminal vesicle enlarged, showing its granular structure.

Figures 3 and 4 are two of the animalcules much magnified, showing the mouth with the (probable) stomach and intestines in the interior.

Figures 5 and 6 are two others, equally magnified, showing the outer thin skin torn off, and in shreds, as it often is from their active movements and mutual struggles.

Figure 7 shows dried semen, such as is often found on the linen, and which frequently is the certain evidence of onanism, or of rape. The three animalcules contained in it are stiff and dead. This is under the microscope.

Figtre 8. This shows a spot of fresh semen, as seen under the microscope; the animalcules are living and moving, among a mass of mucous globules, and seminal resicles. Compare these living ones with the dead ones. 
PLATE VIII.

Fig.1.
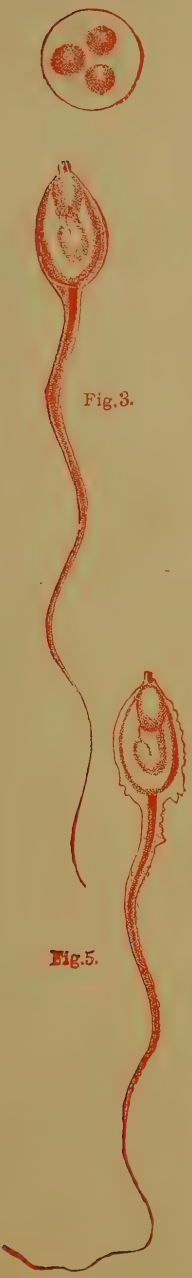

Fig.8.
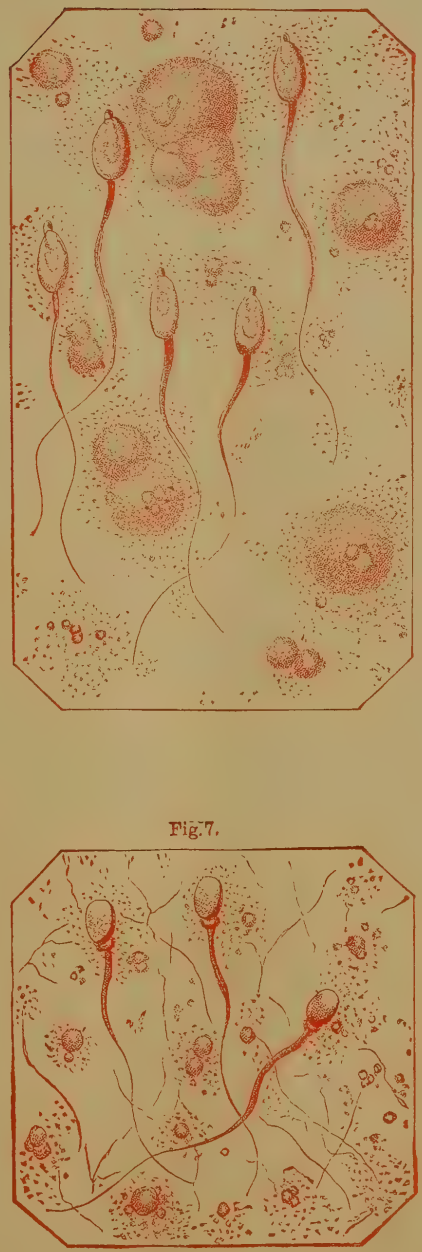

Seminal Frluid of a Man.

Fig. 2.

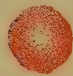

Fig.4.
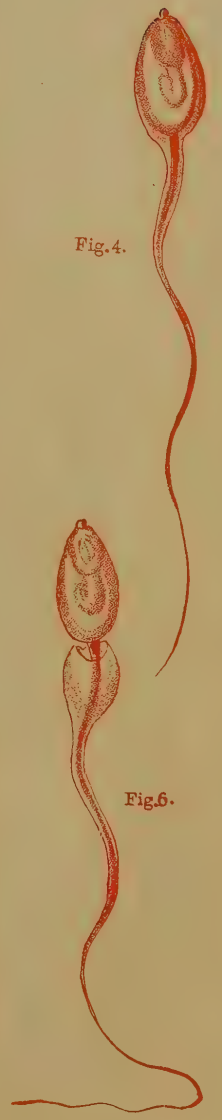

Fig.6. 

by mental and moral conditions than that of seminal secretion. It may be increased by dwelling upon sexual matters with the thoughts, or it may be decreased by forcing the mind away from them.

Emotions of various kinds may be powerful enough to utterly suppress sexual excitement, or to raise it to a pitch utterly beyond all control.

There is so much that is curious and wonderful about the seminal animalcules, that it is not surprising they should have formed the basis of many strange theories. That they are necessary to the beginning of life in all the higher beings is beyond question, and that they are living themselves is equally certain. Whether they really propagate, like other beings, we do not certainly know, though many physiologists are convinced, from close observation, that they do. If they do not, then they must be generated spontaneously! In either case they must be regarded as necessary to the formation of the human being in its first stage!

Those who have doubted their vitality can scarcely have seen much of them. No one who has watched their fantastic and active movements, and observed their gradual development, like that of any other similar being, from a cell, or egg, and seen them stupefied, or even killed, by drugs, can well conceive of them as not living. If they are not living creatures, then thonsands of others are not that we always regard as such. For my own part, I have no doubt of their vitality, and I believe them to be spontaneously generated from the epithelial cells of the tubes of the testicles.

In different beings, as before observed, the animalcules vary very much in form, and we will presently give delineations of some of the most remarkable of them.

To those who wish to examine them microscopically, it will be useful to know that they can be best seen in the semen of the male of the common fowl, especially in the spring. They are always most numerous, most active, and largest, at the time of breeding, in all animals. In fact, at other times, they are often almost entirely absent, or only the vesicles are found.

The semen of the male frog also shows them very well.

The zoospermes were first positively discovered by Ham, in 167\%, at Leyden, and afterwards more thoroughly examined by Leeuwenhock, who announced the fact of their existence to the Royal Society of England. Immediately all the savants then living became interested, and the microscope was brought into general use for their examination. King Charles himself had them displayed before him, and his whole court followed suit. In fact, the whole learned world was much excited, and the most curious speculations and theories were based upon the remarkable discovery.

The zoospermes were first discovered in the human semen, but examination soon showed that they existed in that of all beings, down to inșects.

The form of the zoosperm varies not only in the different classes of animals, but even in the species, so much so, in fact, that some physiologists have thought the different species could be distinguished by them ; some of these differences are noted elsewhere, both pictorially and by description, but only those which have been thoroughly identified. The older physiologists, who worked with imperfect microscopes, gave very erroneous representations of them, but the more perfect instruments we now possess enable us to observe them plainly, and to portray them accurately.

The great controversy has been as to their nature, many being loath to admit that they are real living beings. $\Lambda$ careful examination of them, however, can scarcely leave a doubt on this point. If they are not living creatures, then neither are large 


\section{PLATE IX.}

SEMINAL ANIMALCULES OF THE FROG.

Figure 1 shows an animalcule with the granular globule still attached to the lower end. It is nearly straight.

Figure 2. It is seen beginning to bend, and it goes on bending more and more, as seen in Figures 2, 3, 4, 5 .

In Figure 6 the two ends cross.

Figure \%. The two parts begin to twist.

Figures \%, 8. The twisting has proceeded still farther.

In Figure 9 it is seen with the two parts firmly twisted into one, the loop at the top seeming to form a head.

Figure 10 shows a seminal vesicle bursting, and the animalcules escaping in a bundle, each one with a small yellow granular globule attached to one end.

Figure 11 shows the bundle beginning to break up, so that each becomes separate.

Figure 12. Semen of the frog in water, showing the animalcules, the mucous globules, and seminal vesicles.

Figure 13. Mucous globules.

Figure 14. The yellow granular globule, which is attached to one end of each animalcule when it first comes out of the resicle.

Figures 15 and 16 show two of the animalcules much enlarged.

These changes in form are very curious to observe, and are well worth close atten. tion. The semen should be taken at spawning time, in the spring 
PLATE IX

Fig. 12
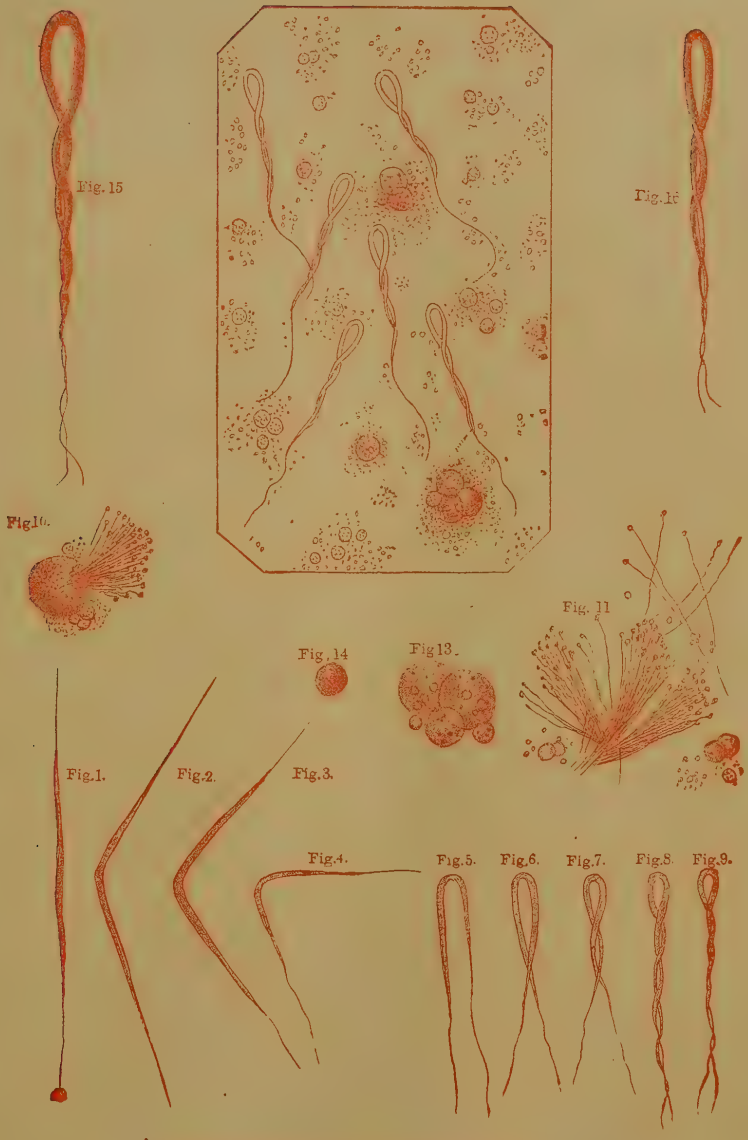

Sominal F'lind and Animalcules of the Frog. 

numbers of insects and infusoria, for the zoospermes have all the vital properties of these in perfection.

In fact, the investigations of Pouchet and others prove that they have internal organs-presumably digestive-and also fins, by which they swim, as fishes do: they also develop from eggs, just like many other animalcules.

The manner in which the zoospermes move is different in those of different animals; some move simply by lashing with the tail, while others progress by means of a fin on the back, and others again revolve in circles, so that they vary in this respect as much as the different kinds of infusoria.

In the human zoosperm, the motion is always straight forward, and it seems to be effected partly by the undulations of the tail, and partly by the motion of a real fin, on one of the edges, which can be readily seen when the animalcule is examined in profile. It is also covered by a kind of membrane, or skin, which is sometimes cast off-as snakes cast their skin -and is then seen to hang about them in shreds, as seen in some of the illustrations we give.

Schwan even asserts that the human zoosperm possesses a sucker, by which it can attach itself firmly to any part with which it may come in contact; and Ehrenberg asserts the same. Gerber goes so far as to tell us that he clearly detected organs of generation in some that he examined.

Close observation proves that the zoospermes in all animals, develop in vesicles, or cells, as shown in the human being. In many persons suffering from wasting diseases these vesicles are often absent, or very small, and they consequently have no animalcules or very imperfect ones.

Lallemand has demonstrated that the zoospermes exist at first as small globules, and that they grow and develop into a larger and more perfect form gradually, as other animals do. It is, probably, this growth of the zoospermes which causes the testes, in certain animals, to increase so remarkably in size at the season of coupling. In the drake, for instance, they then become three times as large as at other seasons.

It is conjectured, with good reason, that when the testes of these animals are at the smallest, they do not contain animalcules at all, but only their ovæ. After a time these become ripe, break open, and emit the animalcules, which then perfect their development, and by their increase of size, cause the enlargement of the testes.

That the animaleules usually decrease in size in old age, or during certain diseases, is well established, and they are also dull and slow in their movements in such cases.

Henle assures us that the power of locomotion, in a healthy zoosperm, is such that it will traverse the distance of an inch in seven minutes and a half; which is considerable, when its minute size is considered.

When moving, they will turn aside to avoid any object, or to pass by one another, just as other animals do, indicating even will, or choice. Prussic acid kills them instantly, and so does strychnine, after throwing them into convulsions. A slight shock of electricity deprives them of life as certainly as a stroke of lightning does a man.

Meyer and Werneck even assert that the pollen of plants consists essentially of animalcules, having all the characteristics above described; and certainly, as elsewhere shown, the resemblance between them is very close, both in form and action. 


\section{PLATE $\mathrm{X}$.}

SEMTNAL ANIMALCULES; AND EGG, OF A RABBIT.

Figure 1 shows some of the mucus, mixed with semen, taken from the organs of a female rabbit, twenty hours after connection with the male. The animalcules are still living, in the midst of blood corpuscles and mucous globules.

Figure 1a. A mucous globule much magnified.

Figure 2. The same fluid taken thirty hours after. The animalcules are seen to be dead, and more or less broken up.

Figures 3 and 4 show animalcules much magnified, seen in different ways.

Figure 5. The bodies of dead animalcules.

Figure 6. A separate body magnified. There is apparently no trace of internal organs.

Figure 3. Smaller animaleules.

Figure 9. Egg of the rabbit, fifteen hours after connection with the male.

Figure $a$. Seminal animalcule of the bat.

Figure $b$. Seminal animalcule of the bear. In this there are seen two openings, the one at the top supposed to be the mouth, and the other the anus.

Figure $c$. Seminal animalcules of the Guinea-pig. 
FLITE X.

Fig.3.

Fig.1.

Fig-4
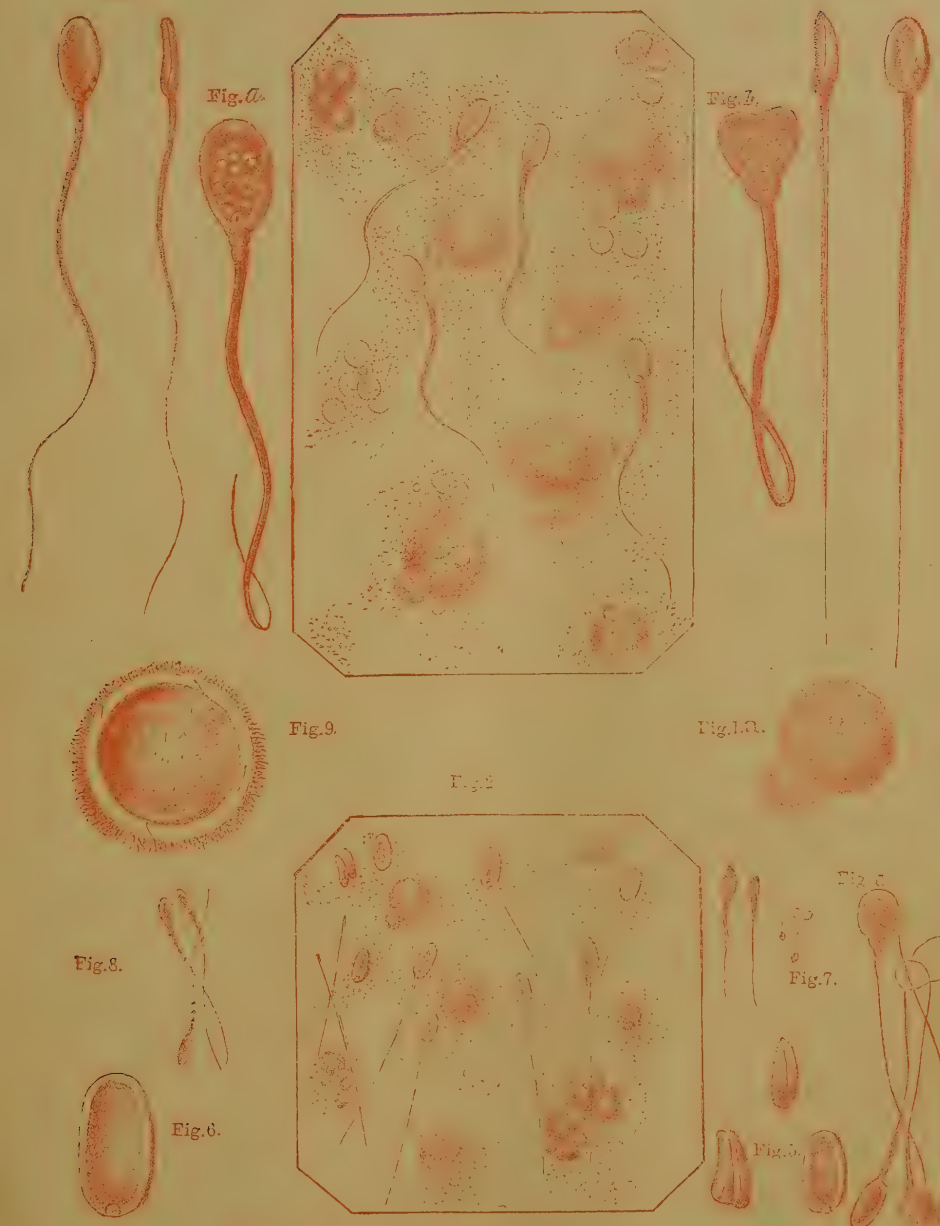

Fig.9.

I: 3.1 .2$.

T....

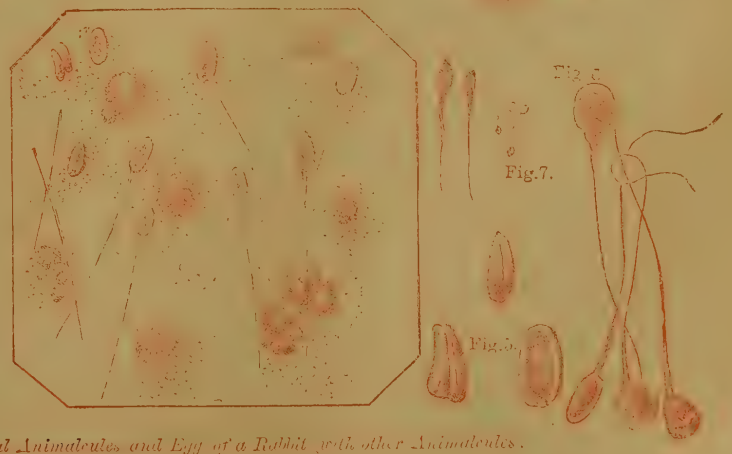

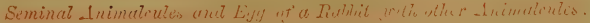



And this accords perfectly with what is shown elsewhere, that plants and animals are, essentially, in the primitive form, identical with each other.

It may be stated as an absolute fact that living animalcules, variable in form, are found in the semen of all animals, and that they are the real vivifying, or impregnating principle of the semen. If they be filtered out, the remaining part of the seminal fluid has no effect on the female egg whatever. They are not found before puberty, and in those animals which propagate only at certain seasons, the animalcules are found in the semen only at those seasons.

In the polecat, the head of the animalcule is round, large, and flat, so that when they are laid sideways, only the head and tail can be seen. They much resemble tadpoles, and have similar movements, effected entirely by the bending and straightening of the tail. The movement is always forward, and never backward, as is the case, indeed, with those of most animals.

The animalcules of the $d o g$ are much like those of the polecat, but are not so large.

Those of the rabbit, shown in the illustrations, are longer than those of the dog, and they are the most active and the most varied in their motions of all the animals yet examined, which makes them very valuable for observation.

The animalcules of the Guinea-pig are longer than any of the others above named, and much resemble those of the polecat, excepting that on the head is noticed a circular semi-transparent mark.

In the field mouse they are very long, and shaped like eels, which they also resemble in their mode of swimming. Their heads are marked by several transparent dots, similar to the one observed in the polecat, which give them a very peculiar appearance. The rat and common mouse are very similar to the field mouse.

The animalcules of the horse are not large in proportion to the animal, and have round heads, in the center of which is a clear, bright, globulár point.

Those of the common fowl and the pigeon are very much alike, having an oblong head, with the usual long tapering tail. Those of the duck are shorter and thicker, and are only found in the spring and beginning of summer. In fact, in all birds that have a pairing season, we find the animalcules only at that season.

The largest animalcules, not only in proportion to the animal, but absolutely, are found in snails, which seem to have been unusually favored by nature, in regard to sexual development.

In whatever light they may be regarded, these beings possess great interest. They are undoubtedly the beginning, in some way or other, of all animals, but we know very little of the way in which they begin. 


\section{CHAPTER XIX.}

\section{IMPREGNATION, EXTERNAL AND INTERNAL.}

POUCHET'S TEN FUNDAMENTAL LAWS WHICH GOVERN THE PROCESS OF FECUNDATION.

1st Law. Generation is essentially the same in all beings, mankind not excepted.

$2 d$ Law. In all beings, the female eggs exist before and independent of conception, the same as the male semen does.

$3 d$ Law. The egg is never impregnated in the ovary or organ that produces it.

4th Law. The egg must always have attained a certain development before it can be impregnated, and must also have left the ovary.

5th Law. In all beings the egg leaves the ovary independent of impregnation.

6 th Law. In all animals the eggs are emitted at certain regular periods, peculiar to each, at which times there also occurs a peculiar excitement of the female organs.

7th Law. Conception can occur only when the semen is present at the same time with the perfectly developed egg.

8 th Law. The menstruation of the human female is strictly analogous to the periodical erotic excitement of other animals, sometimes termed the rut or heat.

9th Law. Consequently, conception is necessarily connected with menstruation, and there is, therefore, in human females, a period when impregnation can occur, and one when it cannot, and those periods can be pointed out.

10th Law. In the human being, impregnation always takes place either in the womb, or in the very end of the tube next to the womb.

IT has already been shown by the previous explanations, that the two generative principles, the sperm cell and the germ cell, must be brought together before they can originate a new being by their joint action. This union is called impregnation, or fecundation, and it is effected in many different ways; sometimes it occurs in the body of the female, and at other times without. When it occurs within the female body it is effected by the act of copulation, for which special organs exist, which will be described farther on; when it occurs without the body, the process is much more simple, no act analogous to copulation then taking place.

The actual process of impregnation, or that union of the two principles from which the new being originates, has always been a physiological mystery, and a fruitful theme for philosophical speculation. It is evident, however, that the only way to clear up such a mystery, is to examine the generative organs, and their products, under every possible variety of circumstances, and to do this with care and patience for a length of time, so that a sufficient number of observations may be made. This task has only bcen undertaken very recently, and consequently our knowledge of this mysterious process, until lately, has been altogether incomplete and imperfect. The investigations already referred to, and others which will be men- 
tioned farther on, have developed the laws of fecundation, and removed that process altogether from the field of mere speculation. M. Pouchet was undoubtedly the first who clearly enunciated these laws in any publication, though others had arrived at them independently; we will, therefore, state them as he has done, and then make whatever comments and further statements may be necessary.

The First of these Laws has been already well illustrated in our first articles, where it has been shown that the generative process is essentially the same in man as in all other beings, though it was formerly thought to be different. All animals, it was there explained, are dereloped from eggs, formed in the female's body, only in some these eggs are impregnated and developed internally, and in others externally; and in some, as the human being, for instance, they are very minute, and, therefore, diiiticult to discover.

I'Lere are four different varieties of the generative process; the viviparous, or that in which the eggs are impregnated and developed into the new being within the body, as in the human being; the oviparous, or that in which the eggs are impregnated within the body, but expelled and hatched without, as in birds; the ovoviviparous, or that in which the eggs are impregnated within the body, and hatched while they are passing out, as in some insects and reptiles; and lastly, tho marsupial variety, or that in which the young are half-formed within the body and complete their growth without, as in the kangaroo. To one or the other of these varieties the generation of every animal can be referred, though in some there may be unimportant peculiarities in the process.

An example of ovoviviparous generation may be seen in the common meat-fiy, which does not lay eggs upon the meat, but little larvæ, or maggots, perfectly formed, the eggs being hatched while passing down the canal from its body. In come species, the young have even developed into perfect insects, and are ready to undergo their metamorphosis when they pass from the body of the mother. The young scorpion is perfect, and begins to walk immediately it is born, having been hatched and developed within the parental body, and the same thing is observed in the common aphis, or green plant-louse. Some insects can even generate both ways, and produce sometimes eggs, and sometimes perfect young, or even both together, in immense numbers. The structure of the egg is always the same, but in thэ oviparous animals it has added to it a quantity of extraneous nutriment by which the new being is nourished while in the shell, or outer covering. The eggs of the viviparous have nothing of the kind, because they are attached, from the first moment of conception, to the mother's body, and derive their nutriment from it. Tha large portion of vitellus, or yellow, which we see in the egg of the chicken, is only intended to supply nutriment to the young, and so is the albumen, or white, which, with the shell, form no part of the egg, properly speaking, but are formed around it, after it leaves the ovary, and while passing from the body.

An examination of the ovarium of the bird will make many of these statements ieadily understood, and will be found a very useful study. It consists, during the laying period, of a large number of ova, of various sizes, all fastened by ligaments, or small stems, to a central point, which is the true ovarium, and from which they all originate. Some of the ova, or eggs, are very minute, like mustard-seeds, while others are larger, and a few are nearly as large as when expelled from the body, but none of these have either white or shell while they remain connected with the ovary. As the egg enlarges, the ligament which holds it becomes less, and eventually, when 
it has attained its full growth, the ligament breaks and the egg is dropped into the canal, or passage, by which it is to escape from the body. It then consists merely of the vitellus, or yellow, and the cicatricula, or germinative vesicle, but as it proceeds along the passage, the white, or albumen, is deposited around it, and the shell forms around the whole, till it assumes the form we usually see. The shell and the albumen, therefore, are mere extraneous matters, and not essential parts of the egg or ovum, though necessary to its protection and development when out of the body, and it is not unusual for the egg to be expelled without them, especially when the bird is diseased, or not provided with sufficient lime for the shell.

The true definition of a viviparous animal, therefore, is one whose egg cannot develop without being connected with its body, while the egg of an oviparous animal is capable of developing alone, merely by the application of a proper degree of heat.

The truth of the Second Law is obvious in respect to all oviparous animals, especially birds, who are known to have eggs, and to lay them, before being impregnated, but it is not so obvious in respect to viviparous animals, whose eggs are so small that they are only discovered by the microscopical anatomist. A consideration of the facts already adduced will prove, however, that in the whole class, mankind included, the law also prevails, and that eggs are formed and expelled in them also independently of impregnation. The celebrated Harvey was convinced of this fact, though he had not the proof of it, and he laid down an axiom, in accordance with his conviction, which can now be received without question-"Everything living," said he, "comes from an egg." There are some of the lower animals, it is true, that seem to reproduce their young without eggs, by fissiparous or gemmiparous generation, but these are now known to be only modifications of the oviparous process. In fissiparous generation the parent simply splits up, or divides spontaneously, into two or more parts, which grow into new beings that also divide again in their turn in the same way, and thus the species are continued. The fresh-water polype is an instance of this mode of generation, and if it be cut into pieces with a knife each part will grow into a perfect being, which may also be divided in the same way, apparently without limit. In gemmiparous generation the original being simply gives out little buds, or germs, from its body, which develop into perfect beings, as we see in the sponge and the hydra; the buds being sometimes cast off to develop alone, and sometimes all remaining attached to the parent till a large bed or mass of them is formed.

These animals that propagate by the fissiparous process are all exceedingly simple in their organization, and many of them may be turned inside out, like a glove, without the slightest injury or inconvenience. It is probable, therefore, that the whole being is merely like an ovary, and that every atom of it is a germ or egg, capable of development alone, like the bud of a tree. Those that propagate by the gemmiparous process are also very inferiorly organized, and in all probability the buds or germs which they give off are really ova, or eggs, expelled spontaneously. In fact, many of these beings propagate by the oviparous mode as well, and their whole substance seems to resolve itself into germs of new organizations.

The Third Law says that the semen cannot reach the eggs, to impregnate them, while they remain in the vesicles of the ovary, and a slight consideration of the numerous obstacles interposed will show that this must be so. In the first place, the action of the Fallopian tubes, and the cilia which line their interior, as before explained, 
is such that nothing can pass towards the ovary from the womb, but only in the other direction. And besides this, while the egg is in the vesicle it is surrounded by a number of different membranes, either of which would present an impassable barrier to the semen, even if it could reach the exterior of the ovary. But there is still another obstacle if these were overcome, as if nature had taken special care that no such event should take place. The interior of the tube is compactly filled with a thick mucus, in which the cilia work, and through which the semen could not possibly force its way. In fact, there seems to be considerable difficulty even in forcing the egg down the tubes the right way, and it is probable that very frequently it does not pass down before its structure is broken up, so that it cannot be impregnated. This is apparently the reason why there are but few women who continue to bear children uninterruptedly, most of them having more or less interval between, frequently of years. They form the egg regularly every month, and might conceive therefore every ten or twelve months, but all the eggs do not reach the womb in time, a large number of them being so long in passing down the tubes that they are spoilt before the semen can reach them. Perhaps this is an express provision, to prevent women from being debilitated by sickness, and worn down by anxiety, as most of them would certainly be if they were to bear children continually. With human beings there are many considerations which make it undesirable for reproduction to be frequent, and this is probably a natural check. Some females, it is well known, are not restricted in this way, but continue to conceive regularly a short time after every delivery. In such persons there is no doubt a uniform transmission of the egg, which, therefore, always reaches the womb in a state fit for receiving the male semen. In many cases of barrenness also, I find that stimulating the Fallopian tubes, at the proper time, will remove the disability, apparently by quickening their action, and causing the egg to reach the womb earlier, and in a better condition for being impregnated.

The old theory of impregnation was that the semen was absorbed, or sucked up, into the womb and along the Fallopian tubes till it reached the ovary, when it impregnated one of the eggs and so stimulated it to commence developing. It was then supposed that this impregnated egg, after a time, separated from the ovary and passed down the tube into the womb, where it formed into the foetus. The facts just mentioned, however, show the fallacy of this theory, even if the correct process had not been given before, but still it has been received so long, and has become so orthodox, that many celebrated men hesitate to reject it even now.

Abundant proof has been obtained that the thick portion of the semen must actually touch the egg itself, without any obstruction, or there can be no impregnation. Spallanzani proved this by his experiment upon the eggs of fishes. $\mathrm{He}$ found that if semen from the male fish were put into the water, along with the female eggs, they would, after a time, begin to develop, and ultimately form into young fishes, but not if the semen were kept away. He then filtered the semen, and tried the thin part of it, but that had no effect, though the thick part, which contained the animalcules, impregnated immediately. Somerphysiologists had concluded that it was merely the aura, a kind of steam from the semen, which impregnated, and he therefore exposed some of the eggs to this steam, for various periods of time, but always with no effect. The same results have also followed experiments made upon animals, by myself, for in no case did impregnation follow from the mere aura. of the semen, though it was applied directly to the mouth of the womb, as well as in the ragina. It is therefore certain that the thick semen itself must touch the 
egg, and this it cannot do while the egg is in the vesicle of the ovary, because it cannot reach the ovary.

The Fourth Law asserts further that before the egg can be impregnated it must have acquired a certain development, and must have separated from the ovary. Reason alone would assure us of this, because it is evident that the egg must be perfectly formed before it could be affected by the semen, and when it has attained this stage it is ripe, and is cast off from the ovary like a ripe fruit from the tree.

The precise period when the egg leaves the ovary appears to be when it has exhausted all the nutriment in the vesicle, as evidenced by the complete absorption of the white fluid, and it is detached in order to seek the means of further growth elsewhere, as the ripe seed of the plant is thrown to the ground.

In the great majority of animals the egg is not impregnated till it has passed a long way from the ovary, which is usually deep within the body, and sometimes it even leaves the body before it is fecundated. The eggs cannot be impregnated if taken from the ovary, as experiment has proved, but they must have left it spontaneously, and sufficiently long for the peculiar change we have before explained to take place in them. Impregnation could not take place, therefore, from the semen reaching the ovary, even if its passage there was possible.

In the case of the bird, the egg is impregnated immediately it leaves the ovary, before the shell is formed over it, but not while attached by its ligament. The female bird is provided with a peculiar pouch or receptacle, into which the semen is absorbed at the time of copulation, and in which it will remain unchanged for a long time. This pouch is so placed that the egg passes by it on leaving the ovary, and in such a manner that it absorbs a portion of the semen contained in it, and thus becomes impregnated. The quantity of semen thus stored up is something considerable, and as only a small portion is needed to fecundate each egg, it is possible for a single copulation to impregnate all the eggs that may be laid for a long time after, as we often see in the common fowl.

In some animals the egg is not perfect enough for impregnation even when it leaves the ovary, but is kept for a time longer in a peculiar organ provided for the purpose, in which it maturates more perfectly, and is then expelled into the passage to meet the semen. This is the case with many fishes and reptiles, and if the egg be taken before its sojourn in that peculiar organ, it cannot be fecundated.

It is erident, therefore, that the egg must have attained a certain development before it can be impregnated, and that it must also have left the ovary for some definite time.

The Fifth Law, wbich asserts that in all beings the eggs are formed and leave the ovary independent of xmpregnation, is almost proved sufficiently by the facts already adduced, but a fev, additional observations will make it still more clear. With respect to birds, this law was long known to be correct, because they frequently produce eggs without having ever had any connection with the male; and it was also equally evident in regard to most fishes, whose eggs are impregnated after they leave the body. In frogs also, as before stated, the male deposits his semen on the eggs as the female expels them from her body, which proves that their formation and expulsion is independent of impregnation. The difficulty in proving that this law applies to all beings, especially to the human being, arose from want of proper observation, and from the supposition that the egg in them was in sume respect different to that of oviparous animals. Now that the universal similarity of the egg is proved, how- 
ever, and that we know it is produced by a similar process in all, it is also made evident that it is formed and emitted independent of impregnation. In fact, one essential part of the egg, the vitellus, from which part of the new being is formed, is found in undoubted virgins, and even in children occasionally, when it could not, of course, have had its development influenced by impregnation.

Nevertheless, it must be observed that sexual excitement may hasten the ripening of the eggs, because it 1ray excite the ovaries, and expedite their functions, as our former observations have shown. In some cases it even appears that the egg will partially develop from mere excitement, without any contact with the male principle, as several instances already given have proved. In this way are produced those imperfect foetal growths occasionally met with in the ovaries, and which have been found even in children. And in the same way, in all probability, arises that partial development of the new being found sometimes in the unimpregnated egg of the bird, many instances of which are upon record.

In short, the growth and expulsion of the egg is a process belonging to the female system alone, and no more requires the influence of the male, in any way, than he requires the influence of the female to cause the testes to form the semen. Many females, who possess sufficient physiological knowledge, and who have been observant of their own systems, know precisely the time when the eggs leave their bodies, and can readily obtain them every monthly period. This I have known many do, and it is sometimes necessary in determining the causes of sterility, which occasionally results from the egg being imperfectly formed, and we cannot ascertain whether they are perfect or not without examining them.

The Sixth Law merely states that in all animals the expulsion of the egg occurs at regular intervals, varying in their duration in the different kinds. In some beings there is only one expulsion during their lives, and this usually terminates their existence, as we see in many insects. In some the expulsion is annual, in others, biennial, and in others again every three years, and sometimes it is as often as daily; in the human being it is monthly. This regular ovarian expulsion also occurs along with the periodic excitement called the rut, or heat, in the lower animals, and the monthly period, or menstruation, in the human being. In fact, the periodic excitement results from the periodic expulsion, and both are parts of one grand phenomenon.

This periodic excitement, especially as it appears in the form of menstruation in the human being, exerts a most potent influence over the rest of the system, and makes the female in many respects essentially different from the male, as fully explained in our article on Menstruation. It commences first in the ovaries, but is propagated from them to the whole of the generative apparatus, and sometimes even to remote parts.

The excitement caused by the expulsion of the egg is not, in the inferior beings, accompanied by such a discharge as we observe from the human female, though in nearly all there is some secretion, and in particular species it is even colored. In all cases, however, the excitement of the parts is obvious enough, and is sometimes quite remarkable externally. In some of the apes not only are the external genitals inflamed, but also the parts around the anus, and even the thighs, which are sometimes covered with large tumefactions, of a bright red color, during every period. In all birds the inflamed condition of the external parts, while they are laying, may be readily seen, and it is observable also in fishes. Occasionally this external excite- 
ment occurs in human beings at such times, and some females are always troubled then with swollen labia, or eruptions on the skin.

In every instance the excitement and flow is terminated by the expulsion of the egg from the ovary, which constitutes the crisis. In no instance is there any excitement, or flow, in those females that have been castrated, because they can have no expulsion of ova, but in all those whose functions are natural, the excitement occurs at regular periods, and is always accompanied by the maturation and discharge of ova.

When animals are domesticated their periods are considerably modified, being usually hastened, but still they almost invariably observe a certain degree of regularity. Many females are also much affected by their mode of life, being made to menstruate, or flood, almost continually, by the influence of stimulating food and drink, and by too much artificial heat.

The Seventh Law enunciates a most important truth, which is the foundation of much valuable advice, and gives us the key to the true time of conception. It states that conception can never occur except when the male semen is deposited in the female organs at the same time that a ripe egg reaches them, or, in other words, for a copulation to be fruitful it must coincide with the expulsion of the egg. The truth of this will be obvious from our previous statements, for it is evident that if the semen cannot reach the egg while it is in the ovary, and that has been shown to be impossible, it can only do so after it is expelled and brought into or near the womb. In fact, the egg has some further change to undergo after it leaves the ovary before it can be fecundated, and this is the reason for its being somewhat delayed by passing down the tubes. This law is strictly in accordance with the fact before mentioned, that the expulsion of the egg takes place just when the flow is over, as that is the time when conception really occurs, and when most animals also desire association. It is not at the commencement of the rut that female animals desire the male, but after the discharge has continued for a few days, and just when it is ceasing. The slut, for instance, will repel the dog at first, and so will the female rabbit repel the male, and even fight with him, until about the third day of heat, and then she submits. This is evidently because the eggs have not descended till that time, and nature has so provided that association shall only be sought when it is likely to be fruitful. If any of these animals were compelled to copulate during the first days of the excitement there would be no fecundation, because the presence of the semen does not then coincide with the presence of the egg.

The Eighth Law is merely a distinct enunciation of a truth already abundantly proved, namely: that the menstruation of the human female is identical with the peculiar excitement observed periodically upon all other animals, and called the rut, heat, or cestrum.

According to the Ninth Law, it is possible, at least in the human being, to designate the precise time when conception is possible, and also that in which it is impossible. This law also follows naturally from the foregoing explanations, they having shown that the egg remains but a certain number of days in the womb, after which it passes from the body and is lost, and since the semen can reach the egg only while it is in or near the womb, it is evident that the days during which it stays there are the only ones in which conception is possible, and that at all other times it is absolutely impossible. When we have ascertained, therefore, the precise time which the egg stays in the womb, and tube, we know to a certainty the time when 
conception can occur, and also when it cannot. In another article I shall point out this time accurately, and explain how it is ascertained.

The Tenth Law is important because it shows where fecundation occurs. Acrording to this law the two principles can only meet in the uterus, or at the uterine ends of the Fallopian tubes. The proofs of this are many and various, and quite sufficient to put its truth beyond a doubt. In the first place it must be borne in mind that the semen cannot pass down the tubes, as already shown, and consequently cannot get farther than the womb. In fact, if animals be killed as long as twenty-six hours after connection, the semen is still in the womb, and if killed after that time it has gone no farther, but has begun to decompose. In some few cases it has been found a little way within the Fallopian tabe, and once or twice nearly as far as the middle of the tube, but no farther. In no instance have the animalcules of the semen been found on the ovary, nor beyond the middle of the tube, though sought for in hundreds of cases. It is true that in some cases anatomists have thought that they discovered the animalcules upon the ovary, but it is now generally admitted that they were mistaken, and their error probably originated in this way : There are often fragments of mucous membrane, partly organized, which much resemble the animalcules, and without very close inspection may readily be mistaken for them. These are called false zoospermes, and in all probability it was some of those that came under view. Every accurate observer has failed to deteci them in any other parts than those mentioned.

\section{WHEN CONCEPTION IS POSSIBLE AND IMPOSSIBLE.}

Numerous observations have established the following facts respeccing the time of conception in the human being, and they may be relied upon with the utmost certainty.

The Graafian vesicle, which contains the egg in the ovary, enlarges while the menstrual flow is taking place, and it bursts open, to let the egg escape, on the first, second, third, or fourth day after the flow has ceased, but most usually on the first day.

The egg is then taken hold of by the fringes at the end of the tube and carried into the passage, down which it slowly progresses, taking from two to six days to reach the womb.

The time, therefore, in which the egg reaches the womb, varies from one or two to ten days after the menstrual flow has ceased.

When the egg reaches the womb, it would-if there were no special provision to prevent it-immediately fall down to its mouth, and escape from the body, but this is provided against. While the egg is passing down the tabes, or during the latter part of the flow, a peculiar delicate membrane, or skin, called the decidua, forms around the inner walls of the womb, so as completely to block up its mouth. This membrane presses against the opening from the Fallopian tubes also, so that when the egg passes out of the tube it pushes against the membrane, and makes a hollow, or kind of nest, in which it lies. This, therefore, prevents the egg from passing immediately away, and it evidently must be retained in the womb as long as the decidua remains.

The time that the decidua remains attached also varies from two to six days, but nsually it is about four, and at the end of that time, unless conception occurs, it 
looses from the walls of the womb, passes out of its month, down the vagina, an? takes the egg along with it, so that both leave the body and are lost. If impregnation takes place, however, or, in other words, if the male semen reaches the egg while it is thus detained, it remains, and both it and the decidua grow fast to the womb. The egg then forms the rudiment of the new being, and the membrane becomes one of its coverings or envelopes.

When the egg and the decidua have fallen, or, in other words, when the egg is thrown out of the body, there cannot, of course, be any conception till another period comes round, because there is no egg in the womb to be impregnated. After this time, therefore, conception is impossible, and its maximum limits at least may be stated with certainty. From the above statements it will be seen that the egg reaches thie womb some time between the second and tenth day after the menstrual flow has stopped, and that it then remains there from two to six days at the utmost, but after that it passes away. Consequently, conception is possible as long as sixteen days after every monthly flow has stopped, but after that time it is impossible! In fact, it is hardly ever the case that it can take place so long as sixteen days after, because the egg is seldom more than two days in reaching the womb, and if it remains six, as an extreme limit, eight days is probably about the average. If the truth could be ascertained, I have no doubt but that nine out of every ten pregnant females have conceived within the first seven days after the flow, and that impregnation would not follow connection after the tenth day once out of fifty times, but still it is requisite to state the latest possible time, and that is sixteen days.

An instance illustrative of this principle is recorded in history. Henry II. of. France had been long married without offspring, and had consulted varions medical men as to the cause, without success, till he sent for the celebrated Fernel, who, upon due consideration, simply advised him to always associate with his spouse $\mathrm{im}$. mediately after the cessation of her periods. This advice was acted upon, and she, conceived, after being childless eleven years. In all probsbility the egg escaped in her case very soon, and association had never before been had till after it was lost.

Every other being also has its limited time, but it is various in different kinds. I have ascertained it in several, and invariably, if they were not allowed to associate with the male till that time was passed, they never conceived. There are signs, however, by which any intelligent and observant female can ascertain that time in her own case, and those signs we will now explain.

Some time within the first five or six days after the cessation of the flow, but usually on the first or second, all females experience a sensation of weight and uneasiness, or of slight pain, in the region of the Fallopian-tubes, or across the abdomen, on a line with the lower edge of the hip-bones. This sensation may be very slight in some, but in others it is quite acute, and there are few but what can detect more or less of it if they observe. This indicates the passage of the egg down the Fallopian tube, and is caused by its contraction. In fact, many females can distinctly feel the tubes drawing together, as they express it, and sometimes the contractions may even be seen externally. Previous to these contractions the mucus discharged from the vagina is usually thick and adhesive, but after they have ceased, it becomes thinner and more transparent. The passage of the egg down the tabe is indicated, thereLore, by very obvious signs, which, I am confident, are but seldom absent.

The passage of the egg out of the womb, or the fall of the Aecidua, which makes 
conception impossible afterwards, is even more strongly and constantly marked, and can be known by nearly all females. The first indication is an increased flow of thin watery fluid from the vagina, so abundant sometimes as to wet all the external parts, and not unfrequently to cause some little irritation. Occasionally the discharge is tinged of a pale pink, but more usually it is colorless, and like the white of an egg. This may continue only for a few hours, or for a day or two, and is always followed by the escape of a small grayish white clot, somewhat firm and elastic. This clot is opaque, and varies from the size of a pea to that of a small bean. It much resembles the clots which are often coughed from the throat in bronchial affections, and is readily detected. Just previous to this appearing, and when the thin discharge is about ceasing, there is also felt a slight contraction and pain in the womb, accompanied with a feeling of weight and bearing down, similar to what is experienced during the menstrual flow itself. If this clot be examined with a microscope it will be found to consist of the decidua and the egg, which have thus been expelled. In fact, the slight pain and distress experienced, are caused by the womb contracting slightly to effect the expulsion, the same as it does during a miscarriage to effect the expulsion of the fotus. This is, then, the phenomenon of the fall of the decidua, or expulsion of the egg, called by the French the ponte, or laying, and when it has taken place there can be no impregnation till after another period.

In some females this expulsion of the egg is almost as distinctly marked as the monthly period itself, and even causes as much distress. In others, however, all the indications are very slight, but still I believe they are always manifested sufficiently for the time to be detected, if careful observation is kept.

The time when the expulsion occurs also varies in different persons, and under different circumstances. On the average, it is about the seventh or eighth day, but may be as late as the sixteenth, as before explained. The clot, of course, is always present at the time, and indicates it beyond a doubt.

I have known many females who have ascertained this time quite readily after the signs had been explained to them, and I believe nearly all would do so with a little trouble. Many of these have even detected and preserved the clot, which, on being placed under the microscope, has shown them the egg and its decidua most perfectly. Several of these clots I have in my cabinet, both of the human being and also of animals. Every female who thus ascertains the precise period of the expulsion of the egg, of course knows when conception in her case becomes impossible, because it cannot occur after the egg has escaped.

There are, however, many causes that may lead to error, and which may deceive persons very much if they are not acquainted with them. Thus, some females are constantly liable to mere floodings, or discharges of blood, from weakness, which they mistake for real menstrual periods, and thus miscalculate. Others, again, have periods that are colorless, as elsewhere explained, and they, therefore, never suspect what they are when they really do occur. All females are liable at times to these unusual appearances, and are likely, therefore, to suppose that they have a period when they have not, and that they are free from it when it is actually taking place. In this way mistakes are very apt to occur, unless the individual has been sufficiently observant to detect true menstruation by other signs than the mere color. It must be remembered that every discharge of blood is not a menstrual discharge, and that many true menstrual discharges are perfectly colorless. One sign can be always relied upon, however, to detect the true period, and that is the odor of the 
discharge, which is so peculiar, that when once known it cannot be mistaken, there being no other discharge resembling it. In an ordinary flooding there is seldom any particular odor, but this peculiar one is always present at every menstruation, though it be as thin and colorless as water.

It is owing to these occasional deviations and unusual appearances that some females have supposed they conceived immediately before the period. They had simply experienced a flooding, and mistook it for menstruation. Others have thought that they conceived without having menstruated, especially when nursing . but in them it had been colorless and unnoticed.

In very many cases I have made practical use of these facts, when consulted in cases of barrenness, and frequently with the most satisfactory results, as will be shown when speaking upon that disability.

In every instance-it may be confidently relied upon-conception takes place within sixteen days after a menstrual period, and usually within eight or nine days, though it may be often difficult to ascertain the period, and another phenomenon may be mistaken for it. At all other times impregnation is absolutely impossible, excepting possibly for a brief period before the actual cessation, in the way that will be explained in our next article.

\section{MANNER OF IMPREGNATION.}

The precise manner of impregnation, or the way in which the two principles actually unire, can only be understood by bearing in mind the account given of the semen in a former article. It was there shown that the essential part of this principle consists of certain little living beings, called the seminal animalcules, which, undoubtedly, are the true impregnators. If they are absent, or if their vitality be destroyed, the semen has no effect whatever on the egg. This fact has been ascertained for some time, but it is only recently that the mode in which they operate has become known.

When speaking upon the female egg, in a former article, it was stated, that while in the orary it contained a peculiar body, called the germinal vesicle, which, by a spontaneous movement, was cast out as soon as the egg entered the tube, in such a way as to cause a rent, or torn place, in the membrane surrounding the egg. This bursting open of the ovum had been noticed by many observers, but the object of it was long a mystery, till, fortunately, a curious discovery revealed its intention. It was found that if one of these seminal animalcules came in contact with an egg, which was opened in this way, it immediately crept in at the opening, and buried itself in the interior. The object, therefore, of the passing out of the vesicle, is, evidently, to open a passage, by which the animalcule can reach the interior of the egg, among the vitellus, or yellow, and when there it forms part of the rudiment of the future new being, as will be explained farther on. In this way, then, the two principles really unite, each being indispensable to the other, and the two together providing all the elements for the embryo, - the animalcule probably being the germ of the nervous system, or that part in which animal life really resides.

This also explains other circumstances formerly noticed, and shows that every peculiarity exhibited by either of the principles has its object. It was stated, for instance, respecting the animalcules, that they had a remarkable tendency to move in a straight-forward direction, and with considerable velocity. Now this tendency 
is evidently calculated to carry them up into the womb, so that they may reach the egg, and without it they might never arrive there. The semen is deposited, during coition, in the vagina, and was always supposed to be absorbed or sucked up into the womb, though not known to be so. It is probable that such absorption, or suction, does take place sometimes, but by no means invariably I am convinced, and I have no doubt whatever, that conception can occur without it. Many females habitually lose most or all of the semen after every association, and yet they conceive, though there evidently can occur but little passage of it in either of the above ways. The fact appears to be that the animalcules can pass up into the womb themselves, by their own motion, the tendency above noticed, to move forward in one direction, enabling them to do so. Immediately they are deposited in the vagina, if their vitality is perfect, all that find themselves placed in the proper direction, begin to move upwards, and they continue to do so till they reach the uterus, as nothing seems to make them ever turn in the opposite direction. When any of them reach the interior of the womb, if an egg be there that has been opened by the vesicle passing out, one of them passes in, and thus effects the impregnation. This fact has actually been seen under the microscope, and the entrance of the animalcule within the egg is an undoubted occurrence.

It is easy to see from this, why it is that conception does not occur, as is often the case, when the male is too debilitated to form perfect semen. The animalcules are then too weak to pass up into the womb, and consequently there is no impregnation. Any cause, therefore, which weakens their energy, and prevents their usual lively forward motion, is apt to prevent conception. . As long as they are alive, however, provided one of them can be conveyed to the egg, impregnation may be effected, which explains why some females, whose organs act energetically, can conceive from these debilitated individuals while others cannot do so. If the womb has great power it may draw up the semen, and so allow the animalcules to act, though they could not have moved up themselves, as they ordinarily do. In this way the greater energy of the female may partly make up for the exhaustion of the male, while, on the other hand, if the animalcules be unusually vigorous, they may reach the ovum entirely by their own unaided powers, and then impregnate when the female organs are totally powerless. From this we see why it is that conception can occur during sleep, or even during perfect unconsciousness from drugs, or blows upon the head, though most persons suppose otherwise. This has been proved, however, by numerous cases in human beings, as well as by direct experiment upon animals, and the reason will now be obvious enough. The condition of the female, though she be perfectly insensible, may not prevent conception, because the animalcules can move up into the womb by their own powers, and thus impregnate without any knowledge or concurrence whatever on her part. Many cases have been known in which females have conceived after having been violated but once, though people generally, and even medical men, have doubted it, and the possibility of their doing so will be obvious after this. It must be borne in mind, also, that in such cases the brutal violator is usually a man of strong passions, and of great sexual power, which may probably canse the animalcules to be unusually vigorous, and thus increase the likelihood of conception. I once knew a female who became pregnant after violation, during which she was perfectly insensible, but who never became so after marriage; the reason why, it was of course not possible to ascertain with certainty, but it may probably be found in the above explanation. 
This also shows how erroneous it is to suppose, as most people do, that a female cannot conceire unless she experiences sexual enjoyment, or if the association be repugnant to her. There are numbers who never knew what the sexual feeling was, and some who have even suffered both pain and disgust, constantly, in association, and yet they have become pregnant. Nor will this appear extraordinary after our explanation, which shows that the female may be quite passive, so much so, in fact, that conception may take place artificially, without connection. Experiments upon animals have proved that if the semen be merely thrown into the vagina, at the proper time, with a syringe, it will impregnate. And in some cases of malformation in married men, which prevented proper connection, the same practice has been adrised, and with complete success. In fact, the presence in the female organs of the perfect male semen, at the proper time, is all that is needed to cause conception, no matter how it may have come there, nor with what feelings its introduction may have been attended.

It should be observed, however, that though sexual feeling in the female is not absolutely necessary to conception yet, in many cases, it may much conduce to that event. Pleasurable excitement at the time of connection disposes the organs to more energetic action, and some females may possibly not conceive without it, though certainly all do not require it. We know that this excitement makes the tubes contract more rigorously, and this causes them to bring the egg down earlier, and probably, also, it may make the womb contract, so as to draw up the semen more completely. In many cases barren females, of a cold temperament, have conceived immediately after having the sexual feeling produced.

From the foregoing statements it will be seen that conception does not always take place at the moment of connection, nor even immediately after, and we shall soon discover that it may be delayed for a considerable time. As long as a living animalcule remains in the female organs it is possible for it to reach the womb, and thus effect impregnation if the egg be there. We have simply, therefore, to ascertain how long the animalcules retain their vitality, after being emitted in coition, and we shall then know the period during which impregnation may be delayed. In some females the semen is either absorbed, or the animalcules move up themselves, very quickly, so that they are impregnated almost at the moment of emission; but in others there is no absorption at all, and the animalcules may move very slowly. The actual time when the two principles unite, therefore, after a fruitful connection, is very different in different persons. It appears, according to accurate observations, that the animalcules can remain alive in the female organs as long as twenty-six hours after they have been deposited there in connection, and it follows, therefore, that the impregnation may not take place till that time after. It is found that they begin to die, usually, after the second hour, and fewer of them are found alive as the time advances. At twelve hours usually half of them are dead, and at twenty hours but few are found living, though one or two have been discovered even at the twentysixth hour. As they die they break up, the tail separates from the body, and both parts begin to dissolve. It is possible, therefore, that the impregnation may take place at any time within twenty-six hours after connection, and it is manifestly absurd to talk, as some persons do, about the importance of a proper state of mind at the moment of conception, as if that moment could be known. Perhaps the most frequent time is about two hours after connection, or when the animalcules begin to die, but of course there will be great variation. When the womb contracts with 
energy, or the animalcules are unusually vigorous, the conception will be quick, and when otherwise, the reverse. And this makes it more likely to be quick in those of warm temperaments.

It is barely possible that the animalcules could live through the latter part of the flow, if connection were had before it had ceased, and if so impregnation might follow such connection. Supposing the coition to occur twenty-six hours before the egg reached the womb, some of the animalcules might still be living when it arrived there, and of course could cause its impregnation, though unlikely. This is the only possible way in which conception can be effected before the cessation of the monthly flow. In many cases, however, the egg reaches the womb in less than trentysix hours after the flow stops, and therefore connection may always cause conception at any early time after, even immediately. The full time, therefore, during which impregnation is possible is for the sixteen days after the flow has ceased, and perhaps for the twenty-six hours before it ceases, at all other times it is impossible.

It may appear to some persons, who have not bestowed full attention upon the subject, that there is danger in making such facts as these known, because, they say, young persons, knowing that there are times when they can indulge with safety, will be led to do so, when they would not if they feared the consequenoes. All this I have duly considered, and yet have come to the conclusion that there would be no advantage, in any way, in attempting to suppress such truths. In the first place, as society is now constituted, and with the means of disseminating all kinds of knowledge so complete as we have them, it is not possible to prevent any interesting fact from becoming generally talked of, if it be known to ever so small a number. Some idea of it is sure to get abroad, and most probably an erroneous one, calculated to mislead and do more harm, a thousand times over, than the truth could ever do. If only medical men could read and write, and if it were certain that none of them would ever speak of such things, they might be kept secrets, but such is not the case. In short, it is impossible, even if it were advisable, to prevent such matters from becoming generally known, in some form or other, and it is far better for them to be known truly than otherwise.

It seems to me also that it is forming a very low and degrading opinion of young persons, especially of females, to suppose that they are only kept from indulgence by fear of the consequences. If their virtue is solely dependent upon this, it is scarcely deserving of the name, and, in my opinion, is not very safe even with the fear. I feel certain, however, that there are not many young females who would either be disposed or persuaded to such practices, even if they were assured there was no risk. Those who think that such a disposition is common amongst them are very much mistaken, and judge from very imperfect experience. Persons who think so are generally of loose habits and principles themselves, though they may, from caution, disguise it, and their experience of females has usually been of the most unfortunate class, whom they have erroneously taken for correct types of the whole sex. The great majority of females are actuated by far more powerful and more desirable motives than fear of consequences, and it is well they are, for that alone would be a wretched dependence. I much doubt if any one ever remained permanently virtuous from this fear alone, for some time or other the fear would either be overcome, or means would be found of aroiding the consequences.

A very little consideration will, I feel assured, show the fallacy and injustice of 
this imputation, and explode the erroneous doctrine that ignorance is necessary to virtue. If it be true that young persons would practice association if they knew there was no danger, it follows, of course, that they are disposed to such indulgences, and that they are pleasing to them. Now, if this be the case, why is it that we do not find them, at the present time, taking and allowing other liberties, which would certainly be pleasing enough to make them desired, and in which they do know there is no danger? If we are to suppose, in respect to any two young persons, that the only reason they do not actually associate is the fear of consequences, we may justly conclude that they are, the whole time, in the habit of all other practices that can in any way gratify their propensities, and which they know are safe. No one, I expect, will presume to say that such vicious practices are universal, and yet, if fear alone prevents worse practices, and these are known to be perfectly safe, why are they not universal ? The truth is, as before remarked, that there are, especially in young females, other motives and sentiments of a higher order, which are the true barriers against vice, and when these are absent, fear alone is seldom any safeguard whatever. There are few adult persons, if any, who do not know that association can be practiced without danger, by observing certain precautions, which still leave the indulgence pleasing enough : and yet, I presume, no one will contend that such a practice is pursued, though it certainly ought to be universally, if fear of consequences alone restrain, because here there is no danger.

Besides all this, there is another consideration, which should not be lost sight of. If it be contended that young people would immediately seek indulgence when they knew there was no danger, it must be admitted that they are usually in the habit of confidential communication with each other on such matters, and of discussing the chances of escape from the consequences, or else a mutual understanding could not be come to. Will any one either contend or admit that this is the case? I presume not; and I am confident it is not so. With all virtuous-or even commonly decent young persons, before marriage, such subjects are never spoken of in a familiar manner, and any attempt to do so in either, would nearly always alarm the other, and put them on their guard. How, then, could the subject be ever introduced between them, so that everything relating to times and periods could be calculated? The idea is as preposterous as it is unjust, and cannot be admitted for a moment, in reference to young people generally.

It is pretty evident to my mind, that any young persons who would deliberately enter into such calculations, and come to such a mutual understanding, merely from becoming possessed of this piece of information, could not have been virtuous before. They must have been in the habit of other familiar practices, and, in all probability, of forming plans, or they could not see any opportunity in this.

It is time now that the people became acquainted with one most important truth, namely, that ignorance is but a poor crutch for virtue, even when it can be maintained, but at the present time it is doubly worthless, from the fact that intelligence is liable to knock it from under the moral cripple at any moment. Knowledge and good principles are far more worthy of confidence, for they will never fail in the hour of need, nor can they be weakened by any additional information fortuitously acquired; whereas, with ignorance, there is constant danger.

It is true there are some people who will make an improper use of any knowledge that can be given them, but that is no reason why all others should be deprived of it. These people are moral lunatics, and to withhold all knowledge from others, 
on their account, would be about as just and wise as to keep all in ignorance that fire will burn, because some madmen and criminals commit arson.

I have also noticed, that those who express such fear, that, to "some people" this knowledge will be dangerous, never include themselves among the number. They will not admit that it is dangerous to them, but fear that others may not be equally good.

It may also be remarked that in practice there are so many causes of uncertainty, as already explained, that the number of days is not to be always relied upon, as a means of prevention!

The mammalia are all viviparous, while birds, fishes, and most reptiles are oviparous. In all viviparous and ovoviviparous animals the egg is impregnated within the body, also in many oviparous.

When the egg is developed out of the body, as in all truly oviparous animals, we commonly say it is hatched, and in the ovoviviparous it is simply hatched within the body.

Female fish deposit their eggs in the water, some in one situation, some in another, and the male, by some instinct, follows and deposits his semen upon, or near them, so that it reaches and impregnates them. The two sexes, therefore, may have no actual association, and may never come in contact. At the present time, as is well known, a knowledge of this fact has been put to an important practical use, in increasing the supply of valuable fish. The eggs, called the spawn, are taken in immense numbers from a few female fish, and artificially impregnated with sperm taken from a male. They are then artificially hatched, and when matured enough, are placed in waters it is desired to stock with them.

In this way one female may be made to produce many thousands, the development of which is insured by their being properly protected while young. When left under natural conditions, the bulk of the eggs and very young are to a large extent devoured by other fishes.

Shad, salmon, and other valuable fishes are thus artificially produced every year, by millions, and the eggs of different kinds are sent all over the world to stock new waters.

In frogs there is no copulation, the eggs being impregnated after they leave the female's body, but the male fastens himself to her, in a peculiar manner, so that his sperm reaches the eggs as they come out. In the land salamander, which is ovoviviparous, and breeds in the water, the eggs are impregnated in the female's body, but without copulation; the male merely ejects his semen into the water, along with which it is carried into the oviduct of the female, and there impregnates her eggs, which are hatched within the body and expelled alive.

Some of the ovoviviparous animals produce only eggs at one season, and living young at another. This is often the case among insects. Sometimes even, a female, with a large stock of impregnated eggs in her body, will begin by hatching them within, and expelling them alive, but finally will expel the eggs themselves, to be hatched without, as in birds.

In plants, as already stated, impregnation is essentially and practically the same as in animals. There is the ovum, or seed, analogous to the egg of the female animal, and the pollen, which is the same as the sperm of the male animal, and these two must always be brought together before a new plant can be developed. The two principles are sometimes on the same plant, and sometimes on different 
ones, and they are brought together in many different and curious ways, very much like the same acts in animals. There is, however, this difference, the organs of reproduction in the plant are not permanent, as they are in the animal, but fall off, or decay, as soon as impregnation is effected and the seed developed.

The pollen of the plant, however, never exists in a fluid form, like the animal sperm, but always in the form of little grains, often very minute. These grains have two coats, an outer and an inner, or perhaps it would be more correct to say the pollen grain is a cell, with two investing membranes. When one of these sperm cells, or pollen grains, comes in contact with the stigma, or top of the pistil, which is the tube leading down to the female germ, it undergoes a curious change. The inner membrane separates from the outer one and rolls itself out into a thread, or filament, which is pushed down the hollow female pistil till it reaches the germ cell, or rudiment of the seed, which lies at the base of the pistil, and so impregnates it. This, as will be better seen farther on, is exactly the same act as the impregnation of a female animal by the male. Very often the pollen is carried from the male plant to the female for many miles, by the wind, or by insects, and if anything prevents the female plant from receiving the pollen at the proper time, no fruitful seeds are formed. As a rule, the male pollen and the female germ must belong to the same species, or they cannot unite to form a new plant, the same as the male and female animal must be of the same species to breed together. This rule, however, is often deviated from to a certain extent, so that animals not of the same species, but nearly related, will breed; as the horse and ass, for instance. The progeny of two different kinds of animals is called a mule, or hybrid, and they may be either male or female, but can never breed together. This is because the semen of the male mule, as before stated, seldom contains animalcules. The female mule occasionally develops perfect ovæ, and may be impregnated by the male ass, or horse.

It is exactly the same with the plant; different kinds may be crossed within certain limits, and the product is a hybrid, or mule, which usually is unable to fertilize itself, bnt may be often impregnated by either of the parents.

Plants may be fertilized artificially, by taking the pollen from one plant and dusting it on the pistils of others. Gardeners and horticulturists in this way mix different kinds, and so produce numerous varieties of flowers and fruits. When the male and female principles are on different plants, as is the case with some fruit trees, it often happens that they may not be near enough to intermix, and then the female is always barren.

Even with many of those that have the male and female organs on the same plant, self-impregnation does not take place, the flowers being so constructed that their own pollen cannot reach the pistil. In these cases, pollen is conveyed by some outside agency, from other plants, so that there is constant cross fertilization. Insects are the great impregnators of plants, by passing continually from one flower to another; in doing so they get dusted with pollen from one which they convey to another, and in this way they often make crosses. Some plants depend entirely upon insects for their fertilization, and would die out if all those which visit them should become extinct. There are even particular insects which live on certain flowers, and which alone are capable of fertilizing them. This is the case with the Tipula pennicornis, a small insect which lives on the plant called the Aristolochia clematis. This little creature, in its ramblings about the flower of the Aristolochia, carries the pollen upon the pistil, and so effects impregnation. It seems, in fact, to live on that 
particular plant for this very purpose, so that they are necessary to each other. There are many other similar instances known to botanists, and some even more remarkable. Usually the insect is after the nectar, or honey, when he thus acts as fertilizer to the plant, but sometimes it almost appears as if the fertilization was its special purpose in nature. There are some plants so entirely dependent upon particular insects for their fertilization, that if they were taken to new countries it would be necessary to take those insects with them, for they would soon die out, because the insect is necessary for the fertilization of their seeds.

The common Indian corn is a good example of self-impregnation in plants. The blossom at the top is the male portion, which produces the pollen grains, or dust; the cob is the female portion, and contains the germs of the future seeds. From the cob, when young, there is protruded a number of threads, usually called the silk, which hang down, and on which the pollen from the blossom above falls. These threads are tubes, and they convey the pollen grains down to the germs, which are thus impregnated. As soon as impregnation is effected both the blossom and the silk wither and die, while the seeds begin to perfect themselves. If the blossom be cut off one of these plants before the pollen is ripened, and care be taken that none is brought from other sources, that plant will not produce perfect seeds, that will grow into other plants, but will be barren. It is well known how easily different kinds of Indian corn intermix, when grown near one another, owing to the pollen of different kinds reaching the same cobs.

This plant also shows how readily the different parts may change from one to another. It is quite common to see grains of corn growing on the blossom, and blossom being produced at the end of the cob. In the one case the male pollen grain has changed into a female germ, and in the other the germ has changed into pollen.

This, however, is only what we constantly see taking place in other parts. Thus thorns will develop into branches or leaves, leaves into flowers, and flowers again into leaves. They are all fundamentally the same, having the same cell origin, and there is, therefore, nothing surprising in their transformation from one to another. An apple can be traced back and shown to be a modified leaf, and so with the flower and other parts.

The male pollen and the female germ are only cells, originally alike, but more or less differentiated, and capable of interchanging one with another.

The quantity of pollen produced by some plants is something astonishing. In the coal beds, whole seams of coal are formed of nothing else but the pollen of plants, which grew during the carboniferous era. Even now, the pine forests near Lake Michigan often send forth such immense quantities that it thickens the waters of the lake for many miles. In many parts of the world, at particular seasons, the air is filled with clouds of pollen dust, from certain plants, so that the light of the sun, even, is obscured by it.

At a meeting of the Linnæan Society, Mr. W. G. Smith exhibited some sections of a boletus, or common puff-ball fungus, to show the arrangement and number of the spores. He stated that in a specimen five inches in diameter, there were seventeen thousand pores, or tubes, each one of which, when cut across, showed two thousand cells upon the surface. The cells in the entire plant, he estimated, were at least five thousand millions, and the number of spores contained in them, at least sixty thousand millions! With such a superabundance of these spores, of all kinds of 
funguses, floating in the air, it is no wonder they spring up everywhere, when the conditions are favorable. It is quite probable, also, that the same spores, under different conditions, may develop into different kinds of organisms.

In nearly all plants, in fact, nature produces immensely more pollen than is needed for fertilization, even after every possible contingency of failure is provided for, and it becomes a question what is the purpose of this apparently useless superabundance? In all probability it serves some other purpose than that of reproduction, but we have not yet learnt what that is. It is the same with the semen of many animals, especially man, which is always secreted in much greater quantity than can possibly be expended in propagation alone. The question may therefore be asked here the same, for what purpose is it? To this we can give no answer at present, but doubtless it will be found, at some future time, that it serves some other necessary purpose.

When the pollen grains of plants form themselves into filaments, in the way already described, to enable them to penetrate the female tube, they resemble the seminal animalcules of animals so closely that the two can scarcely be distinguished. They also penetrate the germ of the plant in the same way that the animalcule penetrates the female egg, which shows the strict similarity between the two.

The precise way in which the sperm and the germ are brought together, with the organs concerned in the process, both in plants and animals, will be described farther on, in the article on Copulation. 


\section{CHAPTER XX.}

\section{SEXUAL UNION, OR COPULATION.}

WHEN the male principle is added to the ovum, so that foetal development commences, the egg is said to be impregnated, or in other words the female conceives. Conception, therefore, is the union of the two principles, and foetal development is the result of that union.

In different beings, as already explained, impregnation is effected in many different ways, being sometimes internal, by the act of copulation, and at other times external, without any kind of association whatever. In many of the lowest beings there is no copulation whatever, and frequently even no difference of sex, each individual being hermaphrodite, or possessing both principles, but in all the higher beings a personal union, in some form or other, always takes place. This union, or copulation, is practiced, bowever, in many different ways, some of them exceedingly curious, and in all cases the beings are impelled to it by a peculiar and powerful instinct, the gratification of which constitutes perhaps the highest of all physical enjoyments, and leads also to other enjoyments of a superior order.

It is a remarkable circumstance, and one which shows how careful Nature has been to insure reproduction, that the young of all beings, at the proper age, not only experience sexual desires, but are also led, unconsciously at first, to practice those peculiar positions and modes of bodily union by which alone those desires can be properly gratified. In no instance do young animals fail in this particular, though they may have been kept carefully secluded from all others of their kind from the moment of birth. Immediately that the eggs are ripened in the female ovary, and the animalcules fully developed in the male testes, the sexual impulse is mutually experienced, and each is impelled to seek the society of the other.

The immediate causes which lead to actual personal union, between two young beings of opposite sexes in a state of nature, when neither has seen nor in any way known the manner of the act, have frequently been discussed by philosophers, and some curious experiments have been made for the purpose of ascertaining them. A careful study of the actual process of sexual union, and of the form and condition of the body at that time will, however, solve the mystery to a great extent, and will show that certain physical wants and adaptions inevitably lead to certain peculiar maneuvers. The infant will seize the breast to nurse immediately it is born, and has even been known to suck the finger of the acconcheur before birth, when the hand has been in the womb during some operation. This is evidently owing to a peculiar sensitive condition of the nerves of the lips and tongue, which impel to the act of suction, and in like manner the peculiar sensibility of the nerves of the genital organs, at puberty, impels to those peculiar acts by which it is similarly relieved.

There are many circumstances connected with each sex which make them attractive to the other, and which tend to draw them together. Some of these consist in 
obrious excitants of the senses, while others are more mysterious in their action, though their influence is equally perceptible. Among most of the lower animals, the female always emits a peculiar odor, at the time of heat, which when scented by the male immediately causes in him the sexual excitement, and draws him towards her by an irresistible impulse. Without this peculiar odor he experiences no excitement, and will not attempt to copulate, but that alone will excite him even when the female is not present, as experiment has proved. The olfactory sense, therefore, is an important agent in this process, at least among the lower beings, and perhaps it operates even in others, in some instances, more than is suspected. In those beings that are capable of reasoning and comparing, the sense of sight may also assist, by making differences in organization obvious, and suggesting adaptions. Besides these, however, there are certain other influences which, for want of a more explicit term, we will call attractive, the nature of which cannot be ascertained, though their power is obvious. These are evidently connected with the action of the sexual organs, being experienced only when they are in perfect action, and only operating in relation to the opposite sex. It has been suggested that this mutual attraction is a species of real animal magnetism, the male being positive and the female negative, so that they are drawn irresistibly together, like the needle and the loadstone.

In the human being there are also, at that time of life, peculiar moral sympathies, and intellectual requirements, which lead to mutual caresses and endearing embraces, even before the actual sexual impulse is fully awakened, and these bring about the mode by which the novel desires may be gratified, and the peculiar sensibility of the parts relieved. It is probable that in the human being the act of sexual union always results, in cultivated people, more from moral sympathy and intellect than from the mere senses, though these undoubtedly operate, especially sight and touch. Experiment has shown that the generative organs of each sex, when they are both in a proper state, exercise a mutual influence one upon the other, so that their contact can be distinguished from that of any other part, however similar. This has been proved by bringing various parts of the body in contact with the genitals, while the individual was blindfolded, and in every instance the touch of the corresponding parts of the other sex was known instantly. This arises in all probability from their possessing a peculiar power of exciting each other, which causes a species of shock, like that of electricity. It is easy to see from this how an accidental contact of these parts, during a mere caress, would suggest their mutual adaption, and would lead to actual association.

Besides these provisions there are also others, equally necessary, and equally curious. Thus, the nervous sensibility is placed so that it influences certain muscles, the action of which causes peculiar motions of the body, such as are necessary during actual association. These motions are, in fact, often practiced, by the young, before actual connection is thought of, showing that they originate involuntarily. This is the case with both sexes, and the motions peculiar to each are precisely those best adapted for favoring actual connection with the other. Human beings, however, as society is now constituted, seldom acquire their knowledge of this process by nature's slow and sympathetic teaching, but precociously, by the gross, premature, and lascivious medium of instruction from others. This is perhaps unavoidable, but it is on many accounts to be regretted, and is certainly less conducive to true morality, and to human happiness. As the sexual impulse is now experi- 
enced it is usually both forced and exaggerated, and is but seldom brought into play by the natural instincts and requirements alone.

The different organizations of animals make the act of copulation vary very much, both in its manner and duration. In some it is a complicated act requiring intimate internal union, and considerable time, while in others it is merely external and effected in a very brief period. It is impetuous and violent in some, and slow and gentle in others, but is possibly productive of intense enjoyment in all, no matter how brief may be its duration, nor how forcible its consummation. Some part of the process is, however, to the females of many animals, extremely painful, as is evinced by their cries and efforts to escape, and by the exhaustion which they afterwards exhibit.

The long duration of the act of copulation in the dog is well known, but in some other animals it is much longer, especially among insects, with some of whom it continues for days, and always terminates the life of the male, while the female only lives sufficiently long afterwards to deposit the fecundated egg, and then she dies -also. The long duration of the act in the dog is owing to two causes; the male organ has a number of knots, or swellings, towards its termination, around which the sphincter muscle of the female vagina closes with such force that the two cannot separate till the parts become flaccid. So powerfully does this muscle act that even if the male be killed, or the organ cut off, the vagina will still retain it, till relaxa. tion takes place. The same phenomenon is often seen in insects also, and the long continuance of the act is undoubtedly owing to the semen being slowly emitted, and very gradually absorbed into the female organs.

In other animals, on the contrary, the act of copulation is almost instantancous, the semen being darted out in a single jet and absorbed immediately. This is the case with most birds, some of whom connect while on the wing. The reason for this quickness will be obvious on inspecting their organs, which are not adapted for continued intercourse. In fact it can scarcely be said that birds copulate at all, except a few species. The male has no true penis, but merely a slight protuberance, like a button, which cannot enter the female organ, but merely ejects the semen upon its mouth. The female also has no vagina, there being but one passage, called the cloaca, which is common to the excrement, the urine, and the semen. In some few birds, however, as in the ostrich, the penis is considerably developed, and enters the vagina, so that they really copulate. As a general rule also the clitoris is absent in female birds, which has led some physiologists to conjecture that they have no pleasurable excitement during the act, but this perhaps is erroneous, as some other part may be more than usually sensitive in their case. There are a few kinds, as some of the ducks for instance, that have the clitoris very large, and in the ostrich and cassowary it even has a groove, like a urethra, so that it resembles a penis. Ducks are well known to exhibit great amative excitement, the reason for which is evidently their possessing this large and sensitive clitoris.

In most reptiles also the act is equally imperfect, as in very few do the males have a properly developed penis, but merely a small bulb, or protuberance. The tortoise, and the crocodile, however, have a single penis, and the alligator has a double one. In the lizard and serpent it is also double, and in the rattlesnake each part is also divided again. Excepting at the time of copulation this organ, however, is not visible, being drawn into a sheath, from which it is thrust, at the proper time, by appropriate muscles. Some serpents copulate always at one particular season, 
and then great numbers assemble together and twine and interlace themselves into an immense pyramid, with their heads directed outwards. Humboldt tells us of one of these living pyramids which he met with in South America, and which he describes as being the most fearful and horrible sight that ever met his gaze. The whole combined mass mored slowly on over the plain, while each individual writhed its body, darted out its forked tongue, and hissed in the most horrible manner. Very few females among the reptiles have anything like a clitoris, though it is found in some, as in the tortoise, for instance.

The frog exhibits very well the mode of impregnation without copulation, though in all probability not without mutual pleasure. At the time when the female is ready to eject the eggs the male climbs upon her back, embraces her firmly around the body with his long legs, and as the eggs are emitted he covers them with the semen. They are then left in the water by some species, and in others are fastened to the female's back for a while, by a thick mucus, secreted for the purpose. The embrace of the male frog is well known to be so powerful that the female seems nearly cut in two by his limbs, which contract with such force, and are so rigid, that they may even be torn off before letting go their hold. The object of this powerful compression seems to be the forcing out of the eggs, which probably could not be effected by the female herself. It is for this reason that these animals are called accoucheurs or midwives, because they cause the female to lay their eggs.

In male fishes we seldom find anything like a penis, though sometimes there is an organ which partly answers the purpose of one. It is merely a cartilaginous prolongation, like the spine of a fin, which hangs down from the body. Sometimes, in fact, it forms part of the anal fin, though in other cases it is separate from it. Down this imperfect organ there runs a shallow groove, which serves as a conduit for the semen. In many species there is nothing like copulation, nor do the two sexes ever meet, except accidentally, but in others the male organ is applied against the female parts at the time when the eggs are emitted, and the semen is then ejected upon them. In very few is there even the slightest entrance effected. The whale, it must be remembered, is not a fish, though this may seem strange to some, but merely a mammiferous animal that lives in the water. Its organs, therefore, are like those of the other mammifers, and it truly copulates, the male and female standing partly erect, out of the water, when doing so.

The various forms of the sexual organs in different beings of course necessitate different modes of connection, and probably varies much the sensations connected with it, but there is always a powerful instinct, which insures its performance, in all. Perhaps some of the most singular modes of copulation are found umong insects, and other inferior beings, and especially among those that are hermaphrodite. In some insects there is but one female to many males, and no actual union ever takes place with any, the merest touch of the female's body being sufficient to satisfy the instinct of each. This is the case with bees, the males of whom will crowd round the queen in hundreds to touch her body. In other species, however, the sexes are always in equal couples, and when they copulate, the connection continues for days together uninterruptedly, the female carrying the male about with her on her back. Some kinds of hermaphrodite snails exhibit a very singular mode of mutual impregnation, each individual being provided with a number of horny darts, or spears, inclosed in a sheath, which they dart at each other in turn, having first assumed a proper position for the amorous 
combat, as illustrated in a previous article. The double connection of the common earth-worm, which is bermaphrodite, may be seen on any dewy morning, when they rise out of the ground, and it usually continues till the sun rises, which would seem to intimate that the continued union is productive of pleasure, because it can be terminated at will. In the perfect hermaphrodites, which self-impregnate, it may be a question what kind of feeling is experienced, if any at all, because they are both male and female, but it is certain that they are as strongly impelled to the act as those beings that associate with an opposite sex.

A very surious study is afforded also of the various modes by which the two sexes discover each other, at the proper time, in those species in which they do not live together. Some insects, for instance, have a peculiar song, or cry, by which the female attracts her partner, and others are decked out in brilliant colors for the same purpose. Some, which come out only at night, have a lamp provided to light him, as we see in the glow-worm and fire-fly. The peculiar cry of the locust, the ticking of the death-watch, and the chirp of the grasshopper, are intended for this purpose, and probably also the song of the bird has, to a great extent, the same object. In fact, every animal has a peculiar cry, which it utters only when desiring the company of the other sex, and which is mutually understood.

With respect to the feelings which the act of coition produces, and the instincts or desires which lead to it, they probably vary indefinitely. In all the higher beings the desire to cohabit arises from a specific irritation of the genital organs, acting in conjunction with certain moral sympathies and intellectual perceptions. And when the connection occurs in a proper manner and under proper circumstances, it is always productive of intense and peculiar enjoyment to both. This is especially the case with human beings, and with all others similarly organized. The peculiar excitement which first causes coition to be desired, and which also makes it so intensely pleasurable, arises from the development of certain parts, namely, the clitoris in the female, and the glans penis in the male. The perfection of either of these organs in the one sex is invariably attended by a similar perfection in the corresponding part of the other sex, so that they are mutually excitable, and generally pretty equally so. We never find a well-developed and sensitive glans in the male, but we also find a well-developed and sensitive clitoris in the female, or else there is some other part, as the neck of the womb for instance, which acts in the same manner. In many of the lower beings, who have none of these parts, it is probable that nothing like what we call sexual feeling is ever experienced, but that they are impelled to connection simply by the mysterious workings of the parental instinct, which, as we well know, leads to many actions in which no direct pleasure is felt. The careful depositing of their eggs by insects, in the most proper places, and the patient sitting of the hen upon hers, may be adduced as instances of these blind promptings of the parental instinct, and, probably, in some beings, actual connection is brought abou in the same way.

The more perfect development of the generative organs in the higher order of beings, and their greater sensibility, especially in mạn, is only in accordance with the greater perfection of every other part of the system, and is doubtless intended as an additional means of increasing their felicity. The higher any being is placed in the scale of creation, the more multiplied are its means of enjoyment, and the more intense those enjoyments become, as we see in regard to true sexual intercourse, by an actual union of the organs of the two sexes, or intromission of the male, which is altogether confined to the most perfectly ciganized. 



\section{CHAPTER XXI.}

\section{THE ORGANS OF GENERATION IN OVIPAROUS ANIMALS.}

Is oviparous animals, who only produce eggs, to be developed out of the body, no sexual organs are needed but those which form the semen and the ovæ, and the copulative organs, which are used to bring them together. In viviparous animals, which bring forth their young alive, there is needed, in addition to these, a special set of organs by which the new being is connected with the mother during its growth, and by which it is nourished at her expense.

The oviparous sexual organs are, therefore, the most simple, and will be described first.

The most important of these, the female ovaries and the male testes, have been already fully explained, and it only remains to describe the other organs which serve to bring their products together, or, in other words, to effect impregnation.

In those that impregnate the eggs externally, of course no copulative organs are needed, as in most fishes and frogs, for instance. The female merely expels her eggs and leaves them in the water. The male does the same with his sperm, and the two thus come together without any concurrence of the two parents whatever. In these beings, therefore, sexual generation is reduced to its simplest elements, and but few organs are needed ; still, there are fishes even that must copulate, because the eggs are found hatched inside the female's body, but the precise way in which the act takes place has not been ascertained. In some of these, however, the male possesses a long conical penis, covered with scales, inside which is a canal leading from the testicles, and down which the semen is conveyed. With this organ, no doubt, copulation is effected as in other animals.

Some of the rays have a penis more or less developed, and they couple together, belly to belly, the male being provided with an extra apparatus for holding the Semale close to him during the act.

These, however, are exceptions, and in the great majority of fishes there is no copulative union of the sexes.

Frogs, as before stated, do not copulate, but the male fastens his limbs around the female at the time when the eggs are ripe, and squeezes her body to such, a degree that it would seem impossible for her to live. This is done, apparently, to force out the eggs, which he waters with his semen as they escape. This is a kind of coupling, but not copulation, because the actual impregnation occurs outside the female's body. The common name given to the male frog of midwife, or accoucheur, is therefore well deserved, because he assists the female to bring forth her eggs.

The contraction of the limbs of the male frog, in this act, is probably spasmodic, and involuntary, for it is not possible, except with extreme violence, to make him loose. In fact the limbs may often be torn off in trying to detach him. When there happens to be but few females, so many males will cling around one that they not only stifle her, but many of the males themselves perish, and bunches of them 
may be found with a number of those in the interior dead and putrefying. The males will even thus cling to one another, when there is no female near, or to fish, on which they will fasten in the same way, till they weigh them down. It is quite possible that this act is as pleasurable to the frog as complete copulation is to other beings.

The common frog leaves its eggs, after impregnation, in the water, where they may be seen, in the early spring, in large masses, like jelly, filled with little black specks, which are the future tadpoles. In some kinds, the eggs, after they are impregnated, are glued to the animal's back, and are carried about till they develop into tadpoles, when they drop off.

There are some animals among whom the male takes charge of the eggs after they have been impregnated, and guards them till they have hatched. In Chili there is a species of frog, the male of which has a pouch or pocket on the under side of his body, in which the female's eggs are developed. How they are conveyed there, and how they are first impregnated, we do not know.

The male crab has two penises, one on each side of the thorax, behind the fifth pair of claws. They are horny, pointed, and tubular, and connected with the testicles by long twisted tubes, down which the semen is conveyed to them at the time of copulation.

The female has two corresponding openings, in the same situation, to receive the two male organs, and when they couple, she throws herself on her back, so that they lie belly to belly, and hold to each other by their claws. The male semen is poured into the two female openings, which are connected by means of the oviducts with the ovary, and through them reaches the eggs, which it fecundates.

The eggs are laid some two months after copulation, and are attached in a very curious manner under the female's tail, and she carries them about with her till they hatch into little crabs. These keep near the mother and hide under her when there is danger, till they are considerably grown.

$\Lambda$ similar arrangement is observed in the lobsters.

The generative organs in ants are contained in one of the segments of the abdomen, but their structure and manner of action is not well understood. The habits of the animals, however, at the breeding season, have been well observed, and are very curious. It is well known that they live in societies, like bees, and display remarkable intelligence and foresight in what they do for their common welfare.

There are three classes of them, males, females, and neuters, called drones among the bees, which do pretty much all the work of the community. Not being concerned at all in reproduction, they are devoted to labor and to fighting, which leaves the males and females free to attend to propagation and rearing the young.

The males are born with wings, like the females, but are usually kept close prisoners till they are needed for the purpose of impregnation. When that tima arrives all the inhabitants of the ant-hill turn out together, a crowd of neuters surround the males and take them to a place which seems to have been selected beforehand, where they meet the females, and copulation immediately takes place. Very soon after the act is accomplished the males die, being no longer needed, and the females are conducted back to the ant-hill, where their wings are torn off, and they are then taken into the most secluded chambers of the hill. All this is done by the neuters, who take the pregnant females under their care, and attend to them most assiduously, feeding them and carrying them about, and caressing them in many ways. 
The abdomen of the female swells enormously as the eggs ripen, and when they are fully developed they are laid like those of a bird. This operation, however, is assisted by one of the other ants, who fastens on to the mother, seizes hold of the eggs as they are expelled, one by one, and arranges them in a heap ; afterward these heaps are all taken by the neuters, and the eggs deposited in places prepared for them, when they develop into the larvæ of the future brood.

The bees act similarly, in many respects, to the ants, and they always impregnate but one female, who produces all the eggs for the next swarm. These animals will take any young larva and develop it into a male, a female, or a neuter, according as they treat it. If they lose their queen they immediately take one of the com. mon young, and by feeding it in a particular way develop it into a new queen. This fact, along with several others, shows that sex is entirely a matter of development, both being the same fundamentally.

When only one female in a community breeds, the organs of the other females remain undeveloped, but any one of them can be perfected if required, by appropriate feeding and attention. Some of the ants impregnate but one female, who produces eggs enough for the most numerous swarm.

Among spiders sexual association is an act of extreme danger to the male, who often loses his life in attempting it. The female places herself in the center of her web, and there awaits her lover, who approaches with extreme caution, and tries in many. ways to find ont if his visit is acceptable. He shakes the threads of the web, creeps slowly up and touches her with his claw, retreating quickly back again, and this is done repeatedly, till finally if she remains quiet he springs upon her, embracing ber with his front limbs round the abdomen, and the act is accomplished. If his visit is unacceptable, the female often springs upon him during one of his attempts, stings him, and he dies. She will then tear him to pieces.

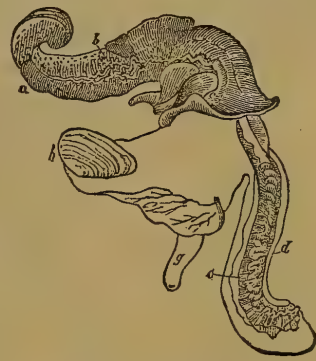

FrauRe 61.-Male Organs of Buccinum, or Water Snail.

$b$ are the testes. $d$ is the penis. $c$ shows the interior of the penis laid open. The convoluted tube is the spermatic duct leading from the

The short hand-like claws or feelers, which are is never retracted within the body placed one on each side of the mouth, in the male completely, and is frequently ex. spider, are supposed to be the organs with which he tended without apparent object.

excites the female, but the actual process is not known. There is no organ analogous to the penis.

In several of the mollusks, or shell-fish, resembling the water-snail family, there is probably a real copulation, for the male possesses a muscular penis, of enormous size, in proportion to the body, and which is capable of being protruded when required for use. It is placed on the right side of the neck. The testes also, which communicate with the penis, are very large.

In the female the ovaries correspond in position with the male testes, and they are connected with a long and tortuous oviduct. In what way the male penis is used we do not know.

The above plate shows one of these animals.

In all the more perfect oviparous animals the eggs are impregnated within 


\section{PLATE XI.}

\section{GENERATIVE ORGANS OF A BIRD.}

Figure 1. The female bird opened to show the connection between the generative and other organs. $a a$. The liver, which laps round the heart. $b$. The stomach, from which proceeds $c c$, the intestines. $d$. The cloaca, or large intestine. $e$. The heart. $f$. The beginning of the oviduct, or egg passage. $g g$. The oviduct. $h$. The ovary.

Figure 2. The generative organs taken out, but still in the same position. The letters up to $h$ indicate the same parts as in Figure 1 . $i i$ are two little intestines nearly always found in birds ; uses unknown, they join the cloaca, as seen. $j j$ are the ureters, which bring the urine into the lower part of the large intestine. $k$. The enlarged part of the lower end of the large intestine, called the cloaca, into which passes the urine, the excrement from the intestines, and also the egg. It is the chamber common to them all. $l$. The rudimentary bladder. $m$. The orifice of the anus.

Figure 3. The same organs open, with the same letters to the same parts. $n$ shows the mouths of the ureters opening into the cloaca. 0 . The passage leading outward of the cloaca. $p$. Opening from the bladder. $q$. Opening from the oviduct, through which the egg passes into the cloaca.

Figure 4. Organ of the male bird. In the male, of course, there is no ovary nor oviduct, but in place of them are found other organs, which are here shown. $a$. The lower end of the large intestine. $b$. The enlarged portion opened. $c c$. Openings of the ureters. $d d$. Openings of the ejaculatory tubes, leading from the testicles, down which the semen is conveyed. e. The ring surrounding the anus. $f f$. The testicles, which are placed one on each side of the back, just beyond the tail, and immediately under the skin. $g g$. The spermatic tubes which convey the semen from the testicles. $h h$. The ureters, which convey the urine. $i i$. The muscles which close the anus. $j j$. The muscles which open the anus.

Figure 5. One of the spermatic tubes enlarged, showing the projecting opening at $c$.

Figure 6. The same portion opened to show the interior.

The action of the organs in both male and female will be readily seen from this Plate. In the female, the eggs are formed in the ovary, $h$, Fig. 2 , and are passed one by one as they ripen into the oviduct, through the little opening seen at $f$, and are conveyed by the oviduct down to the cloaca, or enlarged lower end of the large intestine, into which they pass through the little opening at $q$, Fig. 3. From there they are expelled outward through the anus, $m$, Fig. 2.

In the male the semen is formed in the testicles, $f f$, Fig. 4 , and from there is conveyed by the spermatic tubes, $g g$, to the cloaca, which it enters through the little openings seen at $d d$, Fig. 4 . It will be seen by Figs. 5 and 6 that the end of the spermatic tube projects, like a nipple, into the cloaca. 
PLATE XI.

Fig. 1 .

Fig. 2.
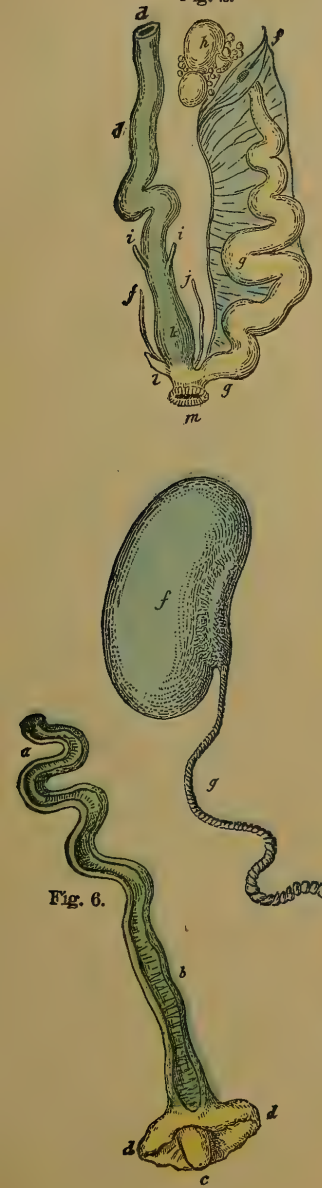
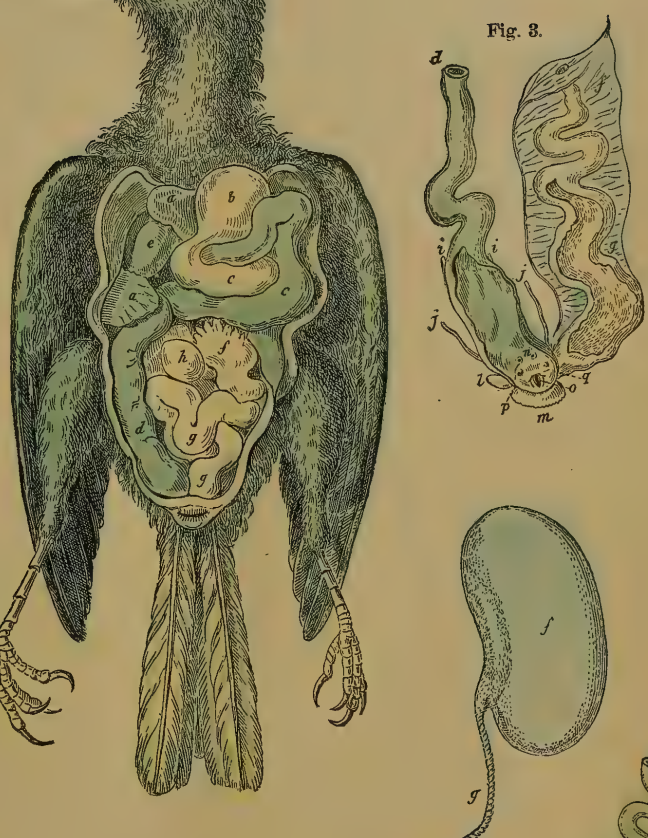

,

Fig. 4.

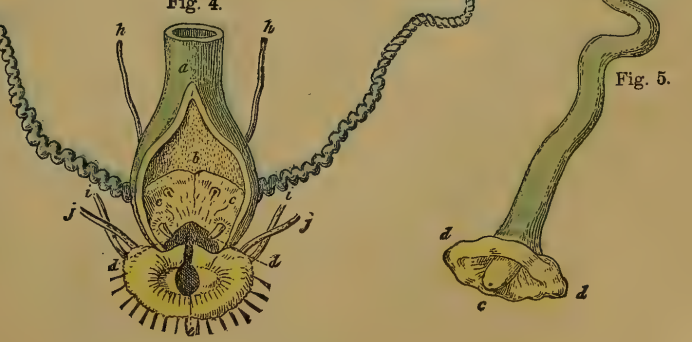

Generative Organs of a Bird. 

the female's body by a more or less perfect act of copulation, and are then expelled to be hatched externally. In some cases, however, as in the ovoviviparous, they are occasionally hatched before leaving the body, but the young are in no way connected with the mother.

A few illustrations of the copulative organs in different types of animals will now be given, and the way in which they act explained.

The bird will be the first explained, because it is an animal with which all are familiar, and one which can easily be made the subject of corroborative observation and experiment.

There are two ovaries in the female, but only the left one is developed, the right one being rudimentary, or undeveloped.

It will be seen that the male has no penis, so that internal copulation between the two sexes cannot occur. The act that takes place, however, serves the same purpose, and no doubt affords the same gratification as the more perfect act in other animals. At the time of association the two birds so place themselves that the mouth of the anus in the male is pressed firmly against the same part in the female, the semen is then emitted, and passes into the cloaca of the female, from whence it reaches the ovæ, by the oriduct.

During the association the external opening of the anus, in both animals, swells out and opens, with considerable energy. In fact it is analogous to erection in other animals.

The act of connection in the common fowl is repeated frequently, as is well known, but probably only a small amount of semen is expelled each time. One connection, it used to be thought, impregnated only one egg, but this is a mistake, for it is well known that one act will impregnate several that are laid afterward. If, however, the male does not continue to associate the eggs finally become barren, though they continue to be laid, and apparently are as perfect as before.

Although this is the usual arrangement in birds, still there are some curious exceptions. Thus the ostrich has quite a large and well-developed penis, conical in form, and with a deep and narrow furrow down the back, which conveys the semen into the female organ. The spermatic tubes open into the cloaca at the root of this penis, so that the semen passes at once down the furrow, when the organ is in use.

The peculiarity of this penis is that it never softens, but is always firm and hard, so that there is a constant state of erection, or readiness ; when not in use it is bent back, drawn into the cloaca, and passes into a kind of bag, or pocket, where it remains till again required to be protruded. When so drawn back. it closes up completely the mouth of the urine tube, and indeed of the whole cloaca, so that whenever the animal requires to urinate, or to void his excrement, he has to protrude the penis the same as when he connects with the female. This is a very singular arrangement, and occurs in no other bird, so far as I know; of course the male and female ostrich copulate perfectly, the same as the higher animals, the male penis being used in the same way as with them.

Among the swimming birds, the ducks, geese, and swans, also have a penis, but different from that of the ostrich. It is composed of two tubes, one within the other, the outer one thin, and wrinkled up, like a spring, and the inner one much thicker. At the time of erection the outer tube unfolds itself like the finger of a glove, and the inner one introduces itself in the interior, making the whole organ quite firm. At other times both are drawn back into a kind of pocket in the cloaca, 


\section{PLATE XII.}

\section{GENERATIVE ORGANS OF A SERPENT.}

The eggs will be seen between $p$ and $q$, about two-thirds of the length from the head, strung together like the beads of a necklace; they pass down the oviduct $p$ as they ripen, and are discharged into the cloaca at $x$, where they are impregnated at the time of copulation ; $s$, the opening of the ureters; $l l$, the liver; $h$, the heart; $k$, the right lung.

Fig. 2. $a a$, the male generative organs, or double penis, with fingers.

Fig. $2 a$. $b c$, scales which cover the opening of the anus, where the penis is protruded.

At the time of copulation the male and female twine around each other very tightly, and the embrace lasts a long time. The penis is double, and the finger-like protuberances being bent back during connection, they serve like hooks to hold the female fast.

The testicles are like a tangle of fine threads, placed near the kidneys $q$, and being very long, the semen is emitted slowly, which necessitates the long copulation.

\section{PLATE XIII.}

\section{GENERATIVE ORGANS OF CRUSTACEANS.}

Figs. $1,2,3,4,5,6,7,8,9$, represent the common barnacle (Cirripede) in different ways.

Fig. 1. The animal removed from its shell ; $f f$, the cirri, or limbs ; $u$, the spermatic tube, or male organ.

Fig. 2. The animal seen sideways; $u$, the spermatic tube, which receives the semen from the granular testicles above, lying each side of the intestinal tube; the sperm is emitted from the end of this tube on to the eggs in the mantle, at the proper season, both being contained in the same animal.

Figs. 4, 5, 6, \%: The testicles or seminal vesicles enlarged.

Figs. 8, 9. The same animal in its shell.

Fig. 8. $f$, the cirri ; $g$, the ovaria ; the female organs, with the eggs.

Fig. 9. $b \quad b$, the tube containing the eggs laid open, and from which they are conreyed to the mantle $g$.

The barnacle is, therefore, perfectly hermaphrodite, the male sperm and female eggs being in the same animal.

Fig. 10. A snail dissected ; $u$, the liver ; $v$, the ovary ; $x$, the oviduct ; $y$, part of the testicle; $z$, the bladder.

Fig. 11. Snail deprived of its shell ; $a$, the large horns; $b$, the small ones.

Fig. 12. The genital organs of the snail removed, as shown elsewhere; $n$, the penis; $f, g, h$, the testicles and ovary; $u$, the common generative cavity; $s$, the love-dart ; $i$, the spermatic tube; 0 , the bladder; $c$, the multifid vesicles; $k$, the place where the semen enters the urethra.

The other parts not being concerned in generation are not bere referred to, and the generative organs of the snail are more fully described in another place. 
PLATE XIr.

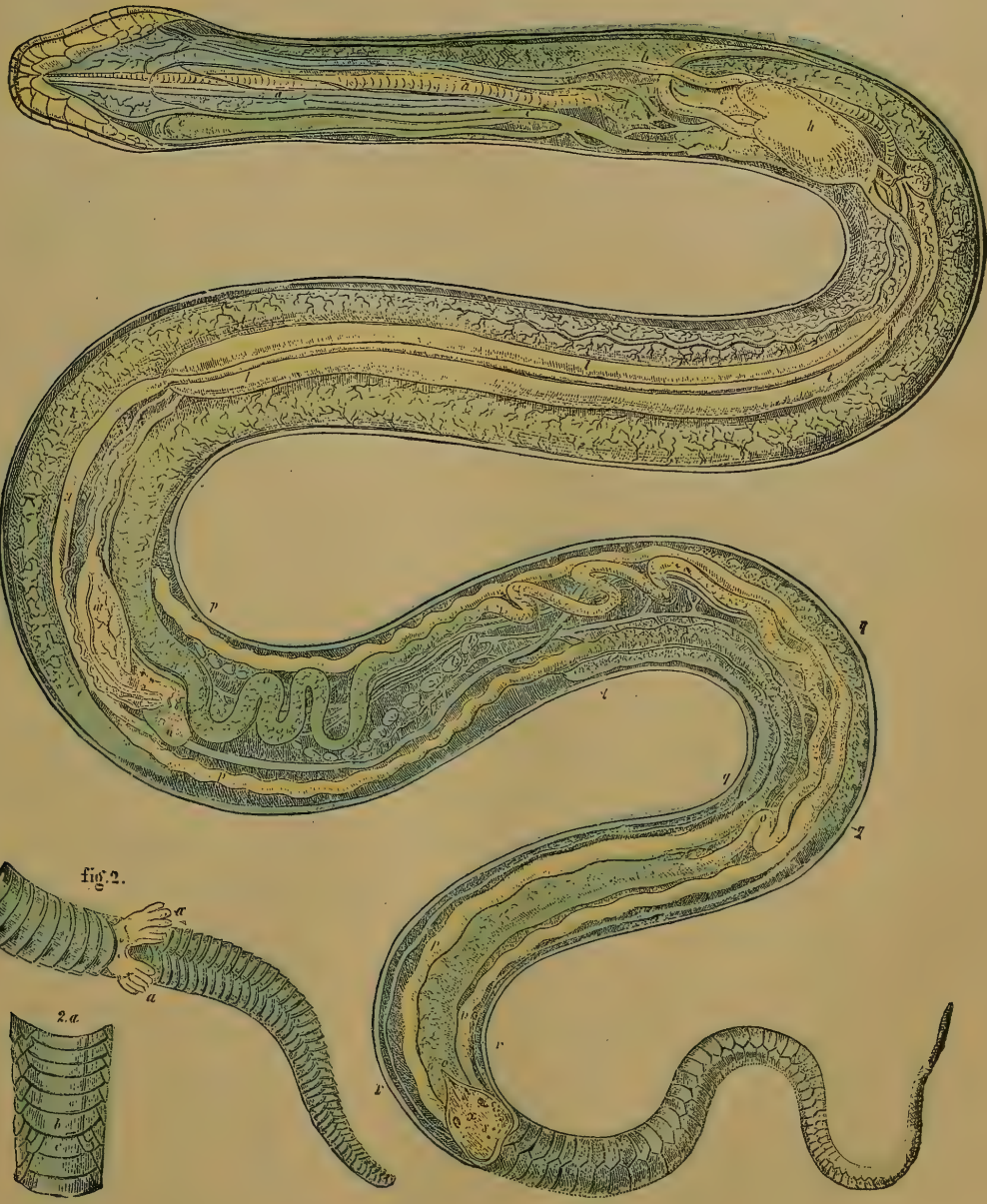

Generative Organs of a Serpent. 

PLATE XIII.
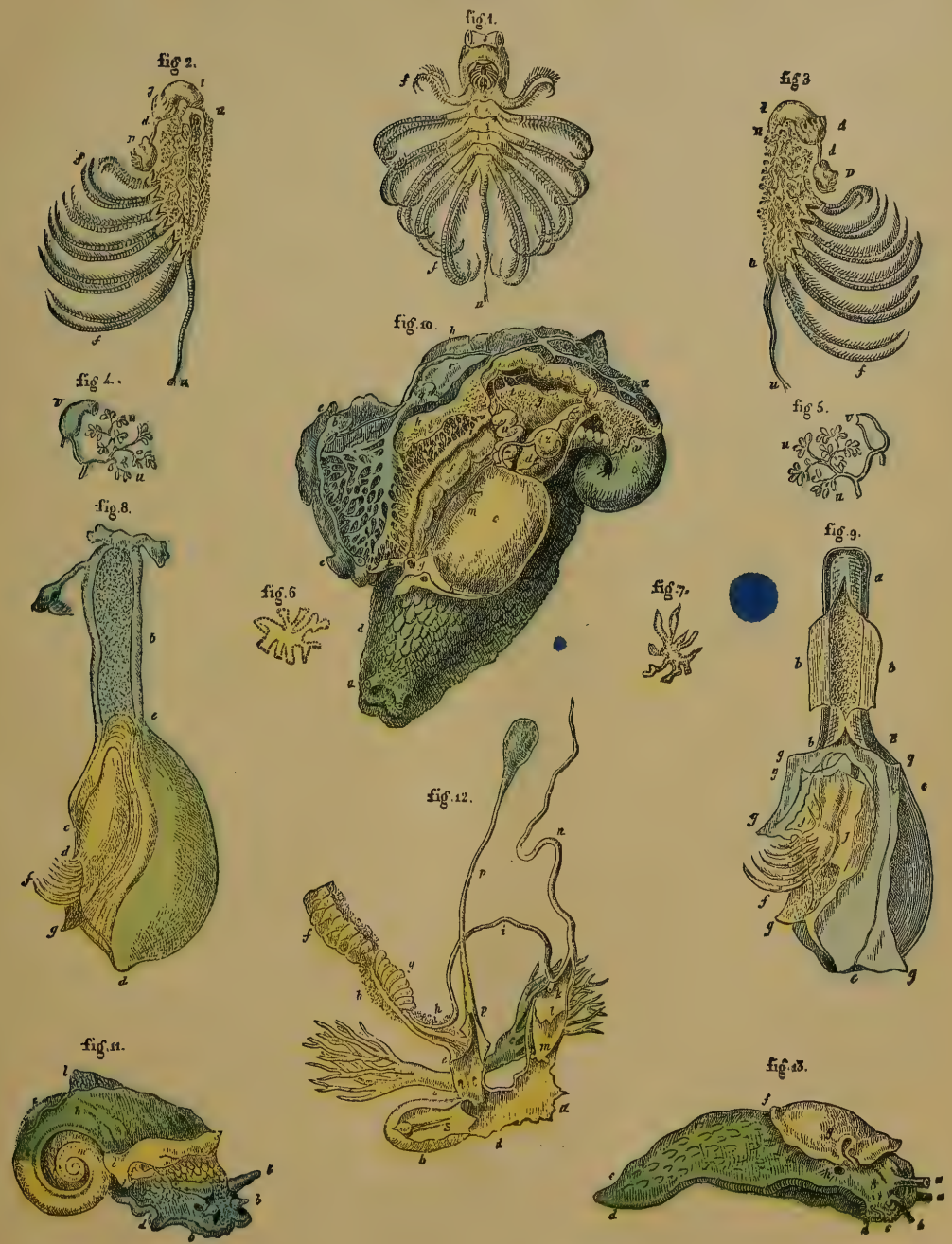

Generative Organs of Crustaceans. 
<smiles>c1ccc2ccccc2c1</smiles> 
but they make no interference with the passage of the urine or excrement, as the a]ways firm organ of the ostrich does. These birds, of course, copulate fully, usually in the water, and the act is more prolonged than with flying birds, some of whom copulate in the air.

In some birds the lower part of the spermatic tube is enlarged into a kind of sac or vesicle, and is always full of semen. The action of the muscles around the anus, at the time of connection, squeezes this sac, and forces out some of the semen into the cloaca.

Why connection should be so incessant with some birds we do not know. It certainly occurs much oftener than is necessary for fecundation, and apparently serves no actual need. Possibly it may be, for the most part, a mere gratification. The excessive secretion of semen may be compared to the superabundant production of pollen in plants, which is certainly far beyond what is needed for fertilization alone.

The egg in the bird, it should be remarked, when it first passes from the ovary into the oviduct, is but little more than a ball of yelk. The white and the shell are added to it during its slow passage down the oviduct.

We will next describe the organs in reptiles, from whom birds are descended, as comparative anatomy and fossil remains conclusively show. The scales of the reptile are modified into feathers, and its upper limbs into wings, while other parts are. cbanged in rarious ways, but all can be fully traced and connected.

Frogs, as before explained, do not copulate, but fastened on the female's back they watch for the eggs, and shed the semen on them as they come out. At the time of fecundation a peculiar growth of small protuberances, like warts, appears on the skin of the belly and under-sides of the feet of the male frog, which he squeezes into the skin of the female, like pegs, to enable him to hold on firmly, without slipping. $\mathrm{He}$ will wait fastened on his companion this way, with his limbs tight around her, for six weeks or more, till the eggs are laid. At the commencement of this singular coupling the female is much swollen, by the contained eggs, but as fast as they are expelled she begins to reduce in size, till at last she becomes quite small, and then the male releases his hold and they separate. They are then both much reduced in flesh, and very weak, but soon regain their usual condition.

The tortoise has a well-formed penis, proportionate to the size of the animal, with a deep furrow along the back, as in that of the ostrich. When not erect it is also drawn back into the cloaca, as in that bird, and prevents the outflow of urine, or excrement, in the same way, till it is protruded.

The males of these animals are less than the females, and ordinarily are very dull and sluggish, but in the breeding season they become unusually active, and fight fiercely for the farors of the female. The great aim in their struggle, seems to be to throw one another on the back, because when one is so placed it takes him a long time to right himself, and in the meanwhile his successful rival has secured the female.

This circumstance, of finding them so often on their backs, led to the opinion that they copulated that way, belly to belly, but this is not the case, for the male seizes the female from behind and places himself on her back, as I have often seen. The penis is then protruded and bent under, the tail of the female being turned sideways, and the anus expanded, to facilitate its entrance into the cloaca.

The embrace usually lasts a considerable time, and one copulation will fecundate 
two or three layings of eggs, which are usually nearly hatched when they are laid. They are placed among dry leaves, or in shallow holes, and left to the action of the sun, which soon brings forth the young. The sea turtle buries hers in the sand, and leaves them to the same influence. The parents have no further care or trouble for their children.

In all reptiles, as in birds, the female has no special organ of connection, like the vagina in the higher animals. The male organ, when there is one, is introduced into the cloaca, or enlarged lower end of the large intestine, which is the common passage for the urine, the excrement, and the eggs ; and which also serves to receive the male organ. When the male bas no penis the semen is simply ejected into the cloaca, as in many birds. In this respect, therefore, birds and reptiles are alike. The bird is in fact, as before stated, only a modified reptile, the change having been effected by the process of evolution.

The ovaries are double in all reptiles, but single in birds. The end of the oviduct is expanded into a kind of bag, into which the egg passes from the ovary, and which by contraction forces it into the oviduct.

In lizards the male penis is double, like that of the snake, and they copulate belly to belly, according to observation. I have been told, by Southerners who have watched them, that alligators copulate belly to belly, in the water, which seems probable from the position of their organs.

In most of the higher reptiles there is a real internal copulation, but yet the male penis is never perfect, nor indeed is it in the ovipara generally. Instead of a urethral passage through the interior, as in the higher animals, there is simply a furrow, more or less deep, on the top, down which the semen flows, at the time of copulation. This shows incomplete development, for the same thing is observed in the human embryo, at an early period. This furrow forms first in the rudimentary penis, and gradually closes at the top to form the interior passage. Sometimes the development is stopped, from some cause or other, at the imperfect stage, and then the boy is born with a penis that has no internal passage, or an imperfect one.

In most turtles the penis has but a single point, but in many lizards, as in most serpents, it is double and provided with recurved spines for the purpose of better holding the female firmly during the copulation. The female turtles also have a real clitoris, or organ of excitement, which can be extended and drawn back, like the male penis. In birds also, when the male possesses a penis the female always has a clitoris, as in the higher vertebrae.

The penis in most insects is a cylindrical hollow tube, sometimes membranous, sometimes horny, and capable of being extended from the body. It is usually straight, and occasionally pointed, but sometimes much enlarged at the end, or curved, or double, and in the common wasp it is spoon-shaped. In some insects it is like a screw, in others covered with spines, and in beetles it is provided with a two-valved sheath, which opens the rulva of the female, to facilitate the introduction of the penis. More curious still, there are some insects in which the penis is placed on the female, who introduces it into the spermatic tube of the male, where it receives the semen and conveys it to the female ovæ. There is a real copulation, but it is the reverse way, the female really entering the male.

In the dragon-fly the male organ is placed forward, at the throat end of the abdomen, while the female organ is at the other end. During copulation, there- 
fore, they have to assume a peculiar position, as may be often witnessed in the summer time.

In some cases there is a remarkable disproportion in size hetween the two sexes, a greater even than is seen between the male and female ant. This is especially noticeable in the Sphcerularia Bombi, a curious round worm, which lives as a parasite on certain kinds of bees. The female is about an inch long, blunt at both ends, and covered with small button-like projections. It has neither mouth, intestines, nor anus, and is in fact only a mass of fat jelly, containing a very large ovary, filled with eggs in various stages of development. It was once thought to be hermaphrodite, as no male was known, but lately the male has been discovered,-it is twentyeight thousand times smaller than the female, and is generally found sexually united with her, but is scarcely discernible.

In short, in the lower orders of beings, there is an endless variety in the form and disposition of the generative organs, and many of them are provided with curious accessory organs, whose uses have not yet been ascertained. In nearly all cases nature seems to have provided more perfectly for the reproduction of the species than for the preservation of individuals. Myriads of eggs are produced which are never developed, and myriads of young die, or serve for food for other beings. With a large number of animals, as in plants, reproduction is the last act ; when that is fully consummated the parents die.

Whether the act is always a pleasurable one, as in the higher animals, we do not know, but it certainly is in some, and probably in all.

We will now describe the generative organs and their mode of action in man, the representative of the highest of the vivipara, the mammifers, from whom all the others may be considered only as deviations. 


\section{CHAPTER XXII.}

\section{ORGANS OF GENERATION IN VIVIPAROUS ANIMALS.}

Ix all true viviparous animals, who bring forth their young alive, perfectly formed, the generative organs are more complicated, more perfect, and more differentiated. for special purposes, than in the oviparous.

In the male, one of the first things to observe is the more complete separation of the sexual apparatus from all the others. Instead of one common passage or cloaca, into which the excrement, urine, and seminal fluid discharge, as in birds, there are two, one for the excrement alone (the rectum), and the other for the semen and urine (the urethra). The penis also always has an internal passage, instead of a mere external furrow ; and is provided with a powerful expulsive apparatus, to throw the semen with force into the female organs. The urine and semen also are kept separate, though they both are finally expelled from the body through the same passage. In addition to the testicles we also find various other glands, the secretion of which is added to the semen, increasing its bulk, and probably modifying it in some way.

In the female of the vivipara, in addition to the ovaries, there is provided an organ called the matrix, or womb, in which the impregnated egg is developed into the new being, and connected with this are various accessory organs, needed for the transmission of the semen and ovum, for receiving the male organ, and for connecting the new being with its parent. These will all be described in detail farther on.

Besides these there are also the mamma, or breasts, to provide nutriment for the young after it is born, and it is from these, the distinctive organs of their kind, that the true vivipara derive their name of nammifera, or animals that suckle their young.

Among all the various classes of nursing animals, or mammifers, at the head of which stands man, we find the same kind of generative organs. They may vary in form, and in the way they act, but they are always essentially the same, both in male and female. If we describe them in man, therefore, they will be understood in all, because mere modifications can be readily pointed out and explained.

\section{HUMAN FEMALE ORGANS.}

The external parts are not necessarily concerned in the process of generation, but still it is advisable to describe them, because certain modifications in their form and size may be of consequence, connected with marriage, and, also, because it is necessary, on various accounts, to refer to them.

The pubic bone, at the lower part of the abdomen, in front, is covered, in the female, by a thick layer of fatty matter, especially after the age of puberty, when it is also covered, more or less, with hair. This prominence is called the mons veneris, and its development gives a peculiar outline to this part of the female form. The 
covering of hair was formerly called the tressoria, and its absence was universally regarded as a reproach. In fact, it was customary to order it to be cut off, in open court, in ancient times, when a female was detected the third time in illicit intercourse, as we find stated by Chitty, in his Practical Treatise on Medical Jurisprudence. In some cases it is very slightly developed, or even altogether absent, and is never seen at all in those who have no ovaries, or in whom they are inactive. It is also liable to fall off after certain diseases, or after taking powerful drugs, and will even turn color after fright or severe agitation, the same as the hair on the head. In some individuals it becomes troublesome, from excessive development, and will occasionally extend itself far over the rest of the body. In some young persons, the

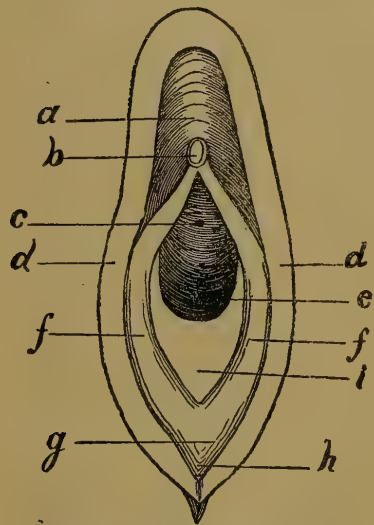

FiquRe 62.- External Sexual Organs of the Human Fremale before marriage.

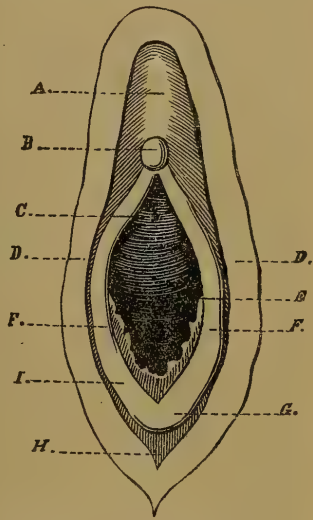

Figure 63.-External Organs of the Human Female after marriage.

FIG. 62.-a. The clitoris. b. The glans, or point of the clitoris. $c$. The meatus urinarius, or mouth of the urinary passage. $d d$. The labia majora, or large lips. $e$. The opening into the vagina. $f f$. The labia minora, or small lips. $i$. The membrane called the hymen, which partly closes the entrance to the vagina in unmarried females. $g$. The fossa naviculaire. $h$. The fourchette.

FxG. 63.-The letters are the same as in Fig. 1, but it will be seen that the membrane called the hymen is broken, and the remains of it, between FF, are seen in fragments, like a fringe. The edges of the fringe finally shrink up into little points, called the caruncula myrtiforma, and finally disappear altogether.

growth of the mons veneris and its tressoria is very rapid at the age of puberty, so that the appearance of the body is completely changed in that respect in a few weeks. It is customary for parents, and even some physicians, to regard the appearance of the tressoria as the certain and invariable sign of womanhood, and they are guided by its absence or presence in their treatment and communications. This sign, however, is not always to be relied upon, for I have known young persons, of not more than nine or ten years of age, upon whom it was very fully grown, and the mons largely developed, though they did not menstruate till several years after ; and I have known others, at eighteen years of age, with scarcely an appearance of it, who had menstruated from the time they were fourteen. As a 
sign of puberty, therefore, it cannot always be implicitly depended upon, though generally it may. I once saw an infant, of four years, on whom quite a large grow th of the tressoria existed; and I have known females pass the turn of life who had scarcely ever had any at all.

Immediately below the mons are two large lips, called the labia pudendi, the labia majora, or external lips, which are formed by a fold of the skin, made ruund and full by a thick deposit of fatty matter underneath. The outer surface of these lips is covered by the tressoria, but the inner surface is smooth, and studded with a number of little glands or follicles, which exude a peculiar fluid, with a characteristic odor. The external lips commence at the frontal or pubic bone, and they descend underneath to within an inch and a half of the fundament. They are united together, both above and below, but perfectly separated in the middle, where they are also the largest and most prominent. Their union below is called the four chette or fork. Sometimes they are very large and prominent, and at other times are very small, and with little elasticity, which makes them liable to injury during parturition. In some young females they grow together from inflammation, and if not separated before marriage, great distress and injury may ensue. The removral of this disability is, however, a very simple matter, and is fully explained elsewhere.

Immediately within the external lips, and lying on their two sides, are the smaller ones, like folds, which are called the labia minora, or inner lips, or the nympha. These two inner lips do not extend so far, either up or down, as the larger ones, nor are they so round and full. In infants, the nymphæ project out farthest, and are seen in front, but at puberty, the external lips develop more fully, so as to close together, and thus shut the nymphr in, and conceal them. This is always the case in virgins, but after childbirth the external lips become more flaccid, and separate, and the nymphæ again project, and are seen externally. In the females of some countries-particularly in the eastern parts of the old World-the nymphr often grow to an extraordinary size, so as to partly close the passage, and it becomes necessary to remove them. I have even sometimes found this necessary in my own practice, not only from their immense growth, but also from their peculiar condition. They are, in many persons, singularly sensitive, and appear to be the principal parts in which sexual excitement is felt, and when they are more than usually large, or irritable, that excitement becomes so great and overpowering that it cannot be controlled, but is really a species of furor, or madness, which irresistibly impels the individual to seek gratification in some form or other, regardless of consequences. The operation of removing them is comparatively simple, and unattended with the slightest danger.

In some of the Hottentot females, the nymphæ are singularly enlarged at that part where they join together above, the enlargement banging down in front of the passage, like a veil. This is called the apron, and seems to be peculiar to cer. tain tribes. It was formerly thought that this apron was a growth produced by artificial means, but it is now generally conceded to be natural. Several of these females have been examined at various times by medical men and travelers, and their accounts pretty much conform with each other. I had an opportunity myself, when in England, of seeing a Hottentot Venus, as she was called, who possessed this apron, and I was convinced that it was nothing more than an extension of the nymphæ. In these females, in fact, the whole of the external organs differ much from those of the white females; the mons veneris being less prominent, the external lips smaller, and the 
passage itself much larger, while the mouth of the opening is more underneath, or farther back, so that, when stooping forward, it is nearly in the same position as in some animals. The length of this apron, in the case which $I$ saw, was about three inches and a half, but they have been observed four or five inches long; and $L a$ Vaillant says, in his journey into the interior of Africa, even nine inches. Whether ihis singular apron serves any specific purpose, it is difficult to tell, but it certainly is a hindrance to connection, unless placed aside at the time, because it hangs down between the limbs, immediately in front. One of these females very much deceive the French physicians who examined her, by concealing the apron in a peculiar sit uation, so that they could not see it, and some, in consequence, even doubted of its existence; but the deception was afterward discovered.

In many of the Oriental nations the enlargement of the nymphæ is so general that their excision is quite a common operation, like circumcision among the men. This is especially the case in Abyssinia and in the country of Ancient Judea. Many of the Mohammedans remove the nymphæ in most of their young girls, in order, as they say, to prevent deformity, but in reality to make them have less sexual feeling, so that they may not be disposed, when women, to desire more indulgence than may fall to their lot in common with many other wives. It is, therefore, the tyranny and jealously of polygamy that leads to this shameful mutilation. A medical friend of mine, who has resided some time in these countries, informed me that he had even known them to close the two lips together, in young female slaves, with a kind of lock, so that association was impossible until it was opened, and the manner of opening it was known only to their masters. In Sonnini's Travels in Upper and Lower Egypt much curious information can be found in regard to such customs. He tells us that, in many of the cities, there is a class of persons who make the removal of the nymphr in young girls a trade, and that they go about the streets crying out, "Here's a good circumciser." And a more ancient traveller, Leo Africanus, informs us that they also call out, "Who is she that wishes to be cut?" The only instrument employed by these operators is a rude species of razor, and they astringe the wound by dusting it with ashes.

It is probable that this custom of female circumcision may not have originated altogether from jealousy, but partly from convenience, because when the nymphæ are large, the secretions of the parts are apt to accumulate under them, and cause great irritation, as is often the case in negresses, and occasionally even among whites. Sonnini also tells us that the lascivious Turks have another reason for removing the inner lips, and that is that the vulva, or mouth of the passage, may be perfectly smooth, and sexual congress more easy in consequence.

It is desirable that the condition of these parts, as well as of the external organs generally, should be known previous to marriage, for I have known many instances in which great distress and unhappiness has arisen from something unusual connected with them. They may be too large, or exceedingly sensitive, or grow together, or even be ulcerated, and though the trouble may be readily removed, yet its existo ence is not desirable at such a time.

At the upper junction of the two nymphæ they project over in a kind of round arch, immediately within which is a small firm body about the size of a large pea, which is called the clitoris. This organ is a most important and interesting one in many respects. It has several points of resemblance to the male penis, both in its structure and functions, being composed of a similar sponge-like substance, capable 
of being engorged or becoming erect, and is highly sensitive. It is, in fact, the principal seat of sensation in most persons, and the intensity of the sexual orgasm apparently depends upon the perfection of its nervous organization. When it is unduly developed or excitable, the sexual propensity often becomes irresistible, causing nymphomania or furor uterinus, and leading to moral delinquency, which arises more frequently from mere physical causes than is usually supposed. According to Chitty, if a female, in ancient times, was detected the fourth time in illicit intercourse, the clitoris was amputated in open court-a fact which shows that the lawmakers of that period were aware of its influence.

In the early stages of fotal existence it is difficult to discover the sex of the child, because the clitoris so much resembles the penis ; and even at birth it is relatively much larger than in adult life. In some persons it attains an unusual size, so as to resemble the male organ very much, and can even be used in the same way with another female, though, of course, imperfectly. This fact I can state positively, for I have seen an instance in which the clitoris was fully as large as the penis is in most boys of nine or ten years of age, and capable also of becoming quito firm and erect. It is cases like these that are supposed to be of both sexes, as will bo seen in the article on hermaphrodites. The clitoris, however, has naturally no passage down it leading from the bladder, the urethra being in its proper position; but in some few cases the passage has been found to exist, although the urine did not flow down it.

In some females this organ is so exquisitely sensitive, that it is scarcely possibln? for them to prevent its becoming excited, and creating sexual desires. Wheneve: the elothes touch it, or eren when it comes in contact with the lips in walking, $i$, becomes congested, and excites both the uterus and the brain. In these cases it in sheer nonsense to say that the strong sexual desire experienced arises merely from depravity, or that it can be overcome by moral efforts alone. We might just as reasonably conclude that the hunger of an empty stomach arises merely from unruly: appetite, and that it also may be overcome by moral effort. In making these remarkș, I, of ccurse, do not intend to deny the great power of a determined will over the feelings, under most circumstances, nor to discourage such efforts; on the contrary they are most important, and often highly effective, but I wish to draw attention to the obvious fact that they alone cannot always succeed. It is unquestionable that in many females, and especially about the age of puberty, the excitability of the nymphæ and clitoris is so great that they cannot overcome or escape from the feelings and desires that this excitability creates; and, beyond doubt, it is from this cause alone that many seek improper indulgence, and become depraved. With these persons, therefore, it is not moral suasion alone, or threats, or the fear of consequences, that can be depended upon to effect a reformation, but the state of the body must also be ascertained, and the physical causes of the unnatural excitement removed. The timely advice of a judicious physician, would, in many of these cases, remove all occasion for moral exhortation or coercion, and effectually prevent any future evil, because licentiousness is fully as often a result of the bodily condition as it is of the mental disposition, or probably even more so. It should never be forgotten, when reasoning upon these subjects, that some persons sannot prevent sexual desire-though good moral training may enable them to struggle against it-while others can never experience it, even if they wish and desire to do so. 
A proper attention to bathing and diet will usually overcome any undue excitability in these parts; and mothers especially a ght to know when this attention is required, both for their own peace and for the welfare of their children. Sometimes they are preternaturally sensitive before puberty, even at a very early age, leading to vicious habits and improper conduct, for which the young person is only blamed and reprimanded, while a want of proper information prevents a removal of the cause.

When the clitoris is too large, it can readily be amputated, more or less, as may be required, and its excitability reduced. This operation I have frequently performed with entire success, at various ages. On the other hand, when it is too small, and not sufficiently sensitive, means may be taken to make it enlarge, and to increase its excitability. This may be advisable in cases of barrenness, and when the temperament is too cold.

The clitoris is present in most mammiferous animals, even in the whale, and in the imperfect kangaroo. In the rat, the rabbit, the ape, and most carnivorous animals, it is especially developed, and frequently contains a small bone, like the penis, as we see in the bear, and the otter. In the spider monkey the clitoris is very much like a penis, being three or four inches long, provided with a perfect glans and prepuce, and also with a urethra, like a groove, down which the urine flows from the bladder. In the kangaroo and opossum, the clitoris is split, like the glans in the male, and in the lemming and some few others, it even has an interior passage, or urethra, which makes it almost identical with the penis.

We read in the Grecian classics that the females of Lesbos were famed for an unusual development of the clitoris.

Cowper's glands are sometimes found in the lower animals, and in some of them the preputial glands are often much developed, which is the reason they emit such a powerful odor. Cowper's glands have also been seen in the human female, though they were formerly thought to belong only to the male organs.

There are never any nympha, or inner lips, in the lower animals, nor mons veneris, not even in the monkey, and the external lips are also small and thin, and without a tressoria, while the mouth of the vagina is round, instead of oval, as in the human being. In the mare, and some few others, there is a small tube on each side of the vagina, called the raginal canal, leading to the broad ligaments of the womb, the use of which is unknown.

These parts, namely, the mons veneris, the two external lips, and the two inner lips, or nymphce, constitute the external genitals in all females, but their form and situation occasionally varies in different individuals and races, as already showr.

The opening between the lips, or the external mouth, is called the vulva or fossa magna, and it is also liable to vary much in different persons. As a general rule, the vulva or external opening, is higher up, or more in front in white females than $t$ is in the colored races, and the vagina is shorter and smaller, while the external ips are more rounded and firmer. There is also a less abundant tressoria in the white female, and the clitoris is not so large on the average. These differences I have taken great trouble myself to ascertain, especially during a recent visit to the South, and I consider them of considerable importance. The form of the external lips alters considerably after pregnancy, and even to some extent after association only. The color of the interior surface also changes from the same causes, being a perfect pink in virgins, but becoming slightly tinged with violet or brown im- 
mediately after marriage. The lips also become less firm and hang lower, and separate further. These alterations are often quite sufficient, with a practiced person, to decide whether association has been practiced or not. It is, perbaps, necessary to remark, however, that other practices, besides actual coition, may cause similar changes.

On separating the external lips and the nymphæ, there will be seen, at the lower part of the opening, by the fourchette, the entrance to the vagina, which is nearly oval, and in virgins is usually more or less closed by a membrane or skin which grows over it. This is called the hymen, and it is popularly, but erroneously supposed to be always present during maidenhood. The space below, between the lowest point of the vulva, or the fourchette, and the anus, is called the perineum, and the space between the upper part of the mouth of the vagina and the clitoris is called the vestibulum, in the middle of which is sitnated the meatus urinarius, or mouth of the passage by which the urine flows from the bladder. This passage from the bladder, scientifically called the urethra, is supposed by many uninformed persons, to be the same as the vagina, or passage from the womb, but it will be seen that they are perfectly distinct, although, in some cases of doubtful sex, the urethra has been found so large as to be mistaken for the vagina, and during violent deliveries they are often torn into one.

The hymen has probably given rise to more misapprehension than any other of the external parts, and there are more popular fallacies and prejudices connected with it. In most young virgins the external opening of the vagina is always more or less closed by a membrane of this kind, which has to be broken in the first sexual congress, but in many it never exists at all, not even in childhood. The idea that a young female is certainly not a virgin if the hymen be absent, is, therefore, erroneous, though it usually does exist. Besides being naturally absent, it is also liable to be destroyed in maly ways. Thus in some it is broken by the first rush of the menses, and in others it may be ruptured by various accidents, such as falls or extreme separation of the limbs. I have even known it to be ruptured, and flooding brought on, by the action of powerful cathartic medicines, which, it is well known, may even cause miscarriage during pregnancy. A long continuance of certain debilitating disewses will also relax the parts so much that no resistance whatever is made by the hymen, even if it remain, which is the reason why those who marry late have seldom any trace of it, because if they escape all the various accidents referred to, thoy seldom escape sickness and debility. It should be borne in mind that the membrane is often very thin, and that it may be broken while using the bath or the napkin, as I believe is often the case with children in the hands of their nurses, and with young persons during their periods, especially if they use those articles too large or too firmly bound against the person. Sometimes, also, the hymen is destroyed by young persons themselves in various thoughtless or improper practices, and sometimes it is destroyed during certain necessary operations and examinations by the medical man. The old Jewish custom, therefore, as stated in the Bible, of examining the bridal sheets for the blood stains as proofs of virginity, was absurd and unjust. When the hymen is perfect, it is true, there is usually more or less blood lost when it is first broken, but not always even then, as I have witnessed during examinations, and sometimes blood will flow from the vagina at such times when there is a physical disproportion between the parties, though the hymen may not exist. In some females these parts are naturally small, and disposed to 
sontract when left to themselves, so that even widows, in a second marriage, will exhibit all the usual indications of virginity. There are even means of forming a hymen artificially, and this has been done so perfectly in some cases, that it has been thought the female had never had association, when she, in reality, had even been a mother! In short, though there is usually more or less pain and difficulty attending the first act of coition, yet there are many exceptions, from various causes; and it is seldom that much of either is experienced if the first act is delayed till after the twentieth year.

In nearly every case the hymen has an opening through it at the lower part, by which the menses escape, but occasionally it is without such an opening, or imperforate, and the menses being, of necessity, retained, the health suffers very much. In such cases constant suffering, insanity, or even death, is not an unfrequent result if relief is not speedily obtained. All that is required in such obstructions is to puncture the hymen, an operation neither difficult nor dangerous in proper hands, It is more to our present purpose to remark, that the hymen is occasionally not only imperforate, but also unusually strong, so that it is difficult or even impossible for the husband to break it. I have had such cases come under my notice in which the marriage could not be consummated, and neither party knowing the real cause of the difficulty, their distress was extreme. The treatment of this peculiar trouble is obvious; the surgeon's knife must first open the callous hymen, and then, if further treatment is needed, the opening must be dilated with appropriate instruments. I have known this membrane to be as hard as if it were ossified, or bony, and so unyielding that it had to be removed almost totally before association could be practiced. After the destruction of the hymen, its fragments usually remain round the external mouth in the form of little protuberances, like pimples, which are sometimes highly sensitive; they are called the carunculce myrtiforma. Not long since a young man killed himself on his wedding night, because he did not find the proofs of his wife's virginity, which he had been led to expect from the Bible, and he believed her unchaste. The event made a great sensation, but the real cause was unknown except to a few.

From what has been already stated it will be obvious that actual proof of violation or unchastity may be very difficult to obtain in many cases. In fact, positive proof is often impossible, and for want of it many a female has been unable to obtain justice for wrong done to her, while many a man has been improperly condemned.

As stated in previous articles, many undoubted virgins would, on examination, be pronounced unchaste, while many really unchaste females would be pronounced virgins. There are, it is true, exceptional cases, but the fact that such do occur makes the matter one of great uncertainty. The truth is, there are no positive means of proving in all cases from the appearance of the female organs, neither virginity, habitual association, nor even violation.

There is, however, one way in which connection can be proved, or even the attempt at it, if recent; providing emission has taken place on the part of the male.

If there has been any discharge of semen, either within the female organs or without, it can be infallibly detected, even though much mixed with other fluids. Its presence may be suspected from its appearance and odor, but the only positive proof is the presence of the animalcules as shown by the microscope. If there be any semen present they can be found, and if they are absent it is a proof there is no semen, and consequently there has been no emission. 
In all cases of alleged violation, therefore, the semen must be sought for, both in the female parts, on her person, and on her clothing. A considerable time may have elapsed since the emission, and the semen may be mixed with blood, or mucus, or may be fully dried, but still the animalcules can be detected. Their shape and general appearance is so peculiar that they can never be mistaken for any other beings, and any one accustomed to observe them can always speak positively as to their presence or absence.

There have been many trials, for alleged violation, in which this evidence has been most important. In fact, the conviction or acquittal of the accused may often depend upon it, as will be seen by referring to any good work on medical jurisprudence.

Viery tells us in his Histoire Naturelle du Genre Humain, that certain savage people fasten the lips of the vulva together, in young girls, with a ring, so that connection with them is impossible without its being known. In Darfour they even sew the lips together, leaving only a little opening through which the courses can flow At the time of marriage the husband opens the passage with his knife.

On the contrary, certain tribes in Asia and Africa have the virgins deflowered by their slaves, and no man will marry a girl while she remains a virgin. Strabo tells us that it was much the same with the ancient Armenians, among whom the virgins always went to one of the temples to be deflowered, because they could not get husbands while they remained virgins. It has also been stated that the ancient Phoenicians habitually made their slaves deflower the virgins.

This shows how ideas and manners vary among different people; what is valued by one is despised by another.

As before stated, virginity may be reproduced (that is apparently) artificially, so as almost to defy detection, after it has been lost. And this has been done in many unsuspected cases.

It is a remarkable fact that the hymen may be so elastic, and the lips and vulva have such contractile power in some females, that they can have connection for a long time, and yet preserve all the appearance of virginity. Parent Duchatelet tells us, in his great work on Prostitution, that two girls, who had been accused of being prostitutes, demanded an examination, affirming they were virgins. An experienced surgeon who examined them stated that he could not be sure about one of them, but that he thought the other might have had connection, though he could not be positive. It was afterward found that they had both long been prostitutes, and had even had the venereal disease. Jacquemin also tells us he has known girls who had been on the town ten or twelve years who could sasily pass for virgins. And Parent Duchatelet tells us further that he saw a woman fifty-one years of age, who had been a prostitute since she was fifteen, in whom all the organs might easily be mistaken for those of a young maiden.

Most of the signs of virginity may, therefore, be very obscure.

\section{PROOFS OF VIOLATION。}

From what has been stated in the previous article it is evident that a female may be violated, even though she be a virgin, and yet it may be difficult to prove the fact. Wsually the violation is evident, but in some cases it is not shown at all by the appear. ance $f$ the female organs, and this fact should be borne in mind. 
In all cases of alleged violation the only sure proof, as before stated, is the presence of the semen, and this should always be sought for. If there has been any emission it may always be found and recognized. When fresh its odor will betray it, and by the aid of the microscope its presence may be proved, even when mixed with blood, mucus, or other fluids. The seminal animalcules can invariably be detected, even in semen that has been dried for months or years, and on wetting dried semen it will always give out its peculiar odor. It has also peculiar chemical reactions, anc if any dry spots of it upon linen be held near the fire they become of a peculiar yel lowish fawn color, and a number of white dots make their appearance which we: not seen before. This peculiarity alone is sufficient to distinguish it from any othei secretion. In all cases where there has been emission, therefore, the presence of the semen can be proved, as it will be found either in the female organs, mixed with mucus or blood, or in spots like gum on the clothes. These spots.placed close to the fire will show as above, and if wet will give out the seminal odor.

Such facts have often been brought forward in trials for rape, and the conviction of the violator has depended upon them.

In former times some anatomists, Haller among others, advanced the theory that the hymen was peculiar to the human female, and made so for moral reasons. They thought it was intended to prove chastity in virgins or the reverse, a notion, as we have shown, altogether without foundation. A precisely analogous part is found in many animals, as Duvernoy has demonstrated, and for many reasons it is ofter totally absent even in young children. If any of these external parts are really peculiar to the human being, it is rather the nymphr, of which scarcely a sign is found in any other animal. If, therefore, the hymen has any special use, it is certainly not that of proving virginity. And, further, as before remarked, it both car be, and sometimes is, imitated artificially by the surgeon, in the most perfect manner. We read in Deuteronomy that, among the ancient Jews, if a virgin could not show, when married, the blood on the sheets, she was to be stoned to death, and no doubt this piece of ignorant brutality has often been perpetrated.

The ovaries have already been fully described, and also the ovum; it will, therefore, be only necessary to show their position in the body, and their connection with the other parts. The remaining organs will be described in detail.

Below, the internal organs are all shown cut open.

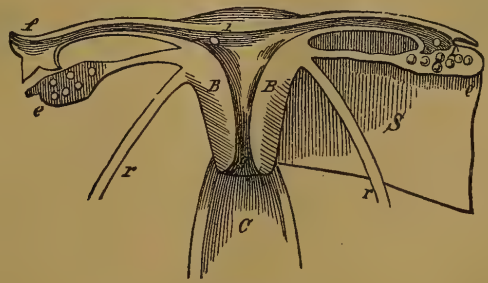

FIGURE 64.

BB. The walls of the womb. C. The vagina. 8. A broad ligament. $r r$. The two round liga ments. ee. The ovaries, showing the ova. $f$. The right Fallopian tube. In the left tube an egg is seen just entering, and at the end of the right tobe one is seen just entering the womb ขथ $\%$ 


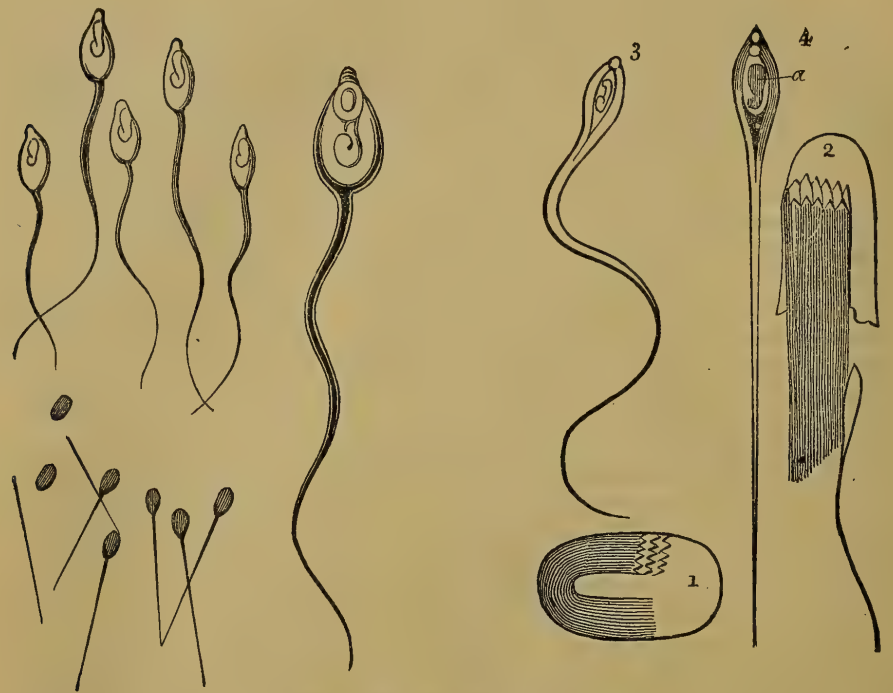

Dried Bemen.

FrguRe 65 - Human Bemen, Recent and Dried.
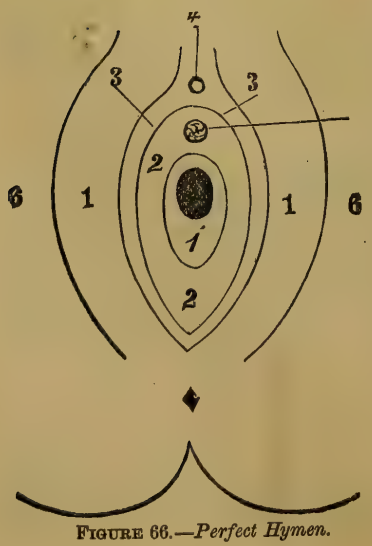
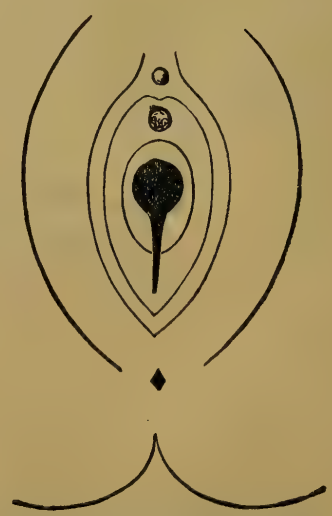

FraURE 67.-After Violent Rupture 
On the preceding page is shown the appearance of the human semen under the microscope, both recent and when long dried. In 1-Figure 64-the animalcules are shown coiled up in one of the vesicles in which they are formed. In 2 the vesicle is opening for them to pass out. 3,4 are perfect animalcules, and in '4, at $a$, are seen the internal organs.

In the dried semen the heads and tails are often separated.

The first of the lower cuts, Figure 66, shows the appearance of a perfect hymen unbroken. The second, Figure 67 , shows one that has been ruptured by some violence.

\section{THE FALLOPIAN TUBES.}

The Fallopian tubes, as already explained, form the only means of communication between the ovaries and the womb, and it is into them that the ripe eggs are passed when they leave the ovary. The structure of these organs is very peculiar, and they are of great importance to health, besides being essential to generation. In dissecting

Fig. 68.

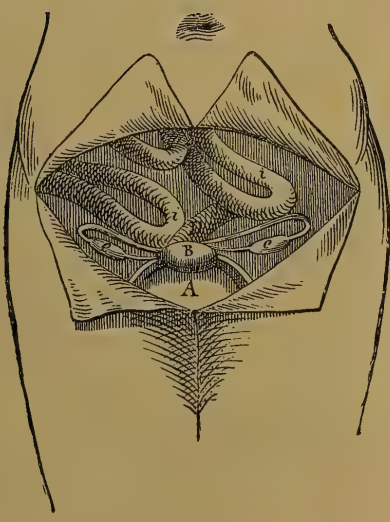

Fig. 69 .

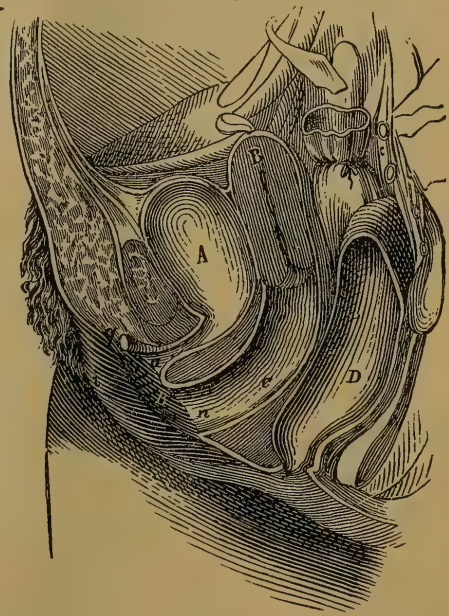

Figures 68 and 65.-Internal Female Organs.

Figure 68. Front view of the femaie organs. A. The biadder. B. The womb. ee. The ovaries with the Fallopian tubes above.

Figure 69. Side view of the female pelvis cut through. A. The bladder. B. the work. C. The vagina. D. The rectum. $q$. The clitoris. $i$. The large lip, or labia

them, the interior passage is found to be covered with a number of cilia, or hairlike threads, which are directed toward the womb. These cilia are in perpetual motion, like small worms, drawing themselves up and then elongating, and the tube itself is also constantly contracting, in successive waves, from the ovarian end to the uterine end. The result of these combined motions is, that, so long as they continue, and ob. 


\section{PLATE XIV.}

In the Surinam toad, the male, when he has impregnated the eggs, places them uniformly on the female's back, where they become imbedded in a kind of sticky jelly, each one making a cell for itself. In these cells they develop, and when the young are fully formed they make their escape, presenting a singular spectaclo as they struggle forth, some head and some paws first. The skin of the back is very thick and soft, to allow of these cells being indented in its substance. The whole process takes some eighty days, and after the young have all escaped the holes fill up, and the animal resumes its usual appearance.

This may be considered a species of external ponch development, in which the male is indispensable as an assistant, besides acting as impregnator.

In the pouched frog there is an arrangement resembling somewhat that of the marsupials. The female has a kind of pocket, or pouch, on ler back, in which the eggs are placed, after they are impregnated by the male, and in which they are carried about till the young are developed. This is not a place formed at the time when it is wanted, like the cells on the back of the Surinam toad, but is a permanent pouch, possessed only by the female, and not developed till she is of mature age.

When well filled with eggs this pouch swells along the whole back, un to the head. It is very firmly closed by a fold of the skin, and the openjug, bejso, quire narrow, is not easily detected. 
PLATE XIV.

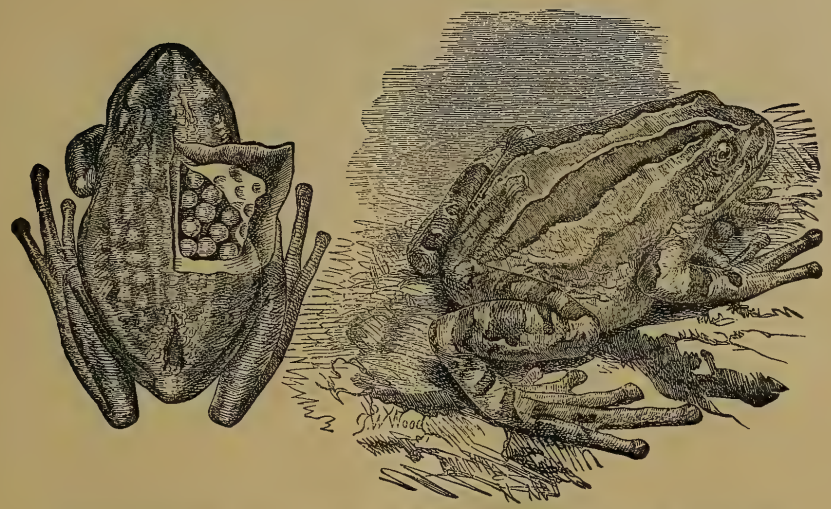

The Pouched Frog. In the Fremale the Pouch containing the Eggs is throvon open.

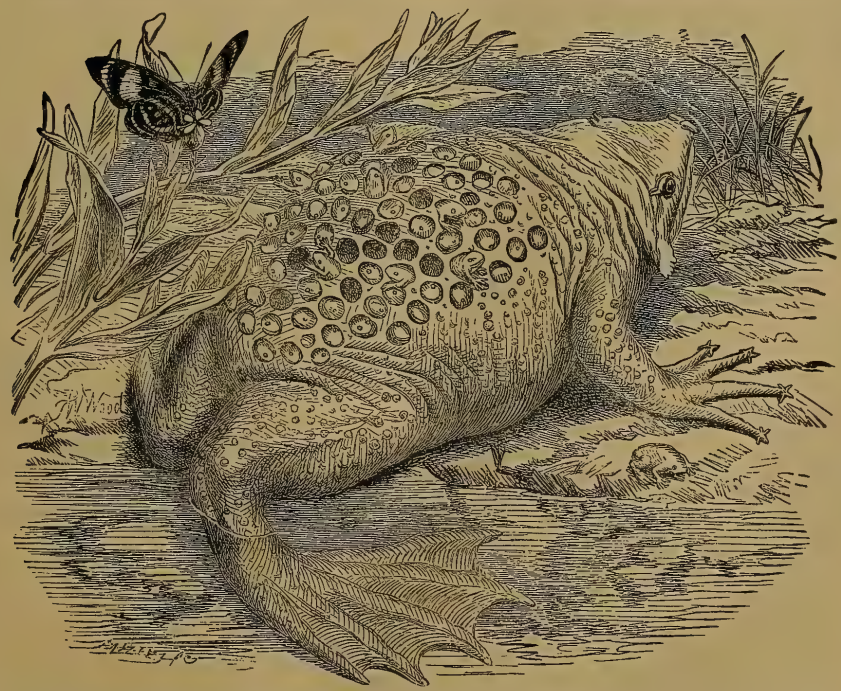

The Female Surinam Toad, with the Young making their Liscape from the Cells on its Back. 

ject of proportionate size can enter at the ovarian end of the tube and be conveyed down to the womb, but nothing can enter at the uterine end, nor be conveyed up to the ovary. The ovarian end of the tnbe is also expanded, so as to embrace or cover any object, and is provided with fimbriæ, or fingers, to grasp with, but nothing of the kind exists at the uterine end. It is evident, therefore, that, except under peculiar and unusual circumstances, explained elsewhere, nothing can pass from the womb to the ovary, but only in the opposite direction. The great use of the tubes, is undoubtedly, to transmit the ripe eggs to the womb, after they are ejected from the ovary, but, besides this use, they also serve another purpose, of great consequence to female health. The continual excitement to which the ovaries are subject, causes them to be always secreting various fluids and other substances, which, if not expelled from the body, are apt to cause many evils. Now the only mode of escape for these secretions is down the Fallopian tubes, which are consequently perpetually embracing the ovaries, by their expanded terminations, to allow of this escape taking place. A portion of those discharges, therefore, occurring at ordinary times from the vagina, are really the secretions of the ovaries, transmitted down the tubes into the womb, and thence to the lower passage. If the tubes are obstructed or paralyzed, as is sometimes the case, this transmission cannot take place, and the ovarian secretions are retained. When this occurs, they either cause continued irritation by their contact with the interior surfaces, or acute inflammation by being absorbed. And in this way often arises inflammation and dropsy of the ovaries, tumors and abscesses.

There are many causes that tend to weaken the action of the Fallopian tubes, and which, therefore, dispose to the above diseases, and also lessen the liability to conception. In some persons they are almost totally torpid, from want of sexual feeling, the production of which puts them in vivid motion almost invariably. It follows, therefore, that this peculiar excitement-which many uninformed persons affect to despise and totally condemn-is really, in many instances, a preventive of disease, and its experience becomes essential to the preservation of health. On the other hand, excessive amorous indulgence will so weaken the tubes, by the incessant excitement to which it subjects them, that they will almost lose their power of contraction, and then the individual will be liable both to disease and sterility. This is, in fact, the chief reason why prostitutes do not conceive so frequently as married females; the continued and excessive excitement which they experience, causes a paralysis of the tubes.

In several instances proof has been obtained that, at the moment when the egg passes from the vesicle, the tube erects, and its fimbriæ grasp round the ovary, so as to include the ovum within the open end. It is probable also that, at the same time, the body of the uterus expands, while its mouth closes, owing to the excitement experienced, and thus there is powerful suction, by which the egg is drawn into the first part of the opening. In some females the motion and erection of the tubes can be distinctly felt, and it is occasionally so energetic, that it may be seen externally. It is always very readily excited, by external treatment, and is often all that is required to remove many diseases, in their incipient stages.

A perfect paralysis of the tubes, or closure of the passages down them, of course, necessarily causes sterility, because the egg cannot reach the womb. This fact is sometimes of practical value in preventing breeding in female animals. Instead of spaying, or removing the ovaries, which is the common operation, a ligature is tied 
round each tube, which, by closing its passage, and preventing the passage of the egg, effectually prevents any future conception. In some females the action of the tubes is very slow, and the egg becomes decayed and spoiled before they convey it to the womb. The sterility arising from this cause may always be cured by quickening the action of the tubes. In ordinary cases, the egg is conveyed down them in about two days, and it first passes into them immediately it is expelled from the ovary, which is just about the cessation of the flow. The egg, therefore, reaches the womb, as a general rule, about the second day after menstruation is over, and then commences the liability of conception. It may, however, pass down in one day, or less, and may be as long as five or six days, or more, as explained elsewhere. It is probable that sexual excitement, just at the termination of the flow, hastens the passage of the egg, and thus makes conception possible so much earlier.

It is probable that many cases of hydatids, and other living bodies, and also polypi, are caused by eggs being retained through the inaction of the tubes. This retention first causes inflammation of the ovaries, and then the inflammation causes the ova to imperfectly develop, as already explained.

At the present time, barrenness from want of passage in the Fallopian tubes, can be cured, an operation being performed, by which they are opened. This consists in passing a silver tube, properly made, into the womb, till the end of it touches the opening of the Fallopian tube, and then a very small probe is thrust out of it and pushed along the passage, so as to open it, or remove any obstructions. With proper instruments, and by using due care, this apparently difficult operation becomes quite feasible, and its results are often as acceptable as they were unexpected. I have known barrenness of many years' standing cured by this practice-conception occurring in a few weeks after.

The usual length of the tube is about three inches, but I have seen them four, and even five inches. Sometimes they are too short, and cannot reach the ovary, which is, of course, another cause of sterility, and an incurable one.

\section{THE WOMB.}

The uterus or womb, called also the matrix, was formerly thought to be the most essential of the female generative organs, but is now known to be merely a receptacle, in which the ripe egg is placed for a short time after its ejection from the ovary, and in which it develops into the new being if conception occurs. There is no uterus, therefore, in those animals that do not bring forth their young alive, the egg in them being expelled and developed externally.

The situation of this organ in the body will be readily understood by the explanations already given. It is placed midway betweer. the lower edges of the two hipbones, and its upper part lies immediately upon the bladder, which is in front of it, while behind it is the rectum, or lower part of the large intestine. The womb does not extend downward but about two inches, or little more, and immediately below, connected with it, is the passage called the vagina, which leads up to the womb, and opens externally at the vulva, between the labia. When viewed externally, the womb and vagina seem to form but one organ, but internally, the distinction between them is easily seen.

The form of the womb is nearly that of a pear, the larger end being at the top. It is not round but flattened, being widest across the body from side to side, and it is slightly curved, or bent, the convex part being toward the backbinne. The lower 
part of it, called the neck, hangs down into the vagina, the walls of which are attached to the exterior of the womb, some distance above. At each one of the upper corners of the womb is one of the Fallopian tubes, with the ovary underneath, the tubes being about three or four inches in length, and the ovarian ligament about two or three inches. Underneath these, some little distance down the sides of the womb, there are also attached two round cords, one on each side, very firm and strong, which are called the round cords, or ligaments of the womb. These are about five inches

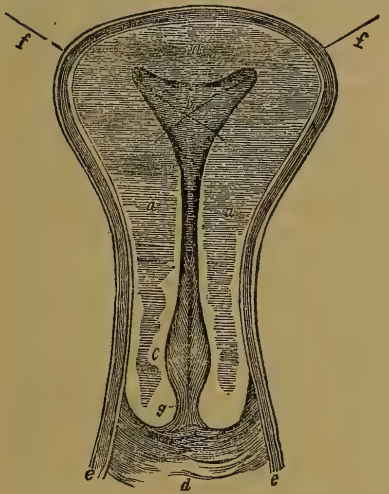

Fit. 70.-Section of the Womb, natural size.

$a a$ are its thick walls. $b$ is the eavity in its upper part, or body. $c$ is the cavity in the lower part, or neck. $d$ is the vagina, ee. The edges of the walls of the vagina cut through. ff. Two threads, passing through the openings of the Fallopian tubes, and appearing in the inside. $g$ is the mouth of the womb, or os tincæ opening into the vagina.

This view, being of the full size, will give an idea of the astonishing change this organ has to undergo in the process of gestation.

long, curved round, and by their other ends firmly attached to the pubic or front bone. These act like stays, and keep the womb in the center of the body, on the rounded top of the bladder. Without them it would be con-

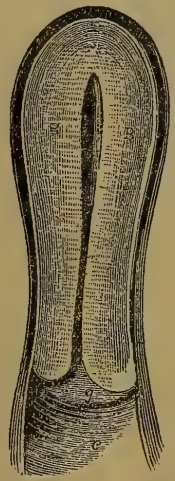

FIGURE 71.-Section of the Womb, natural size, out through the other way.

B. The walls of the womb. C. The vagina, $g$. The mouth of the womb.

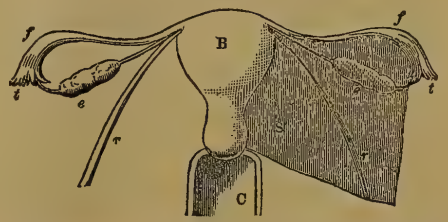

FiguRe 72.-The Womb and its Appendages sepa. rate from the body.

B. The womb. C. The vagina, ee. The ovaries. $f f$. The Fallopian tubes. $r r$. The round ligaments. 8. One of the broad ligaments. $t t$. The fimbriæ of the tube.

stantly liable to displacement, but as each of the ligaments acts with equal force, and in an opposite direction to the other, they necessarily maintain the organ in the center. (See the view of the internal female organs in front.) Besides the round ligaments there are also the broad ligaments, which consist of two broad sheets of strong membrane, one on each side, which extend from the top of the womb, nearly the whole length down, inclosing the round ligaments, tubes, and ovarian ligaments in their substance. These grow fast to the sides of the pelvis, and assist in maintaining 
the uterus, the ovaries and tubes, in their proper situations. There are also two ligaments that connect the womb with the bladder in front, called the anterior ligaments; and two others which connect it with the rectum behind, called the posterior ligaments. All these, however, do but little toward actually supporting the womb, which is really kept in its place more by the firmness and density of its own substance, and that of the vagina below, and by the tension of the muscles in the perineum, than by anything else. When these parts become weak, from debility or disease, the ligaments stretch, the perineal muscles relax, and the walls of the womb and vagina soften till all fall down together, and then we have prolapsus uteri, or falling of the womb, the causes, symptoms, and treatment of which are fully given farther on.

The length of the uterus is about two inches and a half, its breadth at the top about one inch and a half, and at the lower end a little less than an inch; its thickness also, through the flat way, is a little less than one inch. The walls being very thick, the interior cavity is necessarily small, and it is different in form to the exterior. In the upper part the cavity is shaped like a triangle, the Fallopian tubes entering at the two upper angles; in the lower part it is continued downward like a tube which swells out considerably a little more than halfway down, and at its termination opens by what is called the os tinca, os uteri, or mouth of the womb, into the vagina. This opening, or mouth of the womb, is like a cleft, placed cross-wise, on the prominent neck of the womb, and is readily felt at the top of the vagina in manual examinations. The two lips formed by this cleft are perfectly smooth and round in those that have not borne children, but are apt to be torn and covered with scars in those who have. The anterior lip, or the one in front, is considerably thicker than the other, so that the cleft, which is about a quarter of an inch long, is not quite in the center. In virgins the internal cavity is very small, the walls nearly touching each other, and the mouth of the womb, or cleft, is so narrow and its lips so firmly closed, that it can scarcely be ascertained. In young persons, in fact, the neck feels precisely like the end of the nose, the os tincæ merely giving the impression of a slight hollow between the lips. In those that have borne children the walls of the womb separate farther asunder, so that the cavity increases in size, and the os, or mouth, also enlarges and remains more or less open, so that the cleft is plainly felt. In speaking of the whole organ it is usually divided into three parts, namely, that above the Fallopian tubes, called the fundus, that between the fundus and the neck, called the body, and that which projects into the vagina, which is called the neck. The neck projects into the lower passage somewhat less than a quarter of an inch, and is plainly felt at the upper part, like a small firm tumor, across which is the cleft or os tincce.

In virgins the womb is more straight than in those who have borne children, and it is also higher up in the body, and the neck is considerably thicker. In some persons, however, the womb is naturally much lower than it is in others, and also smaller, and is not so much altered by child-bearing even when they have had several،

The substance of the uterus is muscular, and is capable, in its contractions, of exerting most tremendous force. The increase in size which it undergoes at the different periods of gestation, are most extraordinary, and its after contraction to its original dimensions is still more so. Thus at the full period of nine months it will measure over a foot in diameter, each way, in some cases, and yet in a few days after delivery will return to its original dimensions. In the chapters on Midwifery, 
all these changes are fully represented by plates, and instructions are given by which the period of pregnancy may be ascertained by them.

Arteries, veins, and nerves are plentifully supplied to the womb, so that it is abundantly nutrified, and highly sensitive. Indeed there is no other organ in the body, except the ovaries, that has such extensive sympathies, or that is capable of such rapid growth. The womb, however, is altogether dependent upon the oraries both for its development and its functional ability. If there be no ovaries the womb will be found merely rudimentary, and if the ovarian actions cease, those of the womb cease also. The neck of the womb, which hangs down into the vagina, is usually the most sensitive part of it, and is, in many persons, the principal seat of sexual feeling, even more so than the clitoris. In fact, I believe that sexual excitement is never known in its full intensity excepting when it is experienced in the neck of the womb, it being always weak and partial when confined only to the clitoris and nymphæ. It is to this part, therefore, that our treatment must frequently be directed, when that peculiar condition becomes desirable, or not.

When the erotic excitement is intense in the female during connection, the womb experiences a species of erection and vibration, by which it becomes engorged with blood and is drawn with considerable force and rapidity up and down the vagina. This brings the neck into contact with the glans of the male organ, which is also the most sensitive part, and their mutual pressure hastens the orgasm in both. This fact has never been mentioned by any previous writer on physiology, so far as I know, and it is one of considerable medical and moral importance. The idea which some persons entertain that the male organ enters the womb is both erroneous and absurd, as a consideration of its structure will show; neither is it true, as others think, that always when conception ensues the semen is thrown into the womb. It is true, that during a perfect orgasm, such as referred to above, the os tincce opens when the womb descends to meet the male organ, and if the semen is emitted at that time also, it will pass directly into the mouth. This is the reason why conception is more likely when the orgasm is mutual and simultaneous, but still it is not absolutely necessary in either.

Sometimes the womb is very small and imperfect, so that the egg is not retained, and barrenness, of course, results; and occasionally it is absent altogether. A remarkable case of this kind is given elsewhere, in which a young person, who had never menstruated, was married, and it was afterward discovered that she had no womb, though in every other respect quite perfect. This smallness and imperfection of the womb is very likely to be found in those who are late in menstruating, or who have been irregular.

The form of the uterus varies much in different beings, so much, in fact, that it scarcely appears to be the same organ. It is sometimes round, oval, and even triangular, and not unfrequently is forked, or divides into two horns, as in the cow, pig, horse, and whale, in which we also find the Fallopian tubes very long and contorted. It haseven been found double in the human being, in some very rare cases. In most of the carnivorous animals, and in the rodentia, as the rat and squirrel, the uterus is very short, and divides at the lower end into two parts, communicating with two short and straight tubes. In the greater part of the rodentia, in fact, as in the hare and mouse, the womb is really double, there being a separate one in connection with each Fallopian tube, and consequently two mouths, both of which can be distinctly seen in the vagina. In the marsupial animals, as the opossum and 
kangaroo, there is no uterus, properly speaking, but the end of each Fallopian tube, where it opens into the vagina, is expanded, and made to answer the purpose of one. In these imperfect wombs, the young are retained but a short time, and are then expelled, and placed in the pouch outside, as explained elsewhere, in which they are gradually perfected. The vagina, also, is double in these animals, one communicating with each tube. Occasionally the vagina is partly closed, previous to connection, by a species of hymen, as in the mare, the cow, and ape, but it is never so perfect as in the human female.

In very rare cases, as before stated, the womb has been found double in the human being, each organ being distinct and separate from the other, and opening by a separate mouth into the vagina. In such cases, one womb is connected with the right ovary only, and the other with the left, so that conception can occur in one and not in the other at the same time, though it may do so afterward, and cause a superfotation, or conception in a person already impregnated. More frequently the womb is simply divided by a partition inside, and is not properly double, though, possibly, superfoetation might take place even then.

\section{THE VAGINA.}

The vagina is the passage leading from below upward to the womb. At its lower extremity is the vulva, or external mouth, between the lips, and at the top of it is the reck of the womb. The vagina is like a tube, with very firm, thick walls, capable of dilating or contracting to a very considerable extent. The length of it is from four to six inches, though I have seen it as long as eight inches, and as short as three. The diameter varies from an inch and a half to two inches and a half. It is not straight, but curved, the hollow part of the curve being in front, next to the bladder, while the convex part is next to the rectum, or large intestine.

The diameter of the canal of the vagina is not uniform in its whole length, it being scme little narrower in the middle than at either end. It is lined with a mucous membrane throughout, like the uterus, and in virgins is not smooth, but is marked with a number of ruga, or folds, which gradually disappear after connection, and especially after delivery. Under the mucous coat is another thick one of 'cellular membrane, and under that again is another coat, called the corpus spongiosum vagince. This is a true erectile tissue, like the corpus spongiosum of the male organ, and capable, like it, of becoming congested with blood during excitement, and of erecting and contracting. It is this power that enables the vagina to draw down the womb during the orgasm, as explained in the previous article, and it also makes it compress the male organ at the same time, by thickening the walls, and contracting the passage, and thus increasing the pressure and excitement in both. The principal portion of this erectile tissue is, however, confined to the lower part of the vagina, though it exists more or less in its whole length ; and it is a knowledge of this fact that enables us to use many internal instruments advantageously, for the cure of falling of the womb. When the instrument is once introduced, the contraction of the lower part of the passage which is acted upon by the presence of the foreign body, prevents it from being expelled. In some females the erectile tissue is much developed at the narrow part of the vagina, about halfway up to the womb, and it will contract so forcibly there, from any excitement, that a passage can scarcely be 
effected beyond. Those who have the erectile tissue imperfectly developed, are always liable to a lax vagina, which leads to falling of the womb, and also to rupture of the bladder and rectum through its walls. In all such cases, if the erectile tissue is made to act, by the excitement natural to the parts, the relaxation is much relieved, and a step is made toward permanent "mprovement.

At the mouth of the vagina is a strong circular muscle, like that which closes the mouth and eyes. It is called the sphincter, or constrictor vagina, and when it acts properly, the mouth of the ragina is kept nearly closed by it. This muscle is of great importance in maintaining the parts above, by drawing the lower walls of the vagina together, and making them more firm. It also co-operates along with the erectile tissue in increasing the pressure during coition. In some females it acts so powerfully as to close the passage completely, so that an entrance can scarcely be obtained. This is often the case in those who have an irritable clitoris, or nymphæ, -nd every act is as difficult with them as the first, though not painful. When this constriction of the sphincter is conjoined with great engorgement of the erectile tissue, the difficulty is of course still greater, but in all such eases the intensity of the orgasm is also proportionably increased.

The relaxation of the sphincter muscle, which is very common, is a serious evil, as it disposes all the organs above to displacement, and much impairs the sensibility of the parts. The lower part of the erectile tissue, round the base of the nymphæ, exhibits a curious network of veins, called the plexus retiformis, which during excitement are singularly enlarged. They are apt sometimes to become obstructed, and swell, causing varicose veins, and enlargement of the lips.

The hymen, which partly closes the mouth of the vagina in virgins, has already been explained. The opening in it is usually crescent-shaped, and is thought to have originated the symbol of Diana, the goddess of chastity, which was a half moon or crescent.

Immediately within the vagina, on each side, are certain little openings called the glands of Duvernay. These secrete a thickish gray-colored fluid of a peculiar odor, which is often discharged in great quantities during connection, and was formerly thought, by uninformed persons, to be a kind of semen. The situation of these glands causes them to be compressed by the constrictor muscle, which is the reason why they discharge most during the strongest excitement. In some persons the quantity of fluid amounts to several ounces.

In addition to the glands of Duvernay, there are also a number of mucous follicles, both in the vagina and on the inner surface of the lips, which also discharge freely under similar circumstances.

The vagina, like the other parts, is liable to rarious malformations. Thus in some it is too small, and in others it is closed by the inner walls or external lips growing together. In others, again, it is unnaturally large, so that the womb continually falls down to the lower part of it. Many of those cases in which the ragina is closed, are not discovered till marriage, and then great distress and suffering result. Many such instances are given in another part, and also the means of remedying the defect, which can be often done without medical assistance. When tlie canal is too short, great distress may often ensue in marriage, unless certain precautions are observed.

Most of these difficulties appear much worse than they really are, it merely requiring time and skillful appliances to remedy the worst of them. 


\section{PLATE XV.}

\section{THE FEMALE UTERUS AND ITS APPENDAGES.}

Figure 1. A. The body of the uterus. B. The vagina. C. The neck of the uterus, in the center of which is seen the mouth of the womb. D. The interior of the vagina. E. The fimbriated end of the right Fallopian tube, grasping the ovary. F. The right Fallopian tube. G. The left Fallopian tube. н. The fimbriated end, or pavilion, of the left Fallopian tube open, and just about to fasten on the ovary. JJ. The ligaments of the ovaries. LL. The round ligaments.

Figure 2. An ovary cut through, to show the oræ, $a d . \quad b b$. The pavilion of the tube. $c$. The opening of the tube $e$.

Figure 3. This was a remarkable case in which one of the Fallopian tubes was obstructed so that no ovum could pass down it. It will be seen that both the orary and Fallopian tube are deformed in consequence of this obstruction.

The use of all these parts in the processes of impregnation and foetal development, can from these illustrations be readily understood.

In the act of copulation the semen is deposited in the vagina, from whence the animaleules ascend into the womb, and along the Fallopian tubes to the ovary. If a ripe ovum is there at the time, impregnation may then take place, after which the egg descends into the womb, and there develops into the new being, as will be explained farther on. When the new being is fully developed, the mouth of the womb and vagina expand and it is expelled by the process of natural delivery. 


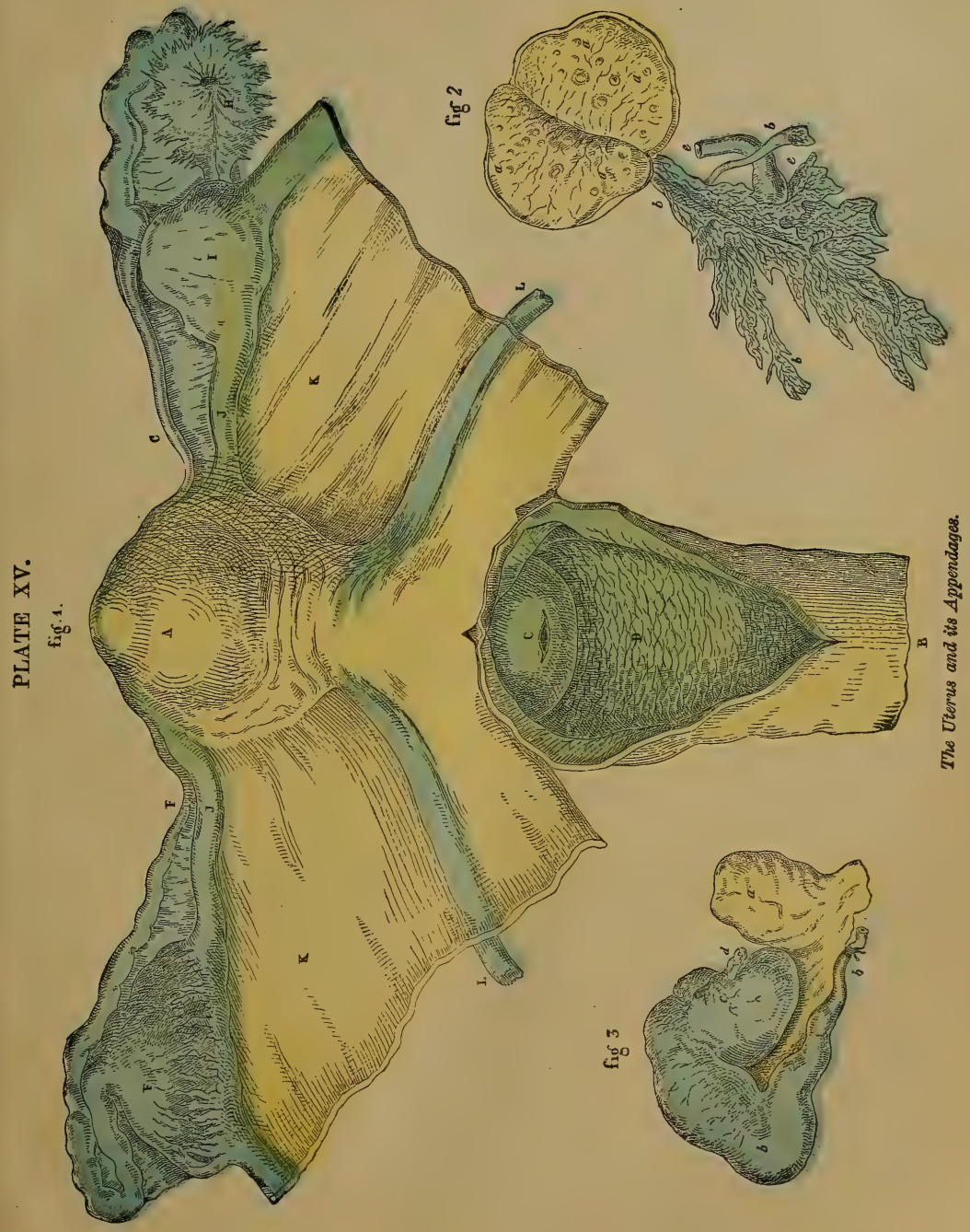



In rare cases, the vagina has been found double, like the womb, sometimes with two uteri, and at others with only one. I once saw a case of this kind myself, in which connection could be effected perfectly in either of the two passages, each having a perfect external mouth and sphincter muscle of its own, one being below the other.

The uterus is variable in different animals, in many ways. In some it is single, as in the human species, while in others it is double, triple, and even quadruple. It is globular, ovoid, elongated, or triangular. In the apes the uterine walls are very thick, as in the human being, while in many other animals they are quite thin, almost like the bladder. When the walls are thick, and the internal cavity small, the changes which the womb undergoes during gestation are very remarkable. Is increases wonderfully in size, and its small mouth expands sufficiently to allow of the birth of the new being, after which it contracts again to nearly its former condition. In the double uterus, as in the rabbits, where many young are formed at once, each one is partly inclosed in a separate enlargement, connected with the others by a narrower part. In the marsupials the womb undergoes but little change, because the young is retained there so short a time, and leaves it while very small.

The Fallopian tubes differ but little in different animals, except in length, and in being more or less straight or twisted. In viviparous animals they terminate in the uterus, and in the ovipara in the cloaca.

The vagina, and its mouth, the vulva, vary as much as the penis does in the male, and correspondingly, because it is in them that the penis is inserted, in the act of copulation. Its size, length and form, are therefore always proportionate to that organ. In some animals it has great power of constriction, and closes firmly on the male organ till copulation is complete, as in the dog.

The clitoris is usually present, and is as variable as the other parts. It is always the principal seat of pleasurable sensation, and those animals in whom it is large are very lascivious, as the apes for instance. In the female bear it is very long, and curved like a double S. In marsupials it is double, like the male penis. In those animals in which we find a bone in the male penis there is also one in the female clitoris.

In the hyena the rulva is cross-wise, instead of length-wise of the body, as in other animals. In form it is usually long oval, but is sometimes round. Its situation is commonly near the anus, but in the lamantine they are eight inches asunder, while in the marsupials the two orifices are united in a common ring.

Instances have been noticed, in the human being even, of all these organs, womb, ragina, and clitoris, being double, as in some other animals.

\section{HUMAN MALE ORGANS.}

The course of the semen will be readily understood from the following illustration, which is made simply diagrammatic, so that the relative positions and connections of the parts can be better understood. It is formed in the testicles, of which the left one is shown in the scrotum (1). From the testicle the semen passes up the tube called the vas deferens (2), which runs up the side of the bladder and around the back of it, where it enters the seminal vesicle (3), and from that passes along the ejaculatory canal (4) (which is only a continuation of the ras deferens), and enters into the urethra (7) through two small openings, called the seminal ducts, just 


\section{PLATE XVI.}

THE HUMAN MALE GENERATIVE ORGANA.

Figure 1. A. The bladder. E. The spermatic cord, which is composed of the spermatic artery and spermatic nerve, going to the testicles, and the spermatic vein and vas deferens leading from it. These are all contained in one sheath, as will be seen. The opening through which all these are connected with the interior of the body is the one through which most ruptures occur. It is called the inguinal ring, and is in the groin. $c c$. The vas deferens. E. The mons veneris. F, G. The muscles which corrugate the scrotum, and raise the testicles. I. The skin thrown back. J. The pubic bone. к. The ischiac bone. $\mathbf{x}$. The under part of the penis. M. The scrotum. P. The glans penis. Q. The seminal vesicle. R. The prostate.

Figure 2 shows the connection between the vas deferens, seminal vesicles, and ejaculatory canal. a. End of the right ejaculatory canal. $b$. A portion of the right seminal vesicle thrown back. $c c$. Cells of the vesicle. $e$. A cut through the wall of the vesicle. $f, g$. The two vas deferens. $h$. The left seminal vesicle, not cut open. $i i$ shows the external appearance of the vesicle. $j$. The end of the ejaculatory cansl. 

below the veru montanum $(6)$. The urethra is the passage common to both the urine and the semen, and down this the semen flows whenever there is an emission, as during connection. It is quite a long course from the testicle where the semen is made, to the end of the penis where it is finally expelled.

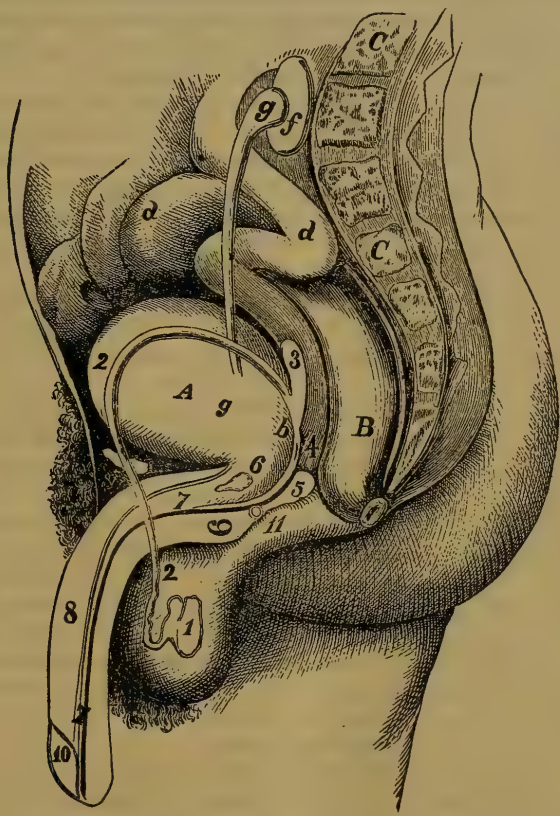

Fraure 73.-Section of the Male Pelvis, to show the Situation of the Different Parts.

A. The bladder. B. The rectum, or end of the large intestine. C. The lower part of the back bone, or sacrum. $d d$. The small intestines. $f$. One of the kidneys. $g g$. The ureter, or tube which conveys the urine from the kidneys into the bladder.

1. The left testicle. 2,2 . The vas deferens, or tube which conveys the semen from the testicle. 3. The left seminal vesicle, with which the vas deferens is connected. 4. The ejaculatory canal, into which the semen next passes. 5. The prostate gland, with which the ejaculatory canal connects, and through which the semen passes into the urethra or urinary passage from the bladder (7). 6. The veru montanum, or small protuberance which partly closes the neck of the bladder. 7, 7. The urethra, or passage by which the urine escapes from the bladder down the penis. 8. The upper part of the penis, or corpus cavernosum. 9. The lower part, or corpus spongiosum. 10. The glans, or head of the penis. 11. One of Cowper's glands.

The use of the penis in copulation, it will be seen, is to convey the semen into the female vagina.

This illustration does not of course give the exact appearance of the organs, nor show their structure. It is intended merely to explain their position and connection; 
it is a key to the large one, which will show them as they really appear, and exhibit their structure. By this illustration also the course of the semen can be fully understood, which it could not be unless the parts were arranged in this manner. The body being supposed cut through, the organs are shown only on one side. There is a testicle, vas deferens, seminal vesicle, and ejaculatory canal on each side, all these parts being double. Each side is distinct from the other, which explains why the testicle and all its adjuncts may be destroyed, or be deficient, on one side, and yet be perfect on the other-the urethra is of course common to the two.

As soon as the semen enters the urethra it has added to it the secretion from the prostate gland, through which it passes, and also of Cowper's gland, close by. These secretions probably modify it in some way, or possibly only act as diluents. It is thought also that it undergoes some change, or ripens, in the seminal vesicles.

The penis is a hollow spongy organ down which runs the passage from the bladder, called the urethra, by which the urine escapes, which also serves for the exit of the semen, as before explained.

The anatomical structure of this organ is not thoroughly understood by anatomists, owing to the difficulty which necessarily exists of dissecting it in its several states. Sufficient, however, is known to explain its physiological action, which is all we now require to know.

The body of the penis consists of two distinct parts, each of which is very porous, or rather spongy. The upper part, which is the largest, is called the corpus cavernosum; the under part, which is much the same in its structure, is called the corpus spongiosum. Both parts extend from the pelvic bones to the glans at the end. The corpus cavernosum is divided down the middle into two parts, by a septum, or partition, and some physiologists on that account speak of two cavernous bodies, or the corpora cavernosa; it is, however, strictly one. These two parts are rounded on the under edge, so that when they come flat together there is a groove formed underneath, and in this groove lies the urethra. They are both firmly attached to the front bones of the pelvis, under the perineum, by two roots called the crura penis.

The corpus spongiosum surrounds the canal of the urethra underneath, and fills up the remainder of the groove, so as to round the whole organ. It terminates posteriorly in what is called the bulb of the urethra.

The whole organ is surrounded by the skin, excepting the end, where we find a body called the glans penis, which is both different and separate from either of those described. The inner fold of the skin of the penis is attached to the termination of the corpus cavernosum, while the outer fold is extended beyond, so that it only partly covers the glans, but is not attached to it, and may be drawn back. This loose skin is called the prepuce, or foreskin, and is the part cut off in the rite of circumcision. In some persons it extends farther over the glans than it does in others, but generally leaves more or less of it exposed. The glans is probably an enlargement of the peculiar erectile tissue surrounding the urethra, and is covered by a highly sensitive and vascular skin, of an exceedingly delicate structure. It is in the form of a section of a cone, and terminates on the posterior or upper margin of an elevated ridge, called the corona glandis, behind which is a depression called the cervix, or neck. In this depression are several glans called the glandula odorifera, which produce a whitish secretion, of a peculiar odor, that sometimes accumulates in great quantities in those who neglect proper cleanliness. On the under side of the glans the prepuce is attached nearly at the end by a cord or ligament, called 
the fronum, or ligamentum proputii. This ligament, or cord, is sometimes too short, and during erection is so pulled upon as to cause great annoyance; occasionally it even ruptures, or tears, causing severe pain, with loss of blood.

These parts constitute the substance of the penis, and are therefore most essential to the performance of its proper functions.

The peculiarity of the structure of the corpus cavernosum, and of the corpus spongiosum consists in their being full of curiously arranged blood-vessels and cells, or cavities, like those of sponge, all communicating with each other, and being connected with the main branches of an artery and a vein. In ordinary states these vessels, excepting the larger ones, and also the cells, are nearly or quite empty, but under appropriate excitement the blood from the artery is impelled into them and fills them up, in consequence of which the organ enlarges, like sponge when filled with water. This is called the phenomenon of erection, and it depends upon a peculiar sensibility proper to the parts, which are therefore sometimes spoken of as being composed of erectile tissue. There is no other part of the body that in any way resembles the penis in structure, except the clitoris in the female, which has. a similar tissue, and is usually capable of erection to a certain extent, in precisely the same way.

When the excitement is withdrawn, the blood ordinarily flows back by way of the cavernous vein, and the erection subsides, but sometimes its return is prevented and the erection then remains, though all excitement is gone. The corpus spongiosum is so distinct from the corpus cavernosum that erection will sometimes take place in one and not in the other, which necessarily curves the organ, or draws it into the form of a bow, producing what is termed a chordee. The erection and emission of semen is also assisted by a number of different muscles, particularly by one called the erector penis, or ischio cavernosus muscle. Sometimes in erection the rush of blood will be so sudden and violent that the vessels will burst, and the erectile tissue be thus totally destroyed. In some persons the filling up of the blood-vessels always occurs in a very short time, while in others it is the reverse ; and in like manner the erection subsides in a short time in some, while in others it will continue for a long period and subside very slowly. This depends upon some peculiarity in the vital action of the blood-vessels, not yet understood. In old age the blood generally flows in slower, and flows out much quicker than it does in youth, so that the erection is longer in taking place and goes down more rapidly.

The uses of the penis, as before remarked, are twofold. Firstly it serves as a conduit to convey the urine from the body, and secondly as a conductor to carry the semen into the female organs. For the first use erection is not necessary, but it is for the second, and therefore its proper occurrence is both natural and essential to the performance of one of the functions of our nature.

The form of this organ varies in different animals, for the purpose of adaption, and is sometimes very singular. In some it is covered with spines, which give great pain to the female during connection, as in the cat, while in others its structure causes that act to be much lengthened, as in the dog. In birds, the male organ is merely rudimentary, so that there is no actual union, properly speaking, but merely an emission into the female organs. In the human being there are occasional deviations from the ordinary development, and sometimes even peculiarities in structure. Thus instances have been known of the interior of the corpus cavernosum being more or less ossified, so that a distinct bone always existed in 


\section{PLATE XVII.}

\section{STRUCTURE OF THE PENIS AND TESTICLE.}

Figure 1. The penis seen underneath. $a a$. The corpora cavernosa. These are the bodies that swell up and cause erection, when the blood fills them. $b$. The glans penis, at the base of which may be seen the little glands which secrete the white odorous matter which is often formed under the prepuce. $d d$. The prostate gland. ee. Cowper's gland. $j j$. The vas deferens. кк. The seminal vesicles. $l$. The membranous part of the uretbral canal. $m$. The bulb of the urethra. oo. The ureters, or canals bringing the urine from the kidney to the bladder.

Figure 2. The penis split open, and seen from above. aa. The corpora cavernosa. bb. The glans penis. $c$. The fossa navicularis. $c c c$. The canal of the urethra. $d d$. The prostate. $f$. The veru montanum. The two larger openings seen by the veru montanum are those by which the semen enters the urethra, the smaller ones are those by which the prostatic secretion enters. Still farther down, about an inch, is seen the opening where the secretion comes in from Cowper's glands. $h h$. The fibrous partition between the two parts of the prostate gland. nn. Part of the bladder. $p p$. Openings of the ureters. $v v v$. The corpus cavernosa laid open to show the vessels.

Figure 3. A section on the medial line of the urethra, $c, i$, and of its bulb, $m$. e. Cowper's gland.

Figure 4. Veins and arteries of the testicles. $j$. The vas deferens. $s$. Its continuation into the epididymus. $t$. The head of the epididymus. $u$. The testicle covered with its membrane. $v v$. The veins, and $y y$ the arteries of the testicle. 


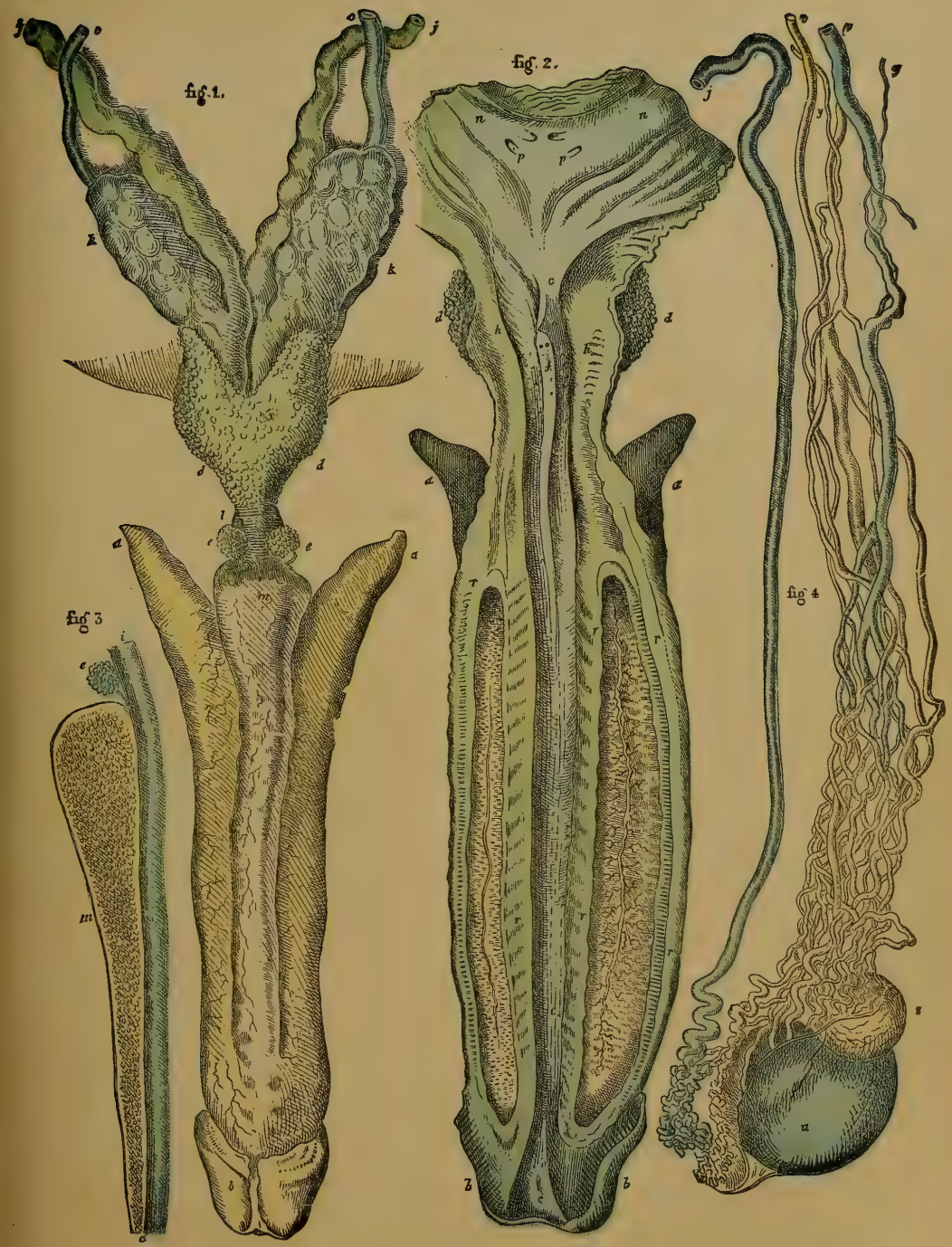

Structure of the Penis and Testicles. 

the middle of the organ. This is often the case in negroes, and in some of the lower animals it is natural. In a few rare instances the penis has been found double, or rather divided into two parts, only one of which, of course, contains a urethra, though both being capable of erection as I observed in one case in my own practice. Probably amputation of the imperfect part might have been safely effected. but as little inconvenience was experienced it was not thought necessary.

The various peculiarities of structure and development that interfere with the functions of this part will be treated under appropriate heads as we proceed.

\section{ABSENCE AND MALFORMATION OF THE PENIS.}

Besides being liable to be lost by several accidents, and by necessary operations, the penis may be also deficient from birth. I have seen instances where it was not more than a quarter of an inch in length, and sometimes only a slight swelling, like the top of a small tumor. In such cases, of course, there can be no connection, but still such men may be fathers, providing all the other parts are perfect, because, as before explained, the semen may impregnate if it be only shed within the external lips, which of course may be effected in the worst of these deficiencies. I have known instances of married couples, with families, who never had any association, from similar causes. It is unnecessary to say, however, that marriage should never take place in such cases without the nature of the infirmity being first known, though I believe the law would declare any marriage binding if impregnation was possible. In giving an opinion under such circumstances, it is, however, difficult to decide this point. In general, in healthy females, the placing of the semen artificially in the vagina will induce conception, but not always. Hunter relates an instance where he advised the injection of the semen with a syringe, after its escape from the husband, and impregnation followed. There are some females, however, in whom its absorption will not take place without a certain amount of excitement, dependent upon actual association, so that there will always be more or less uncertainty, and much less probability than when no such deprivation exists. Independent of this, however, there are other considerations that should forbid the marrying of men so situated, unless with a full knowledge of the eircumstance and its consequences by both. In some of these cases, especially, when a portion of the organ is left, as after operations and accidents, the difficulty may be much remedied by an instrument, so constructed as to fit on the part remain. ing, and resembling that which is lost. I have known instances of conception following the use of such an instrument, when the penis itself was not more than a quarter of an inch long. But then the semen was formed in great quantities, and was remarkably healthy.

In some children the penis is tied down to the scrotum, or some other of the reighboring parts, by bands, which never allow it to be extended, and of course pre. rent the performance of its proper functions. I saw one child of seven years in whom it grew flat on the abdomen, causing great trouble and annoyance in urinating, from the direction in which the fluid had to flow. Nearly all such cases can be easily corrected by a slight operation at any age, the adhesion being usually only by the skin, but they are better attended to early in life. The one referred to was put right very readily, and in two years' time scarcely a trace of the operation could be seen. 
Occasionally the penis will have a wrong direction, being turned so much either on one side, under, or upward, that association is impossible. If this depends upon contraction of the skin, or of the muscular fibers, it may be corrected by simply djviding them; but if it results from a tumor, or swelling, that must be removed before any alteration can be effected. Aneurisms, and swellings of the reins will sometimes bring about such deviations, and so will too long-continued erection, by rupturing some of the cells or ressels, and so causing accumulation of blood. I knew one instance of this kind in which every time erection occurred a large tumor was formed on the left side, full of blood, which of course turned the end of the organ to the right side, and thus prevented connection. This accident had been caused by numerous forcible and long-continued erections in one night, during intoxication. The tumor was as large as an egg, and when full could be distinctly felt to pulsate. It was also very painful, and appeared almost ready to burst. The remedies proposed were cold astringent lotions and wearing a thin plate of smooth horn orer the part, bound on so firmly as to prevent any swelling from accumulation of blood. This plan succeeded rery well in giving relief, though it is probable there will always be more or less tendency to a recurrence of the trouble.

Besides scrofulous and other tumors in the penis, there wili sometimes be bony swellings, and accumulations like calculi or stone in the bladder. These may either compress the urethra, and so prevent the passage of the urine and semen, or they may curre the organ so as to prevent its use; in general, however, they can be removed.

Sometımes the frænum or cord that binds down the prepuce at the end underneath, will be so short or contracted that during erection the point of the glans will be pulled under. This not only prevents the semen being thrown straight forward, but eren prevents connection in many instances, either by causing serere pain, or by bending the end of the organ too much. This difficulty is easily remedied, by cutting through the cord with a pair of scissors, or a lancet. I adrised a gentleman out West how to do this, in a letter, and he wrote afterward to inform me that he had succeeded perfectly, with his razor. It is simply necessary to take care to cut only deep enough to just sever the cord, and afterward to keep the parts stretched asunder, so that they do not grow together again; a simple dressing of cloths dipt in coid water is all that is required after. I have known the cord to be eaten through with caustic, but the plan is not so good as cutting, being more tedious and painful, and leaving a larger scar. In some persons it has been broken suddenly during a riolent erection, or on attempting coition, but such accidents are always painful, and are better aroided by a timely operation.

\section{WANT OF DEVELOPMENT, OR CONGENITAL SMALL SIZE OF THE PENIS.}

It is sometimes difficult to say whether the penis is too short or not, because the:s is no precise standard or limitation, and in different people the development raries very much. In some persons it never grows from the condition in which we find it in childhood, while in others it will attain a medium size, and in others again it will be nearly rudimentary. This may also be totally independent of any deficiency in the other organs, though most usually they correspond more or less. Thus I hare seen a man of forty years of age in whom the penis was only two inches long, and about as thick as the little finger, but whose testes were of a full average size, and who had 
strong sexual feelings, with a full flow of semen. Sometimes the organ can scarcely be traced at all, being merely like a wart or small tumor.

When the non-development of the penis is dependent upon a general torpor of the genital organs, more especially of the testes, their action must be aroused, and their functions fully established, in the manner pointed out in the chapter on the testes. If this can be done, the penis may be made to grow even to an advanced period of life, as I have there shown.

In those cases in which the penis alone is not sufficiently developed, a different treatment is required, as it is simply a local effect we wish to produce. In some of these instances the organ, though small, is capable of perfect erection, and both connection and impregnation may be effected by its means; it is not, then, a matter of such urgent moment for any improvement to be effected, though under certain circumstances it may be desirable. More frequently, however, erection either does not take place at all, or so imperfectly, that coition is impossible, and the flow of semen is so imperfect and irregular that impregnation can seldom be effected, even artificially. Under such circumstances, it is a matter of the greatest consequence to produce an increased development, so that both these functions may be performed; and it may be both new and pleasing, to many persons, to learn that there are means by which this desirable end may be often attained, even under the most unpromising circumstances. It is proper to remark, however, that the cases now referred to are those in which the small size is congenital, or existing from birth, and not those in which the organ has decreased, from disease or excess, after having been of average development, though even in many of them, when the constitutional stamina is not too much impaired, the same means will frequently restore what has been temporarily lost.

The causes that prevent the proper development of this organ, as well as of others, are of course unknown in those cases that are congenital, because they operate before birth, but in those that become arrested during childbood or youth, we generally trace it to early masturbation, blows on the testicles and other accidents, or to some severe disease which has impaired the vital energy very much. Some diseases are particularly apt to affect young persons in this way, as the mumps for instance, which often make the testes swell.

Scarlet fever and measles, when severe, I have known to seriously injure the virile power, but not so frequently as rickets or scrofula.

A similar deficiency is sometimes found in females; in some the uterus or ovaries being very small, though the vagina may be large enough to allow of coition, while in others these organs will be of usual size, but the vagina will be too small, so that marriage is not allowable. In another place I refer to such cases, and explain what can be done to relieve them.

To effect an enlargement of the penis, in addition to every means proper to improve the general health and impart stamina, there are certain mechanical and manual applications, the effects of which, under right direction, are often of the most unexpected and pleasing character. To understand the nature of these, and their mode of action, it is necessary to bear in mind the anatomical structure of the organ, and the requisites for erection. That phenomenon, it will be recollected from our previous description, depends essentially upon the filling up of the vessels and cells of the spongy and cavernous bodies with blood, and of course, if there be any fault in their make or mode of connection, or if the blood does not flow into them, erection 
cannot take place. Now this is precisely the fault that is found to exist in most of the cases of non-development above referred to, and is what requires to be corrected. On dissecting such cases after death we find that the cells and minute vessels have never been congested or filled with blood, and consequently the organ has never been

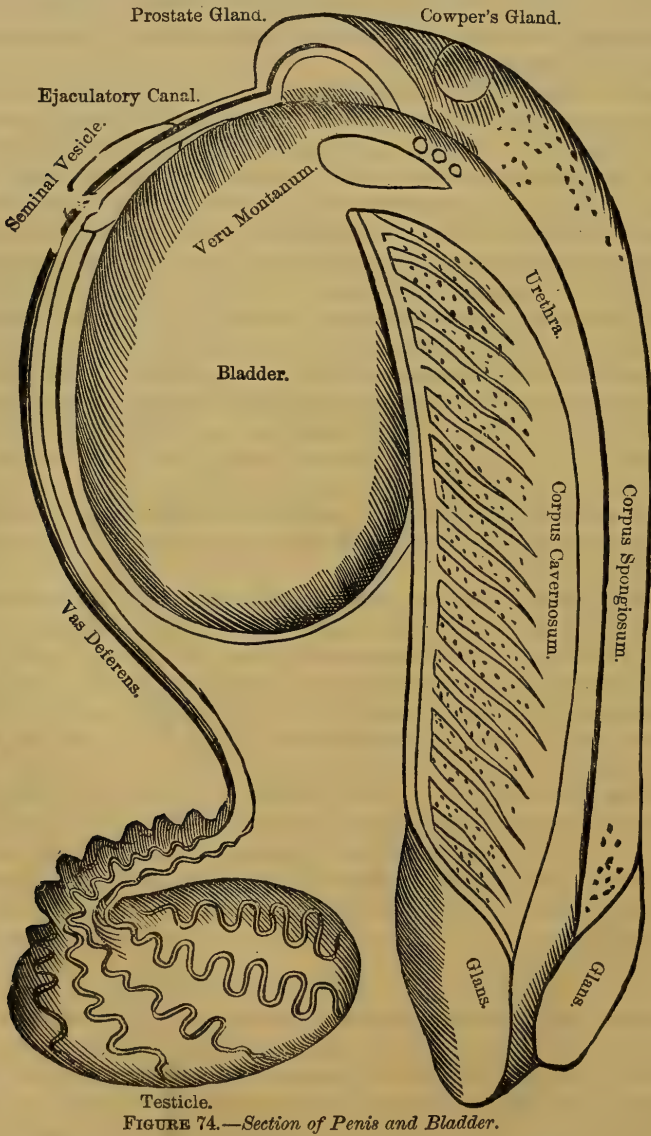

able to grow nor become erected. In the same way after long-continued excess, or debilitating disease, the artery seems to lose its power of transmitting blood with suffcient vigor, and the cells, from want of being filled, decrease in size, and eventually 
grow up more or less, causing the organ to shrink. This is the reason also why absolute suppression of sexual excitement, if continued too long, will make the organ waste away, instead of increasing its power, as many uninformed people suppose.

The object to be accomplished it will be seen is to open these cells, and cause the blood to flow into them, so as gradually to increase their size, and dispose them to fill spontaneously from natural excitement.

In some persons who have always shunned all thoughts of sexual matters, from a notion that they are improper, it is sometimes sufficient merely to encourage such thoughts, to a proper extent, and the excitement this gives rise to in the parts will act farorably on their growth. In others the daily employment of a warm local bath, with brisk rubbing, and the use of a stimulating ointment, will be found still more efficacious; and if this treatment be regularly persisted in, under judicious direction, combined with proper internal remedies, it will succeed in a large number of the cases ordinarily met with. It is requisite, however, that the external and internal stimulants should be exactiy apportioned to the wants and capabilities of the individual's system, and that a strict watch should be kept upon the action and effects of each, so as to know when to increase or decrease their power, and when to suspend their action altogether. Until over forty years of age, if the form of the organ is perfect, and its development not too small, a considerable change may be effected in this way, though the younger the patient is the more readily the parts are acted upon.

I once had a patient call upon me from Cuba, the son of a rich planter, who was troubled with this imperfection, and who was intensely desirous that it might be remedied so as to allow of marriage. He was about twenty-three years of age, and of a strong, robust habit of body, with excellent health. On examination the penis was found about two inches and a half in length, and about as thick as the forefinger, properly formed, but with little more sensibility than any other part of the body. The testicles were fully developed, and the sexual feeling was quite strong. There had been frequent emissions of semen, under strong excitement, but no erection, and consequently no connection could take place. Upon inquiry, I found that he had been brought up to a very rigid code of morals, and had imbibed certain notions about the necessity of not indulging sexual desires if the mind was wished to become powerful : as he was very ambitious of distinction he made a perfect anchorite of himself. The bodily effect of such a course has been seen-its effect on the mind was to make him wayward, irritable and unhappy. A short time before he came on to see me he met with a young lady with whom he fell violently in love, and immediately the desire for marriage arose, but with it came the fear that he was totally incapacitated. The new desire, so strongly awakened, together with the fears he felt, operated so intensely upon him that he became almost insane. On assuring him, however, that there was a reasonable prospect of his attaining a more perfect state, he became calmer, and patiently submitted himself to the prescribed treatment.

The first object was to induce as much heat as possible in the organ, so as to promote the flow of blood to it. This was accomplished by the use of a hot stimulating lotion two or three times a day, followed by brisk rubbing with flannel and soft brushes. In three weeks the effect of this treatment became obvious-erections occurred, partial at first, but ultimately quite forcible, and the organ evidently began to increase permanently in size. In addition to this he was directed to use some stimulant drops, and to live generously, to impart as much vigor as possible to the 
generative organs. The flow of semen soon became much larger than before, under this treatment, and the procreative instinct much more powerful. There was still one fault, however, and that was a want of power in the muscles that assist in erection and coition, more especially in the erector penis muscle. This was remedied by frequent shampooing, and pressing of their fibers till they acquired volume and firmness, the same as any other muscle would do under similar treatment.

This system was rigidly pursued for six months under my own inspection, at the end of which time the penis was four inches long, when erect, and quite firm, so that coition was possible. At this period he was desirous to return home, and as he was evidently determined to pursue the same treatment himself, I consented to his doing so, though I would have preferied for him to have stayed still longer. I heard from him eleven months after his departure, and he then informed me that the improvement had still continued till he no longer thought it necessary to proceed. He was then intending to marry in about three months. The delight and gratitude of this young man were unbounded, rescued as he was from the very depths of despondency and despair, and raised, as he expressed it, "to the highest pitch of human happiness."

In the course of my practice I have had numerous similar eases, some of them resulting satisfactorily from the same treatment, and others requiring a different plan, which I will now explain.

When the means above described fail to induce a sufficient flow of blood into the erectile tissue, an instrument is employed, called a congester. It consists of a tube, the size of which is adapted to the organ, to which is fitted an exhausting air-pump. The penis being introduced into this, the air is more or less exhausted, and the blood of course flows into the contained part immediately. So great is the rush of blood, in fact, that if the exhaustion was continued too far, or made too suddenly, the tissue would burst. In a short time, with care, the part begins to swell and look red, and erection, more or less complete, soon takes place. This never fails, unless the vitality of the part be totally gone, or the structure of the tissues completely disorganized. I have seen some of the most remarkable results follow from the use of this instrument that were perhaps ever witnessed, in a medical way. I have known patients in whom the whole organ was not half an inch long, and without the slightest tendency to erection, and yet the congester has caused it to grow, and has given it power, until perfectly capable for the purposes it was intended for. Sometimes there only appears a simple protuberance, like a tumor, while at other times the organ is long and surprisingly small, and quite flaccid, but still the congester will impel the blood into the tissues and produce the effect desired. Sometimes, it is true, we cannot gain so much as would be desirable, but nearly always sufficient for Nature's requirements, and very often as perfect in condition as if no imperfection had ever existed.

In conjunction with the congester it is also requisite, in most cases, to act upon the muscles by shampooing, as they are usually deficient in power, and without their action the penis cannot erect, though it may become firmly congested.

This practice of shampooing the perineal and genital muscles, to improve the erectile power, was originated in Asia, but has been known and practiced in Europe for many years. The process is both tedious and somewhat painful, and requires both skill and knowledge in the operation. In Turkey men make a regular business of this, and they succeed admirably. In this country it is necessary to direct the 
patient himself, or hired assistants, and the constant supervision of the medical man is therefore required. To perform this operation to advantage, it is best to have the parts made perfectly bare and smooth, and then lubricated with a proper ointment. The operator then presses the end of the forefinger firmly into the muscle, passing it along backward and forward, in the direction of the fibers, till the muscle becomes hot and swells. This is done with all the muscles whose action is required, and it should be practiced every day till the effect is manifest. At first the shampooing causes considerable pain and soreness, but this soon passes away, and then the muscle feels firm to the touch, and is found to be much stronger.

It must be recollected that the various means $I$ have described require a long period to be put fully in operation, and are such as can be commanded only by those who have plenty of both time and money at their disposal.

With those who are fortunately so situated as to have these essential requisites, the gain is certainly great, and well worth what it costs, and I have never known one, who was successfully treated, who did not say he thought no price could be dear to pay. Many a man has been saved from insanity or suicide by these means, and many a domestic hearth has been made the scene of happiness and delight, that was previously the abode of recrimination and despair.

I have treated patients of all ages, from mere youths up to maturity-the oldest I recollect being about fifty-two-and in most of them with a success that has been as pleasing to them as it was gratifying to myself. Some of the means I have mentioned are scarcely known in this country, and are certainly not put into general practice ; the account I have given of them may, therefore, be the means of giving many sufferers the first intimation that help can be had.

One of the most remarkable cases I ever treated wás that of a young man of nineteen, who was brought to me by his father, himself a physician. In this person there was scarcely any appearance of a penis, but only a small tumor, not projecting more than a quarter of an inch, in the center of which was the opening of the urethra. It was quite sensitive, however, and seemed rather as if compressed downward. The testes were of average size, and the semen secreted in sufficient quantity, apparently, so that nothing seemed wanting but a perfect penis. I at once told his father that I felt assured much improvement could be optained, but that it would require much time and attention, with great endurance on the part of the patient himself. They were both delighted to hear this, and the young man testified his desire that I should commence the treatment immediately, which I did. A congester was constructed specially for the case, and applied daily. The lower part was of glass, so that its operation could be seen, and it was observed that immediately the tube was exhausted of air the penis seemed to be drawn forward, and extended to full two inches. The patient complained of great pain in the part during the operation, from the rush of blood into the cells, and it remained exceedingly tender for several days after. The congester was not applied again till this soreness had subsided, but in the meantime the stimulating hot lotions were used, and shampooing of the muscles was practiced. It was observed that even the first application had evidently caused some protrusion, and the young man remarked that the internal sensations were different from what he had ever before experienced. The internal medication in his case was of a more stimulating character than ordinary, because the sexual impulse was not very strong, and only occasionally manifested. His diet was directed to be as nourishing as possible, with wine for drink, and every day he rode out on horseback after 
a warm bath, followed by brisk rubbing of the whole surface of the body. After the first effect had subsided the congester was used daily, and followed by the shampooing, for ten weeks, by which time a permanent advance had been made. The penis measured full two inches in its orlinary state, and in the congester was extended to three. Partial erections occurred at times during sleep, and the procreative instinct became more active and permanent. I then directed him to return home for three months, and only continue the general treatment, so that I might see if Nature herself could complete the work. At the end of three months he came back to me with a still further improvement, though slight. He was then put under the old treatment again, and this time the effects were still more satisfactory. In two months, under the congester, the penis measured four inches, and in the ordinary state remained permanently at three, with firm erections and copious emissions of semen. Finding, therefore, that every requirement of nature could be fulfilled even as he was, and that further improvement would eridently take place with the growth of the system, I desisted from further treatment and sent him home cured. His father was as much astonished as gratified, and another physician who had seen him and pronounced him an hermaphrodite, would scarcely believe it was the same being.

Another case was that of a man who had married at thirty-two, though imperfect, from a mistaken idea that marriage would effect a cure. The result may be imagined; the misery of two human beings could scarcely be more complete. In his despair a friend brought him to me for my opinion. On examination I found the penis not very small, nor in any way imperfect, but it had never been erected, and seemed incapable of being so. The semen was secreted plentifully enough, and the instinct was as strong as was desirable. I told him without any hesitation that he could be made perfect enough for his marital duties in a short time, providing he would follow strictly my directions, and submit to my treatment, which he was willing enough to do. The congester was applied, and with the happiest results. At the third application a powerful erection was produced that did not subside for a considerable time, owing to want of perfect action in the cavernous veins. This, however, was soon remedied, and in two weeks, by the use of the congester alone, natural erections occurred spontaneously, as perfect as could be desired. In a word, he was perfectly cured, and is now the father of two children.

I have also had numerous instances of persons who had lost the power of erection from sexual and other excesses, from mental anxiety and from the effect of debilitating disease. In a great portion of these the result has also been favorable, though in many all vitality had left the organs before $I$ saw them, and in others the structure was completely disorganized. Many young men especially, victims of masturbation, whose organs had ceased growing, have by these means been rescued from impotency and imperfection. Many a man of mature age also, whose powers were unimpaired, but who could not exercise them, owing to this particular debility, has been restored to his former capability in the same way.

The congester is not an instrument adapted for self-treatment, and I would not advise any one to attempt its use without proper directions and supervision. I have known it to do great mischief with inexperienced people, and fail in accomplishing any good. In one man who had applied it too forcibly and suddenly, the cells were nearly all ruptured, or broken into one another, so that severe inflammation was produced, and the power of erection was forever lost.

There are some means, however, that all persons may use, provided they know 
when uney are appropriate to the case. The pressing and shampnoing may be partially practiced by the patient himself, though very imperfectly, but the general directions as to diet and exercise may be observed of course by all. Perhaps, howerer, there is no other functional disability so difficult to treat, or that requires so much skill and such unremitting attention.

In addition to the means already described, there are some others occasionally useful, but which are not so generally applicable. Galvanism is sometimes an excellent agent, when there is nervous insensibility combined with the other disabilities. A very good mode to use it is to galvanize the metallic congester, while the organ is engaged within it. The power must not be too great, however, nor the application continued too long, or there may be partial paralysis.

The French have a practice of flagellation, which is sometimes very efficacious, and will induce erection in a short time. It is rather severe, however, and few have courage or endurance sufficient to continue it long enough to derive full benefit. The flagellator is made of six or eight small twisted thongs, about as thick as a violin string, but very flexible, and about eight inches long. To operate with it to the best advantage the parts should be made bare, and perfectly smooth, and the flagellator must then be applied the whole length of the penis, and on the pubes, perineum, and inside of the thighs, till the flesh is quite red and smarts. The flogging must never be so hard, or long continued, as to make any bruises, nor leave any soreness, but merely sufficient to make it red and feel hot, with slight smarting. Usually about a quarter of an hour is sufficient every day. After the flagellation the parts should be well bathed in hot water, and the patient should recline.

This treatment may seem singular to those who never heard of it before, but it is undoubtedly more efficacious, in numerous cases, than any one could well believe who had not seen it practiced. I have known many patients resort to it, with the happiest results, who could not stay with me long enough for the usual treatment. In some it will produce powerful erections the first time, and lead to an influx of blood to the parts that soon stimulates their growth.

Firing is another practice that may be resorted to, if others fail, for rousing the dormant energies of these parts, or causing growth. It consists in burning the parts with a smooth iron button, made hot by plunging it in boiling water. The parts are first made smooth, and then the button is taken out of the water and pressed suddenly on, repeating it as fast as possible, till the whole length of the organ has been operated upon. No part should be touched twice, nor should the iron remain on more than an instant. The pain is very slight, and no blister is raised, the places only turning white at first, and afterward remaining red. The firings should be repeated only at intervals of three or four days, waiting till the effects of one are gone off before another is practiced.

This process is sometimes astonishingly effective, a single application produaing such a powerful effect that no further treatment is required. Care is required, however, not to produce too much inflammation, nor to operate too near the testes. Sometimes the development will be much less on one side of the penis than the other, or less in the corpus spongiosum than the cavernosum, so that the organ will not be straight but curved; or it may be straight in the ordinary state, but not capable of erecting in all parts alike. This state of permanent chordee is perhaps better treated by the flagellation or firing than by any other means, because they can be applied locally, and only to the affected part. 
It may perhaps be as well to remark here that a modification of the congester is sometimes of great service in certain torpid states of the female organs, and that some of the other treatment is also occasionally applied to them, in a modified form, with the happiest results.

The penis is, perhaps, more variable in its form and situation, among the different mammiferous animals, than any other organ. It is only among the bats and apes that it hangs down from the pubic bone, like it does in man, being in the others always included in a sheath. In the cat, the rat, and some other animals, it is directed backwards, and in the beaver it is drawn far back into a kind of canal, like a vagina, while in the kangaroo it is even surrounded by the sphincter muscle of the anus. In many animals the prepuce is very long and like a sheath, and the penis is ordinarily drawn into it, when not erect, as in many of those above mentioned, and as we see in the horse ; but sometimes the penis is permanently so long that it cannot be drawn into the sheath in a straight form, but has to be bent.

The position of the penis is variable in different animals, according to the mode of their copulation. In man, apes and bats it is covered by a sheath of the commion skin of the body, which grows fast to it, except on the glans at the end, and hangs free from the bottom of the abdomen, being supported by two special ligaments. Underneath, as far back as its root, it is confined under the skin, nearly to the anus. In carnivorous animals, pachyderms, ruminants, horses and amphibia, the sheath does not grow fast to the penis, and is confined to the body as far as the navel, the naked penis being protruded from it only during erection, or while urinating. The substance of the under part of the sheath is quite firm, to enable it to sustain the weight of the penis, which is often considerable. In the elephant the weight is so great that a solid ligament is needed underneath.

The opening of the sheath, in the above cases, is usually near the navel, and it is often not so long as the organ it has to contain, in which case the penis has to bend, or fold itself when drawn within. In the elephant it is very long, and to bring it fairly under cover of the sheath, it has to be bent like a double letter $\mathrm{S}$. In the camel, dromedary and cats it is bent back, so that it points behind, which explains why the males of these animals urinate backward. It is only during erection, when it is unbent, that they point the penis forward.

In the agouti and the marmot, the penis after being pushed out of the end of the sheath, is bent back under the skin, till it reaches just under the anus. In some others, as the rats, hares and opossums, it is carried back, in the same way as above, and issues nearly from the anus itself.

The form of the penis varies as much as its size. It is of small diameter in the boar, and in cattle, and usually tapering, while in the horse and elephant, it is large, of equal size in all its length, and flat at the end. In the rhinoceros it is large and conical ; in the dolphin it is large, conical, and flat. In the gnawing animals, and quadrumana, it is cylindrical, and in the rat it is shaped like a letter $\mathrm{S}$.

The structure is similar, and erection is caused in the same way in all cases, by the blood filling up the vessels of the corpus cavernosum, as water fills a sponge. In the elephant it would take at least a gallon of blood to cause a perfect erection.

In those species the females of which have a double vagina, like the kangaroo, the penis is also double, so that there is one for each passage, each having a tube to convey semen, though there is but one urethra for the urine, which opens between the two glans. The alligator also has a double-headed penis. The glans 
on the end of the penis is even more variable than any other part, being seldom soft and spongy, as in man, but frequently hard, horny, and covered with sharp points, and sometimes even it scarcely exists in any form. In some of the apes it is spread out like a mushroom, with slit edges, and occasionally covered with sharp, hard spines. This is the case also in the bat, and partly so in the shrew-mouse, while in the hedgehog it is divided into three lobes. The hyena has it formed like the broad knob of a door, and in the bear and dog it is like a long club. The glans of the cat is covered with horny spines directed backward, which probably cause pain to the female, and draw forth those horrible cries which these animals emit during copulation. In the Guinea pig it is covered with scales, and has two horny hooks, while in the hare it is drawn out to one long, thin point, and in some other animals into two points. In some it is even covered with stiff hairs, and in many has rough knobs, or tubercles. In the rhinoceros the glans is bell-shaped, in the horse it is bulbous, and in some of the whales it is shaped like a tongue, while in others it is conical. The most singular form, however, is in that curious animal, the ornithorynchus, in which it is very large, square, divided in two parts, and covered all orer with spines. The bone of the penis is found in many animals, as well as in the Negro occasionally. It is very large in the dog, but small and thin in the cat, while in the raccoon, and rat, it is crooked, like the letter $\mathrm{S}$, and in some others it is formed like a hook. In the squirrel its termination is flattened out, like a shovel.

It is found in all the quadrumana, gnawing animals, seals, and whales, and also in all the digitigrades (animals that walk on their toes, instead of the flat of the foot), except the hyena. In the bears, rats, and dogs, it forms the greater part of the organ. In cats, the ichneumon, and some of the rodents, it is small, while in the whale it is quite large, reaching nearly to the end of the penis, and terminating like a club.

The testicles having been already fully described, the whole male generative apparatus can now be fully understood, both as regards its own specific action, and its conjunction with the female organs in the act of sexual conjugation.

Many other particulars as to these parts will be given when we come to describe their diseases and malformations, and when explaining fotal growth and childbirth.

In regard to the position of the testicles, we find three different classes. In one class they are always within the body, in another they are always without, and in the tnird they only descend at the period of pairing, being at other times within the body. I have even known men in whom the testicles descended into the scrotum only when they were sexually excited, they being at other times in the abdomen.

The animals that carry the testicles exterrally, do so in a proper pouch, called the scrotum, which is placed differently in different animals. Apes and carnivorous animals carry the scrotum behind, under the anus, and both testicles lie in it together, with nothing between them. In the kangaroo, the hare, the jerboa, most of the ruminants and the solipedes, such as the horse and ass, the scrotum is divided into two distinct parts, so that the testicles are completely separated from each other by a partition.

In the moles, rats, beavers, squirrels and many others, the testicles descend into the scrotum only at the time of the rut, and when that is over ascend into the abdomen again. In the civet-cat, and in many pachyderms, or thick-skinned animals, like the 
hog, which have no true scrotum, the testicles are still always outside. They lie in the thickness of the perineum, just below the anus. The camel carries them in the skin of the groins.

The ornithorhynchus, seal, whale, elephant, and many others of the pachyderms, carry the testicles always inside, where they are attached to the loins, much as in birds.

The seminal vesicles, as before explained, probably act as reservoirs, in which surplus semen is stored between periods of copulation. They are not always present, some animals being quite destitute of them. Like the testicles themselves, they are often quite small, except at the time of the rut, and they vary greatly in form and size. In some animals their walls seem to be glandular, which makes it probable that they also secrete some fluid to mix with the semen, or else they in some way modify that fluid.

The prostate gland undoubtedly secretes a fluid which mingles with the semen, and is probably essential to it. This gland exists in all the quadrumana, bears and rats. It is double in the ruminants, and in the bats is so large that it surrounds the whole urethra, like a ring. In cats and dogs it is very large, making quite a projection. The elephant has four prostates, two on each side, of unequal size, and they are placed inside the seminal vesicles. Horses also have four prostates, but they are differently disposed.

Cowper's glands, usually considered as a small prostate, are very small in men, but in some animals are quite large; they probably secrete some necessary addition to the semen, like the prostate itself. They are much larger in apes than in men, and still more so, proportionately, in bats and cats. They are largest in the hyena. The pouched animals (marsupials) have several of these glands, sometimes as many as six. In the squirrel and marmot there are two, resembling bladders. In the boar they form a long tube, while in the elephant they are round and flat, and quite large.

A want of careful observation has led some anatomists to confound Cowper's glands with the seminal vesicles, but they are always distinct enough, both in structure and function. The vesicles contain semen, but these glands contain a peculiar fiuid of their own, very different.

The glans at the end of the penis varies in form and structure as much as any other part, being in all cases adapted to the part of the female it has to reach in the act of copulation. This is necessary, because it is the part which causes in her the proper degree of excitement.

\section{GENERATIVE ORGANS OF THE MARSUPIALS.}

Our previous explanations have shown that there are two very distinct kinds of animals, among those with which we are ordinarily acquainted, namely, those that bring forth eggs only, which are developed externally, and those which develop the eggs in their bodies, and bring forth their young alive. The females of these latter all possess a peculiar organ called the matrix, or womb, in which the new being remains connected with the mother, and is nourished by her blood, till it is enough developed to live alone, then it is born and she further nourishes it with her milk. The womb, therefore, is the distinguishing organ among females of this kind, and there is nothing like it in those that bring forth eggs only.

There is, however, a class of animals, found mostly in Australia, which are inter- 
mediate between these two. They are called marsupials, or pouched animals. The kangaroo is typical of the marsupials. The females of this class bring forth their young alive, and have a womb in which it is formed, but it is very imperfect, and so is the connection between mother and child, so that the offspring is not retained in the womb till it is perfect, as in the true viviparous animals. It is brought forth half formed, like an early miscarriage in more perfect beings, and is then placed in the pouch, or pocket, which is under the belly, outside. In this pouch are the teats, or external openings of the milk ducts, and each little half-formed being, as it passes out of the womb, is attached to one of these teats, and enclosed snugly in the pouch, where it remains till its development is sufficiently advanced for it to live alone.

It will be seen from this that the marsupials are intermediate between the oviparous and viviparous animals. They bring forth the young alive, but only half formed, and complete the development in a sort of extra external womb-the marsupium, or pouch.

All these animals are peculiar in many ways, some of them very much so, and they are in every way of an inferior type to the true viviparæ. The brain, in the kangaroo, is very imperfect, so that the animal has but little intelligence, not even enough to recognize its keeper and feeder. The hind legs, also, are the only limbs perfectly developed, the front ones being very small, and useless for progression. The animal, therefore, uses its tail, which is enormously developed, and with this and the two large hind legs bounds along by successive leaps. It also possesses certain peculiar bones, called the marsupial bones, because they are found only in marsupial animals. These bones are placed under the abdomen and serve to support the pouch, and the young, in the female, and are important also to the male, in connection with the generative apparatus.

The sexual organs, and the process of generation altogether, in these beings, are very peculiar, as will be shown further on.

In all of them the uterus is double, and the vagina is also divided more or less completely into two distinct canals. The generative tubes and the digestive both terminate in a common cloaca, as in birds, thus showing an approach to the ovipara. In the male the penis is double, or divided, corresponding to the double vagina of the female, and in all probability the act of copulation is double.

The American opossum is a marsupial, but has not all the peculiarities of the class so prominent as in the kangaroo. The young, when born, are blind and shapeless, and do not weigh more than a grain each when they are placed in the pouch. There are often from ten to sixteen of them. When perfect they leave the pouch, but often run back to it for shelter, when there is danger, as indeed all young marsupials do. The way in which the young opossums travel when older is very droll to witness. The mother curls her long tail over her back, on which the young ones stand, and each one keeps his place by curling his tail round the mother's, and so they travel.

There are many different kinds of these animals in America, especially in the south, some of them very small, like mice, and until Australia was explored they were thought to be the only ones of the kind in existence.

There are many fossil marsupials, and, in fact, it would seem that at one period they were a prevailing type. Some naturalists have suggested that Australia, which is peculiar in many respects, is in reality a fraction of the world of that period.

The mouth of the young marsupial, and the teat of the mother, are so formed 


\section{PLATE XVIII.}

GENERATIVE ORGANS OF THE MARSUPIALS.

Figure 1. A female opossum, showing the pouch open, and the young oner attached to the nipple.

Figure 2. The milk apparatus of the female kangaroo, showing its numerous nerves, $c, d, e, g$, and the powerful muscles, $f . b$, by which it is compressed to force out the milk.

Figure 3. Internal generative organs of the female kangaroo. aa. The two uteri. $b b$. Where they open into the vagina. $c c$. The uterine tubes. $d$. The left ovary. ee. Blood-vessels. ff. The principal veins. $g$. One of the tubes open. $h h$. The ureters leading from the bladder. $i i$. The large ligaments of the womb. $j j$. The two vaginas. $k$. The bladder. $l$. The external opening of the vagina. $m$. That of the bladder. $n$. The common cloaca.

Figure 4. A foetus just born. Figure 5. The same.

Figure $4 a$. The head of a young kangaroo cut through, to show how the nipple is held in the mouth.

Figure 6. The external sexual organs in the male kangaroo. $a$. The testicles placed forward. $\quad b$. The penis drawn back into the body. .

Figure \%. The same organs dissected out. $a$. The testicles. $b$. The penis a little protruded. $c$. The spermatic tubes. $e$. The bladder. $f$. The neck of the bladder. $h$. The rectum. $i$. The muscle which draws the penis back into the body. $j$. The gland of the penis. $d d$. The ureters.

Figure 8 shows part of the pouch of a female kangaroo. $b$. One of the nipples pulled out, as when in use by the young. $a$, is one when not in use.

Figure 9. Head of young kangaroo cut open, to show how the windpipe and csophagus are arranged, so that it can swallow and breathe all the time without inconvenience. $a$. The œesophagus. $b$. The windpipe, going to the nostrils. 

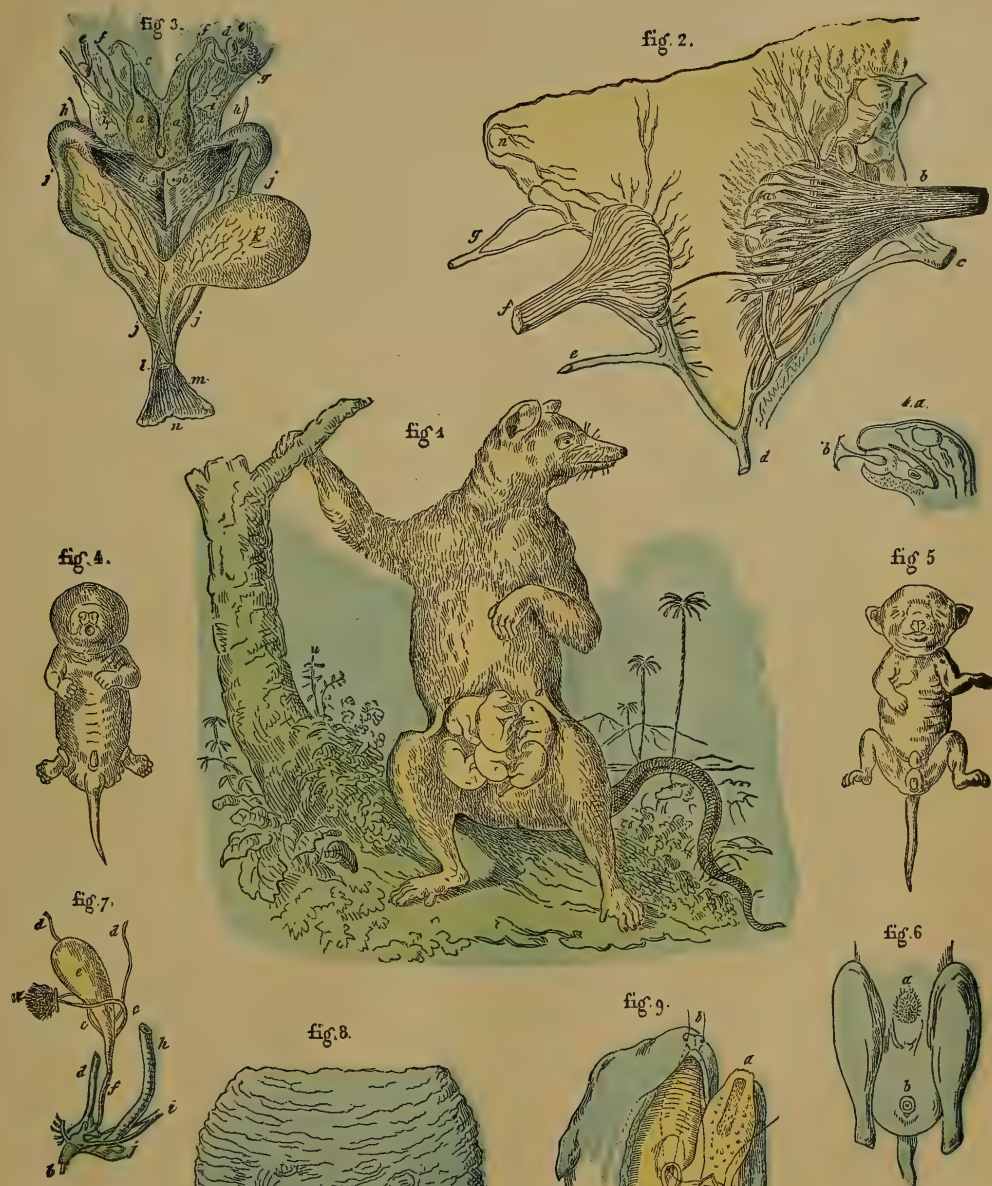

that when once the teat is in the mouth the hold never relaxes. The milk, therefore, is all the time being absorbed, though slowly, and owing to a peculiar formation of the larynx this occurs withont interfering with breathing. It will be seen that this is analogous to the constant absorption of blood by the young of more perfect animals, in a true womb.

The time that these half-formed young remain in the womb is very short, in the opossum only twenty-six days, and in the kangaroo only thirty-nine. When first brought forth they are very imperfect, almost shapeless, and in the smaller animals much resembling earth worms. The earlier observers, who only saw these minute creatures attached to the nipples, thought they grew there, like buds. The subjoined cut shows a young Kangaroo, when first placed in the pouch, natural size; the skin is thin, and almost transparent, in fact almost like that of a worm.

The mother, it is said,

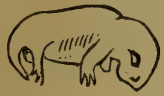
uses her mouth to transfer the young to the nipples, and this is much facilitated by the close connection beFieviRe 75.- Young Kanga- tween the vagina and the
roo, just born. pouch. They remain fast to the nipples a long time, in the kangaroo about two months, and suck at intervals after they are detached, like other animals, for some months longer.

It may be supposed that the young marsupial, so imperfect, cannot have muscular strength enough to hold on voluntarily to the nipple. And this is probably true, the hold being very likely spasmodic, or involuntary, and aided by the mutual adaptation of the teat and the mouth. Nor could it draw the milk by its own efforts, at least not at first. The flow is therefore regulated by the action of a special muscle, in the abdomen of the mother, which compresses the mammary gland and squeezes the milk gradually into the mouth. These beings evidently form a link between the egg-bearing and the youngbearing animals, for they possess characteristics common to both, but fully belong to neither.

FrGURE '76.- Young Kangaroo in
In past ages they formed one of the links, in the its Mother's Pouch adhering to the long chain of evolution, by which the more perfect

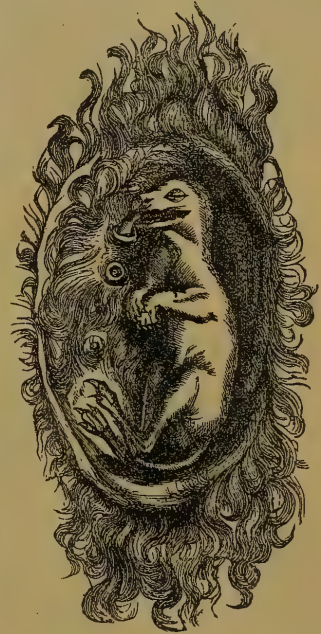
Teat.

animals of the present day have been developed from the imperfect ones of a more early period.

These particulars will, however, be better understood by reference to the accompanying plates. In some animals of this kind, it should be observed, the pouch is not perfectly developed, the skin being only drawn into deep folds, or wrinkles, which apparently serve the same purpose.

\section{MONOTREMATA.}

There is another order of animals, containing only two kinds, which are still lower than the marsupials, and which, in their generative organs, approach very 
closely to birds. This is the order monotremata, which is found nowhere else but in Australia, and consists only of the ornithorhynchus, or duck mole, and the echidna, or porcupine ant-eater. In both of them the intestine, the urinary passage and the seminal duct, all open into a common cloaca, as described in birds. The females have no marsupial pouch, like that of the kangaroo, although there are the marsupial bones. The testicles of the male remain always in the body, there being no scrotum, and the vas deferens discharges the semen into the cloaca. There are no nipples on the females' breasts, the milk ducts opening, in the echidna, into a kind of small pouch, and in the ornithorhynchus on a flat surface. So far as observed, the young appear to have no direct connection with the mother by a placenta, and the way in which they are carried and nourished is not known. They are born quite blind, and almost skinless, so that they are evidently not retained long in the body. From the peculiar formation of their mouths, and the absence of nipples in the mother, their manner of nursing is a mystery.

The manner in which these very exceptional animals copulate, and other particulars as to their generation, have not been ascertained. I have been assured, however, by a gentleman long resident in Anstralia, that in the act of sexual union, the female duck mole lies on her back, and that the act is very prolonged.

The ornithorhynchus is perhaps the most remarkable animal known. It has a body like an otter, covered with fur, the tail is broad and flat, like a beaver's, the feet have claws and are webbed, and it has a bill like a duck's. It has no teeth, and its food consists mainly of insects, and it burrows in the ground like a mole.

The echidna resembles somewhat a hedgehog, having spines, and stiff bristles on the back. The feet are not webbed; it burrows in the ground, and lives on insects, which it catches by means of a long sticky tongue. Its snout is long and pointed, and like the duck mole, it has no teeth. Its principal food is ants, from which it is called the porcupine ant-eater.

No doubt these singular animals are as exceptional in their generative processes, in many ways not now known, as they are in other respects.

The following table will give a synopsis of all the different modes of reproduction, as ahove described : 


\section{PLATE XIX.}

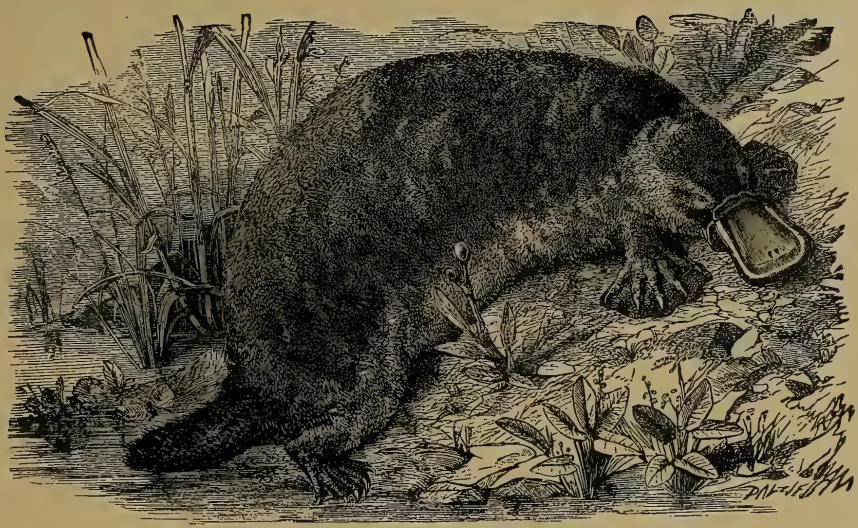

Duck=bitbed Platypus, or Ornythorynchus.

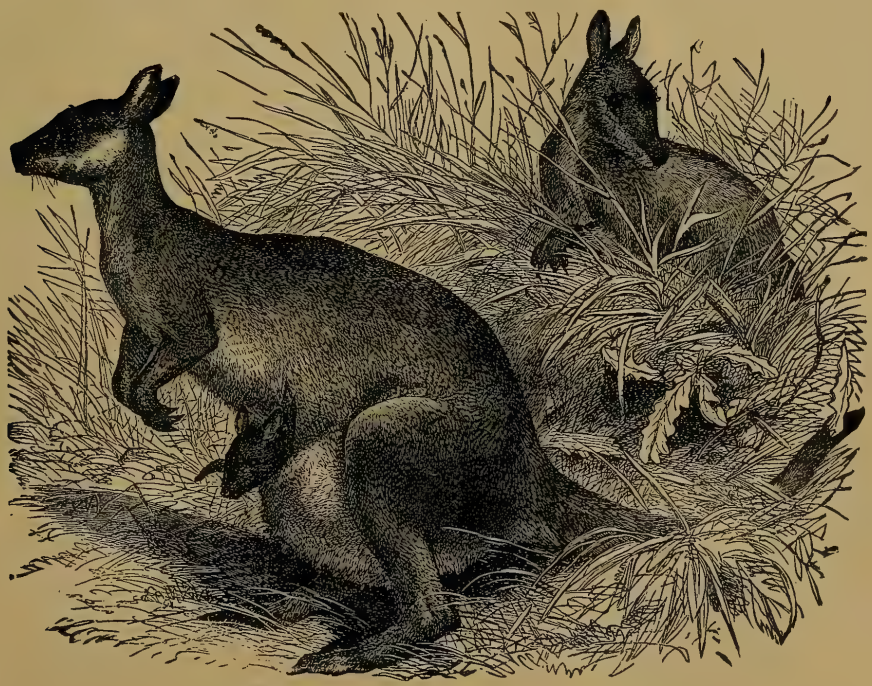

Whallabee Kangaroo, with Young in Pouch. 

PLATE XX.

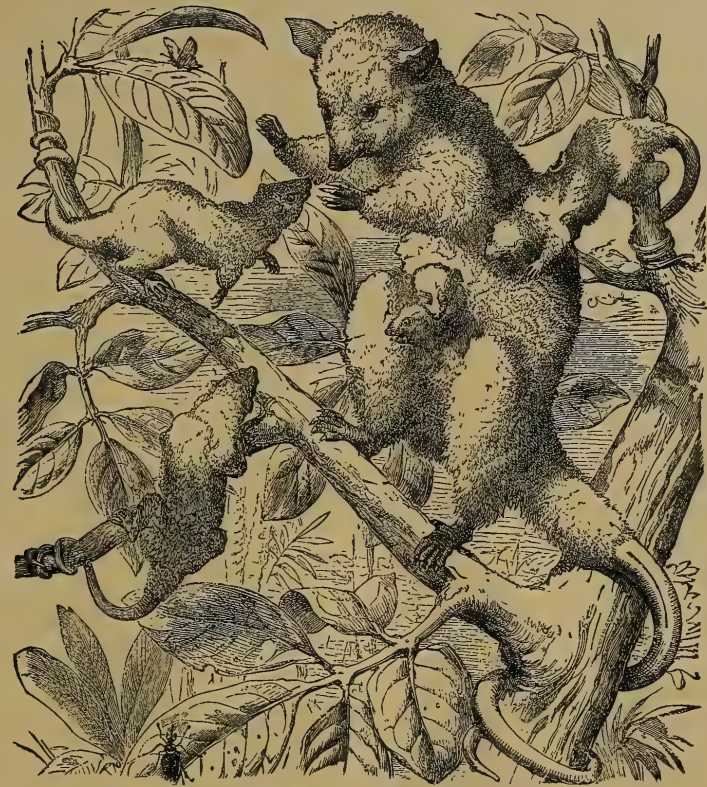

Crab-eating Opossum, with Young in its Pouch.

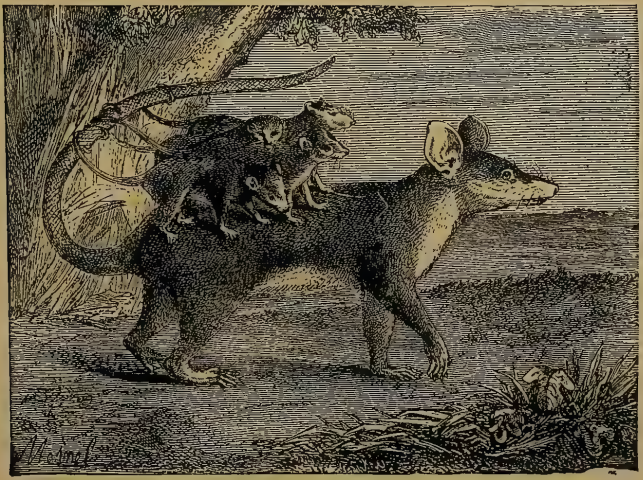

Female Opossum carrying its Young. 

I.

NON-SEXUAL GENERATION.

VARIETIES.

Fissiparous.

When the parent simply divides into two or more parts, each becoming a new being.

\section{Gemmiparous.}

When the parent gives off buds, which grow into new beings, either attached to the parent or separate.

\section{II.}

\section{SEXUAL GENERATION.}

VARIETIES.

Hermaphrodite.

Where both sexual organs, male and female, are found in the same individual, some being capable of self-impregnation, others needing the concurrence of two, ormore, to mutually impregnate each other.

\section{Dioccious.}

When the male and female organs are placed in separate individuals; the male and female principles being united within the body in some, and without the body in others.

\section{MANNER OF DEVELOPMENT.}

OVIPAROUS.

The eggs laid and hatched outside the body. As in birds and insects.

$$
\text { OVOVIVIPAROUS. }
$$

The eggs partly developed within the mother's body, but the young being in no way connected with her.

\section{VIVIPAROUS.}

The eggs developed in the mother's body; the new being nourished from her blood, and brought forth alive, and capable of living independently.

\section{MARSUPIAL.}

The eggs developed in the mother's body, but the young only half formed, and then placed in an outside pouch to be completed.

\section{MONOTREMATOUS.}

Development mainly external-no placenta, and no marsupial pouch. 


\section{CHAPTER XXIII.}

\section{THEORIES OF GENERATION.}

Having thus stated the provisions which have been made by nature through fecundation of the ovulum, by the concurrent offices of the two sexes, we may here examine various speculations and opinions which, from time to time, have been entertained relative to the nature of this marvellous and mysterious process; speculations which, although for the most part exceedingly hypothetical, and often completely visionary, have been dignified with the appellation of theories of generation. This it is our intention to do very briefly, and to notice only the more important of these theories; for the total number of hypotheses which have been advanced on this subject is so great, that their mere enumeration might occupy many pages. Drelincourt, who lived in the latter part of the seventeenth century, collected from the writings of his predecessors as many as two hundred and sixty-two "groundless hypotheses" concerning generation; " and nothing is more certain," observes Blumenbach, "than that Drelincourt's own theory formed the two hundred and sixty-third."

These theories may be arranged according as they relate to the action of the parent organs, or to the changes in the egg occurring during the formation of the new animal; and Haller divided the first of these classes into three divisions, according as the offspring is supposed to proceed; first, exclusively from the organs of the male parent, which is the theory of the Spermatist; or, secondly, entirely from those of the female, which is that of the Ovists; or, thirdly, from the union of the male and female products, which is the theory of Syngenesis. The second class, again, may be arranged under two heads, according as the new animal is supposed, first, to have its parts rendered visible, by their being expanded, unfolded, or evolved from a previously existing though imperceptible condition of the germ, which is the theory of evolution; or, secondly, to be newly formed from amorphous materials at the time when it makes its appearance in the ovum, which constitutes the theory of Epigenesis.

The theory of the Spermatists regarded the male semen as furnishing all the vital parts of the new animal, the female organs merely affording the offspring a fit receptacle and suitable materials for its nourishment, until it could exist by the independent exercise of its own functions. One of the earliest supporters of this hypothesis was Galen; but its modern revival dates from the period of the discovery of the seminal animalcules, which were regarded by Leewenhoek as the proper rudiments of the fotus. They were even considered by some to be miniature representations of men, and were styled homunculi; one author going so far as to delineate in each, the body, limbs, features, and all the parts of the grown human body. Even Leewenhoek describes minutely the manner in which they gain the interior of the ovum, and are retained after their entrance by a valvular apparatus.

The Ovists, comprising some of the older philosophers, such as Pythagoras a 
Aristotle, maintained that the female parent affords all the materials necessary for the formation of the offspring, the office of the male being merely to awaken the dormant formative powers residing in the female products. Malpighi and Harvey asserted that the rudiments of the fœtus are derived principally from the female ovum; an opinion which was also elaborately defended by Vallisneri (Della Generazione, part 2).

The theory of Syngenesis, or of the simultaneous combination of products derived from both sexes, which after sexual intercourse, are supposed to unite together to form the germ, is also of very ancient date. In connection with this theory may be mentioned that modification of it which may be termed the theory of metamorphosis, according to which a formative substance is held to exist, but is allowed to change its form, in order to be converted into the new being; as also the hypothesis of Buffon, which was eagerly adopted by Needham, who conceived that certain molecules, which they termed organic, and which they believed universally to pervade plants and animals, were all endowed with productive powers, which enabled them, when placed in suitable situations, to attract one another, and to compose by their union living organized bodies. They imagined, that in the process of generation the superabundant portion of these organic molecules were accumulated in the generative organs, and there constituted the rudiments of the offspring.

The hypothesis of evolution, or of pre-existing germs, coincides with that of the Ovists, in considering the foetus as solely the production of the female; but it farther assumes that it already exists, with all its organs, in some part of the female system previous to the sexual intercourse; and that it receives no proper addition from the male semen, the action of which is merely that of exciting the powers of the fotus, and of endowing it with vitality. The observations of Haller with respect to the gradual enlargement or evolution of the chick during the process of incubation, were conceived to lend great support to the advocates of this theory, of whom the most strenuous and enthusiastic was Bonnet. This naturalist, so celebrated for the boldness of his speculations, contended, not only that the whole of the parts of the foetus pre-exist in the ovum, before they actually make their appearance, but that the germs of all the animals which are in future to be born, also pre-exist in the female parent; so that the ovaries of the first parents of any species of animal contained the germs of all their posterity, included the one within the other, like a nest of boxes; from which comparison he termed his theory that of "emboitement." This extravagant notion was adopted by many physiologists, principally from its affording some kind of explanation of what no other theory seemed in the least adequate to solve. Spallanzani, in particular, was a zealous defender of the hypothesis of pre-existing germs. It appears, however, to be totally irreconcilable with the phenomena of hybrid productions, and of the resemblance which, in so many instances, the offspring bears to its male parent.

We have already mentioned that Harvey and Malpighi ascribed the formation of the foetus principally to the powers of the female. This opinion gave origin to the modern theory of Epigenesis, first clearly promulgated by Casper Frederick Wolff, who not only described a successive production of organs, of the previous formation of which there existed no trace; but showed, also, that after parts are first formed, they undergo many important changes in their shape and structure, before arriving at their finished state. The more recent researches, aided by delicate microscopical observation, of Meckel, Pander, Baer, Bathké, Oken, Purkinje, and Valentine; Ser- 
res, Kolando, Dutrochet, Prévost and Dumas, Coste, and others, have demonstrated that the theory of Epigenesis, or superformation of parts, is much more consistent with the observed phenomena than that of evolution. The facts which have thus been brought to light are of peculiar interest with reference to the plans of nature, into which they give us a more extended insight, by exhibiting new and unexpected affinities between remote families and classes of animals; by showing that at one period the type of their formation is nearly the same, and by explaining the seeming caprice of nature in instances of monstrous and defective formation.

The fact that the new being is often a perfect mixture of both parents, would seem sufficient to prove that it is not formed exclusively from either the egg or the semen, but from a union of the two. And further, the fact that it is not in any particular part that it always resembles, either the one or the other, would show that the union is not effected on any strict plan. The fact that a child may resemble either father or mother, in many different ways, is well known. In a large family some of the children will resemble the mother in features, and dispositions, while others will resemble the father in the same way.

In the lower animals, when the new beings are formed from only one parent, they resemble that parent. It is only when sexual difference comes in, and the two parents are concerned in reproduction that we find great differences in offspring.

In those cases, among the higher animals, where a new organism is formed from the female egg alone, it is never perfect, as already explained, which alone would seem to prove the need, among them, for the concurrence of both egg and semen.

In their primary condition the egg and seminal animalcule are probably the same kind of simple cell, but they become afterwards differently specialized. The seminal germ is apparently further developed than the ovum, and assumes a different character in consequence. They both probably contain the same fundamental organization, but the seminal germ becomes more vitalized, or capable of motion, as we see in the animalcule, while the egg remaining more inactive is but little else than a mass ol! protoplasm, with a small amount of motive energy ; when they unite, therefore, the male germ gives the life, or motive energy-in the animalcule-while the female germ gives the nutrient material by which the new being is formed. In this way both concur, and the union of the two results in the perfect new being.

Still even in the female the egg may, in some cases, have much more vital force, or motive energy than ordinary, while the sperm may have less, in which case the female would influence the formative process more than the male, and impress her likeness upon the offspring more than he would. That there are these differences in the vigor-if the term may be used-of the male and female principles is undoubted. Usually they are tolerably well balanced, but cases are not unfrequently met with in which the female completely neutralizes the male, and her children resemble her alone.

In other cases it is the reverse, and the family represents the father alone.

Breeders of animals often understand this important fact very well, and by proper pairing, and attending to the relative condition of the two parents, at the time of connection, they will produce offspring resembling one or the other. Negro women, it is well known, will bear much lighter colored children to some white men than to others, and some mules will resemble the ass much more than they do the horse.

The most probable theory would seem to be that the male germ, and the female germ, both have within them the formative rudiments of a similar new being, and 
that the corresponding elements unite, part to part, and thus produce a more perfect organism than either could alone.

The one that gives the preponderating portion of any part stamps its impress on that part, and thus transmits its own resemblance.

The actual commencement of development is probably due to the male germ, because it is already, at the time of impregnation, endowed with motion, or life, owing to its having further progressed.

The reason we do not find the male germ alone forming a new being (beyond the animalcule) like the female germ, is simply because it has no stored up stock of nutriment, such as we find in the female egg; and there is therefore nothing by which further development can be effected. But the animalcule itself is, in reality, the male germ alone, developed to that extent, and it is in fact a more perfect development than the female egg ever reaches alone.

The animalcule is really a new human being, produced by the male germ only, as far as the formative material in that germ could effect its development; but when the nutrient matter of the female egg, and its formative power, is added, then the development becomes complete. 



\section{PART X.}

REPRODUCTIVE ORGANS IN PLANTS, AND THEIR CORRESPONDENCE WITH THOSE OF ANIMALS. 



\section{CHAPTER XXIV.}

\section{ORGANS OF GENERATION IN PLANTS.}

From what has been already explained it will be obvious that plants, in many respects, resemble animals much more closely than is usually suspected, and this is especially so in regard to the organs of generation, and the way in which they act. There is scarcely a sexual organ found in animals that we do not find the exact analogue of in plants, and the various processes, even to the act of sexual conjugation, are identical in both.

In the lower animals propagation is effected by the parent simply dividing into two or more parts, or by sending out buds, each part or bud becoming a new being. The same process, exactly, occurs in plants, - they can propagate either by simple division or by budding, in the same way. In the higher animals there are two principles concerned in propagation, the male sperm, and the female egg, or ovum, which unite to form the new being; and it is the same in the higher plants, which propagate by the union of the male pollen and the female germ. Even the organs by which the two principles are brought together are remarkably similar in both, the hollow tube of the pistil corresponding to the female vagina, and the elongated pollen grain to the male penis. There is a real act of conjugation, or sexual union, in the one case as in the other, and as many curious modifications, both of form and mode of action, are found in the plant as in the animal.

At the present day, the fact that plants are truly sexual, male and female, is very generally known, and in many ways practically used, but it has been known only a short time.

It waş not till 1"16 that Vaillant, a French botanist, first clearly explained the true nature of the stamens and pistils, and showed that plants propagated sexually, like animals. This was one of the greatest discoveries ever made in botany, and also a highly suggestive fact in natural history generally, because it showed man how nature works by similar agencies in different fields. It was a long step toward a perception of the great truth of the oneness of many natural phenomena, when they are rightly understood, which are ordinarily thought to have nothing in common. Establishing the similarity of plants and animals, in the matter of propagation, led the way, at a later period, to the still more important discovery that man and all other animals are identical in the same way.

Plants, as before explained, like animals, may be either hermaphrodite-that is, have both male and female organs on the same plant; or they may be diœcious-that is, have the male organs on one plant, and the female organs on another. The hermaphrodite arrangement is the most common, so that the male and female principles being close together there is seldom any failure of fertilization.

When the male and female organs are separated, by being on different plants, which may not grow near each other, fertilization often fails, and the female plant 
is barren. Nature, however, has so well provided for carrying the pollen great dis. tances, by the wind, or by insects, that the male and female may be many miles asunder and yet impregnation occur.

The date palm, on whose fruit a large number of the Arabs mainly depend for food, is diceious, and if no male trees are near to fertilize the female ones, they are sterile, and produce no fruit. The Arabs therefore always attend to this, and if no male plant is near their plantations, they fetch branches, with the pollen on them, from a distance, and hang them in the female trees. The pollen dust is then blown about by the wind, settles on the female pistils, impregnates them, and they produce fruit. In time of war, between different tribes, it is a common practice for one tribe to destroy the male date-trees of the tribe they are contending with, and thus starve them.

The common persimmon is diœcious, and it is not unusual to find female trees producing no fruit, because no male trees happen to be near. Sometimes when the grapevine is just ready to fertilize, heavy rains occur, which wash off the pollen, so that it never rises, like dust, to fertilize the germ, and in consequence there is a failure of fruit. The same thing often happens with other plants, in unfavorable seasons, the perfect dryness of the pollen being indispensable, so that it may rise, which it will do sometimes in a perfect cloud.

In the conservatory at Berlin there was a fine female palm-tree, which had been there for eighty years, sterile; but which was at last fertilized by some pollen sent from a distance, by post, and it then produced fruit. It was then left barren again for eighteen years, and again fertilized in the same way. Gardeners, at the present time, when they think their plants, or flowers, may not be properly fertilized naturally from any cause, take care to fertilize them artificially. This they do by taking pollen, in a proper state, and dusting it upon the pistils of the female flowers, sometimes using a fine camel's-hair brush for the purpose. By the same means they produce hybrids, or crosses, by placing the pollen of one kind upon the pistil of another kind, just as mules are produced by the union of the horse and ass. There is a limit, however, to the extent to which this can be done in plants, as there is in animals. The two parents must be related, within certain degrees, or the fertilization will not take place. Why this is we do not know. Possibly, in the case of animals, the form of the seminal animalcule may be, in some way or other, adapted to the female germ; and the same may be the case with the pollen of the plant and the future seed.

It is a curious circumstance that mules, or hybrids, both animal and vegetable, may be perfectly developed in every other way, but are never so in the sexual organs. They may even surpass the parents, generally, but cannot continue their kind by propagation.

It has been shown before that in animals, even in the human being, the female egg is formed and expelled withont any intercourse with the male, but it comes to nothing if it be not impregnated. And exactly so it is with plants. The female germ is always formed in the ovarium, at the foot of the pistil, but if it be not impregnated by the male pollen it does not form a seed, but only a mass of alhuminous pulp.

All germs, however, have an innate power of derelopment, which may enable them, under peculiar circumstances, to form a new organism without the concurrence of another germ. Thus the ovum in human virgins, as before explained, may 
form into an organism, to a certain extent, without any concurrence on the part of the male whatever. Such formations, however, are never perfect, and do not come to anything. They begin, but do not complete development.

In plants also, the female germ may, in some cases, develop without receiving the male pollen at all, and even reach perfection. An Australian plant which was grown in England, in the Botanic Gardens, was found to be female, and there was not another plant of the kind, of either sex, in Europe, and yet it produced perfect seeds, which germinated and grew into new plants.

The same thing has been observed in a few other cases, but must be regarded as exceptional only, and possibly when more closely observed, the occurrence may be explained satisfactorily. We know that there are some insects in which one sexual connection will impregnate several successive generations, without any other male contact, and it may be that some such phenomenon occurs in these plants.

Commonly, in hermaphrodite plants, the male and female organs are close together, forming part of the same corolla, or flower. The female organ, called the pistil, is in the center, and the male organs, called the stamens, are ranged around, within the petals of the corolla, as seen below.

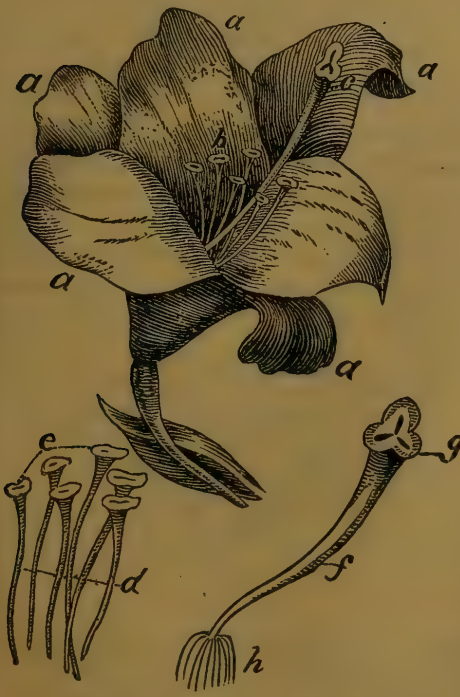

FraURE 77.-Flower of the Lily.

aa are the petals, or flower leaves. $b$ the stamens, or male organs. $c$ is the pistil or female organ. $d$ are the six stamens separate; $e$ being the anthers on the tops of the stamens. $f$ is the pistil separate, with the stigma $g$ on the top, and the germ $h$ at the bottom.

The male pollen is formed at the top of the stamens, which usually end in a protuberance, or curiously shaped part, called the anther, which is often jointed to the stem of the stamen, and has quite a range of motion.

The female germ, or future seed, is placed at the bottom of the pistil, in what is called the ovarium, analogous to the ovary of the female animal.

The pollen, when ripe, is in the form of fine dust, which is readily blown or carried around. If a grain of this dust alight at the top of the pistil, called the stigma, a curious process takes place.

There is a very minute passage down the center of the pistil, leading to the germ, and down this passage the pollen has to be conveyed, in order to fertilize the germ. In its ordinary state the pollen grain is too large to pass down this narrow way, and it therefore undergoes a very curious change. Resting on the stigma it begins to push downward a prolongation like a root, which works its way down the passage in the pistil till it reaches the germ, and impregnates it.

This is a true act of sexual conjugation, exactly analogous to copulation in animals. As soon as it is over the flower begins to wither, the leaves, stamens and pistils dry up and fall off, and the germ develops into the seed, or fruit. 
There may be either one stamen, and one pistil, or several of each, though usually the stamens are more numerous than the pistils. There may also be only one seed, or fruit, or several. In short, similar variations to what we see in animals.

The following cuts will show some of these varieties:

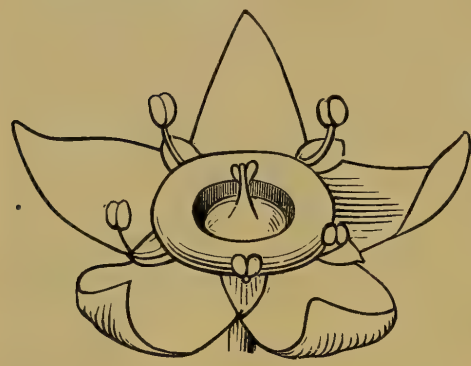

FIGURE 78.

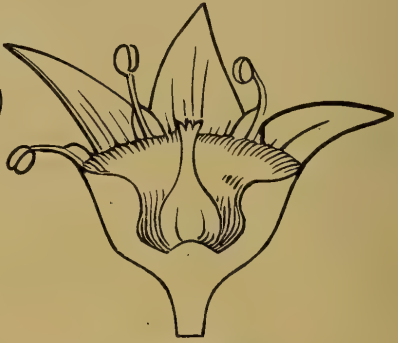

FIGURE 79.

The Stamens, Pistils, and Germs, in Plants.

In figure 78 the five male stamens, with double anthers on the top, may be seen in the spaces between the five petals ; with the female pistil in the center. In figure 79 the flower is cut through, to show how the pistil is connected with the germ, or the seed, in the orarium. Figures 80,81 , show the same.

Sometimes the male and female organs, instead of being contained in the same flower, as in those just shown, are in separate flowers of the same plant, as in the

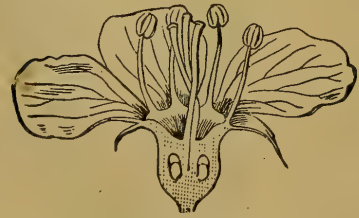

FIGURE 80.

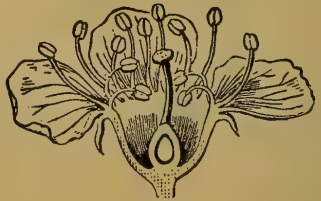

FIGURE 81.

hazel, in which the male organs are the catkins, which, when ripe, are covered with yellow pollen dust. The female flower is very small, and red in color.

At the time of fertilization the flower is at perfection, in every way, but immediately sexual conjugation is completed it fades and dies, as many of the lower animals do. When ready to fertilize, the stamens and pistils often exhibit curious spontaneous movements, ealculated to aid in the grand process of fecundation. It would seem as if the access of sexual vigor endowed the whole plant with an energy and sensibility far beyond what is shown at other times, just as we see an animal bound into superabundant life at the period of puberty.

The various forms of the stamens and pistils, and the strange ways in which they 
act, to bring the pollen on to the stigma, are exceedingly interesting to observe. In some, as in the barbery, the stamens are held bent down by the closed petals, which thus cover the pollen and keep it dry. But as soon as the bright sun shines upon them the petals spread out straight, and carry the stamens with them. These, however, gradually work clear of the petals and again curve inward, so that the anthers, with the pollen upon them, approach and touch the stigma on the top of the pistil. At the right moment the least touch or shake will cause this action to occur immediately. The settling of an insect is one of the more frequent of these assistant concussions.

In the nettle, and some others, the stamens are folded back, at the bottom of the flower, like coiled springs, and the least touch, or shake, makes them spring up in an instant with a force that throws the pollen in a cloud all over the pistil.

The rue has eight or ten stamens, spread out flat, with the petals, and if carefully watched one of these will be seen to bend forwards till its anther touches the stigma, and sheds the pollen upon it, when the stamen again bends back flat, and another takes its turn.

In Figures 80 and 81 some of the stamens are seen approaching the pistil to deposit their pollen upon it. Each one touches it in its turn, or kisses, and then springs back.

In self-fertilizing plants, just at the time when the pollen is ripe, the stigma usually becomes sticky on the top, so that the pollen falling upon it is retained, and at the same period, in those that need aid, the flower secretes the honey or nectar, which insects seek, and in doing so scatter the pollen, and convey it from one plant to another.

In many flowers the stamens are so situated, in reference to the pistils, that this approach cannot take place, nor can the pollen reach the stigma at all without some extraneous assistance. In these cases it is carried by the wind, or, more frequently, by insects, many of whom are peculiarly organized to fit them for the purpose.

A very curious circumstance was lately noticed, in regard to the common red clover, showing the mutual dependence of plants and animals upon each other. This plant has a very long tubular flower, at the bottom of which is the nectar, or honey, and within the tube is the female pistil. The pollen is so placed that it needs to be carried by some agency to the stigma, and this would be readily effected by many insects seeking the honey, were it not for the form of the tube. It requires an insect with a long thin trunk, or sucking pipe, which can be thrust down to the honey, and the common bumble bee has just such an organ. It is this insect, thereforc, that effects the fertilization of the clover, in getting its nectar, the trunk of the common hive-bee being too short.

It was observed in some places where the red clover was sown, that, though growing well, it did not produce sufficient seed. There was pollen enough, and both pistil and germ were perfect, so that the failure evidently was in fertilization. This failure was traced to the absence of the bumble bee, and then came the question, why this insect was absent? Further observation explained this also, by showing that this bee makes its nest in a hole in the ground, among the grass, and that the common field mouse, being fond of honey, destroyed the nest and young bees to get at the small store of it which the nest contained. As a consequence, when the field mice abounded the bumble bees were scarce, and the clover was only partially fertilized. By multiplying cats and other such animals, which preyed on the mice, they were 
soon so reduced in numbers that the bumble bees became abundant, and the clover was perfectly fertilized! Few people would suspect any connection between cats and clover seed, and yet it is obvious enough, when the mutual dependence is traced out.

Many equally curious instances could be given, some of which particularly show the mischief which is often done, by ignorant people, in deranging the balance of nature. These people look only at one animal or plant, and observe only one event, without tracing out the connection between all beings and all events, and so learning how they mutually influence and are dependent one upon another.

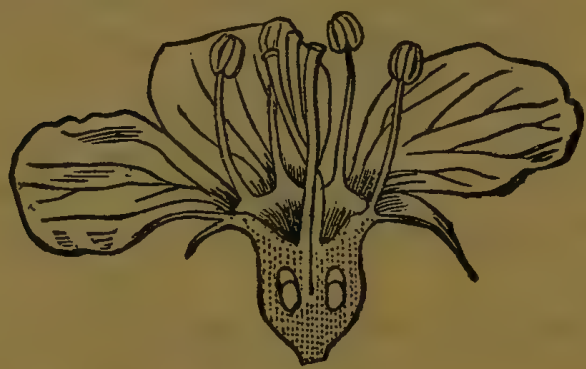

FIGURE 82.

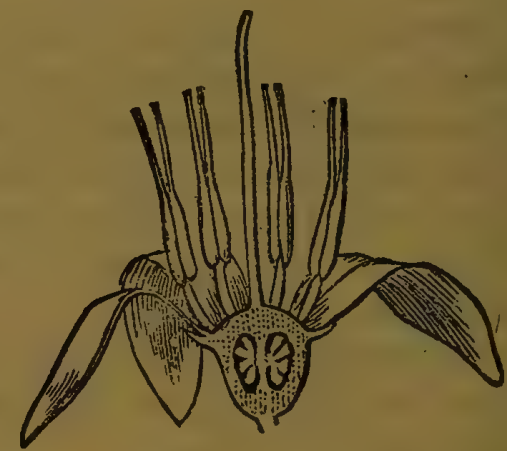

FigURE 83.

Figure 82 and Figure 83 show different arrangements of the sexual organs. In Figure 82 th? stamens are placed on the lower part of the petals, while in Figure 83 they are on the germ cell itself. The pistil is in the midst of them in both cases, and connected with the germ below. In Figure 82 one of the stamens is just touching the stigma, on the pistil.

Mr. Darwin, in his wonderful book on the fertilization of plants, gives a vast amount of interesting information on this subject, which is well worth study. Among other important facts, his experiments have shown that the pistil, in regard to the pollen, has a power of selection; for when the pollen of different varieties is mixed and applied to the stigma, it will always take one particular kind, and that only, though it will take one of the others if that be not present.

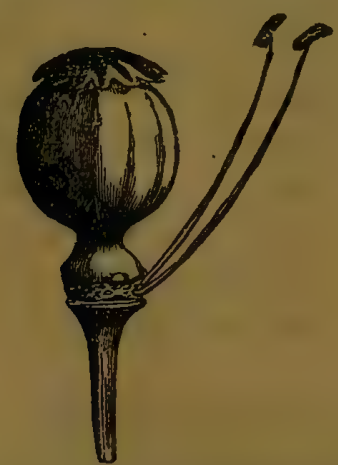

FrouRe 84.-Pistil of the Poppy.

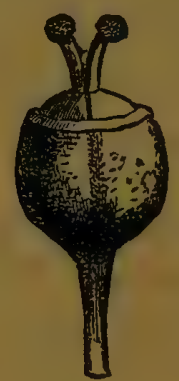

FIGURE 85.-Pistil of the Madder-plant.

Figure 84 shows the seed capsule, or pistil, of the poppy, with two of the stamens.

Figure 85 shows the double pistil of the madder-plant, with all the stamens removed.

It is quite possible also even in animals, when they mix promiscuously, that the semen of some males may always be absorbed in preference to that of others, so that their descendants will preponderate over the others, and thus become a special breed.

Another curious fact may also.be noticed. It is chiefly those plants that need insects to fertilize them which produce honey, while those in which the pollen is 
blown about by the wind are nearly always without it. In such plants also the stamens generally project beyond the corolla, or else there are no flower petals at all, so that the pollen is freely exposed to the action of the wind.

There is a curious water-plant, called the Vallisneria Spiralis, which grows at

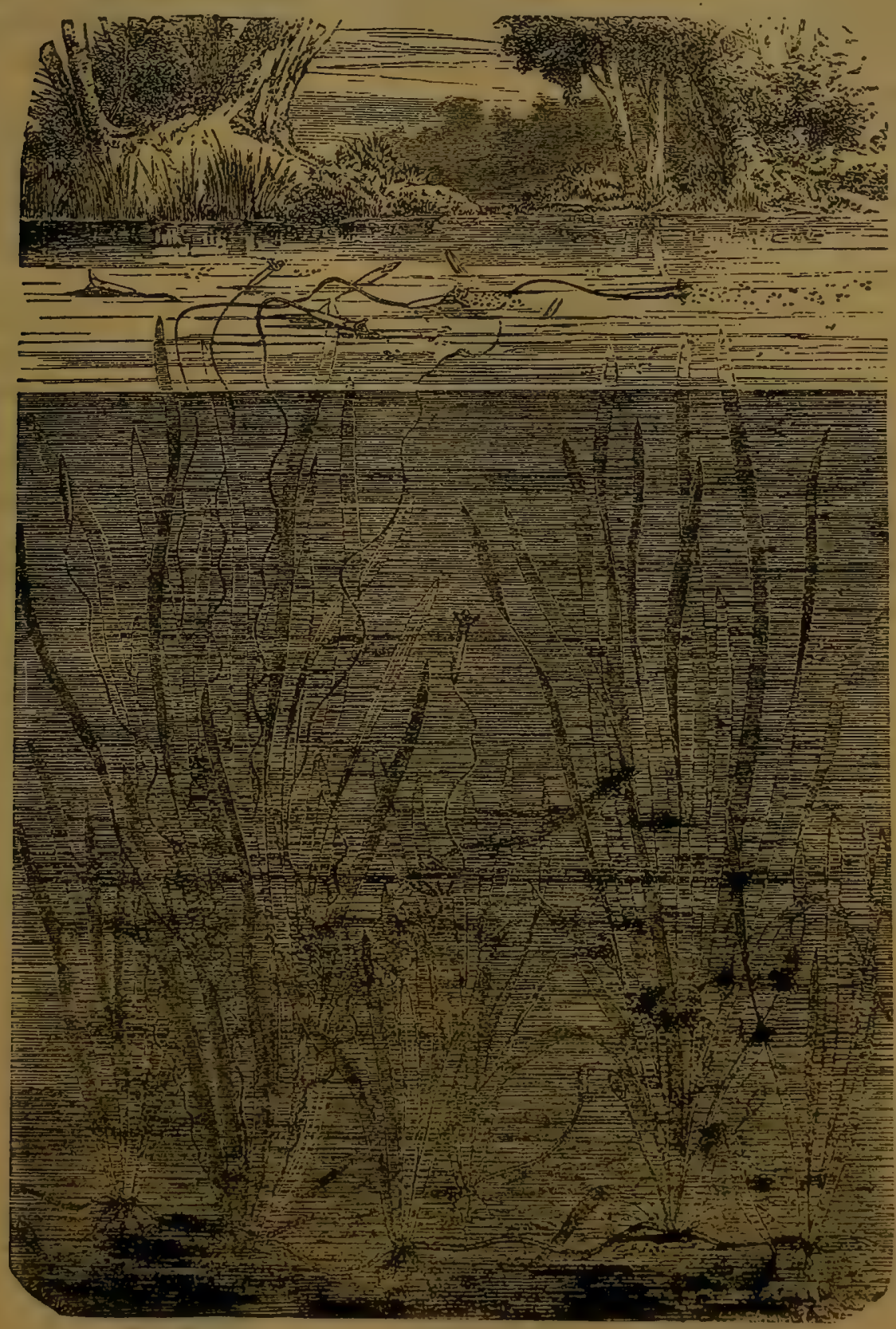

FrgURE 86.-The Vallisneria Spiralis.

the bottoms of ponds, in which the contrivances for assuring fertilization are well worth studying. It is diœecious, but the male and female flower stalks usually grow very near each other. At the time of fertilization, the female stem lengthens so that the flower is carried to the surface of the water, where it expands. The male flowers grow on short stems, at the bottom of the water, but at this time they become de- 
tached, in some unknown manner, and float up to the top where they too expand, and are drawn toward the female flowers, so that the pollen is shed upon the stigma, and the germ is fertilized. The male flowers then wither and die, while the female descends again to the bottom, and there the seed is perfected.

The spiral stems of the female flowers, as shown above, by expanding, project the flower to the surface of the water, and after they are impregnated by contracting, draw them down again. The male flowers, thrown up from below, are seen on the surface, ejecting pollen grains.

The amount of pollen produced by some trees, and the distance to which it is carried, is astonishing. Where pine forests abound it often descends, like rain or mists, over a large extent of country. Indeed, it is often called sulphur rain, from its color, and before its real nature was known, very curious notions prevailed as to what it was.

There is a plant called lycopodium, something like a large moss, which produces such a quantity of pollen that it is gathered in bags, and used for various purposes. It is very combustible, burning with a vivid flash, and is employed in theaters to make lightning. If a handful be scattered in the air, and a light applied to any part, the whole cloud flashes into a bright flame at once. It is easy to see how conflagrations in forests may be accelerated, or even originated, by this substance, for the slightest spark would be sufficient to cause its ignition.

The forms of the pollen grains are very varied and often peculiar, resembling closely the lower protozoa in animals, as seen in the following illustration :

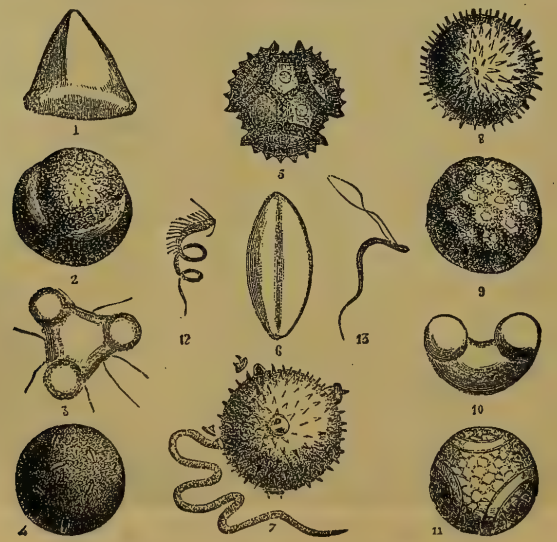

Figure 87.-Various forms of Pollen Grains.

There are also other phenomena connected with the inflorescence of plants, not less suggestive than those already given. In many of them the temperature rises to a most remarkable extent, so that the flower becomes actually hot. In some arums, in fact, the temperature rises as high as $143^{\circ}$, a heat sufficient, under some con- 
ditions, to make it wither up. Touching one of these flowers is like touching hot iron. Probably most flowers, at the time of fertilization, develop heat as well as motion, as a consequence of the activity of the sexual organs, which is strictly analogous to the erotic fever in animals at the corresponding period.

But not only do plants develop heat, and motion, at the period of greatest sexual exaltation. Many of them give out flashes of light at such times, and others again currents of electricity, like what occurs in animals. Reproduction, in short, is nature's supreme effort, and both in plants and animals it brings all her foress intc active play.

The countless millions of germs produced by some of the lower plants has already been referred to, as well as the astonishing amount of male pollen; but even in tha higher plants the quantity of seeds produced seems almost fabulous. A single poppy-plant has been found to contain 32 ,000 seeds, and a tobacco-plant 40,000 , while an elm-tree may produce in one season half a million seeds. Of course, only a small fraction of all these seeds can form new plants, while but a still smaller fraction of the male pollen is needed in fertilization. And this superabundance, it must be remembered, is not occasional, but constant, season after season. Nature has provided, in every way, all the elements of reproduction, not only in abundance, but apparently in extravagant excess.

It must be remembered, however, that both germs and pollen are essentially protoplasmic, and very possibly they may be important agents $\mathrm{n}$ the reproduction of that natural protoplasm, before referred to, which abounds in the air and in the water. When not used in their quality of germs, pollen, or seeds, they

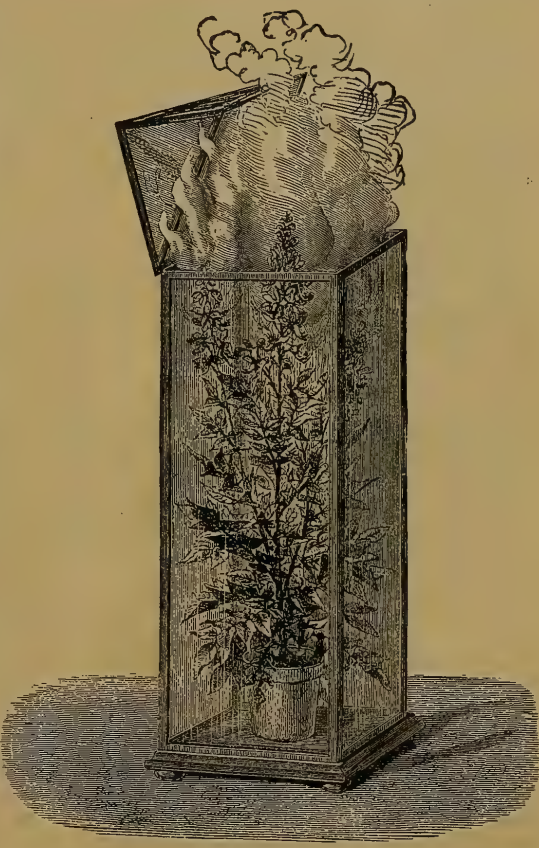

Figure 88.

Figure 88 shows a plant of the Bastard Dittany (Dictam nus Fraxinella), inclosed in a glass case to confine the in. flammable vapors which arise from it. On opening the case and applying a light, the vapors at once burst into flame. Many plants, during the period of flowering, give out these inflammable vapors, as well as flashes of light, heat, and currents of electricity ; all resulting from sexual activity.

may simply disintegrate into that impalpable, universally diffused organic dust which 
the air everywhere contains, and which constitutes what experimenters call the floating atmospheric germ. The vitality of some seeds is very remarkable. They will endure the greatest extremes of both heat and cold, and may be kept for hundreds of years, and yet germinate when placed under proper conditions. Certain seeds, which often come to Europe in wool, imported from Brazil, may be boiled for four hours, and yet afterward grow if planted. Many others will stand boiling for a shorter time. Some raspberry seeds taken from an old Celtic tomb, seventeen hundred years old, were sown in the Horticultural Garden, London, and grew, and the bushes from them may still be seen there.

In simple cellular plants, though the contents of two cells unite to form the generative germ, there is no difference, so far as can be ascertained, between the two. The union is probably only analogous to the process of fission, or division, in the fully-developed plant itself; the substances from two cells uniting in the samc way as the two halves of a one-celled organism, and making one complete cell betwcen them. The union of a portion, or the whole, of the contents of two different cells, seems to develop a more energetic action than is seen in either cell alone, or more force of growth. This arises, probably, from there being some small difference between them, and the one complements the other.

The way in which the contents of two cells mingle to form a new one is very simple. They merely approach till they touch ; then burst at the point of contact, the contents of the two intermix, a membrane forms around the intermixture, and a new cell is formed containing the essential elements of the original two, which shrivel up and disappear. The new cell thus produced from this union is called the sporangium, because it produces the spores from which new plants arise.

Sometimes, instead of the two cells bursting when they touch, their investing membranes simply unite, and expand between them, forming a new cell, into which both pour their contents, and thus form a sporangium as before.

In other cases, when the two cells unite one empties into the other, and thus forms the sporangium, instead of a new cell being formed. Probably this is the first beginning of a differentiation of cells. One of them varies in some way from the other, and is attracted to it; or, in other words, a kind of sexual difference has taken place-one is male and the other female, though imperfectly.

Among the higher cryptogamous plants, and in some of the sea-weeds, certain of the cells produce thread-like bodies or filaments, exactly resembling the spermatic animalcules of animals, which, when ripe, are scattered around by the bursting of the investing membrane, and move freely about of themselves. When one of these sperm filaments merely comes in contact with a germ cell, it seems to stimulate it, and cause increased development by its mere presence, but it is uncertain if it ever really enters the germ cell. There may be some osmotic absorption, however, through the investing germ cell membrane.

The cell which grows and develops the new organism is always called the female, or germ cell, analogous to the egg in animals, and the filamentous one which stimulates it is called the male or sperm cell. They may either be formed on the same plant (hermaphrodite) or on different plants (diœeious).

In the simpler forms, where two of the same kinds of cells unite, the new one (embryo) is perfect from the first, and is at once cast off to commence life on its own account. But when we come to the actual union of two different kinds, a sperm cell and a germ cell, by the sperm filament penetrating the germ cell, and uniting with it, 
or by osmotic action through the membrane, the case is different. The sperm cell is usually small and imperfect, while the germ cell is provided with a large amount of nutritious material, like the yelk and white of a bird's egg, by which the sperm embryo is nutrified and developed to a much more perfect stage before it is cast off. In other words, it is retained till it is formed into a perfect embryo, ovum, or seed, which is different from either the sperm cell, or the germ cell, from which it is derived.

These different processes are clearly shown in the following illustration :
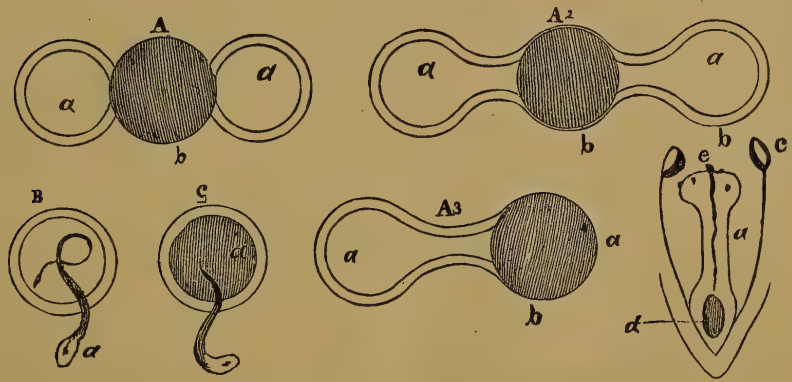

Figure 89.

Figure A shows how the two cells, $a, a$, have burst on contact, and their contents uniting form the sporangium, $b$.

Figure A 2 shows the investing membrane of the two cells, $a$, $a$, expanded, and the contents of both intermixed in the new-formed space; making the sporangium, $b$.

Figure A 3. In this the contents of the cell $a$ have passed bodily into $a^{*}$, thus forming the sporangium in one of the original cells, by the union of the contents of both. This is probably the first commencement of sexuality.

$\mathrm{B}$ is a sperm cell (male) of one of the higher cryptogams; it contains a moving filamentous body, resembling the zoosperm of an animal, which is just escaping from it.

$\mathrm{C}$ is a germ cell (female) of one of the higher cryptogams, filled with protoplasmic material analogous to the yelk of the animal egg. A filamentous male germ is seen in contact with it, effecting its impregnation either by actually entering it, or by exerting some influence upon it, by osmotic action, through the investing membrane.

In perfect plants, which produce seeds, as before shown, the sperm cell, or pollen grain, in like manner, pushes out a long tube, which forces its way down what is called the style, or pistil, of the flower, till it reaches the germ cell, and fertilizes it, so that it can develop into the perfect embryonic germ or seed. This curious process, as before observed, is wonderfully like the act of copulation in animals, the pollen tube acting the part of a penis, and conveying the fertilizing male principle to the female germ.

This is shown in the last figure. $a$ is the pistil of a flower, with the seed $d$ at the bottom. $\quad c$ is one of the stamens, there being one also on the opposite side. $e$ is one of the male pollen germs lengthening itself out like a thread, down the tube of the pistil, to reach the germ $d$.

Much more that is exceedingly interesting could be said on this matter, but this is sufficient to show the remarkable correspondence between animals and plants in 
the process of reproduction. It will also show that the old poetic dream of the loves of flowers is probably a reality! Any one who has studied the curious ways in which the male and female organs of flowers unite, how they bend, and turn, and twist, to come together for a short embrace, and the close union they form, can scarcely help thinking that pleasurable sensation, of some kind, must accompany the process. It is, perhaps, really the same in kind as love in animals, only different in degree. 


\section{PART XI.}

\section{PARTHENOGENESIS, OR VIRGIN GENERATION; AND}

THE ALTERNATION OF GENERATIONS. 



\section{CHAPTER XXV.}

VIRGIN GENERATION.

Is some of the lower animals the process of reproduction presents a most remark. able peculiarity. We find in them, at some period or other during their career, both males and females, and, of course, the two sexual elements, and they propagate in the usual way by uniting them.

In addition to this, however, there is a period in which the female propagates alone, without any concurrence with the male; in fact, at that time no males exist. This is called Parthenogenesis, or virgin generation.

The best illustration of this remarkable mode of propagation is found in the green Aphis, or plant-louse. These insects are always to be met with, during spring and summer, on the young shoots of the rose tree, which are often covered with them. They are small and plainly visible to the naked eye, plump, round, with six legs, and bright green in color. In front the aphis has two long feelers, and behind two odd-shaped spikes. It has no jaws, since it lives entirely by sucking the juices of the plant on which it lives, and from which it seldom moves, unless forced to do so.

The aphis is always full, and frequently even overflowing with the plant-juice, thus causing that peculiar sticky, sweetish, varnish-looking substance called honey dew, often seen on the leaves and stems of plants. Ladybirds, ants, and several kinds of grubs, feed on these plant-lice, not eating them, but using them as we dc cows. They tap them, or milk from them the juice they contain, and which they keep continually drawing from the plant.

It may readily be supposed these insects are terribly hurtful to regetation, and indeed gardeners consider them among their worst foes. One particular kind, which lives on the hop-vine, often causes in England a loss in revenue alone of upward of a million dollars in a single season. They propagate with such extraordinary rapidity that when the season is favorable for them, nothing can withstand their power of destruction. And yet the greater part of this astonishing multiplication is effected by females only !

During the early summer all the aphis are wingless females, and a brood of them begins in this way. An egg is laid the previous fall, usually in the axis of a leaf, which in the warm spring hatches out into a wingless female insect, with six legs, as above described. In a few days this wingless female produces eight more living creatures, just like herself.

And each of them, in like manner, soon produces eight more, and so on, for six, eight, and even ten, successive generations! This ratio of increase would make it possible for one single egg, in one summer, to produce ten thousand million insects ! We need not wonder, therefore, at their astounding numbers, and at the rapidity with which they multiply.

But the most remarkable thing, connected with this prolific propagation, con- 
sidered physiologically, is that it all results from virgin females only, not a male being produced! Where then, it may be asked, does the egg come from with which we started?

It comes in this way : toward the end of the summer the production changes, and the same wingless females bring forth aphides with wings, and which are both male and female, perfect. These copulate in the usual way, and the female deposits her eggs on the plant to be hatched the next spring, and to commence the same round as before. Then both parents die, and no more males, or winged females, are seen till next autumn.

It is supposed, therefore, that the influence of the autumn impregnation is continued through the ten or more generations of the next spring. But why only females should result from it for so long a period, and yet finally perfect males and females both should result, we do not know.

It would rather seem as if the early broods were real virgin productions, and all female from lack of vigor in the parent. As the season advances, and the plant juice becomes richer, the parent may become more vigorous, and capable of producing perfect males and females.

It will be seen that the reproduction of this insect depends entirely upon the production of the egg at the end of the season. The aphis itself perishes entirely in the winter, but the egg survives, to be hatched when warmth returns in the spring. The one way to lessen or destroy them, therefore, is to destroy the eggs, for a single one hatched is enough to produce thousands of millions of the aphides.

We do not know that the eggs have any destroyers, though fortunately there are plenty for the insects themselves; but in spite of all, the plant-louse never fails.

The following plate shows the progression of this remarkable creature from its commencement in the egg.

It has been suggested that the so-called wingless females may really be hermaphrodite, but no trace of a male apparatus has been detected in them. Even if they were, it would still be a strange anomaly for them to produce finally true males and females; and besides these true males and females produce only eggs, while the wingless insects produce living insects, like themselves.

Consider it in whatever light we may this abnormal mode of propagation is very wonderful, and gives rise to many plausible speculations.

The generation of the hive bee is, in many respects, analogous to that of the aphis. We find among them three different kinds of beings-the males, which are produced only at certain times of the year-the workers, which are only imperfect females-and the true females. These three varieties all result from eggs laid by one female, and the difference between them is brought about in a very curious manner.

One female prodnces all the eggs that a hive requires to form a new swarm, some thirty thousand or more, so that only one is reared. If two are produced they always fight till one is killed, the males making no interference. When ready for impregnation, the single queen takes a flight through the air, a kind of nuptial journey, during which the males attend and impregnate her, probably repeatedly. After this is effected she returns to the hive, and enters upon the business of laying eggs, the workers forming the cells, making the honey, and attending to her and the eggs. The males being no longer needed soon die off.

This single impregnation suffices to fecundate all the eggs she afterward lays; the semen she has received being stored up in a pecnliar organ adapted to the pur- 
pose. This seminal reservoir communicates by means of a tube, with the oviduct, down which all the eggs pass, and it is so made that she can open and close it at will. All the eggs which are to produce workers, or future queens, are impregnated as they pass down the oviduct, the seminal tube being opened at that time to let the semen reach them. But when the eggs pass down that are to form future males, the seminal tube, it is said, is not opened, and so they are not fecundated at all. This has been apparently proved by destroying the tube which conveys the semen, in which case the female produces nothing but males.

If this be really the case, and it would seem to be so, then all the males are produced by the female only, and have no male parent at all. In support of this it may also be noted that when two kinds are crossed the males all resemble the queen only.

Some naturalists, however, contend that the eggs of insects are of no sex, but may be developed into either, according as the resulting larvæ are fed and treated. And this possibly may be the case, for as before explained, all cells are primarily alike, and male and female are only different stages in their development.

Parthenogenesis occurs in many other beings, besides those above described, but the process is essentially the same in all.

The occasional imperfect organisms developed in the human virgin, from her ovæ, are of course true cases of parthenogenesis, and it is quite conceivable that in some former state of the world, among beings very different from what exist now, it may have been a frequent occurrence.

It has been suggested that the wingless aphides, produced by the virgin females, should be regarded only as buds, like those formed on plants, and not as true sexual products, while the final perfect males and females should be regarded as the flowers and seeds which the plants finally produce.

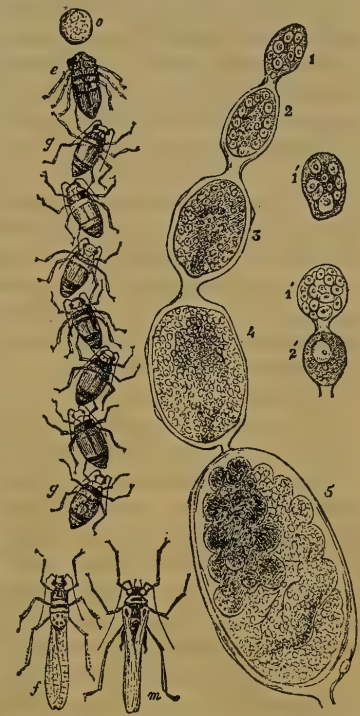

FiguRE 90.-Parthenogenesis of the Rose Aphis.

$o$, is the original egg laid on the rose stalk in the fall. $e$, is the first insect hatched from this egg in the spring. $g$, to $g$, are seven different generations, each one produced by the one before it, and all wingless females alike. $f$, and $m$, are the ninth generation, or sometimes the tenth or eleventh. They are produced last in the-season, and are perfect male and female. These copulate, and the female lays the eggs to be hatched the next spring. The male has organs like testicles, which secrete a true sperm, and the female has an ovary which produces eggs, like the more perfect animals.

From 1 to 5 shows the ovarian tube, in which the aphis is deveioped. Beginning at 1, we find a small number of germ vesicles, which, as they develop and multiply, passi nto $2,3,4,5$, successively. $1^{\prime}, 2^{\prime}$, represent single vesicles magnified.

These successive onlargements of the ovarian tube are needed to accommodate the continually increasing brood. In each chamber the larva has become more perfected, till finally in 5 it is ready to come forth as the grub $g$.

By some, each of the imperfect stages of the aphis is regarded only as a kind of budding, the true sexual reproduction occurring only in the final stage. tive.

Regard it as we may, however, the whole process is very wonderful, and highly sugges- 
This explanation is more ingenious, it seems to me, than well-founded, and does not meet the difficulty so well as that given above. Nor does it seem to apply at all to the occasional cases of parthenogenesis in the higher animals, and in plants, such as have been narrated in previous articles.

Some of the small water insects exhibit the phenomenon of parthenogenesis, especially those called water fleas. In some of these one impregnation will last the female her whole life, and the young females which she produces will produce young all their lives without any male intercourse whatever.

In some of the barnacles the disposition of the sexual elements and organs is still more singular. Usually they are hermaphrodite, but not in the ordinary way. The animal seems to be only female, having no separate male organs, and instead of them there are two males, lodged in the same shell, which impregnate only her. They do not leave that shell at all, nor fecundate any other female, and evidently serve the one only. They are very imperfect as animals, having neither mouth, anus, stomach, nor limbs, like those of the female. They seem, in fact, to be nothing more than separate living sperm cells, full of sexual animalcules, which they discharge at the proper time, and then die.

In this case, we seem to have the male testicles separated from the rest of the hermaphrodite body, and formed into living organisms by themselves. They perform no other function than that of secreting semen, and when that is discharged they perish. This, it will be seen, is strictly analogous to those cellular organisms which produce only germ cells ; and which may be considered as living female ovaries, which discharge their ovæ and then die.

Both the male and female organs, therefore, may live, and perform their respec tive functions, as independent beings, without being structurally connected with any other bodies. Still more singular than this, there are other beings, of a like kind (the Scalpellum vulgare), which are also hermaphrodite, but in whom the male organs are apparently too small to secrete enough sperm to insure fecundation. To com. pensate for this, there is always found closely connected with them a number of independent males, which by their seminal secretion make up the deficiency. These males never separate from the hermaphrodite body, and when no longer needed, die. Their sole purpose evidently is to make up for the smallness of the male organs which form part of the parent body. They serve, in fact, the same purpose as those before described, but are more perfectly organized. They never pair with simple females, but only with the hermaphrodite they live with.

In what is called alternation of generation, parthenogenesis frequently occurs, with change from one mode of generation to another. The common tapeworm is an instance of this, and a very instructive one.

In their perfect state tapeworms are always found in the intestines of warmblooded animals, their presence causing much sickness and distress. How they come there, and the change they undergo, is understood by few of those who suffer from them.

This animal, as usually seen, is composed of a number of flattened joints, all alike, connected together like a chain, sometimes of immense length. The real animal, however, is but small, constituting the round upper end, called the head, or sometimes the nurse. It is very curiously formed, having a circle of hooks, or suckers, or sometimes of both, by which it holds on to the inner wall of the intestines. It has no digestive organs, and no mouth, so that it lives entirely by absorbing the fluids of the body to which it is attached. 
The joints, as they are called, which stretch out, one below the other, down. ward from the head, are all simply so many hermaphrodite propagating bodies. They are all alike, each one having male and female organs, and being capable of producing ovæ, or eggs. The head itself, the real animal, has no reproductive organs, and apparently could not, alone, continue its kind. All the propagation is effected by the joints. Whether there be any nervous system in the tapeworm has not been ascertained. There is, however, a kind of tube on each side, running the whole length of the animal, called the water vascular system, which binds all the parts together. At each joint a small tube goes across from one side to the other, like the rounds of a ladder, and thus all the joints are organically connected. In the last joint this cross tube opens into a peculiar contractile vesicle.

The joints are all formed from the head, by budding, one after another, each new one being produced between the head and the nearest joint, so that those nearest the head are always the youngest, and the end ones the oldest.

Each separate joint has both male and female organs, perfect, consisting of an ovarian tube, and a seminal tube, which both open together into a small projection on the side, and are ejected through an opening called the generative pore. This pore is placed alternately on the right side of one joint and the left of the next, and so on.

What is called a tapeworm, therefore, consists of the real animal, the head, and the joints (named proglottides). It may be altogether only a few inches long, or many yards; every joint, or proglottis, being nourished by what is imbibed from the intestine through the head. Possibly the joints may also absorb, by osmose, from the fluids in the intestines. It is, in fact, a fearful parasite, feeding all the time on its victim, and perpetually multiplying itself.

The most remarkable thing about this creature, however, is the way in which it is ieveloped, for it does not reproduce its kind directly, nor where we usually find it.

The sexual joints, which form the eggs, are produced only in the intestines of warm-blooded animals, as in man, but the eggs never hatch there, so that no new worms are ever formed there, and usually there is but one. This is why it is sometimes called the "solitary" worm. Before the eggs can be hatched they must be swallowed by some other animal, as they never develop in the one in which they are formed.

The joints, one after the other, when their contained eggs are all fertilized, become fully ripe, detach themselves, and are expelled from the body with the excrement. After this discharge, they soon become decomposed, and the contained eggs are liberated.

Each egg is covered with a firm capsule, or sac, which protects it from injury, and it often contains the rudiments of the young worm so far developed that its head and suckers can be distinctly perceived, though very minute. At this stage the egg must be swallowed by some warm-blooded animal, and so be carried into its intestines, before its development can proceed any farther.

When once in the intestine, the capsule is soon ruptured, or dissolved by the gastric juice, and the young tenia is liberated. It is then ordinarily only like a small vesicle, or sac, but it is provided with three pairs of flinty spines, or borers, with which it bores its way through the walls of the intestines, and so reaches some of the neighboring parts, or some blood-vessel, which it enters, and may then be carried in the blood to some internal organ, often the liver. 
It is now calıed a "proscolex," and having got so far, immediately sets to work to develop further. Wherever it may be, it forms around itself an inclosure, like a round sac, called a cyst, in which it lies, and at its posterior end it develops a small round vesicle, filled with fluid. It is now called a scolex, or sometimes a hydatid. While in the cyst it consists only of the head, with its hooks and suckers, and the vesicle of fluid attached behind. It has no other organs of any kind, and it is unable to proceed further with its development where it is. It may, however, propagate in this encysted stage, by simple budding, but only produces a scolex, like itself, except very rarely. In some exceptional cases it produces an organism like a half-developed tenia, but never a perfect one.

If the scolex, however, reaches the intestines of a warm-blooded animal, by being swallowed, it attaches itself by its hooks, or suckers, and soon forms the perfect head of a new tapeworm. The vesicle drops off, and the formation of joints commences.

When first formed, the joints are not perfect, but as the chain of them is gradually lengthened, those first formed ripen, the eggs are produced and impregnated, and they become finally ready to fall off and begin the circle again as proglottides. The whole animal, head and joints together, is called a strobila.

The animal, therefore, goes through the following stages : 1st, the egg, produced from the generative joint, or proglottis; $2 \mathrm{~d}$, the proscolex, or embryo, which is set free from the ovum after that has been swallowed by some warm-blooded animal ; $3 \mathrm{~d}$, the scolex, or encysted embryo, a little further developed than the proscolex, but still with no generative organs, though it may propagate by budding, beings like itself (formerly called a cystic worm) ; 4th, the strobila, or perfect tapeworm, with head and joints developed from the scolex after this has been again swallowed by a warm-blooded animal.

The course of one of these worms may be traced in this way: An individual afflicted with tapeworm is constantly evacuating the ripe joints, with their eggs. These are very small, and may either be washed by rain, or otherwise, into water, or they may dry up and be blown about by the wind. There being so many eggs thus dispersed, some of them, if pigs be around, are sure to be swallowed by these animals with something they eat, and once in the pig's intestines each one soon forms into a proscolex, which bores its way into some part of the body, and becomes a scolex. Usually they pass into the muscles, and when in large numbers cause one form of what is called the measles. In the pig itself, the animal remains a scolex only, but may propagate by budding, as before explained. If, however, the pig be killed, and a man eats part of its flesh, especially the ham, he necessarily swallows the scolex, and once in his intestines it fastens itself to the walls, and becomes a true tapeworm, or strobila, ready to form joints and begin the same round over again.

In the cystic, or scolex state, it was formerly called the cysticercus cellulosus, and was chiefly noticed as the agent that caused the measles. Measly pork, therefore, is simply the flesh of a pig infested with tapeworm in the scolex stage.

It would seem almost like what is called poetic justice, that the cat is afflicted with a tapeworm which results from a scolex contained in the mice which it eats, and in like manner the tapeworm of the fox comes from the hares and rabbits it devours. The tapeworm of the dog comes from a cysted worm, which causes the staggers in sheep; and in man there is a variety which comes from measly beef.

What are called hydatids, in the human body, result from the scolices of the tape- 
worms of other animals, especially of the dog, which by some means obtain access to the interior of the body.

It is very difficult to get rid of a tapeworm, because it is of no use to merely break off some of the joints. If the lead is not got rid of, the animal is still there. When a part of the joints protrudes, a steady, firm pull upon it, not enough to break it off, will often make the head let go, if the pull be kept up for some time. Several drugs have more or less power over the tapeworm, either killing it, or causing paralysis, so that it looses and comes away. Turpentine is very effective for this purpose, but the new remedy, kousso, is the best yet discovered.

It is very certain that the principal source of the tapeworm in man is swine's flesh. And those animals that feed around the most promiscuously are, of course, the most likely to be infested with it. The flesh of all measly animals ought to be carefully destroyed.

Altogether some 200 varieties of tapeworms, and of others resembling them, have been described, about ten of which affect the human body.

In the perfect form, tapeworms are found only in the vertebrate animals, though in the larval, or scolex stage, they are found in some of the invertebrates. In birds they are very numerous, especially in water birds, but they are rare in reptiles, or fishes, except the cuttle-fish. The hog itself, it will be observed, never has the tapeworm, in its perfect form, but only the scolex, which he passes on to man to be completed.

The scolex, it should be remarked, sometimes reaches the brain, causing epilepsy, insanity, and even death. Still, old men have been found, after death, infested with them in almost every part of the body, and yet, while living, apparently but little inconvenience resulted from their presence.

The adjoining plate shows the various stages of development in the tapeworm.

In the hydroid polyp, called the sertularia, the generative process is still more remarkable. The egg which it produces swims about, for a time, by sneans of cilia, or hairs, which it uses as oars, but finally becomes attached to some object in the water, and then develops a mouth and limbs, and becomes a new being. It then commences to produce others like itself, by budding-all of them growing together, forming a colony, in which each is independent, though all are united. None of these new beings have any sexual organs, and consequently they are unable to propagate, except like the parent, by budding.
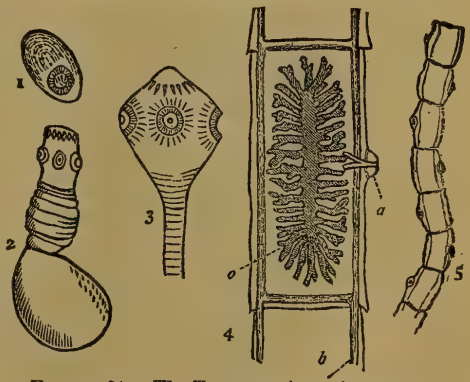

FIGURE 91.-The Taperoorm in various stages.

Figure 1. An egg, containing the embryo.

Figure 2. A cysticercus, or scolex.

Figure 3. Head of a tapeworm enlarged, to show the hooks and suckers.

Figure 4. One of the joints magnified, showing the ovary 0 , the generative pore $a$, and the water vaseular canals $b$.

Figure 5. A portion of the jointed part of the tapeworm, to show the generative pores on alternate sides.

The water vascular tube on one side is connected with the one on the other side by two cross tubes, one above and one below.

After a while, however, some of the buds grow into beings entirely different in 
appearance from these, and possessed of sexual organs, which produce fecundated eggs, like the one begun with, and then immediately die. Both kinds remain attached together, and the first kind seem simply to produce nutriment, by which

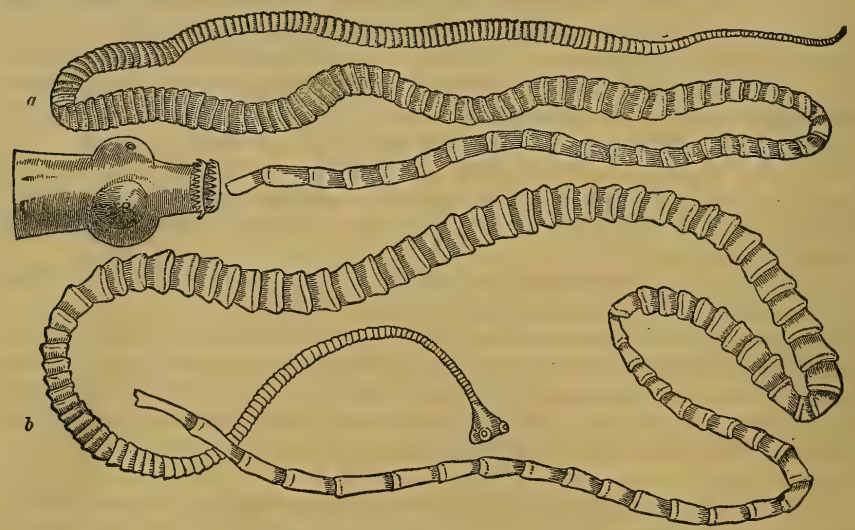

Figure 92.

Figure a. Tapeworm of the lark, with the detached head much magnified to show the suckers and hooks.

Figure $b$. Tapeworm of the cat.

all alike are supported. There are thus two kinds of beings formed by simple division of the parent, one whose duty it is to provide nutriment, and the other to produce eggs. To express it another way, the stomach is placed in one being, and the sexual organs in another, but the two may still be united together.

In some beings of this kind, the process is varied a little. The new beings destined for reproduction are separated from the others, and live for a while independently before they develop the generative organs. They become also totally different from the parent, developing, in fact, into a species of jelly-fish, or medusa, which is sexually perfect, and produces eggs, but these, instead of developing into jelly-fish like those they come from, produce only simple hydroids, like the original one commenced with.

In some others, again, the primary egg forms into a round, free, swimming body, which attaches itself finally to some object, and then further develops into a being formed like a trumpet, with mouth and limbs, like the hydra. This trumpet-like body propagates abundantly by division, but only beings like itself, without sexual organs of either kind. At last, however, the trumpet-like parent enlarges, changes! in form, and splits into several pieces, which swim separately away and form into so many new beings, entirely different from the parent. They become, in fact, medusæ, or jelly-fish, occasionally many feet in diameter, with perfect organs of digestion and finally, also, of reproduction. These, when full grown, give birth to perfect eggs, and then die. Their eggs, however, do not grow into anything like the large jelly fish parent, but into small hydras, like those with which the circie began. 


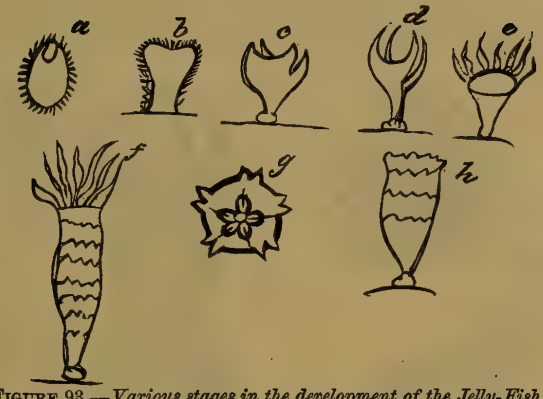

FigURE 98.-Various stages in the development of the Jelly-Fish.

a. The original egg, with its fringe of cilia. $b$. The same attached at one end, and beginning to lengthen, while the top sinks in and the corners rise up. $c$ shows a still further change, the corners being lengthened into tentacles, which finally multiply into a large number, as in $d$ and $e$. The body then lengthens, and is divided into segments by a series of rings, as in $f$. These segments gradually separate, and are at last held together only by a slender filament down the center. They are, in fact, like so many plates, piled one upon another. Finally, the upper plate separates and floats away, like $g$, and the others follow in succession. The root, however, remains, and continues to form new ones, as in $h$. Each of these segments, or plates, then develops into a perfect jelly. fish, as below, and this produces eggs, which begin the same round over again.

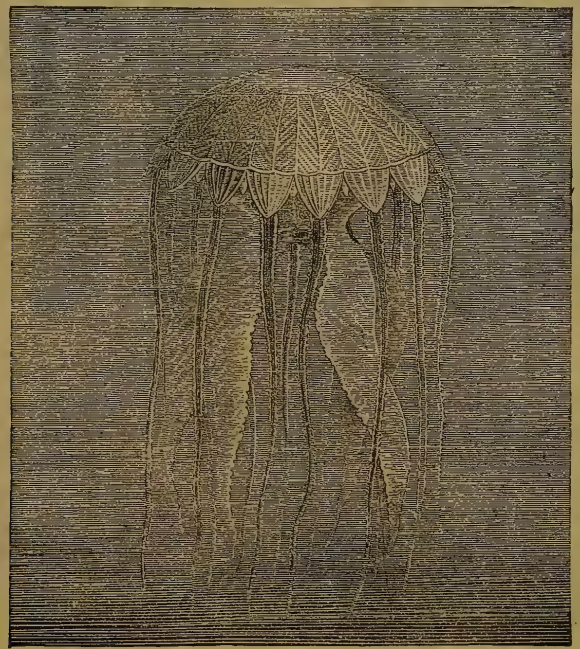

Frgure 94.-The perfect Medusa or Jelly-Fish; resulting from the simple egg $a$, through all the various stages above described. 
In this remarkable series of transformations, we begin then with a minute hydra, which produces free swimming eggs, which develop into the trumpet-like bodies, and

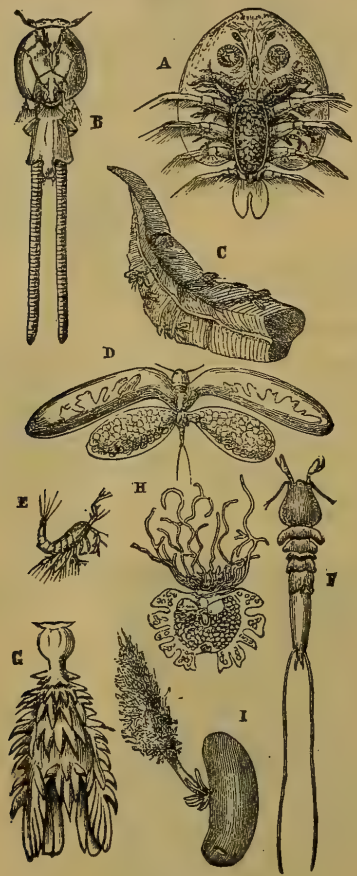

FigURe 95

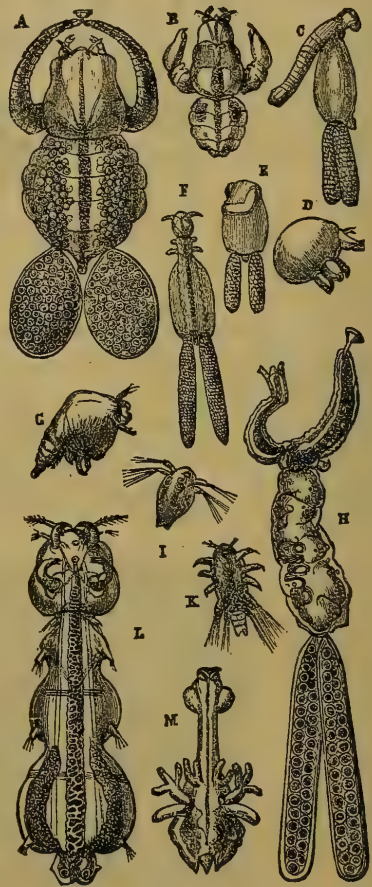

FIGURE 96.

Some of the most remarkable Parasites found upon Fish and Crustaceans.

Figure 95. A is the argulus, which lives under the fins. B. The caligus, found mostly on the cod. C, D, E. The nicotho, or lobster louse, found chiefly on the lobster's gills. F. The dichelestium ; this creature works its way under the skin, near the gills, of many kinds of fish. $G$. The chondracanthus found in the gills of the John Dory. H, and I. Two remarkable parasites found under the abdomen of the lobster.

Figure 96. A. The female perch sucker. B. The male. $\mathrm{C}$ and $\mathrm{D}$ are the female and male or the anchorella. $\mathbf{E}$ is another anchorella. All these infest the backs of cod and haddock. $\mathbf{H}, \mathbf{I}, \mathbf{K}$, show the various stages in the development of the tracheliastes; in $\mathrm{H}$ its two long egg bags are seen protruding behind. L, M. The lampoglena. All these last bury themselves in the flesh in various parts of the body. One of these parasites, the penella sagittata, or sprat sucker, attaches itself to the sprat's eye, and hangs from it.

In short, the variety of these beings is endless. Every part of the fish is affected by them, and they seem of ten to cause great suffering.

these divide up to form jelly-fish, which may become quite gigantic, and which produce eggs that develop back again into the minute hydra, 
Before the real pedigree of these singular beings was made out, each different stage was taken for a different animal, and described as such by naturalists. It is very possible that many of those we now consider distinct are really only similar separate stages of one and the same being.

Similar changes occur in an endless variety of ways, showing that nature can propagate in many different modes, and change from one mode to another, even in the same being. The sexual organs and elements are evidently only the common organs and elements of the body, specialized for purposes of propagation, and sometimes resuming again their former simpler functions. As formerly explained, in the simpler beings any part may serve, for the time, any purpose for which it may be needed, and be again relegated to its former uses.

Some naturalists, Huxley among the rest, do not consider the above process as one of alternate generation, but regard the whole series of changes, from the egg through all the transformations back to the egg again, as one act. Much may be said in favor of this view, and it certainly simplifies our conception of the phenomena; but the whole subject requires further elucidation. No matter how it may be regarded, this strange series of metamorphoses, ending at last with the same being it began with, is certainly one of the most wonderful of nature's operations.

In the vegetable world there is often what is equivalent to the alternation of generations in animals. Some quite large and well organized plants produce no seed, but only small spores, such as form the lowest mosses and lichens. These spores produce a plant inferior to the parent, but which is able to produce a seed, and this seed develops into a plant like its grand-parent, and not like the one it sprang from.

The perfect germ cell or seed, is not formed at once, in this case, but by two efforts. The simple spore is only the first stage in the process of its evolution, the final stage being reached when the seed itself is formed.

The parasites which live upon other animals are all very singularly formed, and have very peculiar habits, according to the parts on which they live. Their mode of reproduction is often very obscure. 




\section{CHAPTER XXVI.}

\section{FIRST CHANGES OBSERVED IN THE OVUM AFTER FECUNDATION, AND THE WAT THE EMBRYO BECOMES CONNECTED WITH THE MOTHER.}

THE description already given of the structure of the egg, unimpregnated, will make the following account of the changes it undergoes after fecundation, and the innal development of the embryo from it, readily understood.

The precise way in which the sperm affects the egg, so as to cause these changes, we do not know ; it is only the changes themselves that we can observe. Observations on the frog show that when fecundation takes place, the animalcules become imbedded in the gelatinous covering of the ovum, almost the moment they touch it, and pass at once into the vitellus or yelk, where all further trace of them is lost. Most probably they there combine with the vitelline material, and commence the new being. All this is accomplished by the motion of the animalcule, for without that it could neither reach the ovum nor enter it. When dead or rigid, they cannot impregnate.

It seems probable that when the germinal vesicle is ripe, it becomes filled, in the interior, with cells, which, when it bursts, become mixed with the cells of the vitellus, and so disappear. The germinal vesicle is therefore an egg within the egg, and it is probably one of the cells of the vesicle which the animalcules enter, and not one of the ordinary cells of the vitellus. This is why the yellow of the vesicle iis often called the germ yelk, because it is the real point of origin of the new being, while the yellow of the ovum is called the food yelk, because it only supplies the nutrient material by which the new being grows. Probably the germinal dot is merely the ripest germ cell, and the one into which the animalcule enters. That the perfect new being is a product of the two principles, the male and female, there is no doubt, though a partial organism may occasionally result from one principle alone, as shown elsewhere.

When impregnation has been effected, then begins the nutrifying and growth of the embryo, some steps in the progress of which have been observed, but more in the lower animals than in the human being.

At the time when the ovum is leaving the ovary, it has somewhat the appearance shown below.

It will be seen that the cells on the outside layer or proligerous disk, as it is called, which surrounds the zona pellucida, or white, are club-shaped, their thick ends being outward, and their points all touching the surface of the ovum within. These cells remain thus, more or less, during the passage of the ovum down the Fallopian tube, and are found upon it even after it enters the womb. In other animals, however, as in the rabbit, they disappear much sooner ; ultimately they disappear entirely in all cases, so far as observed. (Figure 9\%.)

Figure 98 shows the same ovum when these outer cells are nearly all gone. 
During the passage to the womb, the ovum becomes covered with an albuminous envelope, resembling the white of a bird's egg, which is called the chorion, and which, as will be shown further on, plays quite an important part in the formation of the new being.

The first change observed in this membrane is that it becomes spongy, or covered sn the surface with minute projections, like fine moss. It is probably by these that

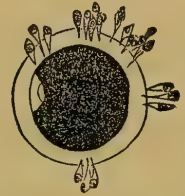

Figure 97.-Ovum from the ovary of a female dog, in heat.

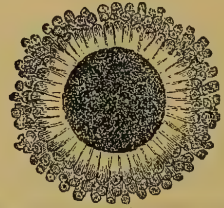

FraJRe 98.-The same ovum as in the preceding plate, showing the disappearance of the club-shaped cells.

the fluids of the Fallopian tube and womb are absorbed and made to contribute to its growth.

The womb itself also begins to change, as if it were preparing itself for the new visitor. All over the interior there gradually forms a fine membrane or lining, called the decidua, which folds inward when the ovum enters from the tube, and forms a cushion on which it lies. When there is no conception, the decidua is cast off along with the unimpregnated ovum, but when conception occurs it remains, and assists in forming the placenta, by which the child is connected with its mother.

At a later period, the decidua is found to consist of two layers, the outer one called the decidua vera, lining the interior of the uterus, and the inner one, called the decidua reflexa, covering the ovum. There are some differences of structure between these two layers in the early stages, but later on they become united so as to be indistinguishable.

The fay the ovum becomes inclosed by the decidua reflexa is well shown in the following figures :

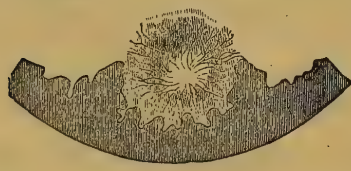

FIGURE 99.

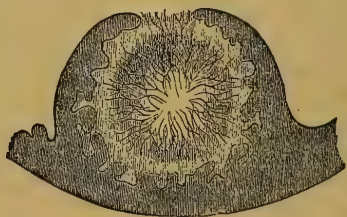

FrgURE 100

In Figure 99, the ovum is seen pressed up against the decidua vera, lining the interior of the womb ; and the decidua is beginning to push out arms around it.

Figure 100. In this illustration the two arms thrown out by the decidua vera have nearly surrounded the ovum, or have become reflected around it, thus forming the decidua reflexa.

When this stage is reached, the two deciduas are indistinguishable; the surface of the ovum, it will be seen, is quite shaggy, or covered with a hair-like growth of small vessels. These, as before explained, suck up nutriment from the surrounding fluids, and so begin the first stages of nutrition. 
At a later period, these hair-like tufts become mixed with blood-vessels, which finally predominate, and by which more complete nutrition is effected. These bloodvessels communicate with the embryo through the chorion, and with the vessels of the mother's womb by the decidua, forming finally what is called the placenta, the organ by which mother and child are united.

The manner in which the embryo receives its nutriment from the mother, varies somewhat in different viviparous animals. In the lower types, the new being, for the most part, derives its nutriment indirectly from the surrounding fluids; and even in many of the higher types, the connection between parent and offspring is not close and intimate, but occurs at a number of seattered points. In man, however, as in all the highest types, the connective ressels between mother and child are all concentrated at one point, forming a large mass, the placentc. In this organ the pure arterial blood of the mother is poured into certain cavities, from which the vessels of the fœtus absorb it, without directly connscting with the vessels of the mother. Into the same cavities also the blood of the foetus, and its refuse material, are thrown, and taken up by the veins of the mother, to be mixcd with her venous blood, and purified in her body. All animals in which this occurs are called placental, while those in which there is no such close connection, as in the marsupials, are called non-pla. cental.

It is instructive to note here that the placental connection explains how the mother may be affected, through the child, by the father. It is certain that diseases may be transmitted from father to child, through the semen, especially syphilis, and beyond doubt the child transfers these diseases to the mother, in the impure blood which it returns to her through the placenta. Many diseases thus communicated may affect the mother ever afterward, though the child may experience little or nothing of them. And not only diseases, but physical, mental, and moral impulses may thus be given by the male to the female, through the child, which may pro. foundly influence her bodily and mentally as long as she lives. This is why some women, who marry again, often have children resembling their first husband, in feature, health, bodily constitution, and mental peculiarities. In fact, a woman is probably always influenced, permanently, by every man by whom she bears a child, so that her last children, if she have several husbands, may, in one sense, belong more or less to them all. This fact has lung been known in regard to animals, though not practically acted upon to the extent it might be. In some future time the desirable qualities of many different males will thus be concentrated in the offspring of one female, to the great improvement of a race. 


\section{CHAPTER XXVII.}

\section{DEVELOPMENT OF THE NEW BEING FROM THE GERM.}

THE first beginning of the new being, so far as our observation is able to go, is a single small cell, lying in the midst of the vitellus, or yellow of the egg. It resembles a drop of albumen, or white of egg, such as might be taken up with a pin. It is, in fact, a speck of protoplasm, such as those that form the moners, and infusoria generally.

This simple cell, the germ of a future human being, in no way differs, so far as can be traced, from the cells from which all other animals, or even plants are developed. Man, in fact, has the same origin as all other living things, animal and vegetable, down to the simple green mould which spreads over a damp wall.

Even the first steps in the process of development, up to a certain point, are the same in man as in all other vertebrate animals; and it is not possible, till that point is passed, to tell whether the germ will form a fish, reptile, bird, or mammal.

The germinal vesicle, as already stated, disappears as the egg ripens, but if fecunlation occurs it is succeeded by the embryo cell, which we have already spoken of as lying in the substance of the vitellus. The first changes observed in the embryo rell are these : it divides first into two cells, then into four, eight, and so on, to an indefinite extent, and it is from these new cells, into which the original cell is multijplied, that all the different parts of the future embryo are formed.

The yelk of the egg also undergoes a similar change at the same time, dividing first into two portions, and then into four, and so on, till it forms just as many separate parts as there are new cells formed from the primary embryo cell.

Each cell absorbs to itself one of these portions of the yelk, which forms its share of the primary nutritive material ; for the purpose the yelk serves is to provide material by which the new being first begins to grow.

In the mammalia, these changes occur while the egg is passing down the Fallopian tube to the womb, and by the time it reaches there the subdivision, of both cells and yelk, has proceeded so far that the whole mass seems made up of numerous minute grains, which occupy nearly all the original space of the zona pellucida, or white.

These changes are very elearly shown below.
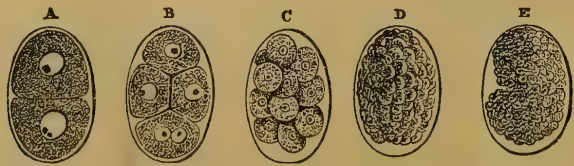

FrgURE 101.-Division of the Yelk in Eggs of Ascaris.

This shows the yelk dividing first into two, as in $\mathbf{A}$, then into four at $\mathrm{B}$, and so on up to $\mathrm{E}$ 
The next figure shows the corresponding changes of the ovum of a dog.

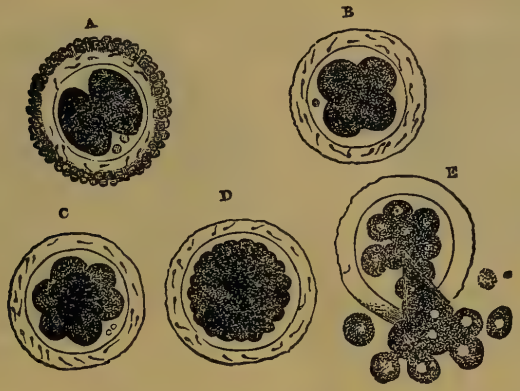

FigURE 102.-Division of the Telk in Egg of the Dog.

A, shows the ovum with the yellow first divided into two. The white contains several seminal animalcules. This is from the Fallopian tube about half an inch from the womb. B, shows the further division of the yelk into four parts, and the gradual disappearance of the outer projections. This was taken just at the entrance of the womb. c. A still later stage, with the division carried still tarther. D. An ovum from the womb. The subdivision of the yelk has now gone so far that it is a mere mass of granules. E. This represents an ovum burst, by compressing it, to show the yelk segments, each containing a transparent vesicle, or cell, in its interior.

It is not possible, for obvious reasons, to obtain the ovæ at every corresponding known stage in the human being, but we know them to undergo similar changes.

Up to this stage, the separate yelk grains, with their cells, are all loosely aggregated together, each one distinct, but with no definite investing membrane. One soon forms, however, around each, converting it into a cell, of which the yelk is the contents, and the vesicle the nucleus.

The outer layers of these cells adhere together, forming an investment for the whole, which binds them together into a globular mass.

When this process is fully completed, the interior of the mass is found to be hollow, and to contain a clear fluid. It is then called, by some physiologists, the blastodermic vesicle.

Gradually this globular mass or vesicle becomes larger, and a darker colored roundish spot is seen upon it, called the germinal area. It seems to be formed by the gathering together of a number of the original small cells which have become opaque.

The wall or outer membrane of the vesicle, called the germinai membrane, now thickens, and gradually divides into two layers, which at first seem both alike, but eventually differ very much, and fulfill very different purposes in the future develop. ment.

The outer one, called the serous layer, or sometimes the animal layer, forms the foundation of the future spinal colnmn and nervous system; the inner one, called the mucous layer, or vegetative layer, forms the foundation of the future nutritive organs. This division first begins in the germinative area, but soon extends over the whole germinal membrane. 
The germinative area, at first roundish, gradually becomes oval, and then pear. shaped, as shown below.

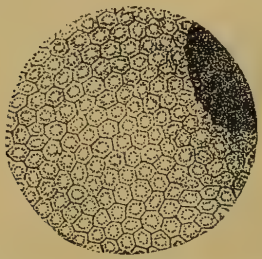

FrGURE 103.-The outer layer of cells will be seen squeezed together till they are hex. agonal, like the cells of a honeycomb. The dark spot, or germinal area is seen to the left, at the top.

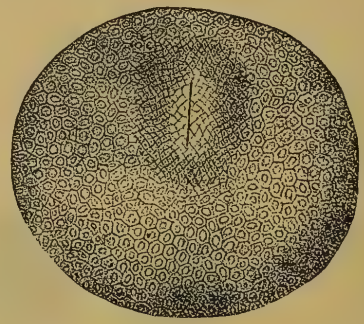

FiguRE 104.-The Blastodermic Vesicle.

In the center of the pear-shaped area, Figure 1.04, is seen a clear white space, called the area pellucida, bounded by a dark ring, which is afterward called the area vesiculosa. Down the center of the area pellucida is seen a thin dark line, called the primitive trace! which appears to be formed from the serous layer only,-this line or primitive trace, is the actual beginning of the future human being!

The outer dark pear-shaped ring, is in two portions, or separate rings, anited together, called the dorsal lamince. They play a very important part in the furthes development, as will be shown.

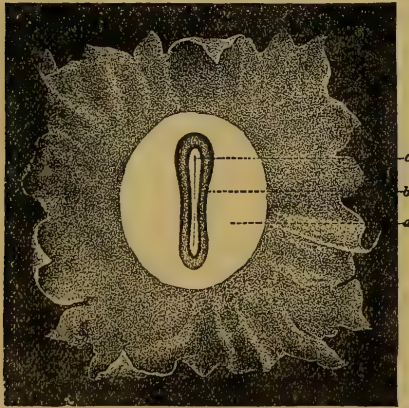

Fretae 105.-Fïrst changes in the Germinr. tive Area.

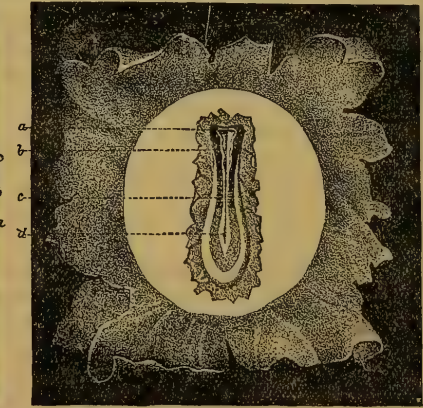

FraURe 106. - Ovum more advanced, showing the beginning of the Brain and Spinal Column.

These rings, as will be seen in the above illustration, assume finally a shape like a guitar, and gradually swell up all round, so that the shallow groove, called the primitive trace, becomes buried deeper and deeper between them. This goes on till the edges of the two rings fold over, come together, and so form a tube. At the same time the upper part of the groove (the primitive trace) divides into three separate parts or vesicles, which are the beginnings of the three principal parts of the future 
skull and brain, and the lower part of the groove becomes the future backbone and spinal marrow, as shown in Figures 105, 106.

Even at this early period a few rudimentary plates of bone, or what will become bone, may often be traced.'

In birds and fishes, the bones of the future spine are indicated by a straight cord of round cells, called the chorda dorsalis. In some of the lower fishes these never become bony, but always remain simple soft cells, like those in the human embryo.

While this is going on, an accumulation of cells takes place between the two laminæ of the germinal membrane, and gradually form themselves into the future blood-vessels. From each side of the dorsal laminæ also a prolongation is sent out, which forms what are called the two ventral laminæ, from which are formed the ribs on each side. These gradually bend over toward each other till they finally join, on the future breast-bone, and thus shut in the cavity of the chest.

The outer portions of the two layers of the germinal membrane fold over under the abdomen, so as to inclose that, and on the under surface a small groove gradually forms, which becomes the future intestinal canal.

Up to this point, the embryo has been nourished directly by the matter of the original vitellus, or yelk, with which it was in contact, but its increased size and complexity of structure now require a more perfect distribution, and a different mode of assimilation. This is effected by the formation of the blood-vessels, which are gradually evolved from the nuclei of the cells, the cavities of which have become connected. The first function of the new-formed vessels is to absorb all the nutritious matter of the yelk, and convey it to all parts of the embryo by circulation, so that each part receives what it needs. This continues till the yelk material has been entirely absorbed and appropriated. The first movement of nutritive fluid being toward the embryo from the outside, before any heart can be detected.

At quite an early period, in mammalia, the yelk sac is gradually separated from the embryo by that portion next the body becoming contracted. The connecting link, however, always remains, forming what is afterward called the umbilical vesicle.

The heart is formed from a cluster of cells, beneath the upper part of the spinal column. It begins to pulsate even before it has lost its cellular character, and becomes muscular by degrees. In the chicken, it may be distinctly perceived in $2 \%$ hours after incubation has begun. The different parts of the heart are developed successively, and the circulation is at first carried on just as it is always in fishes, the true mammalian heart coming afterward. Thus all mammalia, man included, at a certain stage, are fishes, in the circulating apparatus as well as in other respects.

The allantois in birds is the organ by which the embryo breathes, or is brought in contact with the air which comes through the shell. The human embryo, however, uses the mother's lungs, as explained elsewhere, and in it the allantois is merely the medium of connection between the embryo and the chorion, at the placenta. It is the same in all other mammalia, and in some it extends around the whole embryo. Ultimately, as the connection between mother and child becomes more direct, through the blood-vessels of the uterus and placenta, the allantois shrivels up, and almost disappears, being no longer needed. The same thing also occurs in regard to the umbilical vesicle, which disappears in the same way, excepting a small portion which develops into the urinary bladder. The duct by which it was connected with the abdomen also shrivels up in the same way, all but a small 


\section{PLATE XXI.}

\section{THE WOMB AFTER IMPREGNATION.}

Figure 1. $a$. Walls of the uterus, cut through, showing their spongy structure. b. Mucous deposit, which afterward forms the lining membrane, or decidua vera. c. Inner mouth of the womb, or os uteri internum. $d$. Mucous deposit in the neck of the uterus. e. Outer mouth of the womb, or os uteri externum, or os tince. $f$. Base of the womb, or fundus of the womb. $g$. Uterine end of the Fallopian tube.

Figure 2. Longitudinal section of the uterus. $a$. The decidua vera. $b$. The decidua reflexa, hanging like a sac in the cavity of the womb.

Figure 3. Shows the formation of the decidua reflexa, by the gradual entrance of the ovum. $a$. The ovum, pushing its way into the womb, and carrying the decidua before it. The different rings show the decidua reflexa at different stages, till it is pushea against the decidua vera. 


\section{PLATE XXI.}

Fig. 1

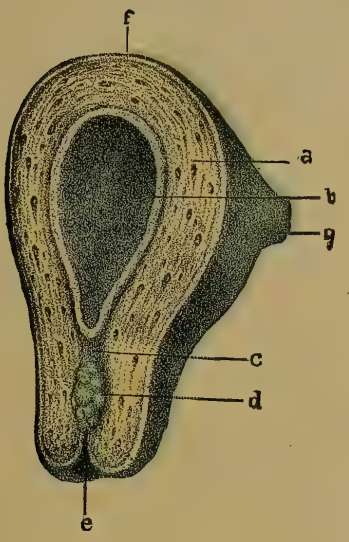

Fig. ?.

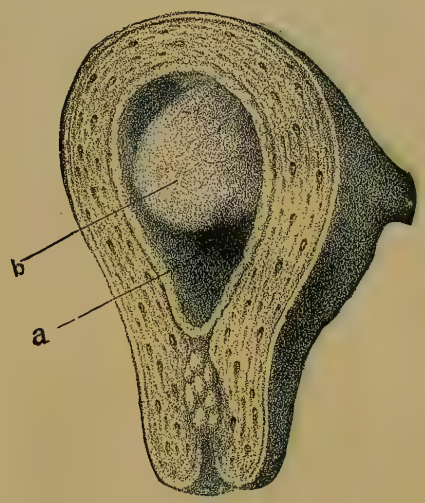

Fig. 3.

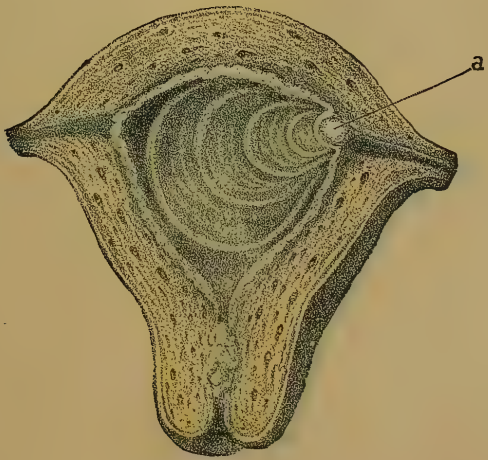

Section of the Womb. 

part, which remains and forms the ligament called the urachus, by which the bladder is suspended to the navel, or umbilicus.

The amnion contains a peculiar fluid, called the liquor amnii, which in composition is similar to the serum of the blood. The embryo floats in this liqnor, and probably absorbs it as nutriment. During the first two months, the space between the amnion and the inner membrane of the chorion is also filled with a peculiar gelatinous substance, which probably likewise assists in the nutrition, before the formation of the placenta and blood circulation.

The umbilical cord, by which the child is connected with the mother, when fully formed, is composed of a portion of the amnion, the umbilical vesicle, the vessels by which the yelk was absorbed into the embryo, the urachus, and the blood-vessels which pass from the mother to the child. At a later period, the cord is composed mainly of these bloodvessels, which in man consist of two arteries going from the mother, and one vein going from the child.

The plan of the circulation of the blood is the same in the embryos of all kinds of vertebrates, at an early period, and gradually changes in each till it attains the form peculiar to that type. In man it resembies them all in succession.

The liver, in the human being, begins to be formed about the third week, and it is from the first very large, being at the fifth week one half the weight

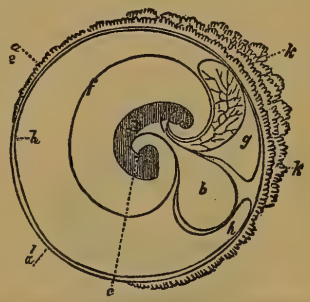

FigURE 107.-Diagram of the human Ovum at about the second month of Embryonic Life.

$a$ 1. Smooth part of the chorion, or outer membrane. $a 2$. The portion of the chorion called the villous, from the formation of numer. ous small vessels, like roots. $k k$, shows these vessels much enlarged, and beginning to collect into the mass called the placenta, through which the embryo is nourished by the mother's blood. $b$. The um. bilical vesicle, or remains of the yelk sac. c. The young embryo. $f$. The inner layer of the investing membrane, called the amnion. $g$. The allantois. $h$. The outer layer of the amnion, which unites with the chorion. of the whole embryo. About the third month it reaches nearly to the pelvis, and almost fills the abdomen. After this it begins to gradually decline, but remains very large, in proportion to the body, up to the period of birth. During foetal life, the liver appears to perform a very important part in the purification of the blood.

The lungs first appear as two buds, at the upper part of the alimentary canal, and progress very slowly, because they are not needed during foetal life.

The urinary organs present some very interesting features in the course of their development, representing, as they do in their early stages, the permanent forms of these organs in all the lower types. In the chicken, the first sign of a urinary apparatus is discernible on the third day; it is then in the form of two tubes, one extending down each side of the spinal column, from the heart downward toward the allantois. On the fourth day, there are formed, in connection with these tubes, certain bodies called the corpora Wolffiana, or Wolffian bodies. These are evidently secreting bodies, and the fluid they secrete is poured into the cloaca, or end of the large intestine. These Wolffian bodies, and certain clusters of convoluted vessels which form with them, are the only urinary organs of fishes; but in the bird they develop further, and in the higher vertebrata finally become true kidneys.

In the human embryo, the Wolffian bodies appear about the end of the first month, and about the seventh week the true kidneys begin to be seen, as if growing from 


\section{PLATE XXII.}

HUMAN EMBRYO AT A VERY EARLY PERIOD, FROM TEN DAYS UP TO THREE WEEKS, MAGNIFIED.

Figure 1. A very early stage. $a$. The area pellucida, or white of the egg. $b$. The primitive dot, or first sign of the embryo. $\quad c$. First appearance of the heart. $d$. The upper margin of the vitellus, or yelk. e. First appearance of the omphalo vessels. $f$. Area vasculosa, or space where the future blood-vessels first appear: $g$. The space which separates the white from the yolk.

Figure 2. Embryo more advanced. $a$. The primitive dot, or nota, more raised. $b$. The tail end of the embryo. $c$. The omphalo vessels. $d$. The amnion.

Figure 3. Still further advanced embryo. $a$. The head. $b$. The caudal or tail end. $c$. The omphalo vessels, much increased. $d$. The amnion.

Figure 4. A still further stage. $a$. The head. $\quad b$. The narrowing part of the yelk bag, which forms the beginning of the umbilical vesicle. $c$. The tail end.

Figure 5. Further advanced stage. $a$. Pedicle of the yelk sac. $b$. Allantois. c. Heait-like bodies, which afterward become the villosities, or nutritive root-like vessels.

Figure 6. Most advanced stage. a. pedicle of the umbilical vesicle. $b$. The allantois, extending toward the chorion. c. The villosities. 


\section{PLATE XXII}

Fig. 1

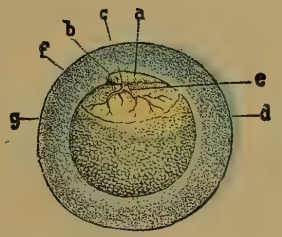

Fig. 3.

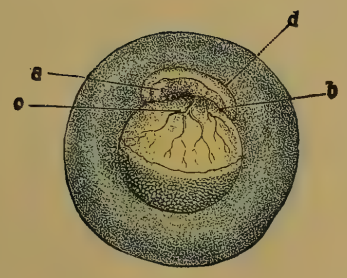

Fig. 5.

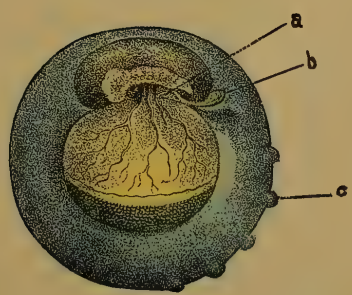

Fig. 2.

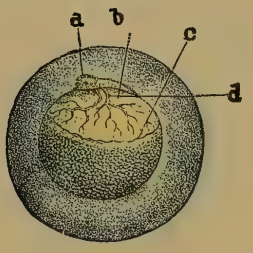

Fig. 4.

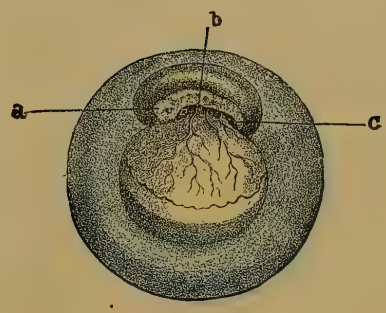

Fig. 6.

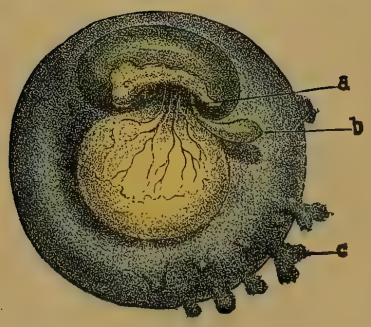

Human Embryo at a very Early Stage. 

them, though they are, in fact, independently formed. After the third month the kidneys begin to increase in size, and the Wolffian bodies decrease, and this goes on during the whole foetal period, so that we finally see the kidneys fully formed and active, while the Wolffian bodies have almost disappeared.

There are several other organs which are thus formed, and apparently used, in early embryonic life, which finally disappear, and are succeeded by the permanent ones which we find at birth. These temporary ones, as before explained, are really the permanent forms in the lower types of animals, through all of which the human being passes before it becomes fully developed.

The essential generative organs in both sexes-the female ovaries and the male testes-are both developed close by the Wolffian bodies. They are not formed from them, however, but originate independently, like the kidneys. In the chicken, the first rudiments of these organs are seen about the fourth day, and there is then nothing to indicate whether they will become testicles or ovaries. Like the kidneys, they increase as the Wolffian bodies decrease.

In the human embryo, the sexual rudiments first show themselves soon after the kidneys, or about the end of the seventh week. At first they are exactly the same in both sexes, but gradually the peculiar form of each begins to show itself. In the testes, the epididymus shows itself about the tenth week, and they begin to descend to the lower part of the body about the middle of pregnancy, reaching the abdominal ring by the seventh month, and the scrotum in the ninth. Although usually found fully descended at birth, they are not always so, but occasionally one or both is delayed for some time, or even never leaves the body. In these cases the man is often thought to have no testicles, because they are not in the scrotum, but they may be just as active as if they were there, as explained elsewhere.

In some animals, as in the ram, the testicles always remain in the body.

The female ovaries undergo much less change, from their first formation, than the male testes, both in structure and position. In fact, they remain permanently very near where they were first formed. The common canal into which, in the testes, all the seminiferous tubes empty, becomes in the female the Fallopian tube. There is, of course, one of these on each side, but they gradually grow together at the upper part, and form the uterus by their junction. The uterus is thus made up of the enlarged inner ends of the Fallopian tubes, the outer ends of which are in contact with the ovaries. The part in the male corresponding to the womb in the female, is the prostatic vesicle, called sometimes the sinus pocularis. This is connected with the ends of the vasa deferentia, leading from the testicles, just as the womb is with the Fallopian tubes. In fact, all the parts, in either sex, are represented by corresponding parts in the other sex, simply developed in a different way. Starting the same, one grows more in one direction, and the other in another, and this makes the difference of sex. The organs are the same in both, essentially, but differently dereloped.

This is strictly analogous to what we see in the vegetable world, where similar buds may form thorns, leaves, flowers, or fruits. In fact, we often see common leaves changed into flower petals, stamens into pistils, and pistils into stamens. It is merely a matter of development, the fundamental germ being the same in all.

In the human being, and all other animals, it is the same. Every part originates from some of the cells into which the primary germ cell multiplies, as explained in the beginning of this chapter, and thus all parts begin the same. Not only are the 


\section{PLATE XXIII.}

STILL MORE ADVANCED STAGES, PRECEDING THE THIRD WEEK, MAGNIFIÉD.

Figure 1. a. The chorion. B. The villosities. $c$. Amnion. d. Embryo. e. The heart. $f$. Pedicle of the umbilical vesicle. $g$. The umbilical vesicle. н. Vessels of the allantois.

Figure 2. Still more highly developed. $a$. The chorion. $b$. The villosities. $c$. The amnion. $d$. The embryo. $e$. The heart. $f$. Pedicle of the umbilical vesicle. $g$. The umbilical vesicle, much diminished in size. $h$. Vessels of the allantois, now connected with the villosities.

Figures 3 and 4 are parts of figure 2, more highly magnified. 
PLATE XXIII.
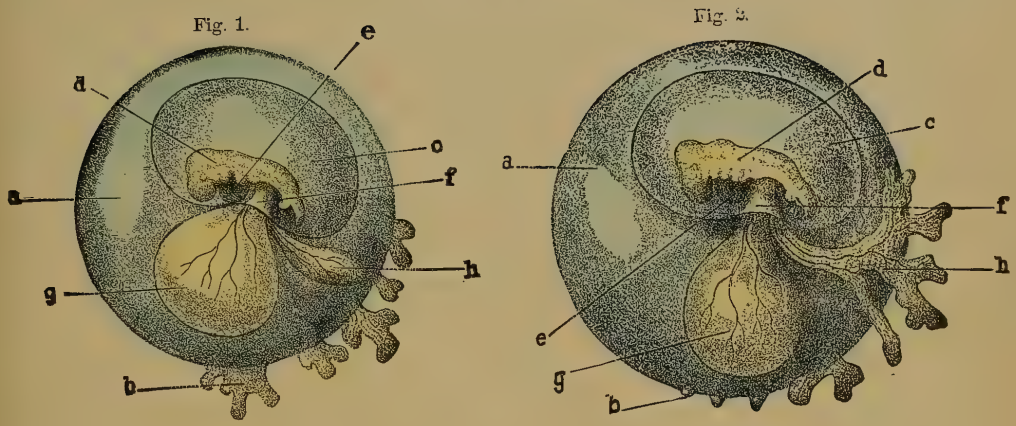

Fig. 3.

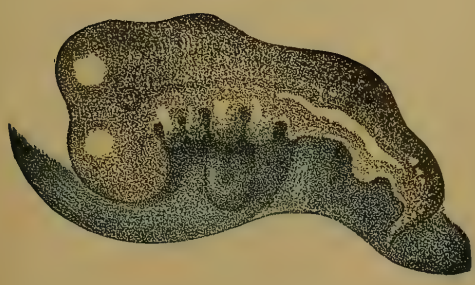

Fig. 4

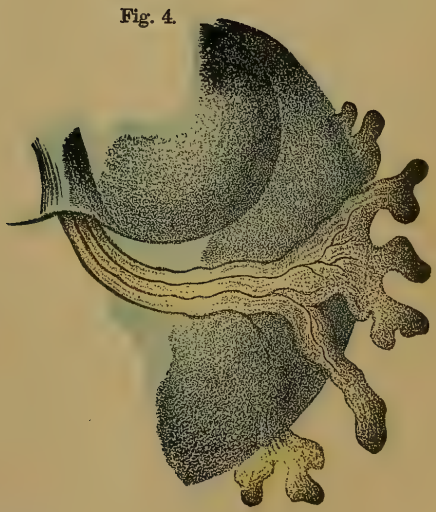

Further Developed Embryo. 

two sexes alike at first, but every part of each one is the same in the beginning, and becomes differentiated by a process of evolutionary development.

The skin, which is to surround and inclose all the organs, begins to form at a very early period, from a number of minute granules, which are developed in the original germinal membrane. These granules are, at first, seen to be always in rapid motion, like the seminal animalcules, and this continues till they are fully consolidated into the membrane called the skin. This motion is apparently essential to the proper development of the skin, which would probably be imperfect if it did not take place, and from some stoppage of it, possibly, many diseases and imperfections of the skin may be owing.

It is worthy of notice, that the same causes which arrest the motion of the seminal animalcules, have the same effect upon the skin granules. Opium, for instance, arrests them immediately, and so does alcohol! It is quite conceivable, therefore, that the use of opium, or alcohol, in excess, by the mother, at a certain stage of pregnancy, may originate skin disease in the child, even before it has well begun to be formed. And the same may be true of many other agents.

We see, therefore, that it is important to consider the welfare of the future new being, and what may be to its benefit or injury, long before it is born.

It is a very short-sighted view to suppose that our care in regard to it should begin only at birth, for its future constitution, bodily and mental, may be irrevocably influenced from the very moment of conception.

The cells, or granules, which form other parts, as well as those which form the skin, are also seen to exhibit this rapid motion, and it probably occurs in them all. It is the incipient development of life. The embryo itself, in its earliest stages, is usually seen to be in rapid motion, like the germ in many of the lower organisms, as described in the chapter on spontaneous generation.

In the development of the external organs of generation, there is much that is very interesting and instructive to observe. In the early stages, there is no distinction whatever between the two sexes, and the conformation of the organs, both in man and all the higher animals, is precisely the same as it is permanently in the oviparous vertebrates. Up to the fifth or sixth week there may be seen in the embryo, externally, the opening of a cloaca, as in birds, in which the ureters, the intestines and the sexual ducts all terminate. About the tenth week, the intestinal opening, or anus, and also the urinary and sexual canals, begin to be divided from each other by partitions forming between them, and the bladder is developed. At this stage the parts have much the same conformation as in certain birds, and in the non-placental mammals.

The external opening of the genito-urinary canal is now seen to be surrounded by two thick folds of skin, which may become either the large lips of the female vulva, or the two halves of the male scrotum. Between these two folds of skin there is also formed a kind of longish bud, of rather firm consistence, which has a gland on the end, and a furrow, or cleft, on its under surface. In the female this organ is drawn back considerably into the canal, and forms the clitoris, while the two sides of the furrow, or cleft, form the small lips, or nympha. In the male, however, it develops further, and becomes the penis, the two walls of the cleft closing over and forming the tube called the urethra, or common passage for the urine and semen.

The penis, therefore, is the same as the clitoris, only more fully developed,- the scrotum corresponds to the two large lips, and the walls of the urethra to the nymphæ. 


\section{PLATE XXIV.}

Figure 1. Human embryo of 3 weeks pregnancy; natural size. A. The embryo. B. Umbilical vesicle. $c$. Amnion. D. Chorion. E. The villosities, or root-like vessels which absorb nutriment. F. Exterior of the decidua vera, or lining membrane of the womb. G. Interior of the same.

Figure 2. The same embryo magnified. A. Rudiments of the face. B. Vesicle which becomes the front part of the brain, or cerebrum, at the lower part of which may be seen a small point, which is the beginning of the eye. c. Vesicle of the third ventricle. D. Vesicle of the corpora quadrigemina. (C., D. and E. are parts of the brain.) E. Vesicle of the medulla oblongata. F. Beginning of the walls of the abdomen. G. The heart. н. Umbilical vesicle. I. Amnion. К. The pedicle of the umbilical vesicle. L. Rudiments of the lower limbs.

Figure 3. Human embryo at the fourth week; natural size. A. The embryo. B. Umbilical cord. C. Amnion. D. Umbilical vesicle. E. Internal surface of the chorion. F. The villosities. G. The external surface of the decidua vera. H. Internal surface of the same.

Figure 4. Embryo in the fourth week, magnified. A. Vesicle of the cerebrum. в. Vesicle of third ventricle. c. Vesicle of the quadrigemina. D. Vesicle of the cerebellum (all the above are parts of the brain). E. Dorsal laminæ. F. Rudiments of the upper limbs. G. Rudiments of the lower extremities. H. The tail, or end of the spine, curved backward. I. The heart. K. Sheath of the umbilical cord. L. The amnion. м. The umbilical vesicle withering away. N. Vesicle of the medulla oblongata, or top of the spinal marrow. o. The indentation, which afterward becomes the neck, and separates the head from the trunk.

N. B. - If these plates are studied in connection with the detailed description, previously given, of each stage, both will be readily understood. 


\section{PLATE XXIV.}

Fig. 1.

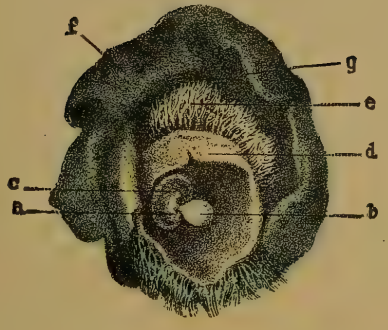

Fig. 3.

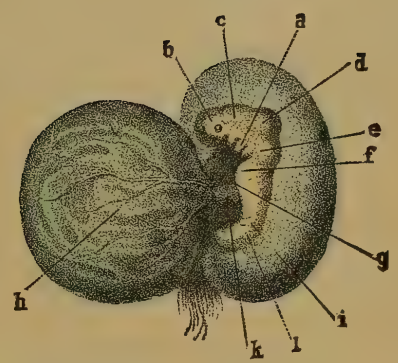

Human Embryo at Thres Weeks, Natural Size.
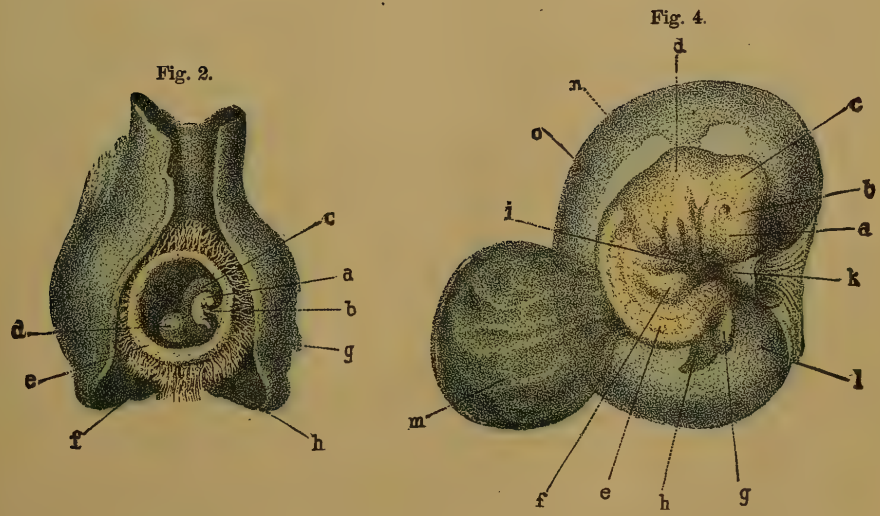

Human Embryo at Third and Fourth Weeks, Magnified and Natural Size. 

The male, in short, is merely the female in a more advanced stage of evolution, not only externally, as here shown, but also internally, as explained before.

The urethral canal, in the male, is usually completely inclosed about the fourteenth week, but sometimes it does not inclose completely at all, and then we have the malformation that will be explained further on, in which there is an opening by which the urine escapes at some other place than the end. Most cases of what are called hermaphrodites, in human beings, arise from imperfect, or abnormal development at this stage. Sometimes, in the male, the parts will remain, more or less, in the female stage, while in the female, on the contrary, some of them will advance to the male stage. Instances of both kinds, with full explanations, will be given in a subsequent article, but the following illustrations will make the matter readily understood.
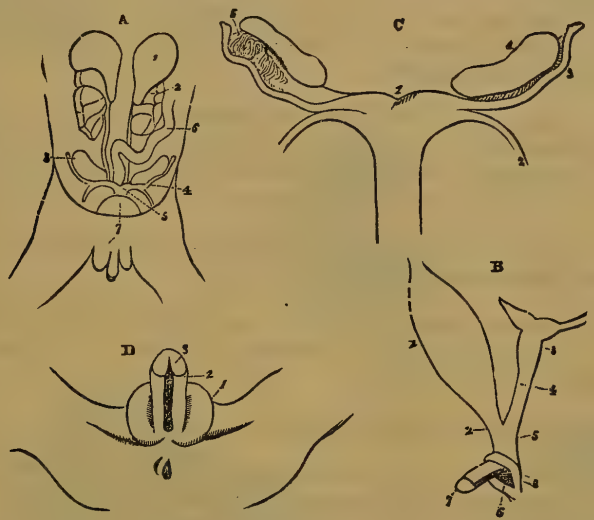

FredRe 108.-Urinary and Generative Organs of the Human Embryo, when about three and a kalf inches long.

A. General view of all the parts. -1 . The capsules on the tops of the kidneys; very large at this stage. -2. The kidneys, yet quite small. -3 . The ovary.-4. The Fallopian tube. -5 . The uterus.-6. The intestine.-7. The bladder.

B. The bladder and generative organs of the same, seen sideways.-1. The bladder.-2. The urethra.-3. Uterus, with two horns. -4 . The vagina. -5 . Part common as yet to both urethra and vagina. -6 . The common orifice for both urinary and generative organs, -7 . The clitoris.

C. Internal organs of the same. -1 . Uterus. -2 . Round ligaments. -3 . Fallopian tubes, -4 . Ovaries. -5 . The remains of the Wolffian bodies.

D. External generative organs of the same embryo.-1. The large lips.-2. The nymphæ. -3. The clitoris, with the open cleft underneath. This may either remain what it is at this period, -a female clitoris,--or it may develop further into a male penis.

This would almost certainly be taken for a male embryo, on a cursory inspection, and indeed, the correspondence of the several parts with those of a male is very striking. The clitoris (D 3) is a true penis, except that it has an open furrow underneath, instead of a closed tube; but it is readily seen how this furrow becomes a tube, by the two sides closing over, and then it is a true male organ. The large lips (D 1) only need to grow together to form a scrotum, into which the ovaries may descend and become testicles. 


\section{PLATE XX̃V.}

Figure 1. Human embryo at 5 weeks; natural size. $a$. Head of embryo. $b$. The heart. $c$. The villosities. $d$. Amnion reflected. e. Outside of the decidua vera. $f$. Outside of decidua reflexa.

Figure 2. Same embryo magnified. $a$. Rudiment of the ear. $b$. Rudiment of the shoulder-blade bone. $c$. The heart, now divided into two parts. $d$. Beginning of the arm. e. Beginning of the leg. $f$. Commencement of the back-bone. $g$. The abdomen. $h$. The lower end of the spine, or tail.

In the rudiments of the limbs, $d$. , e., the bulbs at the ends are the hand and foot, while the thinner part forms the arm, or leg.

Figure 3. Human embryo at 6 weeks; natural size. $a$. The embryo. $b$. Umbilical cord. $c$. Umbilical vesicle. $d$. Amnion. e. Chorion. $f$. Outside of decidua vera. $g$. Outside of decidua reflexa.

Figure 4. The same as figure 3 magnified.

Figure 5. Embryo at 6 weeks, magnified. $a$. The heart. $b$. The division of the ventricles. $c$. Beginning of the stomach. $d$. Rudiments of the muscles of the aidomen. $e$. The intestinal canal, beginning to contract. $f$. The os coccyx, or tail-like end of the backbone.

The gradual evolution of one part after another can now be very readily seen; and it is easy to understand how slight a thing may interfere with the development of any part, in these early stages, and so lead to deficiency, or deformity of that part. 
PLATE XXV.

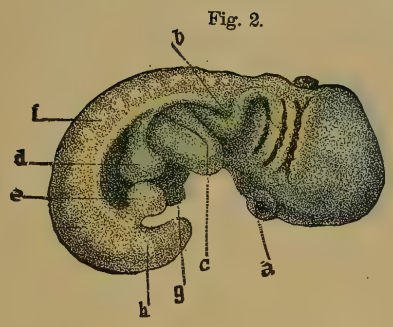

Fig. 5.

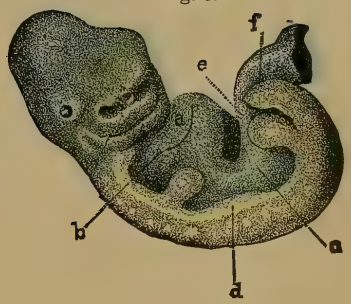

Fig. 4.

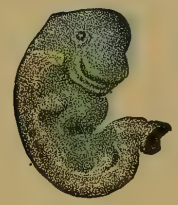

Fig. 1.

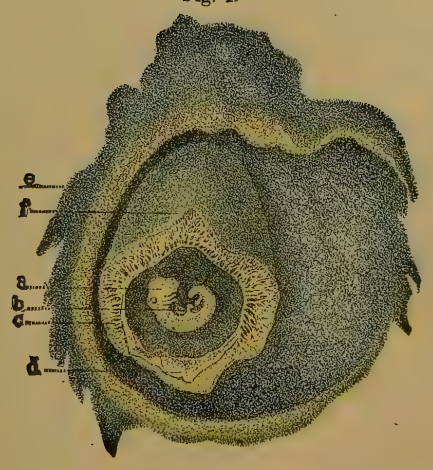

Fig. 3.

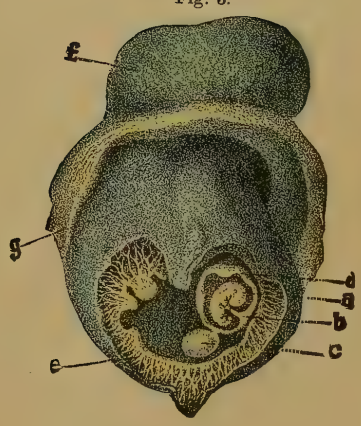

Human Embryo in the Fifth Week. 

At this stage it is really of neither one sex nor the other, but may become either male or female.

In short there is no part, in either sex, that a part corresponding to cannot be found in the other sex, but differently developed. It is not at all surprising, therefore, that irregularity of development should often occur, making an individual of doubtful, or double sex, like the so-called hermaphrodites.

It has already been remarked that the part first distinctly developed is the spinal column. At first, however, this is merely a jelly-like chain of connected cells, tapering at both ends, and inclosed in a sheath, or investing membrane, which eventually becomes fibrons. This is called the chorda dorsalis, and in man is only temporary, being succeeded by the true backbone, and spinal marrow, which are formed gradually. In the lowest vertebrates, however, such as the amphioxus, and some fishes, the spinal column never advances beyond this stage, but remains always the chorda dorsalis, as we find it in the human embryo at an early stage.

In vertebrates a little higher, a true bony spine is formed from the fibrous sheath, which gradually ossifies; but in man, and all the higher types, the bony plates are formed independently, and more perfectly. In short, the development of the spinal column becomes more perfect in each type, as we ascend in the scale, just as we see the other organs do, till in man it becomes the most perfect. It has, however, in him to go through all the stages, from the simple chorda dorsalis upward to the true spinal column.

The limbs, upper and lower, in all vertebrates, develop from leaf-like buds, which grow from the sides of the trunk, and they also go through several modifications of development. Thus, in the human embryo, the toes and fingers are at first united by a membrane, or webbed, as in the swimming animals; but the web gradually disappears as growth progresses.

In the brain, also, the gradual progress, from the lowest type to the highest, is distinctly traceable. At an early period, the human brain is almost exactly like that of a fish, so that the two are scarcely distinguishable. At a later period, it equally resembles the bird brain, and still later, that of the marsupials. It becomes truly human only after having been fish, reptile, bird, and marsupial.

The same law of development prevails with the eye, and all the other organs of sense, which in their earlier stages are not human, but like those of the lower vertebrate types.

This important fact is very suggestive, as it shows us to what a great degree, and in what way, a human being may be affected, for good or ill, before birth.

The quality of the mother's blood, and her nerrous condition, at any stage of foetal development, must exert a vast influence over the bodily development of the new being; and whatever influences it bodily, does so mentally and morally, through all its future existence. But how few human beings ever give this a thought, or rather, how few are acquainted with the fact. Dr. Combe says, "We have demonstrative evidence that a fit of passion, in a nurse, vitiates the quality of the milk to such a degree as to cause colic and indigestion, or even death, in the suckling infant. If, in the child already born, and in so far independent of the parent, the relation between the two is thus strong, is it unreasonable to suppose that it should be yet stronger, when the infant lies in its mother's womb, is nourished indirectly by its mother's blood, and is, to all intents and purposes, a part of her own body? If a sudden and powerful emotion of her own mind exerts such an influence upon her 


\section{PLATE XXVI.}

Figure 1. Head of human embryo of 5 weeks, magnified. aa. The two sides of the nostrils. $\quad b$. The lobus frontalis. $c c$. Edge of the lobus frontalis. $d d$. Lobes of the upper jaw. e. Front part of the tongue. $f$. The ear. $g g$. Lower jaw. $h h$. Arches of the palate. $i$. The line showing where the tongue was originally divided into two lobes.

Figure 2. Magnified head of embryo of 6 weeks. $a . b . a b . c$. Rings of the nose. $c c$. Lobes of the upper jaw.

Figure 3. Magnified head of embryo of 6 weeks. $a a$. Rings of the nose, nearly closed. $b b$. Rudiments of lower jaw.

Figure 4. Magnified head of embryo of 7 weeks. $a a$. Rudiments of lips, nearly united. $b b$. Right and left frontal cartilages, a beginning of the frontal bones of the skull. $c$. The frontal sinus, or open space between the frontal bones.

Figure 5. Magnified head of embryo of 8 weeks. $a a$. The two hemispheres of the brain. $b ., c . d$. Other parts of the brain and future skull bones. e. Upper part of the nose. $f$. Lachrymal canal. $g g$. Rudimentary eyelids. $h$. Point of the nose. $i i$. The cheeks. $k k$. Upper lip. $l$. Union of the upper lip. $m$. The palate. n. Thê tongue. $\quad 0$. Corner of the mouth. $p$. External ear. $q$. Throat.

The origin of many well-known deformities of the face can be easily explained from these figures. HARE LIP, for instance, is caused by the two portions ( $a a$. in figure 10) not coming together, as they are in figure 11. Cleft palate is also caused in the same way. 
rhin: itis
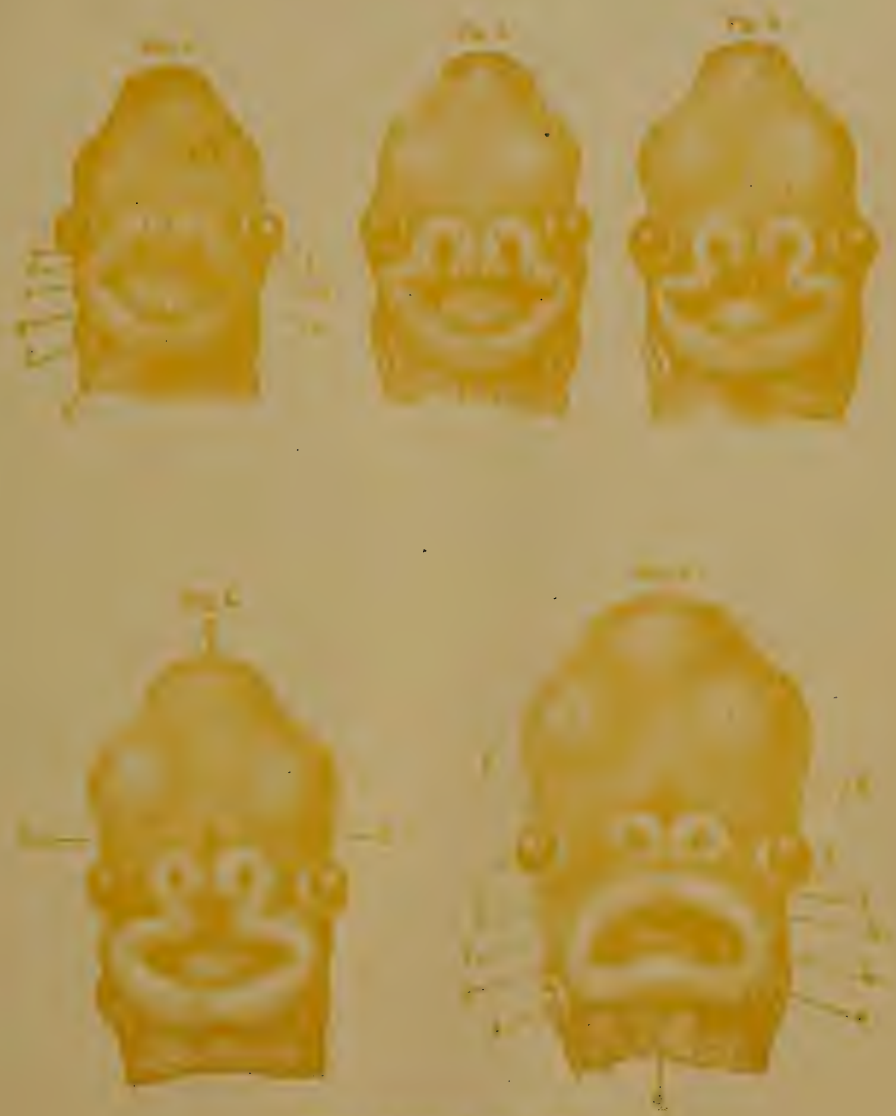

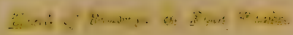



stomach as to excite immediate vomiting, and upon her heart as almost to arrest its motion and induce fainting-as we know it will - can we believe that it will have no effect on her womb and the fragile being contained within it? Facts and reason then alike demonstrate the reality of the influence, and much practical advantage would result, to both parent and child, were the conditions and extent of its operation better understood."

A striking instance of the truth of this is mentioned by Baron Percy, connected with the siege of London, in 1793 . Besides a violent and long-continued cannonade, the arsenal blew up, with fearful noise and destruction, spreading consternation all over the city.

Within a few months after the siege was over, sixty-two children were born, out of which number, Percey tells us, sixteen died at birth, thirty-three lived only eight to ten months, eight were idiots, and died before five years old, and two came into the world with fractured limbs ! So that fifty-nine out of the sixty-two, or nearly two out of every three, were actually killed by the mother's fright !

Among other instances, I know of one in which the mother, when between two and three months pregnant, was for three weeks in constant fear of her life at sea from storms. Her child, a son, in all his after life has, beyond question, been a sufferer from this continued state of fear in his mother before birth. Nervous, excitable, prone to alarm and ungovernable impulse, he has been a constant source of anxiety to his friends, and of misery to himself. Finally, he became a wretched inebriate, and for a long time had to be kept under restraint. None of her other children, developed under better influences, exhibited the slightest tendency to anything of the kind, and yet the family likeness in this son was unmistakable.

Many other such cases could be given, but it is not necessary; it being now very generally acknowledged that habitual mental conditions in the mother during gestation can, and do, influence her offspring, both bodily and mentally. And it should be remembered that the influence may be good or bad. It is just as easy to thus impart to the child a healthy mind and body, with good impulses, as the reverse; and at some future day, it will be seen that the education (or proper development) of a child must begin before birth, and not be neglected, as now, till several years after. When this truth is practically acted upon, many evils we now vainly try to cure will be prevented.

We thus see that a child, before birth, and probably in the very germ, may be permanently affected by the quality of the mother's blood, or by her mental and emotional condition. After birth, it may be equally affected by the constitution or quality of her milk, which, in the same way, is dependent upon the state of her blood and the condition of her nervous system.

We will now describe, in detail, the appearance of the embryo at various stages of its development, so that the changes it undergoes may be better understood.

At the earliest observed period. - The embryo is about as large as a pin's point, and weighs not more than a grain. The rudiments of the spinal marrow resemble a small white thread. The eyes first appear on the sides of the head, like those of quadrupeds, and move round to the front later.

Three to four weeks. - At this period the embryo has the form of a serpent, its length being from 3 to 5 lines. The head is indicated by a slight swelling, and the lower end terminates in the umbilical cord. The beginning of the mouth is seen as a small cleft or gash, and the eyes are two black dots. The limbs show like two 


\section{PLATE XXVII.}

Figure 1 Head of human embryo at 2 weeks, magnified. a. b. c. a. Parts of the brain, which is now very large, in proportion to the rest of the body, $f$. The eye. $g g$. Rudiments of the face. $h$. The heart drawn upward.

Figure 2. Head of embryo of 16 days old, magnified. $a$. Rudiments of the upper jaw. $b$. Rudiments of the tongue. $c$. Rudiments of the under jaw. $d$. Rudiments of the bone of the tongue (os hyoides). ee. Rudiments of the frontal lobe of the brain. $f f$. Rudimentary eyes. $g$. The heart, separated from the face.

Figure 3. Magnified head of embryo at end of $3 \mathrm{~d}$ week. References the same as in figure 2.

Figure 4. Niagnified head of embryo in 4th week. aa. Beginning of the upper part of the face. $b$. First beginning of the nose. c. Corner of the future mouth. d. Open cavity of the mouth. $e$. Rudiments of the tongue. $f f$. The two hemisphere of the brain. $g$. Fissure of the future lachrymal canal.

Figure 5. Head of embryo of 4 weeks, magnified. $a$. The lobus frontalis. $b b$. The two sides of the nose. $c$. Tip of the tongue. $d$. The lobus mandibularis. $e$. Rudiments of the ear. $f f$. The opening of the ear. $g$. Ring of the eyelid.

Figure 6. Magnified head of embryo of 5 weeks old. aa. Eyes, closer together. $b b$. Hemispheres of the brain. . c. Forehead. $d$. The corpora quadrigemina, a portion of the brain. e. Separation between the two hemispheres. $f$. First appearan se of the fontanel, or open space between the bones of the skull. 


pairs of small warts. The abdomen is nearly filled by the liver, and the bladder is very large. The villosities, or rootlets, by which it absorbs nutriment from the surrounding fluid, are diffused all over the surface of the chorion, or investing membrane. At 25 days it is about as large as an ant, and somewhat like it in form. At the end of the first month it is as large as a bee, and resembles a small thick worm curled up.

Six weeks. - It is from 7 to 10 lines long, and weighs from 40 to 75 grains. The face now is marked off distinct from the cranium, and the head from the chest. Little apertures are distinctly visible, indicating the mouth, nose, ears, and eyes. The arms and hands are about the middle, and the fingers may be seen; the legs and feet are near the anus. The umbilical cord, or navel string, is formed, and the placenta begins to grow.

Two months.-Length 16 to 20 lines; weight 150 to 300 grains. The elbows and arms are now separate from the trunk, and the heels and knees show plainly. The nose, lips, and eyelids begin to take form, and the anus is marked by a dark spot. The clitoris or penis is formed, and rudiments of the lungs, capsules of the kidneys, spleen, and cæcum can be made out. Bone begins to form in the front of the skull, and in the ribs. The chorion and amnion membranes begin to come together, and the placenta assumes its permanent form. The ressels of the umbilical cord now begir to twist round one another.

Three months.-Length from 2 to $2 \frac{1}{2}$ inches; weight 1 to $1 \frac{1}{2}$ ounces. Head very large; edges of the eyelids in contact; mouth closed ; fingers quite separated. The lower limbs are now larger than the rudimentary tail, which exists in the early stages before the limbs show at all. The clitoris or penis is very long; the two ventricles of the heart quite distinct; all parts of the brain much more developed. The placenta now is distinctly formed and isolated, while the umbilical vesicle and the allantois have quite disappeared.

Four months. - Now called the foetus. Length from 5 to 6 inches ; weight $2 \frac{1}{2}$ to 3 ounces. Skin tolerably firm, and rosy in color; mouth quite large and open; nails perceivable; sex indicated clearly by the form of the genital organs. The gall-bladder appears; navel at the bottom of the abdomen. Chorion and amnior perfectly united.

Five months. - Length 6 to 7 inches; weight 5 to $\%$ ounces. Head still very large, compared with the rest of the body. Hair appears; nails quite distinct. Heart and kidneys very large; germs of the second teeth appear. The meconium or fluid in the intestines becomes yellowish green.

Six months. -Length 9 to 10 inches; weight about 1 pound. Eyelids still grown together. The navel gets higher in the body; face purplish; hair white. Testes near the kidneys. Bony matter forms in the sternum, or breast bone.

Seven months.-Length 13 to 15 inches; weight 3 to 4 pounds. Skin rosy and thick. ITails not yet reach the ends of the fingers. Eyelids no longer grow together; gall-bladder contains bile. Brain firmer; testicles lower down. Middle of the body a little below the end of the breast bone.

Eight months.-Length 14 to 16 inches; weight 4 to 5 pounds. Skin covered with a sebaceous scum. Nails reach the ends of the fingers. Bone formed at many points. Brain shows convolutions. Testicles descend to the abdominal ring; middle of the body near the navel.

Nine months. -Full term. Length 17 to 21 inches; weight 5 to 9 pounds. Head 


\section{PLATE XXVIII.}

Figure 1. Human embryo at " weeks; natural size. $a$. The ear. $b$. Umbilical cord. c. Amnion. $d$. Chorion, refiected. $e$. Umbilical vesicle, now hanging only by a long pedicle. $f$. Tubes of the villous roots. $g$. Vessels of the umbilical cord, spreading on the inside of the chorion.

Figure 2. The same embryo magnified. $a$. The cerebrum, or front part of the brain. $b$. The third ventricle. c. Corpora quadrigemina. $d$. Cerebellum. . (a. $b$. $c$. $d$. are all parts of the brain.) e. The ear. $f$. The arm. g. Leg. $h$. Hand. $i$. Walls of the abdomen, now closed over. $k$. Foot.

Figure 3. Embryo at 8 weeks; natural size. a. Embryo. B. Umbilical cord c. Amnion. d. Chorion, reflected. e. Umbilical vesicle, now nearly all shrivelęl up. $f$. The villosities, or nutrifying vessels. g. Marbled appearance of the inside of the chorion.

Figure 4. The same embryo magnified. a. b. c. d. Parts of the brain $e$. The ear. $f$. Beginning of the neck. $g$. The eye. $h$. Upper arm. $i$. Elbow.

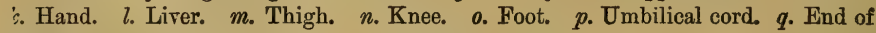
the spine, now shortening from the previous tail-like form, and rounding into the pelvis, $r$. Cavity of the mouth.

Figure 5. The same embryo seen in front. This shows how the mouth and nose begin to form, and the line $a$ shows how the two sides, or walls, of the abdomen come together, and so inclose the internal organs. This line can be eacily traced in aduls life, especially in women, and is called the linea alba. 

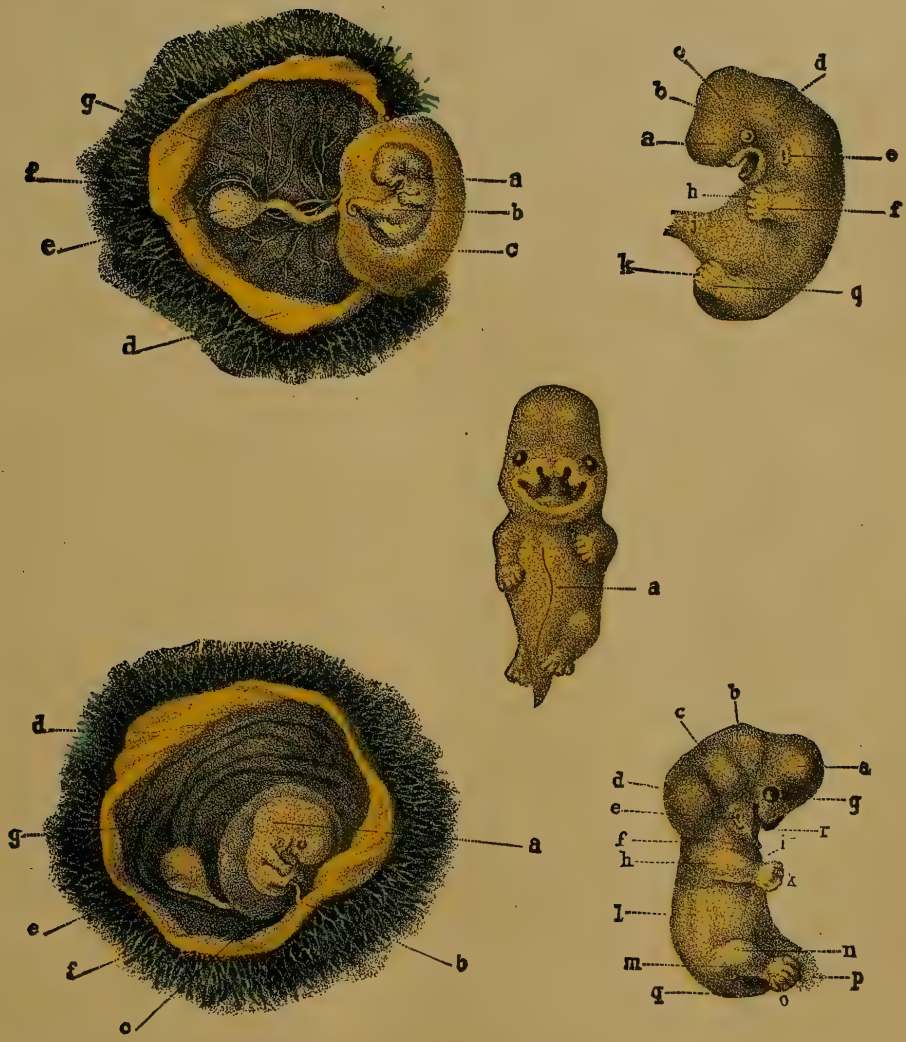

A Human Being at Various Stages. 

covered with hair. Skin thickly covered with sebaceous scum. White and gray matter of the brain become distinct. Centers of bony formation at most important points. Liver descends to the narel. Testes descend into the scrotum. Middle of the body at the navel, or sometimes a little below.

Male children are larger and heavier, at birth, on an average, than female children. Dr. Joseph Clarke puts the average of males at $7 \frac{1}{3}$ lbs. and females $6 \frac{2}{3}$ lbs. He says those that weigh less than 5 pounds at full term, seldom thrive, or-live long. Several instances are on record of children at birth weighing 15 pounds.

As a rule, more males are born than females, although in adult life females preponderate; which shows that more males perish, from various causes, before maturity. It is curious, also, that among illegitimate children the proportion of males is less than among those born in wedlock.

More male than female children are born dead, and more die during the earlier periods up to puberty. For a short time after puberty, more females die than males, but from 18 to 28, more males die than females. From 28 to 50, the deaths are most numerous among females, but after 50 the two sexes differ vory little in this respect.

The accompanying plates show the development of the embryo at its early stages, with all the accessories.

In its earliest periods it will be seen to consist of three parts : the head, heart, and trunk. The limbs and other organs do not show till later. This shows the fallacy of the idea that the human being exists from the first, in its adult form, only very minute. In the early stages, man is a mere grub, or worm, and goes on from one inferior type to another abore, and becomes a perfect man only at last.

The genital organs are the most irregular of all in their development. In some embryos, of three months, they are as much advanced as in others at four. Frequently it is difficult to distinguish the sex even at four and a half months. Up to three and a half months, the organs are the same in all, male and female, both in origin and development, so that when the different points are spoken of up to that time, they may be called either by the male or female names, but without its being understood that they are absolutely either the one or the other.

The first absolute sign of the genital organ may be distinguished about the fourth week, with close observation; but the exact period at which the divergence begins which makes the future being male or female, we do not know.

It is obvious, however, from the above explanation, that the male is a further stage of development than the female, of the same parts, and in a different direction. The most essential organs in the female, the ovaries, are internal, and the corresponding organs in the male, the testicles, are external! the womb is also internal, and the corresponding part in the male, the prostatic vesicle, is external, so that the male resembles the female turned inside out as it were.

This sexual difference is accompanied by other bodily differences, so that woman, as a rule, does not develop like a man. She is not inferior, in the vulgar meaning of the term, but she is not the same, and is adapted to a totally different sphere of life. Neither can with advantage take the place of the other. 


\section{PLATE XXIX.}

THIS PLATE IS INTENDED TO SHOW ALL THE PARTS REFERRED TO IN THE PRECFD. ING PLATES ON A MORE PERFECT SCALE; PROPERLY PLACED AND CONNECTED.

a. The embryo.

b. Amnion.

c. The umbilical cord.

d. Choroid space.

e. Pedicle of the ambilical vesicle.

f. The umbilical vesicle.

g. The villosities surrounding the outside of the chorion.

h. The decidua vera.

i. Decidua reflexa.

k. Part of the decidua terminating in the uterine end of the Fallopian tube:

l. Mucous secretion in the os uteri.

$m$. Wall of the uterus.

nn. The ends of the Fallopian tubes.

The womb in this plate is supposed to be cut through, lengthways. 


\section{PLATE XXIX.}

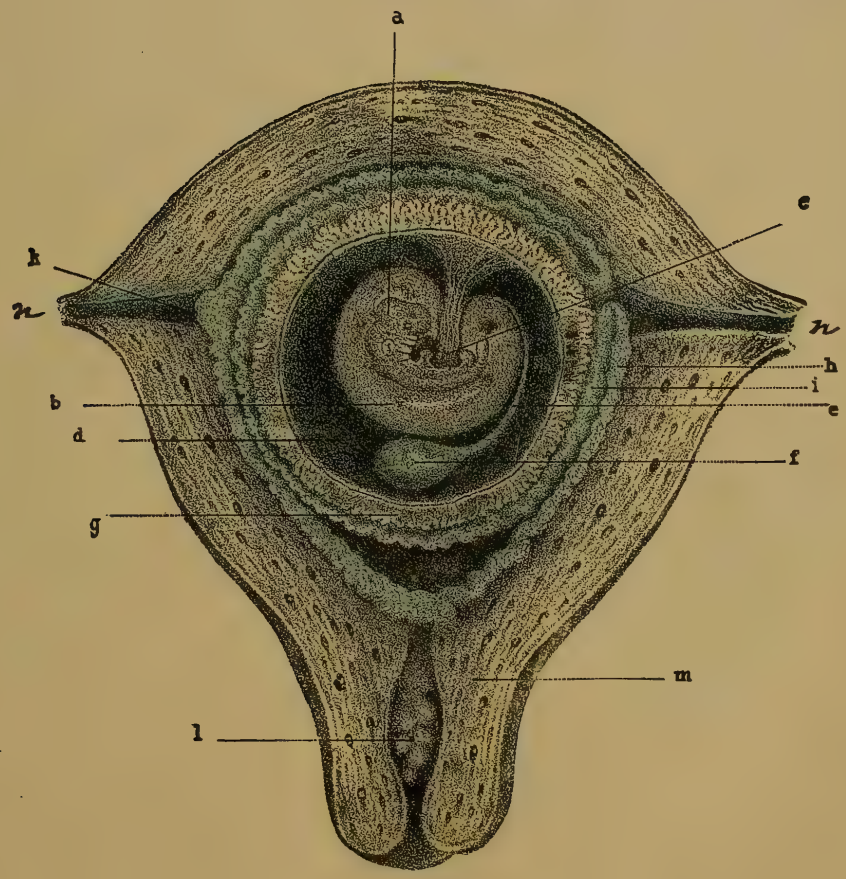

Section of Impregnated Womb 



\title{
CHAPTER XXVIII。
}

\author{
FETAL NUTRITION.
}

THE manner in which the new being derives its nutriment, or the material by which it grows, is, in a great measure, unknown to us, though we certainly obtain some informatiou about it by a study of the apparatus employed in the process.

For the first fifteen or twenty days the substance called the vitellus, which is analogous to the yelk of the ordinary egg, appears to supply most of the material that is required in the formation of the new being, if not all; and, indeed, this substance does not totally disappear till after the third month, though we cannot suppose it to be the sole source of nutriment then. It is also supposed, by some, that the amniotic liquor, in which the fotus floats, may afford some nutriment, either by being swallowed, or by being absorbed through the skin. It is certain that this fluid is nutritive, and there is nothing impossible in its absorption, though it is not very likely to occur to a sufficient extent. The idea that it can be swallowed, however, is erroneous, because the mouth of the foetus is firmly closed while in the womb; and besides, children have been born alive without mouths, and even without heads, and of course they could not have swallowed anything. It is now generally conceded by physiologists that the material required by the foetus, for its nutrition, is obtained from the blood of the mother, through the medium of the placenta, and the ressels in the umbilical cord. It is, however, a matter of dispute whether the maternal blood is sent directly, in its ordinary state, into the body of the child, or whether it first undergoes a preparatory process, which most modern authors suppose it does.

From the earliest period of gestation, the middle membrane, called the chorion, is covered, on its outer surface, with a number of small protuberances called villosities, which subsequently become true blood-vessels. About the fourth month these have increased very much in size and number, and have all become conglomerated into one mass, in form like a mushroom. This is called the placenta. It is almost entirely formed of blood-ressels, which seem to attach themselves at one end, by open mouths, to the open mouths of other blood-vessels on the inner walls of the uterus. At the other end these vessels are drawn together and lengthened out into a long tube called the umbilical cord, or navel string, which finally enters, the body of the child at the navel, and so establishes the connection between it and the mother.

The blood-vessels in the placenta, umbilicus, and fotus, like those in the maternal body, are of two kinds, arteries and veins. The arteries, which come from the left side of the heart, carry the pure blood, which contains all the materials for forming and nourishing every part of the system. The veins contain the blood in its impure state, and take it to the right side of the heart, from whence it is forced into the lungs to be purified by the act of breathing. The blood is made impure by some of its constituents being absorbed, to form the different parts of the body, and by having thrown into it a quantity of waste and poisonous matter no longer needed. 


\section{PLATE XXX. \\ DEVELOPMENT OF THE GENITAL ORGANS.}

Figure 1. Genital organs of an embryo, 8 weeks old, magnified. $a$. The external lips. $b$. Clitoris. $c$. Central cleft. $d$. The coceyx.

Figure 2. The same at 9 weeks. $a$. External lips. $b$. Clitoris. $c$. Central cleft. $d$. Anus. ee. The nymphæ. $f$. The coccyx.

Figure 3. The same at 10 weeks, magnified. $a$. The glans. $b$. The furrow, caused by the bending of the glans. $c$. External lips. $d$. The central cleft, contracted at its lower part. $e$. The anus.

Figure 4. The same at 11 weeks, magnified. This shows the perineum perfectly formed, at $a$, so that the anus and the genito-urinary passage are now separated.

Figure 5. Genital organs of a male embryo at 3 months, natural size.

Figure 6. Genital organs of a female embryo at 3 months, natural size.

Figure \%. Genital organs of male at 3 months, magnified. aa. The scrotum. $b$. The raphe, which divides the scrotum into two parts. $c$. The penis. $d$. The glans penis. $e$. The central cleft now nearly closed. $f$. The anus. $g$. The os coccyx. $h$. The perineum, or space between the genitals and anus.

Figure 8. Female genital organs at 3 months, magnified. $a a$. The nymphæ. b. The cleft, more widely open, instead of being closed, as in the male. $c$. The clitoris, corresponding to the male penis. $d$. Lower end of the nymphæ. e. Perineum. $f$. The anus. $g$. The os coccyx. $h h$. Large lips. $i$. The mons veneris. 
1 1 41
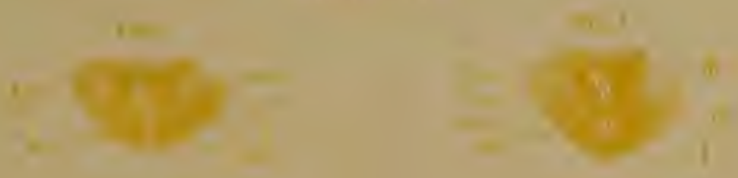

\section{$+2$}
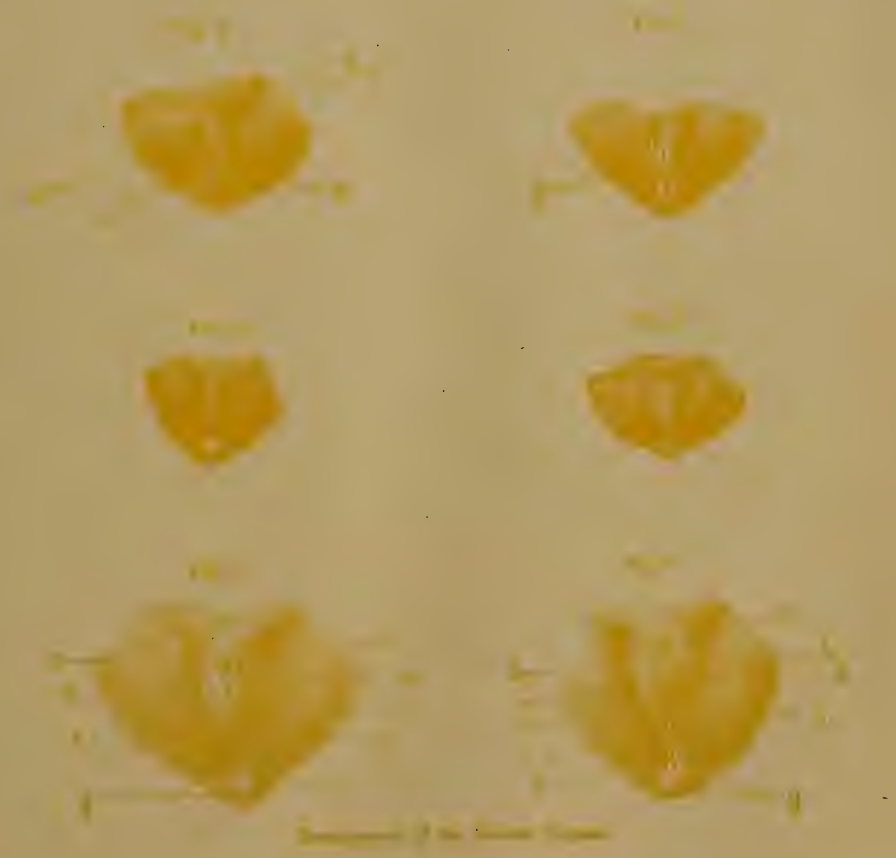

The course of the blood, therefore, is from the left side of the mother's heart along her arteries till it reaches the arteries of the uterus, from thence it passes into those of the placenta, and thence into those of the umbilicus which convey it into the body of the child. When there it circulates in its arteries, supplies the material for its further increase and development, becomes in consequence impure, and passes into its veins, the same as in the maternal body. From these veins it passes into those of the umbilicus and placenta, and, apparently, into those of the mother, by which it is conveyed to the right side of her heart, and by its action to her lungs, to be again purified when she breathes. This explains what was previously stated, that the child uses the mother's heart, lungs, and stomach while in the womb, and has, therefore, no occasion to use its own.

The diameter of the placenta is about six inches, and its thickness about one inch and a half. The length of the umbilical cord is from eighteen to twenty-four inches, its diameter about half an inch. These dimensions are, however, subject to great variation. Instances are mentioned of the cord being five feet long, and as thick as the child's arm. I have seen one myself four feet long. Sometimes it will be very short, not more than eight or ten inches. It is composed of one artery and two veins, twisted together like the strands of a cable, and a sheath surrounding them composed of the chorion and amnion. Between the sheath and the vessels is a thick gelatinous fluid called the gelatine of Wharton.

This explanation, it must be remembered, is in fact merely hypothetical. The direct passage of the blood through the placenta, from the mother's vessels into those of the cord, is denied by many physiologists, who contend that there is an intermediate set of vessels in the placenta, in which it first undergoes important changes. They also contend that the impure blood does not pass through into the mother's veins at all, but is purified in the placenta, and immediately returned. Some have even averred that the placenta is not required at all, to supply nourishment, but is merely a purifying organ. It is now known, however, that it is not absolutely essential to either process, for children have been born alive, and perfectly formed, which merely floated loosely in the amniotic liquor, having neither placenta nor cord, nor any other connection with the mother. How they were nourished we cannot tell. These, however, must be regarded merely as curious exceptions, there being little doubt but that foetal nutrition is ordinarily effected through the placenta and cord, by means of the mother's blood, somewhat in the manner we have described.

\section{PECULIARITIES OF THE FETAL CIRCULATION.}

From the circumstance of the foetus not using its heart and lungs, like the adult, its circulation has several modifications.

The engine by which the blood is forced along its vessels is the heart! This is divided into two distinct parts, each of which has two cavities, the upper one called the auricle, and the lower one the ventricle, which communicate with each other by curious valves. In the adult, the whole of the impure blood is poured into the right auricle, that from the lower part of the body by the inferior vena cava, and that from the upper part by the superior vena cava. From the right auricle it passes into the right ventricle, which pumps it into the lungs, by way of the pulmonary artery ; here it is purified by the act of respiration, and then brought, when pure, by the pulmonary veins, into the left auricle, and passes from thence into the left ventricle, which 


\section{PLATE XXXI.}

THE PLACENTA AND UMBILICAL CORD, SHOWING THEIR CONNECTION WITH THE FETUS.

A. The placenta. D. The foetus. B. The umbilical cord. On the under surface of the placenta, $A$, the ramifications of the blue reins and the red arteries are plainly shown, and their continuation into the twisted vessels of the umbilical cord, $B$, which at the navel, c, enter the body of the child. From the navel they are continued up the interior of the body to the heart, F. E. The liver.

Length of the umbilical cord, or navel string, from one foot and a half to two feet. It apparently has no nerves, for the child shows no sign of pain when it is cut.

The placenta usually weighs about a pound, but sometimes considerably more. When there are two or more children, each one has its own placenta, though they occasionally coalesce together.

The placenta, cord, and membranes, form what is called the after-birth, because they eome away after the child. (See Frontispiece.) 


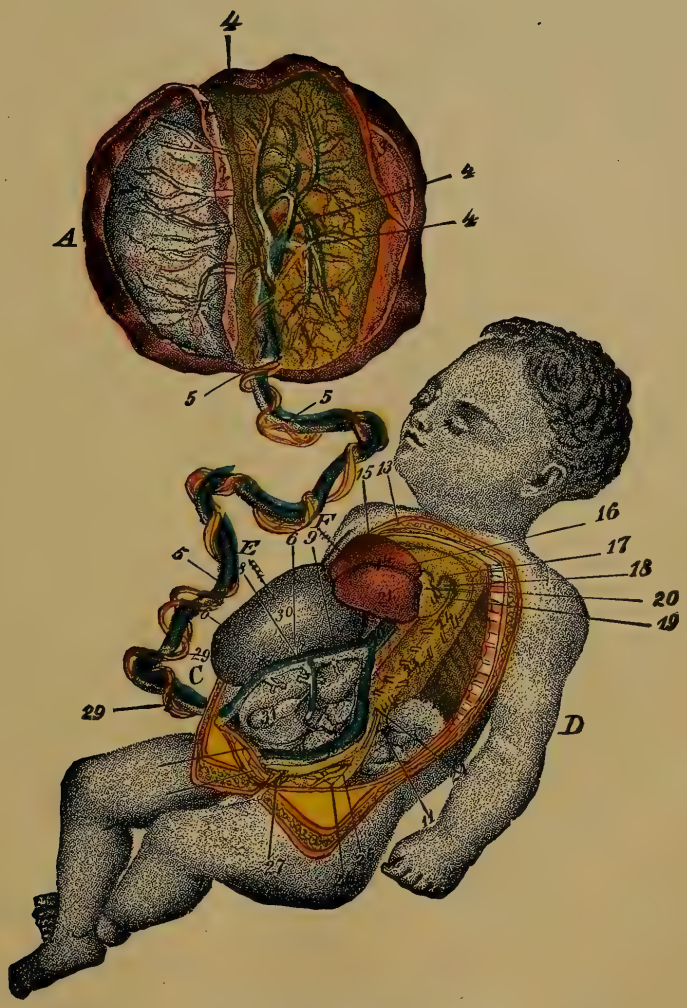

The Foetus with its Appendages. 

pumps it into the great aorta, and from thence into the smaller arteries all over the body.

The two sides of the heart, therefore, do not communicate directly with each other, but there is a strong partition between them. In the fotus, the arterial blood from the mother, when it leaves the umbilical artery, enters first the liver, runs through its vessels, gives off the bile found in it, and then joins the vena cava inferior. By this passage it is taken into the right auricle, along with the impure blood of the vena cava. From the right auricle it passes through a hole in the partition directly into the left auricle, instead of taking the indirect route by the lungs as in the adult. From the left auricle it passes into the left ventricle, and is from thence distributed by the arteries all orer the body. This opening in the partition is called the foramen ovale!

After birth, when the blood begins to pass through the lungs, this passage closes up. By the eighth day it is generally obliterated, often much sooner, though occasionally it has remained open longer without inconvenience. In some cases the foramen ovale does not close at all. The child has then what is called the blue disease! The whole body is of a uniform leaden, or blue color, and the whole systen. is generally languid and sluggish. The blue color is caused by the dark blood of the veins mixing with that of the arteries. These children mostly die early, but some live to be five or six years old, and one I saw twelve, but this is rare. No remedy can be had for this affliction, and I have never known it to cure spontaneously. Some children are so very dark for a few days after birth as to cause great alarm., This is owing to the foramen ovale being very open and closing slowly. No apprehension need be experienced in such cases, as they soon come right.

The impure blood from the upper part of the fœtal body, which is brought down by the superior vena cava, also enters the right auricle, but does not pass from thence through the foramen, like that from the inferior vena cava. By a peculiar arrangement this blood is made to pass down into the right ventricle, and from thence along the pulmonary artery, the same as in the adult state. Only a very small portion, however, passes into the lungs, the great part being taken along a tube called the ductus arteriosus into the great artery called the aorta, where it begins to turn down to the lower part of the body. In consequence of this, the arterial blood going down to the lower part of the body is mixed with this portion of impure, venous blood, brought by the ductus arteriosus from the superior vena cava; while that going to the head, and upper part of the body remains pure. And this is the reason why the lower part is always so much smaller than the upper part, previous to birth ; it receives less pure nourishment. The head and chest appear, at an early period, almost as large as the rest of the body.

This circumstance also explains why, in the great majority of cases, the right arm is preferred to the left, and has more real power. The place where the ductus arteriosus pours the impure blood into the aorta, is almost immediately opposite to where the artery is given off which feeds the left arm. In consequence of which, in most cases, a small portion of this impure blood becomes mixed with the arterial blood, and the left arm is, therefore, in the same situation as the lower limbs, and like them is comparatively imperfectly developed. The right arm is not liable to any such deprivation. In some cases the insertion of the ductus arteriosus is lower down, so that no such mixture occurs. Both arms are then equal, and this accounts for the fact that in some persons there is no difference. In some cases, no doubt, 
zarly habit may overcome this natural inferiority, and even give the preference to the left arm; but such instances are rare.

The ductus arteriosus closes up about the same time as the foramen ovale.

The two veins which convey the impure blood back to the mother, to be purified, originate from the iliac artery, pass up the sides of the bladder toward the navel, enter the sheath of the cord, and so reach the placenta. They are obliterated about the third or fourth day after birth, and assume the form of a cord.

The real source of all the blood in the body of the child is a mystery; it would certainly appear most likely for the whole of it to be derived from the mother, but there are many circumstances which make it probable that the child may form some itself, by digesting the fluid it is supposed to absorb. This view is supported by the fact that there is found in its bowels at birth, and even before, a greenish substance like excrement, called meconium. This has every appearance of being the product of digestion, though some suppose it to be derived from the liver. It occasionaily contains hair, and other anomalous substances.

The most recent investigations in regard to fœtal nutrition show that the connection between mother and child is established in the following manner: In the walls of the womb there are formed, during gestation, certain cavities, called sinuses, into which the curling arteries of the womb pour blood. The tufts of foetal vessels in the placenta dip into these cavities, like roots dipping into water, and absorb the blood as needed. The mother, therefore, supplies the blood to the fœetus, but its blood-vessels and hers are not continuous one with another. This is shown in the following cut :

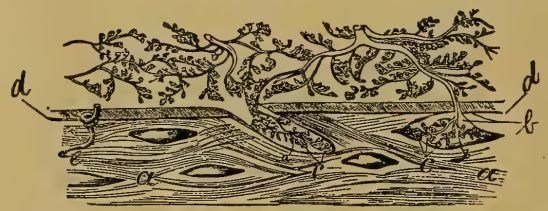

FIGURE 109.-Connection between the Womb and Placenta.

b. One of the cavities, or sinuses, into which the fœtal blood-vessels are seen to dip. Another is shown further along. $c c$. Are the fœtal vessels, dipping into the sinuses. $d d$. The decidua, lining the inside of the womb. e. One of the uterine curling arteries which pour the blood into the sinuses. 


\section{CHAPTER XXIX.}

\section{EXTRA-UTERINE CONCEPTION, AND UNNATURAL OR MONSTROUS GROWTHS.}

IT sometimes happens that a foetus is formed outside of the womb, either on the ovary, in the tube, or in some part of the abdomen, as among the intestines, for instance. These are called extra-uterine conceptions, and their origin has always been a mystery. It was long thought that such cases proved the old doctrine of conception, which supposed that the semen was conveyed to the ovary, and impregnated the egg there, otherwise, said its advocates, how could the foetus ever be found outside the womb, if conception takes place inside?

The true cause of an extra-uterine conception is this : Any sudden and violent emotion, as a fright, for instance, will sometimes reverse the action of the Fallopian tubes, so that they will convey anything from the womb toward the ovaries, or contrary to their usual course, so that if an egg should have passed down near the womb, but not have quite left the tube, it might be taken back again during this reverse action. Now, according to our previous explanation, it will be seen that the egg may be impregnated, in some cases, while in the uterine end of the tube, because the semen occasionally penetrates so far ; and it is therefore possible that an egg so impregnated may be conveyed to the other end of the tube, or even out of it completely, by this reverse action. It is not necessary for the development of the egg that it should be in the womb, but, on the contrary, it will develop in any part, if it can attach itself to some blood-vessel, though it will never form into a perfect human being except inside the womb. In these cases, therefore, when the egg after impregnation is taken to the other end of the tube, or to the outside, it is possible for it to grow in this way, though imperfectly, and thus form an extra-uterine conception. I have two beautiful models representing actual cases of this kind. It may even be taken, by the motion of the body, after it becomes loose, to various parts of the pelvic or abdominal cavities, where it will attach itself and develop in the same manner. In other cases it has been known to imbed itself in the walls of the womb, and develop there.

Several instances of extra-uterine conception have come under my notice, and I have bestowed considerable attention upon them. Sometimes the development will be indefinite, having no resemblance to a human being; while at others it will be tolerably perfect, and attain a large size, as large in some instances as a fœtus of five months. It is usually, however, a monstrosity, imperfect in some par. ticular. The placenta and cord are found, as in the inter-uterine conception, as also the amnion and chorion, but only occasionally a membrane analogous to the decidua, this being properly a product of the uterus alone. The expulsion of these products cannot, of course, be effected in the ordinary way; they have either to be removed by an operation, which is rarely resorted to, or else left to nature, in which case they may terminate in various ways. Some authors say they will occasionally 
be absorbed, and so disappear. More generally, however, labor pains come on at the ordinary time, decay commences, an abscess is formed, and the remains of the fotus work through the opening. If she does not immediately succumb, the wound may then heal, and the woman perfectly recover her health. Cases of this kind have often been met with. I remember one in which all the parts did not come away under six months; the head was nearly perfect. Sometimes the pains will return every nine months, for a long time, before decay commences. In other cases, instead of decaying, the fœetus, with its appendages, will become callous, and form into a hard tumor, which may remain during the individual's life, without causing serious results. I saw a lady very recently who had carried one of these tumors for nine years! And I assisted at the dissection of another in whom it had cxisted for thirtecn years. It was as large as the head, and fixed on the right side of the abdomen, apparently just underneath the skin. These accidents, though scrious, aro not necessarily always fatal. Females have been known to suffer from them ceveral times in succession, though sometimes the next conception will be perfectly natural. Very generally, however, the first case is followed by barrenness.

\section{FORMATION OF ONE CHILD WITHIN ANOTHER.}

Fœtal development will sometimes occur under more extraordinary circumstances even than those already mentioned. One footus may be contained within another. A case of this kind occurred at Verneuil, in France, in the year 1804, in a child named Bissien, who differed in no external particular from other children, but always complained of something being the matter in his left side. A small tumor appeared there early, but the development of his body and mind went on as usual, and nothing particular was noticed till he was thirteen years of age. The tumor then suddenly increased in size, he began to pass from his body a quantity of putrid matter mixed with long hair ; fever set in, and he died when about fourteen. Upon making a post-mortem examination, there was found between the intestines and spine the remains of a fœtus. The teeth, nails, hair and bones, were not like those of a mere infant, but evidently indicated that the inclosed foetus was as old as the one in whom it was formed! Such cases are extremely rare, and I believe this was the first that was properly observed or explained. Singular as it may appear, it can be readily explained, if the description we have given of the process and organs of generation be borne in mind.

In all such cases there have been two eggs impregnated, as in a case of twins, but only one has developed into a child while in the womb, and the other has become inclosed within its body. The egg thus inclosed may retain its vitality, but not develop for an indefinite period, perhaps not till many years after that child is born, and very likely there are many cases in which it never does. There is nothing more ext:aordinary in its development, however, when it does take place under such circumstances, than there is in extra-uterine conception in the mother's body, because the conditions are the same. The most wonderful circumstance is that the egg should remain so long dormant, and still be able to grow after such a lapse of time.

I have met with several cases of included fotuses in dissecting animals, and a physiological friend informed me that he once found one in a man of thirty, which was so perfect that he could perceive it to be of the male sex. This man was, there fore, really pregnant with his own twin brother. 
As a proof of our explanation of the causes of extra-uterine footuses, it may be stated that, in every such case when its history could be traced, a fright or other accident had been experienced about the period of conception. It is a singular fact, also, that the most of such cases have been from illicit intercourse, in which females, of course, are often liable to the fear of discovery and exposure, and to be disturbed.

The most convincing proof, however, that extra-uterine conception is owing to fright, or disturbing violence, has been obtained by experiment upon animals. It has been found that a blow upon the head, if it be given about the time of concepjon, will nearly always cause an extra-uterine development. It is dangerous, there'ore, for association ever to be practiced when any disturbance may be experienced immediately after. If conception has already taken place, such violence or fright may materially affect the development of the new being, by suspending the vital power for a time. Thus a celebrated physiologist gave a female dog a violent blow on the head, at the time of conception, so that she was partially paralyzed for some days, and when she brought forth her young, all of them, except one, either had no hind legs, or were deformed, or puny and weak. In another similar experiment, four deformed young ones were born and three others were formed extra-uterine. The four eggs had therefore evidently reached the womb at the time of impregnation, while the other three were at the uterine end of the tube, which, having its action reversed, took them to the outside.

All our ideas connected with the development and birth of man, are so associated with the maternal womb that it sounds strangely unnatural to speak of children being formed in any other part of the body. Still, it is a fact that they sometimes are, as already shown; nor will this seem so mysterious and wonderful when the true nature of foetal development is borne in mind.

The female germ cell, or ovum, receives such an electrifying influence from the accession of the male sperm cell, in fecundation, that it will develop anywhere if it have the requisite conditions of warmth, moisture and nutriment in an available form.

It is true all these conditions are found best in the womb, and the new being can also find its way, from there, into the world with safety to itself and the mother. An impregnated egg, however, will form a child in the ovary, the Fallopian tube, in the walls of the womb, or in the abdomen itself, among the intestines-in fact, almost anywhere in the body where accident may convey it.

In very ancient works such cases are recorded, but their nature not being known, all kinds of theories were adopted in regard to them. It was only when the human female anatomy and physiology were practically studied by competent observers that they could be understood.

It is somewhat remarkable that the womb, even when the child has no connection with it, is still affected by the impregnation. It enlarges, becomes engorged with blood, the neck clogs up with mucus, and a deciduous membrane forms to line its interior. It is, therefore, evidently in sympathy with what is going on, though not directly concerned in it.

Sometimes the ovum, in these extra-uterine cases, arrives at full maturity, dies, putrefies, and by causing inflammation, makes a passage for itself, by which the remains escape. Sometimes it passes away in fragments by the bowels; at other times by an abscess, on the outside of the abdomen. Occasionally, it works its way into the vagina, and still more rarely into the bladder. 


\section{PLATE XXXII.}

EXTRA-UTERINE CONCEPTION-OVARIAN.

This represents a remarkable case of extra-uterine conception, in which the child was formed in the ovary itself. There was, of course, no connection with the womb, nor were there the usual membranes, but a confused placental mass connects the child with the cavity in the ovary in which it was formed.

A. The amnion. B. The chorion. cCc. The placenta. DDD. Fragments of the corpus luteum. EEE. Covering of the ovarium. F. The Fallopian tube. G. The omentum or membrane covering the intestines. 


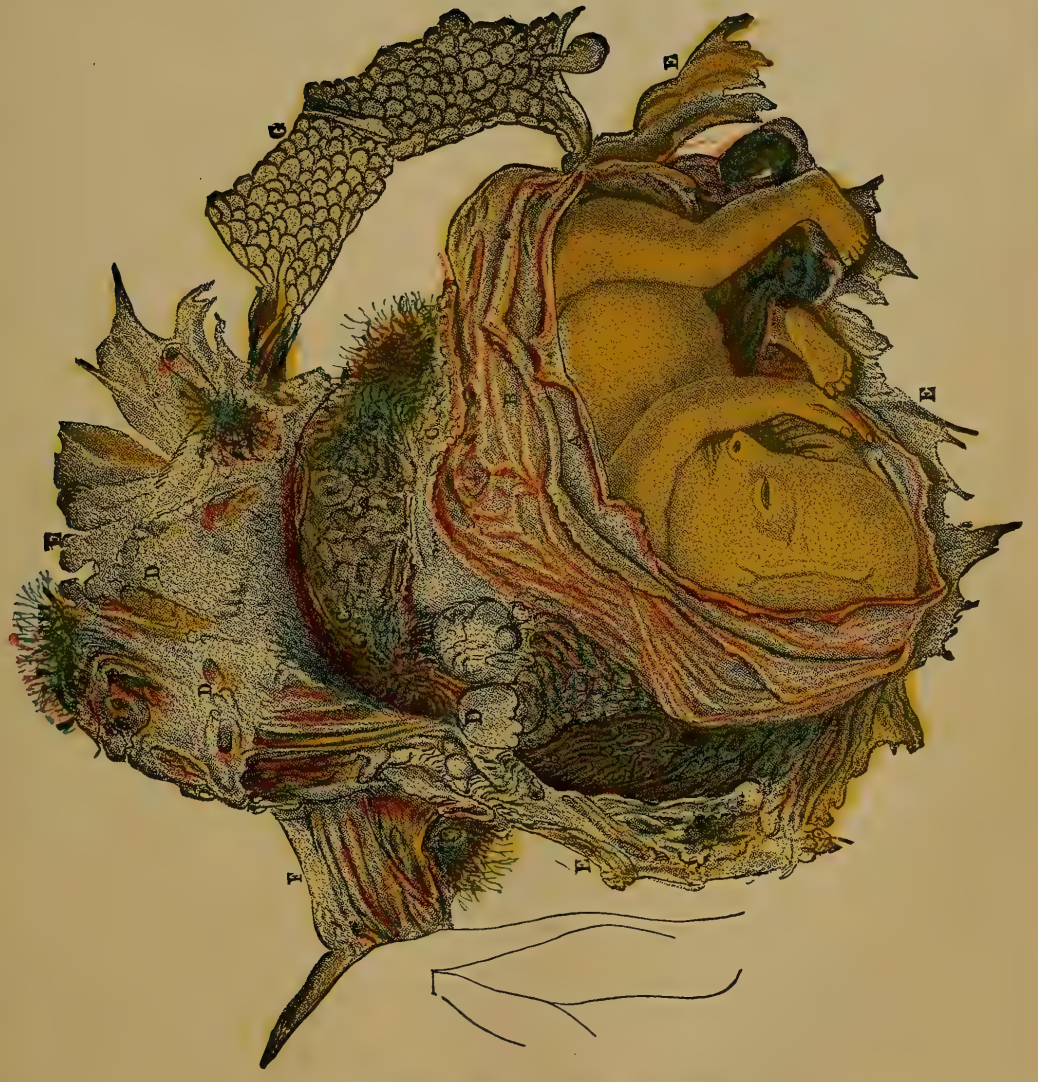

A Remarkahle Case of Ovarian Fecundation. 

In other cases, instead of decaying, it passes into a substance like adipocere (waxy), and simply makes a tumor, which may remain during the female's life without causing serious trouble. Women have had these extra-nterine tumors so altered, and have afterward borne children in the natural way while they still remained. In the year 1828, a woman was received into the fever hospital, in Cork Street, Dublin, who had a remarkable enlargement of the abdomen. She stated that eight years before she had been in labor two days, but was never delivered. Two years after she conceived again, and went her full time, as she also did on two other subsequent occasions. Finally, an abscess formed near the navel, and from that the original child was expelled, which had been conceived eight years before. It was twenty-two inches long, remarkably well preserved, and had two feet of the umbilical cord attached to it.

A still more remarkable instance was related to the Academy of Medicine, in September, 1833. The body of an old woman of seventy-eight was brought into the Anatomical Theatre, Geneva, in whose pelvis was discovered a tumor, connected with the bladder, uterus and vagina, but not communicating with them. On cutting this open, it was found to contain a fœtus, three months old, crusted over with phosphate of lime. She was the mother of three children, and died of old age. From her history, it was supposed she had carried this foetus for upward of thirty years.

An instance is even recorded where a woman had two extra-uterine foetuses at the same time. She conceived, went the full period, had some labor pains, which subsided, and finally relapsed into her usual condition of health, and menstruated regularly; a hard tumor, however, remained on the right side of the umbilicus. Three years afterward she again conceived, and the same thing occurred, labor pains ceasing, and a hard tumor remaining - this time on the right side.

Subsequently, the first tumor became tender, inflamed, and an abscess opened, from which was extruded a quantity of pus and foetal bones. Two months afterward, the other tumor was opened artificially, and similar remains were expelled. Both openings healed up, and the patient returned to her usual state of health.

In these cases, the fotus never lives beyond the full period of gestation, nine months, and usually dies before then. When this occurs, the uterus contracts, with labor pains, and the decidua is expelled, with loss of blood, the same as in true labor.

When the conception is in the tube or ovary, it nearly always dies before the full term ; the sac then bursts, and the contents escape into the cavity of the abdomen, causing inflammation, hemorrhage, and death.

In a few still rarer cases, the fœtus forms perfectly, and at the full period is extracted alive artificially. In such cases, it has been found as well developed as one from the womb itself. Wherever it may be, a placenta, with cord, usually forms, which attaches itself to some neighboring part, and by which nutrition is effected. The development may occur, however, without this, as some of the cases prove.

In numerous cases, the foetus has been removed by the surgeon after its death, and often to the saving of the woman's life, although the operation is necessarily a dangerous one. Much, however, depends upon the position of the tumor, and the place where the opening has to be made.

In twelve cases recorded by Ramsbotham, four of the women died from the sac bursting into the abdomen, causing hemorrhage. Three died from ulceration conze. 
quent upon nature's effort to expel it. Four recovered, two getting rid of the foetus by way of the intestines, one by an operation, and one by its forming a permanent tumor. In the remaining one, nature had made no effort at removal in any way.

In one case, a woman of 84 was found with an extra-uterine fœetus, which she had carried forty-eight years. Others at thirty and twenty years have also been seen, and one extreme case of fifty-two years, in which the foetus weighed eight pounds.

When the conception is in the Fallopian tube, it is seldom carried over two months, and when in the ovary not more than five or six months, but when in the abdomen, it may be carried for an indefinite period, as the above cases prove.

It is remarkable that many of these women, thus carrying children within them for a large portion of their lives, in an unnatural condition, yet enjoyed good health, and even became mothers in the meantime in the natural way.

As to the causes of extra-uterine conception, we are much in the dark. Almost all of the cases have occurred in women who had previously borne children in the natural way, so that it would not seem to result from any defect in formation. Many physiologists ascribe it to fright or shock, either at the time when the egg leares the ovary, or at the time of impregnation, as before stated.

Baudelocque tells us of 'one case, in which a woman, while with her lover, was frightened by some one trying to enter the room; she had extra-uterine conception. In another case, the woman, under similar circumstances, was alarmed by a stone being thrown through the window, and the same result followed. It is worthy of remark also that more such cases occur in unmarried women than in married onespossibly from irregular indulgence or fear of its consequences.

Certain experiments have seemed to prove that fright during impregnation may cause extra-uterine conception in animals. It is, however, very rare among them, probably because they are not so subject to emotional terror at such times.

It is my opinion that the condition of both parents at the time of conception, bodily, mental, and moral, is of great consequence to the future child, and that it should be much more considered than it is, along with the condition of the mother during gestation and nursing afterward. It is quite possible that the influences which operate, for good or for evil, upon a child before birth are more powerful than all that can be brought to bear upon it after birth.

\section{FALSE CONCEPTIONS.}

A variety of abnormal productions are found in the uterus, called moles and false conceptions, which are different from those not connected with impregnation, such as tumors, polypi, etc. The mole of generation is an abnormal development of the impregnated orum. It has various forms, but most frequently resembles a mere shapeless mass of flesh, inclosed in an envelope full of fluid. On carefully dissecting this substance, we can usually discover some traces of the fotal structure; at other times we find nothing but the bag of fluid. Sometimes the production will remain attached to the mother by a kind of cord and placenta, and develop into a shapeless monstrosity; at others it will be entirely disconnected. These growths probably originate from a blighted ovum, which retains sufficient life merely to develop, but not to organize. I have known them to attain a large size, and some females to have many of them in succession. What causes moles we do not know, nor can we always distinguish one from a natural pregnancy. Occasionally they assume the most fantastic shapes, and resemble the most incongruous objects. It is this circumstance, no doubt, which 
gave rise to the statements we sometimes hear and read of in old works, of women bringing forth animals, plants, etc. ! I have seen some moles myself which could be easily mistaken for such things by persons who did not attentively examine them, and whose imaginations were a little lively. A kind of imperfect animalcule, called the hydatid, is also found in the uterus. It merely resembles a bag of jelly, and floats in a fluid. Its size raries from that of a pea to a chestnut. Sometimes only one is found, at others a number. When removed from the fluid in which they live, and put in warm water, they will often move, which shows them to be alive. Similas beings are formed in the liver and kidneys. (See article on the tapeworm.)

\section{DEFORMITIES AND MONSTROSITIES.}

Monstrosities. These anomalous productions, called also lusus naturce, are of various kinds. They may either have more parts than natural, or less, or unnatural parts. Sometimes there is a confusion of parts only. Thus we sometimes have a fotus with two heads, or an additional number of hands or feet. And sometimes we have them with only one leg or arm. Then again we see others with supernumerary parts that resemble no member in particular. And at other times we find some of the parts transposed, particularly the viscera. The causes of these accidents are not well understood. An opinion prevails very generally that they are altogether owing to some personal violence, or strong mental emotion experienced by the mother dur. ing pregnancy. Thus fright, sudden joy, or the sight of any disagreeable object are thought to be able to produce them. In many cases this opinion is probably correct, so far as the mere fact is concerned, but some very absurd notions are entertained as to the manner in which these causes operate. I shall, therefore, endeavor to give a scientific explanation.

A deficiency of any part, or an imperfect development of it, is evidently caused oy something disturbing the vital process, and depriving that particular part of its power of growth, either permanently or for a time ; but what those causes are it is impossible to tell. Sometimes the toes, or the fingers, or some of the limbs become imperfect in this way, and sometimes the heart, or some other internal organ, and children have even been born with no heads.

The disturbing cause may either operate from the first, and then there is no trace of the part, or it may operate at a later period, and then the part is merely smaller and more imperfect than the others. Thus sometimes we see one arm or one leg only half as large as its fellow, and sometimes the whole body is dwarfish and the head large. At other times the roof of the mouth is imperfect, or an eye, or the ear, so as to cause congenital deafness and blindness, and sometimes the upper lip is imperfect, causing hare-lip.

There is no foundation, however, for the notion that these deficiencies are always caused by frights or fancies, or that the mother can produce them by injuring her. self in the same part, or by merely placing her hands on it, as many suppose. In many such cases there is no doubt, if the truth could have been known, that the deficiency existed before the fright was experienced; but people are apt to suppose that it must have been caused by the fright, merely because it followed after it.

Sometimes when there are two ova impregnated, instead of both forming perfectly, as in twins, or one being included within the other, as in the case of the boy Bissien, they will become so intermixed as to be grafted, as it were, one upon the other, or grow together. The parts where they touch, then, do not form, and these 
only develop certain portions of the different fœtuses connected together. In this way are produced those monstrosities that we see with two heads, two bodies, or many arms, or legs. If there should be more than two ova join together, of course the confusion of parts would be greater, and the monster still more unnatural.

Two perfect twins are also liable to grow together, if they touch, and so become connected in any part. Thus some have been found joined at the back, others at the stomach, and some by the side, like the Siamese Twins, between whom there was a ligament.

Most of these monstrosities are probably caused by some disturbing agency at the time of conception, or during pregnancy ; but monsters may also result from imperfect eggs, as before explained, and also from imperfect or deformed animalcules.

They may originate with the male, therefore, as well as with the female, and I have known a man who had three deformed children by one wife, and two by another, owing to imperfect animalcules, as I proved by observing them.

It is certain, however, that cases occur sometimes that may well excuse the common belief, especially as people generally are not in the habit of properly connecting cause and effect. Thus a pregnant mother has seen a man who had lost his arm, and her child when born has been similarly deficient. No doubt, however, other pregnant women might have been worse affected by the sight, and yet have had perfect children, and probably she would have had the one-armed child just the same if the man had not been seen by her. It is more likely that her child's arm was not formed at the time of her fright, from some other cause, for if it were, we must suppose that the fright destroyed it, and then comes the question how or in what way was it carried off?

In Fleming's Zoology a remarkable instance is given of a cat, who was much terrified, while with young, by having her tail severely trodden upon, and who brought forth, at the usual time, five kittens, only one of which was perfect, all the others having their tails distorted in a singular manner, and all alike. This, however, was from real bodily injury, affecting the vital power, and not from imagination.

It is quite conceivable that the condition of any part of the mother's body, at any particylar period of pregnancy, may influence the corresponding part in the new being she carries in her womb, and affect its development. Especially if any violence be done to any part of the mother, so as to arrest its growth, or cause an abnormal condition of it, we should expect that the same part in the child would in some way be similarly affected.

Thus in the case of the kittens, above referred to, the normal condition of the tail, in the mother, was suddenly and violently changed, and apparently the same part in all her kittens suffered a similar change.

In case of a slight injury, or one the effects of which soon pass away, no such result may follow, but if the hurt be severe, and its effects lasting, it may be otherwise.

In all such cases it seems necessary there should be nervous shock, as well as bodily hurt, for it is only through nervous agency that we can conceive of the mother affecting the child in her womb,-except through blood poisoning, and that would affect the whole system equally.

Pregnant women are constantly subject to unfarorable influences, which affect their children in many unsuspected ways ; and at no period of their lives do they need more watchful care and attention, nor miore entire freedom from all injurious conditions. The formation of the child's head especially, may be readily affected by the 
bodily and mental condition of the mother during pregnancy, and the possible consequences of this may be seen from the following facts:

The British Medical Journal presents, at some length, the results arrived at by Prof. Benedict, in his examination of the brains of criminals-some sixteen in all. Every one of these, on comparison with the healthy brain, proved to be abnormal. Not only, too, has he found that these brains deviate from the normal type, and approach that of lower animals, but he has been able to classify them, and with them the skulls in which they were contained, in three categories. First, absence of symmetry between the two halves of the brain; second, an obliquity of the interior part of the brain or skull-in fact, a continuation upward of what is usually termed a sloping forehead ; third, a distinct lessening of the posterior cerebral lobes, so that, as in the lower animals, they are not large enough to hide the cerebellum. In all these peculiarities, the criminal's brain and skull are distinctly of a lower type than those of normal men.

Now, that these abnormal conditions may often result from influences acting upon the mother, during pregnancy, is scarcely a matter of doubt, and thus a child may be made a criminal before its birth ; or in other words, a moral monstrosity.

REMARKABLE CASE OF A FETAL MONSTROSITY.

The case represented in the following cut is one recorded a short time ago in the London Lancet. It was the mother's thirteenth pregnancy, and her previous children had been quite perfect. She had received no fright of any kind, nor had she been subject to any unusual longings.

It will be observed that the upper part of the body and the head are quite perfect, but that from below the chest and the middle of the back, all is imperfect, displaced, and deformed.

About a month previous to her confinement, she had a slight flooding, which, however, increased, and every day more and more blood was lost, up to the time of delivery. This, however, could not have caused the monstrosity entirely, because it is evident the deformity must have existed before the eighth month, and was doubtless the result of some abnormal direction of the nerves and blood-vessels. The deficient nutrition of the parts, however, owing to the loss of blood by the flooding, may have made the case much worse.

In all cases of deficisncy of any part, there is always an absence of the nerves and blood-vessels of that part, and in all cases of wrong position or deformity the blood-vessels and nerves are wrongly directed, or turned from their usual course. In the same way, if we tie a ligament round the bark of a tree, so as to compress the sap-vessels, the tree will bulge out at that part, or be deformed, and if we

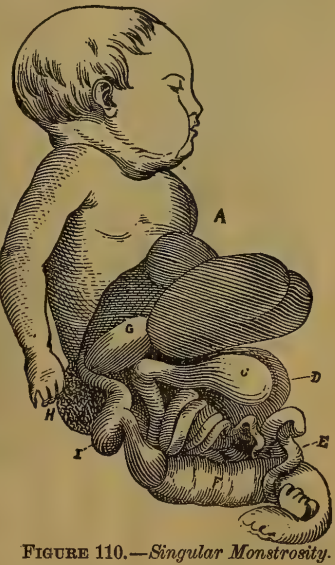

A. The heart. - B. The liver. - C. The stomach.-D. The spleen,-E. small intestines.-F. The large intestines.G. H. The kidneys.-I. The ureter.

The feet and legs are conjoined, only the toes being separate. cut through the sap-vessels entirely, the parts above will die, or be deficient. 


\section{MONSTROSITY.-DEFICIENCY OF PARTS.}

Of all the irregularities of montrosity, instances in which there exist a deficiency of parts are most commonly met with ; and this deficiency may exist in many organs. Among those that can be brought under the examination of the eye, the mouth and lips are perhaps most frequently the seat of this abnormal development. Sometimes there is a simple fissure in the upper lip, forming the single hare-lip; at other times there is a double fissure, and a want of a greater or less portion of the palate ; sometimes, again, the palate is faulty, while the lips are perfect. Not unfrequently, also, there is some imperfection in the genitals. The interior part of the bladder and the parietes of the abdomen, just above the pubes, have been found wanting; so also has a portion of the muscles and integuments round the navel. In the former case, the mucous lining of the bladder is continuous at its circumference with the skin, and forms a soft, red, sensitive protuberance in the pubic region; the ossa pubes do not meet, and the recti muscles are separated to some extent. Such an extensive malformation could not exist without disturbing the arrangement of the genital organs. In the latter, the intestines in the neighborhood of the

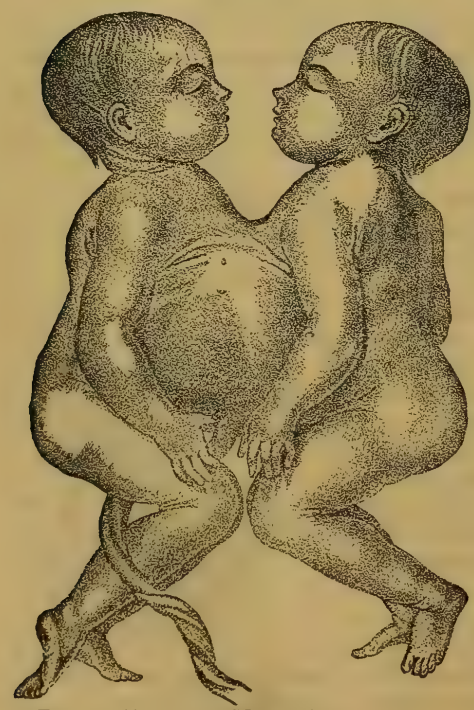

FrguRe 111. - Double Monstrosity united at the Sternum. umbilicus appear to have no covering but the peritoneum, and the chorion and amnion continued from the placenta. Often a large portion of the bowels is received into the cord itself ; and cases are on record in which the whole contents, both of the abdomen and chest, were without any covering or skin. The septum between the ventricles of the heart, and occasionally the diaphragm, have been deficient or imperfect. Sometimes one or both arms, at others, the legs, are scarcely formed at all; and when this is the case, Nature seems to make up for the deficiency by granting an extra growth to other parts ; thus, in a foetus preserved in the London Hospital Museum, the head and trunk are nearly twice the natural size, while the arms and legs are not more than three inches long. A want of the spinous processes of three or four contiguous vertebræ, is not a very uncommon species of monstrosity. This constitutes spina bifida. There is usually a soft fluctuating tumor in the situation of the malformed bones, caused by water contained within the sheath of the spinal marrow. A midwife, under my superintendence, delivered a woman, a few years since, of twins, each laboring under spina bifida situated low in the lumbar vertebræ. 
But the most interesting and singular variety of deficient organization is the acephalous monster (that is, literally, brainless). In this there is a total want of the bones at the sides and upper part of the cranium, as well as of the brain and the membranes ordinarily covering it. The base of the skull is ill shaped, and covered by a membrane continuous with the integuments. There is no forehead, but the skull runs backward from the superciliary ridge. Sometimes, under the membrane at the base of the skull, there is a quantity of soft pulpy matter; but more frequently the spinal marrow commences, as it were, abruptly. The preparations of the acephaloid foetus (which have been multiplied ad infinitum, and specimens of which may be found in every museum), prove that the case is by no means very rare; and they show also that the brain is not essential to our being while in utero; for many of these children have arrived at the full intra-uterine size-nay, some are actually larger than an ordinary fœetus; as if nature had intended to compensate for the loss of the brain by allowing an exuberant growth to the body. In these instances the nerves are well formed, and even those of the senses which ordinarily terminate in the cerebral mass itself, such as the optic, are not wanting. Acephaloid children have been known to live some hours, and even days. I myself saw one alive thirty-six hours after its birth, which cried (though feebly), sucked, and seemed to perform all the animal functions much more perfectly than could have been supposed. The spinal marrow has been found wanting in some cases, when the brain was deficient. There is a woman now living in Double X Place, Globe Road, Mile End, who has had six children, and each alternate one has been acephalous, the others healthy, and born living. It has been observed by her attendant, that with each of the monstrous fotuses there has been an excessive quantity of liquor amnii, not so, however, with the others. Many explanations have been offered to account for the origin of the acephaloid foetus. Professor Rudolphi, of Berlin, indeed has proved, by a collection of specimens, that it originates in hydrocephalus; and the last fact that I have mentioned would seem to bear out this view of the question ; for I have myself frequently observed that

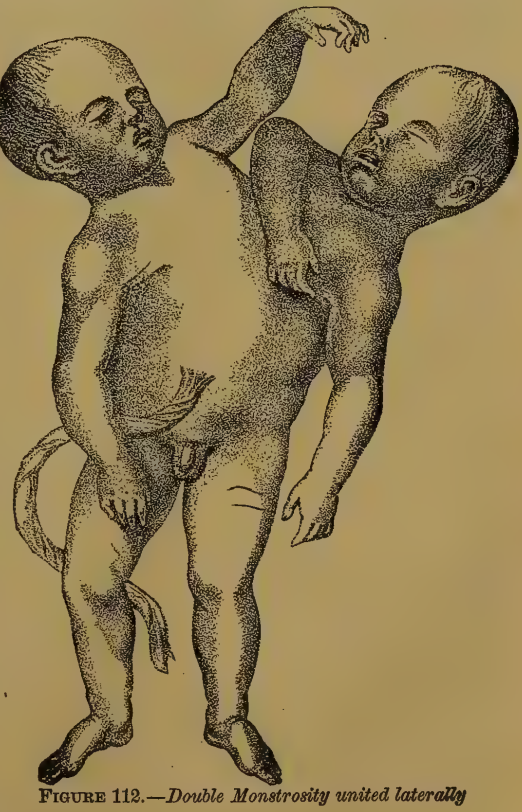
when the foetus is dropsical, there is an excessive quantity of liquor amnii. My 
friend, Dr. Mackenzie, of Glasgow, writes to me, "When visiting the Anatomical Museum at Berlin, in 181\%, Professor Rudolphi pointed out to my attention a series of preparations explanatory of the formation of acephali. Embryonic hydrocephalus is the cause. He showed me an embryon, on the upper part of whose head was a vesicle ready to burst-a second, in whom the envelopes of the brain had burst, the pieces floating round the basis of the skull-and a third, in whom these floating remnants were partly gone, thus verging on the common acephalus, as we find it when born after nine months intra-uterine life."

\section{REDUNDANCY OF PARTS.}

Organs are not unfrequently redundant : thus occasionally there are supernumerary thumbs, fingers or toes; such an irregularity being sometimes confined to one limb, sometimes affecting all. 'It is evidently both erroneous and unjust to call a child a monster, merely because it possesses a toe or a finger more than the natural number; for the very word conveys a horrible, or at least an unpleasant, impression. It is worth remark, that this deviation from natural formation sometimes runs in families. Meckel (Pathol. Anatomy, vol. i., p. 19) has observed this ; there is a curious case of the same kind in the fourteenth volume of the Medical Gazette, p. 65 ; and two similar instances have come under my own eye. In the year 1831, two children were brought to my house, twin boys, of a fortnight old, one of them with a supernumerary finger and toe on each hand and foot, the other with only one extra finger on the right hand; the toes had apparently well-formed joints, by which they were connected to the metatarsal bones; the fingers merely hung by a pellicle of skin. T saw the mother afterwards, and found she had a supernumerary finger and toe on each hand and foot, with perfect joints, and capable of motion. She told me she had borne twenty-one children-that all the girls but one were born with extra fingers and toes; but only one of the boys, besides the twins, was affected in the same manner. She also said her mother and one of her sisters were the subjects of the same kind of irregularity. The other case much resembled this.

Sometimes a larger and more important member than a finger or toe is supernumerary. Thus Sir E. Home has described, in the 80th volume of The Philosophical Transactions, an Indian child which had two heads, united together at their crowns -the upper one being inverted. The subject died of the bite of a rattle-sriake, when it was about four years old. It was found that the two skulls were nearly of the same size-equally complete in ossification. "The frontal and parietal bones, instead of being continued over the top of the head, meet each other, and are united by a circular suture. The two skulls are almost equally perfected at their union; but the superior skull, as it recedes from the other. becomes imperfect, and many of its parts are deficient. The number of the teeth is the same in both. There is no septum of bones between the crania, so that the two brains must have been contained ji one bony case." The dura mater of each, however, was continued across, so as to divide the cerebral masses from each other, and their membranes were perforated by a number of large vessels by which the upper brain was nourished. The skull was deposited in the Hunterian Museum, and is now in the possession of the Royal College of Surgeons.

In the lower animals, monstrosities occur much more frequently than in man; and the domesticated are more obnoxious to these irregularities than those in the 
wild state. Monstrous pigs, sheep, puppies, kittens, ducks, and chickens, are to be seen in every collection of specimens devoted to the elucidation of the subject of reproduction.

Two children have been joined together by the back, the sides, and by the sternum and abdomen. Figures 96 and 97 , the originals of which are in the London Hospital Museum, show the possibility of such a confusion. Nor are such specimens by any means singular; but many similar are preserved. Instances, indeed, are not wanting of individuals variously connected by nature, surviving their birth, and even living to maturity.

The Siamese twins were connected only by a band about four inches long and eleven in circumference, situated at the lower part of the sternum, involving the ensiform cartilages, and possessing at its lower face an umbilicus. The length of the band allowed them to turn a little sideways towards each other. Their nervous systems seemed to act more in unison than in the case of some others; for they both slept at the same time, and one could not be awakened without rousing the other; their pulses were not always alike. Hunger affected both simultaneously; they both preferred the same kind of food, and were both satisfied with nearly the same quantity, and at the same time. But the vascular systems were distinct, or had but slight communication; for asparagus eaten by the one did not impregnate with its peculiar odor the urine of the other; and not the least pulsation could be distinguished in the band.

The Siamese twins are now dead, after having lived thus conjoined for many years. They married two sisters, and both had families. One died first, and the other did not long survive his separation from him. It was found, on the postmortem examination, that the liver of one, and some of the larger vessels, extended along the band of union into the body of the other, so that they could not have been separated with safety, as Sir Astley Cooper suspected.

While this book is going to press there is now exhibiting in New York City "The Benoit Twins," two sisters, joined together something like the two in figure 112. The two bodies, heads, and arms are distinct, but they have only two lower limbs between them. They are now some five years old, in good health, and quite lively.

In such a case each head seems the seat of a separate intelligence, though probably there is a sympathetic connection between them. One may sleep, however, while the other is awake, or feel hunger or thirst when the other does not. Each seems to influence one of the lower limbs only, and there are probably some parts equally under the control of the two.

Instances also are recorded of the union of a perfect with a partially developed body, of which A-Ke, a Chinee, sixteen years old, may be adduced as an example. He had the loins, nates, upper and lower extremities, of a small parasitical brothes escaping from the abdomen between the umbilicus and the sternum. This prodigy, I believe, was shown in England some years ago, and small models of his person must be familiar to every one who has had the curiosity to inquire into this subject. Another case very similar to the last is related by Ambrose Paré. The man exhibited himself in Paris in 1530, was forty years old, and had growing out of his abdomen a small body, perfect in all its parts, but wanting the head and shoulders. Paré has given a drawing of this, as well as many other monstrous productions, and Palfyn zives the history of a man having a small body attached in the same wav; but ir 
this instance, also, there were arms external, and the head only was wanting. Wins low relates that he saw a girl of twelve years old, well-formed, and of the common size, with the abdomen and lower extremities of another body hanging from the left side of the epigastric region; and in the 79th volume of The Philosophicas Transactions there is an account of a well-made Gentoo boy, who had the pelvis and lower limbs of a little brother suspended from the pubes.

Rueffe, Paré and Palfyn all speak of a man, alive in 1519, from whose abdomen a small though well-formed head appeared to grow; and Winslow saw, in 1698, an Italian, who had another head much less than his own, connected to the chest below the cartilage of the third rib. The man felt any impression on this extra head.

Again, an imperfect body has been found entirely enclosed within another. Ir the Gentleman's Magazine for December, 1748, mention is made of a child born with a large bag extending from the perineum to the toes, which in a few days burst, and a mass of florid flesh protruded, in which were distinctly perceptible a hand and foot, with perfect fingers and toes; but no organs could be traced, nor any rudiments of either sex. Richerand mentions the case of a lad who died at thirteen years old, and who, from his earliest infancy, had a tumor on the left side of the lower part of the abdomen, which was very painful. He was seized with fever and increase of pain in the prominent part, and voided by stool purulent and fetid matter, and a ball of hair, after which he soon sank. The tumor was found to consist of a cyst, having a recent communication with the transverse colon, and containing the rudiments of a fœtus. There was discovered a brain, spinal marrow, very large nerves, muscles, and the skeleton of the head, vetebral column, pelvis, and imperfect limbs, with a short umbilical cord attached to the mesocolon. No organs of digestion or respiration, urinary or generative, could be found. The case was drawn up at length by M. Dupuytren, and drawings were made by MM. Cuvier and Jadelot, and a detailed account was published in the Bulletin de l'Ecole de Medicine, Gazette de Sante, 1804, and some other works of the period. A somewhat similar case was published by $\mathrm{Mr}$. George Young, in the first volume of The Medico-Chirurgical Transactions; it was of a child whom he saw frequently during life, in consequence of a tumor in the abdomen, which gradually increased till his death; he survived nine months. A cyst was found occupying a large portion of the abdomen, which contained four pints, fourteen ounces of greenish-looking fluid, and an imperfectly-formed fotus adhering to it by a conical process arising from the umbilicus. The surface was covered with that sebaceous matter so usually found on the skin of infants at birth ; and the skin itself was rosy, and of a healthy look. The extremities were distinct, but short and thick; the fingers and toes were furnished with nails; there was a well-formed penis and a cleft scrotum. There was no brain, nor spinal marrow, nor diaphragm; neither heart, nor liver, nor urinary organs, nor any internal organs of generatior. Scarcely any muscular fabric was discovered in the whole mass. The alimentary canal was the most perfectly formed of the internal organs; a part of the intestines, indeed, was in all respects naturally constructed. Mr. Highmore, a surgeon of Sher bourne, in Dorsetshire, opened the body of a boy named Thomas Lane, between fifteen and sixteen years old, in June, 1814, in which he found the rudiments of a human fœetus. The two last-mentioned specimens are preserved in the Museum of the Royal Coilege of Surgeons.

In L'Historie de l'Académie Royal des Sciences, vol, ii., p. 298, 1733, there is an account given by M. D. Sainte Donat, a surgeon at Sisterton. of a foetus found in 
the scrotum of a man. And Velpeau presented to the Paris Academy, in 1840, a preparation of the rudiments of a fœetus-the whole mass being as large as a doubled fist-which he had removed from its connection with the right testicle of a man, æt. $2 \%$, named Gallochat. The tumor had existed from his birth.

Parts misshapen, though properly situated, are by no means uncommon; sometimes this unnatural formation is the result of defective, sometimes of redundant organization; thus the different features of the face may be malformed; the scrotum is sometimes cleft; the urethra and rectum imperforate. Club feet are usually classed among this variety of monstrosity; but it appears to me that they often owe their origin to accidental causes rather than natural formation. The distortion may not unfrequently arise from the limb being cramped in utero, owing, perhaps, to the awkward position in which the child lies, or to there being but a small quantity of the liquor amnii.

Misplacement of perfectly-formed parts is the least common of all kinds of monsters. I do not know that, even among all the extravagant stories in the older works, there is any account of a well-formed arm rising from the pelvis, or a leg from the shoulder; and we should certainly not give credence to it, were we to meet with such a tale. But the viscera have occasionally been found transposed, both in the chest and abdomen ; and such a case may be considered a monstrosity of this description. When the viscera of the chest are transposed, those of the abdomen are almost always in the same condition; but there are some exceptions to this general observation. I do not know any instance on record, however, of the abdominal viscera being transposed, where tho chest did not also participate in the malformation. In the 18th volume of The Medical Gazette p. 393, for June 11th, 1836, there is a paper by Dr. Watson, in which he enumerates thirty-three cases of this irregularity; nineteen of the subjects were males, six were females, and in eight the sex is not mentioned. In four the anomalous formation was detected during the lifetime of the individual. A fœetus with the heart on the right side, and other viscera transposed, is preserved in the London Hospital Museum ; the subject was in other respects misformed. And in the same volume of The Medical Gazette just cited, p. 600, a case is given by Mr. Cooper, of Brentford, of a female infant, in which the viscera of the chest were transposed; but those of the abdomen were in their natural situation; so that these cases are not so singular as some have imagined.

It may be thought a needless waste of time to enter so much at large upon subjects from which no practical good appears likely to result; but its interest has seduced me into these details. Besides, by studying nature in her imperfections and irregularities, we are more likely to arrive at some knowledge of her laws, than if we regard her only in her healthy condition. By learning what parts she can dispense with, we ascertain those organs essential to existence, and by tracing the deviations from her common course, we may perhaps be hereafter led to a more correct acquaint. nce with her mode of operation.

\section{ORTGIN OF MONSTROSTTIES.}

It is not my intention to endeavor to account for the origin of monstrous forma. tions in general; but I may cursorily state, with regard to deficient and redundant monsters, that some suppose the germ, before impregnation, is improperly formeo ; others, that it is an undue admixture of prolific particles at the moment of fecundation; others, that monstrosity has taken place after conception, owing to some 
irregular vascular excitement, or deficiency of nourishment-thus the vessels of the redundant part being more numerous and more active than they ought to be, produce an excess of growth, whilst those of the deficient parts are just in a contrary condition. Where a connection of two children, nearly or quite perfect, exists, I cannot help thinking that union takes piace not only after fecundation, but after the fretuses have grown to a certain size. In the case of the Siamese twins, or those shown in figures 111 and 112, I presume that they were originally true twin conceptions, but that the membranes which ought to have enveloped each body, so as to form an inseparable barrier between them, were imperfect, and that, in consequence, the bodies were allowed to come into close contact with each other; that there is such a strong formative power existing in the vascular system of the fœetus, that when the two cuticular surfaces came together, vessels shot from one to the other, and the parts became permanently united by adhesion, in the same way that two fingers would coalesce, provided the skin was removed and they were kept together. We know that sometimes twins are contained in the same bag of membranes, and in such case, provided they lay for any length of time in contact, we may believe it quite possible for a junction of the two bodies to occur.

Richerand (Elements of Physiology, trans. 1815, p. 462) tells us, "by placing in a confined vessel the fecundated ova of a tench, or any other fish, the numerous young ones which are formed, not having space sufficient for their growth, adhere to each other, and fishes truly monstrous are produced." And in the vegetable kingdom it is not very unusual for two fruits, in contact and cramped in their growth, to unite indissolubly.

\section{DOUBLE PEOPLE。}

Concerning double people, twins united in an abnormal manner at birth, the authentic records are numerous, but a few examples must suffice.

In 1\%01, united twins were born at Szany, in Hungary. They were christened by the names of Helen and Judith, and were exhibited for some years in the chief cities of Europe. They were joined together at the lower part of the back, the faces and bodies being half sideways, or diagonal, neither back to back nor side by side. The two girls were not equally strong, nor equally well made; one had a more resolute will than the other, and settled all questions as to whether to move, and whither. Being carefully educated, they read, recited, and sang well, conversed in Hungarian, German, French, and English, and afforded much scope for study to psychologists ; for there was sufficient difference between them in strength, temper, health, and intellect, to give play to two sets of forces, mental as well as bodily. It was observed, however, that when one was ill, the other became more or less affected with the same complaint; and it was deemed probable that their deaths would be nearly simultaneous. This proved to be the case. Judith was attacked with a complicated disease of brain and lungs, in 1723, and died. Helen, who at the commencement of her sister's malady was in good health, soon sickened with her, and the two died almost at the same instant. They were buried in a convent grave-yard at Presburg, and the particulars of their remarkable history found admission into the Philosophical Transactions of the Royal Society.

There was another case of a man named Lazarus, or rather a double man named Lazarus-Johannes, very attractive to sight-seers in Germany several years ago. There was much of a curious character in the degree in which the feeding of Lazarus helped 
to feed Johannes, without any distinct participation of the latter in the eating process. As the Johannes portion of the duplex was less fully developed than Lazarus, sow!9 discussion arose among the ecclesiastics, as to whether each half had a soul to be saved, distinct from the other; it was decided in the affirmative, and the two names of Lazarus and Johannes were given in baptism. The men were alive at the age of twenty-eight, but we have no mention of their age at death.

The Siamese twins were more completely two human beings than any others we have here spoken of ; for the only physical or organized band of connection between them was at the two chests. In one of Dr. Todd's medical works, a description is given, which conveys a sufficiently clear notion of the nature of this band, to those who have neither seen the twins themselves nor pictures of them. When first exhibited, they were not exactly opposite to each other, but stood side by side, or rather obliquely one by another ; but this position, there can be little doubt, was acquired by the attempts which they had instinctively made to separate from each other in walking, or in lying and sitting down, and by the extension they had thus effected in their band of union, which was considerably more slender than in any other yet described. It was quite impossible for them to remain always face to face; therefore their bodies acquired an oblique direction, in which they also moved. The consequence of this was, that the right limbs of the one and the left of the other individual were the principal organs of movement, and that the intermediate limbs (that is to say, the left of the one and the right of the other) remained nearly passive. In organic and animal relation of life, they appeared to be independent of each other. Each had his own circulation of the blood, and his own respirative and digestive functions. The curious yellow-skinned couple were wont to play at battledore and shuttlecock with each other; one had a battledore in his right hand, the other had one in his left, and very deftly they tossed the feathered messenger to and fro.

\section{TWINS AND SUPERFETATION.}

Twins that are both born at the same time, and of the same age, have evidently originated from two eggs impregnated at the same time, and triplets from three, and so on. It is a question, however, whether it is possible for one impregnation to occur after another, while the female is yet pregnant. This is called superfotation, and its possibility is by some denied, though there is every reason to believe in its possibility within certain limits. Dr. Ryan remarks :

"Physiologists are at issue upon the question of superfotation, that it is possible for a pregnant woman to conceive a second time. According to Aristotle, a female was delivered of twelve infants, and another of twins, one of which resembled her husband, the other her lover. Some writers maintain that superfœtation is possible during the first two months of pregnancy; the majority hold it possible in a few days after conception, before the uterine tubes are closed by the decidua. This is the received opinion, though cases are on record which justified Zacchias and other jurists to conclude that superfotation might occur until the sixtieth day, or even later. Nothing is more common than to see a full-grown infant born, and another of the second, third, fourth, fifth, or sixth month expelled immediately after. I need not cite authorities upon this point, as obstetric works abound with examples, a few of which may be given. Dr. Mason published an account of a woman who was deliv. ered of a full-grown infant, and in three calendar months afterward of another, 
apparently at the full time. A woman was delivered at Strasburg, the 30th of April, 1\%48, at ten o'clock in the morning; in a month afterward, M. Leriche discovered a second foetus, and on the 16th September, at five o'clock in the morning, the woman was delivered of a healthy, full-grown infant. Degranges, of Lyons, attests a similar case ; the woman was delivered at the full time, the 20 th of January, 1780 ; in three weeks afterward she felt the motions of an infant, and her husband had no intercourse with her for twenty-four days after delivery. On the 6th of July (five months and sixteen days subsequent to delivery), she brought forward a second daughter, perfect and healthy. On the 19th January, 1781, she presented herself and both infants before the notaries at Lyons, to authenticate the fact. Buffon related the case of a woman in South Carolina, who brought forth a white and black infant; on inquiry, it was discovered that a negro had entered her apartment after the departure of ber husband, and threatened to murder her, unless she complied with his wishes. Dr. Mosely relates a similar case. A negress of Guadaloupe brought forth a black and mulatto, haring had intercourse with a white and black man the same night. Another negress produced a white, black, and a piebald infant. A domestic of Count Montgomery's produced a white and black child at one birth. Gardien relates a similar case, on the authority of M. Valentin. A mare also has produced a foal and a mule, she having been impregnated by a horse, and five days afterward by an.ass.

"Another argument, which I have never seen, occurs to me from analogy, which deserves mention, nameiy, that each dog will produce a distinct puppy; this no one can deny, for the offspring will resemble the different males that fecundate the bitch in succession. If a number of healthy, vigorous men were to have intercourse in succession, immediately after the first conception, I think it probable and possible that similar superfoetation would happen. I am proud to say that Dr. Elliotson is an advocate of superfotation; he explains Buffon's case this way. Magendi is of the same opinion. Medical men must bear in mind that women have had three, four, and five cbildren at one birth. Various cases of infants of different sizes, being expelled in succession, are recorded in our own periodicals.

"One of the Pennsylvania newspapers, in 182\%, recorded the case of an Irish lady, who in eighteen months had at three births twelve living children, all born prematurely. She and her husband were healthy fresh-looking people, and only two years married. Cases of twins, triplets, quadruple, and quintuple births are of very rare occurrence; but of these more particularly hereafter. Dr. Golding delivered a woman of six infants during the year 1829."

It is, perhaps, possible that eggs may be formed sometimes during pregnancy, and possibly also the animalcules may make their way between the deciduous membrane and the walls of the womb to impregnate them, and thus superfotation may occur. I think it likely, however, that some of the cases mentioned may have been caused by there being a double uterus, and each one having become the seat of impregnation, independent of the other, and at a different time. Some of the cases of resemblance may also have originated in the way explained in the article on The Permanent Influence of the Male over the Female Organs.

It is a vulgar error to suppose that twins will not breed, or that one of them will be sure to be barren. When of the same sex one or both frequently are barren; but in other cases both are fertile. When they are of different sexes one is nearly always imperfect, as in the case of the Free Martin, explained farther on. 


\section{PLURAL BIRTHS.}

Women, although usually uniparient, like other uniparient animals, sometines produce more than one offspring at a birth; and when the gestation is plural, twins are by far the most frequent.

The average of twin eases varies considerably in different parts of the world ; and we find also no little difference in the tables kept by separate individuals in the same country. Thus Denman shows that in the Middlesex Hospital, in London, one occurred in about every 95 labors; in the London practice of midwifery the estimate is stated as one in 48 ; Conquest considers it one in 90 ; Gooch, one in about 70 ; Blundell states, that from the statistical accounts transmitted to government in the year 1801, it appeared that in Great Britain one in 65 was a twin case. Bland in London, and Boer at Vienna, found the average one in 80 ; in the Maternity at Paris, one was met with in 88; in the Maison d'Accouchemens, one in 91; Mad. Boivin met with one only in every 132; Dewees averages the frequency in North America as one in $75 ;$ Dr. Arnell's average is also one in $75 ;$ Mr. Moore's, one in 76. From Collins' table of 129,172 women delivered in the Dublin Lying-in-Hospital, there were 2,062 cases of twins, being one in about every 62 labors; 29 of triplets, or one in 4,450, and one of quadruplets. From tables which I have myself kept, I find that out of 35,743 cases that occurred in the royal Maternity Charity, from January 1st, 1828, to December 31st, 1843, there were 386 instances of twins, or one in nearly every 93 labors. Of these 135 were of different sexes; 123 were both boys ; and 128 both girls-183 of these children presented both with the head; 152, the bead and breech, or lower extremities; 33 , both breech or lower extremities; 14, one head, one tranversely; 3 , one breech, the other transversely; and in one both presented transversely. It is curious, too, that when the children were of different sexes they mostly presented with the head and breech. It is generally supposed that triplets are to be met with once in about 3 or 4,000 labors; and the returns from Dublin would lead us to believe that estimate tolerably correct; but I am inclined to think the frequency of these cases generally much overrated, for out of these births there was but one case of triplets. Quadruple cases are so rare as to defy anything like an accurate calculation.

It is popularly supposed that climate, and the state of civilization to which the country has advanced, exert an influence on the multiplication of the human species; and that certain external circumstances are favorable or otherwise to the frequent production of twins ; but this is by no means proved, although we know that some animals, the sow for instance, farrow more young at a birth, and also more frequently, when domesticated, than when in a state of nature. Dewees says, that if the various tables can be relied on, it is certain " there are conditions and circumstances which give rise to more double births" in America than Europe; while Collins remarks, "it is singular that in Ireland the proportional number of women giving birth to twins is nearly a third greater than in any other country from which I have been able to obtain authentic records."

I have heard these two opinions, apparently contradictory, attempted to je recon. ciled by the explanation that a large proportion of the first European emigrants to America were from the Emerald Isle. Denman, too (chap. xvii. section 1), thinks climate and the state or degree of civilization have their influence over the fecundity of human beings. 
It is also a belief that preternatural fecundity is, to a certain extent, hereditary ; and Dewees states, that "some facts within his own knowledge would seem to countenance this supposition; but they are not sufficiently numerous or strong to confirm it." He looks upon it, however, as, in some instances, constitutional, and adduces the case of a woman, whom he knew, that five times produced twins, and never had a single child, and another who thrice brought forth twins, though not consecutively.

Gottlob mentions one who in three births produced eleven children.-(Elliotson's Notes to Blumenbach, p. 48\%.)

It has been observed, indeed, that some seasons appear more prolific than others, as well in the human race as other productions of nature; but whether this is quite accidental, or dependent on some fixed laws, is not easily determined. Denman thinks " it can scarcely be doubted that there is some relation in those years between the animal and vegetable creation."

Rare as instances of quadruplets are, the prolific powers of the human female are not eren limited to the production of four children at a birth. In the Museum of the College of Surgeons in this city, there are five fœtuses preserved which were expelled at one birth, under the care of the late Dr. Hull, of Manchester; they had advanced to five months intra-uterine age.

When there is more than one fœtus in utero, each is generally smaller than in single births, and in proportion to the number will the size of the children be less. Thus Dr. Joseph Clarke's estimate of the weight of twins is twelve pounds and a half a pair. We often remark also that in twin gestations one fœetus at birth is sensibly smaller than the other. Should the uterus contain more children than two, the woman seldom carries them to the full term, and they are consequently rarely reared.

In the London practice of midwifery, which is a copy of the late Dr. John Clarke's lectures, and some other works on the science, it is stated that Dr. Osborn met with six distinct ova thrown off at one abortion, but on what authority I have not been able to discover.

Paré (lib. xxv. chap. 3), tells us, that in his day the wife of the Lord of Maldemeure, in the parish of Sceaux, near Chambelly, produced six children at a birth, after which she died; and that the then present Lord of Maldemeure was the only surviving one. His history of this extraordinary occurrence is so circumstantial as to impress us with the belief that he was himself fully convinced of the fact.

Twins may possibly proceed both from one ovarium, or the rudiments of one fortus may be furnished by each gland. When the conception, however, is more than duplex, it is clear that one ovary must supply two ; for no instance has yet been met with where these organs were in excess. It is commonly supposed that twins are the result of one connection, and instances are noted where this must have been the case. But it is not equally plain that this is a universal rule, and it appears to me by no means impossible that a second impregnation may take place soon after a former one has occurred. It is not difficult, indeed, to imagine that such an event may happen at any time previously to the uterus becoming lined with the secretion afterward converted into the deciduous membrane, or until its mouth is plugged with that viscid mucus which divides its cavity from that of the vagina, and which, after its formation, would entircly prevent the immission of the seminal fluid in coitu.

Dr. Dewees (Philadelphia Med. Muserm, vol. i.) has related that a servant in Montgomery county was delivered of a black and white child at one birth, which were often seen by the doctor. He states also, that on the report of the pregnancy, both 
a black and a white man disappeared from the neighborhood, and Elliotson, (Notes to Blumenbach, p. 485) has put on record that Mr. Blackaller, of Weybridge, sent him the following account : $-\mathbf{A}$ white woman of very loose character left her husband, and some time afterward returned pregnant to the parish, and was delivered in the workhouse of twins, "one of which," says Mr. Blackaller, "was born of a darker color than I have usually observed the infants of the negroes in the West Indies to be ; the hair quite black, with the woolly appearance usual to them, with flat nose and thick lips; the other had all the appearance common to white children." That these respective twins were not the offspring of one parent is very evident, and a second impregnation, therefore, must have taken place; but we have proof, in two at least, that the connections followed each other quickly, before any changes could have been commenced in the uterus. With the knowledge, then, of such accidental occurrences in our possession, we are warranted in believing that, in the case of a woman living with her husband, twins might possibly be the result of two separate connections if only a short period intervened between them.

In regard to multiparient animals, whose uteri are cornuated, it is a well-known fact that more than one connection may be fruitful if they follow each other within a short time. Thus if a bitch, while in heat receive two or three dogs of various species in succession, she may bring forth mongrel puppies of different kinds, some partaking of the character of one dog, and others of the rest.

Each individual child which the uterus contains, according to the law of nature, is distinctly enveloped in its own membranes-so that its body is not in contact with that of its brother-possesses its own quantity of liquor amnii, has a separate cord and separate placenta-the circulations not inosculating. Generally the placentæ are attached together at a part of their edges, and often, on regarding the maternal face, they appear but one mass ; at other times they are situated distinctly from each other at different points of the uterus; again, occasionally, though very rarely, the vessels of the one child anastomose with those of the other. It has been remarked that both children have been found in one bag of membranes, and cases are recorded where the placenta was in all respects single, and the funis also arose singly, and divided into two branches when about to terminate in the umbilicus of each fotus.

See a case by Dr. H. Davies (Medical Gazette, May 14, 1841, p. 307) of three children at a birth, in which two of them lay in one bag of membranes, though the circulation did not inosculate. Also another (May 28, 1841, p. 384), very similar, by Mr. Dodd, of Northampton. In the same periodical for June 11th, 1841, there is also a case of five at a birth, given by Mr. Wardleworth, in which three of the umbilical cords arose from the placenta by one common origin, and the other two cords by another. The three umbilical veins united to form one, and it would seem that there were but five umbilical arteries.

Besides the instances mentioned there are a few more well-attested cases of five children at a birth. One will be found in the Gentleman's Magazine for 1736; the patient lived in the Strand; another in the same periodical, 1739, at Wells, Somersetshire; one occurred in Upper Saxony; one near Prague in Bohemia.

In the British and Foreign Medical Review for 1839, a notice is given of a woman at Naples being delivered of five children at seven months; in the Dublin Med. Journal for January, 1840, there is an account given of Dr. Evory Kennedy having shown to the Dublin Pathological Society five ova of between two and three months, which were expelled at once under the superintendence of Dr. Thwaits. 
They were all male children. And if we could credit newspaper reports, we might add the following:-The wife of a cannon-founder at Luginski, in Russia, was delirered, on May 22d, 1836, of fire giris, of whom four were living and likely to do well. The Giornale del Duc Sicilie states that a woman was safely delivered, on June 21, 1838, of a boy and four girls, all of whom died at the expiration of half an hour. The wife of a landed proprietor at Altruitweida, near Mitweida, in Saxony, was recently delirered of fire daughters, who though perfect in their conformation, died in about half an hour after their birth. A woman in New Hampshire was deiirered of five living children at a birth, in the beginning of the year 1841 . Mrs. Mauger, of St. Owen, Jersey, had five daughters at a birth at six months, on May 20, 1840. Sir Thomas Urquhart, the translator of Rabelais, had twenty-five brothers and eleven sisters, all of whom were liring at the same time. Dr. Plot, in his Natural History of Staffordshire, published in 1686, relates that a Lady Child of Shropshire, was married at twelve years of age, had her first baby, a daughter, before she completed her thirteenth year. This daughter also married at the age of twrelre, and gare birth to a child before she reached thirteen. Thus Lady Child became a grandmother before twenty-seven.

The most miraculous instance of supposed fecundity in a human female is that of the Countess Henneberg, recorded on a marble tablet, which still is, or at least was, in the church of Lonsdunen, near Leyden. The monument bears the following announcement :-

"That Margaret, wife of Hennan, Earl of Henneberg, and daughter of Florence, the fourth Earl of Holland and Zealand, being about forty years old upon Easter dar, $12 \% 6$, at $9 \mathrm{~A}$. M., was brought to bed of 365 children, all of which were baptized in two brazen basins by Guido, the suffragen of Utrecht. The males, how many soever there were of them, were christened John, all the daughters Elizabeth, who all, together with their mother, died on the same day, and with their mother lie buried in this church at Lonsdunen." This supernatural infliction is accounted for on the principle of retributive justice ; for we are informed that the countess being solicited for alms by a poor woman who was carrying twins, shook her off with contempt, declaring that she could not have them by one father, "whereupon the poor woman prayed to God to send her as many children as there were days in the whole rear, which came to pass, as is briefly recorded in this table for perpetual recollection, testified as well by ancient manuscripts as by many printed chronicles."

The credulity of the people who raised the memorial must create a smile, and yet no doubt the story may not be without some slight foundation. It is probable that the poor lady died after haring given birth to a number of watery cysts, which were looked upon as ova. A rery slight stretch of the imagination might transform them into children in embryo, and in the rigid adherence to the Catholic forms of worship, it might hare been thought necessary that the baptismal ceremony should be performed, though they were nothing more than a mass of hydatids, as is clear from the declaration that "they were baptized in two brazen basins." The noble lady probably sank from flooding.

\section{MISCELLANEOUS MATTERS CONNECTED WITH THE FOREGOING TOPICS。}

Some of the terms which have been used, or that will be used further on, may require explanation, so that their exact meaning may be understood. 
Miscarriage is the name generally given to an expulsion of the new being from che womb before the period when it can live. Usually this is seren months, but as children have lived that were born still earlier, it is perhaps now proper to use the term miscarriage only up to the sixth month. After the sixth month it is called a premature labor.

The term abortion is also used to designate any premature birth before six or Beven months, and is more general than miscarriage.

In regard to the vitality of the new being, it seems certain that it has a life of its own, quite independent of that of the mother. This is shown by those cases in whicl: the fœtus lives and grows, without any rascular connection with its parent whatever, as when it simply floats in the amniotic liquor. In many cases also, when the orum has been expelled at an advanced period quite intact, with the membranes unbroken, the foetus has lived, and its circulation has continued for an hour or more. When connected with the mother, it derives nutriment from her bejond doubt, and is immensely influenced by her mental and bodily condition, as before explained, but it has its own independent life, eren from the beginning. At the first it is only a simple cell, and may be nutrified, like all other cells, by simple osmose, through its membranous covering. Even in after life, when made up of a congeries of cells, the same process may still take place, as we see in those cases where the fotus is nourished solely by the fluids with which it is surrounded. It forms its own blood, and circulates it with its own ressels, even when most intimately connected with the mother. Her blood is not used directly by her child, in the state in which she uses it for her own body, but the child absorbs from it, in the placenta, the materials by which its own blood is made. Close as is the connection between them, the two are independent lives, but intimately bound up with each other. The child is, in reality, dependent on the mother for nutrition, and not for vitality!

The old idea that the foetus really swallowed the amniotic liquor and digested it, as we do food, is quite erroneous. In the first place, at an early stage there is no mouth. In the second place, a fotus has been found which had lired and grown, with no continuous intestine. Another was born, full grown, without head, heart, or intestincs. Animals hare also frequently been born alive, and full formed, without mouths or noses, and even without heads. In all such cases, nutrition must hare been effected by simple absorption or osmose, through the skin, as in all cells.

That substances do pass direct from the mother into the child's body is demonstrated, and it is an important fact. Thus when animals with young have the dye-stuff madder given them in their food, it will pass into the body of the young, and stain their urine, teeth, and bones red.

Women just previous to labor hare also had rhubarb given them, and it has been found, after birth, in the blood flowing from that part of the navel-string connected with the child, and also in its first urine, and in the amniotic liquor.

Without doubt, therefore, any medicine the mother may take, at such times, or indeed anything whatever entering her blood, may pass directly into the child. If this fact were more generally known, much more care would be taken in regard to using medicine by pregnant women, and no doubt ignorance of it often makes them, unintentionally, do great harm to their offspring; perhaps for all their future lives.

The sacrum or os sacrum, the lowest part of the back-bone, will be referred to more especially when we treat upon parturition, but there are some particulars about 
at which will be well to state here. It is important, in connection with the expulsion of the fotus, whether at full term or prematurely.

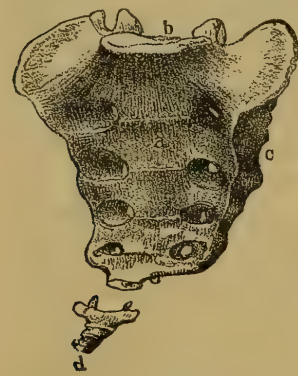

Figure 113.-The Sacrum, and Os Coceygis.

a. The hollow of the sacrum. b. The top, where the upper part of the back-bone rests upon it. $c$. The side. $d$. The os coceygis, which is detached, in order to show how it is connected. This small bone has three, and sometimes four joints, which enables it to bend back during parturition, and so facilitates the exit of the child.

This bone forms the back of the basin of the pelvis, and is the largest part of the spinal column. The spinal marrow, proper, stops at the sacrum, but a thin nervous thread passes down the center of it, called the cauda equina, or horse tail. The os coccygis is the small bone at the very end of the sacrum, forming the lowest point of the spinal column.

There has been much curious speculation as to the origin of the name of this bone,-sacrum. In some way or other it seems, in old times, to have been specially devoted to the Deity, and held sacred, but for what reason is now unknown. Probably this arose from its connection with the sexual organs, and especially from its importance during child-birth. Some say it should be secret instead of sacred, and that it was so called from its association with the mystery of birth. Even among the ancient Jews there were some singular superstitions about this bone. One of the Rabbinical doctrines was that, though all the rest of the skeleton would decay, this one bone would not, and that it would become the germ, as it were, of the new body at the time of the resurrection. It was called luz, and believed to be incorruptible.

In a very old Hebrew book, called Medrac Rabbath, which treats upon the deluge, we are told that when the world was drowned at that period, the destruction of all human beings was so complete, that every $7 u z$ even was destroyed, from which man might be again formed, so that Noah and his family alone could re-people the earth. It also states that one Rabbi Joshua, to prove to the Roman emperor the indestructible character of this bone, tried to grind it in a mill, and to burn it with fire, without success. He also tried to crush it with a hammer, on an anvil, but the anvil itself split, and the hammer burst.

The Arabs also held this bone in the same veneration, as Sale tells us, in his Introduction to the Koran. Mahomet, he says, teaches that the body of man decays in the earth, except the bone called al ajib, which is the same as what we call the os coccyx, or rump bone. This bone, which is the first point formed, remains undecayed, and is the seed from which the whole body is afterward recreated.

The origin of this singular idea it is impossible now to trace. It is, of course, unnecessary to say that it has no foundation in fact. It is, perhaps, the lightest bone in the body, being very spongy, and therefore most likely to decay first, and it certainly is not the first formed, as this old superstition taught. 


\section{CHAPTER XXX.}

\section{DUBATION OF PREGNANCY, AND PERIOD WHEN THE CHILD CAN LIVT,}

THESE are two questions of great interest, and about which there has always been much dispute.

The duration of pregnancy, or the precise term of utero-gestation, is not fixed. If appears, from accurate observation, that there is no absolute period determined by natural laws, and therefore there is none laid down by human enactments. An approximation can be made, by taking the average of a number of cases, and the period of limitation may also be determined in the same way. The most usual period is about nine months, or from thirty-five to forty weeks, some females going beyond the thirty-six weeks, and others not so long. First children are frequently born under the nine months, and more so than those that come after; this is a fact not generally known, and ignorance of it has often given rise to unjust suspicions. It is quite possible for a female to be delivered, with the child at full period, in a little over eight months after marriage, without there being any just grounds whatever for suspecting unfaithfulness.

Dr. R. Lee, in his Lectures on the Theory and Practice of Midwifery, gives the best summary that we have in the language, of our information on this subject; I will therefore quote from this work, making such comments and additions as I may think advisable.

"The Roman law fixed the period of gestation at ten lunar months. The civil code of Prussia ordains that a child born 302 days after the death of the husband shall be considered legitimate. By the law of France, the legitimacy of a child cannot be called in question who is born 300 days after the death or departure of the husband. The laws of England declare that the usual period of human utero-gestation is nine calendar months, or forty weeks ; farther than this they do not fix a definite period: the law is not exact as to a few days. Nine calendar months contain only $2 \% 5$ days, and only 273 or 272 if February be included. To fix bastardy on a child in Scotland, absence must continue till within six months of the birth, and a child born after the tenth month is accounted illegitimate.

The difficulty of determining the precise time when impregnation takes place in the human subject, renders it almost impossible, in any case, to calculate with absolute certainty the duration of pregnancy. We are, however, in possession of a sufficient number of observations to establish the fact that the ordinary period is about forty weeks, or 280 days ; but it is certain that it does occasionally exceed or fall short of this period by several days. As we never can be certain of the precise day, between the periods of menstruation, when conception occurs-whether it takes place immediately after the last period, or before the expected period, or midway between these-it is obvious that all calculations founded upon the cessation of the catamenia must be extremely uncertain. The error of the calculation will be still 
greater if the catamenia should have appeared, or a discharge like the catamenia should have occurred once or twice after conception. Impregnation most frequently takes place soon after menstruation, but in others it does not happen till later; so that two women may have menstruated at the same time, and one may have reached the full period two weeks before the other; and to this extent, or nearly so, an opinion founded on this disappearance of the catamenia may be erroneous.

"Calculations of the duration of pregnancy, founded upon what has been observed to occur after casual intercourse, or perhaps a single act, in individuals who can have no motive to tell us what is false, are likely to be much more correct; and the conclusion to be drawn from these is, that labor usually, but not invariably, comes on about 280 days after conception, a mature child being sometimes born before the expiration of forty weeks, and at other times not until the forty weeks have been exceeded by several days. A case came under my observation very lately, in which I had no doubt the pregnancy existed 287 days: the labor did not take place till $28 \%$ days had elapsed from the departure of the husband of this lady for the East Indies. Some women are always delivered before the end of the forty weeks, according to the usual calculation, and their children are mature.

"In the evidence given on the Gardner Peerage case, the period of utero-gestation was limited, but not strictly, by some of the witnesses, to forty weeks, or 280 days ; by others it was extended to 311 days. Dr. Merriman, whose opinion is always entitled to much respect, thinks the greatest number of women complete gestation in the 40th week, and next to that in the 41st. Of 114 pregnancies, calculated by him from the last day of menstruation, and in which the children appeared to be mature, 3 deliveries took place at the end of the $3 \%$ th week ; 13 in the 38 th; 14 in the 39 th ; 33 in the 40 th ; 22 in the 41 st; 15 in the $42 \mathrm{~d} ; 10$ in the $43 \mathrm{~d}$; and 4 in the 44 th week.

"How long before the expiration of the 40 weeks a child may be born with the power of supporting life has not been determined. Where I have induced premature labor for distortion of the pelvis, before the end of the seventh calendar month from the last menstruation, I have never seen a child reared. The lady of the clergyman in Fife, whose case has lately given rise to so much discussion, was delivered $1^{175}$ days after marriage, and the child lived five months. To what extent gestation may be protracted in some cases beyond the 280 days it is very difficult to determine, and the opinions of the most eminent writers differ upon the subject. I should suspect some great error in the calculation where the period of gestation exceeded 300 days. But the experiments made on the lower animals prove that there exists in them a great variation between the shortest and the longest gestation; and it is difficult to comprehend why there should not be a difference in this respect in human species."

In a trial which took place in this country, in the county of Lancaster, Pa., as reported in the Medical Examiner for June, 1846, it was decided that gestation may be prolonged to three hundred and thirteen days! The female swore that conception must have taken place on the twenty-third of March, 1845, and the child was not born till the thirticth of January, 1846, or over eleven months. The judge directed the jury to return a verdict in her favor, and I suppose this case establishes a precedent for America.

In a recent number of the Medical Gazette, I find a case reported, wherein tho period was said to be prolonged still farther. A man left his wife in New South 
Wales, he coming to England, and twelve months after he left, she was delivered of a child, which she claimed to be legitimate. He denied this, however, and the judge in the Consistory Court decided, without hesitation, in his favor. Taking the medium between these two cases, therefore, it appears to be decided that the extreme limit is somewhere between eleven and twelve months! It must be recollected, however, that both were perfectly arbitrary, and that, for anything known positively on the subject, both may be either right or wrong.

Except when labor is brought on prematurely by violence, it usually commences at what would have been one of the monthly periods; or in other words, after a certain number of full months, and never at any time between! If, therefore, a female passes over the ninth month, she will probably go to the tenth. This has been proved by extensive observation, and is only another proof of the regular method in which nature conducts all her operations. The same law is also observed in abortions, which generally take place at one of the months, unless brought on suddenly by violence.

Dr. Ryan remarks that "Hippocrates, Aristotle, Galen, Pliny, Avicenna, Mauriceau, Riolan, La Motte, Hoffman, Schenk, Haller, Bertins, Lieutaud, Petit, Levret, Louis, Astruc, etc., maintained that pregnancy usually terminates at the end of the ninth calendar month, but might be protracted to the tenth, eleventh, twelfth, and, some of them said, to the fifteenth.

"It is also decided by a preponderating majority of the profession, in all countries, that the term of utero-gestation is not uniform; in other words, not invariably limited to nine months. This position is strongly attested by the analogy afforded by the inferior animals; for it appears by the extensive observations of $\mathrm{M}$. Tessier, on the gestation of heifers, mares, sheep, swine, and rabbits, that all these animals exceed their usual period of delivery. (Trans. de l'Acad. des Sc., Paris, 181\%.) Further evidence is afforded by the vegetable kingdom, in which we observe in the same field, on the same tree, shrub, etc., different parts of vegetables arrive at maturity with more or less celerity. Petit informs us that many faculties of medicine, forty-seven celebrated authors, and twenty-three physicians and surgeons, concluded pregnancy might be protracted to the eleventh or twelfth month. He cites a case on the authority of Schlegel, in which pregnancy was protracted to the thirteenth month; the child was admitted to be legitimate, on account of the probity and virtue of the mother, which induced her shopman to marry her, and she bore two children by him, each at thirteen months. Tracy, a naval physician, relates a case at the fourteenth month. Dulignac, a French surgeon, positively asserts that his own wife quickened at four months and a half, and on two occasions she went on to the thirteenth month and a half, and on the third to the eleventh month. Desormeaux relates a case of a woman who was maniacal, who had three children, and whose physician, after all means had failed, recommended pregnancy. Her husband had intercourse with her once in three months, of which he kept an exact account. She was closely watched by her domesties, and she was extremely religious and moral; she was delivered at nine months and a half. (Velpeau.) The last author attests a case which went to three hundred and ten days, and Orfila two of ten months and a half. I have repeatedly known women mistake expected delivery, four, five, and six weeks.

"The term of gestation seems capable of being prolonged by peculiarities in the constitution or rate of development of the fotus, which are derived from the male parent; for it was ascertained by the late Earl Spencer, that of 75 cows in calf by a 
particular bull, the average period was $288 \frac{1}{2}$ days, instead of 280 ; none of these having gone less than 281 days, and two-fifths of them haring exceeded 289 days.

"Although the duration of pregnancy is commonly stated at nine solar months, it would be more correct to fix the period at 40 weeks, or 280 days; which exceeds nine calendar months by from 5 to $\%$ days, according to the months included. The mode of reckoning customary among women, is to date from the middle of the month after the last appearance of the catamenia ; but it is certain that conception is much more likely to take place soon after they have ceased to flow, or even just before their access, than in the intervening period; so that, in most instances, it would be most correct to expect labor at forty weeks and a few days after the last recurrence of the menses. This, at least, is the average result of observation, in cases in which the period of conception could be fixed, from peculiar circumstances, with something like certainty ; but there can be no doubt that variations of a few days, more or less, are of continual occurrence. The period of quickening may be relied on in some women, in whom it occurs with great regularity in a certain week of pregnancy ; but in general there is great latitude as to the time of its occurrence. The usual or average time is probably about the 18 th week.

"The question of the extreme limit of gestation is one of great importance botb to the practitioner and the medical jurist; but it is one which cannot yet be re. garded as satisfactorily decided. Many persons, whose experience should give much weight to their opinion, maintain that the regular period of 40 weeks is never extended for more than two or three days ; whilst, on the other hand, there are numerous cases on record, which, if testimony is to be believed at all (and in many of these, the character and circumstances of the parties place them above suspicion), furnish ample evidence that gestation may be prolonged for at least three weeks beyond the regular term. The English law fixes no precise limit; and the decisions which have been given in our courts, when questions of this kind have been raised, have been mostly formed upon the collateral circumstances. Very important evidence on this subject is afforded by observations on the lower animals, which are free from those sources of fallacy which attend human testimony. The observations of Tessier, which were continued during a period of forty years, with every precaution against inaccuracy, have furnished a body of results which seems quite decisive. In the cow, the ordinary period of gestation is about the same as in the human female; but out of $57 \%$ individuals, no less than 20 calved beyond the 298th day, and of these, some went on to the 321st, making an excess of nearly six weeks. Of 447 mares, whose natural period of gestation is about 335 days, 42 foaled between the 359th and 419th days, the greatest protraction being thus 84 days, or just one-fourth of the usual term. Of 913 sheep, whose natural period is about 151 days, 96 yeaned beyond the $153 \mathrm{~d}$ day; and of these 7 went on until the $15 \%$ th day, making an excess of 6 days. Of 161 rabbits, whose natural period is about thirty days, no fewer than 25 littered between the $32 \mathrm{~d}$ and 35 th ; the greatest protraction was here one-sixth of the whole period, and the proportion in which there was a manifest prolongation was also nearly one-sixth of the total number of individuals. In the incubation of the common hen, Tessier found that there was not unfrequently a prolongation to the amount of three days, or oneserenth of the whole period. In regard to cows, the observations of Tessier have been confirmed by those of Earl Spencer, who has published a table of the period of gestation as observed in 764 individuals; he considers the average period to be 284 or 285 days; but no fewer than 310 calved after the 285th day; and of these, 3 went on to 
the 306th day, and 1 to the 313th. It is curious that among the calves born between the 290 th and 300 th days, there was a decided preponderance of males-there being 74 to 32 females; whilst all of those born after the 300th day were females. The additional series of observations subsequently made by Earl Spencer, in regard to the constant protraction of the period in 75 cows in calf by a particular bull, has been already noticed. Another series of observations has been published by Mr. C. N. Bement, of Albany, U. S., who has recorded the period of gestation of 62 cows. The longest period was 336 days; the shortest, 213 days. The average period for male calves was 288 days; and for females, 282 days. On the whole, it may be consid. ered, that in regard to the human female, the French law is a very reasonable one; and there is quite sufficient analogical evidence to support the assertions of females of good character, having no motive to deceive, which lead to the conclusion that a protraction of at least four weeks is quite possible, and that a protraction to the extent of six weeks is scarcely to be denied.

"In regard to the shortest period at which gestation may terminate, consistently with the viability of the child, there is a still greater degree of uncertainty. Most practitioners are of opinion, that it is next to impossible for a foetus to live and grow to maturity, which has not nearly completed its seventh month; but it is unquestionable that infants born at a much earlier period have lived for some months, or even to adult age. It is rare in such cases, however, that the date of conception can be fixed with sufficient precision to enable a definite statement to be given. Of the importance of the question, a case which some time since occurred in Scotland affords sufficient proof. A vast amount of contradictory evidence was adduced on this trial; but, on the general rule of accepting positive in preference to negative testimony, it seems that we ought to consider it possible that a child may live for some months, which has been born at the conclusion of 24 weeks of gestation. In the case in question, the Presbytery decided in favor of the legitimacy of an infant born alive within 25 weeks after marriage. A very interesting case is on record, in which the mother (who had borne five children) was confident that her period of gestation was less than 19 weeks; the facts stated respecting the development of the child are necessarily very imperfect, as it was important to avoid exposing his body, in order that his temperature might be kept up ; but at the age of three weeks, he was only 13 inches in length, and his weight was no more than $29 \mathrm{oz}$. At that time, he might be regarded, according to the calculation of the mother, as corresponding with an infant of 22 weeks or $5 \frac{1}{2}$ months; but the length and weight were greater than are usual at that period, and he must have been probably born at about the 25th week. It is an interesting feature in this case, that the calorific power of the infant was so low, that artificial heat was constantly needed to sustain it; but that, under the influence of heat of the fire, he evidently became weaker, whilst the warmth of a person in bed rendered him lively and comparatively strong. During the first week, it was extremely difficult to get him to swallow; and it was nearly a month before he could suck. At the time of the report, he was four months old, and his health appeared very good. Another case of very early viability has been more recently put on record by Mr. Dodd : in this, as in the former instance, the determination of the child's age rests chiefly on the opinion of the mother; but there appears no reason for suspecting any fallacy. The child seems to have been born at the 26 th or 27 th week of gestation; and having been placed under judicious management, it has thriven well. One of the most satisfactory cases on record is that detailed by $\mathrm{D} x$ 
Outrepont (Professor of Obstetrics at Wurzburg), and stated by Dr. Christison in his evidence on the case first alluded to. The evidence is as complete as it is possible to be in any case of the kind; being derived not only from the date assigned by the mother to her conception, but also from the structure and history of the child. The gestation could have only lasted 27 weeks, and was very probably less. The length of the child was $13 \frac{1}{2}$ inches, and its weight was $24 \mathrm{oz}$. Its development was altogether slow; and at the age of eleven years, the child seemed no more advanced in body or mind than most other lads of seven years old. In this last point, there is a very striking correspondence with the results of other observations upon premature children, made at an earlier age. A very remarkable case has been since put on record by Dr. Barker of Dumfries, in which the child is aftirmed to have been born on the 158th day of gestation, or in the middle of the twenty-third week after intercourse. Its size, weight, and grade of development were conformable to the asserted period : for it weighed only $1 \mathrm{lb}$. and measured 11 inches; it had only rudimentary nails, and scarcely any hair except a little of reddish color on the back of the head; the eyelids were closed, and did not open until the second day; the skin was shriveled. When born it was wrapped up in a box and placed before the fire. The child did not suck properly until after the lapse of a month, and did not walk until she was nineteen months old. Three years and a half afterward, this child was in a thriving state, and very healthy, but of small make ; she then weighed $29 \frac{1}{2}$ Ibs."

The precise period, therefore, when the child can live, if brought into the world, is not determined, any more than the time it may remain in the womb. Some children may be able to live a considerable time before the full period of gestation, and others may not till some time after, there being a great difference in regard to their development.

One may be as fully developed at six as another at seven months. The common opinion is that the child cannot live if born before seven months. This, however, is incorrect. Many instances have been known of births at six months, and even earlier, in which the child lived, and became strong and healthy. Van Swieten mentions the case of one Fortunio Liceti, who was born before the sixth month. He was not larger than the hand, but grew to the average size, and lived to be seventy-one years old. 'Jr. Gunning Bedford mentions a similar case, in his translation of Chailly's Midwifery. There are even cases mentioned of children living at five months, but it must be borne in mind that it is seldom possible to determine the exact period. As a general rule, however, the child does not live till after the seventh month, though there undoubtedly have been cases where it has lived before the end of the sixth month. The law adopts the medium period, and declares the child capable of living at the end of the sixth month, and not before. There is no reason whatever for supposing that it is less likely to live at eight months than at seven, or that it will not live at all at eight months, as some do. 


\section{CHAPTER XXXI.}

\section{MENSTRUATION.}

Ir is well known that in all healthy and properly developed females, after a certain age, denominated puberty, there occurs a discharge of blood and mucus from the vagina, at certain regular periods, usually a month distant from each other, and which lasts, as a general rule, from two to four days. This discharge is called the courses, or the menstrual or monthly discharge, and it is intimately connected both with female health and with the process of conception. The real cause and nature of this singular phenomenon has always been a matter of dispute among philosophers and physiologists, and it is only in modern times that the truth has been known. Even at the present time, many of the best informed people, including some medical men, are not acquainted with it; and, in consequence of that ignorance, we have all kinds of errors prevalent on the subject.

Some of the most curious and important discoveries in human physiology have been made by observing the lower animals, with whom we can make experiments and observations in a more complete and methodical manner than with our own species, while the general laws which regulate their physical functions are the same with those that regulate ours. It was formerly thought that many organic actions in the human being were totally different to any that took place in the inferior animals, but it is now known that this is an error. There is no physiological action occurring in our own systems that we cannot find the counterpart of in other beings. It is true it may vary some little in the manner of its occurrence, and in unimportant details, but still it is always essentially the same action, and serves the same purposes. Thus it was formerly thought that this very function of menstruation was one peculiar to the human being, and that nothing analogous to it was to be observed in the lower animals, but it is now known that a corresponding phenomenon occurs in nearly all, in some form or other.

To understand how menstruation is produced, we must refer back to what has been stated in regard to ovulation, and the functions of the ovaries. It is only since a comparatively recent period that the existence of eggs or ova in the human female has been satisfactorily proved; but it is now known that they do exist the same in her as in all other females, and that they are uniformly developed according to a regular plan. The ovaries contain the ova or eggs in a rudimentary state, and they begin, at the age of puberty, to ripen or develop, as explained in the article on the Functions of the Ovaries. At the age of puberty, the first egg is ripened and expelled, in the manner already explained, and the same process occurs at every monthly period afterward till what is termed the change of life, usually about forty-five years of age, when the last ovum has been expelled, and the ovaries cease their functions. Now this ripening and expulsion of the egg every month is a very curious and important phenomenon, and exercises a powerful and peculiar influence over both body and mind, 
making the female essentially different to the male in her physical requirements and capabilities, and also in her nervous sympathies.

It is undoubtedly true that the monthly ripening and expulsion of the egg in the female, and its development into the new being when conception occurs, is the great and principal business of her organic system, and that it absorbs more of her nervous power, and more of her physical strength, than any other process she performs. In fact, all other processes, both nervous and nutritive, appear subservient to this, and chiefly intended to carry it on. There is nothing analogous to this ovulation in the other sex, and therefore there is nothing to compare it with, and that is the reason why the peculiarities of the female constitution and character are so imperfectly appreciated. In man there is no periodical function that absorbs, as it were, all the rest, and to which they are merely auxiliaries, but each acts independently, and it is only in exceptional cases that any one preponderates over all the others. Thus we sometimes see cases in which, either from organic peculiarity or from weak indulgence, the stomach is so active that digestion is the all-absorbing process, and every other function is imperfectly performed in consequence of its preponderating requirements. The person can neither think, nor perform muscular exercise, because he has no vital energy for anything but digestion. In the same manner, others do little else than think, through the brain being the over-active organ. Such instances may enable any one to conceive what follows when any one function overpowers, as it were, all the others, and to see how they must necessarily be subservient to it. But it must be remembered that such cases as these are exceptional and unnatural ones, and that they are not of the same character as the peculiar function referred to, though a consideration of them may enable any one to better understand its influence. The monthly formation of the egg in the female is not an exceptional occurrence, nor an unnatural over-excitement, but a legitimate and necessary result of her peculiar organic action, and the consequences of which she cannot therefore escape from. From the age of puberty till the change of life, nature is constantly laboring at this one function, and the female seems to live chiefly for this purpose. This is the true explanation of those peculiarities that are seen in the female character, especially of its excessive sympathy, sensitiveness, and excitability, and also much that is peculiar in female diseases. The incessant action of the ovaries keeps the nervous system in a constant state of irritation, and makes all the organic functions liable to derangement, so that it is impossible for a female to preserve that equanimity of mind and that evenness of temper and disposition which to individuals of the other sex is a comparatively easy matter. The female is, in fact, in a great measure, like a man who is constantly subject to annoyance from those around him, and who is obliged to use constant efforts to keep himself cool. Her situation is indeed, in some respects, even worse, because the cause of her uneasiness is inherent in herself; she cannot escape from it, and knows not what it is, and those around not knowing it either, she meets with but little sympathy and consideration. There are numbers of females who are most unfortunate in this respect, some being subject to distressing depression of spirits, or the most melancholy despondency ; while others are irritable, or peevish, or subject to ebullitions of the most frantic gayety; and others, again, constantly change from one mood to another, without any apparent reason for so doing. Ignorant persons attribute these eccentricities to mere caprice or whim, and fancy that females can avoid them if they choose. Sometimes they are blamed or scolded for them, and are thought to be perverse or contrary, and sometimes females even accuse themselves 
of being ungrateful and dissatisfied, and in this way increase their distress. If, however, the true nature of their constitution was understood, it would be seen that no blame whatever should be attached to them for these peculiarities, since they cannot be avoided, but, on the contrary, every allowance should be made for their involuntary aberrations, and the fullest sympathy exhibited for the distress which they really endure. The ovaries and the nervous system exert a reciprocal action, so that one can influence the other to a remarkable degree, which is the reason why many female diseases can be so much modified, or even produced, by certain states of the mind and feelings. It is often the case that a female suffering from indisposition is not benefited at all by medical treatment, but through some pleasing impression on the mind or feelings, is relieved immediately. I have often seen females completely prostrated, with scarcely energy or ability enough to breathe, who have been restored almost instantaneously by a word of hope, an expression of sympathy, or a little kind and pleasing attention, especially if it was from some wished-for but unexpected quarter. In such cases, uninformed people are apt to suppose that there has been no real indisposition at all, because the improvement was so rapid, and without medicine. A proper understanding of the subject, however, would show them that these apparent caprices are as real as any other forms of disease, and that moral or mental medicine may be as active as drugs, and often much more beneficial. In short, if the nervous system is kept in a constant state of irritation, and the feelings and sympathies are habitually outraged, it is often impossible to do much good in female indisposition. The conduct of those around the patient is of more consequence than the physician's prescription, by far, and may, according to its propriety or impropriety, either accelerate or impede the cure. There are many men who habitually act in such a way toward their female companions as to both cause them suffering and prevent its removal, and that too without either desiring or intending to do so. They do not act from unkind motives, but their ignorance prevents them from seeing the consequences of their conduct. Conceiving females to be like themselves, and knowing that they can shake off the vapors, as they call them, and that their nervous systems are not easily irritated, they cannot feel a proper charity toward their sensitive companions. Females, on the other hand, feeling that they are not understood, nor their condition properly appreciated, and having no one to repose confidence in that they think can appreciate them, are apt to become morose, and retiring within themselves conceal their suffering and disquiet from every one around them.

This ignorance respecting the female constitution is, therefore, a serious evil, making them liable to suffer, and causing the other sex to withhold from them that sympathy and charitable consideration so much required, and which would be generally bestowed, if men were better informed as to its necessity and utility.

The ripening and expulsion of the egg is effected by a real inflammation, similar to what is seen when a splinter of wood, for instance, is expelled from the flesh by the process of festering, and it is this periodical inflammation that causes the sympathetic irritation above described. The inflammation is slight at the beginning of the month, but gradually increases toward the end, when the ovaries are found to be highly congested, and the blood-vessels in them and the uterus are much engorged. About the time when the egg is expelled from the vesicle, the inflammation reaches its height, and to relieve it the vessels pour out a quantity of blood and mucous, in the same way that a discharge occurs after inflammation in other parts. This is the true cause of the menstrual flow. It is a consequence of the action of the ovaries, 
and is only seen in those who possess these organs perfect. Females who have no ovaries, or in whom they are torpid, never menstruate.

The importance of a knowledge of these facts, both to the preservation of health and also in medical science, is very great. The medical treatment of deranged or suppressed menstruation has always been chiefly empirical, and seldom of much service, because the real origin and nature of the flow itself was unknown. In fact, there is no denying that, instead of doing good in these cases, medical science has led to much evil, and probably has caused more disease than ever it has cured. And yet, when properly understood, these derangements are usually readily corrected, and by very simple means.

In some young females this discharge occurs suddenly the first time, without any premonitory symptoms whatever, and occasionally it continues to do so at each of the succeeding periods, but more usually it is indicated by certain well-marked signs peculiar to that condition alone. Generally the female experiences considerable excitement just previous to its appearance, with a sensation of fullness in the head, slight fever, and pain in the back and abdomen. In some, these symptoms are much aggravated, so that they suffer severely, even more than at the time of parturition. There are females who are made perfectly delirious with the pain at these times, or so completely prostrated that they have scarcely strength to move. Others are more fortunate, and experience little or no inconvenience at their periods; but these are the exceptions, and there are but few who are not more or less affected, particularly by lowness of spirits or irritability, and on that account considerable allowance should be made for what may appear strange or unusual in their conduct and manner. This is what is usually termed being unwell, and it is generally indicated by certain changes in the countenance, as well as by the signs mentioned above.

In the first twenty-four hours, the discharge is commonly slight, and pale in color, but afterward it becomes more profuse, and like real blood. The time it lasts is about four days, but varies considerably. Thus in some it endures a week, or more, and in others only a day, or even but a few hours. Some of these irregularities are natural, and must not be interfered with, but others are accidentally produced, and should be corrected. The discharge subsides into a colorless mucous secretion, commonly termed Leucorrhoea, or the whites, which when it remains constant, and too abundant, constitutes a real disease.

The quantity of fluid lost is on an average about six ounces, but it varies much in different persons, in some being very abundant and in others very small. I have known females to lose over a quart each time, without any apparent ill effects. To some extent it appears to be affected by climate, being more abundant in tropical countries and less so in cold ones. In some cases it is nearly or quite colorless, owing to there being little or no blood mixed with it, and then the individual is apt to suppose she has not menstruated when she really has. It is for this reason that such persons can never correctly estimate the proper time when conception can occur. The real period is not suspected by them to be so, because it is colorless, and then if any flooding, or mere discharge of blood from weakness takes place, they think that is the period, and in this way they fail in their reckoning.

It was formerly thought that the menstrual discharge was something peculiar, and that it was possessed of certain deleterious properties, but this is now known to be a fallacy. It is nothing more than real blood mixed with the ordinary mucous secretion of the parts. Its odor is peculiar, and sometimes powerful, owing probably 
to its having been retained in the uterine vessels some time before its discharge, and having in consequence undergone some change, or fermentation. And this accounts for its odor being always stronger, and its color darker, when it has been retained longer than usual.

In former times menstruation was attributed to the influence of the moon, and it was thought that it only took place when she was at the full, but this is well known not to be the case; there are probably females menstruating every hour of every day in the year. It is true the usual period between the cessation of one discharge and the beginning of another, is generally equal to the time of the moon's revolution around the earth, being twenty-eight days, but they do not otherwise correspond. Indeed, in some there are not more than two or three weeks between, while in others there are five or six, or even more, and yet this may be to them perfectly natural and proper. The real cause of menstruation is the ripening and expulsion of the egg, and of course it occurs whenever an egg is developed, whether that be frequently or rarely. It was found from observation that, in one hundred females, sixty-eight menstruated every twenty-eight days ; twenty-eight every three weeks; and one every second week; while ten were irregular.

The first appearance of the menses varies from about the twelfth to the seventeenth year, in our country, but it is affected by various circumstances. In the greater number of females it commences from fourteen to fifteen, though it is sometimes delayed till twenty or more, and occasionally is seen at nine, or even earlier. I have seen a case myself in a mere infant. Out of four hundred and fifty cases observed at the Manchester Lying-in Hospital, England, ten menstruated first at eleven years of age, nineteen at twelve,-fifty-three at thirteen,-eighty-five at fourteen,-ninety-seven at fifteen,-_seventy-six at sixteen,-fifty-seven at seventeen, twenty-six at eighteen,- - twenty-three at nineteen, - and four at twenty years.

The time when the menses cease, or the turn of life as it is called, that is when every ovum is developed, is usually from forty to forty-five years of age, but like the commencement this is also liable to considerable variation, some females arriving at the turn when they are but thirty, and others not till they are fifty, or even more. Sometimes after it has apparently ceased, at the usual time, it will appear again, for a time or two, many years after, at advanced age. This is probably owing to one or more of the eggs having been left undeveloped in the ovaries at the time of the turn, through being imperfect, and their ripening afterward. In such cases conception is possible at these after periods, which accounts for those instances of child-bearing in old females, which are occasionally met with, sometimes as far as the sixtieth year. of course conception is possible as long as proper menstruation continues, but never when it ceases, or has not appeared. It is true, that in some cases females have borne children who have apparently never menstruated, but these were undoubtedly cases in which it was simply colorless, and small in quantity, so that they did not observe it, or else thought it was only the whites. The menstruation, in some form, must always occur before pregnancy can ensue, but the excitement and inflammation may be so small, in particular constitutions, that none of the usual indications are observed. It is owing to this that some females, who think they do not menstruate often enough, are deceived, because many periods are apt to be unobserved by them. And on the contrary many others who fancy they have their turns too often are equally deceived ; many of the supposed menstruations being mere floodings, or discharges of blood from weakness or over-fullness of the vessel. A mere show of 
blood therefore is no proof of menstruation, nor is its absence any sign to the contrary.

In one series of observations it was found that in seventy-seven females one ceased menstruation, or arrived at the turn of life, at thirty-five years of age,--four at forty, -one at forty-two, - one at forty-three, - three at forty-four,--four at forty-five, three at forty-seven, - ten at forty-eight, - - seven at forty-nine, - twenty-six at fifty, two at fifty-one, - - seven at fifty-two,--two at fifty-three,-two at fifty-four, -one at fifty-seven, two at sixty ; and one at seventy!

It is commonly supposed that menstruation commences earlier in hot countries than in cold ones, and in consequence of the heat, but it is by no means universally so. Mr. Robertson has shown by his researches that it commences everywhere at about the same average age, and that the early intercourse of the sexes which takes place in the Indies, and other warm countries, is owing more to a depraved state of morals, and to unrestrained intercourse than to any influence of climate. He remarks that the early marriages we see there are " to be attributed not to any peculiar precocity, but to moral and political degradation, exhibited in ill laws and customs, the enslavement more or less of the women, ignorance of letters ; and impure or debasing systems of religion." He also thinks that if the same manners and customs prevailed in England, or America, the same effects would be seen, and this is fully borne out in those pitiable instances, occasionally seen in our large towns, of juvenile prostitution. Many of these degraded and brutalized children at eleven or twelve years are as much women, in certain respects, as they ought to have been at seventeen or eighteen, and of course any other children would be the same if exposed to the same influences, unless, as fortunately is often the case, the initiation into vice caused their death.

In cities generally, on the average, menstruation commences earlier than in the country, owing to the more exciting circumstances that surround young persons, and which awaken the sexual instinct precociously. This is particularly the case in those places where morals are bad, and familiar intercourse between the sexes is unrestrained. In the Eastern parts of the old world marriages are often contracted while the female is very young, but it does not follow that she was fitted for it; and in all probability if those very females had been educated like our own they would have been in no respect different. We are told for instance that Mahomet consummated his marriage with one of his wives when she was but eight years old. In this, however, we simply see the proof of her degradation and enslavement, and not of her natural precocity. So far as is known also there is no difference as to the time of the first menstruation among the different races of human beings. Thus, for instance, it is no earlier under the same circumstances, in the negress than in the white female.

As a general rule the earlier menstruation commences, and the more frequently it occurs, the earlier it will cease, and to this there are but few exceptions. It is therefore of considerable importance to the future health of the female that this grand event should not be accelerated by any factitious causes, but should be brought on by the slow and unaided process of natural development. Young females should be allowed to remain as children, or girls at least, much longer than they usually do, and not be forced into young women too soon. For every year earlier that they become young women they probably become old ones five years before they otherwise would have been. It is of the ntmost importance that young females should have their muscular systems well developed previous to puberty, and that 
they shon!d not have their minds and feelings too much excited. Nothing tends to bring on puberty more than a morbid excitement of the feelings and sympathies, such as results from silly romances, and over-wrought love-tales. Excessive study also is very injurious, and the too constant attention to what are called mere accomplishments. These are often pursted to the utter sacrifice of what is useful or beneficial, and result in nothing but premature development of those instincts that had better lie dormant till a later period. In fact, the education of young girls seems too often to have but one object, and that is to force them into women as rapidly as possible, to the utter ruin of their health and happiness.

In former times, as we find from the Bible, a woman was thought to be unclean while menstruating, and was shunned as something hurtful and deleterious. According to Pliny, the ancient naturalist, it was thought that she would destroy grafts, or bees, and blight corn, make iron rust, and even cause madness in dogs. Nay, he even goes so far as to say that the menstrual fluid, by its odor, will cause fruit to fall from the trees, destroy insects, and cause seeds not to grow. Many barbarous nations at the present day entertain similar notions, and at such times compel females to secrete themselves, and shun society, when they really need the most sympathy and kind companionship. M. Moreau de la Sarthe, in his Natural History of Women, tells us that the South Sea Islanders, and the South American Indians, always send their females to separate huts during these periods, and that the Mlinois Indians formerly punished any woman with death who failed to give due notice of her being in that condition. According to history we also find that by a decree of the Council of Nice, women were forbidden to enter the church while menstruating. In the laws of the Israelites it is enacted, that "If a man shall lie with a woman having her sickness, and shall uncover her nakedness, he hath discovered her fountain, and she hath uncovered the fountain of her blood, and both of them shall be cut off from among their people."-(See Leviticus, chap. 20, v. 18.)

Such notions it will be seen are now happily to be found chiefly among barbarians, or in the records of a former ignorant age, though there are individuals who entertain them even yet. Indeed at the present time there are persons, especially among the ill-informed in England, who believe that meat will not take the salt if the process be carried on by a female who is menstruating. Others again think that bread will not rise, that beer will sour, and milk curdle, if a female so cireumstanced have anything to do with them. It is perhaps scarcely necessary to say that all such notions are as erroneous as they are absurd, and that they are practically disproved every day, by thousands of females who pay no attention to them, and who yet conduct all the above operations as successfully as if nothing of the kind was taking place.

The first appearance of this function is an important event, and should be carefully watched for, so that nothing may be allowed to interfere with it, and also that means may be taken to bring it on if it be too long delayed. Young females ought especially to be timely informed about it, so that they may know how to conduct themselves, and may not be needlessly alarmed, as many are when it first appears. These matters, however, belong more especialiy to medicine, and will be found fully explained in the chapter on the Diseases of Woman.

It is especially important to bear in mind that females are usually more irritable and unsettled at these times, and that full allowance should be made for their being so. In a young person this is more apt to be the case, from the very novelty of her situation. The strange phenomenon that is occurring in her system, the development 
of her person, and the new feelings and instincts that are awakened, all exert a powerful influence, which is still further increased by the mystery with which every* thing relating to these wonderful operations is enshrouded. In the absence of proper information, imagination is busily at work, curiosity is excited, and the mind becomes filled with strange fancies and romantic dreams, which often exert a baneful influence in after life. Proper instruction, at the proper time, with a wellregulated mind and body, would give more correct ideas of her real duties and sexual situation, and prevent much of that sickness and unhappiness of mind which are so commonly seen after marriage.

There are few objects more interesting to the philosopher and philanthropist than a young female at this period of her existence, when the body is assuming its natural beauty of form, and becoming fit for its wondrous functions, and when the expanding mind receives the first faint perception of her real destiny.

To a great extent, the development of the whole physical system depends upon the action of the ovaries, so that if they are absent, or inactive, every other part of the organization remains imperfect. The destruction of them in early life causes a similar imperfection to what follows the removal of the testes in the male, and even at adult age, as already shown, they exert a paramount importance over the other organs. It is apparently the effort that is required to develop them, in fact, that makes the body grow and perfect itself so rapidly at puberty. Every one must have noticed what an astonishing change occurs in a young female at that time. The bust becomes full, the pelvis enlarges, the features change-especially in their expression--the mind takes a different turn, and the manner and conduct become altogether different, denoting the new feelings and instincts that begin to be experienced. In short, the girl is changed into the woman, and is conscious herself of the alteration. All these changes result from the action of the ovaries, and if they are incapable of performing their functions, no such alterations take place, but on the contrary, the system either remains always as it was during girlhood, or develops in an unusual manner, similar to the male for instance. Nature seems to refuse to put forth her energies to perfect the rest of the system if she cannot first perfect the essential organs of generation, and the first menstrual flow, or the ripening of the first egg, is, therefore, the constant and necessary prelude to womanly development.

In reference to marriage, menstruation ought always to precede that event, and generally for a considerable time-twelve months at least-especially if it commences early. It is not always that it continues regularly from the first commencement, but ceases for some months, or even longer, and then commences again.

The proper age for marriage is, of course, variable in different individuals, some being properly developed years earlier than others, and no general rule can, therefore, be given. One necessary condition is the perfect establishment of menstruation, as already stated; and, perhaps, the next most essential requisite is the proper development of the body, especially of the pelvis and genital organs, for if these have not attained to a certain growth before marriage, they may never do so afterward. A neglect of these matters leads often to the most serious and unhappy consequences, from which there is no escape. Nevertheless, there are cases in which marriage may be required to perfect the development of the system, and in which it will always remain imperfect without, but these are very rare, and are usually indicated in an unistakable manner, 
The proper time for marriage is midway between two of the ordinary periods, let the space be what it may. I have known instances of young females marrying either at the menstrual period, or so near that nervous agitation, consequent upon the ceremony, has brought it on, and many evils have followed therefrom, to say nothing of the annoyance and distress. This was, of course, the fault of those who had these young persons under their care, and who had neglected to inform themselves upon so essential a point. Immediately after, and immediately before menstruation, are neither so proper as the midway, the organs and the nervous system being at both these times more or less excited and irritable. Marriage just before menstrua tion has been known to arrest it, so that it never afterward returned.

As a general rule, menstruation does not take place during nursing, though, occasionally, it does so, even commencing as early as the first month after delivery, and continuing on uninterruptedly. The reason why it does not take place at this time generally, is, because the blood and the vital energy which is ordinarily expended in ripening the egg, is needed during nursing, to secrete the milk, and it would exhaust the system too much to carry on both functions at the same time. In those cases where menstruation and nursing do occur simultaneously, it is either because there is a superabundance of vital energy, by which both can be supported, or the ovaries are in a state of chronic irritation, owing to which they act when they ought to be dormant. In the first ease, no injury may result from both taking place at the same time, but when there is not a real excess of energy, this double drain nearly always exhausts the strength, and impairs the health. It is not, as some suppose, necessarily improper, or injurious to the child, for nursing to be allowed while the turns continue, unless the health and strength of the mother suffer thereby. If she becomes weak, the milk is often imperfectly formed and watery, so that the child is not perfectly nourished by it, but there is nothing positively hurtful in its nature under such circumstances. It is not necessary therefore to discontinue nursing at such times, unless the mother evidently suffers from the anusual condition.

During pregnancy the menses do not appear, for the same reason, though in some females they are thought to do so. All the energies of the uterus and ovaries are then needed in developing the new being, and the ovaries are necessarily dormant. Besides this, the interior of the womb is covered, immediately after conception, with the membranes surrounding the fœetus, which effectually close the mouth of each Fallopian tube, and of the womb. If either an ovum or the menstrual fluid were to form therefore, it could not pass away, unless these membranes were detached, which would cause abortion.

When a discharge occurs during pregnancy, therefore, it is not a real menstruation, though it may take place regularly at the month, from the habit of the system, but it is simply an escape of blood from the vessels of the vagina, or neck of the womb, owing either to their weakness or over-fullness. It is really a flooding, therefore, which may do no harm while it is confined to the parts below ; but if it extends to the interior of the womb, it is nearly sure to cause miscarriage. This is one reason why much sexual excitement is improper during pregnancy, because it is apt to excite the ovaries to form the ova, and thus lead to miscarriage by their expulsion.

After marriage the question is often asked of the physician, whether connection during menstruation is improper? To this it may be answered, that, in some cases, st is both disagreeable and painful, and therefore obviously improper; but, in other 
cases, it is rather desired than otherwise, and is apparently not at all injurious, and then it must be objected to on other grounds than being unnatural. Perhaps there are but few persons who need any particular reason for abstaining at such times, considerations of delicacy alone being sufficient. The feelings and instincts of the female herself are all that need be consulted, and it is very seldom that they will direct her wrong. It is certain that there are persons who never experience a desire for association, except at such times, and we are certainly not justified, on scientific grounds at least, in saying that it should then be forbidden. The old idea that certain diseases originated from association at such times is altogether erroneous, and without the slightest foundation.

Until recently, it was thought that menstruation occurred in human beings only, but it is now known that it occurs in most animals, though in a different form. Every being that brings forth its young alive, has a certain period in which the development of its ova or eggs is effected, and at those times when they are fully ripe, there occurs a function analogous to menstruation. Thus taking most kinds of cattle for instance, as the wild deer, they are capable of conception only at one time in the year, and will only receive the male at that time. This is what is called the season of Rut or Heat, and on dissecting them, the cause of it becomes obvious. They ripen an egg only once in the year, and when that occurs it causes the excitement which makes them desire association, and also results in a peculiar discharge from the genital organs, which is, strictly speaking, the same as human menstruation, though it is nearly colorless. A discharge of this nature is seen in all animals at such times, and, occasionally, as in some of the monkeys, it is even tinged with blood. It is, therefore, merely in its color, quantity, and frequency of appearance that it varies; in some taking place but once a year, in others every two or three months, and in the human being monthly, according to the frequency with which the eggs are ripened. These facts have led some physiologists to suppose that the most appropriate time for association in the human being, is near to the monthly periods, because in the animals above referred to, it is only at such times that they desire it. In the human being, however, there are many essential differences, in regard to the commerce of the sexes, and especially in the feelings that lead to it. In the lower animals, it is, of course, a mere amorous propensity that impels, and which is excited only by peculiar conditions of the genital organs in both; but in human beings there are other feelings, of a higher order, which are often more powerful than the sexual instinct itself. The mere animals being impelled to the act only by physical excitement, depending on a certain condition of the parts, will, of course, feel the impulse only when those conditions exist, but the human being may also be impelled by mental and moral agencies, though the physical excitement may be weak, or even if it be quite extinguished. . It is not always therefore solely for the indulgence of the mere sexual propensity that human beings associate but for that conjointly with other instincts, and therefore the same rule should not apply to them. It is, perhaps, desirable, physiologically speaking, that association should never take place without both physical and moral enjoyment in both, and therefore those times should be chosen when the female organs are most dispused to these peculiar excitements. This time is not always the same, being just after the period in some, and just before it in others, and occasionally only during the flow itself. As a general rule, it is found that in the great majority of females, the inclination is strongest immediately after the flow, and it is also then that conception is most likely to ensue. This is 
analogous to what is observed in the lower animals, in whom the flow has always passed its height before the heat is experienced. In medical practice, it is found that those means which we use, in cold temperaments, to produce sexual feelings, always act best just after the period is over, and this is, therefore, doubtless the most proper and favorable time for association, though there is nothing inherently wrong in it at other times.

Formerly a notion prevailed that association during the flow was wrong because the offspring resulting therefrom would be diseased or insane; and in fact, certain peculiar affections were thought to have originated in that way. This, is, however, altogether erroneous, because conception cannot occur at that time, as shown in another place.

It is probable that the menstrual flow is also made use of by nature as a means of periodical purification, and that many matters which would be hurtful to the body, if retained, are removed by it. This accounts for the fact that females can work without injury at certain employments in the metals, where poisonous fumes are evolved, and which would kill men, the deleterious matter being carried off in this way. It is for this reason also that the turn of life, when the flow ceases, is so critical a period. The cessation of this periodical purification, of course, makes the body more liable to disease, and more disposed to suffer from congestions of blood, because there is now no monthly abstraction to give relief. It is, therefore, at this time, particularly necessary to attend to all the other secretions, especially the skin and bowels, to keep them active, so as to make up for that which is suspended.

It may not be out of place to remark here, that the existence of this function alone makes it impossible for woman-except in a few peculiar individual cases-to pursue the same arocations, and follow the same mode of life as man. It makes her, of necessity, not so continuously active, nor so capable of physical toil, while, at the same time, it causes her to yearn for sympathy and support from some being that she feels is more powerful than herself. 


\section{CHAPTER XXXII.}

\section{CAUSE OF THE DIFFERENCE IN SEX, AND PRODUCTION OF SEX AT WILL.}

THESE have always been fruitful subjects of discussion both among physiologists and popularly, but until recently nothing certain has been known about them. Nevertheless, I am of opinion that they will eventually be perfectly understood, and that the sex of every child will be known previous to its birth. Our knowledge at the present time, it is true, is not perfect on this point, but still much more is known than what is usually supposed, and as such information may occasionally be really valuable, besides being of great interest, I shall lay it before my readers.

All the old ideas on this subject are utterly unfounded, and generally as absurd as they are erroneous. Such, for instance, as supposing that if the parties lie on the right side, during the act of association, the offspring will be male, and if on the left side, female. Or imagining, as others do, that males are more apt to follow from connection in the early part of the day, and females when it is practiced in the evening. Neither is there any foundation for supposing that it depends upon which sex the parents most strongly desire, as many know well from experience.

The idea about the position, during the act, determining the sex, originated from an unfounded theory of the physiologists themselves, namely, that the right ovary produced males, and the left females. So generally was this opinion received, and so far did it influence even practical men, that about the year $182 \%$, a physiologist named Millot, published a book on "The Art of Procreating the Sexes at Will," in which he gave directions for producing whichever might be desired. He even gave the names of several mothers who were said to have succeeded in their wishes by following his directions, but of course did not enumerate those who were disappointed, though experience has fully demonstrated that they were undoubtedly equally as numerous. In short, the theory, though captivating, is founded on an untruth, and cannot, therefore, be practically true.

In several instances it has been demonstrated, most conclusively, that each ovary can produce both sexes. Thus instances have been known where one has been destroyed by disease, or where it has been naturally deficient, and yet the female has borne both boys and girls. In one case not only was the ovary and Fallopian tube absent entirely on one side, but even the corresponding half of the womb itself was imperfect, and yet she had borne eleven children of both sexes.

The fact appears to be that the sex is determined by the joint action of several distinct causes, the principal of which at least are known, so that the great majority of children can be made of whichever sex is desired, providing certain suggestions are attended to. And I may remark here, that this assertion is not based upon theory alone, but upon certain observations, and also upon a long series of experiments with animals. The peculiar nature of my practice has of course brought many persons to me for information on this very topic, and I have therefore been able to 
verify the correctness of my conclusions. In every case, unless certain inappropriate conditions existed before marriage which could not be corrected, I would guarantee either the one sex or the other, providing my advice was strictly attended to!

To understand how this can be done, I must first state what has been ascertained respecting the influence of relative age. It has been found, by actual observation of some thousands of cases, that the oldest parent most frequently imparts the sex, unless the age be so great as to verge upon decrepitude. Thus, for instance, when the fathers are younger than the mothers there will be born about ninety boys to one hundred girls, and very nearly the same when they are of equal age. When, however, the fathers are from one to six years older than the mothers, there will be born one hundred and three boys to one hundred girls; and when the fathers are from nine to eighteen years the oldest, the number of boys will be one hundred and forty to one hundred girls; but if they be more than eighteen years older, the number of boys will be two hundred to the hundred girls.

In the same way, just in proportion as the mothers are the oldest, the number of girls will predominate; till, when they are from eighteen to twenty years older than the man, there will be twice as many girls as boys. It may of course happen that this rule may not hold good in many single families that may be noticed, but it will always do so when the average is taken of a large number, and the chances of course are in the same ratio in every instance. Thus in every case when the father is over eighteen years older than the mother, it is two chances to one that the child will be a boy, and in three hundred such births there would be just two hundred male to one hundrea females; while, if the mother be so much the elder, the chances and results will be just the same the other way.

The relative age, therefore, has a most potent influence over the sexual formation, but still there are evidently other agencies also, because it does not operate in every individual case, and we must therefore endeavor to discover what those other agencies are. My own impression is, that in the exceptional cases, where the elder parent does not impart the sex, it is owing to the younger parent being much the more vigorous. This view I have had many opportunities of verifying, in confidential communications, and I have almost invariably found it correct. This also shows why it is, that the greater age is no advantage beyond a certain period. Thus, for instance, if the father be over fifty, while the mother is under thirty-five, the rule will change, and the number of girls will predominate. We also find that the greater number of first children are boys, especially if born soon after marriage, owing to the father being naturally most powerful then. In illegitimate children, on the contrary, there are most girls, probably because in many of these cases the female is more vigorous than ordinary. In those countries where polygamy predominates, or where the men have several wives, there are many more girls born than boys, owing, no doubt, to the male power being weakened by excess, and expended among - many, which causes the female power to predominate. For this reason polygamy must always continue itself, because the number of females will constantly. oe greater than the number of males; and if there were no foreign admixture to take place, a nation would probably become extinct, in time, under such an institution.

It is stated, in the article on the influence of connection after conception, that the more frequently it takes place, the more the child will resemble the father in many particulars, but not necessarily in sex. If, however, the mother have much less sexual 
power, and experiences little or no enjoyment at those times, the father is likely to impart sex also, as well as general resemblance.

There are many females who are capable of proper excitement at other times, but not after conception, owing to some change in the action of the organs, and if connection still continues in such cases, the offspring is nearly sure to be a boy, because the father then predominates. On the contrary, there are other females who never experience excitement till they have conceived, and then it is often so great as to preponderate, and very likely to cause a girl to be produced. This accounts for those instances in which children are produced of the same sex as the parents who are the least vigorous-they being, in fact, the most so at a particular and critical period, though nsually otherwise:

The production of either sex, therefore, is, to a very great extent, within our power, providing we can fulfill the principal of the above indications. If, for instance, a boy is desired, the father should be older than the mother-say at least five yearsand conception should not be allowed to take place during the first five days after the monthly period. . The relative warmth of temperament should also be regulated, so that the female do not preponderate, especially at the time of conception and during the first two or three weeks afterward. If a girl be desired, of course the opposite conditions should exist, and in every case where the age is not appropriate, the other particulars must be the more scrupulously attended to. The means by which the warmth of the temperament may be increased, in either sex, is a portion of the medical art, and is explained in another place. Suffice it to say here, that it can nearly always be accomplished, even in those females who have been always perfectly indifferent.

Many intelligent breeders of animals are practically acquainted with these principles, and will undertake to breed almost any proportion of either sex, by properly mating the parents as to age, vigor, and frequency of association, besides causing the offspring to resemble which they please, and to partake of any general characteristics.

Taken in conjunction with what is stated in another article, respecting the influence of the male in connection after conception, and also with what is stated as to the power of the mother's imagination over her offspring, it will be seen that these facts are of the greatest value, and it will one day be accounted of the utmost importance for every married person to be acquainted with them.

From what is observed in some animals, and also in the vegetable world, the conversion of one sex into the other is actually demonstrated. Thus it is well known that bees, when deprived of their queen, will make another; and this they do by taking one of the larvæ or grubs, such as produce, under ordinary circumstances, a common worker or drone, and treating it in a peculiar manner, feeding it upon different food, and carefully tending it in a different way to what they ever tend the others. The result is, that the grub, which would have been an ordinary bee, under the usual conditions, is by this treatment formed into a queen or perfect female. In this case, then, sex is evidently a result of development, effected chiefly by a peculiar kind of nutrition. Botanists also know that plants frequently change their sex in a remarkable degree, under peculiar cultivation, some becoming nearly altogether staminate or male, and others nearly altogether pistillate or female, though in their natural condition they remain uniformly one or the other, or a proper mixture of both. 
A still further confirmation of the identity of these organs in the early stages, is afforded by some cases of accidental hermaphrodism. Thus, in many crustaceous animals, as crabs, for instance, it is not at all unusual to find a perfect ovary on one side, and a perfect testicle on the other. I have observed the same peculiarities in fishes also, and in one case at least it was found in a human being. Birds scarcely ever have the ovary developed but upon one side, the other being merely rudimentary, and sometimes even formed something like a testicle.

Many circumstances make it probable that the first stage of development of the primary cellules is always into ovaries, and if they develop no further, of course the being remains female, and all the other parts correspond. If, however, any additional impulse be given, they develop further, and become testicles, the other parts changing also, and thus forming a male.

There are therefore varions causes that influence sex, as already shown, but there is one that really determines it, in nearly all cases, and that we will now explain, but first give a short sketch of the various opinions held on the subject, from the most remote times.

Hippocrates taught that both the male and female secreted a semen, which was a kind of essence, coming from every part of the body in each. He also considered that the semen, in both, consisted of two parts, one male and the other female, and that when the two male semens combined a proper boy was formed, and when the two female semens combined a proper girl was formed. But if the male part of the father's semen united with the female part of the mother's, there would be either an effeminate boy, or a boyish girl, according to which semen predominated.

This, of course, was all theory, and without the least foundation in fact.

Some followers of Hippocrates went further than this, and undertook to give the signs by which it could be told, in either male or female, which semen predominated in them, and consequently which sex they would be likely to procreate; but all these signs were mere fanciful speculations.

Others considered, as before stated, that the semen from the right testicle produced males, and that from the left, females; but this theory had no better foundation than the other. Nevertheless practical rules were given, founded upon this theory. Thus, those who wished boys were directed to tie a band round the cord leading from the left testicle, or even to have it cut out, so that semen could come only from the right one. Those who wished girls, of course were to do the same with the right testicle, so that semen could come only from the left one.

No doubt much mischief and disappointment was caused by the promulgation of such a theory, but it held its ground for a long time. Hufeland first showed its improbability by referring to the fact, that if a number of fish eggs are impregnated with the same semen, some will form males and some females, and not all one sex or the other. Those who acted practically upon the theory soon found out it was not to be relied upon. Besides, men with only one testicle were known to become father of children of both sexes.

A similar theory was then broached in regard to the female ovaries, - that the eggs from the right one produced boys, and those from the left one girls. This, however, was equally unfounded with the other, and was disproved by the fact that females with only one active ovary had children of each sex, the same as men with one testicle only were fathers of both boys and girls.

One celebrated physiologist even asserted that the womb was divided into seven 
parts, three on the right side for males, and three on the left for females, with one in the middle for hermaphrodites. Of course this was all fancy-a mere speculation.

Harvey taught that the female semen formed the egg after the male semen came in contact with it, and that from this egg the new being was formed. He was quite unaware that the egg was formed independent of any connection with the male.

Buffon, still holding to the teaching of Hippocrates, that each sex secreted a semen, contended that the animalcules in the male semen formed boys, and those in the female somen girls.

More modern theorists have supposed that sex was a mere matter of development, and that all were the same, or hermaphrodites, at first. And it is true that in the early stages it is impossible to tell one sex from the other, the organs being precisely the same in all cases. The different parts of the sexual system, in males and females, correspond to each other, and in the early stages no one can tell what the future sex might be.

\section{PRODUCTION OF SEX AT WILL.}

To understand the true theory of the cause of sex, we must refer to the Physiology of Generation, as already explained.

The female forms the egg, and the male forms the semen, both independent of the other, but the egg cannot develop into the new being till the semen unites with it. The female ripens one or more eggs each month, at what is called the monthly period, and these eggs are retained in the womb, when passed there from the ovary, only for a certain number of days. It is therefore possible for the conception to occur only during those days, for the semen cannot cause conception if there be no egg in the womb for it to impregnate.

The majority of conceptions occur within eight days after the monthly period, though a few may occur as late as twelve days after, or in very rare cases, perhaps fourteen. It may also be possible a day before, in very few cases, as previously explained. At all other times conception is impossible.

Now, it must be borne in mind that the egg at first is not quite perfect,-it gradually ripens as it proceeds on its way to the womb. Very often it is not ripe enough to be impregnated when it first reachss the womb, but has to remain there some days first, and this is why some females cannot conceive till some days after their periods. In others, on the contrury, it is fully ripe when it reaches the womb, and if not impregnated immediately, it becomes over ripe, and breaks up. In such cases, if the woman is not impregnated immediately her period is over, she cannot conceive at all, and this is one reason why many are sterile,--they are always too late.

It is upon this fact, of the gradual ripening, or perfecting of the egg, that the true theory of the cause of sex depends, as we will now show.

It must be borne in mind that the egg can be impregnated only at a certain. stage of ripeness, or maturity, and that before that stage, or after it is passed, impregnation cannot take place. Thus M. Coste has shown, in his observations upon poultry, that their eggs can be impregnated only in the upper part of the oviduct, and that when they have passed to the lower part they are over ripe, and can no longer be impregnated。 
And this is strictly analogous to what occurs in plants, there is only one stage in the development of the pistil in a flower when the pollen can fertilize it. Before that stage arrives, or after it has passed, fertilization is impossible.

This particular stage of maturity, or ripeness, in some cases endures but for a very short time, but in others it is much more prolonged, both in plants and animals. But in all cases it is the limit within which impregnation is possible.

Now it has been discovered, through observations upon the lower animals first, that the sex of the future being developed from any egg depends, mainly, upon the stage of ripeness that egg was at when impregnated.

Messrs. Schirac and Huber discovered, in their observations upon bees, that an egg only partly developed always produced a female, while one fully developed, or ripened, always produced a male.

The queen, or fruitful female bee, only needs to be impregnated once to make fruitful all the eggs she may lay for the whole season. It is observed, however, that all the eggs she lays during the ten first months produce only females, while those that she lays during the last two months produce males. The reason of this is that the first eggs are not fully ripened, or developed, while the last ones have arrived at full maturity. Consequently the first are only capable of forming females, while the last ones are perfect enough to form males.

Acting upon this fact it is possible to make her produce male eggs only. Thus, if she be kept from impregnation during the first few weeks, till all the eggs are well ripened, they will be all males, and the working bees may treat them in any way they please, but can never form a female from them.

The sex, therefore, of the future being depends upon the maturity of the egg from which it is developed, and consequently there are male and female eggs, and the sex is determined even before impregnation! Nothing which can be done, therefore, at the time of conception, or after, can alone determine the sex.

The most recent observers assure us that though the sex of the new being seems the same in all cases, at very early periods, still it is only apparently so, and that there is an essential difference from the very first moment. They assert that the sex is established, and can be distinguished, from the very first! In fact, as above stated, it is probably established in the egg itself before impregnation.

Although these facts were known long ago, in reference to plants and the lower animals, yet it is only recently they have been recognized as equally applicable to human beings. This arose from the circumstance that the true plysiology of generation in human beings, and other mammalia, has only been recently discovered. Directly it was ascertained that all mammiferous females, the human female included, formed eggs, the same as birds or bees, at regular periods, and that the new being was formed from those eggs, it was at once concluded that they were subject to the same laws of development. A celebrated professor of Geneva, M. Thury, was one of the first to put this to a practical test, in the following way:

Assuming, in regard to eattle, that at the beginning of the rut, or heat, the eggs would not be in so perfect a state of development as later, and therefore most likely to produce females, he gave instructions accordingly to a stock breeder, M. G. Cornaz. He adrised him, if he wished female young only, to let the mothers be impregnated only at the very commencement of the heat, when the eggs were not fully ripe. If, on the contrary, he wished all male young, he advised him to not allow the sexes to associate till later, when the eggs of the mother would be more mature. 
The result was just as he had predicted. Those begotten at the very beginning of the rut were all females, while those begotten later were all males, with very few exceptions. So convincing was the experiment that the breeder, M. Cornaz, states most emphatically he was able to have nearly all males, or all females, in his stock, just as he chose, by observing these simple directions !

The period of the rut is longer or shorter in different kinds of animals, and it varies even in individuals of the same species. In all cases, however, the eggs may be impregnated at any time while the heat lasts, but they are invariably not fully developed in the early stages, and consequently female, and become male only at later period, when fully matured.

In cows the heat lasts from twenty-four to forty-eight hours, varying in different individuals. All that was needed, therefore, was to find out the habit of each one, and then allowing connection with the male only in the first half of the period, or the last, and she could be made to produce either a male or female at will.

The importance and value of such a discovery as this can scarcely be over-estimated, and it must be remembered that it applies to all animals, without exception.

It must be borne in mind, however, that in animals who lay many eggs in succession, like birds and bees, and with whom one impregnation affects all the eggs laid for a long time after, it is much more difficult to use the discovery practically. Still, even with them, the first-laid eggs almost always produce females, because not fully matured, and the males come after.

It was formerly thought that the bees could form a new queen from any larva, simply by feeding it with a peculiar kind of food, but this is now known to be a mistake; they can develop a barren female-that is, a working bee-into a fruitful female, or queen, but cannot change the sex.

It is further to be observed, that if the ovulation, or egg-laying, be continued too long, or if from any cause the female's generative organs be much weakened, the lastlaid eggs may also be imperfectly formed, and again produce only females, as at first!

Sometimes animals that are too richly fed, and also live in too artificial a state all the time, have the period of heat very imperfectly marked, and with them therefore it would be difficult to apply the rule successfully. It is much the same sometimes even with human females, many of whom menstruate very irregularly. The result thus obtained, therefore, by these experiments is this: That the sex of any new being depends upon the degree of development of the egg from which it originated at the time when that egg was impregnated.

When an egg is formed in any animal, it is not fully perfected when first separated from the ovary, but gradually develops as it progresses along the female organs. And if the male semen impregnate it in the early, or imperfect stage, it produces a female, but if the impregnation be delayed till the egg is fully ripe it produces a male.

This fact is as fully applicable to the human female as to any other, and enables us, in nearly all cases, to produce either sex at will! We have only to bear in mind that menstruation, in the human female, is strictly analogous to the rut in other beings, and that it is caused by the production and throwing off of the egg.

Now the egg of the human female is at first only partially developed, though capable of being impregnated, and it ripens more perfectly during its stay in the womb. If impregnation occurs in the first, or imperfect state, the egg will develop 
into a girl, but if it occurs at a later period, when the egg is perfected, it will develop into a boy!

The production of either sex, therefore, depends upon the period when impregnation takes place, and thus either boys or girls can be produced at will!

The rule may be broadly stated thus :

To produce girls impregnation must take place only on the last day of the monthly period, or during the two first days after it has stopped.

To produce boys impregnation must not take place till at least three days after the complete stoppage of the monthly flow, and better not till the fifth or sixth.

The egg remains in the womb not more than about twelve days after the stoppage of the courses, in any case, as already explained, and usually not nearly so long; perhaps averaging not more than six or eight days. This is the limit during which it can be impregnated, and in the first part of this time it is not fully perfected, and can produce only a female. Later, when more perfect, it produces a male, and still later, when over ripe, it decomposes, or breaks up, and can no longer produce anything, or be impregnated.

There are, of course, many differences in different individuals, not only as to the time during which the egg remains in the womb, but also as to the rate at which the egg ripens.

In some females the egg ripens very quickly, and consequently they may produce boys earlier than others, while some, on the contrary, ripen it very slowly, and they may produce girls to a much later date than usual. There are some females apparently in whom the egg is always perfect from the first, and they always bear boys, while in others it is never perfect, and they, on the contrary, always bear girls. This is why the rule may sometimes fail, but such cases are very rare.

To make quite sure of having female offspring, however, connection should not take place after the second day following the stoppage of the monthly flow. And to make sure of male offspring it should not take place till five or six days after.

A little study of the peculiarities of each parent should be made, and then there will be no difficulty in so advising as to insure either sex that may be wished.

In a previous article on the cause of the difference in sex, it was shown to what an extent sex was influenced by several causes-such as difference of age, temperament, and physical condition; these were then thought to be the actual causes of sex. We now see that they are only secondary causes, and act indirectly, through some influence on the egg or the semen. Thus, for instance, a female, who is feeble, will perhaps be able to develop the eggs only enough to produce females; or, they may not be capable of impregnation till they reach the male stage, the first, or female stage, being too imperfect. In a vigorous female, on the contrary, the eggs may be perfect enough in the very earliest, or female stage.

It must be remembered, also, that the semen varies in power, the same as the egg does in degree of development, and thus the relative vigor of the two parents becomes an important indirect influence in the production of sex. But all such influences operate only partially, and in few cases.

\section{RULES TO INSURE EITHER SEX.}

The rules to be observed, then, are simply these :

To insure a girl, practice association only on the last day of the monthly flow, or during the two first days that follow its stoppage. 
Also let the woman aroid all kind of excitement or fatigue, and use the most strengthening food, to insure the greatest vigor; while the man should do the reverse of this.

To insure a boy, never practice association till the sixth day after the stoppage of the monthly flow.

Also, let the male live in such a manner and take such food as will insure the greatest bodily vigor; while the female should live low, and exhaust herself to some extent by bodily exertion.

By observing these rules either sex may be produced at will. 


\section{CHAPTER XXXIII.}

DOUBTFUL OR DOUBLE SEX.- HERMAPHRODISM.

IT is generally supposed that individuals are occasionally born that are both male and female, and it is certain that sometimes it is very difficult to decide upon the sex, through the form of the genitals being so unusual. In the lower animals, perfect nermaphrodites are not at all unusual, especially in those that are low down in the scale of creation. Indeed, hermaphrodism becomes more frequent in proportion as we descend, till, in some of the very lowest species, there are none but hermaphrodites, each individual being both male and female, impregnating itself, and bringing forth its own young without the concurrence of any other individual. In none of the so-called hermaphrodites in the human being, however, is this ever the case. They cannot perform the functions of both sexes, though uninformed persons suppose they can, not even when the resemblance to both is most perfect. All such cases are either of one sex, with some deformity which also makes them resemble the other, or else they are mere monstrosities, and, properly speaking, of no sex at all.

The greater number of so-called hermaphrodites are truly females, in whom the clitoris has assumed an unusual development, so as to resemble the male penis. In some instances this development has been so large, and the power of erection in the part so complete, that it could be used like the male organ, with another female, and thus an imperfect connection could be held, but it of course could not lead to conception, owing to there being no secretion of semen. In other cases, the womb has been extended from the vagina, and while in that situation has been used for a similar purpose, and supposed by ignorant persons to be truly a male organ. A proper investigation, however, soon reveals the truth in all such instances.

In men we sometimes find the scrotum cleft, and an opening through it into the bladder, which has been taken for a vagina. In such formations it is occasionally possible for one of the same sex to have connection, by this unnatural passage, but of course without any result, there being neither womb, ovaries, nor ovæ.

Cases of sexual monstrosity are found of infinite variety, all of which it is neither necessary nor useful to describe.

Many of these deformed females, who are called hermaphrodites, also resemble the male in other respects, such as the form of the pelvis and shoulders, the shortness of the hair, and tone of voice, and also occasionally in having an imperfect beard. This has still further led to wrong conclusions, and has tended to confirm the popular misapprehension. M. Béclard describes a curious case of this kind, and I have met with several such myself. In one instance that I saw, a young person of sixteen, who had always been considered and treated as a boy, was found, upon full examination, to be really a girl. The vagina was completely closed by a membrane across its external mouth, and the clitoris was at the same time much enlarged, so that there seemed to be something like a male organ, but no indication of the usual female 
passage. This led to the mistake, which probably would never have been rectified, but for her falling sick, and complaining of peculiar pains in the abdomen, the character of which induced an examination, which led to the discovery. It was with the greatest difficulty that I could convince the parents that they had mistaken the sex of their child, whom they insisted in considering a boy. I felt certain, however, that the pains complained of arose from menstruation, and that the usual flow would be seen if the vagina was not closed. I therefore made a thorough examination of the membrane, and determined to puncture it, so as to open the passage, which I ascertained existed beyond. A small incision was accordingly made, through which a probe readily passed to the usual depth of the vagina, without any difficuity. This was kept open and gradually enlarged till the finger could be introduced, when the womb was distinctly felt at the top, and in a short time after the menstrual flow occurred, and continued regularly. The only deformity now existing was the enlarged clitoris, and this, at the earnest request of the parents, was amputated, till it was no larger than usual. She was now perfectly female, and in a short time little or no difference could be seen between her and most other young women of the same age. If this had not been done, she would always have been considered an imperfect male, or an hermaphrodite, and would have led a life of misery in consequence. I have since heard that she afterward married and became a mother. It is worthy of remark that previous to the operation, her general appearance was certainly more that of a boy than a girl, the hair being quite short, the voice rough, and the pelvis quite narrow. Very soon after the operation, however, and especially after menstruation had begun, the appearance changed rapidly, so that in a short time she differed but little from other young persons of her sex. The hair grew long, the roice softened in its tone, and the pelvis rapidly attained its full dimensions.

In the year 1818, an hermaphrodite was exhibited in London, but, on examination by a medical class, she turned out to be a female with an enlarged clitoris.

A celebrated Prussian physician, Rudolphi, gave a description before the Academy of Sciences, in Berlin, in the year 1825, of the most perfect case of admixture of the sexes perhaps ever seen. It was a child that died soon after its birth, and which was found to possess a testicle on one side and an ovary on the other, besides a uterus, vagina and penis. In this case, the two sexes were undoubtedly united, but had it lived, probably both sets of organs would have been inactive, or one set would have disappeared and left the other. No single instance has ever been known, in the human species, in which both sets of organs performed their functions in the same individual. Uninformed people judge from mere external appearances, and these are often deceptive.

A curious instance occurred a short time ago, in one of the Eastern States, in which an individual, who had always passed as a man, voted at an election, which was decided by that one vote, but the losing party objected to it, on the ground that the voter was $a$ woman. It being a case of doubtful sex, what decision was come to I never ascertained, but the question was a curious one, and must, of course, be decided by medical examination.

In many of these cases, the inclination of the individual is sufficient to decide the question, as they nearly always desire to associate with those of the opposite sex.

Perhaps the most complete case of hermaphrodism, among the higher order of animals, was observed by Dr. Harlan, on an ourang-outang. It had ovaries, Fallopian tubes, uterus and vagina-being the complete female apparatus, and also two 
testicles, with the epididymi and vasa deferentia, and also a perfect penis, being the complete male apparatus.

The case represented by the following cuts is that of a female who died in the Fever Hospital, Leeds, Englaud. Her previous history was unknown, and as no one claimed the body, it was sent to the dissecting-room, when the curious conformation of the genital organs was first noticed.

It will be seen that the clitoris is so developed as to resemble a real penis, and that it also has a perfect passage, or urethra, down it, communicating with the bladder,

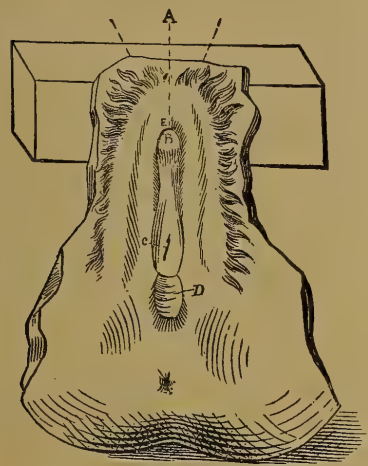

Frgure 114.-Tiew of the Organs wohen the Clitoris was raised up toroard the Abdomen.

A. A probe passed down the passage in the clitoris. B. The glans of the clitoris or penis. C. The probe passing out of the lower end down the passage of the clitoris, close by the meatus urinarius, or mouth of the passage into the bladder, which was the same as in other females. $D$. The folds or rugæ in the entrance of the vagina. E. The commencement of the passage down the clitoris, at the top of the glans.

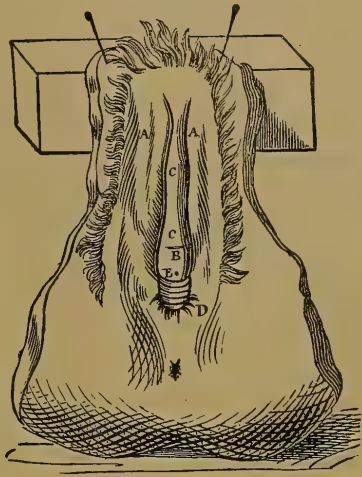

FraURe 115.-Viero of the Organs with the Clitoris hanging down in its natural position when not erect.

A, A. The large lips. B. The glans of the clitoris. C, C. The body of the clitoris or penis. D. The vagina. E. The opening in the gians.

It is probable that the urine actually passed down the passage in the clitoris, when that hung down, but that it passed out of the natural opening (at C, Fig. 114) when the clitoris was held up. There seems little doubt of this organ having been fully capable of the usual functions of the penis, with another female.

and down which, in all probability, the urine could flow. In every other respect, the organs are in no wise different from those of other females; but the clitoris could, in all probability, erect and perform the part of a penis.

In its collapsed condition, the clitoris measured about two inches and a half in length, or about half the average size of the male penis, and when erect must have measured four or five inches in length. Its diameter was probably about an inch and a quarter, and its structure evidently indicated that it was capable of perfect congestion and erection. Every other organ was ncrmai, except the ovaries, which were very large, and in appearance much resembled the male testicles! They were undoubtedly female in their action, however, for she had, in all probability, been pregnant, and the corpora lutea were readily distinguishable. 
Among neat cattle, there are often found instances of a curious admixture the sexes, in what is called the free-martin. They occur in this way: When a cow has twin calves, one male, and the other apparently female, the male will grow up into a perfect bull, but the other is often of no sex at all, or rather of both. There is, to a certain extent, a development of both sets of organs, but each imperfect, and sometimes they will both admit the male and also attempt to associate with the female, but, of course, neither act is productive.

John Hunter remarks, in his Animal Economy, "There is one part common to both the male and female organs of generation in all animals which have the sexes distinct-in the one sex it is called the penis, in the other the clitoris; its specific use in both is to continue, by its sensibility, the action excited in coition till the paroxysm alters the sensation. In the female it probably answers no other purpose; but in the male it is more complicated, to adapt it for the purpose of conducting and expelling the semen that has been secreted in consequence of the actions so excited.

"Though the unnatural hermaphrodite be a mixture of both sexes, and may possess the parts peculiar to each in perfection, yet it cannot possess in perfection that par: which is common to both. For as this common part is different in one sex from what it is in the other, and it is impossible for one animal to have both a penis in $\mathrm{l}$ a clitoris, the common part must of course partake of both sexes, and consequently render the hermaphrodite so far incomplete; but those parts peculiar to each sex mas be perfectly joined in the same animal, which will convey an idea of the truest hermaphrodite. Although it may not be necessary to constitute an hermaphrodite, that the parts peculiar to the one sex should be blended with those of the other, in the same way that the penis is with the clitoris, yet this sometimes takes place in parts whose use in the distinct sexes is somewhat similar, the testicle and ovarium sometimes forming one body, without the properties of either. This compounded part, in those animals that have the testicle and ovarium differently situated, is generally found in the place allotted for the ovarium; but in such animals as have the testicle and ovarium in the same situation, as the bird tribe, the compound of the two, when it occurs, will also be found in that common situation.

"The parts of the female appropriated for the purpose of supplying the young with nourishment are variously placed in different animals. In the horse, black cattle, sheep, and other graminivorous animals, their situation is between the hind legs; which is also the place allotted for the testicles of the male of this tribe, and probably of all those in which the testicles come out of the cavity of the belly. In the hermaphrodite, therefore, which has both these parts, the testicles must, to a certain degree, descend into the udder, though that cannot receive them so readily as th scrotum.

"The hermaphrodites which I have seen have always appeared externally, and at first view, to be females, from the penis being the part principally deficient, and there being an opening behind like the bearing in the female ; and as the testicles in such hermaphrodites seldom come down, the udder is left to occupy its proper place. In animals, the female of which is preserved for breeding only, as sheep, goats, pigs, \&c., these are generally kept, from their being supposed to be females.

"Among horses such hermaphrodites are very frequent. I have seen several, but never dissected any. The most complete was one in which the testicles had come down out of the abdomen into the place where the udder should have been (viz., more forward than the scrotum), and though not so pendulous as the scrotum in the 
perfect male of such animals, had all the appearance of an udder. There were also two distinct nipples, which, although they exist in the male, have no perfect form, being blended with the sheath or prepuce, of which there was none here. The external female parts were exactly similar to those of the perfect female; but instead of a common-sized clitoris, there was one about five or six inches long, which, when erect, pointed almost directly backward.

"I procured a foal-ass, very similar in external appearance to the horse abovementioned, and killed it to examine the parts. It had two nipples, but the testicles were not come down, as in the above, owing perhaps to the animal's being yet too young. There was no penis passing round the pubis to the belly, as in the perfect male ass.

"The external female parts were similar to those of the she-ass. Within the entrance of the vagina was placed the clitoris, but much longer than that of a true female, it measuring about five inches. The vagina was pervious a little beyond the spening of the urethra into it, and from thence up to the fundus of the uterus there vas no canal. The uterus was hollow at the fundus, or had a cavity in it, and then divided into two horns, which were also pervious. Beyond the termination of the two horns were placed the ovaria, as in the true female; but I could not find the Fallopian tubes. From the broad ligaments, to the edges of which the horns of the uterus and ovaria are attached, there passed toward each groin a part similar to the round ligaments in the female, which were continued into the rings of the abdominal muscles; but with this difference, that there accompanied them a process or theca of the peritoneum, similar to the tunica vaginalis communis in the male-ass, and in these thecæ were found the testicles, but I could not observe any vasa deferentia passing from them.

"Here, then, were found in the same animal the parts peculiar to each sex, although very imperfect, and that part which is common to both, but different in each, was a kind of medium of that difference.

"Something similar to the above, I have seen in sheep, goats, \&c.; but I shall not at present trouble the reader with a description of hermaphrodites in general, as it is a very extensive subject, admitting of great variety, which would make them appear a production of chance, whereas the intention of this account is to point out a circumstance which takes place in the production of hermaphrodites in black cattle, that appears to be almost an established principle in their propagation, and is perhaps peculiar to that species of animal.

"It is a fact known, and I believe almost universally understood, that wheu a cow brings forth two calves, one of them a bull-calf and the other, to appearance, a cow, that the cow-calf is unfit for propagation, but the bull-calf grows up into a very proper bull. Such a cow-calf is called in this country a FREE-MARTIN, and is commonly as well known among the farmers as either cow or bull. Althougk it will appear, from the description of this animal, that it i $:$ an hermaphrodite (being in no respect different from other hermaphrodites), yet I siall retain the term, free-martin, to distinguish the hermaphrodite produced in this way from those which resemble the hermaphrodite of other animals; for I know that in black cattle such a deviation may be produced without the circumstance of twins, and even where there are twins, the one male, the other a female, they may both have the organs of generation perfectly formed; but when I speak of those which are not twins, I shall call them hermaphrodites-the only circumstance worth our notice being a singularity in the mode 
of production of the free-martin, and its being, as far as I yet know, peculiar to black cattle.

"This calf has all the external marks of a cow-calf, similar to what was mentioned in the unnatural hermaphrodite-viz., the teats and the external female parts, called by farmers the bearing; and when they are preserved by those who know the above fact, it is not for propagation, but for all the purposes of an ox or spayed heiferviz., to yoke with the oxen and to fatten for the table. I need hardly observe here, that if a cow has twins, and they are both bull-calves, that they are in every respect perfect bulls, or if they are both cow-calves, they are perfect cows.

"It is known that they do not breed; they do not show the least inclination of the bull, nor does the bull ever take the least notice of them. They very much resemble in form the ox or spayed heifer, being considerably larger than either the bull or the cow, having the horns very similar to the horns of an ox.

"The bellow of the free-martin is similar to that of an ox, having more resemblance to that of the cow than of the bull. Free-martins are very much disposed to grow fat with good food. The flesh, like that of the ox or spayed heifer, is generally much finer in the fiber than either the bull or cow, is supposed to exceed that of the ox and heifer in delicacy of flavor, and bears a higher price at market.

" However, it seems that this is not universal ; for I was lately informed by Charles Palmer, Esq., of Luckley, in Berkshire, that a free-martin having been killed in his neighborhood, from the general idea of its being better meat than common, every neighbor bespoke a piece, which turned out nearly as bad as bull-beef-worse, at least, than that of a cow. It is probable that circumstance might arise from this animal having more the properties of a bull than a cow, as we shall see hereafter that they are sometimes more the one than the other.

"Although what I have advanced, with respect to the production of free-martins, be in general true, yet, by the assistance of Benjamin Way, Esq., of Denham, near Uxbridge, who knew my anxiety to ascertain this point, I was lately furnished with an instance which proves that it does not invariably hold good.

"One of his cows having produced twins, which were to appearance male and female, upon a supposition that the cow-calf was a free-martin, he obligingly offered either to give it me, or to keep it till it grew up, that we might determine the fact. As I conceived it to be a free-martin, and was to have the liberty of examining it after death, I desired that he would keep it; but, unfortunately, it died at about a month old. Upon examining the organs of generation, they appeared to be those of the female, and perfectly formed; but to make this more certain, I procured those of a common cow-calf, and comparing them together, found them exactly alike. This made us regret that the animal had not lived to an age that might have determined if it was capable of breeding; for the construction of the parts, being to appearance perfect, is not sufficient of itself to stamp it a true or perfect female; as I can suppose that the parts being perfectly formed, but without the power of propagation, may constitute the most simple kind of hermaphrodite. It is, however, most probable that this was a perfect female, which is an exception to the common rule, and $I$ have been informed there are instances of such twins breeding. If there are such deviations, as of twins being perfect male and female, why should there not be, on the other hand, an hermaphrodite produced singly, as in other animals? I had the examination of one, which seemed, upon the strictest inquiry, to have been a single calf; and I am the more inclined to think this true, from having found a 
number of hermaphrodites among black cattle, without the circumstances of their birth being ascertained.

"Hermaphrodites are to be met with in sheep; but from the account given of them, I should suppose that they are not free-martins. I have seen several which were supposed to be hermaphrodites, but which were imperfect males, having the penis terminating in the perinæum, the orifice of which appeared like the bearing in the female. Such are not naturally stimulated to put themselves in the position of the female when they roid their urine, so that when it passes the surrounding parts are wetted by it, and being covered with wool, and retaining the urine, keeps them continually moist, and gives the animal a strong smell. They are mentioned as both male and female.

"I believe it had never been even conjectured, notwithstanding all these peculiarities, what was the true nature of the free-martin; and from the singularity of the animal, and the account of its production, I was almost tempted to suppose the whole a vulgar error. Yet by the universality of the testimony in its favor-it appearing to have some foundation-I eagerly sought for an opportunity to see and examine them. I have succeeded in this inquiry, and have seen several, the first of which was one belonging to John Arbuthnot, Esq., of Mitcham, and was calved on his own farm. He was so obliging. as to allow me to satisfy myself, first by permitting a drawing to be made of the animal while alive, which was executed by Mr. Gilpin, and afterward to examine the parts when the animal died. At the time the drawing was made of Mr. Arbuthnot's free-martin, John Wells, Esq., of Bickley Farm, near Bromley, in Kent, was present, and informed us that a cow of his had calved two calves, one of which was a bull-calf and the other a cow-calf. I desired Mr. Arbuthnot to request Mr. Wells to keep them, or let me buy them of him ; but from his great desire of natural knowledge, he very readily consented to preserve both till the bull showed all the signs of a good bull, and when the free-martin was killed, he allowed me to inspect the parts.

" Of all the specimens which I have dissected, I shall only give the descriptions of those which point out most distinctly the complete free-martin, with the gradations toward the male and female.

\section{MR. WRIGHT'S FREE-MARTIN, FIVE YEARS OLD.}

"This animal had more the appearance and general character of the ox, or spayed heifer, than of either the bull or cow. The vagina terminated in a blind end, a little way beyond the opening of the urethra, from which the vagina and uterus were impervious. The uterus, at its extreme part, divided into two horns. At the termination of the horns were placed the testicles, instead of the ovaria, as is the case in the female. The reasons why I call these bodies testicles, are the following : First, they were above twenty times larger than the ovaria of the cow, and nearly the size of the testicles of the bull, or rather of those of the ridgil, the bull whose testicles never come down. Secondly, the spermatic arteries were similar to those of the bull, especially of the ridgil. Thirdly, the cremaster muscle passed up from the rings of the abdominal muscles to the testicles, as it does in the ridgil.

"There were the two bags placed behind, between the bladder and the uterus. Their ducts opened into the vagina, a very little way beyond the opening of the urethra; but there was nothing similar to the vasa deferentia.

"As the external parts had more of the cow than the bull, the clitoris, which may 25 
be reckoned an external part, was also similar to that of the cow-not at all in a middle state, between the penis of the bull and the clitoris of the cow, as $\mathbf{I}$ have described in the hermaphrodite horse. There were four teats - the glandular part of the udder was but small.

"This animal cannot be said to have been a mixture of all the parts of both sexes, for the clitoris had nothing similar to the penis in the male, and it was deficient in the female parts, by having nothing similar to the ovaria ; neither had the uterus a cavity.

\section{MR. ARBUTHNOT'S FREE-MARTIN.}

"The external parts were rather smaller than in the cow. The vagina passed on, as in the cow, to the opening of the urethra, and then it began to contract into a small canal, which passed on to the division of the uterus into the two horns, each horn passing along the edge of the broad ligament laterally toward the ovaria.

"At the termination of these horns were placed both the ovaria and the testicles -they were nearly of the same size, and about as large as a small nutmeg.

"To the ovaria I could not find any Fallopian tube.

"To the testicles were vasa deferentia, but they were imperfect. The left one did not reach near to the testicle; the right only came close to it, but did not terminate in a body called the epididymis. They were both pervious, and opened into the vagina near the opening of the urethra.

" On the posterior surface of the bladder, or between the uterus and bladder, were the two bags, called vesiculæ seminales in the male, but much smaller than what they are in the bull; the ducts opened along with the vasa deferentia. This was more entitled to the name of hermaphrodite than the other, for it had a mixture of all the parts, though all were imperfect."

Human children have been born analogous to the drones among bees-that is, of neither sex. These children had no sexual organs whatever, male or female, external or internal. All those I have had accounts of were like the male in one respect, in having a penis, but it was used only as a urinating organ, and in no way whatever sexually. In a certain sense, therefore, they might be considered imperfect males, like the bee drones. None of these, so far as I know, ever attained maturity; had they done so, it would have been exceedingly interesting to note their development in other respects. Among the bees the drones are the real workers, and the existence of the community depends upon them.

It is possible that human beings naturally without sexual attributes, might attain great development in other ways, and be valuable to society. Such beings should not be compared with eunuchs, or with those who have lost sexual power, because they are entirely different. Their systems would never feel the effect of sexual stimulation, nor be influenced by sexual growth, and therefore would never experience any deprivation, like the eunuch and debauchee.

In such eases the whole force of development, ordinarily expended sexually, might be diverted to brain growth, and thus an intellectual giant result. Such cases, however, are so rare that it is of little use speculating about them, nor do we know of any means of producing them at will, were it ever so advisable to do so. 


\section{PART XIII}

\section{MISCELLANEOUS TOPICS CONNECTED WITH \\ MARRIAGE. \\ .}





\section{CHAPTER XXXIV.}

\section{ON CONNECTION AFTER CONCEPTION, AND ITS CONSEQUENCES.}

Some persons suppose that when conception has occurred, no further association should take place between man and wife until after delivery. One reason assigned for such forbearance is that sexual connection should not be indulged except for the purpose of procreation. This notion is, however, manifestly absurd, and impossible to be acted upon. There are but few females who can tell when conception has taken place till it is considerably advanced, and they must, therefore, either wait a long time after each act to see if such be the case, or be continually breaking the rule. But, independently of this, there is no doubt whatever that connection is both proper and beneficial after conception as well as before, providing it be not repugnant or hurtful to the female, and is not carried to excess. In no case, however, should it be indulged in if it causes her suffering, or is disagreeable to her, for then it will have a most injurious effect upon the nervous system, and may also lead to miscarriage. The same evil results may also follow from excessive indulgence, even when not hurtful or disagreeable, and this must therefore be aroided.

So far, however, from sexual indulgence being improper in all cases atter conception, it is often required, and various evils may follow from its denial. When the temperament is warm, and the sexual instinct unusually strong, as it often is during pregnancy, indulgence is imperatively needed, and if it cannot be had the most injurious consequences may take place. I have known instances of this kind to result in a peculiar nervous frenzy, or partial derangement, and in miscarriage; in short, the indications and obvious requirements of nature should be the guide in this case, as in all others, and not the dreams and theories of speculating physiologists.

Besides these reasons, there are also others, connected with the child, which show the important influence of this after-union in many ways. It is a question often asked, whether the new being is in any way affected by connection after impregnation? And a notion prevails extensively that in some way or other it is so. This notion, like many others, has probably originated merely from observation, without any knowledge of its scientific accuracy, but recently its truth has been demonstrated by experiment as well as by observation. Several intelligent breeders of birds and other animals had long remarked that the male could influence the offspring after conception as well as before, and they acted upon this knowledge, practically, in the production and preservation of particular varieties. Dr. Delfraysse, of Cahors, in France, was the first, however, who recorded any special observations of this kind. He found that the first connection merely gave life, or impregnated the egg, and that the after-connections imparter to the young the colors of the male, and that the more this after-connection was repeated, the more closely would the offspring resemble the father. In what way this effect is produced it is difficult, in the present state of our knowledge, to even surmise; but, notwithstanding this, the fact is one 
of great importance. It has been suggested that the resemblance to the male, observed in such cases, resulted from an effect upon the imagination of the female through the medium of the sight, the colors being, as it were, impressed upon her mental vision. This, however, is certainly not always the case, even if it be so occasionally; for a friend of mine, at my request, tried the experiment upon a hen that had been blind during the whole of her laying period, and in her case the chickens produced from her eggs invariably resembled the male in color, just in proportion to the frequency with which association took place. And in another instance, two heifers when put to the male were both blindfolded, one having but one connection, and the other several. Each brought forth a calf-that from the mother who had but one connection resembling both parents, but mostly the mother, while that from the other, with whom there had been several connections, resembled the male parent in almost every particular of color, marking, and general appearance, though she had been carefully blindfolded each time. It is not through the imagination alone, therefore, that the paternal influence is exerted, though it may probably be so in some cases, as, for instance, in that of the mare and the quagga, recorded by Sir Everard Home. The quagga is a species of ass striped like the zebra, and one of these, a male, impregnated an English mare in the park of the Earl of Morton, in Scotland. There was but one counection, and the offspring was a hybrid, or mule, marked like the father. This hybrid remained with the mare about four months, and probably she might also have seen it again about ten months afterward. After this, during the next five years, she had four foals by an Arabian horse, and, strange to say, though she had not seen the quagga during this time, they were nevertheless all marked more or less like him. Now if this singular resemblance was effected through the imagination of the mother, as Sir Everard supposes, the most wonderful circumstance is that the effect should endure so long, even after the quagga was removed. It rather makes it probable, even in this case, in my opinion, that some permanent influence was exerted upon the female ovary, as in some other cases that I shall allude to further on, when speaking of the permanent influence of the male upon the offspring of the female. I am not disposed, however, to deny the influence of the imagination altogether, in all cases.

In the human being, it is of course more difficult to make corresponding observations, but still it is not impossible. My own professional ministrations have been so confidential, and so numerous, that I have enjoyed many opportunities of testing this interesting question, and I am fully satisfied that the same rule holds good in regard to human beings as with the animals already referred to. In our own species, howerer, it is not in respect to the color of the skin that the influence of the male in after-connection is made manifest, so much as in the color of the hair and eyes, and in the expression of the features, though the peculiar tint of the father's skin, as to being light or dark, is often so imparted. Certain propensities, labits, and modes of thought are also given in the same way. I have made many doservations of cases in which all the necessary particulars were fully known to me, and invariably I have found that the child resembled the father in proportion to the frequency with which association was practiced after conception. The mere bodily resemblance seems to be most readily imparted, especially the color and expression of the eyes, and the color of the hair. The mental qualities, and disposition, are more apt to vary, unless the connection is very frequent, and then in the majority of cases they will be like those of the father. I have known married persons to act 
upon these principles, in order to produce certain characters in their offspring, and with great success. In all such cases it has been found that the more frequently connection takes place after conception, the more decidedly the child will resemble the father, especially in the particulars above mentioned, while if such after-conneotion takes place but seldom, or not at all, it will on the contrary resemble the mother, in the same way. This fact may often be of great service to married persons, as it gives them a certain power over their offispring, and enables them to insure or prevent the transmission of the character of either one at will, if it be desirable to do so.

This influence, it should be remarked, does not, however, extend to the sex of the child, which appears to depend upon other causes, and until these causes are fully understood, the above facts lose half their value, becanse it might be advisable to impart the character of one of the parents to a male child but not to a female, or the reverse. The causes of the difference of sex, therefore, should be attended to likewise, and they will be found discussed in another part of our work. When all these matters are fully understood, I have no doubt but that any form of body, any disposition, and any given character of mind, as well as either sex, may be given to every child before its birth! Such a statement may seem strange to those who have not considered these matters scientifically, but to those who have it will be nothing new or surprising. I have known breeders of birds and other animals, for instance, who would undertake to produce, in a given number of young, ninety per cent. of either males or females, just as might be desired, and alike in color to a hair or a feather, besides being all endowed alike with certain prominent traits of character. And when the procreation of the human being is as carefully attended to as that of these inferior beings, the results will be equally certain, the organic and physiological laws being the same in both, in regard to this function. I leave every person of common sense to answer the question for himself, whether it is not more important to understand these laws in relation to the human being than in relation to the inferior animals alone? It seems clear to my mind that it is only by attending to such laws that the human race can be truly and permanently improved in body and mind, and made to attain its fullest perfection of development. By education after birth, we can only partially modify and regulate the development of the bodily and mental powers with which the individual is born, and very often their natural force successfully resists the most powerful influences we can bring to bear upon them, which is the reason why education frequently fails either in preventing evil or in leading to good. By acting upon those laws, however, which govern the child's organization, mentally and bodily, before its birth, every power and quality may be made to have precisely that degree of development which may be most desirable, so that education will always produce the results we wish from it, and disease and vice be forever removed. At present, however, it is scarcely allowable to talk of improving human beings by such means, though it is thought quite right, and even praiseworthy, to do so respecting dogs, horses, and cows; as if they were of the most consequence.

My readers will bear in mind that the law I have now been explaining, when fully stated is this: That frequent connection after conception causes the offspring to resemble the father, and that no connection afterward, or but very little, causes it to resemble the mother. This is undoubtedly true in the great majority of cases, and the degree of resemblance will usually be proportionate to the frequency in the one case, and to the unfrequency in the other. If, therefore, no connection took place after conception, as some would-be philosophers contend should be the case, all 
children would in time resemble their mothers only, and there would be a uniform and unbroken transmission of certain fixed characters, without any variation, which of course would be a great evil, even if it did not in time extinguish the race. This is another proof of the error of such a doctrine. On the other hand, if the afterconnection was always frequent, children would as constantly resemble their fathers, which is equally undesirable. To produce a mixture of the characters of both, therefore, when it is best to do so, the after-association should occur, if other considerations do not forbid it, to a moderate extent, according to the peculiar habits, temperaments, and relative vigor and age of both parties. This will, however, be better understood by referring to what is stated in another part of this book, on the proper frequency of sexual association.

An interesting question arises, further, when a female conceives by one man, whether connection afterward with another man would cause the child to resemble him, the second partner? Of course, such a question is not easy of solution in regard to human beings, but from observations made upon animals, it seems certain that the second partner can really impart his likeness to the child that was begotten by the first, and thus actually exert more influence, or impart more resemblance, than the father himself, who only gives life, but not always form and character !

In one instance I knew a widow who secretly married in about three months after the death of her husband, and while, as it appeared afterward, she was pregnant by him. The child, however, resembled her second husband, though there was almost a certainty that no previous infidelity had been practiced, because the individual was at a distance when the conception must have occurred.

It has even been conjectured, by some philosophers, that if a female have association, at any time, with a man who exerts a strong influence upon her, any children she may have afterward, by any one, will be liable to resemble him, even for many years afterward. And, indeed, the cases above given prove this.

This singular fact is explained by supposing that, in the act of sexual union, the male not only impregnates the egg, but also exerts a more or less permanent influence upon the female organs, owing to which they have a tendency afterward to bring forth new beings upon the same plan, or resembling each other. This was probably the case with the mare impregnated by the quagga, above referred to, and it explains why the foals produced afterward, though begotten by a horse, still resembled the other animal.

Instances of a precisely similar character are sometimes seen in human beings. Thus a female married a second time will have children resembling the first husband, and sometimes even in a third marriage, as I have witnessed myself. Such remarkable resemblances can be explained only by supposing a permanent influence to be exerted by the male; and probably that influence is likely to be exerted most power. fully by the first partner. The true explanation of these remarkable facts should be generally known, to prevent improper and unjust suspicions, which I have known to be entertained in such cases, and which, in the absence of proper information might well be excused.

Many persons would suppose immediately that these resemblances were simply the result of imagination, but I do not think so, at least not always. I have known instances of this kind, both in the lower animals and in human beings, in which the influence of the first partner was visible for a long time afterward, and in which I was assured the imagination had no share. 
Breeders of animals are aware of many such facts, and have frequently stated them to me. Thus for instance, when a mare has a mule foal by an ass, it will frequently happen, if she have a foal afterward by a horse, that it will to a certain extent resemble the ass. This resemblance is most frequently traced in the form of the mouth and lips, and in the greater length of the ears. A friend of mine, at my request, tried some experiments, on several animals, for the express purpose of testing this curious question, and the result was a striking confirmation of the truth of the explanation I have given. Many of these experiments were so managed that the imagination could not possibly operate, and yet the influence of the first partner was distinctly perceptible during several conceptions afterward. We can only come to the conclusion therefore that the male does often exert a permanent influence on the female organs, and especially by the first acts of association. In all probability this permanent effect is most likely to be seen when the male is relatively the most vigorous, or where the association has been very frequent, but it may be manifested even after a single act, as was shown in some of the experiments made by my friend. Among other singular cases bearing on this subject I may also mention the following, which was told me by an old physician in Scotland, who knew all the parties concerned. A young female was forcibly violated by a person whom she did not know, and under such circumstances that she could not see him; it was known, however, by her friends who he was, but from a wish to avoid exposure, the occurrence was kept secret, though unfortunately she became pregnant in consequence. The child strongly resembled its guilty parent, and what was still more singular, she married, and had two other children which also resembled him, though by her husband, the young man having left the country in consequence of his offense. Every one will see how naturally unjust suspicions might be entertained in many such cases, if they were not explained.

In the procreation of animals, such facts may be of the greatest importance. Life may be given, for instance, by the male that has the most constitutional stamina or vigor, and yet particular qualities may also be obtained from others, in which ho may be deficient. 


\section{CHAPTER XXXV。}

\section{NPLUENCE OF THE IMAGINATION OVER THE GENERATIVE FUNCTIDNS, AT EVERY PERIOD.}

As a general rule, there can be no doubt that the sexual instinct is first awakened by the generative organs, but after it has been once called into action, it may be afterward awakened by the imagination alone, which also exerts a peculiar and marked influence over its manifestations. It is certain that if the generative organs do not exist, there will never be any sexual desire, which is a proof that the action of the brain is merely reflex, or secondary, and not primary. It is true that some infants have been known to excite themselves even before the organs were perfectly formed, but such anomalies are evidently owing to a peculiar local sensibility, constituting a disease of the parts, and in no way invalidate the obvious principle we have laid down. In all such cases, the unnatural and precocious sensibility disanpears immediately when the organs are restored to a bealthy condition.

Sexual desire, therefore, at first, originates from a positive want, arising from organic action, the same as hunger arises from want of food. Very soon, however, this want awakens the imagination, which often acts so forcibly as to increase the desire a thousand fold. This is especially the case in cities, where there are so many causes to call forth the instinct prematurely, and to keep its gratification almost constantly denied. Some peculiar temperaments also, and certain organizations, are more disposed to a preponderance of this desire than others.

That acute observer, J. J. Roussean, has well exhibited the effects of the imagination upon the sexual instincts, particularly in his Emile. Buffon had remarked, before him, that young persons were more precocious in cities than in the country, simply because they were fed on more stimulating food, and were warmer housed and clothed. Rousseau remarked, however, that this explanation is not the true one, but that it is owing more to difference in manners and habits, and this is undoubtedly correct. In those places where the people live a quiet, simple life, with nothing to excite the imagination, sexual manifestations are not seen till late in life, and then not strongly ; but where the manners are free, and social observances lax, it is the reverse, though their nourishment may be poor and scant. It is undoubted that sood and clothing exert a great influence, and in some cases more than in others, but he imagination often exerts a greater, particularly over the first manifestations.

It is probable that there are many causes inherent in the present constitution of society which, in spite of all we can do, have an invariable tendency to inflame the imagination on these subjects, and to direct attention to them at an early period. The very concealments even which are now necessary, become provocatives, and perhaps, have more to do with these evils than we suppose. Rousseau remarks that children have a peculiar sagacity in seeing through all these concealments, and in detecting every artifice that is made use of to blind them. The mysterious language that 
they hear, and the half-hidden acts of tenderness that they see, he remarks, are only so many stimulants to their curiosity, and, in all probability, they learn more from these attempted precautions, than from any other lessons.

Even DRESS, necessary though it be, and conducive to true modesty, as it undoubtedly is calculated to be, has yet had its share in these teachings. The halfconcealment, half-disclosure which it leads to, and sometimes even the exaggeration which it causes, excites curiosity, and gives the imagination a boundless and mysterious field to roam in. Such evils are perhaps unavoidable in the present state of society, but the conviction arises irresistibly, to all who consider the subject fairiy, that in a more enlightened age they will be corrected.

Between the two sexes there is a wide difference as to the manner in which the imagination acts, owing to the difference in their characters and organization. In the young woman there are two powerful sentiments which oppose each other, and which by their antagonism originate those caprices and eccentricities which are so captivating, at the same time that they are so tantalizing. In the first place, she naturally desires to please, and all her arts and actions toward the other sex have this object in view. It is essential to her happiness, to her very existence even, that she should endeavor to be liked, or loved, and no misery is so great to her as the consciousness that her endeavors are in vain. That being that has not this desire of pleasing is not a woman, in character, though she may be a female in organization. In the second place, there is an innate sentiment in woman of modesty, or shame, which controls her desire to please, and prevents her from exhibiting that desire in the way she possibly might wish to do. These two sentiments are, therefore, continually struggling for the mastery, and their alternate and intermixed manifestations produce that bewildering but universally adored mystery, the female character. Sometimes one of these sentiments preponderates and sometimes the other, while at other times they properly control each other; and this gires us a key to all the apparent vagaries which this peculiar character presents. When shame preponderates we have prudery, when the desire of pleasing preponderates we have forwardness or coquetry, and when both are properly active we have that affable, engaging demeanor, corrected by true modesty, which makes woman truly entitled to the name of Angel, and commands reverence even when it does not awaken Love.

So intimately are these two sentiments connected with the female character that we see them exhibited at the earliest age, even little girls being prudes, coquettes, and true women, equally with those of more mature years.

With man this is totally different. He desires more to be pleased than to please others, and has but little of that sentiment which would lead him to conceal his feelings. He, therefore, makes the first advances, and presses his suit, while woman coyly resists, and pretends indifference, even when her ardor is really equal to his own. Upon two such different characters it is obvious the imagination must exert a very different influence, and with a different degree of force. From peculiarities in her organization, explained in the article on menstruation, the female is most under its dominion, and it is in reference to her, therefore, that its power over the generative functions is most marked, though it is manifest enough in both.

Many cases in which the imagination is supposed to have exerted a peculiar power especially in pregnancy, have really been produced more by the imagiration of other people, but still there are sufficient authentic cases upon record, some of which are instructing as well as interesting. 
The celebrated Descartes had for his first love a young lady who squinted, and never after could he admire any one who saw straight. His imagination associated all her charms with that peculiar obliquity of vision, and could not see them if that was absent.

Raymond Lully, the great philosopher and chemist, was violently enamored of a beautiful Spanish lady named Elenora, who returned his affection, and even encouraged his advances to a certain extent, but whenever he pressed her to grant him the last faror, invariably refused, though evidently not offended at his importunity. He discovered eventually that her objection to a closer intimacy arose from her having a cancer in the breast, which she wished to keep secret, and thus there was a perpetual struggle between her love and her shame. This discovery instantly' cooled all his ardor, but did not extinguish his love. His imagination vividly pictured to him how delightful it would be to effect.her cure, and then claim his happiness as a reward, thus insuring both her love and her gratitude. All his talents and time were henceforth devoted, almost without intermission, to this special object, and no doubt his mind constantly reveled in the delightful anticipation of success. Unfortunately, however, he did not succeed, the disease was proof against his science, and showed itself more powerful than his love.

I once knew an instance myself where a young man's desire was quenched instantly, and permanently, on his marriage, by the discovery that his wife was marked across the bosom by a large novi, which looked like a burn. Her bust was faultless in form, and his imagination had no doubt often pictured it as being equally beauteous and perfect in every other respect; when this blemish was so unexpectedly discovered, therefore, all his feelings underwent a complete revulsion, and disgust took the place of admiration.

Many similar instances might be given, and perhaps more cases of mutual unhappiness after marriage arise from such discoveries than is usually supposed. Especially may this be the case where young females are induced, or forced, to marry old men, or those who have been debauchees, as is too often the case. A melancholy instance of this kind occurred but a short time ago, not far from New York, which resulted in the suicide of the unfortunate victim, her horror and disgust when the actual condition of her husband was known completely overpowering her reason. Many often under such circumstances drag out a miserable life, in constant despair and grief, while their friends; and the public generally, offer congratulations upon the excellent alliance they have formed. In very many cases the imagination, working under the veil of ignorance, forms such perfect pictures of the object loved, both bodily and mentally, that humanity as it actually exists can never come up to them. and the consequence is that the reality is sure to disappoint. The ardent imaginations of females make them peculiarly liable to this romantic dreaming, and they are, therefore, more frequently the victims of this disappointment, which they feel acutely, and may even never forget.

How far the imagination may influence the sexual functions it is of course diffi. cult to tell, though it is undeniable that it does so to a great extent.

Le Bon tells us, in his Physiology of Generation, that the Parliament of Grenoble once gave a very singular decision, in a case of disputed paternity; showing what extreme views were held in former times as to the influence of the imagination over conception. The case was this : The Lady d'Auvermont gave birth to a child after her husband had been absent four years, and when, as she averred, she had had no 
intercourse with other men. She stated that in a dream she imagined herself with her husband, and that the impression upon her was so strong as to cause her to con. ceive. The Parliament called a special commission of matrons, midwives, and doctors, to consider the case and collect evidence. A number of other noble ladies, being called upon by the commission, stated that such an occurrence was perfectly possible, and by no means rare, for they themselves had frequently conceived, in the absence of their husbands, by the force of their imaginations alone. The Parliament upon this decided that the husband was the father of the child, and that he must acknowledge his wife to be a chaste woman.

As a corollary to this, I may mention that eminent spiritualists have expressed to me their belief that materialized spirits could, in some cases, cause a woman to conceive, independent of association with a mortal man !-of all which every one must form his own judgment. I doubt, however, if, at the present day, any court would render, on such a plea, a decision like that of the Parliament of Gremoble.

Not only can desire be engendered or annihilated by mental impressions, in despite of all other conditions, but the actual growth or development of the organs themselves can be retarded or accelerated by the same means. I have known men who never felt sexual désire, and whose organs were very imperfectly developed until a late period, and then quite suddenly the long-suppressed feelings were experienced, and the parts began to grow, simply from the stimulus of seeing some person of the opposite sex who was adapted to make the proper impression upon their minds. Such instances are, indeed, by no means rare, as every person of experience must know, and they prove that, in many cases at least, a certain impression must be made upon the mind before the mere animal feeling can be experienced, or the physical development take place; or, in other words, they prove that with some persons there are only certain individuals of the opposite sex who can call forth those feelings in them, and that if they never meet with these individuals, it is probable that such feelings will never be experienced, or at least only to a slight extent.

A knówledge of this fact will often explain to us many of those distressing cases of indifference and dislike to be met with between parties, and will also be a valuable guide in giving advice, particularly in those instances where there is only apparent impotence without any real deficiency.

There seems to be good reason to suppose that the sexual instinct is materially dependent upon a particular part of the brain, though we cannot tell what part jt is, nor whether it is a mere development of it that is needed, or some peculiarity of structure or organization. It is not at all uncommon to find men perfectly organized, in every respect, with vigorous minds, and with every other faculty in full play, but yet almost wholly destitute of desire for sexual enjoyment. In some of these cases, it is true, the generative organs are small, or evidently inactive, but in others they are of full average development, healthy, and active. In such cases we can only account for the singular indifference exhibited, by supposing that the part of the brain which regulates the reproductive instinct has not had sufficient power, or else that the proper object has not yet been presented to the senses, as before explained.

Besides this particular influence, the generative organs can also be much affected by the general action of the brain and nervous system, the same as all the other organs. Thus if a man exhaust most of his nervous energy in thinking or in mus- 
cular energy, the other functions, including the generative, must be proportionally weakened. I have met with numerous instances of this among men of business, many of whom would become quite impotent when more than usually absorbed in their pursuits, and regain their powers in a short time after their care and anxiety were lessened. The following case of this kind I select from my note-book as being more than usually instructive. The patient, a young man of twenty-eight, had been mar ried three years, and had one child; he was very fond of his wife, and she in return reciprocated his affection. He had never been addieted to excesses or abuses of any kind, and until about six months before I saw him was in the full enjoyment of his generative powers. About that time, however, he experienced a sudden and severe loss in his business, which had previously been very prosperous, and the care, anxiety, and incessant exertion he underwent, in endeavoring to extricate himself from his embarrassments, brought on various physical and mental troubles that he had never before experienced. Among the rest, he found himself perfectly impotent, having completely lost both power and desire. This distressed him very much, both for the loss itself and also from apprehension that it was the beginning of general decay. In this dilemma he came to consult me, and was exceedingly anxious to know my opinion as to the prospect of his ultimate recovery. After a careful examination, I felt convinced that there was no real loss of power, but merely a temporary absence of the requisite nervous stimulus, owing to the excessive mental labor and anxiety he had undergone; I therefore inquired as to his future prospects, and was gratified to learn that he was now quite relieved of his difficulties, and was beginning to regain his usual health and spirits. On learning this, I unhesitatingly assured him that in a short time his generative powers would reiurn, and more especially if he could abandon all care and thought about them. I gave him a slight stimulus, and some general directions as to diet, external treatment and exercise, and arranged to see him twice a week. In one month afterward he was as well as ever, though he had beeu for nearly seven months as impotent as if the organs had been totally destroyed. I have also frequently had business men remark to me that they were liable to experience more or less deprivation of sexual power, and to feel much less desire, at those periods of the year when trade was most active, and their minds in consequence most absorbed. An author also told me that when writing any very particular part of a book, or when anxiously expecting the criticisms of the press after its issue, he was always for a time perfectly impotent. In the lives of several severe students we have further corroboration of this fact, many of them having been remarkable for their coldness and incapacity, particularly those engaged in absorbing abstract studies, like the mathematics. Sir Isaac Newton is said to have never known sexual ardor, though in every respect a perfectly formed man, and it is probable that this was in a great measure, if not entirely, owing to his incessant and allabsorbing studies. In short, there is no question but that intense mental occupation lessens sexual ardor in most persons, and that it may sometimes even extinguish it altogether. This is a fact of considerable importance both medical and moral, and one that should be more fully considered than it has hitherto been. There is no doubt that a great part of the licentiousness which exists, particularly in youth, is in a great measure brought about, or at least made much worse, by mental and bodily idleness. If the mind is not occupied by some proper and congenial study, that will pleasingly engage it at every leisure moment, a habit will soon be formed of indulg. ing lascivious thoughts during such vacant periods, and if at the same time a due 
proportion of the vital energy is not absorbed in physical exertion, the sexnal organg will soon become so constantly and intensely excited that such thoughts will become paramount over all others. I once pointed out the philosophy of this to a gentleman who came to consult me both for himself and for his son, aged seventeen. The father was nearly impotent from intense occupation in business, and the son was nearly dead from constant licentiousness and intemperance. I found on inquiry that the young man had been brought up as a gentleman, and was not even expected to employ himself with anything useful; in consequence of which, from mere idleness, he resorted to licentiousness and drinking as a regular occupation, till he was scarcely capable of anything else. Moral suasion was utterly useless to effect a change, and habit was too strong for the fear of consequences to break through, so that it seemed as if nothing could be done but abandon him to his fate. His father bitterly deplored the condition of his son, and earnestly entreated me to give him any information I thought likely to be of service in preventing similar misfortunes to his younger brother.

On explaining to him how the sexual power and propensity is influenced by a proper exercise of the rest of the system, the philosophy of his own and his son's condition was immediately apparent. "Yes," exclaimed he, "I have exhausted myself by over-exertion, and at the same time, I have left my son a prey to his licentious desires merely from idleness. I now see plainly enough that had part of my burden been laid on his shoulders it might have saved both, but from mistaken kindness, and false pride, I condemned him to a life of inactivity and consequent depravity, and myself to a drudgery that has left me a mere ruin of what I was." Now this is a case instructive to all, and there are many others in society precisely similar.

Certain feelings are also very influential orer the generative functions, but only temporarily or with particular persons. Thus some men have found themselves suddenly impotent, with certain females, merely from disgust at something that was unexpectedly displeasing in them, and others have experienced the same difficulty from the fear of discovery or infection. Some men will experience a total loss of power on finding their companions too cold, or too ardent, or meeting with some unusual difficulty, but perhaps the most frequent cause is timidity, or self-distrust. I have known several men, every way competent, who were so possessed with the idea of their own incapacity, that they invariably became impotent whenever they attempted an approach to the other sex. This timidity is sometimes exhibited in the most striking manner, the patient being intensely agitated, and so nervous that his whole frame trembles, and his bodily powers sink so much that often fainting ensues. This peculiarity appears to be constitutional, and is often seen in those who are by no means nervous, in the ordinary acceptation of the term, and who are collected enough in regard to other matters. The only remedy for such an infirmity is constant association with one object, in marriage, by which means a proper familiarity is induced, and in time the individual loses his distrust, and becomes convinced of his perfect capability. In most of these cases, there is a real excess of power, rather than a deficiency, and the very intensity of the feeling tends to prevent its gratification, by completely absorbing all the vital energies. I have frequently been consulted by persons so circumstanced, as to the propriety of marriage, they fearing that the failing could not be recovered from, and it has been with the greatest difficulty that I could persuade them to the contrary. In every instance, however, I have found marriage to effect a cure, though it might not be immediate. Some have worn off 
their distrust very soon ; others have experienced it for months, but eventually have been surprised that they ever had it at all. It is the fear of failure that causes it, with these people, and when that fear is once shown to be groundless, the cure is complete. In some aggravated cases, a little medical assistance is available, but it is of a nature not necessary to point out here. I once saw a man who had been married for three years, without being able to associate with his partner, and solely from this cause. In all probability he never would have done so, had it not been for the advice he receired, and yet there was no real deficiency of any kind. The celebrated John Hunter gives us a similar instance, which he met with in his practice. The patient was perfectly incompetent, solely from the fear of failure, which so operated upon him as to always make him fail. Hunter was persuaded there was no other difficulty, and that it was merely necessary to break this spell; he therefore required of him, as one essential requisite of the treatment, that he should remain with his companion, but on no account whatever make any attempt for six nights, let his desire be ever so strong. The result was, that before the period fixed had gone by his desires were so strong he found it difficult to obey the injunction, and feared he should have too much power, instead of too little. In fact, the cure was complete, without any further treatment. The only thing required in such cases is a judicious and honest physician, who will first ascertain that there is no real deficiency, and then explain to the patient the real nature of his case and the means by which it may be relieved. If this be done in a proper and sympathizing manner, a cure may always be effected, but by a wrong course of procedure the evil may be confirmed.

A too great intensity of the sexual feeling itself, during association, will sometimes cause impotency, by overpowering the patient before the act can be properly constmmated. I have known instances of men who always became then so intensely excited that they fell into a kind of dreamy stupor, and had involuntary emissions while in that state. This, however, can always be remedied by proper treatment.

Several instances have come to my knowledge, of men being impotent at their marriage, from their first discovering some disagreeable fact respecting their partners. In one instance, the lady had a small abscess on the arm, which she had bitherto voncealed, and doubtless thought it a matter of little or no consequence, as her health was good, and her appearance remarkably pleasing. Her partner, however, thought differently, and such was the effect upon his mind that he could never afterward experience the slightest desire toward her. In some cases, such simple discoveries as false hair, or false teeth, have had a similar effect. It is not so much that the circumstance is excessively disagreeable in itself, as that it is unexpected, and its discovery destroys the dream of comparative perfection hitherto indulged. With uncultivated and unimaginative people, such causes might operate but slightly or not at all, because they form no such ideal image; but with men of refinement it is different. There is no doubt but that a good deal of the dissatisfaction and loss of power, which many men experience after marriage, is owing to this circumstance. They are ignorant of the real physical and moral nature of the being they take to their arms, and have formed a picture of her in the imagination very different from the reality, so that when the truth is known, their feelings undergo a complete revuision. This ignorance sometimes extends to the most ordinary functional phenomena of the female system, and the first knowledge even of that has, to my own knowledge, produced a very disagreeable and lasting effect. In short, it is in this, as in every- 
thing else, 1gnorance and concealment produce evils that only knowledge and mutual confidence can prevent or remove.

It is still a question, however, whether the imagination of the mother can affect the child before birth, and if so in what way, and to what extent? The popular belief in its influence this way is well known to be very strong, and probably it has some foundation, though there is no question but that it is carried too far. The well known case in the Bible, in which Jacob caused his father-in-law's animals to bring forth striped young, by placing peeled wands before the mothers, shows that this notion was entertained long ago, and the wonderful marks attributed to longings which we see every day show that it still exists. (Genesis, chap. xxx.)

Hippocrates, who wrote some thousands of years ago, relates that a celebrated queen was accused of adultery, because she was delivered of a black child, herself and husband being white. The great physician, however, remarked that at the foot of her bed there hung the picture of a negro, and he at once cleared her from the difficulty, by asserting that this picture had influenced the child through the medium of her imagination, it being constantly before her. A contrary case is recorded, by the historian Heliodorus, of an Ethiopian queen, who brought forth a white child in consequence of looking, at the moment of conception, upon a picture of Andromedus. At the present day, such an explanation of how these cases came about would scarcely be received.

These are not mentioned here as authentic cases, it will be borne in mind, but merely to show the bent of the popular belief.

In many old works which people are still in the habit of reading, merely from the name, such as "Aristotle" for instance, pictures are given of children resembling animals, which are there represented to have come either from the mother seeing such, or from having actually associated with them. All these, however, are gross exaggerations, and many of them even mere fabrications. In none of these works is there anything approaching to science, but on the contrary the merest rubbish and trash, utterly worthless for any purpose whatever.

Among more probable cases may be mentioned that of a lady who had a child covered with hair, and with hands fashioned much like the paws of a bear, and which she attributed to having often seen a picture of John the Baptist, clothed in a bear's skin. Malebrande also tells us of another infant, which was born with all its bones broken, and its joints dislocated, in consequence of the mother having seen an unfortunate criminal broken alive on the wheel. In short, such instances are numerous, and they show how firmly this belief is grafted on the popular mind, whether it be true or false.

It is quite common to observe, on the skin of new-born infants, certain brown, yellow, red, blue, or black marks, which are generally supposed to have been produced by the mother having longed for something while pregnant. These marks vary much in their form, size, and appearance, and are usually of so indefinite a character that a little stretch of the imagination may easily make them resemble anything. It is scarcely necessary to remark, that there are but few females, if any, who do not long for something during their pregnancy, and if this cause could produce such marks, but few children would be without them, whereas they are, on the contrary, rather scarce. The fact is that when one of these marks is discovered upon an infant, the mother begins to think of something she very much wished for, and then she easily sees that the mark is like it, but it is very seldom the case that any one else 
perceives the resemblance, unless it has previously been suggested to them. : have known one of these navi materni, or mother's marks as they are called, taken for half-a-dozen different things by as many different people.

The real cause of the mother's marks is a disease of the skin which produces an alteration in its texture. In general they are of little consequence, and remain stationary as long as the individual lives. It is seldom that success attends any attempts to remove them, and as a general rule they are better left alone, the effects of an operation being more likely to disfigure and injure than the mark itself. There is one kind, however, which differs from all the others, and which requires attention. This kind presents the appearance of little red warts, with flattened tops, connected with the skin by small necks, and full of blood-ressels. These are called fungus homatodes, and they are caused by obstructions in the little vessels under the skin, which makes the blood accumulate in minute tumors, or aneurisms. These may continue to grow, or even ulcerate, and lead to serious consequences; it is therefore best to remove them. This is done either by tying a silken string round them, to gradually strangle them off, or to use a sharp knife. In many cases, however, they may be destroyed by simply washing them in alum water, or a solution of sulphate of copper, or in keeping a silver coin pressed flat upon them for some time.

The fear that many people have of causing these marks is quite amusing, and has sometimes been acted upon for particular purposes. Thus I saw some time ago, in a medical work, an account of a lady in England who induced her husband to buy a carriage and horses, which she longed for, by assuring him that if he did not do so the child with which she was pregnant would be marked with them!

In no case does the mother ever announce before the birth what kind of a mark the child will be born with, and yet if she knew about the longing that caused it, she ought to be able to do so. It is always after the mark is seen that its resemblance is sought for, and then of course something can be thought of that may at least be supposed to be like it.

In one of the French medical journals, some years ago, M. Girard gave a very curious and instructive instance of the fallacy of this popular belief. In the course of his practice he became acquainted with three pregnant females, all of whom had been so strongly impressed by some object presented to the mind that the children were expected to be marked, but neither of them were so. On the other hand, three others, who had experienced neither frights nor longings of any kind, had their children terribly deformed with nævi. And this is in fact duily seen, numbers being born with marks, though the mothers did not long at all, and others being free from them though they did long, and intensely too. In fact, if their longings could do what some people suppose them capable of, there would be few children without marks, for nearly all females experience these imperious desires. Another circumstance, too, should be borne in mind, -if the imagination can exert such a power over the child as to canse deformity, it can also equally cause beauty, or give any particular feature, or sex, so that every mother must be supposed to have the power, by her imagination, to make her child be just what she pleases. Experience, however, shows that this power does not exist, and no mother who longs for a son can be certain of bearing one by so doing, nor can she by her imagination give a Grecian nose or auburn hair. If this could be done, we should have none but Venuses and Apollos born, but unfortunately for the gratification of fond mothers it cannot be, and this fact alone proves the imagination is not so powerful as some suppose it to be 
It should be remarked, however, that the generative act is certainly the most exalted that the animal organization can perform, and requires the greatest expenditure of vitality. The union of the two sexes is accompanied by an excitement more intense than is ever experienced at any other time,-in fact, it results in a positive convulsion, and often in partial derangement of mind, as if the two parents, while giving life to the new being, almost, for the instant, surrendered their own lives. This is the case at least when the conditions are perfect on both sides; but though this excitement must of course be always experienced by the male, yet the female may be perfectly passive. In such cases it may be questioned whether the act is really so perfect as when both are in the normal condition, and whether this remarkable exaltation and expenditure of vitality is not really necessary in both, to properly impress the new being, and make it active and vigorous. It is possible, as before explained, that conception may occur without any emotion whatever being experienced by the female, but there is very good reason for supposing that the children resulting from such conceptions are often imperfect, or deficient in mental and bodily vigor. In fact, experiments by artificial impregnation, upon animals, have proved this, and have shown that the vivid and overpowering emotion of sexual excitement should be experienced by both parents, in order to give that impulse to the new organization which is necessary to its most perfect development.

This accords with the popular notion respecting illegitimate children, who are generally believed and with sufficient reason too, to be on the average more talented and handsome than others. It is supposed that the intense warmth of temperament which, in most of these cases, leads to the breach of morality and social propriety, is advantageous to the new being, because it is conceived with more energy and power. The imagination of the parents is also more acted upon by the very circumstances of their association. The necessity for deceiving others, and of practicing secresy in their meetings, together with the charm of mutual confidence, and perhaps the indulgence being a forbidden one, all conspire to produce an exaltation greater than the ordinary circumstances usually give rise to.

It is certain also that children who are conceived during sickness, or when old age has vitiated the parents' energy, are never so vigorous and healthy as others.

After fecundation, the new being remains for nine months connected with the mother, and its development within her body is as much a natural function of her organization as is digestion or the circulation of the blood. Now both these functions, in common with all others, are well known to be affected by moral causes to a great extent, which alone would make it probable that gestation is also. Thus grief, joy, or sudden fright, will often prevent digestion entirely, and so derange the action of the heart that the circulation may completely cease, as in fainting. There is every reason to presume, therefore, that these emotions can also influence fotal development, and modify the new being both in body and mind. Indeed many cases have been known which directly prove this, and no doubt the moral temperament and bodily condition of many human beings is thus in a great measure determined before their birth.

In connection with this subject, it is most important to bear in mind that the child must be formed entirely from the mother's blood, for there is not an atom of its material that can come from any other source. The condition of the mother's blood, therefore, is of great consequence to its future well-being, for if that be imperfect, or diseased, the body formed from it must be so likewise. Now it is well known, that 
the quality, and even the composition of the blood is very much affected by the state of the mind, and by the emotions experienced. In despondency and grief it is imperfectly formed, being thin and watery, and it circulates sluggishly through the heart. On the contrary, joy makes the circulation brisk, and nutrition perfect, so that the blood is rich and pure, while anger makes it boil through the veins, and changes its very composition. In fever it is well known the blood is so altered that when drawn from the body it speedily putrefies, and it is almost the same during a riolent fit of rage, as I have seen when bleeding for a fit of apoplexy brought on by that cause.

It is not bodily disease only, therefore, that can change the quality of the blood, but also the state of the mind and feelings, which must be capable, therefore, of affecting the child through the medium of the blood.

Now when we reflect how sensitive females usually are during gestation, and how many causes then annoy and disturb them, it is readily perceived that their offspring must of necessity be much under their moral influence, or in other words be affected through the imagination. This influence, however, is chiefly exerted in a general way, and not in the production of merely local effects, like marks.

It is deeply suggestive, also, to the reflective mind, to contemplate the fact that when a female is pregnant with a female child there are three generations nourished by the same blood at the same time! There is the mother herself,- - the child in her womb, - and within its body the rudiments of the ovaries from which, if it ever become a mother, its children will be formed! Who does not see from this how literally true it is that the physical sins, at least, of the parents, are visited both upon the children and the children's children ? There are conditions of the blood which no doubt can in this way affect both the child that is forming and also its future children, through the rudimentary ovæ, and those conditions may originate from the imagination. A violent fit of anger in a mother, therefore, or of any other powerful emotion, may cause suffering and disease both to her child and her grandchild.

Another fact may also be mentioned, to prove that the child can be influenced by moral emotions. It is well known that many diseases of the womb, and also miscarriage, are often caused by fright, anger, and grief, and it is scarcely possible to believe that the child in the womb is not influenced by the same causes. During times of great public excitement and danger, as in revolutions and civil wars, it has been observed that miscarriages are more frequent, and that more of the children born then are idiotic, or become insane, than is usually the case.

It is true that there has not yet been discovered any nerrous communication between the mother and child, but this by no means proves that the emotions of the mother cannot influence her offspring. The blood itself is regarded by many physiologists as being truly living, and this certainly is connected in both. But whether it be living or not, it is certainly the material from which both are formed, and there is no question as to the emotions of the mother affecting it.

In works on medical jurisprudence many trials are recorded in which the power of the mother's imagination has been called in question, but it has never been legally admitted. About forty years ago, a mulatto female, in New York, bccame the mother of an illegitimate child, the father of which she asserted was a negro, named Whistelo, who was accordingly arrested and brought to trial, as he denied the fact. The child was not at all like that of a negro in any particular, being whiter, and with straight hair, but Dr. S. Mitchell contended it might have been influenced by 
the mother's imagination, and that consequently Whistelo might have been the father. The eourt, however, thought otherwise, and it was unanimously and very properly decided that the father must have been a white man, or a mulatto, and consequently Whistelo was acquitted.

Many of these resemblances which are supposed to originate with the imagination of the mother may really arise from other causes, as shown by the case of the quagga and mare, given in the article on The Permanent Influence of the Male upon the Female. In fact, that article should be referred to in connection with the present one.

It is a familiar fact to medical men, that many diseases are transmitted from the mother to the child while it is yet in the womb, and also that many drugs can influence it under the same circumstances, but this must, of course, take place through the medium of the blood.

The ague, small-pox, and the venereal disease, are frequently given to a child before its birth, and possibly also many diseases of a more chronic nature.

To show how crude the popular notions on this subject are, and how little they are founded upon correct information, it is only requisite to state that many people believe it is the child itself that longs, while in the womb, and they think the mark can be taken away by giving the child the object it wanted immediately it is born. Thus I have known an infant of two days old given a piece of beef-steale to take away the supposed image of one on its cheek.

Some suppose the marks are only given at quickening, others at six months, some at three and others again at any time. 


\section{CHAPTER XXXVI.}

DEFICIENCY AND TOTAL LOSS OF THE GENERATIVE POWER.

THIs is a subject that has never yet been fully treated upon in a popular way, though it is unquestionably one of the most important and interesting. Dr. Curling remarks, when speaking of the testes, "Threir functions are so involved in those of other parts, are influenced by such peculiar causes, and are so dependent on and modified by particular events and circumstances, that the investigation of them, when disordered, necessarily becomes of a complex and difficult character. The product, too, of these glands, is one, the qualities of which it is almost impossible to appreciate, and which during life is never afforded in a pure and unmixed state; and further, taking into account the repugnance felt to such inquiries, it is scarcely surprising that the subject has been but imperfectly investigated, and rarely treated of by the pathologist and practitioner. Indeed, the little information we possess respecting it is chiefly to be found under the head impotency, in works on medical jurisprudence, in which it is cursorily considered, principally in relation to points of medico-legal interest, and scarcely at all in relation to practice."

This is strictly true, and it will, I dare say, surprise many persons, to learn that physicians, generally speaking, pay but little attention to such matters. Such, however, is the case, as is well known to those who have occasion to apply to them, either for advice or information. I have found it absolutely necessary to set out in my investigations, on many important points, as if nothing were known, and hunt out the requisite information by the tedious but sure process of actual experiment and extended observation. Very many of the statements made in this work will probably surprise those who see them for the first time, owing to their novelty, and to their variance with old notions. None of these statements hare been made, however, without good and sufficient evidence having been obtained of their correctness, while the old notions with which they conflict, are merely suppositions and assumptions, utterly destitute of any foundation whatever. This is especially the case in regard to the functional and sympathetic causes of impotence, and also its medical and moral treatment, which may be truly said to be, nearly invariably, of the most unsatisfactory character.

In pursuing my own investigations into these important and interesting subjects, I have left no means of acquiring information untouched. Besides studying and experimenting, as far as was proper, in numerous cases that came under my notice professionally, I have fully experimented upon hundreds of animals, to the utmost extent that humanity would allow. By these means I have ascertained many important facts, and studied the action of many powerful medical agents, which could not with propriety and safety have been tried upon human beings first.

Functional or sympathetic disability of the reproductive organs appears in two 
forms, impotence and sterility, which are frequently, but erroneously, confounded together. Sterility means a total absence of the reproductive capacity, while impotence is merely an inability to associate with the other sex.

The various kinds of deformity, deficiency, and acute disease that cause destruction of the generative power, are fully treated upon elsewhere, and we have now only to explain those mysterious sympathetic and functional agencies, which, though they are often more powerful, are yet so different in their operation, and hitherto so little studied, that but little is generally known respecting either their nature or mode of action.

In the female, though there are many causes of sterility, there is but one cause of positive impotence, and that is deformity or absence of the vagina. If this canal exists, and is of sufficient size, she can always receive the embraces of the other sex, though they may be fruitless.

With man, however, this is different; not only may he be sterile from various causes, but also impotent. Desire may be strong, and the semen abundant and perfect, but still he may be unable to convey it within the female organs. There may be no power of erection, or the passage of the urethra may open in the wrong place, or it may be obstructed by stricture ; in all which cases the man is impotent, though not necessarily sterile, for if his semen could be placed, even artificially, in the female organs, it would impregnate.

All these defects are capable, in most instances, of being remedied, as $I$ have shown elsewhere. The penis can not only be made to erect, but to grow when too small, and sometimes can even be made, when it is nearly totally absent. Its proper sensibility can also be created or restored, and the urethral passage can be either restored to its proper dimensions, or made to open in the right place, so that in every respect it can be made capable of performing its peculiar functions.

In like manner, the vagina can be either enlarged or opened in the female, and the only cause of impotence in her can therefore be removed, as shown in the part on The Diseases of Woman.

With sterility, however, it is not always so easy to deal, depending, as it often does, upon peculiar organic deficiencies, or resulting from mysterious sympathies, it frequently baffles all our endeavors to understand or relieve it.

The ancient Greek and Roman females used to hang a wood or metal image of the male organs round their necks when they desired children, as a charm, firmly believing that it had power to make them fruitful.

In the long-buried cities of Herculaneum and Pompeii, many of these images are dug up, some of them being most elaborately and beautifully carved. They are generally about an inch long, though some are of the natural size. A friend of mine, a short time ago, presented me with several of them. In Cochin China, as I have been assured by a medical man long resident there, it is the custom, when a female semains long barren; for the priest to give her a wooden model of the male organ, which has been blessed by him, and which she uses herself. This is supposed to remove the sterility, and is implicitly relied upon.

Even in our own times and country, charms are often practiced for the same purpose, and medical means are employed, almost as ridiculous, and quite as useless. In some parts of the world, the waters of certain springs are supposed to make women conceive, and many resort to them for that purpose. A famous well of this kind once existed at one of the monasteries of England. 
Perhaps the most frequent cause of impotence and sterility in the male, however, is spermatorrhoea, or excessive seminal loss. This may arise from many different causes, but principally from excesses, and from masturbation. It may occur in two ways, either visibly, as in those who lose it in sleep, or during the motion of the bowels, and it may also take place in an unseen form, which is the worst of all.

There is, in fact, scarcely anything more important for a man to know than the causes, effects, and treatment of this terrible affliction, and there are few indeed who do not practically experience more or less of its consequences.

It is, undoubtedly, the most frequent of all the causes of impotence and sterility, and also of premature decay of the system generally. Every man, young or old, ought to know this; for if such knowledge was universally possessed in time, it is incalculable how much suffering, disease, and untimely death would be prevented.

It should also be borne in mind, as explained in a former article, that the male is often sterile from imperfection of the semen. Sometimes there are no animalcules at all, and at other times they are dead, in either of which cases he is sterile, or incapable of impregnating. If the imperfection is not of long standing, however, he may not be impotent, but may still be able to practice association; though, eventually, even that power will be lost, for the organs soon lose all sensibility if they are not stimulated by perfect semen.

In some men the animalcules disappear, or die, for a short time only, from disease, or from taking drugs, and afterward re-appear. In others again, I have found that they only appear at a particular time of the year, so that these individuals can impregnate then, but at all other times are incapable.

The worst cases of sterility in the male are those connected with a wasting of the testes, which may take place from numerous causes, some of them apparently trivial, to which all men are more or less liable. To guard against such evils, however, is easy, with proper information.

There are also certain mysterious causes of sterility, the nature of which we cannot understand. Thus some females will conceive by one man and not by another, and some men will impregnate one female but not another, which shows that there is a certain adaptation needed between the two, though we cannot tell in what particular that adaptation consists.

There are often cases, in both sexes, where there is neither sexual desire nor capability till some particular object is found, as shown in a former article on the influence of the mind over the generative powers, and also in the articles on the power of the imagination, and on the brain, all of which should be referred to in connection with this subject.

The principal causes of these disabilities in the female have been explained in the previous articles, particularly in those upon the ovaries and menstruation. The nonformation of the egg, its not passing down the tube in time, and the non-retention of it in the womb, are among the most frequent causes. Many married couples are also childless because they do not associate at the proper time, as explained in the article on conception.

At the present time there are but few causes of barrenness in females but what can be removed, except those depending upon imperfect or deficient development, and even many of these are capable of being remedied. The vagina, or mouth of 
the womb can be opened or enlarged. The Fallopian tubes can be opened, and the ovaries can be stimulated to act in cases where they bave been dormant for years. All which operations come constantly within the scope of my practice, and with very few exceptions they are uniformly successful.

In nearly all cases when a female has painful menstruation, attended by a discharge of membranes or clots, it is owing to a constriction of the mouth of the womb, which also prevents conception. The operation for opening it therefore relieves both the suffering and the sterility.

The treatment most frequently required in females is that for stimulating the ovaries to form the eggs, and strengthening the womb to retain them sufficiently long; a weakness or irritability of one or the other of these organs being the most frequent cause of female sterility known. A want of sexual feeling is also a cause of barrenness sometimes, indirectly, and the production of it leads at once to conception. In nearly all cases, however, this peculiar sensibility can be produced, to any extent that may be required, and by means comparatively simple, and perfectly harmless. Diseases of the womb and vagina also often lead to sterility, especially leucorrhoea, or the whites, the discharge from which kills the animalcules, and thus prevents conception. I have known many females barren from this cause who conceived very readily, by simply using an injection of warm water before connection, to cleanse away the acrid discharge.

Moral causes do not operate so strongly and uniformly with the female as with the male, because she is in a great measure passive, and may even be made to conceive in spite of herself.

Although impotence and sterility are usually spoken of as if they were the same thing, there is yet a difference between them, as elsewhere stated, which must not be lost sight of. Impotence is simply want of power or capability for association, which may arise from temporary or accidental conditions. Sterility, on the contrary, arises from total absence of some natural requisite to procreation. Thus, a man may be impotent from loss of the penis, because he cannot copulate; but if he still secretes perfect semen, he is not sterile, for a woman might be impregnated by his semen artificially.

In like manner, a w uman may be impotent or incapable of intercourse, from the vagina being closed, and yet her ovaries may be perfect, and the ovum be regularly formed. In such a case, she would not be necessarily sterile, for on opening the vagina, to allow contact of the generative elements, she might conceive at once.

As a rule, impotence is most common in the male, and sterility in the female. Commonly, sterility is nearly always referred to the female, but it depends upon the male much oftener than is suspected, as shown elsewhere. Woman, it must be remembered, is the passive and merely receptive party, and has not to exhibit power analogous to that of the male, and for this reason is less seldom impotent, and never in a corresponding way.

The mental and moral causes of impotence are much more frequent than is generally known, but are principally confined to cultivated, sensitive, and conscientious people ; coarse, ignorant, uncultivated men seldom suffering from them.

Many estimable men are totally incompetent for the sexual relation, from no lack of natural power or capability, but simply from peculiar nervous and moral susceptibilities. Many men are incapable merely from too violent desire, or from prolonged 
over-excitement, and are surprised to find that after complete temporary exhaustion they become capable. The more frequent moral causes of incompetence, however, are all the depressing passions, fear of not succeeding or of not being loved, simple timidity, shame, some sudden disgust, dislike, hatred, jealousy, terror, surprise, and apprehension of consequences. Most of these causes, as before remarked, operate only with the most refined and cultivated people, and seldom have much effect upon those who are coarse and merely animal in their nature.

The imagination, with many men, acts more powerfully than anything else. They either fancy something wrong with themselves or with their partners, and conjure up difficulties which have no real existence; in fact, they create troubles beforehand, and having persuaded themselves that they shall meet with them, naturally do so. This is often the case at the time of marriage. I constantly see young men, a few days after marriage, in the greatest consternation and despair, fully persuaded that they are hopelessly incompetent, and will never be able to consummate the act. In such cases, it is nearly always over-eagerness, too much effort, and excited imagination which creates the difficulty at first, and then mortification and fear for the future come in to make matters still worse. The natural difficulties attendant on first associations also complicate the trouble, and utter failure results, sometimes causing such shame and despair as to lead to suicide. Many men have killed themselves, under such circumstances, who were naturally fully potent, and who would in a short time have experienced no difficulty whatever. All that they needed was to know enough of themselves, and to have the courage to wait.

Very frequently a chivalrous consideration, and tenderness for their partners, or excessive modesty even, leads to the same result, and thus it is that the best of men often suffer the most. Frequently also, such men, from over-conscientiousness, will confide to their partners that they are doubtful of themselves, and crave their indulgence for possible failure. This is a most unfortunate thing to do, for nothing disheartens a man so much as the knowledge that others suspect him or doubt his capability. The very sympathy and condolence he receives even make matters worse, by intensifying the sense of his unworthiness.

In such cases, a man should reflect that with a young and innocent woman, whatever oocurs seems right, because she knows not to the cor rary, unless he tells her. It is also easy for him to make it appear that his diffidence, or temporary failure, is caused only by his deference and thought for her, and not from any incapacity on his own part.

Few people have any idea of the practical value of a little information of thist kind. If given in time, it would often prevent distress of the most poignant kind at marriage, and separation or life-long misery afterward.

As a practitioner, conversant daily with such matters, I may say, for the encouragement of over-sensitive bridegrooms, distrustful of themselves, that the first association seldom occurs immediately. Generally several days elapse, or even weeks, sometimes even months, and yet all comes right eventually, so that the man afterwards wonders how he could ever have experienced any difficulty.

It is some compensation that the imagination may, in many cases, help to cure these evils, as well as to cause them. When there is no real physical reason for the impotence, but only a nervous one, anything which favorably affects the nervous system may remove it at once. Immediately that a man regains confidence, and begins to see that his trouble is only temporary, it disappears rapidly. 
In former times this was well understood by both priests and philosophers, and thus arose all the charms, amulets, and other such means for curing impotence and sterility, of which we read in ancient books. One of these charms, given by the priest with the assurance that it would cure, would often be effective, from the very confidence which it inspired; and no doubt the assurance felt by many a sterile woman, that she would become a mother, from the possession of a precious amulet, aided powerfully in bringing about the desired result. In the old records of Egypt, Greece, and Rome, we find much curious matter of this kind, giving strong confirmation of the power of the imagination in impotence and sterility.

Witchcraft, of course, was early resorted to for the removal of such disabilities, and even now similar superstitious observances are not quite unknown. Among ignorant people the old beliefs, modified in various ways, still remain, and the priest, or the witch-wife, is still thought, by many, more efficient than the physician.

Montaigne, in his essays, treats this subject with much skill, good sense, and acuteness. He was perhaps the first to give a philosophical explanation of it, and his remarks are well worth reading even now.

That there are persons naturally weak sexually, or partly impotent, is undoubted; and this condition they may be born with. In some cases it results from imperfect stamina, or from the unfavorable effects of certain diseases of other parts. In other cases however it is probably inherited. Boys which result from too early connection, or too late, or from the union of parents exhausted, or imperfect naturally, are very apt to lack sexual power. Such children are often of a weak, lax habit of body, with deficient hair, especially on the pubes. Their voices are often shrill, or weak, their testes small and soft, and the scrotum lax and pendulous. In short, they are largely feminine.

Mere functional impotence may arise from simple excess naturally, but much more frequently from masturbation. Of the two abuses the last is undoubtedly the worst, its effects being more permanent. A man may recover from over-indulgence, at least in part, even when it has been excessive, but prolonged masturbation causes evils irremediable. And this is why many men who have passed years in vicious dissipation end better than those who have been socially virtuous, but addicted to solitary vice.

In masturbation the act is always incomplete and unsatisfactory, and is followed by a feeling of disgust which grows constantly deeper. The orgasm being brought on by unnatural means, and by mere force of imagination, is not only more exhausting than is actual connection, but gives much less pleasurable feeling. In fact, almost all pleasure finally is lost, and the practice is kept up from mere habit, unless superseded entirely by urinary loss. As a rule, unless abandoned early, masturbation causes total impotence, or else destroys all natural propensiiy, so that female society becomes distasteful.

Among other results of this fatal vice may also be mentioned the want of correspondence between the orgasm and the muscular power. The emission in such cases occurs too quick, that is before erection, or it may fail altogether. Occasionally, however, the erection fails entirely, or lasts but a few moments. Not unfrequently there is neither erection nor emission, when wanted, though both may occur at other times.

Similar results, however, may follow from over mental work, worry, or anxiety of mind. Also from excitement kept up too long without indulgence, and from the 
habit of withdrawing, by the male, before emission. Many men injure themselves seriously by being constantly in female society, where their passions are excited, but have to be restrained. All such, who cannot control themselves, should keep away from influences they cannot resist. Some of the most virtuous and honorable men suffer intensely in this way, and accuse themselves of being wicked when they simply require marriage, which to some is a real necessity.

It must not be forgotten that too long continued continence may also be a cause of impotence. The sexual organs, like all others, may become enfeebled simply from want of proper use. Nature seems to think, in such cases, that it is useless to continue power in organs that are never employed. Moderate natural association is undoubtedly favorable to the continuance of sexual power, in all cases.

Impotence may result, as stated elsewhere, from the use of narcotics, stimulants, and other drugs, and also from exhausting labor, insufficient food, and debilitating disease. Impotence often results from mere imperfection, or want of development, of the penis, as we have shown before, and may then be often remedied. Inability to obtain erection of course makes a man impotent, and it may arise in many ways When from bodily debility alone, if the man is not too old, a cure can usually be effected, unless he has been much addicted to masturbation. But when it arises from failure of nervous power the case is more difficult.

It must be borne in mind that all our natural functions, bodily and mental, are carried on solely by the nervous power! This is to the animal organism what steam is to the steam-engine, or electricity to the electric telegraph. Without sufficient steam the engine cannot move, no matter how perfect its structure may be, nor can the telegraph send a single message unless there be plenty of electricity from the battery. In like manner we can do nothing, bodily or mental, if our nervous power be deficient.

It is in the brain, spinal marrow, and other great nervous centers, that this neryous power is engendered, and it is distributed from them to the different parts of the system by the white cords, called nerves, which are found in every portion of the body. Each organ receives its due share, when the action of the system is properly balanced, and thus all work harmoniously for the common need. As there is but a given amount of this nervous power produced, however, in a given time, it is evident that if any organ receives more than its due share, some other organ must receive less, and its function in consequence be imperfectly performed. Thus if a man uses his brain too much, in study, he so exhausts his nervous power by thinking, that there is not enough left for other purposes. Commonly, in such a case, his stomach acts imperfectly, from lack of sufficient nervous stimulation, and he becomes dyspeptic; or his heart may become feeble, or his kidneys act imperfectly ; in some way or other he is sure to suffer. Many men weaken their sexual power in this way, and become more or less impotent. This is a common cause of sexual debility among students, business men, and those subject to much worry and anxiety of mind.

In all such cases, the first thing to be done is to give the brain complete rest, and to tone up the system generally. In this way more nervous power is engendered, and it is more evenly distributed. If the patient be not too much run down, and can give the brain perfect rest, the sexual power may be restored; but it is vain to expect any help from medicine alone. Rest, change of occupation and scene, are the 
first essentials of treatment in such cases, and with these may be combined good tonic and aphrodisiac remedies.

Some men in this state still keep on with their brain work, and try to force the sexual system to action, at the same time, by using stimulants, and aphrodisiac medicines. They may succeed for a time, but it is literally burning the candle at both ends, and when they finally break down, as they are sure to do, there is no hope of restoration.

Excessive sexual indulgence, too long continued, leads to the same results. It not only weakens the sexual organs themselves, by over use, but, by exhausting unduly the nervous power, all the other organs suffer the same as when tne brain is over used. The whole system is run down, and when finally impotence comes, there is nothing to fall back upon, and recuperation is impossible.

This is why impotence resulting from, or connected with, nervous exhaustion, is so difficult to treat successfully. There is much building up to be done, and much regulation of the functions, so that they may be properly balanced, and the nervous power be evenly distributed.

In my practice, I always find a large increase in the number of patients impotent, from nervous exhaustion, after any period of business embarrassment, like one of our panics. Those who do not become insane, or commit suicide, among the vic. tims of the panic, usually become sexually powerless. It is only those with well balanced functions, calm unexcitable nervous systems, and good digestions, who escape.

I have been assured by many ardent business men, who are all the time in a whir] of excitement, that the only time they really enjoy the society of their wives is during their summer holiday, when their brains are comparatively at rest. But some of them so completely exhaust themselves, by worrying over the ups and downs of stocks, that even in their period of relaxation they find themselves powerless.

The same law applies to women. Continued worrying and fretting, or anything which leads to mental depression, or moral dissatisfaction, is especially hurtful sexually. Such causes may not prevent conception, nor make a woman incompetent for sexual intercourse, but they may make it distasteful to her, and prevent her from either experiencing or imparting that enjoyment which ought to accompany the act. This is, in one sense, impotence, because the woman is not capable of fully performing her part in the congress.

A large number of women are habitually cold in temperament, and never experience sexual ardor, although they become mothers. Such women are, of course, not sterile, but, as before remarked, they are to a certain extent impotent. It is true, that sexual ardor is not necessary to them, and that they may become wives and mothers without it; but its absence is nevertheless a deprivation, and both reason and experience assure us that they would be better if it were experienced.

It is probable that the absence of sexual feeling in women, in all cases, is owing to unfavorable mental and moral conditions; or to some bodily derangement. It is usually accompanied by peculiar nervous states, and by various undesirable eccentricities of character and disposition. A woman so conditioned seldom exhibits all those qualities which make her relations with the other sex a sure source of happiness to both. Any one conversant with such matters, as a medical adviser, must be 
well aware that many married people become estranged, and many homes made un happy, by coldness and indifference on the part of the woman.

Indifference, or want of sexual ardor, is much rarer in men than in women, but still it is to be met with. I have known men almost totally deficient in sexual feeling, and yet, apparently, well-developed, and fully capable, as men. This unusual condition probably arises from some form of nervous derangement, and is therefore not organic, but merely functional, like what we sometimes see after a weakening disease. The same thing may also result from any powerful revulsion of feeling, or from intense devotion to some absorbing pursuit.

More frequently, however, the man does not lose his sexual ardor, but merely becomes extremely fastidious and capricious in regard to his indulgence. He is never quite satisfied, and invariably attributes his disappointment to some fault in the woman. His coldness and indifference, so he thinks, is entirely owing to lack of warmth, or some other deficiency, on her part. Such men seldom dream that they thernselves are to blame, and often are quite astonished, and even offended, when such a thing is intimated to them.

This partial indifference, or fastidiousness, in men, is, to a certain extent, a form of impotence. They are not nearly so likely to become parents, and some women can never conceive by them. In such cases the fault is, of course, attributed to the woman alone, but unjustly. It arises simply from want of that mutual enjeyment, and perfect satisfaction, which, to some females, is indispensable to impregnation. It is more than probable also that such a condition of mind and feeling, if habitual, is unfarorable to the production of healthy or abundant semen, as it is also to the formation of perfect ovæ in women.

Any imperfection in the-quality' of a man's semen not only makes him impotent, to some extent, if not sterile, but also affects unfavorably the woman with whom he associates. It may either simply fail to stimulate her system as it should do, or it may not impregnate, or, what is of still more consequence, if she do conceive, the probability is that she will prematurely miscarry! Many women habitually meet with this misfortune from no fault of their own, but simply because their husband's virility is impaired. This is very apt to follow, as before explained, from excessive indulgence, or from masturbation, and very often from particular diseases, especially syphitis!

The man who has constitutional syphilis may, apparently, recover his health perfectly, and exhibit complete sexual power, but the woman who conceives by him will almost invariably miscarry. I have known many cases of this kind, and in every one, till the matter was explained, the fault was laid to the woman. But what is more singular, these women, when married again to men who have never been so diseased, will still continue to miscarry just the same. It would scem, therefore, that some injurious influence is exerted on the female generative organs by such a condition in the male; but in what way we do not know.

It is fortunate, however, that in such cases miscarriage does occur, for the few children that do arrive at the full period almost always suffer from the disease of the father, in some way, though neither he nor the mother show any signs of it.

And here let me remark that this disease, syphilis, is one of the most serious evils that afflict society! It is also one of the most general, causing untold evils, the true cause of which is unsuspected. No family is safe from it while it exists, and once introduced it may be transmitted, in its hereditary form, to a long series of innocent 
descendants. There are few families, indeed, that do not inherit some taint of it, from their ancestors, though nothing of the kind is known or suspected.

It is a great misfortune that this fearful scourge has been taken under the protection, as it would seem, of certain well-meaning persons who consider it a judy. ment upon men for sexual vice. 'They contend that no attempt should be made to cure, or eradicate such a disease, so that it may still remain a terror and a punish. ment. A more unfortunate or mischievous idea was nerer entertained, nor one more repugnant to humanity and common sense. Carried out to its logical conclusion, the same argument would apply to most other diseases, for they arise also from an infringement of some moral or physical law ; or, in other words, from some vice. Besides, the worst consequences of syphilis, in many cases, are experienced by others, by innocent persons, and not by the original offender. A man contracts syphilis, is apparently cured, marries, and has children born with a syphilitic taint, from which they suffer through life, and perhaps their children also, unless they are fortunately sterile. 'The mother likewise may become diseased, from her children, and be made a confirmed invalid in consequence. Scrofula, and many think cancer, originate thus from constitutional syphilis, and it is well known these diseases are practically incurable. To carry out this theory of judgment and punishment, however, all this suffering of innocent people, and deterioration of the race, had better be endured, these people say, than that the original disease should have been prevented, or effectually cured. As to the value of the fear of syphilis in preventing sexual indulgence, we have only to see how it acts practically, to be aware what little effect it has.

But putting all this aside, it is simply our duty, as it is to our interest, to prevent or cure every disease or infirmity that afflicts humanity, as early and as effectually as possible, and to pay no attention to judgments or punishments.

It will scarcely be believed, at some future day, that a Congress of the United States, in the middle of the nineteenth century, actually passed a law forbidding the importation or sale of the artificial coverings, called condoms, used to prevent renereal disease! This was done at the instigation of those people who believe that syphilis should be preserved, as a punishment and judgment.

Our immediate concern with the disease, however, is in its relation to impotence and sterility, of which it is a frequent and unsuspected cause.

In man stricture is a more common cause of sterility than is suspected. During the orgasm the stricture is more contracted than at other times, and the semen cannot be expelled through it. Long-continued gleet, or the use of strong injections, are very apt to lead to this form of disability. Sometimes the stricture is in the seminal ducts, or they may be obstructed by stone, or by small tumors, or fungous growths.

Extreme smallness of the male organs is not necessarily a cause either of impotence or sterility, except, perhaps, with particular females. Blows, bruises, and other injuries to the testicles, are often causes of impotence, and so is long-continued pressure, as in horseback riding. Mumps are a very frequent cause of impotence, when the swelling changes from the throat to the testicles. They are also, in the same way, injurious to the femalc ovaries and womb.

Analogous to stricture in the male, we sometimes find narrowness of the vagina in the female. This may be so extreme as to prevent intercourse entirely, as was said to be the case with the celebrated Joan of Arc. Still, in such a case, the 
woman might conceive, if otherwise perfect, from the semen being merely placed in the external opening, and thus she would be impotent, but not sterile. In fact, instances have been known where conception took place while the vagina was too narrow to admit of connection, and it had to be artificially enlarged to allow of the birth of the child. A complete closure of the vagina, either by an imperforate hymen, by growing together of its walls, or by membranes across it, is, of course, a cause of sterility, but if the obstruction is far up, it may not prevent connection. Many of these cases can be readily corrected by a comparatively simple operation. I once knew three sisters, all with the ragina closed just below the neck of the womb. Of coursc they never menstruated, but always had monthly hemorrhages from the noce or bowels, to compensate for it. One was married, and the obstruction was removed afterward, so that she became a mother, with no unusual difficulty. Another one was also married, but as neither she rur her husband desired children, and intercourse could take place, nothing was done in the case. The third one never married while I knew them. It was with much interest I learned that a great aunt was similarly deficient, and I have no doubt this was a decided instance of hereditary transmission.

Perhaps the most frequent cause of sterility in the female is the smallness of the mouth of the womb; and this may be either natural, or may arise from spasmodic closure at the time of excitement, or from inflammation, or from some abnormal growth. Simple swelling, from irritation, or from congestion, may also lead to the same result. Of course, the partial closure prevents the passage of the semen to the interior of the womb, and consequently there can be no conception. In nearly all cases, this disability can be remedied, either by removing the diseased condition of the parts, or by expanding the mouth of the womb by bougies. I am constantly seeing and treating cases of this kind.

In cases where the constriction is very firm, and cannot be permanently overcome by the bougie, impregnation can be effected artificially, as fully explained in the article on Artificial Impregnation.

It must, however, be borne in mind that, in addition to all the above causes, both sterility and impotence often result from imperfection in the quality of the male semen. It may be abundant in quantity, and seem perfect, and yet will neither excite the female nor cause impregnation. In my practice, I constantly meet with cases of this kind, usually resulting from excesses, or from some form of abuse.

Dropsy of the testicle, or hydrocele, does not always cause impotence, nor even impair sexual power, though it does so occasionally. Tumors, however, especially hard, fleshy ones, almost always do injury, and so does simple swelling sometimes, such as follows a blow, or gonorrhoea.

The violence many men do to themselves, in hindering the emission of semen by compressing the penis during the orgasm, is a frequent cause of impotence. Some do this from the mistaken idea that they then retain the semen, and consequently suffer no loss. It is, however, merely forced back into the bladder, instead of escaping externally, and is expended the same as if it had been lost in the natural way.

The injury done in this way is of a very serious nature, and well calculated to destroy sexual power altogether, besides leading to stricture, inflammation of the prostate, and weakness of the neck of the bladder.

More frequently the above practice is pursued as a means of avoiding the impregnation of the female, and it then does harm to both. In her it leads to nervous 
Irritability, coldness of temperament, and leucorrhœa. In some cases, it even causes symptoms much like epilepsy.

Among other causes of derangement of the sexual organs in females, leading to displacement of the womb, miscarriage, impotence, and sterility, may be mentioned improper dress. Corsets, especially, do immense harm in this way, as may be seen when the natural position of the organs in the body is observed, and compared with the way in which they are squeezed together when the waist is compressed. It is very unfortunate that fashion so frequently adopts some deformity, and imitates it. Some savages squeeze the head till it is flat like a plate; others blacken the teeth, or put a large ring in the upper

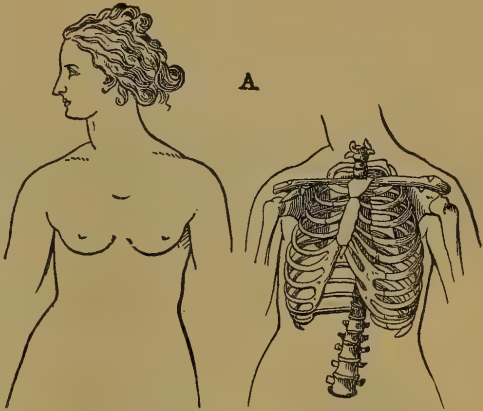

FIaURE 116. - Waist of Venus de Medicis. lip or nose. This is fashion with them, and we think it very silly, if not disgusting, without reflecting that our own fashions are just as absurd, and often much more injurious. Any deviation from the natural form of the body is a deformity, whether natural or artificial. The Chinese ladies deform their feet to make them small, and so do our ladies, in a different way. They bunch them together in tight, ill-shaped shoes, till the toes are immovable and covered with corns and bunions, while the heel is placed under the hollow of the foot. The evil of this is not confined to the pain and discomfort in the foot itself, but it interferes seriously with walking, and by changing the gait and position of the body, tends to displace the internal organs.

A small foot-that is, one smaller than Nature makes it-is a real deformity, and not a beauty. It should bear a certain proportion to the body, and in all cases should be fully capable of every motion belonging to it.

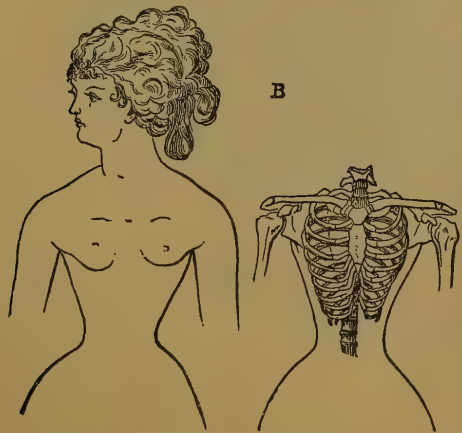

FreuRs 117.-Waist of a Eashionable Lady.

A small waist-that is, one smaller than Nature makes it-is as much a deformity as a hump back, and may be much more hurtful. The idea that it is a point of beauty could arise only from ignorance and artistic obtuseness. It is on a par with the idea of the savage, that there is beauty in a flattened head, or an upper lip stretched as wide as the hand.

Our immediate concern, however, is with the effects of waist squeezing on health, and especially on the health of the sexual system, and in this respect it is a very serious evil indeed. especially to young girls. 


\section{PLATE XXXIII.}

Figure 1. 6, 7, show the ressels in the spermatic cord uncorered. At 15 is the place where an external rupture usually occurs. 11, 12, 13, 14. The large bloodvessels and nerves in the groin, going to the leg.

Figure 2. At 6 the hernia is seen protruding, covered by the sheath of the spermatic vessels. At 7 this sheath is laid open, showing the peritoneal covering underneath.

The other parts are the same as in Figure 1.

The place where the rupture protrudes is in the groin, and it pushes outward, instead of down into the scrotum as in infants. 


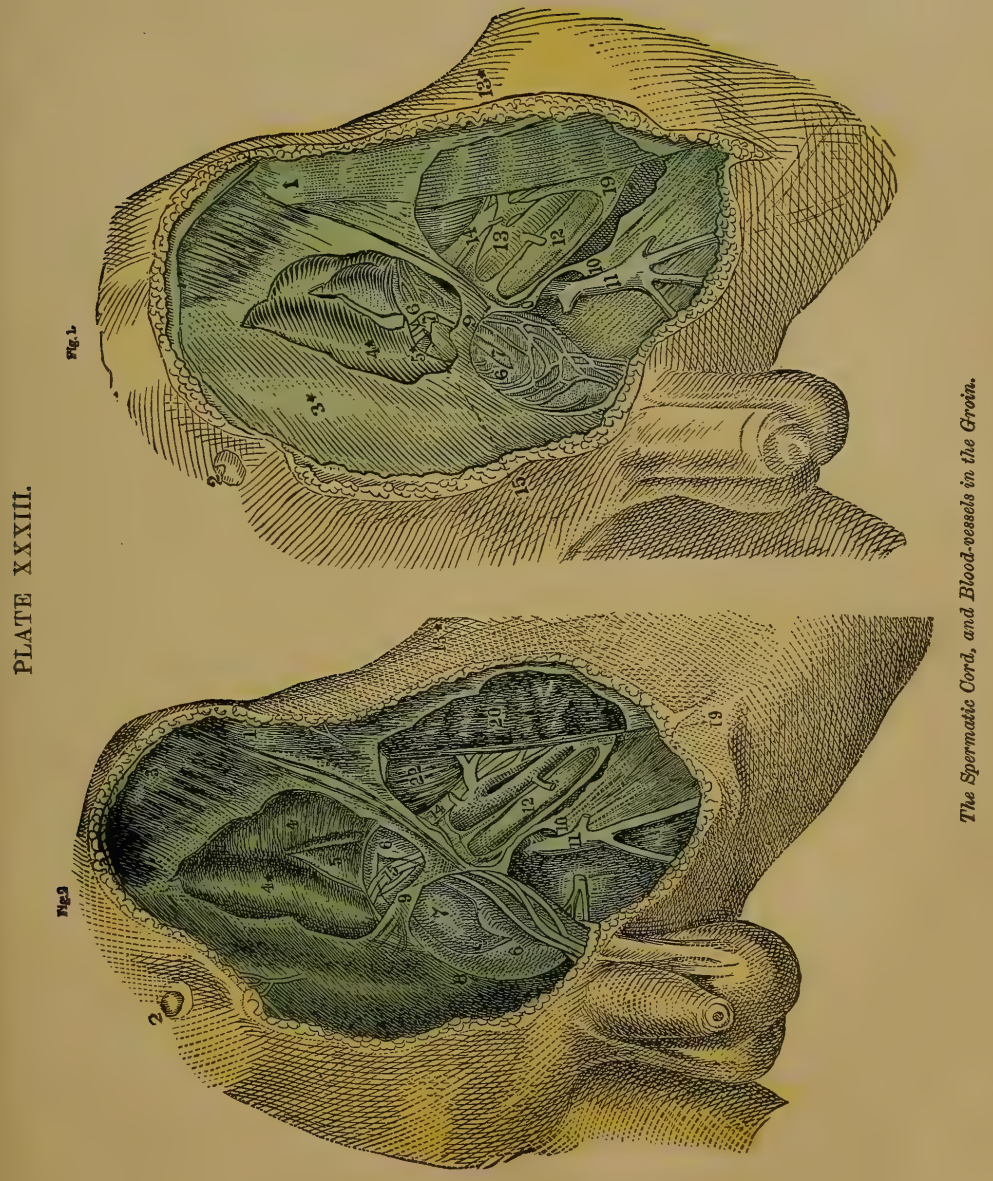



natural waist, and one shaped in the fashionable way by corsets. Compare them, and see in which lies the beauty. Also observe, by our previous plates, the position of the female organs in the body, and then inquire what becomes of them when the waist is compressed, as in the second figure. Especially notice the bones :

Inguinal rupture is an accident rery apt to make a man impotent, or at least to impair his powers, and the way in which it does so will be readily understood from our previons explanations. The rupture is formed by a portion of the intestine and omentum bursting out of the abdomen, at the inguinal ring, and it canses more or less pressure on the spermatic cord and blood-ressels. This interferes with the circulation of the blood in the testicles, and consequently impairs their nutrition. It is not always serious in this way, however, but is very apt to be so.

Sometimes more harm is done by a badly-fitting truss, such as is worn for this accident, than by the rupture itself.

The colored plate opposite page 418 shows the nature and situation of inguins] rupture, and the way in which it bears on the spermatic cord. 


\section{CHAPTER XXXVII.}

\section{INFLUENCE OF DRUGS OVER THE SEXUAL POWERS.}

Cantharides, or Spanish flies. - This article is popularly supposed to have an undoubted stimulating effect upon the sexual powers, and many persons will be surprised to learn how little foundation there is for such a belief. In fact, upon most persons, cantharides have but little or no effect at all in that way, except they are given in such quantity as to be poisonous, and then they only act by causing severe inflammation, not only in the genitals but also in all the neighboring parts. It is quite common for even a small dose to create great irritation of the bladder, with complete inability to discharge the urine, and this may take place without any unusual sexual excitement at all, though most usually the generative organs are stimulated more or less. It is a great mistake, therefore, to suppose that cantharides have a constant and specific action on the sexual organs, for they merely create an intense irritation, which affects these organs along with others, in the same way that many other irritant poisons do. All the popular notions on this subject are utterly unfounded, and quite opposed to the truth.

It is rery seldom that cantharides are of any service whatever in the treatment of impotence or spermatorrhœe, though a combination of these with other articles is useful in certain cases. They form the main ingredient in all the quack stimulants for the generative organs, and the use of them in this way unfortunately causes great mischief. Numbers of young men are permanently ruined, from spermatorrhœa, through taking these preparations of cantharides, and I have known many married persons rendered hopelessly sterile from using them as stimulants. I had one distressing case of a young man, who was persuaded by a thoughtless friend to take some Spanish flies as an experiment, to see if they would not increase his desires and powers. The quantity he took was only a moderate dose, but the effects were most alarming. He completely lost all power of discharging the urine, though the bladder was full almost to bursting, and experienced such agonizing pain in the prostate and urethra that he was nearly delirious. Priapism took place, but so far from being attended by increased pleasure, it only added to his sufferings, and yet he could not prevent it. Fortunately, he had timely assistance, and the immediate danger was obviated, but very soon after, he began to be troubled with involuntary emissions in the night, and eventually when urinating, so that he became completely impotent, and so weak he could scarcely stand. I cauterized him, and used every other means the case would allow, but in spite of all, the trouble continued to some extent, and probably always will. He had been suffering, however, over four years when I saw him.

I also had a case of a young person of the other sex who was seriously injured by cantharides, given as a trick, and who had involuntary discharge of urine ever afterward. 
Camphor.-The action of camphor upon the genital organs is sedative rathes than stimulant, and when taken improperly or in excess, it may almost entirely destroy the sexual feeling, at least for a time. It is, therefore, given in cases of priapism, and in excessive excitement, whether from moral or physical causes. If cantharides or any other irritating poison be taken, camphor is usually a valuable palliative, and it is sometimes of great service in certain forms of spermatorrhœe. If taken in too large doses, however, or for too long a time, it will cause involuntary emissions.

Nitrate of potash or saltpeter.-It is commonly supposed that this substance acts as a direct sedative to the sexual organs, and that if taken in any considerable quantity, it will destroy all feeling, but this notion is a very erroneous one. Like all other diuretics, nitre stimulates the genital organs, and if taken in too large doses it will even produce inflammation, like cantharides. Instances have been known where a discharge from the urethra has followed its use, like that of gonorrhoea, and afterward involuntary emissions have been experienced.

Ergot of rye, or secale cornutum. - This substance, as is well known, is used to expedite delivery in females, which it does by increasing the action of the womb. Its use, however, is dangerous, except in proper hands. From recent observations, it appears to stimulate the male organs also, and the men of those parts where it grows among the rye are noted for their ardent desires, while the females frequently miscarry. The ergot cannot be given alone, either with safety or advantage, but its combination with other articles forms a valuable remedy both for impotence and spermatorrhœa. It is one of the ingredients of a stimulating and invigorating medicine which I use extensively in my practice.

Coffee and tea.-Both these articles, but especially coffee, act as direct stimulants to the generative organs, and if taken in excess, may produce all the effects of the mast powerful drugs. I have known coffee cause priapism, lascivious dreams, and involuntary emissions, and nearly always its continued use will counteract any treatment that can be followed for relief.

Phosphorus. - This article is similar in its action to cantharides, but much more energetic, and consequently it is much more dangerous in wrong hands, but when properly administered, it is frequently of great service. It is one of the ingredients of the invigorating medicine which I formerly spoke of, with which I have often produced the most unexpected restorations to power and health. Phosphorus should, however, never be experimented with by those not familiar with its action, for in some cases it will lead to the most disastrous consequences, and its evil effects are not easily recovered from.

It is beyond doubt a most powerful stimulant to the generative organs, and also a most dangerous one. Instances have occurred of men being made perfectly delirious with satyriasis, from merely taking an ordinary medicinal dose of it, and women from the same cause have become so furiously excited as to forget every consideration of prudence and decormm. In one instance, a physician found his patient utterly unable to subdue the ardor that consumed him, by any means whatever, until complete exhaustion ensued, and he died. In less than thirty hours this man had cohabited sixty-five times, without erection having subsided or the flow of semen ceased. Similar effects are also observed upon animals, showing that the power of this drug is specific. A chemist having thrown out some of his refuse preparations, in which was some phosphorus, they were partly drunken by a drake, who immedi- 
ately afterward commenced cohabiting with his female companions in the most furious manner, and continued to do so till he fell down dead.

When incautiously used, therefore, this drug is exceedingly dangerous, and many cases of severe suffering have resulted from its unwarranted employment. Not only will it cause delirium, but it will also create the most burning and destructive inflammation of the stomach and intestines, which nothing can subdue. So perfectly does it pervade the very substance of the body, that, in many cases of death from its use, the corpse has been perfectly luminous, and the phosphorus has been distinctly smelt in the blood. A physician, who dissected a body of this kind, found that even his hands, and the instruments he had used, were luminous, and smelt quite strongly of it.

Even workmen who employ phosphorus, as match-makers for instance, unless they are very careful, are apt to suffer seriously in consequence of breathing its fumes. In some cases, the bones have even decayed, and ulcers have formed of the most malignant character. Children have been poisoned by eating the phosphorized ends of matches, it is well known, and some people have been made quite sick by only breathing the fumes when striking a friction match.

Ether, and other similar articles, have occasionally a singular effect upon the generative instinct, and awaken it when nothing else will. In many cases, where ether has been taken to produce insensibility, during surgical operations, the patient has been, in imagination, enjoying the pleasures of amative indulgence during the whole period. This has been the case with females while in labor, and insensible from ether, several having confessed that so far from suffering, they actually experienced the warmest feelings, and imagined they were enjoying the embraces of their husbands. In some of these cases, females have experienced these feelings, under such circumstances, for the first time, and never after did so while awake. A short time ago, I knew an instance of a young married lady who took chloroform to have a tooth extracted, and instead of putting her to sleep, it created a singular amative excitement, which, in her half-unconscious state, she could not control. Her advances to the dentist were obvious enough, but fortunately he was a man of honor, and took no advantage. In a short time the excitement wore off, but she had a distinct recollection of her situation, and was most deeply mortified and hurt when she thought of it. At other times she was rather indifferent to such pleasures, especially after the above occurrence. In some peculiar cases I use these agents in my practice, but only under certain circumstances.

Aromatics and spices have in general a stimulating effect on the generative organs, the same as on other parts, but their power varies very much in different persons, and under different circumstances. There are varions spice mixtures and combinations in popular use for this purpose, but they should not be indiscriminately used. Sometimes they are highly injurious, like all other stimulants, and even when they do cause an increase of power or feeling it is only temporary, and often followed by directly opposite effects.

In short, none of these articles operate specifically, in a beneficial manner, on the generative organs, though certain combinations of them may do so under particular circumstances, like the medicine I have referred to as being used in my own practice.

There is one drug, brought from the East Indies, the Cannabis Indica, which is the most regular in its action, and produces the most constant beneficial effects of anything yet tried. It appears to act as a special nervous stimulant, exciting thase 
parts of the brain, which influence the sexual organs, so that they feel directly an increase of power. It also causes great mental activity, disposes to cheerfulness, and induces a feeling of warmth and comfort over the whole system. Those who have taken it, in a proper manner, are delighted with its effects, and never complain of any after-depression or reaction in any way. If given improperly, however, or in too heavy a dose, it first causes excitement of the wildest character, with an uncontrollable disposition to bodily activity, and afterward a complete mental and physical prostration. In short, it is most powerful, either for good or for evil, according as it is used, and is the only means we possess, in numerous cases, of restoring sexual power and desire. In the East Indies it is commonly used, like opium in China, for the purpose of producing pleasurable excitement, and also for removing impotence.

Medicines that excite the sexual organs are called aphrodisiacs and in various parts of the world they are in great demand, though but seldom administered so as to be of any real service. As I have already remarked, some of these medicines, when properly used, have undoubted aphrodisiac powers, but they are by no means applicable in all cases. They may frequently fail of producing any good effects whatever, and sometimes may even cause irretrievable mischief. Their successful administration, therefore, requires a perfect knowledge of their properties, and an extensive observation of their effects under all circumstances. It is for this reason $I$ have not given any recipes for these drugs, for no one can tell when they should or should not be used unless they know something about them, and the effects of taking then improperly may be so serious that experiment with them is dangerous.

Medicines that decrease the sexual powers are called anaphrodisiacs.

Every young man should read attentively the remarks upon the influence of tobacco and alcohol, further on. The real power of these drags is but little known, and the mischief they do to the sexual organs is unsuspected. Married persons should also be acquainted with many of the facts there given, as they will show that in many instances the most temperate use of these articles is hurtful, and that they often cause impotence and sterility, as well as insanity.

These remarks were intended to apply more especially to the male, but they are equally applicable to the female also. In fact, to females they may often be of more importance than to males, because the female system is more easily affected by many of these drugs, and they act upon them with more intensity. I have known little giris affected in a most deplorable manner by having such drugs given to them, and I am confident that the practice is productive of more mischief than is generally suspected.

Odors and scents. - It will scarcely seem possible, to those who have not considered this subject philosophically, that a mere scent can have any effect at all over the generative powers, but such is undoubtedly the fact. The different parts of the nervous system are so mysteriously and sympathetically connected that any impression, however slight, made on one nervous fiber may react upon others in a remote part of the organization, and thus exciting the olfactory nerve, by some peculiar odor, may react upon and excite the sexual organs, as powerfully as if they were directly irritated.

Some persons are much affected by odors, which operate upon them either stimulants or as sedatives. That there are odors which specially excite the sexum. instinct is beyond question, though different people experience their effects in very different degrees. There are also others that exert an opposite influence, though seldom in so decided a manner. Very sensitive people, particularly those in whom 
the sexual instinct is naturally strong, may be as much excited by a mere scent as by a medicine conveyed into the stomach, as I have frequently seen. Hysteria is often excited in this way in females, and various forms of nervous excitement frequently supervene in the other sex from the same cause.

It may be stated, as a general rule, that all powerful odors may produce effects of this kind, and they are, therefore, better avoided, particularly the habitual use of them. There are some particular scents that exhibit this power more constantly, and to a greater degree than others, and several of these are articles of common use in the toilette. An enumeration of these would embrace many of the choicest perfumes used, but it is scarcely possible to particularize among so many, nor is it necessary. The very origin and natural use of some of these indicates clearly enough the purpose nature intended them to fulfill, in the animals from which they are taken, and I cannot but think that few females at least would use them, if they really knew what they were. Musk, especially, is an article of this kind, the aphrodisiac effects of which I have sometimes seen exhibited in the most unequivocal manner.

The readers of classic poetry will call to mind the story of the Indian Prince, who exhibited such marvelous powers merely from smelling the flowers of the nympha odorata; and also several other instances in which the aphrodisiac power of different odors is distinctly alluded to, showing that the general truth was known centuries ago. Some of these accounts are of course much exaggerated, but most of them are founded unon actual truths, as I have in some cases proved, and I believe the statement about the nympha is one that is entitled to consideration.

In Turkey, an odoriferous pastile is in common use in the harems, and is reputed to have great stimulating power. It is compounded principally of musk, civet, ambergris, cinnamon, and a variety of vegetable oils. One of these is constantly worn in the dress, and sometimes it is powdered and rubbed over the person.

Some of these scents, as musk for instance, are probably the sexual odors of the animals from which they are taken, and are intended to attract the other sex. This may possibly account for their peculiar power, and make it less singular. Dimerbrock rolates an instance of a man who rubbed musk upon his genitals, before cohabiting, and who became so swollen and excited in consequence, and his partner likewise, that they could not separate till a variety of refrigerant means had been resorted to. And in another instance it was observed, that one of these scents excited an insane person, though he gave no such indications without it.

Experiments have shown undoubtedly, that the peculiar odor of the genital organs, of either sex, will excite the other sex, though the individuals may neither be visible nor known to be near. 


\section{CHAPTER XXXVIII.}

\section{ON THE PREVENTION OF CONCEPTION.}

THrs is a subject which many persons may think not necessary to be treated upon, but there are peculiar reasons why it ought not to be passed over in silence. It has been, of late years, so much talked of, and so many unscientific works have been published, pretending to give information about it, that every one is familiar with the idea. To say that there are means of preventing conception, is only stating what every person has already heard, or believes, and is, therefore, nothing new. Even if such information was likely to be productive of great evil, as some imagine, it is now impossible to prevent its dissemination, and it is, therefore, useless to avoid the topic. I think, however, that the danger apprehended from it is altogether fallacious, and the fear arises from a wrong view of the case, as shown in the article on Conception, to which I refer my readers for the arguments.

Many of the practices resorted to for preventing conception are altogether ineffective for the purpose, and some are decidedly hurtful, but this not being known, people resort to them, and are both deceived and injured. It is, therefore, the duty of every physician to show the inutility and danger of such practices, and not to shun the subject.

Independently of this, however, there are many great and good men who think that harmless means of preventing conception may be practiced with propriety, or even become advisable in peculiar circumstances, and that there may be nothing either immoral or improper in their use. It is well known, for instance, that there are many severe diseases to which females are subject, that never can be removed while they conceive, but which, if uncured, are sure to become fatal, and probably also descend to their children. Some females also have deformed pelvises, and can never bring forth live children, while others are certain to die if the child remains in the womb till it is a certain size. Besides these cases, however, how many there are that remain in constant ill health and suffering from continued child-bearing, without the possibility of relief or escape. In our country, fortunately, there are but few persons that cannot find means to maintain a family, though it be large, but still, with many it may be a severe struggle to do so, and a constant increase may condemn the parents to poverty and difficulty, and the children themselves to neglect.

Now it cannot be denied that people are situated under all these different circumstances, and that the continual increase of their families entails all these evils both upon them and their children, but whether this affords a sufficient reason for limiting the number, must be left for every person's own decision. I am acquainted with many moral and religious people who think that the practice, under such circumstances, is perfectly justifiable and proper, and some even consider it a duty. Others, however, think the contrary, and hold that every evil or inconvenience ought to be 
undergone, whether poverty, sickness, or even death, rather than avoid it by such means. For my own part, I would neither give advice, nor offer an opinion on the subject, as I consider that all persons should decide for themselves, and that their decision concerns themselves alone. My duty is simply to show the injury of those practices now in ordinary use, and also the ineffectiveness of most of them.

It is not generally known that it is a regular custom in medical practice, when a female has a deformed pelvis, or is otherwise incapable of being delivered at the full term, to produce abortion at an early stage. This, however, is the invariable custom, and in practical works upon midwifery the means are explained. This is done because it is thought better to sacrifice the foetus only at any early stage, than to let both die, as they assuredly would, if the gestation were allowed to proceed. Now it may well be a question in such cases, whether it would not be better to teach how to prevent the conception altogether, and I leave it for others to decide which is the most objectionable, prevention or abortion?

There are few persons except medical men, who have any idea of the extent to which the revolting practice of abortion is now carried, or of the awful consequences that frequently follow from it. Every female who undergoes any of the disgusting operations practiced for this purpose, does so at the risk of her life, and to the almost certain destruction of her health if she survives. I have had many of these miserable victims come to me afterward for advice, and more wretched objects cannot be conceived. Some of them have been almost torn and cut to pieces, and others so injured, that their lives hung as it were by a thread. Those that take drugs for this purpose are also equally exposed to risk, and suffer in their health to an equal extent, so that their lives become a positive burden to them. In short, this is one of the most terrible evils of the present time, and every one must earnestly desire to see it abolished, or some lesser evil take its place. Every female may be told with truthand, indeed, every one ought to know-that there are no safe means of procuring abortion. It is true that some few may undergo the ordeal in safety, but none can depend upon doing so, and the chances are ten to one that death, or the evils above referred to, will follow!

A general knowledge of this fact would, no doubt, do much to prevent the practice, but still it would not do away with it altogether, unless some reliable means of prevention were known. Strange as it may seem, many of the worst sufferers have assured me that they would undergo the same risk again, rather than have more children, and some have even said that they would die first. In such cases, therefore, there is simply a choice between the two practices of abortion and prevention, and $I$ am confident there are thousands who feel in this way.

A gentleman called upon me a short time ago, who was suffering from a terrible scrofulous affection, which had appeared since his marriage, and by which his first child was afflicted in an awful manner. He assured me that both himself and his wife would rather suffer death a thousand times than be the authors of such another miserable being, and that they thought it would be a most grievous sin for them erer to be parents again. In another case, the mother had periodic attacks of insanity after she had borne two children, one of whom had already shown symptoms of the same terrible affliction, and they, with good reason, feared that if they had others, the same calamity might befall them. Now, in such cases, I leave those who condemn prevention altogether to decide what should be done. For my own part, as I remarked before, I leave all to decide for themselves, according to their conscientious 
notions, and I think that no one person's decision, let it be what it may, should in any way affect another person. In a word, I think it is every one's own affair.

Besides such instances as the above, I often meet with others equally distressing, and such as are common enough. An industrious, hard-working mechanic, called upon me once and stated his case, in the hope I could give him advice. He had four children, the eldest only eight years old, and after every confinement since the first, in consequence of an injury then, his wife was from three to six months completely bed-ridden, and unable to attend in any way to her household duties. His employment was often restricted, and his means so limited, that hired help was out of their power, and there, said he, "My wife had to lie, day after day, and week after week, and see everything go to ruin in the house, with the children dirty and ragged, without being able to rise and help herself." Now this may be considered an extreme case, but there are thousands of others that approximate to it, and people, so situated, naturally ask of their medical adviser, "What shall we do ?" If these men give them no reply, as is generally the case, and no other means are offered to them, they too often resort to the dreadful practice of abortion.

I know some people will say that it is possible for such persons to avoid having a family without using preventive means. And so it is; but the deprivation required will not be undergone by the great mass, and cannot be undergone by others without the most immoral consequences. It is sheer absurdity to suppose that the promptings of nature can be totally unheeded, except in peculiar individual cases, and illicit intercourse, or vicious habits of self-indulgence, would certainly follow a total deprivation of the marital right, in most instances.

Many medical men and philanthropists have perceived these difficulties, and have pressed a consideration of them, but few have chosen to give actual advice. I think it is best to leave it altogether an open question as to the propriety of prevention, or in what cases it is allowable.

T'he most obvious means of prevention are those alluded to in the Bible, as having been practiced by Onan, and which have doubtless been in use for thousands of years. If the seminal fluid be not placed within the female organs, of course there can be no conception, and all that is required, therefore, is to cease association before emission occurs. But, independently of the uncertainty of this being done, at least in many cases, it is not advisable. There is good reason to believe that, in every act of association, the presence of the male principle within the female organs is always required, even when there is no conception. It is, in all probability, more or less absorbed in every case, and even when it does not impregnate, it prevents irritation and exhaustion. In fact, without it, the act is merely a species of masturbation, unsatisfactory and injurious. It is also extremely hurtful to the male, and in a way not at all suspected. When emission occurs without the female organs, it is always more incomplete and slower than when it occurs within, owing to the absence of the customary warmth and pressure, and of that peculiar influence which the organs of on sex exert upon the other. A portion of the semen, therefore, remains undischarged at the time, and escapes slowly afterward, thus giving rise to a weakness and irritation of the urethra and seminal ducts, which, in time, becomes permanent, and lays the foundation for involuntary losses and final impotence.

I have known many married men much injured in this way, without being able to even conjecture what had hurt them. And I am confident that much female exhausfion and nervous irritation result in the same way. 
The partial adoption of this plan is not liable to the abore objections to quite an equal extent, but still it is so, more or less, and it is perhaps still more difficult to practice. But, independent of these considerations, it cannot be relied upon, for conception may follow if the seminal fluid be placed in any part of the vagina, as before explained, or perhaps even in the external lips. It is true it is not so likely to occur under such eircumstances, but still it may do so. In some men the penis is imperfect, the opening of the urethra being under, and some distance down, instead of being at the end, so that they can never eject the semen to the top of the vagina, but only into its lower part. Still these men may be fathers, though not so frequently as others, unless with certain females. Dr. Dunglison, in his Human Physiology, remarks of this imperfection, that "we cannot, therefore, regard it as an absolute cause of impotence, but the inference is just, that if the semen be not projected far up into the ragina, and in the direction of the os uteri, impregnation is not likely to be accomplished; a fact which might be of moment to bear in mind where the rapid succession of children is an evil of magnitude."

This plan, therefore, diminishes the liability, but does not totally prevent.

The next most general plan is the use of injections after association, either for the purpose of removing the semen, or of destroying its power. For the purpose of removing it, however, they cannot always be relied upon, for sufficient will often be retained in the folds of the vagina to cause conception, notwithstanding the injection. For the same reason, no certain dependence can be placed upon introducing any object into the vagina before association, as a sponge, for instance, which, on being withdrawn, may bring the semen with it. In many cases this succeeds, but often it will not, because a small portion of semen is sure to be left on the walls notwithstanding, and that may impregnate. There is another objection also to this, which should forbid its general use. The object introduced, of course, comes immediately before the mouth of the womb, and thus prerents the contact of that part with the male organ. Now this contact is often necessary for the production of a proper state of excitement, as formerly explained, and when this does not occur, there is simply an injurious irritation to the female, without any gratification. I have known it also cause irritation of the meatus in the male.

The use of injections to destroy the power of the semen would seem to be the most reliable means, and when of the proper kind, they are so, but the unscientific use of them has led to serious evils. The way in which they operate, when effective, is by killing the seminal animalcules, and any injection that will not do this, will not prevent conception. There are many substances that will apparently kill them, but which only leave them paralyzed, so that they afterward recover; and there are other substances that will destroy them, but only when used so strong as to injure the female organs. The solutions of various salts, for instance, act in this way, such as alum, sulphate of zinc, chloride of zinc, and sulphate of iron, none of which, according to my experiments, will always kill the animalcules, unless used stronger than is allowable with safety to the female. Very many I have met with seriously injured by the constant use of powerful injections of this kind, some having inflammation of the womb and vagina, some excoriations, and others hemorrhage. Besides which, they in a short time destroy the sensibility of the parts entirely, and lead to total indifference and sterility. The only articles proper to be used in this way are such as destroy the animalcules without acting on the female organs, and ihere are but few that do so. 
The employment of injections is objectionable, however, on other grounds. It is not advisable, as before stated, to remove the semen from the vagina, nor to prevent its being deposited there, because it is better for it to be absorbed, even when there is no impregnation. In all cases, also, it is necessary for them to be used immediately after emission, and the too early separation, together with the anxiety and revulsion of feeling attending upon the preventive act are both agitating and injurious, to say nothing of inconvenience. Some females, also, absorb the semen so quickly that the injection can scarcely be used in time, and with some men the emission is so slow that the first part may impregnate before the whole has been expelled. To be in any degree certain, therefore, when using injections, it is necessary for the act to be to a certain extent incomplete, and this often causes a weakness in the male and nervous irritation in the female.

The employment of a covering to the male, in the form of a thin skin tube, called the condom, is of course efficacious as a preventive, but is liable to many of the above objections. The emission is never quite perfect when it is used, and the mutual contact of the male and female organs with each other being prevented, as well as the contact of the semen with the vagina, there is not a complete gratification, and to the female great nervous irritation often follows.

Among some persons a plan has been adopted more injurious than any of the above, though not known to be so. It consists in forcibly compressing the male organ close to the scrotum, just previous to emission, so that the semen cannot escape. Some men think that by such means nothing is lost, and that the connection does not exhaust them, but this only shows their ignorance of their own structure. In all cases where the compression is practiced, the emission is as complete as if nothing of the kind had been done, only it takes a different course. By referring to the plate showing the internal male organs, it will be seen that the semen passes into the nrinary passage, from the prostate gland, through certain little openings called the ejaculatory ducts, close to the veru montanum, or little protuberance in the middle of the passage, close to the bladder. Now the reru montanum is so formed, being pointed forward, that it directs the semen along the passage toward the external opening, which is the course it should pursue, but when compression is practiced, so as to close the passage, it cannot escape in this direction. Under these circumstances, therefore, it is compelled to flow by the large end of the montanum and enter the bladder, from whence it is expelled afterward along with the urine. The consequence of this is that it soon begins to take that course always, whether compression be practiced or not, and the man becomes sterile in consequence. He is also liable to inflammation of the urethra, veru montanum, and bladder, and suffers from spermatorrhoea, till eventually his powers are lost altogether. It is, in short, a most destructive practice.

M. Parent Duchatelet gives us some curious information respecting this practice, in his work on "Prostitution in Paris," which may be read with profit both by the physiologist and philosopher.

I may perhaps as well remark here, incidentally, that some young victims of masturbation practice the same thing, under the mistaken idea that no evil ensues from their vice if the emission does not take place. The folly of this will, however, bo apparent from the above explanation.

Those females who think they can escape being impregnated by simply aroiding all excitement and pleasurable feeling, are more deceived than those who rely on any of the other modes, as former explanations have shown. 
It is evident, however, that the prevention of conception, when association is practiced, is not so easy as some have supposed, and that it is not altogether harmless either.

To prevent disappointment and criminality, it is thought advisable to make known the following facts: By a law of the State of New York, and also by a special act of Congress, it is forbidden, under any circumstances, to give any one such means, or information, as may enable them to prevent conception! The law makes no exceptions, not even though the plea may be to preserve health or life!

It is also forbidden to import or sell the ordinary membranous, or rubber coverings, used to prevent venereal disease.

In regard to miscarriage, or abortion, it should be universally known that there is no medicine whatever which is sure to effect either the one or the other at any time! Nine-tenths of the remedies advertised for such purposes are mere deceptions, and are not intended to have any effect whatever; while the remainder are more dangerous to the female than to the foetus, and still uncertain in their action.

The operation for abortion is never safe at any time, or in any hands, and every woman who submits to it, not only risks her health, but puts her life in peril! 


\section{CHAPTER XXXIX.}

TOPICS OF SPECIAL INTEREST.

\section{Influence of Food and Drink over the Sexual Powers.}

THOSE who think that food and drink exert little or no direct influence over the sexual powers are greatly mistaken. They in fact operate most powerfully, both directly and indirectly.

It is very essential to the preservation of the sexual power that the general health should be good, and that there should be no serious derangements of any of the vital functions. When the general health is impaired and the vital energies are low, the sexual organs are sure to be weakened, and usually more in proportion than any of the others. Owing to their extensive sympathies also, they are sure to be affected by the diseases of all the other organs, and not unfrequently this sympathetic injury becomes very serious. The stomach particularly exerts a great influence over the generative organs, both beneficial and injurious. Long-continued dyspepsia is nearly always accompanied by weakened sexual power and desire, and even temporary attacks of indigestion will, for a time, produce similar effects. On the other hand, a healthy stomach, with perfect digestion and nutrition, is highly conducive to sexual vigor. We may even go much further, and show that high feeding is nearly sure to over-excite the genital organs, or, in other words, that gluttony leads to licentiousness. This is a truth too often lost sight of in the education of children, many of whom, though predisposed to sexual ardor, are stimulated with rich food and exciting drinks till their passions become overpoweringly strong. In short, the stomach exerts a most decided sympathetic influence over the generative organs, and we are thus enabled, by proper attention to the diet and drink, to either increase or weaken their power to a great extent.

Some kinds of food stimulate the sexual organs, while other kinds have the contrary effect upon them. Shell-fish, as before stated, are usually stimulating, owing to the phosphorus they contain, but other fish have partially this power. Flesh-meat is stimulating, merely because it is nutritious, but it is a great mistake to suppose that it is of necessity more so than vegetables. There are some vegetables that are often more stimulating than flesh, especially those that are farinaceous or contain much starch, as the potato for instance, which, when of good quality, contains most of the elements the body needs. Most strong-tasted or aromatic regetables have a stimulant effect, such as celery, parsnips, onions, and asparagus, especially, and so have all seasoning herbs, such as mint, sage, pennyroyal, and thyme. Spices and condiments have a still stronger action, especially the peppers and nutmeg. Mushrooms stimulate some people very much, and truffles still more, and even olives exert a marked influence at times. The flesh of birds, I think, is not stimulating, except that which is red, such as ducks and geese. I have several times been assured that 
eating freely of the canvas-back duck, when in season, has been highly beneficial to those who were weakened by excess, probably partly from its own nature and partly from the wild celery on which it feeds. Of all meats, however, turtle has the greatest reputation for exciting the generative organs, and I think with good reason. It is undoubtedly highly nutritious, and it appears also to contain some heating principle, which specially affects those parts.

As a general rule, all watery regetables, such as turnips, cabbage, and squash, have no such effect as those enumerated, and are therefore proper when we wish to keep down excitement. Acid fruits also come under the same category, and indeed fruits generally, except some highly-flavored ones, such as peaches and pine-apples, which are undoubtedly aphrodisiac, except they disagree with the stomach.

Tomatoes are rather stimulating, and so are most kinds of beans, especially the lima beans, but peas are not so. Wheaten bread, or wheaten flour in any form, is more stimulating than the flour of any other grain, while Indian meal is probably the least so. When we desire an anaphrodisiac effect therefore, Indian bread should be used, with mush, samp, or hominy, instead of wheaten bread or potatoes. Rice is unstimulating, but sago, tapioca, and arrow-root are the reverse.

In regard to drinks, it may be stated that all alcoholic liquors are highly stimulating when first taken, but they soon lose their power if used too long or intemperately, and then they become injurious. Wine has a more strengthening effect than spirits of any kind, and ale or porter is still better than wine. Those who desire to keep their passions down should not take either wine or malt liquor in any quantity. Most of the cordials in use are highly exciting, owing to the spices they contain, and so are many of the so-called bitters. Coffee is almost as stimulating as wine, and should never be used by those who are disposed to involuntary emissions, nor by those whose desires are too strong. Tea is different from coffee in this respect, and is therefore the better drink in such cases. Milk, though highly nutritious, is not stimulating, and it therefore forms an excellent drink for those who are disposed to emissions or exciting dreams; such persons, however, will do better to use cold water only, and they should also avoid all warm fluids, no matter how simple, because warm drinks always excite the flow of urine, and of course stimulate the sexual organs also. Those who cannot use the cold water only may safely drink soda and mineral waters as much as they choose, or lemonade if it agrees with them.

The Turks regard all kinds of fish as being stimulating to the sexual powers, and they resort to them on that account. Some kinds besides shell-fish may probably be so, because they contain phosphorus, which is the real cause of their power when they have any. A French writer, Hecquet, gives us a curious account of an experiment made by one of the Sultans, to test this. He had two Dervishes brought before him, men who mortified the flesh in every way, and who practiced the most rigid celibacy. He had them fed upon the most stimulating and nutritious meats, till they became quite stout and strong, and then commanded them to be constantly attended by two of the most beautiful young females in the harem, who were directed to use all their arts to excite their amorous desires. The Dervishes, however, resisted all these powerful influences, and maintained their celibacy inviolate. He then directed them to be fed on fish, and to be waited upon in the same way. This course was found to succeed, the rigid Dervishes forgot their vows, love triumphed, and the influence of this peculiar diet was fully established.

Young meats are not nearly so stimulating as those of mature animals, nor so 
nutritious. In roasting meat, especially beef, when it is properly done, there is a peculiar and delightful odor given from what is called the bark or brown, which indicates the presence of a principle, termed osmazome, which is not found in real or lamb. This principle is highly stimulating and generous, and undoubtedly conducive to generative power.

In well-prepared soups we smell the osmazome, and then they are of service, but without it they can do but little good.

Good, rich beef roasted, especially the outside, is perhaps as good an article for strengthening the sexual powers as any that could be eaten, and it may often be used alternately with some of the other articles mentioned, with great advantage:

Fat is of little service for this particular purpose, it having a direct tendency, as is well known, to form fat, which is not required.

\section{PROPER TIME FOR SEXUAL INDULGENCE.}

The importance of this subject is greater than, at a first glance, it might appear to be, and in giving advice, as a medical man, I often find it necessary to refer to it.

Perhaps, however, the most important suggestions, as regards the preservation of the procreative power, are those relating to its actual use. It is weil known, respecting all the other vital functions, that their healthy performance and preservation depend materially upon their being exercised at proper times and under proper circumstances, and it is the same with the generative functions. Many persons think, because the genital organs are usually capable of action at any time, and under almost any circumstances, that it is therefore of little consequence what time is chosen, or under what circumstances it may occur. This, however, is a great mistake, as any one may soon discover by studying his own experience.

The time for sexual indulgence should be so chosen that the temporary excitement and after-exhaustion resulting from it may not interfere with any of the bodily or mental functions, nor distress the system by necessitating too much effort during any needful exertion. Ignorance of this important rule, and consequent neglect of it, very often leads to great inconvenience, and even serious mischief. Sexual indulgence just after eating is nearly certain to be followed by indigestion, even if it does not cause immediate vomiting, owing to the temporary loss of nervous power thereby produced, which arrests the action of the stomach. Just before eating, also, the same evil may follow, from the stomach being made so weak that digestion cannot properly commence, and the food consequently ferments. Many times I have heard men confirm this truth, when explained to them, though they had previously never dreamt that their troubles arose from such a cause, and when our previous explanations are borne in mind, respecting the nervous sympathies of the sexual organs, the philosophy of it will be evident. The proper time for this indulgence, therefore, in reference to taking food, is at a sufficient interval after eating for digestion to be nearly accomplished, and before another meal begins to be needed. By observing this rule, the action of the stomach is not interfered with, and no indigestion or nausea is likely to follow. It is true that most men experience a stronger desire for indulgence immediately after a full meal, particularly when stimulating drinks have been used, but this does not prove that they choose the best time. The desire they then experience is merely a factitious one produced by the general excitement of the whole system, and the exhaustion afterward falt is nearly always in proportion. In the same manner 
a man, while under excitement from alcohol, may feel disposed to great bodily activity, and may exhibit astonishing strength, but when the stimulus is withdrawn he feels a corresponding prostration and lassitude. This is the reason also why sexual indulgence should not be sought during such excitement, for the disposition is nearly sure to be stronger than natural, and the over-excitement is followed by proportionate exhaustion. In poetry, I am aware, Venus and Bacchus are associated together, but poetry is not always physiology, nor even common sense, nor should the licentious furor produced by wine be in any way considered as the promptings of nature.

Upon the same principles, it is obvionsly injudicious to seek indulgence just previous to any mental effort being made, because the vital energy will be too much exhausted to allow of such effort being made with advantage. Nor is it advisable immediately after any great mental effort, because it is injurious to have two causes of exhaustion in action at the same time. The same remarks also apply to muscular exercise, which should neither immediately follow nor closely precede sexual indulgence, for the reasons above given; in short, the period chosen should be one when both body and mind can enjoy repose, at least for a short period, both before and after, and when none of the functions are likely to be disturbed.

The time of day is a matter of secondary importance, or rather no preferable time can be named, because it must so much depend upon how the individnal is circumstanced. That of course will be the best time when the above-mentioned rules can be most fully observed. Some medical writers suggest the evening, because the business of the day is then over and the repose of night is to follow, and this probably is the best period, generally speaking. Others again recommend the morning, because there is then the greatest vigor, and in case of conception the offspring may be benefited thereby. This, however, I feel assured, is a bad suggestion, for the business of the day will be very apt to oppress a man who starts exhausted, and the various functions of his system will very likely be imperfectly performed.

The celebrated Buffon was accustomed to indulge just after his dinner, and possibly in his particular case it might have had no ill effect, but most certainly the practice cannot be generally advised, and there are few persons but what would be injured by it.

Perhaps the best course, when a man is much exhausted by the fatigues of the day, is to take a first sleep, for two or three hours, and then wake up for the purpose, devoting the remainder of the night afterward to undisturbed repose.

\section{EFFECTS OF OVER-EXCITEMENT AND ABSTRACTION OF MIND.}

Abstraction of mind, or its complete absorption in some much-liked prirsuit, is highly unfavorable to the manifestation of sexual power. Many men who were really strong and vigorous in their sexual systems have been comparatively impotent from mere pre-occupation of mind, as some of our former articles have shown. Such is the ease also with females, who are very apt, when absorbed in their domestic duties, and in the anxieties attendant upon a family, to become completely indifferent to amative enjoyment. Indeed, it is a common remark that most of them soon fail in this respect, and seldom maintain the ardor they experienced at first, and no doubt for the above reason. Those that remain childless, or who have no care and anxiety, do not experience this deprivation, but, on the contrary, their power of enjoyment often increases. 
A celebrated medical author relates an irstance of a great mathematician who married, and who, though every way capalle, was utterly unable to consummate fully the act of sexual union. Always before it was complete some of his mathematical problems would come up in his mind, and so completely abstract him, that love was momentarily forgotten, and the excitement went down. His lady complained to the physician above-mentioned, and asked his advice. He recommended her to partially intoxicate her husband some night, with champagne, and induce him to seek her society while experiencing the, to him, novel exhilaration. She did so, and the result was as desired, so that in a short time she became a mother. During the unusual excitement of the time his mathematics were forgotten, and love had the desired opportunity to triumph.

Several instances have been known where over-excitement has led to apoplexy, and to paralysis. I know a young man now, who became completely blind from excessive excitement when first cohabiting with a female. And I was told a case of a husband who actually died while embracing his wife after a long absence. In another instance, a man became insane from over-excitement, on the occasion of his marriage, and a female who was exceedingly amorous, completely lost the use of her limbs in the same way. Palpitations of the heart, nervous tremblings, and partial loss of sight are frequent occurrences at such times in both sexes, and when excessive are apt to become permanent.

\section{DURATION OF THE SEXUAL POWER.}

The duration of the sexual power, like any other, materially depends on the manner in which it is used, and this should therefore be duly considered by those who think the preservation worth striving for. A certain amount of natural indulgence is probably essential, in most cases, to perfect health, but when that amount is exceeded, of course, more or less permanent injury results, as before shown. Every individual should therefore endeavor to discover, for his own guidance, the proper limits to his gratification, and if he will attend to what has been previously stated on this point, that limit may be readily ascertained. By doing this, a real gain will always be made, for the extra duration of the power which this will insure will more than compensate for any temporary denial. With those people whose systems are in regular action, and whose health is nearly uniform, the observance of a regular period is found to be advantageous, and highly conducive to the preservation of the virile power, as it prevents both excess and graduial decline.

These hints and suggestions, though apparently simple and commonplace, are nevertheless of great value, and if duly observed would probably do more toward preventing untimely decay than all the medical treatment ever practiced. Decay is cansed, in numerous instances, by a number of small causes operating together, and if each of those be removed, as it may generally be very readily, the decay is of course prevented. People are too apt to take notice only of the more striking agents of destruction, passing unnoticed these apparently simple ones, as being of small consequence, while, in reality, they are the most important.

There are few persons of good health who will attend to the above suggestions, and the advice formerly given, but what may preserve their powers to an indefinite period of their existence, particularly if they practice cold local bathing over the parts, and avoid all improper excitement. There is no particular time of life when the 
powers of the male system decay, but they may be preserved to extreme old age, as many cases have proved. Old Parr, for instance, was condemned to do penance when over a hundred years old, for an amorous intrigue, and he had several children after that period.

In females, however, the power of generation ceases at the turn of life, but not the power of association, which of course remains the same. It is a remarkable fact also that the disposition to, and the capability of, enjoyment remain as strong after that period as before, or even become stronger in many, which would seem to prove that association is quite proper as a means of indulgence only, or certainly the desire for it would become extinct.

The explanations already given will show that both power and capability of enjoyment may be either increased and made to endure, or decreased and early extinguished, according to the mode of life which the individual pursues. There are, however, many modifying circumstances not generally taken notice of, but which are of considerable importance.

There is no question but that association between persons properly adapted to each other is less exhaustive, and may be more frequently indulged, than between those who are naturally unfitted to be companions. And it is also certain that the circumstances under which the association occurs may very much determine the effect it will have. It is requisite, for the act to be truly pleasurable, and advantageous, that it should be fully approved both by the feelings and the judgment; otherwise it will be more or less regretted, and more or less injury will follow, no matter what amount of mere animal gratification be experienced. This is the reason why mere licentious debauchery is always followed by remorse and ill health, while legitimate association in marriage, with a loved and respected partner, leads to no such evil results. It is a fact equally important to individuals and to society at large, that the institution of marriage is conducive both to health and to happiness, and that the duration of life, in both sexes, is longer in that state than in any other. Many men fall into a great error in regard to this subject, and suppose that they can realize more pleasure in the unlicensed indulgence of the single state than when married. This is, however, a fatal mistake, for they really enjoy less, and are after all dissatisfied with themselves, while the duration of their powers is materially shortened.

Some little time ago, I had a very interesting conversation on this subject with a Swedenborgian, who remarked that many of the principles laid down in my lectures exactly corresponded with his spiritual views on marriage, and that his own experience fully corroborated the truth of what I had stated. He told me that in his youth, he was unfortunately led into a licentious course of life, and experienced in consequence all that self-accusation and loss of real pleasure which I described, but that since his marriage, and in consequence of the important truths learned from Swedenborg's writings, he had subjected his passions to the control of reason, and had led, as he exp.essed it, a new life. He assured me that with the partner of his bosom, association was never followed by exhaustion to either, but, on the contrary, by a feeling of increased strength and pleasure to both, and I have no doubt but he spoke the literal truth, for I have been frequently told the same by others. He regarded this as a spiritual effect, while $I$ looked upon it as a simple physiological one; but be that as it may, the fact is an important one, both as regards health and morals.

Another important requisite for the healthy action and extended duration of the sexual power, in both, is a near correspondence in age. Experience has proved beyond 
doubt that when there is great disparity of age in marriage, the elder person is nearly sure to benefit at the expense of the younger, sometimes even sufficiently to compensate for the loss resulting from great excess. This fact was acted upon, medically, in former times, and is now even, in some countries, by procuring young females to sleep with old men, so that they may be strengthened thereby, which they nearly always are, though the females suffer a corresponding loss, and not unfrequently waste and die in consequence. Such unnatural practices are, therefore, properly discountenanced now, both by reason and morality, though we sometimes see a near approach to them in marriage. It is even known that when children sleep with old persons they suffer from it, and sometimes even die, without the cause of their sickness being suspected. In all probability young men who marry old females suffer in the same way, and to an equal extent, providing they are as exclusive in their companionship, but there are many causes that may make it otherwise in their case.

What constitutes a great disparity of age must, of course, depend upon various circumstances, besides the number of years. Some persons are younger at forty, or even fifty, in respect to health and probable longevity, than others are at twentyfive or thirty, and this must be taken into account. Generally speaking, however, there should not be much more than ten years difference, under any circumstances, and only half that is better, the man being the elder. Besides health, this principle of similarity of age has an important bearing upon the relative number of the sexes born, as shown elsewhere.

The explanation of the above-mentioned fact is probably this : all living bodies are constantly giving off portions of their substance, in the form of insensible perspiration, and these particles thrown off are in the same state, in regard to age and health or disease, as the body from which they emanate. The same bodies are also as constantly absorbing, both by the lungs and by the skin, whatever is presented to them in a proper form, which partly counterbalances the loss. Young healthy persons are therefore always giving off a stream of fresh, wholesome material from their bodies, and old, or diseased persons, as constantly giving off a stream of morbid and decaying matter, which explains why it is that the young suffer and the old benefit when they live together. The waste of the old persons is in part made up by absorbing the fresh exhalations from the young, and they become thereby rejurenated, while the waste of the young persons is only made up by absorbing the decaying exhalations from the old, and they in consequence speedily decay and become old likewise. The celebrated Hufeland, in his Art of Prolonging Life, gires some curious instances of the practical application of this fact, which are highly interesting, in a scientific point of view, though morally reprehensible. Among others, he tells us of an old man who had the superintendence of a kind of almshouse, in which were a large number of young girls, in whose society he passed nearly the whole of his time. He contrived to have a number of them always around him, so that he was constantly in an atmosphere, as it were, of youthful exhalation, and by these means he preserved his life to an extreme old age, with all his powers in full vigor. A similar practice, to a certain extent, has even been adopted in London and Paris very recently, as was discovered in the evidence of a police trial. It appeared, from the statements made, that a number of poor young married females were hired to attend, at certain establishments, for so many hours in the day, to associate with superannuated old men. And not only did these young females associate in company with the aged patients, 
but they also supplied them with what ought to be kept for infantile nutrimen alone-in short, they acted as wet nurses to them! The results of the practice were said to be very satisfactory; but fortunately there is not sufficient degradation and porerty, in this country, to make it available here, though I have known it attempted. With persons of equal age, and similar condition of health, the exhalations are similar, and there is an equal loss and gain on both sides. During sexual excitement the insensible exhalation is much increased, and therefore the effects above-mentioned are more evident at such times; and this perhaps explains, as my Swedenborgian friend remarked, why it is that in a proper marriage no exhaustion at all is experienced, there being merely a reciprocal interchange exactly corresponding in both.

PROPER AGE FOR MARRIAGE.

The proper age for marriage cannot always be determined by the number of years the individual has lived, some being fully as much developed at fourteen or fifteen as others are at seventeen or eighteen. The law, of course, fixes a definite period for each sex, as it is requisite to do, but nature makes many variations. The ancient Greeks fixed the period of marriage very late, from an idea that it would insure more vigorous offspring. Some of their lawgivers assigned thirty years for the female and from thirty-five to forty for the male, but others decreased this extreme period five or eight years, still leaving it, however, very advanced. The ancient Germans, according to Tacitus, never allowed young persons to marry, but compelled the strictest celibacy in the male till five-and-twenty, and in the female till twenty-one. This rule we are assured was never infringed, and they believed that the children were more strong, healthy, and long-lived in consequence. At those times perhaps, when none of the artificial excitants of civilization existed, and when all lived, almost from the mother's arms, in the constant practice of laborious muscular exertion, with coarse food and thin clothing, this continence might be practicable, but it certainly is not now.

In other parts of the world, where the habits and social condition of the people are different, we find the opposite extreme, marriages often taking place between mere children, and females of twelve years old becoming mothers. Both extremes are undoubtedly liurtful, the too early marriage being, however, the worst, both for parents and children.

A female who delays marriage till after twenty-eight is liable to many uterine derangements, and runs more risk during childbirth than even at a very early age. Perhaps it may be said with propriety, that it is better for a female to marry before she is twenty-four, and not till she has turned fifteen at least, or better still sixteen or seventeen, the medium age of eighteen being esteemed the must desirable by experienced physiologists. Much, however, will depend, as before stated, upon the development of the system, and upon the inclination. Mothers ought to be able to tell whether the development is such, in every respect, as to make marriage allowable or not, and it should be esteemed their duty to ascertain such an important fact. In the course of my practice I have met with many cases of deplorable suffering, both of body and mind, from neglect in this way.

The proper age for the male is from twenty to twenty-five. It is true that he is capable of becoming a father at a much earlier age, but it is not at all advantageous for him to be so, because previous to that time the vital energy is all required to 
complete the growth of the system, and it cannot be abstracted in the emission of semen without injury. It is an undoubted fact that in most young men, previous to seventeen or eighteen years of age, the seminal animalcules are very small, and often imperfect, which shows that though they may impregnate, yet it is not probajle that perfect offspring will result from them. There is, however, a difference among males as there is among females, though it is not perhaps so great, as a gen. oral rule.

\section{ADVANTAGE OF TEMPORARY SEPARATION.}

It $t$ is an undoubted fact, that a short absence, or partial separation, occasionally, tends both to increase marital pleasures, and to make them endure longer. It also makes conception more likely, as the organs act more energetically after a period of repose, and when stimulated by a short restraint. Many eminent men are said to have been conceived after a separation of this kind, and their genius has been attributed to the greater vigor experienced under such circumstances. It is said, for instance, that Sir Isaac Newton's father had been absent at sea for a long time previous to his being conceived, and that both his father and mother had strongly desired their meeting after this irksome separation. In many cases, I have acted upon this principle, in giving advice, with happy results, and I have no doubt of its being well worthy of attention practically.

On the same principle, some authors contend that it is advisable always to leave at least three years between every two births, and they contend it is better both for mother and child. It has even been advanced as an argument why females should know how to prevent conception, because it is thought that a small number of children will be more perfect, individually, than a large number.

\section{PRECAUTION AT THE TIME OF MARRIAGE.}

From our previous explanations, it will be seen that there may be many little peculiarities of organization, and many conditions of the genital organs, especially in females, that may make the first association not only difficult and painful, but even seriously hurtful. An imperforate or very strong hymen, a relatively small vagina, a partial closure of the lips, or an irritable condition of the parts generally, may be mentioned among others, and both parties ought, at such a time at least, to know that such imperiments occasionally exist. In most of these cases, a little care and gentleness may obviate both pain and difficulty, while a want of it may create lasting trouble and dissatisfaction. If young persons, of both sexes, always perused some book like this, these minor difficulties would be easily overcome in every instance, and even more serious impediments would be so well understood that they would neither alarm nor disgust, as they now too often do. In all cases, however, the existence of impediments of this kind should be known to mothers, or if they are not sufficiently informed, and suspect them, the advice of a medical man should be sought.

It appears to me that no young person should enter into marriage totally ignorant of its duties and liabilities ; and common humanity--to say nothing of prudenceimperatively demands that no young female should be condemned to it. I have known many instances of the terrible consequences resulting from a neglect of this necessary precaution, and, in many cases, when I have been timely applied to, I have been the means of removing impediments and difficulties that otherwise would have led to deplorable results. Owing to my books and lectures, a large class of cases of this kind constantly come under my care, and I therefore speak on sufficient grounds. 


\section{CHAPTER XL。}

\section{PHILOSOPHY OF AMATIVE INDULGENCE.}

THOSE who suppose that sexual enjoyment is altogether immoral and unworthy of rational beings, and those who regard it as a mere sensual gratification, are both in error. The instinct or desire for it is innate in all beings, and exercises a most powerful influence, both upon individual action, and upon the destinies of nations. That influence may be productive of good or evil, according as those moved by it are ignorant or properly informed, but there is nothing necessarily wrong in the instinct itself, that gives rise to it. The charms of mutual love, the relations of family, and the compact of society, are all dependent upon it, and would never originate without. Dr. Dunglison remarks, in his Human Physiology, that "In man and the superior animals, in which each sex is possessed by a distinct individual, it is necessary that there should be a union of the sexes, and that the fecundating fluid of the male should be conveyed within the appropriate organ of the female, in order that-from the concourse of the matters furnished by both sexes-a new individual may result. To this union we are incited by an imperious instinct, established within us for the preservation of the species, as the senses of hunger and thirst are placed within us, for the preservation of the individual. This has been termed the desire or instinct of reproduction; and, for wise purposes, its gratification is attended with the most pleasurable feelings which man or animal can experience."

The true origin of this instinct has been discussed in a former article, and frequent reference to it has been made in connection with various other explanations, so that its influence and uses are tolerably well shown already. It undoubtedly originates from the action of the sexual organs themselves, and its mental manifestations are merely caused by the reflex action of those organs on the brain. In proportion to the activity of the testes in the male, and of the ovaries in the female, is the extent of the sexual power, and in proportion to the number and sensibility of the nerves of certain parts is the intensity of sexual feelings and desire. To say that all these are experienced in different degrees, is but stating what is generally known, though few persons know the occasional extent of that difference. While some experience sexual desire so weakly that they can easily overcome it altogether, others feel it so overpoweringly, that every other impulse besides is utterly powerless, and for the sake of one indulgence, all risks are run, and all consequences madly braved. There are people even-females at least-who never even feel the slightest amorous propensities, and there are others in whom they becone so imperious as to cause actual mania. It is, therefore, very difficult to be strictly just, when judging of the virtues or failings of people in this respect, and the utmost charity should at least influence our thoughts, whatever prudence may point out as requisite in our actions. There are, no doubt, many immaculate people who owe their virtue chiefly to organic deficiency, which lessens the inclination to indulge, and there are no doubt others 
shat fall, from unusual organic rigor, which, perhaps, few, if any, would have been more successful in withstanding. This is not said, be it remembered, as an excuse for licentiousness, nor to undervalue the power of a well-regulated mind, in controlling these impulses, but merely to state the case as it really exists. That the sexual powers and desires may be either exalted or depressed, by the state both of the mind and body, has already been abundantly shown, and all persons with sufficient knowledge may regulate that state in a great measure themselves. It is the duty, therefore, of those acquainted with such truths to make them generally known, and thereby hasten the time when the mere animal instinct will be controlled, at least sufficiently to prevent evil, by the intellect.

The phenomena attendant upon copulation, or the actual union of the two sexes, have already been discussed, and also the causes that may be supposed naturally to lead to it. In both sexes, when the union is really desired, and no obstacle interferes, it leads to the highest and most absorbing excitement that animated beings can experience. Both sexes are thrown into a species of mental ecstasy and bodily fever, during which all other thoughts and functions are totally suspended, and all the vital forces are concen trated in the reproductive system. In the female, the uterus and vagina are engorged with blood, the labia are tumefied and irritable, and the clitoris becomes congested, erect, and highly sensitive. In the male similar changes are also observed, to fit the organ for its peculiar use. "It is first necessary that, under the excitement of the venereal desire, the organ should attain a necessary state of rigidity, which is termed erection. In this state the organ becomes enlarged, and raised toward the abdomen; its arteries beat forcibly: the nerves become tumid; the skin more colored, and the heat angmented. It becomes also of a triangular shape, and these changes are indicated by an indescribable feeling of pleasure."(See Dunglison.)

At this time the adaptation of the male and female organs for each other becomes most manifest, and the manner of union is clearly indicated. The penis being drawn up toward the abdomen, it necessarily has an upward curve, which precisely adapts it, in the usual position, to the curve of the vagina, and brings the mouth of the urethra almost directly against the mouth of the womb. The cushion of the mons Veneris prevents injury by external pressure, and the increased flow of mucus from the ragina moderates the heat, and lubricates the walls of the passage.

Dr. Dunglison remarks, respecting the male organ, that, in all probability, "The arteries first respond to the appeal; the organ is, at the same time, raised by the appropriate muscles, its tissues become distended, the plexus of veins turgid, and the return of blood impeded. In this way the organ acquires the rigidity necessary for penetrating the parts of the female. The friction which then occurs keeps up the voluptuous excitement and the state of erection. This excitement is extended to the whole generative system; the secretion of the testicles is augmented; the sperm. arrives in greater quantity in the vesiculæ seminales; the testicles are drawn up toward the abdominal rings, by the contraction of the dartos and cremaster, so that the vas deferens is rendered sborter, and, in the opinion of some, the sperm filling the excretory ducts of the testicle is in this manner forced mechanically forward toward the vesicles. When these have attained a certain degree of distension, they contract suddenly and powerfully, and the sperm is projected through the ejaculatory ducts into the urethra. At this period, the pleasurable sensation is at its height. When the sperm reaches the urethra, the canal is thrown into the highest excitement, and 
the isch1o-cavernosus and bulbo-cavernosus muscles, with the transversus perinei anc levator-ani are thrown into violent contraction; the two first holding the penis straight, and assisting the others in projecting the sperm along the urethra. By the agency of these muscles, and of the proper muscular structure in the urethra, the fluid is expelled, not continuously, but in jets, as it seems to be sent into the urethra by the alternate contractions of the vesiculæ seminales. These muscular contractions are of a reflex character, being independent of the will, and incapable of being controlled by any exertion of it. They are induced, as in deglutition (swallowing), by a special excitant-the food in one case, the sperm in the other."

This highest point of enjoyment is termed the orgasm, and in some it is so intense that all consciousness of everything but the intense pleasurable excitement ceases. The duration of the orgasm is short, it being over immediately the flow oi semen is ended, which is usually in a few seconds. The momentary ecstasy is followed by a state of dreamy languor and exhaustion, which is often not devoid of pleasure, though of a different kind, and there is an almost invariable desire for repose. So intense is the orgasm in some cases, that the individual utters loud cries, and becomes delirious, or occasionally insensible. The exhaustion afterward is also sometimes very great, and the individual will be almost unable to move.

In the female, an orgasm is not always experienced, and many even know not what it is, though they may be capable of considerable excitement. When it does occur, it is exhibited in the same way as in the other sex, though often much more intensely, being accompanied by cries and convulsive motions of the most energetic character. The after-exhaustion is usually not so great in them as in the other sex, and the dreamy languor is more pleasing. It will often endure for hours.

In the male there can, of course, be but one orgasm at once, because no other can be experienced till a fresh supply of semen has been secreted, which requires more or less time. Some, however, can have two or three secretions in an hour or two; but it is unusual, and the effort is always very exhanstive and hurtful. I have known an instance in which a man has forced eight or ten orgasms in a single night; but in such a case $I$ have no doubt there was a peculiar conformation of the organs, owing to which but a small portion of semen was emitted at once, and probably no more altogether than most men emit at once. In general, no repetition of the act is desired under several hours, or perhaps not for days, and it is certainly improper for it to be sought earlier than when naturally desired.

In the female the orgasm is not caused by any secretion, like that of the semen, and consequently the excitement is not necessarily subdued by the first, but several orgasms may follow each other in quick succession. This is sometimes carried to a great extent, each one becoming more vivid than the others, till fainting ensues. In general, however, there is but one, as with the male, and when there is a proper adaptation, the two orgasms correspond, which mutually heightens the pleasure of both, and conduces to conception, though not necessary to it in all cases.

The after state in females is not always the same, but is often one of sadness and weeping, or of violent hysterics. Some females even say that this is always the case when they conceive, and that they thereby know when that event occurs. It has been even said by some that during a vivid orgasm, resulting in conception, they could see, mentally, the new being they were about to bear, and one female assured me that in this way she had a perfect view of the form and features of her child as it afterward appeared at birth. Perhaps we ought rather to believe that the image so 
strongly impressed on her mind, at such a moment, was given to the child in conse. quence of that impression.

In most females there is a sudden and increased secretion of mucus from the vagina at the moment of the orgasm, which is erroneously thought by the uninformed to be a species of semen, but it has nothing whatever to do with conception.

In many of them the orgasm is very difficult to be produced, and they therefore seldom experience it, and in some even it is never felt. In others, however, it is produced very readily, and will even occur during sleep, or from exciting the breasts. Owing to this peculiar nervous susceptibility sexual excitement will also often follow various moral emotions, and an orgasm will occasionally supervene without there being any licentious tendency. This peculiar liability is in fact the cause of many female enthusiasms, which are often only the results of this powerful emotion directed by circumstances and education. When strongly experienced, if conscientious motives are powerful enough to forbid its natural indulgence, it takes some other direction, and imparts that fervor and devotion which is so amiable a part of the female character, and which all admire, though few suspect its origin. This nervous susceptibility, however, is unfortunate for them in some respects, as it makes them liable to undesirable influences, and often overcomes them in spite of themselves.

It has been asserted, by a very eminent physician, that it is simply owing to the susceptible state of the sexual system that many females are so readily impressed, as it is termed, by mesmerism, and similar nervous excitements, and that those who are uninfluenced by such agents are always of cold temperaments. The truth of this, as a general rule, every medical man of experience must have perceived, and in some instances it has been proved by unfortunate and unlooked-for occurrences.

A short time ago I induced a lady, who was formerly much addicted to mesmeric practices, to give me her experience, written down, and a curious revelation it is. She confessed that whenever she was capable of being acted upon, mesmerically, the mesmeric state was always preceded by one of sexual excitement, often amounting to a perfect orgasm, and that if this feeling was not experienced she could not be mesmerized. Sometimes the exaltation of the nervous system was so great she could with difficulty control herself, and so many orgasms would follow each other that she would be completely exhausted, and would faint away. According to her statement, the mesmeric sleep, or ecstasy, was nothing but the dreamy languor following a sexual orgasm, and though it may not be precisely the same in all similar cases, yet I am satisfied it is in many. I have seen exhibitions of this kind with young females, in which I could plainly perceive, from observation of such phenomena, that sexual excitement, though modified and disguised, was the moving impulse. Several respectable ladies have also assured me that they were fully aware of this from their own partial experience when being mesmerized for the cure of disease, and they afterward refused to submit to such influences again, or to allow their daughters to do su. In short, I am satisfied that such influences are often dangerous to morals, and also destructive to health.

Similar results to the above often follow intense devotional excitement, when car. ried so far as to overpower the reason-such, for instance, as the wild fanaticism of a camp-meeting, or protracted revival meeting, the female actors in which are often so carried away by their fervid feelings as to be totally insensible to the nature of what they experience. This I say, of course, merely as a medical man, and from the number of patients I have had who have been the victims of these exhibitions, I feel fully jus 
tified in making the observations I have. Hysteria and other nervous affections, palpitation of the heart, and irregular menstruation are a few of the evils that I thus find produced, to say nothing of the liability to affections of the brain and chlorosis.

One of the most remarkable circumstances connected with the experience of the sexual feeling, in females, is the fact that it will often be felt with one companion, even to excess, but not with another, though there may be neither dislike nor disinclination. This shows how much it is under the influence of the mind with them, and to what an extent it is modified by other emotions. Some little matter, perhaps a mere association of ideas, may be sufficient to prevent excitement entirely, or raise it to the highest pitch. This also shows that there is a natural adaptation required between married persons, and that marriage is never precisely what it ought to be unless that adaptation exists. It is not easy, however, to say in what that adaptation is to be found, nor can its absence or presence be known precisely, except by experience.

In addition to its other uses, sexual excitement is undoubtedly beneficial in various ways to the organization generally. It serves as a wholesome stimulus to the nervous system at ordinary times, and as a means of expending surplus energy when the vital functions are too active. It is very seldom the case that there is perfect health without it, and scarcely ever is there an exemption from severe nervous affections. This accounts for the fact that married people are always longer lived, on the average, than those that remain single, notwithstanding that they have more anxieties, and that married females are subject to so many accidents. A celebrated physician (Pidoux), who had been much employed in nunneries, assures us that almost invariably the nuns are afflicted with floodings, and with other uterine diseases, after they attain a certain age.

In short, marriage, or the union of the two sexes, is ordained by nature, and this ordinance can no more be violated without evil consequences than can any other. The physical enjoyments appertaining to marriage also form part of that ordinance, and are undoubtedly both proper and advantageous within certain limits.

In all cases where the sexual system is mutilated, so that none of those feelings and desires are experienced, the individual remains ever after imperfect, both bodily and mentally. Proof of this is to be seen daily in our domestic animals, the nature and form of which are changed in the most remarkable manner by castration or spaying. The most remarkable effects of this kind, however, are seen among human beings, in those unfortunate creatures termed eunuchs. Stunted or deformed in body, imbecile in mind, and perverse in disposition, they drag on a wretched existence for a little more than half the usual term of human life. Decrepid and decayed while yet young in years, old age comes prematurely upon them, and an untimely grave closes their imperfect career. Nature, in short, seems to say, that where the generative apparatus is absent, the rest of the system is not worth preserving, and she therefore leaves it to speedily decay.

Even in after life, when all has apparently become perfected, the presence and proper action of these organs is necessary to maintain health and vigor. If any accident occurs by which they are destroyed, or their powers seriously impaired, everything else suffers, and the whole system speedily goes to decay; without them, everything else seems to be abandoned.

The sexual system is therefore necessary, at first, to effect the full development of 
the whole organization, and it is equally necessary afterward, to maintain it in healthy and vigorous action.

Perfect continence, in those who have natural sexual tendencies, is always attended by a variety of evils, some of them of a serious character, showing that temperate indulgence, so far from being hurtful, is both necessary and beneficial. Perfect continence, in the male, leads to spermatocele, spermatorrbœe, and even insanity. In the female, it leads to ovarian and uterine diseases, hysteria, and mania, and in both it originates the most singular and distressing vagaries of mind and thoughts. In severe cases, it leads to erotomania, satyriasis, or nymphomania.

An instance occurred in England, of a young female, who became insane, from not being allowed to marry - thongh the true cause was not suspected-and who was confined in a private asylum in consequence; while there, one of the keepers noticed certain peculiarities in her conduct, and abused her for his own gratification. The result was, however, that she perfectly recovered her reason.

In short, it is with these as with all other organs, a temperate and proper use of them is conducive to health, and creates happiness, but abuse or destruction of them leads to misery and death.

Constant and healthy exercise of the whole muscular system is also of great importance to the preservation of sexual power. It is true that if a man takes little exertion-particularly if he lives high-he will be apt to exhibit an unusual tendency to amorous indulgence, because, as before remarked, gluttony and idleness lead to licentiousness. This effect, however, is only a temporary one, and, sooner or later, the individual finds that he has permanently exhausted his vital energy, and that his health and strength are seriously impaired. The vital power that may be safely expended in sexual indulgence is only the surplus, after every part of the system has appropriated its due amount, and if more be so expended, some part must suffer. In other words, we may suppose that every healthy man has a certain stock of vital energy, which we will call his capital, to which he keeps adding more or less, by the function of nutrition; this addition may be compared to interest, which may be expended without any loss of capital, and, of course, without making him any poorer. If, however, by any excess he expends more than this addition, the capital is proportionally diminished, and permanently too, for it can seldom be made up again.

Now, the idle man does not expend enough vital energy on his muscular system to keep it healthy, but at the same time gives a superabundance of it to the sexual organs, so that they are over-stimulated, and suffer from excess. They become habituated to great indulgence, and are constantly causing a drain on the vital power, that soon exhausts both principal and interest, and leaves the individual completely exhausted.

The philosophy of this has been frequently alluded to in the course of the present work, but it is so important that I wish to present it in a strong light. I am fully persuaded that there is no case of precocious or excessive sexual propensity, unless caused by disease, that cannot be easily subdued by muscular exercise. No matter how vigorously the seminal glands may act, in a state of leisure, they must become less active if the body be exhausted by active exertion, and to this rule there is scarcely any limit. One of the Reports of the Massachusetts Lunatic Asylum strongly impresses this truth, and shows conclusively that we have, in hard labor, a certain means of subduing this propensity to its proper limits under any circum. 
stances. The application of this truth to young persons is obvious, numbers of them being made licentious only by bodily inactivity and over-feeding.

The invalid, or the man whose powers are impaired, must, of course, husband his strength, because he does not require exhaustion, but only sufficient exercise to insure health.

Exercise of the mind is also equally as important as exercise of the body. The man who is mentally idle, is nearly certain to experience too strongly the force of the animal propensities, and licentious thoughts are too often indulged merely from the. absence of better ones. It must be recollected, however, that too much mental ex. ertion, particularly if attended with care and anxiety, is most destructive to the sexual power, and frequently leads to impotence, as many of our cases have shown. Those who wish, therefore, to preserve their virility, should endeavor to maintain a happy medium, laboring with the mind sufficiently for health and utility, and endeavoring to preserve perfect calmness and equanimity.

One singular circumstance may be mentioned here, in connection with the genital organs, which is both curious and important. They appear to possess, in an eminent degree, the porver of retaining animal fuids in their substance without those fluids becoming decomposed. Thus, in many eases, sacs of water, blood, and other fluids, have been formed and retained in these parts, both in males and females, for months and years, and yet no change has taken place in these fluids. Now, in all cases where such accumulations take place in other parts of the body, decomposition speedily ensues, an abscess forms, and perhaps serious wasting disease commences. The genital organs, therefore, possess a preservative power greater than any other park and this is doubtles owing to their great vitality and vigorons circulation 



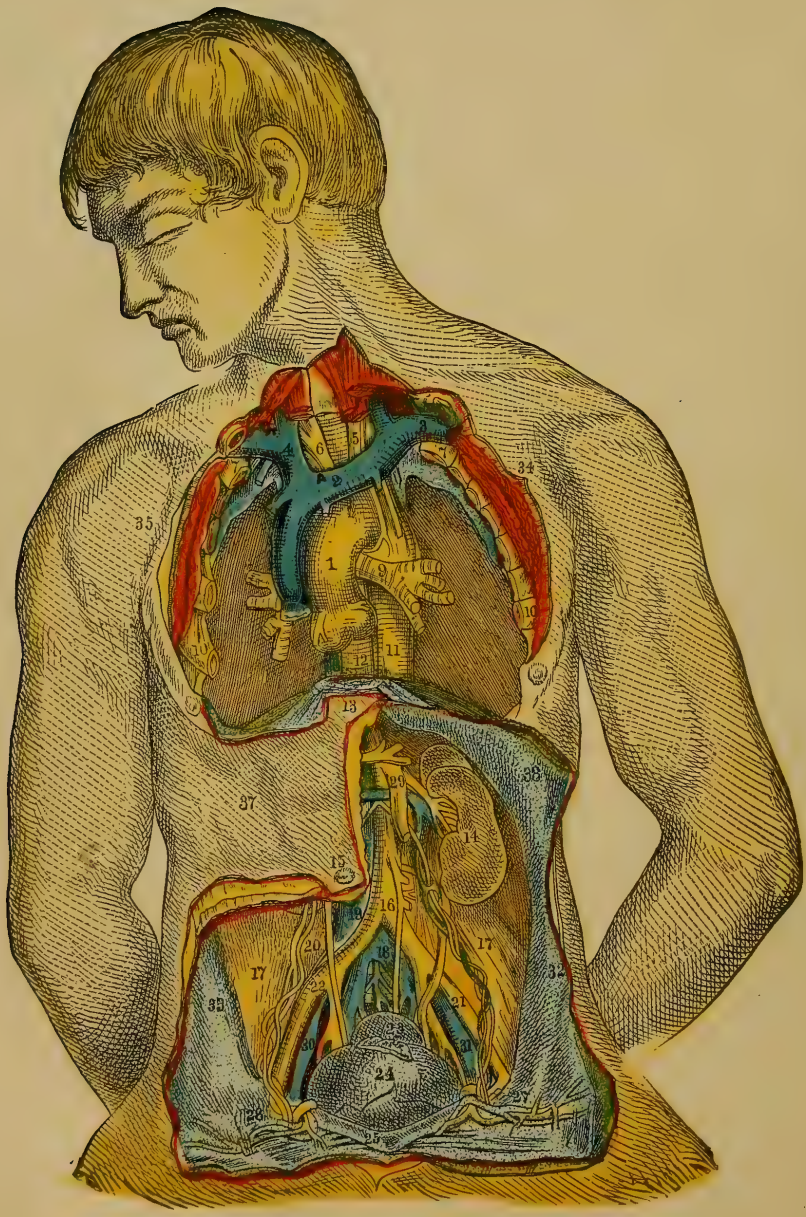

Internal Organs of the Pelvis. 


\section{CHAPTER XLI.}

\section{INFLUENOE OF THE BRAIN OVER THE GENERATIVE POWERS.}

Ir is important, in connection with sterility, that the direct influence of the brain upon the generative organs should be noticed, especially as it is manifested in cases of injury.

In another part of this work a number of instances are narrated in which impotency followed injuries of the head, and we will now narrate a few others, because this is a most important fact, in many respects.

About five years ago I was consulted by a married man who had totally lost his sexual powers from striking his head against a beam. The blow had stunned him for a time, but did not lead to any serious symptoms afterward. He found, however, in two or three days after that he was perfectly impotent, and had so remained for eighteen months, when I saw him. There was but little loss of desire, with no wasting of the genital organs, nor any other indication whatever of his deprivation. He had previously been a man of temperate habits, and at the time of the accident was as vigorous as most men. The blow, it may be as well to remark, was received on the top of the head, and was not followed by any swelling or pain in the cerebellum or neck. When I saw him he was in perfect health, and in good spirits; in fact, nothing was complained of but this unfortunate impotency, which he was very desirous of having removed.

The great point was to ascertain, if possible, in what way the concussion of the brain had suspended the transmission of nervous power to the genitals, and how it could be restored. I recollected that in several cases where injuries to the head had paralyzed particular muscles, or limbs, their power had been restored by galvanism, applied so as to pass along the course of their nerves, from the spine. It seemed to me as if the blow had impaired the proper connection between the spinal marrow ana these nerves, at their roots, and that the passage of the electric current, in some way or other, restored that connection. It was similar, in fact, to starting the electric telegraph again by mending the wires, or making the connections perfect, after they had been destroyed by violence. I therefore applied galvanism, passing the current from that part of the spine where the spermatic nerves originate, to the pubes, perineum, and neighboring parts, applying also a stimulating liniment, and vccasionally using the congester. The result was highly satisfactory, and speedily obtained. At the third application he experienced a decided tingling about the perineum, and along the penis, and tlie next time a partial erection occurred. After persevering for five weeks, using the galvanism daily at first, and then every other day, and finally but twice a week, he was fully restored, without any apparent tendency to a relapse. In this case, it will be observed, that the injury was not received at the back of the head, on what the phrenologists call the organ of amativeness, but at the top, nor did it in any way whaterer affect the cerebellum. 
In another similar instance, impotency, with complete loss of desire also, followed a fracture of the skull over the left temple, and no means that were used had the slightest effect in restoring it. In a few months the testes began to waste, and eventually almost totally disappeared, but the general health was only slightly affected.

In the American Journal of the Medical Sciences, for February, 1839, Dr. Fisher relates a curious instance of a gentleman injured in a railway car. He was looking out at the moment when a collision occurred, and the shock threw the back of his head against the edge of the window with such force as to stun him; he, however, recovered his senses and was taken home, but suffered great pain in the back part of the head and top of the neck. His right arm was numbed a little, and some difficulty was experienced in passing the urine, but in two weeks he was able to walk out, with no other inconvenience than a slight dimness of sight. About the fifth week, he discovered that he was impotent, and had lost all sexual desire. The means used to restore his genital powers were only partially successful, nor was his memory so perfect as before, but all the other difficulties disappeared under proper treatment.

In the Lancet, for August, 1851, is an account of a medical student, who received a blow on the face, in a quarrel, which knocked him down, so that he fell on the back of his head. He was totally unconscious for eight or ten hours, but gradually recovered, and on the following day even resumed his studies, which he continued unremittingly for the next six weeks. He, however, became exceedingly irritable, with a feeling of general uneasiness, and after the first week he observed the genital organs begin to waste, and desire to weaken, till he finally became nearly impotent, but afterward recovered under proper treatment.

Many instances have been observed of soldiers being wounded in the head, and suffering afterward under the same disability. It is perhaps proper to remark, however, that this is not the only nor even the most frequent result of such injuries, as many patients so hurt suffer no deprivation of their genital powers, but have some other functions impaired. Thus, some lose their sight, some their hearing, and others become paralytic in their limbs.

The prospect of recovering the sexual powers, when lost from injuries of this kind, is very small, especially if the parts have really begun to waste. The treatment, at first, must be that best calculated to subdue the irritation which is probably existing in some parts of the nervous system, and afterward, if requisite, to rouse the spermatic nerves to more energetic action. Every case, however, will require something peculiar to itself, which can only be discovered by a patient and careful attention to all its symptoms.

A further corroboration of the facts above stated may also be found in certain physiological indications observed in those who have died from strangulation. It is well known that in very many men who have been bung, erection and even seminal emissions have occurred, and experiments upon animals have often led to the same result. This is attributed to the pressure of the rope on the back of the head, which in some way or other excites the spermatic nerves. I have even known pressure made on that region purposely, in a particular manner, in order to excite erections, and frequently with perfect success. Some of the females in the Turkish harems understand this, and they habitually chafe or shampoo the back of the neck of their companions of the other sex, for this very purpose. I have frequently made an application of this important fact in my practice, in cases where there was morely a 
suspension of that sympathetic influence which the brain ordinarily exerts upon the sexual organs.

A full consideration of all the facts and arguments bearing upon this influence of the brain over the sexual functions, has left the subject, so far as I am concerned, in great obscurity. That a singular influence is often exerted by the brain in this way, sometimes beneficially, and at others the reverse, is undoubted, but whether such influence emanates from a particular part of the brain, or from the whole organ is uncertain. The phrenolngists affirm that only a particular part of the encephalon is concerned in this phenomenon, namely, the lower part or cerebellum, which rests upon the spinal marrow.

But after a careful consideration of all the reasons brought forward in support of this affirmation, I am not yet convinced of its correctness. That many facts favor such a theory I am willing to admit, but it is also certain that many others militate against it, and, as a searcher after truth, I must consider everything that bears upon the question, even though opposed to my previous opinion. I set out with firmly believing that the cerebellum was the organ of the sexual propensity, and my investigations have made me doubt it. It is not true, I am convinced, that the strength of a man's propensity can be estimated by the development of his cerebellum, nor is it true in regard to animals either. If it were so, we ought to find that organ largest in those who exhibit the propensity most, and in numerous cases it is not so, though in others it is. A celebrated German physiologist made some investigations bearing on this point, of an interesting character ; he had numerous opportunities of dissecting horses, and curiosity induced him to weigh the cerebellums of these animals, some of whom had been castrated when young, and others left entire. Now if the cerebellum be truly the organ of amativeness, it ought, of course, to be largest in the entire horses, who have always exhibited that propensity, and we should expect to find it almost disappeared in the others, seeing that they could never have felt anything of the kind. The result of the experiment was, however, on taking the average of an equal number of each, that there was scarcely any difference, or if any at all, the castrated ones had the largest cerebellums. In observing idiots, also, some of whom were notoriously licentious, and others directly the reverse, I have not found that the development of the cerebellum corresponded to the phrenological system. Neither can it be contended that the size of the cerebellum in the castrated animals was oniy the result of disease, for no difference could be detected in it between them and the others. All that can be said, therefore is, that certain agencies acting on the cerebellum, sometimes cause sexual manifestations, and at other times check them. The same agencies also acting on other parts of the brain will sometimes produce the same results, and sometimes when the cerebellum is acted upon, it is not the generative organs that are affected, but the sight, hearing, or speech, which might, therefore, just as properly be considered under its exclusive influence.

It should also be stated, as bearing on this subject, that certain influences operating on various parts of the body will often affect the generative organs in a decided manner. I have known a blister on the leg cause the most uncontrollable sexual desires in one man, and the application of caustic to the throat do the same in another. In applying blisters to the top of the neck also, though it is followed by erections in some, yet in others no such effect takes place, and occasionally it will produce a nervous twitching, like St. Vitus' dance, in the arms. Flogging the back, it is well known, even when very severe, will frequently cause erections and emissions, as in 
the case of soldiers when undergoing that brutal punishment. Rousseau tells us, in his Confessions, that flogging boys at school, in the disgraceful manner formerly practiced, is sometimes followed by similar results, and he remarks that the pain of the punishment may be forgotten under the powerful excitement it leads to-a fact of deep moral importance. In short, there seems every reason to believe that the strength of the sexual propensity is dependent upon some peculiarity of the sexual organs themselves, though it may be often modified by various mysterious sympathies emanating from other parts. If the semen be never formed, there will never be any sexual desire, and if the amount secreted be unusually large, the desire will be proportionally great, independent of all other influences. In those who feel desire without having any semen, as is sometimes the case in impotency, or even after castration, it is only the remembrance of a lost pleasure.

In treating disabilities of the generative organs, however, the possible influence of injuries to the head, even at former periods, and long ago, should always be borne in mind.

Similar facts I have also noticed in females, showing that the influence is similar in both. Some have never conceived after receiving a blow upon the head, and others have always miscarried after. In some it has entirely destroyed all sexual feeling, and in others it has, for a time, excited it to a most uncontrollable height. 


\section{CHAPTER XLII.}

\section{STERILITY, AND ARTIFICIAL IMPREGNATION.}

OF late years, much attention has been bestowed upon the subject of sterility, and much success has attended the efforts of physicians to cure it. This success has resulted from a better knowledge of the various causes of sterility, in both sexes, and of the means by which such causes could be removed. Those who have read our previous chapters will be aware that a childless marriage may result, on the part of the male, either from actual impotence, from malformation of the organs, or from an imperfect condition of the semen. On the part of the female, it may result from various causes. She may either be imperfect in the ovaries, so as to form no eggs, or the eggs themselves may not be perfect ; or she may have such an irritable womb that constant miscarriage will occur, even if she does conceive. Besides these causes, the passage into the womb may be too small, or it may contract spasmodically, and thus prevent the entrance of the semen. In like manner, the Fallopian tubes may be so contracted that the egg cannot pass down them till it is too ripe, or spoilt, and, therefore, incapable of impregnation.

Most of these causes are capable of removal, as shown in previous chapters. In the male, various malformations can be corrected; the organs can be strengthened, and the testes can be made to secrete semen more abundantly, and of a better quality.

In the female, also, the ovaries can be strengthened, so as to form more and better ovæ, or eggs; the irritability of the womb can be removed, so that when she conceives the embryo can be retained : the Fallopian tubes can also be opened, when contracted or closed, and the passage into the womb can be enlarged, so as to admit the semen into its cavity. Thus most of the causes of sterility are removable, and it is perhaps safe to say that nine out of ten childless couples may be made to become parents.

The operations for opening the Fallopian tubes and the passage into the womb are now regularly performed, and with the happiest results. Men with small organs have them enlarged, and those with ill-formed ones have them re-formed, so as to make them fit for their natural uses.

It sometimes happens, however, that the man may have the opening of the penis not at the end, but far down the organ, and in such a case, though he may have abundance of good semen, he may fail to impregnate. The semen, in such a case, is not thrown up to the womb, and unless the female have unusual powers of absorption, it may never reach there, and of course cannot impregnate the egg. Such an imperfection can sometimes be removed by making a new opening in the proper place, and closing the other; but this cannot always be done.

Sometimes, also, in the female, the womb may be out of place, so that its mouth is not properly presented; or the passage into it may contract, in spite of all we can do, with such force that no semen can possibly enter. This is very apt to be the case with females of very warm temperaments, and explains why such women often 
do not conceive. No doubt some females can absorb semen from the vagina, as explained elsewhere, but these are exceptions. In most cases, the semen, or the animalcules, must directly enter the womb.

Now, it is in precisely these cases in which the semen cannot reach the womb during or soon after connection, from some of the causes above named, that artificial impregnation is so applicable and so generally successful.

As we have already explained, connection is not essential to impregnation; the female may conceive without any contact whatever with the male! All that is needed is for healthy, perfect seminal animalcules to enter the womb, and unite there with a perfect egg. It matters not how the semen is got there, whether through the medium of the male organ or through the medium of a syringe! And upon this fact is based the practice of artificial impregnation.

Experiments, made a long time ago, showed that a bitch when in heat could be impregnated by injecting semen with a syringe up the vagina. And further, that by mixing the semen from different dogs, a mixed progeny could be produced, some resembling one of the dogs, and some another.

Finally, some physicians, seeing the anxiety of many childless parents for offspring, and feeling sure that this longing could, in many cases, be easily gratified by artificial impregnation, urged it upon their patients. A proposition so strange and novel was, of course, received with great surprise and many objections, and it was long before the matter was put to the test. Finally, a French physician prevailed upon several childless couples to adopt the means he suggested, and the success which attended them at once established the practice, till it has now beeome quite common, and no couple now in France consent to be without children, if they wish them, till these means have been tried. There are physicians, even, who make this a specialty, and do scarcely anything else but cure sterility, by artificial impregnation.

It is true old John Hunter had suggested this practice to one of his patients many years ago, and it had succeeded, but the fact had been lost sight of. It is only in recent times that the practice has become recognized as a legitimate one in medical practice.

It is a curious circumstance that in an old $A r a b$ book, published nearly twelve hundred years ago, a case of artificial impregnation is fully described. It seems that in one tribe there was a famous stallion, so fleet that no other horse conld compete with him, and his master could make raids and always escape, owing to his fleetness. A man of another tribe, however, who had been injured by the owner of the famous stallion, determined to have one of the same breed, so that he might compete with him. The book relates, therefore, that when his mare was in heat he took some cotton and soaked it in the mucus from her ragina; then, during the night, he stole to the side of the famous stallion and put this cotton to his nose. The odor of course excited the horse, as it always does, and finally had such an effect upon him that he discharged the semen, which the cunning Arab caught upon some clean cotton, and then, hastening home, he placed it in the vagina of his mare. The consequence was that she became pregnant, and ultimately brought forth a male colt, which became the equal of his father, and the Arab was thus able to make raids in his turn upon the hostile tribe. There was one wide, deep ditch in this part of the desert which only these two could leap.

Artificial impregnation is performed in this way. The physician is provided with a properly constructed syringe, having a long nozzle, very small, and properly curved. 
The semen, freshly obtained, is sucked up into the syringe, the small end of which is pushed up into the womb, and then the semen is injected. Of course it is then put just where it is wanted, and if a healthy, well-formed egg be there, impregnation follows.

There are various precautions to be observed, however, to insure success, connected with both sexes. In the first place, we must ascertain when the female passes the egg, as explained in a previous chapter, because it is of no use placing the semen in the womb when the egg is not there to receive it. Nor is it any use before the egg reaches the womb. It is requisite, therefore, to make the matter more certain, to study the female before, during, and after menstruation.

Of course, the most likely time will be immediately after the cescation of the courses, and from then till six or eight days after; or, in some few cases, perhaps, just before.

After the operation the female should remain perfectly quiet for an hour or so, and avoid all violent exertion or excitement for some time after. If the period comes on again at the usual time, it will show that impregnation probably did not occur, and the operation should be repeated a little earlier or a little later, for it is not possible, in all cases, to be sure of the proper time, and, occasionally, the injection has to be made six or eight times before impregnation takes place. I remember one instance in which the operation was repeated eleven different times in as many months, with no success, but on the twelfth it did succeed.

In this case the first injection was made the first day after the period, the second the second day after, and so on till the eleventh day; the twelfth injection was then made before the flow had quite ceased, and that succeeded.

It must be remembered that some women have a flow at regular periods, as usual, even after conception. It is therefore necessary to be very cautious and not repeat the injection too soon, unless there seems to be no doubt as to its being a real menstruation. In fact, it is better to let two or even three months pass, so that there may be no risk of causing miscarriage. With care, however, this accident may not necessarily occur, even if injection be practiced after conception has taken place.

It is also advisable that the man should prepare himself some time beforehand, by aroiding all exhaustion or excitement, so that the semen may be abundant, and of good quality.

Although the operation is simple, and easily made, even by the parties themselves, still it is better done by some one who has the proper instrument, and who is familiar with the anatomy of the parts. No injury need be feared under any circumstances, nor any unpleasant consequences whatever. The only precautions to be observed are, to have the syringe properly warmed, to introduce it slowly and gently into the passage to the right depth, and to have it filled with the semen, so that no air may be introduced with it.

I need only remark that the semen must be freshly obtained, and used immediately.

Some physicians use a speculum when introducing the syringe, but that is not necessary. It is necessary, however, to ascertain first the length of the vagina and the height of the womb, so as to know exactly what depth the syringe should penetrate.

Details as to the position in which the female should be placed, and other matters, need not be given here, as they can be communicated if necessary. 
During the last five years, I have performed this operation thirteen times, and known of its being performed thirty-seven other times, making fifty in all. Of these fifty, forty-three have been successful, and the other seven failed, I have no doubt, from imperfection either in the semen or the egg.

In such a matter as this, I consider no apology or excuse necessary. It concerns ouly the parties themselves. If childless people wish offspring, and safe and harmless means of gratifying them can be adopted, it rests entirely with them alone whether they will remain without children, or obtain them by these means. As to the practice being in any way improper or immoral, I cannot so consider it, but rather the contrary. The parentage is of cqurse the same, and the child so produced is just as perfect as if it came in the natural way.

Independent of its value as a means of insuring offspring, this practice may often lead to valuable results in another way. It is well known that many childless women suffer from a variety of complaints which can never be removed while they remain childless, but which disappear immediately they become mothers. Now in such cases artificial impregnation enables us to insure them that relief which they perhaps would never obtain without.

It should also be remarked, that when impregnation has once been effected artificially, it usually occurs afterward naturally, without any difficulty.

At the termination of our great war, I was waited upon by an officer, who had been wounded at the battle of Shiloh. The whole of the penis was shot away, leaving the testicles unhurt! His secretion of semen was abundant, and it was often ejected in large quantities, with considerable excitement. He was married only a month before joining the army, and his wife had not conceived. Of course any connection was out of the question, although an artificial penis had been adapted to him, by which he could urinate with comfort. Both himself and wife, however, were intensely desirous of having children, but thought, of course, there was no hope for them.

Being aware of his condition, I spoke to him of the practice of artificial impreg. nation, which he heard of with the greatest joy, and at once consulted with his wife on the matter. The result was that they both agreed, and the operation was performed successfully the first time. That child is living now, and is as fine a boy as ever gladdened parents' hearts. They have resolved, when he is seven years old, to have another, or earlier if he should die.

In another case, the man had lost all power of erection, from paralysis, although the secretion of semen still continued, and there were frequent emissions. They had had five children before, but all were dead, and they never hoped to have another. By accident, however, he heard of the practice of artificial impregnation, and wrote to me about it. An appointment was made, and he paid me a visit, with his wife. Feeling satisfied, at the irterview, that there was no reason why the operation should not be performed, I undertook it at the proper time, and repeated it four times before it was finally successful. The result was all that could be wished.

Now who shall say, in these cases, that there was anything objectionable in the practice? Rather, I should say, they show its great value, and what a blessing it is to humanity.

It is true, a cousin of the officer, whose case is described above, did complain, and thought himself injured, because the child superseded him as heir to the officer's property, which he had fully calculated upon inheriting. I have also heard some 
persons contend that those who cannot have children by the usual means should remain without them, and that it is unnatural, if not even sinful, to obtain them by artificial means. I leave every one to decide this point for himself, and in the meantime am prepared to practice the operation for all who need and wish it.

In addition to the precautions already indicated, there are also two others to be taken. First, the semen must be examined, microscopically, to see if it contains living animalcules; because if it does not, of course the operation will be useless. Second, the mucus of the vagina must be examined, to see if it be too acid or too alkaline, as either of these qualities may cause the death of the animalcules; and, in fact, sterility is often owing to this very circumstance.

Of course, if there be any organic disease of the womb, the operation is inarmissible, but a mere displacement is of no moment, and is, in fact, often cured by pregnancy.

In conclusion, I would draw attention to the fact that artificial impregnation has long been practiced, in numerous cases, though not till recently in human beings. Horticulturists, from remote times, have artificially impregnated plants, and crossed them in every way, by placing the pollen (or semen) of one kind upon the pistil (female organ) of another kind. Of late years, also, the practice has become habitual of impregnating fish eggs (or spawn) by the semen taken from a male fish, and merely added to the water in which the eggs are placed. In this way the semen from one male can be made to impregnate thousands of eggs. This is artificial impregnation.

It is only necessary to bear in mind that the process of impregnation is the same in all beings, and merely consists in the union of the male principle with the female egg. In some beings this occurs within the body, by the process of copulation, as in human beings, and in others it occurs without the body, as in fishes, and in such cases the male and female may never come into contact at all.

It matters not how the semen reaches the egg, providing they come together in the right circumstances; and in the human being they must unite in the female womb. But their union may result in a new being just as certainly when they are united artificially as when they are brought together in the usual way. 


\section{CHAPTER XLIII.}

\section{AGE WHEN BOTH SEXES BEGIN TO BE CAPABLE OF BEING PARENTS, AND WHEN THEY CEASE TO BE SO.}

The Male.-The man is different from the female in this respect, that there is no positive proof of his incapacity, except in particular cases. As long as he secretes semen, and can have connection, no matter how imperfectly, it is presumed he may become a parent. But the female, at a certain age, becomes naturally sterile, so tliat the cessation of her capability is fixed.

The age at which the male becomes first capable varies very much, not only in different races and countries, but also in different individuals. It, of course, depends on the occurrence of puberty, or the perfect secretion of semen, and this may be either unusually early or very late. It is often much earlier than is suspected.

In the time of Henry the Eighth, it was decided that procreation could not be effected before fourteen years, and that if the wife of a husband under that age had children, they must be bastards; but such a decision was absurd, for instances are numerous enough of perfect capability much earlier than that.

In fact, we read in The Berlkeley Manuscripts, that Maurice, third Lord Berkeley, was married at eight years old, and was a father before he was fourteen. Numerous other instances are also given of similar precocity. There is one instance recorded by a celebrated physician of a young woman who slept with a boy of ten years of age, and encouraged him to take liberties with her, thinking there was no danger, but who, to her great shame and surprise, became pregnant. In fact, there is no certain age when capability, in the male, may be said to begin, nor is it easy to ascertain it with certainty, even by examination. Many who are undoubtedly capable show no signs of it, while others who give every indication of puberty are still powerless. I have seen the organs in a boy of seven years very largely developed, and in a man of thirty scarcely more so than those of an infant, although he secreted perfect semen.

Of course, the only proof of puberty, or capability, is the secretion and emission of perfect semen, while its non-secretion is equally a proof of incapability, no matter what may be the age or apparent perfection of the organs.

The first semen formed, it must be borne in mind, is not always perfect, and that is the reason why many boys, though fully capable of connection, and having abundant secretion, still cannot impregnate. Very frequently, however, it is perfect from the beginning.

The age when man begins to be capable is therefore not fixed, and the same may be said of the age when he ceases to be capable, which is equally undetermined.

There 18 no question but that many men retain the virile power till extreme old sge, while others lose it very early. As a general rule, the power begins to perceptibly wane after fifty years, and by fifty-five, or sixty, the number of animalcules in 
the semen becomes constantly less, and they become also less perfect. As long as a man secretes semen containing healthy, vigorous animalcules, he may be the father of a perfect child, no matter what his age may be, even though he may be incapable of perfect connection. An instance of this may be found in the case of David in his old age, as recorded in the Bible.

If the animalcules fail altogether, or become too imperfect, no impregnation can occur. If they are only partially imperfect, conception may occur, but the child will be imperfect. This, however, is not the case with old men only, but often with young men, from disease, or debility.

In the year 1813, a curious case was brought up for trial in the English House of Lords, which turned upon this very point of age. It was called "The Banbury Peerage Case." The main argument urged against the claimant was this, that his ancestor could not have been the son of Lord Banbury, because that nobleman was eighty years old when the child was born! The judge, however, decided that this objection was worthless. The law, as he truly said, fixes no age when a man becomes incapable, while experience shows that there is no universal natural limit.

Dr. Gregory, of Edinburgh, says a man may be capable till a hundred years, if not more. Haller says till ninety, at least, and it is recorded that old Parr was a father in his one hundred and fortieth year. Sir Stephen Fox married at seventyseven and had four children,- - the first child was born when he was seventy-eight, he had twins the next year, and the fourth child was born when he was eighty-one. Old Parr's son was older than Lord Banbury when Parr himself was a father.

Neither old age nor extreme youth, therefore, are sufficient to make man incapable. The law knows no limits, nor does science, and from seven years upward the male may be fully capable of parentage.

The Female. - There is also great uncertainty as to the time when the female may first become capable. Usually not before fourteen or fifteen, but numerous instances have been known of pregnancy at thirteen, twelve, and even at eleven! In Abyssinia and Bengal, mothers of eleven are not at all uncommon. Probably with us twelve years may be considered about the limit. In the year 1828, a lady visited Ballston Springs who was a grandmother, though not quite twenty-eight. In the Transylvania Journal (vol. vii., page 447) there is a case recorded of menstruation at one year, and of pregnancy before ten. The girl was delivered of a female child weighing $7 \frac{1}{2}$ lbs., when she was but ten years and thirteen days old! This was on the 20th of April, 1834.

In some parts of Africa, the girls menstruate at eight or nine years, and the same in Persia, though it does not appear that they begin always to bear children so soon. Many people suppose the North American Indian females menstruate later than the whites, but it is known not to be the case, for they observe about the same time.

Many instances of very precocious puberty are on record. Sir Astley Cooper mentions one at four years, and another even at three and a half. Dr. Francis also mentions one at four and a half years, in which the sexual organs and the breasts were similar to those of a full-grown woman at the same period.

As an almost universal rule, pregnancy never occurs till after menstruation, but in some rare cases it has occurred before. It is probable, however, that in such cases it was slight, and had simply escaped observation, as it frequently does in some women.

A similar uncertainty attends also the cessation of the faculty of child-bearing. As a general rule this faculty ceases when menstruation stops. It is well known, 
however, that many women have borne children after menstruation had ceased for a considerable time.

The usual age when a woman can no longer become a mother is about forty-five, or from that to fifty, as the limit. There are, however, numerous cases on record of pregnancy at fifty-two and fifty-four years of age, and some even in still older women. At a trial in France, it was shown that a woman of fifty-eight had become a mother, and many authors have given cases up to sixty years, and even more. Beck, in his Medical Jurisprudence, quotes a case from the Boston Medical and Surgical Journal, of a woman at Whitehall, in the State of New York, who became a mother at sixty-four. Dr. Vandeveer, of Long Island, attended a lady in confinement in her sixty-second year.

Mr. Robertson tells us that out of one thousand cases of pregnancy registered at the Manchester Lying-in Hospital, four hundred and thirty-six were upward of fortysix years old, one was fifty-four, one fifty-three, one fifty-two, nine fifty, six fortynine, eight forty-eight, and thirteen forty-seven.

It is related that Madame de Stael menstruated at sixty, and Richerand gives a case at seventy. Magendie and Rush also relate cases at the same age.

In short, though the limit of menstruation and child-bearing may be said to be from fifty to fifty-two, still it may be, and often is, protracted much beyond that.

The reason for this occasional prolongation of capability will be understood from our previous articles. As long as a female forms perfect eggs, and retains them long enough in the womb, she may become a mother.

In conclusion, we may state that though no means are known by which the procreative power can be prolonged, in a woman, or brought back when extinct from age, yet in man it is often different. Many men after having lost nearly all sexual power, for many years, even in advanced life, have had it restored, by proper treatment, to a considerable extent. In the course of my practice I have seen numerous cases of this kind, and have now a man of eighty-two, fully capable, more so in fact than he was at sixty.

The proper course to be pursued to retain, or restore sexual power, must of course depend upon the peculiarities of the case, and requires a medical consultation. I will merely say that there are but few men hopelessly impotent, if they only can and will do as directed.

In many trials for divorce, it is often a question as to the capability of one or both of the parties. It can, of course, always be known whether a female is capable or not, by the fact of her bearing children or remaining barren. In regard to the man, it is always assumed that he is capable, so long as his organs are perfect and he is capable of connection. But, as already shown, this is a mistake. A man may be incapable merely from imperfection of the semen, and this can be proved only by examining it microscopically.

Common justice, therefore, demands, when divorce is claimed because the woman does not bear children, that the semen of the man should thus be examined, to see if the fault may not lie with him. I am aware that this is a point not yet allowed in medical jurisprudence, becanse the fact is so new, but it is nevertheless a valid one, and will before long be so regarded.

It must also be borne in mind that barrenness may result not from any imperfection on either side, but simply from want of adaptation, as explained in previous 
articles. Both may be sterile, in reference to themselves mutually, kut not in reference to others.

It is an important thing to bear in mind, however, that sterility in the male may exist along with the power of perfect connection, and that this peculiar state can be positively proved.

In connection with this subject it may be asked whether a woman can conceive without her own knowledge, as during sleep for instance?

This question has occurred as a legal one in many celebrated trials, and is now fully decided in the affirmative. It is beyond question that a female may be violated during sleep, and may be impregnated without knowing it. This is a fact that should be borne in mind, as it may often be important.

There are many peculiar states of the female system, as in some diseases, which cause a stupor so profound that violation may undoubtedly be effected while it lasts, without the victim being aroused. Even ordinary sleep may sometimes be heavy. enough to allow of such a crime.

It is, however, highly improbable, though perhaps not impossible, for such to be the case with a virgin, owing to the intercourse being so much more difficult. Medical men have held different opinions on this point, but I believe its possibitity is fully admitted, in some exceptional cases. Of course, all such alleged occurrences should be received with extreme caution and distrust, and subjected to the most rigid scrutiny; for it is much more likely that the female is either deceiving herself, or trying to deceive others, than that so unlikely an event should take place.

These remarks refer only to natural conditions of the female system. If stupefying drugs have been given, there may be such insensibility and perfect unconsciousness that nothing may be known on waking of what has taken place.

In regard to conception, there is no doubt, as before stated, that it can take place while the female is perfectly unconscious from any cause. She may be simply asleep, or in a stupor from disease or drugs, and yet if connection takes place she may conceive. No knowledge or feeling on her part is at all necessary. There are numerous well-authenticated cases of this kind on record, and I have known several myself. Women have often been violated while intoxicated, without knowing anything about it, and conception has followeả. Capuron mentions a case of this kind, of a young female whose lover made her drunk and abused her, and she conceived, but knew nothing of it till she was four months pregnant. Many similar cases are recorded by other writers.

It should be remarked, however, that in such cases we can scarcely conceive that any violence was practiced, because, if there were, the female could scarcely fail to notice and even feel the injury, when awake, and suspect the cause. This must especially be the case with virgins or very young females, and when such persons assert that they have been violated or impregnated, and yet knew nothing of it till a late period of pregnancy, there is at least room for grave doubt and distrust.

On the other hand, it must be remembered that in some very young females, undoubted virgins, the organs are naturally in such a state as to allow of connection without the least violence or injury whatever, and women have even conceived, after repeated connections, who have preserved the hymen unbroken till the time of delivery.

It is a common error to suppose that a first and only connection never leads to conception. Many women, and men too, have found out the falsity of this notion, 
to their cost. It is true that a first and only connection does not usually result in conception; but this is not owing to any natural law-it is merely owing to the difficulties ordinarily attending the first act, and its consequent imperfection. In animals, a single connection, even the first time, usually results in impregnation, and there is no reason why it should not do so in the human female. If there be a perfect egg in the proper place, and the semen reaches it, conception may take place from a first and only connection, just the same as from a later one.

It is also equally true that conception may follow violation, whether the female was conscious of it or not, in virgins as well as in others. Formerly, it was thought that whenever conception occurred it proved consent on the part of the female, and many people suppose so even now. There is no foundation whatever for such a notion, and it has often caused females to suffer gross injustice. No matter what violence they might be subject to, or even if they knew nothing of it, if pregnancy followed, it was thought to be a proof that they must have consented, and also that they must have had more than one connection. The cruel injustice resulting from such erroneous notions has often blasted the reputations of innocent persons, and led to despair and suicide.

As a proof that conception may follow connection while the female is unconscious, I may here mention a case which occurred in my own practice. A young married couple found it impossible to consummate the marriago, owing to the nervous fear of the lady, and to the extreme smallness of the organs. The slightest attempt at the act threw her into convulsions from mere fear and dread. I advised that she should be placed under the influence of chloroform, and that the act should be consummated while she was unconscious. To this she gladly agreed, and the experiment was attended with full success. No injury resulted, and she had no recollection of the affair at all. Still she conceived, and became the mother of a very fine child. Afterward no difficulty was experienced.

It is undoubtedly the fact that many women are quite unaware of being pregnant till a very late period, sometimes even up till the time of delivery. To many this will appear very strange, but it is nevertheless true. In several instances, where females have been impregnated while asleep, or during stupor, they have neither known nor suspected it till the natural result forced it upon their attention. M. Desgranges informs us of a young female who allowed her lover to have intercourse with her while in the bath, having the idea that conception could not possibly follow under such circumstances. She, however, became pregnant, but was totally unaware of it, and would not believe in her situation till delivery took place. In fact, if a woman believes, from any cause, that she cannot become pregnant, she may not know nor suspect that she is so till the last moment. Many have been thus deceived from putting implicit trust in certain precautions, while others have thought they could not be pregnant because the hymen was unbroken, or because the act of connection was only partially performed. I have even known married women, who had borne children before, arrive at the period of actual labor, without an idea that they were pregnant. The possibility of such ignorance should be borne in mind, as it may often be important when a woman is accused of concealing the birth of her child.

ON THE STATE OF MIND IN FEMALES $\Lambda$ T THE TIME OF DELIVERY.

It is not generally known, but should be universally, that many females during pregnancy, and especially at the time of delivery, are in a peculiar mental condi- 
tion. Some are really insane, for more or less of the time; others have peculiar manias, and very frequently they are quite unaware of the nature and consequences of their acts.

There is every reason to suppose that, in many cases, where women have destroyed their infants at birth, they acted not from depravity, nor from a desire to get rid of their offspring, but simply from a morbid impulse, which made them quite unaware of what they were doing. Many have committed this act who had no motive whatever for doing it, and some oven while strongly desiring children. Instances are known where mothers have thus destroyed their offspring while in this peculiar condition, and on recovery, have known nothing about it.

Now, if a poor woman who has been seduced, or violated, kills her child, it is at once concluded that she does it willfully and knowingly, to get rid of it. That such is the case sometimes there is no doubt, but at the same time it must not be forgotten that the poor creature may be really perfectly innocent of any criminal intention, and may even not have known, at the time, what she was doing.

It must also be remembered that in a case of illegitimate pregnancy, the poor mother, from her dread of discovery, anxiety, shame, and sense of injustice, is much more likely to be thrown into a morbid state of mind than one more happily situated. There is no doubt but that many such have been unjustly condemned for doing that for which they were in no way whatever responsible. 


\section{CHAPTER XLTV.}

HEREDITARY DESCENT, AND IMPROVEMENT OF THE RACE.

WHEN the mass of the human race get orer their present fear of knowledge, and realize that it is really power for indefinite good, they will turn their attention to the improvement of the race, and human beings will be produced, superior, in every way, to any the world has yet seen. Not only can the $b o d y$ be perfected, so as to be stronger and more beautiful, as well as free from disease, but the mind also can be made far superior to the most gifted ever yet known. The power of the mind depends on the perfect development and organization of the brain, and there is no question but that the brain can be perfected as well as the muscles.

In the brain of every kind of animal we find certain parts developed which are not found at all, or only rudimentary, in the animals below them that have less mind; and it is the same in the human race. It is, therefore, only the more perfect brain which gives man the more perfect mind, and it is only by perfecting the brain that we can effect further improvement in his mind.

In examining the human brain there are certain parts found, small and apparently rudimentary, whose uses are not at all known. Now it is probable that these are merely organs not yet perfected or developed, but which may be developed by judicious attention to training, intermarriage, and selection.

It seems to me more than probable that human beings will, in the future, be produced with brains, and consequently minds, as far above those of our present greatest men as they are above the brutes; and that in those days men will comprehend and reason understandingly upon matters which we now esteem unfathomable mysteries, and far above all humian comprehension.

I have full faith that the man of the future will be as far above the present man as the present man is above the orang-outang.

But for this to be effected marriage must be a science, based upon a knowledge of physiology and the laws of natural selection and hereditary descent, instead of a mere matter of chance, as it is now.

We think it quite right and laudable to so attend to the breeding of animals as to bring them to the most perfect point of development, and yet we shrink from applying the same laws to human beings; though nothing is more certain than that the one could be perfected equally with the other. Let any one look at an ill-bred, uncared-for domestic animal, and then look at a thorough-bred of the same kind, and note the difference,- - they are scarcely like the same beings. All the bad points are carefully bred out, in the improved one, and the good ones developed to the utmost. The same results would follow among human beings if procreation was made a science, as I cannot but hope and believe it some day will be.

If men were only rational enough to see this truth and act upon it, we should be able to gradually perfect the nervous system the same as we do the other organs, and 
consequently the mind also. Education improves or develops the mind, by causing a more perfect development of the brain, and this affects not only the individual so educated, but also his children, by the law of hereditary descent. Parents with well-educated brains, on an average, will produce children with better developed brains at birth than those of uneducated parents. And with continued careful training and selection, this course of improvement might go on indefinitely; how far we cannot even imagine, but doubtless to the production of human beings as far above the highest yet seen, mentally, as they exceed the merest brutes.

Men have found out how to develop in animals any mental trait they may wish, as in the pointer and the shepherd's dog for instance, and they have also found out that the young of these educated animals are more easily trained than the young of uneducated ones. This is owing to the law of hereditary descent, which gives to the brain of the young dog a similar development to that of its parent to start with. The advantage, however, so gained may be more or less lost, in subsequent generations, by want of care in mating the parents, and so allowing one to spoil the other.

In the same manner we see particular dispositions and qualities, particular mental powers, and even insanity, transmitted from parent to child. This is because the child inherits the same form and kind of brain. Now we all know what wonderful results have been obtained among animals by proper training and selection in mating, and beyond doubt still more wonderful results would follow, among human beings, from similar care. The human brain is more susceptible of impressions by training than that of any other animal, and there seems no limit to its capacity for development. Hereditary descent is also more marked in the human animal than in any other, so that what is once gained can be perpetuated.

I say again, therefore, that when men have progressed far enough to attend to these matters, as regards their own race, the same as they now do to the lower animals, human beings will be born immeasurably more perfect, both bodily and mentally, than anything we can now conceive.

At present, however, it is considered almost blasphemous to speak of such things, and therefore we go on perpetuating disease and madness, from generation to generation, when we might easily get rid of them.

In all forms of nervous disease, and especially those affecting the mind and disposition, this law of hereditary descent is especially operative. And this constitutes one of the main difficulties in treating such diseases; for what can the physician do when the patient has been born with a certain kind and form of brain, making him have inevitably certain mental and moral infirmities? Neither medical treatment nor moral preaching can do much good in such cases, and yet in our ignorance they are all we depend upon.

Fortunately, Nature here steps in with another law, which counteracts gradually the deplorable effects of man's ignorant inattention. This is Darwin's Law of Natural Selection, or the gradual weeding out of the more imperiectly dereloped beings. Those with the most perfectly developed bodies and minds, by their greater capacity or power, lord it over the weaker ones, and gradually push them out of existence. The same as, in a forest, the strongest growing trees inevitably smother and kill the more tender ones.

At the present time, we often gain, by education and training, a splendid development of body or mind in some favored individual, but lose it when that individual 
dies. Instead of perpetuating it, or even improving upon it, in his children, the chances are that it will be lost from want of proper selection in mating, and inattention to the laws of hereditary descent.

It is well known that marriage is entirely a matter of chance, at the present time, as to any fitness between the parties. They may be naturally suited to each other, or they may not; but such suitability or unsuitability is never taken into account. The consequence of this is that we go on perpetuating disease, insanity, and imperfections of every kind, when we could just as easily get entirely rid of these scourges.

Even our greatest men marry without any thought as to whether their partners are such as they should be to insure perfect children. By this inattention we lose all the advantage of their excellent development, and their children, instead of being superior to their fathers, sink below them, or may be, are even inferior to the ordinary run of children. This is why great men or great women so seldom have children equal to themselves, although, by proper mating, they might have offspring far superior.

It is useless, at the present time, to attempt to give rules for scientific procreation, or even to lay down general principles, for no one would yet act upon them. The first thing to be done is to educate the public mind up to the point of not being afraid of the subject, and to lead the more advanced minds to see its importance. The practical application of such knowledge will follow, and people will then wonder that such an important matter should have been for so many ages neglected.

The question is often asked whether it is proper-aside from social or moral considerations-for very near relations to marry?

It was formerly thought, and is now by many, that the marriage of near relations, as brother and sister for instance, must necessarily be an evil, and result in diseased offspring. Recent investigation, however, has disproved this, and has shown that it is not the mere relationship that causes the evil, but simple unfiness. Any marked peculiarity or bodily condition that is the same in both parties, is nearly sure to be doubled in their offspring, and as there are few families without some taint or some objectionable peculiarity, the marriage of near relations, each affected the same way, increases the evil by doubling it in their offspring. But this is not merely because they are relations; for two perfect strangers would equally affeet their children in the same way if they were equally unsuited.

Good points can be perpetuated and increased by judicious breeding as well as bad ones, as breeders of animals well know. And these men invariably breed in and in, in the closest manner, often between parent and child, brother and sister, and grandchildren and grandparents. So far from this resulting in any inferiority, the very finest and healthiest animals are thus produced. Of course, the breeders take care never to breed among relations who have any mutual imperfections, because they do not want to increase them; and if any such imperfection should exist, they cross with some stranger till they get rid of it, and then they continue to marry near relations in the closest manner.

Near relationships, therefore, are not objectionable in marriage, speaking physiologically, providing the parties are naturally suited to each other, but may even be an advantage. There are, however, other reasons, social and moral, which forbid and make them improper. I merely speak of them here in a physiological sense. The subject will be more fully discussed further on. 
Direct experiment has shown that many disorders can be niade hereditary, even when produced artificially; especially those connected with lesions of the nervous oystem.

All the large blood-vessels, like other parts of the body, have special nerves connected with them, which regulate their action, and if these nerves be cut through, or destroyed, the blood-vessels and the parts they nourish are singularly affected. Thus in a guinea-pig, if the nerves connected with the carotid artery be severed, on one side of the neck, all the parts on that side of the head which are fed from that artery will become hotter from increased circulation. The eyelid also, on that side, becomes puffy, and droops. The ear becomes so much hotter, that in white animals it can be seen congested with blood.

After a while the parts heal, and the animal becomes, in most respects, as before. The eye, however, remains permanently smaller, with a contracted pupil, and the lachrymal gland overflows constantly. The eyelid partly recovers its natural state, but the membrane with which the animal clears the eye remains always congested. As long as the animal lives this condition continues, and if the affected eye be examined, after its death, it will invariably be found smaller than the other.

The most singular fact, however, and the one which bears on the question of heredity, is this: If such an animal breeds, even with another that has not been so operated upon, the young from that union, though apparently perfect when born, in a few days exhibit all the above phenomena. Their ears are thickened, corresponding to the one so affected in the parent that was operated upon, and they have similar small eyes, but on both sides. These young may be close bred, in and in, for several generations, and all their descendants will exhibit the same peculiarities. In fact, they seem to become fixed.

It is very singular, however, as shown by dissection, that the nerve which was destroyed in the first parent, and never reproduced, is yet perfect in the descendants. In this respect they are just like other guinea-pigs, and yet continue to show the same symptoms as their mutilated ancestor.

If a certain part of the brain, in one of these animals, be punctured, the ear on that side becomes gorged with blood, dry gangrene sets in, and part of it falls off, sometimes in a few hours. The eye also, on that side, bulges out, and becomes larger.

If one of these animals, so treated, bear young, even with a perfect companion, the offspring are affected in the same way. Their eye uls enlarge and protrude, and in a few days their ears drop off from gangrene.

The young of these diseased animals, and their young also, indefinitely, if they breed in and in, will all show the same peculiarities, but if they breed with perfect animals, only some of their young will exhibit the diseased condition, while others will be perfect.

Dr. Brown-Séquard found that he could produce epilepsy, artificially, in guineapigs, by wounding certain parts of the spinal cord, or of the sciatic nerve. And the epilepsy continued even after all trace of the operation had disappeared.

The sciatic is the great nerve of the leg, and when it is destroyed, the limb loses all sensation, and all power of motion, so that the animal has no feeling whatever in it, and drags it about. In consequence of this, the skin becomes rubbed off, so as to expose the flesh, and then the animal begins to bite and eat it away, so far as there is no feeling in it. The inner toe, however, retains its feeling, because it receives 
nerves from another source, and this part the animal does not eat. All the wounded parts soon heal, when the dead portions are gone, and the animal is thus left with a one-tied foot.

This is one effect which follows from the operation, but there are others still more romarkable. In a short time, sometimes in two hours after, a large portion of the skin of the face, on the side operated upon, becomes peculiarly affected. It loses all ordinary sensation completely, so that it cannot feel heat, cold, pressure, nor electricity, but becomes remarkably ticklish.

On tickling it, the muscles of the jaw, nose, and eye, on that side twitch vrolently; and gradually those on the other side become affected also, in the same way. The twitchings seem to be quite involuntary, and often persist constantly, as in St. Vitus' dance. Finally, true epileptic fits begin, with convulsive movements of the head, eyes, limbs, and chest, accompanied often by a sharp cry, and then the animal falls, just as we see in human epileptics. After a while the fit passes off, and the animal recovers, but remains more or less stupefied for some time, and occasionally seems to be really insane! Eventualiy the fits come on without any tickling, the animal having become a confirmed epileptic.

Finally, however, if the animal lives long enough, the convulsions get less violent, and longer between, till at last they cease altogether, and perfect recovery takes place. The affected skin loses its peculiar ticklishness, and regains natural sensation; the hair falls off from it, and a new growth takes its place. The only difference then to be found between the animal operated upon and other guinea-pigs is, that it has but one toe on the side where the nerve was severed.

Symptoms almost identical with those above described occur, in most cases of epilepsy, in human beings. There are almost always portions of the surface of the body peculiarly affected, in which a singular sensation arises before an attack, and spreads to other parts. This is called the aura, and it usually begins in one special spot. If this spot can be determined and reached, so that it can be removed or cauterized, a cure is generally effected. In the same manner the epileptic guinea-pig can be cured by cauterizing the affected area of skin.

The most important fact in connection with the above experiments, however, is this, that many of the young of the guinea-pigs so operated upon are affected like the parents. They are born with one toe only, if the parent had but one, and though apparently healthy at first, they soon become epileptic, continue so for a while, and finally recover as their parents did. The same portion of the skin loses its natural feeling with them, the hair falls off it, and a new crop grows when the disease is gone. In short, the young guinea-pig, which has not been operated upon, passes through the same range of symptoms as the parent that has been, and is even born with a limb mutilated in the same way.

Now in the animal operated upon, the disease and the mutilation both result from the cutting of the nerve, and the cure takes place only when the cut nerve grows and unites again. This is all very obvious, and easy to understand; but in the young, who inherit both the one toe and the epilepsy, exactly as in the parent, the nerve is not severed at all. In fact, the closest observation can detect no difference, in that respect, between them and other young guinea-pigs. Why then should they have but one toe, and be epileptic? This is what we do not know ; we can only refer to the fact, as an illustration of heredity.

It is worthy of notice also, in connection with this, that insane patients often 
have their ears affected, and lose portions of them, just like the epileptic guineapigs; probably from the same cause-impaired nervous action of the part.

Sometimes only a few of the young pigs are born epileptic, unless both parents wcre so affected, and it is most singular that all so affected are born also with the one toe only; the bodily malformation and the nerrous disease thus going together.

Epilepsy may arise from several causes, besides being inherited. It often follows from injuries to the head, from violent anger, from intense sexual excitement, and from continued drunkenness. Whatever the cause, if men or women, so afflicted, become parents, their children are almost sure to suffer in the same way. Such people, therefore, should never become parents, nor should those suffering from scrofula, cancer, phthisis, or any other serious constitutional disease. Insanity, or any dangerous or hurtful mania, should equally forbid parentage, so that all such causes of suffering and deterioration may be stamped out. Attempts at curing them amount to very little; the true policy is not to propagate them.

In the case of the guinea-pigs above referred to, although the young ones showeci no sign of anything wrong in their nervous structures, like that produced by the operation in their parents, still there is every reason to suppose that, in some important part of their nervous centers, a lesion did exist. The cut nerve in the parent was only the line of communication between the outer skin and some point in the sensorium, and the real injury was done there. When the young were born, that point in them, in all probability, was similarly affected, and hence they too were epileptic. The nerve might be intact, but something was wrong in the sensorium, and the disease did not disappear till the sensorium became perfect.

The fact of the one toe being transmitted makes it almost certain that other injuries were transmitted also, but in positions where we could not directly trace them.

The importance of all this, as a matter of heredity, can scarcely be overrated. I have no doubt myself but that the confirmed dipsomaniac, who will drink, no matter how he and others suffer from it, has a diseased spot in his brain. There is some lesion or injury in the great nervous center, as there is in all cases of mania, and this, or the tendency to it, he may transmit to offspring. He therefore never ought to become a parent. Many a woman sacrifices herself by marrying such a man, to reclaim him, and nearly always fails ; thus throwing herself away, and running the risk of becoming a mother of children similarly cursed.

Again I would remark, for it cannot be too often repeated, that by proper pairing, and observing the laws of heredity, the bodily and mental diseases and imperfections, of all kinds, which now afflict us, could be entirely got rid of ; and all those qualities which are desirable in us be magnified and perpetuated.

At present we try to cure disease by medicine, and vice by punishment or moral suasion, with but indifferent success. We keep lopping away at the constantly springing branches of the tree of evil, but leave the vigorous root untouched, so that our labor is fruitless and never ends. By attention to the laws of heredity, and proper pairing, we should destroy the root at once, and the tree would die iurever.

The bringing of children into the world is not a matter which concerns the parents alone, nor principally. The future of the children themselves, and of society, as it may be affected by them, should be considered first. At present it is 
seldom that any consideration whatever is given to either the one or the other. The thoughtless selfishness of the very poor, in this respect, is often encouraged by their spiritual teachers, who preach to them that Providence will provide. And this in face of the fact that thousands of their children, all around them, are born to misery, crime, disease, and untimely death. They are, however, no worse than the rich, who often from ignorance, or greed, deliberately marry disease and deformity, and perpetuate it as a family inheritance.

As a rule, like begets like, and children more or less resemble their parents, as is well known, but why it should be so is only beginning to be asked. Men have hitherto been satisfied with the bare fact, without seeking for the reason, but at the present day it is different. We want now to know the natural law which thus connects parents and offspring, and to understand why it is that though they usually resemble each other, yet at other times they totally differ.

That children generally resemble their parents is a fact of great practical importance to those who choose to act upon it. Among the ancients, especially the Spartans, practical use was made of the fact, and propagation was so regulated as to insure the raising of perfect and healthy children only ; who were expected, in their turn, to be the parents of other children equal to themselves. All the weak, or malformed, were eliminated without scruple, so that their imperfections should not be perpetuated. The effect of such a course, as may well be conceived, was to create a very superior race of people, and had the practice become universal, the race generally would probably have been, in every respect, much more perfect than it is now.

Nature herself, as Darwin has so well shown, does much in this way constantly. The sick and feeble have a less chance of growing up than the strong and healthy, or of maintaining themselves after, and usually die earlier. Both they and the deformed also are less apt to be chosen in marriage, and thus propagate less. Among savage people this is especially the case ; the strong, skillful, and cunning, among men, kill off their less fortunate brethren, or monopolize all the means of living; while among women those most physically perfect are chosen as wives, in preference to their less attractive sisters.

By this rude process of natural selection, the human race has, undoubtedly, been gradually but surely improved; and the same process, to some extent, is working even now. As people become civilized, however, this natural mode of improvement is much interfered with, and marriage is determined by other considerations than those that prevail in the savage state. The sick and feeble are cared for and protected, and the malformed, or imperfect, are not destroyed, nor left to perish.

Whether this is, on the whole, a gain, or really more humane, has been questioned, and with much show of reason. By caring for the diseased, the feeble, and the malformed, and allowing them to become parents, we undoubtedly propagate and perpetuate disease, debility, and deformity.

Perhaps the true compromise between care for the individual and care for society, may be found in simply preventing parentage, whenever, from any cause, it would be likely to result in undesirable offspring. It would seem as if this were a right inherent in society for its own protection.

Special cases, in which family traits of a marked character are transmitted, are numerous enough, and a fow of them are well worth referring to. 
Many family names among the Romans were founded on such traits, recognized as permanent. Thus we find Nasones (big-nosed), Labones (thick lips), Capitones (big-headed), and many others. At the present day, the Austrian royal family is noted for large lips, and the Bourbons of France for large noses. The prevalence of this latter feature, accompanied by a peculiar form, is also well known among the Hebrews.

Very often these family traits are quite persistent, so that nearly all the members will have them, but at other times they appear only in particular individuals, and even disappear entirely for several generations, and then come up again. Instances of this may often be seen in old family picture galleries, where a certain prominent feature, or peculiar face, can be traced at intervals through a long line of descent, as if the same person was born over again, from time to time.

It must be remembered that, in all these cases, no care has been taken to insure these traits being transmitted, and the fact that they are so, to the extent that we see them, shows the strength of the hereditary tendency. With the constant inter: mixture of other blood, which takes place in all families, the wonder is that individuality is not lost altogether.

A well-known case is recorded of one Edward Lambert, whose body was covered with a horny shell, somewhat like an alligator's hide. He was the father of six children, all of whom were covered with the same kind of shell by the time they were six weeks old. They all died but one, and he married and transmitted the horny skin to his sons. For five generations this peculiarity was noted in all the male members of the family.

A few years ago a Russian was exhibited in Paris who was covered all over the body, even the face and eyelids, with long silky hair, like that of a Skye terrier. He had a son and a daughter, both of whom had the same peculiarity as the father.

The bearded lady will be well remembered by many, she having been exhibited over most of the United States. She was full-bearded like a man, and had a hairy forehead. Her daughter exhibited the same peculiarities as the mother.

Many other similar cases are recorded, and in all of them, if the individuals married, the peculiarity was transmitted to their offspring. Usually in these cases of superfluous hair-growth, there is some abnormality of the teeth also. At times they are deficient, and then again they are in excess.

Baldness is often hereditary, and so are peculiar forms of the limbs. Families have been known in which the male members all had six fingers, or six toes; and others in which all the members had a peculiar gait or limp. Hare-lip, and cleftpalate are very apt to be transmitted, and sometimes albinos appear regularly in certain families.

Why or how these peculiarities begin we do not know, but it is obvious that they result from some constitutional change, and not from any accidental cause. As a rule, we do not find any artificial mutilation, or impress, become hereditary, no matter how long it may be kept up. Thus, every male Hebrew is born still with a prepuce, notwithstanding that every one has been circumcised for thousands of years. And every flat-head Indian is born with a natural shaped head, although all his ancestors, for unknown generations, have had their heads flattened out like a plate, artificially.

It is probably the same with all peculiarities, bodily and mental. We can seldom make them permanent by inducing them artificially, but when we find them appear 
naturally, we can perpetuate and increase them by proper attention to mating and parentage.

This fact should be regarded as a fundamental one in education. Every child should be looked upon as an individual, with peculiarities of his own, some to be encouraged and some to be repressed. Each one has some mental faculty predominant, and his education and after profession should be based upon that. If he be forced into any other line, for which nature has not adapted him, his life will be more or less a failure. We cannot create faculties, but when found, we can give them their fullest development and perpetuate them.

Thousands of valuable lives have been thrown away, and years of time wasted in trying to make mathematicians and linguists out of those whom nature had not adapted for such pursuits, but who were perhaps admirably fitted for others. The true educator is he who recognizes the natural bent and capacity of a child, and adapts his education to it. Our present plan of trying to form all on the same model, and to make all follow the same school course, results, for the most part, in a dead level of mediocrity, or in downright failure.

This educational fault is seen more palpably in girls than in boys, for there is even less variety with them. They each and all have the same little dab of French, music, and other so-called accomplishments, but not one is ever educated individually, so as to turn to the best account the faculties nature has given her. A girl with a real taste for drawing, and not the slightest capacity or ear for music, must nevertheless spend just as much time at the piano as a born musician, and as little at drawing.

It is probable that every individual could attain a fair standing in some pursuit, if not eminence, if proper attention were paid to their education in the first instance, and to their profession afterward.

A very remarkable instance of a natural peculiarity being transmitted, is that of the Ancou sheep, so often referred to. An intelligent farmer in Massachusetts, who was annoyea by his sheep jumping the fences, and straying away, noted among his lambs one with very short legs. This being a male, he kept it to breed from, and soon saw that many of his descendants had short legs also. By keeping these apart, and mating them together, he soon got a breed well established, with legs so short they could not jump the fences.

Long-horned cattle and short-horned cattle have also been established in this way, and recently, in Texas, hogs have been found with solid hoofs, instead of cloven, from which, no doubt, a race could be fixed, if they were properly bred in and in.

Some families are notoriously long lived, and others short lived; some are unusually prolific, and others the contrary. Gout, calculus, and several other diseases are often inherited, as certainly as the family features.

By care in mating, any peculiarity can be either perpetuated or obliterated. It can either be bred in or bred out, systematically and certainly.

Tricks of habit may become hereditary, as well as bodily traits. The following extract from an excellent article in the Cornhill Magazine gives some very singular instances of this:

"INHERITED TRICKS. - The inheritance of tricks of habit is one of the most perplexing of all the phenomena of heredity. The less striking the habit the more remarkable, perhaps, is its persistence as an inherited trait. Giron de Buzareingues states that he knew a man who, when he lay on his back, was wont to throw his right 
leg across the left; one of this person's daughters had the same habit from her birth, constantly assuming that position in the cradle, notwithstanding the resistance offered by the swaddling bands. Darwin mentions another case, in his Variation of Animals and Plants under Domestication. A child had the odd habit of setting its fingers in rapid motion whenever it was particularly pleased with anything. When greatly excited, the same child would raise the hand on each side as high as the eyes, with the fingers in rapid motion as before. Even in old age, he experienced a difficulty in refraining from these gestures. He had eight children, one of whom, a little girl, when four years of age, used to set her fingers going, and to lift up her hands after the manner of her father. A still more remarkable case is described by Galton. A gentleman's wife noticed that when he lay fast asleep on his back in bed, he had the curious trick of raising his right arm slowly in front of his face, up to his forehead, and then dropping it with a jerk, so that the wrist fell heavily on the bridge of his nose. The trick did not occur every night, but occasionally, and was independent of any ascertained cause. Sometimes it was repeated incessantly for an hour or more. The gentleman's nose was prominent, and its bridge often became sore from the blows which it received. At one time an awkward sore was produced, that was long in healing, on account of the recurrence, night after night, of the blows which first caused it. His wife had to remove the button from the wrist of his night-gown, as it made severe scratches, and some means were attempted of tying his arm. Many years after his death, his son married a lady who had never heard of the family incident. She, however, observed precisely the same peculiarity in her husband; but his nose, from not being particularly prominent, has never as yet suffered from the blows. The trick does not occur when he is half asleep, as, for example, when he is dozing in his arm-chair ; but the moment he is fast asleep, he is apt to begin. It is, as with his father, intermittent, sometimes ceasing for many nights, and sometimes almost incessant during a part of every night. It is performed, as it was with his father, with his right hand. One of his children, a girl, has inherited the same trick. She performs it, likewise, with the right hand, but in a slightly modified form; for after raising the arm, she does not allow the wrist to drop upon the bridge of the nose, but the palm of the half-closed hand falls over and down the nose, striking it rather rapidly--a decided improvement on the father's and grandfather's idea. The trick is intermittent in this girl's case also, sometimes not occurring for periods of some months, but sometimes almost incessantly."

Similar instances are met with in the experience of most people, but their signifiance is not generally seen.

Peculiar strength or activity is often transmitted, and so are keenness of vision and hearing. On the contrary, deafness and poor sight, stammering, squinting, loquacity or its opposite, taciturnity, are frequently hereditary, and so are peculiar likes and dislikes. Some families are noted for good memories, and others again for the contrary. The family to which the celebrated Professor Porson belonged almost all had remarkable memories. He himself was so noted that way that it was said he could not forget anything which he had once known. He could read a book through, and remember all of it, and how often any particular word occurred in it, and where.

It is not surprising that any remarkable faculty is seldom seen to the same degree in a man's children as in himself. To use an illustration, suppose a man with memory fifty per cent. above par marries a woman whose memory is fifty per cent. below par, the probability is that their children will have only ordinary memories; the defi- 
ciency of the one will counterbalance the excess of the other. The same is true of any other faculty.

It must be remembered, however, when speaking of remarkable capacity, or genius, that a man may possess either, and yet not become eminent. Besides the faculty, he must have constitutional energy, strong will, perseverance, and the power of application, without which the brightest faculties may lie dormant, or be but half used. A man of transcendent intellectual gifts may transmit them all to his son, but if the son inherits from his mother, at the same time, a languid temperament, or constitutional inertness, he will make no use of them.

The law of heredity applies to the whole nature, bodily and mental-to every part individually, and to its whole collectively. In applying it practically, the influence of one part upon another must be considered, and also the influence of each upon the whole. It is only by doing this that we can succeed in working out what is undesirable, or reducing it to its lowest terms, and in raising to the highest possible pitch whatever is most worthy of being conserved.

In regard to moral qualities, there is no doubt but they are also transmissible, equally with the mental. Whole families have been noted, for many generations, with an inborn tendency to be criminals. Others show simply a tendency to vagabondage, and others again to certain pursuits and occupations. The Hebrews seem born with a capacity to handle money, and to appreciate the value of jewels. For centuries they were prevented being anything else but jewelers and money-changers, and no doubt the faculty thus acquired has been hereditarily transmitted.

Insanity, lunacy, and idiocy undoubtedly run in certain families, and may be always expected in them at intervals.

In 1,300 cases of insanity, Esquirol found 300 cases of hereditary transmission, and no doubt there were many others, if the family histories had been traced far enough baek ; for it must be remembered that insanity, like any other established trait, may miss several generations, and reappear again. It is still there, but lies dormant for a time. Insanity may also be partial, and in some cases exhibit itself only in eccentricities. Moreau mentions the case of four brothers, whose grandfather died insane. Their sather was simply a shiftless man, incapable of applying himself steadily to any pursuit, while their uncle, an intellectual man, was noted for many oddities of character. One of the brothers was a raving maniac at intervals ; another was melancholy mad; the third was irritable, with a tendency to suicide; the fourth was a natural artist, but exceedingly suspicious and timid.

The insane tendency, in all these cases, was modified by their respective mental and bodily constitutions, but it was there. One peculiarity of hereditary madness is, that it seldom shows itself till late in life, thus often giving rise to false hopes that it may not occur. In women, it is usually after the change of life, but sometimes occurs during pregnancy or child-birth. In men, as a rule, it occurs most frequently from fifty to seventy-five years of age, unless brought on earlier by intemperance or sexual abuse.

Idiocy usually shows itself in childhood or early youth. Puberty is a dangerous period when there is a tendency to idiocy, especially with those addicted to sexual abuse.

Idiots are rare among savages or semi-civilized people, probably because they seldom survive long, no one giving them that extra care which their unfortunate condition demands. In some communities, idiots are always left to perish, or are 
destroyed. We nurse them, and even allow those with the taint of idiocy to marry and propagate a race of imbeciles.

The passion for gambling, like that for drinking, is often inherited, and dominates the whole character. There are born gamblers, born drunkards, and born thieves and murderers, beyond doubt; that is, there are people born with tendencies to these vices and crimes, so strong that all the ordinary influences cannot restrain them.

The conduct of society toward such erratic members must always be regulated by expediency, and not by abstract justice, nor by dogmas about moral responsibility. It is necessary for the welfare of society-nay, even for its very life-that such people should be restrained, or even put out of existence. And, above all, they should never be allowed to propagate! It is bad enough to have natural thieves, lunatics, murderers, or idiots, to care for and control, but it is infinitely worse to allow them to originate generations of such.

The original Jukes girl, on the upper Hudson, was not only thoroughly depraved herself, but she originated a family equally depraved. Of eighty descendants of hers, one-fourth are convicted criminals, and the rest nearly all drunkards, lunatics, paupers, and harlots.

How to deal with this matter practically must, in each case, be left to every person's own judgment; but most certainly, in view of these facts, no one ought to marry and become a parent without giving them some consideration.

At present, society can do but little, even in the worst cases, and must, perforce, see crime, idiocy, and pauperism propagated, without the faintest attempt at interference. It will not always be so, I feel sure, and the first step toward improvement must be in giving the subject full discussion, and showing its importance.

About thirty years ago, a book was published in England, called "Marcus on Painless Extinction," in which were advocated the right, and even the duty, of parents to put undesirable children out of existence at birth, by a painless process. The work made an immense sensation, and was finally withdrawn, but it served the purpose of calling attention to a subject previously almost totally ignored. It was supposed to have been written by an eminent statesman, for the purpose of stimulating public inquiry and discussion. I mention it merely for its historical interest. The celebrated Malthus advocated simple moral restraint to effect the same ends-a means which it is obvious would be effective with very few, and not at all with those with whom it would be most desirable.

\section{INTERMARRIAGE AND PAIRING.}

These subjects are among those about which people generally know but very little, but upon which they have very decided and fixed opinions. It is only quite recently that any attempt at all has been made, systematically, to gather facts bearing upon them, and the facts show, most conclusively, that the popular notions are erroneous.

This is especially the case in regard to intermarriage, or the union of persons nearly related. Very few people, except those acquainted with the facts, doubt for a moment that the marriage of near relations always results in imperfect offspring, and it will surprise many to learn that there is absolutely no foundation at all for such a belief.

Ancient history shows that in early periods the nearest relations intermarried 
freely, and it is not easy to say when, or why, the practice was first discontinued. It is probable that the church, during its most ascetic period, first began to interfere with the freedom of marriage, for its own profit and advantage. At best marriage was, in the early ages, only tolerated, as a concession to human weakness, and as a necessary means of continuing the race. The consent and sanction of the church was made imperative, on every union, and the church alone decided who should marry and who should not. At first only the very nearest relations were forbidden to intermarry, but gradually the prohibition became extended to first cousins, and then to the fourteenth degree, till finally any degree of relationship or affinity whatever, no matter how remote, or even god-parentage, was declared a bar to marriage. It was, however, distinctly understood that the prohibition was not absolute, in all cases. The church could grant a dispensation, where relations were determined to marry, and, for a fee, make it lawful for them to do so. This is the case even now in the Romish church, and cousins may marry providing the priest has been paid for his sanction. This proves that the objection is considered as merely ecclesiastical, and not natural, except by those who believe that the priest can really work a physiological miracle, and really change the blood.

These early theological notions, however, originated and perpetuate even now the prevailing notions in regard to intermarriage. Even where the church has lost its authority, the old dogmas it taught still rule over men's minds, and form their opinions.

It was formerly thought that the intermarriage of near relations (except with the special sanction of the chnrch) was sure to entail the curse of heaven upon the spouses. Not only would their children suffer in many ways, but their orchards would be barren, their cattle would die, and in many other ways they would be accursed. That no real danger of these evils was apprehended is proved by the fact that they could be averted, in all cases, by a church ceremony, dnly performed and paid for. In fact, near relations might marry, if they could afford the cost.

Even at the present day there are people who believe that a god-father and goddaughter ought not to marry, and that some punishment is sure to follow them if they do, though they may not be in any way related. Many churches also discountenarice the union of first cousins, and some clergymen will not marry them. The civil law, however, fortunately, places no such restriction, and people can now marry without church sanction.

As before stated, it is only quite recently that any doubt was felt as to the neces. sary hurtfulness and immorality of the marriages of near relations. The old notion being fixed that they were so, every case where evil of any kind followed such marriages was carefully noted, while all those cases in which no harm resulted were passed by.

By degrees, however, independent observers began to present their facts, and to controvert the prevailing opinions, but they had a hard up-hill fight, the whole power of the church, of tradition, and of fixed prejudice being against them. It was only when statistics were collected, and experiments made with the lower beings and with plants, that the true state of the case came to be seen. Breeders of animals proved that when a really good kind was once obtained, they could breed in and in, in the closest manner, not only without harm, but with positive advantage. In cattle, for instance, the children have been crossed with their parents, and the resulting offspring back again with them both, the last generation being more perfect than the first. 
The real point established by these experiments, and upon which the whole question turned, was this : Any character, or quality, good or bad, which is possessed by both the male and the female will, if they marry, and are prolific, probably become intensified in their offspring.

As a rule, however, marriages of near relations should be carefully considered, for this reason. There are few families without some taint, and therefore both may be reasonably supposed to be similarly affected by it. If they are, they should not marry. Very frequently, however, the nearest relations are quite unlike each other, and have no unfarorable tendencies whatever in common. Very frequently, in fact, first cousins are better adapted, naturally, to marry with each other than with strangers.

It should be borne in mind also that this law of double inheritance, by offspring, works two ways. Health, strength, beauty, mental power, and good moral tendencies, if possessed by both parents, may become doubled in their children, just as surely as disease, deformity, insanity, or immoral tendency. Whether the parents are nearly related or total strangers does not affect the result in either case. As remarked before, it is simply their fitness or unfitness, physical, mental, and moral, that should be considered, and not their relationship. If they are both similarly tainted, though they may be total strangers, their children will probably be doubly so ; and if they are both healthy every way, though related in the nearest degree, their children will probably be healthy also.

It is a popular notion that two persons who are alike should not marry, whether related or not. But that all depends upon whether the peculiarities in which they resemble each other are objectionable or not. If so, that is a reason against the marriage, but it may be that the peculiarities are such as it would be desirable to perpetuate, or even intensify, and then the marriage would be one to be desired.

This subject of proper mating in marriage, is, beyond question, the most important that can engage human attention; and the almost total neglect of it, shows how slow man is to appreciate properly what most concerns him. By due attention to this matter, when the necessary facts have been gathered, disease and all vicious tendencies can be annihilated, and man's mental and physical power be increased far beyond anything we can now conceive !

At present it is all hap-hazard, with the chances the wrong way. Men of intelligence, who will not mate their horses, dogs, or cows, without the most careful scrutiny, in order to insure perfect offspring, will nevertheless marry their children to disease, vice, and insanity, without a thought!

In some future age, when man comes to be guided by reason and knowledge, instead of tradition and superstition, the propagation of children will be as carefully attended to as the propagation of animals is now. But that will not occur till man learns the fact that he is an animal himself, and subject to the same laws as his fellows.

The remarkable success which has been obtained by improvers of the breeds of eattle and other animals, shows how much can be effected in this way. These men have found out, practically, that by proper pairing they can breed out any undesirable quality, and increase any desirable one. The value of domestic animals has been increased in this way enormously, and there seems no obvious limit to the improvements. This applies not only to bodily characteristics, but to mental and moral ones also ; our present domestic animals being from birth, incontestably more docile and teachable than their remote ancestors. 
Much of this improvement has been effected by close in and in breeding, or by the mating of near relations; it being a rule with many breeders, when they have established a good breed, to keep clear of any outside intermixture. All they regard is the qualities of the animals they pair; if these are what they wish, relationship is not taken into account. If a stranger has the desired qualities in the greatest perfection, it will be taken, if not, a member of the same family will be chosen.

The same principles are established in regard to plants, as shown by Mr. C. Darwin in his work on The Fertilization of Plants. After giving the results of his numerous experiments and observations, he sums up with saying that there is no necessary intensification of taints, and that in and in breeding is harmless, so long as the sexual elements are sufficiently differentiated. If plants grow constantly in the same place, and under the same conditions, they gradually exhaust the needed elements, and thus become less capable of self-impregnation, because they cannot perfect the sexual element. In such cases, a cross from a plant grown in another locality, results in more vigorous offspring, but it matters not whether it be a stranger or one of the same family.

It is quite possible this may be the case, to some extent, with human beings, in whom new conditions may effect favorable changes, as they do in plants. But all animals have this advantage, that they are not tied to one spot, as most plants are, and therefore can vary their surroundings at will.

That crossing is often an advantage there is no doubt, both in plants and animals, but it is so only when the cross brings some new good quality, or increases one already established. It makes no difference whether the cross is made with a stranger or with a near relation that has been raised under new influences.

Mr. Darwin planted cross-bred seeds and in-bred seeds of the same plants, on opposite sides of the same pot, and found that the cross-bred ones usually grew much more luxuriantly than the in-bred ones, but not always. The explanation, no doubt, was, as before stated, that, in the cross, the male fertilizer was grown under different conditions, more favorable for the elaboration of the pollen. A new plant raised from sead in a place well suited to it, would fertilize itself, or breed in, as perfectly as if it were crossed. It is the same with breeds of animals ; adaptation is what must be considered, without regard to relationship.

Even if it should be found to be a law of nature that crossing should take place, to some extent, it would not show that intermarriage is necessarily hurtful ; for the nearest relatives, among animals, cannot breed so close as the plant which constantly fertilizes itself; because animals are all the time changing their conditions, more or less, while the plant is always fixed in the same.

Mr. Darwin says, "From the facts given in this volume [The Effects of Cross and Self-Fertilization in the Vegetable Kingdom], we may infer that with mankind the marriages of nearly-related persons, some of whose parents and ancestors had lived under very different conditions, would be much less injurious than that of persons who had always lived in the same place, and followed the same habits of life. Nor can I see reason to doubt that the widely-different habits of life of men and women, in civilized nations, especially amongst the upper classes, wouid tend to counterbalance any evil from marriages between healthy and somewhat closely-related persons."

This remark may be sometimes of practical value. If a union be desired between 
two very near relations, much alike, any possible evil may be much counterbalanced, as $\mathrm{Mr}$. Darwin remarks, by having them reared apart, under different conditions, or, at least, kept so as long as possible. This, of course, applies to all animals, human beings included, and to plants also.

Even the different occupations, and mode of life during the day, of husband and wife, no matter how much they resemble each other, will help to differentiate them, and so counteract any possible evil from their near relationship.

Observations on individual cases show no more harmful results from intermasriage of near relations, than from the marriage of strangers ; and statistics give the same result.

Mr. George Darwin was perhaps the first man who went into this subject systematically, for the purpose of getting at the real facts. Ho found that the prevailing notions were all based upon conjecture, imperfect observation, and tradition, aind that there was really but very little positively known about it.

He first set to work to discover what proportion of all the marriages, in a given number, were between first cousins, and found it to be three and five-tenths per cent. in the middle and upper classes and landed gentry, and four and five-tenths per cent. among the aristocracy. He then got the statistics of numerous lunatic and idiot asylums in England and Wales, and ascertained how many of the cases therein were children of first cousins. The result was about four per cent., or nearly one-half of one per cent. less than among the children of those not nearly related.

The inquiries were more especially directed to deafness, sterility, low vitality, and inferior mental and bodily vigor. The results proved that there is, to say the least, no more danger of either of these defects to the children of first cousins than to those of other people.

Mr. Darwin found, for instance, that among 366 families which furnished deaf mutes, only eight were unions between first cousins-that is, a little over two per cent. only!

He also found that in the peerage, and among the landed gentry, marriages between first cousins were more fertile than ordinary, and that their children were even more fertile than usual, whether they married relatives or not.

Statistics show that about twelve per cent. of all marriages, in England, aro barren. But Dr. Bemis shows, from an analysis of 833 cases of marriages of near relations, that less than seven per cent. of them were barren.

In addition to this we have many instances of small communities, isolated from the rest of the world, where close intermarriage has been the rule for generations, without any special bad results, if not sometimes with advantage.

Dr. Voisin tells us that the commune of Batz, situated on a peninsula, and separated from the main-land by a salt marsh, is almost entirely isolated, the inhabitants having very little intercourse with the main-land. They number about 3,300, and have intermarried amongst one another for many generations. Dr. V. did not find amongst them, however, a single case of deaf-mutism, albinoism, blindness, malformation, or mental disease, although almost everybody was related. The number of children amongst them was over the average, and they were unusually healthy. The average of barren marriages was only four per cent., which is very low indeed.

They are a simple but intelligent people, habitually sober, and crime is almost unknown amongst them. 
Among the Jews, as is well known, marriages of very near relations are common, and yet they are among the most healthy people in the world, and the most free from defects, both bodily and mental.

This subject has been treated upon more fully because it is advisable the truth should be known. It would often be advantageous for first cousins to marry, and it would be a pity that an unfounded notion should prevent it. Of course there may be family or other reasons why near relations should not marry, but there is no natural reason why they should not.

In the case of the commune of Batz, above referred to, the founders were probably all sound, healthy people, and close intermarriage has been advantageous, by keeping their offspring like them. Had some of their forefathers been deaf, or imbecile, the intermarriage might have been a great misfortune, by intensifying their bad traits and perpetuating them.

All which proves, as before remarked, that in marriage it is the sound and healthy condition of the parties that should be considered, and their mutual adaptation; it will then be of little moment whether they are related to one another or not.

\section{IMPROVEMENT OF BREED.}

To show the importance of a proper attention to pairing, in the breeding of animals, we may mention the fact that with sheep, the improvement of the breed has practically doubled the amount of mutton from a given number of animals! The same result has also followed the improvement of cattle, from whom double the amount of milk, butter, cheese and beef are now obtained, compared with those of former times. In horses, pigs, and all other domestic animals, it is the same; they have all been doubled or trebled in value by systematic improvement. So expert have breeders become, that they will produce almost any form, size, or color that may be desired, by proper attention to pairing.

It cannot be too often repeated, that the same laws apply to human beings, and that, beyond doubt, man can be improved every way, physically and morally, as certainly as the lower animals, and by the same means!

At some future day this will be acknowledged and acted upon, and society will rightly attribute all cases of vice, malformation, and disease, to its own neglect, and not to any inherent defect in human nature itself.

Those who would like to see what can be accomplished in this way, even by unenlightened people, should read the history of the ancient Spartans, with whom the admiration of physical perfection was a real passion.

Nature herself, by the process of evolution, is constantly at work perfecting our race. By the agency of natural selection, the strongest and those of acutest intellect multiply faster, and endure longer, on the average, than those less fortunate. They crowd them out, override them, and push them to the wall. It is in this way that man has emerged from the savage state, and become what he is. Age after age, the superior ones have overcome the inferior, and their offspring have inherited their supe. riority. Gradually, but surely, by natural means alone, the breed of human beings has improved, but very slowly, compared with the improvement which can and will be effected when man pays as much attention to his own propagation as he now does to that of the animals he controls.

It should be borne in mind, further, that when an improved breed is once obtained, 
constant care is needed to keep it pure and to perpetuate it. Neglect brings contamination, and degeneration speedily follows, as breeders, both of plants and animals, have found to their cost. None but the finest and most perfect males and females should be allowed to propagate, and they must be paired with special reference to the particular qualities we wish in the offspring.

Many physiologists have gone so far as to say that our extreme care of the sick, and our medical art, is a real misfortune to the race. It keeps alive the sick and feeble, and so allows them to propagate their debility and disease, whereas, if left alone, they would die off, and their infirmities would die with them. They say this may seem cruel to the individuals, but would it not be better so, than that thousands of others should be born to suffer in the same way? Would it not be better to end all this, than to make it permanent? to purify the race, than to keep it tainted?

Nature herself follows this course. She makes no provision for the sick and feeble, but allows them to die off at once, instead of becoming the parents of others like themselves. All wild animals cast out and shun the sick and injured of their own kind, and so prevent them from propagating. This is, no doubt, one great reason why diseases of any kind seldom become permanent or constitutional among animals in a state of nature.

Common humanity will, howerer, always make us care for the sick and feeble of our kind, mitigate their sufferings, and keep them alive as long as possible; but it is not necessary nor advisable that they should propagate. That concerns society more than it does them.

It certainly is a public calamity when people afflicted with mental or bodily disease, or moral defects, become parents! and they never ought to do so.

This is a matter that concerns society at large more than it does individuals, and society will one day take charge of it. At present, ignorant and thoughtless people can go on propagating disease, insanity, and criminality, and no one has the power to hinder them. It is even considered an offense to speak to them about it, or to question their right to do as they choose in the matter.

It will not always be so, however, I feel sure, and perhaps these few remarks may assist in bringing about the much-required change.

Many interesting instances are well known of transmitted tendencies in families, for many successive generations; the notorious Jukes family, for instance, already referred to, almost every member of which is a criminal or pauper from birth, all of them being descended from one vagabond pair. On the contrary, other families have been as noted for eminence in other ways. The Napiers, for several generations, have been distinguished as mathematicians, the Candolles as botanists, and the Darwins as naturalists.

The true policy of society is to encourage this family transmission of qualities, even thлugh it may lead to close intermarriage, for by this means the capacity for particular pursuits is increased, and the special tendencies intensified.

A natural-born scientist, in any department, is rare, and of inestimable value. Under proper conditions, such a man attains the very highest rank, and makes his influence felt in all subsequent generations. Mr. Charles Darwin is a man of this kind, and a striking instance of the influence of hereditary descent. He is, in fact, the elder Darwin more fully developed ; and his children are already treading close upon their father's heels. What some future Darwin may become, if the family tend- 
ency continues, we cannot conceive, although it would seem very difficult to surpass the one we now have.

It becomes a duty, in the members of such a family, to be extremely careful in regard to marriage, so that the brain development and stored-up mental habits of their great ancestors may not only be maintained and transmitted, but, if possible, be even improved upon. In such a case, intermarriage may be extremely desirable, if it tend to preserve or increase the family capacity and tendency, while marriage with strangers, if it led to a contrary result, would be a real misfortune to society. 


\title{
CHAPTER XLV.
}

\author{
HYBRIDS, HYBRIDIZATION, AND CROSS-BREEDING。
}

\section{Hybrids.}

As a rule, only animals of the same kind breed together, and their progeny is of the same kind. But sometimes animals of different kinds will mate, and their progeny will then be a mixture of the two, or a hybrid, as when the horse and ass breed, together, and produce the hybrid called a mule. It was formerly thought that animals of different species could not breed together, and that when any two did breed it proved them to belong to the same species. This, however, is now conceded to be erroneous, for not only different species, but even different genera will cross, and it is only those of different orders which are incapable of intermixing. At what precise point intermixture between two different animals becomes impossible we do not know, but it is certain that it becomes rarer the more remote they are from each other.

It is possible that hybridization would be more frequent, even among widely separated beings, if it were not for differences of structure, which interfere with copulation and gestation. The male sperm and the female germ, even in those of different orders, might intermix and form a hybrid, if they could be brought together under proper conditions. The generative elements are the same in all kinds of beings, but each kind has a particular mode of congregation and gestation.

We see this exemplified both in plants and animals, many kinds of both being crossed by artificial aid which never are naturally. Different kinds of fishes, for instance, are crossed this way.

One of our previous articles has explained how the human female may be impregnated artificially, by throwing the semen into the womb with a syringe, and it is quite possible that in this way animals might be crossed who cannot copulate.

In some cases of hybridization, the male and female of both kinds intermix either way, and this is called bilateral, or two-sided crossing. Thus we have a mule either from the male ass and female horse, or from the male horse and female ass. In other cases the male of one kind can cross with the female of the other, but the process cannot be reversed. This is called unilateral or one-sided crossing. Thus the male goat will breed with the female sheep, but the male sheep cannot impregnate the female goat.

One-sided hybrids are the most common, and even in the two-sided, one way always produces a more perfect being than the other. The mule, for instance, which has the horse for father, is a larger and more perfect animal than the hinny which has the ass for father. Mules are also more readily and certainly obtained than hinnies.

We have no means of judging beforehand whether any two different animals 
will cross, for some that seem very near together will not do so, while others, apparently very remote, will.

Although it is laid down as an invariable rule that different orders will notintermix, still there are some alleged cases of their having done so. The jumart for instance, was said to result from the union of the horse and cow, either way, and this was believed down to the time of Buffon. Thorough investigation however showed that the so-called jumarts were only hinnies, from the union of a horse with a female ass.

All the different species of equus, the horse, zebra, ass, and quagga, breed together; the dog will breed with either the fox or the wolf; the lion with the tiger; the male sheep with the female deer; and the hare with the rabbit. A mastiff dog has also bred with a lioness.

Among birds the swan and the goose ; the grouse and the black cock ; the pheasant and the common fowl ; the canary and the goldfinch will intermix, as also many others.

Among reptiles, the toad and the frog will cross. And among fishes many curious intermixtures have been obtained.

Hybrids may be of either sex, but the generative system is usually imperfect, so that they are either totally barren, or procreate only to a limited extent. Even when they do procreate, it is usually with one of the parent stock, and but very rarely with each other. The male hybrid is more usually sterile than the female. The female mule, for instance, sometimes has a foal by a male horse or ass, but never by a male mule. In fact, the semen of the male mule usually contains no animaleules, as before explained, so that it could not impregnate.

One very remarkable exception, however, must be named.

M. Roux, of Angoulême, France, has successfully crossed the hare with the rabbit, and the hybrid, called a leporide, is found to be both prolific and valuable.

These and similar experiments have been thought to prove that there is not, naturally, any such thing as difference of species.

It has been asserted that all hybrids gradually lose their fertility, and thus, if left to themselves, they would die out in a few generations. This is undoubtedly true of most of them, but there are exceptions.

I have been assured by those who have carefully observed, that even the mulatto, the cross between the white and the black of the human species, is not nearly so prolific by itself as it is with either the pure black or white. While lecturing in Washington, I had much conversation with the late Mr. John C. Calhoun on this subject, and also with Governor Tazewell of Virginia, and many others. The universal testimony was that two mulattoes, when married, scarcely ever had the average number of children, and that their offspring, if they married, had a still smaller number, while theirs again, when married, were almost invariably barren. At the same time, either generation would regain its prolificness by connecting with either black or white.

Mr. Calhoun informed me that it was once a law in the West Indies, as he had been told, that all mulattoes of the fourth generation of regular descent were declared free, but that none were ever found. And it is certain that children of mulatto descent are very rarely to be met with.

In my visit to the South, by favor of the above-named gentleman, and others, I had an opportunity of examining a large number of cross-breeds, between black and white, of various degrees, and the result fully satisfied me that few of them were 
sexually perfect. In the male the testicles are generally small, and lack firmness, while in the female the ovaries and womb are also small. The quadroon, and octoroon, are more perfect than the offspring of two mulattoes, because of the pure white parentage.

Some cross-breeds seem to be an improvement, in certain particulars, upon their parents, but as a rule it is the reverse, although it is occasionally advantageous to breed a certain amount of one kind into another.

The crossing of different vegetables, fruits, and flowers, has undoubtedly given us many improved and valuable varieties, some of which are capable of continuing their kind by self-fertilization, while others are not.

Every plant always prefers the pollen of its own species, and will take that alone, when mixed with other kinds. To effect a cross, therefore, of any flower, its own stamens must be cut away before their pollen is shed, or it will be sure to be taken in preference to that of the plant we wish to eross with.

It is the same with animals, the semen of each kind being always preferred to that of any other animal.

Generally, with plants, the hybrid resembles the male parent more than it does the female ; and it is most frequently so with animals. Thus the mule is more like the horse, and the hinny is more like the ass. The mulatto by a white father is also whiter than the one by a black father.

In addition to the hybrids already mentioned, I also find a few others, which are deserving of notice.

M. C. F. Rafinesque, professor of botany in the University at Lexington, Ky, states that a cat was left alone, for some months, in a cabin in Kentucky, with no other cats within fifteen to eighteen miles, and yet was found by the owuer on his return with five young ones. They were not young cats, however, but apparently hybrids between the cat and an opossum. The body, and fur, were like that of the mother, but the head, pars, and tail were like those of the opossum. These creatures lived some time, and were shown as curiosities, but they never propagated. In all probability the eat, when in heat, not meeting with a male of her own kind, associated with a male opossum. But if this were so it is a very remarkable case of hybridity, for these animals belong to different orders and types.

M. Rafinesque also says that hunters assure him that the raccoon will cross with the red fox, and he has even seen the skin of one of these hybrids, which apparently resembled much that of the raccoon, but was a real mixture of the two. In this case also the parents were of different orders.

The male buffalo, it is well known, will cross with the common cow, and the progeny will breed, but the domestic bull will not so readily cross with the female buffalo. These half-breed buffaloes are now quite common in the West, and are said to be quite valuable.

The Canada goose will cross with the domestic goose, and the progeny will breed; and the same is the case with the common duck and the muscory duck, though all these are considered to be of different species.

In all probability many rare and unexpected hybrids could be obtained, by artificial means, and some of them might be valuable, as well as interesting.

When the pairing animals, or plants, are nearly related, so that their offspring is not very dissimilar to them, it is commonly called a cross only, and not a hybrid, but the distinction is only conventional. 


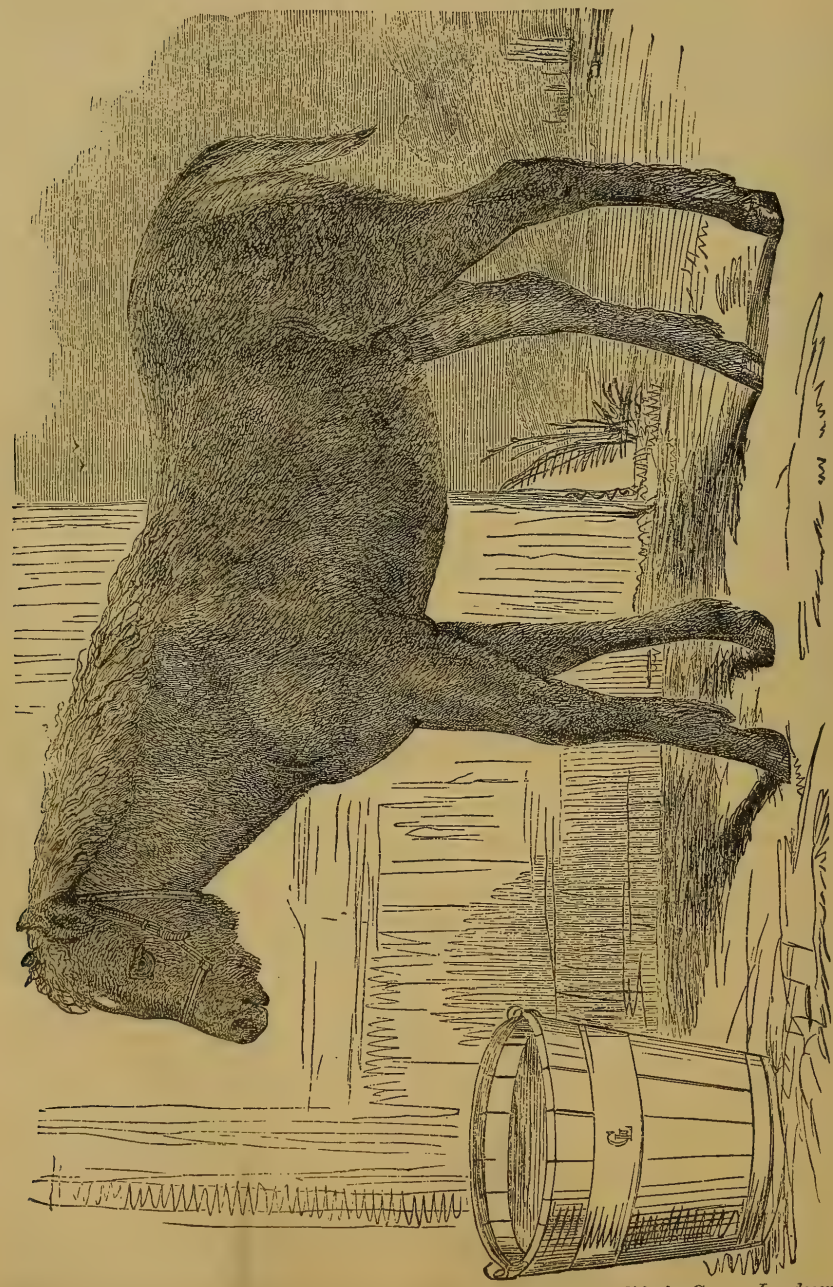

FraURe 118.-Remarkable Hybrid, from the Nero Forest. Drawn from life, by George Landseer. 
if few years ago a remarkable hybrid was found in the New Forest, in the South or England, of which we give an illustration. The account given of it states that " this remarkable filly (seven months old) was found a short time since in the New Forest, and is evidently of a mixed breed, between the horse and the deer. Her mother (a pony mare) was observed to associate with some red deer stags in the New Forest for some months, and, at last, this foal was seen by her side. The nose shows a proximity both to the stag and horse; her forward is round, like that of the deer; legs slender and distinctly double; hoofs pointed, and partly double; color brown, lighter under the belly, and tail like a deer.

"This extraordinary animal is the property of T. G. Attwater, Esq., of Attwater, at the village of Bodenham, three miles from Salisbury. Dr. Fowler, of that city, has inspected the hybrid, and is quite satisfied of the correctness of the preceding statement; and Colonel Buckley (a keeper of the New Forest) has likewise seen the animal, and is of a similar opinion."

This is one of the most remarkable and best-attested instances of hybridization, between animals very remote from each other, that I have ever met with, and proves that with due care, crosses may be effected to a greater extent than is usually supposed possible.

A gentleman who had lived many years in Africa, and traveled much in the interior, assured me that the people all fully believe in crosses between the chimpanzee and native women. They assured him that it was dangerous for a woman to go alone into the forest, if male chimpanzees were there, because they always seized and violated them. He said further that he had seen many children singularly monkeyfied in appearance, which are said to be the result of such forced unions. What was very remarkable, none of. these children spoke. Certainly such hybrids would not be nearly so wonderful as many of those we have described, and there is no reason, structural or otherwise, why they should not be produced. The chimpanzee and the lowest. negro are certainly as nearly related, structurally, as the lowest negro and the Caucasian, and they lreed together, either way. 
the peculiar pneumonia which is not unfrequently favored and even excited by the stenosis of the left auriculo-ventricular orifice. Only lat the remedy be administered in a small dose; this is of paramount importance. Even if large doses seem to agree at the beginning, yet in the long run they exert a decidedly pernicious influence.

We advise the use of Belladonna in all cases where Aconitum seems indicated by the symptoms. In this kind of disorder Aconite never exerts a favorable influence. Belladonna is especially indicated by the paroxysmally increasing pulmonary hyperæmia and the headache which sometimes reaches a terrible degree of intensity. It is less frequently efficacious in the resulting hepatic derangements.

Pulsatilla cannot be numbered among the prominent remedies; we would at most employ it in the higher grades of bronchial eatarrh.

Veratrum album competes with Belladonna as far as the affected organs are concerned; yet there are symptomatic differences. It is suitable for cerebral and pulmonary cougestions setting in with pallor and coldness of the outer skin, or with a decidedly cyanotic tinge.

Opium, in small doses, in the case of drunkards is a main remedy for celebral hyperæmia, less for the respiratory difficulties. In such cases it often acts with wonderful rapidity and completeness, although the effect does not last.

Tartarus stibiatus is indicated by bronchial catarrh with profuse secretion of mucus, and by a gastric catarrh the symptoms of which may be compared in the Mat. Med. Pura.

Arsenicum which seems indicated much more frequently than it really is, has only shown a decisive effect in our hands against the sleeplessness which is a not uncommon symptom in these disorders; it has never seemed to be of any use in affections of the respiratory organs for which it seems such an excellent remedy if these affections are not occasioned by valvular defects. Nor does it ordinarily seem to have any effect in dropsical difficulties.

The remedies we have named so far, are in general adapted only to overcoming single ailments either acute or subacute; to this list we will add the following: Phosphorus, Squilla, Secale cornutum, Iodium, Ammonium carbonicum. Another series of drugs has to be opposed to chronic secondary affections which, although necessary consequences of the cardiac disorganizations, very often admit of a diminution, or at least of an arrest of the symptoms. 
China and Ferrum here occupy the first rank; the former more especially, if the anæmic phenomena which are an inevitable consequence of the deficient activity of the left ventricle, are associated with frequent paroxysms of passing congestions of the brain, and if the hepatic functions are greatly interfered with. Ferrum is indicated rather by a tendency to pulmonary congestions and to hemorrhage from the bronchia, by prominent symptoms of gastric catarrh, and, like China, by enlargements of the spleen. Ferrum is not very suitable to old people; China, on the contrary, is eminently so.

In chronic ailments Arsenicum deserves more attention than in acute complaints. It may be tried in liver-complaint as well as in renal affections; sometimes it renders good service, but more frequently it leaves us in the lurch.

Baryta carbonica has already been mentioned in the bronchial catarrh of old people; we likewise recommend it, if the catarrh is occasioned by valvular deficiency.

Carbo veget. may still afford help, if every other remedy had left us in the lurch. This remedy embodies in its pathogenesis all the consequences of the anomalies here treated of: a disposition to atonic hemorrhage; the anæmic symptons in cyanosis; œdematous swellings, pulmonary redema; passive hyperæmia of the brain, lungs, liver, spleen; chronic bronchial catarrh in every stage, pulmonary hemorrhage; gastric catarrh. There is scarcely another remedy that represents so clearly a definite morbid condition. Clinical results have substantiated the truth of this similarity.

Beside these remedies, those that have been named for fatty degeneration may likewise be ranked here, especially Plumbum, Cuprum and Aurum. For single symptoms: Lycopodiurn and $\mathrm{Na}$ trum muriaticum are particularly efficacious. The last-mentioned remedies likewise embrace within their curative range, if help is at all possible, the last link of this series of consecutive disorders, namely: local and general dropsy.

The mode of living has an influence upon the final result that must not be underrated. Bodily motions and exertions are regulated without the least difficulty; proper dietetic precantions are easily violated. Inasmuch as the whole tendency of the anomalies, of which we have treated, is to change the blood to venous blood, since the interference with the lesser circulation only admits of an imperfect oxygenation of the blood: our whole aim should be to furnish the patient with such nourishment as will not require the 


\section{PLATE XXXIV.}

POSITJON OF THE ORGANS IN THE MALE PELVIS.

24 , is the bladder; 23 , the rectum ; 14 , the kidney; 16 , the large artery, whicu forks, one part going to each leg; 21 , the branch going to the left leg, and 22 to the right. The tube crossing 22 is the ureter, or tube conveying the urine from this right kidney to the bladder; $2 \%, 28$, are the right and left abdominal rings, filled with the spermatic vessels, arteries, veins, and nerves. These are the places where ruptures occur. 18, is the large vein, under the artery, and corresponding to it : 15, the navel ; 25, the pubic bone.

In the chest, 1 , the large aorta ; 3,3 , the right and left sub-clavian veins ; 11, the descending aorta; 12 , the œsophagus leading to the stomach. 


\section{PART XIV.}

\section{SPECIAL DISEASES OF THE GENERATIVE ORGANS,}

MALE AND FEMALE. 



\section{CHAPTER XLVI.}

\section{DISEASES, MALFORMATIONS, AND DERANGEMENTS OF THE MALE SYSTEM.}

IT is of the greatest importance that every man should know sufficient of himselt to be able to detect the various derangements of his system at the earliest possible moment, and that he should also know the proper steps to take for their prevention and removal. He who knows nothing of this kind, and goes to a physician only when he feels pain or inconvenience, will often find that he then cannot be benefited, the favorable moment having gone by unknown to him, through his ignorance. Some of the most severe and dangerous diseases of the testes, for instance, cause neither pain nor inconvenience till they are considerably advanced. I shall therefore give all the indications that can be relied upon, of each disease, and also the treatment to be pursued, making it in every case, as far as possible, such as may be practiced by the person himself.

\section{TYDROCELE, OR DROPSY OF THE TESTIOLE.}

This is sometimes called a swelled or watery testicle. Properly speaking, this is but seldom an affection of the testicles themselves, but of the scrotum in which they are contained. There are three kinds of hydrocele: first, that in which the fluid

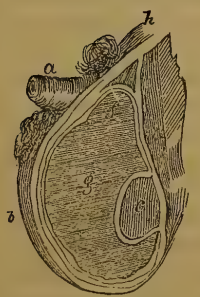

FIG. 119.

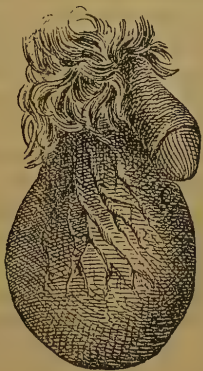

FIG. 120 .

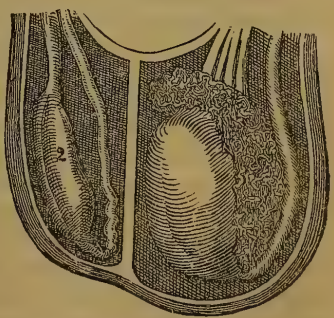

FIG. 121.

A case of Hydrocele laid open.

Figure 119.-a. The Penis much contracted, $b$. The Scrotum. c. The Testicle. $f$. The Tunica Vaginalis, which, it will be seen, is double, from being reflected over the Testicle, which is on the outside of it. $g$. Is the water, which is between the two folds of the Tunic. $\hbar$. The Spermatic Cord. FrgURE 120. - External appearance of the Hydrocele, showing the veins also in a case of Varicocele.

Figure 121.-Wasted Testicle. 1. Shows the left Testicle perfect. 2. Shows the right Testicle wasted away, as it often does from masturbation, and sometimes from hydrocele. 
collects in the substance or tissue of the scrotum; secondly, that in which it is secreted by one of the coats of the scrotum; and thirdly, that in which it collects in the spermatic cord.

First Variety of Hydrocele. - This is scientifically called Hydrocele Edematodes, and it is usually connected with general dropsy, or arises from the treatment of some of the other varieties. It is, however, but seldom met with, and rarely arises of itself. In some cases it has been brought on by wearing an improperly-constructed truss, by blows, or even by tight clothing, but much more frequently it is only a consequence of some other disease, particularly dropsy of the abdomen, which is likely to extend to the scrotum. In this form of disease the testicle is usually softish at first, and when pressed the mark of the finger remains of a white color for some time after. As it progresses, however, the scrotum becomes harder, and perfectly smooth, the penis enlarges, particularly at the prepuce, and in very bad cases the skin inflames and sloughs away.

The treatment of this form of hydrocele must vary somewhat according to the conditions under which we find it. If it results from general dropsy, it can be cured only by the removal of that, and will require but little local treatment. If there be any injurious pressure, it must be immediately taken away, and frequently the doing so will effect an immediate improvement without anything further being done.

The local treatment, after attending to the above directions, must consist of frequent bathing with cold alum water, one ounce to a pint, or of simple cold water. A suspensory bandage must also be worn constantly, except when the patient can remain perfectly still, without standing too long. The bowels must be kept free, and but little fluid drunk. The following mixture may be taken for four days, and then omitted four days, and so on alternately till it has been taken twelve days in all, unless the swelling is obriously going down after the first four days, which it will often do, in which case it need not be continued.

R. Hydriodate of potassa, thirty-six grains ; distilled water, one ounce. Dose, ten drops, morning and night, in half a tumbler of water.

Second Variety of Hydrocele. - This is usually called Hydrocele of the Tunica Vaginalis, the fluid being secreted by the inner coat of the testicle, and, therefore, contained in the cavity of the scrotum. The swelling is observed on one side only, in most cases, like a smooth egg or pear-shaped tumor, of a natural color. It begins at the bottom of the scrotum, and gradually progresses upward, until it sometimes reaches the top and presses against the abdomen. It is quite soft to the touch at first, and the fluid may be distinctly felt to fluctuate or shift its position as the tumor is moved. As the disease progresses, however, it becomes harder, and does not fluctuate, and in form it becomes more decidedly oblong.

From the above description, it will be seen that this form of hydrocele is easily distinguished from that previously described, because in this the swelling is observed on one side, and commences at the bottom, while in the other it is diffused more or less over the whole scrotum at once, and is evidently in the skin, or cellular tissue. Sometimes, it is true, both halves of the scrotum may begin to fill up with fluid, but even then each one is sufficiently distinct from the other for both to be distinguished, and for the nature of the affection to be readily seen.

A very good way to examine a hydrocele is to place a candle behind it and look in front, when it will usually appear semi-transparent, and sometimes so perfectly so that the testicle may be distinctly seen in the middle of the water, like the yelk of an 
egg in the midst of the white. When the testicle cannot be seen in this way, it is often difficult to find it, and its position can only be ascertained by a hardish feeling in the back part of the swelling near the top.

The quantity of fluid secreted in some of these cases is very great, as much as six quarts having been removed by Mr. Cline from Gibbon, the great historian. There may, however, be but a small portion, and it may remain for many years, or even during a person's life, without increasing, though the probability is against this, and in some cases it increases very rapidly.

It is singular, also, that even in some very bad cases there is but little distress, and, except from the inconvenience of its weight and size, many patients suffer but small annoyance from it. Sometimes, however, it causes a troublesome sense of uneasiness and pressure in the testes and groin, and occasionally even produces numbness of the limbs. When very large, the penis is drawn into the swelling, so that it appears smaller, and its erection becomes difficult and painful ; the spermatic cord is also pulled down, and becomes tender, and the motion of the limbs is much interfered with.

There is not much to be feared from a hydrocele of this kind, if the general health be good, unless it be complicated with a real swelling of the testicle; the case then becomes very difficult, and nothing can be done till the testicle itself is cured. I have known a man of sixty years of age who had a hydrocele from the time he was fourteen; it was of a considerable size, but had never much incommoded him, nor in any way interfered with his health or functions. The difference in the symptoms of a hydrocele and a swelled testicle will be pointed out in the article on Sarcocele.

The causes of this form of hydrocele are but little known. It is undoubtedly brought about, in some cases, by injuries, such as blows, pressure upon the saddle in horse-riding, and by badly-made trusses. Too much standing will also dispose to it, particularly in those with a relaxed state of the muscles. In general, however, it results from some constitutional tendency, the nature of which is unknown, and which cannot be ascertained before the effect is produced. In most instances, its beginning is altogether unknown to the patient, and it progresses so slowly and insidiously that an advanced stage may be reached before anything wrong is suspected. I have known young men suppose it was merely a natural increased growth of the parts.

The Treatment. - In the early stages, it is sometimes sufficient to use cold lotions two or three times a day, as prescribed for the first variety, particularly that of alum. Frequent cold bathing, in addition, will assist, and if the bowels be kept free and but little fluid be drunk, the hydrocele will occasionally go down considerably, or even disappear altogether. I would advise any one to continue this simple treatment even if it only arrested the disease, for though it might not positively cure at first, still if it keeps matters from becoming worse, Nature herself may work a cure in time. A suspensory bandage should be worn from the very first, and as much rest should be taken as circumstances will allow. After using the simple alum-wash for some time, if the swelling still continues, the following lotion may be applied instead, night and morning :

R. Powdered Peruvian bark, one ounce; boiling water, one pint. Boil these for ten minutes, and then add, when cold, half a pint of spirits of camphor.

This is perhaps the best lotion that ever was used for this purpose, and has done more goor than all others put together. The parts should be bathed with it for 
about ten minutes before the suspensory bandage is put on in the morning, and for the same time after it is removed at night.

In some cases, the following wash has been found to succeed, even where the other did not :

R. Sugar of lead, one ounce; laudanum, a teaspoonful ; water, one pint.

This is to be used as a lotion, the same as the other, and both must be applied cold.

Very little can be done by internal medication, except to keep the bowels free, though occasionally the following recipe may assist:

R. Vinegar of colchicum; vinegar of sqnills, and nitric ether, of each half an ounce- - to be mixed. Of this mixture a teaspoonful may be taken in a drink of water three or four times a day. Frequent bathing, and clothing the body warmly are also beneficial.

When all these means fail, however, as they too often do, some kind of operation must be resorted to, either to give temporary relief, or with a view to cure. It is customary, for the first purpose, to puncture the sac of the scrotum with a sharp instrument, and let out the water. If nothing more be done than simply letting out the fluid, it will usually fill again, though occasionally it does not. To effect a perfect cure, the scrotum is injected through the same wound, after the fluid has all escaped, with some astringent solution. Cold water only is used by some practitioners, but more frequently a mixture of two parts port wine to one of water. Solutions of iodine and of hydriodate of potassa have also been used, and in some cases, the same fluid that was discharged, but the port wine and water appear to act the best of any.

The manner in which this injection appears to effect the cure is this : it excites a considerable degree of inflammation in the testicle, and also in the coats of the tunics, so that they grow together, and in this way the cavity in which the water accumulated is entirely obliterated.

In most cases, if properly performed, this operation is quite successful, causes but little pain, and is perfectly free from danger. In some instances, however, it is unsuccessful, owing to the fluid not being well injected, and occasionally there is much more inflammation caused by it than what is desirable, attended by serious constitutional irritation. The puncturing instrument, and the tube to convey the fluid, must be very carefully introduced, so as not to injure the testicle, but they must also be carried sufficiently far to insure all the water being discharged. The proper place to make the puncture is nearly at the bottom of the tumor, hehind; the fluid may remain in about five minutes, and about as much must be injected as was drawn out.

Sometimes a difficulty occurs in this way: after the fluid has escaped, the tunica vaginalis draws together, so that the opening into it does not correspond with the opening outside, and if the instrument has become displaced before the injection is thrown in, it is difficult again to introduce it. In fact, it is better if this occurs to leave off till another day, and operate again, for the attempt, if too often made, may cause serious and useless inflammation. There is also danger, if the instrument is put in again, that it may not go into the cavity, but merely into the substance of the skin, and the fluid is then thrown into the cellular tissue, and not only does no good, but may even remain and produce a real dropsy of the scrotum, or hydrocele cedematodes, the same as described under the head of the first variety.

In fact, some surgeons purposely perform the operation in such a way as to 
change the hydrocele into a simple dropsy of the scrotım, by letting the fluid into the cellular tissue, by simply introducing a needle. The new disease is certainly more easily cured than the former one, and the pressure of the water on the scrotum often prevents any more being secreter in the tunic, but still in many cases a cure is not effected, and sometimes is made more difficult. I would much rather advise the total discharge and injection.

This operation is very simple and successful in skillful hands, but often fails from want of skill or proper care. If too much inflammation follows, poultices must be applied and other simple means used to subdue it, and the patient must keep still. It must be borne in mind, however, that considerable inflammation is necessary, to effect a cure. I once knew a man who operated upon himself with a common penknife and a small catheter. He effectually discharged all the water, but knew nothing about injecting anything in return. At the end of two years there was but little accumulated again, and he thought so little of what he had done, that he said he should always repeat the operation himself, as often as might be necessary.

It is sometimes necessary to do this to young children, and it must be remembered that in them the testicle is much lower than in adults, and greater care is, therefore, needed not to wound it.

A simple dressing of mild ointment, or even of wet cloths is all that is needed after the injection is withdrawn.

Some practitioners have used setons, and others galvanism, to cure hydrocele, but though each method has been successful in some cases, yet they are not more so than the injection, which is much more simple, and causes much less pain. Either of these methods may, however, be tried, if that fails.

After the water is drawn off, the testicle should be carefully examined, as it can 'then be readily felt, because if there be any swelling of it, or any indications of cancer, the injection must not be thrown in till that has been beneficially treated.

In some persons the water will accumulate in spite of all, and it is necessary to discharge it frequently. In infants it will often disappear spontaneously, without any treatment, but it rarely does so in adults, though I have known some in whom brisk exercise alone would disperse it.

Sometimes this form of hydrocele is congenital, or exists from birth. In these cases the fluid descends from the abdomen, the opening between it and the scrotum, by which the testicles descended, not having closed. Many persons have been deceived by this affection, and have taken it for a rupture, but a little careful examination will soon disclose the truth. By gently compressing the tumor, the flu:d will rise into the abdomen, through the ring, and return again when the pressure is withdrawn. To a certain extent this trouble is more general than is supposed, and is frequently ascribed to wrong canses. It is advisable to have it attended to as early as possible, because there is danger, if left over the first month, of its continuing during the whole of childhood, or perhaps even till adult age, and leading to other derangements.

In the early stages, and sometimes even after it has existed long, it is possible to cure it in a very simple manner. The water must be gently pressed back into the abdomen, and then a truss or bandage of some kind must be worn, so constructed that the pad will press exactly on the ring, and thus prevent the fluid from returning. In a short time the passage grows up, and there is then no further danger. The period required to effect a cure varies much in different cases; thus in some it 
will be complete in two or three weeks, while in others it requires as many months, or even much longer. Cold lotions must be used in these cases as with adults.

In case of failure, with these means, which will sometimes happen, the only other remedy is the injection, the same as already described. The operation is precisely the same as for an adult, but must be conducted with more care, there being more risk of serious inflammation. It must be recollected also that while the injection is being made the upper part of the scrotum must be held firmly together, just by the ring, to prevent the injected fluid from passing up into the abdomen, which it would otherwise do, and perhaps cause serious trouble. A truss or bandage must be worn for some time after the operation, to prevent any more fluid coming down, and also to retain the bowels in their place.

Third Variety of Hydrocele. - In this form of hydrocele, as already explained, the seat of the watery effusion is not in the scrotum, but in the spermatic cord. It may occur in two ways, first in the substance, or cellular tissue of the cord ; and secondly, within certain cavities in the sheath or tube itself.

The first form of spermatic hydrocele is very rare, and is but seldom of much account. It is similar in its nature to the first form of hydrocele in the scrotum, or hydrocele cedematodes; in fact, it is the same disease only confined to the sheath of the spermatic cord. Its causes are also in all probability the same, and it requires the same treatment. When it results from general dropsy, which is usually the case, no cure can be expected until that is remedied.

The palliative treatment must consist in wearing a bandage and using cold astringent lotions, and it is but seldom that anything more is required. Occasionally, however, the swelling becomes so great as to cause serious inconvenience, and the patient insists upon having relief immediately. Under such circumstances the only mode of proceeding is to open the swelling, and so let the fluid escape. There is, however, some danger in this, and in most cases it is better not to perform the operation. Many persons have mistaken this affection for a small hernia, or a swelled vein.

The other form of spermatic hydrocele is usually termed encysted hydrocele of the spermatic cord, because the fluid is contained in one or more sacs. The swelling in this uase is in the form of an egg, and situated between the testicle and the groin. It is usually firm to the touch, with no fluctuation, and perfectly distinct from the testicle, which may be felt below it. Sometimes the sac of fluid is near to the ring, and can be pressed up into the abdomen, so that it will disappear, but only to return immediately the pressure is withdrawn. In such cases it may easily be mistaken for a hernia or rupture, unless proper care be taken. On examination, however, it will be found that the vessels of the spermatic cord can be distinctly felt, even when the tumor is down, by merely pressing it on one side, which is not the case in rupture. The functions of the bowels also are not interfered with in hydrocele, while they are very much so in hernia, when it is down.

Occasionally the watery tumor descends much lower than usual, and may then be taken for hydrocele of the tunica vaginalis. It is only requisite, however, to remember that when the fluid is contained in the scrotum it surrounds the testicle, which can scarcely be felt through it, but when it is contained in a sac, in the sheath of the cord, it is always either above or on one side of the testicle, which is quite separate from it.

The treatment should consist at first in fomentations, as directed for the other 
varieties, and in keeping the bowels perfectly free. This plan is the best one with children, who are often afflicted in this way. A mixture of two parts alcohol and one of water, is very good to use night and morning, or either of the recipes already given. With regard to internal medicines, they are perhaps less proper in this variety than in either of the others, but if thought necessary there are none better than those before advised.

Sometimes, especially in children, a small puncture may be made and the fluid let out, but in adults this is often of little use, as the sac fills up again. To prevent this the port wine injection must be used, or the sac must be fairly cut out. Some practitioners merely lance it open the whole length, and Sir Astley Cooper was accustomed to insert a seton, a plan which I have known to succeed frequently, both in children and adults. The particular plan to be pursued must, however, depend upon the circumstances of the case, and I should advise every one to hesitate about submitting to any operation, if they can keep tolerably comfortable, and get no worse without it, which they nearly always nan if they will persevere with the simple directions given, and wear a suspensory bandage.

In children the following lotion, applied freely two or three times a day, will in most cases cause the water to disperse without any further treatment :

R. Hydrochlorate of ammonia, one ounce; distilled vinegar, four ounces; water, six ounces.

The same lotion, with half the water, will also be excellent for adults.

\section{SARCOCELE, OR CHRONIC FLESHY SWELLING OF THE TESTICLE.}

This affection is the real swelled testicle, or chronic fleshy enlargement of the substance of that organ.

The causes that lead to this enlargement are various, and some of them not yet understood. Cancer and scrofula are perhaps the two most frequent causes, but it often arises when they do not exist, and when no other immediate agency can be detected. Sometimes a chronic swelling will take place in the testicle, and after existing for a considerable time, entirely disappear without any evil consequences. More frequently, bowever, the result is more serious, and a malignant tumor is eventually developed, either cancerous, scrofulous, or sarcomatous.

Sarcomatous Tumors are of various kinds, and are the same in the testicle as in other parts of the body. The most frequent kind is that called medullary, because it resembles the substance of the brain. It is a most dangerous affection, and unless attended to at the very earliest moment is nearly sure to be fatal. The whole substance of the testicle is converted into a kind of white pulp, similar in appearance to the brain, and in a short time the disease is propagated along the absorbents till it attacks all the neighboring parts. The glands in the groin soon swell to an enormous size, and slough and bleed, and eventually the lower part of the abdomen becomes affected in the same way till the parts are all destroyed and the patient sinks. This is thought by some to be the same disease as fungus hoematodes, and in many respects it closely resembles cancer. There is, however, sufficient difference between them to enable the surgeon to distinguish with ease, but to the patient the distinction is of little consequence, each being equally dangerous, and the treatment bejng the same for both.

Sometimes the mistake may be made of confounding sarcoma with hydrocele, 
unless a strict examination be made. In hydrocele, it must be recollected, the swelling begins at the bottom, and gradually extends upward to the abdominal ring, but no farther ; it is also semi-transparent, and fluctuating. In sarcoma, on the contrary, the swelling is evidently in the whole substance of the testicle at once, and extends upward into the spermatic cord; it is also not in the least transparent, and is much heavier than water. From want of attention to these points of difference the swelled testicle has often been punctured, to let out the water.

Cancer in the Testicle is precisely the same in its origin and progress as in any other part of the body. The testicle becomes the seat of a hard tumor, through which dart deep-seated lancinating pains, which shoot up to the loins, and down the limbs. Eventually this becomes an open sloughing ulcer, which destroys the substance of the organ, and gradually extends to the abdomen, causing a profuse offensive discharge, and a rapid impairing of the general health.

Scrofula of the Testicle. - This disease is scarcely ever met with except in those who plainly exhibit a scrofulous habit of body. It causes a swelling of the testes similar to that of cancer in its feel and appearance, but unaccompanied by any of the lancinating pains. When the tumor is cut into, it seems filled with a whitish or yellow substance like curds or soft cheese, along with a small quantity of pus. The commencement of this affection may be very slow and insidious, and for a long time, even after it has become fully established, nothing serious may be indicated. There is nothing to alarm the patient much till the tumor breaks open and becomes an ulcer, its progress then is often very rapid, and all the neighboring parts speedily become diseased and destroyed.

The causes of that peculiar tendency to scrofula and cancer which many persons exhibit are as yet unknown to us; they are, however, in all probability what is termed constitutional, and not produced by any accidental agency after birth, though there may be many causes that will excite or call out these diseases, when they would otherwise have remained dormant, either for a longer time or perhaps altogether.

The treatment of the various forms of sarcocele above described may be given in a few words, for unfortunately but little can be done with them.

In some few cases of simple swelling, of the medullary or fatty character, it may perhaps be dispersed, in the very earliest stages, by using leeches and cold lotions or mercurial ointment externally, with mercury and iodine internally, but this can seldom be depended upon. Unless such means evidently decrease the swelling immediately, no further time should be lost with them, or the chance may go by of doing good by other means. The removal of the testicle, by an operation, offers the only chance of effecting a certain cure, and this is of no use either unless performed at first, for if the disease has progressed till the neighboring parts are attacked, the removal of the testicle will not check it. Unfortunately, many patients delay having this necessary operation performed till it is too late, and they then conclude it is in itself of no use. It must be borne in mind that some of these cases are very rapid in their extension, and that the surrounding parts may be deeply affected without giving any sign of it. In cancer, especially, it is necessary to operate as early as possible, for even when the testicle itself shows but slight signs of the disease, it may have extended to the loins and abdomen. There have undoubtedly been many cases of sarcocele, of all the above kinds, that have been entirely cured by removing the testicle, and which have never appeared again.

In general only one testicle is diseased, and that only needs removing, though 
there is danger of both becoming affected by delay. The operation itself is comparatively simple, and not attended with so much pain or danger as many might suppose it to be.

It is very common, as before remarked, to find sarcocele accompanied by hydrocele, and frequently, on evacuating the water in hydrocele, the testis is found enlarged, though there were previously no signs of it.

It is generally conceded that blows or other violence may produce simple induration or hardness of the testicles, leading to medullary or fatty tumors, but not to cancer or scrofula, though they may excite such diseases to break out. The too frequent irritation of bougies and injections is also suspected of injuring in the same way.

\section{FUNGUS OF THE TESTICLE.}

This affection is different from either of those previously described, though it has some resemblance, at certain stages, to cancer. It is fortunately more capable of being beneficially treated, however, and is not so likely to extend to other parts.

It is supposed to be caused by bruises or other violence, or by gonorrhœa and gleet, particularly when injections have been used. The first indication is a simple swelling without pain, which bursts and forms an abscess discharging pus, and from the opening a fungus begins to protrude. This fungus may attain an immense size, if not removed, extending to the abdomen and becoming very virulent. The discharge also may become so profuse as to cause much general debility and constitutional irritation.

In the first stages of the swelling, when it is known to arise from external violence, it may sometimes be reduced by leeches, warm fomentations, and poultices, with purgatives used internally, and even after the abscess has opened fomentations and poultices may be sufficient to prevent any extension of the mischief. When the fungus has appeared, these simple means become useless, and resort must be had. either to caustic or the knife to remove it. In my opinion, the caustic is the best; remedy, and seldom fails to remove the diseased growth without any injury to other parts. If the disease has not progressed too far, it may often be cured without injuring the testicle at all, though it was formerly thought necessary to castrate in every case, and some practitioners even do so now.

I once knew a man who had one of these fungous growths, arising from a bruise, who was cured by the daily use of powdered burnt alum, dusted over the fungus, and followed by a warm linseed poultice. This was done morning and night, and by these means only, combined with the use of simple purgatives, and the solution of hydriodate of potassa internally, as directed for hydrocele, he fully recovered in about six weeks. The testicle, however, remained hard, and in all probability its power was lost.

In all cases of bruising, or other violence, the timely use of rest, poultices, and warm fomentations, may prevent many of these evils.

There are several other kinds of tumors and swellings of the testicles occasionally met with, besides these mentioned, but they do not differ essentially, either in their nature or treatment, and often it is scarcely possible to distinguish between them. One peculiar form of cancer is frequently met with in England amongst chimneysweeps, and is caused by the irritation of the soot lodged in the furrows of the scrotum. It is met with sometimes, but rarely, on the hand or foot. It is commonly termed the sweeps' cancer. 
HERNIA HUMORALIS, ORCHITIS, OR INFLAMMATION OF THE TESTICLES.

This sometimes appears to arise from some unknown constitutional cause, and comes on very slowly, but more usually it is from some obvious agency, and assumes from the first an acute form. It arises frequently from blows, falls, hard riding, and strains, but most generally from the use of injections and bougies, in gonorrhoea and stricture, or from the performing of operations like those for hydrocele. I have also known it to follow intense sexual excitement, where gratification was impossible and the semen had no tendency to escape involuntarily. In children it very frequently follows or accompanies the mumps.

Inflammation of the testicle usually commences with slight pain and soreness in the part, attended by swelling, which is at first soft and yielding, but gradually becomes hard, and sometimes hot and very painful. The scrotum loses all its rough ness by swelling so much, becoming smooth and red, and occasionally so tender that it can scarcely be touched. As the inflammation progresses, the swelling extends up the spermatic cord, and severe pain may be felt in the loins, and sometimes even in the limbs, till the patient suffers the most excruciating agony.

In many, even of the most severe cases, but little pain is experienced, and the inflammation will subside, under proper treatment, leaving no evil effects whatever behind. There is danger, however, of its being followed by abscess, or hydrocele, if neglected, even if it does not excite tumor or fungus. A loss of sexual power is also apt to follow inflammation of the testicle, either from its deranging the structure of the organ, or from its obliterating the passage in the vas deferens, and thus preventing ever after the passage of the semen from the testicles to the urethra.

Orchitis arises much oftener from gonorrhœa than any other cause, the inflammation extending from the urethra, along the vas deferens, till it reaches the epididymis, and finally the testicle. The epididymis is always first attacked in these cases, and very frequently the disease extends no further, when it is called an epididymitis. If it reaches the testicle, it is then called hernia humoralis.

When the inflammation accompanies gonorrhøa, it will generally be found to arise whenever the discharge is suddenly checked, and immediately the discharge is allowed to return the inflammation ceases. This shows the close sympathy there is between the urethra and the testes, and what danger there is in irritating the urethra in any way. I have known inflammation of the testes arise in one hour after using a strong injection.

The treatment of this severe affliction must consist, in the first place, in perfect rest on the back, the scrotum being supported by a suspensory bandage or truss. Cold lotions must be freely and frequently used, and the bowels opened regularly with salts or castor oil. No stimulating food or drink must be taken, and the mind must not be agitated, nor the feelings excited in any way. The best lotion is a mixture of half a pint of water to half a pint of alcohol, with a large spoonful of laudanum added. If the pain be very severe, this lotion may be made hot, or a hot linseed or bread poultice may be applied. A hot bath is also frequently of service.

A perseverance in these means will usually reduce the inflammation and pain in one or two days, unless the exciting cause continues to operate. In very severe cases, however, particularly those from bruises, it may be necessary to apply leeches, or to open some of the veins of the scrotum, which nearly always gives relief if the blood flows freely. If the pain be so bad that the patient cannot rest. he may take twenty 
or thirty drops of laudanum at bed-time, in a little flax-seed tea or barley-water, or in simple water alone if these are not to be obtained conveniently. The following pills are the best for this purpose, however, when they do not disagree with the stomach, which unfortunately they are apt to do, but they may be tried:

R. Opium, with soap, twenty grains; camphor, half a drachm; to be made up into twelve pills, with as much simple mucilage as may be requisite. One of these may be taken every six hours if required.

The following ointment, applied externally, may also give great relief from pain when the lotion fails to do so:

R. Belladonna ointment, two ounces; camphor, one drachm; paregoric elixir, one drachm.

This must be mixed into an ointment, and a portion rubbed carefully over the tender parts as often as the pain becomes severe.

When the inflammation has been fully subdued, there is danger of the testicle being left permanently hardened, or indurated, which is nearly sure to destroy its power, if it does not originate other diseases. To prevent this, if the slightest hardness remains, it must be frequently bathed with hot water and poulticed, or if these fail, it must be rubbed with the camphorated mercurial ointment. Galvanism has been used with success when the hardness resisted all other means, and as it is a safe remedy it may be always tried. The only internal medicine likely to be of use is the solution of hydriodate of potassa, before directed, and even this should be but seldom taken. The regular use of the camphorated mercurial ointment, followed by hot fomentations, is the most generally successful treatment.

The best remedy in some cases of acute orchitis, particularly when arising from the sudden stoppage of a gonorrhœal discharge, is compression. This is effected by means of strips of sticking-plaster, which are stuck firmly around the organ, and also passed underneath, the pieces being about a quarter of an inch wide, and long enough to go round and meet. These of course cross each other, and when drawn pretty tight, and made to adhere fast, they press considerably, and draw the whole organ together. The parts require to be shared to apply them, and they must be reapplied as often as they work loose, or as fast as the swelling shrinks. In most cases, the patient experiences great and immediate relief from this application, owing to the support it gives; it must always be used, however, with the suspensory bandage.

Compression is, in general, only appropriate in cases of acute orchitis arising from gonorrhœa, though it may be advantageously resorted to, in some few instances, when it originates from other causes. I have used it when the swelling arose from intense sexual excitement, and also in one or two instances from blows, and with advantage; but generally the treatment before given will obviate the necessity for compression if it be persevered in. Latterly, the compression has been effected by means of collodion, a substance made by dissolving gun-cotton in ether, which sticks much more forcibly, and is applied more readily.

The symptoms of epididymitis are the same, and so is the treatment, as when the whole organ is attacked, which it is nearly sure to be eventually if the epididymitis continues.

There is always reason to fear that a severe attack of orchitis will permanently injure the testicle, more or less, by obliterating some of the seminal tubes, even if it does not close the ros deferens, or harden the epididymis. One testicle, may, however, be inflamed, and suffer, while the other remains perfectly sound. After having 
been once inflamed, the testicle appears more susceptible of the same misfortune again, so that those who have suffered from it should be as careful as possible to avoid subsequent attacks, or the evil effects will probably increase each time. Impotence not unfrequently follows orchitis.

Sometimes the inflammation ends in suppuration, the matter escaping by numerous little sinuses or openings, which eventually close and heal when all is discharged. In all these cases, however, the testicle is more or less wasted, and sometimes entirely destroyed. At other times, the pus will not discharge at first, but assumes the form of a firmish curdy mass, similar to the substance of the brain, and remains for a long time. The organ is then much more liable than before to inflammation, and its internal structure gradually undergoes a change by which its secreting powers are totally lost. In some of these instances, the testicle becomes nearly as hard as a stone, and on being dissected appears much like cartilage or bone.

In some persons acute orchitis much resembles rheumatism, being affected by the changes of the weather or by exposure, and coming and going again in a short time. Indeed, some writers speak of it then as rheumatism of the testicle, and treat it the same as that affection in other parts of the body. I have known some men so extremely sensitive in this organ that an attack of orchitis was sure to follow if they merely pressed the testicles on crossing the limbs, and especially if they rode on horseback. In fact, many a severe case has arisen from being thrown forward upon the pommel of the saddle.

Inflammation of the testicle sometimes appears in very young infants, not more than a few days old, and without our being able to assign any cause. I have thought sometimes that it arose from teething, and at other times from an improper mode of carrying the child, by which these organs were bruised. I saw one instance wherein the inflammation, which was very severe, appeared on the day of birth. In general, these infantile cases can be cured by simple fomentations, or cold lotions, with a dose or two of castor oil. When very severe, a leech may be applied, and three or four grains of the powder of mercury and chalk given. When arising from mumps, it, usually subsides when the primary cause is removed, though it may remain afterward, and must then be treated as above advised.

It is somewhat disputed among medical men whether these inflammations in infants ever permanently injure the testicle or not, but I am persuaded they often do so, and, in all probability, many a man has been made impotent for life by this affection when a child. It is, therefore, of the first importance not to neglect this trouble, though it may be but slight, as the after effects may be serious.

It is proper to remark here that the mumps arise in adults as well as in children, and that they may affect the testicles, and cause impotence, as well at one period as at another. Such cases as these afford a singular proof of that remarkable sympathy which exists between distant parts of the body, but the nature of which we cannot explain.

Either of the following recipes give excellent cooling lotions, applicable to all cases:

R. Lime-water, one ounce; alcohol, seven ounces ; mixed together.

R. Hydrochlorate of ammonia, one drachm; cold water, five ounces; alcohol, one ounce ; mix together.

The last lotion is an excellent one to apply to the scrotum and perineum. In many persons, however, hot fomentations succeed much better than cold lotions. 
It is often very beneficial, particularly when the pain is severe, to cause a little nausea or vomiting; for which purpose a quarter of a grain of tartar emetic may be given every three or four hours, till the effect is produced. This frequently gives great relief, and in a short time, when all other means fail.

In very obstinate cases, attended with pain, two or three grains of calomel should be given, at bed-time, mixed with eight or ten grains of Dover's powders. This may be given two or three times a week.

It is sometimes a good plan to use the plaster of ammonia and mercury to strap the testicle with, in the manner before described, so as to gain the advantages of compression and the effects of mercury together.

If the inflammation and tenderness all subside, but the swelling and hardness continue, the following solution may be rubbed over the scrotum every three or four days :

R. Iodine, one drachm; iodide of potassium, half a drachm; alcohol, one ounce ; dissolve all together.

In many persons, particularly those of a scrofulous habit, acute orchitis has a tendency to assume the chronic form, after the first severe symptoms have subsided, and this is perhaps a worse state than the other. In chronic orchitis a deposit of yellowish matter takes place, in different parts of the testicle, at first soft but gradwally becoming harder, till at last the organ feels like a stone. This matter blocks up the seminiferous tubes, and destroys their power of secretion, so that impotence ensues. It was formerly the custom to call such cases schirrhus, but this is improper, as it might lead to the idea that they assume a malignant form, which is not the case. Chronic orchitis may either follow from the acute form, or it may arise spontaneously, like scrofulous affections of other parts ; and it also frequently follows a long course of intemperance or licentious indulgence, and may even be produced by the long-continued and injudicious use of mercury.

This form of the disease may give rise to but little inconvenience for a long time, though the swelling may be of considerable size, unless a blow or strain be experienced, when the symptoms become immediately acute, and relief is sought for. Usually in a few weeks the swelling is observed to point in some particular part of the scrotum, and eventually it breaks, discharging some pus, together with a fungouslooking body, which appears rough and bleeding. In a short time the opening enlarges, and more or less of the testicle itself passes through, the whole forming a granulated tumor of a yellowish white color, studded with pale red or black patches. This tumor is tightly embraced round its neck by the edges of the opening through which it passed, and which become very thick and red. A thin watery discharge flows from it, often mixed with semen, but rarely with blood.

As soon as this break occurs, and the parts pass through, great relief is felt, and the disease may remain for a long time without undergoing any further change. The tumor itself is rarely tender, but may be handled, cut, or burnt with caustic, with but little inconvenience. It is not unusual to find this singular protrusion in scrofulous children who have had inflammation of the testicle.

It was formerly the custom always to remove the whole testicle when afflicted with this fungous growth, but now the practice is seldom resorted to. The protruding part is cut off with the knife, or burnt off with caustic, and the skin of the scrotum being then brought over it, the wound is healed, and no further trouble is experienced. In many cases a cure is even effected spontaneously, or by means of a 
simple wash of six grains of nitrate of silver to one ounce of water, with some inter. nal alterative medicine.

The best medicine in chronic orchitis is blue pill, five grains of which should be given every night, with one grain of opium, till the gums feel a little sore.

In some cases a better treatment is to administer the compound extract of sarsaparitla internally, and sprinkle the fungus itself with equal parts of powdered savin and sulphate of copper, occasionally varying the medicine by giving a little of the wine of iron, particularly if the patient be weakly and sinking.

It must be admitted, however, that inflammation of the testicle is, in any form and under any mode of treatment, a disease extremely dangerous to the patient's sexual powers, though it may not compromise his life, nor interfere much with his general health.

\section{OSSIFICATION OF THE TESTICLE.}

In some few cases, the testicle has been known to ossify or become more or less converted into bone. The causes of this degeneration are unknown, and unfortnnately we know of no remedy. I have thought, in some few cases I have seen, that it was more likely owing to excessive continence than anything else, but it is impossible to decide.

The ossification generally commences in the middle, and may be felt like a hard kernel, which gradually extends till the whole organ is affected. In all cases when a hardness of this kind is felt, immediate resort should be had to fomentations and poultices, because it may be but a simple induration which they will remove.

It is probable that ossification and induration most frequently arise from orchitis, particularly when there have been many consecutive attacks.

\section{ARREST OF DEVELOPMENT AND WASTING OF THE TESTES.}

The testes, like other parts of the body, are liable to be arrested in their development, from causes unknown to us, and this arrest may either be permanent or the development may be completed at some after period of life. I have known instances of men, at various ages, with testes remarkably small, and passions nearly dormant, in whom a sudden development took place from the sight of some female who excited their desires to an unusual degree. In all probability these persons would always have remained as they were, but for this occurrence, as many others similarly circumstanced do; and we have thus a proof of the decided influence that the awakened feelings may have on physical development.

In one instance where I was consulted, in a case of this kind, the left testis was about the size of a small hazel-nut, and the other still smaller, the person being abont twenty-eight, and possessing the usual feelings of his sex, though in a slight c'egree. Many circumstances induced me to think that the organs were healthy, and that in all probability their further growth would ensue, under proper treatinent, and from the new impetus given to his desires by his wish to marry. I, therefore, advised a stimulant plan of treatment, similar to that which will be directed in a subsequent article, and advised him to wait patiently. The result justified my opinion; the organs began to enlarge very soon, and in two years' time were of full average size, so that he had no misgivings whatever about marrying.

It is very often the case that persons who had scrotal hermia in childhood have 
the testes small, owing to the pressure on the cord of the instrument worn to cure it, and with some who have had mumps their full growth is never attained.

Any causes that prevent the full supply of blood from going to the testes will prevent their growth, or cause them to waste, and it is in this way that many such cases arise. If the spermatic arteries be small, which supply them with blood, they do not receive sufficient nutriment, and, therefore, cannot grow nor secrete much semen. These arteries are very long, and exposed to several eauses of injury as they proceed through the abdomen, so that they frequently become more or less injured, and the testicles suffer in consequence. Sometimes they are pressed upon by the other parts, in passing through the ring, and at other times they are affected by aneurism, or their walls thicken and partly close up the passages. In old people, the spermatic arteries are very apt to become more or less obliterated, and this is the chief cause of that wasting of the testes so often seen at that period of life. To fully prove this, the spermatic artery of a dog has been tied, leading to one of the testes, and that in a short time was completely wasted away, while the other remained perfect. It has even been proposed to perform this operation, which is comparatively simple, instead of castration, when we wish to destroy the procreative power in animals. Such facts make it erident that the power of the testes, and consequently the amative propensity of any man, depends materially upon the size of the spermatic arteries - probably much more so than upon any peculiar structure of the brain. It is certain that if these arteries be destroyed in early life, no amativeness can ever be felt, nor any procreative power be established. A knowledge of this fact teaches us that the extent, both of the power and the propensity, is very much, if not entirely, under our control, if the supply of blood admitted to the testes can be duly regulated. This is a point never before attended to in medical practice, that I am aware of, but I have satisfied myself of its correctness by repeated experiments, and I look upon it as being of the greatest value. There are many means by which the amount of blood flowing to the testes may be regulated to a great extent, some of them increasing and others decreasing it, as I have shown in many of the cases described. It is often the case that badly-fitted trusses, by pressing on the arteries, will cause the testes to waste, while, on the contrary, an ill-made suspensory bandage, or even tight clothing, by chafing the parts, will draw the blood to them till they are intensely excited, or even till inflammation ensues. This shows us what principle to act upon in practice, adapting the appliances to the peculiar circumstances of the case. Hot stimulant applications will bring the blood to any part, while cold astringent ones will drive it away, and these alone, judiciously used, will often accomplish more than all the internal medication, or mere moral chiding ever yet tried. Besides these, however, there are various other means, mechanical and medical, which will be described as we proceed, and sometimes instruments may be constructed, for special cases, that will effect almost miraculous results.

I have sometimes used a modification of the instrument called the congester, Wich will be described in a subsequent article, for the purpose of drawing blood to the testes, and of enlarging permanently the spermatic artery. In short, all the means resorted to for causing an increased flow of blood to the penis may be used, to a certain extent, and in a modified form, to the testes. As before remarked, I have had numerous patients, of all ages, whose testes had always been too small and inactive for the performance of their functions, and yet, by appropriate treatment, most of them have attained their proper growth and full powers. 
Wasting of the testes, after they have been of a proper size, is a much more serlous matter, as it usually results from some disease that is likely to permanently destroy them, though occasionally the causes of it are under our control, and the loss may be repaired. In addition to all the causes above enumerated that prevent development, we may also enumerate hydrocele and hæmatocele, of long standing, and also scrotal hernia, all of which may cause the testes to waste, by the continued pressure which they exert. Spermatocele will also lead to the same result, as stated in the article on that disease. Too long-continued and strict continence will also waste the testes in many persons, notwithstanding what is said to the contrary by some writers. These organs can no more preserve their powers when entirely unused than others can, nor is it in any way conducive to their health to leave them totally inactive. I am aware that it has been said that those who take vows of celibacy still preserve these organs, and in full development, but that has very little weight, because no one can tell what may have been the actual observance of those vows, nor how far involuntary action may have taken place. I am myself fully convinced, from numerous observations, that total inaction of the testes, in every form, is most pertainly followed, in most cases, by their wasting and decay. I have known men who boasted that they were strictly continent, and had been so for years, without any apparent injury of this kind, but on proper examination I have satisfied them that the semen passed almost constantly in the urine. It is scarcely necessary to say that much an action was unnatural, and decidedly injurious. The assertion, made by some theorizing physiologists, that the semen, when not discharged, is absorbed into the blood and invigorates the system, is unsupported by a single fact, or even by plausible reasoning, and therefore requires no refutation. Many a man who has prided himself upon his immaculate purity, and denounced those who were unable or unwilling to totally abstain, has been himself the victim of a constant pollution, both unpleasant and injurious. True virtue consists in a proper use of those powers given to us, and not in their total abrogation.

There are several causes of a nervous character that will also lead to wasting of the testes, such as paralysis of the lower part of the body, or injury of the spine in the neighborhood of the nerves leading to them, and sometimes even long-continued anxiety of mind. The most frequent causes, however, are prokably inflammation and the mumps, particularly in early life. Excessive indulgence not unfrequently ends in gradual wasting, and masturbation still oftener, especially if accompanied by intemperance in strong drink. I have known intense excitement followed by inflammation and subsequent wasting in a very short time, and $I$ have known inebriates wake from their dreams of intoxication to find themselves impotent, in numerous instances.

There are some drugs which exert an influence this way occasionally, and to a very marked degree. Mercury will in some, if long continued, so will opium, and iodine still more frequently and decidedly. It is, therefore, the duty of the physician to watch well the effects of all such remedies. Tobacco, I am satisfied, is decidedly injurious to many men, and when used to excess, will impair the tone and energy of these organs to a great extent; in several instances, I have had good reason to attribute wasting of the testes to its influence.

Injuries of the head must also be enumerated as occasional causes of wasting of the testes, though we cannot explain why. Several instances of the kind have been noticed, particularly by army surgeons, and the fact is established beyond doubt. 
Baron Larrey gives a remarkable case, which came under his own notice. It was that of a soldier, a healthy, robust man, with strong sexual propensities and endowments, who had a portion of the back part of his head eut off by a saber blow. He recovered from the wound, but lost the senses of sight and hearing on the right side. Pain was also experienced down the spine, and a peculiar creeping feeling in the testicles, which also began to waste, and in fifteen days were no larger than beans. He completely lost all desire for sexual enjoyment, and apparently even all remembrance of it. M. Lallemand also mentions a case, of a French soldier similarly injured in the expedition to Algiers, who speedily experienced wasting of the testes, loss of sexual desire, and all power of erection.

Bruises of the testes are nearly certain to be followed by inflammation and wasting if severe, and few injuries cause more acute physical suffering, or affect the system more generally. Sickness, vomiting, and death-like fainting generally result from bruises of these organs, and sometimes even delirium. Constant pressure, from almost any cause, even though slight, will also cause wasting, as is seen in many persons who pass much time on horseback. It was even the custom formerly, in Turkey, to make eunuchs by squeezing the testes instead of castrating, and some persons operate upon animals in the same way now when they wish to emasculate them, the squeezing causing them to waste away. Cutting these organs with sharp instruments, so as not to bruise them, may not be followed by any evil effects whatever. Many instances have been known of their being cut and torn considerably, both by accidents and luring surgical operations, but with no detriment to their powers, unless inflammation or mortification has ensued. Fanatics and insane people have injured themselves in this way frequently.

In Lapland, those among the male reindeer which are not needed for pairing, have the testicles destroyed while young, by the old women, who chew them with their gums till they are all broken up. This is done in place of cutting them out at a later period.

All that we can do in these cases of wasting of the testes is to find out, if possible, the immediate or exciting cause, and remove it. Vory frequently, however, no cause whatever can be ascertained, and often when it can e it is not under our control. Still no such case should be left unattended to, and its treatment, if any be thought advisable, should not be neglected a single day.

\section{TUBERCULAR DISEASE, OR CONSUMPTION OF THE TESTICLE.}

This is essentially the same disease as consumption of the lungs, being characterized by the production of tubercles in the substance of the organ, which eventually suppurate and break, and entirely destroy its substance. In most instances, the patients are either decidedly scrofulous or evidently disposed to consumption, and generally both testes are attacked, either together or consecutively.

The symptoms are usually a slight uneasiness, in some particular part of the testicle, which is soon followed by violent swelling, either in the body of the organ or in the epididymis, but with very little acute pain, if any. The swelling feels uneven, or studded with little lumps, one of which eventually projects and bursts, discharging a quantity of pus, and thick curdy matter of a yellowish color. It may, however, be a year or more after the swelling occurs before it breaks, though when one opening is formed others are apt to follow. The opening evidently communi- 
cates with the interior of the organ, and after venereal excitement it is not unusual for semen to flow from it, along with the pus.

In some few cases the tubercles will heal, and the wound close, leaving the testicle only partially wasted, but more frequently they continue to discharge till it is all completely gone, or till the whole system is so affected that death ensues. Occasionally the whole testicle will pass through the wound, and will remain protruded till it is entirely gone.

This affection occurs sometimes in children of a scrofulous habit, and completely destroys the testes in a short time.

The treatment must depend upon many circumstances, such as the patient's age, general health and habit of body, and mode of life. As a general ruie, it must be constitutional, or calculated to act on the whole system, so as to induce a beneficial change in its action. The alterative medicines are therefore most to be relied upon, such as mercury, iodine, and sarsaparilla, and in cases of tonic debility iron must be administered. The diet, air, and climate, also exert much influence. Consumptive people are always more or less liable to this affection, and I am persuaded that in many it exists sufficiently to impair the power of the organ; and cause partial impotence, eren when it does not proceed to the suppurative stage.

\section{FOREIGN BODIES IN THE SCROTUM ALONG WITH THE TESTICLES.}

Sometimes little round bodies like peas are found in the tunics, composed of firm cartilaginous matter or bone. I have seen one as large as a marble, and hard as ivory. It is seldom there are more than three of them. The origin of these bodies can only be conjectured, though they are probably only diseased secretions (like those sometimes found in the joints), which were first attached to the tunics, and then became loose.

Worms, hydatids, and other living beings are very rarely met with, though they have been occasionally.

In some instances the scrotum has contained the remains of a fretus, which had evidently descended from the abdomen along with the testicle, as explained in a former article.

\section{NERVOUS AFFECTIONS OF THE TESTICLES.}

The testes, like other parts of the body, are subject to several kinds of nerrous affections, which frequently cause exquisite misery, though they may not lead to any positive injury.

Irritable Testis. - This is a form of nervous disease in which the testis is in a constant state of peculiar uneasiness and irritation, rather than acute pain, though sometimes it is more painful in one particular spot. It is so exceedingly sensitive that the touching of the dress, or the mere rubbing of the scrotum against the limbs, causes such distressing annoyance that the sufferer dislikes even to move. Sometimes the irritation extends up the cord, so that the movements of the bowels, or the passage of urine, become exciting causes, and the patient cannot even cough without an increase of his misery taking place.

In some cases this morbid sensibility affects both testes, and in others only one, which is usually the left. It does not appear to cause any alteration in the parts, nor swelling, except occasionally a little fullness, particularly of the cord, and some 
relaxation of the scrotum. It is seldom that an attack passes off verr scon, but more usually it lasts several months, during which the sufferer loses all relish for society, and almost all capability for enjoyment in any form. All his thoughts are fixed upon his sufferings, and the idea takes possession of his mind that he will never be better, or that he will be impotent, or die of cancer, and some request their physicians to castrate them, to avoid these dreaded evils.

The causes of this distressing affection are partly constitutional, it being chiefly met with in those who are naturally weak, irritable, and disinclined to physical exertion, or to be hypochondriacal and dyspeptic. It is, however, produced, in most cases, by some derangement of the genital organs themselves, more especially such as are brought on by masturbation, excessive indulgence, or involuntary emissions. Young persons of a nervous habit and strong sexual feelings, are also liable to it while unmarried, and I have been consulted in many such cases which could not be benefited by any kind of treatment till marriage took place. In a modified form it is often experienced about the period of puberty, in consequence of the great and unusual activity of the organs at that time, and much evil may result if a word of advice and caution be not then given. The young person will in all probability discover that a temporary relief can be obtained by the vicious practice of self-indulgence, and not knowing that this will really increase the irritation, eventually he goes on with the practice till his health is seriously im. paired and his sufferings aggravated almost beyond endurance.

The treatment of irritable testis depends in a great measure upon the peculiar condition of the patient, and the state of his general health. In many cases it is so entirely of a nervous character that we need merely advise a change of air and scene, or cheerful company, or some interesting mental occupation, in short, anything that will arouse the sufferer to activity, and turn his thoughts away from his affliction. If he be dyspeptic, it is essential that his digestive organs should be attended to, and if he be costive, which is often the case, the bowels must be brought to a more regular state before improvement can even be hoped for. In cases where there is great debility, tonics must be used, such as the steel drops, or Peruvian bark, and a generous diet must be advised, with a little wine. The use of cold water externally is of the very first importance, as it gives tone to the parts, and removes the morbid sensibility, more perhaps than anything else. The parts should be freely bathed with it two or three times a day if possible, or at least night and morning. In obstinate cases, a plaster of belladonna ointment may be placed over the whole scrotum, or laudanum may be used as a lotion. A good suspensory bandage is also very fre. quently of great service.

In addition to any treatment, however, and still more essential, is a knowledge of the cause of the trouble. If any of the abore-named practices are persisted in, or if the patient's situation in life is unsuited to his temperament, no great good can possibly result from medical treatment alone. These things must therefore be spoken of, either to the patient himself or to his guardians.

It is not necessary to perform castration for this disease, as it is for some others, because it is not a serious one, and generally either subsides of itself in time, or can be relieved by appropriate treatment.

In one instance, a gentleman was affected with this morbid irritability, in one o: his testes, just before the time appointed for his marriage, and was so convinced that it was but the beginning of a greater evil, that in spite of all advice to the contrary, 
he insisted upon having the organ removed, which was done. Directly after, however, the other began to be as irritable as the lost one had been, but this of course he was not so desirous of parting with, and therefore bore with the trouble. He was married and had no further trouble afterward. The removed testicle was perfectly healthy and sound.

Neuralgia of the Testes. - This is a nervous disease of a much more serious character than the one already described, and more difficult to treat. It is characterized by acute pains, sometimes lancinating and at others dragging or pricking, which are usually accompanied by spasms of the cremaster muscles by which the testes are drawn forcibly up to the groin. In general these pains come on periodically, as in other cases of neuralgia, and between the paroxysms the testes are often perfectly free from pain, even when handled, though there is occasionally a little morbid sensibility in them, with perbaps a little soreness on the edge of the hip-bone. The attack may last only a few minutes or many hours, and is usually confined to only one testis; some patients have it come on twice a day, others once a day, and some again only once in several days. Some are affected with sickness and vomiting, and others with shiverings and cold perspirations, while others again experience such intense agony that they roll upon the ground and groan, or perhaps faint away.

In nearly every instance when examinations have been made of the testes so afiected, after their removal, no alteration whatever has been detected in their structure, nor any indication of disease to which the neuralgia could be ascribed. In some long-continued cases, where the pain has been great, there has been a little 6welling and inflammation, but this is rare.

The causes of neuralgia of the testes are but little known, or rather, perhaps, not known at all. It is met with at all ages, and in almost every variety of constitution, though most frequently attacking those who are subject to derangements of the digestive organs. It very often appears to result from some disease of the testes, particularly orchitis, and from varicocele, or disease of the kidneys. Many persons experience it from gravel, and still more from the passage of a stone from the kidneys to the bladder. Gouty subjects are liable to it, and so are those affected with enlargement of the prostate gland.

In the treatment of neuralgia of the testes, the first thing is to ascertain if there exists any other disease, which may possibly cause it. The digestive organs must be attended to, and the patient must be advised to avoid all causes of mental disquiet, or nervous agitation. Internal medication is seldom of much use, though in some cases relief is obtained by taking iron, in various forms, particularly the pills of the carbonate of iron, and if the attacks be regularly periodical, quinine may be of service, in doses of five grains, three or four times a day. Turpentine is occasionally very efficacious, in the following form:

R. The yelk of one egg; oil of turpentine, three drachms; syrup of orange-peel, and syrup of tolu, of each two ounces; laudanum, one drachm.

These are all to be well mixed together, and three table-spoonfuls to be taken daily.

Warm fomentations of hops, or poppy heads will sometimes benefit, but at other times ice-water will be still better. A blister may be put upon the scrotum, if all other means fail, and a quarter of a grain of morphia placed on the raw surface. A belladonna plaster will sometimes relieve, or an ointment composed of one grain of aconite to one drachm of lard, rubbed over the parts twice a day. The tincture of 
aconite is sometimes still more efficacious when rubbed on the scrotum with a sponge, and will often so benumb the parts that no pain will be felt for hours. Twenty or thirty drops of laudanum are sometimes beneficial, internally, and the following preparation still oftener :

R. Extract of hyoscyamus, five grains; acetate of morphia, half a grain ; to be taken twice a day.

Neither bleeding nor mercury appears to be of any use in this disease, but galvanism, properly applied, is frequently of great service.

When the disease is too severe to be borne, or seriously affects the patient's health, if all other means fail, castration may be performed. It should not be done prematurely, however, nor without due consideration, for sometimes the disease will subside spontaneously, after enduring a long time; and even when the operation has been performed the neuralgia has often remained in the cord as severe as ever. I have known the disease remain for two years, causing the most agonizing suffering nearly the whole time, and then go off and never return.

Several cases of this singular disease have lately come under my care, and in no two of them has the same treatment been beneficial. Each one has had to be studied and prescribed for separately, but in none was an operation necessary.

In all cases of severe pain, the hypodermic injection of morphia is the best mode of giving relief. It is applicable in swelled testicle, and all other diseases here described. The operation is simple, and once instructed, the patient can perform it himself.

\section{SPERMATOCELE, OR SWELLING OF THE TESTES FROM ENGORGEMENT OF SEMEN.}

It is very seldom that this affection is met with, though it sometimes occurs from obstructions in the vas deferens and urethra. It may also arise in falling of the cord, from its becoming twisted or knotted, and from swelling of the prostate gland, causing pressure on the ejaculatory ducts. The symptoms are swelling and heat in the testes, with a distinct sense of fullness in them, and aching pain. There is also usually considerable priapism and intensity of sexual desire, but not always.

The treatment consists first in removing all causes of obstruction, if any exist, and then in cold lotions and rest, with purgatives. Sometimes spermatocele is met with as the simple result of undue continence, but this is rare. The effects of it, if long continued, may be inflammation of the testicle, with hydrocele, and ultimately complete impotence. If the means above directed do not give relief, leeches may be applied to the perineum, or general bleeding may be practiced from the arm. The diet should also be very spare and simple, and the drink cold water. The mind must not be allowed to be idle, nor the imagination too much excited, and the body must be inured to regular and brisk exercise in the open air. If, notwithstanding all these, the trouble still continues and threatens to be serious, nature indicates but one more mode of relief, which is sure to succeed. In very obstinate cases of spermatocele, the pressure of the semen has been known to burst the seminiferous tubes, and I am persuaded from what I have seen that it frequently injures the structure of the testicle. I once saw the testicles of a young man dissected, who died in an epileptic fit brought on by an intense struggle to suppiess all sexual desire. They presented the most confirmed case of spermatocele perhaps ever seen, being engorged with semen till much larger than the natural size, and evidently in a state of chronic 
inflammation. The tubes were blocked up with hardened semen, almost of the consistence of cheese, and many of them were broken and run together. In a short time the structure of the organs would have been completely destroyed. The vas deferens and epididymis were also engorged in the same manner, and in many parts were beginning to change their structure.

To mitigate the severe pain, the hypodermic injection of morphia will be found especially serviceable.

\section{SCROTOCELE, OR RUPTURE OF THE INTESTINES OR OMENTUM INTO THE SCROTUM.}

To understand the nature of this affection, it is necessary to refer back to what has already been stated. During foetal life the testes are contained in the abdomen, from which they descend into the scrotum about the ninth month, by an opening called the abdominal ring. After they have descended this opening usually closes, and no further direct communication then exists between the two cavities. In some cases, however, this closing up is not accomplished before birth, and then there is a liability for the intestines, or their covering, the omentum, or both, to descend after the testes into the scrotum, forming the scrotal hernia. In most cases this takes place very early, but it may be delayed some months or years, and has taken place as late as the thirtieth year. The symptoms are much the same as those of other ruptures, excepting that the tumor is found in the scrotum. If the bowel is compressed in the ring till the passage in it is obstructed, great suffering results, with inflammation and nearly certain death if relief is not obtained. I have known infants suffer severely from this trouble, and in fact be almost lost from it, withont any idea on the part of their parents as to what ailed them. I have also known boys become subject to it suddenly from leaping, or from straining of the bowels, and suffer the most dreadful tortures before they told how they suffered, or before any one found out what was wrong.

If the rupture exists from birth, the testes cannot be felt while it is down, becanse they are covered by it, but when the rupture occurs in after-life the testes can be felt behind, in the lower part of the scrotum. In some cases the hernia is small, and descends only a small distance, so that no great inconvenience is experienced, and it may exist in this way for years, or even for life, but there is always danger of its becoming worse. Occasionally a quantity of fluid descends from the abdomen, either with a rupture or without, constituting a true hydrocele, but differing from that occurring in after-life by the fluid returning into the abdomen when pressed upward. Children are sometimes born with a large accumulation of fluid in this way, and in others it appears a few days after birth. In these cases the fluid also usually disappears into the abdomen when the patient lies down, and may be kept there when erect by pressing the finger on the abdominal ring, but immediately the finger is taken away it reappears.

The treatment of scrotal hernia is much the same as that of other ruptures, and when properly conducted usually produces a cure, unless there is some malformation of the parts that cannot be corrected. The protruded parts are first pushed back into the abdomen, leaving the testes in their place, and then a properly-constructed truss is worn that presses on the abdominal ring, to prevent their return. If this be worn regularly, and the parts never allowed to fall again, the passage will generally close up, and the cure be thus made complete in a few weeks. The older the patient 
is, however, the longer time it will require to effect a cure, and the greater chance there is that it may not take place at all, in which case a truss must be constantly worn.

Great care is required in applying the truss that it does not press on the intestine, or on the testes, for if it does so, great pain and perhaps inflammation may result. It must also be carefully ascertained that the testes are in the scrotum, because if they are not the truss will be improper, as it will prevent their descent.

In congenital hydrocele the fluid may be kept back, more or less completely, in the same way as the intestines, and in young persons it usually absorbs in the course of time. In very bad cases of scrotal hernia, when the intestine is strangulated, and cannot be replaced by external manipulation, an operation is needed, which consists in cutting the neck of the sac, or the ring, a little larger, so as to allow of its return. This, however, must always be performed by an experienced surgeon, and in such hands is perfectly safe and comparatively easy.

Parents cannot be too careful in observing their children, so as to detect any trouble of this kind at the earliest moment. From want of attention this way a scrotal hernia may take place, and produce serious effects, before anything of the kind is suspected, and the proper treatment may thus be too long neglected. A severe fit of crying is very likely to bring this on, in infants who are disposed to it, and hard coughing may do the same in after years. It is very seldom cured, so as to do without a truss, after puberty.

VARICOCELE AND CIRCOCELE, OR SWELLING OF THE VEINS OF THE SCROTUM AND SPERMATIC CORD.

Varicocele is simply a swelling of the veins on the surface of the scrotum, and is never of a serious nature, unless caused by other diseases. It appears to arise spontaneously in many cases, but more frequently follows severe fatigue, long standing, or debilitating diseases. All that is required is for the patient to wear a suspensory bandage, use the cold astringent lotions directed in hydrocele, and rest. If he be of a full habit of body, it may also be requisite to order a low diet for a time, and the strict use of cold water as a drink.

Circocele is a swelling of the primary veins of the spermatic cord, within the scrotum, and may become much more troublesome than varicocele, though it is but seldom serious. The swelling is felt in the scrotum like a firm knotty tumor, on one side of the testicle, and becomes larger when the patient coughs or strains, but subsides when he lies down. It is on this account that circocele has sometimes been mistaken for a rupture of the omentum into the scrotum. It only needs a proper examination, however, to show the truth. When the patient lies down, push the tumor up into the abdomen, and press the finger firmly on the abdominal ring, then let him rise, and if it be a rupture the tumor cannot descend again while the finger is held there, but if it be a circocele it reappears immediately.

It is seldom that anything more is experienced than a sense of weight and uneasiness in the parts, except in severe cases, and then there may be pains in the back and loins, with weakness in the thighs, and eventually a wasting of the testicle.

The treatment must be almost precisely the same as given for other swellings. Cold astringent lotions, the suspensory bandage, purgatives, and rest, by lying upon the back, is all that can be generally advised, though there may be particular 
crreumstances in each case to indicate something more. There are cases so severe as to require the removal of the testicle, but fortunately they are rare.

Many sufferers would escape this affliction if they would wear a suspensory bandage in time, when the swelling and inconrenience are first observed, and many would have no return of it if they did not leave off the supporter too soon. The veins on the right side appear to be seldom subject to swelling, nearly all the cases being on the left side, though occasionally both are affected, but the left always the most so. This is probably owing to the position of the colon, or lower part of the large intestine, which descends on the left side, and by pressing on the veins prevents the blood from freely returning, and thus causes the swelling below. It is on this account that persons who suffer from constipation are most liable to varicocele, and that it is always worse when the bowels have been long unmoved and are full. It is for the same reason also that the left ovary, in females, is most apt to be affected with varicocele. Among other general causes of this disease may be mentioned excessive indulgence, masturbation, inflammation of the testicles, and ruptures or tumors in the abdomen. Very fat people are sometimes affected with it, owing to the pressure of the fat in the lower part of the abdomen, and those who wear trusses are liable to it from the pressure of the instrument, unless it be well made, and carefully adjusted. Riding, hard running, leaping, and lifting will also bring on swelled veins, and sometimes even burst them, particularly if the scrotum be much relaxed. It is most frequent at the age of puberty, though met with occasionally at other periods.

The characteristics of this disease are so clearly marked that a mistake can seldom occur in regard to it; the cord is plainly observed to be swelled, the enlargement being greatest below, on the testicle, and on pressure it feels like a roll of knotted cords, or a bunch of earth-worms. This swelling is always greatest at night, or after exertion, and from coughing or straining in any way. It may also be reduced by lying down, and by the application of cold. Many patients discover that it is nearly always much better after coition, and they are, therefore, apt to indulge frequently, under the idea that it does them good. This, however, is a great and fatal mistake, the temporary relief being merely owing to the contraction of the scrotum, and to the increased speed of the circulation, which always occurs immediately after coition. As soon as this temporary excitement is over, the relaxation is greater than before, and the swelling of the veins increases, as all those who have tried the experiment well know.

In general, if taken early, the disease may be readily checked by the means already described, but if neglected it may become very severe and obstinate, and sometimes give rise to neuralgic symptoms. There is also danger of wasting of the testes, as before remarked, owing to the circulation of the blood being impeded, and the usual supply of nutriment being thus cut off. Many instances of this kind are related in medical works, and I have seen several myself. In some cases the testes will waste away, and almost totally disappear in a few months after the varicocele commences. This, of course, destroys all sexual power and feeling, and makes the patient a eunuch. It is therefore advisable, if all the usual means fail of arresting the swelling, and particularly if wasting commences, to resort to some other treatment, and several modes have been adopted by different surgeons, with varied success. Sir Astley Cooper, and some others, used to cut away a piece of the scrotum, and then draw the parts together and let them heal. This, of course, made the scrotum less, and by drawing the testes 
firmly up to the abdomen, afforded a beneficial support to the parts above. In many instances this operation has effected a cure, but in others the relief from it has been but slight. The disease has also reappeared, with all its former severity, many years after being cured in this way. This operation is not applicable to all cases of the disease, and even in skillful hands is frequently attended by great danger.

Besides this plan, some surgeons have cut through the veins, or tied them, and sometimes even cut part of them out. Of course, either of these plans leads to the destruction of the testes, besides being liable to cause inflammation of the veins, and other serious results, and they are therefore very objectionable, though often successful in curing the varicocele. M. Delpech, a celebrated French surgeon, operated upon a man in this way, and cured him, but the testes afterward wasted away, and this being unexpected and undesired, the man was so enraged that he assassinated the surgeon.

The only treatment that can effect a cure without sacrificing the testes is the application of pressure in such a way as to lessen the circulation of the blood in the reins, without stopping it entirely. This can sometimes be accomplished by a peculiarly formed truss or bandage, and at other times by a ring; but the making and fitting of these instruments is a matter of great difficulty, and requires to be done for each case separately. I have often had the pleasure of affording relief in this way, but only after immense trouble on my own part, and great perseverance and patience on the part of the patient.

When nothing else can be done, castration must be performed, and our surgical records give us many instances of this operation being resorted to.

\section{HAMATOCELE, OR SWELLING OF THE SCROTUM AND SPERMATIC CORD FROM THE EFFUSION OF BLOOD.}

This affection differs from hydrocele in being an effusion of blood, instead of water, either into the scrotum or spermatic cord. It is sometimes caused in performing the operation for removing the fluid in hydrocele, by wounding one of the blood-vessels, and thus allowing the blood to run into the cellular tissue, or tunica vaginalis. It may also occur spontaneously from the rupture of a branch of the spermatic vein, and may result from blows or sprains, the same as effusions of blood in other parts of the body.

This accident is rare, and seldom serious. If the patient keeps perfectly still, supports the scrotum with a bandage, and uses fomentations of hops, boiled in vinegar, or spirits of wine and water, or vinegar and water, and keeps the bowels gently relaxed, nothing more will in general be required. Sometimes, however, the blood-vessel remains open, the blood keeps flowing, and the swelling becomes so large, and presses so much on the testes that great distress is experienced. In these cases, an incision must be made, the blood let out, and the vessel tied, unless it can be closed by pinchjng it together externally, which may be done if the place of rupture is discovered. If there be any inflammation, it must be combated by leeches, cold lotions, and other usual remedies, and if it suppurates, a poultice must be applied.

\section{PRURIGO, OR ITCHING OF THE SCROTUM.}

This is one of those annoying complaints, which though not at all serious, are still sufficient to make any one suffering from them completely miserable, and even 
sometimes almost desirous of death, as the only means of relief. The itching is sometimes felt without there being any unusual appearances in the parts. bot more frequently a number of roundish red pimples are seen on the scrotum, which, by the patient's scratching to relieve himself, often become much enlarged and highly inflamed. In long-continued cases, the skin becomes considerably thickened and very hard, and a disagreeable discharge takes place from the sebaceous glands. I have known persons so tormented with this disease as to be frequently delirious, and utterly unable to obtain the slightest alleviation of their distress.

The real causes of prurigo are entirely unknown to us, but it is undoubtedly much aggravated, if not brought on, in many instances, by want of proper cleanliness. The plentiful and regular use of cold water would prevent more of this trouble than any kind of medication can ever cure. In many persons, the secretions of the parts are naturally very acrid, and if not speedily removed, they are sure to irritate every spot they touch.

Old persons are most subject to this complaint, though it occasionally attacks others, and it is usually confined to the genitals exclusively, but will sometimes extend down inside of the thighs and round the anus.

The treatment must be chiefly external, unless there be habitual indigestion or constipation, in which case a few simple alteratives may be of service. If constipation exists, a little epsom salts may be taken, and if the stomach be disordered, five grains of Plummer's pill may be given every other night, for five or six nights. The patient must be particularly cautioned not to rub the parts, and his dress should by no means be allowed to chafe them, nor should it be too warm and close. Even at night, the bed-clothes must be light, and the bed itself hard and cool. But little exercise should be taken, and that very gentle, and the parts should be thoroughly washed twice a day with warm soap and water. A cooling lotion may also be used during the day, of vinegar and water, with a little laudanum, or what is often better, two grains of bichloride of mercury to two ounces of water. Equal parts of citrine ointment and fresh lard also form an excellent application to be rubbed well over the parts at night. Sulphur ointment benefits in some cases, and a sulphur vapor bath still more, so in others. It is especially important that the diet should be simple, light, and unstimulating, and that no alcoholic or fermented liquors should be taken.

Sometimes the itching arises from the presence of certain peculiar little parasitic insects, in which case they may be readily destroyed by rubbing on a little of the white precipitate powder occasionally. In fact this may also be used with a prospect of benefit whenever the skin is not much broken.

\section{ELEPHANTIASIS SCROTI.}

This terrible disease is fortunately extremely rare in this part of the world, but still it is necessary to describe it in order to complete our treatise. It appears in the form of a peculiar swelling of the scrotum, caused by the infiltration into its integuments of a jelly-like albuminous fluid, which accumulates in some cases to a most enormous extent. The outer surface of the skin appears rough and chapped, or covered with large brown seales, so that it has somewhat the appearance of an elephant's foot. Sometimes, but not very frequently, a number of ulcers are formed, and the chapped places discharge an offensive sanious secretion. 
This disease is chiefly confined to Barbadoes, though found in other of the West India Islands, and also in Egypt, Africa, Greece, and the East Indies.

The size of the scrotum is sometimes almost past belief, and yet in some of the very worst cases, the patients enjoy excellent health, without any disturbances of the iunctions of other parts of the system, which shows that the disease is purely local. Mr. Liston removed one of these tumors which weighed forty pounds, which had been nineteen years growing! M. Delpech removed one that weighed sixty pounds

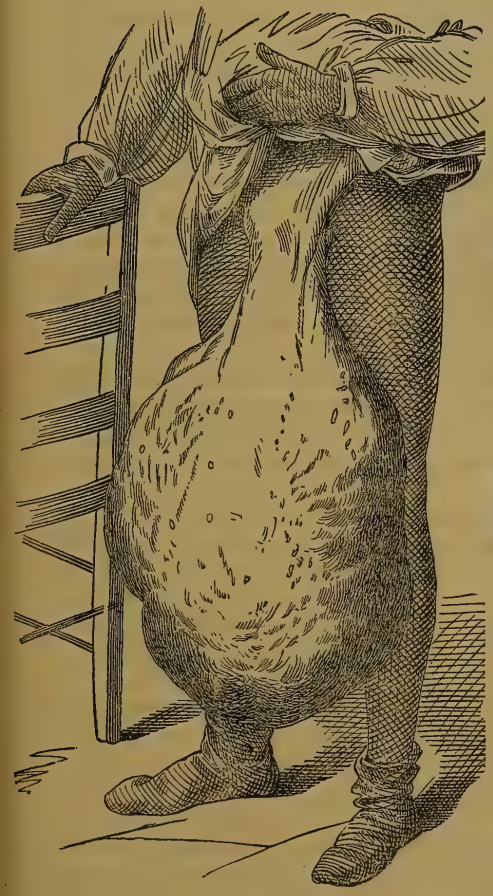

FIGURE 122.

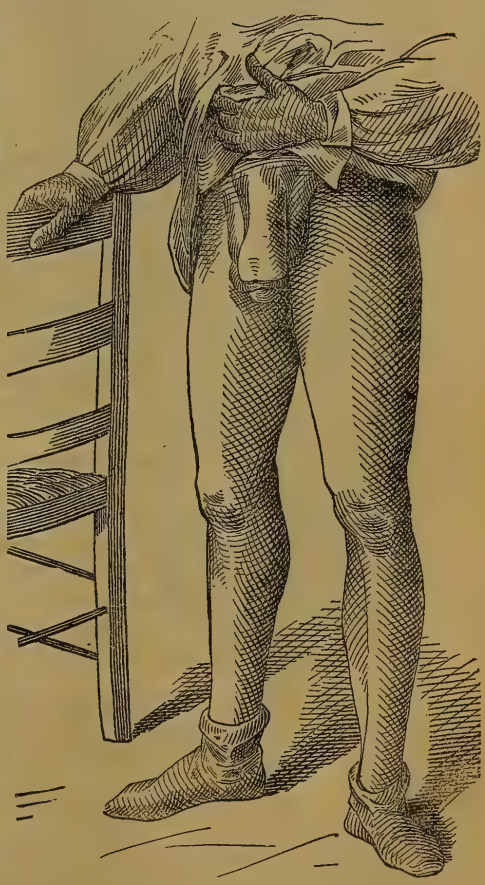

FITURE 123.

and Baron Larrey saw one in Egypt that weighea over a hundred pounds. Instances have even been known of their weighing over two hundred pounds, and sometimes the patients have even been able to sit upon them like a seat. Very often they hang down to the ankles, and are four or five feet in circumference. There is no cure for this affection, so far as yet known, and the only remedy is to remove it with the knife, which has frequently been done with perfect success. Dr. Picton of New 
Orleans, removed one of these tumors from the scrotum of a negro, in 183\%, which weighed fifty-three pounds, and had been growing for ten years. Much larger ones have, however, been removed, and sometimes even without destroying, or in any way injuring the genital organs, so that the patient has been as well and perfect afterward as ever he was before. It is, however, extremely difficult to preserve the genitals, and generally they have to be removed along with the diseased mass. The great danger is from loss of blood, and from this many of those operated upon have died. A Chinese named Hoo Loo came over to London to be operated upon for this disease, and Mr. Key removed the tumor, which weighed fifty-six pounds, but the poor man died from loss of blood.

Elephantiasis, though common in some parts of the world, is rare in the United States. The following case occurred at the Colored Home in this city.

The patient's name was Isaac Newton, native of Georgia, aged 22. He was admitted to the hospital March 20, 1866. He had previously enjoyed general good health, and was in good condition when admitted. About eight years before, while leaping a fence, he fell astride the rail and bruised the scrotum. Some pain and swelling followed, which, however, passed off, and about three months after it began to feel uncomfortable, and the skin commenced to thicken, the thickening increasing till it extended up the penis, and reached the prepuce. It then grew rapidly till at last it hung down near to his ankles. Its appearance when at the hospital is shown in Figure 122.

At first it pained him very much, but latterly he was only inconvenienced by its size and weight, which hindered his walking, his general health being remarkably good-his weight without the tumor, 159 pounds. The tumor weighed, when re. moved, $63 \frac{1}{2}$ pounds. His sexual desires were perfect, and he had occasional erections and emissions.

This enormous tumor was successfully removed, in the presence of many noted surgeons and medical men, May 30, 1866-Dr. G. F. Hollick being at that time house physician. The patient was placed under the influence of ether, and the operation lasted nearly an hour, including the dressing. It was remarkably successful, and on August 6th the wounds were almost entirely healed, the parts had assumed their natural appearance, and his general health was much better. He was even gaining flesh.

April 2, 186\%, he was discharged from the hospital, and returned to Georgia. The parts then presented the appearance shown in Figure 123.

\section{FALLING OF THE SPERMATIC CORD.}

From various causes the sheath of the cord is liable to become excessively relaxed, and weakened in its attachments, so that it falls down more or less into the scrotum. This is indicated by a sense of weight and fullness in the scrotum, and by dull pains in the groin, with uneasiness in the testicle. On examination, a kind of knotty tumor is felt just over the testicle, or down on one side of it, which may be gradually pushed up into the abdomen, and which draws itself up to a great extent when the person lies down. This tumor is the cord, which has fallen in a heap and presses on the testes. In the morning it is seldom to be seen, except very slightly, but usually reappears when the patient has heen on his feet a short time. It is also worse in hot weather, and after great fatigue, or much nervous agitation. Strain- 
ing from constipation will also tend to bring it down worse, and so will sexual excesses.

This is simply a local weakness, but it may nevertheless lead to very unpleasant consequences if allowed to continue unchecked. The constant pressure on the testes becomes very painful, and may lead to inflammation, or hydrocele, and viltimately the cord may form false attachments and grow fast in its wrong position, so that no means can afterward remove it. The treatment is simple but requires perseverance. The parts must be regularly bathed with cold astringent washes, such as alum-water and solution of sugar of lead. This must be done at least morning and night, and, if possible, two or three times during the day, the fluid being dashed on the groin, and under the perineum, as well as on the scrotum. The dress must not be too warm between the limbs, and no lifting or straining must be practiced. As little standing as possible is also advisable, and constipation must be particularly aroided. The most is a suspensory bandage, or

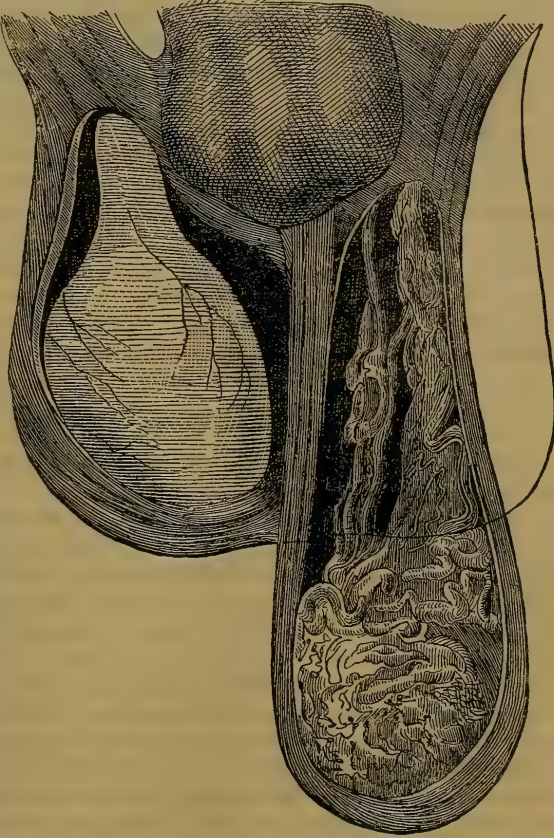

FraURE 124.-Varicocele, falling of the Cord, or dropped Testicle.

This is a very common disease, and a very troublesome one. It will be seen how the veins are swelled and knotted, and how the Scrotum is stretched downward, as if a heavy weight were hung in the Scrotum.

The Testicle itself is buried under the mass of fallen cords in very bad cases, a truss, and blood-vessels, and the pressure they exert, often causes it made to press on the abdo- to waste away.

minal ring. Both these in-

The line shows where the Scrotum should be.

struments should be put on before the patient rises in the morning.

Falling of the cord usually results either from general debility, straining, sexual excesses, or fatigue upon the feet. It may occur only on one side or on both.

\section{RELAXATION OF THE SCROTUM.}

This affection is something like falling of the spermatic cord, being produced by similar causes, and requiring similar treatment. It results from a weakness in 
the fibers of the dartos and great cremaster muscle, owing to which the weight of the testes pulls down the scrotum and elongates it, sometimes to a great extent. In some men I have known it hang, when they have been long upon their feet, full six inches below the pubes. Besides the inconvenience of the falling itself, it is nearly certain if it continues too long, to bring on falling of the cord, and probably hydrocele. It always causes an annoying sensation of weight and dragging, with more or less pain in the groin and weakness in the limbs.

The only treatment required is the regular use of cold astringent washes, as directed in falling of the spermatic cord, with the constant wearing of a suspensory bandage. The same precaution must also be obserred as to regulating the bowels, and avoiding excesses and fatigue. If cold water and the suspensory bandage were resorted to in time, and perseveringly, these affections would scarcely ever become very bad, unless from sudden straining. Sometimes, however relaxation is caused by unusual weight in the testes, from swelling, tumors, or hydrocele, and, of course, can be removed only with the cause producing it.

\section{DISEASES OF THE VASA DEFERENTIA.}

The vas deferens is only a small tube, and is liable to several accidents that will impede the proper performance of its functions.

It is not unfrequent after a recovery from hydrocele, or hernia humoralis, for the vas deferens to become partially obstructed, or even totally obliterated, owing to its having partaken of the inflammation, and its walls having, in consequence, grown together. When the obliteration is complete, the individual is, of course, sterile, because there is no passage for the semen. The testicle may be perfect in its action, but the semen cannot leave it, and this not only produces sterility, but sometimes leads to fatal inflammation of the testicles, from their being constantly overcharged with semen, and unable to relieve themselves. When there is only a partial obstruction the patient experiences a singular difficulty in the evacuation of the semen, which is effected very slowly, and often with great pain. In some of these cres the orgesm will be over and the erection gone down before the semen begins to flow, and then it comes in drops for a considerable time causing great inconvenience and annoyance.

Unfortunately we know of no remedy for this difficulty when it has long existed, but when it is merely a temporary result of acute inflammation, it is of course only necessary to subdue that to give relief. The great point is to prevent such an action, by checking all inflammatory action in the testes, and other parts which lead to the vas deferens, before it becomes affected. This trouble is mostly caused by neglecting hydrocele and orchitis too long, or by improperly treating them, though it may also be brought about by blows over the groin. A temporary obstruction of the vas deferens often arises from its being pressed upon by a swelled vein, or by tumors in the testicle and groin, in which case it is of course relieved only when such cause is removed. It is advisable to let such causes exist as little time as possible, because the retention of the semen may injure the testicle. I have known an improperly constructed truss press on the spermatic cord and close the vas deferens, so that the person was quite sterile while he wore it.

Sometimes the vas deferens becomes dilated, or relaxed, so that its size is much increased, and it nearly or quite loses the power of retaining the semen, or becomes 
so full of it as to produce inconvenience. The causes of this trouble are unknown, though it most probably results from retaining the semen, when it is nearly ready to flow, as often as from any other cause. I have known men afflicted in this way who habitually tried to prevent the flow from continuing, from a mistaken idea thet if they could lessen the discharge they would not be so much waakened by coition. It is scarcely necessary to say that such practices do not lessen the discharge, but merely make it finish afterward in an unseen and dangerous form.

It is not easy to ascertain when the vas deferens is enlarged or relaxed, but when there is good reason to suppose it is so the treatment is simple. Cold lotions of alum-water or sugar of lead, as recommended in former articles, must be constantly used, or ice may be frequently applied so as to astringe the paris, and all improper habits must be immediately abandoned.

In addition to these, the vas deferens is liable to sereral other uffections, as scrofula and tumors for instance, which are, however, very rarely seen, and as their treatment in no way differs from that for the same affections in other parts, they do not require any special notice. In some few cases the vas deferens has been totally absent from birth, while the testes and other organs were perfect. In this state the semen is formed, erection even occurs, but there is no emission, because there is no passage from the testes. This condition of the parts is nearly sure to lead to orchitis, or spermatocele, from the irritation of the retained semen, unless the patient's desires are weak, or kept much under control. If the vas deferens of an animal be cut out, or tied, it is found that the testicle still secretes the semen, though it cannot escape, showing that the power of secretion is not lost by the impossibility of emission.

\section{DISEASES OF THE SEMINAL VESICLES.}

The precise use of these two organs is yet a matter of dispute among physiologists, some regarding them as real glands, by which a peculiar liquor is secreted to mix with the semen, while others look upon them as mere reservoirs in which the semen accumulates previous to its emission. When dried and injected, the vesicles are seen to be two tubes convoluted and turned upon each other so closely that their parts look like cells. The ends of these tubes open into the vas deferens, just where the ejaculatory duct commences.

It appears certain that the vesicles have considerable contractile powers, and this has favored the idea of their being intended to contain the semen, and afterward eject it during coition. When examined after death, however, they do not contain semen, but are filled with a yellowish fluid apparently peculiar to themselves. Their precise use is therefore as yet unknown.

They appear to be subject to obstruction and obliteration like the vas deferens, but we have no means of detecting such derangements, nor can we propose any remedy.

\section{HYPOSPADIAS.}

This term means a case where the end of the urethra does not come to the end of the penis, but opens underneath, the passage not reaching the whole length of the organ. This stute of things sometimes follows severe venereal cases, and other accidents, but its causes when congenital are of course unknown to us, and unfortunately but little success generally attends its treatment: 
This malformation is a cause of great trouble and annoyance in urinating, and interferes more or less with the power of impregnating, though it by no means prevents it altogether, as was formerly supposed.

Sometimes the opening is close by the frænum, and during erection it is firmly closed, owing to the pressure, so that the semen cannot escape from the urethra. In such cases there cannot be impregnation, unless the semen flows after the erection has somewhat subsided, but this it will not always do, because it may run backward into the bladder, and in such cases the patient is necessarily impotent.

When the semen escapes freely, providing it be within the female organ, concep. tion may or may not take place, according to circumstances, let the opening be where it may.

At other times the opening is so near the body that the semen, when it does escape, cannot enter the female organs. In such cases the only resort left is artificial impregnation, as before explained.

The nearer the opening is to the end of the penis, generally speaking, the more chance there is of success, and the nearer it is to the body the less. In some situations any kind of treatment is out of the question. When it is close to the body, the urine and semen run down the scrotum or perineum, causing constant irritation and annoyance, unless an instrument be worn to prevent it.

Sometimes there are two openings, but they seldom communicate, and the fluids nearly always escape by one only.

It was formerly considered, even by the most eminent surgeons, that it was impossible to operate with any prospect of success in these cases, from the nature of the parts, and from the constant flow of urine; they therefore advised to leave them alone, and provide the sufferer with the best remedial instruments, to lessen the inconvenience. In modern times, however, success has attended numerous attempts to correct this malformation, and under favorable circumstances it is always attempted.

The mode of operation is simply to pass a small sharp-pointed instrument straight through the penis, along where the natural opening should be, and thus make an artificial passage, which is kept open by bougies till the cut edges have healed and there is no danger of it growing up again. When this is fully accomplished a catheter-is introduced, and the edges of the old opening underneath are made raw and held together, by needles or other contrivances, till they adhere, and thus the opening is closed. In this way a new passage is formed in the proper direction, and the old unnatural one is permanently obliterated. There are, however, many circumstances that may make the success of the operation very uncertain, and some that may forbid it being attempted.

In general the proper canal of the urethra exists, but in a small state, and is closed only at the very end by a thick membrane. This membrane may usually be easily cut through and the canal enlarged by bougies, by which means, if the false opening can be closed, a perfect cure can be obtained. Sometimes, however, there is no trace of the urethra, and the passage has to be cut through the solid flesh the whole distance, which is apt to excite so much inflammation that no bougie can be worn, and then all grows up again. The false opening is also so large in some cases, or the edges are so thin, that it cannot be closed, and then the new opening may be of little use, though it be formed. In some of these cases, however, a small tube can be worn internally, extending just past the opening underneath, so as to conduct the semen 
and urine to the proper opening at the end ; or a piece of gum elastic, or oiled silk, may be worn firmly over the opening, externally, to effect the same object. By such means many a sufferer has been enabled to urinate in comfort in the natural way, and many an impotent man has become a father.

Instances have been known where the false opening was between the testicles, or even in the perineum, and yet it has been perfectly closed and a new one made the whole length of the penis. Such operations, however, require great skill in the surgeon and much endurance in the patient.

In many instances, when the false opening is near the end of the penis, it will be found that the proper passage is continued the whole length of the organ, and merely closed at the mouth by a skin. I knew a man who was troubled in this way, the opening being just at the base of the glans, who could close it with his finger and send the urine along the natural passage till it made the skin at the end project. Having heard me explain about this in some of my lectures, he determined to try and operate himself. Accordingly he took the sharp end of a penknife, and where the skin projected strongly he made a small puncture very readily, through which the urine escaped immediately. The inflammation soon subsided, and the new opening remained, so that by always closing the old one with his finger, he could urinate as well as if nothing was wrong. I told him that the old opening could be easily closed permanently by another slight operation, but he felt so well content with what was already done, and suffered so little inconvenience, that he would not consent to anything further.

One of the greatest difficulties is in keeping a catheter in sufficiently long to make the urine flow down the new passage while the old opening grows together. Very often the place will be nearly closed, and then a rush of urine will come and break it open, destroying all that had been done. In old cases, also, the edges are apt to be very thin and ragged and the orifice large, so that a perfect juncture is next to impossible. If there is any scrofulous tendency also, the probability of it ever closing is very small. In many of these cases, as in external abscess of the prostate gland, the wound may be perfectly healed for a time, but break out again without any apparent reason.

Many of these deformities can be corrected in infancy, or early youth, and they should therefore be always shown to experienced surgeons immediately they are detected, and not concealed as they are by some parents. It is difficult to say to what age success is possible in such cases; probably there is no particular limit. Some have been operated upon at thirty, and others even at forty or more, but the earlier the better. In general the development of the penis is more or less imperfect above the false opening, and when the full generative power is desirable this must also be corrected, by means explained in another article. Sometimes it is even necessary to effect this development before the operation can be performed.

\section{EPISPADIAS.}

This affection is precisely the reverse of the former, the false opening being on the top of the penis instead of underneath. It is much more rare than hypospadias, and is somewhat more difficult to treat, owing to the opening being farther from the natural passage. The orifice will sometimes be near the end and sometimes close by the pubic bone, occasionally being a little on one side. 
The mode of operation is exactly the same as in hypospadias, but, as before remarked, it is more difficult, and the chances of success are less.

PHYMOSIS.

In this malformation the skin of the prepuce comes completely orer the glans, and the opening at the end is so contracted that it can never be drawn back. This condition of the organ is both unpleasant, annoying, and dangerous, because it prevents proper cleanliness, and thus disposes to various diseases. The secretion of the glandulæ odoriferæ is apt to accumulate under the skin, and, in conjunction with the urine, to create serious inflanmation. Calculi will also form, like those in the bladder, and the swelling will sometimes be so great that neither semen nor urine can pass. In many cases of phymosis the swelling is so great as to cause severe pain during erection, and the glans is so compressed in consequence that the semen cannot escape, and thus the individual is impotent.

The means of giving relief are very simple. It is only necessary to introduce an instrument carefully under the skin and cut up the prepuce, so as to let it open. This may be done with but little trouble or pain, and with slight danger from inflammation if a simple dressing of cold water be applied. It is sometimes necessary to cut off the edges of the wound a little with scissors, particularly if they are anyways callous, or ragged. The whole prepuce is at times so hard and unyielding that it becomes necessary to practice complete circumcision.

\section{PARAPHYMOSIS.}

In this case the prepuce is drawn back over the head of the penis, compressing the organ like a tightly-drawn cord. In some it is permanently in this situation, while in others the patient has drawn it over the glans and has not been able to slip it back again, owing to the smallness of the opening and the swelling of the parts. When it results from this cause, it will often be sufficient to use cold lotions for a time, to reduce the swelling, and then lubricate the parts with some belladonna ointment, when the prepuce may be drawn over without difficulty. Sometimes a little bleeding may be necessary, or a few leeches on some of the neighboring parts.

The only certain cure is to cut the prepuce in the same way as for phymosis, which will of course prevent any return of the difficulty. Patients with phymosis are very apt to change that trouble into paraphymosis by their attempts to draw the prepuce back and to stretch it.

In young children both these states may exist without causing any great annoyance, but as they approach puberty serious trouble may be experienced suddenly. It is, therefore, very necessary for parents to observe such accidents, and watch their progress, particularly near puberty, so that the surgeon may bo applied to in time. Many a man has suffered for life, both physically and morally, from neglect of this kind while he was a child.

I once knew an instance of a youth who had a permanent paraphymosis that had never caused him any trouble till he was about twelve years old, when it began to pain him whenever he urinated, and later, when erection occurred, severely. When about fourteen years of age, in consequence of some unusual irritation, the parts swelled very much, and the prepuce was drawn so tightly around that the glans was 
perfectly strangulated. Not being in the habit of speaking about such matters to his parents, he concealed it till the agony was so great he could hold out no longer. On a physician being sent for it was found that the parts had begun to gangrene, and the urine had been retained so long that inflammation of the bladder had also supervened. By prompt treatment the most urgent symptoms were alleviated, and after a time the prepuce was cut through, so as to give permanent relief. The patient, however, came very near losing the organ itself, if not his life, through want of a proper confidence and habit of communication between him and his parents.

Both phymosis and paraphymosis may result from the inflammation attendant upon other diseases, particularly those of a venereal or syphiloid character, and then it is usually only requisite to remove the primary affection to give relief, though sometimes the operation is needed.

It is necessary to state here that many a child has become addicted to masturbation, and has perished in consequence, simply from having a neglected phymosis; the secretion accumulating under the skin, causing constant irritation and leading to manipulations that would not otherwise be thought of.

I have known many men operate upon themselves, and successfully too, for both these affections ; a penknife, or pair of scissors being the only instrument used. No cutting should, however, be practiced on these parts when there is venereal disease, because the wound may inoculate, and thus the disease be spread.

In some persons the prepuce is absent altogether, and attempts have been made, under such circumstances, to form a new one by bringing forward the skin below, but no great success has attended the operation, nor is it at all essential. The only reason given for desiring it is that the glans is apt to lose part of its sensibility when constantly uncovered, which is undoubtedly the case, as may be seen among Jews and others who have been circumcised; but this is a slight inconvenience, even if it is not often an advantage, as it certainly makes the person less liable to contract disease.

\section{PARALYSIS OF THE MUSCLES OF THE PENIS.}

I first observed this affection in the person of a patient, aged about fifty-three, having previously seen no account of it whatever. Since then I have met with other cases in persons of different ages, thongh always past thirty. In the first case it was apparently the forerunner of general paralysis, an attack of which was experienced some two months later, but partially recovered from. In other cases I have also regarded it as a sign that general paralysis, or apoplexy, was threatened, though it did not always immediately follow.

In this disease the secretion of the semen is not affected, nor is the flow of blood interfered with, the organ becoming as full and as firm as before, but there is no power to raise and directit. The first case yielded in the course of a week to galranism, and some others were alleviated by warm baths and stimulant lotions, but ethers again remained, notwithstanding all that could be done. These were mostly old people, with an obvious predisposition to paralysis. In some cases I have had reason to think that the attack was brought on by previous sexual excesses.

\section{PRIAPISM, OR INVOLUNTARY ERECTION.}

By this term is meant an unnatural and involuntary erection of the penis. In some persons it occurs only at intervals, but in others it is constant for a long time, 
and constitutes a real state of disease. Priapism is not always accompanied by pleasurable feelings, though it usually is, but, on the contrary, it is sometimes painful. In some persons it comes on suddenly, without any premonitory symptoms whatever, but in others it commences gradually, and is frequently indicated by a sense of fullness in the testes, or of pain and heaviness in the head. The patient is utterly unable to control the erection in the slightest degree, nor in general can he by any means prevent it, while the morbid state continues. I have known men who always suffered from this immediately they went to bed, so that their rest was much disturbed. In one young man, especially, the health suffered seriously. Every night, when he had been in bed about an hour, the priapism would commence, and such was the effect on his nervous system that sleep was out of the question while it continued. Very often, for several nights together, he did not sleep more than a single hour, and yet there was in general but little sexual feeling, and that only at first, the sensation afterward being merely one of intense and harrowing excitement. The next day he suffered from headache, pain and weakness in the back, and soreness in the organ itself. In no instance did he have emissions during these attacks, and this is a peculiarity I have frequently observed.

The causes of this troublesome affection may be various, and sometimes can only be surmised. In many cases, especially among young persons in vigorous health and of perfect development, it results from an actual excess of semen, which first causes spermatocele, and then leads to a chronic inflammatory condition, by which the erection is constantly excited. This condition may exist in those who are not at all disposed to lascivious thoughts, and even in those who are constantly striving against them, though it is of course made much worse by indulging such thoughts. Most commonly in these persons the priapism continues till an involuntary emission takes place, and then it disappears for a short time, till the semen has again accumulated in too great quantity. There are some, however, in whom these emissions never occur, and in them the priapism is frequently a constant state, and becomes eventually a real disease. In the early stages marriage is, of course, the only certain and effectual remedy, though much mitigation may be effected by means that will hereafter be pointed out; but when the organs have become diseased or chronically inflamed, marriage would be highly improper till a healthy condition is restored.

It is not always the case, however, that priapism results from seminal accumulation, or superabundant energy, for it is sometimes experienced by those that are rather deficient, or, at least, below the average. I have even observed it in those that were nearly sterile. In these cases it is induced by a diseased condition of the brain, and is usually considered a mere moral affection, though, like many other moral affections, it is simply an indication and consequence of physical disease. In this state there is constant desire at first, sometimes amounting to furious erotomania, but eventually all feeling and desire will vanish, while the priapism will remain, and sometimes even continue after death. Long-continued debauchery is also sometimes followed by obstinate priapism, and eventually by absolute impotency. In the Medical Repository for April, 1824, is a case of this kind communicated by Mr. Callaway. The patient, during a fit of intoxication, associated with a female three times in succession, having emissions each time, but no subsidence of the erection, a circumstance which I have often known to occur during intoxication. To his great surprise the erection still continued the next morning, and it remained for sixteen days, in spite of all the means used to reduce it. The surgeon then made an incision with 
the lancet, just below the scrotum, and immediately there escaped a large quantity of thick black blood, mixed with clots. On pressing the penis the blood all flowed out of it, by the opening, and it immediately became flaccid. The man was impotent, however, afterward, for no erection ever took place again, owing probably to the cells of the corpus cavernosum and corpus spongiosum having grown up, from inflammation. The continued erection was apparently owing, in this case, to inflammation at the lower part of the penis, or in the perineal muscles, which caused the veins to be so pressed upon that the blood could not return by them, or perhaps the veins themselves were swollen and closed up. Some men have brought on a similar condition of the parts by keeping themselves too long excited, without allowing emission to take place, a practice which is very reprehensible, and which not unfrequently causes spermatocele, or even orchitis.

If the erection be too powerful, or too long continued, it will often cause temporary impotence, by so compressing the urethra that the semen cannot traverse along it. When this occurs the semen either escapes afterward, slowly, or else mixes with the urine.

Long-continued priapism is aiways hurtful, and is very likely to destroy the power of erection altogether, ultimately ; it is, therefore, desirable that we should know its various causes, and the best means of treating it. Persons who are not properly informed respecting its nature are apt to consider it as simply a result of loose thoughts, and that only a proper effort is required to overcome it. This is a great mistake, as we have already shown, and one which leads both to the neglect of proper treatment and also to uncharitable judgments.

In addition to the general causes of this affection, already enumerated, there are also several others that have a tendency, more or less, to originate or aggravate it. Want of proper cleanliness, hot clothing, particularly if it chafes, and the too frequent use of warm baths may be mentioned, and also several other diseases, such as gonorrhœa and spermatorrhœa. The gravel, and inflammation of the bladder also excite the penis very much in some persons, and the piles will do the same in others. Stimulating and highly-seasoned food, and hot or vinous drinks have the same tendency, and sleeping in a very warm soft bed is apt to assist. The use of bougies and injections will often produce priapism, and certain medicines still more frequently. Cantharides, phosphorus, and opium, perhaps act the most energetically in this way, but there are others whose effects are very decided, and they all act very differently at times, and upon different persons. The reading of lascivious books, or listening to loose conversation, undoubtedly operates in a similar manner to these physical agents, and the indulgence of lying in bed of a morning, half awake, has the same tendency.

The treatment of priapism must of course be regulated by the cause that produces or aggravates it. When it is mainly produced by neglect of properly regulating the mind, or controlling the desires, the cure must depend entirely upon the individual's own self, or rather upon his strength of mind. When it arises from a too stimulating diet and drink, aided by a deficiency of muscular exercise, which is very often the case in young persons, nothing more is required than to live low, drink cold water, keep the bowels free, and bathe the parts frequently with cold water. If there be a too great secretion of semen, with no sufficient involuntary discharge, marriage is indicated. If there be any other disease, it must first be cured, and if there be heat and pain in the head, particularly in the back part, it 
must be frequently bathed in cold water, and kept cool, precisely the same as for inflammation of the brain, of which in fact the priapism is often only a symptom. During the paroxysm the parts may be bathed with warm water, or a warm enema may be given. Sitting in a warm bath is sometimes the best plan, or over hot steam. In obstinate cases leeches may be applied to the penis, or a vein may be opened in it, but one of the best remedies is to give sufficient tartar emetic to cause sickness ; this generally relieves the priapism. Two ordinary sized pills of gum camphor have been found efficacious in some persons, and simple fasting, till faintness ensued, in others. When the paroxysm is over, strict attention must be paid to the diet, clothing and general conduct, as before indicated, to prevent a recurrence.

I have had some patients with whom I have had to use various mechanical contrivances, to prevent the priapism occurring at night, or while the curative means were being employed. A simple bandage, drawn tightly round the organ when flaccid, will often prevent the erection, but a better plan is to use two grooved pieces of wood, one of which must be placed above the penis and the other below so that they can be drawn together by a band, or screw. The organ can be compressed so tightly by this machine, while in its ordinary state, that erection cannot possibly take place. Several of my patients were unable to sleep till provided with an instrument of this kind.

The longest period I ever knew an attack of priapism to last was six weeks, and that was in a married man. It first began during a short absence from home, and was kept up by the impossibility which he experienced, on his return, of discharging the semen, owing to the swollen and inflamed state of the parts. He suffered from spermatocele, and slightly from orchitis, and was further troubled by violent desire, which he was unable to gratify. Connection was possible, but without emission, and ('onsequently without gratification. I was much afraid, from the violence of the attack, and from the symptoms, that permanent impotence would follow, but by careful treatment, perseveringly attended to, he completely recovered.

I knew one instance in which priapism followed a blow on the head, from which the person died, and it remained after his death, the parts being so firmly congested, and so rigid, that nothing had any effect upon them. In several instances I have known priapism follow the application of blisters to the neck and back, even in young children, a fact that should not be lost sight of, either by physicians or parents.

\section{DISEASES OF THE URETHRA AND THE PARTS CONTAINED THEREIN。}

The urethra, as before explained, is a long canal passing from the bladder down the penis, for the purpose of conveying the urine out of the body, and also for conducting the semen, it being the common passage for both fluids.

The membranous walls of the urethra are rather thick, and are elastic, and the interior is lined with a mucous coat similar to that inside the bladder. The size of the urethra is different in different parts; thus a little way in from the external opening, or meatus urinarius, it expands considerably, and then contracting again expands still larger at about two-thirds of its length down. The substance of which the walls of the urethra are composed appears not to be the same in its whole length, being membranous in some parts and in others spongy, almost like the corpus spongiosum. It therefore participates in the act of erection, and its concurrence is very essential to the proper emission of the semen. Where it first opens at the neck of 
the bladder it is wide, but drawn together by certain muscles, excepting when the urine is evacuated, when the muscles relax and allow it to open. It is not by the drawing together of the walls of the urethra alone, however, that the urine is prevented from escaping, but partly by the presence of the veru montanum. By referring to the plate of the situation of the male organs, the position of this part will be readily understood. It is a small fleshy protuberance, placed on the lower wall of the urethra, just where it opens from the bladder. In shape it is like a cone, with the small end pointing toward the end of the penis. The neck of the bladder closes around this little protuberance while the urine is retained, but during evacuation it relaxes and opens a little, and the fluid then passes on each side of the montanum, which thus acts a similar part to the stopper of a bottle. Many cases of incontinence of urine arise from irritation of the veru montanum, which becomes so tender that the neck of the bladder is kept constantly open to prevent pressure upon it. This irritation may arise from various causes, but most usually we can only guess what they are. The mode of subduing it is simply to use general means for subduing inflammation, such as are suitable for all the neighboring parts. An irritating quality of the urine is very apt to give rise to it, particularly when very acid, and then it is readily corrected by taking a little carbonate of soda every morning before breakfast, and drinking freely of gum-arabic water. I had one patient who suffered terribly from this cause, without knowing, till explained to him, what it was. Immediately the smallest portion of urine was secreted in the bladder it felt as if a piece of red-hot iron was placed in the neck, and all command over it was instantly lost, the urine escaping in spite of all his efforts. The smarting, burning, and pricking sensation he described as most horribly torturing, without there being any apparent possibility of relief. He had been told by some practitioner that it was stone in the bladder, but I felt assured, after careful examination, that it was inflammation of the veru montanum, and advised him accordingly. I prescribed hot fomentations of poppy heads, on the pubes and perineum, with leeches also on the perineum, and inside the thighs. Internally I directed him to take the following powders, with a dose of castor oil every evening, and to drink plentifully during the day of barley water:

R. Dried leaves of uva ursi, or bearberry, one and a half drachms; bicarbonate of soda, one drachm.

To be mixed together well, and divided into twelve powders, one of which to be taken three times a day, in the barley water.

The effect of this treatment was evident on the second day, the inflammation having subsided considerably, and by the third day he was quite well, with the exception of a little soreness when urinating.

Inflammation of the veru montanum is also very apt to be produced by retaining the urine too long, when the bladder is very full, and particularly by trying to prevent the escape of semen, during coition, which is sometimes done by pressing the penis at its lower part. The effects of this practice, which is often resorted to under the idea of preventing conception, are most serious; in addition to the inflammation already referred to, it also leads to involuntary seminal losses, as will be explained further on. Such destructive practices would never be attempted if men were not so thoroughly ignorant of everything relating to their physical systems, and while that ignorance remains it wilı always cause more disease than medical science will be able to cure. 
The veru montanum is also very apt to become diseased whenever the prostate gland is affected, the two parts sympathizing so intimately together.

The semen enters the urethra just at the lower end of the veru montanum, by two small openings, which are very liable to be more or less closed when this organ, or the prostate is inflamed, and thus the flow of semen is partially and sometimes totally prevented.

Sometimes the montanum will swell till it completely fills up the neck of the bladder, so that neither urine nor semen can possibly escape till it has been reduced. It is also liable to be the seat of cancer or scrofula, like the prostate.

The urethra is liable to congenital malformations, as well as to subsequent accidents, and some of these may be of a serious character. In some young persons it is permanently contracted, so that the escape of urine is attended with great difficulty and pain. This fault, however, usually amends with the growth, and with constant use. Children so circumstanced are a very long time in discharging their urine, which flows in a small stream, and with more or less distress. In very severe cases bougies may be used to dilate the passage, but it is better, if the trouble is not too great, to wait till toward puberty, and see if nature herself will not effect an improvement. Still more rarely there are found congenital strictures, or they come spontaneously, without any apparent cause. If these are notvery bad, it is perhaps better to wait till fourteen or fifteen years of age, before operating, as the changes in the system at that time are very great, and an improvement may occur naturally. If they are too severe, however, or endure beyond that time, it will be necessary to use the bougie, which is in reality the only effective remedy in such cases. Many youths cause stricture by compressing the penis in masturbation, and bruising the urethra. I have known many do this to prevent the semen from escaping at the moment of ejaculation, from the notion that if this was done the practice would not injure them. It is of course unnecessary to show the fallacy of such a notion, but it may be advisable to explain again what becomes of the seminal fluid in such cases, for very often not a particle is seen. At the moment of ejaculation the semen escapes by jets into the urethra, from the ejaculatory canal, through certain small openings, called the ejaculatory ducts-which are shown in the plates-and then flows down the canal and escapes from the body. If, howerer, the urethra is compressed, so as to prevent it from escaping externally, it must flow in some other direction, and the only other way is into the bladder, which it enters by forcing open the neck and passing on each side of the veru montanum. It is then expended as much as if it had left the body in the natural manner, as it comes away with the next flow of urine. In the meantime its presence irritates the bladder, and its passage in this reverse way is very apt to cause inflammation in the veru montanum and prostate gland, and even to produce stricture, as before explained, with a weakness of the ducts disposing to involuntary seminal losses.

The urethra is also unusually irritable in some persons, without any particular disease, and burns and smarts when they urinate as if they had gonorrhoea. Some men, and even some children, have more or less of this trouble, either constantly or at times, and suffer from it considerably. It will generally be observed in such persons that the urine is high colored, and deposits a reddish or yellowish sediment on being allowed to stand, indicating either gravel or chronic inflammation of the bladder. The best treatment is that given for inflammation of the veru montanum, further back, and the best prerentive is to pay strict attention to the diet and drink. 
Nothing should be eaten or drunk that is heating or stimulating, or that is likely to produce constipation, which always aggravates these troubles. Spirituous and fermented liquors are very bad, and coffee is usually injurious. The best drinks are soda-water, barley-tea, gum-arabic water, and mucilage of sassafras pith, or bene plant. A little carbonate of soda taken every morning is a perfect preventive in some, and a little magnesia in others. All excesses must be carefully avoided, and the bowels kept constantly free. A frequent warm buth is nearly always beneficial.

Many of the diseases of the prostate gland, and many of the operations upon the penis are frequent causes of stricture and inflammation of the urethra, and they therefore require, on that account, the utmost care and attention. It is not unfrequently the case, in unskillful hands, that after a perfect cure of one of these diseases a stricture is left that is a worse evil than the original one.

\section{THE PROSTATE GLAND.}

The uses of this organ, like those of the vesicles, have not yet been satisfactorily determined. It was formerly thought to be a simple gland, intended to secrete a peculiar liquor which was necessary to mix with the semen. This view, however, has been lately somewhat modified, and it is now considered to be rather a collection of several glands or follicles forming one mass or organ together. These little follicles secrete a peculiar whitish fluid, which is conveyed by a number of small ducts into the urethra, close by the veru montanum, where the semen enters. It is probable that this fluid is, in some way or other, essential to the perfection of the semen as it leaves the body.

The prostate gland is liable to several forms of disease, some of which are both painful and dangerous, and all of which, unfortunately, are but little capable of treatment. It seens specially liable to engorgement, or swelling, and to scrofulous and cancerous indurations. Sometimes also it becomes cartilaginous, or even almost bony, and at other times calculi or stones form in it, similar to those found in the bladder. Inflammation and abscess of the prostate gland are very apt to follow improper treatment for gonorrhœa, particularly when bougies or injections have been used, and it is also a frequent consequence of cauterization for curing involuntary seminal losses. Blows on the perineum may also give rise to it, or too severe and long-continued pressure, from horse-riding, or using a hard seat, or even from very tight small-clothes. This trouble is both an annoying and a serious one, and frequently excessively painful. When the prostate is simply swollen, it merely causes a sense of fullness and uneasiness in the perineum, with difficulty in urinating or discharging the semen, and in passing the bowels. The reason for these impediments will be evident when the situation and connections of the organ are borne in mind. The smallest increase in the size of the prostate makes it press on the urethra and partly close it, so that the flow of urine is necessarily obstructed, and the orifices of the seminal tubes being also compressed, the flow of semen through them is similarly intercepted. In very severe cases a total stoppage of both urine and semen occurs, which if not relieved may lead to inflammation of the bladder and testes of the most acute and dangerous character. When this stage has been reached the pain and suffering become most intense, and if the inflammation and swelling are not speedily reduced, an abscess forms, which eventually breaks and discharges its contents, when some little relief is obtained, though the disease has then assumed a 
much more annoying form, and is more difficult to treat. If the abscess breaks internally, there is a continual flow of pus or matter from the urethra, attended by severe smarting and pain when the urine or semen is passed, and by a constant irritation in all the neighboring parts, which acts on the nervous system in the most distressing manner. Occasionally the abscess breaks externally in the perineum, whick is, if possible, still more troublesome. The pus keeps flowing in the same manner, only not from the urethra, and the same constitutional irritation is experienced, but the pain in urinating is not always so great.

The treatment of this trouble must depend upon the stage at which it has arrived, and the causes that produced it. While there is simply slight swelling and inflammation from bruises or blows, every means must be taken to remove it as speedily as possible. The patient must keep perfectly still, lying on his back most of the time, while fomentations of hot water, with laudanum, are freely applied to the perineum, or flannels dipped in the hot fluid may be placed between the limbs and pressed up against the perineum, changing them frequently, and using them as hot as they can be borne. The bowels must be freely moved with castor oil, and the diet must be light and unstimulating. A very good practice is for the patient to sit in hot water, for half an hour at a time, or over the steam of it. These means persevered in, when the uneasiness and difficulty are first felt, will often subdue the inflammation, and prevent any further evil consequences. A general warm bath, during which hot teas are taken, to promote perspiration and the flow of urine, are also of great service, and when the bruise is very bad, as shown by blackness of the skin, leeches must be applied, either on the perineum or inside of the thighs.

If the inflammation be of a chronic form, not produced by any external violence, the best application is the mercurial ointment rubbed on the perineum till it produces a decided effect on the system. Along with this may also be taken the solution of iodide of potassium, prescribed in hydrocele, the bowels being kept regularly open with salts or castor oil. Cold lotions must be frequently applied of alum or sugar of lead, and no spices or alcoholic liquors must be taken on any account. Sexual excesses are particularly hurtful in this complaint.

Very many incipient attacks of inflammation of the prostate might be cured in this way, and the swelling dispersed, if proper attention were paid to the diet and strict temperance practiced in all things.

Most frequently, however, this trouble continues, and either forms an abscess or an indolent tumor, which every now and then enlarges so much that the flow of semen and urine is entirely stopped, causing intense suffering, and a palliative operation has to be performed to give relief. Many patients suffer from regular periodical attacks of this kind, and in others they come on always after any little extra bodily exertion, or mental anxiety. In these cases the use of purgatives internally, with cold lotions and belladonna or hellebore plasters externally, will frequently mitigate the severity of the pain and cut short the attack. A grain of opium may also be taken, when the suffering is most intense, or thirty drops of laudanum, in some gum-arabic water. The ointment of belladonna and camphor, prescribed in inflammation of the testicle, will also frequently be found of great benefit, and many experience decided relief from leeches to the perineum and thighs. The nature of the operation to be performed, in any extreme case, depends upon the peculiar circumstances attending it, and must be left to the judgment of the physician. The internal application of caustic is practiced by some, and others use 
the lancet freely, but there are both risk and difficulty in both. At the very commencement of the disease it is sometimes possible to introduce a catheter without much trouble, and this may serve to keep the urethra open while the other means are employed to reduce the inflammation. The catheter, however, is not admissible when much force is needed to introduce it, nor when it increases the inflammation. One of the most reliable proofs of swelling of the prostate gland, when the tumor cannot be felt externally or in the rectum, is the impossibility of passing a catheter, owing to the enlarged prostate having blocked up the urethra.

Inflammation of the prostate gland may terminate in induration, or permanent hardness, and also in mortification, as well as in abscess or dispersion. When mortification ensues, it is of course exceedingly dangerous, if not necessarily fatal, and we have no known remedy to cure it. The induration will sometimes exhibit a decided scrofulous tendency, and pursue the same course as scrofulous testicle, and at other times it will become perfectly cartilaginous, or bony.

When calculi or stones form in the prostate, it is sometimes possible to cut them out, providing their presence is so evident that there can be no mistake, but this is very seldom the case. Like most other diseases of the prostate, the indications of this are so obscure, that its precise seat and nature in most cases can only be guessed at.

Sometimes the stones will be discharged, by way of the urethra, and relief immediately follow. Warm bathing and fomentations probably tend to facilitate this mode of escape, by relaxing the parts. I have known persons who had long suffered from all the usual symptoms of enlarged prostate, be perfectly relieved after voiding a few calculi, seldom larger than a pea.

Among other means of obtaining relief, occasionally successful in prostatic enlargement, I may mention injections in the rectum of cold thin starch and laudanum, frequently repeated. Galvanism I have also tried, and in some cases with marked success.

Chronic enlargement of the prostate gland is rather common amongst old men, particularly those who have led a sedentary life, or been addicted to sexual excesses

\section{EXCESSIVE SENSIBILITY OF THE GENITAL ORGANS。}

Sometimes the sensibility of the genitals is so much exalted, either naturally or accidentally, that emissions occur upon the slightest excitement, and the individual is thus made impotent from inability to perfect the connection. This condition is in reality a diseased one, and ought so to be considered, as much as any other we have described.

The seat of this extra sensibility is sometimes in the testes or vas deferens, or in the ejaculatory ducts, but most frequently in the glans penis. When it is rery great the organs are thrown into a violent orgasm almost at a touch, and emission occurs it the very first attempt. I have known men married for years who never had pe. fect association with their partners during the whole time, and simply from this cause. They were in no respect whatever deficient, nor even subject to nervous excitement, but were unfortunately affected by this excessive sensibility. Other men I have known who dare not marry at all from this cause, feeling sure that if they did the marriage could never be consummated.

The causes of this trouble appear to lie in the peculiar structure of the glans, the okin of which is unusually delicate, while its nerves are ramified into thousands of 
minute twigs, which are distributed to every point of the surface. The exquisite sensibility thus produced is so great, in some, that the mere touch of the clothes is sufficient to excite, and the patient is thus kept in a constant state of irritation. Sometimes a similar state is induced by disease, particularly by inflammation, the penis being then as tender as the surface of an abscess just before it breaks, and feeling the slightest pressure or friction.

When this excessive sensibility is produced by any disease, it will usually disappear when the disease is cured, but when it is natural the removal or modification of it becomes much more difficult, though great relief can nearly always be obtained, The first requisite is to remove all extraneous sources of irritation, and to attend to the diet, clothing, and general regimen; then the great point is to harden the skin of the glans, so that the nerves may be more thickly covered, and their sensibility reduced. This must be effected by the constant use of astringent washes, or caustics, and in certain cases by the use of galvanism. Every one is familiar with the effect of certain substances on the hands, in making them hard and destroying the delicacy of their touch, and it will be readily seen that the same means will deaden the sensibility of the glans and other parts. Lime-water is very good in some cases, and water saturated with iron-rust in others, but the best agents are the astringents, such as alum-water, solutions of tannin, or white oak bark, or gum kino or catechu. These must be used every day, as washes, and the glans kept covered with cotton soaked in them. They will always do good, and frequently effect a perfect cure, bu't when they are not sufficient, caustic must be employed, and this must be done by a physician.

\section{PLATE XXXV.}

\section{DESCENT OF THE TESTICLE INTO THE SCROTUM.}

In the fotus, before birth, the abdomen and scrotum form one cavity, the scrotum being in fact only a part of the abdomen, as seen in the plate.

3. The testicle, just under 2 , the kidney. The testicle has to descend from that position down into the scrotum 7 (through 6 to 7 ).

The descent is gradual, from the sixth to the ninth month, the testicle going by degrees from 3 to 4 , to 5 , to 6 , and finally into the scrotum (7) at birth.

After birth the opening from the abdomen into the scrotum closes up, except what part of it is filled by the spermatic cord.

The first position of the testicle, it will be seen at 3 , is the same as that of the female ovary.

10 is the large intestine : 12 , the navel string, or umbilical cord. 


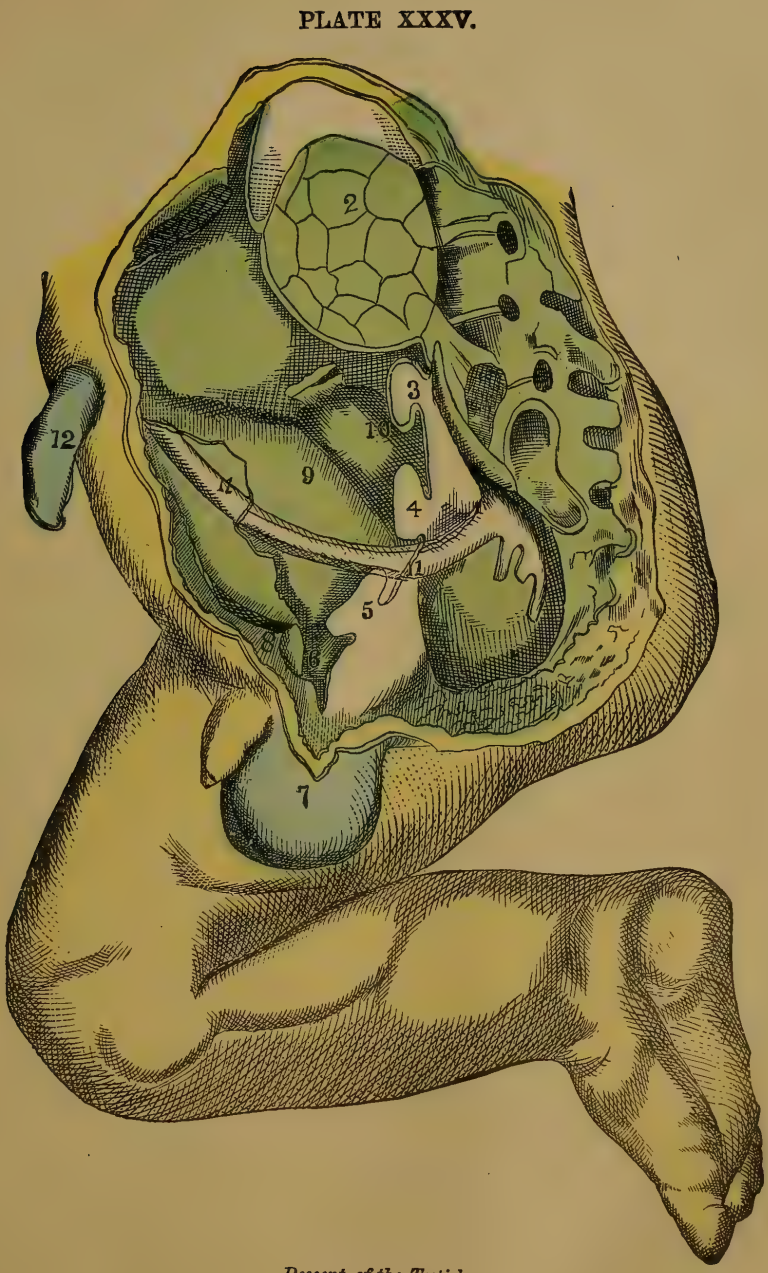

Descent of the Testicles. 



\title{
CHAPTER XLVII.
}

\author{
SPERMATORRHGA, OR EXCESSIVE LOSS OF SEMEN.
}

THIs is a subject of more importance, as regards human health and happiness, than perhaps any other that can be mentioned, and yet it is one about which scarcely anything is known, except by a few individuals. I do not hesitate to say that more eril effects, ten times over, are produced by this almost unsuspected cause than by all the diseases already enumerated, and perhaps even than by nearly all other diseases put together. And not only is it destructive to the body, by preventing its proper development in youth, making it a mass of disease in mature life, and causing its premature decay and death, but it is equally baneful to the mind. By its influence the vivacity and energy of youth are changed to a listless indifference, the vigor of manhood is destroyed, and the calm, peaceful content of mature life is turned into respondency and gloom. Many a young man with mental powers capable of making him both eminent and happy, and with every requisite of bodily health and strength, has terminated a short-lived miserable existence by suicide, or dragged out his life in a state of idiotic imbecility through this unsuspected disease.

The excessive loss may either be the result of licentious indulgence, or it may occur without the individual's cognizance, the effects being much the same in either case, though apt to be ascribed to other causes in the latter case, and also to be often underrated.

The fact that the semen does frequently escape in an involuntary manner is generally known, there being but few men who have not so suffered more or less, and it is also well known that such involuntary losses are very injurious to health, but the real extent, either of the disease or its evil effects, are known to but few. The only cases known to occur, by people generally, are those in which the escaped semen is actually seen, but very frequently the loss occurs and is never suspected. In like manner, the only effects of this disease that are usually taken cognizance of are those which are plain and obvious; but there are many others, much more to be dreaded, that can only be detected and assigned to the right cause by those practiced in observing them. Many men suffer the extreme of wretchedness and disease, become insane, and die prematurely, from this complaint, without ever having dreamed of anything of the kind. Frequently, too, their medical advisers are equally in the dark, and go on attempting to cure the mere effects, while the grand canse of all is left untouched. Spermatorrhœa, as I shall show further on, when excessive, may produce symptoms similar to those of almost every disease the system is subject to, and thus lead to the belief that there is disease of the heart, liver complaint, dyspepsia, and a hundred other affections, of which there is in reality no trace whatever. It may also materially impair the powers of the mind, or prevent their proper manifestation, and so change the feelings and disposition that the individual can scarcely be recognized as the same person, by his conduct. 
The ravages of this destructive disease are not confined to any particular class, age, or condition, nor is it always a consequence of vicious conduct, as some suppose, but, on the contrary, it frequently attacks the most virtuous and exemplary. Some of the causes that lead to it may operate as well upon the healthy and strong as upon the weak and sickly, and attack the middle-aged married man, of temperate habits, as well as the licentious unmarried youth. It is therefore of the utmost importance that this destructive pestilence should be unveiled, so that every one may know how to guard against it and ward off its evils.

To understand why it is that spermatorrhœa leads to such manifold and diversified evils, it will be necessary to refer to the organic and sympathetic connection between the generative organs and the rest of the system, the intimacy and extent of which are but little known.

To a considerable extent, the genital organs are in direct connection with the urinary, and in some places the same parts are common to both. The lower part of the large intestine, or the rectum, is also in close juxtaposition to them, as may be readily seen by referring to the illustrations of the male system. Any disease, therefore, which affects the genital organs is very apt to derange them likewise, and it is quite possible that the secondary disease may be more severe than the primary one. Every one knows that diseases of the bladder, kidneys, urethra, and rectum are quite common, and frequently very distressing, while the causes of them are often undiscovered. In many such cases, they are only symptoms, the primary trouble being spermatorrhøa.

The great cause, however, of the genital organs exerting such a general influence over every part is their intimate connection with the nervous system. There is no other process carried on in the body that requires so much nervous power as the formation and evacuation of the semen, and no other is therefore so exhaustive of the vital energy. Even in youth the amount of this power required is very great, to effect the full formation of the seminiferous glands ; in fact, Nature seems to put forth so much effort for this purpose that every other part is stimulated at the same time, and thus the perfecting of the genital organs is the means of developing the whole system.

This is the reason why those who are castrated are always imperfect, both in body and mind, and die early. If the testes are removed, there is no other part for which nature will sufficiently exert herself to stimulate the whole, and consequently the development is only partial. Those who have ever seen eunuchs will have had sufficient proof of this, but any one may observe the same thing in mutilated animals. Compare the ox with the bull, for instance, or the entire horse with the castrated one, and it will be at once evident that the form of the body, and the disposition, are completely changed. Even in after-life the vital energy required to secrete the semen invigorates the whole system, and disposes it to a constant activity that would otherwise not be exhibited. Men deficient in this respect are never noted for their enterprise and love of adventure, but are always inclined to be calm, nnactive, and retired, even when possessing genius. Nearly all men of strong, energetic minds and daring dispositions are of warm temperaments, or, in other words, have a plentiful secretion of semen. It is, therefore, an essential and important agent, both for perfecting the system in early life and also for rousing it to sufficient exertion afterward, and beyond doubt a deficiency or superabundance of this fluid may exert a decided influence on the character of the individual. In all probability, many are dull and inactive from 
deficiency in this respect, while many others are too impulsive and restless from excess, and yet the truth is seldom suspected. It is too much the custom with physiologists to regard only the brain as being concerned in the production of mental characteristics, and to consider it as the sole fountain of that mysterious influence which is constantly exerted over every part of the system. A truly philosophical view of the subject will, however, I am confident, show that there are other parts whose action should by no means be overlooked, and among the most important of these are the genital organs.

A due consideration of these facts explains the true philosophy of sexual indul gence, and shows why licentious excess produces so many and such severe evils. In a healthy state, Nature goes on supplying the necessary nerrous energy, both to the testes and the rest of the system, till a superabundance of semen is formed, and then there is experienced a desire for its emission, the gratification of which is, physiologically speaking, under such circumstances, both proper and healthful. It is, in fact, only the expenditure of the overplus energy, and does not in any way weaken or destroy. If, however, by artificial excitement, or factitious desire, the seminal emission occurs before this superabundance exists, it becomes exhaustive, and seriously impairs the vital energy. Indulgence should therefore be allowed only when this overplus power excites to it, and any man can easily tell when that is by studying his feelings anil experience, and by not giving way to artificial excitement.

When the seminal emission occurs oftener than nature properly provides for, the nervous energy expended is no longer a useless superfluity, but a portion of the common stock, and its abstraction necessarily weakens the power of the whole system. For a time Nature can, by extra effort, supply the deficiency thus produced, but if the excess be too long continued this effort at last fails, and then a general prostration ensues. The career and ultimate end of any licentious debauchee will well illustrate this, and should act as a timely warning to shun the same evil path.

The reason why the victim of excessive seminal discharge suffers from almost every ailing of body and mind, will now be evident. The stomach cannot digest, the heart cannot propel the blood, nor the brain think, uniess they are each supplied with a due amount of nervous power, and if most of that be expended in the production and evacuation of the semen, of course those organs will be deficiently supplied, and will consequently perform their functions imperfectly. Here, then, we have the cause in such cases of dyspepsia, heart disease, dullness of the intellect, insanity and a thousand other evils.

Besides this exhaustion of the nervous energy, however, it is also probable, from observations recently made, that the semen requires for its perfect formation some important and subtle elements of the body, the abstraction of which, in too great quantities, is highly injurious. It has been supposed, and with considerable plausibility, that a part of the seminal fluid is identical with some portion of the brairs and nervous substance, and that this common material is produced for the use of both respectively. This explains why the mind is nearly always active in those who are of a warm temperament, because the brain is nourished by a part of the same material which is produced to form the semen. It also shows why the mind must suffer when the semen is expended in too great quantity, because the very substance the brain requires is that taken away, and it suffers, in fact, from want of its proper nutriment. In confirmation of this it has been stated that the brain has actually been found wasted and softened in many persons who have died from licentious excesses, and I 
have myself observed the fact, after death from masturbation. In one case especially, the color and consistence of the brain were so remarkably different from those of a healthy person that no one could fail to observe it; in fact, it had the very same appearance as in some states of acute disease, and I have no doubt but that in many of these poor victims the brain is constantly in a state of inflammation, or wasting away. This is probably the true cause of that distress in the head, dimness of sight, and loss of hearing that many of these patients complain of, and which sometimes continue till they become deaf, blind, and insane.

This explanation of the way in which spermatorrhøa produces such varions erile, will make our detailed account of its effects easily understood, and will also make clear the philosophy of its proper treatment, and what should be done for its prevention.

\section{CAUSES OF SPERMATORRHEA.}

There are undoubtedly many causes of spermatorrhœea with which we are but imperfectly acquainted, and probably many that are not yet suspected. Mr. Lallernand remarks that "when it occurs spontaneously, during sleep, in a healthy and continent individual, it doubtless exerts a beneficial influence on the economy, by freeing it from a source of excitement, the prolonged accumulation of which might derange the animal functions. In these cases it has an effect analogous to that pro"luced by the bleeding at the nose, during youth." If, however, the discharge becomes excessive, or continues longer than the state that first produced it, great evil may follow, as already shown. Probably the most frequent cause of spermatorrhoa is too frequent sextal excitement, especially in the form of masturbation. This leaves the organs in a state of irritation which stimulates them to constant activity, and makes them perfectly independent of the will. At first the emissions are always attended by erections and pleasurable sensations, during sleep, but in time they begin to occur without either erection or sensation, and finally take place in the day-time, whenever the bowels are moved, or the urine passed, and in extreme cases there is a constant running away of the semen without any intermission. To understand the reason of this constant and uncontrollable escape of the semen, I must refer to some of the anatomical details given in the description of the male organs. It is there shown that the semen passes, from the testes, along a pipe or duct, called the vas deferens, which opens into the urethra, through the prostate gland, by two little mouths called the ejaculatory ducts. These mouths are always shut in a healthy state, except under the influence of sexual excitement, and then they open to let the semen through, but afterward firmly close. If, however, they are called upon to do this too often, they become irritated or relaxed, and consequently are more disposed to open from slight causes, and have less power to close again. They are especially liable, when irritated, to be acted upon by the urine, which passes over them, and as the bladder itself soon partakes of the same irritation, the urine is being constantly passed, and is nearly always mixed with semen. The pressure of the rectum on the prostate gland, when the bowels are moved, will also cause the ducts to open, and this is the reason why many persons always lose semen when at stool. The ordinary motions of the body even will do the same, in bad cases, and more especially riding, running, leaping, or coughing. Finally, the ducts entirely lose the power of closing, from relaxation, and then the semen is constantly dribbling away.

Whenever the semen can be seen, there can of course be no mistake as to the 
nature of the trouble, but very often it flows involuntarily without being visible, as before stated, and thus the individual may suffer without its being suspected what from. The manner in which this occurs will now be understood, - - the ducts become sensitive to the touch of the urine, which in a healthy state produces no effect upon them, so that every time that fluid passes they open and allow the semen to escape along with it. The bladder itself being irritable also, owing to its intimate connection with the diseased parts, the urine cannot be long retained; the smallest quantity causes an irresistible desire to expel it, and thus the individual is constantly urinating, and constantly passing semen at the same time. It is only very recently that this fact has been ascertained, and doubtless numbers have died in this way, as before remarked, without the slightest suspicion being excited as to the cause of their death. The means by which this mode of seminal escape is ascertained are simple and sure, in practiced hands, as I can testify from abundant experience. They consist in examining the urine with a properly constructed microscope, which exhibits in it the presence of the seminal animalcula. These minute animals are nearly always to be found in the urine of those afflicted with spermatorrhoea, and their presence of course proves the escape of semen beyond a doubt. It is quite common for patients to remark that the urine is thick and ropy, particularly the last drops, and it is usually thought that this arises from inflammation of the bladder, but in most cases it is only from being mixed with semen. In this way I have been able to ascertain the true nature of a person's disease in numerous instances, and to apply the proper remedy, where previously they had been treated only for some symptom of that disease, and of course without any permanent benefit. Many times I have had respectable married men, of temperate habits, come to me with every symptom of spermatorrhœa, but who assured me that they had never been troubled with anything of the kind. They judged so, simply because they never saw anything pass from them, and they did not know that it could occur in any hidden form. On showing these people the semen in their urine they were amazed, and deeply regretted the want of information that had prevented them from knowing the cause of their suffering before. I have no doubt but that this hitherto undetected form of spermatorrhœa has been the cause of incalculable misery to thousands, and that it has condemned numbers to insanity and untimely death. It is perhaps necessary to remind the reader here that when the loss occurs in this way, it is from the ducts being irritable, and not from being relaxed. When really relaxed or open, the semen escapes, more or less, at all times.

It was remarked above, in speaking of the causes of involuntary seminal emissions, that it probably arose most often from too frequent sexual excitement, especially in the form of masturbation. It may be as well to remark, however, to avoid misapprehension, that too frequent excitement in any form may act in the same way. There are undoubtedly many married men who much exceed the bounds of true moderation, and they are apt to think that no harm will follow from such excess, because it is legitimate. This is a great and a fatal mistake; such men are just as liable to suffer as if their gratification was sought under any other circumstances, and I very often have such come to me for advice. The physiological laws, by which health is maintained, are quite distinct from those moral enactments demanded by the welfare of society; and the observance of one of these can never give immunity for the infringement of the other.

It is not, however, excessive indulgence only that will cause spermatorrhœa, for 
the very opposite of it may do the same. There are few men of warm temperament, if healthy, that can remain long strictly continent without having involuntary emissions during sleep. These, as before remarked, are sanitary efforts of nature to relieve herself, and when not too frequent may be beneficial rather than hurtful. Unfortunately, there is always a tendency, if the continence continues, for them to become more frequent, so as eventually to constitute a real disease, and thus many a virtuous young man, who has never indulged in any form, is subject to the same misfortunes as the licentious debauchee, or the victim of masturbation. This is a truth as important to be stated as any other, though its announcement may seem strange to those who hear it for the first time. There are, fortunately, many means that can be used, in such cases, to lessen this tendency to an undue increase of the discharge, and therefore these persons should know of their danger, in order that they may see the necessity for adopting such means. Over-exertion, or great agitation of the mind, will also cause spermatorrhœe, owing to the sympathy between the genital organs and the nervous system, and it is frequently produced in this way in merchants, students, professional men and others. I have known many men of business who always had involuntary emissions when they were much troubled about their affairs, and several law students have assured me that after any unusual application they suffered in the same way. Many other diseases of the generative organs will likewise lead to spermatorrhoa, and so will certain derangements of the neighboring parts, particularly long-continued constipation of the bowels, piles, and gravel. Certain medicines also, especially cantharides, phosphorus, iron, and opium, are very apt both to produce and aggravate it, and so will the use of tobacco, alcohol, and heating or highly-seasoned food. Among occasional causes still less likely to be sus* pected than any above referred to, may be mentioned worms in the rectum, various skin diseases, and diseases or injuries of the brain. Syphilitic and gonorrhœal affections also leave a tendency to spermatorrhœa, and often directly produce it. I have become satisfied also that in many children there is a predisposition to it, inherited from their parents, accompanied, in many cases, with a congenital weakness of the parts, which is frequently denoted by incontinence of urine. The most frequent canse, however, is sexual abuse, though the disease may not assume a very aggravated form till many years after; the follies and vices of youth being thus, in many instances, the originators of disease and misery in mature life.

The general effects already described may follow from great seminal loss occurring in any way, but when that loss is involuntary these effects are usually more severe, and several others are experienced that do not always accompany voluntary indulgence, even when excessive. In fact, involuntary loss is generally indicative of extensive and confirmed disease, and of course its symptoms are various.

Some of the first effects are exhibited upon the parts more immediately connected with the genitals, particularly the urinary organs. The irritation speedily extends from the ducts and vas deferens to the urethra, and finally to the bladder, which becomes in consequence so sensitive that it cannot retain the smallest quantity of urine without inconvenience. The patient is therefore constantly desirous to urinate, though but little fluid escapes when he does so, and is thus kept in a state of continual annoyance, so that he dislikes to join company, or to go anywhere in public, for fear that he should not find opportunities for relieving himself.

I have known men made completely wretched in this way, and in one case, recently, the individual was compelled to give up a profitable and pleasant occupation 
merely because he could not remain at his post sufficiently long at a time. Ultimately this irritation may become so bad that all voluntary power over the bladder is lost, and the urine then escapes constantly, without the patient being able to control it. This irritation of the bladder is usually one of the first indications that a man has exceeded the bounds of moderation, though it does not always occur, even in the most confirmed cases of involuntary emission.

When the irritation has existed long in the bladder it is apt to extend along the ureters to the kidneys, and to produce there all the symptoms of inflammation of the kidneys, and of gravel, with great weakness and pain in the back. It is difficult to convince many patients that they have not these diseases, and still more difficult to show them, when they are uninformed, how their troubles really arise. In fact, I have known numerous cases where physicians themselves have been deceived, and where they have prescribed for these mere symptoms, supposing them to be the primary disease, without ever suspecting the truth.

Another part very apt to suffer from spermatorrhoea is the rectum or large intestine, which is in direct communication with the prostate gland and seminal vesicles, as may be seen by the illustrations. In some persons there is a constant feeling as if the bowels were about to be moved, with a bearing down sensation, and a partial protrusion of the intestine. In others there is a general uneasiness around the anus and perineum, which causes the patient to be continually shifting about on his seat, and moving as if he were in pain. Occasionally there is considerable irritation, or itching, and very often severe piles, from the circulation of the blood being impeded. In short, the rectum may be affected in many different ways, and so may the rest of the intestines from their connection with it. Sometimes there will be a partial paralysis of their muscles from the deprivation of nervous power, which, by arresting the peristaltic motion, will cause obstinate constipation. At other times the mucous coat partakes of the general irritation, and then we have diarrhœea exhibited, and no medication whatever can check it, so long as the spermatorrhœa continues.

Another symptom of spermatorrhoea sometimes met with is a peculiar irritation of the urethra and meatus urinarius, or external opening from the penis. This irritation is sometimes very slight, and only experienced after urinating, but at other times it becomes quite severe, and pretty constant, resembling, in fact, a real gonorrhoea, and being even accompanied by a discharge, showing the existence of inflammation. Many men have become much alarmed from this symptom, supposing it to be an infectious disease, and in several instances I have known it the cause of mutual suspicion, and much domestic unhappiness.

These local effects are usually the precursors of more general and severe ones, the connection of which with the true cause of all, it becomes more difficult to trace. In addition to a universal lassitude and weakness, there is experienced a remarkable loss of power in the lower limbs, owing to which the patient finds it impossible to walk far, or to stand long upon his feet, without being overcome with weariness, and feeling numbed in the legs and thighs. The slightest exertion makes him tremble and look pale, his heart flutters, or stops beating altogether, and he experiences a tendency to faint.

This distressing debility is sometimes so excessive that the individual becomes almost unable to move, and yet he may not be much fallen away, nor look very sick, so that uninformed persons are apt to think it is mere idleness or pretense. In the course of time, however, the stomach begins to suffer, and becomes so weak that diges- 
tion is imperfectly performed, and then emaciation follows, which frequently becomes a complete and rapid wasting away. The loss of nervous power sometimes affects the diaphragm more especially, and then there is great difficulty in breathing, which with other sensations, leads to the belief that the lungs are diseased. And when this occurs along with palpitation of the heart, which originates much in the same way, the poor patient is in a state of constant worriment and fear, nothing being able to convince him that he has not consumption and heart disease all at once.

The head is not exempt from the general influence, and headache, rush of blood, dizziness, and constant drowsiness, are commonly complained of. Partial dimness, or loss of sight, is also frequently observed, as if a cobweb had been spread over the eye, which fills with water, and looks red on the slightest extra use of it. The eyelids, however, are more disposed to inflammation than the eye itself, and it is impossible to do them any good while the spermatorrhœa exists.

The most marked effects, however, are exhibited in the mind and feelings. Mental activity becomes as difficult and unpleasant as bodily, and the patient becomes dull, listless, and moping, his memory fails, his judgment weakens, and all power of application seems lost. When he sits down to study anything, the powers of the mind appear to wander, so that he cannot bring them to bear on the desired point, and frequently he wakes up from a kind of dream and finds that he has quite forgotten the subject altogether. This listless abstraction often gets so bad that the individual is unfit for business of any kind, and not unfrequently it degenerates into insanity. I have known several instances of men failing in their business from this cause, which I have no doubt is oftener connected with human mistakes and errors than people suppose. In youth, especially, this effect is a very serious one, and the bright prospects of many a promising young man have been crushed in this way, without either himself or his friends suspecting the cause. If the records of college and business failures, and of our lunatic asylums, could all be properly written, the numher of victims in each who have been made by this disease would astonish every one. And probably we may add also that moral failing has not unfrequently had the same origin.

The feelings and dispositions of patients of this class, in most cases undergo as decided changes as their mental powers, and equally to their disadvantage. Sometimes they become melancholy and sensitive to such a degree, that they burst into tears from the slightest cause, and constantly think they are purposely subjected to trials and insults that no one around them dreams of. At other times they become irritable and peevish, keeping all around them in as great a state of irritation as themselves, and firmly believing they are the most ill-used people in the world. Occasionally there is some peculiar form of monomania exhibited, one person believing that he is constantly pursued by some enemy, who wishes to deprive him of his life or fortune, while another firmly believes that some terrible misfortune is about to overtake him, from which he can by no effort whatever escape. It is but seldom there is any tendency to violence exhibited, at least toward others, the powers being too much depressed, but sometimes the patient will injure himself. Many instances are on record of monomaniacs, of this class, castrating themselves, under the idea that they could never be better while the genital organs remained. In general, there is a decided aversion to the opposite sex, and a shyness and embarrassment in approaching them. Many reputed hermits and woman-haters have been men of this kind. 
In short, there is no end to the aberrations and vagaries of mind and feeling iniuced by continued spermatorrhœa。

There is, however, one melancholy effect of this disease, occasionally seen, which I would willingly pass over, if it were not necessary to disclose the whole truth, so that the real extent of the evil may be seen.

The effect I refer to is a tendency to unnatural habits and vices, which, in such cases, charity bids us look upon as resulting from a diseased hrain, sympathizing with the derangements of other parts.

The following cases are selected partly from my own note-book, and partly from M. Lallemand's celebrated work, Des Pertes Seminales:

Case I. (Communicated by Dr. MeDougall, in the preface to his Translation of Lallemand.)

" R. Hwas in the habit of taking much and violent exercise. About the age of sixteen he entered a banking establishment in London, in which, by great diligence and steadiness of conduct, he rose, before he was twenty-five, to the post of cashier. The affairs of the house fell into disorder, and ultimately a bankruptcy occurred ; Mr. $\mathrm{H}$ - - from the amount of confidence reposed in him by the partners of the firm, was much harassed during these unfortunate proceedings. Soon afterward he became manager of a large mercantile establishment in the city, and about this time commenced some speculations in foreign bonds. From fluctuations in the share market, he was a loser to a considerable extent; his mind was much harassed, and he began to suspect those about him of dishonesty toward their employers. On investigation these suspicions were proved to be totally unfounded; $\mathrm{Mr}$. H- gave way to great violence of conduct, and resigned his situation. About this time his father died, and $\mathrm{Mr}$. H_— was much disappointed at finding that property which he had incorrectly believed entailed, and consequently his, as eldest son, was left by will to be equally divided between himself and the rest of his family. His conduct at this period was of the strangest description. He dreaded to go out into the streets of the town where his family resided, refused to join in their meals, and ultimately abruptly left their house to return to London. In $183 \%$, his state had become such, that in consequence of his repeated letters, members of his family visited London, and on their return took him with them into Devonshire. About this time his mental disorder put on a decided aspect; and I had then, as well as later, ample opportunities of observing his conduct ; and frequently heard his complaints. Emissaries were constantly on the search for him to arrest him for unnatural crimes committed in London; every one who met him in the street read in his countenance the crimes he had committed; tailors made bis coats with the sleeves the wrong way of the cloth, in order to brand him with infamy; the sight of a policeman in the street alarmed him beyond measure; and often if a stranger happened to be walking for some little time in the same direction as himself, he would exclaim that he was one of the emissaries sent to seize him. At other times he would lock him. self in his room and weep by the hour. He never took his meals with the family, and never tasted food or drink, without first preserving a portion for chemical analysis, as he was convinced his iriends were in a conspiracy to poison him slowly, in order to wipe out the memory of his crimes. These ideas haunted him night and day. His digestion was much disordered; his sleep broken and restless, and his bowels excessively constipated. His face became flushed, and periodical attacks of 
cerebral excitement occurred, during which he complained of vertigo, noise in the head, loss of sight, etc. He complained also of loss of memory, and frequently of bodily weakness, and lassitude. The best medical advice the neighborhood afforded was obtained, unavailingly; the opinions of the gentlemen consulted were that $\mathrm{Mr}$. $\mathrm{H}$ - was laboring under aggravated hypochondriasis, complicated with monomania. Various causes were suggested as giving rise to the disorder, but no previous case of insanity was recollected in any branch of the family. $\mathrm{Mr}$. H- now began to talk of leaving England for America, in order to avoid his persecutors; and to prevent this he was placed under the care of a private keeper. While with this person he frequently and bitterly complained of constant pollutions while at stool, with darting pain, and a sense of weight between the rectum and bladder. He had also urethral irritation, attended with discharge, pains in his loins, and in one groin, weakness of his legs, thick urine, piles, and obstinate costiveness. He kept a diary at this time, which is at present in my hands. Not a day is passed in this diary without mention of the distressing seminal discharges from which he suffered. These were treated as of no importance by his medical attendants, although he never ceased to complain of them, and solicited aid so long as he continued in confinement in England. When led away from his disorder into any discussion on public matters, he was, however, a most amusing and instructive companion; as a man of business he was equally acute, and to a stranger, as long as nothing was done to offend him, he was, to all appearance, a man of observation and experience in life. For about two years and a half he was under the care of various gentlemen, deroted to the insane, and at length he was discharged from an establishment near Bath, by the visiting magistrates, as a person confined without due cause. His first act was to commence legal proceedings against his friends for his detention, and having gained his action, he immediately proceeded to London, and waylaid and violently assaulted a gentleman of high commercial standing in the city. After this offense he was confined for a considerable period, in default of bail, and immediately on his liberation, it is believed that he proceeded to America. From this time nothing was heard of him until September, 1843, when a letter was received by a gentleman who formerly attended him, in which he stated that the same course of persecution was pursued toward him in America, as had been followed in England. He complained of not being able to obtain efficient medical treatment, although he had applied to the most eminent practitioners at Cincinnati, and afterward at Philadelphia and New York. Affer this, nothing more was heard of Mr. H__ until the year 1845, when an American newspaper was forwarded to his friends by an unknown hand, containing an account of his death, and of an inquest held on him, headed 'Death of a Hermit in West Jersey.' It was stated that he had lived on a small farm, entirely alone, with the exception of a dog, and that he had shunned all intercourse with his neighbors. He was taken suddenly ill, applied to a neighboring farmer for assistance, but died in the course of the following day. From information subsequently obtained by his friends, it is believed he died of apoplexy, or perhaps, in one of the attacks of congestion of the brain, from which he frequently suffered before he left his native country.

"The symptoms of this unfortunate case strongly resemble those of the thirtysecond and fifty-sixth cases related by $\mathbf{M}$. Lallemand. It was more aggravated, however, and presented the somewhat uncommon feature of the patient's discovering the frequent pollutions, and constantly complaining of them ; these, unfortunately, being 
treated as matters of no importance. Mr. Hreference to his having either committed or been accused of committing unnatural crimes, and this idea never entirely left him, although during the latter part of his life, his more prominent hallucinations had reference to imaginary persecutors constantly watching him, and endeavoring to ruin him by spreading false reports, and to poison him by adulterating his food, and infusing noxious gases into the air. There can be little doubt, on taking into consideration his complaints of weight between the rectum and bladder, with darting pains, etc., in the same region, that the pollutions arose from irritation in the neighborhood of the prostate; and I think, that if at an early period of his disease this had been relieved, there would have been considerable hope of his recovery from the hallucinations he manifested."

This case I have selected as one that gives a great number of the symptoms usually observed, and as being well calculated to give a correct idea of the immense series of evils that often follow from this disease. The next case is also one of Dr. McDougall's, and is equally instructive. It is a perfect copy of numbers that have come under my notice.

"The other case to which I have alluded as particularly attracting my attention, and which came under my notice about the same time, was that of a young man of high intellectual power and general talents, studying medicine. This gentlemar. was one of my most constant companions, when almost suddenly, a serious change came over him-he shunned society, especially that of females, was morose, taciturn, and frequently shed tears; he sat sometimes for hours in a kind of abstraction, and on being aroused from it he could give no explanation of his thoughts and feelings; he constantly expressed to me his conriction that he should never succeed in his profession, and frequently exclaimed, that he was ruined both here and hereafterbody and soul-and by his own folly. About twelve months previous to this depression of spirits, he had a very severe attack of blennorrhagia, with orchitis and phymosis. This left a degree of irritability in the bladder, which required him to pass arine frequently. His digestion became so disordered that the simplest food would not remain on his stomach, and he had frequent eructations of fluid, which blazed like oil if spit into the fire. This gentleman's father was a physician, and being naturally anxious for his son, obtained for him the advice of many of the most eminent of the faculty. No improvement took place however. After he had been six months in this state, I had an opportunity of spending three weeks by the sea-side, and my friend accompanied me. We slept in the same room, and he was scarcely ever out of my sight. Before our return, his health was almost re-established, and his spirits had returned to their natural condition. Twelve months later, however, he again fell into the same state of despondency, and this time his condition was much worse than on the former occasion. He frequently remained in bed three parts of the day, and no threats or entreaties on the part of his father, could induce him to get up. His intellectual faculties were totally prostrated, and a vacant stare, which took the place of his natural lively expression, induced considerable fears of his ultimately becoming idiotic. I was the only person who possessed any influence over him, which may perhaps be attributed to his feeling that I was aware of the cause of his disorder. This state continued between three and four months, during which time I was with him as much as my other duties would permit, and frequently showed him the folly of the course he pursued. At the expiration of this time he gradually recovered. He has since had a slight relapse once only; he has pursued 
his professional studies with success, and is at present a medical officer in her majiesty's service.

"On this case, I need only remark, that the symptoms did not arise from involuntary seminal discharges, but from excessive discharges caused hy abuse. 'The various treatment recommendeG by the distinguished practitioners consulted, proved unsuccessful, because the origin of the disorder was unrecognized, and the remedies consequently useless, while the habits of abuse were continued."

The following case is one of M. Lallemand's, and is chosen here as an illustration of the fact, already stated, that this disease may exist and become very serious, in married persons. It also shows how physicians may easily mistake the symptoms for those of other affections.

"In the month of January, 1824, I was requested to see M. de S- affected with symptoms of cerebral congestion, from which he had suffered for some time. During several consultations I gathered the following facts :

"M. de S— was born in Switzerland of healthy parents, and his father died suddenly of affection of the brain. M. de S-, possessing a strong constitution and an active mind, received an excellent education, and at an early age turned his attention to the study of philosophy and metaphysics; he afterward studied moral philosophy and politics.

"After having spent some years in Paris, pursuing his favorite subjects, he was obliged to undertake the management of a manufactory, and to attend to details which wounded his pride. He became, by degrees, peevish and capricious-passed, without apparent cause, from an extravagant gayety to a profound melancholy -was irritated by the slightest contradiction-showed no pleasure at fortunate events-and gave way to anger on improper occasions; at length he appeared to feel disgust and fatigue at correspondence or mental exertion."

At this period he married, and Dr. Butini, of Geneva, his medical attendant and friend, wrote respecting him, as follows :

"With this marriage the most happy period of his existence seemed to commence; but soon the germs of the disease, which so many causes had contributed to produce, became rapidly developed. It was perceived that M. de S- wrote slowly and with difficulty, and his style presented signs of the decay of his faculties; he stammered and expressed his ideas very imperfectly ; he experienced, also, at times, attacks of vertigo, so severe as to make him fall, without, however, losing sensibility, or being attacked by convulsions.

"One day an attack which frightened the patient seriously, and left a deep impression on his family, came on whilst writing an ordinary letter. His medical attendants attributed this attack, which left a weakness of the right side of the body, to apoplexy. Twenty leeches were applied to the anus, and the danger seemed at an end.

"Similar attacks, however, oceurred at Geneva, Montpellier, and several distinguished practitioners were consulted: some of these, struck by the misanthropie irritability of the patient, and his solitary habits, regarded the affection as purely hypochondriacal or nervous ; others, taking into consideration his digestive disorder, considered it an affection of the liver; but the great number were of opinion that there existed a chronic affection of the brain, such as encephalitis, or chronic meningitis, arising from hereditary predisposition. This last opinion was held by Dr. Bailly (of Blois). 
"At all these consultations, the necessity of abstaining from serious occupation, the utility of traveling-of various amusements, and of a strict regimen-and the importance of free evacuations from the bowels by means of purgatives and injections-were agreed on. Many of the practitioners recommended the frequent application of leeches to the anus, with milk diet, etc. ; others thought that assafotida, baths, and camphor, were indicated.

"None of these modes of treatment produced any considerable amendment; the leeches weakened the patient, and the milk diet disordered his stomach. His constipation continued. Cold plunge baths, and cold effusion to the head, relieved the insupportable spasms M. de S- experienced in his legs and face; the waters of Aix, in Savoy, and the use of douches also appeared to produce some improvement.

"Still M. de S_ became more irritable, and at the same time more apathetic. His attacks were more frequent and more violent, and he manifested greater indifference toward the persons and things he had before been partial to. The weakness of his limbs increased to such an extent that he frequently fell, even on the most level ground. His nights were restless, his sleep very light and often interrupted by nervous tremors, or acute pains accompanied with cramp. The cerebral congestion increased, and the imminent fear of apoplexy rendered leeches to the anus, venesection in the foot, tartar-emetic ointment, blisters, mustard pediluvia, and the application of ice to the head, necessary.

"Notwithstanding the employment of these energetic measures, another violent attack of congestion occurred. I was summoned on this occasion, and I found the patient restless, agitated, and incapable of remaining two minutes in the same place; his face was red, his eyes projecting, injected, and fixed, his physiognomy expressed extreme dread; his walk was uncertain, his legs bending under the weight of his body; his skin cold, and his pulse small and slow.

"The last circumstance attracted my attention, and I also recommended the application of leeches to the anus. M. de S-_ - immediately threw himself into a violent passion, and asserted that leeches had always weakened him without giving him any relief. I was too much afraid of the occurrence of apoplexy to pay attention to this assertion, and I succeeded in obtaining the application of six leeches.

"The next day I found the patient very pale, and so weak that he was unable tc walk-a source of much annoyance to him, as he manifested a constant desire for motion. An cdematous swelling of the parotid gland and of the right cheek followed, which was succeeded, a few days after, by a similar state of the left leg and foot.

"Sleep had become indispensable, and the patient was much reduced from the want of it; he told me with tears in his eyes, that he had lost his appetite and could no longer relieve his bowels. I also learned that he was habitually costive and flatulent ; that he often had recourse to injections and purgatives in order to relieve his obstinate constipation, and, lastly, that his walks, and the evacuation of his bowels had lately become the sole objects of his thoughts and conversation.

"Having observed analogous symptoms in almost every person affected by diurnal pollutions, I made further inquiries respecting the attack, in which it was supposed that the right side had been paralyzed, and I was soon convinced that the intellectual powers had been wanting, and not the power in the hand which held the pen; botb sides of the body had, in fact, retained an equal degree of strength. 
"Struck by a remark of Dr. Butini's respecting the progress of the disease soon after marriage, I made inquiries of $\mathrm{Mme}$. de $\mathrm{S} \longrightarrow$, and learned that the character of her husband had become so uncertain, irritable, and tormenting, that his friends thought he must be unhappy in his marriage. I then suspected that the origin of the patient's disease had been mistaken, and I requested that his urine might be kept for my inspection. The appearance of the urine was sufficient to convince me that my suspicions were well founded ; it was opaque, thick, of a fetid and nauseous odor, resembling that of water in which anatomical specimens have been macerated. By pouring it off slowly I obtained a flocculent cloud, like a very thick decoction of barley; a glairy, ropy, greenish matter remained, strongly adherent to the bottom of the ressel, and thick globules of a yellowish white color, non-adherent, like drops of pus, were mixed with this deposit. I was therefore convinced that spermatorrhœa existed, together with chronic inflammation of the prostate, and suppuration in the kidneys.

"Notwithstanding the state of M. de S-'s intellect, I was able at a favorable moment to obtain further information. At the age of sixteen, he had contracted blennorrhagia; this he carefully concealed, and succeeded in curing by the use of refrigerant drinks. The following year the blennorrhagia returned, and was removed by astringents. Two years afterward, from drinking freely of beer when heated, the discharge again appeared, and after some time it again returned, from the effects of horse exercise. Since that time M. de S- had felt little sexual desire, and had abstained from intercourse without regret. Ejaculatiòn during coitus had always been very rapid. Fully convinced by combining all these circumstances, I explained to M. de S - the nature of his disease, and he promised me to observe carefully.

"The next day he called me aside, and told me that the last drops of urine were viscid, and that during an evacuation of the bowels, he had passed a sufficient quantity of a similar matter to fill the palm of his hand.

"Eight days after, another attack of cerebral congestion occurred, followed by stertorous breathing, cold skin, and an inappreciable pulse; the patient fell into a kind of syncope, of which he died on the 1st of March, 1824."

Not long since I had under my care the editor of a newspaper, whose case was almost identical with the one above, and who was first made sick, as he informed me, by excessive agitation during an election campaign.

Constipation has been spoken of as a cause of spermatorrhoea, but few persons would suppose it could have the effects that sometimes follow from it. The next case, however, will convince the most skeptical, and though it is not often that we have such a severe case, there are yet plenty that are bad enough.

"M. de B - consulted me in the month of May, 1834, respecting a cerebral affection, on whose nature distinguished physicians could not agree, but which all regarded as very serious.

"He was of a middle height with a large chest and a well-developed muscular system; his hair brown and curly, his beard thick, his face full and deeply colored. Notwithstanding these signs of apparent strength and health, I noticed that his knees were slightly bent, and that he was unable to remain long,standing without shifting the weight of his body from one leg to the other; his voice was weak and husky ; the motions of his tongue seemed embarrassed, and he articulated his words in a confused manner; his attitude was timid, and his manner had something of incertitude and fear; he had been married fifteen days. 
"His mother-in-law and his young wife, who accompanied him, informed me that within this period he had several attacks of congestion of the brain, during which his face was highly injected. At the first of these attacks the surgeon, called in the night, had bled him to the extent of three pounds, in order to prevent apoplexy; repeated venesection, and the frequent application of leeches, had relieved such attacks of congestion, but had not prevented their recurrence. The patient had become subject to attacks of vertigo, and was unable to look upward without feeling viddy; his legs had become so weak that he had fallen several times, even when walking on level ground; his ideas had lost their clearness, and his memory failed sapidly.

"These symptoms had spread consternation through both the family of my patient and that of his wife, especially as several practitioners of reputation were agreed as to the existence of some serious disease of the brain, although they could not decide as to its nature. Most of them, however, were inclined to suspect ramollissement (softening).

"The countenance of the patient during this recital, the coincidence of the congestion with the period of his marriage, and the bad effects of blood-letting, made me suspect the nature of the disorder, and induced me to carefully question him separately. When we were alone, he told me, stammering, that an unexpected occurrence immediately after his marriage, had at first prevented any conjugal intimacy, and that afterward he had found himself completely impotent. He attributed this misfortune to the attacks of cerebral congestion, and to the bleedings he had undergone. On further inquiry, however, I discovered that he was affected by diurnal pollutions.

"The following is the history I obtained from this patient by dint of questioning :-At the age of sixteen he possessed a very strong constitution, and an ardent and passionate character. At school he contracted the habit of masturbation, and at the end of three months he had frequent nocturnal pollutions, with pain in the chest and troublesome palpitations, which warned him of the danger of the vice, and he renounced it forever. When he became free from the restraints of school, he subdued the ardor of his temperament by the most violent exercises-especially that of the chase-and he attached himself to agricultural pursuits with much energy.

"This new mode of life so completely re-established his health, that he was tormented by energetic and continued erections, to subdue which he employed riverbaths, even in the coldest seasons. He never committed excesses of any kind, and had never suffered from any blennorrhagic or syphilitic affection.

"In 1831, the erections were slightly mitigated, but he became very much constipated, which he attributed to the constant use of horse exercise.

"In 1832, he experienced some numbness and creeping sensations in his feet and legs.

"In 1833, frequent dazzling of sight occurred, with vertigo, difficulty of vision, and flushes of heat toward the head and face; the patient attributed all these symptoms to the effects of his still-increasing constipation.

"At the same time that these symptoms occurred, the patient's erections became rarer, less energetic, and after a time, incomplete; his fitness for intellectual labor diminished; the cerebral congestions became more frequent, and more severe, fhist face became habitually very red; his head burning; an almost constant fixed pain came on in the orbits, and his character became fickle and contradictory. 
"His family physician attributing all these disorders to a state of plethora, caused blood to be drawn several times without benefit.

"In March, 1834, M. de B- engaged himself to a young lady, who lived about two leagues from his estate; and in order to visit her without neglecting the care of his property, he was obliged to make long and frequent journeys on horseback ; shortly before his marriage these journeys became so frequent that he might be said to pass the greater part of his time on horseback. His constipation now increased to such a degree, that he passed forty days without fecal evacuation; during his efforts at stool he passed semen in large quantities, and in jets, although the penis remained flaccid. He had previously, several times, noticed the same occurrence, but as he attributed it to his long-continued continence, he paid little attention to the circumstance. His urine was constantly muddy; it was passed slowly and with difficulty, and threw down a large quantity of thick and flocculent deposit.

"M. de B- awaited the period of his marriage with a vague uneasiness, of which he could not imagine the canse; he was much attached to his betrothed, but nevertheless he experienced more embarrassment, than pleastire in her society.

"I have already stated what occurred after his marriage. I should add, that having examined his genital organs, I found them, contrary to my expectations, of unusual development ; the testicles were large and firm, but the scrotum was slightly relaxed. The patient experienced a strange tingling in the organs, and at times felt as if they were compressed by a band of iron. These sensations increased when near his wife, and the penis diminished in size and became retracted toward the pubes, in proportion as he endeavored to excite erection.

"The union of all these circumstances could not permit any doubt to remain on my mind as to the nature of his disease ; it became evident that all idea of cerebral affection must be abandoned, and that the diurnal pollutions, with all the symptoms of which they were the cause, must be referred to the patient's constipation.

"The first indication to be fulfilled, therefore, was to relieve the constipation; indeed, I hoped this was all that would be necessary. The youth of the patient, the development of his genital organs, and the strength of his constitution induced me to suppose that his cure would be prompt and easy. Things did not, however, follow sô simple a course.

"The next day the patient began to use ascending douches, and was put on a vegetable diet with iced milk.

"The first douches caused the evacuation of an immense quantity of fecal matter, in lumps as hard as bullets, and it was not until after the sixth douche that the feces were of normal consistence; I then caused the temperature of the water to be lowered to about $88^{\circ}$ of Fahrenheit, and afterward to about $81^{\circ}$. The last few douches were given at about $68^{\circ}$. After the twelfth douche had been administered, they were omitted, the bowels having acted regularly every day, without the necessity for the slightest straining.

"By this time, the patient's countenance had lost its purple tint, and presented a more natural appearance; the stunning sensations, of which he had complained, diminished by degrees, and at length disappeared entirely; his legs regained their strength, and he was able to continue in a standing posture for a long time without fatigue, and to take long walks without inconvenience; his voice resumed its natural tone, his eye regained its expression, and all his motions acquired firmness.

"At the expiration of a fortnight, the spermatic discharges during defecation had 
ceased entirely, but his urine still continued thick. His erections had already asquired sufficient energy to make him believe himself cured, but ejaculation took place almost instantaneously. The use of ice and cold lotions did not ameliorate his condition.

"Such was M. de B — - 's state at the end of a month, when, in order to act directly on the orifices of the ejaculatory ducts, I determined to canterize the prostatic portion of the urethra. As soon as the inflammation had subsided, his erections became more perfect and energetic, yet ejaculation still took place too rapidly. The period for using the mineral waters having arrived, I sent M. de B- to Aix, in Savoy, where I visited him shortly after. He had experienced very little benefit from the use of the waters, either externally or internally.

"I now prescribed douches, alternately very warm and very cold, on the perineum and loins, the spout being changed when the sensation, either of cold or heat, became very intense. The bath was ended after about twenty or twenty-five minutes, by the cold douche, and the patient's skin remained highly injected for some hours afterward.

"The effects of these douches were conclusive ; after the first, the patient's erections acquired a degree of vigor and duration which reminded him of his early torments. He continued the use of the douches for some days after his re-establishment, and when he left Aix the functions of his genital organs were perfect. Ejaculation was a good deal protracted by the use of the douches.

"I have entered into a somewhat lengthy detail of this case, because the subject affects gravely the most serious interests of society, as well as the happiness and peace of families. Besides, I confess that I was much interested by the unhappy position of a young man whose misfortune was undeserved, and could not have been foreseen, as well as by that of his wife, a young woman scarcely of age, who was obliged to enter into the most unpleasant details.

"It is evident that in the case of M. de B-, the constipation was the cause of the involuntary seminal discharges. The patient had practiced masturbation, it is true, and nocturnal emissions followed; but he had continued the vice only three months, and his health, though disordered for a short time, was soon re-established by the use of violent exercise. M. de B — was even tormented during several years by erections, which must have been very energetic, if we may judge by the means he took to subdue them. From this time he had never committed any kind of excess, and he had never suffered from either blennorrhagia or syphilis. There is then no circumstance in the history of his life, except his constipation, which would account for the involuntary discharges.

"But to what is this constipation to be referred? After all I could learn from the patient concerning his mode of life, I could only refer it to his constant horse exercise. In fact, M. de B- sometimes passed whole days on horseback, either for the purpose of hunting, or of superintending the management of his property. Shortly before his marriage, his rides became more frequent and longer, and his bowels at this time did not act during forty days. The weakness of his legs, the stunning sensations, etc., increased in proportion as his costiveness became more confirmed.

"This case recalls to my mind the well-known observation of Hippocrates on the impotence of the Scythians, and I have no doubt that his opinion was founded on analogous facts. I shall treat this subject more fully in another place; but since at present I am considering the canses of spermatorrhœa which act on the seminal vesicles through the influence of the rectum, I report this striking case showing the effects of long-continued horse exercise. 
"M. de B- was of a well-marked sanguineous temperament, and accustomed to nutritious food; he had a large chest, powerful muscles, and a highly injected countenance; it is therefore by no means extraordinary that he should have been bled frequently for the relief of the cerebral congestions to which he was subject. On the night of his marriage, the blood rushed to his head with greater force than ever, so that an attack of apoplexy was much feared; the weakness of the legs, the frequent falls, and the attacks of vertigo, were therefore afterward attributed to an advanced stage of disease of the brain. This was a very natural opinion, but it was an incorrect one; I doubted it from the commencement, although the patient was brought to me in consequence of a supposed cerebral affection. I formed a different impression, because I had previously seen many analogous cases. There exists in all these patients something peculiar in the expression of the eyes, in the position, in the voice, and in the general appearance-something of timidity and bashfulness-which I am unable to express, but which is instantly recognized by the experienced, although perhaps it is incapable of explanation. However this may be, the relation of the above case should draw attention to the subject.

"I admit that venesections seemed to be clearly indicated in the case of M. de B _ _ , but the loss of blood never produced good effects, either immediate or remote; and by analyzing the case carefully, his attendants would have seen that under this treatment the attacks increased in frequency. But preconvictions throw a thick veil over the most acute perceptions.

"The ascending douches put an end to the constipation; but freedom of fecal evacuation did not suffice to cure the disease. The seminal discharges, during the passage of feces, diminished, indeed, or perhaps entirely ceased; but the patient's urine remained thick and muddy, and his erections were incomplete. The application of ice and of the nitrate of silver, and the use of sulphurous waters, were not sufficient to effect his cure; yet there could not have existed any organic change in his genital organs. We can therefore only attribute the continuance of the seminal discharge, during the emptying of the bladder, to relaxation of the ejaculatory canals, produced by their long habit of allowing the semen to escape in a passive manner, showing how necessary it is to put an end to the habit as early as possible."

It is obvious to my mind that, in this case, as in many others, the great cause of M. de B-'s troubles was his enforced continence. The constant fever of suppressed sexual excitement, and the engorged state of the spermatic vessels, could not fail to cause serious organic derangement.

The next case shows the effects of worms in the rectum, both in producing and keeping up the spermatorrhoea, and also in first leading to masturbation, in childhood.

"M. R—, a student of medicine, enjoyed good health in his childhood, but about the age of fifteen was tormented by frequent and prolonged erections. One evening, for the relief of the itching, of which the extremity of the penis was the seat, he rubbed the organ violently between his hands. This led to the establishment of masturbation as a habit, or rather as a passion, the patient practicing it sometimes as often as eight or ten times a day. His health by degrees became so altered that one of his friends suspected his practices, and told him the dangers of his situation. By degrees he corrected himself, though not entirely before he had attained his twentieth year. On his renouncing masturbation, nocturnal emissions supervened, and often occurred two or three times a night. They diminished after 
a time, but without ceasing entirely, and seminal emissions during defecation and the emission of urine were added to them. Thus his health became daily more and more disordered for nine years, notwithstançing absolute continence, a severe regimen, and the use of sedatives, tonics, and anti-spasmodics. At length he grew incapable of any mental exertion. In 183\%, he came to Montpellier, at the age of twenty-nine, in the following condition :-Extreme emaciation; face pale; appearance stupid and confused; intellect dull; reasoning powers much affected, the patient being incapable of connecting two ideas on the most simple topic of conversation; loss of memory ; constant headache, referred to the forehead and temples, and increased by any mental excitement, being then accompanied by nervous tremors and an almost idiotic state ; sleep broken and unrefreshing ; constant sighing; frequent attacks of congestion in the head, especially at night; violent noise in the ears, resembling the sound of a waterfall ; vertigo ; stunning sensations, giving rise to a constant fear of apoplexy ; tinidity carried to a ridiculous extent; panics of fear even during the day; character gloomy, taciturn, restless, and irritable; horror of the least noise and of all society ; irresistible restlessness ; great weakness ; abundant sweats after very slight exertion; almost constant coryza ; frequent dry and hard cough ; pains in the base of the chest, the region of the heart, and along the spinal column ; appetite voracious; dragging at the pit of the stomach ; difficult digestion, accompanied with the development of flatus; grinding of the teeth during sleep; burning at the point of the tongue; darting pains in the bowels, especially in the rectum ; obstinate constipation, alternating with violent attacks of diarrhœe ; stools containing much mucus, and sometimes streaked with blood; periodical pains at the margin of the anus, in the perineum, penis, and testicles; urine passed in large quantities, and very frequently, always throwing down a whitish, thick, and very abundant deposit; involuntary emissions during defecation, both when constipated and relaxed ; frequent and prolonged erections by day as well as by night, with constant presence of erotic ideas.

"On sounding this patient, I found the urethra very sensitive, especially toward the neck of the bladder, and I consequently thought that the nocturnal and diurnal pollutions were kept up by a state of irritation arising from masturbation. I therefore proposed cauterization. This was performed on the following day, and produced the usual immediate effects, but its curative effects did not take place as I had anticipated. I then directed the patient to notice his feces, and a few days afterward he told me that he had observed numerous little worms, passed in his stools. I now ordered enemata of cold water, and salt and water, which, however, produced only a momentary effect, probably because the ascarides inhabited the upper part of the intestine. A few doses of calomel, however, caused them to disappear without returning; and from this moment the involuntary diurnal emissions ceased entirely, the nocturnal emissions became more and more rare, and the patient's re-establishment progressed very rapidly. M. R- returned to his studies with ardor, and long: afterward all functions were perfectly well performed.

"It appears evident that the irritation caused by the ascarides in the rectum first led this patient to practice masturbation, and afterward kept up involuntary seminal discharges. I did not discover this at first, because the history of his case, sent me by the patient, was so long, and was characterized by such disorder and want of clearness, that I was unable to arrive at any satisfactory conclusions from such a chaos, his answers were still more vague and unconnected, so that my attention had been 
chiefly attracted to the state of his intellect, and the abuses he had committed. But after seeing the little success of cauterization, and again reading his notes, I paid more attention to the circumstances attending the commencement of his practicing masturbation, and I noticed several symptoms to which I had not before attached importance, such as grinding of the teeth during sleep; burning pain in the point of the tongue; pain in the rectum, and at the margin of the anus; the stools always containing mucus, and sometimes being streaked with blood ; and especially the frequency and duration of the erections, and the constant presence of erotic ideas."

I have met with many instances in which great irritation of the genitals was pro. duced by worms, and I have no doubt but that the tendency to masturbation is often caused by them, in both sexes; a fact that parents should bear in mind.

That the tendency to spermatorrhoa is often hereditary, I have no doubt, and I have met with some remarkable proofs of it in the course of my practice; but as they are not of a nature to be readily understood by those not accustomed to observe them, it is not necessary to give the details. I have known many instances of brothers-in one case of five-all of whom suffered from excessive involuntary emissions, at the same age, and without being addicted to abuses of any kind.

Peculiar congenital predispositions often exist, particularly in those of a nervous character, though few practitioners are aware of their real extent. M. Lallemand gives some excellent illustrations of this kind of cases, and I can select many such from my own note-book. The following will, however, be sufficient:

"In general, such patients were of sickly constitution and more or less marked nervous temperament; they had been delicate from childhood, and subject to various spasmodic disorders. Some of them presented involuntary twitching of the muscles of the face, hesitation of the speech, etc. ; their imagination was active, and their moral and physiaal sensibility very acute. They were very restless and bore contradiction, or mental excitement, badly.

"In childhood they presented local symptoms, which indicated peculiar susceptibility of the urinary organs, every impression of fear or anxiety showing itself in this direction. What would have produced shuddering or palpitation in other children, in them caused a secretion of clear watery urine, which they were obliged to discharge frequently; a sense of constriction of the hypogastrium, and a sense of titillation generally accompanied its discharge. This condition of the urinary organs continued more or less severe in all the cases until after puberty, when it became joined with other symptoms. One of these patients one day experienced at the age of sixteen a fit of irritability and impatience, which, however, he succeeded in repressing ; and he then felt sudden and impetuous desire of micturition : whilst emptying his bladder he perceived a large quantity of pure semen discharged with the last drops of urine. This occurrence was the forerunner of nocturnal and diurnal pollutions, which at the age of twenty-seven, had entirely ruined his health. Another, at the moment of competition for a college prize, was unable to find an expression he wanted : at the same time he felt a want to make water, which he resisted by firmly crossing his legs; but his impatience increased and he shortly experienced an abundant emission, without either erection or pleasure. A third patient suffered in the same way under similar circumstances; he saw the moment approach for sending in his thesis ; the more he endeavored to hurry, the less freely his expressions flowed; at length, on hearing the clock strike, he suffered from so great mental disorder that he nearly fainted; at this moment emission took place. A fourth having mounted 
or a high gutter of a house to take some sparrows' nests, looked down into the court below, and was suddenly seized with such terror that he fainted; on recovering and. escaping from his dangerous situation he found that he had had an abundant semsnal emission. The same circumstance occurred to a fifth, who, in descending a ladder missed his footing and fell. Another patient told me that if he looked down from a height, or only fancied himself on the brink of a precipice, he felt a sense of contraction in the genital organs, which passed rapidly to the base of the penis, and ended by causing emission. The motion of a swing produced the same effects in a seventh.

"Almost all these excitable persons were exposed to erection, and even to pollutions, whenever they rode on horseback.

"Although all these involuntary discharges were caused by extraordinary circum stances, I should not have paid much attention to them if they had not been followed by nocturnal and diurnal pollutions, which the most trifling circumstance rendered very profuse. The disease, however, did not always put on a serious aspect immedi ately after these singular accidents ; very often, indeed, it only injured the patient's health long afterward; but as its gravity could not be explained by any occasional cause, I feel myself compelled to admit the existence of a congenital increased nervous susceptibility of the genito-urinary organs. Everything indicates, in fact, that the organs of these patients were rather excitable than weak and relaxed; and this condition was congenital, because manifested from the earliest infancy. This exces. sive sensibility of the genital organs is, however, not always preceded by a similar condition of the urinary apparatus.

"In all these cases, tonics and excitants always produced bad effects; proving that the genital organs were not suffering from atony or weakness."

\section{SYMPTOMS BY WHICH THE SPERXATORRHCEA MAY BE DETECTED.}

In addition to the effects already enumerated, there are several other symptoms of spermatorrhœea that are very useful to note, for the use both of the physician and patient. Some of them are such as are observed in various diseases, but others are peculiar to this affection, and enable us to ascertain its existence when positive evidence is not to be obtained.

Many persons suppose that in all cases the involuntary discharge of semen is indicative of disease, and it alarms them very much. In many cases, however, the emissions occur in those that are continent, from excess of semen, and may then be beneficial rather than hurtful. This is often the case when they are in great quantity, though this peculiarity is apt to alarm, from the idea that the injury is proportionate to the quantity lost. M. Lallemand remarks that:

"The most abundant nocturnal pollutions are far from being always the most hurtful. When they arise from true spermatic plethora, they often relieve erotio excitement, with its accompanying agitation, anxiety, uneasiness, and indefinable trouble in all the functions. They are followed by a general feeling of comfort; the head becomes clearer, the ideas more rapid, and the motions more nimble; there is more inclination to amusement, and to every kind of occupation. I admit that nocturnal pollutions do not often produce such good effects, but then they are not often the result of spermatic plethora ; they may, too, easily lose their character, so that habit alone tends to make them more and more frequent. In the greater number of cases. however, these evacuations are of very little importance. 
"But this state of excitement is too violent to last long: by degrees the organs become fatigued. Deprived of their natural functions, and consequently being unstrengthened by regular exercise, they may at last fall into a state of atony, or the seminal vesicles may preserve the habit of contracting, under the influence of slight or indirect excitement. The evacuations now produce effects quite opposite to those experienced in the beginning. There are on waking, feelings of discontent, idleness, weight in the head, disorder in the ideas, etc., but this condition passes off in the course of the day, and the patient is quite well on the following morning, if no further emission take place. After a time, these effects become more serious and lasting, and two or three days are required to remove them completely. There is, bowever, no disease as yet, because the economy is not permanently disordered, but there is a degree of instability in the patient's health, a valetudinary condition, the progress of which it is necessary to arrest."

Lascivious dreams are usually considered only as canses of noctural emissions, but they are in fact produced, in most instances, by the excitement existing primarily in the genital organs, and are therefore symptoms of excessive vigor, in the first stages, rather than of weakness, or disease. So long as they only present pleasant images, without any disagreeable sensations, and are not followed by lassitude and weakness in the morning, they are not indicative of anything serious. But when these dreams are filled with filthy and disgusting ideas, horrible sensations, and night-mare, during which the discharge occurs without any pleasurable feeling, and is followed by distress next morning, they are sure signs of disease. 'As a general rule, the danger commences when the pleasurable accompaniments of the dream begin to fail, and when the discharge occurs without any sensations at all, or with disagreeable ones, it is truly a bad symptom.

Diurnal, or daily losses of semen are in general worse symptoms than nightly ones, and they are especially bad if they occur spontaneously or from mere exercise. When they occur during the movement of the bowels, or while urinating, though they are usually indicative of a diseased state of the parts, yet they may be made much worse by constipation, gravel, and other affections of the neighboring organs, a fact that should be borne in mind when estimating their value. From not having these circumstances explained to them many persons lose semen in this way, perhaps for years, without knowing anything about it. When their attention is directed to the occurrence, however, it will generally be easy for them to detect the escape, whether it occur with the urine or after defecation. When with the urine there is a sensation as if something heavier than usual is passing, which creates a slight pricking or tingling sensation, and the urine looks thick and cloudy, with globules floating in it like half-dissolved gum-arabic. If the escape occurs during the movement of the bowels, a similar sensation is felt, and the end of the penis will be found covered with a glutinous fluid, which sometimes drops, but rarely runs away. More frequently the flow does not take place till the movement of the bowels is over, and perhaps not till the patient is dressing himself; it then comes suddenly, the whole quantity being discharged at once. This is preceded by a kind of shock, felt in the perineum and neck of the bladder, and sometimes with slight erections, accompanied by pleasure. In some cases a discharge occurs in this way of simple mucus, mixed with the fluids of the prostate and vesicles, and this should be suspected when losses of this kind are complained of, till a proper examination is made. These mucous discharges, however, never consist of more than a single drop or two at most, and 
are quite thin and transparent, while the seminal emission is both thicker and more opaque, and in greater quantity. If the patient empties his bladder before going to stool, the appearance will be more obvious, and if he observes a thick gummy discharge, during or after the passage of the bowels, there can be no mistake as to its being real semen.

It is more difficult to ascertain the presence of the semen when it escapes in the urine, because it is so diluted, and undergoes several changes. I shall therefore be particular to give all the indications that can be relied upon in such cases. In the first place, it must be recollected that the semen never escapes during the first flow of the urine, but always with the last few drops, or even after the bladder is fully emptied. There is in general the peculiar sensation already described, with slight pleasurable feeling, and a few spasmodic jerks of the neck of the bladder, by which the expulsion of the last drops is effected. This is quite sufficient to distinguish spermatorrhœa from gleet, or a discharge from urethral inflammation, as in such cases the mucus always escapes with the first flow of urine, and is not accompanied by any of the sensations above described. The appearance of the urine also, if carefully noted, will nearly always be sufficient to indicate the nature of the affection. The presence of the semen is nearly always indicated by the gum-like globules mentioned above, and also by numerous little irregularly-formed granules, somewhat like bran, which settle to the bottom of the vessel. These granules are soft, and fall down before the urine cools, without ever adhering to the sides of the vessel, which distinguishes them from gravel. In short, no other discharge furnishes anything like these granules, so that their presence is a sure proof of involuntary emission.

Sometimes patients have peculiar sensations in other parts of the body whenever a pollution occurs; thus some experience a pain in the nipple or back of the neck, some a cold chill and shivering, while others feel a burning heat round the anus, and after these sensations they always observe the flocculent deposit in the urine.

As the disease progresses the bran-like granules become fewer in number, and smaller, and at last almost totally disappear, so that the existence of the spermatorrhœe has to be ascertained by other symptoms. The urine is still clouded with the gum-like deposit, and there settles to the bottom a number of little brilliant points, something similar to what is seen in newly-boiled mush. Like the granules, they are soft, and do not adhere to the vessel. These different appearances result from the altered condition of the semen, which, as the disease progresses, gradually loses its usual character, and eventually becomes totally changed.

I have known patients, much engaged in study, in whom involuntary emissions occurred in a very singular manner. They would experience, while sitting perfectly still, a sensation in the perineum or at the root of the penis, as if the parts were suddenly drawn together and pinched. So distinct and strong is this felt sometimes that the person immediately starts and compresses the part in his hands. The sensation lasts but a short time, however, and nothing further takes place, if he remains still, but immediately he begins to exercise, or the next time he urinates, a quantity of semen escapes. This shows that the emission really occurs when the sensation is felt, but there is no action of the muscles to expel it till the parts are in some way made to act for other purposes.

IMPOTENCE FROM INVOLUNTARY EMISSION.

Whenever impotence is not obviously owing to any of the causes enumerated in 
another part of this work, it is nearly always the result of pollution, and perhaps, as a general rule, it arises from this oftener than from anything else. There are two modes in which it may be brought about by this cause : first, by the destruction of the powers of the genital organe, from general weakness; and, secondly, from a peculiar change which it leads to in the semen. For erection to take place, there is always needed the presence of healthy semen in the seminal resicles, and if this does not exist, of course nc erection can occur, and impotence necessarily follows. Any cause, therefore, which impairs the vitality and health of the semen must lead to impotence, and nothing does this more surely than long-continued involuntary emission.

The mode in which involuntary emission, or spermatorrhœa, from any cause, affects the semen appears to be this: It has already been explained how the seminal animalcules are produced from certain little grains or vesicles found first in the semen of the testicles, which break open and allow the animalcules to escape.

Now these little beings are the most essential part of the seminal fluid, and without them it can neither act properly on the male organs, nor impregnate the female ovum. If, therefore, their development is prevented, impotence and sterility must result, and this is what really follows from spermatorrhoea. It is necessary for the semen to remain a certain time in the vas deferens, and vesicles, after it leaves the testicles, so that the granules may burst, and the zoosperms become perfect, and if it be expelled from the body too soon, this has not time to occur. The precise time requisite for the semen to remain in the body, after being formed by the testes, is not known, and it probably varies, both with different individuals, and also under different circumstances in the same person. For a time, the organs can, if healthy, perfect the semen rapidly, so that a man can expel it very frequently, and yet have it healthy, but if this excess is continued too long, the power of the parts gradually weakens, and the semen is at length discharged imperfect. This is precisely what follows eventually, both from licentious excess and from involuntary emissions; the semen has not been allowed to remain in the organs sufficiently long, and when it is expelled no animalcules are found in it, but only the granules from which they would have been developed had it remained. These are what are seen in the urine, in cases of long-continued involuntary emission, like little shining points, and probably also the bran-like grains, observed at an earlier period, are the granules in an undereloped state. In many cases of longcontinued, spermatorrhœa, both from excess and involuntary, the change is still more decided, so that the semen is merely like thin gum-water, and utterly incapable either of stimulating erection or of impregnating. This is the true explanation why those who are exhausted by excesses, and those who have long suffered from involuntary emissions, become impotent and sterile, and it shows us what is really needed to effect a cure. If we can arrest the discharge, and restore a certain degree of tone and vigor to the organs, the semen may again be retained sufficiently long, and may become perfect, so that the powcr of erection and impregnating may be again enjoyed. The chances of this are lessened, however, in proportion to the time the flow has continued, and at a certain stage all our efforts are fruitless. I have, however, known some remarkable instances of restoration, even under the most unpromising circumstances. In one instance, a man aged forty-seven came to consult me, who liad been perfectly impotent for nine years, during which he had not experienced the slightest manifestation of sexual power, nor scarcely ever been free from a discharge, which, however, was almost like water. According to his own statement, this unfortunate 
condition was owing to former licentiousness, his indulgence having been excessive till the wretched state of his general health, and finally his complete loss of power, compelled him to abstain. I was obliged to say to him that the chances of restora. tion were so small as scarcely to be worth calculating upon, and that I should not be justified in giving him any hopes at all. He was so exceedingly anxious, however, and pressed me so earnestly to take him under my charge, that I did so, though with considerable reluctance, and with great misgiving. Fortunately, he was a man of wealth and leisure, and disposed to follow out implicitly all the directions given him. The particular plan of treatment that was followed is not necessary to be described here, as I shall speak upon it generally further on, but the result is stated as an instance of what can be sometimes accomplished, even under very unpromising circumstances. I had this patient under my constant care for fifteen months, at the end of which time his sexual powers were sufficiently restored to allow of his marrying, which he did, and became a father. It took three months to stop the constant emission, and after that six months more elapsed before animalcules began to appear in the semen, after which his improvement was very decided, though in all probability his powers will never be equal to what they were before, nor will they endure so long as they otherwise would have done.

In cases where impotence is but partial, or has existed only for a short time proper treatment can nearly always effect a decided improvement. Every moment however, is precious in such cases, and no man should feel indifferent even to a sligh falling off in his sexual vigor, if it continues, and if he desires to preserve his powers A short delay may lose all chance of restoration; and it should be recollected alse that, in most instances, the derangements which cause impotence have often serious effects, and generally so impair the health as to endanger life.

I am almost daily seeing instances of weakened power from spermatorrhœe, and though I am compelled to admit that in some of them relief is hopeless, yet in many the result of the treatment is most satisfactory, and highly encouraging to those similarly affected. There is occasionally one result of spermatorrhœea different from any of those above described, and which is sometimes of considerable importance, both socially and as a point in medical jurisprudence. Some patients, of vigorous habits of body, will continue to secrete the semen, and retain their powers of association even after the disease has existed for a considerable time. They may, however, be sterile. though not altogether impotent, and the fault of barrenness is ascribed to the female, because no defect exists, so far as can be seen, in the husband. These men are able to associate, as before remarked, and to emit semen, but on examining that fluid, none of the animalcules are found perfect; they being either all dead or half-formed. The semen, in short, is perfect enough to stimulate the male organs to a certain extent, but not perfect enough to impregnate the female ovum, and I have no doubt but that many cases of supposed barrenness in females are owing merely to a defect of this kind in their husbands. I have known men affected in this way, who were remark ably active and vigorous, and in whom no imperfection whatever could be suspected till pointed out by the microscope. M. Lallemand was the first author who alluded to this important subject, and his remarks are well worth reading:

"Infecundity.-Impotence is an absolute cause of infecundity, because it prevents the conditions necessary to fecundation from taking place; but although the act of coitus may be accomplished, it does not follow that the person should always be able to perpetuate his species. Stricture of the urethra may prove an obstacle to the 
discharge of seminal fluid, or the fluid may be directed toward the bladder, or the parietes of the urethra, by deviation of the orifices of the ejaculatory ducts. The secretion may be altered in its nature; it may only contain imperfect spermatozoa, etc. A man may, therefore, be unfruitful without being impotent. On the other hand, I have met with many patients suffering from diurnal pollutions, who had children exactly resembling them, even during the duration of their disease. Indeed, I have seen several cases in which the disposition to involuntary discharges was hereditary, and they affected both father and son. The disease is, however, essentially irregular in its progress; it may continue long without doing serious injury to the health ; long remissions may be experienced, or even a perfect cessation of the complaint for a longer or shorter time. We may easily conceive, therefore, that in the first degree, or during one of the periods of remission, fecundation may take place. When the disease is further advanced, however, many causes concur to render coitus unfruitful. Ejaculation is weak and precipitate, so that the seminal fluid cannot be thrown into the cavity of the uterus ; it is not sufficient in order to fecundate, simply to spread the fluid over the vagina ; it must be projected with sufficient force to pass through the orifice of the aterine neck. Besides, in these cases the erections, even when they permit sexual intercourse, are incomplete and of very short duration; emission takes place without energy and very soon, so that during such rapid acts the uterus and Fallopian tubes have not sufficient time to experience the excitement necessary to carry the semen to its destination, even when it passes the neck of the uterus. The semen itself also undergoes great changes, to which perhaps the loss of the fecundating power is chiefly attributable. Microscopic researches have elucidated this formerly obscure subject; I have discovered, for instance, that the spermatozoa undergo changes similar to those of the fluid which serves as their vehicle; these changes are exceedingly important, and are owing to defective formation. Spermatozoa may be met with in a less thick and less opaque fluid than natural ; for they are not produced by the same parts, or in the same manner; but when the secretion is perfectly thin and watery, the functions are so seriously affected that the animalcules are altered; they are less developed, less opaque, and less active than natural ; indeed, they are so transparent that peculiar precautions are necessary in oreer to make sure of seeing them; their motions are weak, slow, and cease very soon; and they rapidly undergo decomposition. All these characteristics show how much their texture is relaxed, and how imperfectly they are organized.

"It is evident that the least arrest of development in the spermatozoa must prove an insurmountable obstacle to fecundation, even if the only function of the animalcules be to carry the liquor seminis to the orum. When, however, their imperfect development only arises from a too rapid formation, it may soon be obviated. It suffices that the involuntary discharges should cease for a few days only, in consequence of some accidental cause, or of one of the spontaneous changes of this extraordinary disease, in order for the desires to become more lively, the erections more energetic and prolonged, and for the function to be accomplished in a natural manner. Fecundation is therefore possible, as I have previously stated, during the whole duration of one of these intermissions.

"This is not the case when the spermatozoa are malformed, rudimentary, more or less deprived of tail, etc.; for these changes only take place when there is a serious alteration in the structure of the testicles. I have taken every opportunity of dissecting the testicles altered in these cases, and I have always found the secreting 
structures paler, drier and denser than natural, and the cellular tissue more resisting, and with difficulty allowing the secreting ducts to be separated one from another. Sometimes half or two-thirds of the testicle was transformed into a fibrous or fibrocartilaginous tissue, mixed in a few cases with tuberculous matter. It is the same also in the epididymis, where I have even seen traces of ossific deposit in the midst of cartilaginous indurations. These changes, caused by previous inflammation, perfectly explain why the development of the spermatozoa can no longer proceed normally.

"Although, in such cases, the secretion of semen may be more or less diminished, pollutions may still be present if the seminal vesicles have shared the inflammation by which the testicles have been affected, as happens in most cases of orchitis arising from blennorrhagia. I have at present a patient who presents a remarkable example of both these effects arising from this cause : he is now forty-one years of age, and had blennorrhagia, followed by inflammation of both testicles, at twenty-five. Soon after his recovery, he married, but has never had children, although the act has been performed regularly, if not frequently. He became subject to nocturnal and sometimes diurnal pollutions, which increased by degrees. His health became disordered, but coitus was still possible. The semen passed, and even emitted its characteristic odor, but never showed under the microscope other than very small and brilliant globules, without any appearance of tail, but easily distinguishable from globules of mucus, the dimensions of which are five or six times larger. The epididymis of both sides is voluminous and irregular. One testicle is adherent to the skin of the scrotum, and the other appears smaller than natural.

"Malformation of the spermatozoa, therefore, arises from deep-seated changes in the tissues of the testicles, changes which do not permit the animalcules to assume their normal form, and, therefore, render infecundity permanent.

"To sum up then. Involuntary seminal discharges may oppose fecundation previously to actually producing impotence, by diminishing the energy of all the phenomena that concur to the accomplishment of the act, and by preventing the complete development of the spermatozoa, as well as the elaboration of the fluid which acts as the vehicle for them.

"These conditions may be rapidly altered by the simple diminution of the involuntary discharges, and fecundation may again become possible.

"This cannot be the case when infecundity depends on malformation of the spermatozoa-such malformation arising from permanent alteration in the organs that supply them."

Microscopic Examination of the Semen.-This is a subject of great interest to every one, and of immense importance to the physician and patient. The proper mode of pursuing such examinations has been so well explained by M. Lallemand that I cannot do better than copy his remarks, to which I will add here that with good instruments there is no difficulty whatever in the process.

"Microscopic Examination.-Since the discovery of the spermatozoa, their presence in the seminal fluid has attracted the attention of all who have sought means of distinguishing it from other fluids. Microscopic examination of the spermatozoa, however, not only requires an excellent instrument, but certain precautions which may be dispensed with in the investigation of coarser objects. As the spermatic animalcules can be seen only by means of transmitted light, it is necessary that the glass on which the fluid to be examined is placed should be of uniform thickness, 
and without bubbles or striæ. The fluid to be examined should be covered by another layer of extremely thin glass made on purpose, and not by portions of mica, which are seldom free from cracks, and never perfectly transparent. This thin layer of glass is indispensable in order as much as possible to diminish the thickness of the fluid, to render it perfectly uniform, to hinder evaporation, and prevent the objectglass from being soiled by it. A single drop of fluid suffices for a complete observation, a larger quantity always proving inconvenient. The little glass that covers the liquid must be firmly pressed down, so as to spread it out, arrest the currents that take place in it, and drive out the air bubbles. Although the glasses should seem to touch each other, the spermatozoa move with perfect freedom in the space between them, so long as they preserve their energy, and evaporation has not proceeded too far : should such be the ease, however, a drop of tepid water favors and much prolongs their motions. However thin the layer of fluid may be, it is impossible to comprehend its whole thickness at once with a very high power, and it is, therefore, necessary to alter the focus frequently in order to be sure that nothing escapes observation. And this is especially important in examining a drop of fluid obtained from diurnal pollutions, because there are frequently only two or three spermatozoa contained in it. It is also necessary to change the position of the reflector frequently, in order to vary the direction and intensity of the light. The spermatozoa are often exceedingly transparent in cases of disease, and a very bright perpendicular light is by no means the best for showing them. Varying the density of the fluid under examination, either by adding water or by permitting evaporation, is also often useful. The semen contains matters furnished by the seminal vesicles, the prostate, and the urethra, and when the fluid is too thick, these matters hide the animalcules. A drop of water applied to the edge of the covering-glass penetrates underneath it, and the spermatozoa are more isolated, at the same time that their contour is rendered more defined by the diminution in density of the fluid. On the other hand, the refractive power of the spermatozoa differs little from that of the fluid in which they are contained, and their thinnest portions are traversed by the light without affording any distinct images to the eye. In this case there are only seen very small ovoid brilliant globules terminated by a little point. As soon as the water bemins to penetrate between the glasses, the rapid motion set up prevents the objects from being clearly distinguished; but as soon as rest has been re-established the tails of the animalcules appear, and their dimensions seem to have increased in consequence of the diminished density of the surrounding fluid: water suffices to produce this result. It is more sensible, however, when a small quantity of alcohol is added; but the forms of the animalcules are, after a time, altered by this agent; and it is, therefore, advisable to use water only when it is intended to keep the preparation.

"Evaporation sometimes preduces not less remarkable changes in the seminal fluid. I have frequently in cases of spermatorrhœa failed to perceive anything in the fluid under examination for half an hour, an hour or more; then suddenly an animalcule has made its appearance; then a dozen, and then perhaps a hundred in the space of a few minutes. The following morning, when desiccation has become complete, there are no longer any traces of these animalcules, or, at all events, I have been only able to distinguish their tails, the other parts of them being fixed in the dried-up mucus. The absorption of a drop of water has restored the phenomena observed the night before. 
"These phenomena are easily explained; when the refractive power of the spermatozoa is the same as that of the circumambient liquid, the light traverses the whole in the same manner, and the mass appears homogeneous. But evaporation acts more rapidly on the liquid than on the organized bodies contained in it; and when the difference of density alters the refractive power, the forms of the spermatozoa are momentarily defined, because they have become more transparent than the remainder of the fluid. When desiccation is complete, however, the animalcules again disappear, becanse the refractive powers of mucus and dried animalcules are again equal. The absorption of a small quantity of water reproduces the same phenomena, which may be repeated almost indefinitely, since the matter confined between the two layers of glass undergoes no other appreciable alteration.

"In order to be enabled to discover spermatozoa quickly, in cases of disease, it is necessary that they should be well studied in healthy cases. This may be accomplished in the following manner:-After coitus there always remains a sufficient quantity of seminal fluid in the urethra to serve for precise and complete microscopical examination. This may be obtained by pressing the canal shortly after the act, and receiving the drop of fluid from the orifice of the glans on a plate of glass. In this drop of fluid thousands of animalcules may be seen, agitating themselves like so many tadpoles in a pool of stagnant water, only that the tails of the spermatozoa are relatively longer and thinner, and that the head presents a brilliant point near its insertion. Generally the number of these animalcules prevents them from being easily examined, and it becomes necessary to spread them out by introducing a small quantity of water, and pressing firmly down the thin glass that covers them; they are found most separated on the edges of the fluid. If the water added be of the temperature of the body, their motions become free and lively, and continue so until cooling and evaporation affect them. By avoiding these two causes of disturbance, the motions of the spermatozoa may be kept up during several hours.

"However long a time may have elapsed after coitus, there are always spermatozoa in the urethra, provided they have not been washed away by the passage of urine. Although the point of the glans may be quite dry, and pressure along the whole length of the canal may not produce the least dampness, still on passing urine, living animalcules may be obtained from the first drop which escapes. This may be received on the glass, and is, perhaps, the easiest and most natural mode of obtaining spermatozoa for microscopic examination.

"It is evident that the same experiments may be applied in the case of nocturnal pollutions, as well as in all other seminal discharges, in whatever manner they may occur. But many errors may arise from commencing with cases of disease, for it is during perfect health when the spermatozoa are most active, and their development most complete, and they live longer after coitus than after any other kind of seminal discharge.

"Having thus described the means by which my microscopic observations may be verified, I proceed to show their results.

"Spermatozoa. - Out of thirty-three bodies which I have examined for spermatozoa, I only twice found these animalcules in the testicles. In one of these cases the patient died from the effects of a fall, on the day following it ; in the other acute gastro-enteritis was the cause of death. The seminal fluid was most abundant, and contained the greatest number of animalcules, as in the former case. The other patients aied of chronic diseases, after protracted sufferings. One only among them died on 
the second day, of acute peritonitis, but he was seventy-three years of age. In thirtyone of these patients the testicles were soft, pale, and as though withered. On section they presented a grayish aspect, and did not furnish any liquid; the structure was almost dry, and contained a few blood-vessels; the secreting canals were easily separated from one another, and could be spread out under the microscope without breaking. They presented very brilliant granules, all of exactly the same appearance, about the size of the head of a spermatozoon, ten times smaller than corpuscles of blood or mucus, and differing from the latter by the constancy and regularity of their form. These brilliant bodies, which occupied the place of the spermatozoa, are worthy of notice, because they offer considerable analogy to the appearances presented by the semen under certain circumstances.

"In order to observe what is present in the secreting canals of the testicle, it is necessary to spread out a portion of one of them under the microscope, after having examined it dry to allow a drop of water to penetrate between the two glasses, and to follow the changes which take place ; then to press down the glass so as to flatten the parietes of the canal, rupture it, and press out a portion of its contents; lastly, these must be examined again when desiccation is complete, for the spermatozoa found in the canals are then best seen.

"In the epididymis I have never found spermatozoa, except in the two cases in which they were also found in the testicles. In all the others I met with these animalcules only in the vas deferens, or seminal vesicles. There were no animalcules at all to be found in the patient who died at the age of seventy-three. It has always seemed to me that the animalcules were less numerous in proportion as the patients had suffered long; and in extreme cases I have generally found them only in the seminal vesicles. The fewer the spermatozoa the more difficult were they of detection, on account of their extreme transparency. In some cases I have only suddenly discovered them after examining for an hour or two, the liquid having previously appeared quite homogeneous. The dimensions were the same as those of the best developed animalcules, but they were pale throughout their whole extent, and more transparent than the surrounding fluid. Complete desiccation often caused them to cisappear altogether ; but the same phenomena could be reproduced by the absorption of a small quantity of water.

"In cases of phthisis, caries of the vertebre, white swelling, etc., I have had great difficulty in distinguishing the animalcules, probably because these diseases do not cause death for a long time.

"I have almost always found in the seminal vesicles, especially at the bottom of any depression, a thick, grumous, brilliant matter, varying in its aspect and color, but considerably resembling thick paste, and more or less transparent; with a high power the granules of this matter appear large, irregular, more or less opaque, and without any constant shape. They are evidently the products of the internal membrane of the vesicles, for they are found with similar characters in the accessory vesicles of the hedgehog, rat, etc., which never contain seminal animalcules, and do not communicate directly with the vasa deferentia, which, again, never contain any similar substance. This matter is, therefore, analogous to that secreted by the prostatic follicles, Cowper's glands, etc. Its functions are the same, and for many reasons it merits special attention.

"The secretion of semen diminishes in all serious diseases, and seminal evacnations become very rare, especially toward the last. It is not, therefore, astonishing 
that the products of the mucous membrane predominate in such patients orer those of the testicles, and that such mucus should become more consistent during its long residence in the depressions of the vesicles. Hence, the difference observable between the semen obtained from the vesicles after death, and that which is passed by a healthy person. Nevertheless, after long-continued continence, more or less large granules are often seen in the semen of a healthy person, and these are perfectly distinct from the fluid part. When the emissions are more frequent, granules of the same kind may be observed, but much smaller. These facts are important when applied to explain several symptoms of diurnal pollutions.

"I have already stated that on causing the patients to make water in a bath, the semen passed may be easily recognized by means of its globules which whirl about in the middle of the cloud formed toward the close of micturition. From what we have just seen, it is evident that these globules come from the internal membrane of the seminal vesicles. They may be wanting in very severe cases, where the semen has no time to acquire consistence; but their presence leaves no doubt as to the existence of diurnal pollutions, because they can only be furnished by the seminal vesicles. On the other hand, I have invariably found spermatozoa in the urine of patients who observed this phenomenon in the bath. The same remarks hold good when applied to the globules which the urine deposits in certain cases of diurnal pollutions, and which have been compared by some to grains of bran, by others to millet seed, pearl barley, etc., according to their size.. These globules are perceived as soon as the urine is passed; they are roundish, very soft, and do not give any sensation when squeezed between the finger and thumb ; they cannot, therefore, be confounded with urinary salts, which are deposited only when the urine has cooled, have a crystalline form, and give the sensation of a hard body to the finger. The vesical mucus also is only deposited on cooling, and does not furnish brilliant granules. As to pus, its appearance is easily determined. I have found animalcules whenever these globules appeared in the urine; and hence it is that I have pointed them out as certain signs of diurnal pollutions.

"I have also noticed that in some cases the urine, when held against the light, presents in the middle of a floceulent cloud multitudes of quite characteristic brilliant points. These are smaller, and consequently lighter, globules than those which in other patients fall to the bottom of the vessel. They are neither observed in the mucus of the bladder nor in the prostatic fluid, which alone present clouds analogous to those of diurnal pollution. Such brilliant points also arise from the seminal vesicles, and their presence is, therefore, an indication that the urine contains semen. This I have often verified with the microscope. I should, however, warn those who wish to repeat my experiments, that it is not in the midst of the flocculent cloud that the zoosperms are to be sought, but at the bottom of the vessel, to which they soon fall on account of their greater specific gravity. The results of all my observations of the dead subjects, therefore, convince me of the influence of serious and long-continued diseases on the functions of the spermatic organs. But it is not only in the morbid state that these experience great variations; remarkable differences may exist between healthy individuals, not only in the quantity of semen secreted in a given time, but also in the number, appearance, and dimensions of the spermatozoa. In this respect I have observed differences amounting to a third, and, in some cases, to half. The comparison is very easily established. When the semen is kept under a thin glass, as I have before described, it is not in danger of undergoing any 
changes, and may be always, by the addition of a drop of water, compared with a recent specimen.

"Notwithstanding the facility with which nocturnal pollutions may be recognized, I have submitted the semen collected after them, by individuals in various conditions of health, to mieroscopic examination. At first, when the evacuations are still rare and the semen preserves its ordinary characteristics, the animalcules do not present any remarkable circumstances in regard to their number, dimensions, etc. ; but when the disease has reached a sufficient degree of gravity to affect the rest of the system, the semen becomes more liquid, and the spermatic animaleules less developed and less lively. Their number, however, does not as yet sensibly diminish ; indeed, in some cases, it seems increased. As the disorder advances, the erections diminish, the semen becomes more watery, and the animalcules are often a fourth or a third less than natural, and the tail is often distinguished with difficulty under a power of three hundred diameters. At a still later period the animalcules become fewer, and in two individuals, in the last stage of the affection, the semen no longer contained animalcules, although it retained its characteristic smell. Examined with high powers and every proper precaution, I only found, in this semen, brilliant globules, all exactly alike, and about the same size as the head of a spermatozoon.

"The microscopic examinations which I have made of semen passed during efforts at stool give analogous results. When such discharges only take place accidentally, and at long intervals, the semen is thick, whitish, impregnated with a powerful smell, and abundantly furnished with well-developed animalcules. I have sometimes even found a few alive after an hour or two. But when these discharges become so frequent or habitual as to constitute disease, they become less abundant and the semen loses its normal properties. The spermatozoa are generally smaller than in the healthy condition, and always less lively. I have some preparations in which they are only of half the ordinary size, and I have never been able to find a single living animalcule a few minutes after the fluid had been expelled. When the disease has become much aggravated, the spermatozoa become rare, and they are sometimes replaced by ovoid or spherical globules, similar to those of which I have already spoken. In three patients, in an extreme state of disease, I found nothing else, although they passed as much as a dessert-spoonful of semen at each stool. Such cases, however, are exceedingly rare.

"In diurnal pollutions happening during the passage of urine, the following means may be employed to show the presence of spermatozoa:

"The urine should first be filtered in a conical filter, when, on account of their weight, the greater number of the spermatozoa will remain on the lowest part of the paper. By taking this portion and turning it upside down in a watch-glass containing a few drops of water, the animaleules become detached from the paper by degrees, and fall to the bottom of the fluid in the glass. After twenty-four hours' maceration in this position, the paper may be taken away, and the spermatozoa may be readily obtained by using a drop from the bottom of the fluid in the watch-glass for examination. This mode of proceeding is a sure one, but it requires considerable time and trouble for its performance. I have already stated that the urine does not always contain spermatozoa in cases of diurnal pollutions; therefore the urine of the same individual would perhaps require examination on many occasions, before the certainty of their presence could be established, and few medical men in active practice have time to devote to such experiments. I, for one, should have long since given 
$\mathrm{np}$ treating these patients, had I been obliged to repeat in every case such long and tiresome examinations. Ten days or a fortnight are sometimes passed without the appearance of spermatozoa in the urine, and hence all who are accustomed to microscopic researches will admit the indefinite amount of trouble and time required.

"Fortunately, however, there is a more simple method by which such examinations may be conducted. It will be recollected that the semen always escapes either with the last drops of urine, or immediately, or soon afterward. By directing the patient, therefore, to compress the urethra immediately after micturating, and to receive the drop of fluid pressed out on a piece of glass, sufficient animalcules will be obtained from the walls of the urethra for microscopic observation. These being covered with a thin lamella of glass, may be either at once placed under the microscope, or may be allowed to dry, and examined at a future time, a drop of water being previously added. This mode of examination is, therefore, easy for all practitioners who possess a good microscope, after they have accustomed themselves to the inspection of the spermatozoa in their natural state. The changes which I have mentioned as occurring in the semen must be borne in mind, however, and the animalcules must not be expected to appear either so large, so well-defined, or so numerous, as in cases where there is no disease."

\section{TREATMENT OF SPERMATORRHФA.}

In treating spermatorrhoea there are two things necessary to be ascertained : first, the primary exciting cause, and secondly the existing cause, if such there be, that keeps up the disease. Most usually we discover that masturbation has been indulged, or that the patient has been addicted to excess, and it is, of course, necessary that such evil practices be immediately and totally abandoned before any improvement can be hoped for. Next, we must see if there be any skin disease, piles, constipation, worms, gravel, or any other cause that may keep up the irritation, and when this has been removed the actual treatment of the parts themselves may begin. This treatment must consist in the application of those means best calculated to remove the irritability or relaxation existing in the ducts and seminal vesicles, and to give tone to the testes. So long as the ducts and vesicles retain their irritability, or remain open, the semen must necessarily escape, and it becomes therefore absolutely requisite to remove such disability, and restore to them that power of contraction which they possess in a bealthy state.

In some recent cases very simple treatment will suffice. If the patient leaves off all bad habits, avoids constipation, attends carefully to his diet, takes no stimulants either in food or drink, and carefully bathes himself in cold water round the parts, night and morning, a decided improvement will often be experienced. He must, however, avoid all excitement of the mind or feelings, never over-fatigue himself, and not lie in bed after he is awake in the morning. These directions are more especially applicable to those incipient cases, common among young men, when the emission takes place at night, usually in consequence of a dream. It will generally be found in such cases that the loss occurs toward morning, and most frequently when the patient is half asleep and half awake, a state which is very apt to produce sexual excitement. Many young men have told me that they never had an involuntary erection except at such times, and that if they ever remained in that half-dreamy condition it was nearly certain to occur. However disagreeable it may be, therefore, 
the patient must rise immediately he is awake, unless it be too early, and he feels con. fident he can go sound to sleep again. Many persons whenever they awake and feel any tendency to erection, always rise and bathe themselves, and then lie down again, and by these means escape the emission. It is particularly important also that late suppers should be avoided, and that no coffee should be drunk and no tobacco used. This is very necessary, for many of my patients assure me that a single cigar toward bed-time will insure an emission, in spite of all the precautions they can take.

If all young men were to observe these directions habitually, they would seldom be troubled with involuntary emissions at all, because the parts would be so strengthened, and all irritation so promptly subdued, that it would scarcely ever arise, unless from excessive abuse or masturbation. The remarks which I formerly made as to the importance of regular occupation, both for body and mind, are also particularly applicable here, there being no doubt but that idleness very much predisposes to all these evils.

Internal medication is seldom of much benefit, but unfortunately most persons think the contrary, and this great and fatal error is often the means of perpetuating the disease. Men think, when they are afficted with involuntary emission, that it is only necessary to take certain drugs to be made well again. They accordingly either allow the evil to go on till it becomes incurable before they do anything at all, or else they rely upon the medicine alone, and neglect all other means. The consequence is that they obtain no relief from what they have taken, and find that the time has been uselessly lost during which a cure was possible. I do not hesitate to say that any man, by observing the simple advice already given, will be more benefited without any medical treatment whatever, than he can be by the best he can receive if that advice be neglected. It is true that a little medication is occasionally beneficial, but it is not of a specific character, or adapted to all alike, but must be varied according to circumstances, and in all cases it should be regarded merely as assisting, and not as being capable of curing alone. It is more especially when there is gravel, or considerable irritation of the urethra and bladder, that good can be done by medication, and even then it is of a simple character. If there is any heat and burning when the urine is discharged, with a discharge of thin mucus at the beginning of the flow, the following pills will be beneficial :

R. Balsam of copaiva, two drachms ; magnesia, seren grains. To be made into pills of four grains each, of which two may be taken three or fuur times a day.

Or the common capsules of copaiva, or cubebs, may be used.

If the urine is high colored, and deposits a red sediment upon the sides of the vessel, indicating gravel, the following powders will be better:

R. Dried bearberry leaves (uvoe ursi), one drachm and a half; bicarbonate of soda, one drachm. Mix them, and divide into twelve powders, of which one may be taken three times a day in water.

These powders are also excellent when there is simply irritation of the bladder, causing a frequent desire to urinate. For this particular trouble, it is also advisable to drink but little, and never to use hot fluids of any kind, nor spices, wines, spirits, or coffee. A little gum-arabic is useful, kept in the pocket and swallowed occasionally during the day.

There are few cases in which these means will not, at least, give some relief, even if they do not cure, but it may not be immediate. This is a fact that should be borne in mind, so that discouragement should not be felt because the relief is not experi- 
enced at once. The disease, it should be remembered, has nearly always existed a long time, and has assumed a chronic form, so that it can only be successfully attacked in a gradual manner, by slowly producing a change in the action of the parts.

Nevertheless, I have known many benefited almost immediately, and very often I hear the remark, that in one week from the time of commencing the treatment, the emissions decreased one half in frequency. To ascertain the extent of the improvement, and as a guide to the physician, every one afflicted in this way should keep a diary, or date the times when the emissions occur, so that it can be seen whether they are really decreasing in frequency or not.

One of the best means for applying cold water, both for the purpose of strengthening the genitals, and also for relieving constipation, is by means of what is termed the ascending douche; that is, by a stream or jet directed upward. This must be made to play forcibly on the perineum and against the anus, by the patient sitting over the jet. The effects of this treatment, after a time, are often strikingly beneficial. I have known patients who had previously never passed a night without emissions, remain for two weeks without experiencing anything of the kind; and I have known the most obstinate constipation, in some instances of near three weeks' duration, completely cured by it in less than a month. It is, in fact, one of the most valuable remedies we possess in the treatment of spermatorrhœe, and has cured more than perhaps all other means put together. Those who cannot employ a proper apparatus, may use a large and powerful syringe, bent at right angles, so that the jet can be thrown up against the perineum, scrotum and anus. It should be used morning and night, for about five minutes. The man mentioned in the last article, who had been impotent for nine years, owed his cure to this cold douche. I have often found nothing else necessary, even in very bad cases, except proper attention to the diet and regimen.

In case of worms in the rectum, which often keep up spermatorrhoea by their irritation, there are few things that succeed better in dislodging them, and subduing the irritation, than enemas of cold water. These seem to paralyze the worms, so that they lose their hold, and are expelled with the fluid as it returns. They also cool and give tone to all the neighboring parts in a very marked manner, and are, in short, valuable remedies in the treatment of spermatorrhœe. In some instances, they will cause erections from the very first, though the person may have previously been almost impotent.

When the loss evidently occurs more from general weakness than from irritation, the plan of treatment must be somewhat varied. Warm bathing may then be advised, with a generous diet of meat and wines, and the occasional administration of tonics and bitters. Galvanism is also of very great service in many of these cases of debility, applied directly to the parts, or to them and the spine. It will frequently impart a feeling of warmth and vigor from the very first, and restore the natural powers sooner than almost anything else. The patient should, however, be particularly cautioned not to use any of the stimulating medicines, cordials, and tonics, so urgently recommended for this debility. These are mostly composed of Spanish fies, or phosphorus, and are very hurtful, though they may appear to do good for a time.

Several of the mineral waters are highly useful in spermatorrhœea, especially those. that contain iron ; and those that contain sulphur are also of service when used as baths.

When there is any considerable nervous irritability; with restlessness, loss of sleep, 
or bad dreams, a narcotic may be of service. A few drops of laudanumi may be taken at bed-time, or some of the camphor and opium pills, directed in a former article. If the stomach cannot bear opium, it may be given as an enema, either by putting a few drops of laudanum in some starch-water, or by using a decoction of poppy-heads. Some patients even introduce an opium pill, containing one grain, into the rectum at bed-time, and leave it there till morning. This will frequently prevent emission, but is apt to act too strongly on some persons.

McMun's elixir of opium is the best preparation to use, instead of laudanum, or crude opium.

Occasionally setons are of service, placed inside the thighs, or acupuncture with needles, but these must always be directed and applied by the physician.

The position in bed is frequently of some consequence in very irritable persons, and should be attended to. There is no doubt that lying on the back is very apt to cause pollution, by the heat it produces in the loins, and sometimes will continue it notwithstanding everything else that can be done. So well aware are some persons of this, that they invent peculiar contrivances to prevent them ever resting on the back, even for a moment. One of my patients used to wear a broad leather belt at night, with spikes on the inside behind, so that if he turned on his back while asleep, these hurt him, and waked him up. Another wore a pointed piece of wood, so adjusted that he could not turn on his back at all, and by these means he avoided the emissions that used to occur almost nightly. Sometimes it is sufficient to merely sleep upon a hard mattress, with a piece of oiled silk or india-rubber cloth under, to keep the parts cool; or, what is still better, a sheet of lead may be tied over the back and loins when retiring. I have known some patients speak very highly of the effects of this metallic shield.

When there is decided irritation of the genital organs, manifested by redness at the end of the penis, burning when making water, and mucous discharge from the arethra, it becomes of the first moment to prescribe a proper diet, consisting chiefly of milk. This should be used freely, both as food and drink, either thickened with rice, isinglass, or sago, or even with gum-arabic. The beneficial effects of this diet will soon be evident in the decrease of all the inflammatory symptoms. Very little meat must be used with it, but plenty of potatoes, which are not only nutritious, but have also a decidedly good effect on the urine. Some fruits are very excellent, particularly strawberries, and ripe peaches, and so are tomatoes, but any rery acid ones are objectionable. If the milk disagrees with the stomach, which it will sometimes do, a few grains of magnesia may be added to it, or two or three spoonfuls of lime-water, which will generally correct all such tendency. The copaiva and magnesia pills may also be used, or the powders of bearberry leaves, as formerly directed. Wines, coffee, spices, and spirits must be rigidly avoided in all such cases, and, in fact, every kind of excitement, as far as possible.

Cauterization.-This is a process which usually is resorted to when all other modes of treatment fail, though some physicians practice it from the first. To understand how it operates, the action of caustic, when applied medicinally, must be borne in mind. If we have any diseased surface, such as an open ulcer, or an ipflamed mucous membrane, the caustic not only burns off that diseased surface, bur by its energetic action, so alters the condition of the parts, that the disease is frequently removed altogether. This is why it is applied to all virulent sores, and to inflamed sore throats, eyelids, and other parts. Now in confirmed cases of sperma- 
torrhcea there is always either a relaxed or an inflamed condition of the ducts, urethra, or vas deferens, and it is evident that if the caustic can be applied to them, in a proper and efficient manner, it will, in all probability, affect them in the same way that it does other parts when similarly diseased. The great difficulty, however, is to find a means to apply it in the situation required. The ducts being placed at the bottom of the urethra, completely out of sight by any means, and with great difficulty ever reached, it becomes a question as to how they are to be operated upon. This has been decided however by M. Lallemand, who has invented an instrument which enables us to apply the caustic to the ejaculatory ducts, with almost as much certainty as to any place on the exterior. This instrument consists of a silver tube, open at the end, and adapted to the size of the passage, down the inside of which passes a kind of piston, furnished at the end with a piece of lunar caustic. When the tube is introduced into the urethra, the caustic is contained inside of it, but when the open end of the tube has reached the ducts, the piston with the caustic on it is pushed out a little way for a moment, anc of course burns the surrounding parts : it is then drawn back into the tube and the whole apparatus is immediately abstracted. By these means the ducts, the mouths of the prostatic vessels, and the neck of the bladder are effectually cauterized, without any of the other parts being touched. The performance of this operation is certainly a little difficult, and requires great manual skill, with an intimate knowledge of the structure of the parts. An unskillful person, who sould zor properly manage the instrument, or not judge correctly of the proper distance to introduce it, might not only fail of doing good, but even do harm. Many practitioners, also, cause great mischief by letting the caustic remain too long, and burning too much, or by acting only on the healthy parts, and leaving the diseased ones untouched. In short, though the operation is frequently of the greatest benefit, when properly performed, and capable of effecting a complete cure in the very worst of cases, it is also exceedingly dangerous when improperly performed, as too many know. Not only may the irritation be made much worse, but the most severe inflammation may follow from it, so as to prevent the discharge of urine, and lead to abscesses and ulcers of the most incurable kind. Even in successful cases, and onder the most favorable circumstances, great distress is nearly always experienced, and the pain is not unfrequently very severe. Many persons are much alarmed, and even though greatly benefited, cannot bring their minds to submit a second time to it.

In general, however, one operation is sufficient, and when a repetition is required it should seldom be under six weeks or two months after. I have seen patients in a miserable state who had been cauterized too frequently, and with too short intervals, and in all probability, cauterization has, on the whole, done more evil than good. The discovery of certain new remedies, and improved modes of treatment, enable us now to dispense with it altogether, except in some very rare cases, and it is but very seldom resorted to. 


\section{CHAPTER XLVIII.}

THE INFLUENCE OF MEDICINES IN PRODUCING AND CURING IMPOTENCE AND SPER: MATORRHEA.

THERE are a few medicinal substances that act in a direct manner upon the genital organs, some beneficially and others hurtfully, but the greater number operate upon them indirectly. This is a subject about which there is great ignorance, as I before stated, and an immense deal of imposition and pretension. It has always been a favorite notion with the public, that there are specific medicines capable of arousing the sexual ardor under almost any circumstances. From this notion has originated all the various cordials, stimulants, and elixirs, that are constantly pressed upon the attention of the impotent and sterile. None of these things are in the slightest degree capable of accomplishing what is promised of them, as well-informed people are aware, but the public generally are deceived and much injured thereby. There is no doubt but that an immense deal of disease and incurable impotence is caused by the use of these preparations, and much good will result from cautioning the public against them. Very lately it has been ascertained that certain drugs can be made to have a remarkably beneficial action, in particular cases of loss of power, but each case requires a peculiar dose and mode of administration, which makes it impossible to prescribe for all alike. These agents, however, are probably not known, even by name, to the parties who compound the preparations above referred to, and it is fortunate they are not, for if they were, more mischief would be done than by the things now used.

It is, however, not only the action of those drugs that may be beneficial that we hare to study, but also those that may be hurtful, and among them will be found many that few persons have suspected of having any influence on the genital organs at all. Purgatives, for instance, are popularly thought to act only on the bowels, and not to influence sexual vigor at all, but the fact is, they often exert a very marked influence in that way. It is well known that aloes, gamboge, colocynth, and several other purgatives irritate the bowels very much, and this irritation may be extended to the neighboring parts, particularly near the rectum, and in this way they excite the flow of urine in some persons, by irritating the bladder, as well as operate upon the bowels. Now the spermatic ducts, and prostate gland, lie close to the rectum, and of course are subjected to this irritation as much as the bladder, and are equally liable to become unusually sensitive. I have known many persons, in fact, who always had involuntary emissions when they took purgatives, and who were obliged to be exceedingly careful in consequence when they did so. When there is any tendency to spermatorrhøa, therefore, the possible effect of purgatives must be borne in mind, both by the physician and patient, and in case they are absolutely needed those only must be chosen that are least irritating, particularly to the lower part of the bowels. 
Tobacco is an article that exerts a most decided action, in numerous cases, upon the generative organs, though few persons suspect it of doing so. Like opium, and some other narcotics, it often stimulates at first, but afterward greatly weakens the sexual powers, so as to bring on complete impotence in many cases. I am satisfied, from my own observations, that it frequently leads to involuntary emissions, and keeps them up notwithstanrling all that can be done for them. Many young men, patients of mine, have remarked that a cigar at bed-time would be certainly followed by emission before morning, and they found it necessary in consequence to abandon its use. It is true that these results are not generally seen except the tobacco is used in great quantity, but there are some persons that are affected by a very small portion, and who therefore never surmise that it has any influence upon them at all. I once saw a young man, a great smoker, who suffered from constant pollution, and who had been perfectly impotent for five years. He had submitted to every kind of treatment, even to cauterization, but only obtained temporary relief, and at last totally despaired of ever being benefited. On hearing his statement, and learning what had been done for him, I was much surprised, because there were no indications of severe disease, nor were the parts themselves in an unhealthy condition, though relaxed, and the testes still secreted perfect semen in considerable quantities. During our conversation he accidentally alluded to his smoking habits, and said he fre. quently used from two to four dozen cigars a day. I was immediately struck with the similarity of his case to that of a great opium chewer whom I had seen, and I at once concluded that the tobacco was the cause of the mischief. On explaining this to him he could scarcely be brought to think it possible, but eventually he agreed to follow my advice and gradually leave it off. The result even exceeded my expectations, for I was much afraid that some permanent mischief had been done. $\mathrm{He}$ began to mend immediately, and though considerable lowness of spirits, weakness, and loss of sleep were experienced at first, yet all these effects ultimately passed off, and he felt better, and was stronger than while using the tobacco. The most marked effect, however, was the checking of the spermatorrhœea. When I first saw him, he passed semen constantly in his urine, and frequently in the night. He had little or no erection, and such nervous palpitation of the heart occurred, whenever any slight sexual feeling was experienced, that he became utterly powerless, and would undoubtedly have been impotent from that cause alone. This all passed off, the involuntary discharge ceased, and his sexual powers returned as strongly as ever. Contrary to my advice, he commenced using the tobacco again, thinking that it would now cease to affect him, but in three days all the old symptoms returned, and he becume as impotent as ever. On leaving off his smoking, however, he gradually recovered again, though with more difficulty than at first, which made me caution him not to relapse again, for fear the reaction might eventually fail altogether. I have even known married men seriously injured in this way, by merely using tobacco as a domestic indulgence. In one instance a gentleman, engaged in a somewhat harassing business, was induced by a friend to smoke a few cigars at night, to steady his nerves! He found, however, that though he could readily stupefy himself, yet his nerves were no steadier, particularly in the morning, and what was most singular, to him, he lost all sexual power and desire, and become so weak he could scarcely stand. In this dilemma he consulted me, and gave me a full history of his proceedings and experience. On examining his urine, I found, as I expected I should, that the semen escaped with it, and in such quantities that his impotence and weakness 
were no longer to be wondered at. I at once told him to leave off his tobacco, gave him a slight tonic, cauterized the ducts, and directed him to go and bathe in the salt water for a few weeks. He did so and returned perfectly cured.

I could, in fact, give numerous cases, both among single and married, showing the effects of this poisonous drug, and I do not hesitate to say that I think it has more to do with many of these complaints than has been hitherto supposed.

In the thirteenth Annual Report of the Massachusetts State Lunatic Asylum, are some excellent remarks on the use of tobacco, which, though they are intended to apply chiefly to its influence in predisposing to insanity, are nevertheless of great general interest, and I therefore quote them :

"Alcohol is not the only narcotic which thus affects the brain and nervous system. Opium produces delirium tremens and probably insanity. Tobacco is a pow erful narcotic agent, and its use is very deleterious to the nervous system, producing tremors, vertigo, faintness, palpitation of the heart, and other serious diseases. That tobacco certainly produces insanity, I am not able positively to observe ; but that it produces a predisposition to it, I am fully confident. Its influence upon the brain and nervous system generally, is hardly less obvious than that of alcohol, and if used excessively is equally injurious. The young are particularly susceptible to the influence of these narcotics. If a young man becomes intemperate before he is twenty years of age, he rarely lives to thirty. If a young man uses tobacco while the system is greatly susceptible to its influence, he will not be likely to escape injurious effects that will be developed sooner or later, and both diminish the enjoyments of life and shorten its period.

"The very general use of tobacco among young men at the present day, is alarming, and shows the ignorance and devotion of the devotees of this dangerous practice to one of the most virulent poisons of the vegetable world. The testimony of medical men, of the most respectable character, could be quoted to any extent to sustain these views of the deleterious influence of this dangerous narcotic.

"Dr. Rush says of tobacco-'It impairs appetite, produces dyspepsia, tremors, vertigo, headache, and epilepsy. It injures the voice, destroys the teeth, and imparts to the complexion a disagreeable, dusky brown.'

"Dr. Boerhaave says that 'since the use of tobacco bas been so general in Europe, the number of hypochondriacal and consumptive complaints has increased by its use.'

"Dr. Cullen says, 'I have known a small quantity snuffed up the nose to produce giddiness, stupor, and vomiting. There are many instances of its more violent effects, even of its proving a mortal poison.'

"Dr. Darwin says, 'It produces disease of the salivary glands and the pancreas, and injures the power of digestion by occasioning the person to spit off the saliva which he ought to swallow.'

"Dr. Tissot once saw the smoking of it prove fatal.

"Dr. Pilcher details the particulars of a case of a medical student whom he had been requested to see. 'This gentleman suffered under all the symptoms of phthisis. There was muco-purulent expectoration, night sweats, etc. The mucous membrane of the throat, epiglottis, and the neighboring parts, was coated with a brown fur. The patient had been an immoderate snuff-taker; he was told to discontinue the snuff; he did so, and recovered.'

"Dr. Chapman says, 'By a member of Congress from the West, in the meridian 
of life, and of a very stout frame, I was some time since consulted; he told me that, trom having been one of the most healthy and fearless of men, he had become "sick all over, and timid as a girl." He could not even present a petition to Congress, much less say a word concerning it, though he had long been a practicing lawyer, and served much in legislative bodies. By any ordinary noise he was startled or thrown into tremulousness, and afraid to be alone at night. His appetite and digestion were gone, he had painful sensations at the pit of his stomach, and unrelenting constipated bowels. During the narrative of his suffering, his aspect approached the haggard wildness of mental distemperature. On inquiry, I found that his consumption of tobacco was almost incredible, by chewing, snuffing, and smoking. Being satisfied that all his misery arose from this poisonous weed, its use was discontinued, and in a few weeks he entirely recovered.?

" 'Distressing as was this case, I have seen others, from the same cause, even more deplorable. Two young men were in succession brought to me for advice, whom I found in a state of insanity, very much resembling delirium tremens. Each had chewed and smoked tobacco to excess, though perfectly temperate as regarded drink. The further account given me was, that in early life, adopting this bad practice, it grew with their growth. Dyspepsia soon occurred, attended by great derangement of the nervous system, and ultimately the mania I have mentioned. But I have also seen the same condition very speedily induced.'

"Dr. Franklin says he never used it, and never met with a man who did use it that advised him to follow his example.

"The venerable John Quincy Adams, in a recent letter on the subject, says that in early life he used tobacco, but for more than thirty years he had discontinued the practice. 'I have often wished,' says he, 'that every individual of the human race, affected with this artificial passion, would prevail upon himself to try, but for three months, the experiment which I have made, and I am sure it would turn every acre of tobacco-land into a wheat-field, and add five years to the average of human life.'

"Some cases have come under my observation which show the injurious effects of tobacco where no evil was suspected.

"A respectable merchant, who abstained wholly from ardent spirits, applied to me for advice. He complained of great weakness, tremor of the limbs and joints, with lassitude, general prostration of health, and depression of spirits. Knowing that he used tobacco freely, I advised him to discontinue it entirely; he soon became better, and after a time was wholly relieved from these disagreeable symptoms.

"A distinguished clergyman informed me that he had been an extravagant snufftaker; that for years he had had a disagreeable affection of the head, and his health was not good. He did not attribute either to his use of snuff, but thinking it a filthy habit and a growing evil, he resolved to leave it off. He was surprised to find the difficulty in his head almost immediately left him, and his general health became quite good.

"A gentleman of athletic frame, and about twenty-four years of age, applied to me for advice. He complained of insufferable faintness and distress of stomach, morning-sickness, vomiting, trembling, and prostration of strength. He diminished his tobaceo considerably, and was immediately better, but had not resolution to abandon the pernicious practice.

"In our experience in the hospital, tobacco in all its forms is injurious to the insane. It increases excitement of the nerrous system in many cases, deranges the 
stomach, and produces vertigo, tremors and stupor in others. It is difficult to control its use with the insane, and though considerable suffering comes from its entire abandonment, it cannot be generally allowed with safety.

"One patient, while at labor, found a quantity of tobacco, and hid it in his bed. He used it freely, became sick, lost his appetite, and confined himself to his bed completely intoxicated. After some days diligent search was made, and a store of tobacco was found in his straw bed; when this was removed he almost immediately recovered, and in a few days was well as before.

"A person who came into the hospital a furious maniac, soon became calm and improved favorably. He labored in the field with propriety, and exhilited every indication of a favorable convalescence. Suddenly, without any apparent cause, he again became very violent and insane. It was soon discovered that he had in some way obtained tobacco. After he ceased to use it, he again became calm and convalescent.

"An aged lady was brought to us very insane. The practice of her friends for some time had been to give her ardent spirits to intoxicate her at night, and tobacco and snuff, in unlimited quantity, for the day. All these were withdrawn at once; her sufferings for some days were great; but after a time she became calm, and got better as soon as the influence of this excitement was over.

"I have already exceeded my intended limits in the detail of cases.

"It is very natural to suppose that an article possessing the active properties of this fascinating narcotic, should produce most deleterious effects upon health-particularly upon the brain and nervous system.

"The uninitiated cannot smoke a cigar, or use tobacco in any form, without unpleasant effects, - how then can it be possible that a poison so active can be used with impunity? The stomach and brain, subjected to such influences, will become diseased, and show their effects as certainly as if aicohol were used. If asked my medical opinion, which was safest, four glasses of wine or four quids of tobacco daily, I should say unhesitatingly the wine. Of the two evils this would, in my opinion, be the least. Tobacco is the strongest, most dangerous narcotic-the habit of its use is the strongest, and most difficult to overcome, and the influence felt from it most banjful and destructive to health."

Opium acts similarly to tobacco, but much more fatally, the exhaustion caused by it being much less readily recovered from. In fact, if a man once becomes impotent from using opium, it is a great chance if he ever recovers his powers.

Dr. McDougal says that many of his friends, inveterate smokers have remarked to him that a decrease of their sexual desires was one of the marked effects of their indulgence, and I have frequently been told the same. M. Lallemand also gives several instructive cases in which this fact is forcibly illustrated. The following is a counterpart of many that I see :

"I have a young man of very nervous temperament at present under my care, on whom nocturnal and diurnal pollutions have brought on pain in the loins, palpitation, difficulty of breathing, etc., symptoms which were supposed to arise from disease of the spinal cord, cardiac affection, and commencing phthisis. Among the exciting causes of these involuntary discharges, the effects of smoking occupy the chief place. The following is the patient's statement :

" A At twenty years of age I wished to accustom myself to smoking, but a day never passed without my experiencing complete intoxication, attended with vomit- 
ing, vertigo, and trembling of the limbs. I continued the habit, however, and I soon began to perceive that my sight became weak, and that I lost my memory; my hands shook, and my digestion became much disordered. I noticed also great debility of the genital organs; my erections ceased, and at the age of twenty-two I found myself completely impotent.' This patient had rarely practiced masturbation, and had never committed any excess when he first began to smoke; his health had, previously, been excellent. It is therefore evident, that the impotence, as well as the other symptoms, arose from the action of tobacco. Impotence at the age of twenty-two can only be produced by involuntary seminal discharges, provided there be no physical disability. In the present case there was no doubt on the point, the patient himself having discovered diurnal and nocturnal pollutions.

"The action of tobacco on those who smoke for the first time, is too well known to require description; more or less disorder of all the functions, varying according to the constitution of the individual, invariably arises from it; and this disorder always presents more or less of the characteristics of poisoning by narcotics. These effects go off by degrees as the patient becomes habituated to the use of tobacco, and generally, after a time, cease to be manifested at all. Some nervous and excitable individuals are anable to accustom themselves to the habit, as in the case just mentioned; in others again, smoking becomes an artificial habit, which, in many cases, is almost a necessity.

"But this empire of custom has its limits, beyond which the narcotic influence reappears. In such as are not easily affected, this acquired habit is generally supported with impunity ; but even then, if it be indulged in to excess, it must, after a time, be injurious. Thus it is that the most accomplished smokers often experience vertigo, cephalalgia, anorexia, etc., when they have remained long in an atmosphere densely filled with smoke, which is then drawn into the lungs, and probably produces worse effects than when merely drawn into the mouth, or swallowed, as in smoking.

"In a word, then, if the power of habit can prevent the momentary effects of smoking from showing themselves, the frequent repetition of the use of tobacco produces more lasting effects on different organs. Disorder of the digestive organs is well known as occurring in inveterate smokers ; that of the genital organs has not hitherto been noticed. [Many inveterate smokers among my professional íriends, have mentioned to me the diminution of their venereal desires, as one of the effects of tobacco. I believe, however, that it is by no means rare."-H. J. McD.] 


\section{CHAPTER XLIX.}

\section{MASTURBATION AND OTHER SEXUAL ABUSES.}

A VERY few years ago only it was thought wrong even to allude to such a subject as masturbation, much less to openly speak or write about it. Fortunately, however, people have become more rational, and now begin to see that this and similar practices are of the most hurtful character, and that no successful efforts can be made for their removal till they are more fully and generally understood. Various books have been published, lectures have been delivered, and even sermons have been preached bearing upon this subject, till much general information about it is now disseminated, and a very general desire is expressed for something more complete and scientific than has yet appeared. The greater part of the books written on the subject of onauism or masturbation are very incomplete, and not accompanied by those physiological and medical details that are requisite to give a clear view of the evil. The effects of this vice may be partly given in such works, though in an incomplete form, but the manner in which they are produced, their connection with other evils, and the philosophy of their treatment, cannot be understood without such a work as the present. I have therefore delayed speaking upon this subject till all the other topics have been introduced, so that the unnatural character of the vice and its terrible consequences may be clearly obvious.

The mere tolerance of discussion on this subject is a great point gained, and there is now a very general conviction that such a discussion is not only desirable, but imperatively demanded by the best interests of society. It is both curious and instructive to see how this tolerance has been gradually gained, and how a percepition of the manifold evils of self-abuse has extended, though slowly, from a few philosophers to the great mass of the medical profession, and from thence to nonprofessional persons, till at last it has even been made the subject of legislative action.

I shall now proceed to show, by extracts from ancient medical writers, how this subject was regarded by eminent minds in former ages, and then to exhibit the more perfect knowledge and greater interest of modern times, including the approval, hy existing legislators, of investigations bearing intimately upon it.

Several of these extracts are taken from the celebrated works of Tissot and others, and some being from the writings of the Fathers of Physic, who lived centuries before Christ, allowance must be made, in some few cases, both for unintentional exaggeration, and also for deficiency in scientific accuracy. Generally speaking, the statements are fully authorized, and the pictures by no means overdrawn; in fact, it is often the case that the whole truth is not told, simply because it was not known.

"Hippocrates, the oldest and most correct observer, has already described the diseases produced by abusing the pleasures of venery, under the term dorsal consumption. 'This disease,' says he, 'arises from the dorsal portion of the spinal marrow. It principally attacks young married people, or the licentious. They hare 
no fever, and although they eat well, they grow thin and waste away. They have 2 sensation of ants crawling from the head down along the spine. Whenever they go to stool, or evacuate their urine, a considerable quantity of very thin seminal fluid escapes from the urethra. They lose the power of procreation, yet often dream of venereal pleasures. They become very weak, and walking produces shortness of breath ; they have pains in the head and ringing in the ears, and finally an acute fever (Libiria) supervenes, and they die.'

"Some physicians have ascribed to the same cause a disease which he has described in another place, and have termed it the second dorsal consumption of Hippocrates, and which has some relation to the first. But the preservation of the strength, which he mentions particularly, seems to us a conclusive proof that this disease does not depend on the same cause, but seems rather to be a rheumatic affection.

" 'These pleasures,' says Celsus, in his excellent work on the preservation of health, 'are always injurious to weak persons, and their abuses prostrate the strength.' We can find nothing more frightful than the description, by Aretæus, of the diseases produced by a too abundant evacuation of semen. 'Young persons assume the air and the diseases of the aged; they become pale, stupid, effeminate, idle, weak, and even void of understanding; their bodies bend forward, their legs are weak, they have a disgust for everything, become fit for nothing, and many are affected with paralysis.' In another place he mentions the abuse of these pleasures among the six causes which produce paralysis.

"Galen has seen diseases of the brain and nerves from the same canse, and the powers of the body impaired; and he also relates that a man who was convalescent from a violent attack of disease, died the same night after coition with his wife.

"Pliny, the naturalist, informs us that Cornelius Gallus, the old prætor, and Titus Etherius, a Roman knight, died in the act of copulation.

"Aetius says, "The stomach is deranged, all the body wastes, becomes pale, dry, and the eyes sunken.' These remarks of the most respectable ancient writers, are confirmed by the moderns. Sanctorious, who has examined, with the utmost care, all the causes which act on our bodies, has observed that this weakens the stomach, destroys digestion, prevents insensible perspiration, the derangements of which produce such evil consequences, disposes to calculus diseases, diminishes the natural warmth, and is usually attended with a loss or derangement of sight.

"Lomnius, in his fine commentaries on the passages of Celsus, whom we have just cited, supports the remarks of the author by his own observations. 'Frequent emissions of semen relax, weaken, dry, enervate the body, and produce numerous other evils, as apoplexies, lethargies, epilepsies, loss of sight, trembling, paralysis, and all kinds of painful affections.'

"One cannot read without horror the description left us by Tulpius, the celebrated burgomaster and physician of Amsterdam. 'Not only,' says he, 'the spinal marrow wastes, but the whole body and mind become languid, and the patient rerishes in misery. Samuel Vespertius was attacked first with a humor upon the back of his neck and head; it then passed to the spine, to the loins, to the lower and lateral region of the abdomen, and to the hips; this unhappy man was affected with so much pain that he was entirely disfigured, and was emaciated so gradually by a slow fever, that he more than once asked to be relieved from his misery by death.'

"' 'Nothing,' says a celebrated physician of Louvain, 'weakens the system so much.' 
"Blancard has known simple gonorrhœas, dropsies, and consumptions to depend on this cause; and Muys has seen a man of good age attacked with spontaneous gangrene of the foot, which he attributed to the same kind of excesses.

"In the Memoires des Curieux de la Nature is mentioned a ease of blindness. It deserves to be given at length. 'We are ignorant,' says the author, 'what sympathy the testicles have with the body, but particularly with the eyes.' Salmuth has known a sensible hypochondriac to become a fool, and in another man the brain to be so collapsed that it was heard to rattle in the cranium, both from excesses in venery. I have known myself a man, fifty-nine years of age, who, three weeks after marrying b young wife, became blind, and in four months died.

" "The too great loss of the animal spirits weakens the stomach and destroys the appetite; and nutrition not taking place, the action of the heart becomes more feeble; all parts languish, and the patient becomes epileptic.' It is true we are ignorant whether the animal spirits and the seminal fluid are the same; but observations show, as we shall see hereafter, that these two fluids are very analogous, and that loss of one or the other, produces the same complaints. Hoffman has seen the most frightful symptoms ensue from the loss of semen. 'After long nocturnal pollutions,' says he, 'the patient not only loses strength, becomes emaciated and pale, but the memory is impaired, a continual sensation of coldness affects all the extremities, the sight becomes dim, the voice harsh, and the whole body gradually wasted ; the sleep is disturbed by unpleasant dreams, does not refresh, and pains are felt like those produced by bruises.'

"In a consultation with a young man, who, among other diseases produced by masturbation, was affected with weakness in the eyes, he says: 'I have seen several instances of young men who, at mature age, when the body possesses all its strength, were attacked, not only with severe pain and redness of the eyes, but the sight became so feeble that they could neither read nor write.' He adds: 'I have even seen two cases of gutta serena from the same cause.' The history of the disorder which gave rise to this consultation will be read with interest. 'A young man commenced masturbation when fifteen years old, and having indulged in it till he was twenty-three, expcrienced so great feebleness in his head and eyes, that during the emission of semen there was severe pain in the latter. When he attempted to read anything, he had a feeling similar to that of drunkenness; the pupil was extraordinarily dilated; the eyes were exceedingly painful; the eyelids very heavy, and glued together every night; they were often filled with tears, and a whitish matter collected very abundantly in the two corners, which were very painful. Although he ate with 8 . good appetite, still he was extremely emaciated, and after he had taken food appeared as if drunk.' The same author has mentioned another case, of which he was an eyewitness, and which we think proper to mention here. 'A young man, eighteen years old, who had had frequent connections with a servant girl, suddenly fainted, and trembled exceedingly in all his extremities; his countenance was red, and his pulse very small. He recovered from this state at the end of an hour, but continued very feeble. The same phenomena occurred very frequently, with severe pain, and at the end of eight days there was a contraction and tumor in the right arm, with a pain in the elbow, which was always increased during the paroxysm. The disease increased for some time, but was finally cured by Hoffman.'

"Boerhaave portrays these diseases in that masterly manner and with that precision which characterizes all his descriptions. "Too great loss of semen produces 
weakness, debility, immobility, convulsions, emaciation, dryness, pains in the membranes of the brain, impairs the senses, particularly that of sight, gives rise to dorsal consumption, indolence, and to the several diseases connected with them.'

"The cases narrated by this great man to his auditors, in explaining to them this aphorism, which related to the different kinds of evacuations, ought not to be omitted. 'I have seen,' says he, 'a sick man, where the disease commenced by a lassitude and feebleness in the body, particularly in the loins ; it was accompanied by twitching of the tendons, periodical spasms, and loss of flesh, so as to destroy the whole body; also pains in the membranes of the cerebrum, pains which the patient terms (ardeur seche) a dry burning, which constantly inflames this most noble organ.

" 'I have also seen one young man affected with dorsal consumption. His figure was good; and although often cautioned against indulging in these pleasures, he did not regard it, and became so deformed before death, that the layer of flesh which appears above the spinous processes of the lumbar vertebræ entirely disappeared. The cerebrum, in this case, seemed to be consumed; in fact, the patient seemed to be stupid, and became so stiff that we have never seen the body so immovable from any other cause. 'The eyes are so dull that the sight is nearly lost.'

"De Senac mentions, in the first edition of his Essays, the dangers attending masturbation, and states that all who indulge in this vice will be affected in the flower of their youth with the infirmities of age.

"Ludwig, in describing the diseases resulting from too frequent evacuations, does not forget that of the semen. 'Young people, of both sexes, who indulge in lasciviousness, ruin their health by wasting strength which was designed to make them vigorous, and finally fall into consumption.'

"De Gotter details the sad accidents arising from this cause, but they are too long to copy. We refer to the work all those who can read the language in which it is written.

"Van Swieten, after quoting the description of Hippocrates mentioned above, adds: ' I have seen all these symptoms, and several others, in those unfortunate people who indulged in self-pollutions. I have employed uselessly, for three years, all the resources of medicine, for a young man who was diseased, in consequence of this practice, with wandering, frightful and general pains, with a sensation sometimes of heat and sometimes of cold, in every part of the body, but particularly in the loins. Afterward, these pains having diminished, his thighs and legs were so cold that, although they seemed of the natural temperature when touched, he was constantly warming himself by the fire, even during the warmest days of summer. I noticed particularly all this time, a continual rotatory motion of the testicles in the scrotum, and the patient felt a similar motion in the loins.' This account does not mention whether this unfortunate creature died in three years, or continued to languish some time longer, which would be more dreadful; he could not have recovered.

"Kloekof, in a very fine work on the diseases of the mind which depend on the body, confirms by his observations what we have already mentioned. 'A too great loss of semen weakens all the solid parts; hence arise weakness, idleness, phthisis, tabes dorsalis, stupidity, affections of the senses, faintings, and convulsions.'

"Hoffman had already remarked, that those young people who practice the infamous habit of masturbation lose gradually all the faculties of the mind, particularly the memory, and become entirely unfit for study.

"Lewis describes all these symptoms. We shall translate from his work only 
what relates to the mind. 'All the symptoms which arise from excesses with females follow still more promptly, especially in youth, the abominable practice of masturbation, and it is difficult to paint them in as frightful colors as they deserve. Young persons addict themselves to this practice without knowing the enormity of the crime, and all the consequences which physically result from it. The mind is affected by all the diseases of the body, but particularly by those arising from this cause. The most dismal, melancholy indifference and aversion to all pleasures, the impossibility to take part in conversation, the sense of their own misery, the consciousness of having brought it upon themselves, the necessity of renouncing the happiness of marriage, all affect them so much that they renounce the world-blessed if they escape isuicide." "

The symptoms here given are precisely such as are ordinarily seen in cases of selfabuse, but there are many others, arising secondarily, which have only been recently ascribed to this cause. Idiocy and insanity, for instance, and that general failing of all the physical and mental powers, affecting both the individual and his offspring, which leads eventually to the extinction of his family and name. It is only of late that proper attention has been directed to these terrible evils, and that they have been thought to be at all under our control. Formerly they were looked upon as mysterious dispensations of Providence, much to be deplored, but only to be met with patience and resignation. Many eminent writers of the present age have distinctly recognized the influence of self-abuse in the production of idiocy, insanity, and constitutional degeneracy, and have especially urged the necessity of attending to it when treating those evils. Among other recognitions of this kind, I have been particularly struck with one, a legislative document, in which there is more wholesome truth told and more sound reasoning advanced, than in almost all the medical treatises on the subject put together. It is a REPORT on the subject of idiocy, presented to the Massachusetts Senate, by Dr. S. G. Howe, in February, 1848, in compliance with a former resolution of that body, directing such a report to be made. I am only surprised that such a document so valuable should be so little known, and that the Hon. Senators should not have seen that their duty was to give it as wide a circulation as possible. The influence of such a document, from such a source, must have been very great, and no doubt would accomplish more good, in the way of prevention, than all their asylums and medical treatment could in the way of cure. In time this and similar reports will be eagerly sought for, and their great value to the public at large will be universally admitted. I shall quote from the report here for the double purpose of corroborating by it my own statements, and also of making it more generally known.

In speaking upon the necessity that exists for boldly approaching this subject, notwithstanding the prejudice that many persons feel against doing so, Dr. H. makes the following forcible and sensible remarks :

"There is another vice, a monster so hideous in mien, so disgusting in feature, altogether so beastly and loathsome, that, in very shame and cowardice, it hides its head by day, and, vampire-like, sucks the very life-blood from its victims by night; and it may perhaps commit more direct ravages upon the strength and reason of those victims than even intemperance; and that vice is self-abuse.

"One would fain be spared the sickening task of dealing with this disgusting subject; but, as he who would exterminate the wild beasts that ravage his fields, must not fear to enter their dark and noisome dens, and drag them out of their lair ; 
so he who would rid humanity of a pest, must not shrink from dragging it from its hiding-places, to perish in the light of day. If men deified him who delivered Lerna from its hydra, and canonized him who rid Ireland of its serpents, what should they do for one who could extirpate this monster vice? What is the ravage of fields, the slaughter of flocks, or even the poison of serpents, compared with that pollution of body and soul, that utter extinction of reason, and that degradation of beings made in God's image, to a condition which it would be an insult to the animals to call beastly, and which is so often the consequence of excessive indulgence in this vice?

"It cannot be that such loathsome wrecks of humanity as men and women reduced to driveling idiocy by this cause should be permitted to float upon the tide of life, without some useful purpose ; and the only one we can conceive is that of awful beacons, to make others avoid-as they would eschew moral pollution and deaththe course which leads to such ruin.

"This may seem to be extravagant language, but there can be no exaggeration, for there can be no adequate description even, of the horrible condition to which men and women are reduced by this practice. There are, among those enumerated in this report, some who not long ago were considered young gentlemen and ladies, but who are now moping idiots-idjots of the lowest kind-lost to all reason, to all moral sense, to all shame-idiots who have but one thought, one wish, one passion, and that is the further indulgence in the habit which has loosed the silver cord even in their early youth, which has already wasted, and as it were dissolved, the fibrous part of their bodies, and utterly extinguished their minds.

"In such extreme cases, there is nothing left to appeal to-absolutely less than there is in the dogs and horses, for they may be acted upon by fear of punishment; but these poor creatures are beyond all fear and all hope, and they cumber the earth a while, living masses of eorruption.

"If only such lost and helpless wretches existed, it would be a duty to cover them charitably with the veil of concealment, and hide them from the public eye, as things too hideous to be seen : but, alas! they are only the most unfortunate members of a large class. They have sunk down into the abyss toward which thousands are tending. The vice which has shorn these poor creatures of the fairest attributes of humanity is acting upon others, in a less degree, indeed, but still most injuriously, enervating the body, weakening the mind, and polluting the soul.

"A knowledge of the extent to which this vice prevails would astonish and shock many. It is indeed a pestilence which walketh in darkness, because, while it saps and weakens all the higher qualities of the mind, it so strengthens low cunning and deceit, that the victim goes on in his habit unsuspected, until he is arrested by some one whose practiced eye reads his sin in the very means which he takes to conceal it, or until all sense of shame is forever lost in the night of idiocy, with which his day so early closes.

"Many a child who confides everything else to a loving parent, conceals this practice in its innermost heart. The sons or daughters who dutifully, conscientiously, and religiously confess themselves to father, mother, or priest, on every other subject, never allude to this. Nay, they strive to cheat and deceive by false appearances; for-as against this darling sin--duty, conscience, and religion, are all nothing. They even think to cheat God, or cheat themselves into the belief that He who is of purer eyes than to behold iniquity can still regard their sin with favor.

"Many a fond parent looks with wondering anxiety upon the puny frame, the 
feeble purpose, the fitful humors of a dear child, and, after trying all other remedies to restore him to vigor of body and vigor of mind, goes journeying about from place to place, hoping to leave the offending cause behind, while the victim hugs the disgusting serpent closely to his bosom, and conceals it carefully in his restment.

"The evils which this sinful habit works in a direct and positive manner are not so appreciable, perhaps, as that which it effects in an indirect and negative way. For one victim which it leads down to the depths of idiocy, there are scores and hun. dreds whom it makes shamefaced, languid, irresolute, and inefficient for any high purpose of life. In this way, the evil to individuals and to the community is very great.

"It behooves every parent, especially those whose children (of either sex) are obliged to board and sleep with other children, whether in boarding-schools, boarding-houses, or elsewhere, to have a constant and watchful eye over them, with a view to this insidious and pernicious habit. The symptoms of it are easily learned, and, if once seen, should be immediately noticed.

"Nothing is more false than the common doctrine of delicacy and reserve in the treatment of this habit. All hints, all indirect advice, all attempts to cure it by creating diversions, will generally do nothing but increase the cunning with which it is concealed. The way is, to throw aside all reserve; to charge the offense directly home; to show up its disgusting nature and hideous consequences in glowing colors; to apply the cautery seething hot, and press it in to the very quick, unsparingly and unceasingly.

"Much good has been done, of late years, by the publication of cheap books upon this subject. They should be put into the hands of all youth suspected of the vice. They should be forced to attend to the subject. There should be no squeamishness about it.

"There need be no fear of weakening virtue by letting it look upon such hideous deformity as this vice presents. Virtue is not salt or sugar to be softened by such exposure ; but the crystal or diamond that repels all foulness from its surface. Acquaintance with such a vice as this, - such acquaintance, that is, as is gained by having it held up before the eyes in all its ugliness-can only serve to make it detested and avoided.

"Were this the place to show the utter fallacy of the notion that harm is done by talking or writing to the young about this vice, it could probably be done by argument, certainly by the relation of pretty extensive experience. This experience has shown that, in ninety-nine cases in a hundred, the existence of the vice was known to the young, but not known in its true deformity; and that, in the hundredth, the repulsive character in which it was first presented, made it certain that no further acquaintance with it would be sought."

This is speaking to the point, and Dr. Howe never rendered more important ser vice to suffering humanity than when he laid down these momentous truths.

In another part of the Report the effects of ignorance are made terribly apparent, not only upon the unfortunate victim, but also upon society at large, and it is plainly shown what danger every one runs while that ignorance exists.

"In some families which are degraded by drunkenness and vice, there is a degree of combined ignorance and depravity, which disgraces humanity. It is not wonderful that feeble-minded children are born in such families; or, being born, that many of them become idiotic. Out of this class domestics are sometimes taken by those in 
better circumstances, and they make their employers feel the consequences of suffering ignorance and vice to exist in the community. There are cases recorded in the appendix, where servant-women, who had the charge of little girls, deliberately tanght them habits of self-abuse, in order that they might exhaust themselves, and go to sleep quietly! This has happened in private houses as well as in the almshouses; and such little girls have become idiotic!

"The mind instinctively recoils from giving credit to such atrocious guilt; nevertheless, it is there, with all its hideous consequences; and no hiding of our eyes, no wearing of rose-colored spectacles,-nothing but looking at it in its naked deformity, will ever enable men to cure it. There is no cordon sanitaire for vice; we cannot put it into quarantine, nor shut it up in a hospital ; if we allow its existence in our neighborhood, it poisons the very air which our children breathe."

These remarks apply also to our public schools, in most of which this vice prevails to an alarming extent, and sometimes in the most open manner. I have been myself amazed at the revelations made to me on this subject, both by teachers and pupils, and clearly enough has it been proved, to my satisfaction, how that shunning of the subject, which many so systematically practice, leads directly to the production and continuance of the vice.

In some few cases masturbation is learned accidentally, or a knowledge of it arises spontaneonsly, but in a vast majority of instances it is taught, and hence the great importance of preventing, if possible, those who are addicted to it from contaminat. ing those who are innocent. Dr. Howe remarks :

"There is one remarkable and valuable fact to be learned respecting this rice, from observation of idiots, and that is, that some of them, though they have no idea of right and wrong, no sense of shame, and no moral restraint, are nevertheless entirely free from it. They could never have been in the practice of it, else they would never have abandoned it.

"From this may be inferred, that it is a pest generally engendered by too intimate association of persons of the same sex; that it is handed from one to another like contagion; and that those who are not exposed to the contagion are not likely to contract the dreadful habit of it. Hence we see, that not only propriety and decency, but motires of prudence, require us to train up all children to habits of modesty and reserve. Children, as they approach adolescence, should never be permitted to sleep together. Indeed, the rule should be-not with a view only to preventing this vice, but in view of many other considerations-that after the infant has left its mother's arms, and become a child, it should ever after sleep in a bed by itself. The older children grow, and the nearer they approach to youth, the more important does this become. Boys even should be taught to shrink sensitively from any unnecessary exposure of person before each other; they should be trained to habits of delicacy and self-respect; and the capacity which nature has given to all for becoming truly modest and refined, should be cultivated to the utmost. Habits of self-respect, delicacy, and refinement, with regard to the person, are powerful adjuncts to moral virtues; they need not be confined to the wealthy and favored classes; they cost nothing; on the contrary, they are the seeds which may be had without price, but which ripen into fruits of enjoyment that no money can buy."

In the present state of society it is almost impossible, unfortunately, to prevent children from being taught this vice, either practically or by verbal instruction, and it is, therefore, necessary to guard them against it by timely information and warning: 
Even if he be strictly kept from vicious associates the child may learn the habit himself, and may sink and die from it while the parent is glorifying himself on the success of his precautions.

In the article on Insanity in Copland's Dictionary of Practical Medicine, the author, in pointing out the various causes of that terrible affliction, speaks in the following terms respecting self-abuse:

"Many, however, of those causes, which thus affect nervous energy, favor congestion of the brain, and occasion disease of other vital organs, tending to disorder the functions of the brain sympathetically. Of these, the most influential are masturbation and libertinism, or sexual excesses; sensuality in all its forms, and inordinate indulgence in the use of intoxicating substances and stimulants. The baneful influence of the first of these causes is very much greater, in both sexes, than is usually supposed ; and is, I believe, a growing evil, with the diffusion of luxury, of precocious knowledge, and of the vices of civilization. It is even more prevalent in the female than in the male sex; and in the former it usualiy occasions various disorders connected with the sexual organs-as leucorrhoea, displacement of the uterus ; difficult, or disordered, or suppressed, or profuse menstruation; both regular and irregular hysteria, catalepsy, ecstasis, vertigo, various states of disordered sensibility, etc., before it gives rise to mental disorder. In both sexes, epilepsy often precedes insanity from this cause ; and either it or general paralysis often complicates the advanced progress of the mental disorder, when thus occasioned. Melancholia, the several grades of dementia, especially imbecility and monomania, are the more frequent forms of derangement proceeding from a vice which not only prostrates the physical powers, but also impairs the intellect, debases the moral affections, and altogether degrades the individual in the scale of social existence, even when manifest insanity does not arise from it."

Some persons think that masturbation produces only the same effects as natural excess, and in no greater degree, but this is a great mistake. There is the same exhaustion of the semen in both cases, but in self-abuse it is not accompanied by those natural associations that bring it about in a pleasing manner, and leave afterward a feeling of satisfaction. On the contrary it is induced almost wholly by a poiverful exertion of the imagination alone, aided by manual means that are felt to be inappropriate, so that the act itself is but a very imperfect gratification, and the feelings that follow it are rather those of disgust and remorse than of pleasurable recollection. The facility with which the habit can be indulged also leads to its frequent repetition, and as the concurrence of a second party is not necessary there is nothing to prevent its growing and becoming fully confirmed. In fact, the individual becomes a slave to a vice that he himself despises, and which he feels is destroying him. The mental tortures of remorse, fear, and self-condemnation are then added to bodily exhaustion, and we need not wonder at the fearful havoc they produce. The licentious debauchee will often look back with a species of pride and vain-glory upon his numerous indulgences, even when he feels they are killing him, and he may even feel over again, by recollection, some of his former pleasures; but for the victim of masturbation there is not even this small solace. His pleasure is but incomplete at best, and clouded by dissatisfaction, while the recollection of it only excites disgust and fearful apprehensions.

In fact the evil effects of excessive natural indulgence, particularly the mental ones, bear no comparison, for severity, with those of self-abuse, nor are they nearly 
so numerous and varied. Natural indulgence, it must also be recollected, cannot be practiced so frequently as masturbation, and consequently it can never cause such extensive mischief. It is but seldom that natural excesses cause insanity or idiocy, except secondarily in the offspring, but solitary vice frequently does so, both in the individual and in his children.

In the Massachusetts Report it is stated that 191 of the idiots examined were known to have practiced masturbation, and in 19 of them the habit was even countenanced by the parents or nurses! $\mathbf{1 1 6}$ of this number were males, and 75 females. In 420 who were born idiots, 102 were addicted to masturbation, and in 10 cases the idiocy of the children was "manifestly attributable to self-abuse in the parents!" These 10 known cases it should also be recollected justify the conclusion that there are really many more, though not ascertained, and make it clear that much of the idiocy found among children is owing to sexual vice in the parents! What a fearful fact is this to contemplate, and how important that it should be duly weighed, both by the moral reformer and legislator.

In the Annual Reports of the Massachusetts State Lunatic Asylum are also some valuable statistics, showing the connection between masturbation and insanity. In the Twelfth of these Reports, I find that the number of cases existing in the Institute caused by self-abuse is set down at One Hundred and Thirty-nine, and yet great pleasure is expressed that the vice has "fewer victims than formerly." The decrease in the number is attributed, and justly, too, $I$ have no doubt, if there be a decrease, to "the information that has been diffused on the subject, and the warnings that have reached the young through the various channels of intelligence that have been opened on this hitherto obscure subject."

In the Thirteenth Report One Hundred and Forty-five cases are set down as caused by masturbation, and some very forcible remarks are made on the subject which I think it will be useful to copy.

"The causes of insanity may be divided into voluntary and involuntary. Of the former, the principal are intemperance and the secret vice; other causes may be of this class, such as hazardous speculation, many religious vagaries, imprudent exposures, and irregularities. None are so prominent as the two first named, and none so fully stain the character with guilt, which even the occurrence of hopeless disease can hardly wipe away. Intemperance disorders the senses, and induces apoplexy, epilepsy, and palsy. The cases from this cause are about as favorable for recovery as the majority of others, but are most sure to return if the habit of intemperance recurs. The secret vice produces the very worst form of insanity, because it is so difficult to aroid the continuance of the cause, and because the energies of the system are more prostrated by it than by almost any other cause. Such patients become degraded animals, so entirely abandoned to the habit, that hopeless dementia and driveling idiocy generally follow. A few can be influenced to abandon the practice, and a few others can be cured in spite of it; but in almost all cases the disease will become worse, and these dreadful consequences will ensue.

"The secret vice, though doubtless a frequent cause of insanity, and of other severe and fatal diseases far more than is generally supposed is most operative in preventing recovery from insanity, arising from this and other causes. It is extensively and alarmingly the result of an active propensity excited by disease and unrestrained by reason, moral influences or self-respect. Many cases of a favorable character progress toward recovery till this practice is commenced, then the patient becomes list 
less, is inclined to lie down or sit in a bent position, walks moderately, looks feeble, and feels weak and miserable. His mind loses its energies, its scope is circumscribed more and more, till this beastly indulgence occupies all his thoughts, and the remnant of all the physical powers are concentrated to this single effort of gross and debased animal nature. Thus the groveling sensualist lives, often a long life, a degraded sufferer, without a manly thought or a moral feeling worthy of his nature or his destiny, and finally leaves the world without the regret of his friends, a nseless, burthensome, loathsome object of abhorrence and disgust."

In the two Reports, under the head of "Relation of Cause to Recovery," I find two hundred and seventy-one males enumerated, and twenty-one females, from masturbation and its effects; and of this number one hundred and ninety-seven males, and twenty-seven females were incurable! Only two of the females it will be observed being curable.

These Reports also throw much valuable light on the relation between masturbation, as a cause of insanity, and different occupations.

Some persons express fear that if this subject be generally discussed, and all are informed about it, this very publicity will increase the evil, by exciting an amount of attention that would not otherwise have been given to it. The fallacy of this will be evident enough, to all those who are acquainted with the nature and extent of the vice. It is next to impossible to prevent its being known, either naturally or from tuition, and, therefore, no harm can possibly result from proper information timely given, while on the other hand, numbers undoubtedly perish for want of it.

If it were true that a knowledge of the nature and consequences of this habit tends to its being practiced, we ought to find it most prevalent amongst those who have most of that knowledge, and least so amongst those who have the least of it. The truth is, however, directly the reverse, as every sensible person would pre-suppose, and as facts indubitably prove. Those who are educated as physicians, of course, study everything relating to the sexual system, and are acquainted with all its details, while mechanics, generally speaking, never study anything of the kind, because it is not necessary for them to do so. Now, let us see what proportion of the insane, from both these classes, are made so by masturbation.

In the Thirteenth Annual Report, I find that there are in the asylum sixty-two shoemakers, of whom twenty-four were made insane by masturbation, which shows that of the insanity existing in this class of the population, who certainly receive but little of this kind of information, nearly fifty per cent., or one-half, arises from selfabuse! Now what is the proportion when we refer to the medical profession? I can find physicians made insane by other canses, but neither in that Report, nor in the one for the preceding year, do I find a single case of one becoming insane from masturbation! These facts, so far from proving what some assert, that an intimate acquaintance with the physiology of the sexual system leads to its abuse, prove directly the reverse, and show conclusively that the best informed go the least astray.

Other facts in the same Report also show that it is precisely this kind of knowledge that is needed, anci that no other will either lead the thoughts from it or fortify against it. Thus among students the proportion of insane from masturbation is nearly seventy-five per cent., there being eighteen from this cause out of twenty-five ; the balance of the cases being two from ill health, two from domestic affliction, two from religion, and one from epilepsy. Among merchants the proportion is abou 
fifty per cent. ; among lawyers, about thirty-three per cent. ; and among clergymen fifty-six per cent. !

The most frequent cause of insanity is set down as intemperance, but in numerous cases this has been first produced by masturbation, the patient resorting to alcosolic and other stimulants, merely as a temporary relief from the exhaustion produced by this practice. Ill health is also another frequent cause, and how often this arises from self-abuse is well known. In short, there is no doubt on my mind, after duly considering all the facts, that solitary vice produces more insanity than ali other causes put together!

Another valuable fact also shown in these reports is the influence of occupation in leading to solitary vice. It is prover conclusively that light sedentary employments very much favor the formation of such habits, and that, on the contrary, active outof-door occupation has the contrary effect. Thus, among "merchants, printers, students, and shoemakers," fifty per cent. of the insanity arises from masturbation, and only twelve per cent. from intemperance, while among carpenters, blacksmiths, and others who are actively employed, thirty-five per cent. of the insanity arises from intemperance, and only thirteen per cent. from masturbation. Among seamen, again, fifty-four per cent. of the insanity arises from intemperance, and only eleven per cent. from solitary vice. These facts should be duly weighed by parents when choosing employment for their sons. Many a youth of sanguine temperament, urgently requiring a muscular and mental occupation of the most varied kind, is condemned to the monotonous inactivity of a counting-house desk, the distasteful plodding of an office, or some merely intellectual profession, and in consequence becomes listless, dogged and self-debased. In such cases, the abundant vital energy that ought to have been expended in active exertion is retained, and by stimulating the sexual organs to an unnatural degree, leads to solitary vice, both as a gratification and a relief.

The effects of masturbation, most frequently met with, are weakness of the eyes, swelling and soreness of the eyelids, partial deafness, weakness of the limbs and back, headache, dizziness, flatulence, incontinence of urine, diarrhœea, or obstinate costiveness, palpitation of the heart, shortness of breath, loss of memory, and confusion of judgment, with melancholy, or irritable peevishness. Another effect also met with, in many cases, is a partial loss of the power of speech, or a tendency to stammer and stutter. This effect $I$ have often observed in persons who had previously spoken as fluently as any one, and who could not imagine themselves what the difficulty arose from. Most frequently it is attributed simply to that loss of self-confidence and that feeling of shame which all self-abusers experience, and no doubt this does make it worse, but still the main cause of the impediment is a partial paralysis of the muscles of the throat, brought on by sympathy with the irritated parts below. Not unfrequently there is more or less difficulty in swallowing at the same time, with frequent sighing and gulping, as if there was wind in the throat. In fact, these symptoms are very similar to those observed in the hysteria of females, with which they are, to a great extent, identical, both in nature and origin.

Baldness is also a frequent occurrence to those who practice masturbation, and so is premature whitening of the hair.

Palsy and epilepsy are more frequently the results of this practice than is usually thought, and paralysis is quite commonly so. I have known many insiances of young men becoming temporarily paralytic from excessive self-abuse, and very recently I was called to see an old man who was dying from paralysis brought on in this way. 
These affections, though severe, need not be wondered at when the powerful sympa thies of the generative organs are borne in mind, and when it is recollected what an exhaustion of the vital power is caused by their excessive action.

The best way, however, to exhibit the full effects of this baneful vice is to give a few illustrative cases, which will not only portray the prominent symptoms, but also indicate the course of treatment usually adopted. Some of them are contributed by M. Lallemand, and others I have selected from my own note-book.

"M. D- , of Philadelphia, of a very robust constitution, contracted the habit of masturbation while at school, when only eight years old. The first effect produced was a frequent desire to pass urine, and at twelve years of age this irritability had become so great that he was sometimes unable to retain his urine a quarter of an hour. Before entering a house he always took care to micturate several times in rapid succession, and notwithstanding this precaution, he soon experienced renewed uneasiness. He felt as though his bladder was never entirely empty, and the smallest quantity of urine induced spasmodic contractions. The irritability of the urinary organs diminished by degrees after the period of puberty, but never ceased entirely, notwithstanding the various means which were employed on different occasions.

"At the age of sixteen, M. D- endeavored to break off his injurious habits by sexual intercourse, but he found himself completely impotent, and shame induced him to return to masturbation. He afterward made further attempts to correct himself, but he experienced nocturnal pollutions, which often made him lose courage. At length, after many relapses, he succeeded completely, without observing any further nocturnal emissions. Still, his health, instead of improving, became more and more impaired. His erections were less frequent, less prolonged, incomplete, and, at length, gradually ceased, together with all venereal desire.

"At the age of twenty-eight, the state of his urine, its frequent discharge, and the wandering pains in the perineum and testicles, induced a fear of calculus; sounding, however, only showed a morbid sensibility of the urethra, especially toward the neck of the bladder.

"In the beginning of May, 183\%, M. D- came to Montpellier in the following condition :-Much debilitated ; unsteady in his walk ; easily chilled, and taking cold veì quickly; wandering pains all over his body; skin dry; memory impaired; digestion difficult ; extremities cold ; scrotum relaxed, and testicles soft, very sensitive, and often causing a dull pain, as if they were forcibly compressed; the semen - from the account he gave of the last nocturnal pollutions he had experiencedclear, aqueous and inodorous; seminal emissions with the last drops of urine, which were clammy, and passed with difficulty, and excited a sensation of tickling in the neighborhood of the anus, which extended to the orifice of the urethra; he often had diarrhœa, but at other times was very costive, and his stools were passed with difficulty and pain. He did not, however, often pass semen while at stool.

"I discovered, several days following, the presence of semen in M. D__'s urine, and catheterism showed an excessive irritability of the urethra, especially in the neighborhood of the prostate, which, on examination, was found slightly enlarged. Nearly a tablespoonful of blood followed the witbdrawal of the catheter. The circumstances did not leave the least doubt on my mind as to the state of the mucous membrane in the vicinity of the ejaculatory ducts, and consequently I immediately performed cauterization, from the neck of the bladder as far as the membranous portion of the urethra. Twenty days afterward M. D- left Montpellier for Italy, and when he returned, three months afterward, he was completely cured, no involun- 
tary seminal emissions having afterward appeared. His urine was transparent, and could be retained seven or eight hours without inconvenience; its discharge took place without effort, and was not accompanied by any remarkable sensation. Lastly, the patient's impotence, which had been present nearly twelve years, had given place to a virility previously unknown to him. I need hardly state that his physical and moral energy shared in this regeneration.

"I have often had occasion to notice the connection that exists between the spermatic and urinary organs; and I have shown that there is scarcely a cause of spermatorrhœa which does not act more or less on the bladder and kidneys. The cause I am now investigating affords us numerous examples of this connection-of which the case I. have just related is a remarkable instance-the irritation of the urinary organs having been developed very rapidly, having shown very marked symptoms, and having existed alone during several years. The patient was only eight years of age when he first became addicted to masturbation; at this early age the urinary organs alone possessed activity, and therefore they alone were able to suffer disturbance of their functions; on this account the symptoms were confined for a long time to the urinary organs. The character of the symptoms showed that they arose from a chronic state of inflammation, or from an acute irritation of the urinary organs, and this state must have extended also toward the spermatic organs. Thus the increased secretion of the kidneys, and the extreme irritability of the bladder, would give a very clear idea of what took place in the spermatic organs at the period of puberty. As soon as the testicles began to act, they fell under the same influence as the kidneys ; the seminal vesicles were in the same condition as the bladder; in other words, the semen was secreted in large quantities, and was retained a very short time in its reservoirs. Being therefore imperfectly formed, the usual effect on the erectile tissues produced by its presence did not take place, and coitus was impossible at the age of sixteen. The occurrence of impotence at so early an age is sufficient to show that diurnal pollutions had already commenced, although the patient did not discover them for a long time afterward. He was still, however, able to practice masturbation; and this is a circumstance which has great effect in preventing persons addicted to the vice, from renouncing their fatal habits. At a later period, nocturnal pollutions, which occurred after a few days' care, shook the patient's resolution. This is a much less serious. circumstance than the one just mentioned, but at the same time much more common. At length the patient left off his habits, and his nocturnal pollutions disappeared; yet the disorder of his health continued to increase. His prudence, exercised too late, did not arise from the strength of his will, but from the weakness of his genital organs; the disappearance of his nocturnal emissions did not arise from the remedial measures used, but from the increase of his involuntary diurnal discharges, of which he only became aware long afterwards. These common errors are the more dangerous, because medical practitioners are apt to participate in them.

"In the case of M. D- the irritability of the canal was rery great, and the effect of the cauterization was correspondingly prompt and decided."

The above case is a highly instructive one, because it shows both how early the habit of masturbation may be commenced, and also what a general disturbance of the economy it may lead to. The following case is also a very important one, and shows how very readily the symptoms of spermatorrhœea may be thought to indicate other diseases, and what mistakes may be made in consequence :

I am indebted for this very remarkable case to the kindness of Dr. Daniel, 
of Cette. "On the 26th of May, 1836, I was called to F-, a baker, aged twentytwo ; I found him in bed, in the following condition :--great moral prostration, carried even to a hatred of existence ; prostration of strength; anæmia ; lips pale and shriveled; remarkable pallidity; eyes sunken; expression of countenance dull; great emaciation ; skin hot and dry ; pulse small ; voice hoarse, and so low that it was with difficulty a few words could be heard by approaching the ear; constant cough, scarcely permitting an instant's repose; general wandering pains, most severe in the loins, and the sides of the chest; great irritability of the stomach-vomiting being excited after taking almost any kind of liquor or solid food.

"At first I thought that I recognized in this patient the symptoms of phthisis laryngea, complicated with chronic gastritis; but the examination of his chest and abdomen did not support this opinion. The epigastric region was not painful on pressure; the respiratory murmur was heard all over the chest, and percussion emitted a healthy sound, except under the left false ribs, where it was slightly dull, and the patient felt pain.

"His debility did not permit me to practice abstraction of blood; and indeed, the pleuropneumonia of the left side did not seem either very extensive or very acute. I therefore ordered a large blister to be applied over the affected spot, and prescribed a solution of tartar-emetic, and a strict diet. The pain in the side disappeared, and two days afterward, the stomach could retain milk and barley-water. Still nothing explained the patient's emaciation; his almost total loss of voice, hoarseness and constant cough. His parents attributed these symptoms to hereditary phthisis, and mentioned that several members of the family had died of that disease. Minute and repeated examination of $\mathrm{F}$ —_ 's chest, however, assured me that this was not the case. On the other hand, the symptoms were very severe, and I could not discover any risceral lesion sufficient to account for them. In this state of uncertainty, your views on spermatorrhœa attracted my attention. I immediately questioned the patient respecting his past life, and learnt that at the age of seventeen he practiced masturbation with such fury that he had frequently passed aqueous semen, mixed with blood: frightened by these accidents, he had corrected himself completely. But, after about a fortnight's abstinence, he noticed that his urine contained a deposit of thick, whitish, flocculent matter. He never attached any importance to this, although during four years, he observed it constantly, and noticed that it was more abundant after he had been much fatigued in his business. He observed also, that the last drops of urine were thick and viscid, and that a small quantity of viscid matter generally remained at the orifice of the urethra. His bad symptoms first commenced at this time; his erections and desires entirely disappeared; and, by the time he had attained the age of twenty-one, he was obliged to give up his employment, and shortly afterward, his symptoms becoming aggravated, he was unable to quit his bed.

"I examined his urine, and found it in the condition he had described; the deposit contained in it being about an ounce in quantity. I noticed that his testicles were soft, and his scrotum flaccid. He agreed with eagerness to my proposition of cauterizing the prostatic portion of the urethra, and I performed it on the following day. The effect of the cauterization was rapid; the second night afterward the patient slept soundly ; the third day, a change was observed in his voice; and erections occurred during the night. On the fourth day the patient was able to get up and take some light food, which was well digested; his wandering pains had disappeared, and, by the ninth day after the cauterization, the patient's strength had returned." 


\section{CHAPTER L.}

FROTOMANIA AND SATYRIASIS.

THESE two affections are usually confounded together, but there is considerable difference in their nature, though their manifestations are similar. In both of them there is an unnatural excitation of sexual desire, so that it sometimes becomes utterly uncontrollable, and gratification is sought at any cost. In these cases there is a real furore, or madness, which arises from disease, and is not a mere moral aberration, as uninformed people suppose.

Satyriasis arises from a disease of the sexual organs, or of some of the adjoining parts, which keeps them in a constant state of irritation, sometimes so great that the patient cannot obtain the slightest relief, either sleeping or awake, but is kept the whole time in a state of furious excitement.

The diseases that are most likely to produce satyriasis, are those of the urethra and prostate gland, though sometimes gravel, or even the piles will originate it. Dr. Curling remarks that "The irritation attending the morbid condition of the mucous membrane of the prostatic portions of the urethra tends, in a very material degree, to excite both the excessive seminal discharge, and the secretions of the prostate, and to produce that morbid craving for indulgence and abuse, which persons who have brought themselves to this state, find so difficult to repress and resist. It is well known that any irritation at the orifice of an excretory duct usually acts as a stimulus to the secretion of the gland. Thus, hurtful matter in the duodenum produces a flow of bile; and a foreign body in the conjunctiva, as an inverted eyelash, a discharge of tears. So it is with the testes, when irritation exists at the orifices of the excretory ducts. The disorder at this part, moreover, appears to react on the brain, and to become, in part, the cause of the patient's mind being constantly occupied with subjects of sexual excitement, and of his indifference and apathy to other matters. So that the local disease induced by abuse powerfully aids in perpetuating the mischief, and, judging from the experience which I have had in these cases, is the object to which our treatment should be first directed."

In many of these cases it is of no use reasoning with the patient, and telling him to control himself, unless the exciting disease be also corrected ; it would, in short, be of little more use than telling him he must not give way to a diarrhœa or any other morbid action. In a note in Dr. Curling's work this truth is well laid down, and applied to a class of cases for which usually no excuse is thought to exist. The writer says, "This is a truth, I fear, not sufficiently impressed on the minds of medical men. One would be loath to offer any apology for the vicious habits and indulgences to which, it is well known, old men are occasionally addicted,-a melancholy example of the kind, in the higher ranks of life, having lately been brought under public notice. I cannot but think, however, that, in many instances, these cases are not undeserving of professional sympathy, and that the erotic longings which 
sometimes continue to distress the aged, long after the period at which, in the course of nature, they should have ceased, depend as much on physical infirmity as mental depravity, the former inciting and producing the morbid desires. If these propensities were regarded and treated as symptoms of disease (and that they frequently occur in connection with affections of the urinary passage is well known to practical surgeons), I believe they would often subside, and the distressing results to which they lead would be altogether avoided."

The same remarks also apply to every other period of life, and especially to youth, 2s every physician of experience in such matters must be well aware. I know that, in numerous instances, the sexual feelings of young persons are preternaturally excited by local disease, and that their genital organs are thus kept in a state of excitement by causes over which they have no control. This fact should be kept always in view when considering such cases, and we should recollect that a medical preseription may often accomplish reform, when a moral precept has failed, of which the foregoing chapters of this work will furnish many illustrations.

I was once consulted by a married man, the father of a family, whose habits had always been strictly moral and proper, but who suddenly found himself subject to occasional fits of the most intense sexual excitement, over which he had but little control. So completely was he the slave of his morbid feelings, in fact, that it was with the greatest difficulty he kept himself from the most disgraceful and-licentious indulgence. He had latterly shut himself up alone when one of these fits came on, and was at other times in constant fear that he should, some time or other, ruin his reputation forever, even if he did nothing more serious. The condition of this man was truly pitiable, subject as he was to a state of misery for which, if it were known, he would receive condemnation instead of sympathy. "Every one would tell me," he remarked, with tears in his eyes, "that it was disgraceful, and that I ought not to give way to it, but I cannot help it though it were to save my life, and I have sent for you because I think you must understand my true position." I found, on examination, that this gentleman was affected with a chronic inflammation of the prostate gland, and lower part of the urethra, which was liable, from various slight causes, to become temporarily worse, and to produce that excitation of the genitals above deccribed. He distinctly remembered that before each of the fits he had either taken some severe exercise, or been subject to some unusual mental agitation, or perhaps had committed some error in drink or diet, which seemed to bring it on. But of late the parts had become so extremely sensitive that the simplest excitement of any kind brought on an attack, and it was scarcely possible for him to avoid one long together.

I immediately informed him of the cause of his trouble, and as it was not the result of abuse of any kind, and apparently not unusually severe, I felt justified in promising him relief, and immediately put him under proper treatment. The diet and drink were rigidly regulated, bathing and regular exercise enjoined, and a tonic of iron and gentian administered. I also found it necessary to use the caustic internally, and to advise astringent lotions, with occasional injections to keep the bowels free. Under this treatment the irritation soon began to subside, and in two months he had no return of his erotic fits. Now if this man had committed some gross immorality during one of these periods of excitement, it would have been considered merely as the result of moral depravity, and nothing would have been thought of but punishment, instead of medical treatment. It is unfortunately true that moral 
depravity is often the only cause of such improper actions, and then they ought to be visited accordingly; my object here is not to apologize for anything of that kind, but simply to show that there are often other cases, of a totally different character, which should be considered in a different light.

Satyriasis is very apt to follow from the first attempt at masturbation and from excessive indulgence, particularly in those who use stimulating food or drink. I have also known tobacco and opium to bring on an attack, and still more frequently certain medicines when improperly used, such as cantharides and phosphorus.

Erotomania differs from satyriasis as respects the seat of the disease, which in this case is in the brain, and not in the genitals, they being affected only secondarily. It is in fact a species of mania or insanity in which the mind is constantly occupied with sexual matters, and a constant morbid desire is experienced for indulgence, sometimes even when the patient is completely impotent. Dr. Copeland draws the distinction between the two diseases very elearly, and I will, therefore, quote his words, merely remarking that nymphomania, to which he refers, is merely the same disease in the female as satyriasis in the male :

"Erotomania-Monomanie erotique of EsQUIROL-is characterized by an excessive love of some object, real or imaginary. It is a mental affection in which amorous ideas are as fixed and dominant, as religious ideas are in religious monomania or melancholia. Erotomania is very different from satyriasis and nymphomania. In the latter, the mischief is in the reproductive organs; in the former, it is in the mind. The one is a physical, the other a moral disorder. Erotomania is the result of an excited imagination, unrestrained by the powers of the understanding ; satyriasis and nymphomania proceed from the local irritation of the sexual organs, reacting upon the brain, and exciting the passions beyond the restraints of reason. In the former, there is neither indecency nor the want of chastity ; in the latter, there is unrestrained expression of sexual desire and excitement. The one is commonly caused by ungratified or disappointed affection excited in a virtuous mind ; the other, by inordinate irritation or indulgence of the sexual passion.

"In erotomania, the eyes are bright, the manner and expressions tender and passionate, and the actions free, without passing the limits of decency. Self and selfish interests are all forgotten in the devotion paid, often in secret, to the object of the mind's adoration. A state of ecstasy often occurs in the contemplation of the perfections which the imagination attaches to the subject of its admiration. The bodily functions languish during this state of moral disorder; the countenance becomes pale and depressed; the features shrunk; the body emaciated; the temper inquiet and irritable ; and the mind agitated and despairing. The ideas continually revert to the loved and desired object; and opposition or endeavors to turn them in a different direction only render them more concentrated and determined in their devotion. At last, parents and fortune are abandoned, social ties broken asunder, and the most painful difficulties are encountered in order to obtain the object of admiration.

"In some cases, the attempts made by the patient to conceal and overcome this affection occasion a state of irritative fever, with sadness, depression, loss of appetite, emaciation, etc., which has not inappropriately been termed by LORRY Erotic Fever, and which, after continuing an indeterminate period, may even terminate fatally. When a young person becomes sad, absent in mind, pale and emaciated, sighs frequently, sheds tears without any obvious reason, is incapable of mental or bodily 
exertion, scarcely speaks to any one, loses appetite, etc., it is sufficiently evident that the mind is inordinately possessed by some desired object. If a strong effort be not made to dispossess it of the predominant sentiment, or if the object of desire be not obtained, the symptoms become still more distressing. The corporeal functions languish, the eyes sink, the pulse becomes weak and irregular, and the nights disturbed and sleepless. At last a form of slow hectic is produced; and the weaker organs, especially the lungs and heart, are the seat of slowly-produced disease; the whole frame is blighted, and the patient sinks from the injurious influence of the mental affection on the vital organs.

"This form of moral disorder may increase, and affect the intellect in a much more serious manner, until general insanity or mania is developed; and, with the progress of time, it may at last terminate in dementia or incoberent insanity. In each of these, the primary character of the disorder, or the original moral affection, will still continue to be manifested by the frequent suggestion of the same train of ideas, or recurrence to the object of derotion."

The treatment of these cases requires great skill and experience on the part of the physician, and frequently a continued observation for a long time, in order to determine what the exciting cause really is. It may be wholly moral or wholly physical, or it may be partly both, and this must be ascertained before any good can be accomplished. The fact is philosophy is required as much as physiology, and the most perfect confidence must exist between the physician and the patient. The affections have often much to do with these peculiar troubles, and it should not be forgotten that there is a great difference in the temperaments of different persons, and also in the sensitiveness or impressibility of their natures. Some physicians always recommend marriage in these cases, to single people, and there is no doubt but it is sometimes what is required, but at other times it is highly improper. In certain forms of physical derangement especially, marriage would only aggravate the evil, and the patient would in all probability ultimately become totally unfit for the married state. This advice therefore, if followed, would not only fail of doing any good to persons so situated, but would make two unhappy instead of one. - It will be seen that some forms of erotomania are identical with what is called, commonly, love sickness.

Erotomania, or love madness, is a form of mania most often seen among women, but not unknown among men. It is simply a morbidly excited state of the sentiment of affection, or love, and may be exhibited toward very different objects, and in many different ways. It no doubt always originates in sexuality, and its most natural form is that of love for one of the opposite sex ; but if it cannot be indulged in that way, it will expend itself upon other objects. Thus, unmarried females, of naturally warm affections, often bestow their wealth of love upon children, or animals, or even upon inanimate objects. Sometimes they become really mad, and then it is pitiful indeed to see them lavishing the tenderest attentions, or the most intense devotion, upon something which can never render them the slightest return. There is not the least thought of self in any way, nor the least regard for the worthiness or unworthiness of the object. There is nothing but love, absorbing love, which causes complete blindness to everything but the supposed perfections of the being beloved. Bodily or moral deformities, the most obvious to others, are either unseen or totally disregarded, while any desirable attributes which nature may have totally forgotten, are easily supplied by the imagination in perfection. 
Moore has well expressed this in his well-known lines:

\author{
"Oh ! what was love made for, if it be not the same, \\ Through joy and through torment, through glory and shame? \\ I know not, I ask not, if guilt's in thy heart, \\ I but know that I love thee, whatever thou art !"
}

This is love pure and devoted, totally regardless of all else, and ready to undergo any trial or sacrifice whatever, not only without regret, but rejoicing in them as a privilege. Such an intense and absorbing sentiment readily becomes an uncontrollable mania, terrible in its fierceness, pitiful in its melancholy, or ridiculous in its strange eccentricities. Shakespeare gives us some of the best illustrations of love madness that we have-Juliet, Ophelia, and many others, are perfect, each in its own way. Even poor old Lear, king though ho be, is one of the same class. All his love was concentrated on his daughter, and when he thought they were ungrateful, and did not return it, he went raving mad.

In short, love when starved, blighted, betrayed, or slighted, may result in the most fearful depravity, the most terrible crimes, the most mandlin sbsurdities, the most heartrending despair, or the most touching devotion to some beautiful scheme of mercy and benevolence. Happy indeed when it takes the last direction, as fortunately, in women, it is very apt to do.

In those of a pious disposition, thwarted lovo is apt to become ecstatic devotion. The Deity, the Saviour, some saint, or favorite preacher, takes the place of the lover, and is adored with an intensity proportionate to their exaltation.

In all great religious excitements, camp-meetings, and revivals, it is impossible to overlook the part which is played by the erotic feeling. Nothing contributes more to the fervor and devotion, and to that intensity of emotional activity usually witnessed at such gatherings. In fact, it is not uncommon to see, on such occasions, exhibitions of erotomania as unmistakable as any to be met with in medical practice, but disguised, both to the individuals themselves and to those around, under the semblance of religious ecstacy.

It must be remembered, however, that in erotomania, even in its utmost intensity, there is not necessarily, nor commonly, either indecency or want of chastity; on the contrary, there is more often a shrinking modesty and reserve. It is not sensual passion, from organic excitement, but simply excess of love, heightened by restraint and excited imagination.

In this respect it differs essentially from satyriasis, or nymphomania, as it is sometimes called; this results from physical causes, from excitement of the sexual organs acting upon the brain, and producing intense desire for amative indulgence, not love but passion, or true sexual mania.

When in excess, this becomes the fiercest and most uncontrollable of all animai impulses, constituting in fact a true madness, the victims of which will dare or endure anything wnatever to procure the indulgence for which they crave. No fear or thought of consequences, no restraints of morality or decency have the slightest weight, when the mania is fairly developed.

Indulging in libidinous thoughts, and giving loose rein to the imagination, will? of course intensify the erotic fever, and so far it is due to the patient's own neglect of self-control ; but beyond and above all this, in cases of real satyriasis, there is a 
physical cause sufficiently powerful to overcome all moral restraint and all considel. stions of prudence.

When there is an excessive secretion of semon, the stimulus to the sexual organs and to the brain becomes so strong that the will has no power over them whatever, and, in the absence of natural relief, they will be constantly excited in spite of all a man's efforts. It is as vain to expect it to be otherwise as it would be to expect one to become sober when constantly filled with alcohol.

Such a condition could not of course occur where marriage was feasible, and it is therefore chiefly among the victims of celibacy that satyriasis is found.

In the majority of cases of enforced and undue celibacy, however, nature relieves herself by nocturnal and other forms of seminal loss, but often at a fearful cost to the patient. Many a splendid constitution has been ruined, and many a noble mind enfeebled by these substitutes for natural indulgence. When there has to be either erotic mania, or involuntary depletion, more or less mischief must result in some way or other.

In very many cases the individual so urged resorts to masturbation, and this is perhaps the worst evil of all. From an occasional indulgence, perhaps at first as a relief only, it rapidly becomes a habit, which every day confirms and makes more dominating.

The victims of satyriasis are often among the best and noblest of human beings. It is their constant and determined struggle against nature, and their heroic resistance to all temptations for relief, natural or otherwise, which makes them finally become maniacs. Then the ignorant world, looking at them only in their fall, considers them simply as self-indulgent debauchees, who have willfully made themselves depraved.

The really immoral and the self-indulgent do not resist long enough to become maniacs, but give way sufficiently early to save themselves, and when prudent in their indulgences, they often get credit for virtue which they do not possess.

Some people are so constituted that their sexual ardor is always feeble, and it costs them but little effort to overcome it. They, of course, cannot understand the condition of those differently constituted, and are therefore unable to judge them justly. To such people these statements will appear uncalled for, if not perhaps exaggerated, bui the great majority, from their own experience, will acknowledge them to be both truthful and timely.

There can be no doubt but that any conditions of society which hinder early marriages are highly injurious, both to the individual and the community ; for enforced celibacy, among those who are sexually potent, means either illicit indulgence or personal impurity ! It is of no use to half state a truth, and I therefore say, without reservation, that every one, on attaining full maturity, should marry ; for if they do not, vice and disease are certain to result.

Too much is said about the moral benefit which follows a constant struggle against temptation; and a man who is able to contend against his natural propensities, with more or less apparent success, is said to be in a better condition than he who naturally and prudently gratifies them. I do not believe it! And I feel sure that the experience of every observant physician and student of nature will bear out what I say. The victory, if indeed it may be so called, is only in seeming, and no one but the victim himself knows all it has cost. This kind of struggle has, in fact, ruined tens of thousands of the best of men and women, bodily and mentally, even when they have escaped open moral wreck. 
The burning, consuming fever of intense sexual desire, resulting from legitimate physical causes, cannot be overcome except by utter bodily prostration, or by some determination of the impulse in another direction. The constantly oppressed and throbbing brain, irritability of temper, waywardness, and tendency to eccentricity of conduct, if not downright mania, so often met with among our very best young men, result in this way. As remarked before, those who are naturally seif-indulgentand who care nothing for consequences, social or individual, ?ave no such experi, ence, because with them no such impossible repression is even attempted.

On this point I speak strongly, because my professional experience has brought this matter very forcibly to my attention, and I feel sure that enforced celibacy, in the healthy and vigorous, is productive of most serious evils, bodily, mental, and moral.

The records of our lunatic asylums give ample proofs of this ; for it must be remembered that most of the cases there recorded as due to masturbation, really result, primarily, from want of early marriage. Some result, undoubtedly, from hereditary tendency, and many from disease, bodily or mental, but many more from deprivation of natural indulgence.

Actual mania, from intense and ungratified desire, is not at all uncommon in those who rigidly deny themselves all modes of relief. It must be remembered that it is not a mere moral condition, or one resulting from ill-regulated thoughts, though this may of course exaggerate it; but the real foundation of the desire is a bodily need!

Nature has attached to certain organs peculiar sensations, which are always felt in proportion to the activity of those organs, and which can no more be totally subdued by any moral effort, than can the feeling of hunger or thirst. These sensations when too intensely felt, or for too long a time, always affect the brain and nervous system generally, besides causing serious derangements in other organs.

This is frequently seen in animals. The elephant, in captivity, is often subject to mad fits, as they are called, when he becomes dangerous. These are due entirely to want of sexual gratification. The same thing is seen in the males of other animals, when kept too long from female association. Monkeys, it is well known, will practice masturbation in such circumstances, and so, probably, would other animals, if they had hands.

The peculiar madness in dogs, which we call hydrophobia, is only sexual madness; where the male and female are always with each other, it is never seen. In Constantinople, for instance, where dogs breed and live in the streets by thousands, the disease Is unknown.

It is not necessary, however, to pursue this matter further; enough has been said to show that it is a subject more for the physiologist and physician than for the mere moralist and preacher alone. 


\section{CHAPTER LI.}

\section{GENERAL REMARKS ON THE PRESERVATION AND RESTORATION OF THE SEXUAI POWERS.}

IT is unfortunately the case, as our previous articles have shown, that the sexual power is liable to be impaired, or even totally lost, from a variety of causes, and that it is exceedingly difficult of restoration. There are, however, many apparently simple rules which, if duly observed, would prevent much of the injury now experienced, and there are also many others, equally simple, which will often materially assist in restoration. The object of this chapter is to point out many of these, chiefly in the form of suggestions and hints; the strictly medical treatment having been fully entered into already.

It is very essential to the preservation of the sexual power that the general health should be good, and that there should be no serious derangements of any of the vital functions. When the general health is impaired and the vital energies are low, the sexual organs are sure to be weakened, and usually more in proportion than any of the others. Owing to their extensive sympathies also they are sure to be affected by the diseases of all the other organs, and not unfrequently this sympathetic injury becomes very serious. The stomach particularly exerts a great influence over the generative organs, both beneficial and injurious. Long-continued dyspepsia is nearly always accompanied by weakened sexual power and desire, and even temporary attacks of indigestion will, for a time, produce similar effects. On the other hand a healthy stomach, with perfect digestion and nutrition, is highly conducive to sexual vigor. Wa may even go much further, and show that high feeding is nearly sure to overexcite the genital organs, or in other words that gluttony leads to licentiousness. This is a truth too often lost sight of in the education of children, many of whom, though predisposed to sexual ardor, are stimulated with rich food and exciting drinks till their passions become overpoweringly strong. In short the stomach exerts a most decided indirect influence over the generative organs, and we are thus enabled, by proper attention to the diet and drink, to either increase or weaken their power to a great extent.

Next to the stomach, it is important to attend to the state of the bowels, as they exercise considerable influence over the generative organs, and may affect them in a very injurious manner. The bad effect of piles has already been alluded to, and also constipation, but this last disability is of more consequence than it has perhaps been represented to be. No person must expect to escape seminal weakness who is habitually constipated, no matter how vigorous and healthy the genital organs themselves may appear to be. It is, therefore, very important, as a means of preserving sexual vigor, that the bowels should be always properly regulated, and frequently a little attention to this point is all that is needed to complete a recovery. The opposite 
state, diarrhœa, though of course weakening, is not so decidedly hurtful as constiparion, and its effects are sooner recovered from.

Next to the stomach and bowels the urinary organs may be mentioned as exerting great influence over the sexual system. The proof of this has already been given, but I think it necessary to call attention to the fact here as one of the very first importance. If the kidneys or bladder be affected in any way the genital organs are sure to be affected likewise, and if the urine have an irritating quality it is nearly certain to act on the urethra and ducts so as to cause sexual excitement or spermatorrhœa. This is particularly important in regard to children, many of whom are disposed to precocious virility, or to masturbation, simply from being affected with gravel or with some disease of the kidneys or bladder. Those children most liable to such troubles usually find it difficult to hold their urine during the night, and it is very high colored, with a strong odor. Such children are very apt to be subject to spermatorrhoea in after-life, and also to be addicted to self-abuse ; it is, therefore, very important that all such affections of the urinary organs should be promptly attended to. At every after-period of life also such matters require serious attention; for many a man is kept diseased and impotent by the same causes, which may operate so powerfully as to neutralize all attempts at cure while they remain. When any of these diseases exist, at any period, it is requisite, of course, that the diet and drink should be regulated especially in reference to them, the urinary organs being readily affected by those agents.

Constant and healthy exercise of the whole muscular system is also of great importance to the preservation of sexual power. It is true that if a man takes little exertion, particularly if he lives high, he will be apt to exhibit an unusual tendency to amorous indulgence, because, as before remarked, gluttony and idleness lead to licentiousness. This effect, however, is only a temporary one and sooner or later the individual finds that he has permanently exhausted his vital energy and that his health and strength are seriously impaired. The vital power that may be safely expended in sexual indulgence is only the surplus, after every part of the system has appropriated its due amount, and if more be so expended some part must suffer. In other words we may suppose that every healthy man has a certain stock of vital energy, which we will call his capital, to which he keeps adding, more or less, by the function of nutrition ; this addition may be compared to interest which may be expended without any loss of capital, and of course without making him any poorer. If, however, by any excess he expends more than this addition the capital is proportionably diminished, and permanently too, for it can seldom be again made up.

Now, the idle man does not expend enough vital energy on his muscular system to keep it healthy, but at the same time gives a superabundance of it to the sexual organs, so that they are over-stimulated, and suffer from excess, constantly causing a drain on the vital power that soon exhausts both principal and interest, and leaves the individual completely exhausted.

The philosophy of this has been frequently alluded to in the course of the present work, but it is so important that I wish to present it in a strong light. I am fully persuaded that there is no case of precocious or excessive sexual propensity, unless caused by disease, that cannot be easily subdued by muscular exercise. No matter how vigorously the seminal glands may act, in a state of leisure, they must become less active if the body be exhausted by active exertion, and to this rule there is scarcely any limit. One of the Reports of the Massachusetts Lunatic Asylum 
strongly impresses this truth, and shows conclusively that we have, in hard labor, a certain means of subduing this propensity to its proper limits under any circumstances. The application of this truth to young persons is obvious, numbers of whom are made licentious only by bodily inactivity and over-feeding.

The invalid, or the man whose powers are impaired, must of course husband his strength, because he does not require exhaustion, but only sufficient exercise to insure health.

Exercise of the mind is also equally as important as exercise of the body. The man who is mentally idle is nearly certain to experience too strongly the force of the animal propensities, and licentious thoughts are too often indulged merely from the absence of better oues. It must be recollected, however, that too much mental exertion, particularly if attended with care and anxiety, is most destructive to the sexual power, and frequently leadis to impotence, as many of our cases have shown. Those who wish, therefore, to preserve their virility should endeavor to maintain a happy medium, laboring with the mind sufficiently for health and utility, and endeavoring to preserve perfect calmness and equanimity.

\section{PLATE XXXVI.}

DIFFERENT FORMS OF SCROTAL HERNIA OR RUPTURE.

Fig. 1. Hydrocele, or formation of water in the scrotum. \%. The testicle. 6, 6,6 , shows where the testicle came down. 14, is the spermatic cord. 15, the large artery.

Fig. 2. Hernia, or rupture. Descent of a part of the intestines into the scrotum, in front of the testicles (\%).

Fig. 3. Infantile hernia. Partial descent of the intestines, on top of the testicle.

Fig. 4. Oblique inguinal hernia, or descent of the intestine into the scrotum, as sec in the adult.

Hernia, or rupture may either be congenital - that is, caused by imperfection of the parts at and before birth; or it may occur in after life, from violence, or from hard lifting and straining. 
Fig.1.

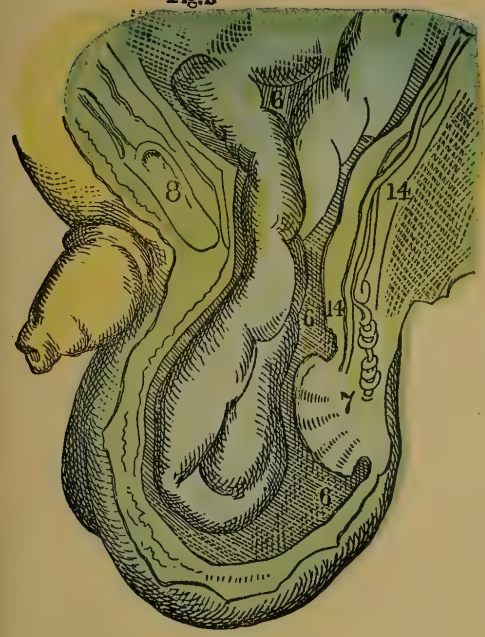

Fig. 3.

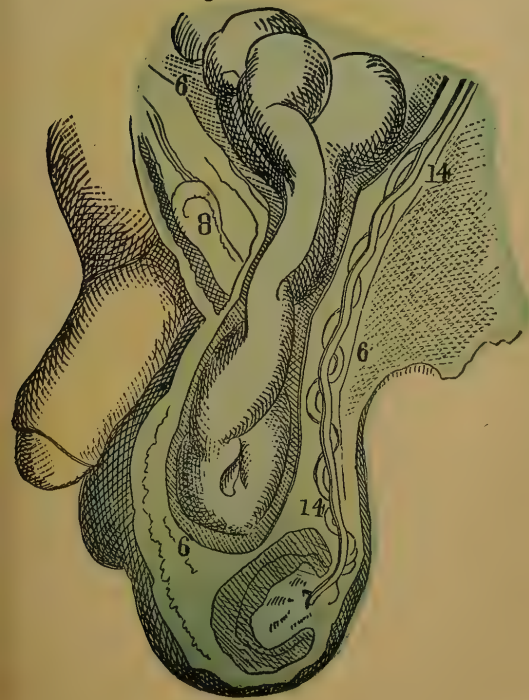

Fig.2

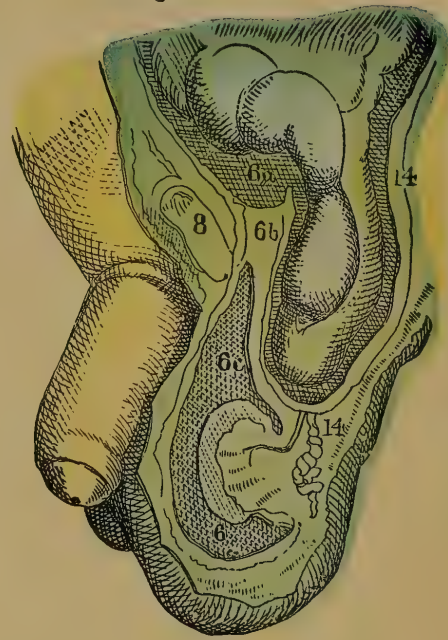

Varieties of Scrotal Hernit.

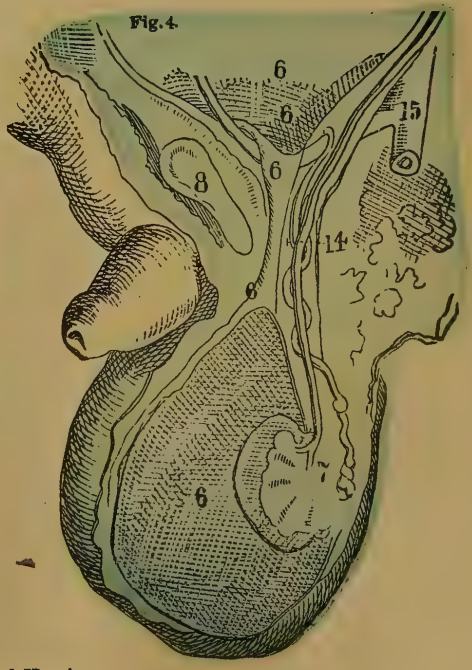





\section{PART XV}

DISEASES OF THE FEMALE ORGANS.

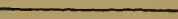





\section{CHAPTER LII.}

MALFORMATION, OR IMPERFECT DEVELOPMENT OF THE DIFFERENT FEMALE ORGANS.

MaLfoRMation, or faulty development of the female organs, is frequently met with, sometimes from accidents, and sometimes from natural imperfection. There are so many and such different cases of this kind that it is impossible to enumerate them all, nor is it necessary. We will therefore confine ourselves to those most generally found.

\section{COHESION OF THE EXTERNAL LIPS.}

Sometimes female children are born with the external lips completely grown together, so as even to close up the passage from the bladder. In this case great distress is very soon felt from inability to discharge the urine, and the assistance of the surgeon becomes immediately necessary. Fortunately, this difficulty is generally very easily overcome. It is seldom, however, that the adhesion is so extensive as to close completely the urethra; more generally it is only partially closed, and the urine escapes in drops or small quantities. More frequently it is only the entrance to the vagina that is closed, and then the difficulty may not be discovered till the period of puberty. At that time great distress is felt from the menses not being able to escape from the womb ; but of this we shall speak in another article. There are many accidents that may cause this adhesion of the labia, such as chafings, inflammation from various causes, and irritation of the urine. In some young persons there is a constant disposition to an inflamed state of these parts, and unless constant attention be paid to cleanliness they are very apt to grow together. In married persons this sometimes takes place from injuries at childbirth and other causes. Let it arise how it may, however, or at whatever period of life, the imperfection should be immediately removed, as serious consequences often arise from itsuch as violent inflammations, retention of the menses, and even dangerous ulcerations. The surgeon should, of course, be applied to in all such cases, and in young persons as early as possible, so that all trace of the imperfection may disappear by the growth of the parts. Very often these things are neglected in children, and then unpleasant exposures have to be made when the parties are grown up. I have known many such left till puberty, or even till marriage, causing then the greatest distress and difficulty. Where anything of the kind is even suspected, it should be at once attended to, and parents should bear in mind that very often the regular use of cold water will prevent the necessity for the surgeon's knife. There is too much neglect of this precaution!

In nearly all these cases, especially when taken in time, no knife is required. In young persons never. There is, therefore, nothing in the operation to terrify. I have found that the best mode is to gently tear them asunder, or gradually separate 
them with a thin piece of ivory, or hard wood, which may be done with little or iso pain. Care must be taken afterward to keep them apart till the heal, or they may again adhere.

\section{UNION OF THE NYMPH}

The nymphæ sometimes adhere from the union of the external labia, and sometimes from other and independent causes. This malformation, like the previous one, may be either congenital or accidental, and its general effects are much the same as those described in the previous section. In such cases, there is always a difficulty in urinating; the nymphæ not directing it in a stream in the proper direction, it flows backward, or over the person, causing great trouble and irritation, and often leads to the fear that there is gravel, or stone, or weakness in the bladder.

Most of these cases of adhesion are so slight that no cutting is required. I have treated many successfully with the simplest domestic means, both in children and adults.

\section{UNNATURAL GROWTH OF THE NYMPH无.}

An unusual enlargement of the nymphæ is sometimes observed even in very young children, but is more usually found after puberty. The causes of this unnatural growth are obscure, and sometimes it appears to arise from a constitutional tendency. The annoyance, and sometimes even positive suffering, is very great, so as to seriously impede the performance of several natural functions. Attention should be paid immediately to these cases, because they have not only a tendency often to become much worse, but even to degenerate into gangrene, fungus or cancer. The use of cold lotions and saline aperients, with perfect rest and careful abstinence from exciting food or drink, will usually be sufficient to check the evil, if used early. When these means fail, however, and the enlargement still continues, leeches may be used, or scarification, and, as a last resort, the parts may be cut away, as is often done in some parts of Asia for other reasons. Certain habits in young persons, and certain excesses in adults, have often more to do with the production of this annoyance than is supposed, and if persisted in will defeat all attempts at cure. Cold water, and entive absence from all excitement whatever, is often all that is required.

\section{UNNATURAL GROWTH OF THE CLITORIS.}

This affection is precisely the same as the last, in its nature and treatment, being merely located in another part. It is, however, much more annoying, and more danger' us, and is likely to lead to immorality as well as to serious disease. The same n eaus may be used as are recommended for enlarged nymphæ, and, if these fail, an putation may be necessary. If proper cleanliness be observed, and all improper 2 xcitement avoided, this last resort is seldom needed. If it ever does become necessary, however, it is consoling to know that the operation is speedy, safe, and almost painless. In some parts of the world it is almost invariably performed.

I a $n$ persuaded that more young persons are subject to these two last-named annoyances than is generally supposed, and I have no doubt but that the unnstural excitement thus produced is a more frequent cause of deviation from the pats of rectitud, than has ever been suspected! A timely attention to physical derangements will often prevent moral ones! 
Exciting food, indolence, and vicious habits, are probably some of the principal physical causes of this evil, conjoined with excited feelings from sentimental reading or improper associations.

\section{CLOSURE OF THE VAGINA.}

Imperforation, or want of passage in or to the vagina is sometimes found at birth, and sometimes arises from accidents in after life. It usually produces no particular inconvenience till the period of puberty, at which time great distress is often produced from retention of the menses.

Sometimes this closure is caused simply by the hymen having no passage through it. In this case, the membrane usually protrudes in a convex form externally, and the fluid may be felt, like a weight, pressing upon it, whenever any accumulation of the menses occurs. In one case of this kind, occurring in my own practice, there had never been a flow though the patient was nearly twenty years old. An examination soon showed the cause. The hymen was completely imperforate, and protruded in the form of a round ball, from the pressure of the fluid behind. The abdomen was much distended, the lower limbs were much swelled, and about once a month the greatest distress was experienced, from the persevering efforts made by nature to relieve herself. At one of these periods a small incision was carefully made, and immediately there escaped nearly three quarts of fluid matter resembling the ordinary monthly secretion, mixed with clots and cakes of dark blood, and membrane. The patient felt immediate relief, and one month after had her menstruæ, and continued to do so with perfect regularity, and without distress. From the suffering previously experienced, and from the wearing down of the system, it was evident she could not long have survived as she was, and what made her case worse, the parties prescribing for her had given a quantity of forcing medicine, to bring it on, as they said, thus increasing the evil. The real cause of the difficulty was never suspected before my visit.

In all cases when the menses do not appear in young persons at the proper time, it should be ascertained, with certainty, whether any impediment of this kind exists or not, before any treatment is recommended, otherwise great mischief may be done,

The most usual symptoms of retention from this cause are, enlargement of the abdomen, which varies much however at different times, with great tenderness to the touch,-pain in the loins and back-weight and dragging down in the pelvis-difficulty of breathing-spasmodic starts and twitches-headache-sickness and vomit. ing-and usually swelling and great tenderness of the breasts. In course of time nearly all the internal organs become more or less deranged, and we find difficulty in passing the urine, or inability to retain it, and frequently great suffering whenever the bowels are moved. In some cases the accumulation has been so great, as to cause severe pressure on the sacral nerves; and thus produce numbness and weakness, or even paralysis of the lower limbs. Sometimes the great enlargement has caused suspicion of pregnancy, and much injustice and suffering have in consequence been experienced. There are cases recorded in which this retention has produced severe nervous diseases, and even insanity. And in more than one instance the fluid has been forced along the Fallopian tube into the abdomen, causing inflammation and death. Dropsy is a very frequent result. In some few instances the fluid is absorbed 
after each monthly period, but this is rare, and when it does occur, it leads to great constitutional disturbance.

Imperforation of the hymen is not, however, the only cause of closure of the vagina. There are sometimes false membranes formed, at different parts of the passage, or the two walls may be even perfectly united in their whole length, forming a solid body instead of a tube! I recollect one case of this kind, in which an operation was performed, and a passage cut, till the womb was reached, and the walls kept from growing together again till they healed. The passage thus produced was very small at first, but gradually enlarged, by proper means of distention, to its natural dimensions. This is a very delicate and difficult operation, however, and not unaccompanied with danger. In the case referred to it was perfectly successful, and in a short time after the menses appeared and became regularly established. The lady subsequently married, and became a mother, with little more than the ordinary pain and difficulty. It is proper to remark, however, that such an operation as this is exceedingly difficult and dangerous, and by many surgeons would not be performed at all, except when it offered the only chance for preserving the health, or life, of the sufferer.

This accident has occasionally arisen from injuries at childbirth, and from criminal attempts at abortion. I have even known it to occur, partially, from other vicious practices, producing inflammation.

In performing the operation of puncturing the hymen, or other membrane, there is always some risk of causing inflammation in the womb ; and it should therefore only be attempted by a competent person ; fatal results having happened from want of proper precautions. It is also desirable to so perform it that the hymen shall not be destroyed, on account of the moral importance attached to it. A little reflection will show how culpably negligent those parents must be who remain so ignorant of the condition of their children, as to allow them to marry with this imperfection, and yet this has been done; and, in one case in my own practice, nearly with fatal results!

Many cases are recorded in medical works in which the vagina has become closed after a difficult labor, and some even in which it occurred after conception, so that an opening had to be cut before delivery could be accomplished. Dr. Ségalas mentions one such case in which the opening could not be made in time, and the patient died from the bursting of the womb.

\section{PARTIAL CLOSURE, OR NARROWNESS OF THE VAGINA.}

This state of the parts is often found at birth, though it may be produced by var rious causes afterward. The closing may be so great as to cause a difficulty in menstruation, with pain, or it may not be discovered till marriage, or even till delivery.

Many cases are on record, and I have known many such, in which the marriage could not be consummatel from this cause. In one of these, to the great distress of both parties, a divorce was about to be agreed upon. The lady was brought to me for another affection; but this being confidentially mentioned, I remarked that possibly the difficulty might be overcome. The patient could scarcely be brought to think so, but ultimately agreed that the experiment should be made. The passage itself was not larger than an ordinary quill, though there was no difficulty at the 
monthly period. By patient perseverance in a proper system of dilatation, with different-sized elastic tubes, filled with air, in less than six months it had attained its proper dimensions; and, to the great joy of both parties, the difficulty was fully removed, and conception afterward occurred.

The narrowness may either exist in the whole length of the vagina, or only in a particular part-this, of course, requires to be accurately ascertained. In some cases it arises merely from a partial growing together of the external lips, and is then very easily removed. The danger, at the period of marriage, in some of these cases, is obvious ; in some of them much after-suffering, and even death, has beer: produced, which might have easily been avoided by a little timely assistance.

This process of enlarging the vaginal canal is one requiring great care and patience. There are few cases wherein it will not be successful, if rightly conducted, though there are many in which it may fail from very slight inattention. In all cases where there is pain or difficulty, at certain times, from this cause, it should be immediately resorted to. The use of cutting instruments, is seldom, if ever, required in these cases ; I never recollect one, and I have had a great many, in which, by the gradual means spoken of, I did not effect a cure. A case is mentioned by Colombat De L'Isère, of a lady thirty-four years of age, who had been married since her fourteenth year, with whom this operation was perfectly successful.

Lacerations, and other injuries, from delivery, frequently produce this difficulty.

The walls of the vagina will sometimes swell from inflammation, and cause a temporary narrowness, which may be overcome by rest and cold injections. Tumors occasionally develop, either on the walls or on the mouth of the womb, and partly fill up the passage. These are probably the worst cases of the kind that can occur. Many medical authors assert that no attempt to remove them should ever be made; in some cases, however, the operation is successful.

When this narrowness of the passage is not discovered before labor commences, there is sometimes great difficulty, and even fatal lacerations, from the parts not giving way readily; but in general the efforts of nature effect a gradual enlargement, even in the worst cases. It would be better, however, to attend to the diffculty in time, if it be known.

\section{CLOSING OF THE MOUTH OF THE WOMB.}

The mouth of the womb may become closed from the same accidents as the vagina, or it may be closed from birth. The same effects also follow from its closure as from that of the vagina, with the exception that it does not prevent the consummation of marriage, though it will prevent conception. The plan of treatment is nearly the same as that laid down for the vagina, but it is much more difficult and uncertain, and by many persons is altogether denounced, excepting as a last resource to preserve health, or life. I have overcome some cases, however, without an operation, by patient perseverance. Very often this defect exists and is unsuspected. It should therefore be always looked for, when no other cause of difficulty is known, particularly in retention of the menses and in barrenness.

ABSENCE OF THE VAGINA, OR WOMB, OR BOTH.

Fortunately these deprivations seldom occur. I have, however, met with some such, and many are on record in medical books; it is therefore advisable to mention 
them. Wither the vagina or the womb may be absent, alone, or both may be absent together. It may also be a congenital defect, or may arise from injuries. The womb may be absent and yet every other part be perfect, so that no indication of the defect will be evident, except on examination. Marriage may then be consummated but must of course be fruitless. Absence of the vagina is of course always discovered and forbids the possibility of marriage. If the womb and ovaries be perfect when there is no vagina, we may have the same distress and difficulty as in closing of the vagina, because there will be no means of escape for the menses if they form. 


\section{CHAPTER LIII.}

DISPLACEMENT OR WRONG POSITION OF THE FEMALE ORGANS.

THE different female organs are liable, from a variety of causes, to be displaced, or they may even be misplaced congenitally. The womb is most frequently found out of its proper situation, and its deviations will, therefore, first engage our attention.

\section{PROLAPSUS UTERI, OR FALLING OF THE WOMB.}

This troublesome affliction, scientifically called hysteroptosis, is found at almost every period of life, and under almost all circumstances. It is, in fact, so general that it may be considered a kind of heirloom, to which every female may consider herself born, and from which she may think herself extremely fortunate if she escapes. It is, in fact, a very rare occurrence to meet with any adult female, particularly if long married, who is not troubled with it, or has not had it. Married females are undoubtedly more subject to it than unmarried ones, but it is found to a great extent even among very young persons. I have known many suffer from it before puberty, and some even as young as ten or eleven years of age. Cases are on record where complete prolapsus existed at birth, giving rise to doubt as to the proper attributes of the child. But without referring to these congenital accidents, we have enough to do, unfortunately, with the disease as it arises in after life.

The primary causes of its fearful prevalence are to be found, undoubtedly, in an almost entire neglect of the laws of physical health, in the education of young females. Want of sufficient self-prompted exercise, with free exposure to air and light ; combined with injurious and absurd modes of dress, and too long continuance in constrained positions of the body, are some of the evils almost universally prevailing. These are sure to lead to bodily debility and imperfect development, particularly when united with over excitement of the mind and feelings. And hence arise the curved spines, the blanched cheeks, the consumptive lungs, and general state of weakness so prevalent among young girls; and the still greater evils so general among adult females. Falling of the womb is more frequently produced by loss of tone in the muscular system than by anything else ; it is, in fact, nearly always a result of debility, except among females who perform heavy labors-and with them it is produced by actual violence, by lifting, straining, or remaining too long on the feet.

Until these errors in the education and mode of life of females are corrected, such evils will always exist; and if any man could prevail on society to adopt a more rational course in this respect, he would prevent more disease and suffering than medical art has cured since it was first originated.

Among particular causes of prolapsus uteri may be mentioned, wearing corsets, too violent exertion, running up stairs, reaching above the head, straining from 


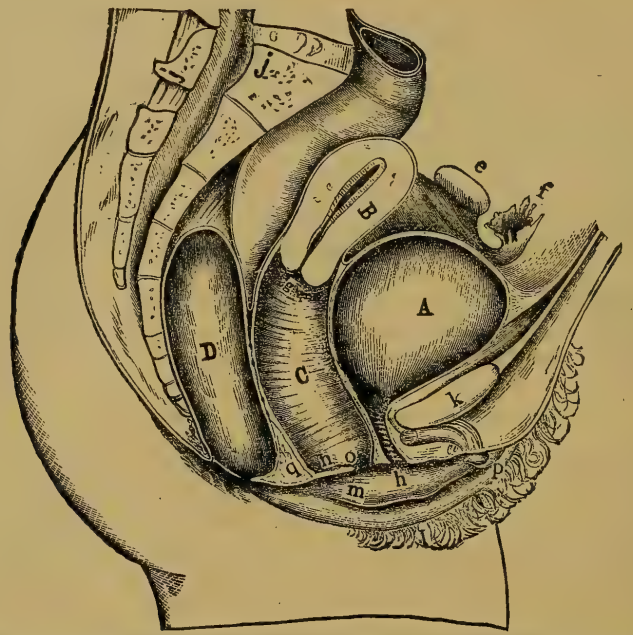

FIGURE 125.-Ltaeral Section of the Female Patvis, to shoro the position of the organs in therr natural state.

$A$. The bladder. $B$. The womb. $C$. The vagina. $D$. The rectum. $e$. The right ovary. $f$. The right Fallopian tube. $g$. The os tincæ, or mouth of the womb. $h$. The meatus urinarius, or mouth of the bladder. $i i$. The small intestines. $j j$. The back bone. $k$. The pubic or front bone. $l$. The right external lip, or labium. $m$. The right internal lip, or nymphæ. $n$. The hymen. 0 . The opening through the hymen. $q$. The clitoris. $p$. The perineum.

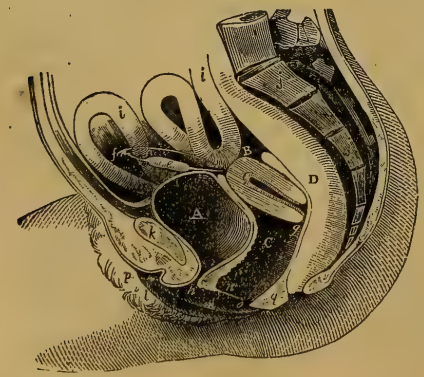

Fredre 126.-Lateral Section of the female Pelvis, to show the position of the Womb in the First Stage of Prolapsus.

$A$. The bladder. $B$. The womb, which is fallen down nearly to the middle of the vagina, which is much enlarged, owing to the womb being forced down into it. $D$. The rectum, also much compressed. $i t$. The small intestines, also fallen down after the womb.

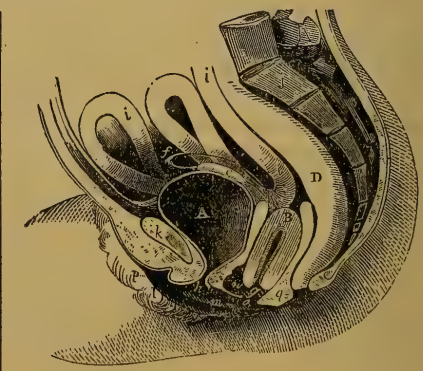

Frgure 127,-Lateral Section of the Pelvis, to show the position of the Womb, and other Organs, in the Second Stage of Prolapsus. $A$. The bladder. $B$. The womb, now fallen to the bottom of the vagina, which is much enlarged, and nearly filled up by the fallen womb. $D$. The rectum, which, like the bladder, is severely pressed. $i$. The small intestines, still following the womb. 
constipation of the bowels, injuries at child-birth, or rising too soon after it, frequent deliveries, and excesses of various kinds.

To understand the nature of this distressing affection it will be necessary to refer again to the plates. It will there be seen that the womb is placed in the pelvis, petween the bladder and rectum, to both of which it is attached, those attachments being the chief means of its support in a vertical position. The ligaments, both round and broad, act chiefly as stays, to prevent the womb moving to the right or left particularly when the female lies down. The muscles of the perineum, or part between the mouth of the vagina and the rectum, also play an important part in sustaining the womb. The whole of the genito-urinary organs, and the rectum as well, are supportea by these muscles, which form what is called the floor of the pelvis. When these muscles are weakened, or relaxed, they allow the parts they should sustain to sink below their proper level, till eventually they become fixed in a wrong position, and their attachments so weakened that they cannot return. The perineum is relaxed by straining from costiveness, by violent coughing, and by lifting, all of which, therefore, lead to prolapsus.

A heavy engorged state of the womb itself also generally accompanies this dispase, and predisposes very much to it by its mere weight. This explains why young persons are more exempt than married ones, because the womb is lighter in them. it also explains how retention of the menses, or any other derangement which in(rreases the weight of the organ, leads to the same result.

This disease is usually divided into three stages, and will be most advantageously Bonsidered in that way.

First stage.-In this stage we find that the womb has merely settled down as it were, a little, and instead of being perched on the top of the bladder, as we see it in Figure 125, it has fallen down between the bladder and rectum, as we see in Figure 126 , nearly to the middle of the ragina, which is, of course, much enlarged from the passage of the womb into its cavity. The immediate causes of this primary displacement are relaxation of the ligaments and the walls of the vagina, assisted in most cases by increased weight of the uterus, from engorgements. The most prominent symptoms are, dull pain in the small of the back, with dragging sensation in the groin, and fullness or weight round the fundament, and in the perineum, with great lassitude and weariness of the limbs. At this stage the disease is comparitively slight, and usually yields to simple remedies. It is at this time, therefore, that proper treatment is most likely to be attended with success, and it should be resorted to immediately, the prospect of cure being lessened by every day's delay.

In examination the neck of the womb is felt very low down, like a tumor, which immediately recedes when pushed, but falls back again when the pressure is withdrawn. The os tincæ will distinguish this from a real tumor, but is not always easy to find, owing to the position of the whole neck being so much changed.

It should be borne in mind here that some persons have the womb naturally much lower than others, and what would be a real displacement in one, may be quite natural in another. The neck of the womb is also very long in some persons, and this circumstance may deceive, unless care be taken.

It is at this time that we often find great relief, or even a complete cure, in some cases, from cold astringent injections and washes, which give tone and strength to the relaxed and weakened muscles and ligaments. Good abdominal or uterine supporters are also proper at this stage, as they hold up the intestines, and other organs 
above, and prevent them from pressing upon the womb. Unless made on proper principles, however, and well fitted, these instruments are more likely to do injury than good, and this is in fact very often the case.

Cold water is one of the best washes, or injections, that can be used. I would not advise any mineral astringents at all, but sometimes it may be advantageous to employ an infusion of white oak bark, two ounces of bark to two pints of water, boiled down to one pint. A stronger mixture may be made by boiling two ounces of pounded nut-galls in a pint of water, for ten minutes. These injections should be employed cold, with a bent syringe, which should be filled about three times at each application, and used night and morning. Cold water, however, is generally sufficient, and if it were plentifully used, in time, would be a great preventive. The cold fluid should also be dashed over the groins and pubes, where the ligaments are attached, and on the inside of the thighs, as well as used with the syringe.

I have found galvanism, however, the most effective agent, both in relieving immediate symptoms, and also in effecting a cure. The effect it produces is that of drawing up the parts, in the first instance, or restoring them to their proper places, and then strengthening the muscles and attachments, so that they are able to retain them. I have known this remedy act, almost from the first application, in so remarkable a manner, that the patient has imagined herself cured at once. The immediate relief it gives is often surprising, but to effect a permanent cure, it of course requires to be continued. I have used it myself in numerous cases, and can safely say with more benefit than from any other means.

The most usual mode of applying it is, from the spine through the ligaments and womb, externally, but in some cases it is requisite to use it internally. It is better, however, always to have it administered by some one who has made a study of the subject, and who fully understands it. There are seldom two cases that can be properly treated in the same way, and I often find it necessary to vary not only the mode of application, but also to procure instruments specially adapted for particular cases.

This derangement is one of those in which it is evident, both from reason and experience, that medicines can render little or no assistance. They are proper so far as they can improve the general health, but cannot possibly have any effect in restoring the displaced womb, though females are often deluded into taking them under that impression, and very frequently to the great injury of their health, as well as the loss of valuable time.

It is seldom the disease remains long at this stage, for if it be not cured it soon becomes worse.

Second Stage.-The womb has now fallen still lower in the vagina, and the general symptoms have become worse. The increased descent is shown in Figure 12\%. The mouth of the womb is near the external opening. The vagina is inverted, or turned inside out as it were, nearly two-thirds of its length, and is much distended. The bladder is pressed upon near its neck and so irritated that a constant desire is felt to urinate, and often a difficulty is experienced in doing so. The rectum is also pressed upon in the same way, near the fundament, and a sensation is constantly experienced as if the bowels were going to be moved. Both bladder and rectum are in fact pulled down, out of their places, and their functions materially interfered with. The ligaments are put upon the stretch, owing to the womb hanging by them, producing a severe pain in the groin, and at the lower part of the abdo- 
men, accompanied oftentimes with a feeling of numbness in the limbs, from the nerves being pressed upon. The pain in the back becomes more severe and more constant, and gradually the whole system becomes deranged.

The nerves of the uterus are connected with those of almost every other organ in the body, as well as with the spinal marrow, and this explains why it has such extensive and complicated sympathies. There is, in fact, scarcely any organ in the body but what may suffer, and appear to be diseased, though perfectly healthy, merely from disease of the womb, which may nevertheless give but few or no indications of disease itself. This is a matter on which medical men have dwelt but very little and about which the public generally know still less. Every female, however, ought to have it explained to her so that she may understand the real cause of her suffering, and the reason for the proposed treatment. Palpitation of the heart, bilious derangements, considerable spinal irritation, inflammation of the bowels, difficulty of breathing, and dyspepsia, besides a host of minor derangements, are often produced by falling of the womb. When this is the case we must, of course, look for a cure only by restoring that organ to its place; but how could a female feel satisfied that any treatment of the womb would relieve the heart, or stomach, unless she knew how intimately it was connected with them?

Many persons suffer much from headache, distressing nervous sensations, with a feeling of irritability that makes them truly wretched, and with a weakness and lassitude making the slightest exertion difficult.

In fact, the general symptoms are frequently very similar to those of pregnancy, and have often deceived persons into a belief that such an event had occurred. Loss of appetite, sickness, or vomiting, with a sensation of weight and fullness in the abdomen, accompanied by a feeling as if a large tumor were about to escape by the vulva. I have known some suppose they were going to miscarry on this account.

Rest in a reclining position usually relieves all these distressing symptoms, not only because it is grateful in itself, but because it allows the prolapsed womb to return, by removing the pressure of the superincumbent organs.

It is of the utmost importance that the womb should not be suffered to remain fallen longer than can possibly be avoided. If it do, there is great danger that new attachments will be formed between it and the other organs, and thus it will be fastened, or grow, in its new position. This accident, in fact, does often take place in cases that have been left too long; and it is then almost impossible to afford relief. The impropriety of using many of the ordinary instruments, when this has occurred, will be evident. Suppose the organs in a female pelvis had fallen into the position represented in Figure 126, and were then to become fast, it will be readily seen that any attempts to force and prop them up will not only be useless, but must cause great suffering. A careful inquiry and examination should therefore be made into every case before any treatment is recommended, so that no harm be done at least, if no assistance can be rendered.

Sometimes a tumor, or polypus, will pass from the inside of the womb, and protrude through its mouth into the vagina. In such cases, without great care, a mistake may easily be made, and the tumor be taken for the womb. The mistake has often been made the other way, and in more than one instance the fallen womb has been cut out, under the impression that it was a tumor !

Prolapsus, in the first and second stages, does not always prevent conception, 
though it is very apt to do so, partly from the womb being in a wrong position, and often inflamed, and also because the pain experienced at certain times leads to retirement.

In general, the fallen womb comes still lower in the early months of pregnancy, but rises afterward. There are instances, however, on record, where it has continued fallen till nearly the full period, and others where it has fallen completely just before delivery. In one case delivery occurred while the womb was part in and part out of the body!

Occasionally a cure has been effected by pregnancy, but much more frequently the benefit is only temporary, and the derangement afterward becomes worse. This is very apt to be the case if the woman be of a relaxed habit of body, and rises too soon after delivery, or walks too far. The reason will be obvious when we reflect that the womb remains partly engorged, and heavier than usual, for a considerable time after delivery, while the ligaments, and attachments, which support it, are weaker. She should, therefore, either rest till the uterus is reduced to its natural weight, and its supports have become strong, or, if she do move about, do so carefully and use an artificial supporter.

When we are satisfied that the prolapsus exists, the next consideration will be the best mode of treating it, and this must depend somewhat upon circumstances. There are many unfortunate cases beyond the reach of the physician, in which he can only be an idle spectator, or at best he can only suggest a palliative treatment, to give temporary relief. Fortunately, this is chiefly through its having been left too long. When taken in time, and always the earlier the better, some degree of permanent good may be effected, if not a perfect cure. Sometimes it results chiefly from some other disease, which of course must be attended to first. Leucorrhea very often produces prolapsus.

The first thing, in most cases, is to enjoin a recumbent position; in fact, the female must lie on her back nearly altogether, during the treatment. This is requisite to allow the parts to return to their natural position, and to prevent their falling again. Sometimes it is necessary first to replace them with the hand. This injunction to rest, however, is not always requisite, nor proper. There are some females whose muscular systems become lax and debilitated from want of exercise and fresh air, and who are benefitted most by moderate exertion out of doors, cold bathing, and a general tonic regimen and diet. A little attention will distinguish one class of patients from the other. The next desideratum is to restore tone and strength to the ligaments and attachments, which may partly be effected by the use of cold water, and astringent injections, as recommended in the first stage. Some practitioners use caustic, and other violent remedies, but I have never yet been satisfied that any good has followed them that could not have been effected by simpler means. We must next endeavor to restore the general health and strength. This is the great point, for, if the system be left weak and debilitated, the womb will fall again directly the patient begins to move about. I have known many females who have been pronounced cured, simply because they were temporarily better from rest, and using stimulating tonics, but who relapsed immediately they began to walk out. If an improvement do not take place in the general health, there will always be liability to a recurrence of the prolapsus, as it is essentially a consequence of weakness and debility, in most cases. The shower bath, or the douche bath over the loins and abdomen, when it can properly be administered, is also a useful auxiliary. Galvanism 
is, however, the best agent for general use. It gives strength to the muscles, and a healthy tone to the organs themselves. After the prolapsus is reduced it should be applied both externally and internally, at least once a day, either alone or in conjunction with the remedies previously recommended. I have known females who could not keep up the womb by any supporter they could use, who could retain it a whole day after the application of galvanism, without any artificial assistance whatever. A thorough knowledge of the parts themselves, and of their precise condition in each case, is requisite however for success, and it is for want of this that so many have failed.

Medicine, in such cases, as previously remarked, except when it can assist in restoring the general health, is altogether out of the question. Mechanical means, when applicable, may render valuable aid, but should never be depended on alone for effecting a cure, nor used indiscriminately in all cases.

The supporter, or truss, is more frequently useful in the first stage, though sometimes it may be worn with advantage in the second. Before recommending it in any case, however, the physician should be satisfied that he has good reason for doing so, because it may oftentimes do harm. The parts should then be properly replaced, and the female should rest on her back some time, by way of preparation, for if the instrument be put on while the parts are down, it will only keep them down instead of supporting them.

These necessary preliminaries are generally omitted, and the consequence is that disappointment, if not aggravation of the disease, is the result. The patient should also recline while being measured for the supporter, and while it is being adjusted to her person, so that it may fit properly when the womb is in its place.

In regard to the choice of a supporter few general directions can be given. Particular circumstances, in many cases, must necessitate a variety of forms and modes of adaptation. Most instruments of the kind are made to one pattern, and too heary, and the point of support is too high, so that they rather press on the abdomen than support it from below. The point of support should either be in the center, immediately over the pubic bone, or on each side, so as to press nearly on the ligaments. On the back it should be supported by a good wide pad or two, or more, so that it may not cause too much pressure on any particular spot. The part passing between the limbs should also be specially constructed, so as not to chafe or inconvenience the person, and so that it can be easily detached if required, though it will be seldom requisite to remove it if rightly made. There may also be fixed to this part, with most persons, a small thick pad to press on the perineum, and assist in supporting it, the advantages of which will be evident when the supporting power of that part is borne in mind.

Another instrument is sometimes recommended, called the pessary. The mode of action and proper construction of which is but little understood. We will, therefore, give a full description of it.

\section{THE PESSARY.}

The pessary is a firm body, larger in diameter than the vagina. It is usually round, oval, or ring-shaped, and on being introduced into the passage pushes the fallen womb before it, and prevents its descent. Suppose the finger of a glove was half turned inside out, and then a large marble pushed up the inside, it is evident 
that the part which was inverted will be again put back in proportion as the marble advances, and cannot return while it remains there. This is precisely the action of a pessary.

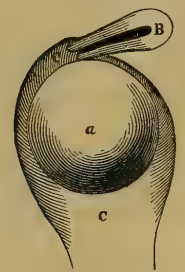

Figure 128.

a. Represents a globe pessary, which has been introduced into the vagina $C$, and thus pushes up and supports the uterus $B$.

health of the parts. health of the parts. Many cases are mentioned where it has led to fatal results. Covering it with wax or gum partly obviates this objection, but adds to its weight, and is liable to wear off.

Hard wood, ivory, and glass are too heavy, though they are perfectly clean, and on that account to be recommended when they can be worn.

Wax and resin are too brittle.

Metals, not easily oxidized, make good pessaries, but are too hard, and will often corrode in spite of all our precautions; besides they are too costly for general use.

Most generally they are made now of some elastic substance impervious to moisture, like oiled silk, or caoutchouc, and either stuffed like a pillow, or blown up with air ; these last being probably the most effective, and liable to the fewest objections.

The form of the pessary has been varied so much by different practitioners that it is impossible to describe all its modifications. It is only necessary, however, to speak of those most in use.

The Globe Pessary is the most generally employed in this country and in England. It is a perfect sphere, and usually made of very thin silver, gilt, or of pure gold. I have seen some made of glass, but they are too heavy, and liable to be broken. Round balls of india rubber are also used, and will often succeed very well. The diameter varies from two inches to two and a half. It must not be so large as to cause pain, but large enough not to fall out when the person stands up, or coughs, or when the bowels or bladder are moved. The introduction of a globe pessary of sufficient size, and properly placing it, so that it will not hurt, or fall out, requires considerable care and time, and should always be intrusted to a competent person, for though it may appear a simple matter, it is in reality a delicate and important operation! One advantage attending this form is that it requires no adjusting, every position being right when it is once in the vagina, while those having a depression must be so placed that the lips of the os tincre will rest in it, and those that have a passage through them must have it so placed as to be vertical. 
The removal of one of these instruments is often more difficult than its introduction.

The Egg-shaped Pessary is not much used, except by some English practitioners. It is much more easily introduced, and more easily displaced ; it is generally perforated through its center.

The Flat Oval Pessary has to be introduced edgeways, and then turned at right angles to the vagina. It is difficult to introduce, and is always becoming displaced; besides it often causes such intolerable pain that it has to be removed immediately.

The Ring Pessary is in the form of a flat, thick ring, with the central opening about three-quarters of an inch in diameter. These rings are made of glass, hard wood, or india rubber. To introduce them, they are passed into the vagina edgeways, and then turned horizontal, which is easily done, because the finger can be introduced into the central opening.

The Figure of 8 Pessary is introduced the same as the oval ones, but is not muck used, especially in this country. It is easily deranged, and is liable to many objections.

The Stem Pessary is one to which a stem is attached, passing down the vagina, and attached to a bandage passing between the limbs, which is again attached to a kelt passing round the waist. This pessary has many advantages, though it has some disadvantages. It needs not be so large as the others, because it cannot of course fall out. It must also of necessity continue at the same height, and cannot well be displaced. The stem, however, is liable to irritate the vagina and external parts, as it is difficult to so construct them as to suit the form and direction of the parts in all their various positions.

Spring Pessaries.-The spring pessary has been modified in many different ways by different practitioners, but is not so generally used as some others after all. In its most common form it consists of a cylindrical spring, about the natural size of the vagina, which is contracted a little at the bottom circle till introduced, and then allowed to spring open, by which means it is held in its place. The upper end is shaped somewhat like a cup, to support the womb. Sometimes the spring is made of gold, and left uncovered, and sometimes it is made of steel, and covered with india rubber.

The Elytroid Pessary is a tube of india rubber, or other elastic material, nearly in the shape of the vagina itself; it has a cup for the womb at the upper end, while the lower one rests on the sides of the vagina just within the vulva.

The Conoid Pessary is in the form of a cone, which is introduced the large end first. It is chiefly used when the vagina itself is much relaxed.

Besides all these, we have various others, as the cup-shaped, bronards, and the simple inflated cylinder.

There is also a horse-shoe pessary, and many others of various forms, some practitioners preferring one and some another. Women will sometimes wear one form with comfort, when they cannot another, but a great many cannot wear any form at all. Still it is well to try them when all else fails.

Inconvenience and Danger of the Pessary.-It is very seldom indeed that a pessary, of any kind, can be worn without great inconvenience, even if it do not injure. Frequently the evils resulting from its use are greater than those it is intended to cure, and it is very questionable whether the benefits derived from its introduction nave been greater than the injuries. It is probable that the instrument, from its very 
nature, will always be more or less liable to these objections, though I have no doubt but that it may be made much more serviceable than it ever yet has been. There are many cases in which it is not proper to be used, as in all kinds of irritation, inflammation, or ulceration, either of the womb or vagina,-also when there is a tumor, or polypus, or confirmed fluor albus. It must therefore be ascertained positively that nothing of the kind exists, in the first place. Then a careful study must be made of the peculiar circumstances and features of the case, so that the most suitable kind of instrument may be chosen, and the proper modification given to it. It is chiefly from neglect of these precautions, and from treating all cases on the same plan, ana with the same instrument, that so little success has been obtained.

There are few persons in whom the presence of a foreign body, like the pessary, in the vagina, does not cause great irritation, and ultimately impair the health of the surrounding organs. Frequently, on their first introduction, such pain is experienced in the loins and groins, and such an uneasy feeling in the passage itself, that the offending object has to be withdrawn immediately. Sometimes, however, the first effects are not so unpleasant, and it can be retained longer, but only to produce other evils at a subsequent period. Among these may be mentioned swelling, numbness, and weakness, of the lower limbs, and swelling of the veins, with difficulty and pain in urinating, or moving the bowels, owing to the pessary pressing on the bladder and rectum. In fact, nearly all the distress produced by the fallen womb itself, on the neighboring parts, is produced also by the pessary even in a greater degree, because it is equally inappropriate to the place, and more irritating. This irritation also gives rise to fluor albus, sometimes to a most profuse extent, or even to ulcera. tion and abscess. This is particularly liable to be the case if the instrument is not frequently removed, and both it and the vagina carefully cleansed. This shoulü never be neglected a single day, for if it be, the fluids which accumulate will become very offensive, and both excoriate and disease other parts, and corrode the pessary it. self. A peculiar growth will also be apt to occur, called a vegetation, which resem. bles bunches of warts, that pour out a purulent matter with a most repulsive odor. The celebrated Désormeaux was obliged on one occasion to cut away an immense number of these vegetations, before he could find the pessary, which had produced ulcrous openings into the rectum and bladder. Professor Cloquet mentions a similar case, where he had to cut away an immense mass of fungous vegetation in a lady who was supposed to have cancer of the womb. To the great surprise of all, an old pessary was found in the midst of the mass, that had been forgotten for ten years! It was completely covered with the vegetation, and incrusted over with calcareous matter. A case is even recorded where the instrument hád been left thirty years, and ultimately produced symptoms like those of cancer, which disappeared, however, when it was removed.

Another surgeon relates that some time after he had introduced a silver gilt pessary, he was sent for on account of the lady being in great distress. He found her suffering from severe pains in the pelvis, accompanied by a profuse foetid discharge. She thought all the distress arose from the pessary, and requested him to remove it, which he did with great difficulty. It was found to be corroded full of little holes, and corered with a hard stony crust. Another case is mentioned of a cork pessary having rotted in the vagina, and produced putrid fever, with inflammation of the bowels. And Delamotte gives the history of a lady from whom he was compelled to extract a cork pessary, which had been worn three years, to which he had to use in- 
struments with all his strength. He was unaware of the nature of the obstacle till it was extracted. It also was completely petrified, like a large calculus from the bladder. Such cases are numerous, and frequently result in fistulous openings into the rectum and bladder, so that the contents of those organs escape by the wrong passage. The celebrated Dupuytren had a case of this kind, where the pessary had eaten its way into both the rectum and the bladder, and had to be cut away a piece at a time, with strong pincers. Stem pessaries are apt to produce accidents of this kind, by the parts becoming displaced and forgotten. M. Lisfranc extracted one through the rectum, which had become lodged crosswise, with both ends penetrating; the patient died.

In those pessaries that have a central opening, as a ring for instance, the neck of the uterus is apt to become gradually drawn into the opening, if it be left too long at a time, and strangulated. A foreign medical journal relates that a young girl, who suffered from prolapsus, was advised to introduce a ring pessary, which she did. The central opening being large, however, the neck of the uterus was first drawn into it, and then part of its body. On examination, the strangled part was found like a tumor, as large as a child's head, protruding from the parts. It was found impossible to extricate it till the ring was cut through with a saw. She fully recovered. I had a case of this kind myself, but fortunately the lady, being aware from her feelings that something was wrong, applied for assistance in time. The neck of the womb had passed through the ring about two inches, but gradually receded as gentle but continued pressure was made upon it, while the pessary was held fast by a ribbon. Part of the womb has been cut off in this way, and life has been lost. It is a very common occurrence for these instruments, when neglected, to become petrified, as it were, or covered with a hard stony crust, which will sometimes be as sharp as a file, and continually chafe the neighboring parts, producing painful ulcers, difficult to heal. These extreme evils are, it is true, the consequences of neglect, but still great distress, if not serious injury, will often follow, even in the most favorable cases, so that constant care and attention are required.

The pessary itself should be smooth and light, and not easily corroded by the fluids natural to the parts. It should be easy of removal, and cleansed, together with the organs, every day. And further, it should never be introduced, if there be any disease or irritation, till that be removed.

\section{TREATMENT AND PROBABILITY OF CURE.}

The treatment, so far as it can well be laid down generally, has been already given in the preceding sections, so that we have now but little to add.

The first thing to be done is to make sure that the case is one of prolapsus uteri, and not one of tumor or polypus. It must then be ascertained how long the prolapsus has existed, and what stage it is in ; whether the womb is capable of being returned to its place, or has formed adhesion; and whether there be any other disease of the organs co-existing. If there be any other disease, local or general, which may be supposed to be a principal, or even an exciting cause, that must be first removed. Then, if the displacement be recent and slight, rest or exercise must be enjoined, according to the condition and previous habits of the patient, with astringent washes and injections, and the cold bath. Change of air, attention to diet, with any other means that will give tone to the system, will also assist. If these means 
are not sufficient, galvanism must be resorted to, under a competent practitioner. All these means must be tried first, leaving the application of mechanical supports till last. I have known the curing of an obstinate constipation of the bowels completely remove all tendency to prolapsus of the womb.

If all these means fail, a supporter or truss may be tried, providing there are no circumstances to contra-indicate it, such as the womb having adhered, or fallen too low, as in the second stage of prolapsus, when the truss is seldom proper.

When all other trusses have been tried sufficiently long without effect, a PESSARY may be resorted to, if there be nothing in the case to make the experiment improper. It must first, however, be carefully ascertained that there is no inflammation or ulceration. Great care must then be taken in properly adapting the instrument, so that it may be worn with ease, and constant attention, for some time after, must be bestowed upon it, to make sure that no injury is being done, and that no alteration is required. If all things remain favorable, and the female herself be strictly attentive to cleaniiness, much relief may be afforded, and possibly a permanent cure effected, by the pessary.

Other means have been recommended and tried by different practitioners, but none of them have been much used. Thus some advise the patient not to rise on the feet for a long time, but to lie with the pelvis higher than the shoulders, in some cases for a month or more. Others use little bags, called sachets, filled with tan or port wine; and others again form a tampon or plug of some astringent material. It has even been proposed to make the vagina nearly solid, by cutting the two walls, and making them grow together! This has actually been done in several cases with complete success, so far as the operation is concerned, but not with the cure of the disease !

Pregnancy sometimes cures prolapsus uteri, but oftener leaves it worse than before. It is sometimes, too, a dangerous complication.

The general tendency of a prolapsus, if not attended to, or if improperly treated, is to constantly get worse, and ultimately to attain the final stage.

Third Stage.-The third stage is that where the womb is completely prolapsed, or protrudes through the external opening. It is usually termed a complete hysteroptosis. When this event occurs, many of the ordinary symptoms of the previous stages are relieved, because the pressure of the womb upon the rectum and bladder is re- moved. The ligaments and attachments are more stretched, however, and the pulling and dragging pains in the back and loins are greatly increased. There can be no mistake as to this stage, because the organ itself may be seen and felt, like a round ball or tumor, between the limbs of the patient. Sometimes this tumor will project six or eight inches, or more. It is composed not only of the womb, but also of the inverted vagina, the bladder and rectum, and uterine appendages, all of which have been dragged down by it. The neck and mouth of the womb may always be distinguished, though much contracted, and at the menstrual period the usual flow will occur from the os tincæ. In most cases, the exposure of this tender organ to the external air, the irritation of the urine, and the friction of the limbs and dress produce violent inflammation, so that it will swell and excoriate, or even become mortified. Sometimes it will remain extruded, however, for a long time with trifling inconvenience, and ultimately become as hard and callous as the external skin. A lady once called upon me, who stated that she was much alarmed by the appearance of a tumor between the limbs, which had appeared suddenly, as she was running up stairs. It was not remarkably tender, nor did it cause her much pain, except occasionally a sharp 
twitch in the groin. It disappeared when she laid down, and sometimes it was not perceivable for a day or two together, if she rested more than usual. This had been the case six months when I saw her. On making the necessary examination, I at once told her it was the womb itself, completely prolapsed. She was greatly surprised and alarmed, and requested me to do what I thought requisite to return it immediately. I at once saw the case was very favorable for treatment, because there was no irritation, no soreness being felt even when it was pressed by the hand. A gentle pressure, rightly directed, soon restored the womb to its place, and relieved the sensation of weakness she complained of. The next desideratum was to prevent its falling again, and to remove the tendency to it. If she could have remained perfectly still, nothing more would have been required during the treatment, as it only came down from exertion. She was required to be constantly on her feet, however, and therefore some artificial support was necessary. A truss would not serve the purpose, so I had a pessary constructed for her, which served the purpose effectually; she could walk, run up stairs, and perform any other active motion without the prolapsus occurring again. I then advised her to take the cold bath regularly, use astringent injections at night, when the instrument was removed, and pay strict attention to her diet, so as to produce regular action of the bowels without medicine. This was persevered in for about two months; she then, by my advice, left home for a month, and went to the sea-side to bathe. At the end of that time, she felt so strong that she thought the pessary might be dispensed with ; it was accordingly carefully left off by degrees, and since then, nearly twelve months, she has remained perfectly well.

Cases have been known where female children have been born with this deformity, as previously mentioned, so that their sex has been a matter of doubt. The celebrated Saviard mentions a case of this kind, where the person was commanded, by the civil authorities of the place where she resided, to wear men's clothes. He, however, reduced the prolapsus, and at once established her sex. Many such cases are on record, and very often, before their nature was known, they gave rise to many of the statements we read of in old works respecting hermaphrodites, which were frequently only deformities of this kind.

The first thing to be attempted in complete prolapsus is to return the womb to its proper place. This can generally be accomplished, though not always. Sometimes new attachments have formed, where it has been left too long, and then all attempts may fail. At other times the difficulty arises from the small intestines, and other parts, having followed the womb, and filled up the cavity it used to occupy.

It is generally considered by surgeons, in spite of all these dificulties, that there are but few, if any, of such cases in which reduction is impossible. We certainly ought not to despair of any recent case, when we reflect that Saviard reduced one in an adult that had existed from birth.

After the womb is replaced, means must be taken to keep it there, till the muscles and ligaments are sufficiently strengthened to retain it themselves. Sometimes simple resting on the back will be sufficient, at others we must use mechanical supports, as with the lady I mentioned.

It is very often the case, unfortunately, that the natural strength of the parts never returns, and some kind of instrument has constantly to be worn. After the reduction is effected, the treatment is, of course, much the same as for the preceding stages, which it then resembles, excepting that there is an unusual degree of relaxation. 
If this unfortunate state of things should occur during pregnancy, and some are more disposed to it at that time, every endeavor must still be made to return the parts to their places, to obviate the great danger and inconvenience that would necessarily follow from the pregnant womb remaining without the body, though it has done so even till delivery. If the womb be too large to return, it must be supported, carefully kept from all irritation, and the patient reclined on her back till the period of birth occurs, which may then take place without extraordinary difficulty. There have been instances known where all attempts to return the protruded womb have failed, and where the sufferer has merely been partially relieved by using a suspensory bandage of some soft and elastic material, or by lying constantly in a recumbent position.

In some of these cases the organ becomes gangrened, or mortified, and to save the life of the patient it becomes necessary to remove it altogether. This operation of extirpating the womb, though necessarily a dangerous and painful one, is not necessarily fatal, it having been performed with perfect safety and success by several distinguished surgeons. It may be performed in two different ways, by the knife or by the ligature, each of which has been tried, and each has its advocates and opponents. With proper attention, bestowed in time, this dreadful alternative need scarcely ever be resorted to, and fortunately it is very seldom indeed that a necessity for it arises. I know one lady who had the womb and the greater part of the vagina cut out, nearly fifteen years ago, on account of a cancer, who perfectly recovered, and has enjoyed excellent health ever since.

\section{ANTEVERSION AND RETROVERSION OF THE WOMB.}

These are two displacements not so common as ordinary prolapsus, but still more frequent than even many practitioners suspect.

Anteversion is a displacement of the womb by its falling forward upon the bladder, toward the bones of the pubes. By referring to the plates, the nature of the displacement will be readily understood. In the natural state the womb is nearly balanced on the top of the bladder. Now if the bladder be suddenly made smaller, frori discharging its contents, and any force from behind-as the passage of the contents of the rectum, for instance, push the womb forward at the same time, it will be evidently liable to fall over toward the pubic bone, or between the bladder and vagina, and thus produce an anteversion.

Retroversion is a displacement of the womb by its falling backward between the rectum and the vagina, being precisely the reverse of anteversion, and produced by directly opposite causeș. If the bladder be too full, the womb will be raised upright, and then a slight concussion from jumping, sudden lifting, or running, may throw it over completely, or retrovert it. In this case, the mouth of the womb presents forward against the bladder, and the top or fundus of it against the rectum; in the prmer case, the mouth presents against the rectum, and the top against the bladder.

Anteversion appears to be most frequent in the non-pregnant, and retroversion in the pregnant state; both may occur, however, in either, though not after four months gestation, the womb being then too large to fall into the pelvic cavity in this way. Retroversion has been known to oceur in virgins.

Both accidents may take place either gradually or suddenly, so that the symptoms may be either inmediately acute or continue to increase. The sensations are 
much the same as those from ordinary prolapsus, but usually more severe. Dragging pains in the loins, small of the back, and thighs, with a feeling of weight and bearing down in the pelvis, similar to labor pains, are first experienced, followed by uneasiness in the rectum and bladder, with a constant desire to urinate and move the bowels. Generally, however, both motions are difficult, if not impossible, and frequently the urine will stop altogether in the midst of the flow, every attempt to expel it being productive of increased distress. This is followed in a short time by inflammation of the womb, which causes the most acute suffering. The menses either cease altogether, or flow continually, and usually a leucorrheal discharge also supervenes. Gradually the whole system becomes deranged, the appetite is gone, the strength fails, fever sets in, and if relief be not given speedily, a fatal result may be expected. The immediate cause of all this difficalty is the jamming of the womb into the small basin of the pelvis, which leads to inflammation, both of it and the neighboring parts. The mischief is of course made greater by any circumstance that increases the volume of the womb, as when it becomes engorged from retention of the menses, or from pregnancy. Sometimes, when the displacement occurs at the change of life, the impacted womb, not having any function to perform, will lose its vitality and become smaller, from wasting away.

It will be readily seen that these accidents are very serious during pregnancy. not only from the difficulty of replacing the womb then, but because sometimes it cannot be replaced at all, in which case the most imminent danger will be experienced. The womb will necessarily keep growing larger and larger, though the space in which it is confined cannot hold it when empty, without great inconvenience ; consequently. it is subject along with the bladder and rectum, to violent and increasing pressure, producing the most intense inflammation, which must ultimately be fatal if not relieved. Under such circumstances, it is recommended by the most eminent surgeons to immediately produce abortion, or even to puncture the womb, to make it smaller by removing its contents, and so permit its return. We have many cases on record where this has been done with perfect success; but still it must always be regarded as a fearful alternative under such circumstances. If proper attention be bestowed by the female herself upon her feelings, and by her medical attendant upon her proper treatment, immediately the accident occurs, relief may in general be obtained by some of the means hereafter to be mentioned.

The cause of these displacements may be either a defect in the form of the parts, or some external violence.

If the pelvis be too large, the organs will be liable to gradually fall, or to be easily forced down. If the womb be too easily movable, it will also predispose very much. The most frequent causes that produce these displacements suddenly are certain violent contractions of the diaphragm and abdominal muscles, as in vomiting, obstinate constipation, straining to expel the urine, or a sudden fright. Also, blows on the abdomen, falls and lifting, particularly when the article raised is pressed against the front of the body-all which are more liable to effect the injury in the early months of pregnancy.

A very frequent cause of retroversion, particulary if the woman have a capacions pelvis, is too great fullness of the bladder. Many a one has had it produced in this way from want of convenience on a journey. The bladder becoming constantly fuller, gradually elevates the womb, until it becomes perpendicular, and then from simply descending a step, rising from the seat, coughing or sneezing, it is thrown 
completely backward, or retroverted. The female feels immediately disposed to bear down, and every time she does so only increases the difficulty by forcing the womb still lower. Sometimes on emptying the bladder it returns again, and the only sign left of the displacement is a numbness over the ligaments, owing to their having been so stretched. If the female be two or three months pregnant, however, this return is not very likely to occur without assistance, and will be difficult even with it. Those who are so situated should therefore be careful, and not place themselves under circumstances where the urine cannot be evacuated when required. Indeed, as a general rule, it is injurious for females to allow the urine to accumulate too much st any time, as it constantly disposes to these accidents, and gradually weakens the aterine supports.

It is probable that in every case of retroversion, unless it occurs from some $\mathrm{ver}_{j}$ sudden violence, the round ligaments are more or less relaxed, and that this relaxation is a principal predisposing cause. In ary case, these ligaments are very much stretched when the womb is retroverted, as it hangs by them, and though they undoubtedly have some elasticity, and may shorten again when the womb is replaced, yet this does not always occur. When once they have been strained in this way, it is probable they seldom or never fully regain their former strength, so that one accident of the kind makes a recurrence more likely. Allowing the bladder to remain too long full will effect the same injury to some extent, because while the womb is thus constantly elevated, the ligaments are more or less distended, and thus gradually weakened.

In anteversion the broad ligaments are much stretched and gradually give way, sometimes even rupturing. The bladder is pressed against the symphysis pubis, and the rectum against the curve of the sacrum. Sudden emptying of the bladder, after it has been very full, will throw the womb forward, and be very likely, when combined with any of the accidents previously mentioned, to produce an anteversion, particularly if the womb itself be engorged and heavy, and the rectum full. Strong purgatives, from the straining they produce, are also likely to assist, and certain excesses, which by all means should be avoided.

The general symptoms of these two accidents are in general so similar that it is sel hom possible from them alone to distinguish an anteversion from a retroversion. A proper examination, however, leaves no doubt, and must always be resorted to if there be not absolute certainty without it. Mistakes have been made, even by eminent surgeons, leading to serious results. The celebratcd Levret had a patient whom he supposed suffering from a stone in the bladder, and upon whom he even performed the usual operation for removing it, though there was nothing of the kind to be found. The patient died from the operation, and upon examining the body, it was discovered that she had an anteversion of the womb, which caused the whole difficulty! The same displacement has also been taken for a tumor and for dropsy, owing partly to retention of urine in the bladder.

Usually there is great inflammation and swelling of the parts, which it is very desirable to reduce, and for which purpose baths, injections, and other means may be used, as circumstances may render most advisable. In many cases, the replacement of the womb has been declared impossible, simply because it was attempted while in a swollen state, and afterward, when the swelling had subsided, it has been effected without difficulty. It is particularly necessary also that the bladder and rectum should both be emptied, because when full they fill up the pelvis very much, and 


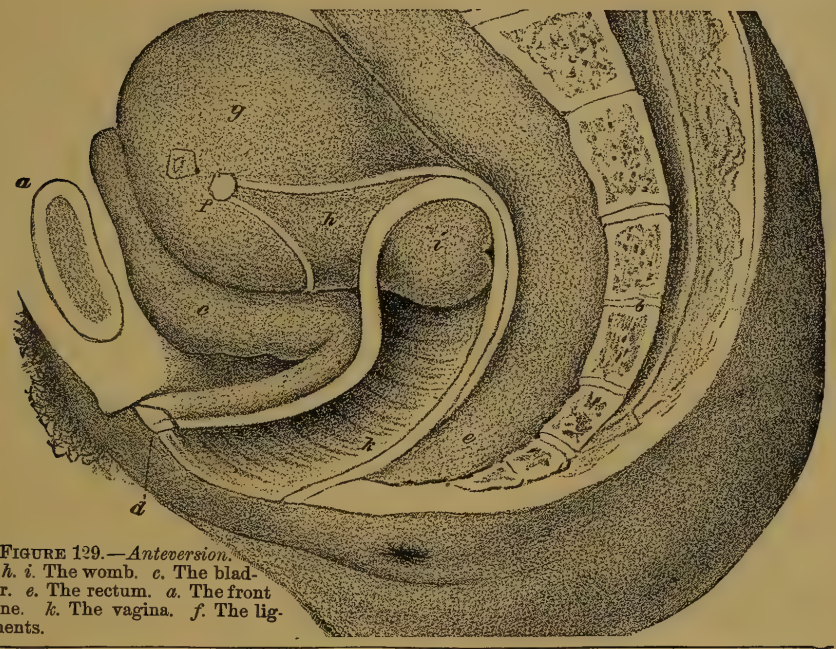
aments.

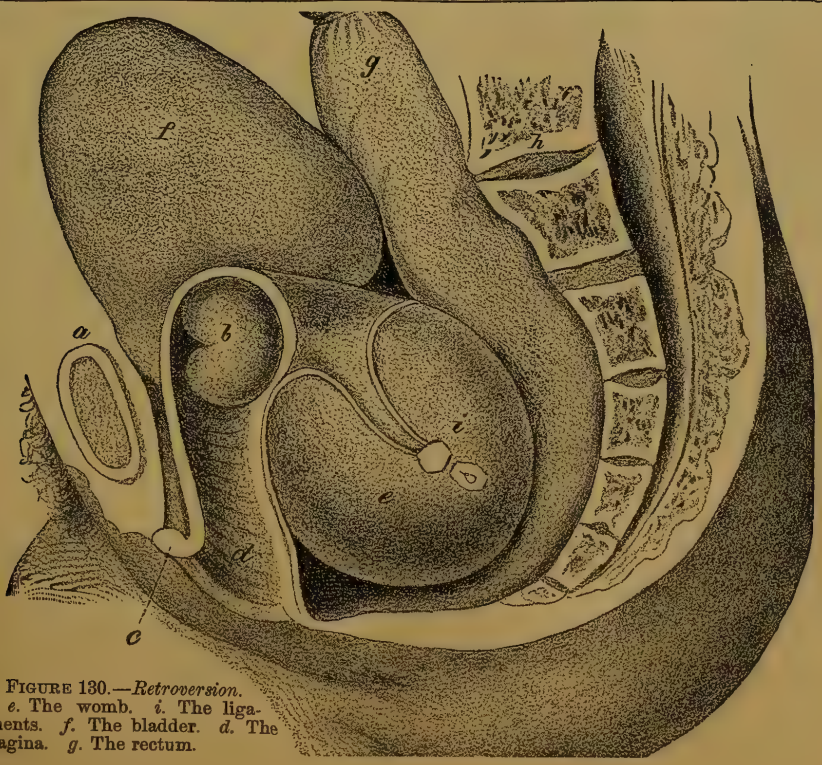


prevent the uterus from rising. In case the urine cannot be expelled naturally, the catheter must be used without delay, as there is danger, if the bladder becomes too full, that it may burst from the constant pressure upon it. The passage of this instrument, however, is often difficult in these cases, owing to the neck of the bladder being so compressed, and the direction of the passage so changed. Very frequently, when all these indications are fulfilled, and the patient lies down, with the hips higher than the shoulders, the womb will replace itself, or will require but little assistance. I know a lady who is constantly liable to retroversion from very slight causes, particularly if riding long in a shaking vehicle, or having to retain the urine。 She has learnt, however, to treat herself, and usually does so successfully. Her first care is to empty the bladder, to effect which she sometimes has to introduce a catheter, which useful manipulation she acquired on purpose. She then passes an enema of thin starch and water, cold, which has the double effect of emptying the rectum and soothing irritation. After these operations she lies down, with her pelvis elevated on two pillows, and in most cases the womb returns to its proper place at once. In some cases where it is not convenient to do all this, the patient need not be left entirely unaided, for frequently immediate relief is afforded by passing the finger into the vagina, and raising up the womb a little. Cold injections, enemas and bathings, are the most valuable preparatory aids, to be followed by the recumbent position. I knew one case where the patient conceived the idea of standing on her head, and she certainly found it to have the desired effect! Nor need we wonder at this, for in that position the womb would be most likely to return, being assisted by its own weight; and besides, the pressure of the intestines and other organs would be entirely removed, which of itself might often be sufficient, for there is no doubt but their weight lying on the womb has a great deal to do with the accident.

The usual mode of assisting, when absolutely necessary, is by endeavoring to draw down the neck of the womb, which of course causes the top to rise, or by pushing the top upward, either from the rectum or the vagina, according to the way it lies, the patient being on her knees and elbows. Sometimes a large bougie, or pessary, is employed to force the womb upward, and a kind of blunt hook to pull it down; but generally the hand only is used, and this is decidedly the best.

There is often, however, great difficulty in effecting this reduction, and it may even become impossible. In one case, where the woman died, the uterus was so firmly fixed that the bones had to be sawn asunder before it could be extricated.

Supposing, however, that the reposition has been effected, we must then follow up with baths and injections, to remove all trace of inflammation, and afterward endeavor to restore the firmness and strength of every part, particularly the ligaments. A douche bath on the groins is very good, or cold wet cloths, with the injections of oak bark, before mentioned, and galvanism. The female must keep still for a long time, avoid constipation, live single, and never allow the bladder to become too full.

The misfortune is, that when either of these accidents occurs it leaves such a permanent weakness afterward that there is always danger of it again. When this $i s$ the case a pessary may be worn, if possible, but it should be made with especial reference to the requirements of the case; one side of the upper part should have a prclongation, or lip, which may be so placed as to support the womb whichever way it falls. In those cases where the weight of the bowels is a chief cause, a truss may ve of service, but it should be applied with great care, and its effects well watchea, 
as it may increase the evil, particularly in retroversion, which I have reason to sus. pect is often caused by these instruments.

The systematic application of galvanism, in conjunction with cold water, if rightly persisted in, will scarcely ever fail of effecting a cure, when that is possible.

\section{ANTEFLEXION AND RETROFLEXION OF THE WOMB.}

These two derangements are so like the two previously described, in their nature, symptoms, and mode of treatment, that any extended description of them is scarcely necessary.

Anteflexion is a falling of the upper part of the womb forward, behind the bone of the pubes, while the lower part keeps its place. It is in fact a bending of the womb, so that the upper part points downward.

Retroflexion is a bending of the womb backward, so that the upper part is parallel with the rectum, while the neck is still in its proper situation.

These derangements may properly be considered as slight cases, or first stages of anteversion and retroversion; they are caused by the same accidents, and may be cured by the same means. They are seldom met with, because they soon become righted, or assume a more serious form. Sometimes this curvature of the womb is natural, or it may arise from disease. It nearly always causes barrenness, because the bending closes up the passage in the neck of the womb. This is one cause of that state of deprivation generally overlooked, and which can frequently be removed by a simple change in position during coitus.

\section{OBLIQUITY OF THE WOMB.}

This is still the same malposition in a yet slighter degree. It consists in a mere leaning of the womb either to the front or to one side. In the non-pregnant state this is so slight a disorder that it seldom requires or receives any special attention. In the pregnant state, however, it is more serious, as it may not only cause great distress but make the labor both difficult and dangerous. In such cases, the mouth of the womb does not present toward the passage of the vagina, but to the back, or to one side, so that the child cannot be expelled. If the medical attendant, however, understand the difficulty, it is easily corrected.

Many women are troubled with obliquity of the womb during pregnancy. In some it always leans over on one side, and in others, to the front; it has been known to hang completely over the external parts so as to cover them, and even to reach nearly to the knees. A properly formed truss will usually correct the obliquity.

Lying constantly on one side may lead to this wrong position, or leaning forward too long at a time; changing the position when sleeping will sometimes effect a cure.

\section{INVERSION OF THE WOMB.}

This accident, which consists in the womb itself being turned completely inside out, like the finger of a glove, is fortunately so rare that very few practitioners have ever seen a case. It always results either from pregnancy, tumors, or some disease that much softens and relaxes the os tincæ.

One of the most frequent causes is pulling away the after-birth too soon, and with 
violence. The upper part of the womb is very likely to be pulled down in this way, and the whole organ inverted. Too violent bearing down is apt to lead to the same result; or a delivery while standing, particularly if the child hang by the cord while that is fast to the womb.

Inversion may occur either along with prolapsus or without it, though most usually they accompany each other. Some authors even consider inversion as merely the last and most serious stage of prolapsus.

Turning the womb, and replacing it, in such cases is a difficult operation, and medical writers are not agreed as to the best mode of performing it. Fortunately the relative superiority of their different modes can seldom be tested.

From the accounts we have of the few cases observed, this is evidently a very dangerous accident, and will most probably result seriously in a short time if relief be not obtained. In every case the treatment must be suggested, in a great measure, by the circumstances of the case, and the practitioner must depend more on his own judgment than on the recorded experience of others.

The usual mode of proceeding, after removing all inflammation by soothing washes and fomentations, is to indent the lower end of the inverted womb, or push it inward, like the bottom of a glass bottle, and keep gradually forcing it further and further till it all passes through the ring of the neck, and is turned right again.

The whole must then be replaced in the pelvis, if there be prolapsus, and the patient must lie still, use cold injections, and, if necessary, a pessary, to prevent a relapse. When the inversion occurs from the weight of a tumor, that must of course be removed before a cure can be expected. This operation of turning the womb back again must be proceeded with slowly and patiently, so as not to irritate it, the inside being now, it should be borne in mind, on the outside! A mixture of one ounce of olive oil, and three grains of extract of belladonna, will make it much more easy, and will relax the neck to a great degree, if gently rubbed upon it. Some authors have advised to cut small slits in the neck to make it expand more readily, but I cannot think such an operation necessary.

If all attempts fail, and the womb shows signs of gangrene or mortification, it is usually recommended to remove it, either by the ligature or the knife, as in cases of irreducible complete prolapsus.

In some cases the inversion is not complete, the upper part of the womb being merely bent in, or forced partly through the neck. If this be unaccompanied by prolapsus it may remain a long time undiscovered, the symptoms not being usually more severe than those of ordinary falling of the womb. There are, in fact, so many of these uterine derangements, which, in their prominent symptoms resemble each other, that nothing but an accurate examination can distinguish them from each other.

Perhaps the most frequent cause of this accident is violence at childbirth. More than one case is on record where an unskillful attendant, in removing the after-birth, has pulled down the womb and turned it inside out. Nay, it has even been literally torn from the body under these circumstances !

\section{FIXTURE OF THE WOMB, OR IMMOBILITY.}

It frequently happens after an inflammation of the womb, or adjacent parts, that the inflamed surfaces will grow together, so that the different organs will all be 
united to each other, and fixed fast to the body. The womb and its appendages are very apt to be attached in this way, and so become immovable. Such an accident, when low down, may not cause any inconvenience unless pregnancy occur--it may then result seriously. The nature of the danger will be obvious, if we consider that the womb is naturally loose, and that it both expands and rises up in the body as gestation proceeds. If, however, it should become attached to any part, that attachment must either be violently ruptured, or it will prevent the requisite change of dimension or position.

Suppose the attachment to be to the bladder, or rectum, it is evident that, as the womb rises, those organs must be pulled up with it, causing great pain, and serious derangement of their functions. If the ligaments become attached they will confine the womb, and prevent it rising up as it enlarges. The result of such a state of things must either be a premature discharge of the contents of the womb, or the tearing asunder of the unnatural attachments, in which case there is danger of ruptured blood-vessels, great inflammation, or abscesses.

It is now known that these adhesions are a very frequent cause of abortion, owing to their prerenting the requisite motions of the womb. The celebrated Madam Boivin published a work on this subject, in which numerous cases are given, and which first made medical men aware of its importance.

I know a lady now who has miscarried nine times in succession, apparently from this cause. The womb is evidently attached to the right side by a kind of hard band which may be distinctly felt, and which effectually prevents any rising up on that side. At about four months she feels this band stretch, and the strain upon it will be at times so great that it seems as if it must break. On the opposite side the womb rises, but not on this, so that it is tilted over as it were. The pain she suffers is very great, and constantly increases till about six months and a half, when the abortion occurs-that being the most usual period in such cases.

It frequently happens when the adhesions extend to the fallopian tubes, that conception is prevented, and it would be well if it always were so, the danger from gestation being so imminent, and the probability of miscarriage so great. Unfortunately in such cases, though we are certain of the nature of the mischief, but little assistance can be rendered. It has been said, it is true, that in some instances the adhesions have been destroyed by using mercurial ointment externally, but I am afraid the remedy will not be found generally successful. The greatest care must be used when there is prolapsus--after childbirth-and in case of accidents, to subdue all inflammation as early as possible, and so prevent these adhesions-for certainly little can be done toward ouring them.

Sometimes the adhesion occurs at the upper part of the womb, while it is fully expanded, in the last months of pregnancy ; and the danger is then equally great, if not greater, than in the former case. No particular inconvenience may be experienced till after delivery, but then the womb, as it retracts and begins to descend, necessarily hangs by the attachment, and in this way is often suspended from the stomach, liver, or colon. These organs then become deranged, painful, and inflamed, so that a fatal result may soon follow, unless the attachment break; in which case there is danger of hæmorrhage or abscess. While the adhesion remains, the proper contraction of the womb cannot take place either, so that there is constant flooding from its large blood-vessels remaining open.

I have known females with adhesions of this kind, most likely by cords or bands, 
who almost constantly felt a dragging and pulling at the stomach, as if, to use their own words, everything was going to be torn out of their bodies. These symptoms would be relieved by lying down, or by pregnancy, because these elevated the womb and relieved the strain on the other organs.

Certain viscious and degrading babits, in young persons, are apt to produce these difficulties, by the continual irritation they keep up, and so are certain excesses in adults.

\section{HYSTEROCELE, OR HERNIA OF THE WOMB.}

This derangement is precisely the same as a common hernia, or rupture, excepting that it is the womb instead of the intestine.

Very few cases, indeed, have been known to occur, so that our description need not be very extended. Most usually the hernia occurs in the non-pregnant state, the womb forcing itself between some of the muscular fibers and appearing just under the skin, like a small pear-shaped tumor. A part of the organ only may protrude, or the whole of it, and sometimes the ovary and tube will follow. The treatment is precisely the same as that of a common rupture, the protruded part being pushed back and a truss worn to prevent its return.

The most frequent causes are blows upon the abdomen, violent lifting and straining, and a former cæsarian operation.

Cases have been known where pregnancy has occurred along with a uterine rupture, so that the development of the womb and the fotus has taken place outside of the abdomen. In some of these the womb has hung down nearly to the knees, and has been cut open and the child taken out, without, however, saving the patient's life. In one case by lifting up, and gently pressing on the protruded organ, it returned into the abdomen, and the female was safely delivered.

The ovaries are also liable to hernia, from similar causes, and also from various diseases. The treatment is the same as in hernia of the womb, unless the ovary be diseased, in which case it is extirpated.

\section{CYSTOCELE, OR HERNIA OF THE BLADDER.}

The bladder, like the intestines and womb, is liable to protrude between the muscular fibers, or through natural openings, and so form a hernia. Both sexes are liable to this accident in certain modes alike, and the female in certain modes peculiar to herself, which are the only ones necessary here to describe.

The causes and symptoms of cystocele are mostly the same as those that produce prolapsus uteri, the action having taken place in the bladder instead of the womb. These two displacements have, in fact, often been mistaken for each other, and it oometimes requires careful examination to distinguish them.

The most usual form of this derangement in females is that called vaginal cystocele, where the bladder is forced backward into the vagina, either by pushing the walls of the vagina before it, or by passing between their fibers. In this case the bladder may be felt, like a tumor at different parts of the vagina, according to the distance it has descended, or it may even protrude through the external lips. In examining this tumor it will be found of a different shape to the prolapsed womb, and with no opening like the os tincæ, which will always distinguish the one from the other. The passage of 
the urine is either stopped altogether, or is difficult and attended with pain, particularly if the bladder has passed through a small opening, and afterward filled. Inflammation usually sets in soon after the accident, and fatal comsequences may speedily ensue.

Cystocele is both dangerous and difficult to treat at any time, but particularly when it occurs during delivery, for if the bladder be in the vagina at that time it will be very liable to injury, besides being a serious impediment to the passage of the child. In one case of this kind, which came within my own experience, the bladder was first emptied by the catheter, returned to its place, and retained there by the hand till the child was expelled. This rupture occurred, apparently, from violent bearing down labor pains while the bladder was full, and showed no signs of returning after the parts were restored to their natural state. Sometimes the protruded bladder, being quite full, will completely block up the vagina, so that the labor cannot proceed, and the passage will be so compressed and twisted that the catheter cannot be introduced. In this case the bladder is usually punctured in the vagina, and, when its contents are evacuated, is returned to its place, and the labor terminated. Great care must be taken, however, to ascertain, with certainty, what it is that presents under these circumstances, the fallen bladder having been mistaken for the bag of water, and ruptured accordingly. It is quite easy, however, to distinguish them, as in a case of cystocele, the tumor is unconnected with the mouth of the womb, while the protruded membranes proceed from it.

In the non-pregnant state the fallen bladder may prevent the flow of the menses, and other fluids, and lead to inflammation of the vagina or womb. The plan of treatment is to return the bladder, by gentle pressure, to its place, and then use astringent washes to close up the opening by which it escaped. A pessary may also be necessary, with a small projection to press on the rupture.

When the bladder is not protruded between the vaginal fibers, but merely pushes the walls before it, the operation is much more easy; the after treatment, however, is the same as already described.

Women who have been too frequently pregnant, or long subject to leucorrhea, and those who keep the bladder too full, are most liable to cystocele. Lifting, straining, running, sneezing, and violent coughing are very frequently immediate causes, and may even produce it in very young persons. I once had a case of a young girl only ten years of age, in whom the bladder descended completely through the external lips, in consequence of violent straining from the whooping-cough. The distress was very great, and the necessity for immediate relief most urgent. The bladder was full, and very tender, and the catheter could not be introduced. I at once put the patient in a warm bath, and then had her laid upon the bed with the hips much elevated. By these means, with a little assistance, the bladder partly returned, so that the catheter could be introduced, the urine was then drawn off and it returned entirely. A small plug of soft lint was worn against the opening in the vagina till the cough subsided, and with occasional injections of oak bark effectually prevented a return. The vagina, however, was much inflamed, and considerable leucorrhea followed; the parts were much relaxed, and the hymen completely destroyed.

Excessive crying has led to hernia of the bladder in infants, and so has the use of strong purgatives. In young girls it has often been produced by the busk, or bone, in the front of the corsets.

In some cases the bladder will not appear in the vulva, but will descend into one 
of the external lips, which will sometimes attain an extraordinary size. The treatment is the same in this case as in the other.

Great care must be observed by those who have once suffered from cystocele, as it is easily brought on again, and every time makes it more difficult to cure.

\section{VAGINAL ENTEROCELE, OR HERNIA OF THE INTESTINE INTO THE VAGINA.}

This is a rupture where the bowels descend into the vagina, in the same manner that the bladder does in cystocele. It is brought about by the same general causes that produce other hernias, and can only be treated in the same way. It is more frequent just after confinement than at any other time, though it may be met with occasionally in non-pregnant persons.

The symptoms of this displacement are not, in general, so serere as those attending cystocele, unless the bowels descend to a great extent, and sometimes they will completely fill up the vagina, or even protrude externally, so that the flow of the menses, and the passage of the bowels will be both prevented. When this occurs during delivery, it may completely prevent the child from passing down the vagina, and then there is danger, both from the suspension of the labor and from the bruising of the bowels. In such a case the hernia must be immediately reduced, and, fortunately, this can nearly always be readily effected.

If the protrusion has taken place in the front part of the vagina, next the bladder, the patient must be placed on her knees and elbows, but if it has taken place in the back part, next to the rectum, she must be placed on her back. The tumor must then be pushed gradually but firmly toward the opening, and the lower part of it worked in with the fingers. In a short time it will begin to move in quickly, and at last will slip by the hand and pass entirely into its place. The cylindrical pessary and astringent washes must then be used to effect a cure.

The protruded bowel is so different from the bladder or womb, that with ordinary attention the one cannot well be taken for the other. Such mistakes, however, have been made, and they show how extremely careful we should be to ascertain with certainty what is wrong.

After enterocele has once happened it is very likely to occur again, particularly if loft a long time without being reduced.

The descent may take place, as in the case of the bladder, into the lip, instead of down the passage, and is then called vulvar enterocele or pudendal hernia. The lip will be swelled, and a firm tumor may be felt in it, as large sometimes as an egg, but becoming smaller when the patient lies down. Its reduction and after treatment are the same as in the ordinary form. I have known females suffering from this pudendal hernia who could not imagine what the swelling of the external lip was owing to, and who vainly tried to reduce it by washes and lotions. They were amazed when told it was a descent of the intestines. Those who labor too hard during gestation are very liable to this accident, particularly if they have borne many children. I once had a poor woman under my care who was afflicted with both cystocele. and enterocele at the same time, from lifting a pail of water. Both of them were reduced, however, and fortunately did not return.

\section{INVERSION AND SWELLING OF THE LINING MEMBRANE OF THE VAGINA.}

It is neceesary to describe this disorder, though it is not a very common or dangerous one, because it is frequently mistaken for hernia, or prolapsus uteri, from which, however, it differs materially. 
In this case the lining membrane of the vagina is distended, and partly separated from the other membranes, either from inflammation or from the infiltration of fluid between them. It falls down, sometimes even through the external lips, and has the appearance of a thick fleshy ring, or cushion, with an opening in the center. The descent, however, may not be complete, or the ring may be a considerable distance up the vagina, and sometimes there will be two or more rings, one above the other. The manner of this descent may, in fact, be well compared to the falling down of the lining of a coat sleeve, when partly unsewn.

The causes of falling of the vagina are such as those that produce the various hernias and prolapsions already described, and also all those that have a debilitating effect on the system. Miscarriage, the employment of instruments in childbirth, continued leucorrhea, excesses, and the vicious habits previously referred to, may also be enumerated. It frequently accompanies falling of the womb, crstocele, and enterocele, all of which are, in fact, frequent causes of it.

The immediate symptoms are comparatively slight, consisting chiefly in an uneasy sensation of something hanging from the vagina, or lips, with dragging, dull pains in various parts ; unless, indeed, the membrane has descended very far, or become much irritated. In this case, the pains become acute, darting to all parts of the abdomen, and the membrane itself being much inflamed, may speedily ulcerate or gangrene, particularly if chafed, or bathed by the urine. The bladder will also sympathize, so that a difficulty will occur in urinating, and a quantity of mucus will discharge from the vagina.

Sometimes the protruded part will extend four or five inches from the lips, and be as large as the wrist, particularly during pregnancy.

The treatment of prolapsus vagina is simple, but often tedious. The first thing is to reduce the swelling and inflammation, without which, of course the parts cannot return. To effect this, all causes of irritation must be removed, the patient must be still for some time, and use cooling lotions or injections, in conjunction with general tonic remedies. Instruments are seldom or never needed, either at the time or after ; indeed, simple rest and cold water would cure most cases, if resorted to in time. Some practitioners use caustic, but I have never seen any good from it in these cases. Occasionally, the protruded part, when long exposed, will become so ulcerated that the removal of it is absolutely necessary. This operation has been performed several times with success, though it is not unattended with danger.

This affection may occur at almost every age and period, but not so frequently in the unmarried, though I have met with it in young persons from nine to twelve years of age. Many are subject to it at the turn of life, at which time it is very troublesome and difficult to cure. Sometimes it comes on suddenly, but most usually by slow degrees.

When it takes place at the time of delivery, it is a very troublesome and dangerous complication, as it interferes with the passage of the child very much. In such cases the protruded membrane is often lacerated severely, and once I saw it nearly torn completely from the vagina.

The ring or cushion produced by this prolapsus may be mistaken for the fallen womb or bladder, unless carefully examined. The difference, however, will soon be apparent, by pushing on the center of the tumor through which the finger will pass readily, and reach the os tincæ beyond. 


\section{CHAPTER LIV.}

\section{VITAL AND ORGANIC DISEASES.}

THIS includes all inflammations, morbid growths, and corrosive diseases of the female organs.

\section{INFLAMMATION OF THE VULVA AND EXTERNAL LIPS.}

Inflammation is very apt to arise in these parts from a variety of causes, with some of which we are unacquainted, and it may become very troublesome, if not serious. Injuries at child-birth very often produce this kind of inflammation, but it frequently arises in young persons from a mere want of rigid and constant attention to cleanliness in these parts. The natural secretions are apt to become acrid, when long retained in the folds of the ragina and labia, and then they irritate every part with which they come in contact. This irritation is sometimes of the most annoying character, and often disposes to those vicious habits we have referred to. When allowed to continue too long unchecked, it produces an offensive purulent discharge, sometimes tinged with blood, and perhaps terminates in ulceration, abscesses, or mortification.

The treatment at first is very simple; constant bathing, either with cold water or cooling lotions, rest, and regular action of the bowels, will be sufficient in nine cases out of ten. A small piece of alum, or borax, about the size of a hickory nut, to a pint of water, makes a good wash ; or a little sugar of lead water, or Goulard's lotion. Ointments of all kinds I think objectionable. When the parts are very sore, equal parts of port wine and water will be a good application.

It may be advisable, when the two lips are much inflamed, to soak a piece of soft lint in the lotion, and keep it between them till they heal, as they are apt to grow together.

If there be any derangemeut of the menses, or constipation of the bowels, it must be immediately corrected-such derangements frequently producing or keeping up this inflammation. Worms will also do the same, particularly the small flat ones in the rectum (Ascarides), which will sometimes even pass into the vagina. Great attention must be paid to the diet, which must be light, cooling, and laxative. No coffee nor alcoholic drinks must be used, nor spices, nor unripe fruits.

There is one form of this disease especially to be dreaded. It is usually callea Carbuncle of the Genitals, or Eruption, and first commences with great heat, redness, and swelling, and terminates in livid colored spots, which soon become small ulcers. If not checked it will rapidly become fatal, from mortification or inflammation of the neighboring parts. The treatment consists in the application of cooling lotions or injections, as before, with washes of camphor, chlorine, and nitrate of silver. The bowels must be opened freely with salts, and other cooling purga- 
tives-nothing irritating must be eaten or drunk-perfect rest must be observedand leeches may be freely applied, if thought advisable, to the parts.

If neglected, this inflammation may produce deep angry u.cers, that will eat into the parts, and even produce fistulas into the bladder or rectum. The surgeon is then needed; and, in spite of all his skill, at this stage he fails often in giving relief. It is therefore especially important to attend to it in time! And still more important to observe, in young persons, that attention to cleanliness and regularity of function, which may prevent it altogether.

The number of cases of this kind that have come under my care painfully convince me of the great want of information on all these important matters that so universally prevails among females, and which directly leads to so many of their distressing afflictions.

\section{PRURIGo OF THE VULVA, OR ITCHING OF THE EXTERNAL PARTS.}

This disease, though not so immediately dangerous as some others, is perhaps the most distressing that can be met with.

It consists in an intolerable and incessant itching of the parts, which nothing seems to allay. Sometimes it is so bad that the fernale is almost tormented to death ; she cannot see company, or walk out, and often shuts herself up alone in her agony. Many have fainted from it, and some have even become delirious. I have seen patients whose hands it was necessary to tie to prevent them tearing themselves to pieces.

The causes of pruritus appear to be most of those that produce simple inflammation, which it very frequently accompanies or precedes. Pregnant females are very liable to it, and in some it will continue, in spite of all that can be done, till after delivery, when it usually disappears. I have known it produce abortion. Some females always have it at the menstrual period, and others during nursing. Occasionally there is a little eruption attending it, but not always, though the parts are generally swollen and red. Parasites are sometimes the exciting cause, and should always be destroyed immediately.

The treatment consists in first attending strictly to the diet, which must be light and unirritating, and to the regular action of the bowels and womb, and in using the cooling washes and lotions before mentioned. If the itching still continues, use either of the following washes to the parts:-Sub-carbonate of potash, three drachms ; water, four ounces. Put a teaspoonful of this into a quart of warm water, and use it three times a day. - A teaspoonful of eau de cologne to a pint of warm water. -Sulphate of zinc, half a teaspoonful to a quart of warm water. Both of these may be used many times in the day.-Borax, half an ounce; sulphate of morphia, six grains; pure water, half a pint. This last seldom fails of giving relief. It should be applied three or four times a day with a piece of soft linen, the parts being first washed with warm soap and water. A tcaspoonful of laudanum will sometimes answer as well as the'six grains of sulphate of morphia.

Caustic has been employed, and blisters to the inside of the thighs, but such violent remedies are seldom either necessary or serviceable. I have known the parts to be deeply scarified with the lancet, and even burnt with a red-hot iron, without at all alleviating the pruritus.

In young persons it seems to be often produced by constipation, worms, and gravel ; 
but it most probably depends, essentially, on some impurity, or irritating quality in the blood, or in the natural secretions of the parts, which should therefore never be allowed to remain long unwashed.

Sitting in cold water, and the application of ice to the parts, has given relief. I hare also effected many cures almost instantaneously by means of a small galvanic plate, so constructed as to be worn just within the valva.

All remedies must of course be applied with caution during pregnancy, and it must be recollected that sometimes the disease will continue, more or less, till after delirery, though the distress from it may be much alleriated.

\section{VAGINTTIS, OR INRLAMMATION OF THE VAGINA.}

This is frequentl? a mere extension of some of the other inflammations already described, and mar be produced by precisely the same causes. It often follows a tedious labor, particularly if instruments hare been used, and is frequently produced by marriage, especially if that occur at an improper time, or if there be any malformations or displacements. Excesses of all kinds are apt to produce it, and the presence of any foreign body, as a pessary for instance; also stimulating food, sudden cold, or violence.

The most general symptoms are pain in the groins and over the pubis, a feeling of intense heat and tightness in the passage, as if it were filled up with somethingdifficulty in urinating, and pruritus. On endeavoring to touch the os tince, the passage will be found nearly closed, from swelling of its walls, and rery tender. In a few days a discharge begins to flow from the vulva, at first like gum-water, but gradually becoming thicker, till it is like cream, and often of a green or yellowish color.

In most cases, the inflammation passes off in abont ten days, and may leare no ill effects. Sometimes, however, it becomes chronic, and then it terminates in leucorrhœa; and occasionally it produces abscesses, or ulcers, when long neglected, and canses fistralas.

The treatment is precisely the same as that for inflammation of the lips and ruilva, excepting that the lotions must be used internally, by means of a female syringe. In joung persons just married, all that is required, in many cases, is to separate for a short time from their husbands.

If an inflammation of the ragina last too long, the walls will be apt to grow together, and so produce a stricture, or narrowing of the passage, which may be a serious difficulty in child-birth, as well as at other times! It is, therefore, advisable to subdue it early.

\section{, METRITIS, OR INFLAMIMATION OF THE TOMB.}

This disease more frequently results from delirery than from any otner canse, and appears to accompany puerperal fever, or, as some suppose, is identical with it, at least in some of its forms.

It is found, howerer, in the unimpregnated state, and may result from a rariety of causes. The inflammations already described may extend to the womb; it may be injured br blows, or other riolence, and irritated $b_{r}$ the retention of the menses. During prolapsus it is always being chafed and compressed, or exposed to the external air, and may thus become inflamed. 
Marriage may produce inflammation of the womb in some temperaments, and a state of singleness in others. Difficult menstruation, irritating injections, forcing medicines, tight corsets, constipation, stimulating food, pessaries, and solitary vices, may also be enumerated. Powerful mental emotions, particularly in hysterical persons, are also frequent causes, and highly excited feelings, especially those connected with certain temperaments. When it occurs during pregnancy, it is very apt to lead to abortion.

The inflammation may be seated either in the substance of the womb, or merely in the mucous membrane, and it may extend through the whole organ, or be con fined to particular parts of it.

The symptoms of inflammation in the mucous membrane of the womb are dulı but constant pain in that part of the organ affected, and in the loins, which gradually extends to the neighboring organs, so that the passage of the urine, or fæces, causes great distress. A sensation of weight is also experienced, which disposes the female continually to bear down, and strain, the same as in labor. The abdomen swells, becomes painful, and very tender to the touch, so much so that sometimes the weight of the clothes can scarcely be borne. The patient has chills followed by fever, and suffers from languor and restless anxiety, which, in severe cases, may lead to delirium. These symptoms are soon followed by a discharge of mucus, more or less profuse, according to the extent of the inflammation, which may be either thin, like gum water, or of the consistence of cream, and sometimes resembles pus.

This, it must be understood, is a description of the symptoms usually accompanying the disease when it affects the whole or greater part of the womb.

When it is confined to some particular part, as to the neck, for instance, the pain and swelling are chiefly confined to that part, and the general symptoms are more local and less severe.

The treatment usually adopted, is that which appears most likely to quickly reduce the inflammation. The bowels must be opened freely, perspiration must be induced, and the hands and feet kept warm. Fomentations must be applied to the abdomen, and diluent drinks freely taken. Hops or poppy heads make an excellent fomentation, and barley, or tamarinds soaked in water, with a little sweet nitre, an excellent diluent drink. A vapor bath will often be very effective in promoting perspiration, and relieving the soreness, and a large meal poultice placed on the abdomen will frequently allay the pain. Bleeding is generally resorted to somewhat freely, and leeches, or cups, to the inside of the thighs, the vulva, and the abdomen; but I am inclined to think that the inflammation can usually be subdued by other means. The patient should lie on ber back, with the knees raised, and the clothes should be kept from bearing upon her.

A decoction of poppy heads may also be used as an injection, in the ragina, and, if the pain be very acute, a teaspoonful of laudanum may be added to it. A mustard plaster will frequently alleviate the pain considerably, when applied on the abdomen, or back, or inside of the thighs. Blisters have been recommended, but they irritate the patient too much, and it is very important to keep her still. She should not be moved, on any account, more than is absolutely necessary. The vapor bath must be given under the bedclothes, so that no moving, or carrying to it will be required. If the purgative does not operate soon, an enema should be given, as it is particularly important for the bowels to act. The enema may be composed of thin starch and water, warm, with a large spoonful of castor oil. 
But little food, of any kind, should be taken till the inflammation is subdued, and then it should be light, chiefly fluid, and very plain. All stimulants must be carefully avoided, whether solid or fluid. The room must be well ventilated, and the patient kept quiet.

If these means, with such others as the particular circumstances of the case require, be faithfully persisted in, they will, in most cases, subdue the inflammation in a short time; but great care must be taken, and perfect rest observed, till all signs of it are gone, as there is always danger of it increasing again, from slight causes.

When the inflammation is seated in the substance of the womb itself, the symptoms are always more acute, the danger greater, and the result more uncertain. The treatment must be more energetic, and our attention more unremitting.

If the inflammatory action be not subdued very soon, the most serious results are to be feared. The general distress increases, the skin becomes hot and dry, the countenance is anxious, the throat parched and sore, the breathing difficult, sickness sets in, or hiccough, the breasts swell and become tender, and the head throbs and burns till the patient raves in furious delirium. The urine is generally red and hot, and the passing of it, or of the contents of the bowels, makes the sufferer scream with agony. She rolls her eyes, picks at the bedclothes, grinds her teeth, and draws up the limbs till they press against the abdomen.

If the pain seems to concentrate at one point, and becomes more poignant, and the patient suffers from night sweats and headache, with inaction of the bowels, it may be suspected that an abscess is forming. This will sometimes break and discharge from the vagina, and at other times will form a fistulous opening through the abdomen, the groin, or at the inside of the thigh. The quantity of pus thus poured out is in some cases enormous; usually the patient sinks immediately after the abscess bursts, but if she can be sustained, the wound may heal after all is evacuated, and a perfect recovery may take place.

The last stages are generally marked by a cessation of heat and pain, by involuntary action of the bowels, coldness of the extremities, convulsions and faintings. If there be gangrene or mortification, a black foetid discharge takes place from the vagina, and sometimes from the bowels.

When this is seen there is scarcely a hope, and very frequently the disease is thus fatal in two or three days from its commencement, though some will linger two or three weeks.

On examining the womb in those who have died in this way, it is frequently found to be quite softened, or even converted into a kind of putrescent pulp which almost runs into fluid when pressed upon.

Both forms of inflammation of the womb are much more dangerous when they occur during childbed, as all those are aware who have seen the rapid and fatal termination of puerperal or child-bed fever. Most cases of ordinary inflammation, in the non-pregnant state, terminate favorably, with proper care, though they may be lingering, and leave much general debility.

The principal danger, after the acute stage is passed, is of the disease becoming chronic, which form, though less severe, and not so imminently dangerous, is still much to be dreaded.

Chronic Metritis, or inflammation of the womb, may be produced by the same causes as acute inflammation, or may follow from it. There are, however, certain 
circumstances and conditions that dispose to it more than others ; as, for instance, a lymphatic temperament, habitual depression of spirits, scrofula, bad air, low damp situations, ill-ventilated houses, a constant use of stimulating food or hot baths, and indulgence of certain feelings. The immediate causes are the same as those already enumerated, and also cold-particularly from sitting on cold damp seats-tight corsets, and habitual constipation.

The symptoms are nuch the same as those in the acute stage. The inflammation, however, does not extend so much to the neighboring parts, nor does the uterus sweil up so suddenly, nor become so excessively tender; sometimes, in fact, it does not swell at all. There is always severe pain in it, however, which is much increased when the female stands long, or walks far, or when she is shaken too much by riding, when the bowels are moved, or the urine passed, and particularly at certain other times! There is also great heat and burning, with a sensation of fullness and weight in the loins or groin. The female becomes irritable, impatient, or sad, or is subject to nervous tremblings.

This disease is frequently mistaken by practitioners for something else. Many look upon it as a purely nervous affection, and go on treating the patient for the mere nervous symptoms, while the real disease remains untouched. And many others, who do discover the true disorder, consider it incurable, and either give it up entirely, or merely administer palliatives, to relieve urgent symptoms and satisfy the patient. It is necessary to say, however, that it is often impossible to ascertain the truth from any of the above-named symptoms alone, because they accompany many other complaints, and an accurate and careful examination is frequently indispensable.

I once had a lady call upon me who had been suffering for two years from what was called, by some physicians, hysteria, and by others dyspepsia, with liver complaint. She had almost constant pain in the lower part of the abdomen, which made her dread moving the bowels, for fear of increasing it. The urine was scanty and high colored, the menses irregular, and the bowels mostly constipated. To use her own words, " the whole inside seemed as if it were burning up." The limbs were weak, the appetite capricious, and the whole nervous system in a terrible state of derangement. Sometimes she would suddenly go very sallow, with the eyes much congested, and at other times she would be very pale, and faint, or sick. From an attentive consideration of the case, I became convinced that none of the previous conjectures about it were correct, but that it was a case of chronic metritis. A careful examination with the speculum proved this conviction to be well founded, and I at once began to treat her accordingly.

The first thing attended to was the diet, which was directed to be very plain. The quantity of food was rather limited ; all spices, coffee, pickles, and warm drinks were forbidden; meat allowed but once in the day, sparingly, and never smoked or salted. Alcoholic drinks, of all kinds, were strictly prohibited, and in their place was substituted cold lemonade, with a little cream of tartar, barley water, and tamarind tea, or simple cold water.

A cold shower bath was directed to be taken every morning, immediately on rising, to be followed by a short, gentle walk when the weather was favorable. After breakfast she was advised to lie on the sofa for an hour, and after that to take another walk before dinner. The same in the afternoon as in the morning. Several times during the day, but particularly morning and evening, an injection was used of cold thin starch and poppy heads. The thin starch alone was also used daily as an enema, 
at first, till the bowels began to act regularly from the improved diet, and then it was omitted. During the first week the abdomen was also fomented every night with a strong decoction of hops. Every kind of excitement was guarded against, either from reading, company, or other causes. The natural warmth of the feet, which she had not felt the whole time, was restored by means of friction and the application of galvanism, and the whole surface of the body, which was habitually chill, was well rubbed every morning till a healthy glow was produced. The only medicine given was a little cinchona, after the second week.

In three weeks she had sensibly improved, the burning sensation was no longer felt, the soreness and pain was gone, except when she walked a little too far. The appetite became good and steady, and her strength much greater. The nervous symptoms began to amend immediately the general health was improved, so that she soon became quite cheerful. A steady adherence to this plan of treatment completely eured her in about seven weeks, and she went home with such a knowledge of the disease, and the causes which produced it, that in future she will most likely be able to prevent it altogether.

In severe cases it is advised, and may sometimes be advantageous, to apply leeches to the perineum, or groins, or blisters to the inside of the thighs and abdomen. I am of opinion, however, that a strict perseverance with the milder course I have described will usually succeed without them.

A teaspoonful of laudanum may sometimes be added to the injection, or fomentation, when the pain is severe, and if it occur in a spasm, like cramp, galvanism will give immediate relief.

\section{ENGORGEMENT, OR ENLARGEMENT OF THE WOMB.}

Cases of chronic enlargement of the womb, commonly called engorgement, are quite common, or rather, they are very frequent. When treating on falling of the womb, we stated that engorgement was a frequent cause of it, and such is now known to be the fact. In many cases of supposed polypus, or tumor, there is merely a swelling or engorgement of the womb, which has also been mistaken for dropsy.

The causes that lead to this disease appear to be much the same as those that produce inflammation, with which the engorgement is sometimes accompanied, though not always. Whatever has a tendency to excite these organs, or to chill the surface of the body, so as to derange the circulation and produce internal congestion, will be most likely to cause engorgement. Among other causes may be specially enumerated, sentimental or impassioned reading and conversation, insufficient exercise in the open air, cold, constipation, derangement of the menses, particularly their stoppage, improper diet, and excesses of various kinds.

The symptoms of this disease are often quite obscure at first. Sometimes there is considerable pain, similar to what is experienced in metritis, but at other times there is scarcely any pain at all, though there is always more or less uneasiness and feeling of weight. The enlargement of the abdomen may be slight, or it may be very considerable, so as to simulate dropsy.

If the disease continue long, the patient is apt to become hysterical, or suffer from cramps and creeping of the skin. The stomach will become deranged, and sickness and vomiting may ensue, with very irregular action of the bowels. The breasts will also frequently enlarge and become painful, precisely as in pregnancy, and 
the patient will be restless and unable to sleep. The menses sometimes stop altogether, for several months, and then a flooding ensues for weeks together ; in some cases they never stop for more than a day or two at a time. Very often there is a purulent and fotid discharge from the vagina, almost constantly, as if the womb were ulcerated or gangrened.

There are two varieties of this disease, different in some of their symptoms, but similar in their effects, and requiring a similar mode of treatment. In the one case there is hardness of the womb, commonly termed induration, as well as swelling; while in the other case it is sometimes even softer than natural.

The general treatment at first should be similar to that for chronic inflammation. After which regular bathing, exercise on horseback, and chafing over the womb with liniments may be added. Dashes of cold water on the lower part of the abdomen are also useful, and cups to the inside of the thighs. If the disease still remain obstinate, a seton or blister may be used on the loins. Another plan of treatment called firing has also been found useful. It may be imitated by taking a small flat-faced hammer, and plunging it for some minutes in boiling water, then on taking it out press it suddenly and firmly on the skin, for a few seconds, heating the instrument afresh for each application. The number of applications may be ten or a dozen on each side of the backbone, at the small of the back, or in the groins. The pain is by no means so severe as might be expecter, if the operation be performed quickly, and it may be done in five minutes. I have known many patients prefer it to either cups or blisters. The effect is often very beneficial.

It should be borne in mind, however, that the mild plan of treatment will usually succeed, though it may take longer time; and this is a disease that requires patience and perseverance, in both patient and physician, to no small extent. Sometimes it is necessary to advise a state of singleness for a time, but at other times marriage will be beneficial. This can be decided upon only after a careful consideration of the peculiar circumstances of the case.

One of the chief resorts of the general practice of the day is copious blood-letting in various ways, but particularly by leeches and cups, to the abdomen, perineum, vulva, thighs, and mouth of the womb. This is sometimes continued daily till the patient faints. As I have before remarked, however, I think the same effects may be produced by milder means.

If the swelling be not reduced there is danger of a purulent accumulation, and of abscess, or, in case of induration, it will be likely to end in cancer.

During the engorgement there is nearly always either prolapsus of the womb, anteversion or retroversion, the unusual weight causing its displacement.

Hemorrhage, or bleeding, sometimes accompanies engorgement, but not always. Tubercles, or small ulcers, are also frequently developed in the womb itself, particularly on the neck, and most frequently in those who are badly fed, who live in illчentilated houses, and who are scrofulous.

\section{SCIRRHOUS, OR CANCEROUS ENGORGEMENT OF THE WOMB.}

It is not my intention to enter into a description of the nature and treatment of cancer of the womb, for several reasons. It is a disease fortunately but seldom met with, and is in no way different from cancer in other parts of the body. Besides, so little is known of its nature, and so little is agreed upon respecting its treatment, 
that any extended account would be merely a record of contradictory opinions, while a meagre one would be utterly useless.

Scirrhous, or cancer, will, however, produce enlargement or engorgement of the womb, so similar in some respects to that already described, that it is necessary to distinguish them.

In scirrhous engorgement the womb is always very hard, and feels in lumps or knots; it increases in size very slowly, and when examined by the speculum, the neck appears of a yellowish white color, like ivory. The pain is often darting and very severe, though sometimes there is none at all.

It may be years before this state of things alters, and the cancer opens into an ulcer, or it may do so very soon. It is also possible, I think, beyond doubt, to resolve or remove the cancerous tumor, by pursuing much the same mode of treatment as we have prescribed for simple engorgement. There is no question but that many cases of undoubted cancerous tumor in the womb have been completely cured by such a course. There are cases, however, in which the treatment must be modified from numerous causes, and in which the result is always uncertain and much to be feared.

\section{RHEUMATISM OF THE WOMB.}

This is a disease about which very little is yet known. There are but few medieal works, even the most recent, that contain any allusion to it, and but few medical men who ever treated a case. It is, nevertheless, more common than is suspected, but from its resemblance to other diseases is confounded with them.

Rheumatism may settle in the womb after having existed in other parts of the body, or it may attack the womb first. The same general causes that produce the disease elsewhere will also produce it here, or it may probably be a consequence of other diseases. The symptoms are, for the most part, so precisely similar to those of ordinary inflammation that one cannot be distinguished from the other, and they have, therefore, usually been confounded together. It is of the greatest consequence, however, to distinguish them if possible, because the treatment proper for one disease will be highly injurious for the other. There is no doabt whatever but that many cases of mere rheumatism have been treated as cases of metritis, and with fatal consequences. Often, on examining the bodies of those who have died from supposed inflammation of the womb, no trace of inflammation could be found! The inference is, that no inflammation existed, but merely rheumatism, which possibly ended fatally merely through this mistake.

In rheumatism of the womb, there is usually more or less cessation of pain at intervals, during which but little soreness is felt on touching. On lifting up the womb also, the pain will often cease entirely, while in inflammation it is always increased. The peculiar gnawing, grinding pain of rheumatism is also very distinct from that of ordinary inflammation, and is always recognized by those who have ever felt it before.

This disease is most likely to occur during pregnancy, and is then very apt to lead to abortion. An attack of it during child-birth will often stop the labor altogether, the woman using every effort to keep still, on account of the agony that any straining produces. The muscular fibers of the womb are also cramped and stiffened by it, in the same way as the muscles are in other parts of the body.

The treatment of this agonizing disease must be similar to that of rheumatism in 
other parts of the body. Brisk purgatives, warm baths, hot fomentations, containing opium and camphor, to the abdomen; anodyne draughts, sweating medicines, and blisters to the loins. In the non-pregnant state, galvanism will be the best agent, and if there be any derangement of the menses, it must be immediately corrected. When rheumatism stops suddenly in any other part of the body, it is very apt to fly to the womb, if that organ be weak, or its functions deranged.

In every case, therefore, where there is a painful affection of the womb resembling inflammation, the physician should satisfy himself, as far as he can, that it is not rheumatism, and should always bear in mind, at least, that it may be so, particularly if the patient has had rheumatism in other parts.

I have so doubt whatever but that many of those cases so often met with, where females suffer excruciating pains in the womb, varying in intensity at different times, and with no apparent inflammation, are really cases of uterine rheumatism. I have a case now of this kind; the lady has been suffering for three or four years, at times almost to distraction, without obtaining the slightest relief from any treatment she has received. Some physicians treated her for uterine inflammation, others thought a polypus was forming, and one alarmed her by suggesting a cancer. On examination I found the womb very little larger than usual, and not hard except when drawn up with pain. No pain was experienced on raising it up, but, on the contrary, great relief. I became convinced, from these and other symptoms, that it was a case of uterine rheumatism, and I have now treated it for some time on that supposition with the happiest results. In fact she may be considered cured, excepting that there is still a little sensibility just before any sudden change in the weather.

I would particularly recommend both physicians and patients to bear this disease in mind, especially in many of those cases when they are puzzled to tell what is the matter.

\section{LEUCORRHEA, OR FLUOR ALBUS.}

This disease, ordinarily termed the whites, is, perhaps, even more common than prolapsus uteri. In large cities particularly, and in certain districts, it is almost universal, occurring in both married and unmarried, young and old, from mere infancy to extreme age. It appears in the form of a discharge from the vagina, like mucus, or pus, or sometimes even like green water, or milk, or curds and whey. Its color also varies, being white, yellow, greenish, or reddish brown, and sometimes it is quite colorless. The quantity may be either small, so as to merely make a show, or it may be larger, sometimes even to half a pint or more in the day.

The discharge itself is very annoying, and causes great distress, but it is also accompanied, in most cases, with more or less constitutional disturbance, which may even become serious.

Leucorrhcea often follows from inflammation of the mucous membrane of the vagina and uterus, but more frequently, perhaps, from tonic debility and weakness. It may therefore be produced by any causes that give rise to inflammatory action, or to general prostration. Among these may be enumerated, deranged menstruation - cold-want of exercise and fresh air-late hours-exciting reading, company, and conversation-depression of spirits-vicious habits-too early, or too late marriage, -exciting food and drink-the use of shell-fish--stimulating medicines-excessestoo much warm bathing - cold, damp, or ill-ventilated houses-thin shoes-the irritation of a pessary, or injury at child-birth, especially by instruments-frequent 
labors-and insufficient clothing. To these may be added numerous others, and generally all those that debilitate the system. All large cities seem to be so many hot-beds to engender this and other female diseases. In them puberty is precociously developed, exciting circumstances abound, and the daily habits of females are calculated to make them weak, and susceptible of cold from the slightest exposure.

In some persons leucorrhœea appears to be constitutional, and probably results from a scrofulous taint. Particular temperaments are also apparently more disposed to it than others. Women of a nervous habit-those with light or reddish hair, and thin transparent skins, and those who swell and puff up in the limbs, from slight exertion, are instances.

The intimate connection between the uterine system and the great nervous centers is also another source of this disease; and hence it is often produced by sudden fright, continued anxiety, disappointment, grief, and passion. Every other organ in the body is also connected, in the same way, with the womb, so that their derangements may cause leucorrhœa. It will likewise frequently result from the sudden suppression of some other discharge, as diarrhœe, vomiting, profuse perspiration, hemorrhage, or the secretion of milk. The incautious healing of old ulcers, skin eruptions, setons, or issues, or even the stoppage of a common cold, may also pro. duce the same effect. Sometimes it appears to prevail epidemically, and in some sections of the country almost every female has it. This is mostly in damp, low situa tions. I know some females who always have leucorrhoea in the spring and fall, and others who have it all the winter. I knew one in whom it took place suddenly, from fright, at seeing a child fall out of a window ; and another in whom it occurred after three nights watching with a sick friend. Very often I have seen it follow the stoppage of the menses, though only for a single term, and also from a long-continued constipatic $\Omega$ of the bowels. In short, everything that deranges, weakens, and diseases other parts of the system, will thus disease the womb, whose mysterious and extensive sympathies connect it with every other organ in the body.

In cases of leucorrhœe it must be first ascertained if there be any exciting canse that produces it, and if so, that must be first removed. Very often the disease depends merely on some other derangement, or on the presence of some irritating foreigit body, the removal of which is all that is required. Most usually, however, it is regularly established, so that the inflamed, or debilitated state of the mucous membrane exists independent of these external causes, and may be either acute or chronic.

Acute leucorrhoea is always attended with more or less of inflammation, and sometimes with slight fever. The discharge, though small and thin, at first, becomes in a short time quite profuse, and highly colored. I have known it in some soak through a dozen napkins in a day. Generally there is pruritus, and similar pains to those felt in metritis, with difficulty in urinating, and burning heat. Certain feelings are also apt to acquire undue strength, from the irritation, and hysterical symptoms supervene, with general restlessness and irritability.

This form of leucorrhoea sometimes disappears and returns again, at regular intervals; between the monthly periods for instance. It may, however, continue an indefinite time unchanged, or it may become chronic. It is usually this form that occurs at particular seasons, from violence, strong mental emotion, and sudden cold.

Chronic Leucorrhcea.-This does not always follow the acute form, but may 
arise from independent causes, most frequently from mere debility. Women of a lymphatic temperament are most subject to it, or those most exposed, or those who have been weakened by frequent child-bearing, and other causes! It also frequently accompanies deranged menstruation.

As a general rule there is no great pain felt in chronic leucorrhœea, nor is there any irritation, but it is nearly always accompanied by distressing weakness and languor. When of long standing, however, the symptoms may become more serious, particularly if the discharge be copious and thick. The female will then complain of a weight, with pain in the back, and in the lower part of the abdomen. The appetite will often become capricious, with sickness at the stomach, palpitation at the heart, headache, giddiness, pain in the breast, and coldness in the feet. The skin feels chilly, wnd the head hot; the eyes ache and feel too heavy to keep open. The hysterical symptoms become more decided, and sometimes we see the patient cast down with melancholy, while at other times she will have fits of langhing, crying, intense passion, and other uncontrollable emotions.

The external indications of this state of disease are very marked. The face is pale, the eyes dark underneath, the eyelids swollen and heavy, every motion seems a labor, and the general air of sadness indicates the misery with which the poor sufferer contends.

Eventually, if the disease be not checked, the general health suffers still more. The continual discharge causes such weakness that the patient cannot stand, or walk. The skin becomes sallow, the breath foul, the flesh soft and loose, and the limbs swollen as if with dropsy. The stomach becomes acid and full of wind, the bowels tormented with colic pains, but obstinately costive, and the urine becomes small in quantity, high colored, and very thick. Finally, the debility both of body and mind is so great, and the distress so overwhelming that the patient sinks in despair, and often prays for death to relieve her misery.

In numerous cases, however, it will continue for years in a comparatively mild form, without ever attaining this extreme stage, though there is always danger of its doing so.

Treatment of Leucorrhoea. - It must be carefully borne in mind that the too sudden stoppage of a long established or very profuse leucorrhœa may cause great mischief, particularly if it be accomplished by a mere local application. The mere drying up of the discharge is not a cure, of itself, unless accompanied by an improvement in the general health.

In the acute form the first thing to attend to is the diet, the regulation of which alone will often effect a great improvement. Everything heating or stimulating in the food must be carefully avoided, and the drinks must be mucilaginous and diluent, like those prescribed for chronic metritis. Injections and enemas must be used also, of the same kind as those recommended in metritis, and the bowels must be kept free. A strong decoction of poppy-heads with a half ounce of borax to the quart, is an excellent injection for this complaint; so also is the oak bark, mentioned when treating on falling of the womb. They should be used tepid, and four or five times a day.

Internal medication may be of use, if it can in any way improve the health, or decrease the morbid action. Purgatives have this effect to a certain extent, by exciting the mucous membrane of the intestines, and so relieving that of the vagina or womb. Many cures have been thus effected by purgatives alone, particularly with rhubarb, which is also a good tonic. Even continued sickness and vomiting will 
sometimes produce the same effect, and hence some physicians have cured their patients by repeated doses of ipecac.

External irritants, as blisters or liniments for instance, to the abdomen, loins and thighs, or mustard poultices, are of great service. Setons, or issues may also be used, and leeches, or cups, with repeated frictions all over the body, to produce proper action in the skin.

All these means, however, are intended for the first period, that is, while i iflammation exists, but when that has subsided the course must be varied. The diet may then be more generous, and tonics may be given, such as the aromatic tincture of iron, bitter teas, or even a little good port wine and Peruvian bark. The injections may also be made a little stronger, so as to be more astringent, and some fresh ones may be used, as alum, or sugar of lead, water, or a solution of sulphate of zinc, or two parts of port wine to one of water. The patient must keep still ; in fact, she must have perfect rest, and must be warmly clothed. If it be the proper season, sea bathing will be of great service at this stage, or, in the absence of that, a shower bath every morning, with good rubbing after. Thick shoes must be worn, and plenty of exercise taken in the open air.

The application of galvanism, by means of a large metallic bougie, will often complete a cure sooner than anything else. It seems to impart tone to the membrane, and effects a change, both in the character and the quantity of the discharge, in a very short time. I have used it in a great number of cases, and can safely recommend it, as a means likely to be successful when everything else fails. One of the most remarkable cures of this disease perhaps ever performed, I had the gratification of effecting by means of galvanism. The patient had suffered for thirteen years, and was in the worst possible condition; so weak she could scarcely walk, and so dejected that it was difficult to rouse her to the slightest effort. I began by prescribing a generous diet, there being no inflammation, and the frequent use of slightly astringent injections, like those referred to. The body was well rubbed after a shower bath, every morning, and a preparation of rhubarb and iron was given internally. This checked the discharge, and improved the general health considerably, in about three weeks. I then began the application of the galvanism, every day, and continued it for three weeks more, at the end of which time the discharge was completely stopped, and the general health so far restored that the patient declared herself quite well. She recovered her flesh, the sallowness left her skin, the limbs became strong, and cheerfulness took the place of the melancholy that had formerly overwhelmed her. The change was indeed miraculous, her friends scarcely knew her, nor could she help fearing, to use her own expression, that it was too good to be true! I have heard from her repeatedly since, however, and she still retains her health.

Great imposition is practiced in the advising of specific internal remedies for this disease. I have known many celebrated practitioners even completely drench their patients with drugs, under the delusive promise that they would stop the leucorrhœea. Excepting in the way already pointed out, there are but few of them that have even the slightest effect in that way. The only medicines that seem really to act on the mucous membrane of the ragina in this disease are turpentine, some of the balsams, copaiva, cubebs, and toln, for instance. One scruple of sulphate of iron, and two scruples of aloes, with as much Venice turpentine as will mix them together, is an excellent preparation; it should be made into twenty pills, and one should be taken three 
times a day. The common copaiva capsules are also often good; two of them may be taken three times a day.

In France and England they also employ copaiva in the form of injection, or enema, or in what is termed a bougie, or suppository, which is formed by mixing up the balsam with wax, or fat, and a little opium, till it is like dough. It is then moulded into the form of a bougie and introduced into the passage, where it may be worn for half an hour, morning and evening.

In the chronic form of leucorrhœa there are no inflammatory symptoms to combat, the disease is become constitutional, and cannot be treated successfully by local medication alone. The injections and baths may be used as already directed, and also medicines, but more attention must be paid to that course of treatment called tonic and alterative. The strong bitters, such as cinchona, gentian and absynthium, are excellent tonics, and may be taken alternately with the different preparations of iron, such as the muriate,- - the aromatic tincture,-or the compound mixture,-and particularly the syrup of iodine of iron, ten drops of which may be taken three times a day. The turpentine and iron pills, previously advised, may also benefit, or the copaiva capsules and suppositories.

It will be a great error, however, and will lead to much disappointment, if too much dependence be placed on any kind of medication, external or internal. It is nothing more than an assistant agent at best. The chief good must result from that change in the air, diet, habits, and general regimen, which effects a modification, or alteration, in the action of the system. There are many medicines that are capable of driving back the disease, or rather preventing it from showing itself for a time, but this is not curing it. The tendency still remains, and on suspending the medicine the disease again appears. Galvanism may be used, with more prospect of good than from any medicine, if conjoined with the plan of treatment laid down.

Leucorrhœa is, however, in most cases, so complicated with other affections, either as cause or effect, that we can scarcely approach to any general plan of treatment. The kind of medicine, and the quantity of it; the particular diet and regimen; and the mode of applying the galvanism, must all be varied in almost every case. By pursuing a certain course with one patient, merely because it was successful with another, we may make matters worse, instead of effecting another cure. There are few diseases, in fact, so difficult to treat as this, or that so frequently defy all treatment. A very old practitioner once remarked to me, that he would rather undertake to cure cancer, or consumption, than leucorrhoea; and he certainly had good reason for making the remark. At the present time, however, a little more success may be reasonably expected, because the causes that produce it are better understood.

It should always be borne carefully in mind, that a mere discharge from the vagina does not constitute a leucorrhcea, nor always indicate one. The discharge may arise from other diseases, particularly from an ulcer, abscess, or cancer in the womb. This must, of course, be ascertained if possible. It is not always easy to do so, how.. ever, and hence arises a great deal of uncertainty. The character of the discharge itself is the only sure indication of the place it comes from ; that poured out by the vagina having different chemical properties from that which escapes from the womb ! the pus from an abscess, and the discharge from an ulcer, are also very different, in many respects, from the secretion of a diseased mucous surface.

It is, perhaps, advisable to remark here, that the leucorrhoeal matter is sometimes 
infectious, and, in married persons, may produce effects on the husband usually thought to arise from other diseases only! Ignorance of this fact I have often known to produce unpleasant domestic consequences, and great distress of mind.

\section{POLYPUS OF THE WOMB.}

This disease consists in the growth of a foreign body in the womb, called a polypus or tumor. It is a somewhat prevalent affection, and a very serious one too. Our notice of it, however, will be brief, on account of the obscurity that hangs over the whole subject.

Uterine polypi are found to vary in size from a small nut to a man's head, and in weight from half an ounce, or less, up to twenty or thirty pounds. Their color is sometimes whitish, at others red, and at others again it is brown, or even black. Sometimes they are quite soft, or spongy, and at others hard, like gristle. Generally they are solid, but sometimes we find them hollow.

The symptoms attending a polypus are almost all those of every other disease, so that there is scarcely a single affection of the womb but it has been mistaken for. It is particularly liable to be confounded with the different uterine displacements, as already stated, and with inflammation of the womb, dropsy, or pregnancy.

The dangers from polypi are numerous. In the non-pregnant state they give rise to profuse floodings and other discharges, which often reduce the system to a state of complete prostration, besides deranging the functions of nearly all the other organs. The probability is also that they will terminate in gangrene or cancer. In the pregnant state, in addition to all these evils, they are apt to produce abortion, or to seriously impede the progress of delivery. In short, there are few diseases of the womb more serious, and in every case where there is the slightest ground for suspicion, the most careful scrutiny should be instituted, in order to ascertain whether it exists or not.

This is also particularly desirable when it is borne in mind that the fallen, or inverted womb, is often mistaken for a tumor, to the great peril of the patient.

The causes that produce these tumors are but little known. Probably all those that lead to inflammation of the womb might be enumerated, including a peculiar lymphatic temperament, or scrofulous taint. There is good reason to believe, also, that those condemned to sedentary occupations, like our unfortunate dressmakers and others, are more liable to them. They also appear to be more prevalent at certain periods of life-between thirty and forty-five years of age for instance. In very old, or very young persons, they are seldom met with, though occasional cases have been observed at sixty years, and others at fifteen, or even younger.

It is supposed that, in every case, there is some immediate cause which first starts the unnatural growth, such as a bruise, or an injury at child-birth, either from the hand, or instrument, or from tearing away the placenta. Injuries occurring at mar. riage may also lead to the same result, and so may the wearing of a pessary, or certain excesses. The mode in which these causes act has been compared to that of the puncture of an oak tree, by the insect called the Cynips Gallce. Immediately after this little fly has punctured the bark, and deposited its egg, a swelling begins, which gradually increases, like the tumor in the womb, and eventually forms what is called a gall-nut.

The situation of the tumor may be either at the neck of the womb, so as to protrude 
into the vagina, or it may be completely inclosed in the uterine cavity, and is then very difficult to discover. Sometimes it will form in the ragina instead. The hollow polypi spoken of have been mistaken for the womb itself, and many practitioners, on cutting one out, have been needlessly alarmed from the supposition that they bad removed that organ. The most serious mistake, however, is that of taking the womb for a tumor, and operating upon it as such, which has been done more than once.

The length of time a tumor may be in growing, or before it compromises the health of the subject, is very uncertain. It may remain quite small for many years, or may never increase, and sometimes, though very rarely, it will disappear. At other times its growth will be alarmingly rapid, and a fatal result may occur immediately after its discovery. There is never security while one remains, no matter how indolent it may appear, as a slight cause may make it immediately active. I recollect a case of a lady who suffered many years, and eventually died from a disease which none of her physicians could make out. She was wasted by a continual discharge, sometimes bloody, and sometimes like pus from an abscess. Severe pains darted through the abdomen, loins, and groins. The womb was excessively tender and swollen, and the limbs so weak that she could scarcely stand. The whole system seemed to sympathize, and became completely prostrated; the slightest motion of the intestines, or bladder, caused an increase of suffering, amounting sometimes to complete agony. At last all action seemed to cease as if from a blow-she fainted while attempting to urinate, and never recovered. On examination after death, an enormous tumor, or polypus, was found inside the womb, which had begun to gangrene, and which caused such pressure on the intestines and bladder that the wonder was how they had performed their functions so long. The weight of this tumor was about nine pounds, and its size that of a large cocoanut. From her own account it had been nearly seven years in growing, and came first from the use of instruments in a difficult labor. Like most other polypi it was connected with the womb by a small pedicel, or neck, not larger than the little finger.

Females have married, conceived, and been safely delivered, with a polypus in the womb; but no one should ever expect to do so, the probability being very much against such a happy result.

Treatment of Polypus Uteri.-This is of two kinds, medical and surgical. The medical treatment consists in supporting the strength of the patient-in checking the discharge by means of rest and injections-and in trying to bring about the absorption of the tumor, which is sometimes effected by a proper attention to diet, conjoined with the administration of iodine. It is necessary to say, however, that there have been but very few cases where this plan has succeeded, and it can never be depended upon. Sometimes, but still more rarely, the tumor is expelled by the natural efforts of the womb, precisely as the child is in labor. Medical men have often been deceived in such cases, and have not found out their error till the woman, whom they thought pregnant, has brought forth a tumor, instead of a fœetus. I knew one case where a lady was relieved of one that had troubled her many years, through slipping on the stairs. She felt something escape, and on looking found the tumor, about as large as an egg, on the floor. It had been connected with the womb only by a small stem, or pedicel, not thicker than a quill, which was broken. The smallness of this neck had probably prevented its growing so fast, and allowed it to escape by readily breaking with the shock. 
Galvanism has been tried, and I can say, from experience, with success. In some cases it will cause an absorption of the tumor, and in others it will bring on uterine contractions and so lead to its expulsion. It is true we can seldom tell beforehand whether the tumor is one of that kind likely to be benefited by this agent, but still it should always be used before resorting to any operation, because it can do no harm, and has, undoubtedly, often succeeded.

The surgical treatment of polypus consists of five different operations, each of which is resorted to according to circumstances, or the predilections of the operator. First, cauterization, or burning it off, either by hot irons or by caustic substances, a plan that can seldom be adopted at all, and is not likely to be very successful when it can. It is scarcely ever resorted to now. Secondly, avulsion, or torsion, or the twisting and tearing it off by means of instruments. This plan is very generally adopted, particularly with certain kinds. The small neck which these tumors often have makes such a process comparatively easy, and the tristing of the vessels prevents any great loss of blood. The pain is seldom very great. Thirdly, the crushing process, which is also rery often used. It consists in crushing, or breaking the tumor, either with the fingers or with proper instruments. This seldom produces much pain, as the tumor is not usually endowed with much vitality. Fourthly, the ligature. This consists in tying a ligature, or cord, round the neck of the polypus, and tightening it each day, till the neck is eaten through. This has sometimes succeeded; though it has often to be abandoned on account of the inflammation it gives rise to. In many cases, also, it is not possible to affix the cord round the neck, though there are many ingenious instruments contrived for the purpose. This mode, when available, has some advantages; there is no cutting to alarm the patient and no bleeding, the tumor being gradually severed from the womb by the destruction of its connecting link. Besides the danger of inflammation, however, already referred to, it is annoy. ing to the patient to have it examined, and the cord tightened every day. Fifthly, excision, or cutting it away with the knife. This mode of operating, though ap. parently the most serious, is in reality, in most cases, the most simple and the least dangerous. The neck, it must be recollected, is generally small, so that no great hemorrhage occurs, which is the chief thing to be dreaded, and inflammation is not neaily so likely to arise as from any of the other modes. Excision is, therefore, generally practiced when circumstances will allow. I recollect one case where the tumor was so large that when the neck was cut through it could not be passed through the vagina till it was cut into four pieces.

After the operation, by either method, care must be taken to heal the wounded surface, and to keep down all inflammation.

When the tumor is located in the vagina, or on the external parts, as it sometimes is, the removal is, of course, more easily effected. Great care must be taken, however, that the supposed tumor is not the prolapsed bladder, intestine, or womb.

\section{HYDROMETRA, OR DROPSY OF THE WOMB.}

This disease is very rare, and I refer to it chiefly because it is likely to be confounded, when it does occur, with polypus or tumor.

Hydrometra consists in the accumulation of a fluid substance either in the walls of the womb or in its cavity, constituting a real dropsy. So few cases have been seen that the causes of it cannot well be traced. Most likely it is produced chiefly by deranged menstruation, or by any of the causes of ordinary inflammation. 
Instances are on record where the womb has been distended, by water within it, till as large as at the full period of pregnancy. Indeed, one surgeon records a case where eighty-five pounds of fluid was evacuated from the womb, and another informs us that he found the organ, after death, large enough to contain a child ten years of age!

The symptoms are similar to those of polypus, with the addition of fluctuation, or motion, like that of ordinary dropsy.

This is more a disease of the married than of the single state, and is not nearly so dangerous as many others we have treated upon.

The treatment varies with the urgency of the case. Sometimes a little emmena. gogue, or forcing medicine will expel the fluid, and a course of tonic medication afterward will prevent its return. It may be necessary, in some cases, to open the mouth of the womb and remove any obstructions, or puncture any membrane that may prevent the escape of the fluid. Cases have been known even where the womb was opened externally, the same as when we tap for ordinary dropsy of the abdomen. In one instance, fifty-three pounds of bloody fluid escaped, and though the patient was fifty years of age she perfectly recovered.

Care must be taken here that pregnancy be not mistaken for a uterine dropsy, an error not impossible to be fallen into.

One form of hydrometra occurs during pregnancy, and consists simply in a greater accumulation than usual of the amniotic liquor. It is seldom dangerous, but by concealing the motions of the child, it may make the pregnancy obscure.

In concluding our remarks on hydrometra, it is perhaps advisable to say a few words on another disease, supposed by some to exist, called physometra, or wind in the womb! Many curious accounts are given by old authors of this affection, but they are generally looked upon as fabulous. Thus, one tells us of a woman who had been long sick, with symptoms similar to those of hydrometra, from whose womb there escaped a kind of bag or bladder, full of wind or gas, which bounded on the floor! Many other accounts equally curious and equally incredible might be given, but it is sufficient to say that the structure and conditions of the parts make any such aeriform collections improbable. Immediately after childbirth, it is true, owing to the alternate expansion and contraction of the womb, air may be sucked up and expelled again, and gas may be generated from the decay of a portion of the placenta if it be too long retained; but these accidental accumplations are not the result of disease.

I have known some females much alarmed by the escape of air from the ragina from its being so unusual, but it is in reality a very simple affair, and of no consequence whatever. This subject, in fact, has only been alluded to from our desire to leave nothing unexplained, and to quiet unfounded apprehension.

\section{HYDATIDS OF THE WOMB.}

This is a name given to a peculiar kind of growth occasionally formed in the womb, the nature of which is not very well understood.

Some hydatids are merely cells or bladders growing together like a bunch of grapes, and filled with a white or yellowish colored fluid. Others are longer, somewhat like a bean, each one distinct by itself, and furnished with a kind of claw by which it is attached. Others, again, are egg-shaped, and occasionally they are of no asticular form. 
It is generally considered that the single hydatids, with the claw, are living singlecelled beings, and those in bunches aggregated cells. It is certain that many of them, when expelled from the womb or vagina, will move in warm water, and apparently live for some time after, but others again shrivel up immediately they are separated from the body. Their nature will be better understood by referring to the previous chapters on cell growth, and on the development of parasites.

The causes that give rise to these morbid growths are very obscure; probably we might enumerate most of those that have a tendency to irritate, excite, and disease the uterine organs.

The symptoms of bydatids also are not at all distinctive. Most usually they are taken for those of pregnancy, hydrometra, or metritis. The enlargement of the abdomen which they cause will sometimes be as great as that at the full period of gestation, or even greater; but does not take place so rapidly, and is unaccompanied by any morements like those of the child. The breasts will swell, however, and the menses usually stop, which makes the female think she is certainly pregnant, particularly when she becomes sick at the stomach, and nervous, as is usually the case.

These symptoms may continue for a long time, and $\mathrm{m}$ :y even remit with periods of perfect ease, till at last the hydatids are suddenly discharged, their expulsion being often preceded and accompanied by pains and floodings, so similar to those of child-birth, that the woman cannot be persuaded she is not really a mother, till the morbid mass is shown to her. Sometimes the whole mass will come away at once, like a large bunch of grapes, and at others, portions will come at intervals. When all the hydatids are removed she usually recovers her health, and may suffer no after inconvenience; the disease being seldom serious in its results.

Some kinds of hydatids are found to exist in the unmarried state, but most usually they are found in the married, and, in many cases are probably connected with an imperfect conception. Frequently they are found along with a blighted fœtus, and very often the duration of their development, and the period of their expulsion, occupy a definite time, like a real conception. In general, they are expelled about the seventh month ; but sometimes they remain till the twelfth or fourteeath. The expulsion is usually followed by a lochial discharge, swelling of the breasts, or even milk fever, the same as a real birth.

When the hydatids are retained too long, severe symptoms may arise, such as flooding, swelling of the limbs and face, with general emaciation, and fainting fits, that may even terminate fatally; but this is seldom the case.

No precise directions can be given as to the treatment of these cases, because we never can be sure that hydatids exist, till we see them expelled. The same general treatment recommended for metritis, may be adopted to relieve urgent symptoms, and means may be taken to bring on the expulsion if we are satisfied that the hydatids are there; but it must always be recollected that there may be a real pregnancy, so that no such means should be resorted to unless there is an absolute certainty as to their existence.

I once saw a case of a lady who had been supposed pregnant, and who was actually attended for labor, from whose womb was expelled a small pailful of hydatids, after which she perfectly recovered.

The single hydatids, with claws, may exist either in the womb, or in the vagina, even near to the external lips. Their origin is enveloped in complete mystery. 
Dr. Ryan gives us the following account of hydatid tumors in his Gynceco. Pathology:-

"Another kind of tumor which frequently attacks the womb, is the hydatid. It is generally observed, in consequence of destruction of the fœtus, in the early months, retention of some part of the placenta after delivery, or abortion. There are no diagnostic symptoms, and consequently the disease is often mistaken for pregnancy, or for various morbid affections already described. The size of the womb does not correspond with the supposed period of pregnancy, and there is no motion or quickening perceived. In some cases, the health does not suffer. I have known a case of hydatids continue for fourteen years, and during the greater part of the time, there was no derangement of health. This case was mistaken for pregnancy, by several medical men, during the period ; indeed, one of them sat up four nights, expecting delivery, the uterine pains were so severe ; and yet there was no pregnancy, and of course no delivery took place. This woman in eight years afterwards, was attacked with uterine pains, fully as severe as those of labor, and expelled a number of hydatids, with a large quantity of water; she discharged some pints, mixed with purulent matter.

When the orifice of the organ is enlarged, and the tumor extensive, the hand may be introduced to expedite the process of expulsion, and to excite the contractions of the womb; but this should only be resorted to in case of hemorrhage, or other urgent symptoms.

"There is generally pain, fever, and constitutional disturbance during, or after the expulsion of the hydatids ; in the case that I have just described the most violent symptoms of peritonitis set in, and nearly destroyed the patient. In such disease, the usual remedies are to be employed. The expulsion of hydatids has been mistaken for abortion, even by the justly celebrated Dr. Cullen. Dr. Hamilton stated in his lectures, that one of his father's patients being ill, Dr. C. was called in his absence, and declared the lady had miscarried. This opinion was the innocent cause of destroying domestic happiness in that family ever afterwards, as she and her husband had lived separately for two years. On Dr. Alexander Hamilton's return, he declared the bodies expelled were hydatids, and that there was no abortion; but the parties were never after happy. Dr. Hamilton also mentioned that a Dumfries practitioner wrote to him concerning a wonderful case, where a female who had aborted expelled seventeen ova; of course these were hydatids. Hydatids vary from the size of a pea to that of an ox's bladder; they are usually small oval bodies, composed of a membrane which surrounds a quantity of fluid, and have a strong resemblance to the ovum in the early months of gestation. Sometimes there is but one hydatid; at other times there will be several, of rarious sizes; they may be attached to each other, like bunches of grapes, or included one within the other. There is a living animal floating in the center of each hydatid. Though the abdomen may be swelled as large as in the last months of pregnancy, yet there will be no motion felt ; the breasts will be flaccid, and no child can be discovered. There may be some slight pain; but there will be indistinct fluctuation in most cases. We can distinguish this complaint from ovarian dropsy; the swelling being in the womb in the one, and in one side in the other.

"The duration of the complaint varies very considerably. I have observed the disease continue for fourteen years; I have seen it so early as the tenth year. There is often a copious discharge of water from the vagina when a hydatid bursts, and the 
tumor of the abdomen will become suddenly diminished. Dr. John Clarke knew a lady to whom this happened, while sitting in an eating-house, and she literally deluged the floor. This disease usually terminates in this way, after any sudden or violent exertion. It has been attempted to remove the fluid through the orifice of the womb, but that is a very doubtful operation; because, if there be more than one hydatid, the sac of one may be evacuated, but that of every one else left untouched. Sometimes the bag or sac comes away, and without much pain. Hildanus mentions the case of a woman who supposed herself pregnant; but, dum noctu marito ren haberet, a sudden inundation swept away all her hopes. I have seen a female, aged thirty, who, during menstruation, expelled a number of small white worms, resembling white silk, eut short, and these were from hydatids; the expulsion of them was always accompanied by a discharge of water, and not from the bladder. There is a similar case recorded by a Mr. Wellson, in one of the early numbers of the Edinburgh Medical Commentaries, vol. iii., p. 36. This disease is often combined with pregnancy, or with a mole, and rarely appears alone. Dr. Monro secundus proposed the injection of some bitter infusion into the uterus, as recommended by Cockson ; which now can be accomplished by means of the patent syringe. When expulsion is likely to be effected and uterine contraction or pain present, some think the ergot of rye might be used with great advantage, by increasing uterine contraction; and more probably expelling the whole of the hydatids from the womb. I have been told of a case where the obstetrician introduced his hand, and brought away a basinful of these substances. Very early in my practice, I was requested to tap a girl ten years old, who had ascites, evident fluctuation, tense abdomen, on the parietes of which numerous veins were evident. To my great astonishment, no more than six ounces of fluid escaped, though the canula was clear, and the fluctuation most evident; this was decidedly a case of ovarian or saculated dropsy, or perhaps hydatids. When we bear in mind that hydatids are vesicles, formed of a thin membranous coat, filled with serum ; sometimes cemented together in the form of a great bunch, and hanging by one or more pedicels; sometimes distributed into separate divisions, fixed by different pedicels, which may be filled with limpid, turbid, or purulent fluid, we can readily conceive how the perforation of one of these, which may vary from the size of a millet seed to that of an inflated ox's bladder, may be followed by a considerable discharge, and yet that the abdominal tumor will not be much diminished, and fluctuation will remain very evident. This disease was described by Atius."

Restoring the healthy state of the womb, and cleansing the passages regularly with injections, usually prevents any further increase of these morbid growths.

\section{CALCULUS, OR STONE IN THE WOMB AND VAGINA.}

Very few people have ever heard of such a disease as this, and I have no doubt but the mention of it will excite considerable surprise. In looking through medical books and periodicals, however, many cases of it may be found narrated, and I have certainly seen two myself.

The body called the stone is sometimes hard and brittle, exactly like a stone from the bladder, with which it might readily be confounded; at other times it is softer, like bone or chalk. The origin of these bodies in so strange a situation is a matter of dispute; some of those in the vagina may be formed from the urine passing in, but those in the womb are most probably derived from a crystallizing of the saline 
matters which naturally exist in the secretions of the parts, or from their incrustation round a tumor or hydatid. In cases of extra uterine pregnancy also, small pieces of bone may pass down the Fallopian tube, and form a nucleus. So may forgotten pessaries or other foreign bodies which are often introduced into the vagina, for various purposes.

These calculi may exist during the whole of a person's life without causing any great inconvenience. They have frequently been found in the womb, or imbedded in its walls, in making dissections. In some cases, however, they produce the most violent inflammation, and all the symptoms that usually accompany polypus, or even abscess, or mortification.

If we are satisfied that one exists, by feeling it with a sound, it must be grasped with a pair of proper forceps, and so removed. It may even be necessary, if it be large, either to cut the os tincæ, to allow of its passage, or to break the stone itself into small pieces. The occasional necessity for these operations will be evident, when we reflect that nterine calculi have been found from the size of a pea to that of a child's head, and weighing from a few grains up to four or five pounds. One surgeon gives us an instance where he removed forty-two small stones from the womb.

The natural power of the uterus itself will frequently expel these unnatural substances, and, when we are satisfied they exist, we may, if they are not too large, advantageously assist its contractile tendency.

In one of the cases which I saw, the stone was expelled along with the menses, and cansed a sensation like the passage of a large clot. It was about as large as a pea, and brittle as glass. The symptoms arising from it had been very slight, but sufficient to indicate that some foreign body was in the womb, which was supposed to be a small tumor.

\section{INFLAMMATION OF THE OVARIES AND FALLOPIAN TUBES.}

All the appendages of the uterus are liable to inflammation, the same as that organ itself, and in many cases it is extremely difficult to tell in what part the diseased action really exists, till the discharge of the morbific matter occurs.

The causes that lead to inflammation of the ovaries and tubes are, probably, the same as those that produce metritis. It appears, however, from observation, that deranged menstruation, or excessive excitement, is more apt to inflame the ovary than the womb. And so are long-continued attacks of hysteria, and the use of forcing medicines, or those intended to produce certain feelings. The important part which the ovaries fulfill, in the secretion of the menses, and in the process of conception, keeps them constantly active, and therefore peculiarly liable to these causes of disturbance. Inflammation of the ovaries, called ovaritis, is also more likely to attack those persons of certain temperaments, unless they exercise great control.

The symptoms of ovaritis are, burning pain in the groin, which darts all over the abdomen, down the thighs, and into the loins; a difficulty in passing the urine, or moving the bowels, sickness, fever, thirst, general depression and restlessness, with lassitude and weakness of the limbs. A small round swelling appears in the groin, or in each groin if both ovaries are inflamed, and gradually extends over the whole abdomen, which becomes hot and tender to the touch, and eventually so sensitive that the slightest pressure upon it will cause sympathetic spasms, and convulsions, of the lower limbs. These symptoms of course vary according to the intensity of 
the attack, and the extent of the inflammation, which may either be confined to tho ovary, or tube, or extend to the uterus, or other parts.

Inflammation of the Fallopian tubes is characterized by almost precisely similar symptoms, so that we cannot distinguish it from ovaritis; this, however, is of little consequence, as nearly the same treatment is indicated for both.

An ovaritis may subside, like any other inflammation, and either disappear alto. gether, in about eight or ten days, or pass into the chronic form. When it continues the result is similar to that of metritis ; suppuration ensues, and an abscess forms, usually about the twelfth or fourteenth day. This is indicated by chills and fevers, lnnguid circulation, and acute throbbing pain in the tumor. The pus eventually makes an opening and is discharged, either through the walls of the abdomen, or into the rectum, bladder, or peritoneal cavity, or down the tubes into the womb and vagina. After this discharge the patient may recover. Very frequently, however, the termination is lamentably different; symptoms set in precisely like those of puerperal fever; the whole of the organs in the pelvis and abdomen become intensely inflamed, their functions cease, fever and delirium supervene, and a fatal issue soon occurs.

When it passes into the chronic form the symptoms gradually subside, though they remain always subject to sudden increase, from slight causes, and the swelling may eventually disappear. More frequently, however, it becomes permanently hardened, or gangrened, or cancerous. It is seldom that any of these diseased states are cured. They may remain, however, for years before they wear the sufferer out, though sometimes they cause death very suddenly.

The treatment of ovaritis, in the acute stage, is similar to that of metritis. A cooling, unstimulating diet-diluent and acidulated drinks-poultices and leeches to the swelling - warm baths, and injections of poppy-heads, or starch and landanumpurgatives-and absolute rest. Plentiful bleeding is almost invariably resorted to, and, if the inflammation cannot be made to subside by other means, it may be advisable, but should be avoided if possible.

If in spite of all these means an abscess forms, it must be opened, when ripe, at the safest and most convenient point, and when all is discharged the wound must be en?ouraged to heal. If gangrene, or cancer, arises, the treatment will of course be the same as for those diseases when in other parts.

When ovaritis becomes chronic, we must endeavor to draw off the inflammation, by making increased action elsewhere; this is called the revulsive treatment. For this purpose we may employ blisters, or setons, or stimulating frictions, to the groins, loins, and inside of the thighs. The ointment of hydriodate of potash is excellent to rub over the ovary. Injections of laudanum and starch will also assist, and occar sional enemas, of starch alone. The bowels must be kept free, and the diet rigidly attended to. Perfect rest must be observed in everything. In conjunction with these means, we may advantageously employ alterative medicines, mineral waters, particularly those containing iodine, and sea bathing. Warm clothing must bs worn, and care taken against catching cold. The result of this treatment, if it be rigidly persisted in, is a perfect cure, in many cases, but the duration of the disease is always uncertain.

The operation of cutting out the diseased ovary has frequently been performed, but is now pretty generally condemned by the most eminent surgeons. It is found by statistics that nearly one half of those operated upon die of the operation; and os 
those who recover, it is questionable whether life is prolonged much, if any, beyond what it would have been without it! The operation is, in short, a fearful one, uncertain as to the sligntest good, and frequently attended by accidents of the most unlooked-for and serious character. The patient's chance is, in my opinion, in most cases, better without it than with it.

It is perhaps advisable to remark, in conclusion, that in some forms of ovarian inflammation, the patient is subject to an intense degree of excitement, which sets all self-control at defiance, and leads to moral consequences that would never have been dreamt of in a state of health. As I have already remarked, moral evils more frequently arise from physical diseases than many persons suspect.

\section{DROPSY OF THE OVARIES AND FALLOPIAN TUBES.}

This disease exhibits itself in the form of an accumulation of fluid in one, or both of the ovaries, or tubes. It is sometimes contained in one vesicle, or bag, and sometimes in several, either associated together, or each one distilict by itself. This fluid, or water as it is termed, is sometimes clear and colorless, and at other times thick and slimy, and occasionally it is reddish, or like coffee grounds. The quantity may vary from half a pint, or less, to five or six gallons, or more. It may be secreted in large quantities in a very short time, or years may elapse before sufficient is accumulated to occasion inconvenience. The dropsy may also be attended by considerable constitutional derangement, or the patient may not be at all incommoded, except by the size of the tumor. I knew one case where the patient had been so swelled, for nearly twelve years, that she could scarcely force herself through an ordinary doorway, and yet enjoyed tolerable health all the time. The causes of this disease are not very well understood, though it is generally supposed to result from previous inflammation. There is little doubt, however, but that it may arise independently from the same causes that produce ovaritis, and from various injuries.

The earliest symptoms of ovarian dropsy are also very obscure. In general there is neither pain nor inconvenience, of any note, and what is experienced is very apt to be taken for the results of pregnancy, particularly as there is usually a similar swelling of the abdomen and breasts, suppression of the menses, sickness, and capricious appetite. Both patient and physician are often deceived by these signs. The gradual increase of the tumor in the groin, however, after the usual period of gestation is passed, and the occurrence of a deep-seated permanent pain in the same part, soon create suspicion of the truth. This tumor is in most cases movable, but not always, and may be years before its size is noticeable. Sometimes it feels in lumps, and is painful, at others it is perfectly smooth, and may be pressed without producing any suffering. Generally it projects more on the one side than the other, and falls over when the female lies on the opposite side, but when both ovaries are affected, both sides appear the same. It never however projects at front like a preg.: nancy, or like the engorged womb. As already remarked an ovarian dropsy may not seriously compromise the health, at least not for a long time, but, as a general rule, there is more or less trouble occasioned by it. The enlarged tumor, for instance, sometimes presses on the intestines, bladder, and stomach, and impedes their functions, producing costiveness, difficulty in urinating, and sickness. It is also liahle to displace the womb, and produce anteversion, or retroversion, or prolapsus. The patient also feels a severe pulling and dragging, when she stands or when she lies on 
her side, and sometimes suffers from difficulty of breathing, owing to pressure on the diaphragm. Various other symptoms, too numerous to mention, are met with in different cases.

Some authors consider this disease as always the result of a cancerous condition of the orary, and if it be so, it is probably the most farorable form in which the cancer could exhibit itself. Both the mode, and the time of its termination, are so uncertain that little can be said about them. Patients have lived to be sixty or serenty years of age, who have had dropsy of the ovary most of their lives. Sometimes the cyst, or bag, will burst, and the fluid will then either be absorbed, or escape through some of the passages, or perhaps produce peritoneal inflammation. The pressure on the different organs may also lead to other kinds of inflammation, and a fatal result may thus be brought about. General dropsy is also likely to be produced, and various forms of cancer or gangrene. In short, though some escape death, and even severe suffering, for many years, the disease has nearly always a fatal termination, sooner or later. Those who are cured, either spontaneously or by medical treatment, are extremely fortunate, and considering how prevalent the disease is, their number is fearfully small.

Medical men are but little agreed as to the best treatment in orarian dropsy ; each one usually adopting a plan of his own, and for the most part merely as an experiment. Almost erery drug in the pharmacopøia has been used-all kinds of baths, blisters, pressure, firing, puncture,-and a host of other means, all of which have been adopted, praised, condemned, and abandoned, in their turn. It is probable that each of these plans may be useful under certain circumstances, and that no general treatment can be adrised that will suit all cases, excepting such as improves the health, and removes any irritating causes that may exist.

As a last resort, when medical treatment fails, either of two operations may be performed ; that of tapping, or cutting out the ovary, and, unfortunately, the success hitherto attending both of them has been so small that neither seems to be justified by the result.

The operation of tapping is, in fact, scarcely considered as a means of cure, but merely as a means of relieving the patient for a time, when the accumulation of fluid has become very great. In many cases the tapping is followed by immediate death, and in many others it undoubtedly shortens life, though it may occasionally prolong it. In the "Philosophical Transactions" is an account of a case of dropsy where the woman was tapped one hundred and fifty-five times, and as much as five thousand seven hundred and twenty pints of fluid drawn off ! It is supposed that life was thus prolonged several years. Many other such cases are on record.

Sometimes, after the fluid is evacuated, an astringent injection is thrown in, to stop any further secretion, and in some cases, it is stated, successfully, though in others with the most alarming results. There are many circumstances, in short, that make the operation altogether inadmissible, and some of them cannot be fore seen.

The removal of the ovary is, probably, a still more objectionable experiment. The results of it for simple induration have been alluded to elsewhere, and it is sufficient to say that it is no more successful for this disease than the other. A few are cured by it, and many die from it. On the whole, the opinion of that celebrated surgeon, John Hunter, is probably near the truth, that patients would probas bly live longer if they were not meddled with. 
Dropsy of the Fallopian tubes apparently results from the same causes as dropsy of the ovary, and can seldom be distinguished from it. The same remarks, however, as to treatment, apply to both.

Besides these accumulations of fluid, however, the ovaries frequently contain hydatids, and various other substances.

Most of these ovarian diseases are found to prevail at that period of life when the uterine system is most active, namely, from twenty-five to forty-five. They are seldom or never seen after the change of life, nor before puberty, and are chiefly con. fined to those who have borne children.

The female organs are, of course, liable to many other diseases, which have not here ieen alluded to, because they belong equally to other parts of the system, and it is our intention now to confine ourselves to those peculiar to the sexual organs oniy. 


\section{CHAPTER LV.}

\section{DERANGEMENT OF THE FUNCTIONS OF THE FEMALE ORGANS, AND OF THE}

NERVES.

Is addition to malformation, imperfect development, displacement, and organio disease, the female organs are also liable to become deranged in their functions, either as a result of some other diseases, or from independent causes. These functional diseases require special and distinct notice, and will solely engage our attention in the present chapter. The most important of them are connected with the process of menstruation, the nature and objects of which have already been explained.

\section{AMENORRHGE, OR NON-APPEARANCE, OR STOPPAGE, OF THE MENSES.}

The menstrual discharge may either stop after it has once commenced, or it may fail to appear at all, and the causes that lead to this suppression, or non-appearance, may be either constitutional, or accidental.

Among the constitutional causes may be mentioned certain peculiarities of temperament, such as that denominated the sanguine, which disposes to congestion of the different organs, thereby diverting the blood from the uterus. This is generally denoted by a full habit, florid complexion, and great activity. The lymphatic temperament, in which there may be great fullness of form, but accompanied by debility, disinclination to motion, and slow pulse. A scrofulous taint appears also to operate in the same way, and hence we often see scrofulous girls, and those with either of the above temperaments, much later than others in commencing to menstruate. Among the accidental causes may be mentioned all those which deteriorate the general health, such as living in a damp situation, not being sufficiently exposed to the sun and air, improper or insufficient food, want of exercise, or excessive labor, and depression or over excitement of the mind and feelings. The occurrence of leucorrhœa, before puberty, is very apt to prevent the menses from commencing, and this is oftener the case than is suspected. Sudden cold should also be particularly mentioned, and the action of strong medicines. Even scents, and powerful odors in general are supposed by many to have an injurious influence. The celebrated Haller especially alludes to the smell of pennyroyal as having the effect of preventing the menstrual flow. Many other diseases undoubtedly cause amenorrhoea, by the increased action they produce elsewhere, and so, I am convinced, will excessive study, by the excitement it keeps up in the brain.

All these various causes may of course suppress the flow, when already established, as well as prevent its appearance.

Many times I have known the receipt of some bad news, a sudden fright, or 
severe disappointment, cause instant suppression, and such vivid emotions as anger, jealousy, or excessive joy will also undoubtedly do the same. Even frightful dreams have had this effect, or the sudden start from hearing a clap of thunder, or the firing: of a cannon.

In addition to all these there must further be mentioned many of the different diseases, displacements, and improper developments of the uterine organs, already described-some of them having a morbid effect, and others merely opposing mechanical obstructions.

The symptoms and effects of suppression, or non-appearance, are numerous and often serious, and may be either local or general. Among the local symptoms are pains and dragging feelings in the loins and groins, with a sensation of weight in the pelvis, and great weakness in the limbs. Sometimes there is also inflammation of the external parts and a peculiar excitement, which becomes, in some cases, excessively annoying, or leads to vicious habits.

The general symptoms are much modified by individual peculiarities, though there are some of them pretty constant in most cases. Thus, we nearly always observe a feebleness and languor of the system, and the loss of that freshness which characterizes healthy youth. The eyes become dull and surrounded by a dark circle, the heart palpitates, the breathing is difficult, the head is dizzy, or constantly aching, pains like those of rheumatism dart about the limbs, and severe cramps often necur in various parts of the body. The mind and feelings also suffer, so that the jatient is dull, impatient, irritable, and melancholy, and so acutely sensitive that the slightest disappointment or contradiction will make her weep. Some, of peculiar temperaments, on the contrary, are singularly excited. They will be continually moving about, though they have no particular reason for doing so, and impatiently seek every kind of amusement and gay society. I have known some of these patients even become ungovernably impetuous and so disposed to activity that the ordinary quiet female occupations were irksome to them.

These symptoms may continue for a considerable time, or they may be speedily followed by more severe ones, particularly by inflammation. Most usually, however, they are succeeded by leucorrhœa, dropsy, diarrhœa, nervousness, convulsions, epilepsy, St. Vitus dance (chorea), or delirium. The flesh wastes away, or hangs flaceid on the bones, the skin is cold and sallow in its color, and the whole system seems to rapidly decay. Eventually, the abdomen enlarges, the breasts swell, the stomach sickens, the appetite disappears, or becomes capricious, and a sensation of discomfort and misery creeps over the sufferer, till she almost loathes existence.

When the suppression occurs suddenly, the female often feels many of these symptoms at once, and very acutely. Thus, some will suffer instantly from a dragging, bearing-down sensation, or from pain in the back, while others will be seized with headache and giddiness, or even faint away ; others will be attacked with leucorrhoea, diarrhoea, or inability to pass the urine, and others, again, will be taken with a chill and fever.

One of the most singular consequences of suppressed menstruation, however, is the appearance of another discharge in some other part of the body, which apparently acts, to a certain extent, as a substitute. The lencorrhœa, and diarrhœa, already referred to, act in this way to a ccrtain extent; but what we have more especial reference to at present are, hemorrhages, or discharges of blood, from various parts of the body. These have been known to occur from the nose, the ears, the bowels, 
the nipple, the bladder, the armpits, under the nails, from ulcers or other sores, and from the gums or teeth. Sometimes these discharges will occur with the same regularity as the real one ought to do, and really'answer for it; but at other times they are irregular, or almost constant.

Lastly, we may mention, as some of the ultimate consequences of suppression, hydrometra, engorgement, gangrene and cancer of the womb, with various chronic affections in other parts, and insanity.

In commencing to treat amenorrhœa, the greatest care and circumspection is required. It may be merely a consequence of some other disease, the removal of which is all that is required to effect a cure. Thus it is produced by disease in the stomach, the heart, and the spine, and by consumption. It may also be occasioned merely by a closing of the natural passages, as in imperforate hymen, or closed vagina, and then of course these only require opening; and lastly it may be the result of pregnancy, which the patient is either unaware of, or wishes to conceal. The practitioner must, therefore, use the greatest precaution, so that he do no injury, either from his own inadvertence, or from the criminal deception of his patient.

It must also be borne in mind that some females are much later than others, and that some, again, stop much sooner, from natural causes. There must, therefore, be no hurry in prescribing, unless derangement in the general health indicates its immediate necessity. Again, in many cases, a considerable time elapses after the first one or two periods before another occurs, and withont any ill effects. I have known the interval between the first and second period be extended to more than twelve months. This is apt to be the case when puberty commences unusually early.

When we are satisfied that the amenorrhœa is really due to some morbid condition, and not to any of the above causes, a careful study must be made of the patient's constitution, habits, and mode of life, before judicious treatment can be recommended. Very frequently nothing more is required than a proper attention to the general health, particularly in those of a weakly constitution, or lymphatic temperament, and in those who have been prostrated by a former sickness. In such cases, the happiest results often follow a change of air and the adoption of a nourishing diet, with a little good wine; the use of mineral waters, particularly those containing iron; cold baths, with good dry rubbing after; plenty of exercise, especially walking or riding on horseback, and dancing. There is no doubt but this difficulty often arises from the early abandonment of youthful recreations. The absurd notions of society condemn, in young girls, those exhilarating sports and pastimes so conducive to happiness of mind and health of body, and the necessity for which in boys is universally acknowledged. The perfect development of the system is sacrificed to false ideas of propriety, or rather, disease is chosen with fashionable observance rather than health without it. There is no doubt whatever but that the too early abandonment of the hoop and the skipping-rope creates an early necessity for the doctor!

The state of the mind and feelings must also be carefully attended to, as their derangements have frequently much to do with this disorder. The patient's friends must carefully remove all causes of excitement or unhappiness, and endeavor to promote a state of cheerfulness and contentment. The morbid melancholy and sentimental dreaminess brought on by reading trashy romances is very hurtful, and should be broken up by exciting mental and bodily activity. I have known many young females attacked with suppression from attending protracted religious meetings, lovefeasts, and camp-meetings. 
When such means fail, medicines may be resorted to, and it is but justice to say that they are often successful in this disease, though they so lamentabiy fail in many others. The best article, and the one most generally used, is iron, which is prepared and used in numerous different ways. The particular preparation of this metal most suitable for any given case must of course depend on a variety of circumstances, and had better be indicated by the medical adviser. As general formulæ however, beneficial in most cases, and not likely to injure, the following recipes will be found excellent:- Sulphate of iron, two drachms; extract of absynthium, four drachms ; syrup of saffron, enough to make it into a paste. This must be divided into one hundred and fifty pills, one to be taken three times a day. Or, sulphate of iron, one drachm; extract of gentian, enough to mix it up. Divide into thirty pills, and take one three times a day. Or, in case there be any indications of scrofula, $M$. Lugol recommends protiodide of iron, six grains ; starch, twenty-four grains, and sufficient syrup of gum, to make it up. This is to be divided into twenty-four pills, one of which may be taken morning and night. The compound iron mixture may also be tried, or the aromatic mixture, in the usual doses, as advised for leucorrhœea.

Warm injections may also be used, if the age and condition of the patient will allow, and warm baths or fomentations at bed-time, with hot bitter teas.

Stronger remedies are of course known, but they are not mentioned here, because they should not be employed except under proper advice, and they might be used under mistaken notions, or from criminal intentions, for other purposes. The above recipes are as simple and harmless, in all states of the system, as any that can be used.

In those cases where the disorder arises from an opposite state of the system, that is, from too great a fullness, and determination of blood to other parts, the treatment must be different. In these cases we must commence by prescribing a rather spare and mild diet, chiefly vegetables, with cold drinks. Cold bathing should also be practiced, and violent exertions, either mental or bodily, carefully avoided. In case such means, when fairly tried, do not accomplish what we wish, warm foot and hip baths may be used, and warm injections and enemas, with stimulating and aromatic fomentations to the external lips, or vulva. The medicines already referred to may also be used, but sparingly, and with caution, and also warm purgatives, as the compound aloetic pill. These means should be tried for about a week before the turn is expected, or ought to occur, and continued for several months if necessary. It frequently happens that no effect is perceived for a long time, but if the symptoms do not become alarming, it is better to persevere with these modes of treatment than to adopt a more powerful one. Some authors speak very highly of the good effects of leeches, applied to the external lips, a few days before the period is expected. And others recommend them to be applied to the breasts! The reason for this apparently strange recommendation being the intimate sympathy between the breasts and uterus, owing to which any increased action in the one, is usually corresponded to by the other. I have frequently applied a mustard poultice to the breasts with the happiest results.

Sometimes the non-appearance of the menses is owing merely to a torpor, or want of action in the uterine organs, which is generally denoted by the manners of the young person, and by the want of development in other parts of the system. She is cold and indifferent, takes no pleasure in the company of the other sex, and exhibits no sympathy or desire for companionship with those who do. The pelvis 
is usually small, and the breasts but little developed. In these cases, it must be recollected that there may be no great necessity for menstruation, and, at all events we should not be in a hurry, nor use powerful remedies to bring it on, unless we have good reason for doing so. If the health suffers from its absence, however, we must interfere, and may then advantageously advise the remedies last mentioned, with warm frictions over the abdomen, and the use of flannel around the pelvis. The patient should also be taken into company, to the theater, and to balls, and may be allowed a rather generous diet, with a little wine. Sometimes a cup is placed on the os tincæ, or if the state of the parts will not allow of it there, on the external lips. Sitting over the steam of hot water is also excellent, and dashing hot water on the pelvis.

In those cases of suppression brought on by powerful mental or moral emotions, or by sudden excitement, we must first endeavor to calm the system as speedily as possible, by enjoining rest, quiet, warm baths, cheerful company, and a little sedative medicine, as a few drops of laudanum, for instance. Then, after a time, the more active means may be resorted to, but very carefully. If the suppression arise from intense excitement in the uterus itself, which is sometimes the case, cold baths, and injections with laudanum, and saline purgatives, will usually subdue it, and effect a cure. Various other medicines have been used in this disease, but I am not aware that any of them have been found more efficacious than iron, which itself is only an occasional assistant. In fact, the uncertainty and frequent inefficacy of medical treatment is generally acknowledged, and has led to the use of many other means, but few of which have, however, been more successful. Among the most efficacious of these may be mentioned the congester, or pneumatic apparatus, inrented by Dr. Sunot. This consists of a kind of large air-tight ease, which may be fitted to any part of the body, or even inclose half of it, and from which the air may be drawn by an air-pump. On fixing this to any part, and exhausting the air, it acts like an immense cup, drawing the blood to that part with great force. It may even be made to act so powerfully as to canse the blood to exude itself through the pores of the skin. The lower part of the body may be thus acted upon to determine the circulation toward the pelvis. I have had one of these instruments in use for soine time, and can safely say that it is one of the most powerful and certain means of bringing on the menstrual flow that we possess. In fact it can scarcely fail! I have known it bring on profuse flooding in five minutes after its application, though the patient had never been unwell for over two years before! Great care must of course be taken in its use, so that it be not employed too powerfully, nor too much. It is often applied to the lower part of the body to relieve headache, which it does by drawing away the blood. Cases have been known, when using it for this purpose, in which it has produced a flow from the womb in females long past the turn of life!

Galvanism, however, if resorted to in time, and in a proper manner, will almost supersede everything else, in this disease. I have employed it in many hundred cases of amenorrhoa, and with such uniform success that I look upon it as nearly certain! In many instances, even after long suppression, the very first application has brought on the flow, and in one instance it did so at the third trial, though the patient had reached her twenty-fourth year without having menstruated. In every case, if the simplest means do not succeed, I should advise galranism before any powerful medication whatever. The manner of its application varies in different 
cases; sometimes it is sufficient externally, one pole being placed on the lower part of the spine, and the other on the abdomen, just over the pubis ; but at other times it is necessary to apply it more or less internally, in various ways not necessary to be here described. Neither pain nor serious inconvenience attends its use, nor can any injurious consequences follow, even if it do no good.

On the use of galvanism in amenorrhoea, the editor of Copeland's Dictionary remarks, in a note : "Galvano-electricity, or electro-magnetism, deserves more particular mention as an emmenagogue remedy. We have succeeded in some chronic cases of amenorrhœa, that had resisted all other means, by daily sending a current of electricity through the uterus, or by inserting one conductor in a tub of warm water, in which the feet were immersed, and applying the other over the cervical vertebræ, thus transmitting the fluid through the spinal axis. Dr. Ashwell states that Dr. Golding Bird has recently employed the same remedy with extraordinary success in the treatment of out patients at Guy's Hospital (London). In some of the cases, where, after the condition of the alimentary canal had become healthy, the amenorrhœa continued, with slight pallor and weakness, electric shocks passed through the loins quickly induced menstruation. In others, its continued repetition, three or four times a week, led to a similar result; and instances were not wanting where a shock suddenly produced a flow. It is, however, a powerful remedy, and should be employed cautiously, lest it may depress the nervous system, and thus protract the disease. When moderately applied, it often rouses into activity the energy of torpid organs and parts; but when used in excess, it may altogether destroy their excitability. It should not be employed in cases of local congestion or general plethora, nor during pregnancy, and it should seldom be used alone."

There is one mode of applying both galvanism and the congester, and also some other means, which will be understood by referring to the explanation of the cause of menstruation. It was there stated that this phenomenon was produced by the periodical ripening of the ovæ, and that it consequently depended on the occurrence of that event. The healthy and regular action of the ovaries is therefore an essential point, and is always wanting, more or less, in this disease. Our applications, therefore, are frequently required to them, and to them only! I have often brought on the menses by simple friction in the groins, over the ovaries, and by stimulating liniments, when all the ordinary means failed. In like manner, we may apply to the same parts blisters, cups, and leeches, or even galvanism, which, in fact, I generally administer in this way first. The patient will often feel a stimulus all through the uterine system, immediately the ovaries are thus excited, and the reason why is obvious, when their functions and sympathies are borne in mind. I knew a lady subject to suppression, who always succeeded in bringing back her courses by a simple treatment, founded on some information I gave her on this subject. She used to apply a mustard poultice over each ovary, after taking a warm hip bath, and then, on retiring to rest, drink freely of some hot bitter tea. No medicine was required.

In some cases, the menses will reappear after marriage, but not always ; and sometimes they will stop from that cause. This is a matter both very difficult and very delicate to advise upon, but it is one that should be seriously considered, nevertheless, for the wrong proceeding in regard to it has condemned many a young person to years of disease and suffering. A physician of experience, by duly weighing all the circumstances of the case, will seldom be at a loss what course to advise, and frequently this is all he need attend to! Some females are attacked with this disease on 
becoming widows, and others, on the contrary, are cured of it. A subsequent marriage will also have totally opposite effects on persons of different temperaments and constitutions.

The state of the mind and feelings, as already shown, is of paramount importance, and must be particularly attended to. A disappointment in love will often cause derangements of this kind, while its happy progress, and true return, will as frequently cure them, when all other means fail.

Those cases which arise from the natural passages being closed, have already been spoken of, in a previous chapter, and their treatment described. I merely refer to them again, for the purpose of pointing out how necessary it is to know if any such difficulties exist, before resorting to medical treatment, or recommending marriage. I read a case in a medical work lately, of a lady who consulted an eminent physician to know why she was barren. She had never menstruated, but had been married some time. Most likely she had been treated for the suppression, medically, and her friends thought, as it did not succeed, that marriage would effect a cure. On making the requisite examination, it was discovered that there was actually no womb, though all the other parts were perfect! The grief and disappointment to all parties may be imagined, and one is forcibly impressed, by so lamentable an occurrence, with the impropriety, if not criminality, of allowing marriage to take place under such circumstances, before a proper investigation had been made. Another case in point also is that of mine, referred to when treating of narrowness of the vagina. And I have had another, since commencing this work, of a very curious kind. The lady had never menstruated, though she was very sick, and had enlargement of the abdomen, every month. All kinds of medicines had been given to her, but they only increased the distress. She was then advised to marry, and assured that she would be better. She did so, but was no better. Her friends then brought her to me to have the galvanism, or congester applied. I told them, however, that I could not use either, till I knew that no physical impediments existed, which I strongly suspected there did. Investigation proved this to be the case; about three-fourths of the distance up the vagina there was a membrane, similar to the hymen, completely closing the passage, like the parchment on the top of a drum. This obstruction preiented the escape of the menses, and had also made other difficulties, which could not be overcome, and which occasioned the more distress because they were not understood. I chose a time, midway between the two monthly periods, and, after carefully reducing all inflammation in the parts, punctured the membrane with a small lancet, introduced through a speculum. About a quarter of a pint of blackish fluid, like thick coffee-grounds escaped, and in rushing out, widened the puncture considerably. A few days after I widened it still more with a bougie, and continued to do so, till it was as wide as the rest of the passage. She remained alone till the next period, when the menses appeared quite regular, and without distress. The other difficulties were also removed, and she is now a happy mother.

I could mention numerous instances of a like kind, occurring in my own practice, both in married and single, of which I have notes, with full particulars.

\section{DYSMENORRHCE, OR PAINFUL MENSTRUATION.}

There are many cases met with in which the menses occur with regularity, and in sufficient quantity, but accompanied by severe suffering-most usually in the 
form of pains in the back, groins, abdomen, and thighs, with a kind of grinding contraction of the womb, burning heat in the parts, and pruritus. Sickness at the stomach, vomiting, shuddering fits, cramps in the limbs, and severe headache are also frequently experienced, and various hysterical symptoms, such as choking in the throat, yawning, restlessness, irritability of temper, and sudden prostration of the strength.

These sufferings may either commence with the discharge, or begin several days before, and may continue some time after it has ceased. Very frequently in these cases the discharge is small in quantity, and escapes by drops, as if with difficulty, and at other times it is chiefly composed of clots, or membranes, or fleshy threads. Sometimes, however, it flows perfectly free, and is quite natural in appearance.

Both married and single are liable to dysmenorrhœea, though it is more frequent in the single. It frequently disappears after marriage, but not always, though it nsually does after childbirth. Pregnancy, however, is not so likely to occur with this disease; the same conditions that cause the pains being also likely to prevent conception.

The causes of dysmenorrhœa are not well ascertained. It is found, however, most frequently in those of a nervous or bilious temperament, and in those who are easily susceptible of great excitement. It is probably very often connected with some in. perfect development of the parts, and with various diseases of them, such as chronic inflammation of the womb, ovaries or tubes. It may also result from obstinate constipation, dyspepsia, mental disturbances, and particularly from certain excesses. It most usually begins immediately after, or with the first menstrual flow, and when established is pretty constant in its appearance, though sometimes it will remit for a few periods.

The treatment of this troublesome disease is by no means agreed upon, for very seldom are two different cases benefited by the same. The first step is of course to ascertain if it result from some other derangement, which it so frequently does, and then remove that. Irritability, or chronic inflammation of the womb, being a very frequent cause, great relief is often obtained by warm hip baths and enemas, with warm injections of poppy-heads, and starch and laudanum. Hot diluent drinks should also be freely used, and warm purgatives, like the compound aloetic pill-in short, the same treatment that was recommended for metritis. Taking an emetic of antimonial wine, just when it is commencing, will relieve some, and a dose of aloetic pills for two days before will prevent it in others. The acetate of ammonia, commonly called mindererus' spirit, will very often give immediate ease; twenty drops of this may be given in a glass of water, and if no relief is obtained, twenty more may be given in half an hour. It should not be given beyond the third dose, however, because it has a tendency to check the flow, and for that reason, in fact, it is better not to be given at all, if other means will succeed. Varions medical preparations are in use for the same purpose, none of which are serviceable in all cases. The following recipe is, perhaps, as generally useful as any:-Camphor, one scruple, with just sufficient spirits of wine to dissolve it; gum arabic, one drachm ; cinnamon water, one ounce. Sweeten it to taste, and drink half of it when the pain commences, and the remainder in two hours after, if necessary. Or the patient may procure a quarter of an ounce of gum camphor, and make it into pills of the usual size, two of which may be taken when the pain begins, and two each hour after if necessary, till six are taken. This is as often useful as any elaborate prescription. 
Laudanum is very generally taken internally, but should always be avoided, if possible, on account of the uncomfortable feeling it produces afterward. The best way is to use it as an injection, or enema, which does all the good without any subsequent evil. Hot poultices, or fomentations, are often serviceable over the womb, or a small blister on the loins. Very often, however, all medical treatment is useless, and some other plan must be resorted to.

Dr. Mackintosh supposed the difficulty was owing to a stricture of the passage in the neck of the womb, and he therefore proposed to introduce a bougie to dilate it. This has been frequently done, and with occasional success. The operation itself is comparatively easy; a small bougie being introduced first, and larger ones in succession, as far as required. In most young persons, however, this cannot be done, and in all cases it is objectionable. Fortunately other means are known, much more certain, and less repugnant to the feelings.

Galvanism is here again our surest dependence. Its effects are, in fact, sometimes as astonishing as they are gratifying. The application is seldom needed in any other way than externally, as in suppression, and it usually relieves in a few minutes, if not instantly! Dr. Mackintosh was quite right when he supposed the difficulty often owing to a stricture, but most generally it is merely a temporary spasmodic one, which is apt to return directly the bougie is withdrawn, but which the galvanism effectually relieves.

It is necessary to state, however, that the length of time necessary to administer the galvanism is uncertain, and that it may exert little or no influence in preventing the difficulty at the next period. My usual plan is to apply it till the pain is fully abated, then in about five minutes withdraw it and await the result, but keep the instrument ready. In many cases there is no return, but in others it has to be continued, more or less, for some hours, or even during the whole period. I then recommence its use about two or three days before the next turn, and continue it up to the time. In this way a cure is effected as often, if not oftener, than by medicines, particularly if proper attention be paid to the general health, and to the removal of other diseases. I have also occasionally advised the use of a small galvanic bougie, which the patient can apply herself, and with the happiest results.

One of the most obstinate cases of this disease I ever saw, came under my notice in Philadelphia. The patient, a highly respectable married lady, had suffered from it for many years. Her general health was very good, constitution sound, and her periods perfectly regular, though the quantity was frequently small. She had never been a mother. Every means that could be suggested had been tried in her case, without the slightest good, and the most eminent physicians had abandoned it as hopeless. The only relief attained was by laudanum, which was taken till it literally stupefied her. The distress usually commenced nearly a week before the period, with drowsiness, languor, and weakness in the limbs, followed by qualms at the stomach. For the first day of the flow she seldom suffered much more, but on the second the spasm commenced, with the most agonizing pain in the womb, and loins, and with vomiting and chills. This would continue more or less for that and the following day, during which time she was confined to her bed, and groaning with pain, so that sleep was impossible. When the attack was over, she would be left so weak, and her nerves so shattered, that it took her a week to recover, and thus onehalf of her life was spent in misery, and the other half in dread of it. A strong dose of laudunum would somewhat relieve her, and force sleep, but left her much 
worse after-it merely made her insensible. During all this time she was excessively irritable, and unhappy in her disposition ; but fortunately, those around her knew the cause, and acted accordingly. Having heard one of my lectures, she sent for me to ask my advice, remarking, when she first saw me, that she had no hope from medicine, having taken it for years, almost like her daily food! I at once suggested the galvanism, but certainly with no flattering prospect of success. At the next period it was accordingly applied, immediately the pain began, instead of taking laudanum, and to the great joy of all, it eased the pain almost immediately. It was found necessary, however, to continue it more or less during the whole day and night, for immediately it was withdrawn the pain returned. In this way she lay in tolerable ease, while the battery was playing upon her, which it has often done almost through a whole night's sleep. We were disappointed, however, in our expectations of a permanent cure, for at each succeeding period the same symptoms returned, thongh they were always relieved by the same means. The galvanism supplied the place of the laudanum, and with none of its injurious effects, so that she was not troubled so long before, nor after. In fact, she often remained quite well up to the time of the attack, and rose immediately it was over as well as before. Her general health became better, her strength increased, and she became much stouter. In this way she has kept on for about two years under my notice, sometimes being a little worse, and at others suffering scarcely at all. I mention this case, because it shows how much relief may be obtained by galvanism, even in the worst cases. I have no doubt but that a resort to it in time would have effected a cure.

I tried the bougie in this case also, but it did no good whatever, neither did the emetic, nor baths. It is probable that if she becomes a mother, the difficulty will disappear; and the treatment, when she was first attacked, ought to have been directed with a view to bringing about that event.

During the time I was treating this, I had another similar case in a young unmarried lady. The symptoms were almost precisely the same, and so severe that for two or three days she was compelled to leave her employment, and go to bed. Medicines or baths did her no good whatever. The first application of the battery, however, gave instant relief, and after continuing it for about half an hour, the symptoms did not return. It was afterward applied just before the period, and invariably prevented the attack. Eventually, in about six months, its continued use seemed to wear the disease out, so that it returned no more.

Like all other remedies, of course, it will sometimes fail, and it did so in one instance, which I mention for instruction. It was that of a young lady whose occupation was teaching. She was intellectual, of a nervous temperament, and very industrious, and I have no doubt but that it was her incessant mental occupation that kept up the disease, for she was remarkably well in every other respect. Indeed, in many other such cases I have known rest, and quiet of mind, with cheerful out-door occupation, effect a perfect cure alone.

At the present time, I have quite a number of patients under treatment by galvanism, for this disease, and in the great majority of them, it is effecting the most beneficial results.

I knew one lady who got tired of the warm bath and hot teas she had been using for so long a time, and who plunged in despair into a cold bath! To her surprise it gave her immediate relief, and she ever afterward resorted to it. I have known others 
again, who found ease in dashes of cold water, cold injections, and even ice, or wet wrappers upon the abdomen. The shower-bath is also frequently beneficial, begun immediately after one period and continued till the next. In short, there are many means of giving relief, but a cure is generally difficult, and sometimes impossible, except through some of the changes in life we have referred to, or by a continual judicious alterative treatment.

Many poor seamstresses and waiters in stores suffer from this disease to a great extent, their occupation making all treatment useless, and their circumstances compelling them to continue it.

The whole difficulty, as already remarked, is often caused by the formation of membranes and clots, which irritate in passing away. I have known some of them as large as the hand.

Dr. Ryan gives us the following account of these cases, as most usually seen:

"The woman experiences severe pain the first day of menstruation, and suffers as severely as if in labor, or by abortion. She often experiences relief by the expulsion of one or many membranous substances from the womb. These membranes are somewhat like the skin of a gooseberry, and are smooth on each surface, thus differing from the decidual membrane. The membrane is so like the covering of the infant in the early months of pregnancy, that a lady, who was a patient of Dr. Hamilton's, thought she miscarried ten times a year, for three years. Denman and Dewees were of opinion that a female, thus affected, could not have children; but Morgagni asserts the contrary, as also Hamilton and Burns. If one healthy period without pain occurs, even at an interval of seven years, conception may take place. Hamilton described cases of pregnancy under these circumstances, and I myself have frequently known pain attend menstruation for months after marriage, and conception take place. I attended with Mr. Bradford, of Fleet Street, a patient aged twenty-three, who labored under dysmenorrhea since the occurrence of the evacuation in her fourteenth year, and still she was pregnant. She never passed any membranous shreds. I know another lady, aged twenty-one, who always suffered severe pain during menstruation, which was much increased by marriage. She is pregnant, however. She never discharged portions of membrane."

\section{PROFUSE MENSTRUATION, OR FLOODING.}

This disorder is usually spoken of as occurring in two forms : Menorrhagia, when there is merely a large quantity of the menses themselves; and metrorrhagia, when the discharge occurs at any other times than the menstrual period.

In menorrhagia, or profuse menstruation, the quantity may be large, and yet come in the usual time, or it may be many days or even weeks in coming, so that in some cases there is only a few days between the termination of one period and the beginning of another. Sometimes there is actually no cessation at all, the flow being incessant, while at other times the separate periods will be short, but close together.

It is very difficult to decide when there is profuse menstruation, the quantity secreted by different females varying so much. Fach one, in fact, appears to hare a quantity peculiar to herself, depending on some peculiarities in her constitution. Thus, one will never have more than a mere show, while another will discharge half a pint, or a pint, and yet both enjoy excellent health. The only means we have of judging is, by observing the general health. If this suffers, and the patient is weak 
and nervous, with no other apparent cause to make her so, we may reasonably conclude that the discharge is too great.

Thin, delicate females generally lose more than those who are full and robust, and in some the quantity varies much at the different seasons and turns of life.

The causes of menorrhagia are, debility, or plethora, various uterine diseases, and derangements of the other organs.

The treatment must of course depend on what we consider to be the exciting cause, and on the condition of the patient. The only general directions that can be given are, to rest, and particularly to lie much on the back, with the pelvis elevated. Those of a strong constitution, and full habit, should also live on a low diet, drink freely of lemonade, or tamarind tea, keep the bowels open, and use the cold showerbath. Those, on the contrary, who are weak should use a nourishing diet, with good wine, take warm salt-water baths, and ride out much in the fresh air.

When this treatment does not succeed, the same means may be adopted that will be pointed out presently for metrorrhagia, but we should never be in a hurry in resorting to medication, for it is seldom needed, and frequently injurious.

Metrorrhagia. - This term includes all those hæmorrhages, or discharges of blood from the uterus, not connected with menstruation, pregnancy, or gestation. These occur at almost every period, having been found in females past the turn of life, and also in children, from a few years old, down to a few months or even days! They are more frequent, however, during the prolific period, and with the married than the single. The causes that produce them are various. Among the predisposing ones may be mentioned all those that produce metritis, or ieucorrhea ; such as cold, improper diet, violent emotions, excesses, and debility, or a too great fullness of the system. Also too frequent child-bearing, and marriage, particularly if that take place at an improper time, or when there exists some physical impediment!

Among the exciting causes of metrorrhagia may be enumerated violent exercise, particularly hard riding on horseback, or in a jolting carriage, lifting, straining, coughing, and blows upon the abdomen. It may also be brought on by other diseases, particularly by inflammation of the uterine organs, or others, and by constipation, or diarrhcea. It often follows from fever or other debilitating diseases, and from long-continued grief, severe study, or exhausting labor. Irritation of the breasts, especially by the child during nursing, will frequently cause flooding, and continue it in spite of any treatment.

There are many nervous females in whom flooding will occur from the slightest mental agitation, and many others in whom every little deviation from nealth is followed by the same results.

The bleeding produced by polypi, tumors and ulcers, or by the different displacements of the uterine organs, or by violence, is not properly a disease in itself, but merely a symptom, and usually stops immediately the cause is removed.

Sometimes the discharge will be small at first, and gradually increase ; and sometimes it will occur very frequently, while at others weeks or months may intervene between the attacks. In some persons it is almost constant, and in others it comes at regular periods, like the menses. The quantity is of course equally variable, from a few drops to a full stream, or sufficient to cause fainting, and even death, in a short time. In these cases, however, it is most usually brought on suddenly, by some violence or strong emotion, and may then be fatal before assistance can be rendered. I have known a female lose a full quart of blood in this way in less than an hour. 
Occasionally a flooding is preceded by pains in the uterus, like those of dysmenorrhœa, and by a sensation of fullness, heat, and weight in the pelvis. The breasts also swell, the pulse quickens, and a general lassitude pervades the system. The face becomes pale, the skin creeps, the feet and hands become cold, and frequently there is pruritus of the external parts. These symptoms are usually modified by the first rush of blood; but if this be too great, or too long continued, the patient complains of a sinking in the stomach, her lips lose their color, her eyes become dim and her hearing dull, she breathes with difficulty, her pulse almost stops, and at last fainting or convulsions terminate the fatal scene.

In those cases where the discharge is great, and frequently renewed, a new train of symptoms sets in. The patient's strength is completely prostrated, her digestion becomes imperfect, her appetite disappears, the skin becomes of a sickly dead white color, and a black, puffy circle surrounds the eyes. In a short time the limbs swell and fill with water, the abdomen also becomes dropsical, dull pains are felt in the stomach, and various nervous diseases supervene. This state of things may continue for a long time, or may be suddenly terminated by convulsions and death.

In regard to the treatment of metrorrhagia or flooding, it must be remarked that, in most cases, it results from some other primary disease, the removal of which is the first and most indispensable requisite for success. A careful study must therefore be made of the patient's constitution and habits, with a view to this desirable result.

To arrest the bleeding, the female must lie on her back, on a mattress, with the pelvis elevated, she must be very lightly covered, kept perfectly quiet, both in body and mind, and breathe pure cool air. The feet and hands, however, should be made warm. Her diet must consist of barley-water, rice, milk, jelly, or very ripe fruit, and she may drink abundantly of lemonade, tamarind tea and ice-water, and eat oranges, cherries, and other ripe acid fruits. In obstinate cases a tea may be given, made of two ounces of comfrey root, or one ounce of rhatany root, boiled in a pint of water, and sweetened. The bowels may also be relaxed, with about three drachms of cream of tartar, and, if they are very costive, which is usually the case, enemas must be given of thin starch and castor oil.

If in spite of all these means the bleeding still continue, or the patient begins to be exhausted from it, injections may be used, of alum-water, ice-water, vinegar and water, or white-oak bark with thirty or forty drops of laudanum to the injection, which should be retained some time. A few drops of laudanum may also be used in the comfrey or rhatany tea, before mentioned; or thirty drops may be added to an enema. The root of the common black currant, and of the ground blackberry, or dewberry, also make an excellent tea to arrest flooding. A handful of each of these, boiled in two quarts of water for twenty minutes, makes perhaps the best preparation for this purpose that could be given. It may be sweetened to taste, and the patient may drink half a teacnpful every quarter of an hour. Cold wet towels may also be laid on the abdomen and under the loins, and, if nothing else stops the flow, and she be rapidly sinking, a cold hip-bath may also be tried.

The great dependence of most practitioners, however, in these cases, is upon bleeding, and opium. Some advise the blood to be taken from the arm, others from the feet, or hands, or by leeches to the temples, between the shoulders, or inside of the arms. The theory being that a new direction is thus given to the sanguine discharge, which leaves the uterus to fly to the wound. Though the philosophy of this 
may not be very evident to all persons, yet there is no doubt but the practice is sometimes beneficial; I think myself, however, that the same good may be usually effected by other means.

In those cases where the discharge is chronic, we must first endeavor to increase the patient's strength. Her diet should be nourishing, but not stimulating, and she may use a little good old wine, with Peruvian bark, or other bitters. The compound mixture, or aromatic tincture of iron, already mentioned, may also be given, and occasionally some of the comfrey, or rhatany tea, or that of the black currant roots. She should also use the cold shower bath every morning, ride out gently into the fresh air very frequently, and go to the sea-side ; in short, do anything that will promote the general health.

The ergot of rye has also been used, in long-continued cases, and savin, but their action is violent and sometimes dangerous.

It is not always prudent to check a profuse uterine hæmorrhage too suddenly, for it is sometimes a salutary effort of nature to relieve herself from some greater evil. We ought rather to promote the general health, and let it gradually cease itself. An issue may be established, inside the thigh, if any bad effects result from the stoppage.

After the flow is stopped, great care must be exercised to prevent its return. A light diet should be adopted, all stimulants avoided, and before each menstrual period careful rest should be observed. Excitement should be particularly guarded against, especially of a certain kind, warm clothing should be worn, and late hours avoided.

In those severe cases, when the gush of blood is almost instantaneous, and so great as to endanger life in a very short time, we may employ, temporarily, mechanical means to prevent it. The best of which, and the most readily prepared, is called the tampon or plug. It may be made of linen rag, cotton, or sponge, in the form of a ball, and introduced into the vagina like a pessary. It should be large enough to completely fill up the passage, but must not be introduced more than about two inches, for fear of irritating and inflaming the mouth of the womb, which is then very sensitive.

A very good way to make the plug is, to cut out round pieces of soft linen cloth, then pass a stout thread through the middle of each and press them close together, till the mass is an inch thick. The string is convenient for pulling it out again, and should always be attached to every one. A small bag filled with tan, or ashes, or sawdust soaked in alum-water, is also very excellent. These plugs should not be withdrawn in a hurry, unless severe symptoms supervene, and when they are removed, care must be taken not to disturb or irritate the parts. If the danger be imminent, and there be not time, or means to prepare a tampon, the lips and vulva should be firmly pressed together with the band, till other means can be procured.

\section{CHLOROSIS, OR GREEN SICKNESS.}

This is a name given to a peculiar disease usually characterized by a pale greenish color of the face, which is also swollen and puffy, and by general debility and derangement of most of the functions. It has also been called white jaundice, white fever, and morbus virgineus.

Great doubt and uncertainty prevails as to the nature of this disease, and its 
origin. Thus some suppose it to originate in the digestive, some in the assimilative, and some in the uterine organs, while others attribute it to debility of the nervous system, and others again to an imperfect state of the blood. It cannot be owing, however, merely to derangement of the digestive or uterine functions, because, in some cases, both these functions are perfectly performed, though not usually. An imperfect state of the blood, on the contrary, always exists in this disease, and is probably produced by nervous debility and derangements, which may therefore be regarded as the primary cause.

The singular alteration in the composition of the blood, in this disease, is very remarkable, and a knowledge of it is highly important, as an index to proper medication and nutrition. If we take one thousand parts of the blood of a healthy woman, and analyze it, we shall find, after allowing for loss, the solid materials to be about one hundred and fifty parts, iron eight parts, and water seven hundred and sixty parts. But if we take a thousand parts of the blood of a chlorotic patient, the solid materials will only be about one hundred parts, iron but four parts, and water eight hundred and fifty parts! From this it is evident that in chlorosis the blood is more watery, and contains less solid matter, and iron, than in the healthy state. This deficiency of the solid parts explains the wasting and flabbiness of the muscles, while the increase of water explains the puffy or dropsical state of various parts. The use of iron in the blood is not yet ascertained, but that it is necessary there can be no doubt, nor can there be any question as to its deficiency causing many disenses. The quantity naturally existing in the human body is much greater than usually supposed. The wife of an eminent man in France now wears a ring, made of the iron extracted from her husband's blood, which he lost during a lengthy sickness. It has even been proposed, on the death of any great man, to make a medal of the iron from his blood, and thus perpetuate a remembrance of him, instead of raising a monument.

It is supposed that this deficiency of solid materials in the blood, is owing to insufficient nervous power in the vessels that form the blood; but be that as it may, we find, as will be seen farther on, that using a diet which contains much of these solids, namely, fibrin and albumen, and taking iron internally, are the only means of euring chlorosis.

This disease is found chiefly in young unmarried women, though occasionally met with in the married, in the pregnant, in those that have borme children, in those past the change of life, and in children, and in some rare instances, even in men. It is, however, more especially a female disease, and in the great majority of cases, is attended by obstinate and peculiar uterine derangement.

The supposed causes of chlorosis are both numerous and various. Perhaps the most frequent are, precocious puberty, growing too fast, a feeble constitution, scrofula, menstrual derangement, melancholy, and mental excitement, and especially certain vicious habits. Late marriage, or widowhood, should also be mentioned, and disappointment in love! In addition to all these, there are also undoubtediy many general causes, such as cold, damp, and dark dwelling-places, bad air, insuffcient or improper food, and a sedentary, luxurious, or indolent mode of life. Drinking vinegar, and eating green fruits, are also specially alluded to by some authors.

The symptoms are so peculiar, and characteristic, that chlorosis is more distinctly marked than almost any other disease we have mentioned. At the commencement the patient is dull, listless, and melancholy; she is disinclined to any motion, and 
sighs or weeps, without knowing what for. The face swells, the eyes become heavy and languishing, with a black puffy circle around them. The hands and feet are cold and pale, like the lips; the breathing is difficult, the appetite capricions, and the digestion imperfect. The bowels are usually costive, and the evacuations like white clay. The heart frequently palpitates on the slightest exertion, or mental emotion, and a constant inclination is felt for sleep, or to remain perfectly inactive. On using the stethoscope, the heart, and some of the large arteries, are found to have peculiar sounds, different from those in health, and the blood when drawn is pale and thin. The ankles also swell, as in dropsy, but when the finger is pressed upon them the mark does not remain, as it does in that disease.

If the disease progresses unchecked, all these symptoms become worse. The patient feels the most unaccountable likings, or disgusts, and exhibits the most depraved tastes. Some will eat charcoal, chalk, plaster from the walls, dirt, ashes, and even flies, spiders, and other insects. Some will have no appetite at all for food, while others will eat so ravenously, that they can never satisfy themselves. Pain at the stomach is usually felt after eating, or vomiting occurs, and the tongue is, in most cases, swelled and coated with mucus. Flying pains are also felt in the neck, shoulders, inms, and down the spine. The urine becomes pale and scanty, and the bowels subject at intervals to a watery diarrhoea.

Leucorrhœa is a common attendant upon chlorosis, and is generally accompanied l)y amenorrhoea, though sometimes there will be more or less flooding. The patient is often worse at the menstrual period, suffering pains like those of dysmenorrhœea, with great depression of spirits, or even partial delirium. The discharge is found to be very thin and light colored, and when left on the napkin, it divides into two distinct parts, one rather sticky, like starch, and the other watery. When dry, it is nearly colorless.

In addition to all these, the most troublesome nervous symptoms arise. The patient either becomes irritable, passionate, and revengeful, or else completely cast down, so that in her despair, she thinks of suicide, or wishes for death. She is either sleepless, or disturbed by horrible dreams; her head aches, her sight is dim, her limbs tremble, and she experiences a constant ringing, or buzzing in the ears. Sometimes there is frequent toothache, ard occasionally twitching of the limbs, and of the muscles of the face. : heir

Finally, this state of things becomes wrtipe and worse. Constant pain is felt in the back of the head and upper part of the spine. The abdomen swells and hardens, the skin looks quite green, the difficulty of breathing becomes greater, the diarrhœa is more constant, fever sets in, and the whole system seems rapidly to waste, as if it meited away! The last stages are frequently marked by general dropsy, pinching up of the features, and blueness of the lips. There is seldom any shock, or struggle even at death; but the sufferer seems to gradually sink and die from mere debility and marasmus.

The duration of this disease is altogether uncertain. It is seldom fatal itself, though it may lead to fatal results by bringing on other diseases, or it may gradually wear the patient out, by exhausting her strength. Fortunately, there are few diseases more certainly curable than this. Under proper treatment it seldom lasts longer than a month or two, and very frequently can be cured in a week. I have even seen a patient who was drooping like a tender flower in the sun, and too weak to stand, visibly improve in two days ? 
The treatment must be first commenced by removing all causes that may be thought likely to continue, or bring on, the chlorosis, particularly all other diseases. The patient must then be placed in a warm and dry situation, where she can breathe pure air. Her clothing should also be warm, and her body well rubbed every morning after a shower batb. Flannel, worn next the skin, has frequently a very excellent effect, and should always be adopted, unless the other means mentioned keep the surface of the body quite warm without it. The diet should consist of eggs, roast meats, rice, tapioca, sago, and milk. Ripe fruits may also be used, and celery is excellent. Good wine may also be used with advantage, and, as a general drink, lemonade, or tamarind tea. Al? articles that are found not to sit well on the stomach, or that are indigestible, should be carefully avoided. Unripe fruit, salads, and pastry, are generally unwholesome. The object of this kind of diet it will be seen is twofold; first, to gently stimulate the flagging energies, and restore the failing strength; and, secondly, to supply those solid materials, namely, albumen and fibrine, of which, as we have before shown, the blood in chlorosis is deficient.

Exercise in the open air is indispensable, but the manner of it must depend on the patient's strength and habits. If she can walk, so much the better, but if too weak for that, or if it distress her, she should ride-either on horseback, which is most desirable, or in an open carriage. Rowing in a boat, and sea-bathing are also very good. It is very desirable, however, let her exercise as she may, that it should be done in company with others, so that there may be the additional stimulus of emulation, and the excitement of conversation. In fact, cheerful associates, and pleasing mental occupation, are highly important. Traveling may also be recommended, both on account of the change of air, and of scene. All causes that tend to either excite, or depress the mind, should be most carefully avoided, and also all reading that calls forth the sensibilities too strongly. Corsets should not be worn, nor should the patient sit up late at night, nor lie too late in the morning.

In very many cases the above-mentioned general means will be quite sufficient to effect a cure; but when they are not, medication must be resorted to; and of all medical substances, iron is the most generally useful in this disease ; in fact, it is almost a specific. The particular preparation used, is not of so much importance as giving it early, and freely. Any of tr iron mixtures and pills already mentioned may be employed, or any of the foll youn : Compound iron pills, two pills of five grains each, to be taken three times ar any. Carbonate of iron pills, dose the same as the other. Syrup of iodide of iron, twenty drops twice a day, in half a tumbler of water. This is particularly useful where there is any tendency to scrofula. 'Tincture of the muriate of iron, ten drops three times a day, in half a tumbler of water. Sulphate of iron and subcarbonate of potash, each half an ounce. These must be rubbed separately to very fine powders, and then thoroughly mixed together, with sufficient thick mucilage of gum tragacanth to make it into a paste. This must then be divided into forty-eight boluses. One of these may be taken morning and night, for the first three days, and one three times a day on the second three days; on the third three days, two may be taken morning and night, and one in the middle of the day; on the fourth three days, two three times a day; on the fifth three days, three three times a day; and on the sixth three days, four pills three times a day. This quantity may be continued till the disease begins to disappear, after which the dose may be decreased in the same way it was increased, or, if the patient seems nearly well, it may be decreased before arriving at the largest quantity. 
This is the favorite prescription of a celebrated physician, who depends on it for curing almost every case. Citrate of iron two drachms, sulphate of quinia half a drachm, water one ounce. Mix these together, and take twenty or thirty drops in half a tumbler of sweetened water, half an hour before breakfast, dinner, and supper. 'The sulphate of iron and gentian pills, formerly mentioned, are also excellent, and so are the iron and rhubarb pills, sold by the druggists, two of which, of five grains each, may be taken twice a day. These last have the advantage of opening the bowels, which should be particularly attended to ; they may therefore be beneficially taken along with any of the other kinds occasionally. It is very desirable not to leave off taking the iron too soon, merely because there is a slight improvement, for by so doing we may cause a relapse. Rhubarb may also be used alone, if necessary, and in case that does not relieve the bowels, enemas should be resorted to.

Emetics have been employed by some physicians, in chlorosis, and drastic purgatives by others, but they are seldom either of service or needed. If iron be properly administered, in connection with a proper course of diet and regimen, it will scarcely ever fail, unless there be a complication with some more serious disease. Immediately after its use is begun the dull eye will brighten, the skin regain its color, the functions become healthy and regular, the nervous symptoms will become less severe, and the strength will gradually return. The philosophy of this will be evident, when we remember that iron is an essential constituent of the blood, and that in chlorosis the quantity is much smaller than usual. By giving it in medicine therefore, we simply supply artificially what has become naturally deficient.

If we have reason to suppose that the chief exciting cause is the predominance of certain feelings arising from over action of the uterine organs, it may be advisable to suggest marriage. In case that is not possible, however, the treatment must be varied, so as to reduce the uterine excitement. Cold baths, and injections, unstimulating diet, saline purgatives, and active occupation may be recommended. These moral causes are frequently the most active ones, and they are the most difficult to remove, because few persons understand them, or know their power, and still fewer know that they can and mostly ought to be, attacked chiefly by physical means!

The subjects of chlorosis are the most interesting perhaps of all that come under the physician's care. Delicate and sensitive, stricken by a disease from which they deeply suffer, but which often leaves their beauty untouched, or even heightens its attractions, they excite the liveliest emotions of pity, and the most ardent desire to render them assistance. Like many other of the affections previously described, this is, unfortunately, very general. A large portion of those now under my care, are victims to it. I am sorry to see this, but some consolation is derived from the fact that relief may confidently be expected by most of them.

When chlorosis commences just before puberty, which it often does, it frequently disappears with the appearance of the menses, and if there be indications of them, it is better to wait awhile, before commencing medication.

Chlorosis may be very easily mistaken for several other diseases, unless care be taken, particularly for jaundice. But no person of competent experience, and who devotes proper attention to his cases, is likely to make such an error. The peculiar state of decay and weakness, called anemia, or decline, has also been taken for shlorosis by inattentive persons. 


\section{HYSTERIA.}

We now come to the most mysterious, confusing, and rebellious of all female diseases. 1lmost every woman has either experienced or seen what is called hysterirs, and the name is so frequently given to the most opposite and discordant symptoms, that it is requisite to explain what is hysteria; and what is not; at least as far as we can.

The name hysteria is derived from the Greek word for the womb, it being generally considered as essentially a uterine affection. The symptoms of this disease comprise, if we were to enumerate them all, those of nearly erery other disease under the sun. In fact, they are so numerous, so various, and so changeable, that describing them all is out of the question. We must therefore confine ourselres to a brief enumeration of the most prominent ones, and more especially of those most frequently found at the commencement.

In some eases, the attack, or hysterical fit, comes on suddenly, but more frequently it is preceded for several days, by more or less derangement of the general health. The female suffers from headache, cramps, palpitation of the heart, numbness of the limbs, coldness of the hands and feet, rush of blood to the head, and redness of the face, with yawning and restless anxiety. She becomes dejected, or melancholy, and will sigh, or burst into tears, and then as suddenly laugh in the most immoderate manner, and without any apparent reason for it.

When the fit really commences, she feels in some part of the abdomen a sensation as if a large round ball, or globe, was moring about; which, after appearing to roll in various directions, generally rises, on the left side, up to the chest and throat, and seems to stop up the passage, so that the patient appears to choke, and is in mortal fear of suffocation. During its progress, this ball seems to distress every organ it passes, and to leave a most oppressive sensation of weight in the chest. In serere cases this is followed by fainting, after which she may either slowly recover, or may have other fits in rapid succession. There may be, however, merely slight convulsions, followed by partial loss of sight or hearing, and confusion of the mind. Sometimes the convulsions will be so violent that two or three men can scarcely hold her, and if not prevented she may seriously injure herself. The body will occasionally twist or bend in rarious ways, the teeth clench, the eyeballs roll, the nostrils distend, and saliva work from the mouth, nearly as in epilepsy. The head is usually thrown back, in long-continued attacks, and the female tears at her throat, owing to its constriction. The cheeks and nose are most frequently cold and white, though sometimes the center of the cheek will be red, as in fever. In many cases the abdomen swells, and very often there is a serere stitch in the side. Partial or complete loss of consciousness, or delirium, may occcur either during the attack, or subsequently, though some females are perfectly sensibie the whole time. The senses are in some cases rendered remarkably acute, so that the patient will hear the slightest whisper, or smell the faintest odor, and see everything that is going on, even though her eyes seem closed. This peculiarity has caused many to be suspected of imposition, by those not acquainted with the disease. This suspicion has also been strengthened by another circumstance: the patient nearly always tells whether she is going to have another attack or not, and is seldom or never wrong. This foreknowledge, however, is simply the result of her sensations, and need excite neither wonder nor uncharitable distrust. 
When the violence of the fit is passed, there is generally observed a singular rumbling of wind in the abdomen, and great quantities of it are discharged by the mouth from the stomach. Vomiting may also ensue, or confused palpitation of the heart, with labored breathing and twitching of the muscles. A severe, fixed pain in the head is also frequently felt in one particular spot, with singing in the ears and bright sparks float before the eyes. Generally, the sufferer utters most piercing cries, so peculiar that they can never be mistaken by those who have once heard them, and so frightful that few can help feeling alarmed at them. In fact, there are few exhibitions of human suffering more likely to appall and excite consternation than an hysterical fit, especially among those to whom it is new. Fortunately, all these symptoms are not observed in every case, for some patients will remain, between the attacks, in a partial stupor, or sleep, during which they will smile and appear quite happy. It has been supposed, in fact, by some that this dreamy, hysterical state is the real mesmeric sleep, or somnambulism.

The final cessation of the attack is often denoted by sighing, sobbing, and crying, or immoderate laughter, similar to what is usually observed at the commencement. This is followed by a gradual subsiding of the more violent symptoms, and by moaning, or deep sighs, after which the heart beats more quietly, the breathing becomes regular, and a gentle heat, with perspiration, appears on the surface. It should also be particularly mentioned that there is nearly always felt a most pressing desire to urinate, and if this be impossible, the pain and anxiety thus excited may bring on another fit. This should be remembered by those who may be with such cases. Another remarkable circumstance may also be mentioned; immediately the patient recovers, an abundant mucus secretion flows from the vagina, though previously it was unusually dry and constricted. This is a proof how much the uterus sympathizes in this disease. I have known this take place to such an extent as to lead to the belief that the urine had escaped involuntarily. . A temporary loss of voice may also take place, but it need occasion no special alarm.

When all is over, there seldom remains anything more than a general weakness, with mental dejection, and occasionally dullness of memory, with a disposition to day-dream, though some will complain of soreness in the limbs, and a sensation as if the head had been struck with violent blows.

The above-mentioned symptoms may either be all observed in any attack, or only a few of them, and they are exhibited so irregularly that anything like a classification of them into stages is out of the question. Their intensity may also be very great, or so slight as to excite no apprehension. Occasionally there are other symptoms added, such as hiccough, or a tendency to bite, as in hydrophobia, and sometimes others of a still more unusual character! The attacks may all be over in a few minutes, or they may last hours, days, or weeks, and sometimes will become periodical. It is difficult to say when a patient is cured of them, since they may return at intervals of six months or a year. There may also be only one fit at a time, or several, and they may either decrease in violence, or the last one be as bad as the first. The effects on the appearance of the patient are also various; thus some will even become more full of flesh, and look better, while others will fade and become thin. This last is more frequently the case, especially with those who have had much leuchorrhea. Many will have a very jaded and dejected look, and become melancholy and apprehensive.

As the patient advances in life the disease usually decreases; but if it do not. 
and is unchecked by proper treatment, it may subside into various other diseases, as metritis, epileptic fits, hypochondriasis, amenorrhea, ovaritis, and several others, and thus become fatal. Sometimes it terminates spontaneously by profuse sweating, diarrhea, eruptions of the skin, or vomiting, and it has often been stopped by a sudden fright.

One thing should never be forgotten in regard to hysterical attacks, and that is the possibility of the female appearing dead, though still alive! There is no question but many have been buried alive while in this species of trance, and in several instances they have awaked during the preparations for their funerals. A celebrated anatomist (Vessalius) actually began to dissect a female in this state, who came to life again. I have a patient at the present time who was found sitting in her coffin, with her shroud around her, when the undertaker came to nail her up. The way to avoid such lamentable mistakes is easy ; the supposed body should not be buried till there be unequivocal signs of decomposition. Very few days will elapse, in any case of death, before the abdomen turns green, and then there can be no mistake. I once saw a case myself of supposed death, in which some of the friends had actually proposed preparations for interment, but after five days of perfect trance the female woke perfectly unconscious of the lapse of time.

The causes of hysteria are as obscure as the symptoms are diversified. Probably some of the most frequent predisposing causes are, weak constitution, scrofula, indolence, a city life, bad physical and moral education, nervous or sanguine temperaments, the over-excitement of certain feelings, and religious or other enthusiasm. It is also most common between puberty and the change of life, but is nevertheless found in quite young girls, and in old women. Young persons just about being regulated are very subject to it, and those who have deranged menstruation, also widows, those who have no children, and those in whom the change of life is about to take place. Some of the immediate causes are, the first period, suppressed menstruation, late marriage, chronic inflammation of the womb, vicious habits, and longcontinued constipation. Vivid mental emotions, and excited feelings, may also be specially mentioned, such as anger, fright, disappointment, particularly in love, reading sentimental and exciting romances, and disagreeable, painful, or sorrowful sights. Some authors also suppose there is an hereditary disposition to hysteria, and others that there is a peculiar temperament which disposes to it. It is certain that imitation has much to do with it, or, in common parlance, it is catching, for very often when one female is taken in an assembly, many others will also be attacked from seeing her. M. Andral mentions a case where a young lady was attacked with hysteria in a school, and so many of her companions followed in the same way, that it was found necessary to close the school for a time to get rid of it. The same thing has often been seen in churches and other public assemblages, and particularly at campmeetings and love-feasts. At some of these places quite a number of persons may be seen raving, rolling on the ground, crying, laughing, and exhibiting all the usaal symptoms of hysteria, simply from excitement produced by the preaching. I knew one young lady who went to a camp-meeting, and was there attacked with hysteria, which lasted nearly a whole day; the people around said she was experiencing religion, and evidently thought her very fortunate. She continued liable to a return of the attack for six months after, but gradully recovered from them by attention to her general health, and by avoiding all excitement.

Women disposed to hysteria are generally capricious in their character, and often 
whimsical in their conduct. Some are exceedingly excitable and impatient, others obstinate or frivolous ; the slightest thing may make them laugh, or cry, and exhibit traits which ordinarily they are not supposed to possess. Like children, the merest trifles may make them transcendently happy, or cast them into the most gloomy despair. Very frequently they are made much worse by seeing that those around them have no real commiseration for their sufferings, and perhaps even think they are not real. A delicate attention, and properly exhibited sympathy, will soothe and calm the excited feelings more than almost anything else.

Various other diseases, particularly of the uterine organs, may also produce hysteria, and many apparently slight causes, such as breathing a close, bad air, either in a public assemblage, or in a bed-chamber, and even particular odors! Thus, some will be attacked if they smell musk, or certain flowers, as roses, for instance; others again at hearing certain sounds, or merely touching certain substances. M. Orfila mentions the case of a young lady who fainted if she saw flax-seed tea made. M. Rostan says he has seen hysteria, with loss of voice, and strangulation, produced even by the color of a certain flower! And many such cases have followed from smelling orange flowers and violets. Particular pieces of music, or the reading. certain passages from books, will affect some, and the sight of certain animals will affect others. A case is mentioned of a young lady who always had an hysteriform attack if she heard the clock strike five, her father having died at that hour; and I knew one who suffered in the same way whenever she saw a ladder, her husband having been killed by falling from one. In short, there is no end to such cases.

There are several other causes, both of a moral and a social nature, that have much to do with this distressing affection, but which I have hitherto only partially alluded to. They are so important, and so little understood or suspected, that I feel desirous of presenting them with other authority in addition to my own. I have, therefore, made the following extract from Copeland's Medical Dictionary. The extract is part of the article on hysteria, and is especially deserving the attention of parents and guardians! Its importance, I trust, will excuse its introduction, though some of the truths in it may be as painful as they are novel.

"There is perhaps no other malady which depends so much as this upon the management of childhood, and on the moral and physical education of early life. A luxurious and delicate mode of living and of rearing; a neglect of whatever promotes the powers of the constitution, especially of suitable exercise in the open air, and of early hours as to sleeping and rising ; an over-refined mode of education, and the excitement of the imagination and of the emotions, to the neglect of the intellectual powers and moral sentiments ; too great devotion to music, and the perusal of exciting novels; the various means by which the feelings are awakened and acute sensibility is promoted, while every manifestation of either is carefully concealed; and studied endeavors to dissemble desires which struggle to be expressed, all serve, especially at a period when the powers of mind and the conformation of the body are approaching development, to produce that state of the nervous system of which bysteria is one of the most frequent indications. About the period of puberty in females, various circumstances connected with their education tend to weaken their constitution, to excite their emotions and desires, and to cultivate their imaginative and more artificial faculties at the expense of their reasoning and moral powers. Whenever numbers associate previous to, or about the period of puberty, and especially where several use the same sleeping apartment, and are submitted to a luxuri- 
ous and over-refined mode of education, some will manifest a precocious develop. ment of both mind and body; but in proportion to precocity will tone and energy be deficient, and susceptibility and sensibility increased. In these circumstances, also, organic sensibility, particularly as relates to the uterine system, often assumes a predominance powerfully predisposing to hysterical affections. There can be no question, although the subject has been but rarely approached by British medical writers, thrat indulgence in solitary vices and sexual excitements is not an infrequent cause of this, as well as of other disorders. Numerous writers have insisted upon the propriety of giving due consideration to this source of mischief, as well as to the ennui and chagrin attending celibacy and contirence. I agree with Dr. Conolly in believing that English practitioners pay, perhaps, too little attention to these and other related circumstances ; and that, in a country where the passions and emotions are so carefully suppressed or concealed, they sometimes seem to forget their silent operation on the frame, and charge the medical writers of other countries with being somewhat fanciful and extravagant.

"Besides the above, there are various circumstances connected with the sociai state that tend to develop these conditions of the uterine organs and nervous system, in which hysterical disorder originates. M. Georget remarks that the progressive steps of life, as youth passes away, are sources of painful moral affections, especiaily to the frivolous, the vain, and the unmarried of the sex. These affections increase the susceptibility of the nervous system, and, with numerous other circumstances yet to be mentioned, dispose to the nervous disorders of the more adranced epochs of life. There can be no doubt that pampered modes of living; an early or habitual indulgence of temper, or of the emotions and desires; the use of wines anil liquors, even within what may appear the bounds of moderation; late hours, anil late rising; insufficient modes of exercise, or the want of it, and of pure air, neglect of the requisite exposure to light and sunshine ; and sedentary occupations, particu. larly in over-heated and crowded apartments or factories, more or less predispose th? female constitution to this affection. Some writers believe that the use of tea and coffee has a similar effect; it is possible that the former, especially green tea, taken too frequently or in excess, will weaken the nervous system, and that the latter will sometimes excite the uterine organs. The influence of climate is not very manifest; temperate and changeable regions certainly furnish more numerous instances of nervous disorder in females than very warm or very cold countries ; but as much is probably owing to the state of manners and society in the former as to climate. Even dress has some effect in the production of hysteria; inordinate compression of the waist by stays not only weakens and displaces the digestive organs, but favors local determinations and congestions, and deranges the uterine functions."

Hysterical attacks are not of themselves dangerous, though they are sufficiently alarming, as they usually subside without much after disturbance, unless dependent on some other disease. Nothing, in fact, is so astonishing to some persons, as to see a delicate female immediately after an hysterical fit. Judging from appearances during the attack, they would readily suppose that the danger was really imminent, and that a slow recovery was the best thing to be expected. But when all passes off in a few minutes, with no indications whatever of the frantic violence so recently exhibited, they are naturally surprised, if not suspicious. It should be remembered, however, that an imitation of one of these fits, even if it were fully possible, wou'd exhaust much more than the fit itself, or most likely would produce complete pros- 
tration. There is no doubt, however, but that many females can work themselves into hysterics, and that many do so, particularly when angered, slighted, or disappointed.

In regard to the starting point, or original seat of hysteria, there seems to be no doubt of its being in the uterus, which becomes subject to a peculiar excitement, or disturbance, that exerts a wonderful sympathetic influence on the whole oystem. The uterus, it must be remembered, is the controlling organ in the female body, seing the most excitable of all, and so intimately connected, by the ramifications of its numerous nerves, with every other part. The multitudinous and diversified symptoms attending its derangements need not therefore surprise us, nor need we wonder that they are not found in other diseases. The ancients compared the womb in the female body to another living being, controlling and directing the body in which it existed! It should also be-remembered, in relation to hysteria, that it is most frequent at that age, and in those temperamens in which the uterine system is most active. In some instances, men are liable to similar affections, and when they are so there is always noticed in them more or less of what is termed the hysterical temperament. In fact, they much resemble females in their nervous systems.

In treating hysteria, the first thing is to relieve the paroxysm or fit, and then try to prevent its return. The first proceeding, if the attack be violent, should be to take care that the patient does not hurt herself by her violence. She must be held firmly, but not so as to injure, or unnecessarily restrict her motions. Every article of clothing should be removed that is in the least tight on any part of the body, and she should then be laid down, with the head elevated. Every person should be immediately sent away, except those whose assistance is really needed, and they should be careful not to hurry and appear confused, nor make unpleasant or desponding remarks about their patient, because she may both hear and understand them, though to all appearanee insensible. Fresh air is indispensable, and it should play upon her as speedily and freely as possible. Strong odors, as ammonia, salts, vinegar, or burnt feathers, should also be applied occasionally to the nostrils, and cologne or cold water dashed on the temples, forehead, and cheeks. If the mouth can be opened, a teaspoonful of cold water should be poured in it, with about three drops of ammonia added, if it can be conveniently obtained. The hands and feet may also be chafed with advantage. In case the attack still continues, a small enema of cold water may be given, containing about twenty drops of laudanum, or cold water may be sprinkled on the chest and down the spine. Fifteen drops of sulphuric ether may also be poured into half a pint of water, and a large spoonful of the mixture given every three-quarters of an hour. In very violent or long-continued attacks, an enema of thin, cold starch-water may be used, with three grains of camphor, ten of assafœtida, and fifteen of laudanum added to it, after being well mixed in a thick portion first. The whole body may also be well rubbed, particularly down the spine, and mustard plasters applied to the abdomen, inside of the thighs and arms. Spirits of camphor, or oil and hartshorn, may also be used as a liniment, and the spine and limbs well chafed with them. As soon as ever she can swallow, let her have a drink of cold water, but don't ask her any troublesome questions, nor make any remarks.

After all the above means have been tried, we may resort to vaginal injections, as those of poppy heads, or starch and laudanum, recommended in metritis. Frightening the patient, or speaking harshly to her, has been recommended by some, but I much doubt the utility of such means. Other practices are also resorted to, the 
character of which betrays a curious opinion as to the nature of the disease! I would, however, caution those who recommend them as to the probable moral consequences afterward, and I assure them that it is seldom or never the case that the same good cannot be effected by less objectionable means.

To prevent a return of the attack, we should employ what are termed anti-spasmodics and tonics. Varions teas may be drunk, as those of mint, balm, mugwort, boneset, and camomile. Tincture of myrrb, assafoetida, musk, and castor, gum ammoniac, acetate of ammonia, and carbonate of ammonia may also be taken, various preparations of all which are kept at the druggists'. Vaginal injections should also be continued, of starch and laudanum, assafotida and camphor, and the bowels must be kept free. If the shock be not too great, a shower bath every morning will be of great service, or a cold plunge. If the patient be very weak and debilitated, we may give her any of the preparations of iron recommended in chlorosis, particularly the carbonate of iron pill, or that of extract of gentian and sulphate of iron, and keep the bowels free with pills of iron and rhubarb. A little good port wine, with Peruvian bark in it, may also be of service, and an excellent effect is sometimes produced by repeated enemas of olive oil. Sulphur baths have also been recommended, and occasional blisters to the abdomen and inside of the thighs or arms, and on the spine.

The diet must, of course, depend on the condition of the patient. If she be of a full, plethoric habit, it should consist of vegetables, light soup, milk, rice, sago, and ripe fruits, with milk or water for drink. Meat should be taken sparingly, and never highly seasoned, and spices or pastry should be forbidden. If, on the contrary, she be thin and delicate, the diet may be more nutritious ; meat may be used more freely, and a little wine allowed. Sea-bathing, traveling, riding horseback, and removal to a dry, warm climate, should also be recommended. The mind must be constantly but pleasingly occupied, and the feelings interested in some innocent, cheerful pursuit. All kinds of sentimental and romantic reading must be avoided, but amusing books of travels and descriptions of scenery may be allowed. Music or poetry, when indulged in to excess, and with those of an excitable temperament, is often highly injurious. More domestic occupation, and less fanciful idling, would prevent numerous disorders in many young females.

In the article already quoted from Copeland's Dictionary, are some further remarks on the peculiarities and predisposing causes of hysteria, whose great value must be an excuse for inserting them.

"Hysterical disorders of the mental faculties consist not merely of the states already mentioned, but of others of a less decided, but not less morbid kind. Hysterical females are not merely capricious or whimsical, but they often become enthusiastic for a time in the pursuit of an object, or in cherishing an emotion by which they have been excited. In many puch cases, the nervous excitement and vascular turgescence of the uterine organs determine the character of the mental disorder, elevating certain of the moral sentiments, or of the intellectual manifestations, to a state of extravagance, passing in some instances into delusion or monomania. Many cases of puerperal mania are merely extremes of the hysterical disorder of the moral and intellectual powers or states of the mind. All these more extreme forms of mental affection are observed only where, in connection with much local or uterine irritation, there is great deficiency of nervous energy generally, and of mental power in particular, or where, with such deficiency, there has been either much injudicious culture, or pertersion, or improper excitement of the imagination. 
"Females sometimes become passionately attached to an object, and this passion may advance even to nymphomania or monomania. The same person, on experiencing a disappointment in her affection, or if she be placed in circumstances entirely preventing the enjoyment of her passion, often becomes enthusiastically religious, especially if strongly excited by powerful popular preachers. After field preachings, or other ministrations of an exciting kind, the most hysterical females, especially those who have experienced the fully developed fits on these occasions, have become, at least for a time, the most religious. In this, however, there is little to regret; there is no harm, and generally much good, from this direction of the feelings, unless, indeed, advantage be taken of this excitement by certain tartufies-especially at lovefeasts, etc. - a circumstance by no means rare.

"The hypochondriacal feelings, the desire to deceive, or to simulate various diseases, or the delusions which sometimes possess the minds of hysterical females, may be classed with the foregoing, as requiring a similar plan of treatment. In all of them the indications of cure are, to remove irritation or vascular turgescence of the uterine organs; to improve the general health ; to strengthen the nerrous system ; to calm the imagination, and to guide the moral impulses of the patient. The means by which the physical portion of these indications are to be fulfilled have been sufficiently explained. The most efficient, however, of these means are not likely to be adopted by the patient if she is entirely uncontrolled by friends. Few will resort daily to the shower bath, or even occasionally to terebinthinate enemata, or submit to a course of tonics, or to a suitable regimen, etc., while she believes her health but little affected. Even when the hysterical disorder is of a very painful kind, the variability or capricious state of her mind leads her to run from one physician to another, before opportunity of administering aid is afforded to any. At last the most notorious charlatans, particularly those who either excite the body through the mind, or the mind through the body-the animal magnetizers, the homoopathists, the St. John Longs of rubbing celebrity, and the Campbells of celestial bed notoriety-fix her attention. At such medical bagnios, there is something promising gratification as well as excitement, and at such places hysterical as well as hypochondriacal patients 'most do congregate.'

"Of the Prophylactic Treatment of Hysteria.-The avoidance of the occasional causes is the chief part of this treatment, and this is very difficult. The moral emotions and desires constitute the principal of these causes, and the prevention of them is not in the power of the physician, and considering the general frailty of our nature, rarely in the power of the patient. A physician sufficiently acquainted with human nature and with human life and society, will frequently discover the connection of the complaint with the feelings and be able to give useful hints to the patient or her friends, as to the moral as well as to the medical management of the complaint. But his proper business is to correct the predisposing or constitutional cause, and to enable the patient to resist the exciting causes. An indolent, a luxurious, and an unoccupied life leads to late hours in bed, to an excited state of the imagination, to susceptibility of the nervous system, to irritation and turgescence of the generative organs, and to general or local plethora. It cannot be sanguinely hoped that females will relinquish ease, luxury, and enjoyment, for the dread of a distant and contingent ill. Most physicians of experience must have often observed the influence of these causes on the health, and have met with instances of females who, when in ease and luxury, were subject to hysteria, having become 
entirely free from it when reverses of fortune obliged them to employ both mind and body.

"Much depends upon the moral and physical education of females about the period of puberty in preventing hysteria. If more time were devoted to air and exercise and less to mere accomplishments-if less strenuous efforts were made to cram much ill-assorted knowledge into the mind during a very limited period-than usually is the case at the present day, an improved state of nervous energy and of constitution generally would result. There would, consequently, arise a race of females possessed of stronger minds, and better able to make good wives and healthy mothers, than those too frequently met with in the easier ranks of life. Of all the physical influences by which the human constitution is permanently impressed in early age, there are none so powerful as light, air, and exercise. Females, while the frame is being developed, should strictly observe early hours, so that the period of repose should never be prolonged much after the dawn of morning. The propriety of sleeping in a large, well-ventilated room, cannot be disputed. It will be prudent, where more than one must sleep in the same apartment, to have separate beds, each no larger than is necessary for one person ; and if the room is sufficiently large and airy, three, but no more, should sleep in it, preferably to two. When very early rising is enforced, the kind of bed on which growing females should sleep, is not very important, although a hair mattress is, perhaps, the best; but the bedclothing should be light and the sitting as well as the sleeping apartments ought to be moderately cool and airy.

"The kind of exercise which is most serviceable is that taken in the open air, anc in the light of day, and which brings into action the voluntary muscles generally, especially those of the lower extremities. It should preferably be on foot, and be regular, daily, and neither too little nor excessive. Sydenham, Fuller, Mandeville, and Manning advise riding on horseback, as affording the briskest motion, and occasioning the least fatigue. It ought always, however, to be used when the stomach is most empty, for, after a full meal, it retards digestion, rendering it uneasy and flatulent. It is most serviceable when hysteria is associated with retention of the menses, and a chlorotic state of the system, or when there is torpid action or obstructicis of the digestive and abdominal viscera. In cases of this description, the advice given by Mandeville will be found of great benefit. This is, to rise before six, to have half an hour's exercise in a swinging chair, fiying horse, or the common swingrope, and then breakfast; some time afterward to get on horseback, for at least two hours, either galloping or trotting as much as her strength will permit her; and, immediately after this, to be undressed, and assiduously chafed or dry rubbed for a considerable time, till her skin looks red, and her flesh glows all over. Manning observes that frictions are useful, not only in the cure of the paroxysm, but also as a prophylactic. He directs them to be used on the extremities and trunk of the body, and especially on the abdomen, when the digestive organs are weak. If hysteria be attended with the anomalous symptoms already noticed, or assume an irregular form, friction applied daily and assiduously along the spine will be of great service. Sailing has been recommended by Dr. Gilchrist in the treatment of hysterical and other nervous complaints, and in certain circumstances it will be found useful.

"Cold bathing, particularly salt-water bathing, and the shower bath, will generally be serviceable at this period of life, if females have no particular dread of 
either, and if the surface of the body be afterward well rubbed, and smart exercise immediately taken. For delicate constitutions, with a predisposition to the disorder, it will be preferable to commence with a warm salt-water bath, or with a tepid shower bath, the temperature being gradually lowered to the usual grade. Sponging the surface of the body also, every morning, with salt and water, or with water containing some vinegar or a little of the nitro-muriatic acid, the temperature being at first tepid, but gradually reduced to the usual mean of cold, will generally prove most beneficial, not only in preventing the complaint, but also in removing it."

It has already been remarked that hysteria frequently depends on some other disease, particularly on deranged menstruation, or indigestion. These primary disorders must of course be removed before a real cure can be hoped for, no matter how successful the palliative means may have been. A careful study must therefore be made of the patient's constitution, habits, and general state of health.

An opinion prevails very generally that in all these cases marriage is advisable, and in the great majority this is perhaps true, but not in all! It is sometimes a very difficult matter to advise upon, and it must be recollected that, if the experiment is unsuccessful, two persons may be made unhappy instead of one, without any advantage to the patient! It is seldom, however, that a competent person, of sufficient experience, will fail to indicate the proper course, particularly if his inquiries be answered with truth and candor. With those of a lymphatic temperament, and in torpor of the uterine organs, I have frequently employed galvanism, with marked benefit, particularly to the ovaries and os tincæ. Some anthors have recently recommended a sudden and unexpected burst of music, as a means of cutting short an hysterical paroxysm, and others have recommended a systematic use of music, suited to the case, as a means of actual cure! This is certainly a more pleasant remedy than many others, and may be in many cases quite as successful.

There are two peculiar forms of hysteria, or rather two kinds of hysteriform attacks, which, by some authors, are considered to differ from hysteria, properly so called. These are named gastrospasm, or spasm of the stomach, and cerebrospasm, or brain spasm. The first of these usually commences with serere pain, or spasm in the stomach, and there is little or none of the usual suffocation, or feeling of the ball rising. The general treatment is the same as that already given for hysteria, but in addition, if the pain continues, a teaspoonful of compound spirits of lavender may be given every half hour, till three or four are taken, and a mustard poultice may be put on over the stomach. If this does not relieve, and no fainting or convulsions ensue, an emetic may be given, such as a teaspoonful of antimony wine in half a teacupful of warm water every ten minutes, till it operates. In the cerebrospasm, a dash of cold water on the head, or a warm hip or foot bath, will be useful, in addition to the general treatment.

There is so little that is peculiar in these varieties, however, excepting what we have already mentioned, that any further attempt at distinguishing them is unnecessary.

\section{HYSTERALGIA.}

This disease is also called neuralgia of the womb. The symptoms are much the same as those of severe dysmenorrhea or metritis, but there is no inflammation or swelling. The pain, however, may be terribly severe, resembling that of tic douieureux, or neuralgia in the face; some persons have been made almost delirious by it. The 
treatment should consist of bathing, nareotic enemas, and injections, purgatives, and mustard poultices or blisters to the abdomen and thighs-in fact, much the same course as for rheumatism of the womb and for metritis. If it comes on periodically, quinine must be used, the same as for intermittent fever.

The causes of hysteralgia are too obscure to be definitely stated. Very frequently it is produced by other uterine derangements, and also by excesses, and by violence; or by improper marriage. It is very rarely met with. 


\section{CHAPTER LVI.}

GENERAI REMARKS ON FEMALE HEALTH AT EVERY PERIOD OF LIFE, AND OI CERTAIN PECULIARITIES OF FEMALE DISEASE, AND ITS TREATMENT.

\section{Puberty and Menstruation.}

Previous to the establishment of puberty, the female system presents no remark able peculiarities to distinguish it from the male system, but when that event occurs a complete change takes place, many new functions being performed, which exercise a controlling influence over all the others. The nature and extent of that influence has already been pointed out incidentally, so that we need do no more here than refer to its importance as connected with female health.

The establishment of the menstrual discharge is an event which every mother should carefully watch for in her daughter, so that no untoward accident may prevent it. About the time when it is expected, the young person should be questioned as to the state of her health and feelings, and her occupation and mode of life should be regulated in anticipation of the change.

The objects to be accomplished are, to favor the development of the uterine system, so that its functions may be properly performed, and at the same time to prevent any undue excitement, either general or local. The regulation of the diet is here of the first importance; it should be sufficiently nutritious, but easy of digestion, and not stimulating. Milk, rice, sago, young meats, and ripe fruits are appropriate for food, with milk, water, or weak wine and water, for drink. All heavy meats, unripe fruits, pickles, strong beer, spices, spirits, coffee, and pastry must be forbidden. Tea may be taken occasionally, very weak, but is better left alone ; and a little light sharp beer may be drunk, if there be sinking and debility, or claret wine.

Warm baths should be taken every other day, followed by a cold shower, and by good hard friction of the skin. Bodily exercise, in the open air, must be rigidly enforced, and of the most exhilarating kind. The young person should be encouraged to run, and to ride, to use the hoop, skipping-rope, and battledore, or other instrument of sport, as much as her inclination prompts. The body should be warmly clad, but not confined in any part, and the shoes should be thick enough to protect the feet from damp. Corsets and paper-soled slippers, if they have unfortunately been adopted, should be thrown aside, and the hair should not be bound in a close hard knot on the head, as that prevents perspiration, and keeps up a constant heat, which is a certain source of headache to many.

It is particularly important that the young person should know the reason for these cares, and that she should be told the nature and importance of the event which is about to occur. She will then be more disposed to observe all necessary regulations, and to communicate any symptoms she may have of its commencement. I have seen so many instances of the evil effects of keeping young persons ignorant 
on this matter, that $I$ am desirous of directing attention to it in a forcible manner. Many, in their ignorance, are dreadfully alarmed at the first flow, and fancy something dangerous, or disgraceful, has happened to them ; they therefore endeavor to stop it, for which purpose some put their feet in cold water, or put cold wet cloths on their persons; others walk till they are exhausted, and others again even take drugs, which they are told of by older companions. The mischief which may result from such practices is incalculable; serious disease, with a life of suffering, or even death, may reasonably be feared. And even when such things are not done purposely, they may be unintentionally, by those who are ignorant of themselves, and with the same evil result.

I once saw a most lamentable instance of this kind. A young lady of a delicate constitution, and retiring habits, entirely uninformed respecting herself, was suddenly surprised by the first menstrual flow. Her alarm was great, but her diffidence prevented her from alluding to the circumstance to her mother, with whom in fact she had but little confidential communication. One of her elder companions however, taxed her with it, and she confessed the truth, saying innocently that she did not know how to stop it! Her friend unthinkingly said that standing in cold water would stop it, for she had done so one night when she wished to go to a party ! The poor victim of ignorance did the same, and was not troubled with another appearance for near six months. During this time she became very unwell. She had a constant headache, with dizziness, dimness of sight, ringing in the ears, rush of blood to the head and face, with sickness at the stomach, and severe pains in her back, and in her abdomen, which was also much swollen. Her appetite was most capricious, her skin sallow, and her hands and feet almost constantly cold. She became at last almost too weak to walk, and so low spirited and dejected, that the slightest word made her cry, while her mind was so weak that at times she could scarcely be called sane. Ultimately she became delirious, and raved for about three weeks, when she partly recovered, but similar attacks afterwards occurred, more or less, every month. Many physicians of the greatest eminence had attended her, but no good whatever seemed to result from their prescriptions. I found, on inquiry, that they supposed it to be a case of non-appearance of the menses, with chlorosis. Being desirous of ascertaining the actual truth however, I requested a female friend to question her closely, during one of her rational intervals. She did so, and the poor sufferer made a full confession. I then at once recommended a course of treatment, which I thought likely to restore the suspended function. Her diet was made light and nutritious. She was taken to the sea-side and bathed regularly, and kept pretty constantly in the open air, on horseback. The only medicine given was a few pills of iron and gentian, and occasionally of iron and rhubarb, to keep the bowels free. A warm hip bath was administered every other day, and a warm injection at the same time. In addition to this, galvanism was applied to the uterus, in the manner indicated in the article on amenorrhoea, and also to the ovaries. No effect was observed for the first month, her delirious spell coming on as usual, and the other symptoms remaining much the same. About three weeks after, however, or nearly seven weeks from commencing the treatment, while she was riding out, the discharge came on quite suddenly and profusely. She was very sick and faint during the whole time it lasted, which was about four days, but after that she felt much better, and more lively. No delirious spell followed, and at the end of a month she menstruated again without any distress. From that time forward she began to im- 
prove, her strength returned, her feelings became more under control, and her mind regained its original vigor. A little attention was bestowed, for some three or four months, for a few days before the periods were expected, to insure their appearance; and a regular mode of life was enforced, beyond which nothing further was done. She is now perfectly healthy, both in body and mind, though she came so near being a victim to absurd prejudice and lamentable ignorance.

It must be borne in mind however, as already stated, that there is considerable irregularity as to the time of appearance, duration, and quantity of the menses, so that it is very difficult in some cases to decide whether assistance is really needed or not. Thus the usual age at which puberty becomes established is fifteen, but in some it may be natural for it to commence two or three years earlier, or later. The usual time for the flow to continue is four days, though it may be occasionally not more than two, or one, or it may extend to a week, or more, without any injury. The average quantity discharged is probably about six ounces, and yet some perfectly healthy females never have more than a mere show, while others may have a pint or more. It should be observed, however, that these irregularities are comparatively rare exceptions; the great majority of females, when healthy, observe nearly the above rule, both as to time and quantity. The only directions therefore, which can be properly given are, to observe well the general health; if that suffers in conjunction with any of these irregularities, it is desirable they should be attended to immediately; but if the person remains well, it is best to wait a little and observe. With young persons however, it is necessary to be watchful, because many symptoms of disease may either be concealed by them, or pass unnoticed, till great injury is done. The moral condition of young females about the period of puberty is also a matter of great importance. All high-wrought excitement, produced by reading fictitious adventures and scenes, and all sickly sentimentality, from reading mawkish romances, or listening to romantic companions, are very injurious. I have no doubt but such things produce numerous cases of hysteria and hypochondriasis, if not more serious disease. I need not reprobate those books, or associates, of a still more objectionable character, as these will never of course be openly allowed, but I would wish to caution against the too frequent contamination, from both sources, which occurs unsuspected. In various ways these books are obtained, and read, by hundreds who are supposed to be totally unacquainted with them, their real character being unknown, except by those who read them. The dangerous excitement thus produced may lead to the most deplorable results, both moral and physical, as every physician of experience well knows. With some temperaments, a too frequent attendance at the theater, or ball-room, may be followed by similar results, and very frequently I have known irremediable mischief produced by the vicious teachings of elder companions, particularly at boarding-schools. A more direct allusion to these things is neither necessary nor desirable here, but it was my duty to give a warning about them! Suffice it to say, that the evil is more extensive than is supposed.

The most proper and healthy education is that which fully develops the body, giving it strength and beauty, and which occupies the mind with useful and pleasing realities, rather than with mere fictitious dreamings. Bodily idleness, and emptiness, or trifling occupation of the mind, combined with improper food, produce more licentiousness and disease than any other causes whatever ! And active employment, with a well regulated diet, will do more toward preventing or removing these evils, than all the drugs in the materia medica, or all the moral precepts ever promulgated. 
It is not generally known that the health of young persons may be seriously affected by too close contact with the old. Such is undoubtedly the ease, however, and the fact should be stated. On this point Dr. Copland remarks as follows :-

"A not uncommon cause of depressed vital power is the young sleeping with the aged. This fact, however explained, has been long remarked, and is well known to every unprejudiced observer. But it has been most unaccountably overlooked in medicine. I have, on several occasions, met with the counterpart of the following case : I was a few years since consulted about a pale, sickly, and thin boy of about five or six years of age. He appeared to have no specific ailment; but there was a siow and remarkable decline of flesh and strength, and of the energy of all the functions-what his mother very aptly termed a gradual blight. After inquiry into the history of the case, it came out that he had been a very robust and plethoric child up to his third year, when his grandmother, a very aged person, took him to sleep with her; that he soon afterward lost his good looks; and that he had continued to decline progressively ever since, notwithstanding medical treatment. I directed him to sleep apart from his aged parent; and prescribed gentle tonics, change of air, etc. The recovery was rapid. But it is not in children only that debility is induced by this mode of abstracting vital power. Young females married to very old men suffer in a similar manner, although seldom to so great an extent; and instances have come to my knowledge where they have suspected the cause of their debilitated state. These facts are often well known to the aged themselves, who consider the indulgence favorable to longevity, and thereby often illustrate the selfishness which, in some persons, increases with their years."

It is very important to caution young persons against carelessness during their periods, particularly against exposing themselves to cold in any way, taking too violent exertion, eating anything indigestible, or giving way to violent mental emotions. A quiet state, both of body and mind, is most favorable, with just as much exertion as feels agreeable. Cold baths may be injurious, unless regularly taken previously. I know many who use them always, not only without injury, but with benefit. As a general rule, it is best to make but little change, unless particular indications point out its propriety.

It should also be recollected that the mind and feelings of young persons at this age are naturally in a very peculiar and interesting condition, and require the most careful and delicate attention on the part of their parents and guardians. They begin to experience new sensations and wants, and to be troubled by new thonghts and vague ideas, which stimulate curiosity, and excite the imagination to the highest pitch. A forced state of ignorance is very apt to aggravate this dangerous condition by enshrouding with mystery everything which is desired to be known. Under such circumstances, the most exaggerated and ridiculous fancies are indulged, even if worse consequences do not ensue, and wrong notions are entertained respecting themselves, and their future condition, which may have a most lamentable influence on their health and happiness. When nature prompts inquiry it is worse than useless to attempt to conceal! The suppression of useful truth then, can only leave the mind open to receive dangerous error! A prudent parent or guardian will always know what to impart, and when to impart it, and will feel the obligation to instruct her charge to be one of the most sacred duties.

It is neither necessary nor advisable to treat all the vagaries and caprices of young persons with indifference, or deride them, but on the contrary they should be 
respected, and sympathized with, or even judiciously indulged, rather than rudely condemned. It should be recollected that these fanciful notions are realities to them, and that it is not by harshness, but solely by kindness, and obvious interest, that we can so far gain their confidence as to convince them of their error. It should also be borne in mind that the female is always subject to certain powerful influences, unknown to the other sex, which modify her whole character, and which make it necessary to judge her with charity, and treat her with kindness and indulgence. Especially should this be remembered with the young and inexperienced, and with those who have been surrounded by unfarorable circumstances. I have known many an apparently severe indisposition, which had defied all medical skill, yield immediately to the condolence of trusted friendship ; and in numerous cases I have seen kindness and sympathy effect a thousand times more than pills and potions! Nor need such a circumstance excite any especial wonder or unjust suspicion, when the peculiarities of the system in females are recollected. With them the extensively connected uterine organs are constantly exerting a paramount influence on the nervous system, either by their own functional activity, or by the stimulus they receive through the brain. Woman is therefore essentially a creature of impulse and intense emotion, and in justice should be so treated. With her an unhappy feeling, a capricious fancy, or a wrong idea, should be considered as real a cause of disease as a tumor or a cancer! This is true of women at all ages, and in all conditions, though sometimes more so than at others. With her also moral treatment is often more efficacious than medical, and is therefore more appropriate. A kind look, or expression of sympathy will light up the languid eye, send a healthy gush through the veins, and impart a wholesome stimulus to the whole system, while drugs will only produce greater prostration of the vital energies. The nature of many female diseases, therefore, particularly those of a nervous character, is essentially different from any experienced by the other sex, and their treatment should of course be different also.

\section{THE CHANGE OF LIFE.}

The uterine organs eventually lose their preponderance, their functions cease, and they exert but slight influence, either direct, or indirect, on the rest of the system.

This great change, called the turn of life, does not take place however without a struggle, and before it is fully brought about the female is liable to many serious accidents. The final stoppage of the menses being in fact as momentous, to some persons, as their first appearance, or even more so, and exerting as powerful an influence on their health.

Many diseases which had lain dormant before, sometimes break out with fatal virulence immediately the change takes place, and many others that had remained comparatively slight, may become seriously aggravated. These evils, however, are by no means necessary or usual results of the change, but mere accidents, resulting from disease or a bad constitution. The cessation of the menses is as natural as their first appearance, and the constitutional disturbance resulting from it is also as likely to be beneficial as injurious. In fact, many females when they fully get over it, seem to become much younger and more healthy. They regain their flesh, their color, and their strength, and actually appear more juvenile at fifty than they did at thirty-five or forty!

Much unfounded apprehension exists both as to the danger at the turn of life, 
and its effects on the person. Unless the system be much diseased or debilitated, however, there is no particular cause for fear. It is true that every one feels more or less indisposition for a time, which may inconvenience and alarm, but which can nearly always be relieved by judicious treatment, and frequently prevented entirely by timely attention.

The usual age when the change commences is from forty to forty-five. It is sometimes, however, protracted to fifty, and even sixty, and in this country it not unfrequently takes place as early as thirty-five, or thirty! It may come on suddenly, so that the female, after having a period as perfect as usual, never menstruates again. Most usually, however, it is established by degrees, the quantity either becoming less and less, or the time between longer and longer, or both. Sometimes it will stop for a long period, and then appear again, as in the case of a lady whom I know. Sho ceased menstruating when she was forty-two, and commenced again when she was forty-six, and continued quite regular till she was forty-nine, when it ceased again; she is now fifty-three, perfectly healthy, and with no signs of its re-establishment.

When any especial disease arises at this period, it must, of course, be treated th? same as at any other, always remembering that it may disappear of itself, when the change is fully established. This is particularly the case with many of the slighter disturbances, such as headache, palpitation, dizziness, dimness of sight, and nervousness. We should not be too much in a hurry, therefore, to commence any strong treatment, but rather wait and observe, and assist nature when the indications are obvious how to do so.

It is particularly desirabie that females should not resort to medicine, as many do, to make the change take place safely. Numerous preparations are palmed upon them by interested persons, which they are told, and believe, will save them from al! danger. No specific of the kind is known, and in the nature of things cannot exist. The only precautions that are necessary and proper, are those which tend to preserve and improve the general health. These should be rigidly observed at all times, bu' particularly so now.

The body should be warmly clad, and regularly bathed, out-door exercise shouls be habitually taken, the diet properly regulated, so as to be nutritious, but not stimu. lating, and the mind should be kept tranquil and cheerful. In short, much the same regulations should be observed in this respect as those we advised at the commence ment of puberty. With women of a full plethoric habit, there is danger, when the excitement subsides in the womb, that it may take place in some other organ. In this way apoplexy is frequently produced, and palpitation of the heart, or various congestions and inflammations. The way to avoid this danger is for the female to lower the tone of her system by adopting a spare simple diet, cool acid drinks, and the shower bath, and to constantly exercise in the open air, so that the blood may be equally distributed over the body. She should avoid all intense mental application, or strong emotions, and not think of the change that is taking place. Some persons make themselves very unhappy in this way, and greatly increase the danger of their situation. They cannot help thinking of their past condition, and dreading the future. Their thoughts, especially when associated with others peculiar to certain temperaments, keep up the excitement in the womb, and protract the struggle. Such persons should recollect that the change may be the very reverse of what they fear, providing they observe proper precautions, and keep themselves tranquil. As already observed, many females regain their health, and improve in appearance, and suffer 
no deprivation but that of fruitfulness! Proper advice, acted upon in time, will effect this great change safely in most cases.

For some time previous to the critical period, or at least as soon as she feels intimations of its approach, the female must be particularly careful of catching cold, or of exhausting herself by late hours, or by breathing a close atmosphere. She should attend carefully to her diet, eat nothing indigestible, and use no spices nor alcoholic drinks. She should also avoid all kinds of excitement, and accustom herself, in every particular, to a regular and calm mode of life. Cold bathing, followed by good friction with rough towels, should be practiced, with sea-bathing at intervals, if practicable.

If there should be any congestion or inflammation in the uterine organs, it must be subdued by injections and fomentations, and other means pointed out in the article on metritis. The headache and dizziness is usually amended by a few purgatives, or low diet, and the shower-bath. Constipation of the bowels, which is a very constant and troublesome attendant at this time, should be combated first by change of diet and friction over the abdomen, and if these do not relieve it, injections of starch and olive oil may be used, or a seidlitz powder taken every other morning.

In conclusion, I would wish particularly to impress on my readers the fact that this change is not, necessarily, a dangerous one, but that most of the evils usually attending it arise from irregular modes of life, improper diet, and excesses of various kinds! A more strict observance of the laws of health would either prevent them altogether, or, at least, much mitigate them.

\section{USEFUL HINTS FOR ALL AGES.}

Women are in every way more sensitive than men, and require more precaution to preserve their systems in health. Want of knowledge respecting themselves also makes them more inattentive, and silly fashions often force them to adopt habits of the most injurious kind. Many causes of discomfort to them, and even of serious disease, are apparently so trivial that they remain unsuspected, or at best they are merely acknowledged. Some of these will now be pointed out, and commented upon.

There can be no doubt but that many young females suffer much from being pent up in ball-rooms, and other such places of resort, where the air is hot and unwholesome, and the associations productive either of excitement, questionable as to its good, or of envy, pride, and fretfulness. This is not, of course, meant to apply to rational, innocent, and exhilarating amusement, which is most beneficial under proper arrangements, but to those assemblages where amusement is the excuse, and rivalry, jealousy, and all kinds of unhappiness the actual realities.

In leaving these heated rooms, flushed with the exertion of the dizzy waltz, it is seldom that any precaution is taken by females, unless some one else advises it. They rush into the cold air with their arms and bosoms uncovered, drink jces while streaming with perspiration, and walk on the cold, damp ground with shoes that afford no protection. The consequences are they take cold, suffer from irregular menstruation, leucorrhœa, metritis, or consumption. All such obvious improprieties might easily be avoided, and are more productive of disease than is usually supposed.

As a general rule, females should wear flannel, particularly arcund the pelvis, to zuard against sudden changes. This is particularly desirable when puberty is 
about being established, during menstruation, and at the change of life. Those who accustom themselves to the shower-bath, however, will not be nearly so liable to take cold as those who do not.

Bad air, and strong odors of all kinds, have great effect on most females, particularly on the nervous. For this reason it is injurious for them to frequent crowded assemblies, or to sleep or live in ill-ventilated apartments. In like manner, the use of scents, which is so general, is very objectionable, or even the smelling of flowers, if too long indulged. We are told of a lady, daughter to one of the Counts of Salin, who died from inhaling the odor of a rose, and of another who was found dead in her bed from having left a bouquet of lilies in the chamber. A celebrated literary lady also nearly met her death from a quantity of flowers, which her friends had left on her birth-day, as testimonies of esteem, being placed in her bedroom. And many instances have occurred of fainting, hysteria, and even miscarriage from similar causes.

The philosophy of this apparently singular phenomenon is easily seen, when the extreme sensitiveness of the female nervous system is called to mind. The olfactory nerves are irritated by the odorous substance, and the irritation is conveyed by them to the brain, which again transmits the disturbance to the uterus and every other part of the body. In short, the odor acts through the sense of smell, the same as a disgusting object does through the sense of sight, or a disagreeable sound through that of hearing.

Too frequent warm bathing is an injurious habit, though a warm bath about once in a fortnight is advisable, and it should always be followed by a cold shower. The plentiful and regular use of cold water, both on the surface of the body and by vaginal injections, is one of the best preservatives of female health. By cold water I mean that which is about the temperature of the body, or nearly as we find it when exposed to the atmosphere during summer. Very cold water is apt to cause colds, leucorrhœea, and other disorders. This part of the female toilette is too much neglected in this country, and many evils arise in consequence of that neglect. In several of the preceding articles it has been shown how excoriations, inflammations, and adhesions, arise from a want of habitual bathing of the parts, especially in young persons ; and how these physical annoyances lead frequently to moral evils! This subject I wish to direct particular attention to again, and to remind females that the most scrupulous attention to cleanliness, in this respect, should be observed, both in the young and in adults. I have no doubt but that many cases of leucorrhœa, pruritus, prolapsus, and other evils, are produced by neglect of it. The French article of furniture, called the bidet, should have a place in every lady's dressing-room, and will be found a source both of comfort and health. The female syringe shoula be of tolerable capacity, but small in the part to be introduced, and curved, and the end should be pierced with several small holes. These may always be obtained at the instrument maker's or druggist's. Napkins used by females should be of soft linen, and never employed roughly, and for particular purposes, should always be well aired and warmed when worn.

In regard to female dress there are many things merely absurd, and which, therefore, need not be noticed here, though their correction is desirable, but there are others positively injurious, and which on that account require to be mentioned. The use of thin shoes, particularly at certain times, has already been adverted to, and cannot be too strongly condemned, and also the practice of exposing the bosom 
and arms to the cold air, after having been in a hot room. Close or heavy bonnets, and those of materials that will not allow ventilation through them, are decidedly injurious, by heating the head, and so is the habit of twisting and tying the hair into a hard knot. The use of corsets has been so frequently deprecated, and its evils so forcibly exhibited, that any special notice here is unnecessary. Suffice it to say, that there are few more fruitful causes of disease, particularly of prolapsus uteri, hernia, dyspepsia, liver complaints and consumption. The corset, in short, destroys both health and beauty, by interfering with the functions of the different organs, and by deforming the body! It is strongly to be hoped that a better taste is now arising, and that the female body will no longer be thought so imperfect naturally as to require crushing and squeezing into shape!

Around the body the dress should be perfectly loose, and no tight garters, bracelets, rings, shoes, or straps, should be worn. Tight shoes frequently cause headache and redness in the face, by preventing the proper circulation of the blood to the extremities, and tight yarters cause numbness and weakness of the limbs. It is desirable, also, that the dress should not press the breasts too hard, particularly at the menstrual period, or during pregnancy or nursing; but it is advisable for it to support them a little when relaxed.

In the article on the causes of disease, in Copland's Dictionary, I find the following apposite remarks, strongly confirmatory of what I have stated, and containing many valuable hints besides:

"Dress, even, has a very evident influence in creating a predisposition to disease. Too little clothing, particularly in females, favors the occurrence of difficult and suppressed menstruation, pulmonary disease, and disorders of the bowels. It was remarked during the French revolution, when it was the fashion to dress classically, -which was almost a state of semi-nudity, and more appropriate to the warmer climates of Athens and Rome than to those of the north of France and this country, - that pulmonary diseases, rheumatism, suppressed menstruation, bowel complaints, catarrhs; and amongst the children, who were exposed with naked busts and thin clothing, croup, and other diseases of the air-passages and lungs, were uncommonly prevalent. On the other hand, too warm clothing is a source of disease, sometimes even of the same diseases which originate in exposure to cold; and often renders the frame more susceptible of impressions of cold, especially of cold air taken into the lungs. The remarks now offered may be applied to overheated sitting and sleeping apartments, and to warm soft beds and bed-clothing. These relax and weaken the frame, dispose to disorders of the kidneys, urinary and sexual organs, and render the system much more susceptible of injurious impressions from without. A predisposition is thus produced, not only to catarrhs, inflammations, affections of the lungs, and rheumatism, but to irregularity in the menstrual discharge. It has been remarked that the females in Holland, who generally use very warm elothing, warm apartments, and warm beds, are very subject to excessive menstruation and fluor albus. Females, also, become disposed to various diseases, particularly those affecting the pulmonary organs and heart, from wearing very tightlaced and unyielding corsets. Indeed, those dressed in this manner can scarcely call the intercostal muscles into action, and can breathe only by means of the diaphragm. The mechanism of respiration being thus impeded, the requisite changes are not fully produced upon the circulating fluid; and congestion supervenes in the lungs, right side of the heart, and parts situated below the seat of pressure. This cause is 
especially injurious to females during growth and pregnancy ; for the chest should be fully and freely expanded, especially at these periods, in order that the circulation through the lungs and heart may be unimpeded; and that the blood should experience those changes without interruption, that are required for the derelopment of the body and of the fœetus. The functions, not only of the lungs and heart, but of the liver, stomach, and bowels, are materially interrupted, and even these organs themselves are removed from their natural positions in respect of each other, by this cause. This is more remarkably the case as regards the colon, which, by the squeezing together of the hypochondria and lateral regions of the abdomen, is thrown into unnatural duplicatures; the passage of fæcal matter along it being thereby impeded, and habitual costiveness, with all its consequences, produced."

Exercise in the open air is as indispensable as proper food, and no female can long remain healthy in body, or comfortable in mind, without it. There are hundreds of women who pass whole days and weeks in the house, and sit, or lie in bed, nearly the whole time. The consequence is they are always sickly, low-spirited, irritable, wearied, and often wearisome. They become dyspeptic, sallow, and weak; their hands and feet are cold, and their heads are continually aching, dizzy, or confused. Those who understand the simplest principles of physiology will see the reason for this, and if those principles were more generally understood there would be less of this irrational conduct seen. In the course of my practice $I$ frequently find it necessary to speak upon these subjects, and have known many cases in which my remarks have worked a reform. The exercise of females, however, should be less violent than that of men, and never carried to the extent of producing much fatigue. It should be varied as much as possible, and adapted to the wishes and wants of the individual, and should invariably be pleasing and agreeable. Tending the flower-garden, seeking plants for the study of botany, or rambling in the fields or by the sea-shore, and riding on horseback, particularly in cheerful company, are all excellent. So is dancing, but not in a close hot room, nor late at night, nor when the body is bound up in a tight dress, or the feet pinched in tight shoes. Under these circumstances the mere exercise will not counterbalance the other evils. With young persons real play, or even actual romping, is required, to exhilarate both mind and body, and send the blow bounding to the utmost extremities of the system.

A celebrated French physician, M. Tronchin, used to command his nervous female patients to scrub the floors, wash the clothes, and perform every other menial labor, and such was his influence that ladies of the highest rank would be seen on their knees, and at the wash-tub, working like their servants, and eating the same food. Though this treatment was unneoessarily harsh, yet its good effects were so palpable, in numerous cases, that none refused to follow it. In Russia, at the present time, when a fashionable lady is worn out with dissipation, and wretchedly nervous from idleness, it is customary to take her to the cottage of one of the poorest peasants, in the forest, and there she wears the same clothes, eats the same coarse food, sleeps on the same kind of bed, and performs the same labor as the peasant women. This is continued sometimes for months, without any relaxation, and usually effects a complete cure.

Copland's remarks on the influence of external circumstances, of various kinds, on the bodily and mental health of young females, are very excellent. In the article on "Age" he says :

"Period of Girlhood, - From the seventh or eighth year to the epoch of com- 
mencing puberty, is chiefly characterized by the continued growth of all the structures, and the development of the manifestations of mind. Toward the middle and end of this period, the physical and mental distinctions of sex become more and more apparent. The frame, when free from disease or hereditary taint, evinces a sthenic diathesis, a predominance of the sanguine, or sanguineo-nervous temperament, and a liability to nearly the same diseases, particularly those proceeding from infection and inflammation, that prevail during childhood. There is a greater liability to be affected with idiopathic continued fever ; with scrofulous enlargements and inflammations, particularly of the lymphatic glands ; with various nervous affections, as epilepsy, convulsions, chorea, etc. ; with cutaneous eruptions ; with inflammations of the throat and air passages ; with tubercles, especially in the lungs and alimentary canal ; with flexures of the spinal column, and with verminous diseases. The nerrous system possesses great susceptibility of impressions, moral and physical ; and inflammatory action has a marked disposition to give rise to new formations, unless when appearing in the advanced stages, or as a sequela, of eruptive or infectious fevers, when it generally occasions serous or sero-albuminous effusions.

"These diseases of this period generally require antiphlogistic remedies and evacuations, especially purgative, either alone or in suitable combination, unless proceeding from depressing causes, particularly those of a specific kind; and even there the necessity of resorting to alvine evacuations, by means of laxatives, or purgatives combined with tonics, is imperative. The vital resistance is usually well marked, excepting in those who have been deprived of wholesome nourishment and pure air, or whose constitutions are radically in fault; and in these, whilst tonics and other means of restoration are required, the due evacuations of morbid secretions and accumulations is equally necessary. Care also should be taken during this, as well as in the preceding period, not to allow the young to sleep in the same bed with the old, nor even with those advanced in age or debilitated, nor with too many-not more than three-in the same sleeping apartment, which ought to be large and well aired. Want of attention to this is one of the chief causes of disease in early life in London, and other large towns. Academies and boarding schools for both sexes are continually furnishing numerous proofs of this too generally overlooked cause of disease, not only at this, but also at a later stage of life. Attention is also necessary to the exercise of both the mind and the body. Active amusements in the open air are now particularly required. As this period advances, the mental powers acquire such a degree of development as to admit of their further improvement and active exertion, not only without risk to the organization with which they are related, but with the certain prospect of advancing them nearer to the perfection to which our natures may attain.

"During this and the earlier terms of life, frequent changes of locality and of air, particularly from one healthy and open situation to another, and especially to one which is more salubrious, where this can be obtained, are extremely beneficial, both in promoting the development of the frame and in removing diseases, particnlarly those of a chronic kind, or which affect the digestive and assimilating organs. In many of these diseases, more advantage has been derived from change of air than from the use of medicine. But, during advanced convalescence from these and febrile diseases, the benefit obtained from change of locality is most remarkable."

"The Period of Adolescence, commences with the first appearance of puberty, and extends to the twentieth year of females, and the twenty-fourth of males. 
Puberty appears at various ages, according to the climate, the circumstances connected with education, and the constitution of the individual. The usual period, in this country, is from the twelfth to the fourteenth year for females, and from the fourteenth to the sixteenth for males. In the northern parts of the island it is often a year or two later, in both sexes. It is frequently observed earlier in boarding schools, botb in respect of males and females. In the latter (in London or its vicinity), I have not infrequently met with instances of menstruation at ten and eleven years; especially in sanguine and plethoric constitutions, and where the apartments, particularly those for sleeping, have been crowded and close.

"This is one of the most important epochs of human existence ; for during it the natural development of the sexual organs imparts a healthy and tonic excitement throughout the economy ; bringing to their state of full perfection all the organs of the body and all the manifestations of mind, excepting those that are derived from experience. The organs of respiration and voice have acquired their full growth and tone, the muscles their due proportion, and the cerebro-spinal nervous system its beautiful organization; placing man, by the exercise of its admirable functions, at the head of all animated creation, the dread of all other animals, the wonder of himself. It is chiefly during this period of life that the mind becomes stored with ideas, derived both from the learning of the ancients, the science of the moderns, and the arts and accomplishments of highly civilized life ; and is more particularly and more ardently engaged in decomposing the information thus acquired, and recombining it in new and useful and attractive forms.

"As the functions and destinies of this period are important, so they require the smperxision of the experienced and the good. For, with this development and activity of both the physical and mental powers, the instinctive feelings and emotions of our uature have also reached the utmost limits of their activity; and many of them, particularly those which are related to the perfect condition of the reproductive organs, acquire an ascendancy, that both the dictates of reason and moral restraint are required to control. Hence the propriety, both at this and the preceding period of life, of improving the moral affections of the mind; of inculcating sound principles of action and conduct, founded on moral and religious obligations; and of placing them in such relations to the feelings, the intellectual manifestations, and, moreover, to the accomplishments, the elegancies, and the endearments of life, as to render them attractive to a state of mind and constitution which is more easily allured by example than taught by precept.

"The evil practices which both sexes are liable to acquire at this period of life, and to which they more commonly become addicted when they associate in numbers at seminaries and academies, demand the strictest prevention. They have been too generally overlooked, both morally and medically, from the circumstance of their eonsequences having been imperfectly appreciated. There is no practitioner of observation and experience,--none even of limited knowledge,-who is altogether unacquainted with the physical exhaustion, the mental torpor, and all but annihilation of existence, which is the ultimate result of indulging them. From this source frequently spring, impotency hereafter; the extinction of families and hereditary honors-honors which such persons are incapable of achieving; the infliction, during after-life, of many of the diseases which proceed from debility, and the exhaustion of the nourishment and vital energy of the varions structures and organs; numerous nervous and convulsive maladies, as hysteria, epilepsy, neuralgia, chorea, 
melancholia, mania, idiotcy, etc. ; the dangerous or fatal visitation of fevers, diseases of the heart, disorders of the digestive organs, premature baldness and old age, the formation of tubercles, and the production of pulmonary consumption; and, lastly, the transmission of weak and decrepit bodies and minds to the offspring, of scrofula, rickets, verminous complaints, marasmus, hydrocephalus, convulsions, tubercles, chorea, etc. ; the curse is visited on the children to the third and fourth generation, until the perpetuated punishment extinguishes the very name of the transgressor."

Many of the occupations in which females pass much of their time are decidedly hurtful to them. Sewing, and other kinds of work which require them constantly to sit, with the head drooping forward, are among the worst. Sad proofs of this are seen in numbers of poor dress-makers and milliners, who are constantly complaining of headache, dizziness, dimness of sight, ringing in the ears, difficulty of breathing, and palpitation at the heart; without enumerating more serious disorders, which, however, are common enough among them. One hour at a time is long enough for any female to sit with her needle, and that should always be followed by some active exertion.

In regard to food, enough has already been said for general directions, at each period of life. It is advisable to add, however, that women, owing to their comparative inactivity, require simpler and less stimulating diet and drink than men, and that they suffer more from excess or impropriety in eating and drinking. Every individual should carefully observe for herself how she feels after different kinds of food and drink, and by such means she can establish much better rules, in regard to her diet, than any physician can do for her. There are few women that are not injured by the habitual use of spices and pickles, or strong coffee or tea. In fact, both drinks should be used sparingly, and very weak, especially by the nervous and by those who wish a clear complexion. White bread is neither so wholesome nor yet so nourishing as that with the bran in it, though a mistaken notion prevails to the contrary. Bran bread contains more of the elements required for the support of the body than pure flour bread ; it also relaxes the bowels in an easy and natural manner, while white bread almost always constipates them.

Constipation of the bowels is a very general complaint among females, and produces the most disastrous results. It should always be attacked by change of diet, exercise, friction over the abdomen, enemas, or galvanism, rather than by purgatives, with which many women seriously injure themselves.

The state of the mind and feelings has a very important influence on female health. Cheerfulness and contentment keep the nervous current equable, dispose to activity, and favor the proper performance of all the functions, while discontent, fretfulness, and irritability have precisely the contrary effects. Many females, owing to a fault in their education, are constantly tormenting themselves, and displeasing others, by getting irritated or fretting about mere trifles of no real consequence whatever. Such persons are always nervous or miserable, and constantly disposed to ill health in consequence. They should endeavor to school themselves into a little more indifference about such things, and remember that putting themselves about over a little annoyance only makes it greater, without doing any possible good. This tendency to distress themselves about small evils, and to fix their inclinations so strongly on trivial things is extremely unfortunate, both for their own welfare and for the comfort of others. It arises entirely from the trashy education which most females 
receive, and from the frivolous nature of their occupations. By directing their thoughts to more ennobling objects, expanding their minds, enlarging the sphere of their observations, and by extending their sympathies, this tendency is removed.

All powerful emotions, as those of anger, envy, jealousy, and hate should be carefully avoided. They derange the stomach, liver, womb, and other organs, and destroy the equilibrium of the nerves. A fit of anger will cause vomiting, diarrhoea, flooding, miscarriage, fatal apoplexy, and other serious results; and habitual ill temper, envy, and dissatisfaction will produce sallowness of the skin, melancholy, or hysteria.

The celebrated Tissot gives us an instance of a female who was taken with conrulsions whenever she heard her rival's name mentioned, and history tells us of a French princess who died from jealousy when she heard that her husband had become attached to another lady. An Athenian lady is recorded to have lost her speech from anger, and another, we are told by Buchan, died from the same cause. Grief has produced similar results, and so has shame, and even avarice, of which we have an instance in the niece of the celebrated Liebnitz. He had left her all his fortune, and immediately on his death she broke open his trunks, which were filled with gold, and died almost immediately from joy at the sight. Had there been nothing, she probably would have died from her disappointment. The only way to avoid these evils is to keep the mind occupied with some useful and pleasing pursuit, and strive to be cheerful, contented, and calm, and never to worry about trifles, or what cannot be avoided.

In regard to the smaller matters connected with the toilette, it may be thought by some that they are unworthy of notice in such a treatise as the present. I think differently, however, and for these reasons : many preparations are used by females which have an injurious influence in various ways, and many others might be used that would have a contrary effect. The objects in view in employing these articles are, the removal or concealment of defects, and improvement of the appearance, which, in themselves, are laudable enough, and I consider it my duty to assist in accomplishing them. A pleasing appearance is desirable in all persons, but especially in females, and it is advisable, within proper bounds, to encourage their efforts to produce ît.

There are few among the thousand and one articles prepared for the toilette that are useful, and very many that are positively hurtful. Among these may be mentioned the different cosmetics for whitening and smoothing the skin, which almost invariably produce the contrary effect. Nearly all these preparations are composed of oxides of mercury, antimony, arsenic, and other poisonous substances, and they frequently cause eruptions, palsy, convulsions, sore eyes, and salivation. The distilled waters are perhaps the least objectionable articles of the kind, though I scarcely think any of them equal to clear soft water alone. The ordinary metallic rouge is decidedly hurtful, and when persons will use something of the kind, the vegetable rouge had better be substituted. This is extracted from the red sanders wood, or alkanet wood, steeped in alcohol, and also from cochineal. Instead of pearl powder there is the preparation of steatite, or French chalk, which may be used for whitening the skin, and which is not likely to do any injury.

The only real beautifiers of the complexion are a regular life, proper diet, exercise in the open air, and pure water. Health of body, and cheerfulness of mind, will send a healthy glow to the cheek, make the skin clear and smooth, and impart 
vigor and elasticity to the limbs. When the skin becomes harsh and discolored from dissipation, exposure, the use of paints and washes, irritable feelings or other causes, there are few external applications that will do it any good. Some preparations will certainly make it appear for a time clear and ghastly white, but they do so by partly destroying its vitality, and eventually leave it discolored, eruptive and wrinkled, thus accelerating old age instead of retarding it. M. Colombat de L'Isère gives the following recipe for a lotion, which will soften and otherwise improve the skin without doing it any injury :-Balsam of mecca, ten drops; sugar, one drachm; the white of one egg; rose water, six ounces. Mix all these articles well together, and strain the liquor if necessary. A soft linen rag may be used to rub it on the face at night, and it must be carefully washed off with clear soft water and some mild soap in the morning. Sweet almond ointment is also very good, if fresh and pure; but the best ointment is made from cucumbers. Equal parts, by weight, of thin sliced cucumbers and pure lard should be boiled together till the cucumbers become crisp; it should then be strained and set aside to cool. This is an excellent application for the skin, and may be advantageously used for various eruptions. It may be colored, if desired. by putting in a little alkanet root while it is boiling, and scented by a few drops of essence of roses. For chapped or discolored lips there is nothing equal to this ointment.

Many of the soaps sold for the toilette have a bad effect on the skin, from containing too much alkali. Those that become hard and crack should be particularly avoided. Almond oil soap, properly prepared, is tolerably good; but the best appears to be a preparation made by the French perfumers, called liquid soap or oleine. Glycerine soap, tar soap, or that containing carbolic acid, are also excellent. All those chemical soaps for cleansing the skin and removing spots, etc., so much vaunted, should be shunned like the plague. They are chiefly composed of arsenic and other poisonous substances. Borax soap, however, is both harmless and beneficial; or a weak solution of borax, not stronger than half an ounce to the quart of water.

The employment of depilatories, or preparations to remove superfluous hairs, is exceedingly dangerous. These articles chiefly consist of quick lime, arsenic, and other caustic substances, and frequently produce ulcerations, palsy, paralysis, blindness, and various organic derangements. Their use must also be constantly persisted in, because, though they remove one crop of hair, they cannot prevent others from appearing, so that the use of them must keep the skin continually covered with a paste of virulent, caustic poisons.

Most of the preparations for dyeing the hair are also poisonous, and sufficient injury has been done by them to warrant us in decrying their use. The hair itself is a great ornament to the head, and most females feel desirous, and very properly, to have it soft, clean, and abundant. There is no doubt but most of the pomatums, greases, and other articles sold for the purpose of making it so, not only fail, but even produce the contrary effects. The head and hair should be frequently well washed with the solution of borax above given, or with tar soap, and when dry thoroughly combed with a very fine comb. This will not only cleanse it, but also polish it, and make it soft and glossy. A little clear perfumed oil may be used, mixed with cologne, but no paste or pomatum. If there be dandruff, it should be removed with the comb and brush, and after the head is well washed and dried a little of the cucumber ointment may be rubbed on the scalp occasionally. The chief causes of dandruff are heat of the head, by study or exciteu feelings, the use of close bonnets. 
or tne habit of keeping the hair constantly twisted up very tight, and the want of regular washing to cleanse the skin and open the pores. Calmness of mind, regulation of the bowels, and the shower-bath will frequently remove this troublesome disorder, without anything else. Pure bay rum is an excellent preparation to rub the scalp with when there is dandruff. It should be well rubbed in the roots of the hair. The article called vaseline, made from petroleum, is a very excellent thing for the hair or skin.

The use of hot curling-tongs makes the hair harsh, and spoils its color, and even disposes it to turn gray. Metallic combs are apt to cut it, and should therefore not be used. It is an excellent plan to stroke it downward frequently with a horse-hair glove, which will soften it and give it a high polish.

The teeth we need say but little about, if they are decayed, as it would be better for ladies, in that case, to apply at once to some good dentist. I would caution them particularly, when needing assistance, not to resort to any of the empirical nostrums advertised, but seek assistance at once from some really scientific man. There is no doubt, however, but that a vast deal of the decay in the teeth, so universally found, might be avoided. General good health, maintained by proper diet, exercise, and other means already pointed out, would prevent much of the evil, particularly if the inside of the face was as regularly cleaned as the outside! Most persons leave their mouths entirely untouched, so that the decaying food and the vitiated fluids are constantly acting on the teeth, and soon corrode them. A soft brush and clean tepid water, used night and morning freely, would prevent much of this decay; and if half a teaspoonful of fine chalk were well washed round the mouth and teeth for five minutes before the brush is used, it would come as near preventing it altogether as probably anything can. Many of the tooth powders used contain acids and other injurious substances, and none of them are a bit superior to fine chalk.

The mouth should be carefully rinsed after taking any acids or medicine, and very hot or very cold substances should never be introduced, as they injure the teeth by sudden contraction and expansion of their substance. Magnesia is an excellent substance to use, either as a tooth powder or to rinse round the mouth at night, as it neutralizes any acid that may be found ; or the solution of borax mentioned above. Goou mild soap, especially borax soap, is, perhaps, the best thing of all to brush the teeth with, both to cleanse and to preserve them. 


\section{CHAPTER LVII.}

ON SOLITARY VICES, AND OTHER ABUSES.

IT is seldom the case that this subject is broached to females in any form, but every person at all acquainted with it will admit that it ought to be so, and perhaps more especially to them than to other persons.

It is not only necessary on account of females themselves being often the victims of these vices, but also because, as mothers, they of necessity exercise a supervision over the conduct of their children of both sexes, and they therefore ought to be acquainted with every matter of importance to their welfare.

I am convinced that much of the evil we see arising from this cause, in children, would be prevented if mothers were better informed about it, and had their attention properly awakened in time.

Some persons suppose that solitary abuse is altogether confined to males; but this is a great mistake. It is doubtless most frequent with them, and in general affects them most injuriously ; but it is useless to deny that it is extremely prevalent even with the other sex, and likewise leads in them to the most serious consequences.

The nature of my professional experience necessarily brings me much in contact with peculiar cases of this kind, and I feel it my duty to refer to this subject in the most emphatic manner, more especially as it has hitherto been generally overlooked.

In no other place could it be so appropriately treated upon as in a work of this kind, intended for the special instruction and warning of both males and females.

From various causes, many of which have been alluded to in our previous articles, and others which will be as we proceed, the sexual instinct or desire is often awakened at too early a period, or excited to a most immoderate degree. Sometimes, even in mere children it is strongly developed, so as to lead to unnatural practices at the most tender age, and at other times it becomes so ungovernably intense that everything is forgotten or disregarded in the blind craving for its indulgence.

In our boarding schools for young females, it is well known to medical men that these vices are fearfully common, though from their nature they are seldom alluded to. The physician contents himself with treating the effects, but never alludes to the cause! I have known cases where every pupil in such establishments has been led astray in this manner, and to the most alarming detriment of their health.

From vicious association, or some other cause, one among the number learns the habit and teaches the others, till all become contaminated, and usually without suspecting either any great impropriety or any injurious result.

I know that many of the most pure-minded and virtuous young females have heen thus led astray, and when made aware, either by proper instruction or by dearbought experience, that they have been doing wrong, they often experience the most 
poignant remorse. It is their fault, however, in only a slight degree, for most of them are kept so entirely ignorant of all they ought to know respecting themselves, that the wonder would be if they kept in the right path. Parents have much to blame themselves for in connection with this subject, particularly mothers; and I trust these few remarks will awaken their attention to a matter of such momentous importance.

Some time ago, I made an allusion to this subject in one of my lectures to females, and was surprised at the number who afterward spoke to me corroborating my statements. Many aged persons, and mothers of experience, voluntarily testified to the truth and value of what I had said, and urged me to press this matter still more than I had done.

One venerable lady, particularly, confessed to me that when she went to a boarding school, in her young days, these vices were so prevalent, and the effects upon the health of the scholars were so alarming, that it was thought some epidemic disease must prevail, and they all went home.

Another lady informed me, with the greatest agony of feeling, that her daughter came home from school to die from these practices, and confessed it to her parent on her death-bed.

I have also received numbers of letters, from females of all ages, making similar confessions, and asking what they must do to recover from the effects of their thoughtless practices. Among them, I select the following one, as the writer is now no more, and I know that no one can even suspect who she was, nor indeed would any of her numerous friends and admirers believe the possibility of her ever having been the victim she was :

"DeAR FrIEND :-It is with feelings of deep shame and remorse that I sit down to make this confession; but in the hope that it may save others from the abyss into which I have fallen, and also be the means of some little good to my own unworthy self, I feel that I ought not to fail in doing so. You, I know, can both sympathize with and excuse me-perhaps more so than I deserve ; and I will, therefore, unburden my mind of a terrible weight which has lain heavily upon it for years.

I am now advanced in life, reing fifty-one years of age, and the mother of two children-one, alas! a sufferer from his mother's folly while she was yet a child.

I was first taught the naiure of sexual feelings, and how to excite them, by a servant girl, when only eleven years of age ; and being naturally of a warm and excitable temperament, the gratification was very great, and was frequently indulged in. I had not the slightest idea, when first commencing this disgusting practice, that it was wicked or hurtful, nor did I even suspect so till my health began to fail. Fortunately, an old medical book fell in my way, which spoke upon these matters, and that first opened my eyes to the sin of my conduct. $\mathrm{Oh}$ ! that such books as yours had then been written, and that one had fallen in my way; years of suffering and mental anguish might have been spared me, and my dear child would not have been a living memento of his mother's folly.

The symptoms which I first began to experience, when about fourteen or fifteen years of age, and which increased as I advanced in life, were of the most distressing character. Extreme languor and weakness, with a disinclination to either bodily. or mental exertion, accompanied by a miserable lowness of spirits that nothing alleriated, were my constant attendants. I hated myself-I could not enjoy life-and I feared death. My head was always heavy and full, and my eyes often red as if with 
constant weeping, while my judgment became gradually weaker, and my memory failed, till I could neither decide what to do in future, nor remember what I had done. Fortunately, I was so circumstanced that others took care of me, or I know not what I should have done.

My physicians attributed my sinking health to dyspepsia, to the change of life, and various other causes, and prescribed medicines and change of air, but not one seemed to suspect the real cause of the evil.

For years I struggled on in this way, striving against the demon of strong desire with all the strength I had, but only to fall at last. Each act of gratification seemed to become more urgent than the former, and also to prostrate me, both bodily and mentally, still lower than before. At last I became utterly prostrated, and lay for many weeks at the point of death, from mere weakness and exhaustion. Providentially this was the means of my salvation. The bodily exhaustion seemed to weaken my morbid excitability, and my fear that I really should die gave me new courage, so that with returning strength I broke the shackles which had hitherto bound me, and became free. From that time I never once debased myself with the degrading practice again, and my health and appearance so improved, that my friends could scarcely believe it was me they saw.

I, however, still suffered from a shattered nervous system, and though well, compared with what I had been, felt that, more or less, the consequences of my fault would follow me to the grave. At times I would be attacked with fits of melancholy and extreme depression of spirits, without any apparent cause, and would become so wretched that death would have been a relief. My old weakness of the limbs would also come on occasionally, and my mind, I feel convinced had not its natural power.

At twenty-two years of age I was married, and lived happily with my husband for twenty-one years, having during that time three children, of whom one died. The youngest of those living, from his birth, exhibited the same unfortunate tendency of the nervous system as his mother, and, with horror I confess it, was evidently born with a disposition to the same evil habits. Oh! the hours of watching and intense mental agony $I$ endured while rearing up that dear child, and oh ! the bitter accusations my own heart brought up against me, for I could not doubt that: his moral infirmity was inherited from nisself.

As soon as he could understand, I hesitated not to speak to him openly and candidly about it, and by gaining his confidence and love, was enabled to save him from certain destruction, though not altogether from suffering.

For myself, I still suffer, though none suspect the cause, and I daily see, among my dear young friends, many bright buds of promise withering away, as I did, and no one dreaming why.

Wherever I can. I speak on this matter, in such cases ; but the ignorance of parents is so great, it is not always possible to do so with advantage. I have the satisfaction, however, of knowing that many have been saved by my efforts in this way, and thus my own fall has perhaps been the means of keeping others in the right path.

Oh, with what delight I first heard your lectures, and read your books! At last, said I, a better day has dawned, and females will no longer be compelled to suffer and die from mere ignorance. May you be spared to complete your work, and may the satisfaction of feeling that you do good, ever attend you.

Most truly yours,

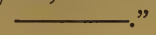


This letter is but one out of a large number equally interesting and instructive, but from the private nature of most of them, and also because the writers are still living, I do not deem their publication to be proper.

The symptoms arising from solitary vice are well sketehed in the above letter, though they are often much more severe, and many are experienced which are not there mentioned.

The hospital, the lunatic asylum, and the grave would tell fearful tales respecting this habit, if their records were truly written.

The immediate effects of this vice are, great lassitude and depression of spirits. This is followed, after a time, by other symptoms, many of which are never suspected to arise from this cause. Most generally the memory soon begins to fail, and the mind cannot be directed to one thing for any length of time, but wanders continually; sometimes it eren becomes unsettled altogether, and complete fatuity results. 'The senses are very apt to fail, particularly the eyes, which become affected in various ways, from mere weakness to every degree of inflammation, and even blindness. The hearing will often become affected, and the head will be subject to a distressing fullness, with dizziness, noises, and soreness all over. The individual becomes excessively nervous, full of apprehension, irritable, and wretched. He dislikes society, from mere incapability of exertion, becomes at last melancholy, or mad, and often terminates his existence by suicide. The different organs become more or less deranged, and perform their functions imperfectly : this is particularly the case with the digestive apparatus, the kidneys, and bladder. In males, the genital organs themselves begin to fail ; they shrink away, the gratification becomes less, and finally complete impotence and aversion follow.

All these symptoms are, it is true, seldom found in one person, but more or less they characterize every case. Some persons will begin to experience them very soon, while others will not for a long time. It is but rare, however, that any one who practices abuse will miss them altogether.

I do not hesitate to say that a very large portion of the human race are guilty of this excess, probably the great majority, and that a large portion of the evils and suffering which afflict society are produced by it. Indeed, I believe that licentiousness, in one form or other, is the cause of nearly all the disease, both of body and mind, which exists !

Solitary vice, however, is much more prevalent than any other form of licentiousness, and much worse in its effects. Dreadful as are the consequences of excess, in the natural way, they are but trivial compared with thiose which follow from solitary vice; nor do I think they can, under any circumstances, equal them.

Most persons are aware that this practice prevails, and that it is injurious, but it is only those who have long been familiar with it, as a subject of practice and study, that can be aware of its great extent and fearful effects. The truth, in fact, can scarcely be believed by those not familiar with it. My own opportunities for acquiring information have been very great, so as to make me acquainted with this terrible evil in every particular, and I do not hesitate to say that it is the master evil of the present day! I am firmly convinced that it leads to more disease of body and mind, more suffering and premature decay, than all other causes put together! Here I make no reservation, nor do I exaggerate, but, on the contrary, I feel convinced that my statement is under rather than over the trutb.

This rice is almost universal, the exceptions ta it being very rare, particularly in 
the rising generation. I believe it may be safely asserted that ninety-nine out of every hundred are addicted to it! And such are the circumstances in which young people are now placed, that, instead of its decreasing, it is every day becoming more confirmed and extended.

I have reason to suppose that it is as general in the one sex as the other. If there be any difference, it is possible that females practice it most; but simply because they less frequently have natural indulgence in their power.

It is often commenced in extreme youth-nay, even in childhood. I have known instances of children not more than eight years of age, and even younger, being addicted to it. In most of these cases no such thing was suspected, and the poor victims were fast hurrying to an untimely grave. Even when told, their guardians could scarcely believe the statement, till their own observation convinced them it was true. They were then extremely anxious to have the evil removed, which, fortunately, was in most cases accomplished. It is not merely an error of youth, however, but becomes a confirmed and growing habit, to which the individual is a victim all his days. I have known middle-aged, and even old persons, who had never been able to emancipate themselves from it.

With regard to the commencement of this practice, some persons have supposed that it must always be learned from another, or at least that some intimation must be had of its nature before it is begun. This, however, I know is not always necessary. From various causes, most of which we have stated in a former part of this work, the genital organs become precociously developed, and highly sensitive. This produces slight irritation and uneasiness, to relieve which the hand is directed to them, the friction of which produces a new and pleasant sensation before unknown. When once this has been experienced, the desire to create it again becomes irresistible, and with each new indulgence the habit strengthens and becomes more confirmed. In most cases the individual is completely ignorant of the nature of this new indulgence, and knows nothing of its probable consequences. This knowledge, if given in time, would often destroy the habit, but it is seldom given till too late to be of service; indeed, in most cases, the victim has to find it out by dear-bought experience.

Nevertheless, this practice is most generally acquired from others, and for this reason prevails in nearly all institutions where young persons are congregated; nor can this be prevented under present arrangements. Many conductors of these establishments are unacquainted with the existence of the evil ; others use every means they can devise to prevent or suppress it, though often without success. From the nature of the practice it cannot be prevented, when there is a disposition to it, unless the offender is kept under constant surveillance!

In my public lectures I have always made this a special topic, speaking the trutb upon it without reserve, but in charity, and with a sincere desire to do good. This has made me the confidant of hundreds, who would never have disclosed their failings to any one else, and has enabled me to gather more facts bearing on the subject than, perhaps, ever came in the way of any one individual before. It is neither useful nor just, however, to expose the weaknesses of human nature, more than is necessary for their correction: I shall, therefore, only make use of the information I have thus acquired in a general way, and for that purpose.

When in New York City, a few years ago, I was accosted, after my lecture on this subject, by an old gentleman, who desired to speak with me in private. When 
we were alone, he said to me: "Doctor, you are the first person I ever heard speak plainly on this evil practice, and as I am, unfortunately, aware, by sad experience, of the truth of your assertions, I felt much interested in your discourse, and resolved, if you thought fit, to communicate the details of a case with which I am but too familiar." I thanked him for his confidence, and he gave me the following particulars :

He had a son, a fine, healthy, lively child, about eleven years old, whom he sent to a celebrated academy for young gentlemen, in the suburbs of a neighboring city. For the first six months he continued to receive the most flattering accounts of his son's progress, and was highly pleased with him when he returned home at the vacation. In a short time after he was surprised and grieved to hear that his health was failing, and that he was much more backward than formerly. Medical advice was sought immediately, and the assurance was given that there was nothing serious the matter, and that he would probably rally in a short time. The child kept on in this manner for twelve months longer, gradually becoming worse, until at last he was brought home. The father described his condition at this time as most distressing. He was thin as a skeleton, weak in body and mind, and completely sunk in a deep despondency, from which nothing seemed permanently to rouse him. At last he took to his bed, and died before he was thirteen. One night, however, while he was sick, the father was sitting up with him, and, being weary, leaned back in his chair, with his eyes closed, as if asleep. While in this state, some motion of his son partially roused him, and through his half-open eyes, he saw him in a situation which left no doubt that he was practicing masturbation. The feelings of the father can better be conceived than described. Being a man of information, he partly knew the consequences of this vice, and immediately the idea rushed upon him that this was the cause of his son's sickness, and he at once resolved to discover if his suspicions were true. In the morning after, he began to talk with his child about his school-fellows, asking him as to their practices in play, etc. ; and at last fixing his eyes npon him, he asked him if any ever practiced this habit before him ? The child burst into tears, and laid his head in his bosom. By a little gentle management he led him to confess that he had been addicted to this vice ever since he went to schoul, having been taught it by a playmate. Sometimes he practiced it three or four times in a day. He also assured his father that there was not one he knew in the school but what did the same, it being considered a meritorious thing, and one which every boy should aim at. The poor fellow had become partly aware, himself, that it was causing his misery, and wished he had not done it; but it had become so much a part of his nature, he could not refrain. The father felt as if a thunderbolt had broken upon him. Here was his only child stricken before his eyes, and nobody suspecting the cause till it was too late. Said he to me- "I hope my sad experience may enlighten some one else in time."

A short time after, while lecturing at the city where his son was sent, I was introduced to the principal of the very school, whom he had already mentioned to me by name. Finding him a man of intelligence, I commenced talking on the subject of solitary vice, and observed that he appeared much interested. As confidence became established, he at last confessed that the prevalence of this practice among his pupils was a constant annoyance to him.

"I know," said he, "that my establishment is only like others, for I do not think there is one in which it does not prevail m.ore or less; but as I know how baneful it 
is, I am deeply concerned about it. I find it impossible to prevent it altogether, do what I will. All our scholars sleep separate, and we keep a constant eye upon them, but still I know the evil exists ; and by some accident or other, each new-comer becomes tainted with it. I am firmly convinced that there is no institution where young people are brought together but in which the practice may be found, and I have no faith in any means preventing it but such as you propose."

Numerous indeed are the melancholy instances of this kind daily to be met with. Many a youth, robust with health, and with every indication of the highest talents, is sent by his parents to some seminary to complete his education, and returns after a time debilitated in mind and body, and without either hope, energy, or capability. They mourn over his ruin, but never dream of what caused it; and even if told, could not, in many cases, understand how it had been brought about. I have a case of this kind in my mind now. It is that of a young man who had made the highest attainments, and who gave promise of being one day among the first and greatest in the land. His friends looked upon him with pride and confidence, and gloried in the prospect of his future exaltation. But alas! a blight came over their hopes; he began to fade, his mind became imbecile, and at last he sank far below the ordinary standard, without even the desire to rise. He was pointed out to me by a relative, who also told me that it was the practice of solitary vice, learnt at college, which had made him the melancholy wreck he was.

On another occasion, an old man spoke to me after my lecture, and told me that he had a son who had long been in a desperate condition, whose cause of complaint he had never been able to ascertain. "But," said he, "from what you say of the effects of this practice, I think that must be it ; I will, however, ascertain if possible immediately." The next week I saw him again, and he told me that he had asker the medical man, who had his son in charge, whether he thought such was the case, and he immediately replied, "Yes ! now you have asked me I can tell you. It is that practice, and nothing else, which has brought your son to his present pitiable condition. I did not like to mention it to you before, for fear you might be, like many others, merely offended with me for speaking the truth; but since you ask, I presume you desire to know." The young man was then so weak he could scarcely stand, and so much affected in his mind that a person was kept with him continually, to prevent him committing suicide. I saw the father, a little time after, again, and he told me, with tears in his eyes, that his son had died in the mean time. "Had it not been for you," said he, "I should never have known what killed him. I have now another child, much younger, who might have died in the same way; but now I know the evil, I trust I shall be able to prevent it."

Another case, somewhat similar, came under my notice of a little girl, who had been taught the practice by a female servant with whom she slept. The mother fortunately discovered it befor the evil was gone too far, and by a proper course of moral and medical treatment it was soon suppressed altogether, and she perfectly recovered.

In one instance I knew a boarding-school where fourteen young females resided, which had to be entirely broken up on account of this practice. One after another fell sick, and all eventually were sent home; previous to which, the principal ascertained, from the confession of one among them, that for a length of time they had all been addicted to this vice. Nine out of these fourteen died in less than five years after ! 


\section{CHAPTER LVIII.}

\section{INTERESTING FACTS RELATING TO PAIRING AND COURTSHIP.}

THE very lowest beings have more in common with man than most people imagine. Not only have they the same bodily organs and functions, and the same emotions; but they have also the same mental powers, and moral impulses, though of course infinitely less in degree. Even love itself, with all its toying and dalliance, to say nothing of mere sensual pleasure-may be experienced by creatures so far down in the scale as to be scarcely considered sentient.

The accounts given elsewhere of the snail and its amours, will prove this, but we will also give some further illustrations, both for their interest, and also because they will serve to broaden our views of life in general, and show that man has not a monopoly either of mind or of the finer feelings.

In regard to the snails, Agassiz remarks, that no one who has seen them, during their amours, can have the least doubt that they allure and excite each other by appropriate movements before the embrace ; and Mr. Lonsdale stated a fact to Mr. C. Darwin, which would show that they are even capable of some degree of permanent attachment. He placed a pair of these animals, one of which was quite feeble, in a small garden, not well provided with food for them. The strong one in a short time climbed over the wall into a better provided garden on the other side, leaving his sickly companion behind ; apparently it was deserted ; but strange to say, twenty-four hours after, the truant returned, and the two then went over the wall together. It would seem as if the strong one went to explore, and really returned with the news of beter quarters to its weakly companion.

Among some of the cuttle-fishes a very singular mode of impregnation takes place. The whole of the male element accumulates in one of the arms, or tentacles, which is then cast off, and becomes an independent being, which attaches itself to the female by its sucker, and lives so for a considerable time, till the impregnation is fully effected, when it falls off and dies. This cast-off fragment is so much like a real separate animal that Cuvier actually described it as a parasite, and named it the hectocotyle. There are several instances known, however, in which the male organ in hermaphrodites becomes a separate being by itself, living an independent life of its own.

In many of the crustaceans, like crabs and lobsters, the male has certain of his limbs peculiarly shaped, as hooks, or pincers with which he can hold the female during the copulation. He also often carries her about with them for weeks together, as if to fully secure her to himself. These singular organs appear to be used solely in connection with the generative act, as no other use for them has been discovered. It is probable, however, that they are often used to fight with, for the male crustareans, like those of the higher animals, will fight over their females. 
As a rule, these singular parts are not fully developed till the male is full grown ; while he is immature they resemble the corresponding parts in the females.

Mr. Bate tells us that he once took a male and female sand-hopper, such as we find on the seashore, who were together, and separated them, putting the fomale with a crowd of others in a vessel. Some time after, he put the male in the same vessel, and he at once dashed in among them, selected out his own partner, and took her away; this showed memory, recognition, and attachment, even in this humble being.

Indeed the mental power shown by some of the crustaceans is quite marked. Mr. Gardner tells us of a burrowing crab which he once watched, and down whose hole he had rolled a shell. The crab not only brought out the shell and carried it to a safe distance, but seeing two others so near his hole that there was danger they also would fall in, he carefully removed them also. Now this showed both appreciation of danger, and reason enough to take precautionary measures against it.

Canestrini assures us that the female spider will often choose one out of a number of males, that have been fighting for her favors, and drive the rest away. In doing so she probably discerns some points of perfection in the chosen one, which make him more pleasing to her. It is often, however, a very perilous thing to be the favorite, for not unfrequently the lady makes a meal of her paramour.

As a rule, male spiders are remarkably small, and to this they no doubt often owe their safety. Compared with the females, they frequently resemble small parasites rather than animals of the same kind, and literally can hide themselves about her limbs and body. In fact, nature appears to have reduced them to little more than moving male organs, intended solely to serve the purpose of impregnation. They seem to be fully aware of the danger they run in making amorous advances, but, as in most other beings, the sexual impulse is too strong to be resisted. Still they display great caution, skill, and agility in their approaches, and know when to seize the most favorable moment.

Some others of the same order of beings have suckers with which they hold the female during the act of coition; and in some insects the females are so provided, and hold the males.

In short these contrivances for enabling the sexes to be conjoined, in the act of copulation, are very varied, and often remarkably curious. Sometimes the jaws are. modified to serve this purpose, and at other times some of the limbs; thus the males of some insects resembling dragon flies have immense jaws, smooth and toothless, with which they hold the female without hurting her. In some wasps also there is the same peculiarity, while the females use the same parts to burrow in the ground with, to make their nests.

The females of some water-beetles have their wing cases deeply grooved, or covered with hairs, or sometimes with holes in them, to give the males better hold ; the males themselves being provided with parts adapted for using these aids.

It is common with insects for the male to be smaller than the female, and sometimes remarkably so, as in the case of the spider. The cocoon of the male silkworm is so much smaller than that of the female that they can be separated by weighing ; and a similar disparity is found in other cocoons. Still there are exceptions to this rule, especially among the beetles and dragon flies, and in those males who have to carry the female in the air, during the copulative act, as some do.

It would be a great mistake to suppose that only the larger, more perfect, or 
handsomest among the lower beings show signs of sentiment in their loves. Sir J. Lubbock tells us that the males of certain little, ugly, misshapen, dull-colored insects pay the most assiduous court to females, coquetting with them in the most amusing manner ; running round them, and butting heads with them, playfully. The female, for her part, pretends to run away, and the male runs after her, gets in front, and faces her; while she, as if bashful, turns away, and he faces her again. Then they whip one another with their antennæ, and toy together in all kinds of amusing ways. Evidently they enjoy this, and it seems certain that the enjoyment is the same as that which is experiencer by the males and females of beings higher in the scale.

It is supposed that the peculiar note of the male of some insects, as the locust for instance, is uttered for the purpose of attracting the females, and indeed they have been seen to flock around a male while thus singing. This is particularly noticeable in the seventeen-year locust, the male of which only drums, and evidently for the purpose of calling the females to him, and probably exciting them. They may also be frequently seen to select, or choose, one particular female out of the number so called.

The male cricket will also place himself at the entrance to the burrow in which is the female, and sing in a peculiar manner till she appears, when he caresses her with his antennæ, and in other ways shows his admiration.

M. Fabre, in describing the eerceris, a wasp-like insect, tells us that he has frequently seen the males fighting for the possession of some particular female, she all the while looking on, and when the fight was over flying away with the conqueror-all which is very human like. The same insects recognize each other, even when they have been long separated, and show real attachment. Huber tells us that ants which had been separated for four months, recognized, and caressed each other when they met, though mixed with strangers.

The ticking noise of the common death-watch is made by the female to call the male, and the males may often be called to a particular spot by imitating the noise. It is probable that they are thus often attracted by the ticking of a watch.

Butterflies are very demonstrative in their amours. The males will fight fiercely for possession of the females, and often mutilate each other's wings in their combats. The females will also coquet with their admirers, refusing some and encouraging others. A pair will often spend an hour or more in dalliance before copulation.

During the marriage flight, the males of some kinds support the females, but in others the females support the males. This is owing to difference in structure.

Several kinds of fishes, especially sharks and rays, which copulate, are provided with claspers to hold the female; and an old fisherman, who had often watched them, assured me that the act is often prolonged for half an hour or more, in sharks.

The capelin does not copulate, but the males assist the female in a very curious way in laying the spawn. They are provided with a ridge of close-set scales, like a stiff brush, and one of them will get on each side, so as to support her, and then both together run her swiftly over the sandy beach, where the spawn is deposited. The brush-like scales enable them to hold her, and to keep her up, she being heavier than the males on account of the spawn.

This assistance to the females in laying the eggs is paralleled by other beings, as by some frogs for instance, as explained elsewhere. It is quite probable also that the action may cause the male to emit the sperm at the same time, and thus insure fertilization of the ovæ.

The males of many fishes fight for the females, and some of them pair in single 
couples. The male stickleback also makes the nest, in which the female lays her eggs, and conducts her to it with most undoubted indications of pride in his work, and admiration and love for his partner. The combats between the male sticklebacks over the females are most furious, and often result in serious injury.

The male salmon is even worse in this respect than the stickleback, and numbers of them are killed every season while fighting over the females. The conquerors always drive away the defeated ones, and guard the wives they have fought for with the greatest jealousy.

M. Carbonier gives some curious details as to the courtship of a Chinese fish, the macropus, which he kept in confinement for the purpose of studying them.

The males are most brilliantly colored, and seem to take great pleasure in displaying themselves before the females; while these, as if to show their appreciation, swim slowly around, and evidently derive pleasure from contemplating them.

It is not all mere play, however, for the males contend with each other fiercely for the possession of the females, and each seeks to obtain one for himself. When he has succeeded, he waits upon his bride when she emits the eggs, and cares for them in a very curious manner. He blows air from his mouth into the water, so as to make a little disk of froth, which floats on the surface. In this raft of froth he deposits the eggs, taking care to keep it always in good order, and watching it till the young are fairly hatched.

The males of some other fishes retain the eggs in their mouths till they develop into young.

In these instances, as in some others which have been mentioned, the male plays the principal part in the actual hatching of the eggs, and caring for them. Hes in fact does much that usually falls to the female's share in the higher animals.

It is worthy of especial note, that though the eggs of the female fish can be im. pregnated artificially, without any association whatever with the male, as in our fish. breeding establishments, still, naturally, the two sexes do seek each other at the tim!: of spawning, and seem to delight in the association. It appears from observation that, as a rule, the female never deposits her eggs, if she can avoid it, except in pres. ence of the male, and he, on his part, never fertilizes them except in her presence.

This proves that all animals, during the pairing time, even cold-blooded fishes, are amatively excited, the two sexes evidently seeking each other's company, and deriving pleasure from the association.

The males use force, artifice, and allurements of various kinds to obtain female partners, and these, on their part, exhibit caprice, choice, or dislike, and coquet just like human beings themselves. In short, it is love and courtship in the lowest beings as in the highest. Even where there is no actual union of the two sexes-no bodily contact of any kind-there is evidently some form of pleasure in the mere act of bringing the sperm and germ together, as in the case of the fishes last mentioned. With them there is evidently a gratification in each other's presence, or close proximity merely, at the time when impregnation occurs.

Some of the male sticklebacks are also excellent nurses of the young, taking the fondest care of them till able to fully shift for themselves. They will gently take them back to the nest when they stray too far, and constantly guard it against all enemies. The female, on the contrary, would destroy her own young if the male did not drive her away. In this instance, therefore, as in many others that have been noticed, the two sexes seem to change characters and duties. 
Some of the pipe-fishes and sea-horses possess pockets, or sacs, in which the eggs are hatched, similar to the pouches of marsupial animals. But, strange to say, in some species the female has the pouch, and hatches the eggs, while in others it is the male. So curiously do the different offices, in the process of reproduction, change places between the two sexes.

Reptiles would seem, to most people, still more unlikely to give any exhibition of love-making; nevertheless they often do so, and sometimes very remarkably. Some of them also have parts of their structure curiously modified, to enable them to hold the female, and these modifications may be temporary, occurring only in the pairing season. Thus, in the common newt (Triton palmipes), the hind feet are usually webbed, so that he swims well, but in the pairing season the web disappears, leaving the claws free, which enables him to hold the female more securely in the act of cohabiting. He is very eager in his pursuit of his partner, and makes a great display of himself before her, by vibrating his broad tail, and elevating the crest on his back. This crest also, it is worthy of remark, is only developed during the pairing season.

The male crocodiles also, like their small brethren the newts, make a great display of themselves before their female partners, by fighting together fiercely, and by splashing and pirouetting around them in the water; at the same time emitting a powerful musky odor.

Indeed most animals, at such times, emit a peculiar odor, which probably attracts the other sex, and may thus enable them to find each other. It may also cause excitement.

The male lizards are very pugnacious, and fight fiercely for the females during the pairing season. Very frequently one will lose his tail in the combat, and when this happens the victor always swallows it.

Birds are very gallant, and practice many curious habits in their amours. Some of these exhibit both intellect and taste in a remarkable degree. The bower bird for instance, makes a real bower, often of considerable size, and ornaments it with all the bright and curious objects it can find. It is not a nest, nor a dwelling-place, but simply a play-place, where the birds resort at certain times, especially in the pairing season, for the purpose of amusement and amative enjoyment. The neatness, taste, and real beauty of some of these love-bowers is really surprising.

Other birds even plant gardens before their places of assemblage, and keep them always full of flowers. They begin by carefully removing every weed, stick, and stone, so as to have a perfectly smooth bed, which they carpet with moss, and then bring flowers and arrange them with great taste. As fast as they wither new ones are brought, so that the garden is always bright and fresh. This also is prompted by gallantry, and by the desire to have their love-making, in every way, as pleasing as possible.

Some birds sing only at the pairing season, and others assume their most brilliant colors at that time, the object apparently being to attract their partners, and to cause mutual admiration.

No animals fight more fiercely for the farors of the females than do birds of all kinds, and sometimes they have special weapons for the purpose.

The males of the beautiful and tiny humming-birds even will fight, in the loveseason, with the most reckless ferocity. Not unfrequently indeed death ensues from their combats. The same thing occurs with many other birds, and often the excite- 
ment of battle so carries them away that they can be readily captured by their enemies. Usually in such encounters, the female looks placidly on, and goes off with the victor. This, however, is not always the case, for sometimes she will watch the fight between two of her admirers, and when they are both exhausted, or one dead even, she will quietly take herself off with some new-comer, who has not fought at all.

The males of some birds, as the polygamous ruff, for instance, are so remarkably pugnacious, especially in the spring, that whole companies of them will fight together in the fiercest manner, so as often to kill one another. These fields of battle are always at the places where the females are about to lay their eggs; and the ground will often be so trampled during the fight that the fowlers easily find it, and as the birds come day after day to fight at the same place, they are easily caught.

Some birds, however, it is said, never fight. Audubon particularly mentions one of our woodpeckers (Picus Auratus), the males of which never fight, though several of them may be courting a female at the same time. These peaceable wooers are, however, very exceptional, for as a rule the males always fight, and especially in pairing time.

The capercailzie, and the black cock, like the ruff, fight in companies, assembling daily for the purpose, for weeks together. The black cock also practices a peculiar love-dance, and sings a peculiar love-song, which the Germans call balz, in pairing time. In fact, the bird seems crazy from amative excitement. He utters the strangest noises, and indulges in the most curious antics, jumping about, often in circles, spreading and flapping his wings, stretching out his neck, and rubbing his head along the ground. So absorbed does he become in these capers that he seems both blind and deaf, and may be shot readily, or even caught by the hand.

After these curious dances are over, the combat begins, and often rages furiously for several hours ; very often the same dancing-places are visited year after year, and a very victorious male will frequently make a kind of triumphaut tour from one to another, in a single day, fighting at each.

Gronse also fight in companies, in the same way, but only in the breeding season.

Audubon tells us that the female of the Virginia goat-sucker holds a kind of court, where she calls around her a number of male admirers, and from among them makes her choice; the favored one then fights the others and drives them away. Contrary to the usual course, in this case, the pairing comes first, and the combat afterwards.

Some good observers, however, assure us that the male birds often make sham fights only, just to display themselves before the female, so that she may the better choose among them. Audubon indeed says, that after one of these make-believe combats, both victors and vanquished will go off together to seek the female, and if she does not at once make a choice, the fictitious struggle recommences. The male field-starlings will often fight fiercely in flocks, but if the female appears they cease fighting at once, and all rush after her as if they were crazy.

The male birds of many species have a peculiar song, or call, during the breeding season, by which they attract, and appear to charm the female. And what is very remarkable, certain parts either grow, or change in form, at that season, to enable them to make these songs or calls.

The male turkey scrapes his wings on the ground, the peacock rattles his wings, 
and the male grouse drums, to call or please the female; that this is so is proved by the fact that after one has made this drumming noise the females near will all fly to him.

Our common grouse, it is well known to hunters and naturalists, perform a very curious love-dance, during the pairing season. They will assemble in large numbers on some level place, and then run round and round, in a regular circle, some to the right and some to the left, till they wear the ground quite bare. During the dance, they indulge in the most comical antics, and the most extravagant gestures. Hunters call them partridge dances.

The solemn long-legged heron even makes himself equally ridiculous by his absurd capers, while courting; and of all birds the disgusting carrion vulture makes himself as ludierous as any of his fellows, at such a time.

That the female bird makes a choice from among her admirers is beyond doubt, and probably this is usually determined by some real or fancied superiority in their singing, or greater splendor in their plumage ; but sometimes it is merely the conqueror in battle that wins her affections. Very frequently, as stated before, the males meet and fight, or practice their peculiar dances, for many days, or even weeks, before the actual pairing takes place. Thus our partridge dances often last over a month, and so with snipes, who frequent the same ground often for many years in succession.

Mr. Darwin shows admirably how this process of selection operates to effect improvement, or change, in many ways. Thus the best fighters and singers, and the handsomest in plumage, being constantly preferred, will in consequence propagate inore than the less farored ones, and, by the law of heredity, transmit their superior ' fualities to their offspring.

It does not appear that the males show any particular preference in regard to the females, except in some few instances, but take them as they find them.

Some birds in Australia make regular hillocks on which to fight, and others icratch large hollows for the same purpose.

Either from disparity of numbers in the two sexes, or from mere caprice, there are frequently unpaired birds, both male and female, and these, though coming together; do not always mate, which would seem to show that one, or both, are difficult to please.

Although, when paired, the two birds usually remain together during the whole breeding season, yet it is not always so. A very close observer assures me he has frequently seen a quarrel, apparently about the nest, followed by a separation, the male going off, and the female finding a new mate. As a rule, when the male is killed, the female soon obtains another, or even several in succession. In one case, when the males were shot, the widow got three new ones the same day.

Sometimes if the female be killed, after the eggs are laid, the male will find $z$ new partner, and they will rear the brood between them.

Although the usual habit is for birds to pair, still we sometimes find two, or even three females to one male, and one nest; and still more rarely, two or more males to one female.

In polygamous birds, as the common fowl for instance, it is the best fighter who monopolizes several females for his own use, and drives the other males away.

In connection with their young also, birds show more of real human feeling or sympathy, and more intelligence too, than they commonly get credit for. Darwin 
mentions a case where a game-keeper killed all the young hawks in a nest, except one, whose wings he clipped. This he did so that the old birds might still come to the nest and be shot. They were shot, and then two others came to feed the poor solitary orphan, and they too were shot; but still others came, till three pairs had been thus killed, one after the other. Should not the bird's nature have full credit for this?

With many kinds of birds, when paired, if one dies the other always pines away, refusing to be consoled. And a bird fancier assures me that when two birds have long been kept together, if one be taken away the other often refuses to eat, and dies. That those who have long been together can recognize each other, when again put together, after a long separation, is well known, and they often show unmistakable delight at the reunion. Their memories are undoubtedly good, for pigeons will return to their old homes even after they have been kept away from them many months.

Birds are not only kind to young ones, to others as well as to their own, but often to each other. Thus blind birds have been fed and protected by their fellows; and when crippled have been carefully tended till well.

There are, therefore, more of the elements of humanity in the bird than is usually supposed, both sympathetic and intellectual. Even caprice, jealousy, and coquetry are plainly shown by them, and also sudden attachment, or love at first sight. Thus Darwin gives an instance where a wild duck, reared in captivity, left her mate, of her own kind, instantly, when a male pintail was put in the water with her. Something in the new-comer took her fancy at once, and she divorced herself without scruple from her legitimate spouse, in order to enjoy his society, though he seemed at first both shy and afraid of her.

On the contrary, some females cannot be made to accept certain males by any means whatever. They may be confined with them, and kept away from all others, but to no purpose ; - that particular one they will not have. Some male birds, however, like certain men, appear attractive to all the females they meet with, and are invariably preferred before all their fellows. Breeders call them gay birds, and they often are obliged to confine them when their particular breed is not wanted.

Many instances are recorded where females have deserted males who had lost their gay feathers, and taken others who still retained them. Albinos, it is stated, are never chosen by their own kind for partners, but this may be only from their strangeness.

It is not always the male that courts the female, though usually so; but in some instances the female courts the male. This is the case with the pea fowl ; and according to Audubon, with the older wild turkeys. The female capercailzies also maneuver round the male while he is dancing, and evidently try to attract him. The females will also fight over the males, with some kinds, reversing the usual practice.

Some female birds are also much larger and fiercer than the males, and when this is the case, it is the male that sits on the nest and hatches out the young, while the female feeds him, and fights, if necessary, for the protection of her partner and progeny. This is the case with the Australian emu, but, strange to say, the female here has also an irresistible tendency to destroy her young, and the male, who has battled and cared for them, has to defend them against the mother the best way he can. This rage seems to last even for some time after nesting, so that if the two come together they almost always fight, and the female is usually the victor. This 
seems singular love-making and parentage, but is probably as pleasing to them as other modes are to other birds. To show the singular contrasts nature presents us with, in regard to these matters, the male ostrich is much larger and more powerful than the female, and yet he also takes the whole care of the eggs and young, equally with the small gentle emu.

Among the mammalia, till we ascend to civilized man, the male almost always wins the female by the law of battle, or by simple violence. The very weakest and most timid, when excited by the erotic fever, will combat for female favors. Even two male hares hare been known, when so stimulated, to fight till one was kilied. Moles, squirrels, beavers, and sheep are equally pugnacious and daring at such times.

In fact, fighting is the rule, and many animals are provided with special weapons, such as horns and tusks of various kinds, which seem to be used only or chiefly in these sexual struggles. The victor drives away his rivals, or kills them, and enjoys his bride or harem alone. It is seldom that the males, in the season of heat, will tolerate each other's company at all ; and yet instances have been known of two or more, acting in concert against a common rival too powerful for either to master alone.

A gentleman residing at the Faulkland Islands, imported an English stallion, with some brood mares; there were also two droves of wild mares on the Island, each with their wild stallion, and these in turn attacked the English horse, and tried to get his mares away from him, but failed. They were then seen to come together, and while the one fought with him the other endeavored to make off with the coveted females. They were however all captured together, by running them into a corral, the wild stallions refusing to leave the mares.

The bony horn of the narwhal, and the prodigious tusks of the elephant, are both used in fighting for possession of the females. Even the male ornithorhynchus has a kind of spur on his fore leg, with which he apparently fights, and which is provided with a bag of fluid, like that at the root of a snake's poison fang; but it is quite harmless. This spur, however, serves another purpose in all probability, for there is a hollow in the corresponding part of the female's leg, in which the spur fits, and most likely this enables him to hold her better during copulation.

it is singular that the stag, if castrated, never renews his horns, showing the connection they have with his sexuality. With the male reindeer, however, it is not so, for he may be castrated and still renew his horns as before. Eunuchs, it is well known seldom have beards. Rams when castrated do not always lose their horns entirely, but even when they retain them they become smaller.

Captain Bryant, gives us some very interesting details in regard to the wooing of seals, who are naturally very intelligent. Their tendency appears to be polygamous, each male keeping as many females to himself as he possibly can. The Captain says : "Many of the females, on their arrival at the island where they breed, appear to be desirous of returning to some particular male, and frequently climb the outlying rocks to overlook the rookeries ; calling out and listening, as if for a familiar voice; then changing to another place they do the same again. . . . A As soon as a female reaches the shore, the nearest male goes down to meet her, making a noise meanwhile like the clucking of a hen to her chickens. He bows to her, and coaxes her, till he gets between her and the water, so that she cannot escape him. Then his manner changes, and with a harsh growl he drives her to a place in his harem, and this continues till the lower row of harems is nearly full. Then the males higher up 
select the time when their more fortunate neighbors are off their guard to steal their wives. This they do by saking them in their mouths and lifting them over the heads of the other females, and carefully placing them in their own harem, carrying them as cats do their kittens. Those still higher up pursue the same method, until the whole space is occupied. Frequently a struggle ensues between two males for the possession of the same female, and both seizing her at once pull her in two, or terribly lacerate her with their teeth. When the space is all filled, the old male walks complacently around reviewing his family, scolding those who disturb or crowd the others; and fiercely driving off all intruders."

The male of the common fowl, it is well known will commonly run down and capture the hen by main force; but he will also use stratagem, when it suits his purpose better. He will pretend to find something to eat, and call the females round him to have it, but when they have all come be changes his note, and at once seizes one without further ceremony. A young cock, who is obliged to keep away from the flock for fear of the old ones, will often adopt this stratagem.

The power of the amative mania in dogs is well known; while under its influence they have no regard for anything but the object of their pursuit, and will endure anything rather than abandon it. Still, Mr. Mayhew assures us, the females will often make a decided choice from among a crowd of suitors; evidently showing a preference for some particular dog. The females of small breeds, he says, almost always choosing a large male. Breeders also notice that sometimes particular animals always pair together, and will not do so with others. Mr. Cupples even gives an instance where a female, who had been separated from her favorite male, would never after associate with another, although in condition. Whether the male showed equal constancy is not stated; but most probably not. Instances have been known, however, of male dogs refusing to associate with strange females, when kept apart from those they had been accustomed to. Stallions and mares, bulls and cows, and even boars and sows, bave been known to show a marked individual preference, and to exhibit much constancy in their attachments.

One strange peculiarity about the sea seal, may here be mentioned. During the breeding season the nose becomes lengthened, sometimes to a foot or more, and is capable of being erected like a trunk. What purpose this serves is unknown, but as it occurs at that season, it is doubtless in some way or other connected with pairing. It would be interesting to know if this would occur in males that had been castrated; the probability is it would not; for the males of several animals that have scent bags, as the musk-deer for instance, fail to develop them when they are castrated, and castrated deer, as before stated, develop no antlers. 


\section{CHAPTER LIX.}

MARRIAGE, AND THE POSTTION OF WOMEN, AMONG DIFFERENT PEOPLE, AND AT DIFFERENT PERIODS.

THE laws and customs which regulate the relations of the sexes to each other vary very much, among different people, and in different parts of the world. Like all other laws and customs, they also change, though often very slowly, in every society from age to age.

From want of authentic records of very early times, we do not know what laws and customs then existed, nor can we judge of this by comparison with what we see among primitive people at the present day, for we have no means of deciding how far they may correspond.

There is, however, good reason for supposing that in the very earliest associations of human beings, when they were first emerging from the lower type, the relations of the sexes were but little different from what we see among gregarious animals generally. Probably at a later period, in the earliest organized societies, all the members of that society mated together freely, or from inclination merely. This is what is called communal marriage, all the men and women being husbands and wires to each other. Indeed this manner of association is even now practiced in certain parts of the world, according to some travelers.

The first breaking up of this custom would probably arise from the dawning of taste, or a feeling of admiration for some particular form of body, or face! No matter how rude and uncultivated this may have been, according to our notions, it was quite sufficient to cause a social revolution. Immediately any females began to be thought superior to the others, in any way, they at once became special objects of desire, and would promptly be taken possession of by those males superior to the others in strength, the inferior females being left to the inferior males. The woman would then become a real possession-would belong to her master-like his horse, or other animal, and wonld be forbidden to associate with any other man. And just as large flocks and herds were desired, so would a large number of wires be coveted, and each man, according to his power, would seize all that he could. Thus arose polygamy, probably the first form of marriage.

So long as the number of the sexes were about equal, and no notion had arisen that one female was more desirable than another, there could be no motive for exclusive association, either with one or more. But immediately one became more desirable than another, then all was changed, and the desired one, if obtained, became private prope: ty.

Selfishness and the wish to outshine others in the amount of their possessions, would operate with many even stronger than mere sexual desire, so that they would 
procure more wives and concubines than they could ever possibly enjoy. This we see in the case of David, and others of the Jewish patriarchs; and at the present day with many African potentates. Whenever might habitually makes right, women, like other possessions, will always be unduly appropriated by the most powerful.

One immediate result of the desire for private possession of women would be, in all barbarous communities, the utter abandonment of all pretense of seeking, from motives of mutual liking or attachment. The female would be at once taken possession of, without any reference whatever to her wish or preference. Superior strength, cunning, or wealth, would then alone determine to whom she should belong.

So long as communal marriage was the rule, or promiscuous association, all pairing wouid result from some preference, or choice, and so far all alike, men and women, would be free and equal; but immediately the custom became established for each man to have only his own wife, if the community were rude and barbarous, the woman became a possession-a slave. So far, then, she gained nothing by the change, but, on the contrary, lost immensely. It was, however, a necessary step in the progress which will lead, eventually, to a far better condition than any in which she has yet been placed.

No matter how obtained, by purchase, force, or stratagem, a woman, as a wife, has always been considered, in barbarous or savage societies, as a mere possession, like an animal. Nor is this idea entirely obliterated even at the present day in the most civilized communities. It crops out in many of our laws, customs, and ways of thinking and speaking. The term, my wife, is still used by many with the same intent and meaning as my dog, or my horse. In some of the most backward villages of England the notion is still held, by the common people, that a man can sell his wife at public auction, and such sales actually take place occasionally, the parties believing them to be legal. The usual process is for the man to lead the woman to some public place, tie a halter round her neck, and then ask for bids. The bighest bidder pays his bid, removes the halter, and takes the woman. This is probably a traditionary remembrance of what used to occur in old times. It is quite common even here for a man to remark of his wife- "she belongs to me"-evidently with a sense of proprietary right; nay, it is not unfrequent for a man to claim a woman as $h i s$, who may not want him, and we often see instances of such men killing women for refusing them and preferring others. We are still far from admitting, at least in practice, that women have the same rights, in regard to marriage, as men, and should be placed, in all respects, upon an equality with them.

Polygamy appears to have prevailed, more or less, with all people, at some period of history ; and it is natural it should do so, not only for the reasons already given, but for others equally cogent.

During the wars which always prevail among uncivilized people, the male captives, on prudential grounds, as well as to gratify revenge, would always be slain, but the women would be spared, and be taken as wives and concubines. The Jewish Chronicles of the Bible show how universal was this custom, and how it was sanctioned both by custom and by religion. God himself is represented as directing the Israelites to slay all the men, but to keep all the maidens for themselves.

Slavery also contributes very much to polygamy, the prepossessing female slaves being naturally taken for wires and concubines.

A natural result of polygamy is prostitution, because when a large portion of the women are monopolized by a few men, the remaining women must suffice for the 
larger number of men. The same result must always follow when, from any cause, a considerable portion of the young people in society are unable to marry. The sexes will associate, and all the restraints of prudence, fear of consequences, or moral principle, amount practically to very little when they are kept unduly separated. Such restraints operate excellently on particular individuals, but they make small impression on the masses of society.

As communities become settled, with established laws, and some notions of equality arise, polygamy naturally declines, and the number of wives held by one man necessarily becomes less. This is seen in Turkey, where, at the present day, the number of wives is usually but two, and seldom over four, except with the Sultan himself. And though the wives may be purchased now, as they were in old times, still they are not now sold again, as they used to be, but are kept as wives, and treated with consideration. In fact, in Turkey we now see polygamy gradually dying out, and being superseded by monogamy. There is no doubt that the institution as now existing there, though repugnant to our ideas and customs, is nevertheless shorn of many of its objectionable features, and is every day ameliorating more and more.

Lady Duff Gordon relates an anecdote which well shows this. A gay Englishman was boasting of his numerous conquests among the fair sex, and rallying a sedate Turk who was present on his polygamy. The Turk replied, "It is true, I have known four women during my life. One of them is dead, and mourned; and the other three are living, honored and respected, in my house, and will do so till they die. Now, where are all yours?"

Notwithstanding all we hear about the terrible Turks, I believe it will be found, on unprejudiced observation, that polygamy has always been less objectionable with them, in practice, than with any other people. And their treatment of women, on the whole, will compare favorably with that of any other people on the same plane of development. Certainly they show themselves superior in this respect, in many ways, to the Hebrews, and other ancient and modern peoples, from whom, in fact, they took their polygamous practices; the Turks not being noted for polygamy till after their contact with Christian nations.

Ry the Hebrew law, polygamy is not at all condemned, but, on the contrary, fully sanctioned; as also is the keeping of concubines. And though Jews always conform, in regard to marriage, to the customs of the countries in which they live, yet so far as their religion is concerned, they may be polygamists. Indeed, many contend that it is the same with Christians, so curiously are the customs of remote ages perpetuated, historically, though Iong abrogated in practice.

Most savage people are polygamous, at least the great men among them, and consider single marriage highly disreputable. Thus, when the Pandyan king was told that among Europeans every man had but one wife, and lived with her till death, he was perfectly shocked. "Why," said he, "how indecent-just like wanderoo monkeys!"

Nevertheless there are some sarages who always live in single marriage. This is the ease with the Veddahs, in Ceylon, who, according to Sir John Lubbock, have a saying that death alone can part husband and wife.

Probably the main causes which would determine the practices of men, in regard to marriage, would be the scarcity or abundance of food and women. When the means of living were easily obtained, the maintenance of a numerous household would be no burden, and a man would take as many wives as he could get; butwhen, 
on the contrary, those means were hard to get, he would lessen the number, and frequently would, from necessity, have to be content with one.

As before remarked, when from frequent wars between different tribes, many of the men were killed, there would be an excess of women; and as many would be left over after all had one each, the rich and powerful would take one or more extra, and. thus would arise polygamy.

Among the peaceable tribes, when the sexes were in nearly equal numbers all the time, single pairing, or monogamy, would be the rule.

When a rude people happened to be so situated that the means of living were pre carious and scant, they would promptly get rid of all useless or superfluous mouths, by killing off the old and sick, as many savages do now. Female children would also be killed, as being comparatively useless and burdensome when grown up. Indeed, female infanticide is now practided, to a considerable extent, in many countries not at all barbarous. Such a practice, however, always arises from deficient subsistence, and never prevails where food is abundant and easily obtained.

In such a society, the number of males would soon be much greater than that of the females, and so far from one man having many wives, it would not be possible for every man to have even one. This would soon originate the opposite of polygamy, or polyandria! By this is meant the institution of one woman having many husbands; or perhaps, more properly speaking, of one woman being wife to many men. This arrangement prevails even at the present day, especially in certain parts of Thibet. A recent traveler has lately given, in Blackwood's Magazine, a very interesting account of the practical working of polyandria, as he there saw it. We are so much in the habit of thinking that nothing can possibly work well which is opposed to our own customs, that it will surprise many to learn that the system, so far as can be judged, is practically free from objection.

The most usual arrangement is for a whole family of brothers to have but one wife amongst them. Each man is a husband to her, and the children have all of them as fathers in common. The traveler assures us that the domestic harmony, and mutual affection all round, would compare very favorably with anything of the kind to be found in our own society. And there is this to be said about it, that there is far less danger of the children being left fatherless, or the wife a lonely widow, than in a single marriage. It is quite possible, indeed, that there would be much less jealousy and selfishness displayed than when the woman was the private possession of one man alone. It is also quite unlikely that they would all unite in ill-treating her; some of them would be sure to take her part, and protect her in 'case of need. The general household would also be better provided, with so many males working for it instead of one, and there would be much less danger of want. If one should fall sick, or be disabled, there would still be the others to depend upon; and, in short, a family would always be in less danger every way, that had so many supporters and defenders. Among the Todas, a girl can accept or refuse any mast she pleases ; and Azara tells us that the Guana women, before marrying one or more husbands, bargain for all kinds of favors and privileges.

The same traveler also assures us that he saw no reason to suppose that the women suffered either injury or sense of degradation in any way, and on the whole, were remarkably well treated and content, considering the rudeness of society generally.

Among the hill-tribes of India, polyandria also exists, modified more or less, but always, it would seem, as a consequence of scarcity of food, the female children, 
as being most useless, being largely made away with. In one village in Eastern India, Col. McCulloch could not find a single female child; all were killed from scarcity of food.

A curious variety of polyandria prevails in some parts of Africa, as we learn from recent travelers there. A woman when she marries may ally herself to her husband for only a portion of the time, instead of for always, and the rest of the time she is free to go with any other man she chooses. The proportion of time she thus keeps to herself depends mainly upon the dower she brings. If she be poor, her friends can obtain perhaps only one day in the week for her, but if she be rich they will claim two, three, or four days, during which her husband has no control over her whatever, and she may do as she chooses. She must, however, be true to him on the days in which he is legally entitled to her.

Whether the man has equal liberty on the off days, and what arrangements are made in regard to the children, we are not informed.

Amongst the ancient Britons, at the time of the Roman conquest, so we are informed by Cæsar, there existed a peculiar institution, which may be called a matrimonial club! Ten or twelve families would live together under the same roof, the busbands haring all the wires in common, the children of each woman being fathered by the man whom she first married. The members of these singular associations were also frequently nearly related, being all brothers and sisters, uncles and nieces, and cousins of all degrees.

St. Jerome speaks of this practice as still existing in his day, and it appears to have lingered long even after the introduction of Christianity.

Among the ancient Hebrews, it may be remembered, as recorded in the Bible, a man often married two or more sisters at the same time. In the Hebrides, according to Solinus, a very singular custom prevailed in regard to the king. He was not allowed to possess any property of his own, but could use that of his subjects at pleasure; and this arrangement extended even to wives. He was not allowed one of his own, but was free to associate with all those of his subjects at his pleasure. This singular rule was established to take away from him all motives for plundering and oppressing the people, because he could never make anything by doing so.

The Sultan of Morocco takes a wife from the family of every great chief in his empire, and thus associates them all with him, and as the child of either one may succeed him, it prevents jealousy, and keeps them all loyal.

What is called the morganatic marriage, which occasionally occurs among royal personages in Europe, may be called a modification of polygamy, and is perhaps a remnant of it.

The king, or other monarch, who is already married to some one of similar rank to himself, also contracts another marriage with some one of lower station. This is called the morganatic marriage. Both are legitimate, in the sense of both women being lawful wires, and taking social rank as such, but the queen only is the consort of the sovereign, and her children only can succeed to the throne, those by the other wife being simple citizens, unless specially ennobled, and taking her name only. Such a marriage is not detrimental to the woman's character.

The word morganatic eomes from the old Gothic Morgjan, meaning limited, or curtailed, which shows how far back the custom originated. The marriage is alsa called vulgarly, left-handed, but it is perfectly legitimate, only it does not confer on the wife the title or fortune of her husband, nor on her children any right of succession 
Among the German princes, morganatic marriages have been customary for many centuries, and in fact prevail even at the present day. The late Archduke John, for instance-the Reichsverweser of 1848-married the daughter of the post master of Aussee, in Styria, and she was afterwards created Duchess of Meran.

It is not only among princes, however, that morganatic marriages are recognized, but also among the nobility, and in Prussia even the inferior gentry claim the privilege.

The royal marriage act of England, even practically establishes morganatic marriage ; for though any member of the royal family can marry whom he chooses, still his wife cannot be queen, nor have any claim on his property, nor are their children legitimate, unless the marriage was consented to by the reigning sovereign, or by Parliament, the sovereign's consent being needed before twenty-five years of age, and that of Parliament afterwards. Any marriage contracted without such consent has no legal standing, though it may give the woman a respectable social position, and it is no barrier to another marriage, with such consent, to another woman, upon whom the man would confer his title and fortune, and whose childwen would legitimately succeed. George the Fourth, it is well known, was married morganatically to Mrs. Jordan, but she nevertheless was never known by any other name.

In early times, in the Highlands, and in some parts of Ireland, there was recognized what was called the hand-fast marriage! This was, in a certain sense, an experimental contract, which was terminated after the parties had lived some time together, if they found that they did not suit each other. Sometimes it was terminated if the woman did not become a mother promptly; and, indeed, the marriage was often made a hand-fast one only in order to test this, so that a man who desired heirs might not be permanently bound to a barren woman.

I have been assured, when in Scotland, that it was often the custom for one of these marriages to be contracted with this understanding: if the woman became a mother within a certain time, then the hand-fast marriage was to be made a permanent one, but if she did not, then they separated.

It does not appear that this curious arrangement was regarded as at all discreditable in any way. Neither of the parties lost caste by it, nor were the children, if they had any, necessarily illegitimate; on the contrary, they often took precedence of those by any subsequent marriage.

Although in a morganatic marriage, in the feudal ages, the woman was allowed by courtesy to be a wife, still it was a serions matter for her, being of inferior station, if she pretended to anything more. Nay, even if her husband made her his consort, and gave her his title, she was still held to be a criminal, and was sooner or later made to suffer. This was undoubtedly with the intention of keeping all suc. cession in the princely line alone. The consorts, whose children were to be heirs to the throne, must be of equal rank with the husband, but the wife only might be of any rank.

A most interesting and romantic instance of this is found in the history of the beautiful and unfortunate Agnes Bernhauer : she was the daughter of a poor citizen of Augsburgh, and lived during the fifteenth century. The Duke Albrecht, only son and heir of Duke Ernest of Bavaria, saw this maiden at a tournament, and fell violently in love with her, as she did with him, he being remarkably manly and handsome. Notwithstanding his rank, however, she would consent to no illicit association, and they were accordingly privately married, he then taking her to a 
castle which he owned, where they lived together in great happiness. His father, however, had formed a plan to marry Albrecht to Anna, daughter of the Duke of Brunswick, and was highly chagrined when he heard of his connection with the beautiful Agnes, which he resolved to bring to an end.

To effect this, he arranged a grand tournament, which his son attended, but to which he was refused admission, on the ground that he was living with a disreputable woman, in open licentiousness. Upon this Albrecht openly proclaimed her his wife, but all to no purpose; he was still excluded from the lists. This so enraged him that he proclaimed her Duchess of Bavaria, his consort, and gave her the retinue and maintenance of a princess, with the castle of Straubing for a residence.

The poor woman seemed, however, to have a foreboding of evil, for she erected an oratory and a tomb in a Carmelite convent, to which she used often to retire.

Duke William, Albrecht's uncle, who was much attached to his nephew, took his part, and while he lived, the couple were not molested ; but at his death, during the absence of her husband, poor Agnes was arrested, at the order of Duke Ernest, and executed. She was accused of sorcery; of having bewitched Albrecht; and being bound hand and foot, was thrown from a bridge into the Danube, in the presence of the whole people. The current floated her to the side of the river, and one of the executioners, by fastening a pole in her beautiful long hair, held her head under the water till she was dead.

Albrecht was so maddened by this that he took up arms against his father, and ravaged the whole country, driving him to such extremity that the emperor, with the other nobles, had to interfere, and finally made a truce between them; so that Albrecht returned to his father's court, and eventually married Anna of Brunswick.

To conciliate his son, Duke Ernest erected a chapel over the grave of poor Agnes ; but twelve years after, Albrecht removed her remains to the convent at Straubing, and buried them in the tomb which she herself had erected.

In this case, if the parties had been content to regard the marriage as simply morganatic, and the Brunswick princess had been also espoused as consort, there would have been no trouble; but the act of declaring a plebeian woman duchess, and refusing in consequence to marry the Princess Anna, was an offense against royalty not to be forgiven.

Concubinage, in conjunction with marriage, appears to have existed from the very earliest times, and to have been viewed in different ways at different epochs. Among the ancient Romans, the marriage law was very strict, and in many respects burdensome, so that free unmarried men got into the habit of forming less onerous contracts, in the form of concubinage. This was, in fact, an agreement for permanent cohabitation, under certain understood regulations. The children of such unions were not regarded as legitimate, but still were acknowledged by the father; and no doubt by custom, both they and the mother had certain rights, and a recognized position, possibly something like the morganatic families of more modern times. Even in the reign of Angustus, concubines were allowed to be taken, but only from women of low position.

The concubines we read of in the Bible and contemporary histories, were probably merely slaves, with no legal rights nor any recognized position. In fact, the distinction between the wife herself and the concubine, in this respect, does not seem to have been very clear in those days.

Betrothment, or agreement to consummate marriage at some future time, was 
once very common, and accompanied by various observances, such as kissing, joining hands, and exchanging rings or pieces of money broken in two. Such engagements were held sacred, and those breaking them were subject not only to social and ecclesiastical censure, but also to legal disability, for they could not contract marriage with a previous betrothment unfulfilled. Thus Henry the Eighth had his marriage with Anne Boteyn declared invalid, on the ground that she had been previously betrothed to the Duke of Northumberland. Church condemnation for failure to fulfill a betrothment did not come to an end, in England, till the reign of George the Second. Since then the only redress in such a case is a suit for damages, for breach of promise - a much more prosaic, but more sensible proceeding.

Not unfrequently, in former times, young children were betrothed to each other by their parents, even at birth, and such contracts were always regarded as binding at the proper age. This custom prevails even now in some countries, where women are appropriated as wives without their consent.

Our modern engagement, with its ring, is a survival of the old custom of betrothment. . In fact, in some countries it is still called betrothment, and is regarded as quite binding. In Scotland a mutual betrothment, legally proved, is in all respects a marriage, and gives equal rights.

In short, there are many curious modifications both of polygamy, monogamy, and polyandria to be met with, even at the present day; and these have not been established by caprice, or by deliberate choice, but have been evolved by the natural growth of the societies in which we find them. Each one is the product of the conditions under which that society has existed, and no other arrangement was possible with those conditions.

In fact, the marriage relations are constantly changing in all communities, even the most civilized and settled; but the changes occur so gradually and naturally, from the changed relations of the sexes generally, that they are scarcely noticed. The condition of a married woman is now, in many respects, quite different to what it was a century ago, or less even. She has been freed from many legal disabilities, and is, in many ways, more a free agent than she used to be. Even in conservative England, a married woman can now receive and hold property of her own, and is entitled to her own wages. A few years ago her husband could take everything from her. In America, a woman's individual rights and liberty are more fully awarded than in perhaps any other country, but even here she is still under many disadvantages, and has not full equal rights and justice with man. She is, however, gradnally but surely getting them, and in a few years they will be fully accorded.

Divorce also is now placed on a more rational and just basis than it used to be, and it is no longer insisted upon that utterly unsuitable people should be indissolubly bound together, when neither individuals nor society would suffer by their separation.

In short, the relations of the sexes in marriage, in our own society, as in all others, are slowiy but surely changing in many ways, and marriage, at some future day, will be very different from what it is now. It would be a great and fatal mistake, however, to anticipate these changes, or to bring them about prematurely. They must come gradually, or be evolved from the natural progress of society. Very possibly some of the marital arrangements of the future, if we knew them, would appear shocking to us, and would cause serious evil if now established. But when the time comes for them, they will be as proper and as useful as our present arrangements. 
If the good people of a few centuries back could have seen society as it is now, in its marriage relations, they would certainly have thought it fearfully deteriorated.

The manner in which men obtain wives, and the customs and observances attendant upon marriage, are remarkably varied. Very often the difference will be great between peoples living close together, and apparently of the same race, with no reason, so far as can be seen, why it should be so. Probably accident or caprice may have established certain customs in the first instance, and then habit or fashion would continue them.

Among all savage people, the law of battle has always prevailed, in regard to women, as in regard to all other envied possessions, and they hare invariably been one of the chief causes of war among men, even within comparatively civilized times.

Not only did men singly contend for women, but tribe would fight with tribe, and nation with nation. Even in the same community, in friendly contest, men strove with each other for female favors, the strongest and most skillful carrying off the prize. Among the North American Indians, Hearne tells us, it was the custom for the men to wrestle for choice of women. A weak man, so Hearne says, unless he were a skillful hunter, or in some way had influence with the tribe, could never keep a wife that a stronger man coveted.

This constant rivalry and effort to excel must have had an excellent effect on the physical development of the young men, and as the best among them would be preferred by the best among the women, it would constantly tend, by natural selection, to the improvement of the race. It was, in fact, a rude way of bringing about the pairing of the best of both sexes.

Similar customs, more or less modified, prevail among other savage people, the rule being recognized that "to the victors belong the spoils." And in every way we can regard it, such a custom is a great step in advance over more barbarous usages. It made the men more manly, and the women more womanly, because each one would constantly try to excel in those qualities which the other admired.

The Australian, perhaps the lowest savage of all, has no idea of excelling in anything but cunning and brute force. He has no choice in women at all, nor any desire to conciliate them in any way, but merely covets them like any other possession. His custom, therefore, is to lie in ambush, and watch till he finds some woman of another tribe isolated from her companions; he then springs upon her, lays her senseless with a blow from his club, and carries her off. That is the whole of the courtship; there is no effort to attract, nor to please-not the slightest idea, in fact, of anything of the kind. Perhaps he kills her with the blow ! If so, he simply leaves her and tries again; and if next time he strikes less hard, it will be so that he may not quite kill but only disable.

The desire of the two sexes to please each other, by conduct, or by personal adornment, is one of the first steps toward improvement, both physically and morally. It is, in fact, the beginning of civilization.

Even among the lower animals, as already shown, it is one of the most powerful means of improvement, since it leads, by selection, to the propagation of the fittest.

Anything which excites endeavor in rude human beings, tends to their improvement, either by the development which it causes in their physical and mental powers, or by the softening of manners and the inspiring of taste. The love of adornment, which we see in most savages, and which probably first arose from desire to please or attract the other sex, has been one of the most efficient agents of civilization. 
Professor Hartz remarks that no matter how poor a man may be, or how miserable, he may take a pleasure in adorning himself ; and he might have added, further, that he is all the better for it. If he have no elothes, nor other personal belongings with which to decorate himself, he paints or tattoos his bare body, and feels both gratification and personal pride in doing so. One philosopher has even contended that clothes were first worn for ornament, and not for use or comfort.

Even the barbarians that lived in eaves, during the reindeer epoch, probably millions of years ago, possessed objects that were valued, in some way, for their beauty, or singularity, and not for their utility.

The different modes of personal adornment are very curious to note. Many of them consist, among savages, in mutilations of different parts of the body, or in deformities caused artificially. Nor is the tendency yet extinct even in civilized society, for we still find that contracted waists and crushed feet are thought desirable among ourselves, just as flattened heads and perforated noses are among the Indians.

Darwin well sums up some of the most remarkable fashions, in regard to the person, in his Descent of Man: "In one part of Africa the eyelids are colored black ; in another, the nails are colored yellow or purple. In many places the hair is dyed of various tints. In different countries the teeth are stained black, red, blue, etc.; and in the Malay archipelago it is considered shameful to have white teeth, like those of a dog! Not one great country can be named, from the polar regions in the north to New Zealand in the south, in which the aborigines do not tattoo themselves. This practice was followed by the Jews of old, and by the ancient Britons. In Africa some of the natives tattoo themselves, but it is a much more common practice to raise protuberances by rubbing salt into incisions made in various parts of the body ; and these are considered by the inhabitants of Kordofan and Darfur to be great personal attractions. In the Arab countries no beauty can be perfect till the cheeks or temples have been gashed. In South America, as Humboldt remarks, a mother would be accused of culpable indifference toward her children, if she did not employ artificial means to shape the calf of the leg, after the fashion of the country. In the old and new worlds the shape of the skull was formerly modified, during infancy, in the most extraordinary manner, as is still the case in many places, and such deformities are considered ornamental." Just as pinched waists and dwarfed feet are with us.

In North Africa it takes a man ten years to get his hair perfectly grown into shape. In other parts of the world all the hair is shaved off, and even the eyebrows and eyelashes carefully picked out. On the upper Nile the natives knock out the four front teeth, so that they may not look like brutes. Others knock out only two, and think Europeans look disgusting with the whole set perfect. The Malays file the front teeth to sharp points, so that they look like a saw, and some pierce holes in them, in wnich they wear studs. One of the African kings told Sir Samuel Baker that Lady Baker would be much improved if he would knock out her four front teeth nd split her upper lip.

Flattened noses are esteemed handsome in some parts, and lips cut open so as to hold flat broad bits of wood or bone are equally in vogue in other parts. Rings and other ornaments are of course worn wherever they can be placed, in the ears, lips, and nose especially, the ear being often made larger than the hand, and pulled down to the shoulder by them.

In all these cases, the great motive is, as Darwin says, "self-adornment, vanity, and the admiration of others." . . . With the men of New Zealand, a most 
capable judge says, "to have fine tattooed faces was the great ambition of the young, both to render themselves attractive to the ladies, and conspicuous in war."

Some New Zealand girls, when urged by the missionaries not to be tattooed, begged hard to have a few lines, so that they might not look too ugly when they got old!

The great impelling motive to all this is exactly the same as what we call fashion among ourselves. The foundation of it is the desire to attract and please the other sex, and to outshine all rivals!

Personal peculiarities which are thought disgusting by one people, are considered desirable by others. Hearne says, "Ask a North American Indian what is beauty, and he will answer, a broad flat face, small eyes, high cheek bones, three or four broad black lines across each cheek, a low forehead, a large broad chin, a clumsy hook nose, a tawny hide, and breasts hanging down to the waist."

The Siamese ladies have small noses, with wide spreading nostrils, a large mouth, with thick lips, and high broad cheek bones. Their male admirers, however, consider them much more beantiful than European ladies.

One peculiarity of Hottentot women has been referred to elsewhere, but there is also another, considered by the male Hottentots to be a great mark of perfection. It consists in a most remarkable development of the posterior regions, which are sometimes so large that when a woman sits down on level ground she cannot rise straight up without help, unless she can push herself along to some slope. Burton tells us that the Somal men, who consider this a great beauty, are accustomed to place the women in a straight line, all facing one way, and then pick out those who project the furthest, posteriorily, as being the most handsome.

If there were artificial means of increasing this development, they would undoubtedly be adopted, and we should see it still more pronounced than it is. The preference given to the largest tends, however, even now that way, by the process of natural selection.

Any natural peculiarity is thus apt to become desirable, and to be valued in proportion as it is developed. Those savages that have long hair value it in proportion to its length and abundance, and not infrequently one is chosen chief because his locks are longer than those of all his rivals. Those savages, on the contrary, who have but little hair, naturally affect to consider it a blemish in any amount, and carefully eradicate every one from their bodies. With them a perfectly hairless body is the highest beauty, as among some of the New Zealand tribes, who have a saying that there is no wife for a hairy man!

Some African chiefs have been known to remark, in regard to European ladies, that they would be passable enough were it not for their white skins, making them look like ghosts! With them a black hide is indispensable to any claim to beauty.

Darwin remarks, in regard to the studying of these apparently trivial details, that no excuse is needed for doing so at all, for, in the words of Shopenhauer, "The final aim of all love intrigues, be they comic or tragic, is really of more importance than all other ends in human life. What it all turns upon is nothing less than the composition of the next generation. . . . It is not the weal or woe of any one individual, but that of the human race to come, which is here at stake."

And this is quite true; there is nothing more important to the human race than that which bears upon the association of the sexes, and its result-propagation!

Mr. Windwood Reade informed Mr. Darwin that the Joloffs, a tribe of negroes on 
the west coast of Africa, were remarkable for their uniformly fine appearance ; and when a friend of his asked one of their chiefs the reason for it, he said, "It is very easily explained; it has always been our custom to pick out our worst looking slaves and sell them." Of course the best looking were kept, and as the females were all taken for concubines, this accounted for the fine children and future adults. These negroes simply applied to their own kind the same rules which they found effective in improving their domestic animals, of which they were skillful breeders. In this respect they were ahead of ourselves.

It is a fact worth noting, in connection with pairing, that among animals in a state of nature, single couples are by no means the rule. Even when the sexes are equal in number, or nearly so, the strongest males often appropriate a large number of females to themselves, and the weaker males are left solitary bachelors. This is seen in cattle, horses, seals, domestic fowls, and many others. From this it has been argued that polygamy is natural, and is a provision by which the strongest and most powerful prevail, in propagation, over the feeble.

I am not aware of any instance of polyandria among animals in a state of nature, or one female habitually serving several males.

One curious result of communal marriages, where all the women of a tribe were wives to all the men of the tribe, was the tracing of the descent of a child necessarily through the mother, because the father could not be known. Every one's ancestry was followed through the female line only, because in this there could be no doubt nor mistake.

This is the custom now, among many of our own Indian tribes, the mother only giving name and social position to the children. When Osceola was a prisoner in Florida, he explained this to one of our officers, who expressed surprise that children were not always named after their fathers,-_"Mother always known," said he; "father uncertain."

Sometimes even the mother seems to have been ignored, and the children as well as the women were all tribal, each belonging to the whole community. This points to a time when the association of the sexes was quite promiscuous, and all interests were in common. It is quite easy to imagine why such a state of things must have existed, as a necessity. When the whole tribe was in constant danger, it was the safest plan; for every individual, and especially every child and woman, would be better protected as part of the whole community, than if left to struggle alone.

There is even reason for supposing that, in some instances at least, human beings have paired, like many animals, only for a season, or for one birth. Indeed, some travelers assure us that arrangements of this kind exist even now in some parts of Africa. If so, it is evident how they have arisen; not from caprice, but from surrounding conditions.

It is not to be supposed that the male, in these unions, would concern himself about the support and care of the children; that would be left to the mother, who would also have to support and protect herself. This, however, she could not do unless food and shelter were easily and surely obtainabie. Such an arrangement, therefore, could only originate and continue in a state of comparative peace and plenty.

It is quite probable, as before explained, that in all primitive tribes, the women were held in common, so that no man could have a wife of his own, all to himself, in his own tribe. If he wished one he must steal or capture her from another tribe, 
and then she was his private possession or slave. In all probability this was one of the first ways in which wives, as private possessions, were first obtained.

A very curious proof that all the women of a tribe were originally considered to belong to the tribe, is found in what was called the expiation of marriage! If a man wished to take a wife to himself, he had to pay something to the community for the privilege, because it was considered that he was making a private possession of what properly belonged to all.

It was probably a long time before this common right was fully abrogated, so that certain women would belong only to certain men; and none be considered the common property of the whole tribe. Nor would this new form of marriage be regarded at all as a step in advance, morally or otherwise, but on the contrary would be looked upon as a dangerous and demoralizing innovation. Under the communal system, according to Sir John Lubbock, instead of a woman being esteemed on account of reserve, or unusual continence, she received honor in proportion to the freedom with which she bestowed her favors. And under such a condition of society this was perfectly natural ; for that which with us now is a social crime, would then be a public virtue.

A curious form of polygamy formerly existed, under the feudal system, in France and other European countries. The feudal lord, or seigneur, when one of his dependents married, claimed the right to assume the husband's place, on the first night of the nuptials ! And this right was both claimed and exercised, until a com. paratively late period. Sometimes, however, the dependent, if rich, would buy off the privilege, and sometimes it was waived as a favor.

In some parts of Africa a similar right is also asserted by the kings of tribes, and so far from being resented, it is considered a mark of favor.

Among the ancient Romans, if a husband admired another man, for any bodily or mental quality, he would often request him to visit his wife, so that their children might possibly resemble his friend. Similar requests were also not unknown on the part of the females.

The Spartans habitually encouraged the intercourse of their best men and women, and, as far as possible, made them the only propagators, without any reference to special marital relations.

In some of the countries of Palestine and Mesopotamia, it was fornerly the custom for every woman, at least once in her life, to prostitute herself to any one who wished, in the Temple, on certain public occasions. This was, in fact, a religious rite, which it would have been sinful to omit; but probably it was, originally, a mere survival of the old communal marriage, or an assertion of the right of every man to every woman.

At a later period the custom became modified, so that certain women only were set aside, or devoted, for this purpose, and were considered sacred and holy. Those who sought their favors paid for them, and in this way the priests derived much of their income. Young girls, even at the present day, are thus deroted to the service of the temples, in India and Turkey; and we see from the Bible that the custom was common in Palestine, even among the Hebrews themselves sometimes, as we learn from Kings, and Hosea! These women so devoted were called Kadesh, meaning pure, or consecrated. See also in Deuteronomy, where it does not say there shall be no Kadesh, but only that they shall not be of the daughters of Jacob. (Chap. xxii. Vs. 17, 18.) 
One cause of polygamy should be borne in mind, as it still prevails. It is customary with the males of many animals, as the gorilla for instance, to fight for possession of the females, and so fiercely that the weaker males are all killed, or driven away to solitary life. This necessarily leaves several females to each of the males that survive, and hence polygamy. Now in all probability the same course would be pursued in all small and isolated assemblages of human beings, in their rudest state; a few of the strongest males killing or driving off all the feebler ones, and then dividing the females amongst themselves. Like other customs, when once established, it would be perpetuated long after the conditions from which it originated had ceased to exist.

It is always a great gain for the women, in any rude community, when the men begin to have ideas of beauty, and to prefer some to others. The favored ones, of course, soon become aware of their power, and in various ways make the men pay for their favors. Even if purchased or taken forcibly, they are at least cared for and protected, like any other valuable property, and receive a certain degree of consideration. The women less favored by nature strive to make themselves attractive by artificial adornments, and by other means, and are thus stimulated to try and improve themselves, crude though the attempt may be. Taste will also vary, as we always see it do, and almost every woman would become an object of desire to some man.

If the sexes were tolerably equal in number, and the means of living were easily obtained, the woman could make her own bargain in marriage, as we find her doing in many parts of the world at the present day. Many of the marriage customs which prevail among rude tribes, in widely separated places, illustrate this very well.

Hearne tells us of a woman among our Northern Indians, who repeatedly left her husband to go and live with her lover; nor was it considered anything more than the exercise of a right, or at least a privilege. And among the Charruas, in South America, according to Azura, a woman can divorce herself when she chooses, and marry again. Among the Abipones, although girls are usually bought from their parents, for wives, still; even after the bargain is made, they often reject the husband and run away from him. Among the Patagonians, and in Terra del Fuego, it is the same. In Fiji, the rule is for the man to seize the woman he wishes for a wife, by force, real or pretended, and take her to his house; but if she does not like him, she runs away to some one else ; if there be no objection, she stays, and that is marriage. When a Kalmuk Tartar wishes a girl for a wife, he races with her, she always having a certain start. If he catches her, she is his wife, but if not, she is free; and we are assured by Clark, who was much with them, that he never knew of a girl being caught unless she wished. The same custom prevails among the Koraks of Northern Central Asia, and with some of the Malays. In each place the same tale is told-that when a girl is caught, it is always because she wished to be.

Even in those parts of Africa where girls are bought from their parents, and beaten if they object to their husbands, they obtain, in some way or other, a certain amount of freedom of choice or refusal ; for we are told that very ugly men, even if rich, cannot get wives at all. The girls also, before they are betrothed, insist upon the men submitting themselves to inspection from every point of view, and showing off their paces. No doubt those who are not desired hear such comments, from the objecting fair ones, that their ardor for them is effectually cooled. Sometimes the women themselves propose to the men, and quite commonly they run off with a favored lover, rather than accept a husband they do not like. 
This power of choice among the women is in all cases an important agent in the improvement of the race, because, as a rule, they will naturally choose the handsomest men, or those who can best provide for them. Darwin shows conclusively how this process of selection inevitably leads to the propagation of the largest number by the finest individuals.

Perhaps one of the best instances known of a community in which males and females were absolutely on an equality in regard to intercourse, and in which marriage was simply a matter of mutual inclination, was that of the Sandwich Islands, as described by Cook, in his voyages. Marriage, in fact, there was none, men and women coming together and separating without any ceremony or agreement whatever, just as they felt disposed. At a grand feast given to Cook, a young man and woman, so he tells us, performed the rites of Venus in presence of the whole company, without attracting any particular attention. The queen herself, in such matters, was equally without restraint, and was evidently surprised-perhaps shocked-at the way her advances were met.

We must be careful, in such matters, not to judge people so situated exclusively from our point of view. Such practices, with them, were not licentious, nor in any way calculated to do harm, as they would be with us. Indeed, Cook distinctly shows that they were remarkably modest, tender, and affectionate with each other, and with no idea of immorality. Similar testimony has been given in regard to certain of the people of Madagascar, with whom the relations of the sexes are equally unrestrained.

It appears, from all that is known, that marriage has everywhere been, primitively, an individual or tribal arrangement, purely civil, like any other personal contract. It is always at a later period that the priesthood in any way assume control over it, and in some countries they have never done so. In several ancient countries of the old World, the priests seem to have undertaken the initiation of young people, at the age of puberty, into the nature of their sexual relations, and to have done so under the guise of a religious rite. These initiations, which occurred at stated intervals, always took place in the temple, or in the sacred groves, in strict privacy and seclusion. They were regarded as sacred mysteries. The church, in fact, gradually assumed the place of the community, and marriage finally could not be legitimate without its sanction. Still this change was gradual, and not complete till comparatively recent times. Among the ancicnt Hebrews, we read of men serving for their wives, as Jacob did for Leah, and of men taking women for wives, or having them given to them by their parents, but no church service or priestly sanction seems to have been required. Neither do we find anything of the kind among the ancient Greeks and Romans till Christianity became the established religion. Then the church took absolute control of marriage, as it did of many other things which previously had been controlled by the state alone.

More recently, and especially at the present day, the tendency is again to make marriage a civil contract only. It is so regarded in our own country, and church sanction is not obligatory. No ceremony of any kind, nor any set formula is required, but only sufficient proof of the fact that the parties have mutually agreed to be man and wife. It is merely to give this proof, that witnesses are required at all, and when either a minister of religion or a justice of the peace marries a couple, he only acts as witness ; and any other witness would do as well legally. In fact, the parties marry themselves, or make their own contract, and the minister, magistrate, or other person who is commonly said to marry them, only bears testimony to the contract. 
In short, the civil marriage, or contract, properly testified to, is demander by law, but all religious or other ceremonial sanction is optional, and adds nothing to the legality of the union.

It is the same with divorce. Formerly this could not take place except by sanction of the church, but now it is a civil matter only. For certain causes, and by fulfilling certain requirements, married people can separate, and enter into new engagements, without the church having anything whatever to do with it. Even in the countries of the Old World which have established churches, as in England, for instance, these principles now prevail, and over neither marriage nor divorce has the church any legal control whatever.

It is worthy of remark also that the tendency of modern legislation everywhere is constantly toward simplifying marriage, and facilitating divorce when shown to be desirable.

The maintenance of the family relation, as we now have it, by the marriage of individual men and women in single pairs, is indispensable to the existence of society ; without it, in fact, society, as it now exists, could never have come into being, nor could it now continue if such marriage were abrogated. But still there are often cases in which both social and individual interests will be better served by annulling the contract than by compelling its continuance, and in such cases divorce should always be obtainable, providing due provision is made for insuring the rights of all concerned.

In all settled societies, one essential condition of marriage is a proper care for the children which may result from it. Whenever marriage ceases to be communal, those entering into it must make provision for their offspring, if they have any, so that they may neither perish nor become burdensome to others. Both law and custom make this imperative, and in fact society could not exist if it were not so.

To discourage illicit unions, the children which may result from them are everywhere subject to various social and legal disabilities, and are called illegitimate. They not only do not inherit the father's property, but even his name is refused them, so that they have to be called after the mother. Formerly bastards were often treated more unjustly even than they are now, and though many of that alass have become great as statesmen and warriors, still their birth was always a stigma to them. Those among them who were entitled to bear coats of arms, no matter how acquired, were compelled to have them crossed with the bend sinister, or mark of bastardy. But, in spite of this, many bastards were very eminent, and some even, like Falconbridge, boasted of their origin. William the Conqueror was a bastard, and so was one of the most famous Austrian dukes ; in fact, history tells of many of them.

Mlegitimacy has always been a difficult matter for legal regulation, because it is manifestly unjust to punish children for no fault of their own, and yet at the same time the offspring of legal marriage must always occupy a different position from that of mere concubinage. By the law of Scotland, which is also our law, illegitimate children cannot inherit from the father, nor, with us, does a subsequent marriage between the parties make them legitimate. In Scotland, however, this is not the case, for marriage at any time may make legitimate all the children the parties may have had before, which seems both reasonable and just. The difference arises from the character of the Scotch law of marriage, which requires only consent and publication. Any parties not already married, who live together as man and wife, and who call themselves so, are to all intents and purposes legally married. In England 
also a bastard can be made legitimate by a special act of Parliament; as was done in the case of the illegitimate children of John of Gaunt, in the time of Richard the Second.

Most foreign countries follow the Scotch law, by making a subsequent marriage between the persons legitimize all the children they may have had before. But with this condition, that at the time these children were born the parties could have married if they chose ; or, in other words, providing there was then no legal bar rier to their marriage.

A curious complication occurs sometimes, when one of the parties may have married another person, in the mean time, and have had other children by them. The question then arises whether the legitimized bastards take equal rank and right with those born in the intervening marriage, and who were undoubtedly legitimate. It is contended that they do not, but the question has never been legally settled, so far as I am aware.

In France, if a man acknowledge an illegitimate child as his, during his life, that child is entitled to a share in his father's property, the same as his legitimate chilrlren.

There are many curious law-points in regard to marriage and legitimacy, which need not here be discussed, though some of them are very interesting. The law in Wngland is not, in many respects the same, in regard to these matters, as it is in Sicotland and Ireland ; especially in regard to what constitutes a marriage. In consequence of this, it sometimes happens that parties are legally married in one of these countries, but not in the other ; and a woman may be a lawful wife in Scotland, and at the same time only a concubine in England.

This confusion all arises from the interference of the churches, and marriage by priests. If the civil marriage alone were everywhere all that was required in law, and compulsory, leaving the religious rite optional, there could be no uncertainty.

An act passed in the reign of George the Second, in reference to Ireland, makes any marriage void between Catholics and Protestants, or between two Protestants even, if celebrated by a Catholic priest. A later act in the time of George Third, modified this so as to allow the Catholic priest to officiate, providing the parties had first been married by a Protestant minister. Any priest violating this law is liable to a penalty of two thousand dollars.

The marriage act of England, at the present time, is the simplest, and perhaps the most perfect in the world. It simply provides that every marriage must be duly witnessed and recorded before the registrar of the district in which the parties live. Very few preliminaries are required, except proper public notice, for a certain time, in the case of minors. There is no ceremony of any kind, the whole transaction being regarded, so far as the law is concerned, as a civil transaction, like any other contract. Any rites or ceremonies, if they wish any, are leit to the parties themselves, but they are not in any way essential to the legality of the marriage.

The registry contains the names, ages, occupations, and residence of the parties, and also the names and residences of their parents, with some other particulars. All these local registries are periodically transmitted to Somerset House, London, where they are safely recorded, and can be consulted at any time for a small fee.

It is impossible to overrate the immense advantages of such a system, thoroughly aarried out, over the slip-shod, loose system, or rather no system, of our own coun- 
try. There can never be any of those interminable suits at law, such as we often have, turning upon the question whether certain parties were ever married or not. If they were married in England, there is the record to prove it; and if it is not on the record they never were married, and that ends it. With us the fortunes and standings of individuals and families often depend upon memories more or less treacherous, and oaths more or less unreliable. It is a constant occurrence, after a rich man's death, for some woman to appear and claim to have been privately married to him! Witnesses are easily found, and she is either bought off, or the estate is wasted in litigation. Such a thing ought not to be possible, nor could it be if we had a proper system of compulsory public civil registration.

In New York we have a registry law, I am aware, but it is so imperfect, and si badly enforced, that it amounts to very little, and is evaded in many ways. Certain religious denominations even oppose any law whatever of the kind, and do all they can to nullify it. The only true system is to make a public civil registration, duly attested and preserved, compulsory in every marriage, and the only thing requisite to make it legal. Then the parties can please themselves in regard to rites and ceremonies, according to their views on such matters.

There is nothing in such a law to which any one can reasonably object, and its benefits are obvious. Even Quakers (who have no marriage ceremony of any kind), Secularists, Free Thinkers, and denominationalists of every kind, accept such a law sladly, and acknowledge its advantages.

The law in England, till recently, was very unjust in regard to the property of married women; all they possessed becoming the property of their husbands, to do with as they pleased. Even if anything was left or given to them, the husband could take it absolutely, as he could anything they might own in any other way. This, however, is now changed in many ways, and there is no difficulty in securing property to a married woman's own use and control. Any woman who earns wages, or has an income in any way, and a worthless squandering husband, can obtain a magistrate's order securing such wages or income to her own use. And further than this, a law is now in the process of elaboration, and will assuredly be soon enacted, compelling any man who neglects to support his wife when he is able, or who abuses her, to keep away from her, if she requests it. He will have no right to go near her, and will be liable to punishment if he does, or annoys her in any way. In short, the whole tendency of modern legislation on these matters, is towards more complete justice to women.

In Scotland, a rich wife is bound to support her husband; and in France a fatherin-law is bound to support his son-in-law, even if his daughter be dead. In England a man cannot legally marry his dead wife's sister, but in the English colonies he can. This prohibition is entirely a church scruple, and will evidently be soon done away with.

Keeping a mistress, in most countries, would be a sufficient cause for divorce, but in France it is not necessarily so, unless the husband bring her into the same house with his wife!

It should be generally known also, that a marriage may hold good in one country but not in another, for reasons which might never be suspected. Thus a Roman Catholic man, say of one of the Catholic states in South America, may marry a Protestant woman here, and she will of course be his legal wife, but if they should go to his own country to live, he could disown and desert her, if they had not been mar- 
ried by a Catholic priest; cases of great hardships and injustice of this kind have occurred to English women on many occasions.

In France also, if a man have parents living, no matter what his age, he cannot legally marry without their consent; and several cases have occurred where English women have married Frenchmen, and found themselves, when in France, disowned, and no wives at all, merely because the parents did not approve of the match.

Such are a few of the anomalies, inconsistencies, and injustices, appertaining to marriage; some of them arising from church interference, and others from the old notion still clung to, that woman should be in every way subordinate to man. The only cure for all such evils is the making marriage everywhere a compulsory civil contract, between equal parties ; and recognizing the woman's rights in herself and her property the same as we do the man's, in the fullest sense.

The following sketch of the position and influence of women in ancient Greece, by James Donaldson, LL.D., from the Contemporary Review, is exceedingly interesting and valuable, in relation to the matters we have been discussing. It will show how different have been the notions and practices of men, respecting women, at different periods, and may well make us ask if there be not much we could learn from these ancient people :

"Everything that has life has a course within certain limits predetermined for it, through which it passes until it finally disappears. The seed of the oak gathers materials from earth and sky until it fashions itself into the majestic tree. It will not become a rose or an elm. So it is with the higher animals and man. The lines of their progress through life are distinctly marked off. But, within the limits special to each class there are different degrees of perfection. All the individuals seem to strive after an ideal which none attain, to which some come very close, and to which all more or less approximate. Man has also his ideal, but, in addition to the instinctive power of soul which strives after the ideal, he has the faculty of being conscious of the ideal and of consciously striving after it. What is true of man is true of woman. What is the ideal of woman? What could we call the complete development and full blossoming of woman's life? I have no intention of answering this question, much agitated in the present day. I do not think that I could answer it satisfactorily, but it is requisite for the historian of woman in any age to put it to himself and his readers. A true conception of woman's ideal life can be reached only by the long experience of many ages. The very first and most essential element in the harmonious development of woman's nature, as it is of man's, is freedom, but this is the very last thing which she acquires. Impediments have arisen on every hand to hinder her from bringing her powers into full activity. Ignorance, prejudice, absurd modes of thought prevalent in particular ages, conventional restraints of an arbitrary nature, laws that have sought to attain special aims without regard to general culture and well-being-these and like causes have prevented us from seeing what woman might become if she were left unfettered by all influences but those that are benign and congenial. It is the part of the historian to take note of these obstacles, and to see what, notwithstanding these, woman can do and aims at doing.

"The first condition, therefore, of a successful study of woman's history, is to come unbiased to the task. We must for the time keep in abeyance our prevalent opinions. There is peculiar need for this in this subject, because, should we have false opin- 
ions, they are sure to be held with a tenacity which is great in proportion to their falsehood ; and should we have true, we are likely to give them an exaggerated importance and power; for all opinions on women are apt to be intense. We have therefore to suspend our ordinary modes of thought, and enter into conceptions and feelings and a manner of life widely different from our own. Some of these differences I must explain before I enter on my history.

"And, first of all, the Greeks looked at the relations between the sexes from a point of view utterly strange to us. Among us there exists a clear and definite doctrine which lays down rigidly what is right and what is wrong. The Greeks had no such doctrine. They had to interrogate Nature and their own hearts for the mode of action to be pursued. They did not feel or think that one definite course of conduct was right and the others wrong; but they had to judge in each case whether the action was becoming, whether it was in harmony with the nobler side of human nature, whether it was beautiful or useful. Utility, appropriateness, and the sense of the beautiful, were the only guides which the Greeks could find to regulate them in the relations of the sexes to each other.

"We have to add to this that their mode of conceiving nature was quite different from ours. To them everything was natural, or if you like supernatural. If wine gladdened or maddened the heart of man, the influence was equally that of a god. The Greek might be perplexed why a god should madden him, but he never doubted the fact. And so it was with love. The influence which the one sex exercises on the other is something strangely mysterious. Two persons of different sexes meet. If we look at them, we see nothing very remarkable in either; and if we continue our look for an hour or two, we might notice nothing remarkable going on. Yet a very extraordinary change has taken place. The hearts of both have begun to vibrate wildly. The commonplace man has had wings furnished to his mind, and he sees heaven opening before his eyes, and an infinite tenderness suffuses his soul. The girl, who could not utter a word in her own behalf before, has had her lips unsealed, and wit and brightness and poetry sparkle in every sentence which she addresses to her companion. She too flings from her the ordinary routine of daily life, and sees before her a paradise of purest bliss and unending joy. Whence comes all this inspiration? Whence this temporary elevation of the mental powers? Whence this unsealing of mortal eyes, till they see the beatific vision? 'From a divine power,' said the Greeks. And this divine power seemed to them the most irresistible of all. It swayed the gods themselves. If the gods themselves could not but yield to the magic power, how could it be expected that a mortal could resist? The religion of the Greeks could not, with such a mode of conception, strongly aid them in selfrestraint. It could merely inculcate forbearance and compassion. And this we find to be the case. In a speech which Sophocles puts into the mouth of Dejanira, she expresses her conviction that a wife bas no right to expect a husband to be always faithful to her, or to blame the woman with whom he falls in love. 'Thou wilt not,' she says, 'tell thy tale to an evil woman, nor to one who knows not the nature of man, that he does not naturally rejoice always in the same. For whosoever resists love in a close hand-to-hand combat, like a boxer, is not wise. For he sways even the gods as he wishes, and me myself also; and how should he not sway another woman who is such as I am? So that if I find fault with my husband caught with this disease, or with this woman the cause along with him of nothing that is evil or disgraceful to me, I am unquestionably mad.' Such religious forbearance is not found 
in poetry only. It is inculcated on wives as a strict part of their duty by a female Pythagorean philosopher, Perictione, who wrote on the harmony of woman, and the sentiment disappears only before a philosophy such as that of Plato and Aristotle, which rose far above the common conceptions of the Divine Being.

"Throughout our estimate of women, it is also of great importance to remember the passionate love of beauty which animated the Greeks. A modern mind can form almost no idea of the strength and universality of this passion. The Greeks loved everything that was beautiful, but it was in the human body that they saw the noblest form of earthly beauty. They did not confine their admiration to the face. It was the perfect and harmonious development of every part that struck them with awe. It would occupy too much space to give a full account of this love of the beautiful, or to bring home the intensity of the Greek feeling. One instance will suffice. The orator Hyperides was defending the Hetaira Phryne, before a court of justice. His arguments, he thought, fell on the ears of the judges without any effect. He began to regard his case as hopeless, when a happy idea struck him, and, tearing open the garment of his client, he revealed to the judges a bosom perfectly marvelous in form. The judges at once acquitted her, and I bave no doubt that the whole Greek sentiment agreed with their decision. But we should make an entire mistake if we were to suppose that the judges were actuated by any prurient motive. One of the writers who relate the circumstance gives the reason of the decision. The judges beheld in such an exquisite form not an ordinary mortal, but a priestess and prophetess of the divine Aphrodite. They were inspired with awe, and would have deemed it sacrilege to mar or destroy such a perfect masterpiece of creative power. And though no doubt there were low-minded Greeks, as there are low-minded men everywhere, yet it may be affirmed with truth that the Greeks did not consider beauty to be a mere devil's lure for the continuance of the race, as Schopenhauer represents it, but they saw in it the outshining of divine radiance, and the fleshly vehicle was but the means to lead on the soul to what is eternally and imperishably beautiful.

"These are only some of the points in which the Greeks differed widely from us, and we must realize the difference before we can read the history aright. But this history has to face other difficulties. The influence of woman is often exercised most powerfully in such a quiet and unobtrusive manner that no historian can take note of it. Who, for instance, could narrate the action of beauty and of beautiful ways upon thousands of hearts? The influence is silent, but not the less potent. We have this additional difficulty in Greece, that almost all we know of women is derived from men. Now men rarely write dispassionately of women. They either are in love with them, or hate them, or pretend to hate them. They have had sweet or bitter experience of them. And when they do write about them, they write according to that experience. But not only is the history of Greek women written by men, but it was written for men. This fact must be specially remembered when we have to deal with the utterances of the comic poets, for women did not act in the plays, nor is it probable that they were even present at the comedies during the best days of Athens. But men taking the parts of women are sure to act them with all the exaggeration and license which are natural to such representations. No great stress must, therefore, be laid on the wild abuse of women which can be culled in large abundance from Greek writers. One early satirical poet divides women into ten classes, of which only one is good. And he proceeds with his invective very much as if women did not exist: 
“" 'Listen, 0 people,' says Susarion, who may be called the inventor of comedy. 'Susarion says this: Women are an evil, but nevertheless, 0 countrymen, it is not possible to have a household without evil, for to marry is an evil and not to marry is an evil.'

"A satiric poet gives it as his opinion that 'a man has only two very pleasant days with his wife, one when he marries her, the other when he buries her.' A comic poet says pithily, 'Woman is an immortal necessary evil.' Euripides says:

"'Terrible is the force of the waves of the sea, terrible the rush of river and the blasts of hot fire, terrible is poverty, and terrible are a thousand other things; but none is such a terrible evil as woman. No painter could adequately represent her; no language can describe her; but, if she is the creation of any of the gods, let him know that he is a very great creator of evils and a foe to mortals.'

"Quotations like these could be made in hundreds, but they really tell us little. They could be matched by a large number of sayings from the same authors, in which woman is praised to the skies. Euripides was specially blamed as a hater of women. The remark was made in the presence of Sophocles. 'Yes,' said he, ' in his tragedies.' And even in his tragedies he has painted women of exquisite tenderness of heart, and capable of the grandest self-sacrifice and of the purest love.

"With these preliminary observations, we enter on our task. I can only select prominent periods. And the first that comes before us is the Homeric. And here we require all the power of transporting ourselves into different times that we can command; for the phenomena are singular and unique. If we look at the external position of women, we must place the Homeric age exceedingly low in civilization. Women have almost no rights ; they are entirely under the power of man, and they live in continual uncertainty as to what their destiny may be. The woman may be a princess, brought up in a wealthy and happy home; but she krows that strangers may come and carry her off, and that she may therefore at some time be a siave in another man's house. This uncertainty seems to have produced a strong impression on their character. They are above all women meek. If the terrible destiny comes upon them, they submit to it with all but unrepining gentleness, and their gentle ways soon overcome the heart of their warrior tyrants, and they make them their companions and friends. But low though this position be, it has to be noted that it is the inevitable result of the character of the times. Might was right. The strong arm alone could assert a right. The warrior had to defend even what belonged to him against any new-comer. He himself sacked the cities of others. His own city, too, might be sacked, and if his wife's fate was to be carried off and to become the mistress of his conqueror, his own was to perish mercilessly by the cold edge of the sword. Man and woman alike held their lives in their hands. Women were not warriors, and therefore they had to depend entirely on the protection of men, and were consequently subject to them. Such was their external position. But when we look to the actual facts of the case, nowhere in the whole range of literature are women subjected to a sway so gentle, so respectful, so gracious. Indeed, it can scarcely be called a sway at all. The physical force, which no doubt exists, is entirely in the oackground. In the front we see nothing but affection, regard, and even deference. The men appear never to have found fault with the women. It was natural for a woman to love, and she might do what they would deem an eccentric or disproportionate action in consequence of this influence; but it was either a man or a god that was to blame. She was for the time mad. Even in the case of Helen, who 
bronght so many disasters on Greeks and Trojans, the men find no fault. She reproaches herself bitterly, but the men think that it was Paris who was to blame, for he carried her off forcibly. How could she help it? And how could she prevent Paris falling in love with her? It was the business of woman to make any man happy whom destiny brought into her company, to diffuse light and joy through the hearts of men. Helen was surpassingly beautiful, knew all womanly works to perfection, was temperate and chaste, according to their ideas, and had a mind of high culture. All these were gifts of the gods, and could not but attract. The Trojans themselves were not surprised that Paris should have fallen under the spell of her charms : for a being so beautiful was a worthy object of contest between Greeks and Trojans. But she did nothing to excite Paris. She would have been happier with Menelaus. And when Paris was slain and Troy captured, Helen gladly returned to her former husband, and again occupied her early queenly position with dignity and grace, as if nothing had happened. The only woman in regard to whom harsh words are used is Clytemnestra ; but even in her case the man is much more censured than the woman, and if she had merely yielded to Etgisthus, under the strong temptations, or rather overpowering force, to which she was exposed, not much would have been said. Agamemnon would have wreaked his vengeance on the male culprit, and restored his wife to her former place. But at last she became the willing consort of Egisthus, and his willing accomplice in the dreadful crime of murder. Yet even for this it is on Egisthus that the poet lays the burden of the blame. For this mild judgment of women there were several causes. First, the Homeric Greeks were strongly impressed by the irresistible power of the gods and of fate, and the weakness of mortals ; they thus found an easy excuse for any aberrations of men, but especially of helpless women; and their strong sense of the shortness of life and the dreariness of death led them to try to make the best of their allotted span. Then their ideas of love and marriage tended to foster gentleness. In the Homeric poems there is no love-making; the idea of flirtation is absolutely and entirely unknown. They no doubt spoke sweet words to each other, but they kept what they said to themselves. And a man who wished to marry a girl proved the reality of his desire generally by offering the father a handsome gift for her, but sometimes by undertaking a heavy task, or engaging in a dangerous contest. And when she left her father's home, she bent all her ways to please the man who had sought after her, and she succeeded. In the Homeric poems the man loves the woman, and the woman soon comes to love her husband, if she has not done so before marriage. The Homeric Greeks are, even at this early stage, out-and-out monogamists. Monogamy is in the very heart of the Greek heroes. No one of them wishes more than one woman. There is a curious instance of the power of heroic affection in Achilles. A captive widow has become his partner before the walls of Troy. She is very fond of him, and he becomes very fond of her. But there is no proper marriage between them, and Achilles could not worthily celebrate his marriage in a camp far from his friends and home. Yet such is his love for her, and her alone, that she is to him a real wife. And, when Patroklos dies, Briseis, in her lament over him, states that he promised that he would make her the wedded wife of Achilles, and take her to Phthia, the native land of the hero, and celebrate the marriage-feast among the Myrmidons. Probably Achilles had often given her the same promise, though he knew that his father might assign him a wife, and there might thus be difficulties in the way, and Patroklos had offered to help him in carrying out his design. If there 
was such true love to a captive, we may expect this still more to be the case with wives of the same race and rank. And so it is. Beautiful, indeed, is the picture of married life which Homer draws. 'There is nothing,' he says, 'better and nobler than when husband and wife, being of one mind, rule a household.' And such households he portrays in the halls of Alcinous and Arete, and in the Trojan home of Hector and Andromache, but still more marked and beautiful is the constant love of Penelope and Ulysses. Indeed, Homer always represents the married relation as happy and harmonious. In the households of earth there is peace. It is in the halls of Olympus that we find wife quarreling with husband. But the love of these women to their husbands is the love of mortals to mortals. They do not swear eternal devotion to each other. They have no dream of loving only one, and that one forever, in this life and the next. They do not look much beyond the present; and therefore, if a husband or a wife were to die, it would be incumbent on the survivor to look out for a successor. Even when a husband is long absent from his wife, it is not expected that he can endure the troubles of life without the company and comfort of one woman's society. Thus Agamemnon takes to himself the captive Chryseis, and comes to love her better than his wife. Thus Achilles becomes so attached to Briseis as to weep bitterly when she is taken from him; but when she is taken from him, he consoles himself with the beautiful-cheeked Diomede. And Ulysses, though he loves his Penelope best, and longs for her, does not refuse the embraces of the goddesses with whom he is compelled to stay in the course of his wanderings. Homer's insight into human nature is apparent in the circumstance that it is only in the heart of a true woman that he places resistance to the ordinary modes of thought. The peculiarity of Penelope's affection is that it will not submit to prevalent ideas; she loves and admires her Ulysses, and she will love no other. Contrary to all custom, she puts off the suitors year after year. The time has arrived when every one expects her to marry again. She has seen her son Telemachus grow to manhood. She has now no excuse. But still she refuses, waiting against hope for the return of him who in her heart she believes will return no more.

"After what I have stated, I need scarcely say that the influence of woman was very great in the Homeric period. The two poems turn upon affection for women. The Trojan war had its origin in the resolution of the Greeks to recover Helen, and the central point in the 'Iliad' is the wrath of Achilles because Agamemnon has taken away from him his captive Briseis. Ulysses and Penelope, as every one knows, are the subject of the 'Odyssey.' The husband consulted his wife in all important concerns, though it was her special work to look after the affairs of the house. Arete is a powerful peace-maker in the kingdom of her husband Alcinous, and it is to her that Nausicaa advises Ulysses to go if he wishes to obtain his return. All the people worship her as a god when she walks through the streets. Penelope and Clytemnestra are left practically in charge of the realms of their husbands during their absence at Troy, each with a wise man as counselor and protector. And the very beautiful Chloris acted as queen in Pylos. Altogether, the influence of Homeric women must be reckoned great and their condition happy.

"For this result two special causes may be adduced-the freedom which the women enjoyed, and their healthiness, possibly also their scarceness.

"The freedom was very great. They might go where they liked, and they might do what they liked. There was, indeed, one danger which threatened them continually. If they wandered far from the usual haunts of their fellow-citizens, strangers 
might fall upon them and carry them off into slavery. Such incidents were not un. common. But, apart from this danger, they might roam unrestricted. They were not confined to any particular chamber. They had their own rooms, just as the men had theirs ; but they issued forth from these, and sat fown in the common chamber, when there was anything worth seeing or hearing. Especially they gathered round the bard who related the deeds of famous heroes, or the histories of famous women. They also frequented the wide dancing-place which every town possessed, and with their brothers and friends joined in the dance. Homer pictures the young men and the maidens pressing the vines together. They mingled together at marriage-feasts and at religious festivals. In fact, there was free and easy intercourse between the sexes. They thus came to know each other well, and, as the daughters were greatly belored by their fathers, we cannot doubt that their parents would consult them as to the men whom they might wish for husbands. Even after marriage they continued to have the same liberty. Helen appears on the battlements of Troy, watching the conflict, accompanied only by female attendants. And Arete, as we have seen, mixed freely with all classes of Phæacians.

"Along with this freedom, and partly in consequence of it, there appears to have been an exceedingly fine development of the body. The education of both boys and girls consisted in listening to their elders, in attending the chants of the bards, and in dancing at the public dancing-place of the town. There was no great strain on their intellectual powers. There was no forcing. And they were continually in the open air. All the men learned the art of war and of agriculture, and all the women to do household work. The women made all the clothes which their relatires wore, and were skilled in the art of embroidery. But they not merely made the clothes, but regularly washed them, and saw that their friends were always nicely and beaufully clad. These occupations did not fall to the lot of menials merely. The highest lady in the land had her share of them, and none was better at plying the loom and the distaff than the beatiful Helen. We have in the sixth book of the Odyssey a charming picture of a young princess, Nausicaa. Nowhere are portrayed more exquisitely the thoughts and feelings and ways of a young girl who is true to her own best nature; who is reserved when reserve is proper, and speaks when a true impulse moves her; who is guileless, graceful, leal-hearted, and tender. Happily I have not here to exhibit her character, for to do anything but quote the exact words of Homer would be inevitably to mar its beanty; but I have to adduce some of those traits which show how the Homeric girls grew. Nausicaa is approaching the time when she ought to be married, and in preparation for this event would like to have all her clothes clean and in nice condition. She goes to her father, and tells him that she wishes to wash his clothes and the clothes of her brothers, that he may be well clad in the senate, and they may go neat to the dance. The father at once perseives what desire the daughter cherishes in her heart, and permission is granted; the mules are yoked to the car, the clothes are collected, and the princess mounts the seat, whip in hand, and drives off with a number of maid attendants. They reach the river where are the washing trenches. The clothes are handed out of the car, the mules are sent to feed on the grass, and princess and maids wash away at the clothes, treading them with their feet in the trenches. They then lay out the clothes to dry. While the clothes are drying, they first picnic by the side of the river, and then, to amuse themselves, engage in a game at ball, accompanied with singing. This is a day with Homeric girls. They can do everything that is necessary-drive 
wash, spin, and sew. No domestic work comes amiss to one and all. And they are much in the open air. They thus all find active employment. Time never hangs heavy on their hands. And the strength and freshness of body produce a sweetnes' of temper and a soundness of mind which act like a charm on all the men who hav to do with them. It seems to me that this explains to some extent the phenomena of the Homeric poems. There is no vicious woman in the Iliad or Odyssey. Some of them have committed glaring violations of the ordinary rules of life, but they are merely temporary aberrations or fits of madness. And there is no prostitution. This healthiness explains also another feature of the Homeric women which deserves notice. There was an extraordinary number of very beautiful women. The district of Thessaly, from which the whole of Greece ultimately derived its own name of Helias, is characterized by the epithet the land of the beautiful women; and several other places are so characterized. But their type of beauty was not the type prevalent in modern times. Health was the first condition of beauty. The beautiful woman was well-proportioned in every feature and limb. It was the grace and harmony of every part that constituted beauty. Hence height was regarded as an essential requisite. Helen is taller than all her companions. The commanding stature impressed the Greeks as being a near approach to the august forms of the goddesses. As one might expect, the beauty of the women is not confined to the young girl between the ages of seventeen and twenty. A Homeric woman remained beautiful for a generation or two. Helen was, in the eye of the Greek, as beautiful at forty or fifty as she was at twenty, and probably as attractive, if not more so. The Homeric Greek admired the full-developed woman as much as the growing girl.

"Such, then, were these Homeric Greek women. The Greek race was the finest race that ever existed in respect of physical development and intellectual power。 Do we not see, in the account that Homer gives of the women, something like an expla. nation of the phenomenon? A race of healthy, finely-formed women is the natural antecedent to a race of men possessed of a high physical and intellectual organization.

"When we pass from Homer, we enter a new region. We do not know how far Homer's characters are historical. We cannot doubt that the manner and ways of the men and women whom he describes were like those of the real men and women among whom he lived. He may have idealized a little, but even his idealizations are indicative of the current of his age. But we know little of the modes in which the various states of Greece were constituted, and of the relations which subsisted between them. We have to pass over a long period which is a practical blank, and then we come to historical Greece. In historical Greece we have no unity of the Greek nation. We have men of Greek klood, but these men did not dream of forming themselves into one nation, ruled by the same laws, and mutually helpful of each other. The Greek mind regarded the city as the greatest political organization possible, or at any rate compatible with the adequate discharge of the functions of a state. And accordingly if we could give a full account of woman in Greece, we should have to detai? the arrangements made in each particular state. There are no materials for such an account if we wished to give it ; but even if there had been, it is probable that we should not have learned much more than we learn from the histories of the two most prominent of those states, Sparta and Athens. It is to the position and influence of women in these states that we must turn our attention.

"To form anything like a just conception of the Spartan state, we must keep 
clearly in view the notion which the ancients generally, and the Spartans in particular, had of a state. The ancients were strongly impressed with the decay and mortality of the individual man; but they felt equally strongly the perpetuity of the race through the succession of one generation after another. Accordingly, when a state was formed, the most prominent idea that pervaded all legislation was the permanence of the state, and the continuance of the worship of the gods. They paid little regard to individual wishes. They thought little of individual freedom. The individual was for the state, not the state for the individual, and accordingly all private and personal considerations must be sacrificed without hesitation to the strength and permanence of the state. A peculiar turn was given to this jdea in Sparta. From the circumstances in which the Spartans were placed, they had to make up their minds to be a race of soldiers. They had numerous slaves in their possession to do everything requisite for procuring the necessaries of life. They therefore had no call to labor. But if they were to retain their slaves and keep their property against all comers, they must be men of strong bodily configuration, hardy, daring, resolute. And as women were a necessary part of the state, they must contribute to this result. The regulations made for this purpose are assigned by the ancients to Lycurgus, but whether he was a real person, or how far our information in regard to him is to be trusted, is a matter of no consequence to us at present; for there can be no doubt that his laws were in force during the best period of Sparta's existence. And the laws bear on their front the purpose for which they were made. All the legislation that relates to women has one sole object, to procure a first-rate breed of men. The one function which woman had to discharge was that of motherhood. But this function was conceived in the widest range in which the Spartans conceived humanity. In fact, no woman can discharge effectively any one of the great functions assigned her by nature, without the entire cultivation of all parts of her nature. And so we see in this case. The Spartans wanted strong men : the mothers, therefore, must be strong. The Spartans wanted brave men: the mothers, therefore, must be brave. The Spartans wanted resolute men-men with decision of character : the mothers must be resolute. They believed, with intense faith, that, as are the mothers, so will be the children. And they acted on this faith. They first devoted all the attention and care they could to the physical training of their women. From their earliest days the women engaged in gymnastic exercises; and, when they reached the age of girlhood, they entered into contests with each other in wrestling, racing, and throwing the quoit and javelin. They engaged in similar contests with the young men, stripping like them before assembled multitudes, and showing what feats of strength and agility they could perform. In this way the whole body of citizens would come to know a girl's powers ; there could be no concealment of disease ; no sickly girl could pass herself off as healthy. But it was not only for the physical strength, but for the mental tone, that the girls had to go through this physical exercise. The girls mingled freely with the young men. They came to know each other well. Long before the time of marriage, they had formed attachments and knew each other's characters. And in the games of the young men nothing inspirited them so much as the praise of the girls, and nothing was so terrible as the shouts of derision which greeted their failures. The same influence made itself felt when they fought in battle. The thought that, when they came home, they would be rapturously welcomed by mother and sister, nerved many an arm in the time of danger. All the training an- 
terior to marriage was deliberately contrived to fit the Spartan women to be mothers. And it is needless to say that all the arrangements in connection with marriage were made solely for the good of the state. All the Spartan girls had to marry. No one ever thought of not marrying. There was one exception to this. No sickly woman was allowed to marry. The offispring must be healthy. And, indeed, if she had had to consult her own feelings in Sparta, the sickly girl would of her own accord have refrained from marriage. For the state claimed a right over all the children. They were all brought very soon after birth before a committee appointed by government, which examined into the form and probable healthiness of the child, and if the committee came to the conclusion that the child was not likely to be strong, its death was determined. nn. Sat there must have been very few sickly women among the Syartans. If a girl survived this first inspection, she had, as we have seen, her trials to go through, and only the strong could outlive the gymnastic exercises, and the exposure of their persons in all weathers during religious processions, sacred dances, and physical contests. The age of marriage was also fixed, special care being taken that the Spartan girls should not marry too soon. In all these regulations the women were not treated more strictly than the men. The men also were practically compelled to marry. The man who ventured on remaining a bachelor was punished in various ways. If a man did not marry on reaching a certain age, he was forbidden to be present at the exercises of the young girls. The whole set of them were taken one wintry day in each year, and, stripped of their clothing, went round the agora singing a song that told how disgraceful their conduct was in disobeying the laws of their country - a spectacle to gods and men. The women also, at a certain festival, dragged these misguided individuals round an altar, inflicting blows on them all the time. Men were punished even for marrying too late, or for marrying women disproportionately young or old.

"Such was the Spartan system. What were the results of it? For about four or five hundred years there was a succession of the strongest men that possibly ever existed on the face of the earth. The legislator was successful in his main aim. And I think that I may add that these men were among the bravest. They certainly held the supremacy in Greece for a considerable time through sheer force of energy, bravery, and obedience to law. And the women helped to this high position as much as the men. They were themselves remarkable for vigor of body and beauty of form. A curious illustration of this fact occurs in one of the plays of Aristophanes. An Athenian lady resolves to put an end to the war between the Athenians and Lacedæmonians by combined action on the part of the wives from all parts of Greece. She has summoned a meeting of them, and as Lampito the Lacedæmonian wife comes in, she thus accosts her: 'O dearest Spartan, 0 Lampito, welcome! How beautiful you look, sweetest one, how fresh your complexion, how vigorous your body! You could throttle an ox.' 'Yes,' says she, 'I think : could, by Castor and Pollux, for I practice gymnastics and leap high.' They were not, however, merely strong in body, but took a deep interest in all matters that concerned the state. They sunk everything, even maternal feeling, in their care for the community. Many stories and sayings to this effect have been preserved. A Spartan mother sent her five sons to war, and, knowing that a battle had taken place, she waited for the news on the outskirts of the city. Some one came up to her and told her that all her sons had perished. 'You vile slave,' said she, 'that is not what I wanted to know ; I want to know how fares my 
country.' 'Victorious,' said he. 'Willingly then,' said she, 'do I hear of the death of my sons.'

"Another, when burying her son, was commiserated by an old woman, who cried out, 'Oh your fate!' 'Yes, by the gods,' said she, 'a glorious fate, for did not 1 bear him that he might die for Sparta?'

"And their courage was not merely of a daring and physical character. It was a moral courage. A Spartan had been wounded in battle and compelled to crawl on all-fours; he seemed to feel ashamed of the awkwardness of his position. "How much better it is,' said his mother, 'to rejoice on account of bravery, than be ashamed on uccount of ignorant laughter !'

"It might be supposed that the peculiar training to which the women were sub. jected might make them licentious and forward, but the testimony is strong that no such results followed from free intercourse with the young men. Adultery was almost entirely unknown.

"Plutarch tells the story that a stranger asked Geradas, one of the very old Spartans, what punishment their law appointed for adulterers. He answered, ' $O$ stranger, there is no adulterer in our country.' The stranger said, 'What if there should be one?' 'He pays a fine,' said Geradas, 'of a bull so large, that stooping over Taygetus it will drink out of the Eurotas.' When the stranger expressed his surprise and said, 'But how could there ever be so large a bull ?' Geradas replied with a smile, 'And how could there ever be an adulterer in Sparta?' This language is perhaps too strong, and there were certain practices allowable which would not be allowed in our communities. The one object of marriage was to produce strong children, and any deviation from the ordinary arrangement by which one woman was married to one man was not only deemed legitimate but praiseworthy, if it secured strong children. In this way a weak man might lend his wife to a stronger, and some women had two husbands. There is only one case on record of a Spartan having two wives, and the case was singular. A greater latitude must have been allowed to women. But all these cases must have been quite exceptional. The wives were true to their husbands, the husbands fond and proud of their wives. A poor maiden was asked what dowry she could give to' her lover. 'Ancestral purity,' she suid. A person was sent to try to persuade a Lacedæmonian woman to aid in some evil practice. 'When I was a girl,' she said, 'I was taught to obey my father, and I obeyed him ; and when I became a wife I obeyed my husband; if, therefore, you have anything just to urge, make it known to him first.'

"Such were these Spartan women for many generations. No word of reproach can be brought against them. It is true that the free intercourse of the young men with the young women, and the slightness of the female garments, shocked the ordinary Athenian, and expressions to this effect occur in some writers, especially Euripides. But the general purity of the Spartan women is guaranteed by all the principal writers who have dicussed the constitution of Sparta as it was during its supremacy -by Plato, Xenophon, and Plutarch. No doubt the system labored under a radical defect. It was exclusive; it drove away all strangers; it discouraged the higher culture, at least in the case of the men; and it suspected all the higher arts as tending to luxury. And when the crisis came, and the old manners gave way, vice and weakness rushed in, and men and women became equally bad. It is in the latter period that the words of blame are heard. Plato justly criticises one marked defect in the Spartan treatment of women. The lawgiver had looked on woman only 
as a mother. He had lost sight of every other function. But women cannot spend their whole lives as mothers. When their infants grew into boyhood they were handed over to the instruction of Spartan men. And then what function had the women to discharge? Lycurgus, or the Spartan lawgivers, took no thought of this. The men were under strict regulation to the end of their days. They dined together on the fare prescribed by the state. They were continually out on military service. They had other employments assigned to them. But no regulations were made for the women. They might live as they liked ; there was nothing to restrain their luxury, and they were not taught the military art like the men. This neglect of the half of the city, Aristotle affirms, was followed by dire consequences. In his day, the Spartan women were incorrigible and luxurious. He also affirms that the Spartan system threw a great deal of land into the hands of the women, so that they possessed two-fifths of it; and finally he accuses the Spartan women of ruling their husbands. Warlike men, he thinks, are apt to be passionately fond of the society of women. 'And what difference,' he says, 'does it make whether the women rule or the rulers are ruled by the women ? for the result is the same.' There seems to have been some truth in this last accusation. Many of the wives were better educated than their husbands, and the fact was noticed by others. 'You of Lacedæmon,' said a stranger lady to Grorgo, wife of Leonidas, 'are the only women in the world that rule the men.' 'We,' she replied, 'are the only women that bring forth men.' There is a great deal of point in what Gorgo said. If women bring forth and rear men, they are certain to receive from them respect and tenderness; for there is no surer test of a man's real manhood, than his love for all that is noblest, highest, and truest in woman, and his desire to aid her in attaining to the full perfection of her nature.

"The student of the history of woman is continually-reminded of the fact that, when men lose their dignity and eminence, woman disappears from the scene, but when they rise into worth, she again comes on the stage in all her power and tenderness. We have an instance before us. Sparta became degenerate. Her name almost vanishes from the pages of the historian. But she was not to die without a final struggle. In the middle of the third century before Christ, two kings of Sparta in succession dreamed of putting down the luxury, and restoring the old Spartan discipline and the old Lycurgan laws. And in the midst of their vigorous and heroic efforts to effect this great change, women again play their part with energy and devotion. The earliest of the two kings was the young and gentle Agis, and almost the first person whom he consulted on his projected reforms was his mother, Agesistrata, a woman of great wealth and influence. She was at first utterly taken aback, for the project included the surrender of all her wealth. But at length she admired her son's noble ambition, and set her nind, with the aid of some other like-minded women, on procuring the support of the women of Sparta. The importance of such support could not be over-estimated. 'They well knew,' says Plutarch, 'that the Lacedæmonian men were always obedient to their wives, and that they allowed them to meddle in public matters more than they allowed themselves to meddle in private affairs.' $\mathrm{Be}$ sides, the women had a great deal of property. Would they surrender their wealth ? Would they give up their luxurious habits? Would they return to the old Spartan simplicity? No; the movement seemed to have come too late. Some were willing to sacrifice ererything, but others would yield nothing, and a strong party was formed against Agis. At first this party was put down with a high hand. Leonidas, the leader, was driven into exile. The daughter of this man, Chelonis, is one of the 
great characters that emerged during these troublous times. She had been married to Cleombrotus, who took the side of Agis. Chelonis was in straits what to do, but she chose to follow the path where gentleness and tenderness were required. She left her husband, and tended her father in distress, reliering his wants, soothing bis troubles, and supplicating the victorious party in his behalf. At length the wheel of fortune turned round. Leonidas became master of the situation. Agis and Cleombrotus were in his hands. Chelonis at once fled from her father, and took her rrace beside her husband. In the wretched robes which she had worn when pleading for her father, she pleaded for her husband. After much entreaty she prevailed, vnd the life of her husband was spared, but he was condemned to exile. Chelonis had again to make her choice. Her father urged her to stay with him, reminding her of the kindness he showed her in sparing her husband, and promising every comfort. But Chelonis did not hesitate. As Cleombrotus rose to go, she gave him one of her children, and taking the other in her arms, and kissing the altar of the goddess, she walked out with him to degradation and poverty. Justly does Plutarch add the remark that, if Cleombrotus had not been entirely corrupted by vain glory, he would have deemed exile with such a woman a greater blessing than any kingdom. The fate of pure-minded Agis was worse than that of Cleombrotus. No mercy was shown bim, and he was put to death by strangulation. His mother, Agesistrata, waited to hear what was to become of him. The officer, who knew that Agis was dead, delusively told her that no violence would be done him. She wished to see him, and take her old mother with her. Permission was granted. The two women entered the prison. The doors were shut. The grandmother was requested to go into the chamber where Agis was. She went in, and was strangled. Then Agesistrata entered, and saw her son lying on the ground, and her mother hanging by a rope. She calmly helped to take the dead body down, and stretching her alongside of Agis, laid both the bodies out and covered them ; and, falling upon her son and kissing him, she said, ' 0 my son, it is your gentleness and goodness that have ruined you.' 'If that is your opinion,' said the officer, 'you had better go the same way.' She bravely held out her neck, and said, 'May this turn out for the good of Sparta!' And thus was stamped out the first effort for the reformation of Sparta.

"The second is also remarkable for the nobility of the women who aided it. Cleomenes, a man of great vigor and capacity, the son of Leonidas mentioned above, came to the throne. His father had compelled him to marry Agiatis, the widow of Agis; but he soon began to lore the noble and gentle lady. They talked much together about Agis and his projects, and Cleomenes at length resolved to carry out the projected reforms. Again the young prince was helped most effectively by his mother, Cratesicleia, who supplied him with resources, and even married again for his sake, for she thereby secured the support of one of the most influential men in Sparta. But again Destiny was too powerful for the reformer. He did, indeed, succeed in introducing his reforms into Sparta, and in again giving her the foremost place in Peloponnesus. But he awoke the jealousy of Aratus, the head of the Achæan League, the Macedonian stranger was called in, and after a fatal battle, Cleomenes had to flee. During the course of his struggles, his noble wife Agiatis died, and was bitterly lamented. His mother, Cratesicleia, was always ready to help him, and stood by him to the last. At one time he required the alliance of Ptolemy, King of Egypt, but Ptolemy would not agree to it, unless the Spartan king sent his mother and child ns hostages. Cleomenes did not venture to mention this proposal to his mother, but 
the mother's keen eye observed that he was keeping some secret from her. At last she prevailed upon him to disclose it, and on hearing it, she laughed loudly, and said, 'Will you not send immediately this body where it is likely to be most useful to Sparta, before it is dissolved by old age ?' After she had gone to Egypt, she heard that Cleomenes was afraid to take certain measures, because Ptolemy held his mother and child as hostages, and she at once wrote to him, 'Do what is proper, and never mind what becomes of an old woman and a little child.'

"The fate of Cleomenes was as tragic as that of Agis. He had sought shelter in 3gypt, but found a prison there instead of a home. He and his companions determined to overpower the sentinels, break through the place of confinement, and rouse the inhabitants to assert their liberty. They easily broke through their place of confinement, but they could not rouse the inhabitants, and so they resolved to die. Each sne killed himself except Panteus, the youngest and most beautiful among them. He had been ordered by the king to wait till all had killed themselves. And so he did. He went round all the bodies to see that they were dead, and then, kissing Cleomenes and throwing his arms around him, he also killed himself. The Egyptian king ordered the execution of all the women connected with the Spartans. The mother was brought forth and stabbed. Other women also were put to death. But the most touching of all was the end of the wife of Panteus. She was still very young and exquisitely beautiful, and she was still in the raptures of first love. When her husband left Sparta for Egypt, her father had refused to let her go with him, and confined her. But she found means of escape. She mounted a horse, and rode to Tænarus, and there embarked on a vessel sailing for Egypt. Now she moved about the women, encouraging and consoling. She led Cratesicleia by the hand to the place of execution. She decently laid out the bodies of the women who were slain ; and then, adjusting her own robe so that she might fall becomingly, she offered herself to the executioner without fear. Thus ended the second effort at Spartan reformation, and henceforth autonomous Sparta and her women disappear from history. We may well conclude the story with the closing words of Plutarch, who, thinking of the dramatic contests which were held in Greece, says, 'Thus Lacedæmon, exhibiting a dramatic contest, in which the women vied with the men, showed in her last days that Furtue vasnot be insulted by Fortune.'" 



\section{PART XVI.}

\section{MIDWIFERY, AND THE DISEASES AND ACCIDENTS}

PECULIAR TO PREGNANCY AND CHILDBIRTH. 



\title{
CHAPTER LX.
}

\author{
STRUCTURE OF THE PRINCIPAL ORGANS AND PARTS.
}

Iv addition to the general explanation already given, there are some of the female organs whose peculiar structure requires to be more fully noticed, on account of its important influence on some of the processes hereafter to be described.

\section{THE WOMB.}

The external appearance of the womb, viewed in front, and in connection with its appendages, is shown in previous Figures. It is placed in the pelvis, between the bladder and the rectum, and at the top of the vagina.

The length of the womb, after puberty, is about three inches; its breadth at the upper part, or fundus, abont two inches; and at the cervix, or neck, about one inch. The cavity in the interior is small, owing to the thickness of the walls, and its form is triangular. The shape of the womb resembles a pear, somewhat flattened, from before backward. Previous to puberty its size is much smaller, and with those who have had children it often exceeds the dimensions we have given.

The neck, or narrow part is much changed by pregnancy. In virgins it is long and pointed, and somewhat enlarged in the middle. In those who have borne children it considerably shorter, more obtuse, and less regular in its form. The cavity in the neck is larger in the middle than at either end, as will be seen in the adjoining Figure.

The os tincce, or mouth of the womb, also undergoes considerable change from the same cause. In the young person it is merely like a small slit, scarcely to be felt, but after pregnancy it much enlarges, and remains more or less permanently open. The anterior lip, or

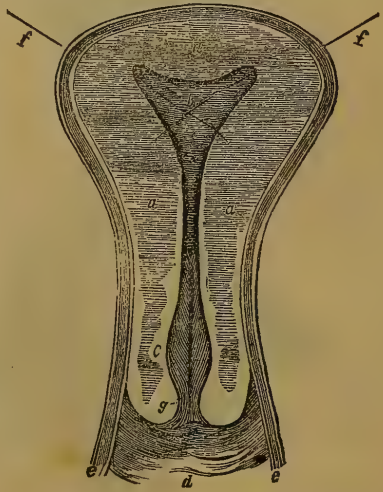

FrgURE 131. - Vertical section of the Womb and Vagina, natural size.

a. a. a. The solid walls of the womb cut through. $b$. That part of the cavity, or hollow of the womb, which is in the fundus, or top. c. That part of the cavity which is in the lower part, or neck of the womb. $d$. The vagina. e.e. The cut edges of the vagina. $f$. $f$. The positions of the Fallopian tubes, which are cut off, and down the passages of which two needles are passed. $g$. The os tincæ or mouth of the womb. the one in front, is somewhat larger than the posterior one.

The body of the uterus is formed of a very dense, gray-colored, muscular sub- 
stance, possessing astonishing contractile power. The internor is lined, like the vagina, with a mucous membrane, and the whole organ is plentifully supplied with arteries, veins, and nerves.

One of the most remarkable properties of the womb is that of being able to distend to an extraordinary degree, and then retract again to vearly its original size. 'The force which it sometimes exhibits during its contraction is very great, being sufficient to separate, and even break the bones of the mother's pelvis, and paralyze the hand of the operator when introduced. The muscular fibers on which this contractile force depends are most obvious during gestation ; they then appear very numerous, and very curiously disposed, some of them ramifying in almost every direction, as will be seen by the Figures below. It is owing to this that the womb contracts in every conceirable direction, and thus presses, during labor, on every part of the child's body.

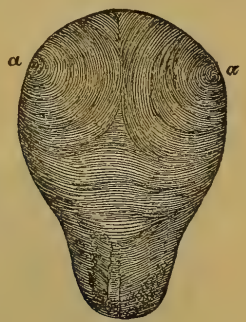

EtGURE 132.

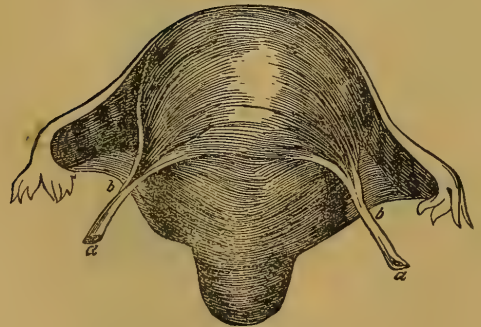

FTGURE 134

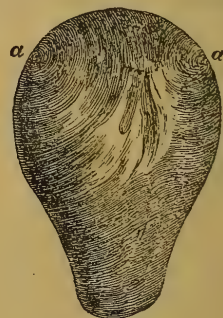

FrgURE 133.

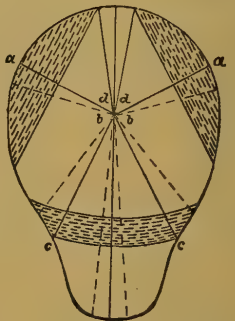

FIGURE 135.

The Muscular Fibers of the Womb.

Figure 132.-This represents the muscular fibers, a little exaggerated, so that they can be more distinctly seen; $a$ a are the orifices of the Fallopian tubes.

Figure 133.-Represents the natural appearance, the fibers not being quite so distinct, though sufficiently obvious; $a$ a the orifices of the Fallopian tubes.

In both figures the womb is supposed to be turned inside out, its peculiar structure being more readily seen interiorly than exteriorly.

Figure 134.-This represents the appearance of the fibers externally, and shows how they terminate in the round ligaments $a a$.

Figure 135. - The lines $a b$ represent the direction of the force of the fundus fibers; $c d$ that of the circular muscles of the body of the uterus; $d e$ the combined force of the muscles.

The dotted lines represent the force reflected by the liquor amnii; the dotted curved lines the direction of the circular fibers of the body of the uterus. 


\section{THE VAGINA.}

The vagina is a membranous canal, lined with a mucous membrane, like the uterus. By its upper part it is attached to the neck of the womb, at about two-thirds of its height, so that two-thirds of the neck hang within the vagina. Below, it terminates in the vulva, or external mouth. The apper part of the vagina is much larger than the lower part, particularly in those who have borne children. It is capable of considerable distension, and after retraction, to allow of the child passing down it from the womb. The external mouth is called the vulva, and is usually partly closed, in the virgin state, by the membrane called the hymen. The length of the vagina is from three to five inches, and its diameter from one inch to one and a half, or even two inches in those who have borne many children.

\section{THE VULVA.}

This is the external opening, or mouth of the vagina, through which the child has to pass at the termination of delivery. The external and internal lips, with the muscular and membranous tissue surrounding it, are all capable of great distension, without injury, to allow of the passage of the child.

\section{THE PERINEUM.}

This is the part situate between the vulva and the rectum. It is composed of a somewhat dense and firm substance, chiefly muscular, and, like all the other parts mentioned, is capable of great distension. It is important, in many of the manipulations during labor, to be well acquainted with it; and when the child's head is passing the perineum requires supporting, to prevent its being lacerated or broken through, an accident which often happens from want of due attention, and which leads to the most serious consequences.

\section{THE PELVIS.}

The pelvis is that part of the bony structure, or skeleton, of the female, in which the generative organs are placed, and through which the process of parturition is effected. An acquaintance with its natural structure, and with the changes which may be produced in its form and size, by disease and other accidents, is indispensable to those who wish to practice or understand midwifery.

In early life the pelvis is composed of several bones, many of which, after puberty, grow together. In the adult female it is customary to speak of but four bones, the sacrum, the coccygis, and the two innominata, or hip bones (see Figures 136, 137). In the young female these are divided into several distinct parts.

These bones are all firmly bound together by a cartilaginous substance, which is placed between where they touch, and is firmly attached to each one. This union is called a symphysis. The one at front which joins the pubic bones is called the symphysis pubis; the two which join the ossa ilii to the sacrum are called the sacroiliac symphysis; and that which joins the coccygis to the sacrum is called the sacrococcygeal symphysis. The two pubic bones are separated a little in Figure 136, simply to show them better. The reader will bear in mind that they are naturally connected by the cartilaginous substance which forms the symphysis. 
These articulations, or joinings, pecome much softened during labor, and give way a little, but not to any extent sufficient to assist delivery. It is a mistake to suppose that the bones separate at that time. The only part that gives way is the sacro-coccygeal symphysis, which does relax, and allows the os coccygis to be pushed back by the child's head a full inch or more, thus enlarging the inferior strait. (See $c$ and $o$, Figure 13\%) Scmetimes this little bone will be even broken off, when there is great disproportion between the head and the strait. I have heard it snap like a stick breaking. There is nothing serious or alarming in this, however, unless it be $a$ first delivery late in life, though it may cause some pain at the time, and a little difficulty in sitting for some time after. In young persons the symphysis is

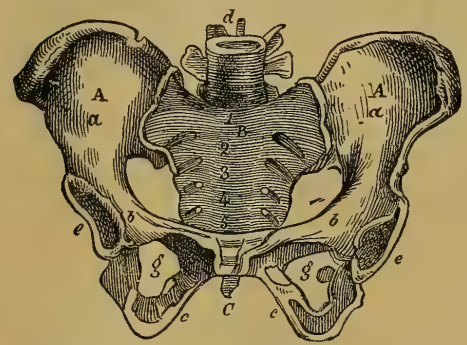

FigURE 136. - Bones of the pelvis.

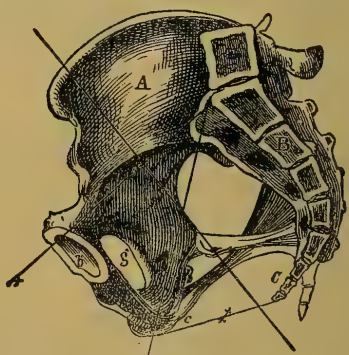

FIGURE 137.

FtGURE 136.-The four principal bones as found in mature life.-A. A. The ossa ilii, or ossa in. nominata, commonly called the haunch, or hip bones. $B$. The os sacrum, or lower part of the back bone. $C$. The extreme termination of the back bone, called the os coccygis.

The divisions into parts, as in early life.-The ilium, $A$, on each side is in three parts; the ilium, properly so called, marked $a a$; the pubis, marked $b b$; and the ischium, marked $c c$. The sacrum is in five parts, marked $1,2,3,4,5$.

$d$ is the last bone of the spine, which joins the sacrum; $e e$ are the sockets in which the upper parts of the thigh bones fit, forming the hip joints; $g g$ the two rings formed by the bones of the pubes and ischium, each called the foramen magnum.

Figure 137.-Section of the pelvis, to show the shape and connection of those parts not distinctly visible in the full view. The section is made down the middle of the back bone, and through the symphysis pubis in front. The letters correspond with those in Figure 136.

$A$. The right ilium. $B$. The sacrum. $C$. The coccygis. $b$. The os pubis. $c$. The os ischinum. g. The foramen magnum. 0 . shows the manner in which the coccygis is bent back through labor.

soft and gives way easily, so that they have little difficulty during delivery from this cause; but if a female marry late in life, after it becomes hardened, she may suffer considerably. In this case the coccygis is usually curved inward considerably, and being firmly fixed, the head cannot push it back, and on that account cannot pass without great difficulty, and with the risk of rupturing some of the soft parts, or breaking the coccygis completely off. There is, in fact, great difficulty and some danger, if the first pregnancy takes place late in life.

The pelvis is usually divided into two parts-the great pelvis, or upper part inclosed between the wide flanges of the ossa ilii and the upper part of the sacrum; and the small pelvis, or basin, which is inclosed between the lower part of the sacrum and coccygis behind, and the ossa ischii and ossa pubis in front. The basin is nearly cylindrical, larger in the middle, and curved towards the front. 
The Straits of the Pelvis. - The bones of the pelvis, it will be seen, form a kind of broad ring, or cylinder, particularly in the basin; and the straits are two pas. sages, one by which the child passes into the basin from the upper pelvis, and the other by which it passes out from the basin into the world.

In Figure 13\%, the line marked $\nmid$ is the antero-posterior diameter of the uppen strait, through which the child first passes, called also the brim, or entrance to the pelvis. The line marked $\ddagger$ is the diameter of the lower strait, through which the child passes into the world, called also the outlet of the pelvis. In Figure 136 the line marked $\nmid$ crosses the upper strait, or brim of the pelvis.

The diameters of the pelvis are the distances between the prominent points of each strait, and are four in number for each, those for the upper strait being represented below

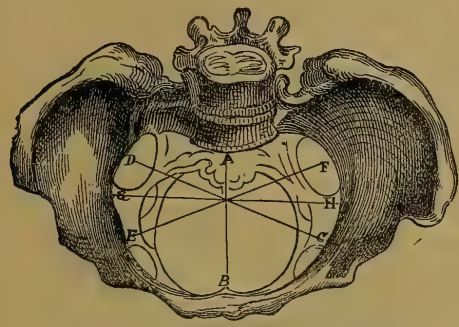

DTGORE 138.-Diameters of the Upper Strait.

$A B$, which extends from the most prominent point of the sacrum, to the top of the symphysis pubis, is called the antero-posterior diameter, or that from before to behind. $C D$, and $E F$, are called the two oblique diameters; they extend from each sacro-iliac symphysis, to the most prominent point of the os ilium, on the opposite side. $G H$, is called the transverse, or bis-iliac diameter; it crosses the pelvis, nearly from one hip joint to the other.

The sacro-antero-posterior diameter measures four inches. The two oblique diameters four inch. es and $a$ half each. The bis-iliac diameter measures five inches.

The inferior strait has also four diameters, represented in Fig. 139.

It will thus be seen that the diameters only average from four to five inches, but it must be remembered that the soft parts, and even one of the bones, very readily give way, and thus they are slightly increased.

When we come to describe the form and size of the foetal child's head, it will be found that its diameters correspond very nearly with those of the pelvic straits through which it has to pass, so that ordinarily labor presents no serious difficulty. If the head be larger than natural, from any cause, or if the pelvis be too small, or deformed, this mutual adaptation does not exist, and delivery of course becomes difficult, or dangerous, and sometimes impossible. The only obstacle therefore, which can seriously impede the expulsion of the foetus, or prevent it altogether, is this want of conformity, in size and shape, between its head and the bones of the 
pelvis. The soft parts may retard labor considerably, by being contracted or rigid, but can generally be made to give way, either by the efforts of nature or by manual assistance; and the fœtal head can be reduced in size if necessary ; but insufficient size, or faulty form, in the bones of the pelvis, is irremediable.

The various causes which produce deformity, or imperfect development, in the pelvis, and unnatural growth of the child's head, will be stated in a subsequent chapter. For the present, we have only to do with both in the normal state.

The importance of an accurate knowledge of the structure of the pelvis, and of the changes which may be induced in it, will now be obvious; neither the theory nor the practice of midwifery can in fact be understood without such knowledge. It is also frequently of the first importance to know, previous to marriage, whetheI the pelvis of a young person is so formed that delivery can be safely effected ! Inattention to this has sacrificed the lives of many, and caused others to live for years suffering and helpless. In another place we shall give some plain rules and directions by which this important point may be determined.

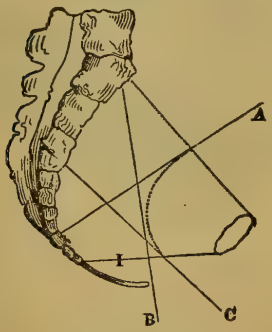

FigURe 140.

The axis, or direction, of the upper strait is denoted by the line $A$, that of the lower strait by the line $B$, and that of the vulva by the line $C$. The force of expulsion tending to push the child in each direction, it has to traverse a path intermediate with them all, or compounded of them all, not being able to move in either alone. This aggregate direction is denoted by the dotted curved line, which shows the direction in which the child passes, and in which the hand must be passed when introduced.

$I$ is the perineum. The dotted line which crosses $A$ denotes the upper strait, and the line $I$ the lower strait.

pelvis, in the human female is a curve, so that the child has to move during its passage in a circle.

It is a great mistake to suppose, as some do, that parturition necessarily imposes upon a woman suffering and danger; or that these constitute a curse from which she cannot escape!

All undue pain, and all danger, from childbirth, result simply from some infringe• ment of natural law, and need not be incurred. If the female be healthy, and well 
formed, and no accident or imprudence occur during gestation, she need neither euffer nor be in peril.

From ignorance, and consequent wrong living, her body becomes ill-formed and feeble, and her nervous system deranged, so that when her traval comes she is unfit to undergo it, and hence her suffering and danger.

Perhaps even before she was born this unfavorable condition was established, more or less, by the faults of her ancestors, recent or remote, who thus left to her the penalty of their wrong-doing, to transmit perhaps to her child in its turn.

In the suvage state women are spared most of those dangers and sufferings which usually fall to the lot of their civilized sisters. And even refined and delicate ladies, under the stimulus of unusual peril, have passed through their ordeal with surpris-

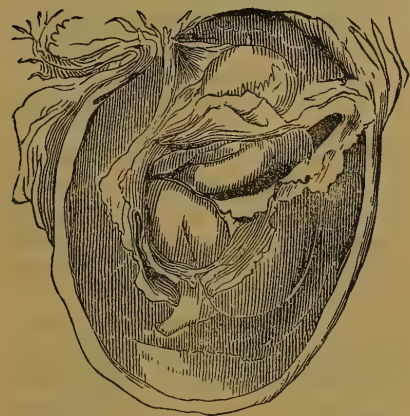

FTGURE 141.-Fetus at 3 months inclosed in the membranes.

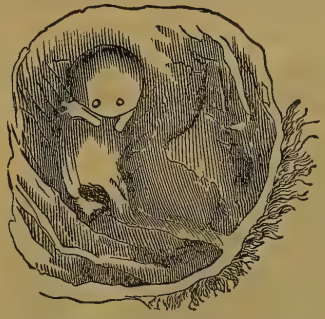

Figure 142.-Foetus at 6 roeeks.

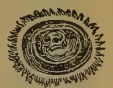

FigURE 143 at 12 days.

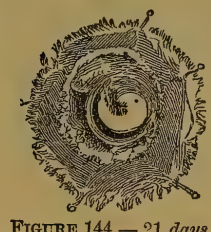

FrgURE $144-21$ days.

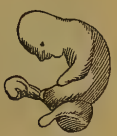

FIGURE 145.Form of foetus at 45 days.

ing ease, and perfect safety. Lady Sale, for instance, in the disastrous retreat of the British troops, from Afghanistan, was delivered in the midst of all the confusion and terror incident to such an event, and without help or rest pressed on with the flying soldiers, on horseback, and got through in safety. Under ordinary circumstances, at home, even moving from one room to another might have caused her death; but in the fearful Khyber Pass the greater fear overcame. the lesser, and parturition did not even hinder her flight.

When the laws of physical health and development are fully understood, and aicted upon, women will not dread becoming mothers, because they will have no reason to fear either pain or peril. Perfect in form there will be no difficulty when their children are born, nor any suffering, more than they can easily and gladly endure. Their children also will be perfect like themselves, instead of being, as they too often are now, diseased and misformed even while still in the womb.

The only curse is ignorance, and when that is removed pain and sorrow, as connected with the birth of man, will cease forever. 


\section{CHAPTER LXI.}

THE BREAST.

THE breasts, or mamma, are not needed in the process of generation, nor are they absolutely necessary even after birth ; but as they are naturally associated, in the

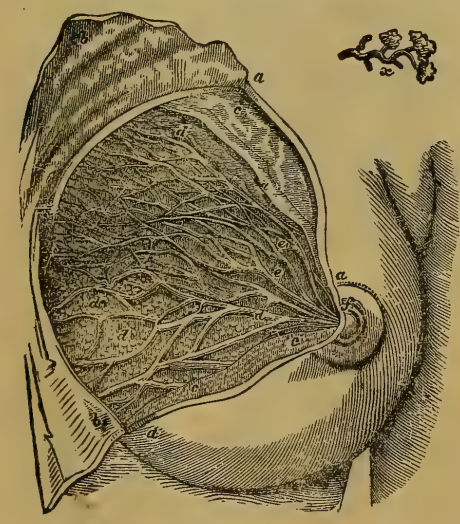

FIGURE 146.

a. $a$. The cut edges of the skin. $b . \quad b$. The flaps of the skin thrown back. c. c. c. The fat which covers the breast. $d . d$. The cells of the mammary gland. e. e.e. The tubes or canals which convey the milk from the gland to the nipple. $f$. The nipple cut down the middle, to show the ends of the milk tubes terminating in it; these are usually about fifteen or eighteen in number. $x$. shows a bunch of the little cells, with the tubes proceeding from them, as they appear when injected. majority of cases, with infantile nutrition, and are besides liable to many derangements and diseases during pregnancy and childbirth, it is advisable to give some account of them.

When one of the breasts is dissected it is found to be composed chiefly of a singular body called the mammary gland, which resembles somewhat a very firm piece of fat, of a yellowishdrab color. In the substance of this gland are an immense number of little cells, or ressels, in which, by some unexplainable process, the milk is secreted, or made from the blood. From these little vessels there proceed small tubes, which gradually unite into larger ones, and these again into larger ones still, until at last all the milk is poured into a few tubes, or canals, which terminate in the nipple. The outer mouths of these terminal canals are only slightly contracted together, so that the suction of the child's mouth, or even the pressure of the milk when the breast is full, will force them open and allow the fluid to flow out.

Sometimes there have been seen two and even three nipples on one breast, and in a few cases one of the breasts has had no nipple at all. The two glands are not immediately connected, but have a very intimate sympathy with each other. The size of the breast depends more upon the thickness of the layer of fatty substance, than upon the development of the gland, so that one female, with a very full bosom, may have but little milk, while another, whose breast is but little prominent, may have a superabundance. The graceful swell of the fully developed breast is, however, a matter of positive utility, as well as of beauty, because it better adapts it to the use 
of the child, and probably also adds to its pleasure, as any one may readily conceive who will observe the delight with which an infant, even when not nursing, will often caress it. Sir Astley Cooper says : "The natural obliquity of the mammella, or nipple, forward and outward, with a slight turn of the nipple upward, is one of the most beautiful provisions in nature, both for the mother and the child. To the mother, because the child rests upon her arm and lap in the most convenient position for sucking; for if the nipple and breast had projected directly forward, the child must have been supported before her, in the mother's hands, in a most inconvenient and fatiguing position, instead of its reclining upon her side and arm. But it is wisely provided by nature, that when the child reposes upon its mother's arm it has its mouth directly applied to the nipple, which is turned outward to receive it, whilst the lower part of the breast forms a cushion upon which the cheek of the infant tranquilly reposes."

With the exception of the dark areola, or circle, and the little tubercles around the nipple, the breast is of the most delicate structure and color, so that it blushes, or reddens, like the cheek, from any sudden emotion, and goes pale during fainting.

As a general rule, no milk is secreted in those who have not become pregnant, nor in those who have passed the turn of life, but occasionally exceptions are observed to this rule.

Baudelocque tells us of a girl only eight years of age, who suckled her little brother more than a month! And Sir Hans Sloane tells us of a lady aged sixty-eight, who nursed several of her grandehildren, though she had had no child herself for twenty years! Dr. Francis, of New York, describes the case of a lady who continued to secrete milk regularly for fourteen years after having lost her child, so that she could always nurse an infant; and Dr. Kennedy relates an instance of another who continued to suckle children, uninterruptedly, for forty-seven years, and who had milk perfectly sweet and good even when eighty-one years old! Dr. Clark, of Alabama, informs us that a married lady, who had never been pregnant, was requested to take charge of an infant during the night, and that to quiet it she had put her nipple in its mouth. This was done frequently, and, to the great surprise of all, it induced a flow of milk. A singular circumstance connected with this was, that the lady soon after became pregnant, though previously barren! This will not appear so surprising, however, to those who know the connection between the breasts and the womb, and who have observed the mysterious bond of sympathy by which their functions are united. (See the articles on Menstruation, and on Sterility, in the chapters on Diseases of Woman, for other instances of this kind.)

The structure of the male breast is precisely the same as that of the female, but it is seldom developed. Instances have been known, however, of the milk being secreted in men, and of children having been nourished by it! Humboldt gives us an instance of this kind, and Professor Hull, of Maryland, exhibited a colored man to his class, in the year 182\%, who had a large full bosom, like a female, and who had often officiated as wet nurse in the family of his mistress. The secretion appears to have been established by his putting the children that he had to nurse to the nipple, to quiet them. When the milk was not needed, it was found as difficult to dry it up as it is in some females, but it was soon made to flow again, by applying a child to the breast for a few times. This man differed in no other respect from any other man! 
In the females of some races of the human kind, the mammæ attain a surprising length, and become very flaccid, so that they hang down to the hips, or lower, and may be thrown over the shoulder for the child to nurse from while carried on the back. Some suppose this to constitute a real variety of the human race, but others suppose it to result merely from habit, which is probably correct.

When the breasts are small sized in young females, their growth may often be promoted, but the means need not be pointed out here. 


\section{CHAPTER LXII.}

gIGNS OF PREGNANCY, AND THE MEANS OF DETECTING IT.

IT is always desirable, and frequently of the first importance, both to the accouch. ear and to the individual, to be able to know whether a female is pregnant or not, or even to be able to judge whether she is probably or possibly so, or not. Sometimes this can be decided positively, but more frequently it is a matter of great uncertainty. The presumptive and positive signs on which a judgment can be formed are of various kinds, most of which can be readily observed, and easily made use of by any person in possession of the information already given in the preceding articles. They will be set forth in the following chapter, together with such other matter as appertains to this part of the subject, in such a manner as will make them available either for professional or for private use.

The signs of pregnancy are of three kinds-presumptive, probable, and certain.

\section{PRESUMPTIVE SIGNS.}

The presumptive signs of pregnancy are only of value in the first three months. They consist mainly of certain nervous and organic derangements, and of certain changes in personal appearance. It is scarcely possible to enumerate all these, nor is it necessary ; we shall therefore only specify those most important, and most generally met with.

Colic pains, and creeping of the skin, with shuddering and fainting fits, very frequently follow immediately on conception, and in many females inform them when that event occurs. Some persons speak of other sensations, of a peculiar nature, by which they always know, in their own cases, when they conceive; but these sensations are felt by so few, and are so little capable of being explained or observed, that they are of no general use. In most cases, within the first three months, and sometimes in the first three days, the face changes remarkably. The eyes are sunk and dull, and surrounded by a black circle, the nose seems pinched up, the skin tirns pale, and red spots, or freckles, frequently appear. Many females also complain of a husky dry throat, numbness in the hands and feet, and a sudden sinking at the heart. These signs, however, are very uncertain guides; very often none of them are felt at all during pregnancy, and sometimes they are all experienced from other causes. One of the most constant signs, according to some, and the most to be relied upon, is an increase in the size of the neck. This I know is often very apparent, and at a very early period. I am acquainted with females who, by simply keeping the measure of their necks, can always tell when they are pregnant. The increase is often considerable in a few days. In young persons of a certain temperament however, the neck is apt to swell merely from marriage, though they do not 
conceive; and some old nurses, we are told, being acquainted with this fact, judge of the honesty of their unmarried charges by such admeasurements !

This singular development is owing, probably, to a sympathetic connection between the uterine organs and certain parts of the brain and large nerves in the neck.

Suppression of the menses is one of the strongest presumptive signs of pregnancy that can be observed, but does not always accompany it, and frequently arises from other causes. In the great majority of cases, it is true, the menses cease to flow, immediately conception occurs; sometimes they will continue for one or more periods after, and occasionally during the whole time of gestation, even up to a few days before delivery. This, however, is a very unusual occurrence, and the stoppage of the menses is by no means so strong a sign that pregnancy has occurred, as their continuance is that it has not. Some females are always irregular, so that pregnancy makes little difference, and in them of course these signs are even less to be depended upon than usual. There have cases even been known of women who have conceived without having menstruated, and of others who never menstruated except when they were pregnant; and it is not at all unusual to see others who will conceive while nursing, and never menstruate between the two pregnancies. Therefore we can only say that the menses usually stop when conception occurs, and that their continuance is strong evidence that it has not occurred, but still both signs may fail.

It is also proper to remark that several medical men have advanced the opinion that the discharge which appears during pregnancy is not the menstrual fluid, but real blood. It has however been accurately examined, and found in no respect to differ from the usual discharge. In my own opinion there is no doubt but that some females really do menstruate while pregnant.

As an instance that the presence of the menses is no proof that pregnancy has not occurred, I give the following case :-Not long since I was requested to see a lady who was supposed to labor under a polypus in the womb. She had been married six years, but had no offspring. On seeing her I suggested, from certain peculiarities in her appearance and manner, that possibly she might be pregnant. The suggestion was reet with a smile, particularly by the medical attendant who was present, and I was told that there was no sign of such a thing, and moreover it could not be, for she had never stopped menstruating, nor was there the slightest change in the breasts, nor any disturbance in the stomach, mind, or feelings. On making the usual examination however, I felt fully convinced I was right, and told them so, but my opinion had no other effect than to induce them not to interfere for a time. They had been talking of an operation immediately. She still continued to menstruate for three months after, but in six weeks from her last period was safely delivered, without assistance, of a very fine living child. No part of the body had undergone any material change, except the abdomen, though many of the usual changes occurred after delivery. In this case the delay probably saved the lives of both mother and child, and deeply grateful they all were for the escape. Many fatal cases are on record of pregnant females who have been killed from mistakes of this kind, owing to a blind reliance on such uncertain signs.

Disturbance of the Digestive Functions. - It is very seldom, indeed, that pregnancy does not produce more or less disturbance in these functions, though it must be remarked that marriage also does the same sometimes, even without conception. These disturbances are generally manifested by loss of appetite; sickness, particu- 
larly in the morning; vomiting, and depraved taste; the individual frequently taking a fancy to the most extraordinary articles, and making herself extremely unhappy if she cannot obtain them. Thus some have eaten flies, spiders, mice, and other living things, and others again have regaled themselves upon charcoal, chalk, slate pencils, and even earth or ashes. Such freaks are called longings, and it is thought highly improper not to indulge them, which is certainly right when they are for articles not positively injurious; but I have known this notion carried to a very hurtful and absurd extent. There is no doubt but these vagaries of the stomach arise, mainly, from its sympathy with the uterus, but it is highly probable that they are often exaggerated, and frequently even produced, by a morbid state of the sensibilities, and by vacuity of mind. The tendency to imitation also, so strong in most females, often leads to the same result. A young female who is declared to be, or who fancies herself, pregnant, listens eagerly to all that is said about that interesting state, by older acquaintances, and when told that they always longed, immediately begins to long also. I have known young persons considerably advanced in gestation, who had never longed at all before, do so immediately after a conversation of this kind. It must be remembered however, that the sympathies of the digestive organs with the womb are very strong, and that the appetite and taste are frequently rendered very capricious at this time, so that the female really likes or dislikes many things that she did not before; but still I feel convinced that the absurd ways in which this caprice exhibits itself, are often owing to the cause I have stated. The wondering ignorance, in which most females are kept, makes them disposed to be led away by a morbid imagination, and constantly liable to be imposed upon by silly and erroneous statements, which they of course implicitly believe. These longings are always the strangest, and most frequently met with, among the most uninformed and unthinking, though they are occasionally met with under all circumstances. As a sign of pregnancy, this longing is not much to be relied upon alone, because marriage alone often produces it, and so do many uterine derangements.

Usually all these disturbances disappear by the third or fourth month, the appetite becomes regular, and sometimes even voracious, and the digestion improves, so that the individual may become quite fat, though previously she was very thin.

Some suffer from constipation, and others from diarrhœa, but this is more rare.

Nervous Derangements. - The changes produced in the minds and feelings of pregnant females are sometimes of the most extraordinary character. Individuals who possess ordinarily the most agreeable tempers and the most amiable dispositions, will become peevish and fretful, and often even violently passionate and malicious. Some have even been known to have a disposition to commit various crimes, of which they had the greatest horror in their natural state. Others, on the contrary, who are usually ill-tempered and unhappy, attain a charming tenderness of manner, and a most pleasing serenity of mind. Their likings and dislikings also change very much, so that their most valued friends will become hateful to them, and those whom they habitually dislike will seem endowed with every lovable quality. Some will become perfect misanthropes, or weep and fret without intermission, while others will exhibit the most reckless and boisterous gayety. I have known some much disposed to study while pregnant, and others who would draw or paint most excellently, though at other times they were but indifferent artists. In short, it is impossible to denote half the singular changes of this kind that are thus produced. Suffice it to say, that 
when well marked, they are strong presumptive signs of pregnancy, especially when coming in connection with other evidences. It must be remembered, however, that hysteria, and some other uterine diseases, are often accompanied by similar changes.

Alteration in the Appearance of the Breast.-The direct and sympathetic connection between the womb and the breast is so great that pregnancy usually causes corresponding changes in both, though not always. In most cases, however, the breasts swell and become painful. The nipple becomes elevated, and the circle around it assumes a dark brown color, and is dotted with small tubercles, from which a thin watery liquor may often be pressed. The nipple will also enlarge, or become erect on being rubbed, and as gestation advances milk may be forced from it. Most of these signs, however, may be wanting in pregnancy, and may arise independent of it. Chronic inflammation and other diseases of the womb, or deranged menstruation, will frequently produce them, or marriage alone, particularly in certain temperaments.

The alteration in the color of the areola, or circle around the nipple, is a sign much relied upon by some, but is frequently a deceptive one, merely from want of close observation. I have known many females, though frequently mothers, whose breasts always retained the bright rosy eolor they had previous to marriage; and I have known young unmarried females with breasts quite dark. The peculiar hue that arises from pregnancy, however, is different from anything I ever saw in non-pregnant females; and though not always to be met with, is, in my opinion, an infallible sign when present. The celebrated John Hunter regarded the sign as an unmistakable one, and he gave a remarkable instance of it in his lectures. In making a post mortem examination of the body of a young female, he observed this peculiar color, and at once proclaimed her pregnant, though the hymen was unbroken. On dissection, he was found to be correct; she was four months advanced. If this sign were constant,

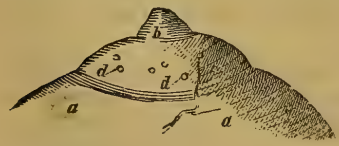

FigURE 147.-Viers of the Breust about the Fourth Month.

$a, a$, the breast ; $b$, the nipple : $c$, the areola, or part which becomes brown; it is elevated above the rest of the breast, as may be seen; $d d$, the little tubercles. pregnancy could nearly always be ascertained, but frequently it does not appear. The peculiar color must be seen to be recognized, as it cannot be accurately described ; perhaps the nearest approach to it is the shell of a fresh ripe chestnut, but it is much darker in some than in others. The dark circle is nearly always more elevated than the rest of the breast, as may be seen by taking a profile view.

Most frequently the breasts do not swell, nor the areola change color, nor the tubercles appear, till about the fourth month, and frequently much later.

All these changes in the breast are also liable to become more or less permanent, after the first pregnancy, so that they are of much less service, and less to be depended upon, in all succeeding ones. They also remain, with most females, during nursing, and are therefore not available in those who conceive while they are nursing. On the whole. however, these signs, especially in those not previously pregnant, may be pretty confidently relied upon, and will seldom deceive an experienced observer.

The secretion of millk is, by most persons, considered a positive sign of pregnancy, but it is not so, for it sometimes takes place in young girls merely from the establishment of puberty, and in some females it always occurs at each monthly period, 
though they have never been pregnant. Instances have been known of women nursing other people's children though they had never conceived themselves.

Miscellaneous Signs. - There are a few other presumptive signs, not easily classified, some of which are of value, while others are so uncertain, or so little available, as to be almost worthless. All these, however, it is necessary to point out, because some of them may be made use of in cases where the more ordinary signs are absent.

In the unimpregnated state, the mucous membrane which lines the vagina is of a bright rose color, but in nearly every case of pregnancy it changes to a bluish, or purplish hue. I do not recollect a single instance, in the course of my own observation, in which this change has not occurred, and the same statement is made by several eminent authors. It is true that in some young females the mucous lining is naturally darker than it is in others, but, like the areola round the nipple, this natural tinge is not like that produced by pregnancy. It is of course impossible to say whether this blue tinge is always produced, though I am inclined to think it is, and I should certainly consider it an almost infallible sign when present. Parent $\mathrm{Du}$ chatelet states that he was present when M. Jacquemin proved this, without a single failure, in four thousand five hundred cases.

Many females are also warned of their condition by pains in various parts of their bodies, the most frequent of which is one felt at the top of the head. Some always have palpitation at the heart, and others experience a singular kind of fluttering in the womb.

Many medical men rely altogether on certain peculiarities in the urine, and, as this sign is really a valuable one in some cases, I will describe the mode of examination fully: The urine is put in a clean vessel, and allowed to stand perfectly still. In a short time, varying from two to six days, a number of little opaque bodies begin to rise from the bottom, like flocks of cotton, which unite together at the top into a thin but firm layer, or pellicle, like cream on the top of milk. This layer is frequently so consistent that it can almost be raised out of the vessel by taking hold of one edge, and may be easily drawn out by passing the finger under it. This substance is called loyestein. It is of a whitish color, semi-transparent, and looks as if it were partly crystallized. After a few days, if left undisturbed, the urine becomes thick and muddy, and the pellicle of kyestein breaks up and falls to the bottom. According to the experience of many medical men, and so far as I have seen myself, this peculiar substance is always to be found in the urine of pregnant females, after the first month, and frequently even earlier. Sometimes a substance similar to it is observed in the urine of those not pregnant, but there is, in most of these cases, sufficient difference between them to enable any one, who has seen both, to distinguish one from the other. The only time, except during gestation, when real kyestein appears to be formed, is while the milk is being secreted and not freely discharged. Thus it may often be found when the female is weaning, and, some writers assure us, in some cases during the whole period of nursing. On the whole, this sign is a very valuable one, and may be much relied upon.

The changes in the pulse, on which some persons rely, are of no value whatever as a sign of pregnancy, since they are no more frequent, and not at all different, so far as I have seen, from what ordinarily occur from other causes.

The development of the abdomen, though an invariable accompaniment of pregnancy, is by no means a certain sign of it, since it may be produced by other causes ; and besides, it is sometimes but little to be observed till a late period. The peculiar 
manner of the development, however, is usually somewhat different from that produced by tumors, and other diseases. Very often the abdomen will be tolerably large by the second month, and then again become so much smaller that the female will think she is certainly not pregnant. This is owing chiefly to flatulence, produced by digestive disturbance during the early periods, but which afterward subsides. In a short time, however, the uterus not only enlarges more, but rises, and the development becomes permanent. This circumstance of there being often two developments has deceived many, and I have known females declared to be not pregnant, simply because the development of the abdomen went down, who, in a short time after, exhibited unequivocal evidences of being in that condition. The first development, or swelling, is merely similar to what often arises from indigestion, and other causes, and is therefore no sign of pregnancy; but the second development is accompanied by other changes, besides being more permanent.

The linea alba, or white line, which may be seen extending from the navel to the pubis, in the ordinary state, becomes much darker, the skin of the abdomen wrinkles, and the umbilicus, or navel, becomes prominent.

Swelling of the eyelids, and puffing of the face, are experienced by some females, but are not very general, and so frequently result from other causes that they are of little value as eridences in this case.

This, I believe, comprises all the presumptive signs of pregnancy that are worthy of notice. Some of them are valuable and may be depended upon, particularly the presence of kyestein in the urine, which may almost be called a certain sign. Others of them are of little value alone, but are useful in the way of corroboration. The more there are of them observed together, in any case, of course the more grounds there are for the presumption that pregnancy exists, and the reverse.

It must be carefully remembered, however, that these presumptive signs are precisely those most likely to be produced by other causes, particularly by marriage only; they must therefore be well weighed, and, unless very numerous, or very distinctly marked, must not be regarded as conclusive. As already remarked, it is only during the first three months that most of these presumptive signs are taken much notic? of ; after that we have others that can be more depended upon, and which will be described in the succeeding articles.

\section{PROBABLE AND CERTAIN SIGNS.}

End of the third month.-The probable signs now to be described are seldom recognized before this time, and not generally with distinctness till a still later period. They chiefly consist of certain changes in the form, development, and position of different parts of the uterus, to ascertain which requires an internal examination. These changes are not observable till the end of the third month, previous to which time we cannot be certain that the womb has really increased beyond its normal size. And even then, when the increase is obvious, we cannot tell how it has been produced; it is not till a much later period, till five or six or even seven months have elapsed, that pregnancy can be ascertained with anything like certainty.

The changes to be noticed are in the form and size of the neck and body of the womb, and in its mouth, and also in the weight of the whole organ. No one, of course, can expect to recognize these changes who is not acquainted with the parts in the unimpregnated state, both in the virgin and in those who have borne children. 
The mode of conducting the requisite examination is by introducing the index finger of the right hand, covered with oil or mucilage, into the vagina, and then carrying it upward till it reaches the os tincæ. By means of this finger the position and length of the neck of the womb are ascertained, and also the state of its mouth, whether it is opened or closed, and to what extent. If it be then placed at the top of the neck, on the under side, and the other hand upon the fundus of the womb externally, and pressing firmly upon it, the organ is inclosed, as it were, between the two hands, so that its size and form mảy be pretty accurately ascertained, and also its degree of firmness, by which a judgment may be formed as to whether it is occupied by any solid body, or fluid, or whether it is empty. In addition, to this, a tolerably

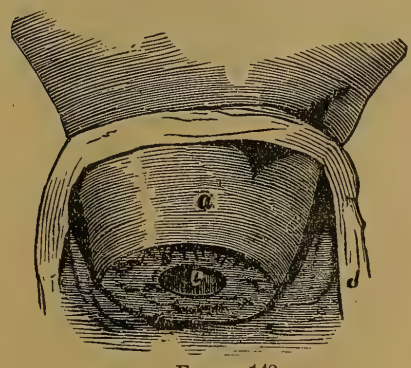

FIGURE 148.

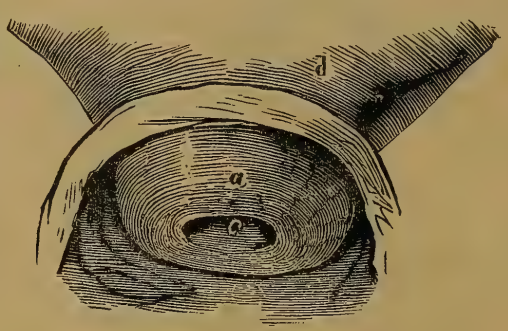

FiguRe 149.

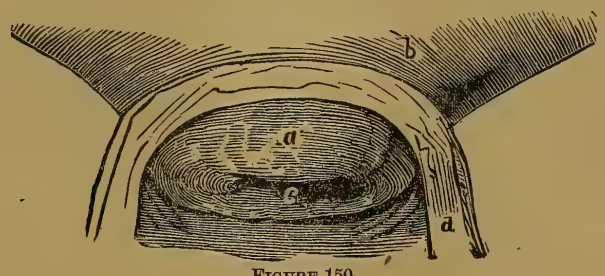

FIGURE 150.

The form and size of the body, neck, and mouth of the roomb, at about the third, seventh, and ninth months.

Figure 148 represents the form and size of the body, neck, and mouth of the womb, at about the third month.

Figure 149, the same at about the seventh month.

Figure 150, the same at the ninth month.

The references are the same in all. $a$. The neck of the womb. $-b . b$. The body of the womb. $-c$. The os tince, or mouth of the womb. $-d$. $d$. The cut edges of the vagina.

accurate estimate may be made of its comparative weight, by balancing and raising it up on the finger. This is called by the French ballotment, and, as will be shown further on, is a valuable means, at certain stages, of ascertaining .pregnancy.

The female may be examined either standing or lying down, though the recumbent position is best, except in certain displacements of the womb, when it is most likely to be thrown into a position in which the neck can easily be reached by the female standing. The position of the neck is very different in many of these dis- 
placements, and during pregnancy, to what it is in the ordinary state, and a person not acquainted with these changes might frequently be much puzzled to find it. As we have already remarked, also, there are certain differences between those who have had children and those who have not. The foregoing three diagrams represent the changes just spoken of at different periods.

It will readily be seen by these diagrams that the alterations in the neck and mouth of the womb are rery marked, and of a character easily to be ascertained by the touch. These three should be compared with the section of the womb in the unimpregnated state.

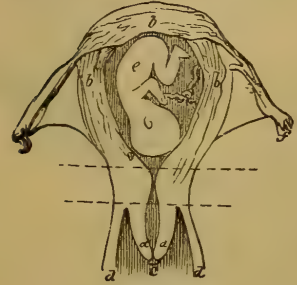

FiadRe 151.-Primipara, or the first pregnancy.

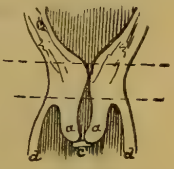

Frgure 152. - Woman who has borne children before.

$a$. $a$. The neck of the woinb. $-b, b, b$. The body of the womb. $-c$. The os tincr, or mouth of the womb. $-d$. $d$. The cut edges of the vagina.- $e$. The fotus. $f$. $f$. The Fallopian tubes, ovaries, and round ligaments.

circular, the lips being quite smooth and closed. In the female who has already borne children it is somewhat open, so that the finger may often be introduced, and the lips feel rough, owing to scars and laceration in previous deliveries. It is also larger altogether, and softer, than in the primipara. The whole length of the neck at this stage is about two inches.

The body of the uterus, when pressed between the two hands, will be found much larger than ordinary, and more round, and it will feel heary when pushed up by the finger.

In regard to the precise value of these probable signs, it can only be said, when they are observed, that it is certain that the womb is enlarged, and most probably from pregnancy. But at the same time it must be remembered that several diseases, and particularly suppressed and irregular menstruation, or the derelopment of tumors and polypi, will effect rery similar changes, and that it is not always possible to say whether they arise from these abnormal growths or from pregnancy, though it can generally be done. But though we cannot, in every case, say when these signs exist, that the female must be pregnant, we can nearly always say, when they do not exist, that she cannot be so, particularly if the other usual signs are absent.

End of the fourth month.-By this time the neck has become a little shorter still, and the mouth more open, but on the whole there is not much change to be felt internally. The body of the womb, however, has now ascended above the superior strait of the pelvis, and begins permanently to enlarge the abdomen. It may be distinctly felt between the two hands, like a firm round ball, somewhat elastic, and 


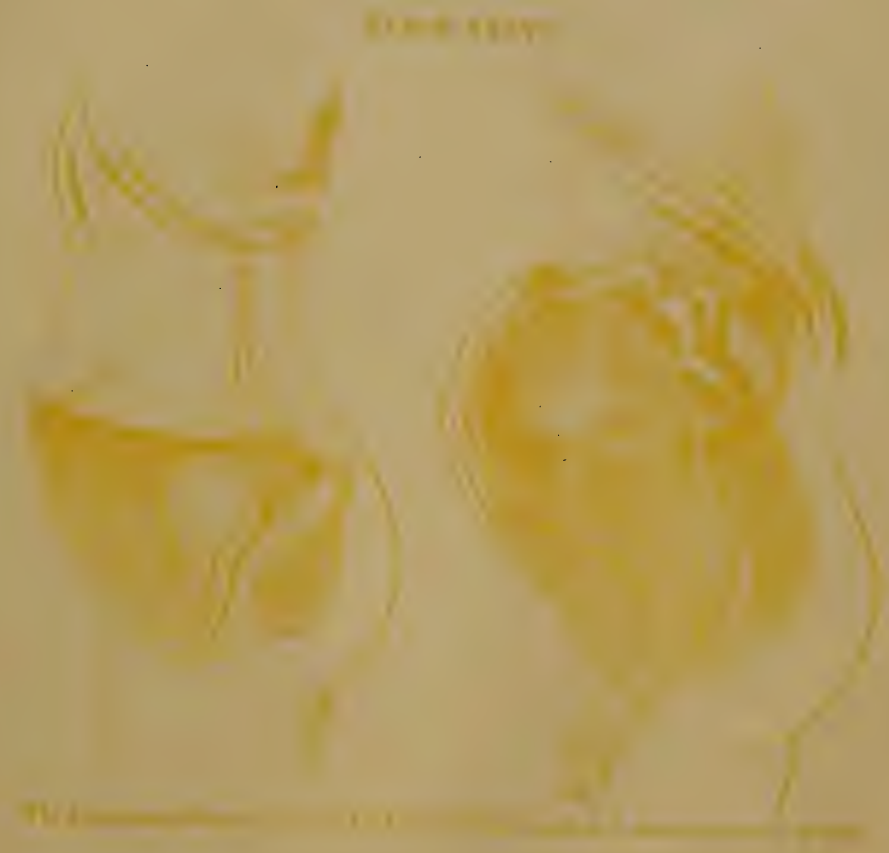



resisting when pressed. This is the period when the motions of the fotus are usually felt first, and these motions, with the ascension of the womb, are sometimes experienced very suddenly, so as to alarm the female, and produce certain curious sensations, with much nervous derangement. This is called quickening, and with some persons, is always so well marked as to indicate not only their condition, but the very period, with great precision. Many, however, never experience anything at all peculiar at this time.

It is customary for the medical attendant, as a means of making the child move, to put his hand first in cold water, and then over the fundus of the uterus; the sensation of cold thus conveyed usually causing it to move immediately. Great care must be taken, however, that other motions be not mistaken for those of the child, an error not at all uncommon. Many a female, and many a medical man also, has been deceived in this way, particularly in cases of uterine or ovarian dropsy and tumor, and even in ordinary flatulence and hysteria. Fomales who much desire offspring frequently deceive themselves in this way, and it is sometimes next to impossible to convince them of their error. Some women possess the power of imitating the movements of the child, with great exactness ; and instances have been known where they have successfully imposed, both on their friends and medical attendants, for a long time in this way. Mr. Dubois mentions instances of females who possessed this extraordinary power, and who, though not pregnant, used to present themselves to his class for the pupils to ascertain the motions of the

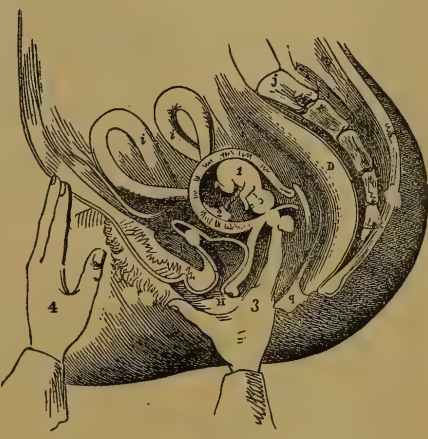

Figure 153.

This figure represents the mode of performing the ballotment to detect pregnancy.

The index finger of the right hand is passed into the vagina till it touches the body of the womb, the neck being thrown back, owing to the tilting of the fundus forward. The left hand is pressed firmly upon the abdomen, just over the pubic bone.

1 , Is the fœetus; 2 , the placenta, connected In with the foetus by the cord; 3 , is the index child. In short, this sign must not be finger of the right hand, within the vagina; 4 , too much relied upon, nor too confidently is the left hand.

expected, for many females observe no in its position, are very well represented in the foetal motions at all till the sixth or figure, and so are the alterations in some of the seventh month, and even then very indis- other organs. The manner in which the bladder, seventh month, and even then very indis- $\mathbf{A}$, is pressed out of its usual shape and size, may tinctly. Sometimes, also, after having be seen by comparing this with previous figures been distinctly felt, these motions will of the unimpregnated state. The shortening of the altogether stop for a long time, and then also equally obvious, and the manner in which appear again.

At this time, however, ballotment can the mouth of the womb is thrown back against the rectum.

begin to be practiced, though it is not quite so certain as at a month later. The manner of performing this important manipulation has already been partly described, and by examining Figure 153, and attending to the following remarks, it may be readily understood and practiced.

When the right hand finger ( 3 , Figure 153) is carried to the top of the 
vagina, it meets with a round soft tumor, which is the head of the child felt through the walls of the womb. As soon as this is distinctly felt, the finger must be withdrawn a little, and then pushed suddenly against the tumor with a jerk; this will displace the foetus, and canse it to rise in the liquor amnii toward the fundus, so that the round tumor will have disappeared. In a few moments it will sink down and may be again felt, and again displaced in the same manner. This is called the ballotment, or balancing it on the end of the finger. The sensations conveyed on touching the fœtus, and when it rises after being pushed, are so peculiar that they are not likely to be overlooked, or mistaken for anything else, after being once experienced. The jerk is not required to be at all violent, and had better be made at first very slight, as it can easily be repeated a little more forcibly if the tumor does not rise at first. Some practitioners practice the ballotment in this way, using the one hand only ; but others place the left hand also on the abdomen (4, Figure 153) at the same time, and immediately after jerking upward with the right hand, they suddenly depress the abdomen, just over the pubes, with the fingers of the left, so as to send the foetus down again more quickly and more forcibly. This is seldom needed, but if the first way does not succeed the two hands may be tried.

A species of ballotment may even be practiced externally, in the following way : The fingers of the right hand are placed on the abdomen, just over the fundus of the womb, like the left hand in Figure 153, and a smart jerk is given downwards and backwards, several times in quick succession. This also displaces the fotus, which may be distinctly felt to float away, each time the percussion is made. No one can mistake this peculiar motion who has once felt it.

Sometimes one of these manœurres will succeed when the other fails, so that it is well to practice them all. They may be performed with the female either standing or lying down, and will sometimes succeed one way when they will not the other.

It is requisite to remember that in presentations of the breech, or trunk, the ballotment may not succeed as well as when the head presents; or it may even fail altogether, so that when it is unsuccessful we must not immediately conclude there is no pregnancy. Tumors in the womb, stone in the bladder, and various uterine displacements, may also create uncertainty, or cause failure, but these accidents are rarely met with, and only interfere materially at an early stage; afterwards ballotment can be practiced notwithstanding them, or auscultation may be resorted to.

In short, this mode of detecting pregnancy is one of the most certain, and the most generally applicable, that we possess.

End of the fifth month.-At this time the uterus has increased considerably in size, and has ascended so high in the abdomen that the fundus is level with the umbilicus, or navel, in a first pregnancy, though somewhat lower in those who have borne children before. This rising of the womb makes the vagina longer, and brings the neck of the womb nearer to its center. In the previous stage the neck was thrown so far back that it was difficult to reach, but now it is much more favorably situated, though much higher. Its substance is softer than before, and the two lips are nearly on a level, and somewhat opened, particularly in those who have borne children before. Indeed, in them the point of the finger may be introduced, as seen in Figure 154.

Ballotment is now much more easily practiced and is more conclusive. A new sign is also to be distinguished, by which we are furnished with another valuable 
means of detecting pregnancy. The child's heart begins to beat so strongly, and its circulation is so vigorous, that the sound of it can be heard externally. The same means are taken to ascertain this that are used in sounding the chest of an adult. If the ear be placed on the abdomen over the womb, the beating of the foetal heart may be heard quite plainly; and if the stethoscope be used it will be still more distinct. This practice is called auscultation. The signs furnished by it are certainly of the greatest value, and frequently enable us to detect pregnancy with unerring certainty. Indeed, not only can we tell by them that a child is in the womb, but often even the very position in which

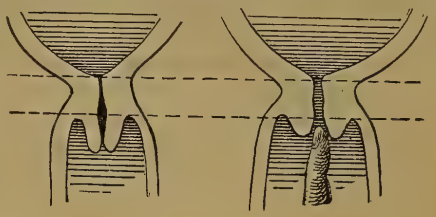

FIGURE 154.

Neck of the womb in a Neck of the womb in a first pregnancy, very female who has borne slightly opened. children before, show. ing how it admits of the introduction of the finger.

This is at the end of the fifth month, and the drawings are about one-third of the natural size. it lies, and whether there be twins, or more. This is done by noting where the heart is situated, by the sound, and whether the beating is single or double.

The nature of these sounds, and the manner of detecting them, require to be carefully explained.

If the person wishing to notice this sign is not already familiar with the beating of the adult heart, he had better become so first. The ear should be placed on the left side of a grown-up person, on the skin, just beneath the breast, and held very still. The heart will then be heard to beat very distinctly, there being two sounds, a long one and a short one, alternating with each other. When this has been listened to for some time, the ear will be able to catch any similar sound, and the auseultation may then be practiced to detect pregnancy.

The ear must be placed on the abdomen, about midway between the pubes and the umbilicus, and towards the left side. No weight should be borne on the body, but the ear must be laid sufficiently close to exclude all external sounds, and no motion should take place, particularly with the clothes. If the sound be not heard in the position first assumed, move a little, in different directions, till that point is attained where it is most distinct. It can scarcely fail to be heard, with ordinary care. A practiced ear will sometimes distinguish the sound as early as the fourth month, but generally it cannot be heard before the end of the fifth, or even till the sixth month. There are several sounds that may either be mistaken for it, or that may confuse the ear. The beating of the mother's heart will sometimes be very distinct, as far as the lower part of the abdomen, but it is much slower; the child's heart throbbing nearly twice as fast. The movements of the fotus, and the rumbling of the intestines, will also interfere ; but when once the proper sound has been caught it may be kept distinct from all these.

The manner in which the child lies in the womb will determine where the heart shall be opposite, and as its position frequently varies, both in different individuals, and at different periods, in the same person, the sound must be sought for at several points, till the right one is found. The most usual position will be seen in several of our figures, and they will give sufficient indication to enable almost any one to practice this mode of detection with success. During the early months the child moves about a good deal, so that the sound may be heard one day in one place, and 
the next in another. About the seventh month, however, it becomes more fixed, so that the place of the heart can be pretty certainly ascertained, and thus the position of the whole body is made out, whether the head is downward or upward, and a tolerable idea can be formed even as to the direction of each part.

Many persons have failed in their attempts to hear the foetal pulsation, but I cannot but think it must have been either from inattention, or from not being acquainted with the sounds of the heart at all. I never recollect an instance when I could not do so, at the proper time. M. Chailly says he does not hesitate to affirm that in every instance they can be detected; and M. P. Dubois distinctly heard them in one hundred and eighty-five females, out of one bundred and ninety-five, in the other ten the child being probably dead. Indeed, the absence of this sound is the most certain sign of the death of the fœetus, as its existence is of its being alive; and medical men now tell whether the child is dead or not by these very means.

In conducting the auscultation, the female must recline, and keep as still as possible, breathing low. The abdomen may be covered with a single thin garment, if absolutely insisted upon; but the judgment will be so much the more uncertain, owing both to the deadening of the sound and to the friction of the material. The experimenter must also recollect that if the head be held down too long, the blood will rush to it, and cause a humming in the ears, which will confuse him; it will therefore be better if the bed be high.

It is always best to use the stethoscope, as it covers only a small space, conveys the sound more directly, and shuts out external noises more effectually. This instrument is extremely simple, consisting merely of a tube of wood, glass, metal, gum elastic, or almost any other material. One end should be expanded a little, like a bell, and the other made small, so as to fit close in the ear-the large end being placed on the abdomen. It may be about a foot in length, though a little shorter or longer will not make much difference. I once used a child's tin trumpet, having no regular stethoscope with me, and succeeded with it perfectly. The large end should be pressed on the abdomen, and the smaller one into the ear, sufficiently close to shut out all other sounds but those coming from the body. This is the same instrument that the lungs are sounded with, when we want to judge of their action and condition.

This is an invaluable means of detecting pregnancy; in fact, at the proper time, and with due care, it may be said to be certain.

End of the sixth month.-This is the period when, according to the law, the child can live. There are no new signs at this time, but those previously noticed are now more distinct. The neck of the womb is still softer and shorter, and the finger can penetrate further in the passage than before. The fundus of the womb is now above the umbilicus, in primipara, though not so high in those who have borne children; and the bladder is above the superior strait.

Ballotment can now be practiced with certainty, the falling and rising of the fœotus being very distinct.

Auscultation also becomes more positive, the sounds being louder and more easily ascertained.

End of the seventh month.-The fundus of the womb has now risen still higher, and the bladder is pushed completely above the upper strait, so that the whole length of the urethra lies behind the pubic bone. It is therefore much pressed upon and swollen, and being much longer, and bent out of its usual course, the urine is often 
passed with difficulty, and the catheter can scarcely be introduced. The upper part of the womb now lies over toward the right side of the body, very evidently. This direction is nearly constant in all females, but the reason for it is not known. There have been many theories to account for the peculiarity, but none of them are either so plausible, or so well supported by facts, as to be generally adopted.

The upper part of the womb being tilted to the right side, the neck of course points to the left, and back-

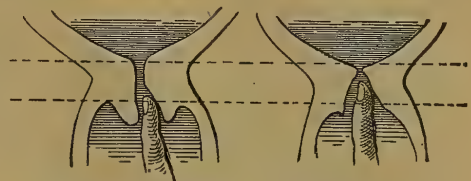

Fit. 155. - First child.

Woman who has borne children.

The neck of the womb in a first pregnancy, and in a female who has borne children before, at the end of the seventh month. ward. It is now very short, even in primipara, but in those who have borne children it is scarcely to be distinguished at all. The finger may now be introduced, even in primipara, half way up the neck; and in others it will reach even into the uterine cavity.

The part below the lower line here, shows that part of the neck which is contained in the vagina. It will easily be seen how much shorter this part is, and how much more open the passage is, in the female who has borne children, than in a first pregnancy.

Ballotment and auscultation both now afford unmistakable evidences as to the condition of the patient.

End of the eighth month.-By referring to the preceding Figures, it will be seen that the part of the neck of the womb above the vagina, which is placed between the two dotted cross lines, remains almost unchanged, while the part within the vagina, or that below the lowest line, becomes less and less, till at this time, in those who have borne children, it can scarcely be felt at all; and even in a primipara it is merely like a small tubercle. About this time, however, the upper part of the neck begins to shorten also, though that is not so obvious, and therefore not so useful for our present purpose.

On making an examination, the mouth of the womb itself may now be felt, at the upper part of the vagina, and far back. It is, however, very difficult to reach, on account of its pasition. The finger will now pass, in those who bave previously borne children, into the cavity of the womb itself, but in others it will scarcely reach so far.

The linea alba becomes darker at this period, and so does the areola around the nipple. Certain peculiar marks also appear on the abdomen and upper part of the thighs, almost like the pits from small-pox. They are usually diamond-shaped, slightly depressed, and dark in color. They appear to be owing to the over-stretching of some of the parts under the cuticle, which give way in consequence. In first pregnancies, and in those who enlarge very much, these marks are sometimes very numerous, and remain for a long time after delivery; occasionally even they never disappear. As signs of pregnancy, however, they are but of little value, because they are often produced by other causes that distend the womb. None of these presumptive signs are now needed, and therefore they are of little consequence, because there are $n$ thers more certain.

The motions of the child itself can now be generally both felt and seen, and an experienced observer may even predicate from them, with tolerable certainty, the 
position in which it lies. Ballotment, by one hand on the abdomen, may still be practiced with success; but in the vagina it is difficult, because the foetus is both more fixed and heavier.

Auscultation is now the surest dependence, however, and may be advantageously resorted to also as a means of determining beforehand the position of the child. This may be done even a month earlier, but not so certainly as now.

To understand how this important point is determined, it is only necessary to recollect, as will be very evident, that the pulsation will be heard the loudest immediately over the heart; and as we know the form and general size of the fœtus, and the manner in which it usually lies, it becomes possible, when the position of its

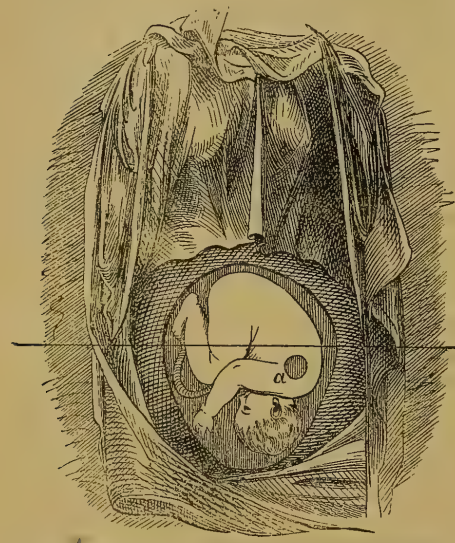

FiaUnin 156. - This plate represents the fotus in the most usual position, the head downwards, and the back of it presenting to the left side.

The black spot, $a$, shows the situation of the heart; usually immediately under that part where the sound is heard the strongest. It is below the line.

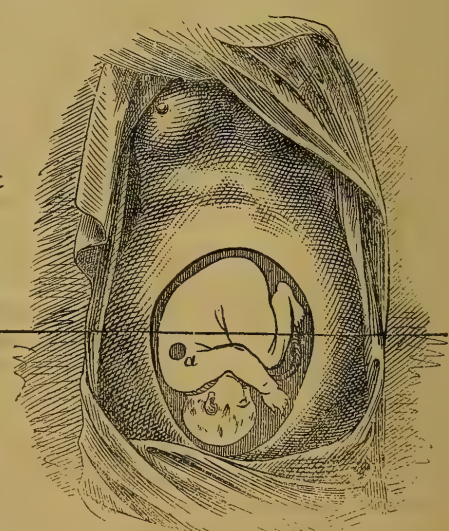

FIGURE 157.-This plate represents the foetus in the next most frequent position, the head downwards, but the back of it presenting to the right side.

The black spot, $a$, shows the situation of the heart, as in the previous plate. It is now below the line, as before, but on the opposite side.

heart is discovered, to trace out from that the position of every other part. This will be evident by referring to Figures $156,15 \%$, and 158 . It will then be seen that, if a line be drawn across the middle of the abdomen, the heart will be above that line when the breech presents, and below it when the head presents, and on the right or left side, as the case may be, in each position.

In case of twins there will be two pulsations, and theya so much interfere with each other that it is difficult to distinguish either. The two children being generally disposed with the head of one to the heels of the other, one heart will be above the line, and the other below, on opposite sides, as shown in Figure 159.

At this period the signs previously observed become more distinct, but there are few new ones. The external lips sometimes swell, and the breathing becomes more difficult, owing to pressure on the diaphragm. The trouble with the urine is also 
apt to increase, and little mucous tubercles, like pimples, occasionally form around the os tincæ, and on the upper part of the vagina.

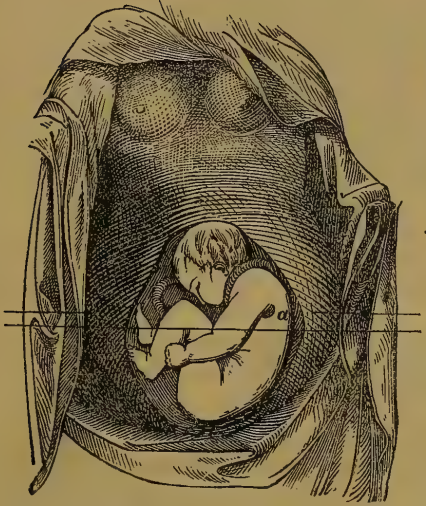

FravRe 158.-This plate shoros the position of the foetus in a presentation of the pelvis, or breech, which happens, comparatioely, but seldom.

The heart, is here above the line, instead of below.

In this case, as in the others, the heart may be on either side of the body, according as the shild faces, but always above the line.

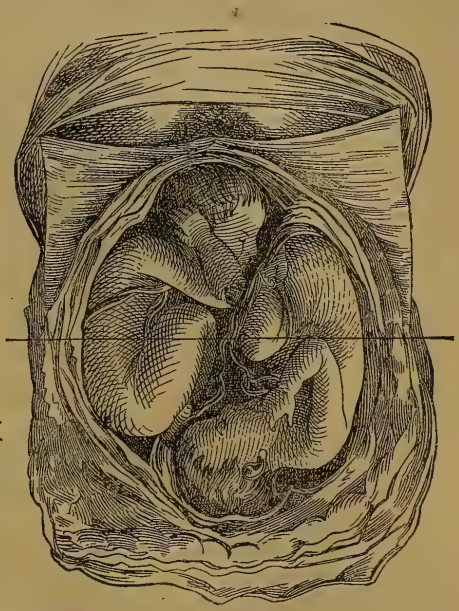

FIGURE 159.-This represents the position of twing as most usually observed, one having a head pre. sentation, and the other a breech.

The heart in one case is above the line, and in the other below.

The head, however, may be on the right side instead of the left, and so reverse the position of the two hearts, but this is very seldom the ease.

When there are more than two, the confusion and uncertainty become still greater.

End of the ninth month.-There is but little difference between this and the previous period. The mouth of the uterus is more open, and, in those who bave had children, the finger will pass directly into the womb, and feel the child, but in primipara there is still a small portion of the neck left.

Ballotment is now more obscure than before, as the fotus is very heavy, and quite low down, and pretty firmly fixed. Auscultation is distinct enough, but not more so than at the previous period. The swelling of the lips, and of the veins of the legs, may increase, and so may the difficulty with the urine; but the breathing generally becomes easier, owing to the womb having descended a little, and so pressing the diaphragm less.

These comprise all the signs and indications of pregnancy that possess any real value. Some of them, at certain times, and under particular circumstances, may be called positive; such as those discovered by ballotment and auscultation, and also the presence of kyestein in the urine. Most of the others merely make it probabie that pregnancy exists, or warrant us in presuming as much. They are not to be depended on implicitly alone, but when many of them are observed together, and no other cause 
can be assigned for their production, the presumption becomes so well supported as almost to be called a moral certainty. A person of experience, who is familiar with all these signs, and with the others produced by disease which resemble them, will

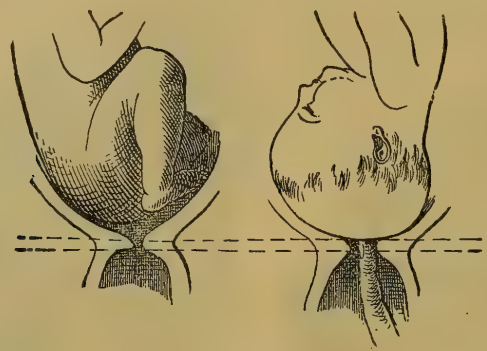

FrguRe 160.

The neck of the womb, at near the end of nine months in a primipara.
The neck of the womb, at near the end of nine months, in a woman who has previously borne chil.

seldom find it difficult to decide; but still there are cases in which pregnancy proceeds, even to its termination, with but few unusual symptoms, so that both patient and attendant are completely at fault. This, however, is very rare, and many eminent authors contend that it is always possible to detect pregnancy, after the sixth month, and I think so myself, unless the child be dead, in which case it will soon be evident in another way. 


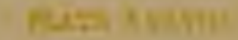

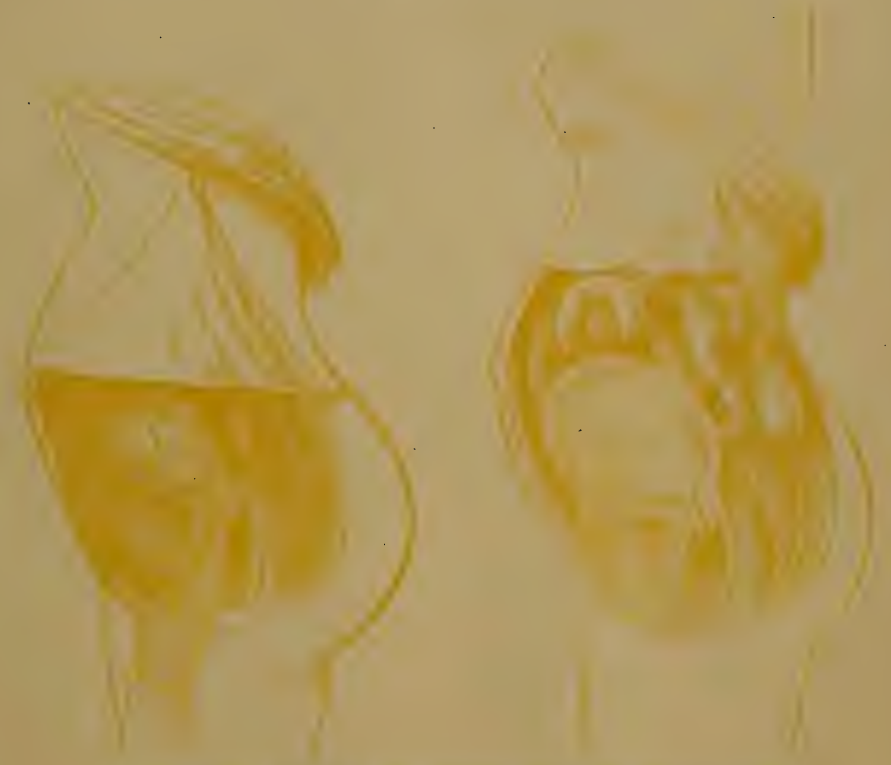

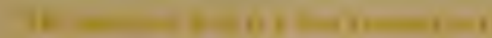





\section{CHAPTER LXIII.}

\section{FORM AND SIZE OF THE FETUS AT FULI TKRM.}

\section{Size and Form of the Body.}

THE average length of the fœtus, at full term, is about twelve inches from the head to the breech, and about eighteen inches. from the head to the feet. Its weight varies from five to eight pounds, perhaps averaging about six, though some have been born weighing only three pounds, or less, and some even as high as fifteen. The breadth across the shoulders is about four inches, and the same across the hips, but both are so easily compressed that during delivery they only measure about three inches, or three and a half at most.

\section{SIZE AND FORM OF THE HEAD.}

The head is the most important part, because it is the largest, and usually presents first. It is therefore necessary to describe it fully, and with special reference to its importance in the early stages of labor, as the part by which the position is usually determined.

The bones of the cranium are not closed together, as they are in the adult, but are separated to a considerable distance, in certain parts, and connected by a strong membrane. These membranous spaces are called sutures and fontanelles, and a knowledge of them is absolutely necessary, as a means of ascertaining the position of the head.

The Sutures.-The first of these spaces, which extends from the lowest part of the middle of the forehead to the occipital bone, is called the sagittal suture, or antero posterior suture. It separates the two frontal, and the two parietal bones. frontal, and the two parietal bones. Fig. 162. - Two malar, or cheek bones, 6, Fig. 162.
The spaces between the two frontal And one inferior muxillary, or lower jaw bone, and the two parietal bones are called where the different bones join each other. the frontal parietal sutures, and those between the two parietal bones and the occipital, are called the lambdoidal sutures. Fig. 162. The sutures and fontanelles can be seen
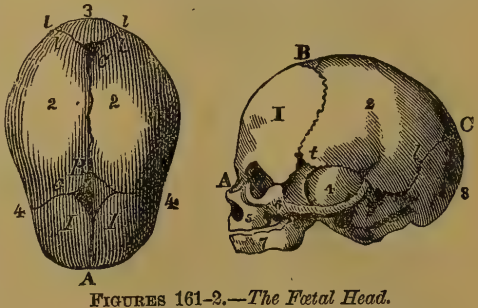

The head is generally divided into the cranium, or that part which contains the brain, and the face.

The Bones of the Cranium.-These are seven in number, viz., two frontal bones, or those forming the forehead, 1, 1. Figs. 161 and 1132.-Two parietal bones, or those forming the sides of the head, 2, , Figs. 161 and 162.-The occipital bone, or that forming the back of the head, 3, 3, Figs. 161 and 162.- And two temporal bones, which lie over and between the ear and the eye, 4, Fig. 162.

The Bones of the Face.-These are five in number. viz., two superior maxillary, or upper jaw bones, 5 , 
The Fontanelles. - When the different sutures meet at a point, the membranous space is greater than at other parts, and is called a fontanelle. Thus where the two frontal parietal sutures meet the sagittal suture, there is quite a large diamondshaped space between the different bones, filled up with membrane. This is called the anterior fontanelle, or bregma-B, Figures 161, 162. Where the sagittal suture joins the two lambdoidal, there is another space, not so large, and different in shape, being triangular; this is called the posterior fontanelle-C, Figures 161 , 162. And where each of the temporal bones joins the parietal, there are two other spaces, called the temporal fontanelles, which are also irregularly diamond shaped, but not nearly so large as the anterior fontanelle-l $l$, Figure 161 .

It is evident that if a person can distinguish these fontanelles, when he touches them with his finger, he can tell what part of the head is presenting, and hence their use.

These spaces allow of the bones lapping over each other, during delivery, and thus the head is made smaller. They do not disappear till some time after birth, and in very young children the brain may be felt, and seen to work, at the anterior fontanelle. Eventually however, the bones come close together, and are joined by a

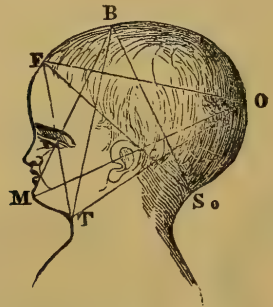

FIGURE 163.

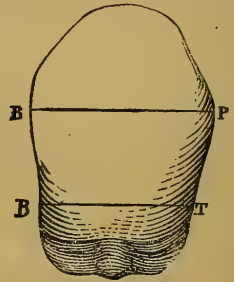

FIGURE 164

FIGUREs 163-4. Diameters of the Head.

1. The Occipito Mental, or from the back of the head to the chin, M, O, Fig. 163, five inches.

2. The Mento Bregmatic, or from the chin to the anterior fontanelle at the top of the head, $M$ B, Fig. 163, four inches.

3. The Occipito Frontal, or from the back of the head to the top of the forehead, 0, F, Fig. 163, four inches.

4. The Trachelo Occipital, or from the throat to the back of the head, T, O, Fig. 163, four inches.

5. The Sub Occipito Bregmatic, or from the nape of the neck to the top of the head, S, B, Fig. 16:3, three inches and a half.

6. The Trachelo Bregmatic, or from the top of the throat to the top of the head, T, B, Fig 163 , about three inches and a half.

7. The Trachelo Frontal, or from the top of the throat to the top of the forehead, T, F, Fig. 163 , about three inches.

8. The Sub Occipito Frontal, or from the nape of the neck to the top of the forehead, S, F, Fig. 163, about three inches.

9. The Bi Parietal, or across the head from one side to the other at the middle of the parietal bones, the widest part, B, P, Fig. 164, three inches and a quarter to three and a half.

10. The Bi Temporal, or across the head from one temporal bone to the other, B, T, Fig. 164, about two inches and a half.

curious kind of dovetailing. The two frontal bones, however, completely coalesce, and form but one, in the adult.

Sometimes the bones will be very perfectly formed, and the fontanelles nearly filled up, before birth, and then the head cannot be crushed much smaller, which 
causes the labor to become both painful and difficult. This is usually called an ossified, or solid head.

Diameters of the Head.-The diameters of the head are the distances between its most prominent points. They are necessary to be known before we can judge as to the possibility of its passing the straits of the pelvis, in the various positions.

Generally there are reckoned ten diameters, and they are represented in the Figures on the preceding page.

The necessity for knowing these diameters will be obvious. It is only by being acquainted with them, and with the straits of the pelvis already described, that we can tell whether the child can pass or not in certain positions, and how we must change its position, when possible, to give relief.

On comparing the diameters of the head with those of the pelvis, it will be seen that some of them correspond in size while others do not, so that in one position delivery can take place spontaneously, while in another it will be difficult, and in some nearly impossible, without assistance. Thus, for instance, if the head should present by the occipito mental diameter (O, M, Fig. 163), it evidently could not pass while in that position, because by this diameter it is five inches in width, and the greatest diameter of the pelvis is only about four inches and a balf. Its position must therefore be changed, and the accoucheur must know how to change it with advantage.

\section{ATTITUDE OF THE FETUS AT FULL TERM.}

The attitude of the foetus is represented in the accompanying figure :

The position in which the footus most usually lies in the womb has already been shown. The head is downwards, and the back part of it turned to the mother's left side. What is the cause of this almost universal position is not certainly known. It was formerly thought to depend on the head being heavier than the other parts, and thus sinking down; but this supposition has been shown to be entirely without foundation. M. P. Dubois has lately adranced the notion that it depends on an instinctive feeling in the foetus itself, which directs it to take that position by which it can most easily make its exit. This opinion appears very reasonable, and is apparently well founded. It is well known that the fotus is susceptible of various impressions while in the womb, and is impelled by unerring instinct to take the breast immediately it is born; nay, it has even been known to suck the finger of the assistant, in cases of face presentation, even before birth ! We can readily believe, therefore, that it is directed to place itself in the womb in the best posi. tion, the same as it is directed to take the finger in its mouth.

In the young of many of the lower animals this is also strikingly exemplified. The young duck in the shell taps with its little beak against the part that is to be broken, and rushes into the water even with a part of the shell still on its back. The young opossums, who are born imperfect from the womb,

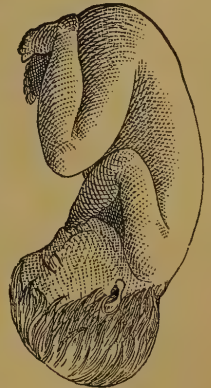

FIGURE 165.-Attitude of the Foetus.

The arms, it will be seen, are crossed on the breast, upon which the chin is also bent; the thighs are close together, and brought against the abdomen; the legs are close bent on the thighs, and the feet are turned up against the front of the legs, the whole body being curved forward. shelter themselves, immediately they come into the world, in the pouch on their 
mother's breast, and fasten themselves to the mammæ till they are more perfectly grown.

It must be remarked, however, that the head does not always present first, though it usually does so. Occasionally we have the breech present, and still rarer even other parts; but these are merely exceptional deviations, the causes of which are unknown. Out of every sixteen children born, fifteen usually come head first. This, however, will be shown better further on。 


\section{CHAPTER LXIV.}

THE APPENDAGES OF THE FETUS AT TERY.

\section{The Membranes.}

THE uses and arrangements of the membranes surrounding the footus have already been explained, so that little more is needec to be said here, because they are not much different at the full term from what they are at an earlier period, excepting perhaps that the amnion is a little more dense and firm. This membrane appears not only to surround the fotus like a bag, to contain the waters, bnt is also reflected close on to its body, like its skin, with which in fact it is thought by some to be connected. The child is certainly born with this membrane still on its body, and does not part with it till some days after birth, when it peels off like a thin dead skin, or powder.

The waters inclosed within the amnion have now increased to their greatest quantity ; and there is also, in most cases, a second body of fluid between the amnion and the chorion, which, coming away before the real discharge, is called the false waters.

The quantity of the true waters, at birth, is about twenty, or from that to thirty ounces, but is very variable. It is of a greenish color, rather muddy, and heavier than water. It contains albumen (white of egg), sulphate of soda, and lime. Ninetyeight per cent. of it, however, is pure water. It appears to be excreted, like perspiration, from the surface of the membranes, and most likely is merely the watery portion of the blood exuded through. The uses of this fluid are various. As already stated, it probably supplies some nutriment to the foetus, which it also protects, in a great measure, from pressure and from concussions. It also prevents the limbs from adhering, and helps to distend the mouth of the womb, in the earlier stages of labor, besides affording an abundant slippery fluid for the purpose of lubricating the parts, thus making the passage of the child more easy.

The other two membranes, the chorion and decidua, are not of much importance in our present explanation ; and practically, in fact, the whole three may be regarded as one envelope, surrounding the child and the waters in which it floats.

THE PLACENTA.

At the full term, the placenta is about six or seven inches in diameter, and nearly circular, though often irregular. Its thickness varies from one to two inches, and is greatest where the cord is inserted. Sometimes it is very large, or very thick, and may then be difficult to extract, and even cause serious accidents.

As already explained, the placenta is composed of a mass of blood-vessels, by means of which the blood of the foetus is, in some way, brought into contact, or com- 
mingled with that of the mother. Its uterine face is irregular, being broken into lobes, or cotyledons, on which may be seen a vast number of little veins and arteries, corresponding with others on the inner surface of the womb. Its outer surface is of a gray red color, and covered with the fotal membranes, under which the large blood-ressels can be traced. The placenta is usually attached to one side of the uterus, near the fundus, or at the fundus, but sometimes it grows wholly or in part over the mouth of the womb; an occurrence which may cause serious consequences.

When there is more than one child, each usually has a separate placenta, and they are all intimately connected. In some rare cases, however, one placenta only exists with twins. Each child has also a separate amnion, and waters; but there may be only one chorion and decidua for the whole, or each may have a complete set of membranes itself. Instances have been known, however, of two children being inclosed in the same amnion, and surrounded by the same waters, having but one placenta between them.

These possible diversities show the accoucheur how necessary it is for him, in any case of multiple pregnancy, to be sure that he has abstracted all the after-birth; and they also caution him not to proceed to unnecessary manipulations merely because it is not the same as in other cases.

\section{THE UMBILICAL CORD.}

This is composed, as already stated, of an artery and two veins, which twist round the artery, like the strands of a rope. These are all inclosed in a sheath, and surrounded by a thick kind of mucus, called the Gelatine of Wharton. Its thick. ness is about that of the little finger, though it may be much larger, having been seen as thick as the child's body. Its usual length is about eighteen or twenty inches, but it has measured as much as five feet. Then again it has been found so small that the ressels in it could not nourish the child. These exceptional variations, however, are very rare. The veins may also be enlarged, or full of knots, and the circulation may be so much impeded thereby as to cause abortion. The various accidents which may result from anomalies in the cord will, however, engage our attention in another place. 




\section{CHAPTER LXV.}

\section{PRESENTATIONS AND POSITIONS OF THE FETUS.}

THE child may present several different parts of its body at the commencement of delivery, and they may be in different positions relatively to the different parts of the pelvis. All these require to be known.

Different authors have made different classifications of the presentations and positions, and have differently named them; but this is of little consequence, since they are still the same, no matter how they are named. I shall follow the arrangement of M. Chailly, because I think it equally perfect, and much more simple and practical than any other yet proposed.

\section{PRESENTATIONS.}

The fortus may present at the mouth of the womb either by the head, the most usual way; by the lower extremities, which is the most frequent way after the head; or by various parts of the trunk, which is the least frequent way of all.

In each of these three full presentations there may be certain variations, which require to be noticed. The head, for instance, may present either by the cranium or by the face ; the lower part of the body may present either by the feet, the knees, or the breech, according as the legs and thighs are flexed or extended, and the trunk may present either on the right or left side, and inclined toward the back or toward the chest, though neither the back nor abdomen ever fully present.

Each of these variations may also have slight variations again. Thus the face may present full, or by one or the other cheek, and so on. These variations, however, are of little practical consequence, because we only find them at the very commencement of the labor, and they always change to the full presentation.

Practically speaking, therefore, there are five full presentations, viz., the cranium, the face, the breech, the feet or knees, and the trunk, either by the right or left side.

The varieties of these, as already remarked, not requiring any special attention from the accoucheur, providing he is not puzzled or misled by them.

\section{POSITIONS.}

The position means the particular direction in which the presenting part of the fotus is placed in relation to the pelvic straits. The pelvis itself is supposed to be divided into two similar halves, the right and the left, and each presenting part has one particular place, which is referred to as the indicating point. Thus, for instance, in the cranium, the occiput, or behind part of the head, is the indicating point ; and we therefore say, in cranium presentations, that it is a right or left occipital 
position, according as the back of the head is to the right or left side of the pelvis. In face presentations, the chin (mentor) is the indicating point, and we therefore say it is a right or left mento position, according as the chin is toward the right or left side. In breech presentations, the child's sacrum is the indicating point, and we then say it is a right or left sacral position, according as the sacrum is toward the right or left side of the pelvis. In trunk presentations, which are always crosswise, the head (cephalo) is the indicating point, and we therefore say it is a right or left cephalo position, according as the head lies toward the right or left side of the mother's body.

In cranium presentations, also, the back of the head is not merely on the right or left side, but may be at two different points on each side. It may be either nearest to the sacrum (posterior), or nearest to the pubes (anterior), but still against the ilium; it is therefore called a right or left anterior, or posterior, occipito iliac position, as the case may be. Sometimes, also, the occiput lodges immediately on the pubis, instead of going to either side, and that is called an occipito pubic position; at other times, on the contrary, it is placed against the sacrum, instead of being on either side, and that is called an occipito sacral position.

In presentations of the head, therefore, we may reckon six positions-the right and left anterior and posterior occipito iliac, and the pubic and sacral.

In presentations of the face the same, they being mento iliac, and so on, instead of occipito.

In presentations of the lower extremities also the same, excepting that they are sacro iliac, and so on, instead of occipito.

In presentations of the trunk we have but two positions for each side, the right and left cephalo iliac; according as the head is on the right or left side of the mother's body. The child always lying, in presentations of the trunk, crosswisethe feet on one side and the head on the other.

Most authors enumerate many more presentations and positions, but they are of little practical utility. When the head presents, for instance, the delivery takes place in nearly the same manner, let it be in what position it may. And in presentations of the face, or of the lower extremities, the particular position is of little consequence, the delivery being usually effected much the same in them all. Some of the positions are, it is true, much more favorable than others, but a spontaneous delivery, generally speaking, occurs in all of them, when the head, face, or lower extremities present. Very frequently indeed, the less favorable positions are changed to the more favorable ones, and the worst seldom do more than impede delivery for a time, unless there be some malformation, or loss of power. I therefore refer to them more for convenience in future explanations, and to enable my readers to know what is meant by them, when they read other books; not because they are really necessary to be understood, or of any great practical use.

The celebrated Baudelocque admitted seventy-four positions, and twenty-two presentations; and the number might be made still greater, if all the variations were to be enumerated. Such classifications, however, are more ingenious than useful, and they are but little noticed even by medical men.

I shall merely describe the mechanism of labor in the most frequent positions, in each presentation, because the others usually change into these ; and even when they do not, the process of delivery is essentially the same, and also the mode of assisting it. 
MODE OF ASCERTAINING THE PRESENTATION AND POSITION.

The Presentation.-Although in general it is not possible to ascertain with certainty what part of the foetus presents to the mouth of the womb, until labor commences, yet a tolerable judgment can frequently be formed before. In head presentations, on performing ballotment, the head is felt, like a firm round tumor, occupying all the space which the finger can reach, very differently from any other part. The peculiar cramps in the female's lower limbs, and frequent inclination to urinate, mentioned in the signs of labor, are also strong indications of this presentation, being seldom experienced in any other. When the labor has actually commenced, there can be but little uncertainty in these cases, for immediately the mouth of the womb is sufficiently open, the finger can be introduced, and the head felt like a smooth, round, and elastic bony tumor, not likely to be mistaken for anything else, if ordinary care be taken. After the waters have escaped, it can of course be felt still more distinctly. If even an inexperienced person bears in mind the shape of the head, and reflects how it must fill up the passage, and how it must feel, from being composed of separated thin bony plates, lying on a soft yielding substance like the brain, he can scarcely fail to recognize it. The sensation is very much like that of pressing a piece of firm cardboard on an inflated bladder, which forms a tolerable representative of the fortal head. Sometimes there is a difficulty from a great quantity of water being intruded between the membranes and the head, which somewhat obscures the touch, but this only necessitates greater care. The water however, may be in such quantity as to entirely prevent the touch, in which case nothing can be done till the membranes break; the presentation can then be ascertained with certainty, and it will be quite early enough to render assistance, if it should be an unfavorable one. I have known some inexperienced persons mistake the bag of water itself for the head, and commit great errors in consequence.

The face can seldom be mistaken, because the nose or mouth may be felt ; and, by passing the finger up the side of the head, the ears also.

The trunk is in general easy of recognition. Nearly always the right or left shoulder occupies the passage, or is near to it, so that the finger may be readily passed under the arm-pit. The shoulder joints, the ribs, or the shoulder blade bone, all feel very different to the head, and are not likely to be taken for it.

In presentations of the lower extremities there is still less danger of error. If the feet or knees occupy the passage, they can scarcely be mistaken. The breech is certainly something like the head in its form, but feels different, and is divided down the middle by the indentation between the two cheeks, along which the finger can be passed till it enters between the limbs.

In irregular presentations, as of the arms for instance, or of one leg, or an arm and $\mathrm{eg}$, it is only necessary to carefully feel them, so as to ascertain their form and the relation of their parts. Thus the fingers can be distinguished from the toes, and the feet from the hands, particularly if the ankle can be felt. The accoucheur should ascertain the particular presentation as early as possible, because he may sometimes be of service in correcting an unfavorable one, if he is certain of it in time, and knows what he is about. He should not, however, use any degree of force to ascertain it, in case he cannot do so without, but wait till the conditions are more favorable. Neither should he, with the same object, rupture the membranes too soon, for 
he may thereby cause considerable delay and difficulty, without any good to counterbalance it.

All the above-named presentations may, and usually do, terminate spontaneously, except those of the trunk, and even they do occasionally, though more frequently they require assistance.

Relative Frequency of the different Presentations. - The most favorable presentations and positions are also always the most frequent, while the unfavorable ones are but seldom met with. According to Madame Lachapelle, in fifteen thousand six hundred and fifty-two labors there are about fourteen thousand seven hundred and forty-nine presentations of the head and face; about five hundred and eighty-six of the breech, knees, and feet; and only about sixty-eight of the trunk or shoulders.

Positions.-The position is generally of but little consequence, because in all the favorable presentations spontaneous delivery occurs in every position alike, and in the unfavorable presentations the same assistance is required in one position as in another. In some cases an unfavorable position of the head may be changed, however, to a better one; and therefore, so far as the head is concerned, the positions are worth ascertaining.

The mode of determining the position is by feeling for the sutures and fontanelles, above described; and this cannot be usually done till after the membranes are broken, when the head can be distinctly touched. By referring to Fig. 161, the shape and position of the fontanelles will be seen, and if the head be supposed placed with the top downward, and the back of it to the mother's left side, they may be readily found with the finger.

In the left anterior occipito iliac position-or that where the back of the child's head is against the left side of the mother's pelvis, and nearest the pubes, while its forehead is against the right side, and nearest the sacrum-the sagittal suture, or opening along the top, will of course run across from right to left. This opening may be distinctly felt with the finger, which should be passed along it towards the right side, and it will then reach the anterior fontanelle; afterwards it should also be passed to the left side, and then it will reach the posterior fontanelle. The difference between these two openings, in shape and size, is shown in previous figures, and even if a person has never seen or felt the head of a new-born child, they can scarcely be taken for each other, after noticing these figures.

If the anterior fontanelle should be felt on the left side instead of the right, and near the pubes, while the posterior fontanelle is to the right, and near the sacrum, the position must be the right posterior occipito iliac, or just the reverse of the former.

If the sagittal suture should be found to run across from the pubes to the sacrum, instead of from one side to the other, it will then indicate either an occipito pubic, or occipito sacral position, according as the back of the head is behind or before; and this can be readily ascertained by finding either of the fontanelles.

In short, if the relative position, forms, and directions of these openings in the child's head be clearly understood, the position of the head can nearly always be determined by feeling them, as will be evident by referring to our former explanation of them.

Sometimes however, the bones overlap a good deal, from the head being pressed, and then, instead of an opening along the top, a seam will be felt. And sometimes from long-continued pressure, a quantity of blood, and watery fluid, will be effused 
under the scalp, so as to prevent the bone being distinctly touched. But these accidents seldom happen, and with ordinary care and perseverance, need not prevent the position being determined, after a little delay.

The position of other presenting parts is easily ascertained, by feeling for some known point-as the nose, or the face, the depression between the cheeks, or the breech, and so on.

Relative Frequency of the different Positions.-The most favorable positions, like the most favorable presentations, are also the most frequent. According to Baudelocque, in ten thousand three hundred and twenty-two cases of head presentation, there were eight thousand five hundred and twenty-two cases where the back of the child's head was on the mother's left side, and towards the front (or in the left anterior occipito iliac position); one thousand seven hundred and fifty-four where it was on the right side towards the front (right anterior occipito iliac) ; twenty-five times to the right side, but towards the sacrum (right posterior occipito iliac); and nineteen times on the left, but towards the sacrum (left posterior occipito iliac). Being most frequently with the back of the head towards the front on the left side, next towards the front on the right side, and but seldom towards the sacrum, or back, on either side. In all these ten thousand cases we do not find a single instance of the head lying from back to front, in the occipito pubic, or occipito sacral positions, commonly called transverse; neither do we find a single instance in fifteen thousand six hundred and fifty-two cases recorded by Madame Lachapelle, which will show how rare such unfortunate positions must be. What this great frequency of one particular position depends upon we do not know-possibly on that cause, previously alluded to, which determines the jnost frequent presentation.

In the next chapter, the mechanism of delivery, or the manner in which the child escapes out of the body, as it most frequently occurs, will be fully explained. 


\title{
CHAPTER LXVI.
}

\author{
THE MECHANISM OF DELIVERY, IN A PRESENTATION OF THE HEAD.
}

\section{The Left Anterior Occipito Iliac Position.}

THIs is the presentation and position most frequently observed, perhaps fifteen out of sixteen times. In most obstetrical works it is called the first position.

By observing the following figures, and referring to the previous explanations of

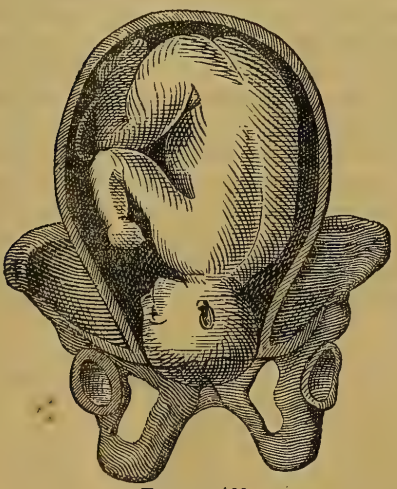

FIGURE 166.

It will be seen here that the neck is straightened out, and that the two fontanelles are on a line with each other.

Note. - The front of the bones is represented in this and the two following figures as if transparent, so that the head may be seen through them.

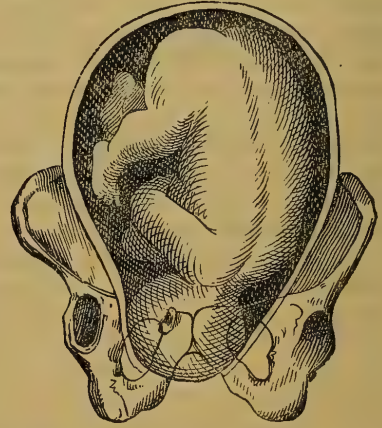

FIGURE 167.-This Figure represents the head descended still lower in the pelvis.

At this time the anterior fontanelle can scarcely be reached, but the posterior one is easily to be reached, being in the open passage, on the left side. The head is now fairly within the pelvic cavity, but still lies across from right to left.

Second Movement, Rotation of the Head.When the fœtus is thus brought to the bottom of the pelvis, its head turns completely round, the back of it being brought to the front, or under the pubes of the mother, and its forehead turned against her sacrum, as represented in the next Figure.

the diameters of the pelvis and footal head, it will be seen that through all its changes of position, while making its exit, the head always presents by one of its shortest diameters to one of the largest diameters of the pelvis, so that the relation between them is invariably the best that could be established; and many peculiar turnings and revolutions occur, apparently for the express purpose of bringing this about. 
Before the rupture of the membranes, the head presents its occipito frontal diameter, which measures four inches, to the right oblique diameter of the pelvis, which measures four inches and a half ; while its bi-parietal diameter, which measures only about three inches and a half, is presented to the other oblique diameter, also measuring four and a half. Even here it will be seen that the passage is larger than the head which has to pass through it, but a more favorable position still can be obtained by a slight movement of the fotus, which nature accordingly accomplishes, and also follows by others, to preserve the advantage, which will next be described.

Movements of the Fretal Head.-There are three of these peculiar movements, each of which takes place at a particular period of the labor, and must be described separately.

First Movement, Flexion, and Descent.--Immediately after the membranes are broken, the contractions of the uterus force the head into the upper strait, by the occipito frontal diameter of four inches, as already shown; but then commences the first movement, which consists in a bending of the child's chin down upon its breast, so that the forehead is carried up into the womb; and the most prominent point of the back of the head presents to the middle of the passage, by the occipito bregmatic diameter, which is only about three inches instead of four. This, of course, makes the passage so much easier, and generally, immediately after this change, the head descends into the basin of the pelvis.

It is not absolutely necessary, however, for this movement to occur, for in a well-formed pelvis, the head can descend without it, though not so easily; and sometimes, in fact, it does not take place, but this is unusual.

It must be recollected that this shifting of the head alters the position of the fontanelles - the posterior one being brought more to the center of the strait, and the anterior one carried up out of reach, while previous to the movement they were both on a level. If an examination is not made, therefore, till after this change, it may be difficult to determine the position, unless this is borne in mind. The accompanying figures show this very

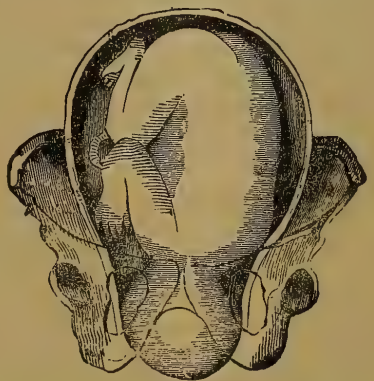

FIGURE 168.-This Figure represents the head still further doron, and beginning to rotate.

Here the head is seen just beginning to turn - the right side, and part of the back of it, just passing under the pubes. As the rotation becomes complete, the neck straightens, so that the two fontanelles are again found on the same level. Finally, the back of the head fully emerges from under the pubic arch, and the chin slides gradually out after it beneath, so that the neck of the child is encircled by the ring of the valva. well.

In Figure 169 it will be seen how the os coccygis, or lowest part of the backbone $(c)$, is straightened out backward, while the head is passing, as explained before; and in Figure 170 it has returned again to its natural position.

The reason for this rotation of the head will be obvious on calling to mind the form of the pelvis and the external opening. On examining the figures, it will be seen that the longest diameter of the vulva, or external opening, the anterior 
posterior, is nearly at right angles to the longest diameters of the upper strait, the oblique. Now, the longest diameter of the head is adapted to this oblique diameter on entering the upper strait, as already explained, and it is necessary for it also to be adapted to the longest diameter of the external opening, the anterior posterior, when making its exit; but as the two are not parallel, the head is compelled to turn, or rotate, in order to pass from one to the other. To accomplish this, however, the neck

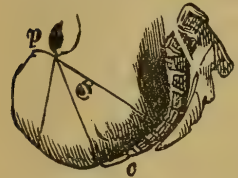

Figure 169.

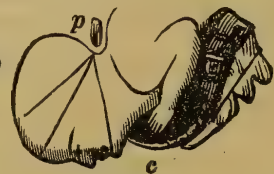

FIGURE 170.

In Figure 169, the back of the head is nearly under the pubic bone, while the forehead is just passing the external opening below.

In Figure 170, the back of the head is completely extruded, and also the chin, so that the whole head is now born. ( $p$. is the pubic bone, in front.) has to be twisted considerably. But when the head is fully delivered, it is immediately straightened again, by the back of the head turning toward the mother's left side, so that its proper relation with the trunk is re-established.

Third Movement, Rotation of the Shoulders.-When the head is delivered, the shoulders come next, which also require to turn round a little, to adjust themselves to the long diameter of the lower strait, and as they turn within the pelvis the head also turns, to correspond, and thus the back of it is brought opposite the middle of the mother's left thigh. Immediately this movement is effected, the shoulders rapidly escape through the external opening, the right one being in front, a little to the left of the symphysis pubis, and the left one behind, a little to the right of the os coccygis. The body then curves upwards, to accommodate itself to the curved axis of the pelvis, and speedily follows the shoulders.

These curious movements cause the child to progress in a spiral direction, so that each part may pass through the pelvis in the most favorable position. Sometimes all these movements are not effected, and yet the delivery may occur, though not so speedily or safely as when they are. The shoulders do not always fully potate, but may nevertheless pass the opening, if the parts be large, and well relaxed. It is questionable, however, if the head can ever pass the lower strait without rotating, when it enters the pelvis diagonally, the occiput on one side and the forehead on the other; as it is necessary for either one or the other of these parts to pass under the pubes.

\section{MECHANISM OF DELIVERY IN ALL OTHER POSITIONS OF THE HEAD.}

The Right Posterior Occipital Position. - This position, called the second by some authors, and the fourth by others, is exactly the reverse of the one just described, the head lying in the same direction, but the back of it being behind, to the right of the sacrum, and the forehead to the left of the pubes.

Precisely the same movements are gone through in this position as in the other, excepting that the head has to rotate considerably further. In the former position, ine back of the head is only a little to the left of the pubes, and therefore has not far to turn to pass under it ; but in this position the back of the head is behind, and therefore has to turn very far round to reach the same position. The rotation is therefore more difficult, not so soon effected, and sometimes likely to be dangerous to the child. 
In the other movements there is no difference worthy of notice, but it must be borne in mind that they all occur the reverse way to what they do in the first position, because the occiput is on the right side, instead of the left.

The Right Anterior Occipital Position.This position is precisely the same as the first, but on the other side. The back of the head is in front, but to the right of the pubes, instead of the left, while the forehead is behind, to the left of the sacrum. This will be apparent enough by observing Fig. 171 .

The mechanism of delivery is precisely the same, and all the movements occur in the same order and manner as in the first position, but the reverse way, the rotation, for instance, being from right to left, instead of from left to right, and so of all the others.

The Left Posterior Occipital Position.Delivery is effected the same in this as in the left anterior, or first position, excepting that the rotation is more extended, owing to the occiput being behind, as explained in the right posterior occipital position.

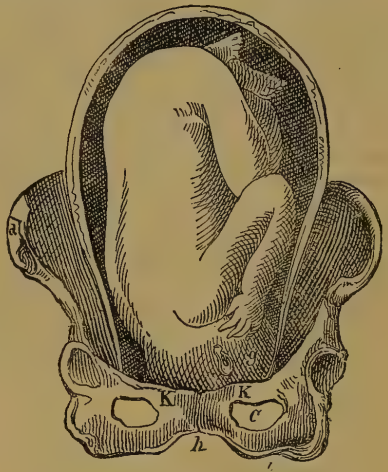

FrguRe 171.-Head in the Right Anterior Occipito Iliac Position.

This is the second most frequent position, the left anterior occipito iliac being the most frequent. c, the foramen ovale ; $d$, the top of the ilium bone, called the crista; $h$, the symphysis pubis ; $\mathbf{K} \mathbf{K}$, the pubic bones.

\section{GENERAL REMARKS ON THE DIFEERENT POSITIONS OF THE HEAD.}

In all the other positions, and their varieties, there is nothing that calls for special notice, or that is material in practice, the delivery being nearly the same in them all. No matter what position the head is placed in, the back of it nearly always comes to the front under the pubes, even though it have to turn half round to do so. The cause of this is supposed to be the peculiar form of the parts, which gives it a screw-like motion in its descent, and the shape of the external opening, which, being longest from before to behind, can only allow the long diameter of the head to pass through in the same direction.

Sometimes, it is true, the occiput passes behind, instead of coming to the front, and then the chin comes under the pubes, while the occiput presses on the coccygis. This is very seldom observed, and when it occurs the labor is more difficult and tedious, though it may still terminate spontaneously.

The resistance of the soft parts, externally, appears to be the chief cause of the head turning; for when they are much relaxed, and the child's head small, it will sometimes pass without, or in the anterior posterior position. And sometimes, when the head is large, so that it distends the parts very much, the shoulders will pass crosswise, there being room enough for them without turning. In some females, formed large, whose organs are excessively relaxed, and whose children are small, the delivery takes place without any of the movements being effected, the child passing straight through in whatever position it may bappen to be ; this is rarely seen, however. 
When there are twins, they do not usually both present by the head, but one by the feet; and frequently the parts are so relaxed by the passage of the first that the second is delivered without rotating at all, though in general it follows precisely the same movements. It sometimes happens, however, that the second birth does not take place till some hours, or even days, after the first.

It may be said, in general, that all positions of the head are favorable to both mother and child, and may terminate spontaneously. It is seldom that anything more than ordinary assistance is required in any of them, and they could in general terminate without any at all, though sometimes with difficulty. The worst cases are those in which the head does not turn round, but remains across, or where the back of it turns behind, instead of coming to the front. In these cases, there is great danger of the perineum or external lips being much lacerated, or even of an artificial passage being torn through the perineum, leading to the most serious after results. About one child also out of every fifty is lost in these unfavorable positions. 


\section{CHAPTER LXVII.}

MECHANISM OF DELIVERY IN PRESENTATIONS OF THE LOWER EXTREMITIES.

THIs presentation includes the feet, the knees, the breech, and also the hips, there being no difference in the delivery for all these parts. It is the same also whether there be one foot, or knee, or both feet and knees.

There are but two positions worthy of notice in this presentation, and they are determined by the child's sacrum. If the sacrum, or posteriors, are to the right of the mother's pelvis, it is called the right sacro iliac position; but if they are on the left side it is called the left sacro iliac position. The direction in which the child's pelvis is placed, is analogous to that of the head, the sacrum answering to the occiput. Thus most frequently the sacrum is on the left side, a little to the left of the pubes (left anterior), while the abdomen faces the right side near the sacrum. When on the right side, however, it is most usually nearest the sacrum, with the abdomen facing the left side near the pubes.

The lower extremities present most frequently next after the head, but still they are but seldom met with. M. P. Dubois tells us that out of twenty thousand labors he only met with eighty-five such cases. In these eighty-five cases the breech presented fifty-four times, and the feet twenty-six, the knees being found but once.

A presentation of the lower extremities may generally be recognized at an early stage, by the head being felt at the fundus of the uterus, and by the pulsations of the foetal heart being heard above the umbilicus, as explained in the chapter on Auscultation. After labor has commenced, the part felt at the mouth of the womb is irregular, and so different from the head, that it is not likely to be mistaken for it. If the knees or feet present, they can always be distinguished ; and if the breech presents, it can easily be recognized by its form, and particularly by the os coccygis, which can be distinctly felt at the bottom of the depression between the two cheeks. The side on which it is felt of course determines the position, and the same with the front of the knees, or the heels. The rectum can also be reached with the finger, when the breech is touched; but great care must be taken not to intrude it too far, because with a female child the vulva might be mistaken for it, and thus the hymen be broken, and other injury committed. The genitals of a male child are more obvious. so that the sex of the child may be usually ascertained, along with the position.

For want of proper care, the breech has been mistaken for the head and face, but this can scarcely happen if the accoucheur is attentive. It is simply necessary to call to mind what must be felt in each presentation, as the nose and mouth with the face; the two cheeks of the posteriors, with the opening between them, and also the genitals, with the breech ; and it can be certainly ascertained which of these parts is really at the opening. With the knees or feet there can searcely be a doubt. 
DELIVERY IN A BREECH PRESENTATION IN THE LEFT ANTERIOR SACRO-ILIAC POSITION.

In this position the legs and thighs are turned up against the abdomen, the breech in full occupying the passage, with the sacrum to the left and in front of the mother's pelvis.

The descent of the breech usually takes place without much difficulty, into the

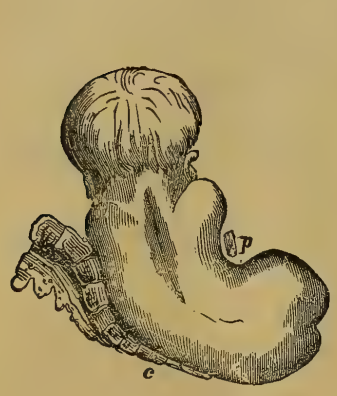

FIGURE 172.

Delivery in a breech presentation, the buttocks having just passed the vulva. ened.

c. The coccygis, much straight-

$p$. The pubic bone in front.

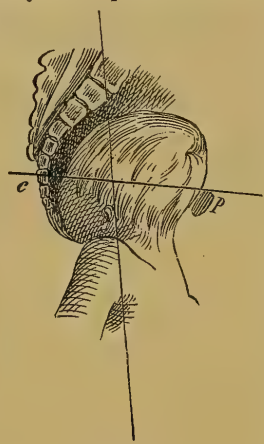

FIGURE 173

Anterior posterior position mains stationary there of the head, the occiput being in front, after the delivery of the body.

$c$. The coccygis.

$p$. The pubic bone, in front.

pelvis, it being small and easily compressed. It descends in the same direction in which it first presents-that is diagonally, like the head-and also rotates, or turns round, so that the left buttock comes in front, just to the right of the pubes, while the right one goes behind, to the left of the sacrum. The left buttock reaches the mouth of the vulva first, in this position, and then rewhile the right one slides along the curve of the sacrum and perineum, and passes out first at the lower part of the external opening. The left, however, speedily follows, and when the whole breech is born it rotates again, one hip coming immediately in front, and the other going immediately behind. Owing to this movement the long diameter of the breech is adapted to the long diameter of the pelvis, as in the case of the head. This will be evident from Fig. 172 .

The rest of the body then rotates in the same way, and the arms and shoulders pass through the external opening in the same direction as the hips. The left shoulder first moves to the right of the pubes, while the right passes behind ; and then, just when they are both passing out, one comes immediately in front, and the other immediately behind, placing themselves in the long diameter of the vulva.

The head passes through the superior strait in the left anterior occipital position, and is often delivered in that way ; but sometimes it rotates, and the forehead passes into the curve of the sacrum, while the occiput is placed behind the pubes. When this occurs the body also rotates, to accompany the head. This state of the parts is represented in Fig. $1 \% 3$.

At this period the head is past the uterus, and there is therefore little or no contraction to expel it, so that it often remains a long time undelivered. It will be seen that the position is very unfavorable, the longest diameter of the head, the occipito frontal, being the presenting one, which makes it lie immovably across. 
The means of assisting in such a case are plain enough ; the forehead must be brought down while the body is raised towards the mother's abdomen; this will throw the top of the head back, towards the sacrum, and change the presenting diameter. The forehead and bregma rapidly escape below, and the occiput passes out last. This is the way in which nature herself also completes the delivery in such cases when she has the power.

\section{DELIVERY BY THE BREECH IN THE RIGHT POSTERIOR SACRO ILIAC POSITION.}

This position is the reverse of the preceding one, the sacrum being behind and to the right, while the abdomen is to the left in front. The same movements are performed as in the first position, and the whole process is similar, only the reverse way. The sacrum being behind, however, has to rotate much further to come in front, precisely the same as with the head when in the posterior position.

'The head generally follows the sacrum, and the occiput comes under the pubes, as already explained; but sometimes only at the moment when being disengaged.

DELIVERY BY THE BREECH IN THE FULL POSTERIOR, OR SACRO SACRAL POSITIOY.

In this position there is no rotation at all, the back of the child being turned full to the back of the mother, and the whole body and head being expelled in that position. In general there is no particular difficulty from this position, but on the contrary it is thought by some to be rather favorable than otherwise. The longest diameters of the foetal pelvis, and shoulders, are adapted to the longest diameter of the mother's pelvis, at the upper strait, and easily pass it. They will also generally pass the external opening in the same direction unless it be very unyielding, or the child very large ; and if they pass, the head usually follows, because the parts have been so much dilated by the passage of the body that they offer but little resistance.

\section{GENERAL REMARKS ON THE PRESENTATION OF THE LOWER EXTREMITIES.}

As a general rule, delivery by the breech, or by any other position of the lower extremities, is less favorable than by the head. The labor is usually longer, more painful, and more exhausting ; still however, it is generally spontaneous, and not necessarily dangerous to the mother. To the child, on the contrary, it is dangerous, on many accounts.

It appears, from the observations of M. P. Dubois, that in this presentation one child is lost out of every twelve, while only one out of fifty is lost in head presentations! The chief cause for this greater mortality appears to be the compression of the umbitical cord, which is greater, and lasts much longer, than when the head presents, as will be evident on examining the circumstances under which delivery is effected in each case. When the head presents, it passes, and also the shoulders, before the umbilicus is reached; the mother's organs are therefore much dilated, and only the smallest parts of the foetus are left, when the cord is engaged in the passage; it cannot therefore be much compressed, nor for any long time, because the labor is then soon over. When the lower extremities present, this is not the case, the smallest parts then pass before the umbilicus is reached, so that the cord has to pass along with the head and shoulders, which are both the largest and the longest in 
being delivered. This compression of the cord stops the circulation of blood between the fœtus and the placenta, as will be evident on referring to the description formerly given of fotal nutrition; and the stopping of this circulation is as fatal to it as stopping the breath is to an adult. When the breech presents altogether, there is not so much danger as with the feet, or knees, because it is large, and in its passage dilates the parts so much that the rest of the body, and the head, follow more quickly. There is, of course, no danger till after the hips have passed, because the cord is not reached before; but the delivery should be completed as soon after they are born as possible, for every minute's delay makes the chances for the child life so much less. 




\section{OHAPTER LXVIII.}

\section{MECHANISM OF DELIVERY IN PRESENTATIONS OF THE FAOR.}

Presentations of the face appear to result from the head being bent backwards, instead of forwards upon the chest. They are easily recognized, because the face has so many peculiar parts, as the nose and mouth, for instance, which are altogether unlike what can be felt in any other presentation. In a very early stage, the forehead may be taken for the vertex, unless care be used, because it feels round and soft like it, but the mistake cannot last long.

The positions in this presentation, as formerly explained, are determined by the chin, and in practice only two are noticed-the right posterior mento iliac, and the left anterior mento iliac. In the first the chin is on the right side, near the sacrum, and in the second it is on the left side, near the pubes. These answer, it will be seen, to the two principal positions of the head itself. It is generally considered that, though the chin, like the head, may assume other positions, yet it does so in but very few cases, and these presenting no peculiarities which require special notice.

\section{DELIVERY IN THE RIGHT POSTERIOR MENTO ILIAC POSITION OF THE FACE.}

The head descends with the forehead and chin nearly on a level, and the nose occupying the middle of the passage. When fairly in the cavity, it rotates, the chin being brought under the pubes, while the back of the head passes into the curve of the sacrum. This is nearly always the process ; no matter where the chin may be when the labor commences, it seldom fails to move under the pubes before it concludes. Occasionally, it may rotate the other way and pass into the hollow of tha sacrum, while the occiput comes in front, but this is very rare.

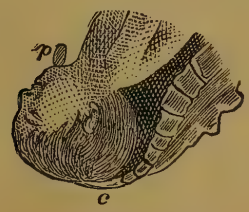

FTGURE 174.

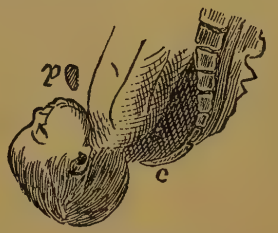

FIGURE 175.

Fig. $174-$ The chin just passed, in presentation of the face.

Fig. 175. -The head full born, in face presentation. $p$. The pubic bone; $c$. The coccygis.

The chin is born first, and then follows, below, the forehead, top of the head, and finally the occiput-the face turning upwards towards the mother's abdomen, as each part is successively delivered. When the head is fully born the body rotates 
inside the same as in the head presentation, and the delivery concludes in precisely the same way.

\section{DELIVERY IN OTHER POSITIONS OF THE FACE.}

The delivery is precisely the same in all the other positions of the face, excepting that in some of them the chin has further to rotate before it can pass under the pubes. In all cases, howerer, it may be safely calculated that it will do so, there having been so few instances known in which it has rotated the other way, into the hollow of the sacrum, which is fortunate, for there is always more or less difficulty and danger when it does so.

Sometimes the rotation does not take place at all, but the face descends diagonally, as the head occasionally does.

On the whole, presentations of the face are not particularly to be feared, as regards the mother. Some authors even consider them quite favorable, and reckon them only as varieties of the head presentation. Madame Lachapelle states, as a principle, that face presentations should always be left to nature. And M. Chailly says he must admit that, in all positions of the face, the labor may terminate spontaneously, excepting when the chin passes behind, in which case it will be protracted, and most likely fatal to the child. The labor is generally a little longer, and more painful, owing to the face not being so perfectly adapted to the passage as the head is; but still it must be regarded as favorable to the mother, though assistance is oftener required than with the head. There is more or less danger to the child, however, owing to the head being kept under pressure for an unusual time, which produces congestion. The neck is also forced against the pubic bone, as will be seen by Figs. 174 and 175 , and thus the jugular veins are compressed. If there be any delay, it is customary to observe the face closely, after the chin is born, and if it appears from any indications that congestion is taking place, assistance is rendered at once. The face will sometimes become so tumefied and engorged with blood, from this prolonged pressure, that it will not appear natural till several days after birth.

Probably about one child is lost in ten or twelve deliveries in these cases; and if the chin pass behind, its death is almost certain.

It was formerly the practice to endeavor to turn the face upwards, when at the superior strait, and so change the presentation to one of the head. This, however, is now abandoned, because the attempt is seldom successful, and does not materially improve the condition of things, besides being painful to the mother. The only extra danger with the face presenting is to the child, and this is not removed by the operation; to the mother, the face is nearly as favorable as the cranium. In regard to the frequency of face presentations, we find that Madame Lachapelle met with but seventy-two cases in fifteen thousand six hundred and fifty-two deliveriss. 


\section{CHAPTER LXIX.}

\section{MEOHANISM OF DELIVERY IN PRESENTATIONS OF THE TRUYK.}

IT has already been stated that in presentations of the trunk, it is nearly always the right or left shoulder which occupies the passage. It is stated, by some authors, that they have felt the back and abdomen, but others think they were mistaken ; and most certainly such positions are extremely rare, if they actually do ever exist.

There are two presentations of the trunk, determined by the side on which the fœtus lies, and denominated accordingly, right or left lateral presentations.

Each of these presentations has two corresponding positions, determined by the side on which the child's head lies. If the head be on the mother's right side it is called the right cephato iliac position, and if it be on the left side it is denominated the left cephalo iliac position. The mechanism of spontaneous delivery is the same in them both, and in all their varieties, and so is the mode of rendering assistance, so that a description of one will suffice.

Sometimes, when the labor has lasted long without assistance, one arm will be forced down first, and even appear externally. This used to be considered a separate presentation, and described as such, under the name of presentation of the hand and arm. There is no reason for describing it separately, however, and no utility in doing so, as it differs in no essential particular from ordinary presentation of the shoulders, and must receive the same assistance.

What it is that produces presentations of the trunk, and other unfavorable parts, is not known, though they are generally thought to be owing to excessive motion in the child, or obliquities of the womb.

Mme. Lachapelle met with sixty-eight cases of trunk presentation in fifteen thousand six hundred and fifty-two labors, which is nearly the same as the face. The right side presents more frequently than the left, and the head is on the left side oftener than on the right, as it is in ordinary head presentations.

As a general rule, assistance is always rendered in presentations of the trunk, and is generally considered absolutely necessary. It is undoubtedly true, however, that nature has effected delivery in such cases unaided, though rarely, and such instances are considered as extremely fortunate exceptions to the general rule. M. Chailly says that the accoucheur should never leave such cases to nature alone, but always aid her ; but other authors trust to her a little more. The most usual mode of rendering assistance is to turn the child, and bring down the feet, a manouvre which will be fully described bereafter.

In some cases the child turns itself, from the contraction of the womb, before it enters the upper strait; and in other cases, when very small, or long dead, it will pass folded double. This self-turning, however, cannot take place after the escape of the waters, so that it seldom occurs when the membranes are broken. 
MECHANISM OP DEITERY IN PRESENTATIONS OF THE TRUNK BY SPONTANEOUS EVOLUTION.

This is the most usual mode for the foetus to escape, in each presentation, and in

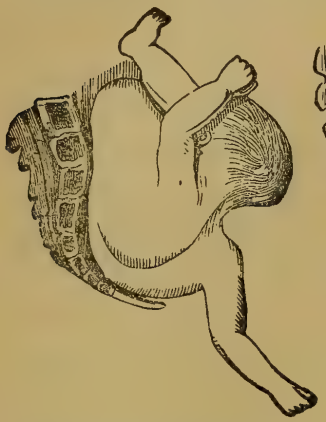

FIGURE 176.-Position of the foetus in a presentation of the right shoulder, and in the left cephalo iliac position.

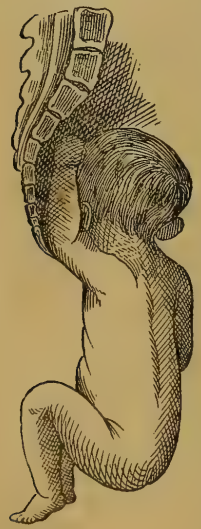

FIGURE 179. $-T h$ t trunk has fully de. scended, and only the herd is left, woith one arm.

every position. By referring to the above Figures, and the accompanying descriptions, it will be readily understood.

Previous to the rupture of the membranes, the child's body lies across, as formerly explained; but immediately after the rupture the shoulders descend into the pelvis, as seen in Figure 176, while the head remains above the pubes; the arm frequently, but not always, protruding externally.

The shoulder then continues to descend, the body following, bent up against the face, as seen in Figure $17 \%$.

Here the shoulder is protruded from the vulva, the back being nearly folded, and the knees turned up against the face.

The whole trunk is now fully delivered, folded almost double, and the legs and feet are turned up against the face. They speedily follow, however, and then nothing is left but the head, and perhaps one or both arms, placed against the sides of it, as shown in Figure 179.

The arm is generally very easily brought down, or it may remain and come with the head. The delivery of the head is effected the same as in presentations of the pelvis, and is seldom attended with much difficulty, the parts having been so much distended. The body always rotates, so that the back comes in front, and the chin passes into the curve of the sacrum.

This is the way in which the delivery is effected by nature in such cases, and it will readily be conceived how dangerous it is to both mothes 
and child, and how seldom it can be accomplished. If the foetus be of full size, and the mother's pelvis no larger than ordinary, it is almost impossible for this spontaneous evolution to take place; and even when it does, it is with the greatest difficulty, the mother suffering in an extreme degree, and running great risk, not only of the most serious after-results but even of death. To the child the danger is equally great, owing to the severe and long-continued compression it receives, and the unnatural position it assumes. M. Velpeau tells us that in one hundred and thirty-seven such cases, one hundred and twenty-five of the children died. The number of the mothers also, who either died or were made sufferers all their future lives, was undoubtedly great, though unknown.

It is evident, therefore, that presentations of the trunk are the most unfavorable known, and labor in them is but rarely spontaneous. Nature can but very seldom effect the delivery of the foetus herself, and even when she does it is with the greatest risk, both to it and the mother. The accoucheur should always assist, therefore, if he can, because even if nature can complete the delivery, it is with much danger. The means of assisting, by turning, will be described in another chapter.

If the footus is not at full term, and of course is under the full size, its expulsion may be left to nature safely, but not otherwise. 


\section{CHAPTER LXX.}

THE PHYSIOLOGY OF SPONTANEOUS DELIVERY, OR CHILDBIRTH, AND THE MANNER OF COMDUCTING A NATURAL LABOR.

HAVING now completed the description of the Mechanism of Delivery in all the various presentations and positions, it is necessary to explain the physiological phenomena attending a natural labor, and the duties of the accoucheur when conducting it, and to show what assistance he can render, and when he should or should not interfere.

OF DELIVERY IN GENERAL.

Different Kinds of Delivery.

When the child is brought into the world by the unaided efforts of nature, and without any accident to itself or the mother, it is called a naturat delivery. When it occurs by the efforts of nature alone, but not advantageously for both, it is not called natural, but simply spontaneous delivery. And when assistance is required it is called an artificial, or difficult delivery. It is also called precocious, or tardy, according as it comes before or after the full term.

\section{CAUSES OF LABOR.}

What it is that causes labor to commence, and proceed, is not fully known. At the proper time the uterus prepares to cast out the foetus it has so long retained, in the same manner that the tree casts off its fruit, and from some efficient cause which we have not yet discovered.

It is probable that when the fotus attains a certain size, it presses upon the nerves of the neck of the uterus and irritates them, and they react again upon the muscular fibres of the womb and cause them to contract, and so expel its contents. This is much the same action, in fact, as vomiting. When any body very repugnant to the stomach is swallowed, it irritates the nerves of that organ, and then they excite its muscular fibres, which by forcible contractions, expel the offender.

It is possible, also, that the foetus itself may instinctively assist in bringing about its own delivery, as was supposed of old by Hippocrates, and more lately by Harvey and others. It is certain that labor is both more difficult and more dangerous when the child is dead, though it may take place as usual after the death of the mother, providing the child be still alive. Several instances of this kind have been known, where the living child was expelled from the womb by the natural process, some time after the mother had ceased to breathe.

The contraction of the muscular fibres of the womb, however, must be regarded as the immediate or efficient cause of foetal expulsion, let them be brought on how they 
may. The muscles of the abdomen and the diaphragm also assist in the last stage, but are not essential.

The young of some of the lower animals are observed to perform certain peculiar motions, during delivery, by which it is much facilitated ; and this is considered a proof, by some, that voluntary movements of the foetus assist in the process. Certainly if it be supposed, as we have shown there is good grounds for doing, that the child assists in placing itself in the best position, it is equally probable that it also assists in its own expulsion, in other ways.

\section{SIGNS OF DELIVERY.}

Premonitory Signs.-A few days before delivery the uterus descends much lower, so that the diaphragm and stomach are less pressed upon, and the breathing and digestion become easier in consequence. The ease which is thus experienced is sometimes so great that the female becomes unusually animated and cheerful, and cannot think she is so near her travail. This is not always the case, however, for some, on the contrary, feel very uncomfortable and melancholy. The lips of the vulva are also apt to swell and become painful, and the lower limbs numbed and cramped, owing to the child's head pressing on the large nerves. The neck of the bladder is also very liable to be compressed, so that a constant desire is felt to urinate, and a similar trouble may also be experienced in the rectum. Most of these inconveniences, but particularly the numbness and cramps in the limbs, are not likely to be experienced except when the head presents, because no other part is so formed as to be able to descend sufficiently low ; when they are felt therefore, the female may console herself by the reflection that they indicate, with tolerable certainty, that the child is presenting in the best position it ean for a safe and speedy delivery.

Standing and walking usually become more difficult, and swelling of the external parts, or piles, are apt to occur. With some females also a sudden diarrhœa or vomiting takes place, and troubles them up to the period when labor commences.

Finally the uterus begins to contract, though insensibly at first; the abdomen becomes unusually hard, and flying pains are experienced, particularly with first children. This continues with more or less of intermission, up to the actual period of labor, which is usually divided into three periods, each of which must be considered separately. 


\section{CHAPTER LXXI.}

IHE PROGRESS, PHENOMENA, AND DURATION OF NATURAL LABOR.

\section{First Period.}

ON making an examination, the mouth of the womb will be found to be dilating, and a discharge of mucus, tinged with blood, issuing from it. The membranes may also be felt protruding into the vagina, and distended, like a bladder. The female

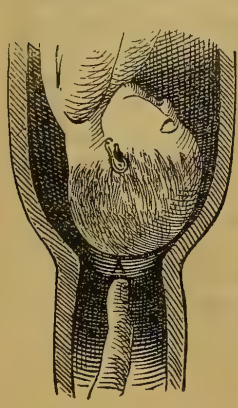

FigURe 180.

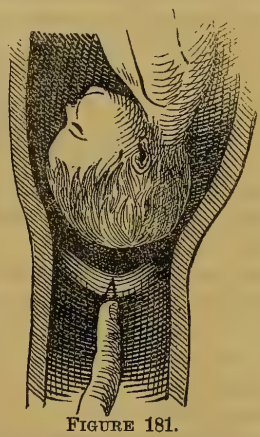
complains of being drawn powerfully together in the inside; she trembles, and gasps for breath; her pulse sinks, and she often becomes sick and deadly faint; she complains of great thirst, and breaks out into profuse perspiration ; frequently she will weep and apparently suffer from some terrible apprehension, while her strength will be completely ex. hausted. Occasionally, however, shi? will be perfectly passive, and almosi immovable, appearing as if in a dream.

The pains, however, gradually become more and more acute, and Fig. 180 shows the state of the parts at the beginning closer together ; the patient is exof labor. The mouth of the womb is considerably di- cited and irritable; her pulse be-
lated, and the membranes, A, are protruding slightly.

Fig. 181 shows the state of the parts at the end of comes quicker again, the thirst inthe first period. The neck of the womb is now so fully creases, and vomiting frequently endilated that it forms a continuous passage with the vagina, while the bag of waters, A, projects far down and occupies the whole width of the canal.

sues. Before each pain she frequently experiences a severe chill, with chattering of the teeth, and not unfrequently becomes perfectly delirious.

With each pain the mouth of the womb expands more and more, till at last it totally disappears, and the cavity of the uterus and the vagina form but one uniform passage, which is completely occupjed with the distended membranes, or bag of waters, which may be felt like a soft round tumor. This is well represented in the above figure.

The first period may be much protracted, and is generally very exhausting, though not attended with any danger or special difficulty.

\section{Second Period.}

At this stage all the previous symptoms become much exaggerated. The oontractions are more powerful, and the pains more acute, but with a perfect period oi 
repose between them, during which the female will feel quite easy, and even some. times fall asleep, but only to be aroused by the pains coming on again. The muscles of the abdomen and the diaphragm are now called into play; the patient strains, or violently bears down, and pants with exertion, while the perspiration streams from every pore, the pulse quickens, and the expression of the countenance betrays the wildest anxiety and excitement.

The bag of waters now descends, and enlarges more and more, until at last being unable any longer to bear the strain to which it is subject, it bursts, and the waters flow away in a profuse gush. Immediately this takes place the head descends, and closes up the passage; the pains cease for a time, and the patient again has a respite, while the uterus apparently gains fresh power. Very soon the contractions recom. mence, more energetically even than before, the head passes the poouth of the womb and enters the vagina, which keeps enlarging as it descends, till it reaches the lower part, or floor of the pelvis. The pains now become more violent than ever, the patient screams with agony, clutches hold of any object near her, throws herself back, draws in her breath, and bears down with all the force she can command.

The fearful cries which most females emit at this time appear to assist the delivery, by the convulsive efforts at breathing which they necessitate, and the expulsive straining also does the same. These natural efforts are much assisted by providing a firm support for the patient's feet, against which she can push, which she will do with tremendous force.

The head now presses, at each pain, against the perineum, which begins to project outward, as also does the rectum. The vulva begins to dilate, the lips separate wider and wider, and part of the child's head becomes visible. Gradually the lips become thinner and thinner, and at last disappear nearly altogether, so that the mouth of the vulva is only composed of thin ring, which seems ready to give way every moment. The head, however, recedes, and the parts again assume something like their natural condition for a short time, when the same process again takes place, and the distention proceeds still further, while the head does not retire so far. This alternate action is repeated perhaps many times, so that the external mouth is opened gradually, and without the lips or perineum being torn, which they would be if the head were to pass suddenly, before they were softened and dilated.

After this has been continued for a sufficient period, a strong expulsive pain is felt, the female screams, the head passes clean through the external opening, and the lips close round the neck. This, however, is only for an instant, the rest of the body speedily following the head, in the manner hereafter to be explained. Most usually, in fact, the whole body follows the head without any stoppage at all, but sometimes there is a delay of a few seconds.

The third period of delivery comprises the delivery of the placenta, which will occupy our attention in another place.

Difforences in the Process of Labor.-Although, in most cases, labor proceeds much in the way I have just explained, and is attended with similar phenomena, yet still we occasionally see marked exceptions. This is particularly the case with regard to pain. Most females suffer severely at this time, and some even the most torturing agony, while others again experience scarcely anything to complain of, and some even feel nothing at all. I am acquainted with a lady at the present time, the mother of several children, who assures me she never felt any pain at all in her labors, nor was she in any way exhausted by them. I have known her rise from her bed in the 
night, from feeling indications of the approaching event, make all her arrangements, and send for the nurse, as if it was the most ordinary affair imaginable. On one of these occasions, before her husband returned with the assistants, she was delivered while alone, without any difficulty, and they found her sitting up in bed nursing her child. She had cut it loose, and tied up the cord herself, having heard how to do so at one of my lectures, and actually brought away the placenta with her own hand. In two days after she was about as usual. And yet this lady was by no means strong, nor remarkably healthy ; and what is very singular, she suffered severe pains at most of her monthly periods ; much more, as she assured me, than from all her labors pú together. M. Chailly also mentions an instance of a young girl of sixteen, with he: first pregnancy, whose vagina was also partly closed by an internal membrane, whose delivery nevertheless was almost painless. She woke up, he tells us, about four o'clock in the morning, with some very slight pains, which scarcely disturbed her, but which continued till about six, when the child was born suddenly and safely, without any assistance, and with scarcely any increase of pain to the mother. I have known many other such cases as these, and plenty of them can be found recorded; but what this fortunate exemption from suffering, in such cases, depends upon, is not known.

The nature, and the seat of the pains, are also very variable. Some only, feel a dull sort of aching, with powerful contraction, or drawing together, while others call it grinding, cutting, and burning pain. Some feel it in the back, and some at front, while others feel it most in the groins, and others again experience it in all these parts at once. The peculiar sharp pain which results from the extreme dilatation of the external mouth, when the head passes, is perhaps the most constantly felt, and the most alike in all.

The manner in which the mouth of the womb opens, and the time required for its dilatation, differ much in different cases. In females who have previously borne children, as before explained, the mouth is always considerably opened at the full term, while in a first pregnancy it is nearly closed, even till some time after the labor actually commences. Sometimes the dilatation takes place rapidly, and at others very slowly; it is especially liable to be delayed if the membranes break too soon, because then the pressure of the bag of waters is lost, and that is an important agent in expanding the os uteri. In some cases the neck of the womb is very hard and rigid, so that a long time is required to make it give way. When any other part than the head presents also, the opening of the mouth will not take place so soon, because no other part so completely fills up the passage.

The breaking of the bag of waters will sometimes occur very early, almost as soon as it protrudes, while at other times it will be delayed till the whole ragina is filled up by it, or even till it appears externally. The quantity of the water discharged at the time of the rupture is also variable; if the presenting part of the fotus does not completely block up the passage, the whole may pass away when the rupture takes place; but if it does, as is usually the case when the head presents, only a part flows then, and the rest comes in gushes, as the head is raised, and when the child is born. The too early escape of the waters, as already explained, may retard the delivery, by delaying the expansion of the mouth of the womb; and in this way unskillful accoucheurs have caused lingering labors, by breaking the membranes too soon.

It is important to recollect also, as I explained before, that a portion of fluid sometimes exists between the amnion and chorion, which may pass first, and induce 
the belief that the true waters have escaped, when they have not. This is called the false waters, or shows, and is not connected with the true waters at all.

The general physiological phenomena of a natural delivery having thus been explained, we have now to state its duration, and then proceed to its conduct or management.

\section{DURATION OF NATURAL LABOR.}

The duration of natural labor is not by any means constantly the same, nor can it be predicted with anything like certainty in any case ; but still by keeping careful records, and by duly observing a vast number of cases, a tolerable approximation can be made. There are various circumstances that tend to lengthen the duration of labor, some general, and others belonging to the individual. The mode of life and early habits of the female, the climate in which she lives, and the manner in which she has conducted herself during gestation, all have an important influence. As a general rule, the period becomes longer in proportion to the civilization of the community in which she lives. The first labor is generally more tedious than the succeeding ones, owing to the slower dilatation of the parts. It is also thought by some, that the labor is longer in proportion to the age of the female, particulary with the first child ; but this opinion is not well founded.

The average duration of labor in our country, is from eight to twelve hours. In some parts it is longer than this, and in others again it is much shorter. I have good reason also to think, that it is longer in cities than in the country.

An experienced practioner can sometimes predict with tolerable certainty, when called to a labor, how long it will be before it is over; but this is seldom the case, and most frequently his success is owing more to chance than to judgment. If the mouth of the womb be well dilated, the contractions powerful, and the patient vigorous, with the presentation natural, he is of course justified in predicting a speedy delivery ; or the reverse, if these favorable conditions do not exist. Many unforeseen conditions may exist, however, and many accidents arise, that may falsify an apparently safe conclusion. No judicious practitioner, except in a few rare cases, will hazard his reputation by fixing any time, and no well informed patient would ask him to do so, because she would know that it was out of his power. 


\title{
CHAPTER LXXII.
}

\author{
THE CONDUCT OR MANAGEMENT OF A NATURAL LABOR.
}

\section{Preliminary Requisites.}

Ir most cases of natural labor there is not much assistance needed. The assistant should, however, possess a certain tact, or manner, calculated to make a favorable impression on the patient. This is especially needed when a man officiates. It must be recollected, that the situation of the female at such times is a very peculiar one, and that the presence of one of the other sex, however necessary, must be more or less objectionable to her. He should, therefore, carefully exhibit in his behavior the most refined delicacy, combined with a warm sympathy and kind consideration; thus soothing her scruples and enlisting her gratitude. He must also appear perfectly selfpossessed under all circumstances, and then she. will have full confidence in his skill and judgment. It may seem scarcely necessary to state these things, but I have often known men officiate without such qualifications, and also be perfectly unaware of their deficiencies. Such accoucheurs never officiate well ; they may be skillful and attentive, but yet unsuccessful, and unappreciated. They are only tolerated, but not respected, and are never fully confided in.

When requested to see a woman supposed to be in labor, it is always advisable to be prompt in paying the visit, because delivery sometimes comes on suddenly and unexpectedly, and both mother and child may be in great danger if no one is near to assist.

Some time before the event is expected, it is advisable to provide certain articles, which will or may be needed at the time, and which should not have to be looked for at the last moment. A pair of sharp scissors, with a piece of strong thread or cord, are indispensable, and a female catheter may be needed. A quill with the feather part on may also be useful, and some pure lard, or sweet oil, is frequently called for. The professional accoucheur will also find it a good precaution to have his stethoscope in his pocket, and a lancet, if he ever relies upon bleeding in any contingency. A small box of belladonna ointment also may often be of great and immediate service.

\section{PRELIMINARY PROCEEDINGS.}

The first thing required when visiting the patient, is of course to ascertain positively whether she be pregnant, and whether labor is really commenced, and if so, how far it has progressed. This necessitates an examination, the proposal and making of which require the most delicate tact, particularly if it be with a comparative stranger, or in a first labor. No allusion to it should be made to the patient herself by the assistant; he should converse with her about indifferent matters, or merely upon her health, and state his wishes to the nurse or female friend, and then retire. This gives them time to inform her of what is required, and to make the necessary prepa- 
ration. On entering the room again, he should not proceed abruptly, but resume the conversation, and make some of the necessary arrangements while carrying it on. He should seat himself by the side of the bed, with his right hand next her, and his face opposite hers. Then, passing his hand under the bed-clothes, after having lubricated it with lard or oil, he can proceed with the examination as if it were a simple ordinary proceeding. By exhibiting no hurry, and appearing to think it nothing unusual, or in any way strange, the female herself will cease to think it so, and will not be flurried or shocked.

The hand must be passed under the female's right thigh, her knees being elevated. She should, of course, lie on her back, and as near to the edge of the bed as convenient. Not the slightest exposure is necessary, nor allowable, under ordinary circumstances.

The forefinger being introduced, ballotment may be practiced, to ascertain if pregnancy really exists; and if the evidence from this source is not sufficient, auscultation must be resorted to. After being satisfied on this point, the mouth of the womb must be carefully examined, and its degree of dilatation noticed. If the female has pains their character and frequency must also be noticed, and the effects they produce on the parts. It will generally be possible by these means to discover how far the labor has progressed, and even to form an opinion how long it is likely to last. The general form of the parts and their size should also be noticed; particularly of the pelvis, so that any deformity or deficiency may be discovered; and lastly, the presentation should be ascertained, if possible, so that it may be known in time whether nature will be sufficient herself, or will require helping. The position need not be cared for at present, because it is of little consequence when the presentation is favorable.

The time required to make the examination need not be long, and should always be as short as possible.

While conversing with the patient, much useful information may be gained. The general state of her health, the nature of her pains, and the time they first commenced, should all be known; and if she has had children before, it will be highly useful to know what kind of a labor she had; whether it was long or short, easy or difficult, and particularly if attended with any accident likely to occur again.

It need scarcely be remarked that great caution is needed in these cases, many eminent men having been deceived as to the patient's condition, as already stated in our chapter on the signs of pregnancy; and many times the doctor has been summoned under the supposition that labor had begun, while it was yet far off. The pains may be false ones, such as frequently occur toward the end of pregnancy, and may all pass away. These false pains, however, can usually be distinguished, being continuous and irregular, while the true ones intermit with periods of almost perfect ease, and are tolerably regular. The false pains are also felt in various parts, while the true ones are chiefly fixed in the uterus and vagina. Sometimes, however, the difficulty in distinguishing them is very great, and the accoucheur has often waited for several hours and even days, the labor meanwhile making no progress ; and eventually all has passed off, and the patient has risen again from her bed. I know one case, where a gentleman attended nearly three days, and at the end of which time the patient rose and walked down stairs. She was not put to bed till stx weeks after. I can scarcely think, however, that these mistakes can happen very frequently, if the examination be properly conducted. 


\section{PREPARATIONS FOR THE DELIVERY.}

If it appears from the examination that labor has really commenced, or is about to do so, everything should be at once prepared. All useless persons should leave the room, and also those who would be likely to alarm or grieve the patient by uttering cries, or exhibiting fear; but no objection should be made to any one being present whom she wishes to see, unless they cannot be depended upon. Thus some females always wish to have their husbands with them, but others do not, though they are arerse to saying so. In these cases the accoucheur, if he be an attentive observer, will soon see what is really desired by his patient, and will manage matters accordingly.

The dress of the female should be perfectly loose, consisting chiefly of a wrapper or nightgown, but sufficiently complete and warm to allow of her getting up to walk in the chamber, if she desires it, as some do. No corsets, garters, or other tight bandages, however, should be allowed.

The bed should be prepared by placing the mattress on the top, or by removing all from it, and then placing a thick layer of blankets or quilts, with a folded sheet over them. This is to provide a firm level surface, in which the body will not sink, and also to prevent the fluids soaking through. It is an excellent plan, if the material can be obtained, to place a thin oil-skin or india-rubber eloth under the folded sheets, as this keeps all perfectly dry underneath. Some persons also place another folded sheet, or a cushion, under the pelvis, to keep it elevated, but this is not necessary, unless the bed sinks in very much. It is also advisable to have a foot-board or other firm body, against which the female can press her feet when bearing down; and a long towel, folded lengthways, should be passed under the back, so that it can be raised up by a person lifting at each end. This will often be found a better mode of pressing the back, which nearly all patients call for, than by merely forcing the hand against it, which is both tiresome and insufficient. Another towel may also be firmly fixed to the bottom of the bed, so that she can pull by it, at the same time that she pushes with her feet.

Some persons are confined on a cot, but this is not a very good arrangement, because it sinks in too much in the middle, and is not sufficiently large and firm. It is advantageous in one respect, however, as it can be placed by the side of the bed, into which the patient can be lifted when all is over, and be comparatively dry and comfortable. This is the most frequent plan in France. If the bed be properly arranged however, the under sheet can be withdrawn, and clean warm napkins then passed under the body, which will be equally as good. The covering should consist of a sheet, with blanket or coverlid, according to temperature, and should, of course, never be removed, except under peculiar circumstances.

The chamber itself should be as quiet as possible, well ventilated, and not too warm. Nothing distresses the patient more than a close, hot atmosphere.

The acconcheur need not, of course, be present while these arrangements are being made; and when he retires he should suggest to the nurse that the female may attend to the bowels and bladder during his absence. This precaution may both facilitate the labor, and prevent much future annoyance. It would even be advisable to administer an injection if necessary, of thin starch and a little castor oil, rather than leave the bowels unmoved.

In regard to nourishment, nothing is needed or proper in the shape of solid food, because all the energies of the system are concentrated in the uterus, and as diges- 
tion cannot therefore go on, it would only be an evil. If the labor is much protracted, however, some broth or soup may be taken, or a little milk. As a general rule, no spirituous liquors or stimulating drinks of any kind should be taken, because they impart no real strength, and may produce inflammation, or congestion of the brain. Some females always prefer tea to drink, others lemonade, toast water, gruel, or barley water, and others again simple cold water, which is perhaps the best of all. In cases of great exhaustion it is sometimes advisable, and even necessary, to give a little wine, or brandy and water, but it should always be cautiously administered.

In some parts it is customary for the female to lie on her side during delivery, with a pillow between the knees; some even choose this mode, and others will desire to stand, or place themselves on their knees. The most frequent position however, and certainly the most convenient, is on the back, though it may often be changed with advantage under peculiar circumstances. In the early stages of labor she can lie, or move about, as she chooses, or even rise if more agreeable.

ATTENDANCE AFTER THE PREPARATIONS ARE MADE, AND DURING THE DELIVERY.

When everything is arranged, the assistant should take his seat on the right hand of his patient and repeat the examination. If the head presents, he need not concern himself much further at present, but if it be any other part, he should prepare at once to change it, or assist, as the case may be. At this second examination the parties present, and the female herself, are usually anxious to know if the child is coming right, and how long the labor is likely to last. The answer to these inquiries should be guarded and circumspect in regard to the duration, because of its uncertainty, but if the presentation is right, it is well to say so at once, because this gives great comfort and encouragement. If it be unfortunately wrong, it is best not to say so abruptly, but remark that it is rather obscure, or cannot yet be fully distinguished, and so keep up the spirits of the female while you await the proper time, or make the necessary arrangements, to interfere ; and then tell her there is a little difficulty which requires to be righted, but which will not be serious, nor cause much delay.

If the labor steadily progresses, it is necessary to remain with the female and attend to it; but if it be delayed, and everything remains natural, she may be left for a time with advantage. When the second stage is fairly commenced however, and especially after the membranes are broken, the attention should be unremitting. The state of the parts should be ascertained frequently, so that the actual progress may be known, and any necessary assistance rendered. The state of the bladder especially should be observed, and if it be full, and the female unable to urinate, the catheter should be passed. Neglect of this precaution may lead to serious accidents. While making the examinations, the hand should be introduced with great care, so as not to bruise or lacerate the parts, and it should not remain longer than absolutely necessary.

Many females exhaust themselves unnecessarily, by bearing down and straining with great force from the very commencement of labor, under the mistaken idea that it is necessary to do so, or will assist. They should be told not to do so however, till after the membranes are broken, and not even then unless the neck of the womb begins to dilate. They should also be told not to make any effort except during a pain, as it will not assist at any other time. 
No attempt should be made, under ordinary circumstances, to rupture the mem. branes, or dilate the mouth of the womb, even though nature may be slow in doing so. Patience must be practiced, both by the female and by her assistant, and sometimes it is severely tried.

When the waters have escaped, and the orifice is opened, an examination must be made, to discover whether the cord has descended, or either of the arms, as is sometimes the case, and if so, they must be returned if possible.

As the head descends to the bottom of the pelvis it compresses the rectum, and produces a feeling as if the bowels must be moved, or even causes them to be so. This is apt to distress the female, and make her wish to rise, which cannot be permitted. If anything of the kind occurs, no notice should be taken of it, or she may even be assured she is mistaken, while a clean napkin may be interposed. This, as Dr. Chailly observes, will soothe her delicacy. Such an accident is very apt to occur towards the end of the labor.

When the head has rotated, and presents at the external opening, or vulva, and begins to distend it, the greatest care is required. This is a critical period, during which the accoucheur can render more real assistance than at almost any other. There is danger at this time, as formerly explained, of the head passing through too quickly, before the parts are sufficiently relaxed, and so causing them to rupture. This is particularly the case with the perineum, against which the head presses with great force. It is necessary therefore to support the perineum, as it is termed, to prevent this accident. This is done by passing the right arm under the patient's right thigh, and placing the palm of the hand flat against the perineum, with the thumb encircling one side of the vulva, and the forefinger the other. The hand is then gently, but firmly, pressed against the part during every pain, so as to prevent the head passing too quickly, and also to elevate it, and thus relieve the perineum of part of the strain, and throw the occiput under the pubes.

Some practitioners also pass the left hand over the thigh, at the same time, and grasp the back of the head with it, thus holding the head as it were between the two hands, so as to direct it at pleasure.

The manner of doing this is represented in Figure 182.

It is also necessary to request the female at this time to moderate her efforts, and not bear down too strongly. If, however, she be too excited, and eager to do so, more care must be used, and the head pressed back still more forcibly, till the parts are fully relaxed. For want of these precautions there is often serious laceration of the perineum and vulva, particularly in first labors, and when the parts are unusually rigid. If proper care be bestowed, however, these accidents ought to occur but seldom, even in the worst cases, and nothing can be more hurtful to the reputation of an accoucheur than for them to happen. Sometimes it is necessary to support the perineum for hours, and to bestow constant attention the whole time. It is often useful to keep applying a little simple ointment, or lard, in the intervals of the pains, mixed with extract of belladonna, which will soften and relax the parts. Dr. Lee also advises the application of a sponge dipped in warm water, and which would probably do much good in many cases.

It will of course be understood that the pressure only needs to be made during the pains; when the head draws back, the ointment or warm sponge may be applied. The knees of the female should be held up by some one, if she bears down too much, so as to prevent her from doing so too powerfully. 
When it is felt that the parts are fully relaxed, and sufficiently distended, the head is left at liberty, during a strong pain, and it immediately passes the outer ring, or is born.

It should then be held up, towards the pubes, and the mucus should be cleaned from the mouth with one of the fingers, so that the child may breathe. A careful examination should also be made round the neck, to see if the umbilical cord is around it. If it be so, but is not tight, it may be left alone, or pulled a little over one shoulder, or even passed clean over the head, if it can be easily drawn out long

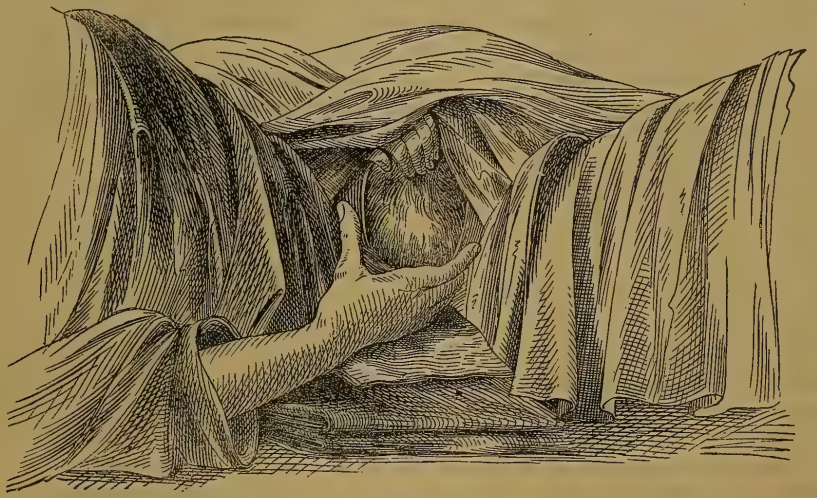

FTGURE 182.

The manner of supporting the perineum, during the passage of the head.

The right hand is placed underneath, so as to push the head gently back, when it presses on the perineum too forcibly, before it is dilated; and also to elevate it towards the pubes.

The left hand is seen above, grasping the top of the head to assist. This may be done or not, according to necessities of the case, or the custom of the assistant.

enough. When it is very tight, and cannot be eased, it must be cut through, or it will strangle the child.

In most cases the shoulders follow immediately after the head, the uterus resting only a few moments; but if they do not, the head may be slightly drawn upon, or the forefinger of the right hand may be linked under the arm, and a little force employed, though very carefully. It is better, however, to wait even two or three minutes, and only resort to these means when there is evidently a partial suspension of the natural efforts. Sometimes also the contractions may be brought on again by merely pressing the hand over the fundus of the uterus, and this should therefore be tried first in all cases, it being better to let the uterus expel the child than to bring it away by manual force.

During the passage of the shoulders, the perineum needs as much care as during the passage of the head, and must be supported in the same way. Indeed, some authors are of opinion that most cases of laceration are caused by the shoulders.

After the shoulders are expelled, the limbs and body speedily follow. The ehild should be received in the hands of the accoucheur, and laid on its side, 
at a little distance from the vulva, so that it may not be suffocated by the discharged fluids. He should then take a strong ligature and pass it twice round the umbilical cord, about two inches from the navel, and also at about four inches, and then cut the cord through, between the two bands, with a pair of sharp scissors. The child may then be handed to the nurse.

The tying of the cord is by some deemed unnecessary, and in most cases probably is so, but as children have been known to bleed to death when it was not done, it should never be neglected. Some practitioners only tie it once, leaving that part open which is still attached to the placenta, and they suppose this is advantageous, inasmuch as it partly empties the placenta of its blood, and so helps to detach it. There is little or no fear, as some suppose, that this bleeding can be extensive enough to hurt the female, or second child if there be one, and even if it were likely to be so it could soon be stopped; it has the inconvenience, however, of soiling the bed more, and this is probably one great reason why the second ligature is applied, which certainly is not necessary.

In my directions I have said that the cord may be tied about two inches from the abdomen, and this will be sufficient if the child breathes; but if not it should be left about four inches long, so as to give room to cut it again, which is occasionally needed, as will be seen further on. The knot should be drawn very tight, and great care must be taken never to tie it so near as to pinch the skin of the abdomen, which passes a little distance up it. A small portion of the intestine will enter the cord sometimes, and swell it out for an inch or more; this must be pressed back with the thumb and finger, and carefully avoided by the ligature. Some practitioners cut the cord first and tie it after, but I think the other plan is decidedly the safest and the best.

After this is accomplished, the accoucheur should place his hand again over the fundus of the uterus, to discover whether it contracts, and also to judge whether there be another footus. If the womb is felt drawn up into a hard round ball in the middle of the abdomen, all is right, and no apprehension need be felt ; but if it remains unaltered in size, and is soft, flooding is to be feared, and the hand should be firmly pressed or kneaded over the fundus, to bring on contraction.

If there be another fœtus, the womb will remain much the same as before labor, and the child may also be felt. It is better, however, to make an examination internally, and then, in most cases, the membranes and presenting part of the second foetus will be found at the upper strait. If there be any doubt after this, it is even better to carry the hand a little way into the womb than to remain in ignorance on such an important point. The delivery of the second foetus usually follows close upon the first, though sometimes there will be a delay of some hours, or even days. And in general there is little or no difficulty with the second, owing to the parts having been already prepared ; but the longer it is delayed the less easy it becomes.

Immediately the birth is fully effected, the female feels, as most of them express it, in heaven; there is an almost instantaneous change, from the most agonizing pain to a state of perfect ease. She ceases her cries, and falls into a quiet and pleasing languor, strikingly at variance with the state of intense excitement she was in but a few moments before. This repose, however, does not last long; the placenta yet remains, and a new effort is required to expel that. 


\section{DELIVERY OF THE AFTER-BIRTH, OR PLACENTA AND MEMBRANES.}

Unlike the foetus, the placenta is fast to the walls of the womb, and can only become separated from them by the contraction of their substance, which usually commences soon after the birth of the child, and is indicated by new pains, and a slight discharge of blood. In about a quarter of an hour, or twenty minutes, the accoucheur should inquire of the patient whether she has felt any of these pains, and he should also examine whether the placenta has reached the mouth of the womb, or vagina, so that he may remove it. If the pains have not yet come on, and the placenta is not in the passage, he should press one hand on the fundus of the womb to promote its contraction still further, and then gently draw upon the cord with the other, holding it as high up as possible, either by a piece of linen around it, or by looping it around the finger. It should be pulled very gently, but steadily, downwards and backwards. If it be snatched, or drawn too hard, it may break, and cause great trouble ; or it may pull down the womb, and either invert it or bring on falling of the womb afterward. The hand placed over the fundus can detect this accident, and if the uterus be felt to sink down, the cord must not be drawn upon any longer. Pulling away the placenta too soon, and with rudeness, has often led to deplorable accidents. In nearly every case it will gradually separate itself, and be delivered in about half an hour, and should only be assisted by slight drawing on the cord, and by pressing the fundus.

When the placenta is completely detached, there is seldom any difficulty in its passing the neck of the womb, and down the vagina, but it usually requires to be drawn through the external opening by the hand. In doing this the membranes may be twisted round the cord, so as to wind them altogether, and strengthen the cord.

In case the separation does not take place, we must wait, and continue the slight strain on the cord and the friction over the fundus. It is not reckoned safe, however, by most authors, to wait more than an hour; and if there are no signs of its coming by that time, artificial delivery is resorted to. This is accomplished by carrying the hand carefully up into the womb, and separating the placenta from its walls with the fingers, and then bringing it down at once.

When the after-birth has passed the vulva, a careful examination should be made of it to see that no part is left behind ; and for still greater security it is advisable to explore the vagina thoroughly, so that any detached portion may be removed. The membranes are very apt to become broken, and fragments of them left, which, though ever so small, may cause trouble. The finger should also be passed into the mouth of the womb, so as to clear it; for sometimes a large clot of blood, or a piece of the membranes, will remain and keep it open, and thus cause severe flooding.

It is generally considered, by those who have bestowed attention on the subject, that assistance should always be rendered, if the after-birth does not come very soon. There is danger, if it be left too long, of the mouth of the womb contracting and retaining it, in which case it becomes absolutely necessary to abstract it, but exceedingly difficult, and even dangerous to do so. Dr. Lee says it should never be left more than an hour, at most, and that it is best never to delay removing it even so long as that.

When left purposely, for observation, it is found to be expelled spontaneously, and soon, only in a few cases ; usually it remains several hours, and most frequently it requires to be removed by hand. No doubt it is natural for it to be expelled 
unaided, but it must be borne in mind that our females are usually too weak, ana deficient in energy, to perform any unusual natural function without assistance. 'The accoucheur must use great caution, so as neither to intrude his help when not required, nor yet to refuse it when really needed; and, above all, he must not substitute violence for skill.

When the after-birth is brought away, a bandage should be passed round the body of the female, made of soft linen, twelve or fourteen inches wide. It should be drawn moderately tight, and fastened securely. If it pass round twice it will be all the better, and it should be drawn down as near the pubes as possible. I know many ladies who prefer the india-rubber bandages, recently invented, as they press more equally and firmly, and are put on with less trouble, being all in one piece and drawn over the feet and limbs.

Some accoucheurs put on the wrapper immediately the child is born, before the after-birth passes away; but I think this is not the best plan. When properly adjusted, the supporting band gives great comfort to the female, and is very useful.

Some ladies provide curious corsets to 'put on, invented for the purpose, which howerer, as a celebrated author recently remarked, "are usually stiff and unyielding, like the prejudices of their patrons, and often prove injurious." None of them are equal to the simple contrivances above mentioned.

\section{ATTENTIONS TO THE FEMALE AFTER THE DELIVERY OF THE AFTER-BIRTH.}

When the after-birth is removed, the patient should be left to repose herself for about a quarter of an hour, during which time most of the blood escapes, and then she must be made as comfortable as possible. In France, and with many persons here, it is customary to cleanse the patient with a sponge dipped in warm water, pass a clean warm sheet under her, and then put on clean linen, after which she is lifted into the clean bed, previously well warmed, the accoucheur himself carrying her there. Most frequently, however, the sponging is dispensed with till some time after, and also the changing of beds - the under sheet merely being withdrawn, and a warm dry one passed in its place, while the patient's limbs are gently wiped. In either case the female should be disturbed as little as possible, particularly if there be danger of flooding, and she should be carefully guarded from cold. When the soiled and wet clothes are removed as completely as possible, warm napkins should be placed under the pelvis and between the limbs, to soak up the discharge, and they should be carefully changed as often as needed, without uncovering the patient. If she be disposed to sleep, however, and is much exhausted, these attentions need not be pressed too much till she is recovered a little.

Many persons here have a dread of using the sponge immediately, and of being carrried to another bed; but there is no danger from either practice, in ordinary cases, when carefully performed; and it is so productive of comfort, that I never knew one but what was pleased with and benefited by it, and desirous of its being done in their subsequent labors.

Some females will even rise and take a cold bath, or be wrapped in a wet sheet, not only without evil effect but with positive advantage. I would not advise any one to do this however, particularly if they are the least timid at it, or doubtful of its propriety. Withont the mental stimulus of faith and hope it may be hazardous. It shows, however, that many of the popular notions as to the requirements and susceptibilities of females in this state are entirely unfounded. 
The patient may either experience great comfort after being thus attended to, or she may complain very much. Some will even be attacked with a kind of chill. Their teeth will chatter, and their hands and feet grow quite cold. This however, usually passes off, and she falls asleep. The accoucheur ought to remain for an hour or two, even though she sleeps soundly, and appears quite well, because she may become suddenly worse, or flooding may set in with such violence as to endanger life in a few minutes, when unchecked.

If the patient desires any nourishment, she may take a little simple soup, or gruel, but nothing stimulating, unless a little wine be needed from extreme exhaust. ion.

\section{ATTENTIONS TO THE CHILD.}

Inspection when born.-As soon as the child is born, its mouth and nose should be cleared from mucus, if that has not been done already ; and if it has not breathed, means should be resorted to immediately to make it do so. Sometimes the whole head is covered with a thin membrane, called the caul, or veil, which is most probably only a portion of the amnion, and which may cause suffocation. I remember a case of this kind in my own practice, in which the caul was unnoticed at first, and the child came near dying from it. Nothing could be seen, and as it bent before the finger, when pressed into the mouth, it was totally unobserved. The nurse however, called out that the child did not breathe, and a close examination as to the cause soon revealed why. On passing the finger under the edge of the membrane, which was round the neck, it came off like a cap, and the child cried immediately.

Washing the Clild.--The cleansing of the child may usually be safely committed to the nurse, or other female attendants, though some of them have very absurd and injurious practices in this respect. Thus I have known them rub the whole body over with whiskey, or raw spirits, before washing it, which must cause great coldness from its evaporation, and also great irritation. The only thing required is perfect cleanliness, and this should be effected in the quickest and simplest manner. Some very mild soap, and moderately warm water, is all that is really needed, though a little sweet oil, or fresh lard, or butter, rubbed on first, appears to facilitate the operation. The drying should be done as quickly as possible, after all the mucus is washed off, and with great care; the napkin being as soft as it can be, and never rubbed hard, for it requires but little force to remove the skin. Many persons take great trouble, and are a long time over this infantile wash without succeeding well with it. They are deceived by the tough mucus slipping under the hand, but still clinging to the body, where they leave it even after using the napkin; it then dries on and forms a hard skin, very difficult to remove, and very irritating. This can be avoided with care, and by using the oil first, which appears to soften the mucus. Some persons use flour, or Indian meal, and others starch, but none of these are so good as the simple means we have described.

Dressing the Child.-After the washing and drying are completed, the child must be dressed, and this is a process in which comfort and utility are frequently sacrificed to mere fashion and prejudice, as it is in adults. The article next the skin should $b_{\ominus}$ of soft fine linen, which may be followed by others of warmer material, according to the temperature. They should all be perfectly loose in their make, ond quite soft to the feel. As far as possible they should all be fastened with strings rather than 
pins. These metallic points are troublesome to fix, and often injure the child, in spite of every precaution. They are also apt to be referred to as the cause of the child crying, and thus prevent other causes being sought for, which frequently exist.

Some people put a thick flannel cap on the head, over a linen one, but others leave this part altogether uncovered, which $I$ think is the best plain. At most there should only be the linen covering; the head being better rather cool than otherwise.

The dressing of the cord is the next duty, and this is done by taking several pieces of soft linen, oiled a little, and cutting a small round hole in the middle of each, through which the cord is passed. The linen then lies flat on the abdomen of the child, and the cord on the top of that, the holes being just large enough for it to pass easily through. Five or six pieces are usually put on, but very frequenly only one is used, and is found quite sufficient. It should be very fine, and soft. When this is done another layer is laid over the cord, and then a bandage of soft linen, about four or five inches wide, is passed two or three times over it, and round the body. This completes the dressing, and the child may now be wrapped up warmly and laid down to sleep-remembering, as Dr. Chailly remarks, that if it be laid on a chair or sofa, it may be accidentally sat upon and killed-an accident which has happened more than once.

\section{ACCIDENTS WHICH MAY HAPPEN.}

Before these dressings are needed, however, there are frequently other things of more importance to be attended to. If the labor has been long, or the presentation unfavorable, the child may be born apoplectic, from the pressure it has received. The face will be puffed up, and of a blue color; the body will be swollen, and the limbs without motion, while the pulsation will scarcely be felt, either over the child's heart or in the cord. It will feel warm, and the limbs will be quite flexible, but still there will be no signs of life. In this case it should be exposed naked to the cool air, and even blown upon ; and if that does not resuscitate it, the cord may be cut through below the ligature, so as to let out two or three teaspoonfuls of blood. After this it generally revives, and begins to move, while its face assumes a natural color, and the swelling goes down. The mouth and throat should also be carefully cleaned with a quill feather, of all mucus.

A more frequent accident is asphyxia, or want of breathing, in which case the surface of the body is cold and pale, and no breath whatever is drawn, though the heart beats quite naturally. Very weak children, or those born before their time, or those delivered by instruments, are most likely to become asphyxiated. The first thing to be done is to carry the child to the open window, if it be not.exceedingly cold, and expose its head and chest to the air, while the rest of the body is wrapped up warm. This will often make it gasp, but if it does not a little cold water may be dashed on its face and chest, and the throat may be tickled with a feather. The breech may also be smartly slapped, and the chest well rubbed with the cold hand. When it begins to breathe a little, it may be put into a warm bath up to the middle, and a warm injection may be given to it. In most cases these means will speedily bring it round, but if they do not, the attendant should place his mouth close over that of the child and breathe into it, so as to fill the lungs, and then press down the chest to empty them again, repeating the process several times. This may be called artificial breathing, and if it succeed once only, there is a probability of its effecting the desired 
olject. The breath, however, must not be blown in too hard, nor too rapidly, or it may injure the child's lungs. Sometimes a tube is used, which is passed down into the throat; but it is troublesome, and not much better than the mouth, if at all. These efforts may be repeated twenty or thirty times if necessary, or even more. In some cases it is requisite to continue using some or all of these means for an hour or two without intermission, before the child begins to breathe freely. I knew an instance even, where the nurse continued to do so for five hours, and at last fully recovered the child, though all present, including the doctor, had given it up. She said she did not despair while it continued warm, though it was doubtful whether the heart beat. or not. This may show that the attempt should not be abandoned too soon.

In case of asphyxia, no blood should be lost at all, but on the contrary the cord should be carefully examined to see if it is tied fast, the bleeding from it frequently aggravating the evil.

Congenital Weakness.-Some children are born extremely weak, and remain constantly debilitated and cold. This is very apt to be the case when they are born before the full term, or when the mother is diseased. They should be carefully wrapped in cotton, or very soft flannel, and kept warm by bottles of warm water. Many instances are on record of these weak children becoming afterwards extremely robust, so that they need not to be regarded with unmixed apprehension, nor neglected from a supposition that they must die.

The Child may be Deformed.- The accoucheur should also carefully examine the child, to see if it be deformed in any way, or has met with any accident, because in some of these cases assistance is required immediately, and may be rendered at once.

The Child's Capability of Endurance.-The capability of the new-born infant to endure extremes of cold is almost as great as that of its mother, and sometimes even it is benefited by them. With many persons it is customary to plunge it in cold water, immediately when born ; and in Russia, we are told, it is even rolled in the snow. In some cases these extremes may be beneficial, but in others I have no doubt they prove fatal. A medium course is best, in most instances, leaving the extreme to be resorted to when we wish a sudden stimulus.

When all these matters are carefully attended to, and both mother and child have remained for an hour or two without any unpleasant symptoms, they may be left to the care of the ordinary attendants, giving them strict orders to send for proper assistance immediately, if anything unusual transpires.

\section{SUBSEQUENT ATTENTIONS TO MOTHER AND CHILD.}

The Bladder.-One of the most important points to attend to is the urine. A few hours after the delivery is fully effected, unless the female is reposing, she should be asked whether she has any desire to urinate; and, if she has, the convenience should be at once afforded to do so. There is always more or less danger of retention of urine, from the pressure that has been exerted on the bladier; and if it be allowed co continue too long, its removal becomes exceedingly difficult. If on making the attempt the urine does not flow, the catheter must be used, and the sooner the better. The pain arising from retention of the urine has often been supposed to arise from inflammation of the womb, or bowels-neither patient nor physician knowing its real 
source, till the passage by the catheter gave relief. There have even been instances of females dying, merely from an overcharged bladder, while their attendants were industriously treating them for uterine inflammation. This accident, therefore, should always be suspected, and a very little attention will prevent any mistake in regard to it. When allowed to become too full, the swollen bladder may be felt, just above the pubes, hard and tender, so that the least pressure upon it causes great pain. If not relieved, it will at last burst.

The Bowels. - If the bowels are not opened naturally, it will be well, the following day, to administer an injection of thin starch and water, or to prescribe a small dose of castor oil, or a seidlitz powder. This should also be repeated for two or three days, till the natural power is restored.

The Food.-But little solid food should be given, and nothing stimulating. Gruel, milk, toast and water, Indian meal, light puddings, or broth, should be the chief articles for some time. Roast apples are also very good, being pleasant and relaxing. For refreshing drinks, if there be any fever, lemonade or tamarind tea may be taken.

The After-pains. - After the expulsion of the after-birth, most females experience more or less severe pains, almost like those of labor, arising apparently from the further contraction of the uterine walls to expel the coagulated blood. These pains are seldom or never felt in first labors, but afterwards they are often most acute. I have known many patients suffer much more from them than they did during labor. They sometimes last only a few hours, or a day, and sometimes even extend to six or eight days. Nothing that we know of can prevent them, thongh many means are known of mitigating their severity. If there be no tendency to flooding, a large poultice may be placed over the abdomen, or it may be fomented, or covered with cloths wrung out in hot water. An injection may also be used, either in the vagina or rectum, consisting of warm thin starch, with about twenty drops of laudanum ; or either of the following recipes may be used internally:-Pills of gum camphor, two about the size of ordinary pills, to be repeated, if necessary, in an hour. Or, syrup of poppies, two drachms; mucilage of gum arabic, two ounces; and solution of sulphate of morphia, ten drops; to be made into a mixture, one-half of which may be taken, at first, and the remainder in two hours, if the patient is not relieved. This seldom fails. It is necessary to bear in mind that the pains arising from inflammation have been mistaken for ordinary after-pains, and serious consequences have resulted from the error. The after-pains, however, are concentrated, and intermittent, while the sensations from inflammation are more diffused and constant, and are also usually attended by ferer.

The Lochial Discharge. - From the time of delivery until the uterus has returned to its ordinary condition, there is poured from it a discharge, at first like blood, and afterwards thin and light colored, called the lochia. The duration of this discharge varies from one week to a month, and its quantity from one ounce to six or eight ounces daily. It gradually diminishes, however, and frequently stops for a few days altogether. In women who do not nurse it is both more abundant, and lasts longer, than in those who do. The bloody color usually disappears after the first or second day, though sometimes it will show itself again, even when the discharge has nearly ceased, particularly if the female exert herself too soon.

It appears that this discharge is essential to health, and great attention should therefore be bestowed on the patient, if it be too small, or cease too soon, or too suddenly. In most cases it ceases naturally during the milk fever, and of course its dis- 
appearance then need not excite alarm. Sometimes also it does not attain its full quantity till some days after its commencement. If, however, it remains small past the third day, or does noi appear when the milk fever is over, means should be taken for increasing it. The best means for this purpose are warm poultices and fomentations over the abdomen, and injections in the rectum of simple warm water. Some practitioners advise two drachms of powdered camphor to be sprinkled on each poultice, and probably it is an excellent addition. Occasionally the lochia is very offensive, and in that case a simple cleansing injection may be frequently used of thin starch, or chamomile tea, with three or four drops of carbolic acid.

During the whole period of the lochia in fact, even in ordinary cases, the femalo will be all the more comfortable, and better, for an occasional injection, and frequent washing. This is very much neglected, though it never ought to be so. The only care required is not to expose her to cold, which is quite unnecessary.

The Mille Fever.-About the second or third day there usually commences a peculiar temporary excitement in the system, called the milk fever, which requires to be described because it may be confounded with something more serious. It is generally ushered in by headache, flushed face, and a hot dry skin ; the pulse beats slowly, and the breasts become hard, while the reins upon them appear very full. In a short time, however, the pulse becomes quicker, a perspiration breaks out, and the breasts become still larger and fuller, so that the female can scarcely bring her arms to her body. These symptoms last about a day, or two days at most, and seldom become much aggravated.

Occasionally the milk fever is preceded by a slight chill, or by a furred tongue, or sick stomach, but not very frequently.

The precise causes of this temporary fever are unknown, though probably it is connected with the full establishment of the secretion of milk, and hence its name. It is seldom very severe in those who nurse, and frequently does not appear at all. During its continuance, and for some time after, the female must carefully aroid exposure to cold, and keep herself quiet; her diet should also be rather restricted, and light and unstimulating. An occasional seidlitz powder may also be of service, or a simple injection.

Making the Bed.-It is not customary to disturb the female, for the purpose of making her bed, till the milk ferer is passed; or, if that does not appear, till the tenth or twelfth day; and then it should be done with care, and so as not to expose her unnecessarily.

First Sitting up, and Going out.-This must of course be determined more by the condition of the patient, and the state of the weather, than by any rules. It may be as well to remark however, no matter how the patient may feel, that the first attempt should always be made with care. Very frequently she thinks herself stronger and more capable than she really is, and premature or undue exertion may do great injury. In most cases the female is allowed to rise within the first week, and sit for a short time in an arm-chair ; after which she begins to walk slowly about the room. The first going out is fixed, by fashion, at one month. Many females, however, are unfit to leave the house till long after that time, and others should by no means be confined to it so long. Of course these proceedings should depend, as already remarked, upon the patient's strength and inslinations, and upon the state of the weather, and not upon any fashionable observances. Some females are quite able to rise, and even walk out, in a few days, with benefit to themselves; and it exhibits 
as great a want of correct feeling, or common sense, for any one to make disparaging remarks on them for their early appearance, as it would if they were to blame the poor invalid for keeping her bed.

The apartment should be kept constantly well ventilated, particularly if the female is confined to it, and all soiled linen, or other sources of foul air, should be removed as quickly as possible. There is reason to believe that inattention to this, and to properly cleansing the person of the female, frequently produces child-bed fever.

Attentions to the Child. - If the infant's bowels are not opened by the end of the first day, it should have a little sugar, or molasses and water, given to it, and if this does not succeed, about half a teaspoonful of syrup of rhubarb may be added. This is, however, but seldom needed, if it be put to the breast within a few hours, as the first secretion of the milk possesses sufficient laxative power itself. It should also be observed whether it has urinated, and if not it should be placed in a warm bath immediately.

Some persons prefer to let the child wait till the milk fever is established, before they let it nurse, but this is very improper. The early feeding does it no good, and the purgatives it requires are injurious. As soon as the female is sufficiently reposed, if there is nothing special to forbid it, the child should go to the breast.

Sometimes the child will remain sleepy and dull, and not seem to require food at all, for several days, and even die at last of starvation, unless aroused. If this lethargy continues, it should be put in a warm bath, and afterward well rubbed, while a little sugar and water is poured down its throat. These attentions may require to be repeated for some time.

About the fourth or fifth day, the portion of the cord above the knot usually separates and falls off, if it has not already done so. If the navel is inflamed, or suppurates, a little simple ointment may be rubbed on, and it should be regularly and carefully washed. In some infants it swells out very much, in which case a pad should be made of soft linen, and laid upon it, over which the ordinary bandage may be drawn. The complete healing of the part does not occur till about the twelfth day, and the bandage must be carefully worn till then at least, and is better contiwued a little longer, particularly if there is any swelling, or if the child cries much, or strains.

\section{CONCLUDING REMARKK.}

From the explanations given above of an ordinary natural labor, it will be evident that but little manual assistance is required, either to the mother or the child, and also what really is called for is of so simple a character as to be easily rendered. It would undoubtedly be improper, and cruel, to leave females at such times without aid altogether; but it is also equally improper and injurious to interfere too much. Excepting in cases of disease and deformity, or of very unfavorable presentations of the fotus, nature herself will nearly always effect the delivery ; and much better, in most cases, when left to herself. Numerous females and infants have been killed, and still more have been grievously injured for life, by rude and uncalled-for manipulations; so that it has been a question with some accoucheurs, of great experience, whether as many would die, or seriously suffer, from receiving no assistance, as do now from being improperly handled. Without going so far, it is undoubtedly true that great mischief is done in this way, which can only be prevented by both accoucheur and patient bearing in mind that nature herself is usually competent, and at 
most only requires skillful and gentle assistance. Some practitioners seem to think that labor is a mere mechanical process, like the removal of a block of stone, and hence they depend entirely upon force; overlooking altogether the wonderful vital powers inherent in the system, which operate with such certainty, and yet so safely, and which frequently succeed of themselves when brute force is completely foiled.

The nature of the assistance proper to be given, in any particular stage of labor, will be evident on inspecting the structure of those parts, of both mother and child, which are brought in connection at the time, and by considering how their mutual selations require to be changed and modified. If those relations are already such as are required, and the system retains sufficient force, nothing $c a n$ be done with any advantage-we must wait, and let nature operate herself. Even many unfavorable conditions may be spontaneously corrected, and it should always be a matter of consideration, when the means of assistance are not very obvious, whether it will not be better to rely upon the natural powers than to interfere. Great evil has resulted from teaching females that labor cannot terminate safely without a great deal of assistance, which can only be rendered properly by those who possess a vast amount of skill and experience. They are thus led to think themselves totally dependent upon the accoucheur, and many of them actually seem to believe that he is as necessary to deliver the child as a dentist is to extract a bad tooth. If they were better informed, they would feel more confidence in their own natural powers, and would not be so unnecessarily alarmed when unforeseen difficulties occur, or when professional aid cannot be immediately procured.

In most cases there is more danger after the labor is over, from puerperal fever, various local inflammations, and other causes, than there was during its progress. Indeed the real danger may be said properly to commence several days after, and the physician is really needed then more than at the time.

\section{PROTRACTED AND DIFEICULT LABORS.}

TLe causes which may impede a labor, and increase its difficulties, are numerous, and they are of several different kinds-some depending upon the mother, and others upon the child. Some of these may be easily removed, or modified, but others present more serious difficulty. It is therefore necessary to enumerate and explain them separately. 


\section{CHAPTER LXXIII.}

THE CAUSES AND CONSEQUENCES, TO BOTH MOTHER AND CHILD, OF PROLONGE: LABOR.

\section{The Consequences of Prolonged Labor.}

A LABOR is usually called protracted or difficult, if the head presents, when it is not completed in about twenty-four hours from its actual commencement. There are many labors, however, that last much longer, and yet terminate quite favorably, and many that are over much sooner, and yet are very difficult. Still, generally speaking, the danger and difficulty increase as the time progresses, and it is seldom prolonged beyond twenty-four hours without serious inconvenience.

It appears, from the statistics of the Dublin Lying-in Hospital, that in seventyeight thousand deliveries, one out of every ninety-two of the mothers died, and one out of every eighteen of the children was still-born. Of those mothers who were in labor with first children, from thirty to forty hours, one in every thirty-four died, and one child in every five was still-born. Of those who were in labor from forty to fifty hours, one died in every thirteen. Of those who were in labor from fifty to sixty hours, one died in every eleven. And of those who were in labor from sixty to seventy hours, one died in erery eight, and nearly one-half of the children. It is evident therefore that, as a general rule, the danger increases with the length of time.

CAUSES CONNECTED WITH THE MOTHER WHICH MAY IMPEDE LABOR, OR MAKE IT DIFFICULT.

\section{Inertia, or Want of Sufficiently Powerful Contraction in the Womb.}

This is most likely to occur in delicate females, and in those who are debilitated by disease. The contractions are very feeble, and, as the nurses say, do not tell; the mouth of the womb dilates but slowly, and the head descends with difficulty into the passage.

In many cases, in fact, the labor is so tedious, from this cause, that the female becomes completely worn out, and finally sinks, while the child is exposed to the greatest hazard from the delay.

It is in these cases that the patient's strength needs supporting, and that stimulants may be useful. A little wine, or brandy and water, will often rouse the failing energies, and bring on a series of strong contractions that will end the labor at once.

The most usual resort however is to the drug called ergot, or secale cornutum, a fungous growth which is sometimes found on ears of rye. This possesses the peculiar property of exciting the womb to contract, the same as an emetic excites the 
stomach to vomit, and it seldom fails in its effect; but still there are many objections to its use. It not unfrequently causes delirium, great restlessness, and anxiety, sickness, headache, and convulsions, or complete prostration, from which the female may be long in recovering. It is also supposed by some to be not altogether free from danger to the child. If however no other means were known of making the womb contract, in such cases, all the probable evils should be risked, because the labor must be completed at all hazards; but other means are known, which succeed even more certainly than ergot, and without any danger. The application of galvanism, if it be used in a proper way, will almost invariably cause the womb to contract, and speedily bring the labor to a safe termination, without the slightest risk or inconvenience to either mother or child. Simple friction over the abdomen will also succeed in many cases, and gently rubbing the mouth of the womb with the finger in others. These simple means should therefore always be used in preference to the ergot, but in case they cannot be resorted to, or fail, the drug must be administered, and I will therefore explain the manner in which this is done. When gathered, the ergot is in large irregular lumps, and should be so kept. When wanted for use, a single drachm should be finely powdered, and divided into three parts; one of these parts to be taken first in a glass of sugar and water, and the others at intervals of ten minutes, unless the effects of the first are very powerful. It is often thrown from the stomach however, even in still smaller quantities, and is then given, by some, as an injection by the rectum, in which mode it seems more powerful, so that a smaller dose is sufficient.

Great caution should always be observed in using this powerful drug, as it will sometimes act so energetically as to burst the womb, or expel the child so suddenly as to lacerate the perineum and other parts. The contractions produced by it are different from the natural ones, being almost constant, without any interval, and gradually increasing in force. They usually come on in about ten or fifteen minutes after the last dose, and continue about an hour and a half. Some practitioners depend almost altogether on the ergot, in every protracted case, and even use it to bring on premature labor, when that is required. Thus M. P. Dubois was once called to a dwarf, whom he delivered with instruments, the first time, but with great difficulty and risk. The next time she became pregnant, he determined to bring on premature labor, and accordingly he administered ergot, when she was about eight months gone. This brought on natural labor, and she was delivered without difficulty. M. Chailly says he believes it will bring on uterine contraction at any time, and that he has never known it to fail. I consider however that there is always more or less risk in its use, and I should certainly prefer any of the other means, particularly galvanism.

It is of the first importance however to be certain, before using any forcing means whatever, that there is no physical impediment. If the pelvis should be deformed or small, if the child's head should be unusually large or dropsical, or if the soft parts of the mother should be undilated and rigid, the most serious consequences must ensue from violent uterine contractions. In like manner, if the presentation be unfavorable, particularly if it be one of the trunk, the danger is equally great. In every case the passage of the child must be physically possible, before it is attempted to force it away. A neglect of this rule has frequently led to fatal results. The ergot has been given and the uterus forced to contract, while the pelvis was too small for the child to pass through : and the consequence has been rupture of the uterus, 
or complete exhaustion, with death to both mother and infant. In other cases the delivery has resulted so suddenly, from the violence of the expulsive efforts, that the vagina and perineum have been lacerated in the most shocking manner.

The ergot is also especially dangerous to very nervous women, or to those who are disposed to congestion, apoplexy, or inflammation.

Among the special causes which often paralyze the action of the womb, may be mentioned a full habit of body, great distention of the uterus from accumulations of fluid, and extreme thickness of the membranes. In some cases, in fact, the membranes will be so strong that the most violent contractions fail to break them, and the uterus completely exhausts itself to no purpose. It is in such cases as these, when the mouth of the womb is fully dilated, that the accoucheur should rupture the membranes artificially. This is usually done with the finger nail by pinching them. Some practitioners, however, use a pointed instrument or a sharp quill; but there is always more or less danger of injuring the child or the mother by such means. The best time for breaking them is during a strong pain, when they are fully distended. The mere scratching, or pushing on them will frequently suffice. I have known cases, however, in which they were so strong that an instrument was actually necessary to open them.

The death of the infant also seems sometimes to check uterine contraction, though probably not from the mere circumstance of its being dead, but because the womb suffers from the same morbid cause which produced its death.

Any strong moral impression may also produce the same state of things. Thus, in some females the womb will instantly cease its contractions, and the labor be ar. rested, from fright, or from strong repugnance to somebody or something in the room. Instances have been known of women being so alarmed on first seeing the accoucheur, or so displeased because he was not the one they wished, that the uterine efforts im. mediately ceased, and could not be again brought on for a long time. The presenas of some person who is a subject of dislike may also have a very prejudicial effect, anil if this is known they should be immediately removed. Dr. Merriman tells us of a female who was seized with a fit, from which she died, simply from seeing a strange doctnr enter the room.

Whatever may be the cause which paralyzes the action of the womb, we should endeavor, if possible, to discover and remove it. If, however, it be beyond our reach, the patient's strength must be supported as much as possible, and the simplest means of exciting the contractions tried first; if these fail, the more powerful ones must be tried, always preferring the safest. Finally, if all fail, the hand must be introduced into the womb, the child turned, and brought away by the feet; or the forceps must be used if absolutely necessary.

\section{RIGIDITY OF THE MOUTH OF THE WOMB, VAGINA, AND VULVA.}

Sometimes the mouth of the womb, or other soft part, will not give way, but remains obstinately rigid, so as to render the continued expulsive efforts of the uterus of no avail. If this state continues too long, the parts become swollen, hot, and dry, and extremely painful, so that the slightest touch causes acute suffering. The abdomen also becomes exquisitely tender, fever sets in, with cold sweats, the head begins to wander, the features express great anxiety and suffering, and the voice alters so that it can scarcely be recognized. These symptoms will sometimes be established, 
and become rapidly worse in a remarkably short time, so that the patient will appear to pass suddenly from a condition of comparative ease and safety to one of extreme peril and suffering. The child also suffers in an equal degree, the continued pressure upon its head having a most injurious effect. The bones overlap to a great distance, the scalp is engorged with fluid, and all its blood-ressels are ready to burst; the brain is severely compressed; the circulation in it is suspended, and apoplexy frequently ensues. Even when one of these protracted cases eventually terminates without immediate mischief, there is much subsequent evil to be feared. The bruised parts frequently slough away, so that fistulas are formed, and the whole remain so permanently weak that they can never afterwards retain their places.

The most usual resort in these cases of obstinate rigidity is blood-letting. This frequently induces relaxation immediately, and also checks the tendency to inflammation and fever. In many cases, however, if not in all, it may be dispensed with, and should always be so if possible. Very frequently it produces as much evil as good, by alarming the patient, and by creating a debility which cannot afterwards be removed. Simple warm fomentations will often make the rigid parts give way; and so will lubricating them with soothing ointment, or, better still, anointing them with the belladonna ointment. This frequently acts like a charm, and opens the rigid os tincæ in a few minutes. Injections of thin starch and laudanum are also excellent, and may be advantageously administered before applying the belladonna. The galvanic battery may also be employed, it having induced relaxation in many cases, when all other means failed; and the practitioner should always have one ready, in case of need.

If the labor really does progress, though slowly, it is generally best to have patience, and let it take its course. If, however, the patient is likely to sink before it is completed, or if it is at a stand-still, and cannot be accelerated, artificial delivery may bo necessary. It is seldom, however, that all of the above-mentioned means fail.

\section{OBLIQUITIES OF THE WOMB.}

Sometimes the womb is so much inclined in a particular direction that its mouth :does not present to the middle of the passage. Thus it may lean over so much to the right side that the mouth may open against the left wall of the pelvis, or it may lean to the left side, or to the front. In all these cases, the expulsion of the child may be totally prevented, because it is forced against the walls of the passage instead of down its axis.

Obliquity is sometimes righted spontaneously, but more frequently it requirer the interference of art. The mode of rendering assistance is to support the womb on the side to which it falls, particularly during the pains, so that its mouth may be directed toward the middle of the passage.

\section{PROLAPSUS UTERI.}

Falling of the womb may retard labor, but is not likely to make it more than usually difficult, or dangerous. It is requisite, however, to bear in mind that the head of the child may, by this displacement, be found in the vagina, and even at the vulva, before it has passed through the mouth of the womb, because the neck itself is already in the passage. The head may therefore be felt low down, and the 
accoucheur may think the labor will soon be completed, when in reality it has scarcely begun. In such cases it merely requires patience and non-interference.

\section{SMALLNESS, AND DEFORMITY OF THE PELVIS.}

These constitute by far the most serious obstacles to delivery, and are most to be dreaded. In treating upon them, it will be first necessary to explain the chief kinds of deformities, and the causes from which they arise, after which it can be shown how they interfere with the progress of labor, and how they can be best remedied.

Deformities of the pelvis may either be congenital, or they may be produced by certain diseases in after life, and also by bad physical education. The principal causes however are two diseases, rachitis, or rickets, and malacosteon, called also mollites ossium, or softening of the bones. Rachitis usually attacks children somewhere between nine months and two years of age, and produces a variety of well marked symptoms; such as large head and belly, protrusion of the breast-bone, flattening of the ribs, emaciation of the limbs, and various deformities of the bones. The patient may recover from the disease, but the deformity of the bones often remains, and therefore no female should become pregnant, who has had rickets, till the shape and dimensions of her pelvis are known, or it may cost her life.

Malacosteon, or softening of the bones, may come on at any period of life, and frequently occurs without any serious constitutional disturbance. It consists in a gradual absorption from the bones of all their solid matter, so that they become soft, and may be bent or twisted like horn. Sometimes this state will be reached rery soon, but at other times the disease progresses slowly. The causes of it are unknown, and it is incurable. I have seen a patient who could bend the bone of her leg nearly double, as if it were a piece of rope.

In several previous chapters, I have spoken upon various other causes which may deform the bones in young females, such as wearing corsets, improper attitudes in sitting, and want of sufficient unconstrained exertion of the body in the open air.

The deformities may be of various kinds, and may either alter the general appearance and the walk, or may not be discoverable except on examination. Sometimes the pelvis is too large, so that the womb and other parts are continually falling down into its cavity, but this is very rarely seen; more frequently it is either too small, or irregular in its form.

In all cases where the irregularity in form, or diminution in size, is such as to prevent the passage of the child, an operation becomes necessary, either upon the mother or her infant, and great danger is consequently incurred by both.

It is therefore the duty of every mother, if she has the slightest suspicion that her daughter is deformed, though it may not be apparent, to have her examined before she is allowed to marry. Many have lost their lives for want of this precaution. Severe blows or falls in early life may also create a pelvic deformity, and this, as a possible consequence of such accidents, should always be borne in mind. The means by which the form and size of the pelvis are ascertained, as before stated, are simple, and such as need not in any way be feared.

To enumerate all the varieties of deformed pelvis, as described by different authors, is unnecessary, and would not be useful here. I shall, therefore, only refer to them generally. Sometimes the pelvis is regular enough in its form, but singuiarly small altogether, not larger perhaps than that of a child eight or nine years of 
age. More frequently, however, one part only is small, while the others are full sized, or the different parts are not in a proper position in regard to each other. Thus sometimes the pubic bones will be flattened backward near to the sacrum, so as to narrow the antero-posterior diameter of the upper strait; at other times one of the sides will be flattened towards the other, as if crushed in, and thus diminish all the diameters; and at other times one side will sink down lower than the other, and thus effect similar changes in another way.

By referring to the description of the perfect pelvis, given in the early part of the work, the nature of these changes will be readily understood, particularly if the figures given there are compared with those given here.

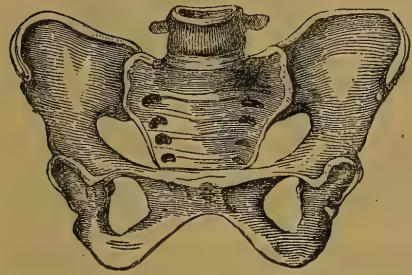

FrGURE 183.-Represents the standard form of the Pelvis.

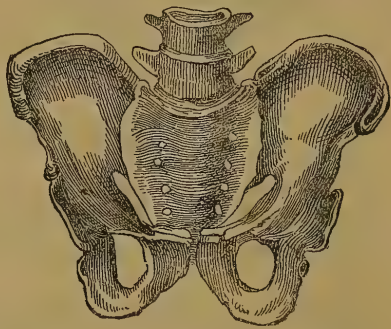

FIGURE 184.-Masculine Pelvis.

Figure 183 represents the standard form, with which the rest must be compared.

Figure 184 represents a pelvis which resembles that of the male in its form, and is theretore called masculine. It is deeper, and less capacious altogether, than the standard one. This form is occasionally met with in females of a peculiar general conformation and temperament, approaching that of the other sex. It is n6t a sufficient deviation from the natural form to create any great difficulty, though it may cause delay.

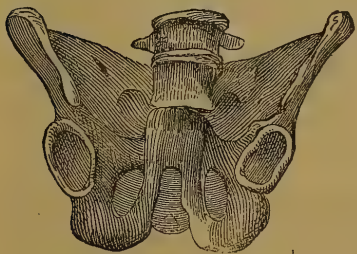

FIGURE 185.-Represents the peculiar deformity most frequently produced by Mollites Ossium.

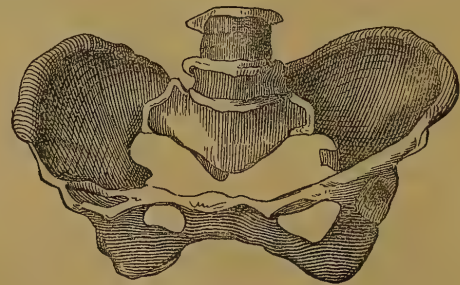

Frgure 186. - This is called an Ovate Pelvis.

Figure 185 represents the peculiar deformity most frequently produced by mollites ossium. The different parts are stretched out as it were, and crushed inward toward each other. The size of each strait is diminished in nearly every diameter, and the whole form is very unfavorable to delivery. This is sometimes called a cordiform pelvis. Observe the difference between it and the standard one.

Figure 186. This is called an ovate pelvis. It appears as if it had been crushed by a heavy weight, from above downward, the sacrum being depressed below the plane of the pubes. In this case the antero-posterior diameter of the upper strait is so much lessened that the two halves appear nearly separated, and form almost a figure of eight (8). 


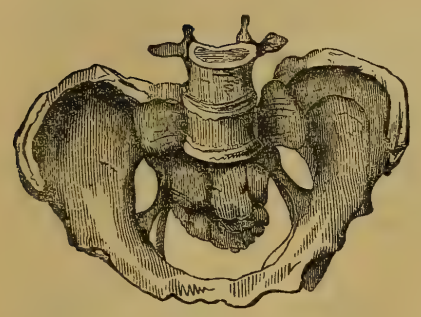

FraURe 187.-This is another deformity, in which one side is sunk below the other, and both twisted round the sacrum.

Figure 187. This is another kind of deformity, in which one side is sunk down below the other, while both are twisted as it were round the sacum.

Figure 188. This is a section of a pelvis to show the effect of a corroding disease of another kind. The whole of this is such a mass of disease and deformity, as to preclude any particular description.

Curvature of the spine sometimes affects the pelvis, when low down, and therefore if any female is affected with it she should not marry before being examined. Several diseases and lesions of the hip-joint, and of the thigh, may also do the same, and should therefore be suspected.

In the great majority of cases, deformities of the pelris remain unknown, till the period of delivery, and all that can be then done is to combat in the best possible way the difficulties they create. It is evident that the amount of difficulty depends entirely on the disproportion between the head of the child and the passage through which it has to be born. If the head be large and the passage small, the difficulty will bi. greatest, but if the head be small it may pass through the pelvis, though under its average size. The development of the head cannot be ascertained however before birth, except when it is unusually large from dropsy, and it is therefore always assumed to be of an average development, and the pelvis is compared accordingly.

The kind of assistance required in these cases depends chiefly on the measure of the pelvic diameters, though it may be modified somewhat by other considerations.

When the smallest diameter of the pelvis measures from three inches and a half to three inches, it is customary to leave the expulsion of the fotus to nature, and it is generally effected, though slowly and with difficulty. If, however, the patient becomes exhausted, or the head be unusually large, the forceps are generally used after waiting five or six hours. In these cases the head often becomes firmly fixed in the upper strait, so that great force is needed to dislodge it. The upper part passes through, owing to the overlapping of the bones, and the scalp then bulges out like a large tumor, from being engorged with blood and serum, but the lower, being more unyielding, remains behind. It is, therefore, impossible for the head to move either way, as it is formed like a figure 8 , and held by the narrow part, as will be seen by the following figure: 
When the smallest diameter is not more than from three inches to two and a half, the birth is sometimes effected by nature, but with extreme difficulty. The accoucheur waits four or five hours, as in the former case, and then if no progress is made he applies the forceps, using great care in doing so. If the extraction is found imposible, with reasonable force, the hear must be opened and made smaller, even though the child be living, because it is more proper to sacrifice it than to risk the life of the mother. In a case like this, however, no one person would like to decide, unless in a great emergency; there should always be a consultation if possible.

A dwarf, named Lepratt, who used to perform at the theaters was delivered with the forceps by M. Dubois, though the pelvis only measured three inches. She perfectly recovered, but the child was born dead: it was of fair average size.

It is contended by some that the delivery may be effected, under peculiarly favorable circumstances, when the passage measures only two and a half inches, and at all events the effort should be made; but for the sake of the mother such cases should not be left long, as the chance is so small, and the risk of delay so great. When the passage is less than two and a half inches, spontaneous or artificial delivery is allowed to be impossible, and the only alternatives then are to dismember the child or open the mother. Which of these should be done depends on circumstances. Whenever the child can be brought away by the natural passages, though it be piecemeal, it always is so brought, unless the danger to the mother be greater than by the cesarian operation, in which case that operation is resorted to. By means of an instrument called the cephalotribe, which crushes the head, the child may be brought away, unless very large, when the pelvis only measures two inches. When the passage is less than two inches, the only resort is to the cesarean operation, which sometimes succeeds, and saves both mother and child, though more frequently the mother sinks.

The necessity of all these frightful operations is now much less than formerly, and may be done away with altogether. This important fact should be known universally, and also the means to be resorted to. In the first place, every young female should be examined, before marriage, by a competent person, if there be the slightest reason to suspect deformity ; and in case the deformity is found to exist, the consequences if she becomes pregnant, must be laid before her. If, after being told this, she will marry, or has already done so, the means of avoiding conception should be placed at her disposal, so that she may not be made, of necessity, a helpless victim. These means may not be described here, though I have no hesitation in referring to them. When I know that the life, or life-long health, of a female, depends on her not becoming pregnant, I consider it my duty to put such means at her disposal, if she desires it. In many instances, I have known females suffer, several times, the most frightful tortures, merely to bring into the world the mangled fragments of a dismembered child, with the greatest risk to their own lives; and in others, I have known them in constant dread of becoming pregnant, because they were conscious it would be their death warrant. In such cases I leave it to humanity, and common 
sense, as to whether such information should be withheld. $I$ could not reconcile it with my notions of duty to withhold it.

In case pregnancy has occurred before the deformity is discovered, and it is then found that a full grown child cannot be born, premature delivery must be brought on; or, in other words, the uterus must be made to expel the child before the full term, while it is yet small enough to pass through the pelvis. This operation is of course only allowable when needed to preserve life, or to escape great suffering and danger. It must always be decided upon by the medical man, and performed by him, so that a description of it is uncalled for here. In Europe it is quite common, and nothing has tended so much to do away with those disgusting and horrid operations, on mother and child, which were formerly absolutely necessary in cases of deformity. If it is found at the first delivery of a female, or before, that she cannot bear a living child at full term, artificial delivery is accomplished at seven or eight months, thus aroiding all the danger to the mother, and frequently preserving the child. In the case of the dwarf, before referred to, when she became pregnant the second time, M. Dubois brought on premature delivery, and the child was born alive, with but little difficulty. According to statistics it appears that when artificial premature delivery has been induced, in one hundred and sixty-one cases only eight mothers have died, and all but forty-six of the infants were born alive. Of the whole number of children, seventy-three continued to live; and of the eight mothers, five died from other causes, leaving but three whose death resulted from the operation. Now when the fearful number of deaths from instruments, and other operations necessary at full term, is recollected, the advantage of this practice will be evident. In the cesarian operation, for instance, which is often the only remaining resort, but one female out of six recovers.

The delivery should be postponed as long as possible, so as to give the best chance for the child living. This must of course be decided upon after the size of the pelvis is ascertained. Seven months is the earliest time at which the foetus is viable, and it is much better left till eight, if the size of the parts will allow of its birth then. In case they are so small that it cannot be born even at seven months, we have unr choice, as M. Chailly remarks, between the dreadful Cesarian operation at full term, and producing early miscarriage.

M. Dubois seems to recommend premature delirery in nearly all cases, if the smallest diameter is under three inches; because, as he remarks, spontaneous delivery at full term is then a very rare exception, and the danger and suffering to the mother is so great. He also recommends it when there are tumors, and even when the female is afflicted with any acute disease. Of course it is always necessary, before operating, to be sure the child is alive.

I knew a lady myself who had given birth, at full term, to seven children, all of which were torn from her with instruments, dead, owing to the smallness of the pelvis. When pregnant with the eighth, premature delivery was brought on, at my suggestion, at about seven months and a half. The fœtus was born with comparative ease, and lived. But for this operation, she probably would never have been blessed with a living child at all. Since then she has avoided conception.

\section{TUMORS IN THE PELVIS.}

Tumors of various kinds are met with, both in the bones of the pelvis and attached to the soft parts. They frequently offer the most serious impediments to 
delivery, and baffle the skill of the most experienced obstetricians. In fact they differ so much in their structure, their size, and their situation, that but few general directions can be given as to their management. In every case where one exists, pregnancy should never occur, if possible to be prevented, before it is removed; for though it may cause no inconvenience at other times, yet during delivery it may necessitate very serious operations, or even cause death. Some of these tumors are mere vesicles or bags, filled with fluid, and may be punctured and their contents let out, so as to make them less. Others are more or less solid but movable, and may orten be supported above the upper strait till after the child is born. When they are so large as to block up the passage, and are either fixed or cannot be carried up into the womb, there is often no other choice than to either eut them out or to open the child's head-the practice being determined by the circumstances of the case. In some instances the bladder itself, distended with urine, has impeded delivery, and been mistaken for a tumor; and in other instances stones in the bladder have caused the same error.

A specimen of one of these tumors is represented in Fig. 190, and one of a polypus in Fig. 191.

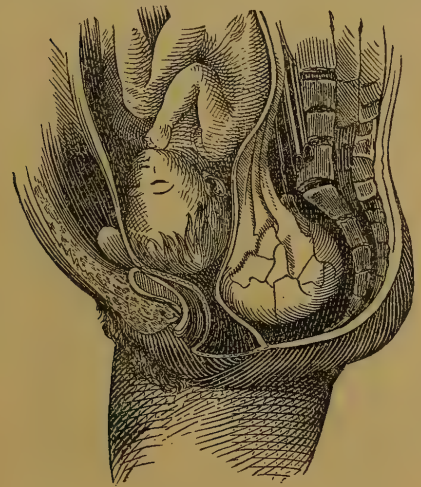

FigURE 190.-Case of Tumor.

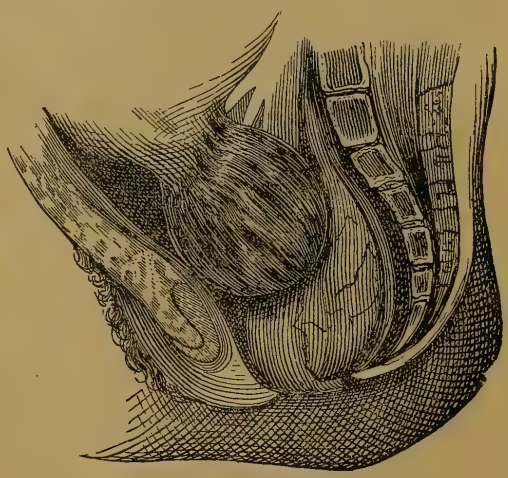

Figure 191.-Case of Polypus.

Figure 190 represents an ovarian tumor. which has descended before the head of the child, and completely blocked up the passage. The delivery, it will be seen, is utterly impossible in such a case, unless the tumor can either be pushed away, or reduced in size.

Figure 191 represents a case which occured in the practice of Dr. Ramsbotham, and which terminated favorably. The polypus had a very long neck, and was forced out of the external opening by the child, which was then born with ease. I once saw a case myself, in which the labor was completely arrested by a large hard tumor about the middle of the vagina ; it could not be moved, and delivery was evidently impossible while it remained. In consultation it was decided to cut it out, as there seemed but little circulation of blood in it, and its situation was favorable for the operation. This was accordingly done with but little trouble, and the child was born without difficulty in about twenty minutes after. The mother perfectly recovered.

\section{TUMORS EXTERNALLY.}

Sometimes tumors exist, externally, on the lips, or in the vulva, but as they seldom offer much obstruction, and are easily detected and managed, but little need 
be said about them. They should always, however, be attended to, if discovered, before labor comes on, or better still, before pregnancy.

In some instances, the veins around the vulva become much enlarged, and resemble tumors, and sometimes even impede delivery. It is usual then to open them, and let out the blood, but not till the head is sufficiently low to press upon them and prevent dangerous bleeding.

OBSTRUCTIONS IN THE VAGINA, AND NARROWNESS OR OBSTINATE RESISTANCE OF THE VULVA AND PERINEUM.

The vagina may be partly closed by its sides growing together, or it may be united by bands and membranes stretching across ; and these obstructions may be sufficient to impede or prevent delivery. Most usually they give way, and are gradually broken down by the pressure of the child's head ; but if they prove too strong, after waiting a reasonable time, they must be cut through. Cases have even been known in which the hymen has been found perfect at delivery, and even offered considerable resistance, so as to necessitate its being cut through before the child could be born. In such cases this membrane is unusually strong, and conception occurs without its being broken.

When the perineum or vulva remains rigid and hard, so that the opening cannot be enlárged sufficiently for the child to pass, it may also be necessary to operate with the knife. But this should never be done till after every means of relaxation has been tried, and the head has been kept back as long as prudent. It is, however, always better to open a passage than to let one be torn, because it may be made in the most favorable place. When the perineum is allowed to be torn, the most serious consequences often ensue, and the patient is made a miserable sufferer for life. The vagina and rectum may be torn into one, or the power of retaining the contents of the intestine or bladder may be forever lost. When an incision is made, none of these evils follow ; the wound speedily heals, and in a little time no trace of it can be seen. It has even been necessary to cut the neck of the womb when it would not open, to prevent the organ from being ruptured; and this has been done with perfect safety. A celebrated practitioner in this city had to perform such an operation very recently, on a female who had injured herself, and made the mouth of the womb grow together, by violent attempts to produce abortion. The delivery took place with comparative ease, and no unpleasant results whatever followed, either to the mother or the child.

\section{CAUSES CONNECTED WITH THE CHILD, OR CHILDREN, WHICH MAY IMPEDE} DELIVERY, OR MAKE IT DIFFICULT AND DANGEROUS.

\section{Procidentia of the Umbilical Cord.}

This means the escape of a portion of the cord before the child itself. It is most frequent in the irregular presentations, as they do not so fully close up the mouth of the womb, and it is most likely to occur at the commencement of labor, though not impossible at a later stage. Very often the cord descends when the membranes break, being carried down by the rush of the waters; and sometimes it is already in the sack, or bag, before the rupture takes place. This accident is comparatively frequent, being found to occur as often as once in about three hundred cases. 
Thie causes which produce procidentia of the cord are most likely these : A large quantity of liquor amnii, and its sudden discharge ; unnatural presentations ; deformities of the superior strait of the pelvis; a very long cord ; and rupturing the membranes too early. But it may also happen from other causes with which we are unacquainted.

There is seldom much difficulty in detecting this accident, because if the membranes are broken, it protrudes into the vagina, and if they remain whole it can be felt within the sack, and its pulsation will be quite distinct. Sometimes, it is true, it may be so firmly compressed between the foetus and the walls of the pelvis, that its pulsation nay be very indistinct, or even totally suspended for a time; but this only necessitates a little extra care.

Procidentia of the cord may be very serious for the child ; in fact, it is a frequent cause of its death. The reason of this will be evident when the functions of the cord are borne in mind. The circulation in it is as necessary for the life of the child before birth as breathing is after, and when protruded first it can seldom escape being so pressed upon as to stop its circulation, and hence the danger. To the mother it makes no difference whatever, unless it be told and alarm her; or unless violent efforts are made to correct it. She had therefore better not know if it occurs.

If assistance is not rendered in this accident, the consequences are almost always fatal to the child, though in some instances the cord has remained hanging from the vulva several inches, for an hour or more, and still the infant has been saved.

If the fallen cord is detected before the membranes are broken, it may frequently be put back into the womb without much difficulty. The accoucheur must wait till the mouth of the womb is fully dilated, and then watch his opportunity, in an interval between two contractions, to push the cord upward, between the foetus and the uterine walls. If he succeeds in this, as is usually the case, he must then break the membranes during the next pain, and this will bring the presenting part at once into the upper strait, and so block up the passage. To effect this manœurre, it is requisite to introduce two or three fingers, and sometimes even the whole hand. It must never be attempted till the mouth of the womb is fully dilated, otherwise the membranes may be ruptured too soon, and the delivery be delayed, thus increasing the danger.

After the rupture of the membranes, the replacing of the cord becomes a much more difficult matter, and frequently cannot be effected at all ; particularly if the head be descended far down. Every effort, however, must be made, and if unsuccessful the delivery should be hastened as much as possible. In many such cases the forceps are applied, and the child brought away at once, because every moment's delay increases the risk to its life.

Several different kinds of instruments have been invented to return the cord, but they are seldom at hand when needed, and none of them are so good as the hand itself.

If the return of the cord cannot be effected, and the progress of the labor will allow of it, the hand is introduced and the child turned, unless the position of the head will allow of the advantageous application of the forceps, in which case they are mostly resorted to. The only general rule is, to terminate the labor as speedily as possible consistent with the welfare of the mother. In spite of all that can be done, the pulsation is often found to cease, and when the child is born it is either quite dead or breathes but a few times.

A very frequent indication that the foetus suffers from compression of the cord, 
is a greenish color of the water discharged, owing to the discharge of meconium from the child's bowels. 'This is brought about, most probably, by its straining, and its efforts to relieve itself.

\section{SHORTNESS OF THE CORD.}

The cord is sometimes too short, and this may operate very unfavorably in many ways. It may keep the foetus in the womb, and prevent it from descending to the

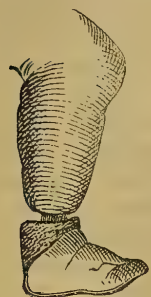

FTGURE 192.

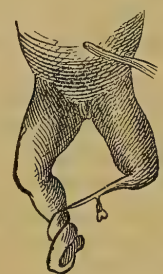

FrguRe 193.

Limbs cut off by the Cord.

Occasionally the cord can be slipped over the head, or limbs, when wound round them, and the strain upon it be thus removed. If this cannot be done, however, and the danger increases, relief may be obtained by cutting the cord, particularly if it be absolutely short. But this must not be done till everything indicates that the labor will probably soon terminate; and the end connected with the child must be carefully held, or tied.

by it M Tasil saw a case whe the ond round the head, and Montgomery gives several instances in which the limbs had been amputated in this way. Two of these are represented above.

\section{DESCENT OF OTHER PARTS WITH THE HEAD.}

One Arm.--The descent of one arm along with the head may cause some dela! and difficulty, but nature nearly always overcomes the impediment. It is seldom that the arm can be reduced, and therefore but little can be done at first; if the delivery be evidently arrested by it, the accoucheur must at last assist in the most feasible manner. Sometimes even it is necessary for him to apply the forceps.

The two Arms. - Even this difficulty is often overcome spontaneously, though much more rarely than the former one. As soon as it is detected, the accoucheur must endeavor to return one or both of the limbs, if the labor has not proceeded too far ; and if he cannot succeed, the delivery must be accomplished as soon as possible, either by turning or with the forceps, unless there be reasonable ground for delay.

The Feet. - Either one or both of the feet may also descend with the head at first, though they usually recede and allow the head to be born alone. When they are se impacted as to prevent the delivery being completed, the accoucheur must interfere. 
In most cases he will find it quite easy to push the feet above the head, and allow that to descend alone; but if this is not possible, he must introduce one hand, grasp the feet with it, and pull them down, while the other pushes the head up. This will turn the child, and if it be in no immediate danger, and the mother is not suffering, the rest may be left to nature; but if the contrary is the case, the delivery must be finished as speedily as possible. When the bead is very low down, it may be necessary to use the forceps, but great care must be observed not to grasp the feet along with the head when using them.

A Foot and Arm.-The proceeding is the same as with the foot alone. If the limbs cannot be returned, the head and arm must be pushed up, while the foot is brought down.

\section{TWINS AND TRIPLETS.}

In most cases where there are two or more children, the delivery is easier than with one, because they are geverally small, and the first one so prepares the way that the rest are born without difficulty. It is also a fact that twins are nearly always born before full term, and consequently are not quite grown.

The expulsion of the second foetus usually takes place immediately after the first, though sometimes the womb stops contracting, and it is not born for half an hour or more, and it may even remain for hours or days. It is a question whether, in such a case, the second delivery should le left for nature to finish, or whether the accoucheur should terminate it sooner artificially. The most general practice is to wait only about half an hour, and then, if the womb is still inert, use friction, or other necessary means, to excite it, and accomplish the second delivery as soon as possible. If there be more than two, the proceeding is still the same.

Some difficulties may arise however with twins, which it is necessary to be prepared for. Thus the two heads may come together, and mutually impede each other. In this case the one that moves the easiest must be pushed up till the other is descended sufficiently low. One head may also descend with one or two feet; in which case, if the feet cannot be returned, the head must be pushed up, and they must be brought down. The force exerted, however, must not be very great at first, because one may belong to each of the children, and much injury may be done; a little gentle traction will soon detect this however, with ordinary care. If two arms, or one arm and a foot descend, the same care is also required, before pulling upon them, to ascertain that they are not parts of the two children. Sometimes when the head of one twin descends along with the feet of the other, they may, if small, descend together. But if this is impossible, and interference is needed, we must first try to push up the head; and if this cannot be done, it must be drawn upon, not the feet; because if the feet were drawn down the two children would soon occupy the passage together, body and head, and would perhaps become firmly wedged. In nearly every case one of the twins presents by the head and the other by the feet, as formerly shown.

EXCESSIVE SIZE OF THE FETUS, OR THE DISEASED DEVELOPMENT OF CERTAIN PARTS.

Foetus too large.-It is very rarely the case that the foetus is so large as not to pass easily through a well-formed pelvis, though such cases have been known. The mode of proceeding is of course precisely the same as if the pelvis were too small. 
If no means will succeed in abstracting the foetus whole, it must be made less; but nature should be first allowed full time to act with all her force.

Hydrocephalus. - This consists of an accumulation of water in the head of the child, and is usually termed watery head. The bones of the cranium will sometimes be widely separated by it, and the head be made so large that it cannot possibly be born till made less. The causes which produce this disease before birth are unknown.

In cases of hydrocephalus, the head does not descend into the straits, owing to its size, and is felt to be full and firm during a pain, but soft and yielding during the intervals, especially at the fontanelles and sutures, which are also very large. The bones are usually very wide asunder, or even totally separated as if floating in the fluid.

In some cases, when the quantity of fluid is but small, the delivery may terminate spontaneously, the head lengthening, from being so soft, and thus adapting itself to the size and form of the strait. Most frequently, however, assistance is rendered in such cases, either by the forceps, which will sometimes succeed, or by puncturing the head and letting out the fluid. This operation has been performed and the child saved, though such an occurrence can never be reasonably anticipated. Such instances, however, show that great care should be taken not to injure the brain, as that would destroy the small chance there is.

Dropsy may also occur in the chest or abdomen of the child, cansing similar difficulty with dropsy of the head. If the natural or artificial expulsion of the child cannot be effected without, the part must be carefully punctured, and the fluid evacuated.

Tumors on the Fretus. - Sometimes various kinds of tumors form on the child's body, but they are rarely so large as to prevent delivery, though they may delay it. If they should be too large, however, it will be necessary to remove them, as in the case of tumors in the pelvis.

\section{OSSIFICATION OF THE HEAD.}

Occasionally the bones of the head will be so hard, and so closely united, that they will not overlap, in which case the labor may be very difficult, unless the head is small, or the pelvis very large. If after waiting a reasonable time, there be no prospect of the labor terminating naturally, and the female is exhausted, it must be terminated artificially, as if it were a case of deformed pelvis. It is seldom, however, that the head does not eventually give way.

VARIOUS PRESENTATIONS AND POSITIONS OF THE FCETUS, FROM WHICH THE LABOR MAY BE DIFFICULT OR PROTRACTED.

Presentations of the Face.-These are usually more difficult and longer than those of the head. They will nearly always, however, terminate spontaneously, or with ordinary assistance; but, if they should not, artificial delivery must be practiced, either by turning, if the case be not too far advanced, or with the forceps. Some of the most celebrated authors recommend that all these cases should be treated like cases of natural labor. Dr. Merriman says that in some very favorable instances turning may be practiced with safety and advantage; but Dr. Lee says, "My firm 
belief is, that the child, even under such favorable circumstances, would have a far better chance to be born alive if the labor were left wholly to nature; or, if the natural powers were inadequate, to be extracted with the forceps." In such cases there is often too little patience, and too much interference.

The Forehead inclined against the Pubes. - In this position the labor may be long delayed, and difficult, and most practitioners endeavor to turn the head round, if they cannot bring down the feet, or else apply the forceps at once. Dr. Lee however remarks, and very properly, "From all that I have seen of these cases, I am disposed to believe that it is best to leave them to the natural efforts, and to avoid all inter. ference, all attempts to change the position, while the pains continue regular, and the head advances, however slowly." If the labor does not progress at all, or the female becomes exhausted, of course artificial delivery is necessary.

Several varieties of head and face presentations may also retard labor considerably, but nature nearly always overcomes the difficulty ; or if she cannot do so, mere ordinary assistance is required.

\section{PRESENTATIONS OF THE LOWER EXTREMITIES.}

It has already been remarked, in another place, that breech presentations mostly terminate spontaneously, and that but few of them require interference, in some of them even, when the pelvis is large, or the foetus small, the delivery is effected quite rapidly. Still such presentations occasionally cause delay and difficulty, and necessitate more or less assistance.

As soon as the mouth of the womb is opened sufficiently, unless the labor is rapidly progressing without it, one of the fingers may be introduced and hooked over the groin, and a little gentle force exerted upon it. This will assist very much, and will often be all-sufficient. If the pelvis is too small, or the foetus too large, and the delivery is evidently arrested, the breech must be pushed up, if possible, and the feet be brought down, as in turning. The remarks of Dr. Lee on this presentation are so plain and practical, and marked with such good sense, that I think a better explanation of what should be done in such cases could hardly be given; I will therefore quote his remarks in full :

"Having ascertained that the nates present, whatever the position of the foetus may be, whether the abdomen look backward or forward, we cannot alter it with safety, and no change can be required to be made till the nates and lower extremities are expelled. The os uteri dilates slowly in most cases of nates presentation, but we cannot employ any means with advantage to accelerate the delivery, and in most cases, if we do not interfere, but wait patiently, they are gradually pressed lower and lower into the pelvis, and at last escape from the vagina without any assistance. If the os uteri and vagina are imperfectly dilated, and the nates are drawn down or pass rapidly through the pelvis, the child is often lost. The membranes should not be ruptured, and the expulsion of the nates should be left entirely to the natural efforts, unless the labor is protracted and exhaustion takes place. Except supporting the perineum, nothing is required in a great proportion of these cases before the nates and lower extremities have been expelled, when it becomes necessary to ascertain precisely the relative position of the child to the pelvis, to rectify this if it is unfavorable, and artificially extract the superior extremities and head, to prevent the fatal compression of the umbilical cord. If we find, after the expulsion of the nates and lower extremities, that the toes are directed forward, or that the child 
has its abdomen applied to the anterior part of the uterus, with its back along the spine of the mother, we should wrap the nates and sides in a soft napkin, and turn the child very gently round during a pain, observing to which side the feet turn, till its abdomen is to the spine of the mother, and the toes are directed backward to the hollow of the sacrum, or to the side of the pelvis. In many cases the nates turn round in the passage spontaneously, so that it is not required artificially to alter the position. It is necessary always to recollect that it is possible to turn the body of the child round without turning the face round into the hollow of the sacrum, and that the cbin may be over the symphysis pubis when the front of the chest and abdomen are turned backward. After the lower extremities and body of the child have been expelled, and placed in the most farorable position for the extraction of the superior extremities and head, it is necessary to proceed without loss of time to draw these through the pelvis, that the child may not be destroyed by compression of the umbilical cord. As pressure upon the cord for a very short time will in some cases kill the child, it is proper to watch closely the pulsations of its arteries. Draw the body of the child forward as far as the arm-pits, and place it over the palm of your right hand and fore-arm, and gently draw the body toward the left thigh of the mother; then pass the fore and middle fingers of your left hand along the back part of the left arm of the child to the elbow-joint, and press down the arm with your fingers along the thorax of the child, and extract it. Then transfer the body of the child and left arm to your left hand and fore-arm for support, and with the fore and middle fingers of your right hand disengage and bring down, in the same way, the right arm of the child ; then pass the fore and middle fingers of your left hand into the mouth of the child, or rather over the lower and upper jaw, and at the same time place the fore and middle fingers of your right hand over the back part of the neck and occiput. and with the fingers of the two hands thus applied extract the head, in the line of the axis of the pelvis. The perineum is very rigid in some cases of nates presentation, where it is the first child, and it will be torn if the head is extracted hastily, and not drawn forward to the symphysis pubis. When you feel the pulsations of the cord beginning to cease, you may be tempted to employ greater extraciing force than the neck of the child and perineum can bear, and both may be destroyed. The only method of obviating this is to press back the edge of the perineum, that the air may gain admission into the mouth of the child, and the respiration go on, when the circulation in the cord has been arrested, until the perineum is sufficiently dilated to slide back over the face, and allow the head to pass. I have seen from twenty minutes to half an hour elapse in some cases, after the cord had ceased to pulsate, before the perineum would allow the head to escape, during which time the respiration was regularly performed. This is not a new practice; it has been alluded to by some of the old accoucheurs, and some others; and the advantages to be derived from it were fully pointed out some years ago by Dr. Bigelow, in a paper published in the American Journal of the Medical Sciences, 'on the means of affording respiration to children in reversed presentations.' The object of Dr. Bigelow in this paper is to show that in many cases the life of the child may be saved by forming a communication between the mouth and atmosphere previous to the delivery of the head. If the head be low down, the fingers alone can give the necessary assistance ; but if it is high in the pelvis, and is reached with difficulty, the assistance of a tube may be necessary. He recommends a flat tube, which is to be guarded, and kept within the fingers of the inserted hand. 
"Where the pelvis of the mother is small or distorted, and the child large and nnfavorably situated, the efforts of nature may be insufficient to expel the child, either alive or dead. The nates may become so firmly impacted in the pelvis, that they cannot advance without artificial assistance. A finger should be passed up to one of the groins, and when a pain comes on, a considerable extracting force may be exerted with it, without injuring the child; or a soft handkerchief may be passed between the thigh and abdomen, and the nates drawn down; but this cannot be done unless they have descended low into the carity of the pelvis. Where these means fail, and it is impossible to extract the child alive, the blunt hook or crotchet must be employed. In cases of nates presentation, where the pelvis is distorted, after the extraction of the trunk and extremities, it is necessary to perforate the back part of the head, and complete the delivery with the crotchet. In presentations of the feet and knees the treatment does not essentially differ from that required in presentations of the nates."

\section{PRESENTATIONS OF THE SHOULDER.}

These are the most dangerous of all the presentations, and most frequently require assistance ; in fact, the delivery can seldom be terminated naturally when the shoulder presents.

Sometimes the child will pass doubled up, as formerly explained, but this must not be too confidently expected. Dr. Lee says :

"It is now a general rule, established in all countries where midwifery is understood, that in cases of preternatural labor, where the shoulder and superior extremities of the child present, the operation of turning ought to be performed. But the hand must not be forced into the uterus, if the orifice is rigid and undilatable ; it should be dilated nearly to the size of a half-a-dollar piece or more, or the margin ought to be very thin, soft, and yielding, if it is expanded to a smaller extent than this when turning is attempted. If the os uteri will not admit the extremities of the fingers and thumb in a conical form to be introduced without much force, if it is thick, hard, and unyielding, some delay is necessary, that the parts may relax, death being almost always the consequence of thrusting the hand with violence through the orifice of the uterus in a rigid and undilatable condition, whether the membranes be ruptured or not. But as soon as it will admit of the safe introduction of the hand, where you have ascertained that an arm presents, no time should be lost in completing the delivery, otherwise the membranes may give way, the liquor amnii be evacuated, and a case of little difficulty and danger be suddenly converted into one equally hazardous to the mother and child. In all cases of labor, where the first stage is far advanced without the nature of the presentation being positively determined, or a superior extremity is felt through the membranes, the patient should be kept in the horizontal position, that they may not be ruptured; and you should remain in constant attendance upon her, and be prepared to interfere the instant the necessity arises."

Speaking of the operation of turning in these cases, he remarks as follows:

"In some favorable cases of shoulder and arm presentation, the uterus is widely dilated before the membranes are ruptured and the liquor amnii discharged ; and no difficulty is experienced in passing the hand into the uterus, laying hold of the feet, and extracting the child by the operation of turning. If the uterus is not contracting strongly and at short intervals, little resistance is offered to the introduction of 
the hand, and the delivery may be speedily accomplished with safety both to the mother and child. But if the membranes have burst, the liquor amnii escaped, and the uterus has been contracting firmly upon the child many hours before the operation of turning is attempted, the child is often destroyed by the pressure, and the coats of the uterus exposed to great danger from contusion and laceration in passing up the hand and bringing down the feet. The shoulder and thorax become so strongly impacted in the pelvis, that great force is required to introduce the hand to grasp the feet, and much exertion necessary before the position can be changed.

In other cases of shoulder and arm presentation, the membranes burst, and the liquor amnii escapes at the commencement of labor, and the os uteri is rigid and undilated, so that the hand cannot be passed into the uterus after the labor has continued many hours. The difficulty and danger of these cases is greatly increased when the uterus is contracting with violence, and the pelvis is distorted, or a disproportion exists between the child and pelvis from any other cause. The greater number of women, if abandoned to the efforts of nature under these circumstances-the uterus having no power to alter the position of the foetus-would ultimately die undelivered, from exhaustion or rupture of the uterus and vagina."

Fortunately these cases are very rare, and when assistance is rendered early, the difficulty is readily overcome. This is a strong reason why all women especially should know what to do, because a little timely help may save much suffering, or even life. 


\section{CHAPTER LXXIV.}

\section{UTERING HEMORRHAGE, OR FLOODING, DURING LABOR.}

THIs is always a troublesome, and frequently a fatal accident. It should be carefully watched for, and attended to as early as possible - a few.minutes frequently determining the recovery or death of the patient.

The chief causes of flooding are, the too early or violent separation of the placenta ; insertion of the placenta over the mouth or on the neck of the womb; laceration of the womb or vagina ; the bursting of a swelled vein ; rupture of one or more of the blood-vessels of the uterus, and breaking of the cord.

Probably the most frequent of these causes are the premature or violent separation of the cord, and the bursting of the blood-vessels. The insertion of the placenta over the mouth of the womb, instead of on the fundus, occurs very seldom, but when it does, severe flooding is nearly certain to follow, because the placenta has then to be torn, by the expansion of the parts, at the very commencement of the labor, and probably continues to pour out blood for a long time before the child is delivered and it can be expelled. In fact, this occurrence, unless the labor terminates very speedily, is nearly always fatal to the mother, and frequently to the child also. In most cases, there is more or less hemorrhage from this cause during gestation, particularly after the sixth month, when the neck of the uterus begins to enlarge more than the placenta, and consequently tears away from it. Abortion frequently results also, if the flooding be not stopped. Madame Boivin tells us that in twenty thousand three hundred and fifty-seven deliveries, there were but eight cases in which the placenta grew over the mouth of the womb, which is equal to one case in every two thousand five hundred and fifty-four. Dr. Churchill has collected the accounts of one hundred.and seventy-four cases of this kind, and he finds that out of these forty. eight terminated fatally; or nearly one out of every three.

The rupture of the blood-ressels may occur when they are too much engorged with blood, or when their coats are weakened and corroded by disease. Shortness of the cord may also produce a rupture of the vessels, by the strain it causes on them and on the membranes.

In many cases the flooding comes on suddenly, without any warning whatever, though most usually it is preceded by a sensation of weight, heat, and fluttering in the pelvis, pains in the thighs and back, flushed face, headache, and dizziness. The pulse also becomes irregular, the hands and feet grow cold, and the ears often ring or buzz. The only certain sign that the hemorrhage has really commenced is the appearance of the blood itself, and this often occurs, as previously remarked, without any premonitory sign whatever.

The danger from homorrhage during labor is greatest when it commences the earliest, because it has then the longest to last. From any of the causes mentioned, it is evident that it must continue till delivery is accomplished, and therefore if it 
appears at the commencement of the labor, it may cause the death of both mother and child, before the labor can be terminated. The danger is greatest, however, to the child, unless the flow be very profuse indeed, and then it is equally so to both. After delivery, the danger is of course only to the mother ; and the rapidity with which it may compromise ber life is in some cases fearful. Dr. Lee thus speaks of such cases :

"But one of the most dangerous varieties of uterine hemorrhage is that which follows the expulsion of the placenta, or its removal from the uterus by art. Sometimes the blood escapes in great quantities from the uterus:immediately after the removal of the placenta, and the pulse ceases at the wrist, and consciousness is entirely lost in a few seconds. There is no symptom before labor has commenced, or during its progress, to warn you of what is about to take place. The child has been safely delivered, the placenta has come away in a short time, and while you are perhaps congratulating yourself on the happy termination of the labor, the blood begins to trickle over the bed upon the floor, or the patient suddenly complains of great faintness. In such cases there may be either a want of uterine contraction, or the contractions may not be permanent, but be followed by relaxation and the effusion of a large quantity of blood, which may either appear externally, or remain to become coagulated, and distend the uterus. For several hours after delivery, in some cases, this alternate relaxation and contraction goes on, to the great hazard of the patient, and if her condition be not clearly ascertained, and the proper remedies be employed, death may unexpectedly take place."

In regard to the treatment, he gives such excellent and practical rules, that I cannot do better than quote them :

"By far the most important remedies in these cases of nterine hemorrhage are constant and powerful pressure over the fundus uteri, the application of cold around the pelvis, and the free administration of wine, brandy and other stimulants-ergot is indicated, but it most frequently produces no effect. The pressure and cold are always within our reach, however sudden the attack may be. The hypogastrium should be strongly compressed with the binder, and a pad of folded napkins placed under it, and in addition the hand should be firmly applied over the fundus uteri. I do not know who it was that first employed compression of the fundus uteri in cases of flooding after the birth of the child; but it has been often recommended, and there are few practitioners in this country who are not fully aware of the importance of the binder and pad in exciting permanent and regular uterine contractions. $\mathrm{Dr}$. M'Keevor states that, in $\mathbf{1 8 1 5}$, it was recommended by Dr. Iabatt in his lectures, and for a number of years before this Dr. Labatt was accustomed to recommend a thick firm pad, or compress over the pubes, previous to the application of the ordinary binder, where, in former labors, uterine hemorrhage had taken place. Dr. M'Keevor states that of 6,665 women delivered during the years 1819 and 1820 , only twentyfive were attacked with hemorrhage after the birth of the child. Of these, fifteen occurred before the expulsion of the placenta, ten afterwards, and in all the results were favorable. He saw only two fatal cases during the time he was in the Dublin Lying-in Hospital, and he attributes this small mortality partly to the process of parturition being left entirely to the unassisted gradual efforts of the uterus ; partly to the patient having been kept cool and quiet, free from all sources of disturbance and irritation ; but, above all, to the careful application of the binder immediately after delivery, by which means the expulsion of the placenta, and permanent con- 
tractions of the uterus, are most effectually secured, and whenever any tendency to hemorrhage did occur before the removal of the placenta, the first point invariably attended to was to tighten the binder, and in the event of this not succeeding, a thick firm compress, made by folding a couple of large coarse napkins into a square form, was placed over the region of the uterus, and the binder again adjusted. In the great majority of instances, these, with the admission of cool air, checked the discharge; if not sufficient, additional pressure was made with the hands.

"At the same time that you efficiently compress the fundus uteri with the binder and pad, cold should be vigorously applied to excite the contractions of the uterus. The best mode of doing this is to plunge a large napkin in a pitcher of cold water, and dash it suddenly against the external parts, the nates and thighs; and this should be repeated till the uterus contracts, and the violence of the hemorrhage is controlled. I am satisfied that this is the most efficacious method of applying cold to excite uterine contractions; it is far less formidable than pouring water from a height over the naked abdomen, but it is not less efficacious, and it possesses these decided advantages over the other method, that while the application is made to the external parts, nates, and thighs, the pressure of the binder and pad is not withdrawn from the hypogastrium, the position of the patient is not changed from the side to the back, the bed is not inundated with water, and the application can be repeated as often, and continued as long, as the urgency of the symptoms may require. The abdomen may be exposed once, and cold water poured over it from a height, and the uterus made to contract, and the flow of blood be arrested for a time; but relaxation of the uterus may follow after a short interval, and the hemorrhage be renewed again with equal violence as at first; but we cannot with propriety expose the abdomen a second time, and empty over it from a height the contents of a great decanter or kettle. Besides, by adopting this practice, we sacrifice the whole of the effects derived from pressure on the fundus uteri. The application of a napkin soaked in vinegar and water to the parts is often sufficient, along with the binder, to restrain the hemorrhage where it is not very profuse.

"I have very seldom introduced a plug of any kind into the vagina in these cases, but when there has been a draining of blood from the uterus, after the practice now described has been employed, a large soft sponge passed into the vagina, and pressed up against the os uteri, has appeared in some cases to promote the coagulation of the blood. The sponge, however, cannot be employed with safety after the expulsion of the child and placenta, unless the uterus be firmly compressed above the brim of the pelvis to prevent its becoming distended with blood. More frequently I have had recourse with good effect, to the introduction of several pieces of smooth ice into the upper part of the vagina, and allowing them to remain there, in contact with the os uteri, and be dissolved ; or pieces of ice have been inclosed in a bladder and laid over the pubes.

"Other means besides those now described have been recommended in cases of flooding after the expulsion of the placenta. It has been proposed to inject cold water into the cavity of the uterus by means of the stomach pump, and favorable reports have been given of the practice. The effect, I think, would be similar to directing forcibly a stream of cold water against a stump, soon after amputation; the coagula in the cavity of the uterus and in the orifices of the vessels would be all washed away : nevertheless, it might perhaps be advantageous in some desperate cases. Port wine and water, as cold as possible, Dr. Collins says, injected into the 
rectum, has been of service. Some of the earlier writers on midwifery, and many in the present century, have strongly recommended the introduction of the hand within the uterus for the purpose of removing the coagula accumulated within the cavity, and to excite the uterus to contract. But it is not necessary to pass the hand into the uterus,for the removal of coagula, because if the binder has been properly applied, and strong pressure made over the fundus uteri, clots cannot accumulate within the uterus, and if they have been permitted to collect in consequence of neglect, then expulsion will immediately follow the use of proper compression of the hypogastrium, without the introduction of the hand. Nor do I consider it necessary, to excite uterine contractions, that the hand should ever be introduced into the cavity of the uterus after the removal of the placenta. I am fully convinced, from repeated observation, that this practice, which is so common as to be almost universal in this country at the present time, is often not only ineffectual for the purpose, in the worst cases of flooding, but that it is often followed by the most pernicious effects; the coagula which nature has formed have been displaced by the hand, and the uterus has not been excited by the stimulus of it to secure a permanent contraction. In the greater number of fatal cases of uterine hemorrhage after the expulsion of the placenta, which have come under my observation, the hand had been introduced into the cavity, and the closed fist had been pressed for a longer or shorter time round and round against the lining membrane, to make the uterus contract. I do not recollect a single fatal case, where the unfortnnate result could be fairly attributed to the want of the introduction of the hand into the cavity of the uterus, and the friction of the knuckles against the lining membrane. I have re. peatedly passed the hand into the uterus to produce contraction, but it has refused to obey the stimulus of the hand; it has remained like a soft flaccid bag, more like a piece of intestine than uterus, and the blood has continued to pour down the arm, until the hand has been withdrawn, and more efficient remedies employed. Leroux was well aware that the stimulus of the hand would not in all cases excite the uterus to contract, for he observes, 'where the os uteri is contracted, the means indicated by Levret are very efficacious, and remove the hemorrhage as if by a charm. But it is uot so in complete inertia of the uterus; often it is widely dilated, and offers no resistance to the introduction of the hand. The introduction even of the whole hand excites little sensation, and the woman will promptly perish from hemorrhage if other means more active and certain are not employed to prevent it.' The tampon or plug is the remedy Leroux recommends in cases of flooding after delivery, and he affirms that it will often succeed in stopping the flow of blood when all other means fail. Dr. Dewees observes, that he has not found it necessary to introduce the hand, for the purpose of stopping a hemorrhage after the expulsion of the placenta, during the lust five-and-thirty years, as he regarded the practice as always frightful, and oftentimes unnecessary and pernicious. But it is difficult to subvert an established mode of practice, however unsound, and probably some of you, without much reflection, because you have heard this recommended, will pass up the hand into the cavity of the uterus after the expulsion of the placenta, on the very first occasion that you have an opportunity of doing so, remove all the coagula, and rub the inner surface with the fist till you are tired, without effect. I have seen cases repeatedly where this has been diligently performed by those who had neglected to apply the pad and bincer, and all the other means now described. If you pass the hand at all within the parts, which I strongly suspect you will do, let me entreat you to carry 
It no farther than the os uteri, which you may, with much less risk and with greater effect, press and rub with the fingers and irritate than the inner surface of the body and fundus of the uterus.

"Mauriceau recommends that women who are subject to flooding after delivery should be bled twice or thrice from the arm during pregnancy, and once, or oftener, after labor has commenced. There are cases of uterine hemorrhage after the delivery of the child and expulsion of the placenta unconnected altogether with any plethora, or an excited state of the heart and arteries, and where bleeding and low diet do not prevent the accident. Rupturing the membranes at the very commencement of labor is by far the best remedy, the only thing indeed upon which any dependence can be placed.

"After attacks of uterine hemorrhage, the patient should not be raised from the horizontal position for several hours, and the strength should be supported by wine, beef-tea, and light nourishment. Brandy in gruel sometimes agrees when wine is rejected. A good large dose of the liquor opii sedativus often produces the most decided benefit after the hemorrhage has ceased; there are few cases before this in which opium does good, though it is constantly given in all the varieties of flooding, even when the great object is to excite uterine action. Where recovery is to take place after uterine hemorrhage, says Dr. M. Hall, the pallor of the countenance, the disposition to syncope, the coldness of the extremities, the feeble state of the pulse, and uninterrupted respiration, pass gradually away. Where the case is to terminate fatally, the symptoms gradually assume a more alarming aspect, the countenance becomes pale and sunk, the respiration stertorous, and the pulse cannot be felt at the wrist. There is great restlessness, and before death one or more fits of convulsions sometimes occur. Where recovery takes place, in some women it is astonishing how little permanent inconvenience is felt from the great loss of blood which they have sustained. In the course of ten days or a fortnight the effects have entirely disappeared ; and this is the most common result. In some women, a violent determination of blood takes place to the brain, marked by heat, strong pulsations of the carotid and temporal arteries, intolerance of light, and all the symptoms of inflammation of the brain or its membranes. A strong febrile attack is also sometimes experienced, without an increased determination of blood to any particular organ. These affections of the brain and nervous system are aggravated by depletion. The patient should be kept in a cool, dark room, and mild cathartics, anodynes, and antispasmodics, occasionally given. Where there is much headache and throbbing, a few leeches should be applied to the temples, and a cold lotion to the scalp."

These remarks of Dr. Lee, as to bleeding frequently making the after symptoms worse, should be carefully borne in mind. There is no doubt but that too copious, or too frequent bleeding, during pregnancy or labor, disposes the female to many serious dangers afterwards. I have known some suffer constant headache, dizziness, and loss of memory, for weeks after from it ; and others have even been made lightheaded.

To the above remedies I would only append one other, which has, on many occasions succeeded, when all others have failed, namely gaivanism. This has, at the last moment, when the female was sinking, brought on uterine contractions, stopped the flooding, and saved her life. The application is very simple; one pole being placed on the back, immediately between the hips, and the other over the uterus. Or one of the poles may be coated with wax, all but the end, and introduced into 
the vagina, so that the unwaxed part may touch the mouth of the womb, while the other is placed over the fundus, or on the back, as found most efficient. The power should be sufficiently strong to produce contraction, and the application must be continued till the contraction remains after the pole is withdrawn. No medical man should give any female up who is flooding, no matter how severely, till he has tried galvanism. In various well-known medical works will be found many cases, with such plain directions that any one could follow them and apply it.

The presentation of the placenta, or its growth over the mouth of the womb, is the most serious cause of flooding, and generally makes any attempt to check it of no avail, except delivery. The discharge however nearly always occurs before the full period, and either causes miscarriage or necessitates premature delivery. Dr. Lee remarks :

"In the greater number of cases of placental presentation the discharge of blood takes place spontaneously in the seventh and eight months of pregnancy, and can be referred neither to bodily exertion, external violence, nor to any unusual determination to the uterine organs, or congestion of their vessels. The hemorrhage generally comes on suddenly, when the woman is in a state of rest, and the blood continues to flow until faintness or even syncope takes place. It often ceases entirely, and the patient resumes her usual occupations, and has no dread of another attack. But after an interval of several days, and sometimes not before two or three weeks, the flooding is renewed, and perhaps with increased violence, or a constant profuse dis charge takes place, and a decided effect is produced upon the constitution, the pulse becomes rapid and feeble, and the countenance pale. Similar attacks return at longer or shorter intervals, and if delivery be not accomplished by art, sooner or later death takes place. The first attack of flooding seldom proves fatal, but it sometimes does so ; for in a case which occurred in the British Lying-in Hospital, the life of the patient was at once extinguished by a single gush of blood from the uterus. I examined the body after death. The center of the placenta was over the center of the os uteri.

"When flooding takes place to an alarming extent in the seventh or eight months of gestation, you ought first to ascertain, by a careful internal examination, whether or not the placenta be situated at the os uteri. It is impossible, from the manner in which the discharge of blood takes place, to be certain of the fact; for there are some cases of hemorrhage from detachment of the placenta from the upper part of the uterus, where the flooding occurs spontaneously, and to as great an extent as in cases where the placenta presents. In some cases $I$ have been induced, from the symptoms, to believe that the placenta was at the os uteri when it was not. As the treatment and the successful or fatal result of the case will, in a great measure, depend on the correctness of the diagnosis, the examination should be conducted with so much care and circumspection as to leave no room for doubt on the subject. An ordinary examination, with the fore and middle fingers, is generaily sufficient to enable us to ascertain the true state of the case; but where the os uteri is very high up, and directed backwards, it becomes requisite to introduce the whole hand within the vagina. The finger should then be passed gently through the os uteri, and, if the placenta adheres to the cervix, it will be distinguished from coagulated blood, the only substance with which it can be confounded, by its firmer, fibrous, vascular structure, and, above all, by its adhering at one part to the uterus, and being separated at another. If you will take the trouble to pass the finger carefully and repeatedly 
over the uterine surface of a recently expelled placenta, you will never, in actual practice, mistake a placenta at the os uteri for a clot of blood, however firm. In all cases it is requisite to proceed at once to determine by an examination, so carefully conducted as to render a mistake impossible, whether or not the placenta presentseven though the hemorrlage should be slightly renewed by the displacement of the coagula; you cannot be too early aequainted with the precise condition of the patient. You ought, at the same time, to ascertain whether the placenta adheres partially or completely to the cervix uteri, and whether the os uteri is in a condition to admit of the operation of turning being performed.

"The operation of turning, which is required in all cases of complete placental presentation, is not necessary in the greater number of cases in which the edge of the placenta passing into the membranes can be distinctly felt through the os uteri. Sometimes there is profuse and dangerous hemorrhage where the placenta does not adhere all round to the neck of the uterus, but only partially. If the os uteri is not much dilated or dilatable, the best practice in these cases is to rupture the membranes, to excite the uterus to contract vigorously, by the binder, ergot, and all other means, and to leave the case to nature: by adopting this treatment the operation of turning may be avoided with advantage in the greater number of cases of partial placental presentation. But, if the hemorrhage is profuse, has returned at different intervals, and a great quantity has been lost, and the constitution is really affected, it is the safest practice at once, if the orifice of the uterus is in a condition to allow the hand to pass without difficulty, to deliver by turning the child.

"Where the placental presentation is complete, the operation of turning should be performed, in all cases, as soon as the orifice of the uterus is so much dilated or dilatable as to allow the hand to be introduced without the employment of much force. It is seldom safe to attempt to deliver by turning before the os uteri is so far dilated that you can easily introduce the points of the four fingers and thumb within it : however soft and relaxed it may be, until dilatation has commenced, and proceeded so far, I am convinced there are very few cases in which the operation of turning will be required, or completed without the risk of inflicting some injury on the os uteri. This is a point of the greatest practical importance, but I do not know in what manner to communicate to you, in words, a more clear and definite idea of the grounds upon which you ought to proceed.

"In every case, before attempting to turn, make a most careful examination of the os uteri, and endeavor, from the degree of dilatation, and the thinness and softness of the orifice, to form a correct judgment upon this point, before interfering, for the hemorrhage will be renewed if the attempt is unsuccessful, and the patient will be placed in a worse condition than she was before. When you have resolved to turn, let the patient lie on the left side, with the pelvis close to the edge of the bed, and introduce the right hand into the vagina as before described, and then pass the fingers and hand gently and slowly in a conical form through the os uteri, giving it time to dilate, and onward into the cavity between the detached portion of the placenta and the uterus; then force the fingers through the membranes, grasp both feet, and bring them down into the vagina, and slowly extract the child as in the case of nates presentation, and do not afterwards be in a hurry to remove the placenta, unless it is wholly detached and lying in the upper part of the vagina. This operation is easily and speedily performed when the os uteri is widely dilated and dilatable. It is, however, a great exaggeration of the facility with which turning 
may be accomplished in these cases, to represent it as a very simple process-like putting the hand into the coat pocket and pulling out your handkerchief. At the best it is a dangerous operation, and you can never tell with certainty whether or not the patient will recover after its performance, however easily it may have been effected.

"But there is not unfrequently most profuse and alarming flooding from complete placental presentation, where the os uteri is so thick, rigid, and undilatable, that it is impossible to introduce the hand into the uterus without producing certain mischief. In thirteen out of thirty-six recorded cases the os uteri was rigid and undilatable. The tampon or plug has no power to restrain the hemorrhage in such cases, nor do I know of any other means-neither cold, quietness, nor opium-which effectually have, and it is sometimes absolutely necessary under such circumstances to deliver by turning, before the hand can possibly be introduced into the uterus without producing fatal contusion or laceration of the part. I have found in several of these cases, however, that the delivery may be safely accomplished by merely passing the hand into the vagina, and afterwards the fore and middle fingers between the uterus and detached portion of the placenta, grasping with them the feet, which are generally situated near the os uteri, and drawing down the inferior extremities into the vagina, and delivering. I know that the inferior extremities may often be brought down in this way where it is impossible to pass the whole hand through the os uteri."

The same state of things may however result from other causes, and a very different mode of proceeding may then be needed, as the doctor very clearly shows.

"Flooding may take place in the latter months of pregnancy, and during labor, where the placenta does not adhere to the neck of the uterus, but to the body or the fundus, and is detached by some external or internal cause. The separation of the placenta from the upper part of the uterus may be produced by violence, as blows, falls, pressure over the hypogastrium, and shocks of various kinds; but it arises much more frequently from internal causes, of which morbid states of the placenta, and twisting of the umbilical cord once or oftener round the neck of the child, are the most common and obvious. This variety of hemorrhage, though usually termed accidental, can rarely, however, be referred to accident. Sometimes the flooding occurs to a great extent without any assignable cause ; a large portion or the whole of the placenta, when in a healthy condition, being suddenly detached from the uterus, when the patient has been exposed to no external accident, or injury of any kind, and when no symptoms of increased determination of blood to the uterus have preceded the attack. When this happens a large quantity of blood is poured out between the placenta and uterus, a small portion of which only at the time usually escapes from the vagina, to indicate what is going on within the uterus. There may be a great internal hemorrhage, accompanied with the ordinary constitutional effects resulting from loss of blood-as faintness, sickness, or vomiting, coldness of the extremities, rapid feeble pulse, hurried breathing; when there is little or no discharge from the vagina to excite alarm, or to point out the source of danger, when it is extreme. It is from the general symptoms of exhaustion, and by the disagreeable sense of uneasiness, weight, or distention of the uterus, experienced, and not from the quantity of blood which appears externally in these cases, that we are led to discover the true state of the patient-to suspect that internal hemorrhage is going on. But much more trequently only a small portion of the placenta is at first de- 
tached, and the greater part of the blood which is extravasated between it and the uterus separates the membranes, and descends by its weight to the orifice, and escapes through the vagina. In all cases, however, of uterine hemorrhage in the latter months, the danger cannot be so accurately estimated by the quantity of blood which appears externally, as by the general symptoms. The portion of placenta which is detached never reunites to the uterus, but when expelled it is usually seen covered with a dark coagulum adhering to the uterine surface.

"When the blood escapes in small quantity, and there are no labor pains present, and no disposition in the os uteri to dilate, and the constitutional powers are not impaired, an attempt should be made to prevent a return of the discharge and the occurrence of labor pains. For this purpose, if the pulse is full and frequent, some blood may be taken from the arm, and the patient should be kept in the horizontal position, surrounded by cool air, cold applications made over the hypogastrium, and acetate of lead and opium, mineral acids, and other remedies that diminish the force of the circulation and promote the coagulation of the blood, should be taken internally. The plug is here totally inadmissable; it can only convert an external into an internal hemorrhage. But where the flooding occurs at first profusely, and is renewed even in a moderate degree, in spite of our efforts to check it, the continuance of pregnancy to the full period cannot be expected; it will be of no avail to bleed and administer internal remedies, except for the purpose of checking the discharge, and thus averting the immediate danger until the uterus is emptied of its contents.

"The operation of turning, which is required in all cases of complete placental presentation, is rarely necessary in uterine hemorrhage where the membranes are felt at the orifice. In a great proportion of these cases, where, on making an examination, you can feel the smooth membranes extending across the neck of the uterus, the flooding will be arrested, and the labor safely completed, if the membranes are ruptured, the liquor amnii discharged and contractions of the uterus excited by gentle dilatation of the orifice, and other appropriate means. The only cases in which this treatment fails are those in which it has not been had recourse to sufficiently early, or where the whole or a large portion of the placenta has been suddenly separated from the uterus, and a great internal hemorrhage has taken place. The uterus will not contract effectually in these cases after the membranes have been ruptured; the pains, instead of becoming stronger, become more and more feeble, return at longer intervals, and during these the blood flows more profusely, and death would take place before delivery, if the child were not extracted by the forceps, crotchet, or by the operation of turning. In all cases, then, of uterine hemorrhage in the latter months of pregnancy, and in the first stage of labor, where the placenta does not present, and the quantity of blood discharged is so great as to render delivery necessary, where it appears improbable that the pregnancy can go on longer with safety, or to the end of the ninth month, rupture the membranes with the nail of the forefinger of the right hand, evacuate the liquor amnii by holding up the head of the child, dilate very gently the os uteri with the fore and middle fingers expanded, and occasionally make pressure with the fingers around the whole orifice; apply the binder, give ergot and stimulants, and the uterus will, in all probability, contract upon its contents, and expel them without further trouble. If the hemorrhage should, however, continue after the employment of these means, delivery must be accomplished by the forceps, craniotomy, or by turning, according to the peculiarities of the case. In women who are liable to attacks of flooding after the expul- 
sion of the child or placenta, rupture the membranes at the commencement of labor, even before the os uteri is much dilated, if the presentation is natural, and you will often succeed in entirely preventing hemorrhage."

The recommendation to bleed may be with good reason objected to, at least in the great majority of such cases; and I cannot but think that a timely and persevering use of the ordinary remedies, namely, keeping quiet, using acid drinks, and cold fomentations to the abdomen, would do away with any necessity for it at all. I question very much if ever bleeding really prevented abortion from flooding, and I cannot but think that it has often brought it on sooner. Nevertheless, if all other means fail to arrest the discharge, and there are no decided objections to the contrary, it might be cautiously tried; though the policy of taking more blood from a person who is already losing too much, is not very evident.

I have often known the most severe flooding stopped, merely by the female lying on her back, drinking plentifully of lemonade, and applying cold wet cloths over the abdomen. A small dose of laudanum occasionally is also useful; and complete rest and tranquility of mind is as indispensable as rest of the body. Many females flood and miscarry merely from worrying and fretting themselves, and from passion, or strong excitement, particularly of a certain kind. This in short must be carefully aroided, and the patient must live strictly as if a widow.

This accident is likely to occur in subsequent pregnancies, at nearly the same time, and should therefore be guarded against by a careful avoidance of all excitement, or violent bodily exertion, during the whole time. Keeping the bowels gently open, and practicing a regular diet, are also requisite. A good supporting bandage is often of frequent service. 


\section{CHAPTER LXXV.}

\section{ECLAMPSIA, OR CONVULSIONS.}

Convulsions are to be looked upon as very serious indications of derangement, during either pregnancy or labor, and are frequently followed by fatal results to both mother and child. They may be of several different kinds, epileptic, hysteric, or cataleptic, though the epileptic form is most common. They often occur during pregnancy, but not usually before the seventh month, though occasionally met with much earlier. According to observations it appears that there is not above one case of convulsions in six hundred deliveries.

The principal cause of this disease appears to be the strong sympathy between the womb and other organs, owing to which they are continually disturbed by the changes it undergoes. Certain temperaments also dispose to it, particularly the lymphatic, and also dropsy, rickets, and other diseases. Strong moral impressions may also have a predisposing effect, such as sudden frights, joy or anger, and also acute pain, or the dread of it.

In most cases, and particularly during pregnancy, the convulsions are preceded, and indicated, by severe headache, and spasm at the stomach with dimness of sight, bright sparks before the eyes, buzzing in the ears, and partial difficulty in speaking. Occasionally, however, the fit comes on quite suddenly, without any warning whatever.

There are few exhibitions of suffering more frightful than one of these attacks, and none that call for more prompt and decided action. In general females are perfectly helpless when one is attacked in this way, and instead of being able and disposed to render proper assistance, they either run away alarmed, or fall into hysterics themselves. It is, however, of the utmost consequence that the sufferer should be attended to instantly, and therefore every female should know what to do in such an emergency, at least till better aid can arrive.

At the first commencement of convulsions the features become gradually fixed, the eyes are expanded and distorted, the breath is drawn with difficulty, and all consciousness appears to cease. The body then begins to twitch, the mouth opens, usually on one side, the tongue protrudes, the head turns on one side, and the blood rushes to it and the face in great quantities. In a short time the jaws close again with great force, and the tongue is bitten if proper care has not been taken to prevent it. At last the eyes begin to twinkle, the mouth moves as if the patient were muttering, and the nostrils expand; the arms are thrust straight down by the sides of the body, with the hands firmly closed ; the legs are stiffened straight out, and the body is bent back like a bow. In short, every muscle is affected with spasms, which are sometimes fearfully violent, and may endure for a considerable time. When they subside, the fit gradually terminates and passes off. During the whole time the breathing is difficult, the mouth froths very much, and the heart palpitates quickly, 
but irregularly. When the spasm is over, the patient falls into a perfect stupor, during which she remains unconscious, but with all the limbs soft and movable, except the fingers, which appear to grasp. The jaws generally remain closed, and so do the eyes, but they may be easily opened, and will sometimes remain open; the breathing becomes powerful and loud, and the pulse beats with rapidity. At last slight motions are observed, and consciousness gradually returns, but the memory is generally gone for some time. This state of stupor usually lasts from ten minutes to half an hour, but has been known to continue for many hours, or even a whole day. The spasm seldom continues more than from one to ten minutes, though it has lasted for an hour or more.

These convulsions might be mistaken for ordinary hysteria by those not acquainted with the difference. In hysteria, however, the female moves about and struggles more; she also cries out, and retains both sensibility and consciousness, so perfectly even sometimes that she requests those around to hold her, which is never the case in convulsions.

During the stupor it might be supposed by any one not aware of the previous fit, that the patient was suffering from apoplexy, or intoxication, the appearance being so similar to that exhibited in those states. This shows the necessity for careful inquiries as to what has previously occurred.

During pregnancy, convulsions generally cause abortion, either by bringing on uterine contractions, or by causing the death of the child. Some few patients have suffered from them, however, and yet gone their full time, but this must never be expected. A gradual extinction of the vital spark, during the stupor, is the ordinary termination, though sudden death is not unfrequent, during the fit. Gradual recovery is occasionally witnessed, but seldom without partial loss of memory, or some other affliction. Madame Lachapelle says that one-half of the females attacked with convulsions die, and of their children many more.

There is no doubt but that the tendency to this fearful affliction may be very much lessened in many females, by proper attention to diet and regimen. Those who are of a full habit, and disposed to headache, and rush of blood to the head, should live low, and carefully avoid everything of a heating or stimulating character, and also every kind of excitement or agitation. The bowels should be kept free, and the skin well rubbed and kept warm, and the head cool.

Treatment.-While the patient is in the fit, care must be taken that she does not fall off the bed, or bite her tongue, to prevent which the jaws must be kept apart, by putting something between, as a piece of soft wood, or the handle of a spoon covered with cloth, or even a knotted napkin. The face should be sprinkled with cold water, and the whole body well chafed, particularly the hands and feet, which should also be made warm as soon as possible. As soon as the spasm is over, it is customary to bleed, either at the arm, or by leeches to the temples and behind the ears. Mustard poultices should also be applied to the feet, and inside the thighs, and an enema should be given of warm water and a tablespoonful of salt. Ice, or cold water, should be applied to the head constantly, and, if possible, the body should be immersed in a hot bath, which will, in many instances, bring the patient round immediately without any other treatment. The bladder should be also looked to, as well as the bowels, and if necessary the catheter should be used. As soon as she can swallow, a few drops of laudanum may be given, or a little ether, but not a full dose by any means.

The propriety of bleeding, even in these cases, is denied by many, and I am 
almost inclined to think myself that a prompt and persevering use of the other remedies mentioned would be fully as successful without it. At all events, the fearful inortality in spite of it proves that it has not much power, and may well raise a doubt of its utility.

Convulsions, however, are so fearful and violent, that few practitioners can resist the temptation to bleed, because it seems so well calculated to give prompt relief, and besides it has popular prejudice in its favor. Some authors, however, assert that it makes the danger greater of paralysis and loss of memory afterwards.

When convulsions occur during pregnancy they seldom cease entirely till the uterus is emptied of its contents. It is therefore necessary to bring on labor, and terminate it as soon as possible, after the parts are in a proper condition. When they occur during labor, it must also be finished in the shortest time possible to afford the best chance of saring the child, and also because no treatment will prevent the attack while the patient remains undelivered. All means of bringing on dilatation of the mouth of the womb, mentioned in previous articles, may be resorted to, excepting ergot, which should never be used in these cases.

M. Chailly tells us that in thirteen cases of convulsions, nine were first pregnancies, and seven of the females were dropsical. Only one was attacked during pregnancy, ten while in labor, and two after. Only two died, and ten of the children.

It is worthy of remark that where pregnant females have had convulsions, appa rently from living too high, the children have also had them after delivery. 


\section{CHAPTER LXXVI.}

\section{RUPTURE OF THE WOMB OR VAGINA.}

RUPTURE of the womb arises from various causes, but most nsually from powerful contractions when the pelvis is small, or the foetus large, or when it presents unfavorably. It not unfrequently results also from force being used, particularly with instruments. In fact there is no donbt but that numerous females die from this accident, brought on by the violence, haste, and want of skill of their attendants. Few injuries are more serious, or more beyond the reach of any remedy than this, though it is sometimes suffered with impunity.

The symptoms of rupture of the womb are strongly marked, and fearfully evident. When it occurs, which is most usually during a powerful contraction, the female shrieks, and instantly complains of an agonizing pain over the seat of the rupture; her face grows deadly pale, her pulse falls, and she faints. In general death is almost instantaneous, though sometimes life may be preserved for an hour or two, but very seldom. There have been cases of recovery, but they are very few, and regarded almost as miracles.

In most cases, directly the rupture happens the fotus escapes through the rent into the abdomen, and most of the fluid with it; but sometimes it still remains in the womb, and then if the liquor amnii is discharged there may little or nothing pass through the opening, and the danger will be much lessened in consequence. In all cases the only proceeding which offers any chance of recovery is, to deliver as soon as possible, because when the fœetus is expelled the uterus begins to contract, so as to close the wound, and when that is effected, if but little fluid has passed into the cavity of the abdomen, all may yet go well. It may frequently happen, when the hand is passed into the womb, to turn and deliver, that nothing can be found, the footus having passed through the opening into the abdominal cavity, in which case the hand must be passed through the opening also, and the fortus be brought back if possible. If however the rent is too much closed, or the child cannot be reached, the Coesarean operation is the only resort.

M. P. Dubois tells us of a case of this kind which occurred in his own practice. The female had only been in labor about an hour when she uttered a piercing cry, and sank as if suddenly mortally wounded. The head of the child, which was previously at the mouth of the womb, could not be felt, and on introducing his hand M. Dubois found its feet were passed through the opening into the mother's abdomen; he brought them back, however, and effected delivery by turning with comparative ease. Strange to say this woman was discharged cured, in fifteen days after, though the uterus was so torn that the intestines had forced themselves through the opening into its cavity, and M. Dubois put them back with his hand, which also passed clear into the peritoneal cavity. In all cases, after the delivery is effected, the womb should be 
again explored, so that if any parts have come through they may be returned before the opening closes, which it may do very soon.

Cases are even mentioned where the child passed clear out of the womb into the abdominal cavity, and remained there till it absorbed, or escaped through a fistulous opening many years after; while the womb healed up, and otherwise the patient perfectly recovered. Recovery however, in any way, is a rare occurrence.

Some females seem more disposed to this accident than others; possibly from a peculiar tenderness in the substance of the womb. All are however liable to it, and this liability should beget a proper caution in all manipulations, and forbid uncalledfor violence in any way.

Rupture of the vagina is much less serious than rupture of the womb, anless it occurs at the upper part, when it may give rise to similar symptoms and results. At the lower part the danger is much less, though still sufficient to excite apprehension.

The treatment is the same as in the former case. Delivery must be effected as soon as possible, and the patient kept still and cool to avoid inflammation.

It is generally thought that the greater part of these accidents result from improper treatment, and particularly from using instruments improperly, or unnecessarily. 


\section{CHAPTER LXXVII.}

\section{OPERATIONS WITH INSTRUMENTS.}

THE use of instruments in effecting delivery is a last resort to save life, and ought to be intrusted only to persons of skill; it may therefore be thought unnecessary to treat of them in the present work, and indeed I should not have done so but for the purpose of satisfying the natural curiosity of females themselres. The greater part of the dread they now experience where instruments are needed arises from ignorance of their nature and mode of action. At the present time nearly all the instruments used, in competent hands, are comparatively safe and harmless, and if females generally understood how they operated, much less fear wonld be excited by their use. Years ago, when cutting and tearing instruments were employed, in nearly every case of difficulty, the lamentable results which followed fully justified the fears experienced; but at the present day such things are seldom seen, except in medical museums, the same purpose being nuch better effected by simpler and more harm. less apparatus. I wish therefore simply to give a brief explanation of the structure, and mode of action, of the instruments now chiefly employed, and to show the extent of their application and the results which have followed from it.

\section{THE FORCEPS.}

The forceps are intended to take hold of the foetus, and assist us to draw it into the world when the natural forces are inadequate, and no hold can be obtained by the hands. They were first invented about the year 1650, by an English surgeon

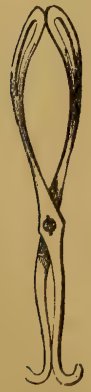

Frgure 194.

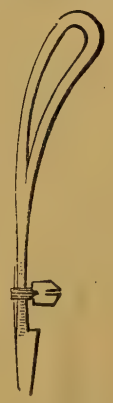

FTGURE 195 named Chamberlin, who made a secret of his invention and realized a large fortune from it. Since that time they have been modified in various ways, by different practitioners, but still remain essentially the same as when first used.

The most usual form, and probably the best, is that represented in Figure 194. It consists of two blades articulated by a button or screw joint, so that they can be easily separated and again adjusted. Each blade is cut out in the middle, and curved, as seen in Fig. 195.

The only part to which the forceps are intended to be applied is the head, to the dimensions and form of which they are specially adapted. Some practitioners have used them on the breech, but the practice is not generally sanctioned, because they seldom retain their hold on this part, and are nearly sure to seriously injure the 
child when so applied. When properly constructed forceps are rightly applied to the head there is but little danger, either to the mother or the child; but in the hands of an unskillful or careless person the consequences of their use may be deplorable to both.

It is scarcely necessary to remark that the forceps are neither cutting nor crushing instruments, but are simply intended to lay hold, like the hand itself, and enable us to draw down the head, or change its position. Most usually they are made long and curved, as shown in the above figure, but sometimes they are made much shorter and straight. They may be used upon the head when it is either at the upper or the lower strait, or while it is in the passage ; but on no account should they be applied till the parts are fully dilated, and everything indicates that the child can pass. Thus they should never be used when the head is too large, or the pelvis too small, nor when there are tumors in the way. In short no attempt should be made with them to force the foetus through a passage which will not admit it by reasonable efforts. M. Dubois says they should never be used when the pelvic diameter is less than three inches, because with such dimensions the child is nearly certain to be crushed to death, and the mother can scarcely escape serious bruises and lacerations. In like manner, if they are thrust into the womb before the mouth of it is naturally dilated they are sure to tear and injure it.

It is not necessary here to give directions for using the forceps in every variety of presentation and position, but simply to show the mode of applying them as they are most frequently required. The two blades are adjusted separately, one to each side of the head, and then locked together, so that the head is firmly inclosed between them, but not crushed. Dr. Denman gives perhaps the best and simplest directions on this point, and I therefore quote from his work :

"The first part of the operation consists in passing the forefinger of the right hand behind the ossa pubis and the head of the child to the ear ; then taking the part of the forceps to be first introduced by the handle in the left hand, the point of the blade is to be slowly conducted between the head of the child and the finger till the instrument touches the ear : there can be no difficulty or hazard in carrying the instrument thus far, because it will be guided, and in some measure shielded, by the finger. But the further introduction must be made with a slow semi-rotatory motion, keeping the point of the blade not rigidly, yet closely, to the bead of the child, by raising the handle toward the pubes. In this manner the blade must be carried gently along the head till the lock reaches the external parts near the anterior angle of the pudendum. The point of the blade, while introducing, sometimes hitches upon the ear of the child, and it then requires a little elevation. But when it has passed the ear, and is beyond the guidance of the finger, should there be any check to the introduction either of this or the other blade, it should be withdrawn a little, to give us an opportunity of discovering the cause of the obstacle, which we must never strive to overcome by violence, though we must proceed with firmness. When the first blade is properly introduced, it must be held steadily in its place by pressing the handle toward the pubes, and it will be a guide in the introduction and application of the second blade. Let the second blade be introduced in this manner. Keep the blade first introduced in its place with the two lesser fingers of the left hand, and carry the fore-finger of the same hand between the perineum and head of the child as high as you can reach. Then take the second blade of the forceps by the handle in the right hand, and, conveying the point between the finger placed within the perineum and the head of the child, conduct 
the instrument, with the precantions before mentioned, so far that the lock shall touch the interior part of the perineum, or even press it a little backwards. In order to fix the two blades thus introduced, that which was placed toward the pubes must be slowly withdrawn, and carried so far backwards that it can be locked with the second blade retained in its first position; and care must be taken that nothing be entangled in the lock, by passing the finger round it. When the forceps are locked, it will be convenient to tie the handles together with sufficient firmness to prevent them from sliding or ehanging their position when they are not held in the hand, but not in such a manner as to increase the compression upon the head of the child. Should the blades of the forceps be introduced so as not to be opposite each other, they could not be locked ; or if, when applied, the handles should come close together, or be at a great distance from each other, they would probably slip, or there would be a failure of some kind in the operation, as the bulk of the head would not be included or they would be fixed on some improper part of the head; though allowance is to be made for the difference in the size of the heads of children. But if a case be proper for the forceps, if they be well applied, and we were to act slowly with them, there would not be much risk of failure or disappointment. The difficulty of applying the forceps is most frequently occasioned by attempting to apply them too soon, or by passing them in a wrong direction, or by entangling the soft parts of the mother between the instrument and the head of the child, against sll which accidents we are to be on our guard.

"When the forceps are first locked, they are placed backwards, with the lock close to, or just within, the internal surface of the perineum ; and they can have no support backwards, except the little which is afforded by the soft parts. The first action with them should therefore be made by bringing the handles, grasped firmly in one or both hands, to prevent the instrument from playing upon the head of the child, slowly toward the pubes till they come to a full rest. Having waited a short interval with them in that situation, the handles must be carried back in the same slow but steady manner to the perineum, exerting, as they are carried in the different situations, a certain degree of extracting force; and after waiting another interval, they are again to be carried toward the pubes, according to the direction of the handles. Throughout the operation, especially the first part, the action of that blade of the forceps originally applied toward the pubes must be stronger and more extensire than the action with the other blade, this having no fulcrum to support it, and chiefly answering the purpose of regulating the action of the other blade. If there were any labor pains when the operation was begun, or should they come on in the course of it, the forceps should only be acted with during the continuance of the pains; the intention being, not only to supply the want or insufficiency of the pains, but to follow them, and imitate also the manner in which they return. By a few repetitions of this alternate action and rest before described, we shall soon be sensible of the descent of the head; and it will be proper to examine very frequently, to know the progress made, that we may not use more force than needful, nor go on with more haste than may be expedient or safe. In every case we ought to proceed slowly and circumspectly, not forgetting that a small degree of force, continued for a long time, will in general be equivalent to a greater force hastily exerted, and with infinitely less detriment to the mother or child. But after some time, should we not perceive the head to descend, the force bitherto used must be gradually increased, till it be sufficient to overcome the obstacies to the delivery of the patient. It was 
before obserred, as the head of the child descended, that the face would be accordingly turned toward the hollow of the sacrum, without any aim or assistance on our part. Of course the position of the handles of the forceps, and the direction in which we ought to act with them, should alter ; for they becoming first more diagonal or oblique with respect to the pelvis, and then more and more lateral, every change in their position will require a differently directed action, because the handles should ever be antagonists to each other. In proportion also to the descent of the head the handles of the forceps should approach nearer to the pubes; so that, in the beginning of the operation, though we acted in the direction of the cavity of the pelvis, toward the conclusion we should act in that of the vagina. When we feel that we have the command of the head, by its being cleared of the pelvis, and the external parts begin to be distended, we ought to act yet more slowly, especially in the case of a first child, or there would be great danger of a laceration of the soft parts; and this can only be prevented by acting very deliberately in the direction of the vagina-by giving the parts time to distend-by duly supporting the perineum, which is the part chiefly in danger, with the palm of the hand-by soothing and moderating the hurry and efforts of the patient-and, in some cases, by absolutely resisting for a certain time the passage of the head through the external parts."

It is merely necessary to remark, in conclusion, that the forceps should never be used till it is manifestly impossible for the child to be born without them ; and it should be remembered that nature alone frequently effects delivery under the most unfavorable circumstances, by giving her time. We should wait therefore as long as the safety of the mother will allow, but never delay a moment when that safety is compromised.

The accidents which have followed from the use of the forceps are numerous and terrible, and I could give a most horrifying account of them if it were necessary. It must be recollected, however, that these accidents have chiefly followed from want of skill in managing the instrument, or from its being used under improper circumstances. It is true that there is always more or less of pain and injury to be dreaded from the forceps, even in the most favorable cases, and with the most competent operators, but this is no argument against their employment altogether. In every case where they are really called for, the female would, most probably, die undelivered, or have to be cut open, so that it is simply a choice of evils, of which the forceps are the least.

The cases in which the forceps are absolutely necessary, however, are VERY RARE, much more so in fact than many people sup-

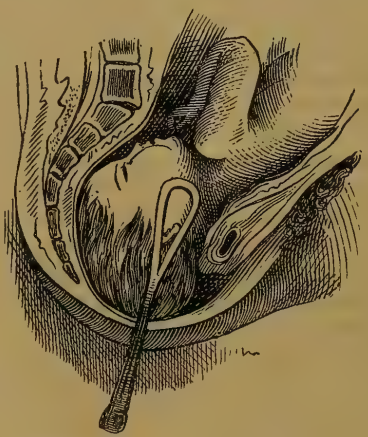

Frgore 196.-The head being dranon. through a narrono pelvis by the forceps.

The manner in which the forceps draw the head is well shown in the above plate, and also the compression of the head itself, which is seen to be squeezed almost to a point at its presenting part. This compression, however, is not likely to do serious injury, unless it be excessive. The child may be convulsed a little from it, but usually recovers, and suffers nothing afterwards. pose. Patience, and the persevering use of ordinary assistance, would probably succeed alone in half the cases where they are now employed. 
In Murphy's lectures on difficult labors, he gives us some valuable statistics on this subject. He tells us that in seventy-five thousand nine hundred and eleven labors, the forceps were used only one hundred and thirty-eight times, or once in every five hundred and fifty labors. In these one hundred and thirty-eight cases thirty-five of the children died, and ten of the mothers. Dr. Murphy, however, thinks that the general results, to both mother and child would be equally favorable if the forceps were not used at all, and he gives the tables of Dr. Collins to support his opinions. From these tables it really appears that, when all the difficult labors were left entirely to nature, the number of deaths was just about the same as when the forceps were used, in fact rather less, while the accidents, and subsequent evils, were not nearly so great. Dr. Murphy therefore thinks that the forceps should never be used, except in a few cases where everything is quite favorable to the passage of the foetus; and the uterus cannot be made, in a reasonable time, to contract and expel it; and also when immediate delivery is needed to save the mother's life, as in flooding. In cases of mere ordinary difficulty or delay, he decries their use entirely ; and he evidently thinks that when the labor is fit to be terminated by the forceps, nature can and will terminate it herself if left alone. There is no doubt but that they are now used a great deal too much, either from a desire to operate, or from want of patience; and I have no hesitation in expressing my opinion that more have been killed than saved by them.

\section{OTHER INSTRUMENTS.}

Respecting other instruments, such as the crotchet, the vectis, and the cephalotribe, or crushing forceps, it is not necessary to say anything here, as their use, when imperatively needed, must necessarily be confined to the surgeon; and fortunately may now be dispensed with altogether. The recently introduced practice of bringing on premature labor, in all cases of deformity or smallness of the pelvis, entirely obviates the necessity for any of these dreadful resorts, if the difficulty be known in time, which it is sure to be when a sufficient degree of knowledge is disseminated.

The Cosarian operation, or cutting open the womb externally ; and cephalotomy, or the opening of the child's head, may also be dismissed with the same observations. They can always be avoided, if the real condition of the patient is known in time ; and if from neglect, nothing else can be done, they must always be performed by a skillful surgeon. 


\section{CHAPTER LXXVIII.}

\section{OPERATIONS WITH THE HAND.}

\section{Turning.}

THIS is one of the most useful operations that the accoucheur can perform, in many cases, and has the advantage of being altogether accomplished by the hand. Its object is to change the presentation, when unfavorable, and to facilitate delivery. Most usually the hand is introduced into the uterus, and the feet are brought down. This is called pelvic version; but sometimes the head is brought to the mouth of the womb, particularly in shoulder presentations, and this is called cephalic version.

Cephaluc Version.-This can seldom be performed, and not often attempted with safety. In some cases, however, when it is ascertained that the shoulder presents, and before the membranes are broken, an effort may be made to remove it and bring the head in its place. To do this the position of the head must be ascertained externally, and one hand placed upon it; then with the two forefingers of the other raise up the shoulder from within, as in ballotment, and endeavor to push the head into its place. If the child be very movable this may sometimes be done, and will be highly advantageous ; but most frequently the substitution cannot be accomplished, and the attempt ruptures the membranes, after which it is still more difficult, and often becomes dangerous. Even if the head be brought down there is always danger of its becoming displaced, and the shoulder again presented, owing to the tendency which any presentation has to be reproduced. To prevent this the hand should be firmly pressed on the fœtus, externally, as soon as the head is brought down, to fix it; and the membranes should be ruptured so that it may begin to descend, after which there is no danger of a change.

Cephalic version can be so seldom performed, however, and is so difficult, and sometimes dangerous, that it is seldom or never attempted ; more particularly as pelvic version can always be substituted, and is more easy and safe. It is true that presentations of the head are the most favorable, providing they occur before the rupture of the membranes; but after that event they may not be so favorable as those of the lower extremities, and certainly are not so easy or safe to induce.

Pelvic Version. - Turning to bring down the feet is performed for various reasons, and under many different circumstances. As a general principle we may say that it is done either to change the presentation, when unfavorable, or to terminate the labor when it is lingering, or when it is desirable to have it over as quickly as possible. The feet may be drawn through the mouth of the womb when it is but little opened, and when they have once passed, the limbs and body soon follow, and the head seldom remains long behind. The fotus may in fact be compared to a wedge, of which the feet are the point, and if they enter the passage the other parts are gradually driven after by the uterine contractions. 
The chief contingencies which call for the operation of turning are, a protracted labor, a presentation of the placenta, causing hemorrhage, and a wrong presentation, particularly one of the shoulder.

The operation of turning is very clearly explained by Dr. Lee, and I know from experience that his directions can be safely relied upon. It very frequently happens, however, that there will be some peculiar circumstances in a case, which will necessitate more or less change in the manner of proceeding, so that the practitioner must after all be guided, to a great extent, by the requirements and conditions then existing. Dr. Lee's directions, therefore, must merely be considered as general ones, to be modified as occasion may require :

"When the operation of turning is required before the membranes are ruptured, and when the orifice of the uterus is widely dilated, and there are long intervals between the pains, it is accompanied with little difficulty and danger. Having explained to the patient and her relatives the nature of the case, let her lie on the left side near the edge of the bed, with the knees drawn up to the abdomen. Sit down by the side of the bed, and quietly take off your coat; lay bare your right arm by turning up the shirt above the elbow, and cover the back of the hand and the whole forearm with cold cream, lard, or a solution of soap. Introduce one finger after another into the vagina, and slowly and effectually dilate its orifice. The hand, in a conical form, and in a state of half supination, must then be pressed steadily forward with a semi-rotatory motion against the perineum and sides of the passage, till it clears the orifice of the vagina. This should always be done very slowly and gently, as it is accompanied with great pain. Let the hand remain some time in the orifice of the vagina, that it may be fully dilated, and offer no resistance in the subsequent steps of the operation of turning. When the hand has dilated the vagina sufficiently, in the absence of pain gently insinuate the points of the fingers and thumb into the os uteri in a conical form, and if it is not sufficiently open to allow the hand to pass, you must proceed next to use artificial dilatation here also, very gently and slowly, always stopping as soon as a pain comes on, but not withdrawing the fingers altogether at the time from the os uteri. Having succeeded in dilating the part without rupturing the membranes, slide the hand up between the membranes and the anterior part of the uterus into the cavity, and grasp the feet when the membranes give way. Most frequently the membranes burst as the hand is entering the uterus before it reaches the feet, and the liquor amnii rushes out and is lost, if it is not prevented by pressing the hand forward firmly into the orifice. Never be contented with one foot when it is possible to grasp both ; and this can always be done when the liquor amnii has not escaped, and the uterus is not closely contracted round the body of the child. Seize both feet and legs, and when there is no pain, draw them down into the vagina; and as the nates descend through the os uteri, the shoulder and arm will gradually recede or be retracted, and will offer no obstacle to the remaining part of the operation, which should be completed as if the nates and inferior extremities had originally presented, and which has already been very fully described. In actual practice, except in twin cases, the membranes have been ruptured and the liquor amnii is gone, in a great proportion of cases-in about ten to one-long before we are called upon to deliver by turning, and the operation is then a much more serious affair. Sometimes, when the os uteri is half dilated, there is an interval of freedom from pain for several hours after the rupture of the membranes, and partial escape of the liquor amnii. Here it is advisable to 
turn without delay; and the hand can be passed up into the uterus and the feet brought down with little more difficulty than if the membranes had not been ruptured."

The operation of turning is, however, beset with many difficulties, and unless the conditions for it are very favorable, and the operator skillful, it may cause greater mischief than it is intended to remedy. The probability is, as in the case of other operations, that it would seldom or never be needed if proper means were used in time, and perseveringly ; and it is yet a question whether the prospect, for both mother and child, would not be more favorable if the delivery was always left to nature, in those cases where version is now attempted. Dr. Collins says, "As to turning, the risk to the mother is, in the majority of cases, so great as to forbid its employment, nor do I think the practitioner justified by the circumstances in so greatly hazarding his patient's life." 


\section{CHAPTER LXXIX.}

\section{THE DISEASES OF WOMEN DURING PREGNANCY, AND IN CHILDBED.}

WOMEN are liable during pregnancy, and after childbirth, to most of the diseases which afflict them at other times, and also to many derangements peculiar to those periods. As a general rule either of those conditions somewhat modifies the disease, and also necessitates certain differences in its treatment. The former part of this work having treated on all those affections common to every other period, I shall, in this, confine myself chiefly to those peculiar to the two conditions referred to; giving their causes, symptoms, and treatment, with practical hints for their prevention.

\section{THE DISEASES OF PREGNANCY.}

The diseases which are found during pregnancy are of two kinds : the first kind called Sympathetic, or nervous, consist of various derangements of different parts of the system, produced chiefly by nervous sympathy with the womb. The second kind, called Idiopathic, are real primary derangements of the generative organs themselves, or of those intimately connected with them. Each of these kinds will be treated of separately.

\section{SYMPATHETIC DISEASES OCCURRING DURING PREGNANCY.}

\section{Sickness and Vomiting.}

Nausea, or sickness, with or without vomiting, is one of the most frequent and troublesome accompaniments of pregnancy. It is so general, in fact, as to be looked upon as one of the earliest and most reliable signs of that state. It is undoubtedly caused, in the earlier stages, simply by the intimate sympathy which exists between the stomach and womb, and which causes one of those organs to be temporarily deranged whenever the other is in any unusual condition. In the latter months, it is also produced by the enlarged womb pressing on the lower part of the stomach, as it rises in the abdomen. In many diseases of the womb, particularly in enlargements and tumors, the stomach will become deranged in precisely the same manner as dur ing pregnancy, and the patient is frequently deceived thereby as to her real condition.

In most cases the sickness does not begin till about the second month, and it seldom lasts beyond the third or fourth. There are some, however, with whom it commences almost immediately after fecundation, and others with whom it lasts till the very commencement of labor. I have even known persons who always experienced the nausea at the very moment of conception, and who were thus aware when that event took place. With some persons the trouble occurs only during certain parts of the day, most usually in the morning, while with others it comes on irregularly, or even 
endures constantly. In most cases it is not very severe, and causes but little distress ; occasionally, however, it is very serious, and may even lead to fatal results, in spite of all that can be done. Abortion is frequently brought on by it; and so are faintings, and spitting of blood. Many women, however, will vomit with violence, during almost the whole period, without either accident or evil effect. The treatment must vary according to the cause of the derangement, its violence, and the effect it produces. In regard to diet but little can be said that will be found generally applicable. Mild and light food is generally recommended, but is not always the best, for some females can only keep on their stomachs the most indigestible articles. Perhaps nothing more can be said, with propriety, than that the patient should take whatever she can retain, particularly if she has become weak from want of nourishment, which is often the case. Some females can only keep down a little broth, or tea, or sweetened water, while others find solid food the best, or fruits. I have known many able to take gum-arabic, either solid or dissolved in water, and retain it, when nothing else could be borne. This is nourishing, and may often keep up the strength till the sickness abates.

There are many remedies that will sometimes relieve, though frequently they are of no use whatever. A little wine or brandy, or orange flower water; - a few drops of laudanum, or ether, or essence of peppermint, may be tried. One or two ipecac, or cayenne, or camphor lozenges, will sometimes be efficacious, and so will a little port wine and Peruvian bark, or a seidlitz powder, or even common soda water. A teaspoonful of powdered charcoal succeeds occasionally, or some very strong bitters, or a cordial, such as a wine-glassful of curaçoa. A plaster of opium may also be placed over the stomach, or one of meal wet with laudanum. A mustard poultice over the stomach will frequently relieve when everything else fails; sometimes it is more effective, however, when placed on the spine, opposite the stomach. As a general rule the bowels should be kept free, either with injections or with mild purgatives, as castor oil, or manna. Regular bathing will often act as a complete preventive or cure, and the vomiting may be frequently stopped by simply dashing cold water over the stomach. Some practitioners recommend emetics, and bleeding if the patient be of a full plethoric habit. Leeches and cups have also been used over the stomach, and sometimes with good effect. Ether and chloroform have also been inhaled, and have operated favorably in a few instances. Plentiful draughts of cold water or swallowing bits of ice will likewise afford relief to some.

In several instances the vomiting has been so violent, and the patient has suffered so much, and become so exhausted from want of nourishment, that it has been absolutely necessary, after all other means have failed, to cause miscarriage, as the only means of saving the patient's life.

Whenever the trouble can be borne, patience is the grand specific. The sufferer must recollect that it will surely cease with delivery, and most probably before.

\section{PTYALISM, OR EXCESSIVE SALIVATION.}

Some pregnant females will secrete an immense amount of saliva for weeks and months in succession, as if they had been salivated. I have never known a case in which this discharge caused any evil, even when very great, though it is often troublesome. It would probably not be judicious to stop it, even if we could do so, as long as it does no harm, though it may be advisable at times to moderate it. The 
only treatment proper to effect this is, to keep the bowels free and the body well bathed, and to gargle the mouth with mint or balm teas, or canella water, or a little syrup of poppies.

This discharge, like the vomiting, arises from the sympathetic action of the uterus, and it generally ceases about the fourth month, though with some it will last the whole time.

ODONTALGIA, OR TOOTHACHE.

This is also a very general trouble during pregnancy, and sometimes a very severe one. Like several other sympathetic affections, it is very irregular as to its first appearance and duration, some suffering from it most of the time, almost without intermission, while others only have it at intervals, and but slightly.

It sometimes depends upon unsound teeth, but is frequently experienced without any such cause, and is then a true neuralgia. When it arises from a bad tooth, the pain is usually confined more or less to the neighborhood of the tooth ; but when it is neuralgic it extends over the greater part or the whole of the jaw and face, and darts about from one part to another. In true toothache there is also usually more or less inflammation and swelling, while in the most agonizing neuralgia nothing of the kind may be seen.

The treatment must be regulated by circumstances. If the pain appears to be kept up by an unsound tooth, it should by all means be extracted, unless the patient be so exceedingly nervous and irritable that abortion is to be feared, in which case the pain must be alleviated as well as it can be, though there is almost as much dan. ger in leaving the tooth in such cases as in extracting it. A few leeches to the gum 3 will sometimes relieve, or a mustard poultice to the cheek, or a blister behind the ear. The stomach or bowels being out of order may also keep up the irritation, and regu. lating them may materially assist in giving relief. Some persons are relieved br lotions of camphor, or laudanum, and others by washes of cayenne tea, or alum water. In the neuralgic form, when no particular tooth can be found in fault, the treatment must be more general than local. The carbonate of iron pills, which can be purchaseâ at the druggists ready made, have frequently an excellent effect; from two to four may be taken at a dose, twice a day, the bowels being kept open, if necessary, by a little tincture of rhubarb. If the pain comes at regular intervals, or intermits, it may frequently be stopped by quinine. Two of the ordinary quinine pills may be taken every five hours, for two or three days. If the head feels oppressed by their use, the dose must be lessened to one. M. Guillemead recommends the following to be tried if other means fail, and I have known it to be of decided benefit. Take the whites of two eggs, and two ounces of common black pepper, in powder, and beat them well together. Spread this on some tow or cotton, and lay it on the cheek. It may be kept on till it causes considerable irritation, and sometimes may be used on both sides.

Some females have been relieved by bathing the face in cold water, or keeping ice in the mouth, and others by hot fomentations. It has also been recommended to fill the mouth with cold water, and bathe the cheek with hot at the same time.

Occasionally an abscess, or gum-boil will form, and when there seems a tendercy to that it may be promoted, by keeping a roasted fig in between the cheek and gum, over the part where the abscess points; when full, it should be lanced, as the dis. charge usually gives relief. 
This pain is however very obstinate sometimes, and defies all treatment, but is seldom of such long duration when so severe.

\section{DERANGEMENTS OF THE APPETITE.}

The powerful sympathetic action of the womb on the stomach produces n-t only nausea and vomiting, but various derangements of the appetite and taste also. All of these require notice, and some need attention.

Anorexia.-This means a complete distaste, or even disgust, for food, sometimes of particular articles only, and sometimes for those of every kind. It seldom lasts beyond the fourth month, but occasionally during the whole period. It is remarkable how some females will be affected in this way, and how little they will eat, for several months together. This however is scarcely ever of any consequence, for the system does not seem to suffer in the slightest degree; on the contrary, the mother will remain quite stout, and the child be born fully developed, though the quantity of food taken has apparently been scarcely sufficient to sustain life.

In many cases there is even a decided benefit from this state of things, particularly in those who are of a too full habit.

As long as the loss of appetite is merely of a sympathetic or nervous character, it is not necessary, nor advisable, to resort to any special treatment. But when it arises from indigestion, or a foul stomach, it should be attended to. A mild emetic of ipecac or warm mustard and water, may be given, or a dose of epsom salts. This state will be recognized by a furred tongue, unpleasant breath, and uneasiness at the pit of the stomach; while in the purely nervous anorexia nothing of the kind is observed. Sometimes it may arise merely from debility of the stomach, and in that case a few of the carbonate of iron pills will be of use. In general the patient is benefited rather than injured by this voluntary fasting.

Boulimia.-This state is the reverse of the former, meaning a ravenons appetite. Some females exhibit it in a most extraordinary degree, and will eat to excess of anything that comes in their way. Many injure themselves in this manner, by causing indigestion, flatulence, heartburn, vomiting, and even inflammation of the stomach. It is of no use reasoning with them, for the appetite is so strong that they will eat let them suffer ever so much.

All that can be done in such cases is, to drink freely of various nourishing liquids, such as soup, broth, rice, milk, or chocolate; and by eating jelly, arrow-root, and eggs. These contain much nourishment in a small space, and satisfy the hunger without overloading the stomach. The appetite may also be deadened considerably by eating figs, dates, sugar, or chocolate; and by drinking soda water.

Capricious Appetite. - Sometimes a female is found to have an inordinate desire. for some one particular article of diet, which she will eat to excess, but will not touch anything else; this is called malacia. Others will have a craving for some article not proper for food; this is called pica. They will devour chalk, cinders, earth, wood, flies, spiders, charcoal, and various other things, sometimes of the most disgusting kind, though ordinarily they may be quite fastidious in their diet. This unnatural desire is also frequently seen in hysteria and chlorosis, and in several aterine diseases.

It does not appear that a moderate indulgence of these unusual tastes is at all $1 \mathrm{Ar}$ iurious, unless the article wished for be of a decidedly hurtful character. On the 
contrary, it is reasonably conjectured, by many physiologists, that they arise from a real want in the system of the very substances longed for. For instance, there may not be in the motber's blood sufficient lime to form the bones of the child, and this deficiency is intimated by her desire for chalk or plaster; nature having no other mode of making her wants known, or of causing them to be supplied. As a general rule, so long as the indulgence is not obviously improper, it should be allowed to a reasonable extent, both to gratify the patient and in answer to what are probably the demands of nature.

It is seldom that interference is needed in these cases, except when there is danger of the patient doing herself harm; we may then try to alter the condition of the stomach, and so change the taste. A gentle emetic will sometimes do this, or a saline purgative. If these fail use a few of the carbonate of iron pills, or some good strong bitters, or teas, drunk freely, such as chamomile, boneset, or century.

PYROSIS.

This disease is more frequently called water brash and sometimes heartburn. It is characterized by the raising of a hot acrid fluid into the throat, causing a sensation of burning, from the stomach upward, even to the mouth. It is a very frequent attendant upon many forms of dyspepsia, and is generally experienced more or less by most pregnant females ; being caused either from improper diet or from mere sympathetic derangement. If it arises only from errors of diet, a reform in that particular is all that is needed; but if it is merely sympathetic, nothing can be done beyond palliating it, to give temporary relief. For this purpose, the patient must take a spoonful of lime water, in half a tumbler of milk, two or three times a day, or some carbonate of soda, or magnesia, with a few drops of laudanum if there be any pain. In those cases which resist such remedies a little of the compound iron mixture may be of service, such as can be obtained at the druggists. A nourishing diet should also be observed, and plenty of exercise should be taken in the open air.

\section{DYSPHAGIA.}

Difficulty of swallowing, which is meant by this term, is a more troublesome and alarming affection, frequently attendant on pregnancy. There is, however, nothing dangerous in it, except that it frightens the patient. Some will gasp and be unable to swallow, or even speak, for a considerable time, and will think they have something in the throat. It is, however, entirely a nervous symptom, arising from uterine irritation, and seldom lasts beyond the third or fourth month. A little cordial, wine, or brandy, will frequently relieve it, or some spirits of camphor rubbed on the neck. M. Colombat de l'Isere recommends the following ointment to be rubbed on the neck : Extract of belladonna, forty-seven grains; extract of stramonium, fifteen grains ; white wax, one ounce; oil of lemons, twelve drops. These must be warmed and well rubbed together. A dash of cold water on the throat and chest will often succeed better than anything else.

\section{GASTRALGIA.}

This is commonly termed cramp at the stomach, or nervous colic. It consists of a severe kind of cramp, with dragging and cutting sensations in the stomach, as if it were being tied in knots and cut to pieces. Sometimes the attack will only last 
for a few minutes, and then totally pass away ; at other times it will remain for half an hour or more, and cause the most intense suffering. The patient will be drawn together, or doubled up, with her hands placed on her stomach, and will groan and exhibit in her features the greatest agony; sometimes even she will faint away with it.

This affection may, like the other, be merely nervous, and then it is attended by nothing but the pain. It may also arise from real inflammation of the stomach, and then it is attended by fever, excessive soreness and tenderness of the stomach when touched, and by a hot, dry mouth. In the nervous spasm the pain is frequently relieved by pressure, but when inflammation exists the pressure increases it.

Some females always have these attacks whenever the stomach is empty, and they pass away immediately anything is taken to eat or drink. With others they are often brought on by overloading the stomach, or by eating some improper articles.

To relieve the spasm, one of the best things is a teaspoonful of compound spirits of lavender, taken without water. This nearly always gives relief in ten minutes at most; but if necessary a second spoonful may be taken in a quarter of an hour. A little brandy, or peppermint, or curaçoa cordial will also succeed in many instances, or simply drinking freely of any hot tea, or swallowing half a teaspoonful of common pepper. A mustard plaster put on hot over the stomach will scarcely ever fail, even without anything being taken internally. M. Colombat gives the following recipe as one which he has found efficacious, and it is certainly a pleasant one : Orange and linden flower waters, each two ounces; syrup of ether and of valerian, each one ounce ; syrup of poppy heads, half an ounce. Of this mixture a teaspoonful may be given every quarter of an hour till the pain abates.

To prevent the return of the attack, the patient rnust carefully avoid everything that disagrees with the stomach, or creates wind, she must keep the bowels free, and accustom herself to regular bathing or rubbing the body. If the stomach appear weak, which is often the case, some boneset tea, or port wine and bark, or a few of the carbonate of iron pills may be advantageous. If there be acid on the stomach, use the means recommended for heartburn.

\section{CONSTIPATION.}

This is a very common trouble with pregnant females, and one that may lead to many others. Very frequently it arises merely from the pressure of the expanded uterus upon the large intestine, but it may also arise from a simple want of power, the uterine action having apparently weakened the force of all the neighboring organs. It is advisable to correct it as soon as possible, let it arise how it may, as it is very apt to cause various derangements of the stomach and intestines, and even inflam. mation of the womb itself. As a general rule, not more than three days should elapse without the bowels being moved, though some will remain a week or more without any apparent inconvenience ; but there is always danger in such delay.

Many females do themselves much harm by taking what they call opening medicines, the action of which is often more injurious than the constipation itself. All urastic purgatives, such as aloes, gamboge, colocynth, and jalap, should be carefully avoided, as they not only make the costiveness worse after their action is over, but they also frequently produce inflammation, and even abortion, by the violent straining they cause. The best medicines, when they are really needed, are manna, seidlitz 
powders, or castor oil. Enemas are better, however, as a general rule, such as those of thin starch, or molasses and water, to which may be added a little castor oil. The grand aim should be, in all such cases, to stimulate the bowels to an increased action without medicines, by a properly-regulated diet! Salads may be eaten wher they do not cause derangement of the stomach, and ripe or stewed fruits, particularly figs, dates, and prunes. Soups are also good, except they contain rice, or vermicelli, or maccaroni. Bran bread should be eaten regularly, and not white. The only meats should be veal or poultry. As a drink lemonade is excellent, with a little cream of tartar, or tamarind tea, or barley-water sweetened with honey. With some patients, a cup of coffee or a glass of beer will always relieve the bowels, especially if a glass of water is also drunk after it. I have known persons neglect the bowels so long that they have become completely impacted by the hard fæces, and could be relieved only by instruments. It is very important to attend to this affection in time, and to persevere with the means of permanent relief regularly.

\section{DYSENTERY AND DIARRHGEA.}

It is frequently the case that pregnant females, instead of being constipated are afflicted with severe diarrhoa. This may arise from inflammation, and is then attended by fever, and extreme tenderness and soreness of the bowels. Most usually, however, it is entirely nervous, and arises from the sympathetic irritation of the womb. There is then no tenderness or soreness, no fever, no derangements of the appetite, nor in fact any other symptom of any consequence. If it remains long unchecked blood will be discharged, from the extreme irritation of the intestines, and it is then called dysentery. This is nearly always accompanied by fever and general irritation. Sometimes there will be a constant and painful desire felt to move the bowels, but with little power to do so, and at the same time a burning heat and unpleasant sensation at the fundus. This is called tenesmus, and the straining from it has frequently produced abortion.

If the diarrhœa is not excessive, and the female does not lose her appetite, or strength, it is better let alone, particularly if she be of a full habit, and disposed to fever. If thought desirable to check it a little, this may nsually be done by a change in the diet. Rice milk, sago, tapioca, and arrow-root may be taken, white bread may be used, and not much fluid drunk. If such means are insufficient, an injection may be thrown up the rectum in the morning, of thin starch, with a teaspoonful of laudanum. The abdomen may also be well fomented, and a dose of tincture of rhubarb taken occasionally. If the tenesmus is very troublesome, an injection of tepid water may be used, and the female should sit occasionally over the steam of hot water ; in extremely painful cases, a few leeches may be used round the fundament, and a hot flax-seed poultice placed over the abdomen. A warm bath is also an excellent remedy with many. When the diarrhoea still continues, notwithstanding the above remedies, resort should be had to tonics and opiates. The patient should take port wine and Peruvian bark, or some gentian wine, and use injections of starch and laudanum regularly. Chamomile tea may also be freely drunk, and an opium pill may be taken at night. Above all, the patient must endeavor to avoid all mental agitation. When dysentery sets in, every effort should be made to subdue it as early as possible. Half a pint of rice milk, with ten or fifteen drops of laudanum, may be taken two or three times a day, and an injection may also be used, night and morn- 
ing, of flax-seed, with fifteen or twenty drops of laudanum. M. Colombat recommends the following recipe as seldom failing to cure: Take the whites of six eggs and beat them up in a quart of water; then use one-third as a drink, and the rest as an injection. A meat spoonful should be drunk every ten minutes, and an injection used every two hours, but not more than one small syringeful at a time. A teaspoonful of syrup of poppies, with some loaf-sugar, may also be added to every spoonful that is drunk. Eggs, jellies, and rich soups, with meat and wine, if there be no inflammation, may be taken regularly, in addition to the articles already mentioned.

\section{DYSPNEA, OR DIFFI'ULTY OF BREATHING.}

There are but few pregnant females who do not complain more or less of difficulty of breathing, and this difficulty may arise from different causes. In the earlier months it is caused by sympathetic irritation only, the same as difficulty of swallowing. In the latter months it is caused by the enlarged womb filling up the abdomen so much that the lungs in the chest are pressed upon, and have not sufficient room to play freely. It may also be caused by a plethoric or too full habit, the lungs then being in reality congested.

The temporary difficulty of breathing, which is felt in the early months from nervous sympathy, needs scarcely any kind of treatment, as it passes off naturally in a short time. In severe attacks, the same remedies may be used as for difficulty of swallowing, before referred to.

That which arises in the latter months, from pressure of the womb, can frequently be relieved only by the patient remaining as long as possible in certain farorable positions. I have known many who could never sleep except when propped nearly upright by means of pillows and cushions, as, immediately they assumed the recumbent position, the upward pressure became so great they were nearly suffocated. In such cases, the patient should be careful never to eat or drink to excess, nor take anything likely to produce wind, because the least increase in the size of the abdomen adds to the difficulty. The bowels should also be kept free, and nothing tight or heary in the way of clothing should be worn.

This difficulty is most frequently seen in those who have contracted chests, and in those who have been accustomed to wear corsets and tight dresses. A deformed pelvis may also give rise to it by forcing the womb above its usual position. Many females both create and increase this difficulty by binding themselves tighter than usual during pregnancy, under the mistaken idea that it enables them to support their burden so much easier.

When the dyspnœa arises from a full babit the patient must live low, keep the body regularly bathed and rubbed, and the bowels freely open by an occasional seidlitz powder, or dose of Epsom salts. If the difficulty becomes at any time suddenly great and alarming, the feet should be placed immediately in hot water, while the patient is upright; a mustard plaster should also be put upon the chest, and an opening injection of starch and castor oil administered as soon as possible. The nsual practice in such cases is to bleed from the arm, to the extent of eight or ten ounces, and in case no other means give relief, this may be tried.

\section{COUGH.}

Like the previous affection cough is most usually produced during pregnancy by sympathetic irritation. It may arise, however, from a partial congestion, or inflam- 
mation of the lungs or bronchial tubes, produced by a too great determination of blood to them. In the merely nervous cough, there is no expectoration, nor any soreness or pain in the chest, and it will frequently disappear for several days together. No particular attention need be bestowed upon this cough, unless it become so violent as to threaten abortion. In that case a pill, containing half a grain of opium, may be taken, or from ten to fifteen drops of laudanum, whenever the attack is severe. Barley water, or gum-arabic water, may also be freely drunk, with a large spoonful of syrup of poppies added to each pint. A small dose of hive syrup, or paregoric, will also be found sometimes better than anything else. An enema of starch and laudanum, as formerly described, will also relieve, in some cases, better than anything taken by the mouth. The body should be kept warm, particularly the feet, and a mustard poultice may be placed over the chest, if the straining at any time becomes too great. Some patients experience relief from an assafœetida pill, or a little musk, and others from a small dram of cordial, or wine.

If there be expectoration, with fever, and tenderness in the chest, or sharp pains when a long breath is drawn, there is reason to fear inflammation of the lungs, or bronchitis. In this case all the above means, except the wine and stimulants, may also be used, only more freely, and the mustard poultice must be kept on till it makes a blister. The patient must live low, her feet must be frequently bathed in hot water, and her bowels regularly opened either with saline purgatives or enemas. All that is requisite is to keep the inflammation from extending till after delivery, when it usually subsides without any further trouble. As soon as the womb is emptied, its pressure upon the abdominal aorta ceases, and the blood can then flow freely to the lower extremities, and thus the lungs become relieved and the inflammation goes down.

\section{PALPITATION OF THE HEART.}

This is also a frequent accompaniment of pregnancy, and one that is likely to cause alarm sometimes, from its violence. Unless dependent upon organic disease of the heart, however, it is in general only a nervous affection, and passes away with delivery. We may always reasonably suppose it to be nervous when it occurs only during pregnancy, and particularly if it is irregular in its frequency and violence. I have known females who were always attacked with it about the same period, and who could therefore always tell when it was coming on, and sometimes even how long it would last. It will sometimes come on during sleep, and so forcibly as tc waken the patient instantly. At other times while awake, it will commence so suddenly that she will sink down as if struck a powerful blow.

The only directions that can be given for alleviating palpitation are, to keep quiet as possible, use the bath regularly, avoid constipation, and live rather low, particularly if the patient be of a full habit. Exercise should also be taken regularly in the open air, but not of a violent kind. She should also sleep with the head on a high pillow, and never eat late suppers, nor take any food that disagrees with the stomach.

All kinds of stimulants, such as wine, coffee, and spices, should be abstained from, and all powerful emotions carefully guarded against. During an attack a few drops of laudanum or an opium pill may be taken, and the feet placed in hot water. An assafoetida pill is sometimes good, or a little ether. Bleeding is generally practiced in extreme cases, but there is often considerable danger in it.

A too full habit may be the exciting cause of the palpitation, as may be seen by 
the patient being always liable on the slightest exertion to flushed face, dimness of sight, ringing in the ears, swelling of the limbs, and puffiness of the gums, sometimes to such an extent that the mouth will taste of blood. Such persons should. carefully observe a moderate, unstimulating and simple diet, and never allow the bowels to remain constipated more than a single day. They should also rub and wash the skin well, and study calmness and quiet.

\section{SYNCOPE, OR FAINTING.}

In this condition, which is just the reverse of the former, the heart suspends its action altogether ; the breathing ceases, all power of motion and feeling is lost, the face turns ghastly pale, the eyes close, and the individual seems as if actually dead. It seldom lasts, however, more than five minutes, when the pulse gradually begins to beat, the color returns, and the individual slowly recovers. Some females are liable to such attacks once a month, others once a week, others every few days, and some at irregular periods. They are generally preceded by a dull pain at the pit of the stomach, fullness in the head, yawning, and loss of sight, or ringing in the ears.

The causes that predispose to this fainting are not very well understood, though there is no doubt but it is mainly dependent upon uterine disturbances. In some females it is brought on by the sudden motions of the footus, or by their remaining too long in one posture. In others it is produced by straining from constipation, or by sudden fright or anger. In very nervous persons it not unfrequently arises from unpleasant sights, smells, and sounds. In fact it is caused in them much the same as a common hysterical fit, such as is described in the article on hysteria. A full habit, and over feeding, or drinking stimulating liquors may also bring it on, and so on the contrary may a state of weakness and exhaustion.

This accident is more alarming than dangerous, except to the child, which may lose its life if the fainting lasts too long.

To recover a person from one of these fainting fits, she should be laid upon her back on a level place, and every part of her dress should be carefully loosed. Som? strong odor should then be applied to the nostrils, such as hartshorn, vinegar, burnt feathers, or smelling salts. The body should be well rubbed over the heart and lungs, either with the hand or with a soft, dry napkin. Cold water may also be dashed on the face, and the hands may be well chafed. If the fit still endures, a mustard plaster may be placed on each arm, or the whole body may be placed in a warm bath, if convenient. Care should also be taken to admit the fresh air freely。 As soon as she begins to show signs of consciousness, a little wine or brandy may be placed in the mouth, and the body may be elevated a little.

To guard against such attacks, the same precautions as to diet and mode cf life must be observed as were directed in the article on palpitation of the heart; and, as this accident is most frequent in those of a hysterical habit, they should carefully follow the advice given in the article on Hysteria.

\section{HEADACHE AND DIZZINESS IN THE HEAD.}

Wach of these distressing affections, both of which are very common during preg. nancy, may arise either from nervous excitement or from a full habit and determination of blood to the head. Nervous headache is generally met with in the earlie: 
months of pregnancy, and is characterized by being frequently periodical, and often confined to particular spots. It also commences suddenly, from some excitement or depression of mind, and leaves little or no distress when it is gone. The headache, which arises from a too full habit, commences with flushing of the face, heaviness in the eyes, dull pain in the forehead, and a sense of uneasiness, with disposition to sleep or doze. It seldom comes on much till the latter months of gestation. Headache may arise also accidentally from derangement of the stomach, but this cause is easily ascertained by the furred tongue, loss of appetite, and bitter taste in the mouth ; it is also felt most acutely in the back of the head, down by the neck, and passes away immediately the stomach is corrected by an emetic, or by fasting.

Nerrous headache during pregnancy often defies all our attempts to alleviate it, though we sometimes succeed in doing so. The best general remedies are warm baths, and, if the bowels are constipated, enemas of starch and castor oil daily. To these may be added occasional small doses of laudanum, or an opium pill, or two grains of camphor. Smelling odors, such as camphor, cologne, or hartshorn, will relieve some, but will make others worse; so that its utility can only be determined by experience. When a severe attack comes on, the patient should put her feet in warm water, or use a warm bath, take a few drops of laudanum, or a little musk, or valerian, and then try to go to sleep. To guard against the attack, she must never overload the stomach, nor take anything indigestible; and never think too much, nor allow herself to become excited or depressed.

When the trouble is caused by a too full habit, she must observe the directions given in the articles on palpitation of the heart, and syncope. The diet must be mild and not too nutritious, the bowels must be regularly moved every day, chiefly by epsom salts and seidlitz powders, and regular gentle exercise must be taken in the open air.

In the latter months it is especially important to attend to a severe headache $\mathrm{im}$ mediately, particularly when the pain is seated at the top of the head, because it is very likely, if unchecked, to terminate in convulsions. The means above recommended must be carefully and perseveringly applied ; the feet must be kept warm, the bowels freely opened, and the head kept cool by wet cloths, or cold lotions, or ice. It is the general practice in all such cases, if the pain does not abate soon, and the pulse be full and quick, to bleed freely at the arm, and the most eminent physicians of the allopathic school assure us, that the life of the patient frequently depends upon its being done promptly. I have no doubt, however, but that relief can be generally obtainea by the simple means described, if they are used early and perseveringly.

\section{INSOMNIA, OR SLEEPLESSNESS.}

There are few affections that cause more real distress during pregnancy than this. Many females will be utterly unable to sleep for many days and nights together, and others can only obtain a few minutes broken and unrefreshing sleep at distant intervals. There is danger, when this state becomes highly aggravated, that it may lead to delirium, or that the want of rest may wear away the strength to such a degree, that the patient will sink from mere exhaustion. There are some females, however, who will remain without sleep, or at most take but very little, for a long time, without suffering any inconvenience.

This affection is essentially a nerrous one, and the only means likely to relieve it 
are those that have a tendency to soothe and calm the nerves. If the patient be surrounded by any irritating circumstances they should be at once removed, or she herself removed from them. Particular attention must be paid to the diet, so that no derangement of the stomach or bowels be kept up, and a regular system of out-door exercise must be practiced. A warm bath just before going to bed, with a good rubbing of the skin, will frequently act like magic in procuring rest. As a general rule narcotic drugs should not be used, but in extreme cases they may be resorted to sparingly. A single opium pill, or a few drops of laudanum may be taken after the bath. If the patient be thin and delicate, she should eat meat, eggs, and milk, and take a little wine, if it causes no unpleasant symptoms. Indeed a glass of wine will frequently act better than laudanum, and so will ale with some, and coffee with others. If the patient be of a full habit these things will be improper, and may injure. She should then be kept quiet, and fed sparingly. Music has a powerful effect in many of these cases :-a slow, solemn air, played while the patient is reclining after her bath, seldom fails in inducing sleep.

\section{TEMPORARY AFFECTIONS OF THE SIGHT, HEARING, AND SMELL.}

These disorders are quite common during pregnancy, particularly in the latter months. Some females will be utterly unable to distinguish any odors, even the most powerful ; others completely lose their taste, and others again become deaf or blind. When they are caused only by the sympathetic action of the womb, such deprivations are seldom of long duration, though they may recur at frequent intervals. In some cases they remain a considerable time, and great fear is felt that they may become permanent, but there is little danger of such a result. I knew a lady who suddenly lost her sight when about two months gone, and who remained totally blind till about three hours after her delivery, when her sight returned in a moment as perfect as before. The same thing has frequently been observed of the other senses. In some cases the vision will not be lost but perverted, and the patient will then see everything double, or larger or smaller than natural, or always of a wrong color. In like manner some will hear imaginary conversations, or will fancy everybody is shouting, or perhaps only whispering, though they are all the time speaking in their natural voices.

These perversions, when thus produced, need occasion no alarm, and seldom require attention, unless accompanied by other urgent symptoms. They may arise, however, from a fullness of blood in the head, in which case they are accompanied by a flushed face and drowsiness, and are preceded by bright sparks flashing before the eyes, or by ringing in the ears.

The treatment of all these affections should be the same as that recommended for most of the previous derangements, particularly for headache, syncope, and palpitation of the heart. If there be nervous excitement merely, it must be calmed in the same way as recommended in the articles referred to, and also in the last one on sleeplessness. If the female be of a full habit, and there is evidently a pressure of blood on the brain, and nerves of the special senses, the same means should be adopted to reduce the system, and draw the blood to the extremities, that have already been described.

In such cases these sudden deprivations of sight and hearing sometimes indicate the commencement of convulsions, or apoplexy, particularly if they occur during 
iabor, when every means should be resorted to instantly to relieve the pressure on the brain. If no simpler means succeed in a reasonable time, it is the general custom to bleed freely from the arm, and there is no question but this frequently removes the difficulty at once, whatever objections may be made to the practice. It is also proper to say that many eminent practitioners, who are not advocates of the lancet in general, strenuously urge that it should be used immediately if the sight or hearing suddenly disappear in this way, at any time. And I certainly have myself known these accidents sometimes followed by a fit of apoplexy, or convulsions, and eren death. Such was the case with a friend of one of my patients. She found one day, quite suddenly, that she could only see half of anything she looked at, and at times it even disappeared altogether. Nothing was done for her, and in about five hours after the first attack she fell speechless, and died before they could lift her upon the bed. It will therefore be a necessary precaution, in all pregnant females of a full habit, to attend rigidly to the advice that has been given, because simple means, used in time, and regularly, may prevent the necessity of stronger ones altogether. In purely nerrous cases of this kind, no apprehension whatever need be felt, and no such practice as bleeding is required.

\section{DISORDERED JUDGMENT, INCLINATIONS, AND PROPENSITIES.}

The sympathetic irritation of the uterus, in some females, produces extraordinary phenomena of this kind, from simple desire to the most furious craving, and from mere caprice to actual insanity. There is no doubt but that many of these unusual desires, or longings as they are called, are either produced or much aggravated by the imagination of the patient, and frequently would never be experienced at all, it: the idea was not suggested by other people having had the same. Custom and imi. tation are very powerful in such cases, particularly when the nerrous sensibility is much exalted. Still the most singular aberrations of this kind will often arise with.. out any such adventitious aid, and the fact should be borne in mind, so that these temporary vagaries may be regarded with proper charity and forbearance.

Some females will entirely change in their dispositions at these times, the most amiable and mild becoming positively ill-natured and malicious; the gentle will turn headstrong; the haughty and proud will become humble, and the gay will become melancholy, or the sad will madly seek every kind of gayety. Such things, however, should never be remembered, nor be brought up against them afterwards, for truly at such times they know not what they do!

Women have been known while in this state to become thievish, or to have an irresistible propensity to burn or kill. Some have eren been known to exhibit great talent for music or poetry, though ordinarily without any capacity for such things. Some will suddenly exhibit a most extraordinary intellect, while others will become quite silly. A medical writer tells us an instance of one female who always had an excellent sound judgment while pregnant, bat no memory, while in her ordinary state she had a poor judgment, but a most extraordinary good memory. The celebrated Baudelocque gives an account of another who could scarcely eat anything but what she stole while going to market, and another writer mentions a lady who longed till she was almost delirious to bite a piece nut of a baker's shoulder, who worked opposite her window. There is even an account of one who longed to eat some of her husband, whom she dearly lored, and who actually killed him to satisfy her appetite, 
and then salted pieces of the body to keep for future use. A writer named Vives also tells us of a female whose husband paid a large sum of money for her to be allowed to bite a young man's neck, it being evident that she would be nearly certain to miscarry unless so gratified. In the year 1816, at Mons, in France, an unfortunate woman in this condition was seized with an irresistible impulse to destroy her children, and actually drowned three of them, and herself afterwards. She had previously sent a poisoned cake also to one at school, but fortunately it was not eaten.

Generally speaking, all these things pass away with delivery, if not before, unless it be actual insanity, which sometimes remains. All that can be done is to attend strictly to the general health, keep the skin, bowels, and stomach in good action, and remove all depressing or irritating circumstances. If there be a propensity to anything decidedly injurious or dangerous, the patient must be strictly watched, but without its being perceived or known by her, for fear of exciting suspicion in those who would be disposed to be cunningly secret or revengeful. Proper diet, regular bathing, and out-door exercise often correct many of these things.

\section{HAMOPTYSIS, HÆMATEMESIS AND EPISTAXIS.}

These three terms mean spitting of blood, vomiting of blood, and bleeding from the nose, all of which frequently occur during pregnancy.

Spitting of blood is most usually observed in nervous women, and in those of a sull habit. It is caused partly by sympathetic irritation, and partly by the womb pressing upwards against the diaphragm and lessening the size of the chest, which deranges the circulation in the lungs, and causes rupture of their blood-vessels. The premonitory symptoms are pains round the waist, cold extremities, creeping of the skin, and a sensation of anxiety or depression round the heart. The attack begins by difficulty of breathing, heat in the chest, and dry cough, followed by spitting up more or less bloody frothy mucus; all which symptoms are much increased by violent exercise, or a hot atmosphere. In ordinary cases, a mere spitting of blood need occasion no great alarm, unless attended by symptoms of inflammation, or unless the patient has had cough, and other indications of pulmonary derangement before conception.

In hæmatemesis the blood is vomited from the stomach, and is in black nlots, frequently mixed with the food, or bile, while that which comes from the lungs in spitting, on the contrary, is bright red, and quite fresh. In vomiting of blood also, there is seldom any cough or exertion of any kind.

The treatment of spitting of blood must be nearly the same as for many other derangements already described. When there is a full habit, the patient must live low, keep the bowels free, and the skin in good order, and avoid all agitation of mind or over-exertion of body. An opium pill occasionally will be useful, or a few lrops of laudanum. The cough must be combated in the way recommended in my previous article on cough. Lemonade or tamarind tea, with some syrup of poppies added, may be freely drunk, or some of the black-currant root tea. The treatment of hæmatemesis is precisely the same. Occasionally, however, the blood will pass into the intestines and occasion colic, and then it must be removed by administering an enema of starch and castor oil, or a little manna may be taken.

Epistaxis, or bleeding from the nose, is much more frequent than either of the preceding, but is seldom of much consequence. In many cases, in fact, it is highly 
beneficial, as it relieves the head from pressure, and thus obviates many inconveniences. If it continues too long, or becomes excessive, it may generally be arrested by putting cold wet eloths between the eyes, and on the cheeks, while the head is kept elevated. The feet and hands should be kept warm, and the air breathed should be as cold as possible. In extreme cases, the nostrils may be plugged with bits of sponge, or cotton, or some powdered alum may be snuffed up them. The best plan is to raise the hands above the head, and put something very cold, as a lump of ice for instance, or a piece of cold iron, between the shoulders; this seldom fails.

Pressing the upper lip firmly down upon the gum just below the nose with the finger, if continued, will stop bleeding at the nose in most cases.

\section{VARICOSE VEINS,}

Very often in pregnant women the veins in different parts, but particularly of the thighs and legs, will swell out in knots, either singly or in bunches, sometimes like strings of beads, or like the links of a chain. These are called varices, and occasionally they attain a large size, and extend to various other portions of the body, as the external lips, vagina, and mouth of the womb. Some women, in fact, have them over nearly the whole body. They are caused by the pressure of the womb on the large abdominal veins preventing the return of the blood, and disturbing the balance of circulation between the veins and arteries. In the majority of cases, unless very large, they cause but little inconvenience, and may be. let alone, but sometimes they cause pain, or become so full that there is danger of their bursting, and then it is necessary to interfere.

The first thing to be done is to relieve the abdominal veins from the pressure of the womb, and this may be done by the patient keeping more or less the horizontal position, and carefully avoiding all violent exertion. The swelling is always worse during the latter part of the day, particularly if the woman has been much on her feet, she should therefore apply a cloth roller round the limbs before she rises in the morning. If this be carefully put on, just tight enough not to interfere with the motion of the limbs nor totally obstruct the circulation, it will prevent the varices to a great extent, if not altogether. Brisk friction with the hand will disperse the swelling in many persons, or warm fomentation, but sometimes cold bathing answers better. It is advisable always to disperse them as soon as possible, for if they remain too long that part of the vein becomes permanently weakened by being overstretched, and will be always liable to swell again from any slight cause. It is particularly advisable in these cases to aroid constipation, and also to keep the skin in good action by bathing and frictions.

If at any time one of these varices should burst, it need occasion no alarm, unless it be seated on a large vein, and the bleeding becomes profuse. To stop it, bind on firmly over the rent any firm cold body, as a flat stone, or a large silver coin, passing the bandage several times round. In slight cases a simple cold compress will be sufficient, or a little powdered alum, or some vinegar and water-in short, any of the usual remedies for stopping bleeding from wounds. The female must be quite still till it is stopped, and must be careful when she begins to move about again, because it is liable to break out afresh. Those of a very full habit must live low, and avoid all stimulants, so as not to increase the quantity of blood in the body more than is necessary. It is advisable to remove the varices, as much as possible, 
before labor comes on, particularly if they are situated on the lips, or in the vagina, because they may burst during delivery and cause considerable inconvenience, or even danger. It is rare that these swellings continue after delivery, but if they should do so, the same treatment must be persisted in as before.

\section{H FMORRHOIDS, OR PILES.}

These are troublesome annoyances at any time, but particularly during pregnancy, and unfortunately they are very common at that time. They are, no doubt, chiefly caused in the same way as varicose veins, that is by the enlarged womb preventing the proper flow of blood in the small veins, and so causing them to swell, and form tumors. They may in fact be called varices, as truly so as those on the limbs. In many persons, however, they are frequently brought on merely by constipation, which will undoubtedly either cause them, or make them much worse when otherwise produced. In general they become worse as the pregnancy advances, because the womb becomes larger and the bowels are more apt to be confined.

As long as they only cause inconvenience, without any particular distress or urgent symptom, they may be let alone, or be slightly treated in the way of palliation, till after delivery, when they will disappear. Occasionally however, they grow to a large size, so as to hinder the passage of the bowels, and prevent the patient from sitting down or walking. They may then cause inflammation, and bring on falling of the intestine, or abortion, by the straining which they necessitate when the bowels are moved. And even if these extreme results do not follow, there may be serious derangements of the general health, indicated by difficulty of breathing, sleeplessness, headache, and fever. In short, there are few of the derangements incident to pregnancy so annoying as this, and unfortunately, from its nature, the sufferer dislikes to speak of it and seek the necessary assistance. Many prefer undergoing the most excruciating agony for months, rather than complain, which shows the necessity for females knowing how to treat themselves, when possible.

The bleeding which sometimes takes place from piles is more often beneficial than otherwise, unless it becomes excessive, from rupture of a large vessel, in which case, if the wound is external, it may be treated the same as the ruptured varicose vein ; if it be internal, the remedies must be injected with a syringe, or a large roll of lint or cotton may be soaked in alum water and passed up the rectum. Frequently bathing the thighs and perineum with cold water will be sufficient.

To relieve the pain and swelling, the female should sit over the steam of hot water, and use the warm bath. If the piles are external, they should be bathed with hot milk and laudanum, or rubbed with any soothing ointment, particularly the cucumber ointment, mentioned in a former article, or with stramonium ointment. If they are internal, the milk and laudanum should be injected if possible, or some thin starch and laudanum, and a stiff roll of cloth may be smeared with the ointment and introduced. In general, ointments or other greasy matters are not so good as the milk or starch. In conjunction with this, the bowels must be kept free, either with enemas or castor oil, or by using a seidlitz powder in the morning. This is indispensable, for if constipation exists, no applications can render much service. The patient must also avoid fatigue, and not remain too long upon her feet, nor sit long, particularly on a hard seat, and if she be of a full habit she must live low, to avoid making too much blood. It is also important, at all times, to avoid using dras- 
tic purgatives, such as aloes, colocynth, or gamboge, as they always make piles much worse, or even cause them.

\section{CEDEMA, OR WATERY SWELLINGS.}

This affection also appears, like the preceding, to arise from obstructed circulation, but instead of the blood accumulating, it is merely the serum, or watery portion of it. The swellings are generally whitish, and spread about, and a small pit remains in them when pressed with the finger. They are found on various parts of the lower limbs, and on the groin or abdomen, and also upon the external lips, in which place they are often exceedingly troublesome. As a general rule, these swellings are of small account, and as they disappear with delivery, but little attention need be bestowed upon them. Sometimes, however, they become very extensive, and so engorged that they inflame and are extremely painful. They have even been known to mortify, and cause considerable sloughing, particularly when chafed and afterwards wet with the urine. In these extreme cases there may be serious disturbance of the general health, from the constant irritation, and from the patient being unable to walk about. I have often known the limbs and vulva covered with patches of erysipelas from this cause. Sometimes the swellings even become so large that they interfere with the process of delivery.

The treatment of this affection consists in rest, particnlarly lying dow $\mu$, saline purgatires, regular and frequent washing the parts with cold milk and laudanum, or with a solution of borax, half an ounce to a pint of water, to be used cold and with a teaspoonful of laudanum added to it. Simple cold water is frequently quite sufficient. In general all kinds of ointments are injurious, but if other means fail to give relief, the cucumber ointment may be tried. The wash should always be used after nrinating, and the parts must not be rubbed, but lightly dried with a piece of soft. linen. Fullers' earth is often an excellent application when there is chafing.

If the patient be of full habit, she must carefully diet herself, and bathe regularly. If she be thin and weak, a generous diet will be adrisable, with meat and even a little swine.

\section{HYDRORRHEA, OR PROFUSE DISCHARGE OF WATER.}

This consists in a discharge of water, more or less profuse, from the vagina, at various periods during pregnancy. Some females will only discharge a small quantity, at intervals, others will have a constant dropping, and others again will pour out an immense quantity, sometimes several pints, or even quarts, in the course of a few days. In general this water is quite limpid and colorless, but sometimes it contains much mucus, and at other times it is tinged with blood. It does not appear that this discharge leads to any evil result, even when excessive, and I only refer to it to relieve anxiety. The origin of this water is not yet ascertained, but it is generally thought to be secreted between the membranes and the womb, and to be quite distinct from the liquor amnii.

PUSTULES, AND MUCOUS DISCHARGES.

Occasionally the external lips will be covered with pustules during pregnamcy, and trequent discharges of mucus will occur from the vagina. They are both however 
caused by the unusual action of the uterine system, and merely require frequent bathing of the parts with milk and laudanum, and regular action of the bowels. The most important thing to remark in connection with them is that they have often been mistaken, even by medical men, for the effects of syphilitic disease, and much distress has resulted from such mistakes.

\section{DERANGEMENTS OF THE URINART ORGANS.}

Several derangements of the urinary organs are liable to occur during pregnancy, partly from sympathetic irritation, and partly from mere pressure. Some of these may be partially relieved, others have to be borne as patiently as they can be till delivery removes them.

The swollen womb often presses on the neck of the bladder, and hinders the passage of the urine, or even obstructs it sometimes altogether, and thus causes straining, burning heat, and great distension of the bladder. In some instances this passes off as the pregnancy advances, owing to the womb rising higher in the abdomen, but in other cases it remains more or less, during the whole term. It is particularly important, in such cases, that the female should not let the difficulty remain too long unremedied, for if the bladder be very full, it may become utterly impossible to empty it by natural effort. Sometimes the difficulty is much lessened by lying on the back a short time before attempting to urinate, or by raising up the abdomen with the hand at the time. Many females can urinate with tolerable comfort while lying on the back or abdomen, and others are much relieved by constantly wearing a liandage. Constipation always makes this difficulty worse, and sometimes even causes it, by keeping the rectum full, and thus increasing the pressure. In all such cases, it will be readily seen that forcing medicines are not only useless, but liable to cause injury. The change of position, rest, and supporting the abdomen are the vineans to be relied upon. If these fail, and the urine accumulates, the catheter inust be used. A warm bath, or fcmentation with warm water and laudanum, will sssist, and sometimes relieve alone. To ease the burning and distress, the patient must drink freely of gum water, or barley tea, with a little syrup of poppies.

There is one manourre which, if practiced aright, will nearly always allow the female to urinate with ease, and fortunately she can practice it herself. It consists in introducing two of the fingers into the vagina, and raising up the womb, as if practicing the ballotment. This removes the pressure from the bladder, and the urine then escapes by natural effort. A few trials will soon enable any one to do this, particularly if they notice well the form and position of the parts, as shown in the plates of this work. A lady who heard me mention this in one of my lectures, afterwards stated that the knowledge of it enabled her to dispense altogether with the catheter, which she was previously necessitated to use during most of her pregnancy.

When there is merely a nervous irritation causing the difficulty, the warm bath, or fomentation with warm water and laudanum will be sufficient, or a little beliadonna ointment may be rubbed over the meatus urinarius, while some starch or laudanum is injected carefully into the vagina.

\section{CRAMPS.}

These arise from the womb pressing on the nerves of the sacrum, and are therefore not under the control of medicine. All that can be done is to change the posi- 
tion of the body as much as possible, from lying down to standing up, and by turning from one side to another. Brisk rubbing with the hand will also assist in giving relief. The cramps, however, usually disappear after delivery, and must, therefore, be borne as patiently as possible till that takes place.

PRURITUS, OR ITCHING OF THE EXTERNAL PARTS.

This troublesome affection has already been fully treated upon in a former article, which may be referred to. 


\section{CHAPTER LXXX.}

\section{IDIOPATHIO OR PRIMARY DISEASES INCIDENT TO PREGNAKOY.}

\section{Flooding or Hemorrhage.}

FLoodirg is one of the most dangerous accidents that occur during pregnancy, its consequences being often of the most serious character. The causes that lead to flooding are very numerous, some of them predisposing to it, and others immediately exciting it. Among these may be mentioned a toc full habit, violent exertion, falls, coughing, vomiting, straining from costiveness or violent purgatires, forcing medicines, criminal attempts at abortion, overwalking, blows on the abdomen, too much dancing or running up stairs, strong mental emotions, fright, or anger, and certain excesses. The immediate cause is the separation of the membrane in which the foetus is inclosed from the walls of the womb. Flooding may, however, result from the placenta growing over the mouth of the womb, and being torn as that opens-usually about the sixth or seventh month. (See the article Flooding during Labor.)

In most cases, flooding is preceded by dull pain in the loins and groins, and a sensation of weight and dragging. Similar sensations, however, are often produced by other causes, which makes it difficult to predicate, with any degree of certainty, whether the patient is about to flood or not. The very first appearance of blood from the vagina must therefore be watched for carefully, as that removes all doubt, and warns us to be prompt with the proper remedies. Sometimes a female will flood internally, the blood being retained by the passage being closed or plugged up by clots, or by its passing behind the membranes, or under the center of the placenta. These internal or concealed hemorrhages are very dangerous, as the patient may lose much blood before her condition is suspected. It is therefore necessary to bear this in mind, and carefully use every means to ascertain whether such an accident has occurred or not. In general the indications are pretty plain, the patient suffering from deep-seated and distressing pains in the back and groins, with great weakness in the limbs, faintness, weak pulse, dimness of sight, ringing in the ears, coldness of the hands and feet, swelling of the abdomen, and finally fainting, particularly if the retained blood suddenly escapes, which it usually does.

In the early months there is more danger to the child from flooding than there is to the mother, because it is nearly certain to lead to abortion. In the latter months, on the contrary, the mother runs the greatest risk, as the child may then live if it be expelled, while the mother may sink and die from excessive loss of blood. There are many females of a very full habit, who suffer but little from hemorrhage, unless it be excessive; indeed some seem to be benefited by it, and are thus relieved from headache and convulsions. It should, however, be carefully watched, and its effects duly noted. 
The treatment of flooding must depend materially upon its severity, and the time when it occurs. In the early months, when the discharge is slight, and when it causes little distress, simple means will answer. The patient must lie on her back, on a hair mattress, with the pelvis raised, by means of a pillowi, higher than the rest of the body. The air must be kept fresh and cool around her; she must keep herself quiet in body and mind, live rather low, and drink freely of cooling drinks, such as soda water, lemonade, tamarind tea, or ice water.

If the flooding does not stop with these simple means, external applications must bo made of cold, wet cloths, or even ice, over the abdomen, and inside the thighs. Finally, if further treatment is still needed, cold astringent injections may be carefully thrown into the vagina. Cold water is perhaps as good as anything for this purpose, and I have frequently known a most severe flooding checked immediately by injecting cold water into the vagina and rectum, and applying cold wet cloths over the abdomen, and inside the thighs. Some astringent drink may also assist, such as a little syrup of comfrey, or extract of rhatany, and particularly a tea made of the root of the black currant, as recommended before. If the patient be nervous and irritable, or suffer much from pain, an opium pill may be taken, or from ten to twenty drops of laudanum.

The general practice in these cases is to bleed freely and give opium! And as this practice certainly does succeed in many extreme cases, I should certainly recommend, if the simpler means fail, to resort to it at once. I dislike bleeding very much in any case, and here it seems particularly inappropriate; I should therefore say try almost anything and everything first, but never obstinately refuse to resort to it if nothing else succeeds.

In some cases a plug or tampon is used to fill up the vagina. It may be made of a roll of cloth, cotton, or a piece of sponge. This practice, however, is useless in the latter months of pregnancy, and very often fails even at other times. When it succeeds it causes the blood to coagulate, and thus closes up the mouths of the ressels. Quite as often, however, it only keeps it in, and makes it accumulate in the womb till it all rushes away at once ; still it may be tried.

If the hemorrhages should occur so frequently, or be so excessive, in spite of all treatment, as to endanger the safety of the patient, there is no other resource left to save her life but to produce abortion, because the presence of the foetus and its appendages is evidently then the irritating cause which keeps up the discharge, and it cannot be expected to stop till the womb is emptied.

\section{ABORTION, OR MISCARRIAGE.}

When the foetus is prematurely expelled before it can survive, it is called an abortion, but if its expulsion takes place so late that it can live, it is called miscarriage. Both these are serious accidents. In abortion the child is lost, as a matter of course, but in miscarriage it may live, after the seventh month. The danger to the mother is considerable from both, though greatest probably from abortion. It is probable that many - rery early miscarriages take place unperceived, the female suffering but little from che accident, and the embryo being too small to be seen, unless carefully looked for.

The most frequent periods for such accidents are found to be six months, five months, and three months; and what is very singular, a much greater number 
of male children are aborted than females, the proportion being about sixteen to eleven.

These accidents are so intimately connected with flooding, that many witers always treat of them together, considering the flooding merely as the most frequent cause and symptom of miscarriage or abortion. In speaking therefore of the imme. diate causes of premature expulsion of the foetus, we place hemorrhage first, and the causes before enumerated, which produce that, as being its most frequent remote ones.

A full habit, with tendency to local congestion, seems to predispose a female very much to miscarriage. Every one so constituted should carefully aroid luxurious living and an inactive life. Violent bodily exertion, falls, or blows, or strong mental excitement are most usually the immediate canses, though with some it will come on spontaneously without any such exciting agencies. Some females will miscarry many times in succession, and always so near the same period, that they can tell to a day or two when it will happen. It seems to become a habit of the womb, with them, to contract at that particular time, and the only way to break through the habit is for them to avoid becoming pregnant for some considerable time, say two or three years after; they may then go the full time, but will seldom do so if they conceive immediately after having miscarried. In some persons miscarriage is caused by a too eager gratification of certain desires, but in others it may arise from the opposite cause.

There is a disease of the womb also by no means unfrequent, though but little understood, which undoubtedly causes much miscarriage, and that is rheumatism of the womb! This mostly exists before the pregnancy, however, and should be then attended to.

Miscarriage also arises in many females from a rigid state of the muscular fibers of the womb, which not relaxing sufficiently to allow that organ to expand, become irritated by the pressure they experience, and begin to contract. This contraction of the womb of course soon leads to the expulsion of its contents, the same as in real labor. Women with their first children are more liable to miscarriage than others on this account, the womb not having become habituated, as it were, to the necessary relaxation.

And this is the reason also why some females, after suffering from this accident many times in succession, at last escape it. In general, they miscarry early the first time, from the womb not relaxing sufficiently, but go a little longer the next time, and longer still the next, and so on, till they reach the full period. The fibers of the womb have gradually become accustomed to relax, and have borne the irritation longer and longer each pregnancy, till at last they have forborne to contract till the proper time. I knew one female who miscarried twenty-one times in succession, getting gradually nearer to the full period each time, till at last she reached nine months, and was rewarded with a living child.

Sometimes the accident may be produced by a uterine tumor, by a great quantity of water in the womb, or even by there being more than one child, because in either of these cases there is required more room than ordinary; and of course from the greater expansion required, the liability is increased. Various womb diseases may also be mentioned as causes, such as adhesions of its body, or ligaments, to the walls of the abdomen, and also a diseased state of the placenta. The pressure of corsets and tight dresses also not unfrequently leads to the same result. Some general diseases undoubtedly often cause miscarriage, such as measles, jaundice, scarlet fever, con- 
sumption, and probably many others, particularly those in which the quality of the blood is much altered, or the nervous power much exalted or depressed. Convulsions have already been mentioned as being frequent causes of miscarriage, and all strong mental or moral impressions. Indeed, these last causes operate more than is suspected, and make it necessary for a pregnant female to be kept as calm in her mind as it is possible for her to be. I have even known one to miscarry from a fright in a dream.

It is also a fact, though not generally known, that there are certain diseases of the father that may produce miscarriage, and unfortunately they are of that kind that often remain for a long time in the system without much external manifestation, so that many persons think they are perfectly free from them even while they are working great mischief.

The death of the child also is sure to produce miscarriage, and this may result from various causes, such as external injuries and violence, or from remaining too long in the warm bath, and thereby causing congestion of blood in the womb. Smallpox and syphilis in the mother may also cause the death of the child, though not always, many having been born at full term with these diseases upon them.

In general the foetus is expelled very soon after it dies, but occasionally it is retained for a considerable time, and may not pass away till it is completely decayed. It has even been known to become almost fluid, and several months elapse before it was entirely expelled. Most women know when it dies, by its seeming to fall down 'to the bottom of the abdomen, like a dull weight, and also by its feeling very cold. Very often, however, there is no indication of its death whatever. M. Chailly mentions a case where the embryo died, probably when about fifteen days old, but the placenta continued to grow, and the lady was delivered, when about six months and a half gone, of the dead embryo, only about a quarter of an inch in length, though the after-birth was nearly large enough for one of the usual size. In this case it had died but not decayed, and remained in the womb six months and a half. In cases of twins also, one will sometimes die at an early period, but remain till the other is born at full term.

Th, growth of the placenta over the mouth of the womb, and shortness of the cord, have already been referred to as causes both of flooding and miscarriage ; and to these may be added monstrous or deformed fœtuses, which rarely reach the full term.

It is probable that there are many constitutional and individnal peculiarities predisposing to miscarriage, with which we are not much acquainted, and which may account for the constant occurrence of that accident in many females, notwithstanding all we can do. A scrofulous taint is with good reason supposed to be one of these, and it is probable that the disease of the placenta, and its consequent separation from the womb, before referred to, is mostly caused by a taint of this kind. In many instances where a female has miscarried from no apparent canse, if the placenta be carefully examined it will be found dotted here and there with diseased spots, sometimes like scrofulous sores! It is advisable always to ascertain this, and to carefully examine the foetus and its appendages. In all cases the advice I gare, to keep from being pregnant for some time, will be found most likely to succeed in averting the accident, both because it gives the womb time to regain its strength and break through its habit, and also because it gives us time to operate upon the constitutional taint, if there be reason to suppose it exists. 
It is a curious fact, but one often observed, that even living in certain localities predisposes to miscarriage. There is a certain district in France where the females are so liable to it, that all who can do so leave the place when they become pregnant, and thus escape the greater risk. Miscarriage also becomes epidemic at certain times, and prevails like contagious diseases ; several instances of which are recorded in history.

Bleeding is also supposed to be a cause of abortion, and probably it may lead to it in certain states of the system, but by no means so certainly as many suppose. Instances have been known of pregnant females being bled from ten to twenty times without any evil result, even though carried so far as to make them faint. Mauriceau tells us of one who was bled ninety times, and yet was delivered of a healthy living child at full term. In like manner many other ordinary causes of abortion will often fail entirely of their usual effects. Thus Mauriceau informs us that a female seven months gone fell upon the hard pavement from a third story window and broke her arm, but yet did not miscarry. Madame Lachapelle also tells us of a young pregnant woman who threw herself down stairs purposely, from fear that she should have to submit to the Cæsarean operation, she having a deformed pelvis. The fall caused her death soon after, but did not make her miscarry. Certain powerful medicines are also taken by some, a very small quantity of which, in most cases, produces abortion immediately, but without effecting what they desire, though it sometimes poisons themselves.

Indeed the power which the womb sometimes exhibits to retain its contents, in spite of the most violent disturbing agencies, is truly astonishing. Cases have been known even where the womb itself has been severely wounded, and yet miscarriage did not take place; as in the case of a poor country-woman whom I heard of, who accidentally fell upon a sharp wooden stake, and ran it far into the body, injuring the womb in a terrible manner, but strange to say, though far advanced in pregnancy, she recovered and went safely through her full time. I have often known women begin to flood and suffer from dreadful pain, with other common symptoms of abortion, as early as the second month, and yet they went safely the full time, though these signs continued the whole time. In some cases the waters bave even been partially discharged, and yet abortion did not result. M. Velpeau tells us of an instance where the bag of waters broke, in a female six months gone, and one arm of the child even came down into the vagina, and yet the arm returned, the discharge ceased, and she went her full term.

The progress of a miscarriage varies according to the time at which it occurs, and the causes from which it arises. When it results from any violence, or accident, it usually takes place in a short time, and is preceded by abundant flooding, which comes on immediately. The discharge of blood, however, is less the nearer we approach the full term, so that a female six months gone is not in nearly so much danger from flooding as one only two or three months gone. The reason is this: in the early months nearly the whole of the fotal membranes are attached to the womb, so that, in case of their being separated, it bleeds from nearly all its internal surface, but in the latter months the only point of attachment is the placenta. In the latter months also the womb contracts vigorously, and so closes its vessels, but in the early months its contractions are comparatively feeble. In those cases also, where the child has been dead a considerable time before its expulsion, there is seldom much flooding, the connection between it and the mother having been more or less destroyed by decay of the parts. The same result mostly follows a miscarriage from internal 
disease, particularly of the placenta. Indeed, in some of these cases, the blood-vessels connecting the foetus with the mother have been so completely destroyed, that no blood whatever could escape from them.

In regard to the probable consequences of premature delivery, it has already been remarked that it is more dangerous in the early months than the latter. It may also be added that it is much more dangerous, at any time, when caused by violence of any kind, or by forcing medicines, than when it occurs naturally. The danger is much increased if it occurs during fever, or any eruptive disease, or if the patient be suffering from diarrhoea or convulsions. As a general rule we may say, in all cases, that miscarriage or abortion is always more dangerous to mother and child than natural labor, both in its present and in its future consequences. During an attack of jaundice an abortion may terminate fatally in a few hours; and very frequently the trouble with the after-treatment is very great and long-continued.

The treatment in an accident of this kind must vary according as we are required to prevent it, or to remedy the evils that follow when it has occurred.

If an abortion be threatened from any cause, the same general practice must be adopted as recommended for flooding, the indications being the same. I believe myself that in most cases, except from accidental violence or internal disease, mis. carriage may be averted. I knew a lady who had miscarried many times, always at. the same period, who aroided it at last by simply preventing constipation from the first commencement of pregnancy, and by using an enema every evening of warm starch and water, pretty thick, with about thirty drops of laudanum. This was ad. ministered by means of a common injection pipe, just before going to bed, and con. tinued till after she had quickened, and repeated occasionally after that, if she felit any premonitory symptoms of uterine disturbance. If the patient be of a full habit, she should also, from the very beginning, live low, keep the bowels free, and the skir: in good action, and take gentle regular exercise in the open air.

When all the means used are found of no avail, and it becomes evident that the fœtus must be expelled, every endeavor should be used to assist nature in its removal as early and as safely as possible. For this purpose, the same treatment, as far as practicable, must be pursued as in a real labor. If the hand can be conveniently introduced, without undue force, it may be so, to remove clots, or to take hold of any part of the foetus which may present, and assist in its extraction. In the early months, considerable help may be given sometimes by introducing the finger into the mouth of the womb, with a little extract of belladonna, to promote its relaxation, but no force must be exerted in doing so. If any part of the after-birth can be laid hold of, it should be withdrawn, but no extraordinary effort must be used to reach it. Frequently it happens that a portion of the after-birth remains in spite of all attempts to take it away, and there is a possibility that it may produce inflammation of the womb, but no very serions appreheusions need be felt of such a result, providing the patient is properly attended to in other respects. The retained portion gradually decays, and passes away, merely occasioning inconvenience, and being very offensive. The danger from leaving it, except at a very late period, is generally thought to be 'ess than that from using any forcible means to remove it.

The best means for correcting the offensive discharge, are cleansing and antiseptic injections. Warm soap-suds made with tar soap are very good, or a decoction of Peruvian bark in water, or six drops of carbolic acid to the half pint of water. Strong coffee is also excellent, or a weak solution of chloride of lime or borax. The bowels 
must be kept free, and the skin carefully cleansed and well rubbed. On all occasions when the hand can be introduced with moderate and safe efforts, it should be so, and the after-birth removed.

In conclusion it should be remarked, that the tendency to miscarry, like many female diseases, is undoubtedly owing, in great part, to the general debility and weakness which characterizes so many women at the present day, and which is brought on chiefly by neglect of their physical education when girls, and by theix artificial mode of life afterwards. 


\title{
CHAPTER LXXXI.
}

\author{
DISEASES OF CHILDBED。
}

\section{Puerperal Fever, or Childbed Fever.}

THIs is undoubtedly the most serious of all those maladies that so often follow labor. It appears from medical records that puerperal fever has been known from very remote times, and that it has frequently become epidemic, or has spread from one to another, like the cholera. In hospitals this has often been observed, and also in cities, sometimes almost every female delivered in the place having been attacked while it prevailed. There is also no doubt but that it is contagious, or capable of being transmitted from one person to another, like small-pox. Numerous instances have been known where nurses and physicians have conveyed it to all whom they attended, during a long period after having been with a single case. One physician, after attending a case of puerperal fever, lost nine patients successively from the same disease, before he suspected the cause ; and an old nurse assured me, that when she was a young woman, she was the unfortunate means of conveying it to two females whom she visited, by merely having been in the room a short time with one who was suffering from it. It is therefore highly important that all persons who may happen to be with a female so affected should not attend another case of childbirth for some time, and particularly that they should not wear any portion of the same clothing they then had on, and that they should bathe the whole body several times. If a case occurs in a hospital or other public institution, the female must be carefully isolated from all the others, and none of her attendants must be permitted on anj account to visit other puerperal patients, till after a sufficient time has elapsed, and every precaution has been taken.

The causes that produce this terrible disorder are not very well understood; some of them probably predispose to it before delivery, or even before pregnancy, while others are connected with labor and its consequences. Among the former may be mentioned improper diet, an inactive life, anxiety of mind, bad air, a damp situation, a full habit, or great weakness, the frequent use of stimulants, and certain excesses ! The principal causes operating immediately are difficult labors, violent treatment, the use of instruments, tearing away the placenta too soon, retention of the lochia, cold, rising from the bed too soon, depression or excitement of the mind, over-exertion in talking to and seeing company, and neglect of cleanliness. The most frequent cause probably is cold or damp, which checks the lochia and the perspiration, and leads directly to inflammation. It is on this account that the complaint is nearly always worse in winter than in summer, and prevails most in low damp situations, and in badly ventilated apartments, or in those insufficiently warmed. In most warm countries, and in those of an equable temperature, where the females remain much in the open air, and use regular exercise, puerperal fever is but little known. 
The nature of this complaint appears to be a severe and sudden inflammation, commencing either in the womb or some of the neighboring parts, which, if not arrested, rapidly extends to all the organs of the pelvis and abdomen, and hastens to a fatal termination with fearful speed. The precise seat, and place of commencement of the inflammation, vary in different cases, but this makes little difference either in the symptoms, consequences, or treatment of the disease, and it is of but little use to give a separate name to all these various forms. Uterine phlebitis, metro-peritonitis, puerperal metritis, and puerperal peritonitis, are all essentially the same complaint, and identical with what is called puerperal or childbed fever.

The disease generally appears from the second to the fifth day after delivery, but may be delayed as late as the fifteenth or twentieth day, or commence as early as two or three hours after; and has even been known to show itself before labor came or.

It usually begins with headache, general debility, uneasy feelings, creeping of the flesh, and chills : then follow tremblings, numbness of the limbs, cold feet and hands, with a burning heat in the body. The abdomen gradually gets tender, so that it cannot bear the slightest pressure, sharp pains are felt in various parts of it, and the patient continually complains of twisting and burning within. She prefers to lie on her back, with the head raised and the knees drawn up, so as to relax the abdominal muscles. Very soon she complains of great thirst, and cries out repeatedly from the sharpness of the pain; the headache increases, and the breathing becomes laborious. Hiccough generally occurs at an early stage, and is usually accompanied or followed by vomiting and diarrhøa, but sometimes by obstinate constipation. The abdomen continues to swell, and becomes still more tender ; the face is pale, bathed with cold perspiration, and indicates in every line the anxiety and suffering under which the patient labors. The features seem to be drawn inwards, and together, or pinched up, and indeed the whole body seems to shrink. In general, the lochial discharge either stops altogether or lessens very much, the breasts remain empty, or nearly so, and the pulse is weak and irregular. In some few cases, however, the lochia continues to flow, or even increases, and the breasts remain full up to the time of death. The urine is high colored and thick, and causes smarting and burning as it passes away. The tongue furs and becomes pointed, and pale colored. The eyes often seem much engorged, and the white parts become yellow, as indeed the skin does over the whole body, owing to derangement of the liver, and alteration in the character of the blood. In most cases the mind retains its faculties nearly till dissolution, but there is frequently a vague sense of uneasiness and fear, with great depression of spirits and weeping. Some even feel assured, from the beginning, that they will never recover, and occasionally become delirious.

The duration of this disorder varies considerably, though in most cases it carries off the sufferer in a short time, frequently even in two or three days. It may however, last five, ten, or twelve days, and has been known to do so fourteen.

The manner in which it terminates is also different in different cases. The fluid resulting from the inflammation may either be absorbed, or suppuration may ensue and the matter be discharged, either from one of the natural passages or from an artificial opening; or it may not be discharged at all. Sometimes gangrene or mortification ensues, and sometimes the inflammation partly subsides and becomes chronic. When it terminates by resolution, which is the most favorable mode, the patient begins to improve about the fourth or fifth day; the pains become less acute, the 
swelling and tenderness become less, and the milk, lochia, and other secretions that were suppressed, begin to reappear. The patient is also able to lie either on the back or sides, and soon feels conscious herself that she is improving. But even when a turn for the better has decidedly taken place, too much confidence should not be prematurely felt, nor should there be any relaxation of attention, for the slightest causes may bring back all the symptoms with more than their former severity. When suppuration ensues, which is most commonly the case, a mass of fluid forms in the womb or abdomen, and is plainly indicated, either by its moving about or by a portion escaping from the body. In this case also the pain and tenderness decrease, and the abdomen seems less hard, but the pulse becomes weaker, a sense of weight is felt about the womb, the extremities become cold, chills come on, and gradually the powers of the system seem to fail till complete exhaustion ensues. When gangrene or mortification takes place, the termination is nearly the same, but more rapid, and all the above symptoms are more marked. When it passes into the chronic form, there is but little permanent abatement in the severity of the symptoms for some time; they partially lessen at intervals, but return again, sometimes with renewed rigor, and it remains long a matter of doubt whether the disease has really passed the critical period or not. Recovery takes place occasionally in this form of the disease, but more frequently the patient becomes daily weaker and more emaciated, diarrhoea and slow fever set in, the vital powers steadily sink, and at last death ensues. This fatal termination may however be delayed for an indefinite period, and may ultimately result from consumption or dropsy, both of which frequently follow chronic puerperal fever.

In regard to the probable termination of this disease, but little hope can be entertained that it will be favorable, nor are there many indications that can be relied upon with certainty as to what course it is likely to take. In general, it is favorable when the swelling subsides and the pains abate in severity, and particularly if the milk and lochia begin to be secreted again. The indications are also good in proportion as the symptoms are mild, and when there is no great sympathetic disturbance of other parts of the system. It is regarded as unfavorable when the pain and tendernozs extend over a large portion of the abdomen, and when the attack commences very suddenly. The danger is also considered greater in proportion as the disease begins nearer to delivery ; and when its first symptoms exhibit themselves before labor, it is always considered mortal. It is likewise more dangerous with twins than with a single birth, and with first children than afterwards. It is seldom possible however to come to any probable conclusion till between the fifth and tenth days, and even then it is in general a matter of great uncertainty.

The best treatment of this fearful disease is one of the greatest problems in med ical science. So many different plans have been adopted, and with such various success, that the history of past cases affords but little reliable data to guide us in future ones. In general, the most powerful antiphlogistic measures, or those thought most likely to reduce the inflammation at once, are immediately resorted to, such as bleeding, purgatives, and cold bathing. Bleeding is in particular the great agent depended upon, either from the arm, or by cups and leeches to the abdomen and vulva. Dr. Gordon, of Aberdeen, in Scotland, who once met with a regular epidemic of puer peral fever in that city, assures us that nothing else succeeded in arresting the disorde. but copious and frequent bleeding, at the very commencement. He carried it so far as to take twenty-four ounces at once, and he says that when he did so the patient 
was nearly sure to recover, but that at first, when he only abstracted about twelve ounces, she was as nearly sure to die. In about fifty cases to which he was called in time, he only lost five, and taking the average of all he attended, the recoveries were about two-thirds of the whole number, which is above the usual proportion.

It appears however, from the experience of the most eminent practitioners, that the bleeding must commence early ; that the first abstraction should not be omitted beyond twenty-four hours after the first symptoms of the disease, and should be as much earlier as possible. With very few exceptions, they also think Gordon's standard of twenty-four ounces not too much. Indeed it is generally admitted that if the blood be not drawn at first, and in large portions, it had better not be drawn at all. There may be, of course, many peculiar cireumstances that will make bleeding improper, which nothing but experience and observation will teach a practitioner, but the number of such cases is thought to be small. The use of leeches meets with but few advocates, and certainly they seem to have had but partial success, compared with the lancet. Dr. Collins, of Dublin, depended chiefly upon leeches and calomel, but he tells us that in eighty-eight cases, fifty-six died when so treated, while in fifteen that were freely bled from the arm only eight died. In short, it appears that the bleeding must be carried far enough, at the very beginning of the disease, to cut it short at once, or it will be of no avail, it being of little or no use merely to check it ! In conjunction with the bleeding, it is also usual to give enemas of starch and castor oil, or something similar, and to bathe the extremities in hot water.

I know that this practice of bleeding meets with strong opposition from many physicians, and that it is objected to by patients generally. I myself am as much opposed to it as any one reasonably can be, and I am well aware of the numerous evils which follow it, but still it cannot be denied that Dr. Gordon's plan has cured a greater number of cases of puerperal fever than any other yet tried. It is true that many of those thus cured may have afterwards died of dropsy, convulsions, typhus, and other diseases produced by the bleeding, but then the risk they ran of dying from these was less than that from the puerperal fever, and in a choice of evils we ought to choose the least. It should also be remembered that some eminent practitioners assert, if this plan be adopted promptly and fully, it will always cure, or at least with very few exceptions.

Several other modes of treatment have also been adopted to dispense with bleeding, some of which have been much more successful than others, though none so much so as we could desire. Thus some practitioners resort immediately to hot fomentations and sweating medicines, or a hot bath if convenient, together with brisk purgatives and injections. Some depend upon calomel in large doses, with leeches to the groins and vulva. Others again use cold fomentations, and cold injections both to the rectum and to the vagina. Others again use blisters over the abdomen, in conjunction with purgative enemas and moderate bleeding; but this mode seems to do but little good. Another plan is to give about six grains of ipecac, and to repeat the dose several times, at intervals of an hour or less, in conjunction with purgatives and warm fomentations. Turpentine has also been used internally and by enema, but seems to have accomplished little good. Perhaps the most frequent plan, after bleeding, is to rub one or two drachms of mercurial ointment well on the skin, over the abdomen, every two or three hours, sometimes for several days regularly, eight or ten grains of calomel being also given daily at the same time. This brings on salivation, and in many cases the symptoms begin to abate in severity as soon as that 
commences. I am not aware, however, that this treatment is any more successful than bleeding, nor do I think the consequences afterwards, in a case of recovery, are any less to be dreaded. It is difficult in fact to say what plan can be best recommended, even in the majority of cases, and certainly no one jet tried is applicable to all, on account of the peculiarities and varying circumstances of each. If the practitioner or patient is not decidedly opposed to the bleeding plan, that has undoubtedly the best recommendation, from former success. Next to that, perhaps, comes the mercurial treatment, which usually meets with as much opposition as the bleeding, but which certainly has been frequently found efficacious. The other plans have met with but little favor, though possibly they might sometimes succeed when the rest fail.

If I were asked what I should advise for those who would not submit to the use either of the lancet or mercury, I should say, commence with a strong dose of Epsom salts, or jalap, and repeat it in about five hours after its full operation. Also apply warm fomentations to the abdomen, or put upon it a flannel bag full of hops soaked in vinegar, as hot as it can be borne, and put mustard poultices on the feet, and inside of the thighs. The hands must also be kept as warm as possible, and the head cool. The diet should be very spare, and contain nothing heating or stimulating, and cooling drinks, such as ice-water, or cold lemonade, should be drunk freely. The purgative should be repeated at least every day, for two or three days, or more if the symptoms are not modified, and the mustard poultices may be regularly used to various parts of the limbs, for the same length of time. In conjunction with these means the breasts should also be kept warm, to promote the flow of the milk, and injections of starch and castor oil should be thrown up the rectum daily. The object being, as far as possible, to keep the surface of the body warm, and to cool the internal fever, at the same time that all the natural secretions are excited as much as possible, to remove any morbid matter that may be formed. It should also be mentioned that the urine sometimes stops, or at least becomes very scanty and thick, in which case a little sweet nitre may be given, or if necessary the catheter must be used. Some bitter tea, as boneset or chamomile, should also be taken occasionally, and a James's fever powder with it once or twice a day, to promote perspiration ; or if there be severe pains, a dose of Dover's powders may be used instead.

If the disease passes the acute stage and becomes chronic, the same means must be pursued, and with strict regularity, or there will be danger of its again becoming acute. In all cases send for the most experienced practitioner as early as possible, and whatever his plan may be, if his past success proves it to be tolerably successful, submit to it, whether it be bleeding, salivation, or anything else. If there be no one at hand on whom dependence can be placed, follow the plan I have laid down as nearly as circumstances will allow, but practice it fully without delay, and till a change takes place. Those persons who make light of this disease, and pretend to say that this or that simple treatment is all-sufficient, either deceive themselves or wish to impose upon others. There are few affections more serious, as will be evident when it is borne in mind that, on an average, two females die out of every three attacked by it. To aroid all liability to it as far as possible, attend well to the general health during pregnancy, have everything comfortable, clean, and wholesome, during labor, and be careful to avoid cold, damp, and all kinds of mental and bodily excitement afterwards. The assistant also, whoever it may be, must be as careful and as gentle as possible, so as to avoid all violence or undue force, and not to hurry 
nature. A want of attention to such simple details has, undoubtedly, brought on many attacks of this fearful disease that otherwise would never have been experienced.

\section{AFFECTIONS OF THE BREAST OCCURRING AFTER PREGNANCY.}

The functions of the breast are liable, from many causes, to become deranged, and such derangements may lead to serious results, both to the mother and the child. It is a common opinion that females who nurse are not so liable to suffer in this way as those who do not, but experience proves this opinion to be untrue ; nevertheless, as it is the duty of mothers to nourish their own offspring, it should be a subject of careful study to relieve them of this liability as far as possible, or to assist them when necessary.

Galactorrhoea.-This means an overflow, or excessive secretion of the milk, which sometimes takes place, particularly in those who do not nurse. At the commencement of the milk fever, galactorrhœa needs but little attention, but if it continue to the second or third day, proper remedies should be applied to correct it. These consist in complete rest, both of body and mind, cooling drinks, and spare diet. If these do not correct it soon, a flax-seed poultice should be placed on each breast, and the patient should be made to perspire, either by warm teas and clothing, or by means of steaming. The bowels should also be freely opened with castor oil, or a seidlitz powder, and it will often benefit very much to give warm water freely to drink, with ten grains of nitrate of potash (saltpetre) to the pint.

In those that nurse, it is very seldom the case that the secretion of milk is too profuse, unless the child has been kept too long from the breast. As a general rule it should be put to nurse in a few hours after birth, even if there be no milk, because its suction will materially help to bring on the flow. It frequently happens, when the child is kept away till the milk comes, that the breasts have swelled so that the nipple is buried and cannot be laid hold of well by the mouth, in consequence of which the child does not get nourishment enough, and the breasts not being well emptied become engorged, and their functions deranged. All this may be avoided by putting the child early to nurse. Sometimes, however, notwithstanding every precaution, the flow of milk is excessively great, and constitutes a real disease, which may cause great weakness and debility. In such cases it will generally be found that the diet is too stimulating or too rich, or that the bowels have been too inactive, and the first step toward an improvement must consist in correcting these faults. The skin should also be kept active by frequent bathing and good friction, and the quantity of nourishment taken should not be greater than the mere healthy support of the body requires. In particular no stimulating liquors should be used.

Agalaxy.-This complaint is the reverse of the former, as it consists in a deficient secretion of milk. The causes of this deficiency are various; sometimes it arises from a constitutional inertness of the breasts, sometimes from insufficient nourishment, and sometimes from profuse discharges in other parts. All excesses also tend to decrease the quantity of the milk, particularly those of a certain kind; and it is seldom so abundant or lasting either in extreme youth or advanced age. The appearance of the menses in like manner generally causes the flow to become less, and it ceases naturally in some much earlier than in others. Sometimes there is a deformity in the child's mouth, which prevents its sucking properly, and the milk may stop for want of being completely drawn. The breasts also may be dis- 
eased, or the nipple not sufficiently prominent, and the same difficulty be thus produced in another way.

In treating agalaxy, therefore, the first thing is to ascertain if there be any deformity or disease in either mother or child, which prevents proper nursing. If there be nothing of the kind, it must next be ascertained whether the mother has any excessive secretion elsewhere, such as diarrhoea, great flow of urine, or heavy sweats ; if she have, these must be corrected. It must next be seen if she takes sufficient nourishment, and of a proper kind for her stomach and bowels. Sometimes a little spiced wine is excellent, or some porter, with white meats, and arrowroot milk. If she be of a full habit, however, and makes much blood, the contrary course must be pursued, and the diet be made low and unstimulating, while the bowels are kept free and the skin in good action.

In many cases when the nipple is small, it may be much enlarged by titillation, just before the child is put to it, after which the suction will increase it still more.

If the female be advanced in life, or very weak, or if she becomes pregnant, it may be better to procure a nurse than to attempt to stimulate the flow at all. The appearance of the menses need not occasion a suspension of nursing, unless it evidently deranges the secretion of the milk, or affects the health of the mother; in either of which cases the child should be weaned at once.

Engorgement of the Breasts. - The breasts are liable to become swollen, or engorged, from colds, blows, hard nursing from the child, over-feeding, and from soreness or excoriations preventing them being fully emptied. This state may occur at any time, but is most frequent a few days after delivery. In general there is no danger from it, unless it be very bad or continues too long; when the breast may inflame and discharge, or become permanently hard. To prevent such accidents, the breasts should always be sufficiently emptied, either by the child or by artificial means, and every precaution should be used against cold or violence. Constipation must also be guarded against, and the diet and drink must be carefully observed, so that it be not too feeding, or too stimulating. Warm fomentations or poultices may also be used when the breasts are painful, and a Dover's powder may be given at night, after bathing the feet in warm water, to promote perspiration.

Inflammation of the Breasts. - This is only a more advanced stage of the previous malady, produced by the same causes, and by want of timely attention. Like simple swelling, it may arise at any time during nursing, but is more frequent a few days after delivery. As soon as the inflammation commences, the breasts become red, swollen, and excessively tender, particularly at one point, which soon begins to project like a nipple, if the disease is not stopped, and at last bursts and discharges the contained pus. Sometimes the inflammation is comparatively superficial, and extends only over a small portion of the surface, but at other times it goes deep and spreads wide. In proportion to its extent is the severity of the symptoms, which are those of inflammation in general, such as headache, thirst, fever, general uneasiness, and cutting pains in the part affected.

As soon as the abscess is formed, and can be plainly discovered, it is usual to open it immediately, because the longer it remains, the more extensive it becomes, and the larger is the portion of the breast diseased. It is necessary however to be certain, before making an opening, that it is really an abscess on which we are going to operate, for sometimes a healthy part of the breast feels very much like one, and a mis- 
take may easily happen; in fact such a mistake has often been made, and by men of experience too. In the early stage of the inflammation every effort should be used to prevent an abscess from forming, by the use of purgatives, sweating medicines, low diet, cooling drinks, and warm fomentations over the whole chest. Some femaies practice cold fomentations over the breasts, and with good success, in the commencement of the inflammation; but it may increase the difficulty with others, and, so far as I have seen, is no more generally useful than the other method. The warm bath all over the body is also very serviceable in a number of cases.

It usually happens however, in spite of every precaution, that matter will form, and its discharge become necessary. As soon as this is evident, it should be promoted as much as possible, by hot fomentations and poultices, till the head of the abscess is sufficiently distinct for it to be safely opened. While the swelling is going on, the pain is often very severe, and it should be eased as much as possible, by using laudanum in the fomentations, or by putting on an opium plaster. After an abscess has opened and discharged, it should be kept open for some time, by little pledgets of lint, to prevent its closing up too soon, otherwise a portion of the matter may be shut in by the wound healing over it, and another abscess will form. Warm poultices and lotions should also be used afterwards, to promote the discharge as much as possible, but they should not be used after it has evidently begun to cease naturally. In short, every means pointed out should be used energetically in the first stage, to prevent the gathering, but if it takes place in spite of them, then it should be hastened and discharged as early as possible, to prevent its extending. After this, when :t has evidently all escaped, the wound may be suffered to heal, and the patient must be enjoined to be very careful in future, for the same accident will be very liable to reappear.

Sometimes these abscesses become very extensive, and remain for a long time. I have known ten or twelve on one breast, and I have known them to continue open for many months. When this is the case it is much to be deplored, as it is very likely indeed to destroy the breast, and may even lead to more serious results. Attention therefore cannot be bestowed upon them too early or too unremittingly, particularly if the female be scrofulous, or of a very full habit. Sometimes the inflammation attacks both breasts, and at other times only one, in which case every effort should be exerted to prevent its extending to the other. In many persons the same side is always affected, and becomes a scape-goat as it were for the other.

When the means used succeed in scattering the swelling, its dispersion is usually followed by some critical discharge, such as diarrhœa, or a great flow of urine, or even by profuse perspiration, which shows how nature operates in removing the diseased matter and cautions us not rashly to check such discharges.

It is a very serious matter for the swelling to indurate or harden, as it sometimes will, without either scattering or dispersing, as it is then constantly liable to become worse again, besides destroying the structure of the gland. Every means should therefore be used to prevent this, by promoting its dispersion or discharge, in the way already pointed out. It is also very good in these cases to bathe frequently with alum water, or decoction of white oak bark, or even to rub on some of the ointment of hydriodate of potassa, diluted with an equal weight of fresh lard. A piece as large as a hickory nut may be well rubbed on twice a day, for three or four days, but it should be stopped immediately the swelling begins to subside, and not used again unless it still remains, or again increases. In many cases pretty frequent friction 
with the hand anointed with a little oil will be all-sufficient, especially if a hot fomentation be used afterwards.

Excoriations, or Cracks in the Breasts.-The annoyance from this cause is sometimes very great, the pain which is experienced when the child begins to nurse being so acute that it is impossible for the mother to allow it to remain. Frequently I have known it compel weaning much earlier than was desirable, and sometimes it has even been so bad that the dress could scarcely be borne against the breasts. The precise cause of this liability to crack is not known, nor do we know of any certain means to prevent it. In many cases, however, I have known it prevented, to a great extent, by having the nipple gently sucked, very frequently, for six weeks or two months before childbirth. This hardens it, and if a wash of borax water be also used after each time, it will be gradually prepared for its proper use. Our means of curing this troublesome affection are very limited, and frequently everything fails that is tried. The mucilage of quince seeds, prepared by bruising and boiling them in a small quantity of water, rubbed over the sores with a soft feather, immediately after nursing, often does much good. The mucilage from the tender tops of young sassafras sometimes succeeds better than that from the quince, and a bruised leaf from the large horse-shoe geranium, laid on like a poultice, is frequently better than either. A good lotion may also be made with a quarter of an ounce of borax, and a teaspoonful of laudanum, to half a pint of warm water, to be used frequently during the day. Some females use a wash made of saleratus, with considerable benefit, and others find relief from one made of nut-galls, or white oak bark. Most of these means, however, are well known, and many others also, which, like them, sometimes succeed and often fail. The artificial nipple, or shield, should be tried if none of these means succeed, and frequently it will enable the mother to allow the child to nurse, though it may not altogether prevent the pain.

It not unfrequently happens that the child's mouth may be diseased, particularly with aphthoe, or thrush, and this may possibly keep up the excoriations. In like manner, the state of the breasts may also influence the child's mouth, and therefore the condition of each should be well ascertained when anything is the matter with either.

\section{BRONCHOCELE, OR SWELLING IN THE THROAT.}

This is often observed in childbed, and sometimes even comes on during labor. It is usually attributed to cold, and no doubt it often does arise from cold, but more frequently it is owing to sympathetic derangement, and from violent attempts to swallow during and after the pains. Many females, in fact, cry out at those times that something has broken in the throat, and they fear they are going to suffocate. As a general rule, the swelling gradually subsides in a short time, without any special treatment, but sometimes it increases and inflames, and an abscess forms, which may become very troublesome, and even dangerous. To prevent this, it should be frequently treated with warm fomentations and poultices, till the inflammation subsides, and then with the same washes recommended for indurated or hardened breast, in the preceding section of this chapter. If the swelling becomes hard, and remains indolent, the ointment of hydriodate of potassa may also be prepared and used, as there recommended. 


\section{PHLEGMASIA, ALBA DOLENS, OR MHLK-LEG.}

This is a painful tumefaction, or swelling of one or both of the limbs, which comes on from the fifth to the fifteenth day after delivery. It generally commences with slight pain, or stiffness, or cramp, becoming more painful as it proceeds ; but sometimes shooting, cutting pains of great violence are felt suddenly, at the very commencement. The swelling also occasionally comes on gradually, but at other times rapidly. In most cases, the patient complains of a sudden pain in the groin and thigh, which is preceded by a chill followed by fever, and then the limb begins to enlarge. Most frequently the lower part swells first, and then it extends upward, sometimes even to the hip. The skin on the swollen part looks white, shining and tight, as if ready to break; it is also extremely painful, so that pressure upon it can scarcely be borne. It looks, in fact, like a thin bag of skin filled with milk, and hence the name milk-leg, from an idea that it was really filled with milk, which had by some means reached there from the breast. This idea is erroneous, in the sense it is usually taken; the milk does not flow into the leg, as many imagine, nor is anything like it to be found there, except a peculiar thin white matter when it breaks. Still, however, a sudden stoppage of the milk may cause such a swelling, like a sudden stoppage of any other secretion, but in no other way. It is probably most frequently produced by sudden cold, which checks that profuse perspiration into which females generally fall immediately after delivery, and so drives the perspirable matter within, and canses inflammation and suppuration. A difficult or prolonged labor may also lead to it, by preventing for a long time the proper circulation of the blood through the large veins of the pelvis, and so engorging those below; or the veins may become paralyzed, as it were, by the pressure they have sustained, and so become for a time unable to transmit the blood. In fact, both the veins and lymphatics become engorged, as if tied above the limb, and exhibit knots and bundles, like bunches of grapes.

Sometimes the fever will occur some $\lambda_{n-\mathrm{s}}$ first, and the female cannot tell what it is owing to, till the swelling comes on; nd even this may take place so gradually, and with so little pain, that the limb may be very large before it is observed. I have known females complain of a slight fever only, on going to sleep at night, and wake up in the morning with a confirmed case of milk-leg, and I have known others start with a sudden pain in the groin, or hip, and be affected in the same way in less than two hours.

The disease usually lasts from a month to seven or eight weeks, and terminates either by a gradual resolution or scattering of the fluids, or by suppuration and discharge. When suppuration ensues, there will sometimes form one or more very large abscesses, which it may be difficult to heal, and which may lead to serious results, either from their extent, or from the constitutional irritation they produce.

The treatment at first consists in warm fomentations, such as those of poppyheads, or hops, with cooling drinks, purgatives, low unstimulating diet, and occasional doses of James's fever powders, to promote perspiration. This is intended to disperse the swelling, and, in general, it does so. If, however, the abscess forms and breaks, in spite of all the means used, it must be treated the same as abscess in the breast, previously described. In ordinary practice, it is the general custom to bleed at the commencement of the disease, or to apply leeches to the groin. This sometimes does good, but frequently is of no service at all, even if it does not make matters 
worse. I would, however, make the same remarks on bleeding here, that I did in regard to its use in puerperal fever, to which milk-leg has a resemblance, in some respects.

Another practice is to use tight bandages, the same as for varicose veins, but I think the plan is not, in general, a successful one, though it may be occasionally. Plunging the limb in cold water, or keeping it wrapped in cold wet cloths, has succeeded much more frequently, and is, with some, a favorite remedy. Stramonium leaves boiled in vinegar, and laid on hot, will also effect a cure sometimes; and so will bathing with hot lye, or alcohol. A large poultice of hops, soaked in hot vinegar, has also been found useful.

\section{TROUBLE WITH THE URINE.}

The bladder, from its position, is very apt to be inconveniently pressed during the passage of the child, and to be temporarily affected for a short time after, in consequence. Sometimes the neck of the bladder will be paralyzed, and the urine cannot be discharged. In this case, fomentations of warm milk and laudanum must be used, or a warm hip bath, if there be no danger of flooding, and the bowels must be freely opened. If this does not relieve, the catheter must be used, and always before the bladder is too full. To avoid its becoming so, the attendant should inquire of the female, during the first day, if she has urinated, or feels any inclination that way, so that he may know in time if the difficulty exists. In general, this paralysis passes off in the course of a day, but may endure longer sometimes; in which case the patient herself should speak of it. Cases have been known where the bladder has become so full as to burst through inattention to this matter. The contrary difficulty is occasionally observed, and the urine cannot be retained, but flows away as fast as it is secreted. It is very seldom, however, that this state remains more than a single day, and more frequently only a few hours. A dash of cold water on the pubes, and against the meatus urinarius, has often corrected it at once, and so has a single purgative dose. If it remain after the first two days without amendment, it is customary to put a small blister on the abdomen, which usually relieves in a short time. 


\title{
CHAPTER LXXXII.
}

\section{USE OF CHLOROFORM IN MIDWIFERY.}

\begin{abstract}
in Inquiry into the Utility and Propriety of Preventing the Pain and Suffering which usually attend Childbirth, with an Account of the Means to be employed for that Purpose.
\end{abstract}

Is a former part of this work I remarked that a great portion, and perhaps nearly the whole of the suffering and danger to which parturient females are exposed, arises undoubtedly from their bad physical education and mode of life; and that, in a more rational state of existence, it was probable that both would be so slight as to excite no apprehension. This improved state of things is much to be desired, and should, of course, be striven for by all friends of humanity. But, in the mean time, it is proper to consider whether there are any means by which those now living can be relieved in their hours of distress. The agony which many females endure at this time is so great that there are few circumstances under which relief is more needed, or would be more acceptable ; and I, for one, cannot subscribe to the doctrine that such relief would be improper, unless it prove to be injurious. There are some persons, I know, who say that this suffering has been ordained for woman, and that it ought to be endured. This notion, I think, needs no refutation, it being just as unreasonable as to say that the sick should be allowed to suffer. and die without assistance, because their condition has been ordained.

Some years ago, a celebrated physiologist, who supposed that the chief cause of pain and difficulty in labor was the size and hardness of the child's bones, advanced the theory that if these bones were less developed, and softer, the pain and difficulty would be materially lessened, if not entirely removed. He proposed, therefore, since the hardness of the bones is caused by the deposition of lime in them, which is derived, of course, from the blood of the mother, that she should avoid taking anything to eat or drink, during pregnancy, that contained lime. This, he supposed, would keep the bones of the child soft till after birth, and so allow them to give way and crush together during delivery, and thus prevent the suffering and difficulty usually experienced. It was also thought that the bones of the mother would be partially softened at the same time, and give way a little, so as to facilitate the process still more.

I am not aware, however, that this theory has ever succeeded in practice, either in the human species or in the lower animals, though frequently tried. Nature wil. work on her own plan, and will develop the bones of the footus, while in the womb, to a certain extent, providing she has the means to do so; and if these are withheld she is very likely to suspend its development altogether, rather than send it forth imperfect. I have known cases where everything was withheld, for the whole period, that contained a particle of lime, and yet the child's bones were as hard at birth as 
in any other case ; the material being, probably, taken from the bones of the mother, which might be thus weakened, and made liable to displacement, without any good result whatever. It is also a question whether such a course, supposing it to succeed, might not be dangerous in another way, by causing an imperfection in the child, which its future growth could not overcome. I have known some cases where this practice appeared to have caused abortion, from imperfect development, and several others in which there was too much reason to fear that the child was injured, though safely born. As this is, therefore, at best, a very uncertain and ineffective process, and is also, probably, dangerous to the mother or child, or both, it does not appear to me worthy of further attention, and I merely allude to it in order to make the present sketch of such means complete.

The other means are such as do not interfere, in any way, with the natural processes, but merely prevent sensation or feeling at the time of delivery. Mesmerism has been recommended, and, in some few instances, tried, for this purpose, but its success has either been so small, or its action so uncertain, that no dependence can be placed upon it, notwithstanding many persons assert its power. Opium and other powerful drugs have also been given, but so much of them is required, at that time, to produce a sufficient effect, that their use becomes dangerous. Other substances, in the form of vapor or gas, have also been used, the effects of which only last for a short time, and are not, generally speaking, at all dangerous. Among them may be mentioned nitrous oxide, or laughing gas, carbonic acid, sulphuric ether, and chloric ether, all of which were first employed in severe surgical operations.

The success of these agents, especially ether and chloroform, in preventing pain, is undoubted; nor do they appear to have any other effect, nor to prevent any necessary effort or process of nature, except in a few cases which will be mentioned further on. Many hundred operations of the most severe kind, such as cutting off limbs, removing tumors, stones, and so forth, are daily performed while the patients are under the influence of these agents, and without causing them the slightest pain; in fact, many remain, during the whole process, in a pleasant dream, and cannot be persuaded, when they wake, that the dreaded operation is over. The same thing is also observed daily in hundreds of cases of midwifery, both in natural labor and when instruments have been used. In numerous instances the female has been put to sleep, and safely delivered, without knowing or feeling anything whatever, during the whole time; the first intimation that she had become a mother being the cheering cry of her new-born babe. In some instances, the state of insensibility has been continued for a long time, and during its continuance the most hazardous operations have been safely performed.

So far as can be safely judged it appears that there is no danger whatever, from the employment of these means, except when improperly administered, and in certain peculiar conditions of the system ; which causes of danger will, of course, be removed by competent experience and knowledge. It is highly encouraging, however, that though ether and chloroform have each been used so extensively and indiscriminately, both by those who understood their nature and those who did not, yet the cases in which they are proved to have done injury are very rare; and in all those that I have heard of, some obvious impropriety had been committed in their use. It should be borne in mind, however, that even if the danger from them was considerable, we might still be justified in their use. It is well known that, in numerous cases, the fear of suffering, beforehand, and its severity while being endured, produce the most 
serious, and even fatal results. Many a patient who might have passed safely through the ordinary effects of a painiul operation, has sunk from the mere effects of fear and suffering. Instances have even been known in which a fear of this kind has caused death, and frequently it has given a shock from which the patient never fully recovered. There is also, in many cases, great danger from the violent efforts and struggles of a person in pain, and many necessary operations are even prevented altogether by them; this is often observed in difficult labors. When insensibility is produced, however, all these causes of difficulty and danger are removed; the patient's fears are quieted, suffering is entirely prevented, and there is no struggling to prevent the necessary assistance.

In regard to the two agents now chiefly used, ether and chloroform, there is no difference in their mode of action, but the chloroform appears to be more speedy, certain, and efficacious, and is, therefore, the most valuable, but proportionably more dangerous when improperly administered. There are numerous instruments or inhalers, for administering these vapors, most of which are both costly and complicated, and all of which may be easily dispensed with. A very good plan is to take a large sponge and dip it in hot water, then squeeze out the water and pour on the ether or chloroform, and hold it over the mouth and nose. In two or three minutes consciousness and feeling will both be gone, and the patient will sink into a calm sleep which will last sometimes ten or fifteen minutes, and may be kept up as long as desired, by putting the sponge to the mouth for a few minutes whenever there are signs of waking. When it is left off, the patient gradually comes round as if waking from ordinary sleep, and frequently speaks of having been in a dream, sometimes of a very pleasant character, but never knows what has taken place. No ill effects follow, but sometimes there is a little drowsiness or stiffness of the limbs, which soon passes off. A pocket handkerchief soaked in the fluid, and held over the mouth and nose will answer equally well; but whatever is used, it must not be pressed close, because a portion of air ought to enter with the vapor to prevent suffocation; and it should also be removed immediately the effect is produced. When it is borne in mind how much these requisites have been neglected, and how impure the ether or chloroform has often been, it is wonderful that more accidents have not occurred; and the fact that so few have happened under such a state of things, and with our limited experience, goes far to prove that there is little or no danger at all in competent hands, with pure materials. The accounts circulated in the papers of "death from ether," and "fatal effects of chloroform," have mostly been gross exaggerations, and frequently false altogether. In most of the cases where death has followed from the use of these agents, it has been proved to arise from other causes, and would have happened if they had not been used. In one or two cases, however, of surgical operations, the ether itself appears to have caused death by producing suffocation, or congestion of the lungs; but, even in these, it has been shown that it was used in an improper manner. Thus a young woman in Newcastle, in England, inhaled ether to have a diseased toe-nail cut off, and died. It appears, however, that there was an evident disposition in her to congestion or rushes of blood, and therefore she was not a fit subject, and besides, the ether was poured on a thick table-cloth, which, of course, prevented the entrance of air along with the vapor, and thus suffocated. I believe there is not a single case on record of injury resulting when due precautions have been used, and I have not heard of one at all in midwifery practice. 



\section{$\triangle D D E N D U M$}

\section{ILLUSTRATIONS OF EVOLUTION; AND THE}

\section{PEDIGREE OF MAN.}





\section{PLATE XLI.}

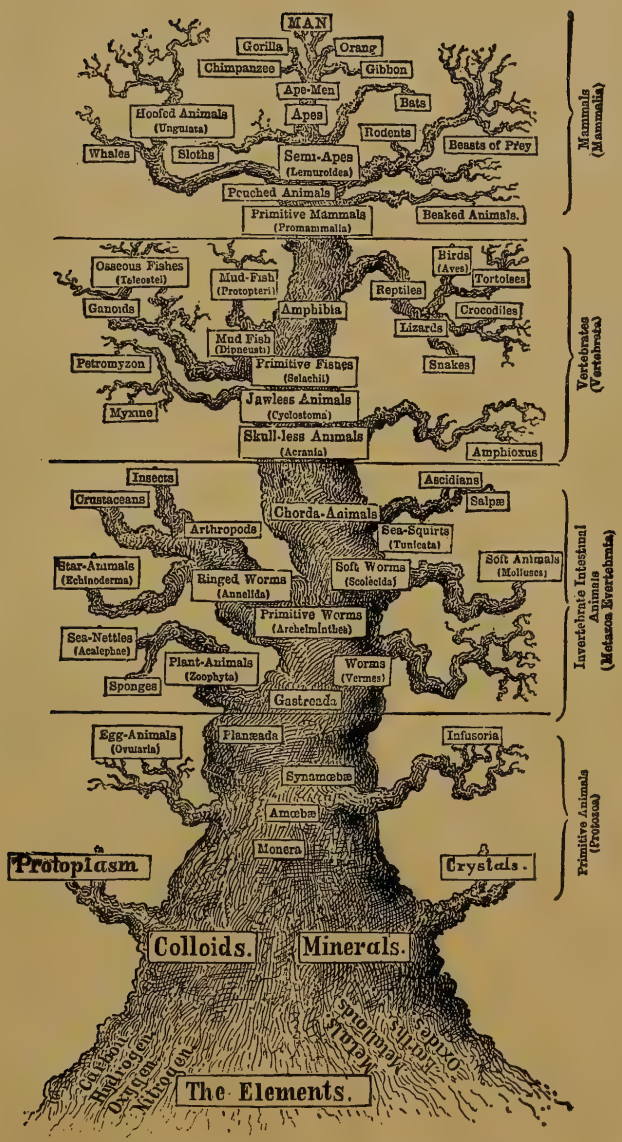

The Evolution of Life and Pedigree of Man. 



\title{
OHAPTER LXXXIII.
}

\author{
EVOLUTION AND THE PEDIGREE OF MAN.
}

To still further elucidate the process of Evolution, and the Descent of Man, ths following plates from Haeckel's "Evolution of Man" are appended to this edition of "The Origin of Life."

Professor Haeckel gives us a Pedigree Tree, showing the steps by which man has been evolved, along with other beings, from the lowest known living forms, the monera. This tree I have extended downwards, so as to start at the beginning. (See Plate XLI. Frontispiece.)

Commencing at the root of the tree we have the primary elements, which begin to arrange themselves together in groups of two or more, forming compound bodies differing from each other according to their composition.

On the left side we have those elements combining which form mineral matters, oxides, salts, and stones. The highest form of organization these compounds attain to is that of crystals. This is their extreme development, their highest type, and nothing further is to be expected from them. We have in them the perfection of geometrical form. They nearly all have straight sides, and regular angles; are homogeneous, and very little liable to change.

Passing to the right side we have certain of the elements, mainly carbon, hydrogen, oxygen, and nitrogen, forming into compounds commonly termed organic; such as ammonia, water, and carbonic oxide. These form into what are called colloid substances, such as gum, albumen, or white of egg, and jelly, which have no regular forms like mineral crystals, nor are they permanent, but constantly liable to change from slight causes.

One form of colloid matter is protoplasm, or the matter of life. It is a somewhat variable compound of carbon, nitrogen, hydrogen, and oxygen, and resembles the substance familiarly called jelly. From this substance, as explained in the earlier chapters of "The Origin of Life," all organic beings are evolved.

Referring to the Tree we find the monera the first and simplest of all living things, mere masses of jelly-like protoplasm, showing life only by simple motion as they are acted upon by surrounding influences.

Next, following the trunk of the tree, come the Amabar, a little higher, showing faint indications of will or choice in their movements; and these branch off into the Infusoria on one side, and into the egg-animals on the other. Ascending the trunk the development goes on till we come to the Gastreads, or animals with true stomachs; these branch off into Sponges, Star Fishes, Mollusca, Zoophytes (or plant animals), and various other forms till we reach Insects on one side, and Ascidians on the other. Some of the branches are subdivided into still smaller ones, but all can be traced back to the primitive form in the trunk from which they have all been derived. This primitive form-say one of the worms-may die out completely, while 
the whole or part of the branches derived from it may remain. Or, on the contrary, all the branches may disappear, and the primitive worm still remain. It is not, therefore, a transformation of the primitive form as a whole into any of the branches that takes place, but some individual member of the primitive family, placed under modifying circumstances, begins to change, and the change goes on till the branch or variety results. The new characters which the branch acquires are communicated to its offspring by heredity, and are thus perpetuated. There is, however, always the primitive form underneath, and very frequently it is returned to, even in the remotest branches.

These beings, so far, are all Invertebrates, or without backbones; but the highest of them, the Chorda Animals, show faint traces of a nervous chord in the position where the backbone should be.

In the next group above we reach the Vertebrate animals, or those with backbones. The lowest of these, however, are skulless, and the backbone itself in some (as the Amphioxus) is little more than a firm jelly. A little higher up, however, we come to Fishes, and finally to Amphibious Animals. From these brancb. out a variety of new forms, such as Reptiles, from which come Birds. The fishes themselves branch off into a great many varieties, differing both in form and habits.

The highest group brings us to the Mammals, or those which suckle their young, to which group belongs man.

Following the main trunk, we have first the Primitive Mammals, or those showing the first imperfect rudiments of mammalian structure. To these succeed the Pouched Animals, then the Semi-Apes, the True Apes, Ape Men, and finally MAN himself.

At various stages, however, in this group as in all the others, branches diverge from the primitive stem, and assume a variety of forms, all, however, being mammals. Thus we have on one side Beasts of Prey, Rodents, Bats, and Beaked Animals, and on the other Hoofed Animals, Whales, and Sloths.

The Apes also have branched off into Orangs, Gibbons, Chimpanzees, and Goritlas; and finally man himself has diverged into several varieties, more or less different, and with distinctive characters more or less permanent.

It is erroneous, therefore, to suppose that man passed through all the forms represented by the branches of the tree. He has not sprung from a gorilla or chimpanzee, but these have branched off from that primitive ape man, from which all alike have sprung. In his embryonic development man shows this, for he passes through all the types below him, as shown on the trunk of the tree, till in his very beginning he is a mere mass of protoplasm.

Man never was an ape, nor have evolutionists ever said he was, in the sense that some people suppose. But unquestionably some individual of the primitive ApeMan family was so far modified by his surroundings, as to become a true man, and from him the race has descended.

He must be traced downwards, therefore, through the different types, as shown in the trunk of the tree. In the same way every branch can be traced back to its original type in the main trunk, and thence downwards to the primitive elements.

Whether still further development may take place, and a still higher being than man be evolved, we know not, but it is quite possible that the tree may finally have to be carried still higher.

The correspondence in structure of man and the animals nearest to him now 

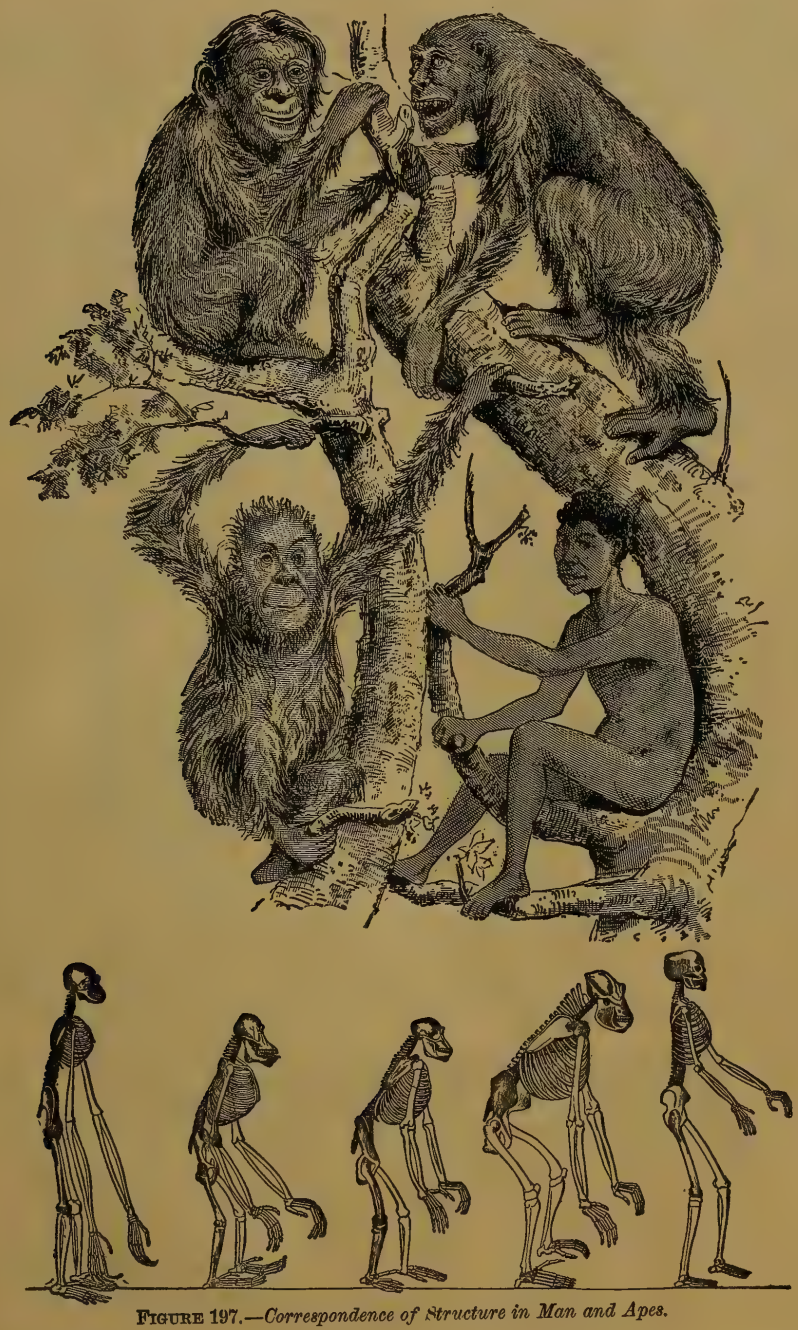

known is well shown in Figure 19\%, both in external form and bony structure. 
It will be observed that the differences are caused not by one animal having parts different from another, but simply in the same parts having different proportions. Each part has in each been modified, in a different way, from a common ancestor.

The embryonic development of different animals, as shown in Plates XLI., XLII., and XLIII., will make it clear how they all start from one common primary form, though they diverge so much in their after development.

In reference to the point illustrated by these plates Huxley remarks : "Is man a peculiar organism? Does he originate in a wholly different way from a dog, bird, frog, or fish, and does he thereby justify those who assert that he has no place in nature, and no real relationship with the lower world of animal life? . . . Or does he develop from a similar embryo, and undergo the same slow and gradual progressive modifications? The answer is not for an instant doubtful, and has not been doubtful for the last thirty years. The mode of man's origin, and the earlier stages of his development, are undoubtedly identical with the animals standing directly below him in the scale. Without the slightest doubt he stands in this respect nearer the ape than the ape does to the dog."

The truth of this is evident from Plates XLI., XLII., which depict embryonic development from man to the fish.

The upper row of figures in each plate shows the embryo of each animal named below at the same early period, and it will be seen that they are absolutely identical, as Huxley says. The embryo of man is exactly like that of either of the others, so that at this stage there is no difference between them. In other words, all these different animals are derived, by evolution, from the same primitive organism, which has been itself evolved from a simple cell, or egg, and that from a small mass of protoplasm.

Even at a more advanced stage, as shown in the middle row, the different beings vary but little from each other, so that the hog could readily be taken for a man.

Even at birth the diviations are only modifications. They all have the same parts, as shown in the bottom row, and are readily recognized as being fundamentally the same. If a perfect series were to be shown, beginning with the one nearest to mar, and following with the nearest to that, and so on downward this would be so evident that no one could dispute it. The chain of descent would be perfect if we could show all the links.

In Plate XLII., the development of the Fish is shown by F. I., F. II., F. III.; the Salamander by S. I., S. II., S. III.; the Turtle by T. I., T. II., T. III.; and the Chicken by C. I., C. II., C. III., all at the same periods. It will be seen that at stage I. they are all identical. They begin to vary at stage II., and diverge still more at stage III., or at birth.

Plate XLIII. shows corresponding stages, I., II., III., of a Man (M.), of a Rabbit (R.), of a Calf (C.), and of a $\mathrm{Hog}$ (H.). It will be seen that at stage $I$. they cannot be told one from another. At stage II. there is but little difference. And at stage III. even, the relation can be distinctly traced.

Taking the development of the face alone, the same fact is shown. Thus in Plate XLIV. we have the development of the face in Man, M. I., M. II.; the Bat, B. I., B. II. ; the Cat, C. I., C. II.; and the Sheep, S. I., S.II ., as seen in the embryo of each. It takes very close inspection to make out any essential difference between man and the sheep, the cat and the bat, or between any two of them at this stage, notwithstanding the great dissimilarity between them in after life. 
PLATE XLII.

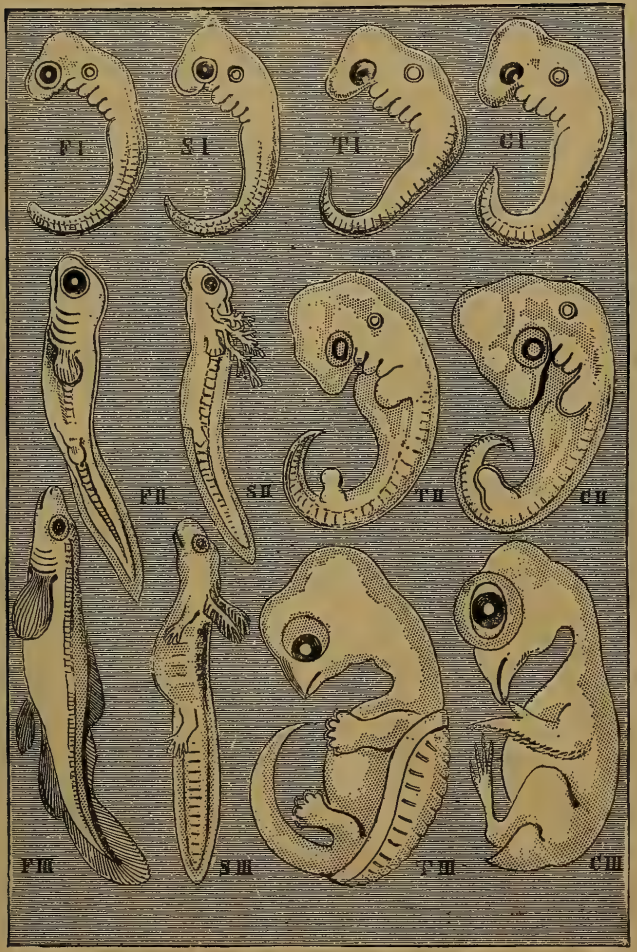

Irmbryonic Development of a Clicken, a Turtle, a Salamander, and a Fish. 

PLATE XLIII.

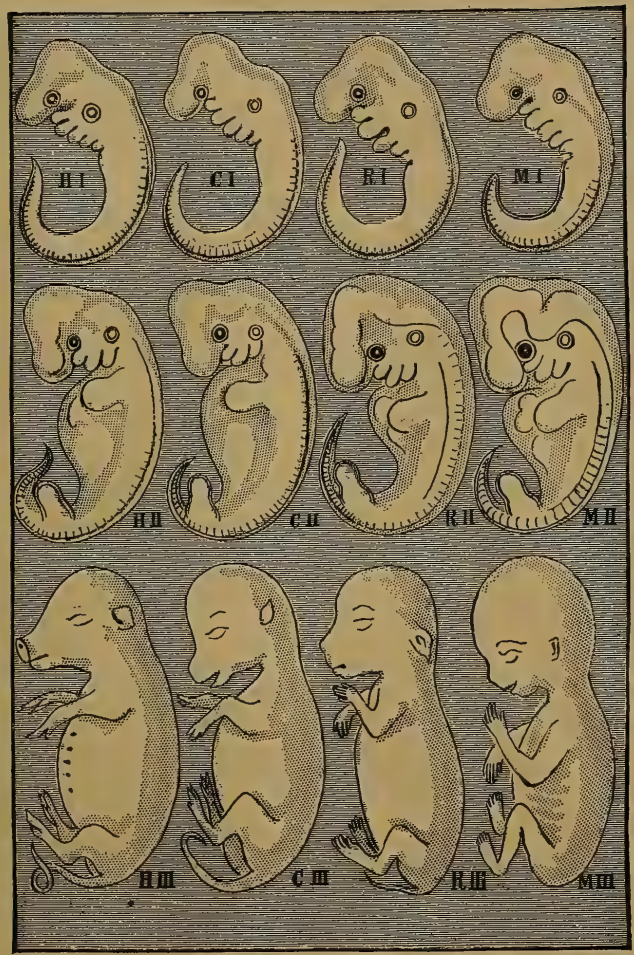

Embryonic Development of a Man, a Rabbit, a Calf, and a Pig. 



\section{PLATE XLIV.}

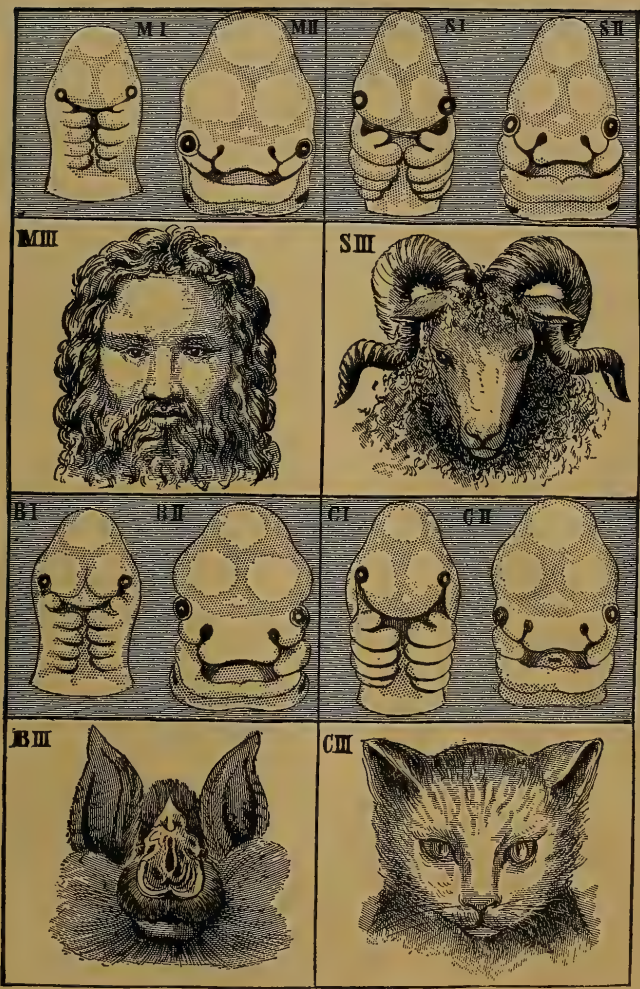

Embryonic Development of the Face, in a Man, a Cat, and a Bat. 

Sometimes particular features are more perfect among the apes than among the lower varieties of human beings, as in the case of the nosed apes, Figs. 198, 199.

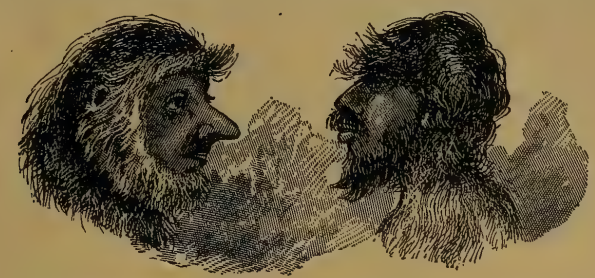

Frgure 198.-The Nosed Ape. FraURe 199.-Julian Pastrana.

Here we have the Nose Ape from Borneo contrasted with the celebrated Julian Pastrana, the ape man. In this case not only is the ape the better of the two in regard to the nose, but even in the whole facial development.

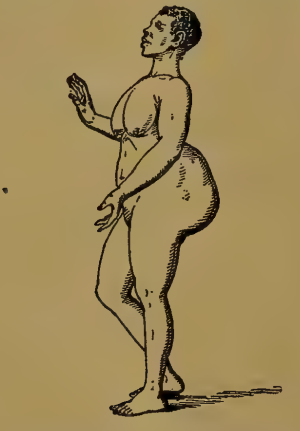

FTGURE 200.-African Woman.

Fig. 200 shows the peculiar development of some of the African. women referred to at page 732. 



\section{INDEX.}

B.

\section{ABORTION, 351.}

extent, and dreadful effects of it, 426 . may result from the father, 193 . or miscarriage, 892 .

Acarus Crossii, 87.

Acid, nitric, a result of plant growth, 89 .

Adaptation, when perfect, prevents exhaustion from connection, 437 .

Adornment, personal, different modes of, 731 . personal, uses of, 730 .

Adultery, none in ancient Sparta, 750.

African Chiefs, their opinion of white women, 732.

After-birth, delivery of, 821 .

After-pains, 826.

Age-Men of an hundred years being parents, 457.

none fixed when a man ceases to be capable; curious case of the Banbury Peerage, 457.

when both sexes begin to be capable, and when they cease to be so, 456 .

Air, difficulty of getting pure, and how to purify it, 81 .

of London and of the Alps, difference in them, 81 .

Alba Dolens, 907.

Allantois, its uses, 305 .

Amative feeling, often absent in females, 442 . indulgence, philosophy of, 440.

Amenorrhoea, or stoppage of menstruation, 660 . Amobas, their structure, and how formed, 69 . Anaphrodisiacs, what they are, 423 .

Ancon sheep, 4\%0.

Animalcules, production of. Experiments of Pouchet and Bastian, 34. seminal, history of, 179 .

number of needed to impregnate, 177. their forms and movements, 181 .

Animals, classification of, 113 . how improved by proper attention to the laws of Heredity, 463 .

which appear only at long intervals and in strange places, 84 .

Ant, female, with egg bag, 147 .

Anteflexion of the womb, 627 .

Anteversion of the womb, $62 \%$.

Annuloida, 115 .

Annulosa, 115 .

Aphis, green, virgin generation of, at all stages, 286.
Aphrodisiacs, what they are, and how they act, 423.

Appetite, derangements of during pregnancy, 875.

Area, germinal, 303.

Arm, presenting with the head, 842.

right, why preferred to the left, 327 .

Aromatics and spices, their sexual influence, 422.

Artificial Impregnation, curious case from an old Arab book, 452 .

when needed and how effected, 452.

Atoms, always in motion, 83.

Attraction, the same as choice and selection, 55 .

Audubon, on bird loves, 717 .

Auscultation, to discover pregnancy, and the position of the child, 780 .

Australian mode of wooing, 730 .

Axis and straits of the pelvis, 762 .

B.

Bacteria, formed in dead bodies, 88. how produced, 31 .

Ballotment, practice of, to ascertain pregnancy, 775.

Balz, or curious dance of the Black Cock in the pairing season, 717 .

Banbury Peerage, curious case of aged parentage, 457.

Barrenness, may result from a fault on either side, 458

Bastards, how considered and treated, at different periods, and among different people, 737 .

Bastian, on Tyndall's experiments, 82.

Bathybius, or deep-sea protoplasm, 26.

Batz, commune of, a case of close intermarriage, 477.

Bearded Lady, case of, 469 .

Beauty, type of, among the ancient Greeks, 747 .

Bemis, Dr., statistics of marriage, $47 \%$.

Bend sinister, meaning of, 737 .

Berkeley, Lord, marrying at eight years old, 456.

Bernhauer, Agnes, affecting case of her mar. riage, 727 .

Betrothment, 728.

Birds, copulation of, 215 .

love making, 716 .

male, combats for possession of the females, 717.

Black Cock, curious dance of when pairing, 717 .

Bladder, rupture of, 630 . 
Bleeding at the nose, 885 .

Blisters, how they affect the sexual organs, 449.

Blood, a protoplasmic fluid, 97.

changes which occur in it, 97.

shower of, explained, 72 .

spitting and vomiting of, 885 .

the mother's, how it may affect the child, 315.

Biood cells, their power of selecting materials, 97.

Blue disease, in new born infants, what it is, 327.

Boarding schools, danger of, 705 .

Brain, evolution of, 104.

human, develops through all the stages of the lower types of animals, 315 .

influence of upon the sexual organs, 447.

parts of it not yet developed-what may they become? 462 .

Brains of criminals, nearly always abnormal, 397.

Breast, abscess of, 904

affections of after delivery, 903 .

alterations of during pregnancy, 770.

engorgement of, 904 .

inflammation of, 904 .

male, sometimes forms milk, 765 .

of the human female, structure of, 764 .

Breathing, difficulty of, 879 .

Breech presentation, delivery in, 800 .

Breed, improvement of, 478 . of human beings can be improved, 478 .

Breeding, cross, 476. necessity for attending to it systematical$1 y, 465$.

Brittleworts, what they are, 76.

Bronchocele, 906.

Brown-Séquard, experiments in production of epilepsy, by hereditary transmission, 465.

Buds, or gemmæ, generation by, 125.

Burdach, on germs, 82.

C.

Crsarian operation, 868

Camphor, its sexual effect, 421 .

Cannabis Indica, its effects upon the sexual organs, 422.

Cantharides, or Spanish flies, its influence on the sexual organs, 420 .

Carbon, and carbonic acid; how formed, and fixed, 45 .

Carbuncle of the genitals, 634 .

Carunculæ Myrtiformæ, 221.

Castration, effects of, 155 .

Catchfly, or Campion, 50 .

Caterpillar fungus, 85 .

Caucasian compared with Bushman, 104.

Cauterization, use of in Spermatorrhoea, 569 .

Canterizing, its dangers, 569 .

Cell, embryo, 301.

membrane of, 65 .

membrane of, how formed, 66 .

Cellar plant, 84 .

Cells, aggregation of into compound organisms, 93.

division of - can it go on indefinitely ? 95 families of, 94

how formed, and what they are, 68 .

propagation of, 94 .

simple, animal and vegetable, 64 .
Cells, size of, 65 .

the modes in which they mingle their con. tents at the time of impregnation, 281.

Cerebellum, its apparent connection with the sexual organs, 449 .

Change of life, 693 .

nature of, 359.

when it occurs, 458 .

Change of one animal into another, 119.

Changes in animals by development, 119.

Child, at every stage, from the germ to birth, 318.

at full term, form and size of, 783 .

attentions to after birth, 823 .

extra large, impeding labor, 843 .

formation of, 297.

how influenced by the mother, 315 .

how it is nourished in the womb, 323.

one formed within another, 330 .

period when it can live, 353 .

size of, at every stage, 319 .

the way it is formed, from the germ, 301

weight of, at every stage, 319.

Child and mother, how they are connected in the womb, 323.

Child bearing, in old age, how accounted for, 458 .

Child-bed fever, 898.

Child killing, by the mother, after delivery, often the result of a morbid impulse, 461 .

Children born without heads, 339.

Children by one man may be affected by another. 392.

double, 338 .

fine, how insured by the Joloffs, 732 .

five at a birth, 349 .

illegitimate, 737.

of either sex, at will, 371.

six at a birth, 348 .

their descent traced through the mother, instead of the father, 733 .

with extra limbs, and double heads, 340.

365 reported at one birth, 350 .

Chloroform in midwifery, 909.

Chlorosis, or green sickness, 673 .

Chorda dorsalis, 305 .

Clitoris, amputation of, 223.

and penis the same, 311 .

containing a bone, 241

double, in some animals, 241.

described, 223.

unnatural growth of, 604 .

Close intermarriage not injurious, 477.

Clots or membranes in monthly flow, 667 .

Clubs, matrimonial, 726.

Coal, or Carboniferous Period, 45.

Colenterata, 115.

Coffee, its sexual effect, 421.

Cohesion of the external lips, 603 .

Colloid matter, what it is, 76 .

Combe, Dr., on the influence of mental and bod. ily conditions of the mother upon her child, 315.

Conception, can it occur after violence? 459 . can it occur during sleep, or in a state of unconsciousness ? 459 .

extra-uterine, 329.

probable causes of, 334 .

two foetuses at one time, 333 .

false, 334 .

outside the womb, 329. 
Conception possible without any male inter- Death, apparent, in hysteria, 680. course, by imagination only, 396 . prevention of, 425 .

when possible and when not, 191

Conceptions resembling plants, animals, and

Concubines, 728 . other objects, 335.

Congester ; instrument to cause growth in penis, 252.

Connection, after conception, can it influence the offspring? 389.

sexual, after conception, and its consequences, 889.

with one man, may influence a woman's children by another man, 392 .

Constancy in birds, 719 .

Constipation, 877 .

Continence, sexual, complete, often a great evil, 445 .

Convulsions, at the time of delivery, 859.

Cook, Captain, account of marriage customs in the Sand wich Islands, 736.

Copulation, cause of the natural impulse to, 203. curious varieties in the manner of, 205 .

in plants, 274.

or sexual union, 203.

Corals, formation and structure of, 93.

Cord, shortness of, 842 .

spermatic, falling of, 516 .

tying after delivery, 820 .

umbilical, 307, 788 .

procidentia of, impeding labor, 840.

Corpora Wolffiana, 307.

Corpus cavernosum of the penis, 245 .

luteum, formation of, 148 .

luteum, number of, 149.

spongiosum of the penis, 245.

Corsets, causing abortion, $\mathbf{4 1 7}$.

Cough, 879.

Courtship and pairing, interesting facts about, 712.

Cousins, marriage of, is it necessarily huxtful ? 477.

Cowper's glands, varieties of, 258.

Cramp of the stomach, 876.

Cramps, 889.

Creation, Vestiges of the natural history of (quotation from), 86.

Crime and disease, the duty of society and individuals in regard to its prevention, $47 \%$.

Cross-breeding, 476.

Crosse, experiments on production of living acarus by electricity, 86 .

Crustaceans, curious organs of, to assist in pairing, 712 .

Currents, electric-the same in plants and animals, 53.

Customs of marriage among various peoples, 735 . Juttle-fishes, curious mode of impregnation of, 712 .

„ystocele, or hernia of the bladder, 630 .

D.

Darwin, Charles, on the Descent of Man, 107. on different modes of personal adorninent, 731.

law of natural selection, 463 .

Deaf-mutes, not a result of the marriage of near relations, 477 .

only a change from one form to another, 66.

Debility and disease, the result of deranged cell growth, 98 .

Deformed pelvis, 835 .

Deformities in the fotus, 335.

Deformity and disease, how transmitted from parents to offspring, experiments of Brown-Séquard, 465.

how cansed by dress, 417 .

Delivery, accidents which may happen after to the child, 824 .

artificial, at eight months, in case of de. formed pelvis, 838 .

attendance during, $81 \%$.

attentions after, 822 .

how to conduet, 808 .

in a presentation of the breech, 800 .

in presentations of the face, 803 .

in presentations of the trunk, 805 .

mechanism of in a presentation of the head, 794.

of a dwarf, 837 .

of the foetal head, 795 .

of the shoulders, 796 .

preparations for, 816 .

signs of, 809 .

spontaneous, in a natural labor, 808 .

state of mind after in females, 460 .

Descent, why sometimes traced through the mother, instead of the father, 733 .

Development of the new being from the germ, 302.

plan of in animals, 118.

Devotional excitement, amative effect of, 443 .

Dialysis, 65.

Diarrhœea and dysentery, 878.

Diatoms, what they are, 76.

Diet, influence of upon the sexual powers, 431.

Differentiated, meaning of, and instances of, 113

Dionea muscipula, 50.

Dipsomania, probably arises from diseased brain, $46 \%$.

Disease and crime, duty of society and individ uals in regard to its prevention, 473.

and deformity, how transmitted from pa. rents to offspring; experiments by Brown-Séquard, 465.

Diseased and deformed people should not propa gate, 478.

Diseases and malformations of the male system, 489.

of women during pregnancy and child. bed, 872 .

Displacement, or wrong position of the femalt

Divorce, 729. organs, 609

a civil aot only, 736 .

Dizziness and headache, 881.

Dorsal laminæ, 304.

Dot, germinal, 154.

Double children, remarkable cases, 838.

inheritance, law of, 475 .

people that lived, 344 .

Doubt, the advantage of it, 102 .

Dress, how it may affect female health, 118.

Dropped testicle, 517.

Dropsy of the fallopian tubes, 657 .

of the ovaries, 657 .

of the womb, 650 . 
Drosera, 49.

Drugs, influence of upon the sexual powers, 420.

Drunkenness, may probably be transmitted by heredity, 467 .

probably arises from diseased brain; $416 \%$.

Duration of sexual power, 435.

Dust, atmospheric, largely composed of infusoria and various germs, 85 .

organic, found in the bodies and bones of animals, 85 .

Dysentery and diarrhœa, 878.

Dysmenorrhœea, or painful menstruation, 666 .

Dyspnœa, or difficulty of breathing, 879 .

\section{E.}

Earth, eatable, what it is, 74 . eaters, 74 .

Echidna, or porcupine ant-eater; generative organs of, 262.

Eclampsia, or convulsions at delivery, 859 .

Egg, expulsion of, 148 .

monthly formation of in the human female, 145 .

shark's, 153.

structure of, 154.

Eggs and seeds, only cells, 144.

different kinds, 152.

or germs, are only specialized cells, $\mathbf{9 5}$.

or ova, in all animals, including man, 142.

Electric battery, the world probably at one time surcharged with electric force, 88.

Electro silicon, what it is, 74 .

Elephantiasis-remarkable case, 514.

Embryo and ovum, in the earliest stages of development, 300.

at every stage, from the germ to birth, 318.

first appearance of, 299.

its nutrition in the earliest stages, 301 .

Engagement of marriage, 729.

Enterocele, or rupture of the intestines into the vagina, 632 .

Entozoa, their origin and varieties, 43.

Epididymitis, 498.

swelled testicle, treatment, 500.

Epilepsy, transmitted by hereditary descent,

Epispadias, 521. experiments of Brown-Séquard, 465.

Epistaxis, 885.

Epizootic influenza, 79.

Erectile tissue, 245 .

Ergot of rye, its uses, 421.

Erotomania and satyriasis, 591. case of, 592 .

Ether, its sexual effect, 422 .

Eunuchs, peculiarities of, 444.

Evolution, extends through all natnre, physical and mental, 106. spontaneous, delivery by, 806 . what it is, 101.

Excesses, sexual, effects of, 577 .

Excessive sensibility of the sexual organs, 581 .

Excitement, devotional, amative effect of, $\mathbf{4 4 3}$. sexual use of, 444 .

Experience, inherited, 105.

Expiation of marriage, 734 .

Extra-uterine conception, 329.
F.

Face, presentations of, 803 .

Fainting, 881.

Falling of the spermatic cord, 516. of the womb, 609 . treatment of at every stage, 618.

Fallopian tubes, 229 . dropsy of, 657 . inflammation of, 655 .

Family peculiarities may be transmitted-cases 469.

Family traits, commonly transmitted, 468.

Father-in-law, in France, bound to support his son-in-law, 739.

Father may disease the mother, through the child, 301 .

Female, human, external generative organs or, 221.

when she begins and ceases to be capable, 457.

organs. displacement, or wrong position of, 609 .

internal, 229.

malformation or imperfect development of, 603 .

system, diseases and derangements of; 603 .

Fever, childbed, 898.

splenic, caused by Bacillius subtilis, 89 .

Fighting, curious modes of, when pairing, by birds, 718.

Fiji, marriage customs of, 735 .

Firing, to cause growth of sexual organs, 255.

Fishes, males, fighting for the females, 715 .

Fissiparous generation, 125 .

Flagellation, use of in causing growth of sexual organs, 255 .

Flies, Spanish, their uses, 420.

Flogging, effects of, upon the sexual organs, 450.

Flooding, 671 .

during labor, 849.

during labor, how to treat, 851 .

during pregnancy, 891.

Flow, monthly, stoppage of, 660 .

Fluor albus, or whites, 643 .

Fotal circulation, peculiarities, 325 .

growth in virgins, 151.

head, diameters of, 784 .

heart, how to hear it beat in the mother's body, 778 .

nutrition, 323.

Foetus, at full term, form and size of, 788.

attitude at full term, 785 .

found in the body of a woman aged 78 , 333.

in a man's scrotum, 343 .

its appendages at full term, $78 \%$.

position of, at the full period, 781 .

presentations, and positions of, 789 .

Fontanelles of the foetal head, 783.

Food and drink, influence of, upon sexus power, 431.

Food, effects of aifferent kinds on sexual organs, 431.

Foraminifera, what they are, 76.

Force, indestructible, probably one, 17 .

Forceps, drawing the head throngh a narrow pelvis, 867 .

the use of in delivery, 864 .

France, marriage law of, 738 . 
Free-martin, a peculiar kind of hermaphrodite, 385.

John Hunter's account of, 385.

Fungus of the testicle, 497 .

\section{G.}

Galvanism, use of, in causing growth of sexual organs, 255 .

Gambling, passion for may be transmitted, 473. Gastralgia, or cramp of the stomach, 876 .

Gastric juice, the same in plants and animals, 53.

Gastrospasm, 687.

Gelatine of Wharton, 788.

Gemmiparous generation, 125.

Generation, alternation of, 283.

dicecious, 141.

fissiparous and gemmiparous, 125.

organs of, in fishes, frogs, and reptiles generally, 212.

in oviparous animals, 211.

in the different types of animals in both sexes, 209.

in the human female, 220 .

primal, or the first origin of life, 27 .

spontaneous, its history, 28.

synopsis of all the different modes of, 268.

theories of the spermatists and the ovists - of syngenesis, epigenesis, and evolution, 264 .

virgin, 283.

Generative organs at various stages of development in a male and female child, to show their identity, 313.

how they develop in the child while in the womb, 311 .

of plants, 271 .

the same in male and female, 309.

Germs and seeds, many of them withstand boil. ing, 82 .

atmospheric, experiments with, 29.

fungus, 36.

universal organic, 63.

of disease, 38.

probably only organic particles, 81 .

their nature and origin, 30 .

Gestation, duration of, and laws of different countries in regard to, 357 .

Girlhood, period of, 698 .

Girls castrated in ancient times, 155.

New Zealand, when converted still desiring tattooing, 732 .

quite young, becoming mothers, 457 .

Greece, Ancient, position and influence of women in (Contemporary Review), 740.

Green sickness, or chlorosis, 673 .

Gregarinas, the lowest forms of living beings, 67 . Grouse, love dance of, 718 .

Guinea-pigs, Brown-Séquard's experiments with in hereditary transmission of epilepsy, 465 .

H.

Hæmatocele, or blood-swelling of the scrotum Hæmoptysis, 885 . and spermatic cord, 513 .

Hæmorrhoids, 887

Hair snakes, so-called, 34
Hanging, curious sexual effects of, 448.

Head, diameters of, 784 .

fœtal, at birth, its bones, sutures, and fontanelles, 783.

injuries to, how they may affect sexual power, 447 .

ossification of, 844 .

remarks on the different positions of, 797 .

Headache and dizziness, 881 .

Health necessary to beauty among the ancieat Greeks, 747.

Hearing, affections of, 883 .

Heart, formation of, 305 .

how to hear it beat in the mother's body 778.

palpitation of, 880 .

Helen and the Trojan War, 745.

Hemorrhage during pregnancy, 891. uterine, during labor, 849 .

Hereditary descent and improvement of the race, 462 .

Heredity, influence of, 119.

laws of, apply to both body and mind, 471.

Hermaphrodism, 132.

Hermaphrodites, different kinds, 132.

Hunter on, 383.

so-called, in human beings, 380 .

Hernia humoralis, or inflammation of the testicle, 498.

Hernia in the scrotum, 510.

Hints useful for all ages, 695 .

Hooker, Dr. J., description of the caterpillar fungus, 85 .

Horse, mucus from the nostrils when diseased, 79.

Horses, habits of, when pairing, 720 .

Hottentot female, curious development of the nymphæ, 222.

ideal of beauty, 732 .

women, singular peculiarities of, 732 .

Howe, Dr. S. G., on self-abuse, 580 .

Hufeland, art of prolonging life, and sexual power, 437.

Human beings, of all types, are probably all from one simple organism by the process of evolution, 106.

body, its composition, 15 .

Hunter, John, on hermaphrodites, 382. on the free-martin, 383.

Huxley on molecular forces, 83.

Hybrid, a remarkable one between a horse and a deer, 485 .

Hybrids, curious cases of, 482.

die out, 482.

hybridization, and cross-breeding, 481.

one-sided, 481 .

two-sided, 481.

what animals will cross to form hybrids, 482.

Hydatids of the womb, 651 .

Hydra, reproduction of, 126.

Hydrocele, or dropsy of the testicle 489 tapping for, 492. treatment of, 491 .

Hydrocephalus, 844 .

Hydrometra, or dropsy of the womb, 650 .

Hydrophobia, probably only sexual madness, 597.

Hydrorrhoea, 888.

Hymen, description of, 239. 
Hymen, the, 221.

the, not a proof of virginity, 227.

Hypospadias, 519 .

Hysteralgia, or neuralgia of the womb, 687 .

Hysteria, its causes, symptoms and treatment, 678.

Hysterical mental disorders, 684

Hysterocele, or hernia of the womb, 630 .

I.

Illegitimate children, standing of, social and legal, 737.

Imagination alone causing a woman to conceive, curious case brought before the Parliament of Grenoble, 396.

causing a black child to be born of a white mother, 401.

influence of, upon generation, 392-7.

in the mother, affecting the child in various ways, 401.

Immobility of the womb, 628 .

Impotence caused by too much mental work, and by drugs, 412 .

Impotence from spermatorrhœa, 555.

or loss of sexual power, 406 .

Impregnation, artificial, a common practice by horticulturists, 455 .

artificial, a successful case of, 453 .

artificial, in the case of a wounded soldier, 453.

artificial, when called for, and how effected, 452 .

can it occur during unconsciousness, or sleep? cases in which it has, 459.

in frogs and plants, 199.

manner of, 194.

may occur after violence, 460 .

the same in plants and animals, 274.

what it is, with Pouchet's Ten Laws, 184.

when possible and when impossible, 197.

Improvement of animals, by attending to the laws of heredity, men equally capable of being so improved, 463 .

in breeding, 476.

of the race, by proper breeding, 475 .

Incontinence of urine, 527.

Indian hemp, its effects on the sexual organs, 422

Indians, American, customs of, in regard to pairing, 735 .

Inflammation of the fallopian tubes, 655 .

of the ovaries, 655 .

of the vagina, 636 .

of the valva and external lips, 634 .

of the womb, 636 .

Infusions, organic, and what they develop, 36.

Infusoria, ciliated, 32 .

from the bottom of the ocean, 75 .

how produced, 31.

Inherited tricks, 470 .

Inorganic, or dead matter and its properties, 18.

Insanity, connected with masturbation, 584. hereditary, 471.

the proportion of, caused by masturbation, 587.

Insects, curious organs of, to assist in pairing, 713.

how they conrt, 714

Insomnia, 882

Instruments, operations with in delivery, 864.
Intercourse of the sexes perfectly unrestrained, in the Sandwich Islands, 736.

Intermarriage and pairing, 473. close, not hurtful, commune of Batz, 478.

Inversion of the lining of the vagina, 632 . of the womb, 627 .

Itching of the external parts, or prurigo, 635.

J.

Jelly-fish, generation of, 293.

Jews, intermarriage among, 478.

Joannis Wieri Omnia, a very curious book, 159.

Joloffs, their practice in breeding fine children, 732 .

Judgment, disordered, 884.

Jukes family, 473 .

K.

Kadesh, meaning of, 734

Kangaroo, generative organs of, 261.

King Charles and the fish, 101.

Knowledge, how we gain it, 101.

Kyestine, a sign of pregnancy, 771 .

\section{I.}

Labor, causes of, 808.

how it may be protracted by various un. usual presentations and positions, 844 .

how to conduct, 808 .

natural duration of, 813 .

progress, phenomena and duration of, when natural, 810

natural, at each period, 810.

delivery in, 808 .

how to conduct, 814

prolonged, caused by small or deformed pelvis, 834 .

causes of, 830 .

consequences of, 830 .

Lady Baker, how an African king proposed to improve her, 731.

Lady d'Auvermont, becoming pregnant in the absence of her husband, by imagination alone, 396.

Lady Sale, delivered during the retreat from Afghanistan, 763.

Lapland, curious practice with young male rein. deer, 505.

Leucophrys, gaping, 69.

Leucorrhce, or fluor albus, 643.

Lewes, $G$. H., on the origin of life, 82.

Life, a form of motion, 19, 83 .

animal and vegetable, identical, 55.

animal life dependent upon vegetable life, 45.

change of, 693 .

change of, when it occurs, and why, 458.

everywhere, 71 .

its basis, 24.

its first beginnings, protista, $\mathbf{4 0}$.

its phenomena in all forms of matter. organic and inorganic, 58.

resemblance of all its phenomens in the animal and vegetable worlds, by $\mathbf{F}$. Darwin, 56.

resulting from the action of electric cur. rents, 86 . 
Life, the aggregate of all the molecular forces comprising the organism, 97 .

what it is, 23.

Light, its effect on infusions, 37 .

Likings, strange, in girls, 675 .

Lips, external, inflammation of, 634 .

Liver, when formed, 307.

Living, or organic bodies ; their properties, 18.

Lochial discharge, 826.

Longings, in the mother, affecting the child, 401.

Loss of semen, excessive, 533.

Love and courtship take place in all animals, even the lowest, 715 .

bowers, planted by birds, 716 .

dance of birds, 717 .

madness, 594 .

making, by reptiles, 716 .

Lunatic Asylum, Massachusetts, reports of bearing on masturbation, 585 .

gtatistics of, bearing upon the use of tobacco, 572 .

\section{M.}

Malays, marriage customs of, 735 .

Male, permanent influence of, upon the female in connection, 392.

Male system, its diseases and malformations, 489.

Mammæx, or breasts, 220, 764 .

Man, ouilt up of simple cells, 70 .

development of, through all the lower animal forms, 118.

resembles a woman turned inside out, 321. sexual organs of, 243.

Mania, sexual, 595.

Manna, what it was, 72.

Marcus, on painless extinction, 473.

Marks, mothers', on children, how produced, 403.

Marriage, a civil contract only, 736 .

a matter of chance, instead of fitness ; consequences, 464 .

and position of women, at all ages, and among all peoples, 722.

at what age allowed to take place, 456.

changes in modern times, 729 .

communal, 722 .

confusion in regard to it in Great Britain, 738.

customs, among various peoples, 735 .

excellent law of, in England, 738.

expiation of, 734 .

hand-fast, 727 .

how considered at different periods, 796.

in ancient Sparta, intended to produce strong and healthy children, 750 .

in one country not always good in an. other, 739 .

in the Hebrides, of the king, curious custom, 726 .

latitude allowed in it in ancient Sparta, 750.

miscellaneous topics connected with, 387. morganitic, 726.

morganitic, affecting case of Agnes Bernhauer, 727.

necessary to the existence of society, 737 .

cf near relations, 464.

ordained by nature, 444.
Marriage, precautions to observe at the time of, 439.

preserves sexual power, 436.

proper age for, 438 .

Scotch law of, 738 .

single, considered indecent, 724

single, how it first began, 722.

the chief object of, among the anciens Spartans, 750.

the law of in various countries, 738.

various forms of, 720 .

when true, causes no loss of power to either in association, 436.

Married women, property of; former injustice of the laws regarding it, 738 .

their rights now better respected, 739 .

Marsupials, generative organs of, 258.

Martin, free, John Hunter's description of, 384

Masturbation and insanity, 587.

and other sexual abuses, 576. causes of, 588.

Dr. S. G. Howe upon, 580.

Matrimonial clubs, among the ancient Britons, 726.

Matrix, or womb, 220

Matter, dead and living all the same, 44.

dead, or inert, does not exist, 88.

indestructible; probably one, 16.

its secondary compounds, 44.

organic and inorganic compared, anã shown to be the same, essentially, 47 .

organic and inorganic, in what respect they differ, 47 .

Meal, mountain, what it is, 74

Measles in pork, 290.

Meat-eating plants, 52 .

Medicines, how they affect the sexual powers, 420.

how they cause or cure spermatorrhœe, 570.

Medusa, generation of, 293.

Membranes, fœtal, 787 .

Memory, good, may be transmitted or spoiled, 471

Menses, suppressed, treatment of, 664 .

Menstruation and puberty, 689

cause of, 359 .

first appearance of, and cessation of, 363 .

in other animals, analogous to that of the human being, 368 .

old superstitions about it, 365 .

painful, 666.

profuse, 670.

stoppage or non-appearance of, 660 .

Mesmerism, effect of upon the sexual system, 443.

Metritis, chronic, 636.

or inflammation of the womb, 636 .

Microscope, how to use in examining the semen directions by Lallemand, 557.

Midwifery, and the diseases and accidents peculiar to pregnancy and childbirth, 755 .

Milk, fungus found in it, 78 .

how formed. 764 .

sometimes formed in the male breast, 765 .

sometimes formed very early, and very late, 765 .

fever, 827 .

leg, 907 .

Mind, effect of its over use, and abstraction, npor sexual power, 434 . 
Mind, probable even in the lowest forms of life, 69. state of in females at the time of delivery, 460.

Miscarriage, 892.

Misplacement of organs, 343.

Mistress, the law about, in France, 739.

Mollusea, 115.

Monads changing to amœba, 35.

how formed, 35 .

the starting points of all animals, man included, 96.

Moners, their origin, 41

Monotremata, generative organs of, 261 .

Monsters, 329.

Monstrosities of conception, remarkable instances, and probable causes, 335.

Monstrous growths, 329 .

Mons veneris, 220.

Monthly flow, stoppage of, 660 .

Morganitic marriage, 726.

Mother and child, attentions to after birth, 825. how they are connected in the womb, 323 .

Mothers, young girls becoming so, 457 .

Motion, the result of cell change, 98.

Movement, Brownian, 31.

Mulattoes, curious facts about, 482 .

Mules, semen of, 177.

Mumps, how they may cause sterility and impotence, 415

Musk, its effect, 424 .

Mutilations considered as adornments, 781.

Mycodermi aceti, or vinegar plant, 89.

Myriana, reproduction of, 128 .

N.

Natural selection, Darwin's Law of, 463.

Nature, includes all in herself, 103.

Navel string, formation of, 323 .

Near relations, effect of their marriage, 478. marriage of, 464 .

Neck of the womb, in a first child and in a subsequent one, 777 .

Neuralgia of the testicles, 508. of the womb, 687 .

New being at every stage, from the germ to its birth, 318.

development of, $297,302$.

New Zealand girls, ideas of ugliness, when converted, 732.

Nitrate of potash, its effect, 421.

Nitrogen, needed by animals, 64 .

Nuclens, and nucleolus, 63.

Nummulites, 75.

Nutrition, fœetal, 323.

Nymphæ, formation of, 311.

odorata, 424.

the, 221 .

union of, 604 .

unnatural growth of, 604 .

৯ymphomania, 595.

0.

Obliquity of the womb, 627 .

Odors and scents, how they affect the sexual organs, 423.

Odor, sexual, its influence, 424.

QEdema, 888.
Old and young, effect upon both of close contact, 437 .

Opium, effects of upon the nervous and sexual systems, 574 .

Opossum, American, generative organs of, 259.

Orchitis, or swelled testicle, 498.

Organic beings, first forms of, 63 .

particles, or germs, everywhere, 81 .

Organisms, the lowest, their universality and enormous numbers, 71.

Organs, female, diseases of, 608 .

generative, of snails, spiders, bees, and crustaceans, 213 .

of swimming birds and their singular modifications, 215 .

male, diseases of, 489 .

misplaced, 343.

sexual, in plants, 271 .

when first visible in child, 309.

Orgasm, what it is, 442 .

Ornithorynchus, generative organs of, 262.

Osmose, process of, 65 .

Ostrich, peculiarities of its generative organs, 215.

Ovaries, dropsy of, 657 .

female, the same originally as the male testicles, 309.

inflammation of, 655 .

of a young girl, removed by her father, effects of it, 155 .

the, 229.

Ovary and ovum, 143.

Ovipositor, uses of, 156.

Ovum, first changes in, after impregnation, 29u

Oxygen, the destroyer, 64 .

\section{P.}

Painless extinction, Marcus on, 473.

Pairing and courtship, interesting facts about, 712.

and intermarriage, 473 .

Palpitation of the heart, 880 .

Panspermism, what it is, 83 .

Paralysis of the penis, 523.

Paramecia, mode of origin, 32.

Paraphymosis, 522.

Parasites found upon fish and crustaceans, 294.

Parr, old, a father when over 100 years old, 457 . old, doing penance for bastardy when over 100 years old, 436 .

Parthenogenesis, or virgin generation, 283.

Pastile, Turkish, 424.

Patagonians, marriage customs of, 735 .

Peculiarities, family, either good or bad, may be transmitted hereditarily, 469 .

Pellicle, primary, how produced, $\mathbf{3 1}$. secondary, how produced, 31 .

Pelvis, bones of, 760 . deformed, no woman with one should ever become pregnant, $83 \%$.

deformed, or small, prolonging labor, 834 . diameters of, 761 .

narrow, with the head of the child fixed fast, 837 .

smallest size of, that admits of delivery. 836. structure of, 759 .

Penis, absence and malformation of, 247. and clitoris, the same, 811 . 
Penis. compressing it to prevent the flow of semen, effects of it, 528 .

how to cause growth in it, when too small, 249.

internal structure of, 250.

paralysis of, 523.

peculiar forms of in all types of animals, 256.

small size of, 248.

structure of, 244 .

tied down by cord, 248.

with bone in it, 247 .

varieties in its form, in different animals, 220.

Perineum, position of, 759 .

supporting during delivery, 819

Pessary, use of, and various kinds of, 615 .

Phlegmasia, 907.

Phosphorus, its effects upon the sexual organs, 421.

Phrenology and amativeness, 449.

Phymosis, 522.

Physiological processes common to all animals,

Piles, 887 .

$$
113 .
$$

Pistils of plants act like the female organs of animals, 274. formation of, 323 .

Placenta, the, 787.

Plants, carnivorous, or flesh-eating plants, 48. cross fertilization of, by C. Darwin, 476 . during inflorescence, emitting light, heat, and electricity, 279.

reproductive organs of, and their correspondence with those of animals, 269 .

which appear only at long intervals, and in strange places, 84 .

Pollen, curious forms of, 276 .

of plants, analogous to the semen of animals, 276.

Polyandria, or one woman with many husbands, 725.

Polygamy, curious form of, in feudal times, 7a4. its origin, 722.

one cause of, 735 .

reason for its decline, 724 .

Polypus in the pelvis, impeding labor, 839. of the womb, 648 .

Polyzoa, 117.

Pork, measly, what from, 73.

Position, left anterior occipito - iliac, 794, $79 \%$.

of the child in the womb, how to discover by the beating of its heart, 780.

right anterior occipito-iliac, 796.

Positions and presentations of the fortus, how to ascertain them, 791. relative frequency of the different kinds, 793.

Power, sexual, deficiency or loss of, 406.

how lost and restored, 598 .

how to preserve, 437 .

Precocious puberty, $45 \%$.

Pregnancy and position of the child, discovered by the beating of its heart, 780 .

duration of, 353 .

examination to ascertain, 773.

how long may it last? 35ธ4.

presumptive signs of, 767 .

probable and certain signs of, 772
Preguancy, signs of, and means of detecting it, 767.

the end of, 782.

Premature labor, 351.

Presentations and positions of the fœetus, 789. of the lower extremities, 799.

general remarks, 801 .

relative frequency of the different kinds, 792.

Prevention of conception, 425.

by compressing the urethra, evil effect of, 429.

why difficult, 427.

Priapism, or involuntary erection of the penis, 523.

Primitive trace, 304.

Procreation, when capacity for it begins, and when it ceases, 456 .

Profuse menstruation, 670 .

Prolapsus uteri, or falling of the womb, 609 .

Promiscuous intercourse, 736.

Propagation, general neglect of the laws of heredity in regard to it, 468.

should be controlled by society, 479 .

should be seientifically regulated, 478 .

Propensities, disordered, 884.

Proper time for sexual indulgence, 433.

Prostate gland, diseases of, 529. inflammation and abscess of, 530 .

various forms of in different animals, 258.

Prostatic vesicle, in man, the same as the womb in woman, 309 .

Prostitution, public, once a religious and social duty, 734 .

Proteus, or amceba, 69.

Protomyxæ, their origin, 41.

Protoplasm, its origin, and elements, 25. its varieties, 26 .

the matter of life, 24

Protozoa, 115.

the degree of heat and cold they can with. stand, 78.

the lowest forms of living beings, 65 .

Prurigo, or itching of the external parts, 635 . or itching of the scrotum, 513 .

Puberty and menstruation, 689.

precocious, 457.

Pubic bone, 220.

Puerperal fever, 898 .

Pustules, 888.

Pyramids of Egypt, built up from fossil infu soria, 75 .

Pyrosis, or water brash, 876 .

\section{R.}

Racodium cellare, or cellar plant, 84 .

Radiolaris, what they are, 78.

Rafinesque, M. C. F., cases of hybrids, 488.

Relations, near, marriage of, 464 . marriage of, not a cause of barrenness, 477 . results of their marrying, 474 .

Relationship, near, not necessarily a bar to mar. riage, 477 .

Relaxation of the scrotum, 517.

Report of the Massachusetts S. Lunatic Asylum on masturbation, 585 .

Reproduction, fissiparous, 127.

non-sexual, 125 .

sexual, 132 .

what it is, 123 . 
Reproduction, when the sexes are divided, 141.

Reptiles, making love, 716 .

Retroflexion of the womb, 627 .

Retroversion of the womb, 622 .

Rheumatism of the womb, 642 .

Right arm, why preferred to the left, 327 .

Robertii cordiceps, and Sphæria, 85 .

Rupture, some causes of, 419.

Rush, Dr., on tobacco, 572 .

\section{S.}

Sacrum, curious superstitions connected with it, 352.

Salivation, during pregnancy, 873.

Saltpetre, its sexual effect, 421 .

Sandwich Islands, former customs of marriage, 736.

Sap, or vegetable protoplasm, 59.

Sarcocele, or fleshy swelling of the testicle, 495 .

Satyriasis and erotomania, 591.

Scotch laws of marriage, 737.

Scrotocele, or rupture of the intestines into the scrotum, 510.

Scrotum, relaxation of, 517 .

Seals, changes in form in the pairing season, 721. curious habits of, in priring, 720 .

Selection, natural, as a means of improving breeds, 478 .

Darwin's Law of, 463.

Self-abuse, 705 .

and insanity, 587.

cases of, 709 .

confession of, 706 .

or masturbation, Dr. S. G. Howe upon, 580.

Semen, composition and uses of, 170 .

how to examine with the microscope, 559.

its quality impaired by spermatorrhea, 559.

microscopical examination of, 559 .

quantity of, needed to impregnate, experiments upon, $17 \%$.

when imperfect, may be a cause of barrenness, 458.

Seminal animalcules, curious theories about, 179.

destroyed by spermatorrhœa, 559 .

how to find with the microscope, 562 .

in different animals, 183.

origin, form, and size, 171 .

the basis of the new being, 179 .

when discovered, 179.

fluid and nervous substance similar, 535 .

losses, involuntary, 533 .

vesicles, varieties of, 258 .

Sensation, common to both plants and animals, 48.

probable even in stones, 58.

Senses, all of them only modifications of touch, 70.

Sensitive plants, 54.

Separation of marriea people, for a time, often beneficial, 439 .

Sertularia, generation of, 291.

Sex, causes of the difference of, 370 .

double, or hermaphrodites, so called, 379.

either male or female, can be produced as desired, $\mathbf{3 7 4}$.

how to produce at will, 371 .
Sex, rules to insure either one or the other, at will, 377.

Sexual excesses, various authors on the effects of, $57 \%$.

indulgence, proper time for, 433.

the philosophy of, 440 .

organs, excessive sensibility of, 581.

external, of human female, 221 .

how they develop in the child while in the womb, 311 .

how to make grow, when toc small, 254 .

in a male and female child, at different stages, to show their identity, 313.

in the child, when first visible, 309.

male and female identical with each other, 309.

of man, 243 .

power, deficiency and total loss of, 406.

duration of, 425 .

its preservation and restoration, 598.

may last till extreme old age, 436 .

preserved by marriage, 436 .

Shampooing the genitals, to make them grow, 253 .

Sharks, and other fishes, with claspers to hold the female, 714 .

Sheep, the Ancon, 470 .

Shortness of the cord, 842 .

Siamese ladies, peculiarities of, 732 .

Sickness and vomiting, during pregnancy, 872 .

Sight, affections of, 883 .

Siredon lichenoides, changing into a Salaman der, 119.

Sleeping of the young with the old, effects of it, 692.

Sleeplessness, 882 .

Smell, disordered, 883 .

Smoking, effect of upon spermatorrhoea, 571 .

Snails copulating, 136 .

sexual organs of, 135 .

water, generative organs of, 213.

Snow, red, 72.

Society is developed by evolution like the in dividual, $70 \%$.

Solitary vices, 705 .

Somnambulism, 679.

Spanish flies, their effects, 420.

Spartans, perfection of their men and women, 749.

their customs in regard to propagation, 734.

Spaying, effects of, 155, 444 .

Species, change of, 109.

Speck, protoplasmic, first formation of, 65 .

Spermatocele, or swelling of the testicle from overfullness of semen, 509 .

Spermatorrhoea affecting the semen, 558 .

causes of, 536.

effects of, 539 .

effects of medicines in causing or curing it, 570 .

or excessive loss of semen, 533.

remarkable cases of, 541, 543, 544, 550 .

symptoms of, 553 .

treatment of, 565 .

why it is so hurtful, 534.

Spermatozoa, history of, 179.

how to find with the microseope, 562.

Spices, their sexual effects, 422.

Spider, male, small size of, and perils of, in con nection, 713 . 
Spider, the female, chooses her partner, 713 . Spirits, can they cause conception in a female? 397.

Spitting of blood, 885 .

Sponges, formation and structure of, 94.

Spontaneous evolution, delivery by, 806 .

Stag, effects of castration upon, 720 .

Stallions, anecdote of, in the Falkland Islands, 720.

Stamens, in plants, act like the male organs of animals, 274.

Sterility, causes of, 407 . curious modes of curing, 407 .

its causes, and cure, 451.

may be caused by imperfect semen, 408 .

not always the fault of the woman, 458 . operations for, 451 .

witchcraft, and charms used to remove it, 411.

Sticklebacks, how they care for their young, 715.

Stone in the womb, 651 .

Straits of the pelvis, 762 .

Stricture, congenital, 528.

from disease of the prostate gland, 529 .

Sutures of the foetal head, 783.

Swallowing, difficult, 876 .

Swedenborgian views on marriage, 436.

Swelling, watery, 888.

Sympathy and intellect shown by birds, 719 .

Symphysis pubis, 759 .

Syncope, 881

Syphilis, in the father, may affect the child, and through it the mother, 301.

\section{T.}

Tape-worm, at all its different stages, 291. generation of, 288 .

of the cat, and lark, 292.

Tartars, marriage customs of, 735 .

Tastes, depraved, in chlorosis, 675 .

Tea, its sexual effect, 421.

Testicle, cancer of, 496. consumption of, 505 .

fungas of, 497 .

ossification of, 502 .

removal of, 496 .

serofulous, 496 .

Testicles, double, deficient, and wasted, 166. foreign bodies in the scrotum with, 506 . in various animals, 169 .

irritable, 506.

nervous affections of, 506 .

peculiar way in which they are formed, and carried in different animals, 257. small, and wasted, 502 .

structure of, in man, 166.

the size of may be increased, 508 .

wasting, the cause of it, 504.

when formed, 309 .

Thought a form of motion, resulting from cell change, 98.

Throat, swelling of, 906.

Tobacco, authorities quoted upon its effects, 572. effect of, in causing spermatorrhoea, 571 .

Toilette, hints about, 703 .

Toothache, during pregnancy, 874.

Toruls, the yeast fungus, 39 .

Trace, primitive, 304.

Trance, in hysteria, 680 .
Tressoria, the, 221.

Trichina spiralis, its mode of life, anci reprodue tion, 73.

Tricks, inherited, 470.

Triplets and quadruplets, 346.

Tripoli powder, what it is, 74 .

Trunk, delivery in presentations of, 805 .

Tumor in the pelvis, impeding labor, 839 . of the womb, 649 .

Tumors, sarcomatous, of the testicle, 495 .

Turning the child, during labor, in case of flood ing, 855 .

in labor, manner of performing it, 869 .

Twins, and more, relative number of, 347 .

and superfotation, 345 .

and triplets, in labor, 843.

can breed, 346 .

connected together, the Siamese Twing and others, 341.

how they present in delivery, 798.

one black and one white, 346 .

position of, 781 .

probable cause of, 345 .

when male and female, the female often imperfect, 382 .

Tyndall, Professor, experiments on spontaneous generation, 79.

Types of animals, 115 .

of living beings, 113.

U.

Umbilical cord, 788.

formation of, 323. protruding; 840 .

Urachus, 307.

Urethra, diseases of, 526 . formation of, in male and female, 311. malformation of, 527 .

Urinary organs, derangement of, 889.

Urine, incontinence of, 527. trouble with after delivery, 908.

Useful hints for all ages, 695 .

Utricularia, or bladderwort, 50 .

\section{V.}

Vagina, and its connections, 238

closure of, 605 .

falling of, 633 .

inflammation of, 636 .

inversion of the lining of it, 632 .

narrowness of, 606 .

obstructions in, impeding labor, 840.

or womb, absent, 607 .

structure of, 759 .

the, 229 .

Vaginitis, or inflammation of the vagina, 636 .

Vallisneria spiralis, curions mode of its impreg. nation, 277.

Varicocele, or swelling of the veins of the scro. tum and spermatic cord, 511.

Varicose veins, 886.

Vasa deferentia, diseases of, 518 .

Vertebrata, 117.

Vesicle, blastodermic, 303. germinal, 154, 301.

Vesicles, how formed, and what they are, 63. seminal, diseases of, 519 .

Vibriones, how produced, 81 .

Vices, solitary, 705. 
Violation, procfs of, 228.

Virgin generation, 283.

Virginity, artificial, how produced, 228. singular means for insuring it in Asia and Africa, 228.

Virtue, as considered under the communal system, 734 .

Vitellus, or yelk of the egg, 154 .

Vorticelli, reproduction of, 129 .

Vulva and external lips, inflammation of, 634. structure of, 759 .

\section{W.}

Waist, female, how deformed by corsets, 417 .

Water brash, 876 . red, 72 .

Watery head, 844.

Weekes', W. H., experiments on the production of life by electric action, 86 .

Whistelo; curious case of alleged parentage, af-

Whites, or leucorrhoe, 648 . fected by the mother's imagination, 404 .

Widows remarrying, may have children like their first husbands 392 .

Wife, when rich, bound to support her husband in Scotland, 739.

Wives, different ways in which they are obtained, 730 .

Wolffian bodies, 307 .

Womb or vagina, absence of, 607 . alteration in the neck of, from pregnancy, 774 .

and its ligaments, 229.

closing of mouth of, 607 .

cut open, 235 .

dropsy of, 650 .
Womb or vagina, engorgement or enlargement of, 640 .

falling of, 609 .

growing fast to various parts of the body, 629.

hydatids in, 651 .

immovable, 628 .

inflammation of, 636 .

inverted, or turned inside out, 627.

muscles of, 758 .

neuralgia of, 687 .

polypus of, 648 .

rheumatism of, 642 .

rupture of, 630 .

rupture of, during delivery, 862.

scirrhous, or cancerous engorgement of 641.

stone, or calculus of, 651 .

structure of, 757.

Women, physical training of in Ancient Greece, 748.

their position and influence in Ancient Greece (Contemporary Review), 740.

Worms, how they copulate, 136.

Y.

Yolk, or vitellus of the egg, 305 .

Young and old, effects upon both of their close contact, 437 .

sleeping with the old, effects of it on the young, 692 .

$\mathrm{Z}$.

Zoospermes, description of, and their move. ments, 181.

history of, 179.

\section{INDEX TO ADDENDUM.}

Amœbæ, 915.

Ape Man, the progenitor of man, 916 .

Ape Men, 916.

Branches of the Tree of Evolution, 915.

Chimpanzees, 916.

Chorda Animals, the lowest type of the vertebrates, 916 .

- Development, embryonic, the same in man and other animals, 918.

Elements, the. How they combine to form colloids and protoplasm, or. crystals, 915.

Embryonic development of man, fish, bird, reptile, rabbit, calf, and hog, compared, 918.

Embryos of different vertebrates compared with each other, and with man, 918 .

Face, embryonic development of the, in man, sheep, and bat, 918 .

Gastreads, or stomach animals, 915 .

Gorillas, 916.

Haeckel, Professor, his pedigree of man, 915.

Heredity, how it perpetuates variety, 917.

Mammalia, P16.
Man, correspondence in structure of man and other animals, 916.

finally evolved, 916 .

how he must be traced downwards, 916 .

is he a peculiar organism (Huxley), 918.

nearer the ape than the ape is to the dog, 918.

never was an ape, 916 .

not sprung from the Gorilla, 916 .

pedigree of, Haeckel, 915.

will he be yet further developed, 916 .

Man's origin, mode of, the same as that of other vertebrates, 918.

Monera. How they are formed from protoplasm, 915 .

Nose Ape, comnared with Julian Pastrana, 919.

Pedigree of man, Haeckel, 915.

Structure of man and other animals the same, 916.

Transformation, how it occurs, 917.

Varieties, diverging;, 916.

Vertebrates, 916.

Woman, African, peculiar form of, 919. 


З 9002086429694

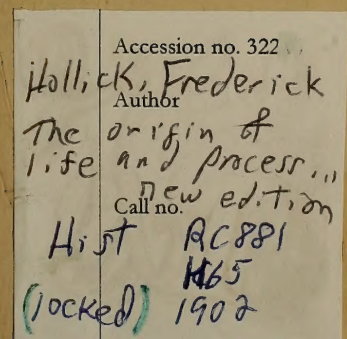


